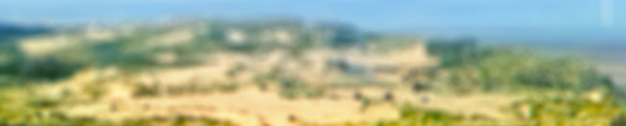

it

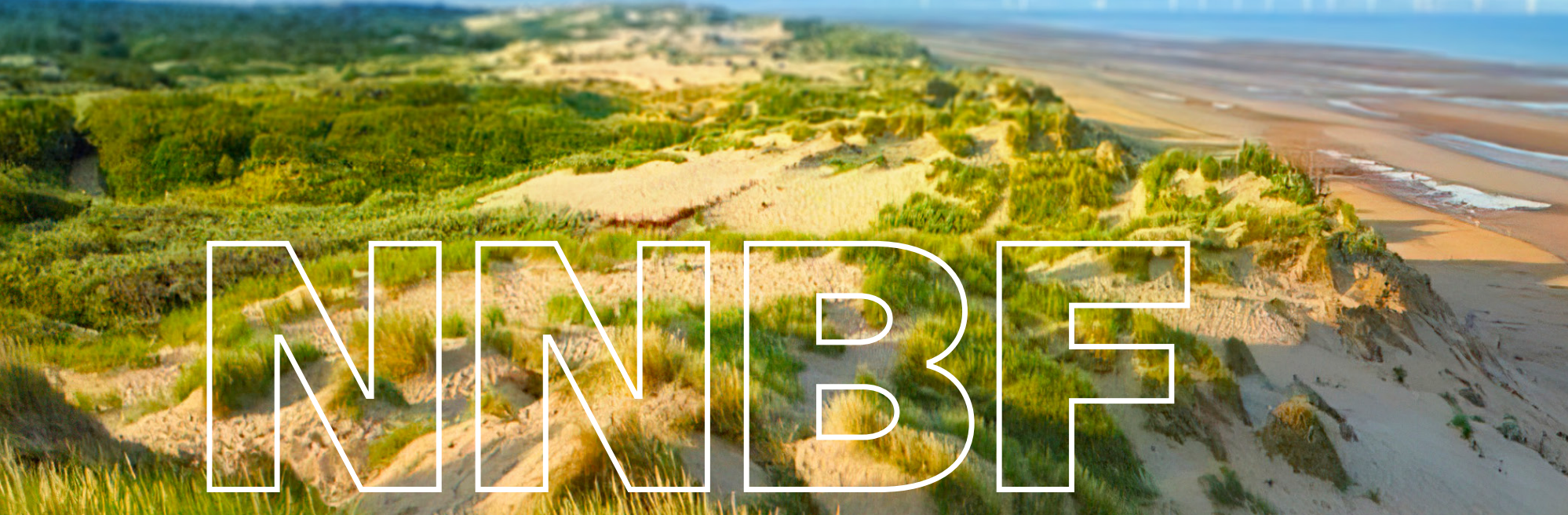

Mif International Guidelines of Natural and Nature-

Based Features for Flood Risk Managelment

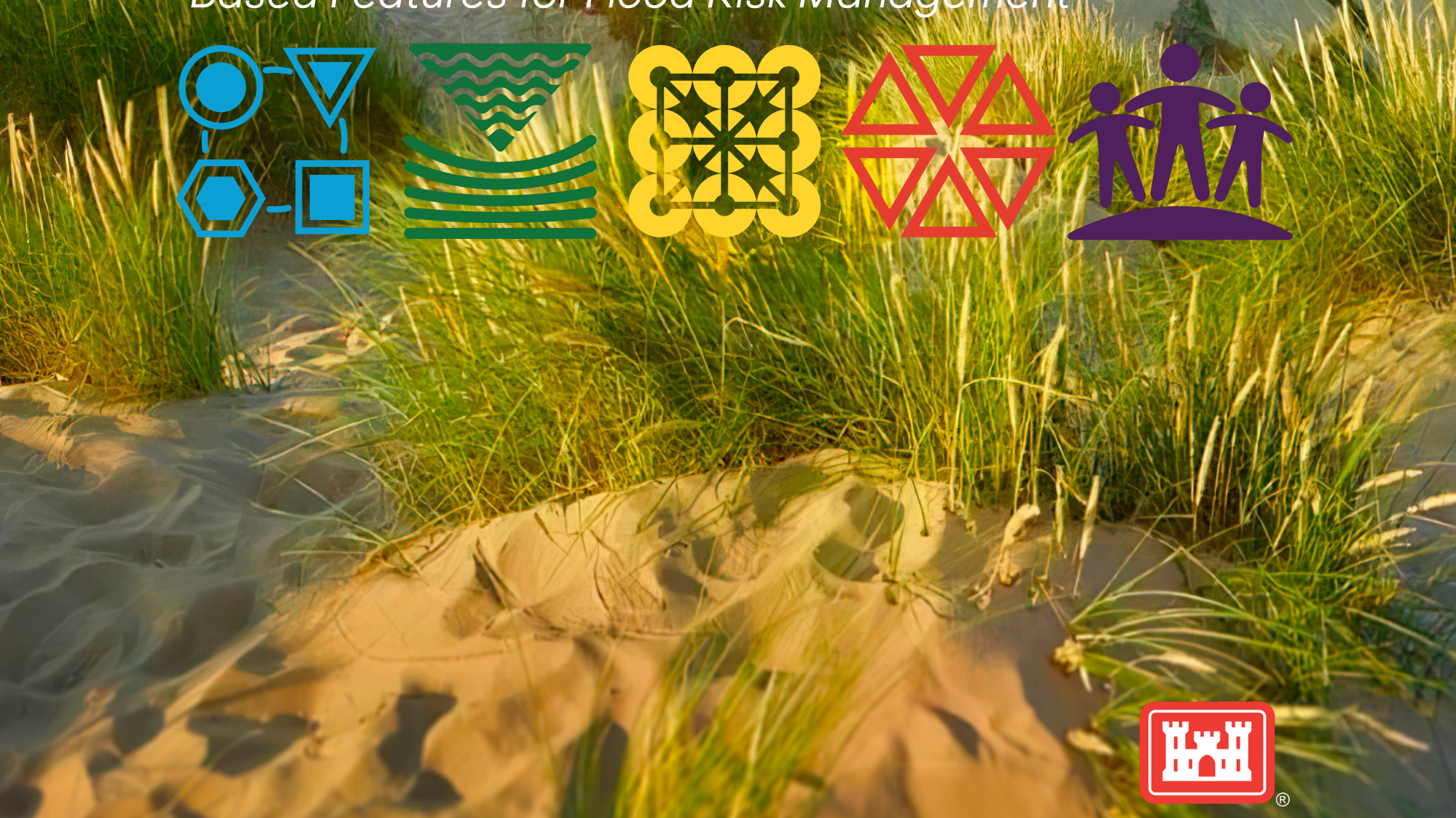


International Guidelines on Natural and Nature-Based Features for Flood Risk Management

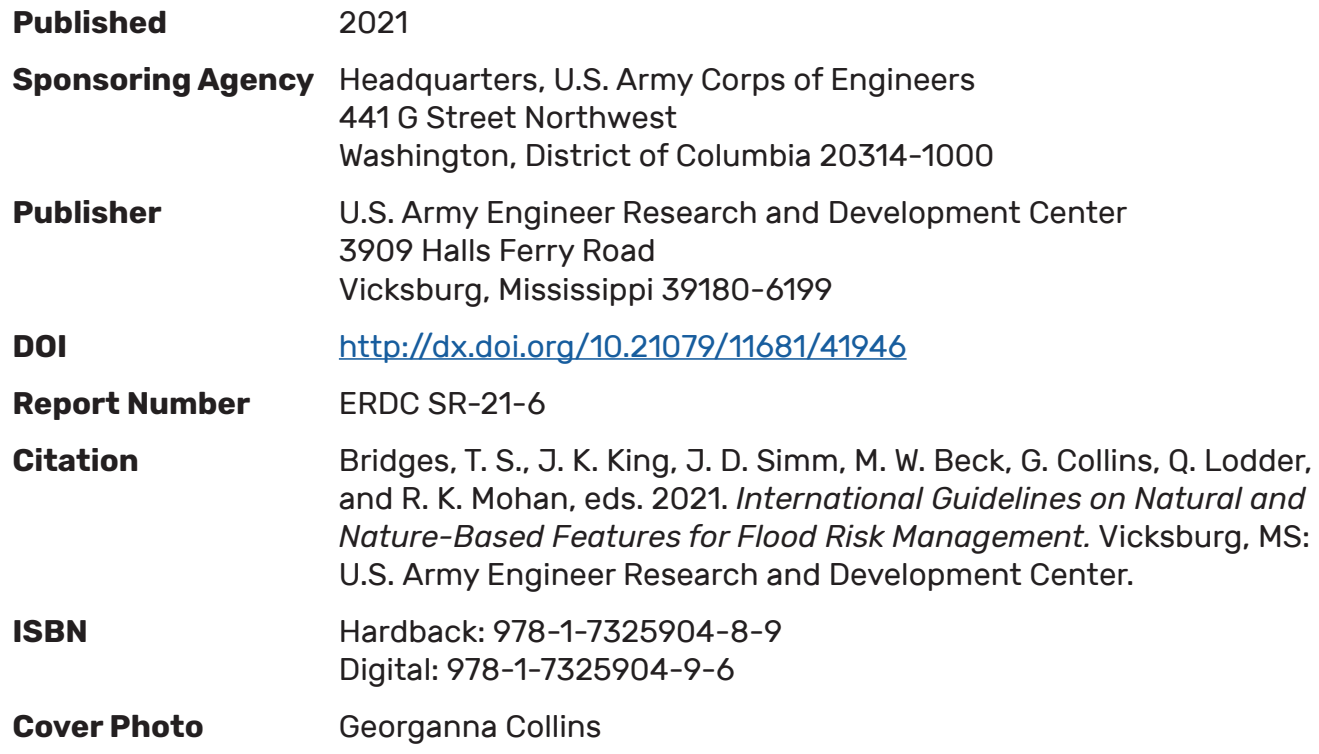
and R. K. Mohan, eds. 2021. International Guidelines on Natural and Nature-Based Features for Flood Risk Management. Vicksburg, MS: U.S. Army Engineer Research and Development Center.

ISBN Hardback: 978-1-7325904-8-9

Digital: 978-1-7325904-9-6

Cover Photo Georganna Collins 

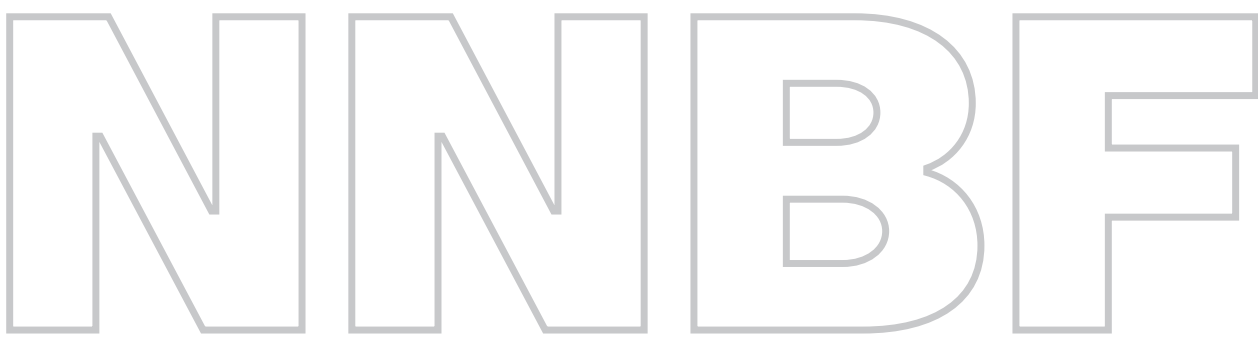

\section{International Guidelines on Natural and Nature- Based Features for Flood Risk Management}

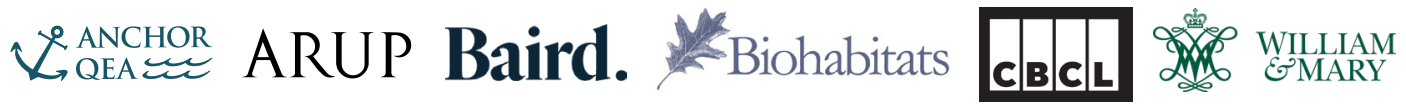

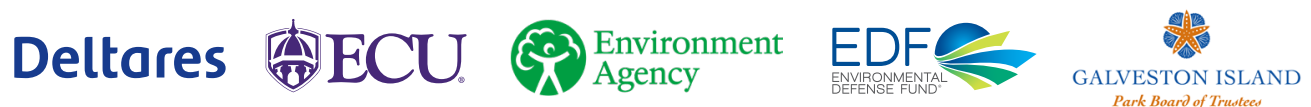

(28) GFDRR

(1) GREAT LAKES DREDGE

\& DOCK CORPORATION HR Wallingford

HZ UNIVERSITY

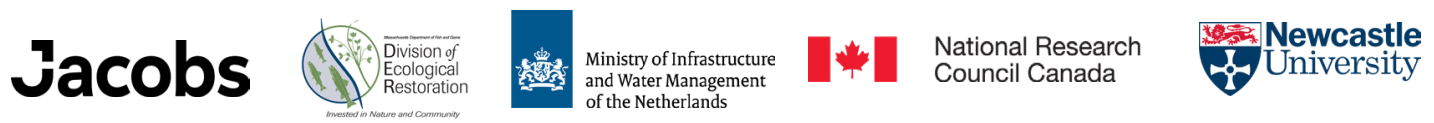
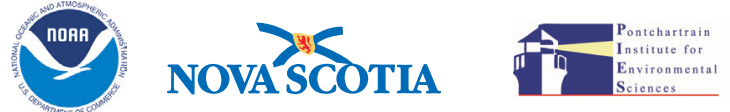

\section{RAMBCLL}

Noyal Netherlands Institute
Nioz for Sea Research

\section{Stanford \\ University \\ TheNature
Conservancy}

NIT

1.

乙居 Tonkin+Taylor

11 UNIVERSITY OF
GEORGIA WHE UNVESITY of
WESTERN

University of Dundee

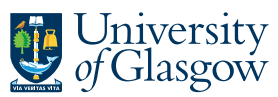

Ano NEW ORLERSITY of

Universiteit Utrecht \begin{tabular}{|l|l|}
\hline Iringi & US Army Corps \\
of Engineers.
\end{tabular}

Van Oord

Marine ingenuity

VING

(4)

WORLD BANK GROUP

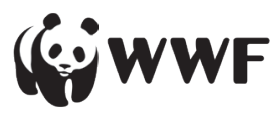




\section{Foreword}

\section{Advancing Twenty-First-Century Flood Risk Management}

To deliver infrastructure that sustains our communities, economy, and environment, we must innovate, modernize, and even revolutionize our approach to infrastructure development.

Change takes courage, but as one starts down the path of innovation, what was once novel becomes more familiar, more established. The U.S. Army Corps of Engineers (USACE) is walking this path with our partners through the Engineering With Nature (EWN) Initiative, integrating human engineering with natural systems. The International Guidelines on Natural and Nature-Based Features for Flood Risk Management are the next step toward revolutionary infrastructure development-a set of real-world guidelines to help familiarize us with what was once novel.

USACE and collaborators around the world have been building, learning, and documenting the best practices for constructing Natural and Nature-Based Features (NNBF) for decades. The consolidation of these lessons into a single guidance document gives decision-makers and practitioners a much-needed resource to pursue, consider, and apply NNBF for flood risk management while expanding value through infrastructure.

Relationships and partnerships are vital ingredients for innovation and progress. The NNBF Guidelines was achieved because of the strong relationships in the nature-based engineering community. The magnitude and diversity of contributors to the NNBF Guidelines have resulted in a robust resource that provides value beyond a single agency, sector, or nation. Similarly, the work of incorporating NNBF into projects will require us to strengthen our relationships across organizations, mandates, and missions to achieve resilient communities.

I hope you are inspired by the collaborative achievement of the NNBF Guidelines and will draw from this resource to develop innovative solutions to current and future flood risk management challenges. There is a lot we can achieve together along the path of revolutionary infrastructure development.

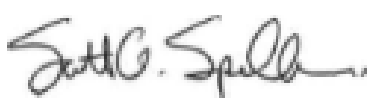

LTG Scott A. Spellmon

$55^{\text {th }}$ Chief of Engineers, Commanding General, USACE 


\section{Natural and Nature-Based Features to Deliver Value for People, Planet, and Prosperity}

For the Netherlands, a country of which about $30 \%$ is below sea level and about $60 \%$ of its surface is flood-prone, "Engineering With Nature approaches" have become essential for improving our flood safety in an adaptive manner. It also enables us to achieve other societal goals regarding spatial planning, ecosystem, navigation and recreation.

As such, "Engineering With Nature" influences not only the flood safety but also the quality of life for millions of people living in these areas. The Dutch Delta Program sets the Dutch national policy and associated programs, backed up by a Delta Law and a Delta Fund. This firmly connects our adaptive flood safety approach with spatial quality ambitions, increasing our nations' resiliency to sea level rise and more extreme weather due to climate change.

"Engineering With Nature" has actually become the preferred innovative option in many Dutch cases. However, we also learned that it involves a different approach as we are working in and with inherently dynamic systems.

Upfront modelling, full-scale testing, extensive stakeholder engagement, and a careful project management and monitoring of its effects have proven to be essential aspects for a successful project. We learned that in the Netherlands, exploiting the full potential of "Engineering With Nature" solutions will also require a transition from our traditional object-based asset management to an integrated, system-based asset management, involving and engaging many stakeholders.

Rijkswaterstaat and the Dutch Regional Water Authorities, together with knowledge institutes such as Deltares, are very pleased with the opportunity to share and discuss our approaches, examples, and best practices with a broad international community. In this way, we aim not only to learn ourselves, but also to contribute to the global adoption of these adaptive approaches for coastal, estuarine and fluvial systems.

Working with "Natural and Nature-based Systems" is a very dynamic science. challenging us to understand our various natural systems even better, adapt to them in a sensible way, and keep learning from our experiences. This guideline reflects our current thinking on using "Natural and Nature-based Features" on adaptive flood safety and biodiversity goals, while simultaneously contributing to many other societal goals. 
We encourage its readers to become inspired, understand the natural systems you are working with even better, work together with your stakeholders, rethink existing engineering approaches, and never stop asking questions and sharing your results.

I wish you joy, wisdom, and inspiration while reading these guidelines.

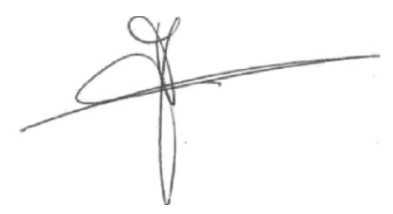

Michèle Blom

Director General, Rijkswaterstaat 


\section{Using Nature's Techniques to Deliver Adaptation and Resilience for the Future}

Natural and nature-based features (NNBF) are increasingly important to the Environment Agency and its partners in enabling flood risk management programs that create better places for people and wildlife. We are very pleased to contribute to this International Guidelines on Natural and Nature-Based Features for Flood Risk Management publication to demonstrate the global adoption of these techniques in coastal, estuarine, and fluvial systems. In the United Kingdom, we describe this as working with natural processes and natural flood management. However, the intent to deliver flood risk management together with the environmental, social, and economic co-benefits that these techniques inherently provide remain the same wherever they are used in the world.

One of the key principles of using NNBF is to expect change and manage adaptively. The strength that these approaches have in delivering solutions that can adjust to a changing environment, together with an inherent resilience to flooding, is shown by the techniques described in these guidelines. The inherent fit of these solutions to provide resilience to more traditional approaches-hybrid solutions-is not new. Indeed, they have a long heritage. In his novel The Wayward Bus, American author John Steinbeck described such a hybrid approach using banks of willows to protect the piers of a bridge from the floodwaters of the San Ysidro River in California. What is new is our intent and willingness to use these approaches. This is clearly laid out in the Environment Agency's Flood and Coastal Erosion Risk Management Strategy.

We are delighted that the Environment Agency, and our partners from the United Kingdom, have directly contributed to eight of the chapters within these guidelines. Working internationally positively encourages both sharing and learning from best practice. This enables the successful development and delivery of programmes and projects based on NNBF.

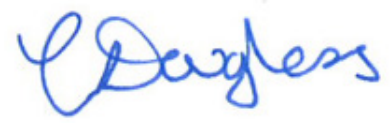

\section{Caroline Douglass}

Executive Director, Flood and Coastal Risk Management, Environment Agency 


\section{A Natural Approach to Our Future Infrastructure Needs}

The mission of the National Oceanic and Atmospheric Administration (NOAA) is to understand and predict changes in climate, weather, oceans and coasts, to share that knowledge with others, and conserve and manage coastal marine ecosystems. Through our mission and service to the Nation, NOAA partners with communities to provide data, tools, and services that help them address current and future coastal hazards. Those hazards include sea level rise, increased storm frequency, land subsidence, and loss of habitat, among others. Reducing risks associated with those hazards to overcome challenges of the twenty-first century will require solutions that harness the power of nature and its inherent potential to provide benefits to our economies, the environment and society.

NOAA recognizes that the scope of flood risk management challenges, worldwide, cannot be fully addressed solely through use of conventional infrastructure and is proud to be a contributor to the International Guidelines on Natural and Nature-Based Features (NNBF) for Flood Risk Management. The Guidelines are a milestone for the technical advancement of nature-based solutions that increase coastal resilience and reduce risk to life and property. As demonstrated by the many case studies and examples contained within this document, the use of NNBF, like marshes, dune systems, oyster reefs, islands, and mangroves, can reduce risks from multiple hazards while providing a broader suite of socioeconomic and environmental benefits. Moreover, the integration of NNBF into our landscapes will achieve many of our future infrastructure needs in a way that is compatible with the natural systems found on our planet.

The internationally authored Guidelines will equip decision makers, project planners and practitioners with solutions that reduce flood and storm risks to local communities through use of NNBF. With this advancement in knowledge and practice, NOAA is also confident that more resilient communities can be attained while preserving commerce, prioritizing equitable economic development, and producing more environmentally sustainable solutions.

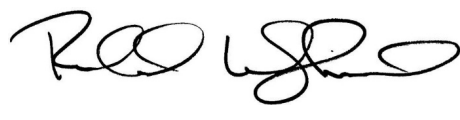

\section{Dr. Richard W. Spinrad}

Under Secretary of Commerce for Oceans and Atmosphere and NOAA Administrator, National Oceanic and Atmospheric Administration 


\section{Mainstreaming Nature-Based Solutions for Resilient Development}

Communities and governments globally are challenged by the increasing impacts of flooding. The poor are the most vulnerable to flooding and the least well-equipped to adapt to a changing climate. In many areas, mounting flood risk goes hand in hand with rapid urbanization and the loss of natural ecosystems that are critical for sustaining livelihoods and mitigating natural hazards. We cannot afford to see climate change, urbanization, and the loss of nature as independent processes, as they all contribute to these rising risks.

Effectively addressing flood risk thus requires using integrative approaches that strengthen climate resilience, protect natural areas and secure development gains. Nature-based solutions (NBS) are such ecosystem-based approaches for delivering infrastructure and to address a range of societal challenges-including approaches to address the rising challenge of flood risk. As more and more countries harness nature to address climate risks, NBS investments are a growing part of the World Bank's flood risk reduction and climate resilience portfolio.

However, bringing investments in NBS to scale requires action on multiple fronts. Governments and development partners should work across sectoral boundaries, put in place enabling policies and legislation and facilitate access to the required financing. Notably, the successful integration of NBS requires that our technical knowledge of natural infrastructure is on par with our understanding of grey infrastructure. Whereas guidelines on NBS were developed previously, including by the World Bank, these did not yet go to the level of detail needed for project-level analysis and engineering design of natural and nature-based features.

This International Guidelines on Natural and Nature-Based Features for Flood Risk Management fill that gap. Bringing together expertise of 175 experts from over 30 partner organizations, the Guidelines present a comprehensive foundation for integrating nature-based flood risk management in flood risk management investments, along with key principles and approaches for stakeholder engagement, systems thinking. adaptive management and economic analysis. In addition, the Guidelines make a crucial contribution to consolidating the growing body of knowledge of the use of specific nature-based features for managing flood risk, such as reefs, wetlands, and beaches and dunes. 
We hope these Guidelines will provide a new baseline for the technical assessment and implementation of NBS for our client countries and partners. This is another step forward in the challenge of finding the most integrative, effective, and beneficial solutions to climate risks in order to protect livelihoods, build resilience, and safeguard development gains.

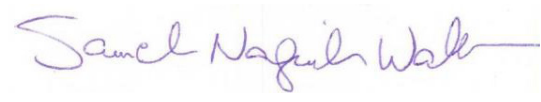

\section{Sameh Naguib Wahba}

Global Director, Urban, Disaster Risk Management, Resilience and Land, World Bank 


\section{Preface}

The application of natural and nature-based features (NNBF) has grown steadily over the past 20 years, supported by calls for innovation in flood risk management (FRM) and nature-based solutions from many different perspectives and organizations. Technical advancements in support of NNBF are increasingly the subject of peer-reviewed and other technical literature. A variety of guidance has been published by numerous organizations to inform program-level action and technical practice for specific types of nature-based solutions. This effort to develop international guidelines on the use of NNBF was motivated by the need for a comprehensive guide that draws directly on the growing body of knowledge and experience from around the world to inform the process of conceptualizing, planning, designing, engineering, and operating NNBF.

International Guidelines on Natural and Nature-Based Features for Flood Risk Management (NNBF Guidelines) is the product of a large-scale collaboration that included 5 years of working-level meetings and knowledge sharing involving key practice leaders from around the world. The project was initiated and led by the U.S. Army Corps of Engineers (USACE) as a part of its Engineering With Nature Initiative. USACE in the United States, the Rijkswaterstaat Ministry of Infrastructure and Water Management in the Netherlands, and the Environment Agency in the United Kingdom were the three primary government institutions that organized and led the effort. Many other organizations also provided critical leadership and participation, including the National Oceanic and Atmospheric Administration, World Bank, National Institute of Standards and Technology, The Nature Conservancy, and the World Wildlife Fund.

More than 180 practitioners, researchers, engineers, scientists, and other professionals from 77 public, private, nongovernment, nonprofit, and academic organizations were part of the global team. All were driven by a desire to collect, organize, and learn from the wide range of experience with NNBF around the world. The dialogue, interactions, and codevelopment of ideas across such a breadth of perspectives and experience provided a robust foundation for building authoritative guidance. The added value of assembling such a diverse team was the formation of an international community of practice (CoP) on NNBF that will continue to advance NNBF implementation. As technical work, publications, and applications of NNBF continue to grow, our NNBF CoP is resolved to update these guidelines and develop additional technical aids and tools, as necessary, to further advance the state of practice and implementation of NNBF. 
The common motivation of the individuals and organizations that contributed to the international NNBF Guidelines was to expand the arsenal of FRM solutions available to decision-makers, project planners, and practitioners. The overarching goals and planned benefits of the effort included the following:

- Presenting a rational approach to the classification, evaluation, planning, design, operation, management (including repairing and upgrading), and construction of NNBF for coastal and riverine shoreline erosion, coastal and fluvial flooding, and flood risk mitigation

- Distilling principles, challenges, methods, and examples from existing guidance, recent research, and practical experience on the use of NNBF

- Developing a conceptual framework that connects the commonalities and bridges the differences in regional and international experiences in risk management approaches and principles for flood risk mitigation

- Providing guidance on engaging with landowners, communities, and stakeholders to secure their support and address challenges related to perceptions of what NNBF is and what it can achieve

- Establishing a mechanism for the rapid dissemination and integration of new knowledge and practice into applications as current and future initiatives are completed

- Emphasizing the context and need for whole-life design of NNBF and FRM measures in general

- Supporting the wider use of NNBF in a technically appropriate and consistent manner-including as a part of multipurpose infrastructure development-that not only secures but also specifies the value of NNBF contributions to FRM and other economic, social, and environmental benefits

- Illustrating the application of NNBF through case studies of existing NNBF projects, applications, and key lessons

- Identifying gaps in scientific and engineering knowledge to focus future actions, investment, and collaboration pertaining to practice, research, and development

The many organizations that participated in writing the NNBF Guidelines are governed by different legal systems and laws, mandates, missions, and policies related to environmental stewardship, FRM, and nature-based solutions. The NNBF Guidelines provides technical information relevant to conceptualizing, planning, engineering, constructing, managing, operating, and adapting NNBF. The guidelines do not contain 
or represent the policy commitments or policy positions of the organizations that participated in their development. Policy development is the sole purview of each organization and the laws and procedures that govern their activities.

The significant technical undertaking of assembling the NNBF Guidelines was overseen by an editorial board that included representatives of public, private, and nonprofit organizations. The chapters were developed and written under the leadership of leads from different organizations; multiple co-authors and contributors provided a range of input from multiple organizational perspectives. The members of the editorial board and others provided a continuous process of technical review and feedback during the development and writing of the NNBF Guidelines.

The process of developing the NNBF Guidelines began in 2016 with the first in-person meeting of the project at the U.S. Army Engineer Research and Development Center (ERDC) in Vicksburg, Mississippi. During this kickoff meeting, a scoping document was prepared to inform the commitment of time and resources by the participating organizations. Breakout sessions focused on cross-cutting topics and specific types of features to include in the NNBF Guidelines. The output of these working sessions was the genesis of the NNBF Guidelines' 20 chapters, organized in three major sections, which include (1) common topics that are broadly applicable to NNBF (Chapters 1 to 7), in order to give the reader a background on general project considerations;

(2) a "component"-based presentation of coastal applications of NNBF (including open coast and estuarine environments) (Chapters 8 to 14); and (3) a discussion of NNBF applications in fluvial or riverine environments (Chapters 15 to 19). "The Way Forward" (a summary of the NNBF Guidelines) is provided in Chapter 20.

At seven in-person working meetings over 5 years, the team of authors and contributors shared information, developed and integrated the chapters, and established a consistent approach. Many of these working meetings included tours of NNBF projects as well as workshops and symposia with regional experts and practitioners who shared their knowledge and experience with NNBF. The meeting hosts and locations were as follows:

- 2016-USACE ERDC, Vicksburg, Mississippi, United States

- 2017-Environment Agency, London, United Kingdom

- 2017-National Oceanic and Atmospheric Administration, Silver Springs, Maryland, United States

- 2018-Rijkswaterstaat Ministry of Infrastructure and Water Management, Delft, the Netherlands 
- 2018-University of California Santa Cruz, Santa Cruz, California, United States

- 2019-Environment Agency, Edinburgh, Scotland, United Kingdom

- 2019-USACE ERDC, Vicksburg, Mississippi, United States

The NNBF Guidelines is intended to inform the efforts of practitioners, organizations, and communities seeking to increase the performance of FRM systems and achieve long-term risk mitigation, increase water infrastructure resilience and sustainability, reduce infrastructure maintenance and repair costs, and, ultimately, increase the value produced by FRM infrastructure investments. The purpose of these guidelines is to provide a good background on the basic concepts of NNBF, as well as its potential applicability to various coastal, fluvial, and NNBF systems to the general reader. The NNBF Guidelines is a step forward in advancing twenty-first century FRM. 


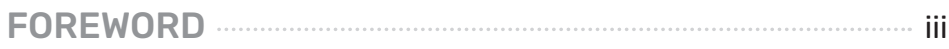

PREFACE ……… $\mathrm{x}$

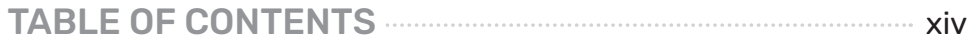

ACKNOWLEDGMENTS $\ldots \ldots \ldots \ldots \ldots$

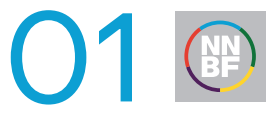

THE NEED AND OPPORTUNITY FOR NNBF: AN

INTRODUCTION TO THE GUIDELINES $\ldots \ldots \ldots \ldots$

1.1 Organization of the Guidelines 6

1.2 Overarching Observations 8

1.3 References $\ldots . . . . . . . . .15$

\section{0}

PRINCIPLES, FRAMEWORKS, AND OUTCOMES _....... 19

2.1 Introduction $\ldots$

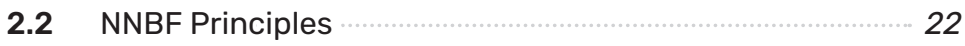

2.3 Frameworks 26

2.4 Outcomes $\ldots . .27$

2.5 Steps Found within Phases of the NNBF Framework …... 28

2.6 References 45

\section{3 遮}

ENGAGING COMMUNITIES AND STAKEHOLDERS IN IMPLEMENTING NNBF

3.1 Introduction 49

3.2 Defining Engagement and Its Importance …_.......... 55

3.3 Engagement within the NNBF Project Framework ……... 64

3.4 Develop an Engagement Plan ……….................... 66

3.5 Articulate Engagement Principles and Set Engagement Objectives

3.6 Assess the Context and Stakeholders …........... 78

3.7 Determine Engagement Methods ………….............. 88

3.8 Assess Resources ……….......... 92 
3.9 Evaluate the Engagement $\ldots$

3.10 Quick Reference ……........................................

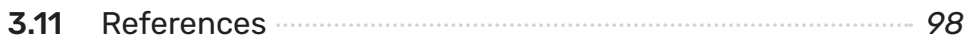

4.1 Introduction …......................... 105

4.2 Principles for Using a Systems Approach in Flood Risk Management

4.3 Implementation $\ldots . .114$

4.4 Summary 149

4.5 Gaps and Future Directions …… 151

4.6 References 152

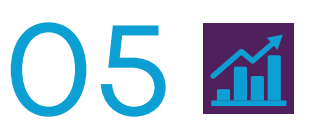

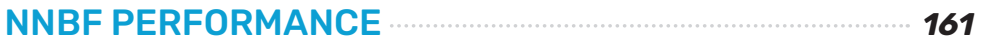

5.1 Introduction 163

5.2 Describing NNBF Performance …………… 164

5.3 Assessing NNBF Performance …… 169

5.4 NNBF Performance Dynamism ……………… 187

5.5 NNBF Resilience ……......................................

5.6 Life-Cycle Approach for NNBF Performance
Assessment

5.7 Uncertainty and NNBF Performance Assessment …….... 195

5.8 Gaps and Future Directions ……………… 197

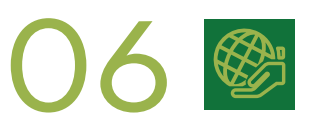

BENEFITS AND COSTS OF NNBF …… 203

6.1 Introduction

6.2 The Benefits and Costs of NNBF ………………. 211

6.3 Scoping and Qualitative Assessment of Benefits …….... 216

6.4 Quantitative Assessment of Benefits and Costs ……….. 224

6.5 Comparing Costs and Benefits of Project Alternatives Using Decision-Support Frameworks 
6.6 Monitoring and Managing the Performance and Benefits of NNBF

6.7 Gaps and Future Directions ……................ 248

6.8 References 250

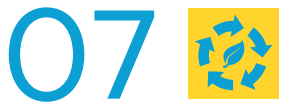

ADAPTIVE MANAGEMENT …… 270

7.1 Introduction 273

7.2 Applicability of Adaptive Management for NNBF ….... 278

7.3 Development of an Adaptive Management Plan ……... 279

7.4 Gaps and Future Directions $\ldots$

7.5 References ……….............. 314

\section{8 圆}

INTRODUCTION TO NNBF IN COASTAL SYSTEMS … 319

8.1 Context for the Use of NNBF in the Coastal Zone ……... 321

8.2 Identifying Appropriate Locations for NNBF and Associated Longshore Alignment of the Risk Management Interventions

8.3 NNBF Geometry and Structure …… 324

8.4 Success Factors for Coastal NNBF 324

8.5 Measures Covered in the Coastal Section of These NNBF Guidelines $\quad 324$

8.6 References 326

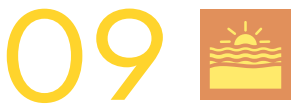

BEACHES AND DUNES ………. 329

9.1 Introduction 332

9.2 Defining the Feature, Its Benefits, and the Context for Its Application

9.3 Conceptual System Understanding 336

9.4 Objectives and Metrics 351

9.5 Design ……................. 357

9.6 Implementation 397 
9.7 Adaptive Management, Monitoring, and Operation and Maintenance

9.8 Gaps and Future Directions …………............. 402

9.9 References

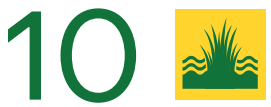

COASTAL WETLANDS AND TIDAL FLATS $\ldots$.

10.1 Introduction

10.2 Defining the Feature, Its Values, and Contexts for Application

10.3 Conceptual System Understanding

10.4 Objectives, Performance, and Metrics …… 431

10.5 Conceptual Design Considerations …… 433

10.6 Developing Detailed Designs and Specifications …….... 448

10.7 Construction Considerations and Methods …....... 471

10.8 Monitoring, Maintenance, Evaluation, and Adaptive Management

10.9 Gaps and Future Directions … 481

10.10 References

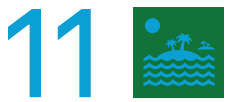

ISLANDS $\ldots$

11.1 Introduction $\ldots$

11.2 Conceptual System Understanding _... 510

11.3 Objectives and Metrics 520

11.4 Design Considerations ……………… 523

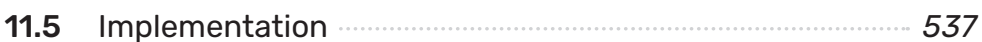

11.6 Monitoring, Maintenance, and Adaptive Management after Construction ….................. 547

11.7 Gaps and Future Directions ……................. 549

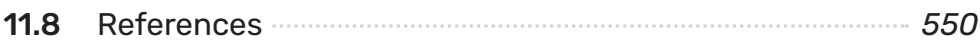



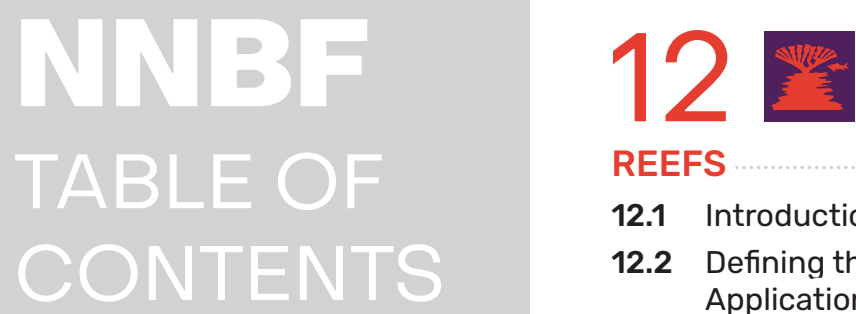

REEFS $\quad 559$

12.1 Introduction 562

12.2 Defining the Feature, Its Values, and Contexts for Application

12.3 Conceptual Understanding $\ldots$

12.4 Project Objectives and Guiding Principles $\ldots 58$

12.5 Design Process ………. 587

12.6 Construction Considerations and Methods for Reef Restoration …............. 603

12.7 Costs and Benefits …… 608

12.8 Monitoring, Operations, Maintenance, and Management 611

12.9 Gaps and Future Directions 616

12.10 References $\ldots 1 \ldots \ldots \ldots$

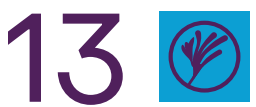

PLANT SYSTEMS: SUBMERGED AQUATIC VEGETATION AND KELP $\quad 636$

13.1 Introduction....... .638

13.2 Defining the Feature, Its Values, and Contexts for
Application

13.3 Conceptual System Understanding …............ 652

13.4 Objectives and Metrics …… 657

13.5 Design Considerations 660

13.6 Construction Considerations and Methods ….......... 677

13.7 Monitoring and Adaptive Management ……… 680

13.8 Inherent Uncertainties $\quad 687$

13.9 Gaps and Future Directions …… 687

13.10 References $\ldots 88$

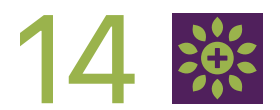

ENHANCING STRUCTURAL MEASURES FOR

ENVIRONMENTAL, SOCIAL, AND ENGINEERING BENEFITS

14.1 Introduction … 703

14.2 Project Goals, Objectives, and Values ……………… 
14.3 Project Benefits

14.4 Design Considerations $\quad 715$

14.5 Costs versus Benefits …… 721

14.6 Agreements and Licenses

14.7 Implementation Phase Considerations …........................ 726

14.8 Monitoring, Operations, Maintenance, and Management 733

14.9 Case Studies $\ldots . \ldots$

14.10 Managing Risks and Uncertainties $\ldots 761$

14.11 Gaps and Future Directions …… 764

14.12 References 766

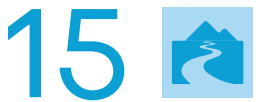

INTRODUCTION TO FLUVIAL SYSTEMS:

KEY THEMES, GAPS, AND FUTURE DIRECTIONS ……. 772

15.1 Objectives for NNBF in Fluvial Settings …… 776

15.2 Gaps and Future Directions ………............... 777

15.3 References 778

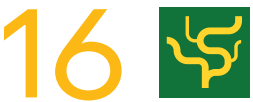

FLUVIAL SYSTEMS AND FLOOD RISK MANAGEMENT .. 780

16.1 Introduction ……… 782

16.2 Stress on Fluvial Systems and the Story of Human
Impacts

16.3 Principles of Fluvial NNBF …… 793

16.4 Chapter Summary $\quad 799$

16.5 References 799

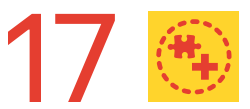

BENEFITS AND CHALLENGES IN THE APPLICATION OF NNBF IN FLUVIAL SYSTEMS

17.1 Introduction

17.2 Challenges in River Management and the Contribution of NNBF

17.3 Constraints in the Application of Fluvial NNBF …….... 822

17.4 The Benefits of NNBF … 825 
17.7 Gaps and Future Directions

\section{8}

DESCRIPTION OF FLUVIAL NNBF

18.1 Introduction

18.2 River and Floodplain Management

18.3 Vegetation Management

18.4 Rural Runoff Management

869

18.5 Urban Runoff Management

18.6 Erosion Management

18.7 References

888

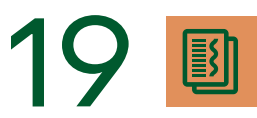

FLUVIAL NNBF CASE STUDIES

891

19.1 Introduction

893

19.2 Vegetation Management

925

19.3 Rural Runoff Management

931

19.4 Urban Runoff Management

943

19.5 Erosion Management

950

\section{$20 \cong$}

THE WAY FORWARD

967

20.1 Developing and Delivering

968

20.2 Communicating and Collaborating

969

20.3 Elevating and Educating

971

ABBREVIATIONS LIST

974

GLOSSARY

978

INDEX 


\title{
Acknowledgments
}

\section{Publication Management and Oversight}

\author{
PARTNER ORGANIZATIONS \\ U.S. Army Corps of Engineers \\ National Oceanic and Atmospheric Administration \\ Environment Agency of the United Kingdom \\ Rijkswaterstaat \\ World Bank
}

Many other organizations also provided critical leadership and participation, including the National Institute of Standards and Technology, The Nature Conservancy, and the World Wildlife Fund.

\section{Australia \\ Canada \\ Denmark \\ Kenya \\ The Netherlands \\ New Zealand \\ Norway \\ Sri Lanka \\ United Kingdom \\ United States}

CONTRIBUTING COUNTRIES

\section{EDITORIAL BOARD}

Todd S. Bridges (Chair), U.S. Army Corps of Engineers, United States

Jeffrey K. King, U.S. Army Corps of Engineers, United States

Jonathan D. Simm, HR Wallingford, United Kingdom

Michael W. Beck, University of California, Santa Cruz, United States

Georganna Collins, Aqua Strategies, Inc., United States

Quirijn Lodder, Rijkswaterstaat, the Netherlands

Ram K. Mohan, Anchor QEA, LLC, and Texas A\&M University, United States

\section{PROJECT DIRECTORS}

Todd S. Bridges, U.S. Army Corps of Engineers, United States

Jeffrey K. King, U.S. Army Corps of Engineers, United States

Courtney Chambers, U.S. Army Corps of Engineers, United States 


\section{Lead Authors and Co-Authors}

\author{
Chapter 1: \\ The Need and \\ Opportunity \\ for NNBF: An \\ Introduction to \\ the Guidelines
}

\section{Chapter 2: \\ Principles, \\ Frameworks, and Outcomes}

\section{Chapter 3: \\ Engaging \\ Communities and \\ Stakeholders in Implementing NNBF}

\section{Chapter 4: \\ Planning and Implementing NNBF Using a Systems Approach}

\section{LEAD AUTHORS}

Todd S. Bridges, U.S. Army Corps of Engineers, United States Jeffrey K. King, U.S. Army Corps of Engineers, United States Jonathan D. Simm, HR Wallingford, United Kingdom

\section{LEAD AUTHORS}

Jeffrey K. King, U.S. Army Corps of Engineers, United States Jonathan D. Simm, HR Wallingford, United Kingdom

\section{CO-AUTHOR}

Todd S. Bridges, U.S. Army Corps of Engineers, United States

\section{LEAD AUTHOR}

Maria Dillard, National Institute of Standards and Technology, United States

\section{CO-AUTHORS}

Cath Brooks, Environment Agency, United Kingdom Helen Fisher, 3KQ, United Kingdom

Hans Pietersen, Rijkswaterstaat, the Netherlands

Alwin Nijhuis, Rijkswaterstaat, the Netherlands

Anita van Breda, World Wildlife Fund, United States

Susan Durden, U.S. Army Corps of Engineers, United States

\section{LEAD AUTHORS}

Jurre de Vries, Rijkswaterstaat, the Netherlands

Denise Reed, University of New Orleans, United States

\section{CO-AUTHORS}

S. Kyle McKay, U.S. Army Corps of Engineers, United States

Tjeerd Bouma, Royal Netherlands Institute for Sea Research; Utrecht University; HZ University of Applied Sciences, the Netherlands

Shannon E. Cunniff, Environmental Defense Fund, United States

Bart Grasmeijer, Deltares, the Netherlands

Pamela Mason, College of William \& Mary, United States

Alex Nicholson, Arup, United Kingdom

Paul Quinn, Newcastle University, United Kingdom

Jane McKee Smith, U.S. Army Corps of Engineers, United States 
Chapter 5:

NNBF

Performance

Chapter 6:

Benefits and Costs of NNBF

Chapter 7:

Adaptive

Management

\section{LEAD AUTHORS}

Candice D. Piercy, U.S. Army Corps of Engineers, United States

Jonathan D. Simm, HR Wallingford, United Kingdom

\section{CO-AUTHORS}

Todd S. Bridges, U.S. Army Corps of Engineers, United States

Missaka Hettiarachchi, World Wildlife Fund, Australia and Sri Lanka

Quirijn Lodder, Rijkswaterstaat, the Netherlands

\section{LEAD AUTHORS}

Boris van Zanten, World Bank, United States

Katie Arkema, Stanford University; Pacific Northwest National Laboratory, United States

Todd Swannack, U.S. Army Corps of Engineers, United States

\section{CO-AUTHORS}

Rob Griffin, University of Massachusetts-Dartmouth, United States

Siddharth Narayan, East Carolina University, United States

Kim Penn, National Oceanic and Atmospheric Administration, United States

Borja G. Reguero, University of California, Santa Cruz, United States

Giselle Samonte, National Oceanic and Atmospheric Administration, United States

Steven Scyphers, Northeastern University, United States

Elizabeth Codner-Smith, The Nature Conservancy, United States

Stéphanie IJff, Deltares, the Netherlands

Marin Kress, U.S. Army Corps of Engineers, United States

Michele Lemay, Inter-American Development Bank, United States

\section{LEAD AUTHORS}

Harry de Looff, Rijkswaterstaat, the Netherlands

Tim Welp, U.S. Army Corps of Engineers, United States

\section{CO-AUTHORS}

Natalie Snider, Environmental Defense Fund, United States

Rinse Wilmink, Rijkswaterstaat, the Netherlands 
Chapter 8:

Introduction to NNBF in Coastal

Systems

\section{Chapter 9: \\ Beaches and \\ Dunes}

\section{Chapter 10: \\ Coastal Wetlands and Tidal Flats}

\section{Chapter 11: Islands}

\section{LEAD AUTHOR}

Jonathan Simm, HR Wallingford, United Kingdom

\section{LEAD AUTHORS}

Quirijn Lodder, Rijkswaterstaat, the Netherlands

Claire Jeuken, Deltares USA Inc., United States

\section{CO-AUTHORS}

Richard Reinen-Hamill, Tonkin + Taylor, New Zealand

Oli Burns, Environment Agency, United Kingdom

Robert Ramsdell, III, Dredging Consultant, United States

Jurre de Vries, Rijkswaterstaat, the Netherlands

Brian McFall, U.S. Army Corps of Engineers, United States

Stéphanie IJff, Deltares, the Netherlands

Corragio Maglio, U.S. Army Corps of Engineers, United States

Rinse Wilmink, Rijkswaterstaat, the Netherlands

\section{LEAD AUTHORS}

Candice D. Piercy, U.S. Army Corps of Engineers, United States Nigel Pontee, Jacobs, United Kingdom

\section{CO-AUTHORS}

Siddharth Narayan, East Carolina University, United States

Jenny Davis, National Oceanic and Atmospheric Administration, United States Trevor Meckley, National Oceanic and Atmospheric Administration, United States

\section{LEAD AUTHORS}

Joseph Gailani, U.S. Army Corps of Engineers, United States

Paula Whitfield, National Oceanic and Atmospheric Administration, United States

Enda Murphy, National Research Council Canada, Canada

\section{CO-AUTHORS}

Jurre de Vries, Rijkswaterstaat, the Netherlands

Gordon Thomson, Baird, United States

Wendell Mears, Anchor QEA, LLC, United States

Danielle Szimanski, U.S. Army Corps of Engineers, United States 
Chapter 12:

Reefs

Chapter 13:

Plant Systems:

Submerged

Aquatic

Vegetation and

Kelp

\section{LEAD AUTHORS}

Ryan J. Lowe, The University of Western Australia, Australia Elizabeth McLeod, The Nature Conservancy, United States

\section{CO-AUTHORS}

Borja G. Reguero, University of California, Santa Cruz, United States

Safra Altman, U.S. Army Corps of Engineers, United States

Janine Harris, National Oceanic and Atmospheric Administration, United States

Boze Hancock, The Nature Conservancy, United States

Remment ter Hofstede, Van Oord, the Netherlands

Emma Rendle, Resilient Coasts, United Kingdom

Elizabeth Shaver, The Nature Conservancy, United States

Jane McKee Smith, U.S. Army Corps of Engineers, United States

\section{LEAD AUTHORS}

Safra Altman, U.S. Army Corps of Engineers, United States

Colette Cairns, National Oceanic and Atmospheric Administration, United States

\section{CO-AUTHORS}

Paula Whitfield, National Oceanic and Atmospheric Administration, United States

Jenny Davis, National Oceanic and Atmospheric Administration, United States

Mark Finkbeiner, National Oceanic and Atmospheric Administration, United States

Brian McFall, U.S. Army Corps of Engineers, United States

\section{Chapter 14: \\ Enhancing \\ Structural \\ Measures for \\ Environmental, \\ Social, and \\ Engineering \\ Benefits}

\section{LEAD AUTHORS}

Burton C. Suedel, U.S. Army Corps of Engineers, United States

Larissa A. Naylor, University of Glasgow, United Kingdom

\section{CO-AUTHORS}

Trevor Meckley, National Oceanic and Atmospheric Administration, United States

Colette Cairns, National Oceanic and Atmospheric Administration, United States

Jason Bernier, CBCL Limited, Canada

Ed Morgereth, Biohabitats, United States

Wendell Mears, Anchor QEA, LLC, United States

Candice D. Piercy, U.S. Army Corps of Engineers, United States

Remment ter Hofstede, Van Oord, the Netherlands 


\section{Chapter 15: \\ Introduction to \\ Fluvial Systems: \\ Key Themes, \\ Objectives, \\ Gaps, and Future \\ Directions}

\section{Chapter 16: \\ Fluvial Systems and Flood Risk Management}

\section{LEAD AUTHORS}

Christopher Haring, U.S. Army Corps of Engineers, United States Ralph Schielen, Rijkswaterstaat, the Netherlands

Jo Guy, Environment Agency, United Kingdom

Lydia Burgess-Gamble, Environment Agency, United Kingdom

\section{LEAD AUTHORS}

Christopher Haring, U.S. Army Corps of Engineers, United States Ralph Schielen, Rijkswaterstaat, the Netherlands

Jo Guy, Environment Agency, United Kingdom

Lydia Burgess-Gamble, Environment Agency, United Kingdom

\section{CO-AUTHOR}

Brian Bledsoe, University of Georgia, United States

\section{LEAD AUTHORS}

Ralph Schielen, Rijkswaterstaat, the Netherlands

Christopher Haring, U.S. Army Corps of Engineers, United States Lydia Burgess-Gamble, Environment Agency, United Kingdom

Jo Guy, Environment Agency, United Kingdom

\section{CO-AUTHORS}

Brian Bledsoe, University of Georgia, United States

Randy Mandel, Ramboll, United States

\section{LEAD AUTHORS}

Chapter 18:

Description of Fluvial NNBF
Lydia Burgess-Gamble, Environment Agency, United Kingdom Christopher Haring, U.S. Army Corps of Engineers, United States Ralph Schielen, Rijkswaterstaat, the Netherlands Jo Guy, Environment Agency, United Kingdom

\section{CO-AUTHORS}

David Ramsbottom, HR Wallingford, United Kingdom Bridget Woods Ballard, HR Wallingford, United Kingdom Marta Roca Collell, HR Wallingford, United Kingdom Rachel Glover, Environment Agency, United Kingdom Felix van Zoest, Rijkswaterstaat, the Netherlands 
Chapter 19:

Fluvial NNBF Case

Studies

Chapter 20:

The Way Forward

\section{LEAD AUTHORS}

Lydia Burgess-Gamble, Environment Agency, United Kingdom Ralph Schielen, Rijkswaterstaat, the Netherlands

Christopher Haring, U.S. Army Corps of Engineers, United States

Jo Guy, Environment Agency, United Kingdom

CO-AUTHORS

Rachel Glover, Environment Agency, United Kingdom

Randy Mandel, Ramboll, United States

Bridget Woods Ballard, HR Wallingford, United Kingdom

Marta Roca Collell, HR Wallingford, United Kingdom

LEAD AUTHOR

Todd S. Bridges, U.S. Army Corps of Engineers, United States

\section{CO-AUTHORS}

Jeffrey K. King, U.S. Army Corps of Engineers, United States

Jonathan D. Simm, HR Wallingford, United Kingdom 


\section{Technical Review and Production}

Final document assembled, technically reviewed, copyedited, and designed by Anchor QEA, LLC, under contract to U.S. Army Corps of Engineers. Jonathan D. Simm of HR Wallingford provided technical and quality reviews of the document, and Georganna Collins of Aqua Strategies provided consulting on graphics and layout, as subcontractors to Anchor QEA. All individuals listed below are part of Anchor QEA.

\section{PRODUCTION MANAGERS}

Ram K. Mohan (Project Director)

Zelini Hubbard (Technical Review and Document Manager)

\section{PRODUCTION TEAM}

Toni Salvador (Editorial Lead)

Zheng Fang (Graphics Lead)

TECHNICAL EDITORS

Katie Atkins

Hannah Garrison

Liz Hanbury

Ken Mayo

Megan Russo

TECHNICAL SUPPORT

Steven Bagnull

Billie-Jo Gauley

Dan Opdyke

Travis Merritts 

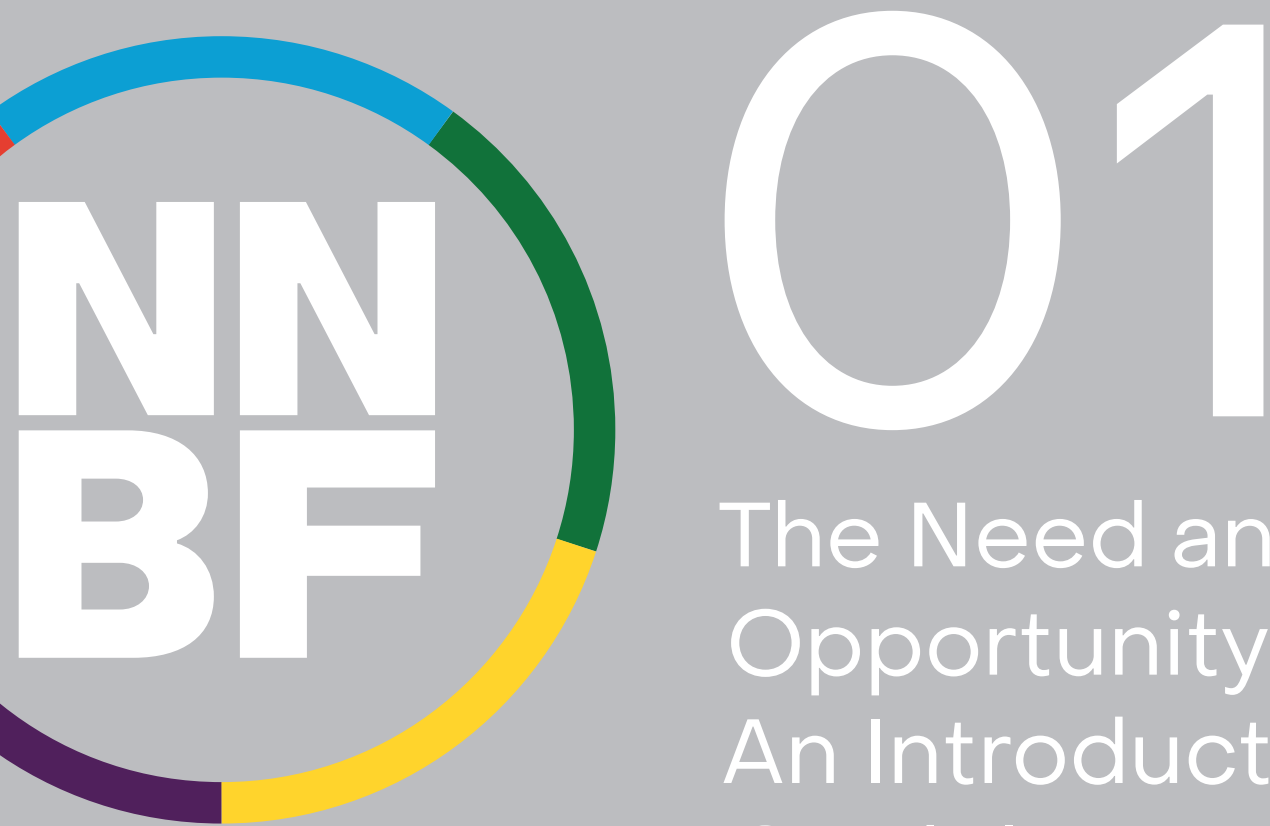

\section{The Need and Opportunity for NNBF: An Introduction to the Guidelines}

\section{Suggested Citation:}

Bridges, T. S., J. K. King, and J. D. Simm. 2021. "Chapter 1: The Need and Opportunity for NNBF: An Introduction to the Guidelines." In International Guidelines on Natural and Nature-Based Features for Flood Risk Management. Edited by T. S. Bridges, J. K. King, J. D. Simm, M. W. Beck, G. Collins, Q. Lodder, and R. K. Mohan. Vicksburg, MS: U.S. Army Engineer Research and Development Center.

Full acknowledgments appear at the end of this chapter. 

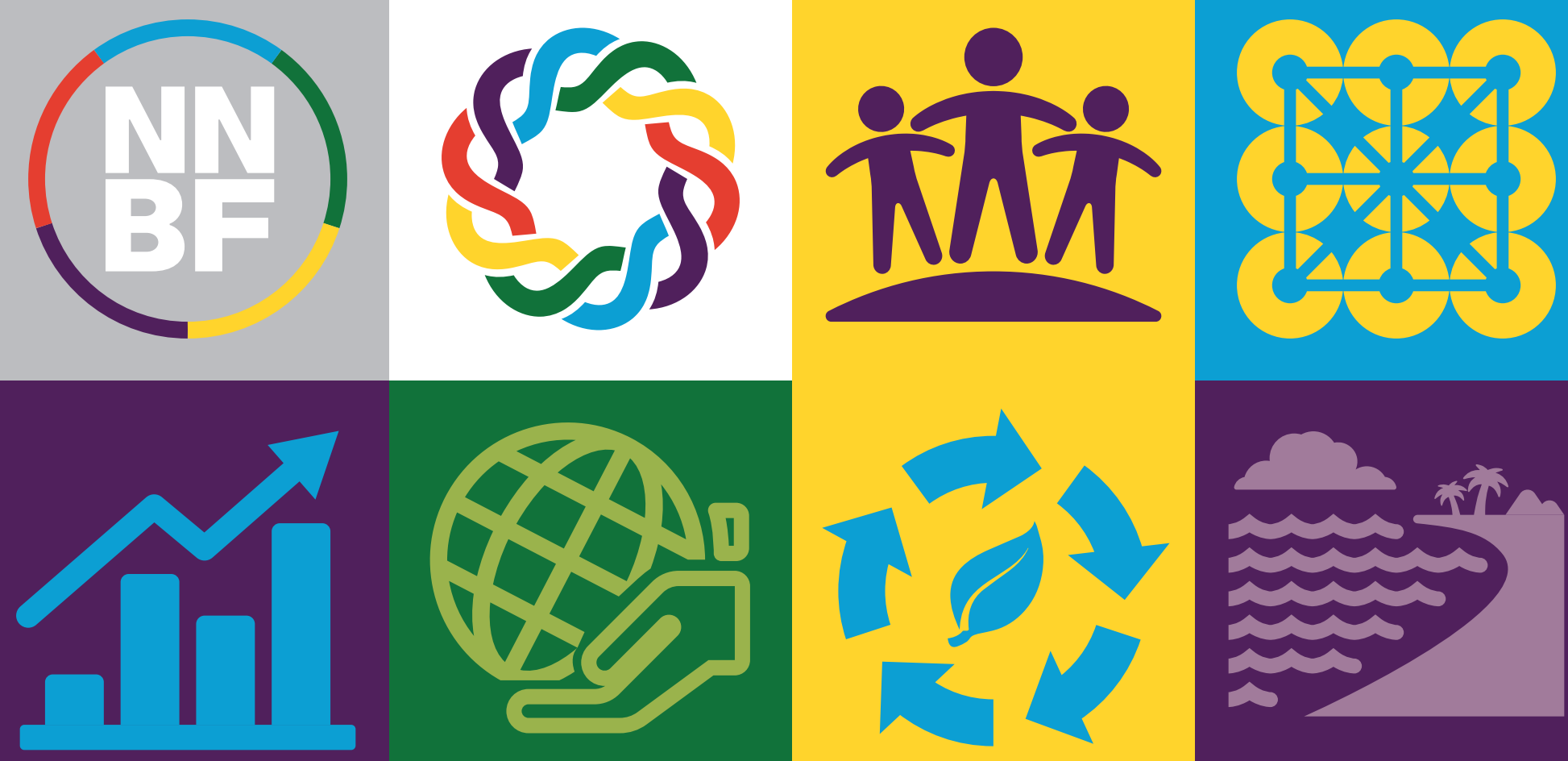
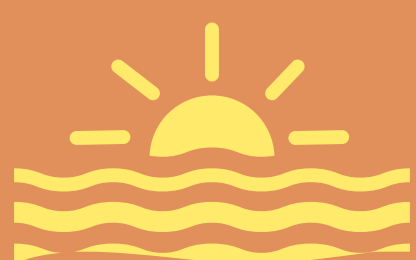
2

Tor
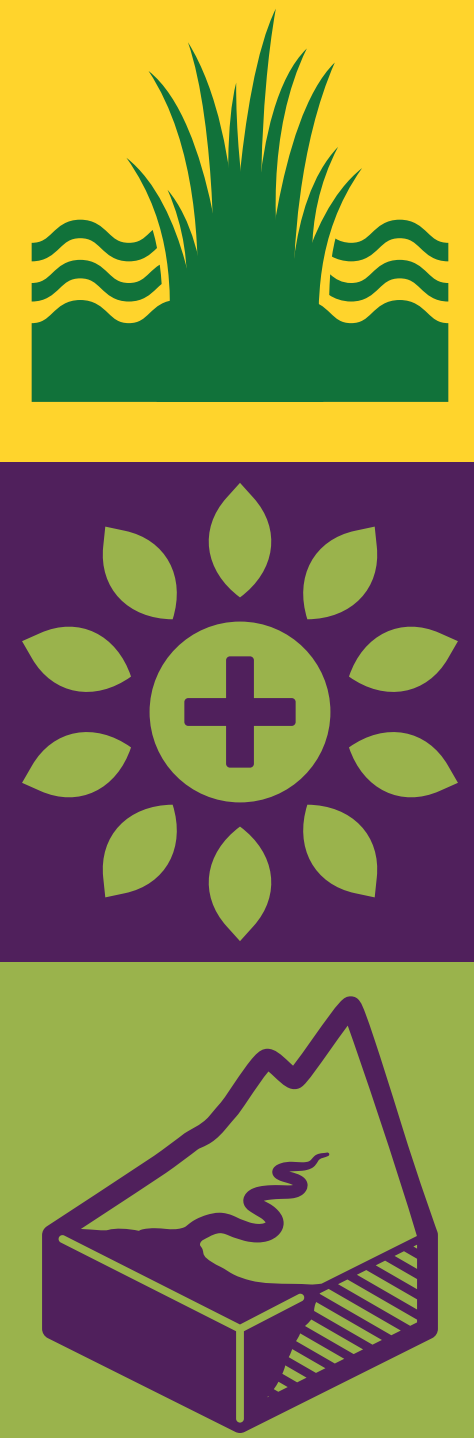

\section{यदित}

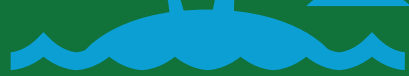

10

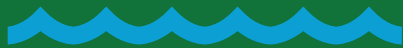

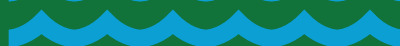

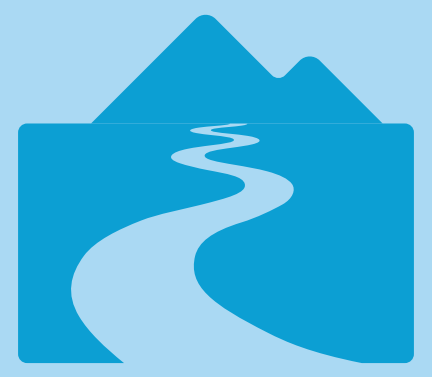

सा? $358 ?$

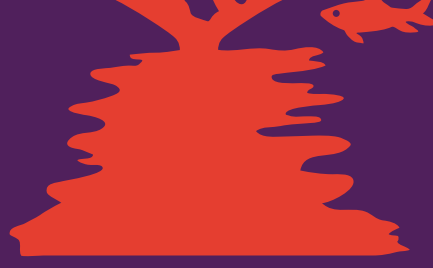

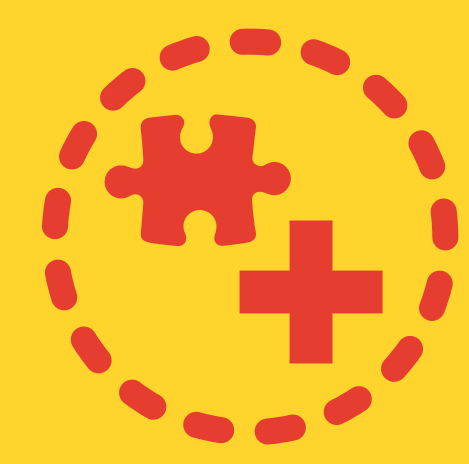
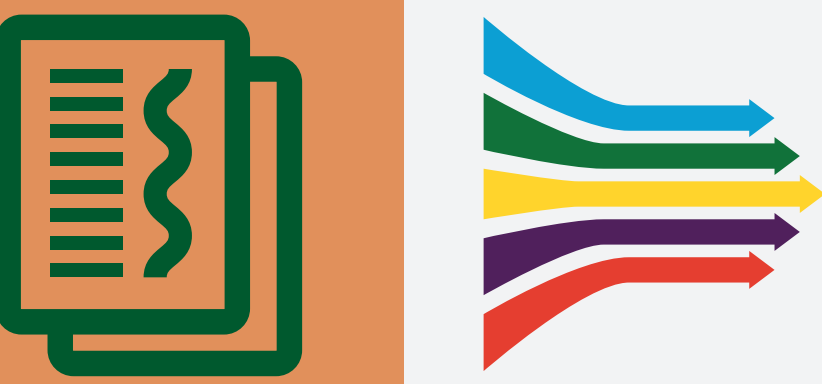


\section{Nature does nothing in vain.}

- Aristotle

The achievements of engineering in the twentieth century are awesome to consider. Engineering systems built over the past 100 -plus years provide the foundation of modern civilization, supporting services related to communication, transportation, and the resources on which humans depend, including food, energy, and water. The portfolio of infrastructure worldwide includes tens of thousands of large dams and dikes (Mulligan et al. 2020). This large-scale engineering has reshaped the earth's landscapes and natural environment.

Twentieth-century flood risk management (FRM) systems have produced mixed results. They have certainly averted damages to life and property on the human-engineered landscape. But it is also true that they have induced risks (e.g., incentivized development behind levees and other structures), are subject to catastrophic failure, and have resulted in a loss of natural habitat and ecosystem services. The challenges of FRM are being aggravated by the realities of climate change. Sea-level rise, the nature and frequency of storms, and other drivers are increasingly revealing vulnerabilities in FRM strategies that were implemented over the past century. Munich Re estimates that global losses in 2020 due to natural disasters totaled approximately $\$ 210$ billion U.S. dollars (USD), of which only USD\$82 billion was insured, with more than 8,000 lives lost (munichre.com 2021). The 2020 North Atlantic hurricane season included a record-setting 30 storms, 13 of which reached hurricane status. Of the 10 costliest natural disasters in 2020, 6 occurred in the United States (munichre.com 2021). The U.S. National Oceanic and Atmospheric Administration tracks weather and climate disasters that produce at least USD\$1 billion in losses. In 2020, a record 22 such events in the United States caused more than 260 deaths and produced a total of USD\$95 billion in losses. Since 1980, 285 weather and climate disasters in the United States have caused more than 14,000 deaths and produced cumulative losses in excess of USD\$1.8 trillion (ncdc.noaa.gov 2021).

With these challenges and consequences in mind, there is reason to ask what kind of infrastructure investment will be needed in the twenty-first century. It is estimated that the world's population will reach 10 billion by 2100 , with a consequent increase in demand for the services provided by infrastructure. The World Economic Forum estimates that by mid-century, USD\$100 trillion will have been invested in infrastructure development worldwide (World Economic Forum 2013). This investment will be directed to maintaining existing systems, upgrading aging and outdated infrastructure, and developing new infrastructure. There is widespread acknowledgment that this investment should be designed to support both the sustainability and the resilience of our economies, environment, and social systems. What will such infrastructure systems look like? How will they work? What innovations will be needed to deliver them? How can conventional engineering solutions and natural systems be integrated to increase and diversify the return on infrastructure investment? 
The development of future infrastructure systems presents an important opportunity to make more intentional use of the processes and functions found in natural systems, strengthen engineering performance, and expand infrastructure value. The predominant materials used to develop twentieth-century infrastructure were concrete, rock, brick, and steel. The amount of human-produced mass in the form of these materials grew rapidly over the past 100 -plus years, doubling approximately every 20 years since 1900, to the point where human-produced mass now exceeds the total living biomass on the planet (more than 1 teratonne; Elhacham et al. 2020). This unsettling milestone raises serious challenges regarding sustainability generally and begs serious questions about how infrastructure will be developed in the remainder of the twenty-first century. The historical approach to infrastructure development was guided, to a significant degree, by the use of human engineering to "conquer" nature rather than "collaborate" with nature. The historian and philosopher of technology Lewis Mumford wrote the following (Mumford 1970):

\section{In the act of "conquering nature" our ancestors too often treated the earth contemptuously, under the delusion that the losses did not matter, since modern man through science and invention would soon fabricate an artificial world infinitely more wonderful than the one that nature provided-an even grosser delusion.}

The purpose of the International Guidelines on Natural and Nature-Based Features for Flood Risk Management (NNBF Guidelines) is to inform the use of natural systems and functions to support FRM. In these guidelines, FRM refers to actions taken to reduce future damage to people and property ${ }^{i i}$ caused by flooding and erosion in coastal and fluvial systems, including actions to address the myriad biophysical processes that contribute to flooding and erosion (e.g., processes contributing to shoreline erosion and loss of land elevation that can increase flood risks over time). The term natural and nature-based features (NNBF) refers to the use of landscape features to produce FRM benefits. NNBF projects may also produce other economic, environmental, and social benefits known as NNBF co-benefits. These landscape features may be natural (produced purely by natural processes) or nature based (produced by a combination of natural processes and human engineering) and include such features as beaches, dunes, wetlands, reefs, and islands. Landscape features can be used alone, in combination with each other, and in combination with conventional engineering measures such as levees, floodwalls, and other structures. The type, number, size, and combinations of measures (NNBF or conventional structures) used in an FRM system depend on the context of the problem and on the geographic setting, the goals of the project, and a host of other factors. There is a need to address FRM at various, interlinked spatial and temporal scales. These scales are also related to project level (local and regional), program level (regional and national), and even policy or strategy level (national and international). The concept remains similar, but the specifics of implementation can vary. 
As used in these guidelines, NNBF are a type of nature-based solution. Different definitions of nature-based solutions for risk reduction and adaptation are in use across the numerous and diverse organizations that are advancing and applying these approaches. The common element among all these definitions is the focus on conserving, restoring, and engineering natural systems for the benefit of people and the ecosystems we inhabit. Related terms, though not necessarily synonymous, include building with nature, Engineering With Nature, nature-based solutions, natural flood management, and green infrastructure (see Figure 1.1). The pursuit and development of such approaches stretch across several decades. In the 1960s, ecologist Howard T. Odum and others developed a foundation for ecological engineering; and in 1969, the landscape architect lan McHarg published his seminal book Design with Nature (McHarg 1969). These efforts, and others, contributed to the development of what are now called nature-based solutions.

\section{Figure 1.1. Terms Related to NNBF}

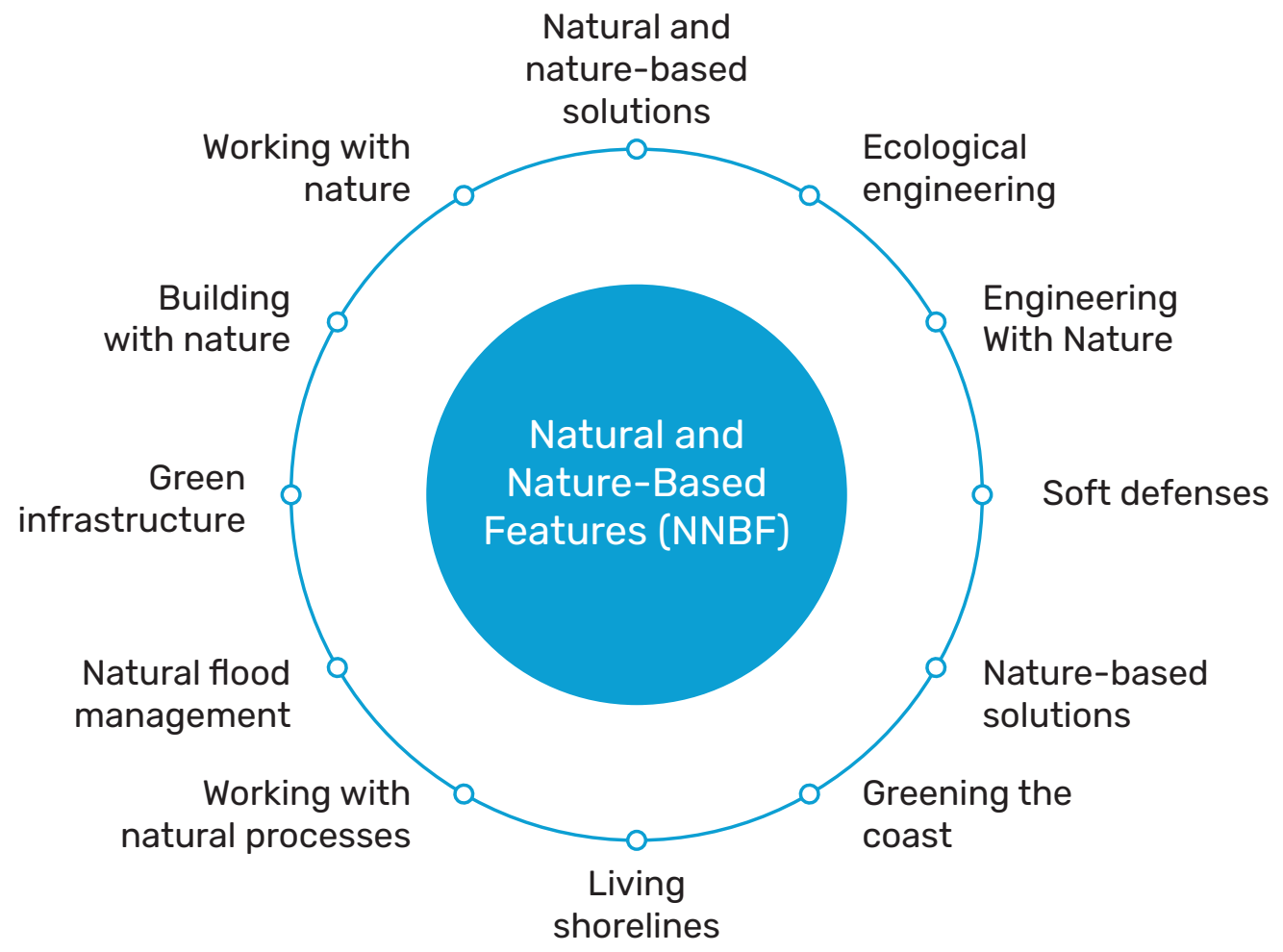

Source: Nigel Pontee, Jacobs 
The use of NNBF in various forms has been growing and maturing for several decades, and NNBF projects have been built and are successfully operating around the world. Collecting and sharing the international experience on NNBF was a primary motivation for developing the NNBF Guidelines. The length of this document (more than 1,000 pages) testifies to the significant amount of global experience and technical work on NNBF, which continues to grow. Hundreds of scientific papers and reports related to NNBF have been produced by organizations, researchers, and practitioners around the world during the 5 years this NNBF Guidelines was developed. That said, the purpose of these guidelines is to inform and guide, not to provide an exhaustive summary or analysis of this growing body of technical literature. This guidance is not intended to be a "cookbook" with NNBF "recipes" to follow. We do not aim to provide the NNBF analog for calculating the size of rock to be used in conventional shoreline armoring projects. The goal of the NNBF Guidelines is to help inform the process of conceptualizing, planning, designing, engineering, and operating FRM systems that include NNBF. The escalating scale of flood risks and challenges calls for new ways of envisioning solutions, layering and combining measures, and phasing the development of FRM systems that include the functions and values nature can provide.

\section{1 | Organization of the Guidelines}

These guidelines are divided into three major sections. The first major section covers a set of common topics that are broadly applicable to NNBF. The second major section addresses coastal applications of NNBF, including open coast and estuarine environments. The third major section covers NNBF applications in fluvial or riverine environments. Throughout the document, examples and case studies illustrate the diverse contexts and progress being made in applying NNBF worldwide.

The guidelines are organized so that readers can begin where their interests lie. Given the conceptual connections and relationships among the topics covered in the chapters (see Figure 1.2), the chapters were developed in a collaborative environment where there was communication and engagement across chapter teams. We wanted the chapters to be able to not only stand on their own but also be part of an integrated treatment of NNBF. Each chapter begins with a list of its key, high-level messages, includes references to other chapters, and uses icons and case studies to draw attention to key topics covered elsewhere in the NNBF Guidelines. The science and practice in this field are rapidly advancing, so we plan to update these guidelines in the future, when the timing seems appropriate to do so. 


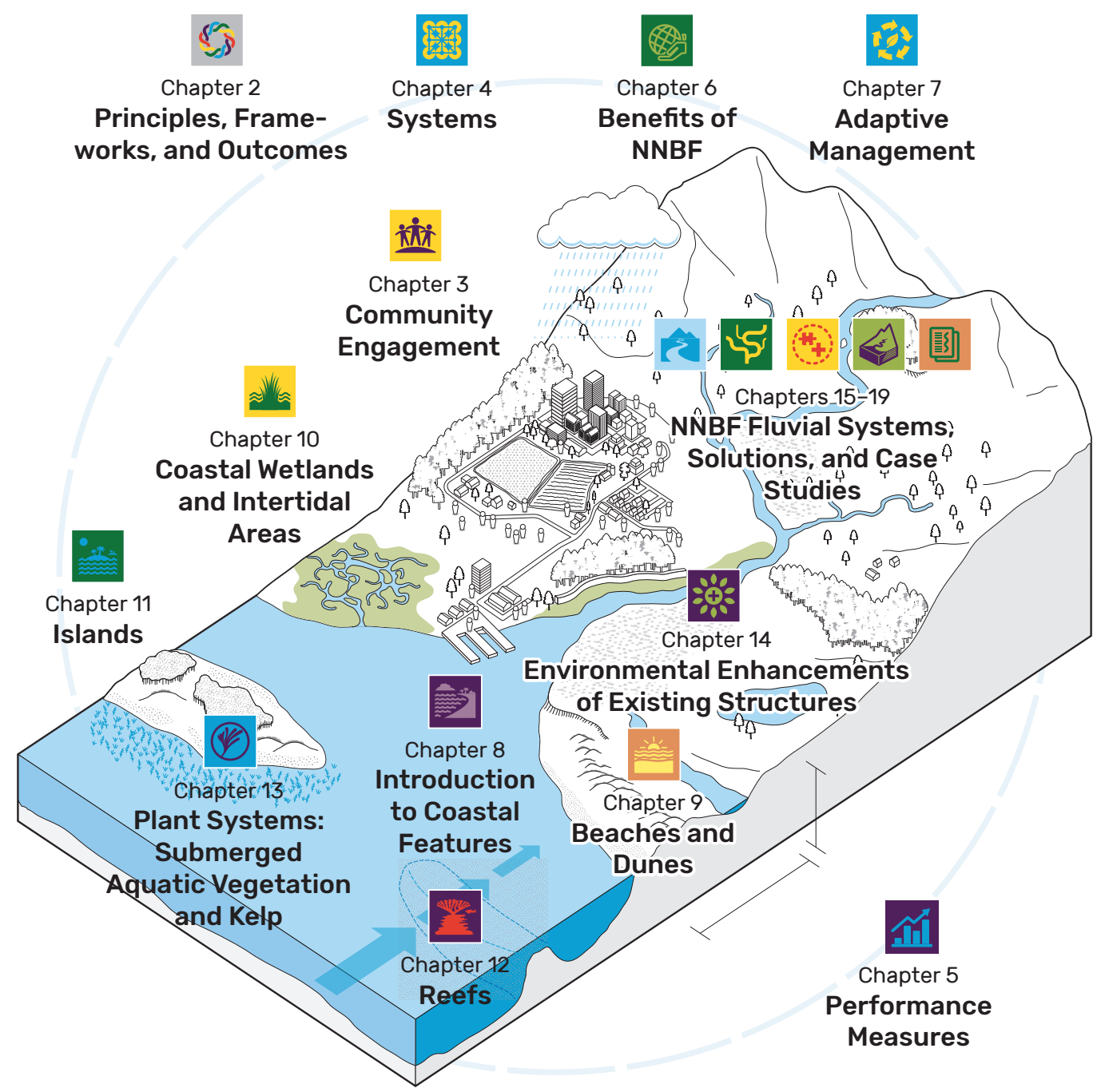




\section{2 | Overarching Observations}

In view of the breadth of material covered in these guidelines, it is useful to offer a few relevant observations and principles to inform our thinking about natural systems and FRM, our approach to implementing NNBF, and future needs.

\section{Natural features and landscapes have always contributed to flood resilience. Since the advent of the modern environmental "movement" in the 1960s, there has been growing recognition of the value of nature. This value takes many forms, including values related to functions we now associate with human engineering (e.g., supporting water quality).}

There is a strong and growing interest in nature-based solutions around the world. For most of human history, if you wanted to reduce your flood risk, you took your cues from the landscape and occupied high, solid ground. In a sense, the increasing attention being given to NNBF is simply an elevation of this commonsense approach to FRM. In fact, observation and common sense alone can reveal the importance of natural features and landscapes. There are more than 2,000 barrier islands worldwide, with a total of more than 20,000 kilometers of shoreline. The United States has more than 400 barrier islands (more than any other country), which total nearly 5,000 kilometers of shoreline (Stutz and Pilkey 2011). Would the extent of U.S. mainland flooding during coastal storms be worse absent these barrier islands? The answer to this question is too obvious to require the use of a mathematical model. A logical extension to this question, relevant to NNBF, would be how can island restoration or creation be used to reduce long-term risks from coastal storms (see Chapter 11)? Wetlands are ubiquitous features along coastlines and rivers around the world, and wetlands can and do provide valuable FRM functions (Narayan et al. 2017). The loss of these wetlands due to human development, landscape-scale engineering, and other processes has exacerbated FRM challenges. Conversely, wetland conservation, restoration, and creation can and will contribute to reducing future flood risks (Chapter 10). These guidelines lay out the use of a broad range of NNBF in support of FRM.

The function and success of FRM measures and systems are related to scale. This is true for conventional and nature-based solutions. Ten linear meters of levee will not provide FRM benefits, nor will 10 meters of constructed reef or wetland. Engineering interventions must be scaled to match the scope of the FRM problem. However, where smaller projects are implemented, they can, and often do, provide cumulative shore, bank, and flood protection benefits. 
Skeptical attitudes about NNBF sometimes take the form of "strawman" arguments about the insubstantial quality of NNBF, as if we could tiptoe our way to FRM by planting a garden of tulips in the right place. But beaches, dunes, islands, and other forms of NNBF are substantial landscape features that exert a physical influence on local hydrology, hydrodynamics, and other processes contributing to FRM. Some have argued that NNBF may be suitable for frequent, small storms but not for infrequent, large events. This gross generalization is not supported by careful analysis (e.g., Narayan et al. 2017; Narayan et al. 2019; Storlazzi et al. 2019). Practitioners must be clear and careful about how NNBF work. A nature-based solution implemented at the scale of an individual property owner to address a local shoreline erosion problem will not provide immediate FRM benefits for that property owner or for the system as a whole.

\section{Sustainable FRM systems will include combinations of conventional, natural, and nature-based elements. The realities of climate change are forcing acknowledgment of two related facts: (1) human activity affects the global system and (2) human engineering cannot "control" nature. There is growing recognition that the scope of FRM challenges worldwide cannot be fully addressed through conventional infrastructure solutions alone. It is not reasonable to think, given the mixed performance of conventional structural measures $\mathrm{s}^{\mathrm{iii}}$ (e.g., walls and levees), that more concrete, rock, and steel alone will be sufficient to address future FRM challenges. Further, it is difficult to envision a national or international floodwall- or levee-building program that could be large enough to address the challenges associated with climate change, sea-level rise, the nature of storms, and projected trends in flooding around the world.}

Sustainable FRM systems will lie along a spectrum of potential solutions (see Figure 1.3). At one end, local conditions and constraints may dictate that conventional, structural engineering (e.g., floodwalls) will be the predominant approach. At the other end of the spectrum, an FRM system may be wholly nature based (e.g., a beach-dune complex). In the majority of future cases, FRM systems will include a mixture, or combination, of complementary NNBF and conventional engineering. The strategic value of considering NNBF is that it often triggers planning-level ideas on long-term solutions that align well with natural behavior. For example, on an eroding coastline, the long-term solution may be spatial adaptation (in most cases)all other measures, whether hard or soft, are often short-term measures. The overarching objectives for informing the design of such integrated systems will be to produce sustainable outcomes that promote the resilience of our communities and environment, while creating long-lasting, diversified value. 
Figure 1.3. Spectrum of Sustainable FRM Systems

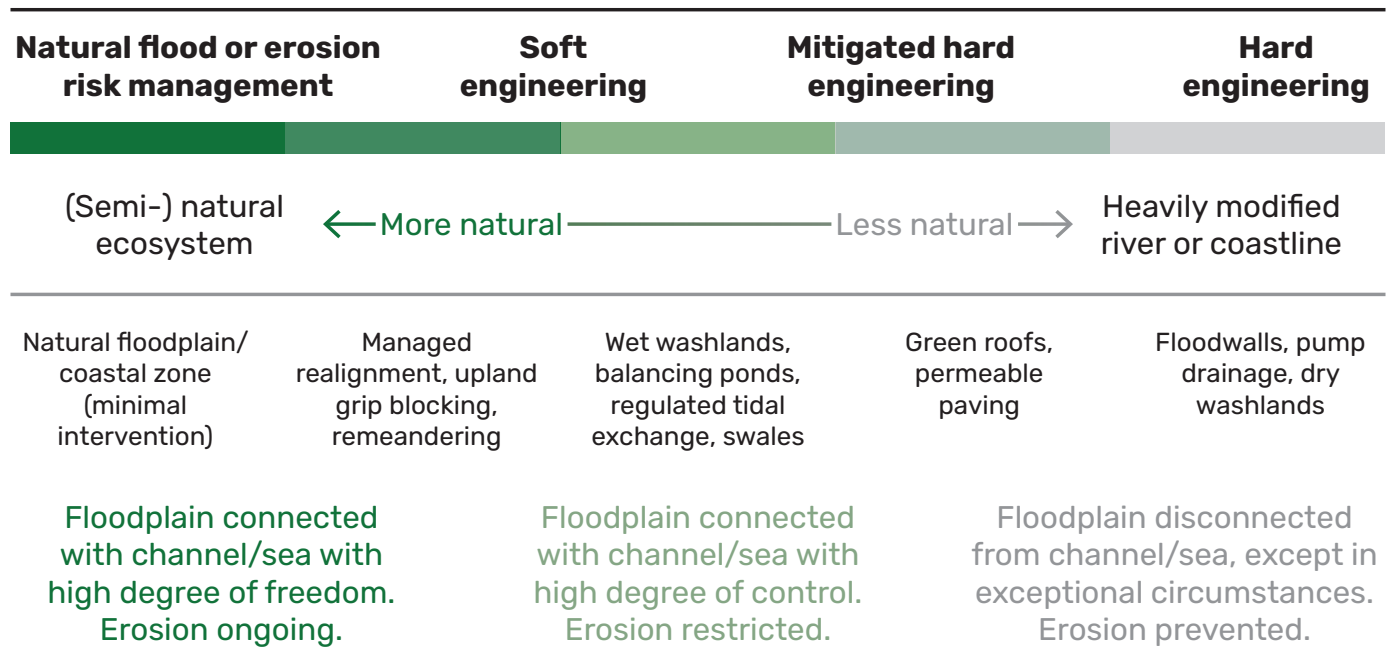

Source: Modified from Environment Agency 2010

The flexibility and adaptability of NNBF are useful for achieving flood resilience.

All engineered FRM interventions and measures are dynamic-they change over time.

Conventional structural measures deteriorate with age and can be damaged by storms. The same or similar processes affect NNBF. Consequently, all FRM measures require investments in monitoring and periodic maintenance.

NNBF are predominantly made up of natural materials such as sediment, biomass (e.g., plants), and, to a lesser degree, rock. Therefore, it can be argued that NNBF are more dynamic than structural measures made of concrete, rock, and steel. However, the dynamism of NNBF also offers benefits.

NNBF have the capacity for natural recovery and are inherently adaptable systems. Because the building blocks of NNBF are natural (e.g., sediments and plants), the environment itself is a source of natural resupply and repair. For example, existing or restored sediment transport processes could be sufficient to sustain a natural island or wetland that is providing FRM value. When a nature-based feature is designed and constructed in synchrony with local biophysical processes, its maintenance can be supported by "mother nature." At the risk of stating the obvious, human intervention is always required-usually at considerable cost-to repair levees and floodwalls. 
The adaptability of NNBF as FRM measures provides value with respect to uncertainties. For example, an island that is enhanced or constructed to attenuate storm surge and waves for a community could be expanded if experience and evidence indicate the need for expansion to increase FRM and other benefits.

NNBF are also amenable to phased implementation due to their dynamic and flexible nature. An FRM study might identify the value of developing 1,000 hectares of wetlands through a combination of conservation, restoration, and new wetland construction. Such an NNBF project could be implemented over many years in a series of construction phases, rather than in one construction "lift" or campaign. In fact, the long-term phased approach could provide opportunities to coordinate and leverage other activities; for example, future navigation dredging can provide a source of sediment over time and a means to reduce and share construction costs. Phased implementation of NNBF could be part of a multiyear-or even a multidecade-resilience strategy for a region.

Creating opportunities to benefit from the flexibility and adaptability of NNBF will involve forethought, long-term planning, and good policy (e.g., to conserve the space or land needed to adapt and expand).

NNBF can increase and diversify the value provided by infrastructure. Worldwide investment in infrastructure is increasing to maintain systems that were built in the twentieth century, to satisfy the increasing demand for infrastructure services by the world's growing human population, and to address the risks posed by climate change. This growing investment has stimulated thinking about how to increase the return on investment in infrastructure. The primary motivation for most infrastructure investment has been traditional economic considerations; however, nature-based solutions provide opportunities to expand the business or value case for infrastructure investment by diversifying the benefits produced to include additional economic, environmental, and social co-benefits.

Progress in the science and engineering of ecosystem services over the past 30 years has brought together ecologists, social scientists, engineers, and many others to consider the value of nature and the services and functions nature provides. The advances made in this field and the practical tools that have been developed have enabled evidence on ecosystem services to inform decisions about infrastructure investment. Chapter 4 of these guidelines considers these approaches in their application to NNBF and FRM.

Progress in modernizing the evaluation of costs and benefits of investments in FRM and NNBF will be key to elevating FRM projects in relation to competing priorities for both public and private investment. The successful integration of NNBF into FRM strategies and systems will support the sustainability of future investments while providing the multipurpose, multifunctional projects that are increasingly desired and expected by communities. 
Innovation in practice will be key to addressing future problems and opportunities. New approaches are needed to address the evolving and growing problem of flooding worldwide.

It is increasingly evident that we live in a multihazard world and that our infrastructure systems need to be adapted to address this reality. The hazards and risks we confront take many forms: floods and drought, wildfires, environmental challenges brought about by concentrated human development (e.g., water supply and quality, harmful algal blooms), loss of habitat and biodiversity, industrial disasters, pandemics, and so on. Most conventional engineering solutions and infrastructure projects in the twentieth century served a single or narrow set of purposes, such as reducing flood risk. The nature of the multihazard world calls for new approaches that expand the functions and services provided by infrastructure systems.

Innovation involves resolving tensions between maintaining established standards of practice and adopting emerging techniques. These guidelines are one of many steps being taken to support needed evolution in FRM practice. Innovation introduces uncertainty and risk into practice-doing something new or different almost always does. However, all engineering practice involves uncertainties and risks that are actively considered and managed as a part of risk-informed decision-making. One simple approach would be to always use the "tried and true" low-risk practice or technique; however, this option is often not affordable, feasible, or ultimately even desirable once benefits are factored into the decision-making process.

Uncertainties and risks exist for conventional structural FRM measures and nature-based measures. Every year around the world, parts of levees, floodwalls, and other FRM structureswhich have been used routinely for hundreds of years-fail in a technical sense before their design specifications are exceeded and fail in a more colloquial sense because water levels exceed their design specifications. Repairs to these structures-and the flood damages resulting from the failures-total many billions of U.S. dollars. Uncertainties and risks also exist regarding the engineering performance and long-term operation and maintenance of NNBF. Numerous NNBF projects have been built around the world in recent decades, and information about their performance is being shared and published by an international community of scientists and engineers. Chapter 5 of these guidelines provides guidance on the performance of NNBF.

The pace of knowledge development and technical exchange related to FRM, particularly nature-based solutions and NNBF, is tremendous. The reality of the "information age" calls for institutions to develop new approaches for scanning, acquiring, and integrating knowledge into policies and practices. Hundreds of technical papers and peer-reviewed publications on nature-based solutions and NNBF became available during the preparation of the NNBF Guidelines, and hundreds more will be written after these guidelines are published. Our goal in developing these guidelines was to provide relevant information and an approach for considering and analyzing NNBF in the context of planning, engineering, and operating projects. 
A commitment to innovate is needed from all organizations connected to FRM, including infrastructure agencies, conservation organizations, environmental regulators, educators, engineering and construction companies, investors, and insurance companies. The urgent need to address flood risks worldwide calls for integrating research and development, scaled demonstration projects, and full-scale projects into an efficient and accelerated approach for delivering solutions.

Policies need to be developed to guide and expand the use of NNBF. The primary focus of flood engineering for the past 100 years has been on conventional structural measures; thus, most existing flood and environmental policies are tuned to this application. This NNBF Guidelines is the product of international experience and recognizes that policy and governance context varies around the world. Although examples from different countries are used or referenced, the application of these guidelines will be based on the policies operating within a specific jurisdiction, governance context, and time.

The following are four major areas where policy advancement is needed to facilitate effective implementation of NNBF:

1. Explicit inclusion of NNBF as a potential source of FRM benefits and updated policies for evaluating the performance of NNBF and of structural and nonstructural measures in equivalent ways

2. Policies that provide direction and guidance for considering the full economic, environmental, and social co-benefits of NNBF and of structural and nonstructural measures that can be compared to the full costs of implementation over the short and long term

3. Approaches for diversifying investment and financing for FRM projects (public- and private-sector experience with investments in nature-based solutions and NNBF can be used to develop new policies for sharing the costs and benefits of projects and accelerating implementation)

4. Environmental policies and regulations that balance NNBF construction impacts on current habitat and environmental conditions with the creation of future habitat, environmental, and social co-benefits through nature-based solutions and NNBF

In all these areas, policy evolution is underway at different rates in countries around the world.

\section{Coordination, collaboration, and partnership will fuel successful implementation of} NNBF. There are many opportunities to bridge organizational boundaries to improve FRM generally and to advance the application of NNBF specifically.

The nature of FRM problems and solutions points toward the need for coordination among the authorities that establish national policy and funding priorities and local authorities that strongly influence, or perhaps largely control, land-use planning and development. Historical 
policies or practices that allowed or even encouraged development in low-lying areas and floodplains have created flood risks over time. Addressing these risks with engineering interventions requires space on land or in the water where FRM measures can be constructed. Flood risks are reduced by creating elevation and roughness on the landscape. In the case of nonstructural measures, for example, this can be accomplished by elevating buildings above floodwater levels. For structural measures this is achieved by constructing elevation in the form of barriers such as levees or walls. For NNBF to be effective, enough space must be available to develop the features at sufficient scale for the elevation and roughness provided by the features to influence local hydrology and hydrodynamics. Coordination between national and local government agencies on land-use planning is key to making room for NNBF and the effectiveness of future FRM.

The organizations and programs that affect the resources and activities that contribute to developing NNBF also need to collaborate. Organizations and programs that engage in navigation dredging and FRM are a prime example. Sediment is a critical construction material for most NNBF. Hundreds of millions to billions of cubic meters of sediment are dredged every year from rivers, estuaries, and coastal areas to support navigation infrastructure and other purposes worldwide. Most of this sediment is discarded, disposed, or dumped in a manner intended to minimize operational costs. Coordination, partnering, and cost sharing that enable the beneficial use of dredged sediment to support both existing natural features and the construction of nature-based features to manage flood risk will advance infrastructure sustainability. Coordination and collaboration among the various government agencies with regulatory authority over the myriad activities involved in developing FRM projects, and NNBF in particular, are critical to progress. The scope of the challenges posed by climate change and flooding calls for innovation on multiple levels, including our approach to regulation.

The size of the challenges, risks, and damages associated with natural hazards is motivating increasing action from a range of public- and private-sector organizations. Partnering between the public and private sectors is stimulating innovation and new solutions involving finance, insurance, infrastructure, and nonprofit organizations. Given the diversity of benefits that can be produced through NNBF, such projects provide natural partnering opportunities for organizations that have different interests and goals.

There is power in collaboration. These guidelines are the product of a collaboration among 180 subject matter experts from 77 organizations and 10 countries and a host of others whose work has advanced FRM through the use of NNBF. The world community faces many common challenges related to FRM; however, local conditions and context provide critical inputs for designing and implementing specific solutions, including applications of NNBF. Collaborations that draw together experience from different contexts provide value that can be shared throughout the international community. The development of these guidelines over 5 years has produced a diverse technical community of practice that will continue to provide value as we learn and share our experiences integrating nature into FRM. 


\section{3 | References}

Elhacham, E., L. Ben-Uri, J. Grozovski, Y. M. Bar-On, and R. Milo. 2020. “Global Human-Made Mass Exceeds All Living Biomass." Nature 588: 442-444. https://doi.org/10.1038/ s41586-020-3010-5.

Environment Agency. 2010. Flood and Coastal Erosion Risk Management Appraisal Guidance. Bristol: Environment Agency.https://assets.publishing.service.gov.uk/government/ uploads/system/uploads/attachment_data/file/481768/LIT_4909.pdf.

infrastructurereportcard.org. 2021. 2021 Report Card for America's Infrastructure. https:// www.infrastructurereportcard.org/.

McHarg, I. L. 1969. Design with Nature. Garden City, New York: Published for the American Museum of Natural History [by] the Natural History Press.

Mulligan, M., A. van Soesbergen, and L. Sáenz. 2020. “GOODD, a Global Dataset of more than 38,000 Georeferenced Dams." Scientific Data 7 (31). https://doi.org/10.1038/s41597020-0362-5.

Mumford, L. 1970. The Myth of the Machine: The Pentagon of Power. New York: Harcourt Brace Jovanovich.

munichre.com. 2021. Record Hurricane Season and Major Wildfires - The Natural Disaster Figures for 2020. https://www.munichre.com/en/company/media-relations/mediainformation-and-corporate-news/media-information/2021/2020-natural-disastersbalance.html.

Narayan, S., M. W. Beck, P. Wilson, C. J. Thomas, A. Guerrero, C. C. Shepard, B. G. Reguero, G. Franco, J. C. Ingram, and D. Trespalacios. 2017. "The Value of Coastal Wetlands for Flood Damage Reduction in the Northeastern USA." Scientific Reports 7: 9463. https:/l doi.org/10.1038/s41598-017-09269-z.

Narayan, S., C. Thomas, J. Matthewman, C. C. Shepard, L. Geselbracht, K. Nzerem, M. W. Beck. 2019. "Valuing the Flood Risk Reduction Benefits of Florida's Mangroves." The Nature Conservancy. https://www.nature.org/content/dam/tnc/nature/en/documents/ Mangrove_Report_digital_FINAL.pdf.

ncdc.noaa.gov. 2021. U.S. Billion-Dollar Weather and Climate Disasters. NOAA National Centers for Environmental Information. https://www.ncdc,noaa.gov/billions/. https://www.doi. org/10.25921/stkw-7w73.

Storlazzi, C. D., B. G. Reguero, A. D. Cole, E. Lowe, J. B. Shope, A. E. Gibbs, B. A. Nickel, R. T. McCall, A. R. van Dongeren, and M. W. Beck. 2019. Rigorously Valuing the Role of U.S. Coral Reefs in Coastal Hazard Risk Reduction. U.S. Geological Survey Open-File Report 2019-1027. 42 p. https://doi.org/10.3133/ofr20191027. 
Stutz, M. L., and O. H. Pilkey. 2011. “Open-Ocean Barrier Islands: Global Influence of Climatic, Oceanographic, and Depositional Settings." Journal of Coastal Research 27 (2): 207-222.

World Economic Forum. 2013. The Green Investment Report: The Ways and Means to Unlock Private Finance for Green Growth. A Report of the Green Growth Action Alliance. Geneva, Switzerland: World Economic Forum. http://www3.weforum.org/docs/WEF_ GreenInvestment_Report_2013.pdf. 


\section{Acknowledgments}

\section{Lead Authors}

Todd S. Bridges, U.S. Army Corps of Engineers, United States

Jeffrey K. King, U.S. Army Corps of Engineers, United States

Jonathan D. Simm, HR Wallingford, United Kingdom 


\section{Endnotes}

'There are 40,000 kilometers of documented levees in the U.S. network and an estimated 160,000 kilometers in total (infrastructurereportcard.org 2021).

ii "Property" may include habitats that have legal environmental protection (e.g., Ramsar wetlands, international; Special Protection Areas and Special Areas of Conservation sites in Europe; and sites with threatened and endangered species in the United States).

iii In these guidelines, structural measures are products of planning, engineering, design, and construction; nonstructural measures are products of public policy, management, and regulatory practices and may include financial incentives. 


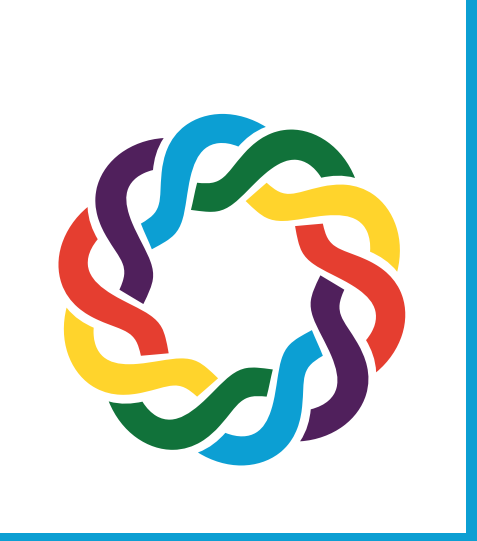

\section{Key Messages}

1. When developing this chapter-“Principles, Frameworks, and Outcomes"and integrating all the chapters that compose the International Guidelines on Natural and Nature-Based Features for Flood Risk Management, these five foundational principles emerged as critical to the overall success of a project:

- Use a systems approach to leverage existing components and projects and their interconnectivity.

- Engage communities, stakeholders, partners, and multidisciplinary team members to develop innovative solutions.

- Identify sustainable and resilient solutions that produce multiple benefits.

- Anticipate, evaluate, and manage risk in project or system performance.

- Expect change and manage adaptively.

2. The framework for natural and nature-based features (NNBF) projects is separated into five phases (each with subsidiary steps): Scoping, Planning, Decision-Making, Implementation, and Operations. These phases highlight a general progression from the initial Scoping Phase to the Operations Phase of a project. However, the framework progression need not be strictly linear; in particular, (1) the iterative approach for refining NNBF options will likely require a return to previous steps in the process, and (2) in the early stages, financial considerations (costs and funding strategy) will need to be considered in parallel with scoping and planning activities. 


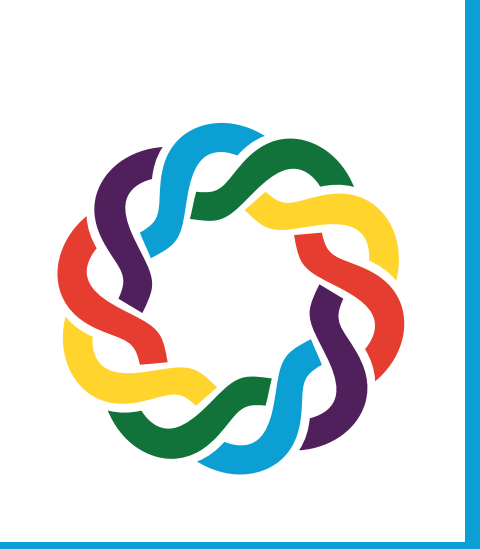

\section{Key Messages (Continued)}

3. Project proponents should anticipate high-level outcomes for each of the framework phases. Familiarity with these outcomes and knowing their connectivity to applicable framework phases will promote the sequential completion of necessary activities and minimize the risk of omitting aspects that are critical to success. 


\section{1 | Introduction}

This chapter provides a framework for undertaking successful natural and nature-based features (NNBF) projects, setting out foundational principles, identifying a framework for structured decision making, and identifying the expected outcomes from the process. The International Guidelines on Natural and Nature-Based Features for Flood Risk Management (NNBF Guidelines) assumes that an initial evaluation of the "systems of interest" has revealed that NNBF should be considered as an element in the overall approach to flood risk reduction. Thus, the principles, framework steps, and desired outcomes are offered to practitioners, along with recommendations for integrating NNBF into a broader, multidimensional approach for managing the system of interest.

\section{2 | NNBF Principles}

During the preparation of the NNBF Guidelines, the following five foundational principles emerged from international practice as critical to the development of successful flood risk management (FRM) projects:

\section{Use a systems approach to leverage existing components and projects and their interconnectivity.}

FRM systems contain many processes and components (including existing projects for FRM and ecosystems restoration). NNBF initiatives to help deliver solutions to flood risk problems, therefore, require thinking about the creation and management of the interconnected systems in which these components and projects, both existing and future, may reside. A systems approach should, therefore, consider all relevant physical, biological, and social processes and their interactions. The approach should recognize that these processes and systems are often more extensive than any initially defined project scope or area. A systems-based approach that recognizes issues across the entire watershed or coastal zone will enable the evaluation and identification of ways to reduce conflict and maximize synergies to produce sustainable solutions.

Part of a systems-based approach (discussed in depth in Chapter 4) involves identifying a range of combinations of additional NNBF that could leverage existing physical systems, ecosystems, and socioeconomic systems operating within the relevant watershed and coastal zones. Such features can help to reduce impacts and life-cycle costs, provide multiple benefits, and buy time for future adaptation. For example, by strengthening sand dunes, building up salt marshes and barrier islands, constructing new offshore reefs, and employing other techniques, planners and engineers can protect coastal communities while enhancing amenities for people, providing fish and wildlife habitat and thus supporting local economies, and minimizing negative impacts of hard infrastructure while increasing their value. 


\section{수술 Engage communities, stakeholders, partners, and multidisciplinary team members to develop innovative solutions.}

Innovation is necessary to advance the practice of comprehensive FRM. This involves taking risks and managing those risks. Innovation in support of NNBF options also involves, at a fundamental level, multidisciplinary teaming. Only by assembling a diverse team will the best set of expertise and skills be made available for problem solving. Similarly, early and frequent engagement with stakeholders and affected communities is central to innovation. This coordination will also serve as a method for gathering all pertinent information, ideas, and strategies. In addition, this engagement with communities and stakeholders (discussed

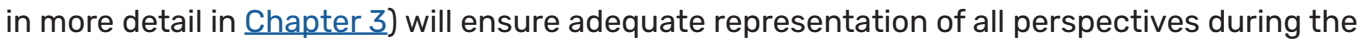
decision-making process.

In summary, delivering on this principle involves the following two key elements:

- Involving multidisciplinary partners and teams that can work together in innovative, creative, and collaborative ways that cultivate new options to meet the evolving needs of communities

- Engaging communities and stakeholders that are the end users of the solution involving NNBF

In many ways, these entities pay the cost of projects, experience the damages incurred as a result of storms, influence the decision-making process, can improve solutions, make solutions fit their circumstances because "one size does not fit all," and help realize the multiple benefits of an NNBF project.

\section{Identify sustainable and resilient solutions that produce multiple benefits.}

Sustainability outcomes are typically identified as enhanced quality of human life, advanced social equity, and increased environmental integrity (Redman 2014). Resilient solutions, on the other hand, are those that allow a system to prepare for threats, absorb impacts, recover, and adapt following persistent stress or a disruptive event (Marchese et al. 2018). However, Marchese et al. (2018) found that implementations of these frameworks had the common goals of providing benefits to people and the environment under normal and extreme operating conditions, with the best examples building on similarities and minimizing conflicts between resilience and sustainability.

The multiple other benefits, referred to hereafter as co-benefits, that these optimal solutions will offer in addition to FRM benefits will include a broad range of ecosystem services for communities, as follows: (1) habitats and associated species, (2) fisheries, (3) climate change 
mitigation through carbon storage and sequestration, (4) tourism and recreation, (5) human health and recreation value, and (6) water quality and sediment management. Regional revenue streams linked to these co-benefits may include those associated with navigation, commerce, fishing, and tourism. (See Chapter 6 for more details.)

Sustainable and resilient solutions are most likely to deliver their multiple benefits by being multipurpose. Such solutions will likely include, but not be limited to, the following components:

- Nonstructural measures (e.g., communication and education that convey information about protecting life and property, enhanced building codes, and established evacuation routes)

- Structural engineering (e.g., breakwaters, seawalls, and levees)

- Natural features that are "created and evolved" over time through physical, biological, geological, and chemical processes operating in nature (e.g., existing wetlands, reef systems, or islands)

- Nature-based features that mimic characteristics of natural features but were created by human design, engineering, and construction to provide risk reduction (e.g., newly created wetlands or islands constructed for the purpose of minimizing storm impacts)

One or more of these solutions may be appropriate depending on the system under consideration. In the coastal context, the nature-based approach may involve multiple parts (e.g., wetlands and reefs integrated with lower or smaller levees) to defend against sea levels and absorb wave energy. In a fluvial context, the approach may involve multiple approaches to slowing, storing, and infiltrating floodwater. Unfortunately, experience suggests that many communities are more interested in gaining confidence that their needs for greater resilience will be met than in prioritizing natural, more sustainable solutions. However, communities may prefer natural, more sustainable solutions in contexts where they are interested in creating and maintaining (parts of) the solution, and the team will need to take those requests into consideration.

It is recommended that when seeking to increase resilience in a system being analyzed, NNBF options should be considered and evaluated first. Only then should the addition of engineering features (i.e., structural measures) be considered. In a sense, NNBF additions should be considered the baseline, using the natural landscape (i.e., natural features) and additions to it (i.e., nature-based features) that produce maximum environmental and social co-benefits while also achieving the desired FRM outcome. Of course, a considerable number of options can exist, ranging from modest applications of a single NNBF to more aggressive applications consisting of repetitive sequences of NNBF interwoven with large structural measures. However, even in locations where a solution relies heavily on conventional approaches, NNBF that contribute to the mitigation of storm and flood risk should be included wherever possible to enhance the natural processes within the system. 


\section{$\Delta \nabla \Delta$ Anticipate, evaluate, and manage risk in project or $\nabla \Delta \nabla$ system performance.}

Risk and uncertainty should be embraced and actively managed when considering approaches to mitigate risks associated with storms or flooding. A risk-averse mindset with regard to project performance should be avoided because it may inhibit the incorporation of NNBF strategies and encourage overengineering and a reversion to traditional structural measures (e.g., seawalls, bulkheads, and levee systems). NNBF strategies can often be designed and maintained to provide an equivalent level of risk reduction as a traditional approach, albeit sometimes with more complexity, different cost structures, or increased monitoring and maintenance. Staying tethered to traditional solutions with known and limited outcomes, as opposed to considering an NNBF alternative, ultimately hinders the development of stronger, more resilient practices with multiple additional co-benefits. Instead, innovative solutions should be embraced, even though this requires the careful balancing of their risk and performance.

\section{Expect change and manage adaptively.}

Conditions in a system are often dynamic, making any project susceptible to a number of potentially deleterious influences. This is true for all projects including structural or nonstructural measures or NNBF. When working with nature, anticipating and embracing change must be at the heart of the effort. In this regard, NNBF projects differ from approaches that rely on only traditional civil and coastal engineering principles, which often can be characterized as a "build and forget" philosophy. But this philosophy-associated with traditional structural measures-runs contrary to the highly dynamic system in which it resides. By comparison, NNBF are known to change over time, but they are also more adaptable. This can introduce uncertainties with respect to future performance and the associated operations and maintenance of a project. However, thoughtfully anticipating these changes, which are considered early and often in a well-structured project development process, can greatly minimize any unforeseen and deleterious consequences. For example, expending time and energy to produce an adaptive management plan will optimize risk management and address uncertainties in any NNBF project. Chapter 7 gives further information on monitoring and adaptive management. 


\section{Definitions of Risk and Uncertainty}

For the purposes of this NNBF Guidelines, risk and uncertainty are defined as follows:

- Risk is a function of the probability that an adverse event (e.g., flooding or coastal erosion) will occur and the consequence associated with that event. Thus, risk $=f$ (probability and consequence), generally simplified to risk $=$ probability $x$ consequence.

- Uncertainty arises as a result of imperfect or missing knowledge. In the context of FRM, two types of uncertainty in processes are commonly distinguished: natural variability (aleatoric uncertainty) and limitations in knowledge (epistemic uncertainty).

\section{3 | Frameworks}

When developing FRM plans, practitioners in a variety of disciplines have often sought guidance from existing frameworks. The framework in this NNBF Guidelines is similar to those used for any planning or engineering project. In fact, NNBF projects do not require a new or unique framework or process, but practitioners pursuing NNBF solutions or the integration of NNBF options into an FRM strategy need guidance as to how NNBF fit into the project development process. Development of this international NNBF Guidelines included a review and reference of two frameworks on the implementation of NNBF: (1) the U.S. Army Corps of Engineers NNBF framework in pursuit of coastal resilience (Bridges et al. 2015) and (2) the World Bank (2017) framework, which focused on the implementation of nature-based flood protection measures (see also Sayers et al. 2013). These frameworks provide complementary guidance for approaching natural infrastructure projects.

Building on the insight of these guidance documents, the framework presented here provides a roadmap for future NNBF applications. In the past, most experience with FRM project development has focused on structural measures; nonstructural measures; and, to a limited degree, NNBF, with the possible exception of beach and dune projects. This framework assumes that an analysis of the systems of interest has revealed that NNBF should be considered in the overall approach to storm and flood risk reduction and focuses on how NNBF fit within the project development process. However, the framework does not include an evaluation or an explicit comparison of conventional measures to NNBF infrastructure. This framework also does not contrast one approach against another (i.e., use of only structural measures versus exclusive use of NNBF). Alternatively, the subsequent sections, and ultimately the framework steps, are offered as a guide to practitioners for pursuing a combination of measures that achieves the integration of NNBF into their broader, multidimensional approach for FRM. 
This framework is divided into five phases that sequentially organize several concepts.

The phases are Scoping, Planning, Decision-Making, Implementation, and Operations.

Figure 2.1 illustrates the different phases that make up the framework and how they relate to one another.

Figure 2.1. Phases of the Project Development Framework

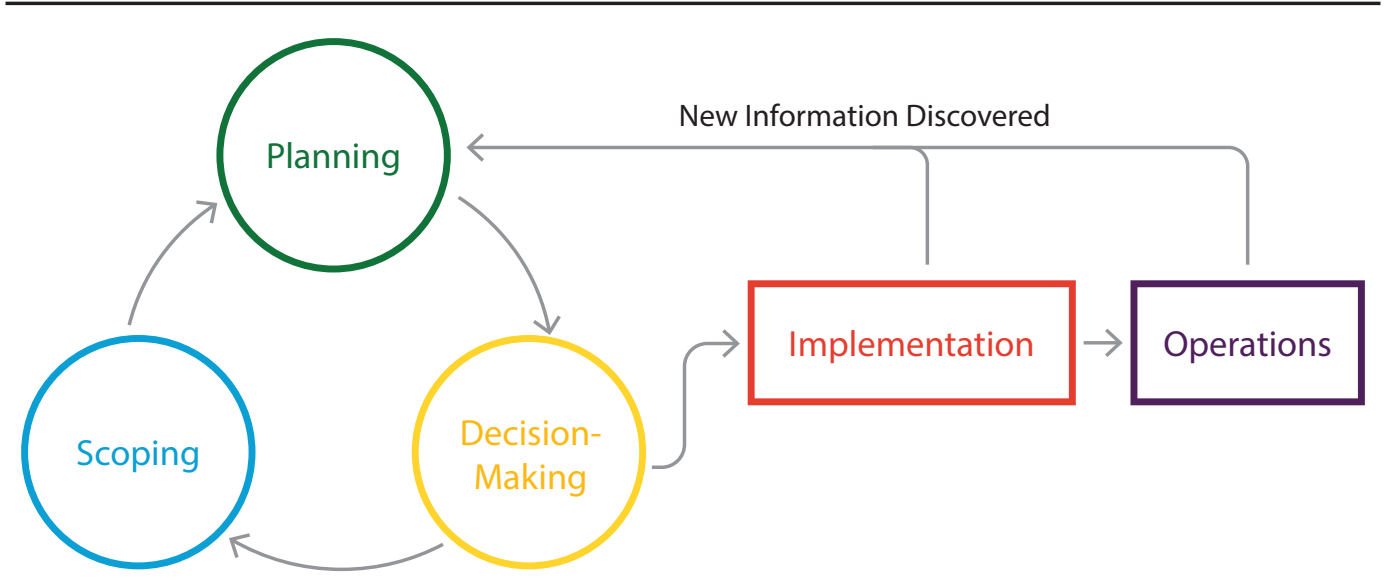

As depicted, these phases highlight a general progression from the initial Scoping Phase to the Operations Phase of a project. However, there are times when information discovered or revealed during a later phase of project development can require additional considerations, which then results in a previously completed phase being revisited. The cycle depicted in the top-right portion of Figure 2.1 highlights the additional time that is likely needed to consider different options and additional input that is accruing prior to the selection of the preferred NNBF option or options. From this phase, there is a logical progression to implementation and operation of the project. Of course, there are factors inherent to this flow diagram that would result in a need to revisit any one of the previous phases. For example, design processes are iterative by definition; however, they also require revision when new data are available, or when new information is obtained on the functionality and success of previously implemented measures (sometimes in other systems).

\section{4 | Outcomes}

When considering the development of NNBF projects, it is important to identify an approach that will render the highest likelihood of success and avoid predictable problems and unexpected costs. This approach should include identifying desirable outcomes at each phase. Many successes over the past 10 years with incorporating NNBF projects into an overall strategy for FRM have been based on well-crafted, organized, and incremental approach plans. 
Within each of the framework phases presented herein, there are anticipated outcomes that will advance the project to the next level of completion.

Figure 2.2 illustrates the different phases of the framework and the high-level outcomes that should be anticipated in association with each of the phases. These phases are then described in more detail in the following subsections.

\section{Figure 2.2. High-Level Outcomes Associated with Each Phase}

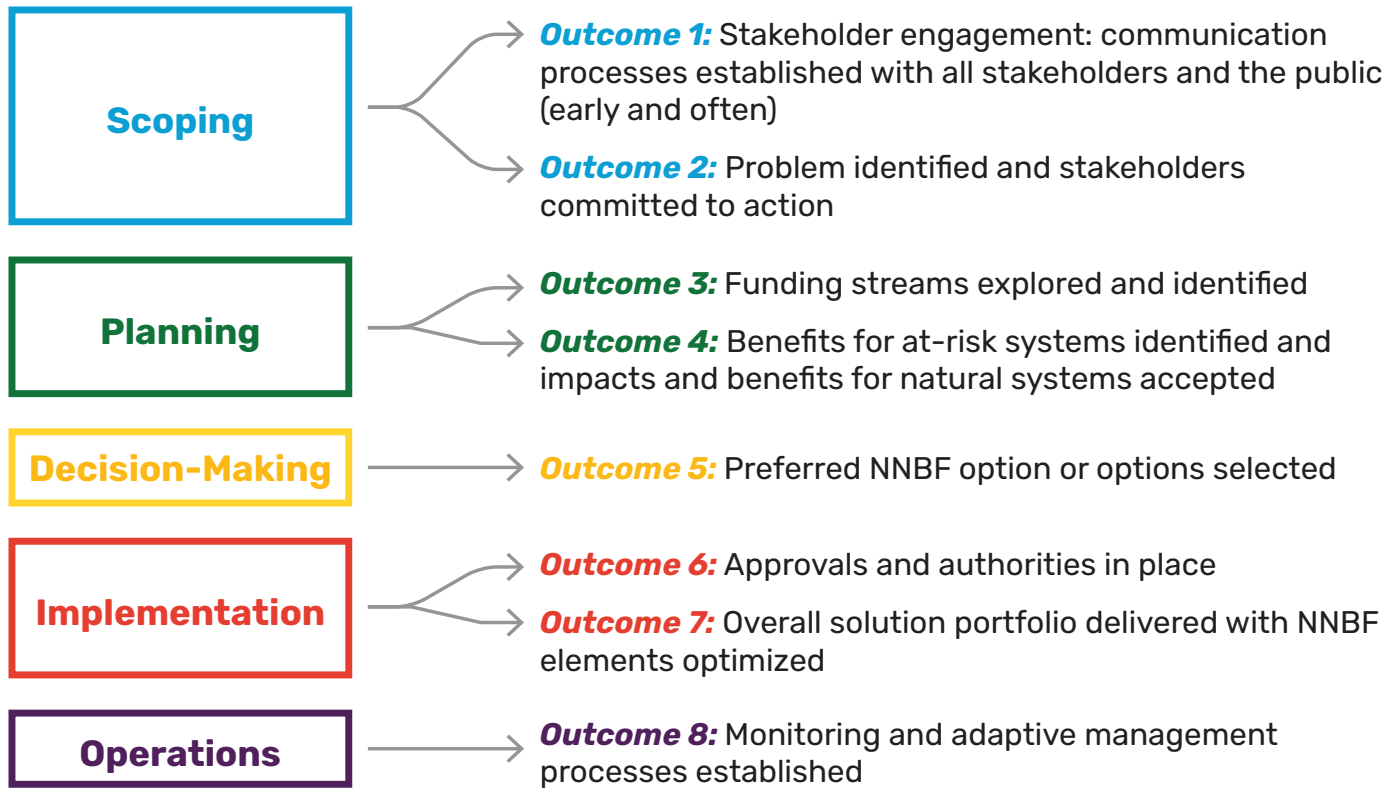

The framework shown in Figures 2.1 and 2.2 illustrates the different phases of an FRM project. Note that a similar concept can also be used for a system-wide evaluation, on projects of varying scales. The larger scales may be focused on developing (national) policy and (regional) strategies, whereas the smaller scales may be focused on specific local FRM measures.

\section{5 | Steps Found within Phases of the NNBF Framework}

This section provides more details on the various steps within the phases of the framework as summarized in Figure 2.3. Steps depicting the NNBF framework (Figure 2.3) and the descriptive text in this chapter are presented in a primarily linear fashion for ease in describing a sequence of activities recommended to achieve a successful NNBF project. Although the 
sequence of the steps is an accurate portrayal of the recommended framework, the order of the steps is illustrative rather than obligatory because many steps trigger interconnected activities that may be undertaken simultaneously. The arrows between multiple phases or steps in Figure 2.3 highlight the iterative processes and potential feedback loops that exist. This is particularly evident with steps in the Scoping and Planning Phases, which highlight (1) the unique financial considerations for investigations and analysis in support of identifying the preferred NNBF options and (2) the actual construction and operation of the NNBF project, respectively.

Figure 2.3. Framework Phases and Their Corresponding Steps in Undertaking NNBF Projects

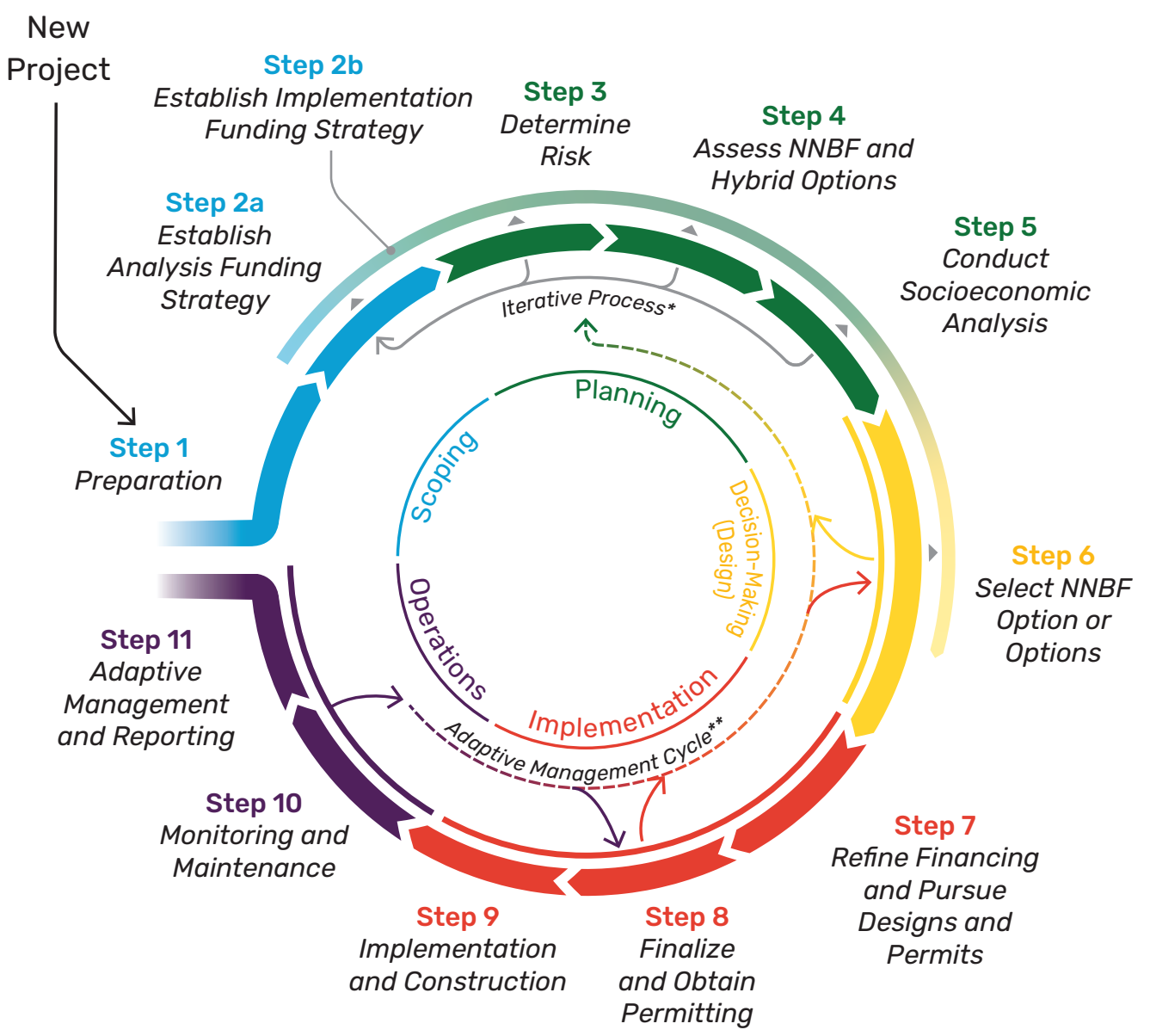


If the outcomes for a corresponding phase have not been achieved in a time frame that aligns with completion of the associated steps, then the technical team should be cautious in attempts to advance the project to the next phase (Figure 2.2). A deliberative and methodical approach to NNBF projects that integrates information and recommendations offered in this chapter is important to achieving success.

\subsubsection{Scoping Phase (Steps 1 and 2)}

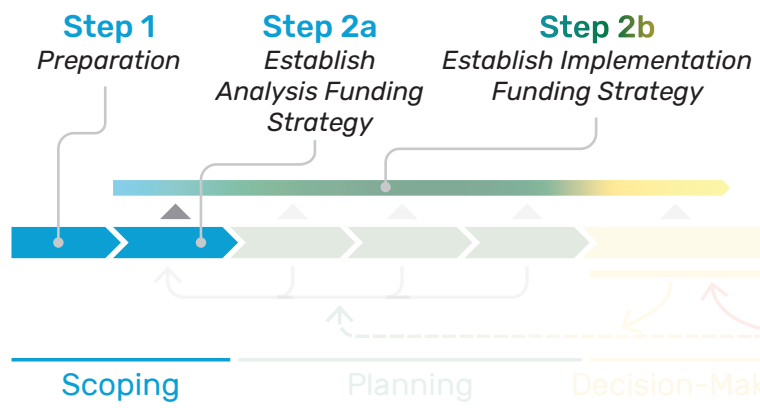

Scoping sets out an initial assessment or investigation of a perceived need or problem. Step 1 , Preparation, includes identifying, organizing, and assembling stakeholders and partners to define problems and objectives. Specifically, Step 1 involves (1) directing practitioners to identify, organize, and assemble stakeholder and project partners; (2) defining problems;

(3) defining the system (see Chapter 4); (4) identifying opportunities and constraints;

(5) setting goals based on identified objectives; and (6) developing a vision for how to achieve the overall project goals, including the potential for NNBF elements. Activities in this step include, but may not be limited to, the following:

1. Assembling multidisciplinary technical and project teams that can include planners, landscape architects, various scientists, socioeconomists, hydrologists, ecologists, and engineers

2. Collaboratively defining the storm or flood risk problem, project purpose, and need

3. Aligning project goals with objectives to achieve the desired outcomes

4. Beginning the process of identifying applicable land, regulatory, governance, and funding requirements

5. Organizing public meetings to engage stakeholders that will help to inform problem identification, opportunities, and constraints, which ultimately results in a community-supported vision for the future steps 
The NNBF project team should include a technical team and a number of other stakeholders and disciplines, as follows:

- The technical team is responsible for planning and designing studies, collecting and interpreting data, and translating and conveying technical information to the larger project team.

- The larger project team may consist of municipal or other community representatives, regulators, financial planners or lenders, cost estimators, decision-makers, project sponsors, and project advocates.

Once assembled, the project team would collaboratively undertake other activities identified in this step, including starting community engagement (see $\underline{\text { Chapter } 3 \text { ). }}$

Steps 2a and 2b of the Scoping Phase, Establish Analysis Funding Strategy and Establish Implementation Funding Strategy, include the identification of funding mechanisms and the preparation of preliminary cost estimates for the following: (1) planning and engineering of Planning Phase activities that are required to arrive at a selected plan, (2) preparation of designs and implementation plans, (3) construction, (4) monitoring and maintenance, and (5) adaptive management.

Given the multiobjective nature of many projects involving NNBF, potential sources of funding may include multiple government, state, and local agencies, nongovernmental organizations, and the private sector. Various funding mechanisms may be appropriate, ranging from conventional funding to private-public partnerships. The identification of potential funding mechanisms, the preparation of preliminary cost estimates for the actual project (with its NNBF elements), and the iterative analysis are all interwoven.

Funding investigations and analysis inform the type of project that is possible (based on cost limitations) while still satisfying project goals and objectives for the system being considered. As such, determining the funding strategy is itself a two-step process (Steps 2a and 2b) that occurs in parallel tracks that are not mutually exclusive:

- Step 2a establishes cost and funding strategies for the actual studies, evaluations, and analyses that will be conducted as part of the investigations that consider the system and the NNBF alternatives.

- Step $2 b$ establishes a funding strategy and an iterative analysis of estimated costs for construction and maintenance of the future, anticipated NNBF options ultimately selected. Step $2 b$ is frequently informed by the outputs (including the project options) generated in Step $2 a$ to Step 5.

Although the funding strategy for the actual NNBF option or options is initiated in the Scoping Phase, the process of refining the funding strategy and ultimately determining the actual cost of the project occurs throughout the Planning Phase, continues in the Decision-Making Phase, and concludes in the Implementation Phase. 


\section{Scoping Phase Outcomes}

\section{Outcome 1. Stakeholder engagement: communication processes established with all stakeholders and the public (early and often)}

- All appropriate stakeholders and the public engaged in an appropriate manner (see Chapter 3 ), recognizing that different stakeholders may wish to be involved to different degrees

\section{Outcome 2. Problem identified and stakeholders committed to action}

- Collection of data and records that characterize the extent of flood and storm damage

- Collation of information on influencing science, FRM engineering, and socioeconomics

- Mapping of the areas of interest to depict main risks and root causes of those risks

- Collection of inputs and documentation needs from stakeholders

- Identification of project goals

- Identification of possible means and measures to deliver project goals

- Definition of budget and securing of funding to begin analysis of baseline conditions and evaluate various NNBF options (i.e., funding to complete the actual studies that lead to project selection)

\subsubsection{Planning Phase (Steps 3 to 5)}

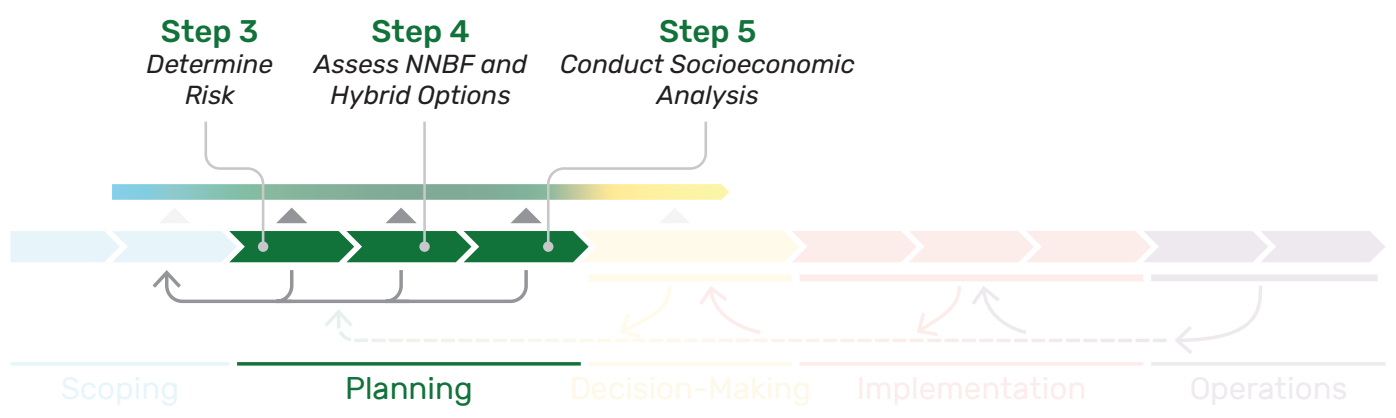

The Planning Phase offers the team an opportunity to better understand and characterize the baseline condition of the existing system and explore NNBF alternatives that satisfy the goals outlined as part of the overall risk management strategy. As shown in Figures 2.1 and 2.3 , there is an iterative aspect to the process. Information, data, analysis, and resulting outcomes, which are accrued for the various NNBF strategies being considered, are investigated, communicated, and rescoped during the Planning Phase to acquire the best 
possible information and data needed to support decision-making. The Planning Phase thus continues the cycle of reoccurring steps, with each cycle achieving greater clarity regarding the most practical, cost-effective NNBF or integrated solution for a given system. As more data become available, with studies and related testing and modeling completed, the evaluation will transition from one that is qualitative to one that is more quantitative.

The Planning Phase begins with Step 3, Determine Risk, in which the system is more fully evaluated to reduce conflict and maximize synergies that produce sustainable solutions. Achieving improved understanding of the system (see Chapter 4) may include a more rigorous investigation into the associated physical, biological, and social processes as well as their dynamic influence or interdependence on flood risk problems and solutions. Acquiring such knowledge may well require the following:

- Collecting and reviewing existing data or records and conducting associated hazard, vulnerability, and risk analyses

- Modeling to understand changes in water levels, erosional forces, and sediment transport patterns under a variety of conditions

All this information will inform the approach to conducting a hazard, vulnerability, and risk analysis of the applicable systems.

Step 4, Assess NNBF and Hybrid Options, tackles the initial and subsequent iterative identification of NNBF or NNBF options integrated with structural measures that meet project objectives. This step will likely involve the multidisciplinary team in data gathering, engagement with stakeholders and partners, and workshops. Chapter 5, "NNBF Performance," and Chapter 6 , "Benefits and Costs of NNBF," offer additional insights for consideration at this step. Chapters 8 to 14, which address coastal systems, and Chapters 15 to 19, which address fluvial systems, provide more information about specific types of NNBF that the practitioner team would potentially consider at this time. The associated analysis to determine the extent of NNBF use and evaluate the NNBF or hybrid options based on best available data, performance metrics, preliminary designs, and modeling efforts is also considered at this step. Considerations in the analysis should include, but are not limited to, the following:

- Consistency of NNBF with the geomorphological context of the system

- Support for NNBF concepts, given the existing physical, biological, and chemical processes in the system

- Potential to leverage mutually supporting combinations of features

- Impact of selected options on helping to manage the hazards and vulnerabilities of the systems at risk of flooding evaluated in Step 3 
Allow adequate time in Steps 4 and 5 for the following:

- Acquiring and evaluating data and information (e.g., online databases, published literature, resource agencies) to incorporate into the baseline and NNBF options analysis (make full use of the skills of the multidisciplinary team containing a diverse group of subject matter experts who are knowledgeable about the systems and NNBF)

- Community and stakeholder engagement (see Chapter 3) to gather timely and site-specific information not available through traditional sources (stakeholders may have a historical perspective of the system, problems, and challenges and be able to offer a valuable unique, firsthand perspective)

Ultimately, the amount of evidence (data and analysis) needed to support the identification of NNBF options, and the selection of the preferred NNBF alternative, will depend on the context and the multidisciplinary team's requirements for decision-making.

The last step of the Planning Phase is Step 5, Conduct Socioeconomic Analysis. This step includes an evaluation of the plausible economic, social, and ecological costs and benefits of the NNBF and hybrid options. Cost considerations (linking back to Steps $2 a$ and $2 b$ ) should also continually be woven into the analysis and weighed relative to the anticipated NNBF-derived benefits. Consideration of socioeconomic and ecosystem services co-benefits (see Chapter 6) will be key to informing selection of options (structural, nonstructural, NNBF, hybrid, and integrated). However, given the multifunctional nature of NNBF and hybrid options, consideration of benefits will be more involved and will require investments and capabilities beyond that of a traditional structural project.

A useful outcome of the Planning Phase is an evaluation table (see Table 2.1 in "Example of Semiqualitative Evaluation Analysis") with categories identified, weighed, and subsequently rated so that numerical rankings between the alternatives can be developed. The approach to populating such tables and the required strength of evidence are determined by the decision-making requirements. If approached correctly, the results of the alternatives analysis would likely identify high-priority, NNBF, or hybrid options for final consideration in the Decision-Making Phase. 


\section{Planning Phase Outcomes}

\section{Outcome 3. Funding streams explored and identified}

- Funding strategies for various NNBF options

- Initial cost estimates for possible NNBF options (partially based on identification of actual and potential financial resources)

- Initial cost-benefit analysis of possible NNBF options to justify funding needs (see also Outcome 4)

\section{Outcome 4. Benefits for at-risk systems identified and impacts and benefits for natural systems accepted}

- Assessment of risk and social and environmental impacts including, but not limited to, the following:

- Maps and datasets indicating current and future hazard exposure and vulnerability

- Maps and analysis showing land use, ecosystem presence and health, and importance of ecosystem for disaster risk reduction

- Model results and associated exhibits indicating present-day flood zones with (and without) the project for different return periods and estimates of associated consequences

- Identification and quantification of FRM benefits and other co-benefits of NNBF options through analysis of whole integrated system

- Establishment of measurable project performance criteria for NNBF options aligned with overall project goals

- Successful communication with stakeholders and public, with all parties understanding the proposed approaches and associated outcomes

\section{Example of Semiqualitative Evaluation Analysis}

Table 2.1 gives an example of a semiqualitative evaluation analysis. The measures for each metric are based on simple scales or are index based, reflecting the relative lack of data typical in an initial feasibility-level study. Subject matter experts have provided input for each class of NNBF, but specific alternatives could be evaluated as well (Bridges et al. 2015). 
Table 2.1. Example Evaluation Table with Specific Categories Identified, Weighed, and Subsequently Rated

\section{OBJECTIVE CATEGORY: RESILIENCE}

\begin{tabular}{|c|c|c|c|c|c|c|c|c|}
\hline Objective & $\begin{array}{l}\text { Metric and } \\
\text { performance measure }\end{array}$ & 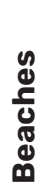 & 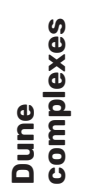 & $\frac{n}{\frac{n}{0}}$ & 起 & $\underset{\substack{0 \\
\hdashline}}{4}$ & 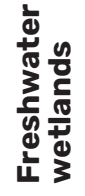 & 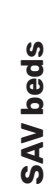 \\
\hline \multirow{2}{*}{$\begin{array}{l}\text { Increase } \\
\text { ecological } \\
\text { resilience }\end{array}$} & Fish and wildlife habitat & & & & & & & \\
\hline & $\begin{array}{l}\text { Species diversity } \\
\text { (extent to which diversity reflects } \\
\text { historical values, using a scale from } 0 \text { to } \\
10, \text { with } 10 \text { being best) }\end{array}$ & \# & $\#$ & \# & \# & $\#$ & \# & $\#$ \\
\hline
\end{tabular}

Improve social Storm-related mortalities

resilience Number of mortalities averaged over 10

years

$(0=10,0-10=7,11-50=4,50-100=1$,

$>100=0$ )

\section{Historical districts protected}

Number of properties

$(0-10=3,11-50=5,50-100=8,>100=10)$

\section{Population change}

Expected 10-year average population

change as a percentage

(any decrease $=0,0 \%-1 \%=3,1 \%-3 \%=5$,

$3 \%-5 \%=7,>5 \%=10$ )

\section{Increase Recovery time}

economic Estimated no. of months to recover

resilience following a Category 3 storm

( $0-3$ months $=10,4-6$ months $=5,7-12$

months $=3,>12$ months $=1$ )

Percent of population that is employed

Estimated unemployment rate

$(<4 \%=10,5 \%-7 \%=5,>7 \%=3)$

Improve

institutional

resilience

\section{Population covered by flood insurance}

Percent housing units covered by flood

policies

$(0 \%-20 \%=3,21 \%-50 \%=5,51 \%-75 \%=7$.

$>75 \%=10$ ) 


\begin{tabular}{|c|c|}
\hline Objective & $\begin{array}{l}\text { Metric and } \\
\text { performance measure }\end{array}$ \\
\hline \multirow{2}{*}{$\begin{array}{l}\text { Improve } \\
\text { structural } \\
\text { feature } \\
\text { resilience }\end{array}$} & Average annual damages avoided \\
\hline & $\begin{array}{l}\text { Estimated relative to current condition } \\
\text { (much lower }=0 \text {, about same }=5 \text {, much } \\
\text { higher }=10 \text { ) }\end{array}$ \\
\hline
\end{tabular}

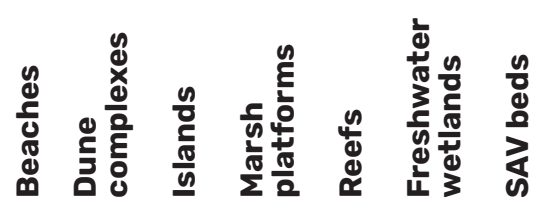

Density of commercial and industrial building infrastructure, including ports

Higher density is better; structures per 1,000 residents

$(<1,000=3,1,001-1,500=5,1,500-2,000=$

$7,>2,000=10$

Note:

SAV: submerged aquatic vegetation

Source: Adapted from Bridges et al. 2015

\subsubsection{Decision-Making Phase (Step 6)}

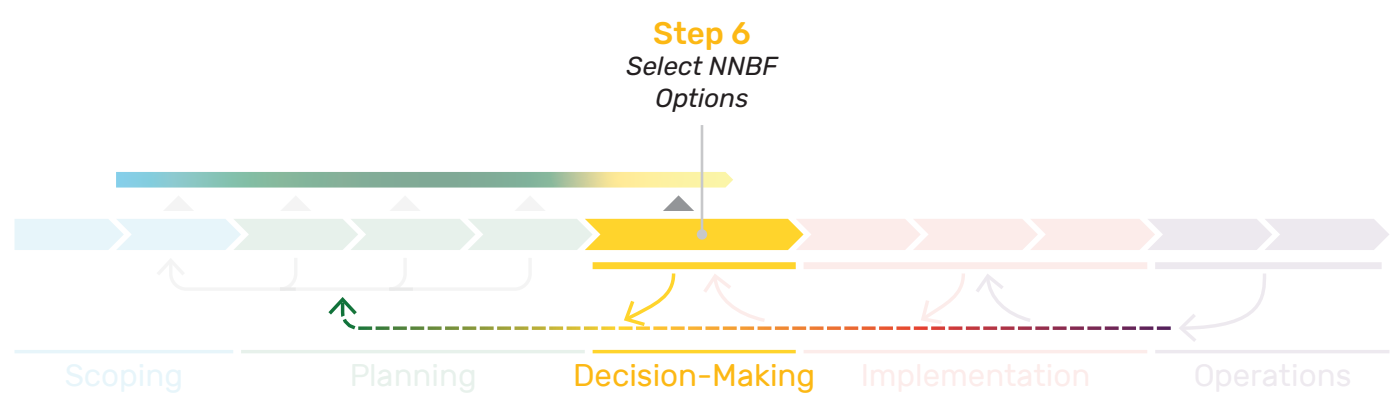

The Decision-Making Phase is when the preferred NNBF option or combination of options is selected as the best approach for integration into the overall risk management strategy for the system.

Step 6, Select NNBF Options, requires the practitioner team to select the preferred option or options that were developed, refined, and put forward at the conclusion of the Planning Phase. Typically, the decision is based on selection of the desired level of resilience or "design event." A layered or nested approach using a mix of NNBF, structural, or nonstructural interventions 
may offer the greatest resilience. The newly proposed system for which options are being evaluated should integrate with the existing risk management strategy, including existing flood risk-reduction plans and associated existing measures (e.g., nonstructural, conventional, or nature based).

A second evaluation table, like the evaluation table presented in Section 2.5.2 (Table 2.1), could be constructed in the Decision-Making Phase to further differentiate between the preferred alternatives that may have achieved similar ranking during the alternatives analysis in the Planning Phase. In all likelihood, the decision context and criteria for this evaluation will ultimately focus on (1) what responsible parties are willing to contribute in the way of investments; (2) requirements for land acquisition; and (3) regulatory, governance, or funding requirements. In most instances, the cost (e.g., construction and maintenance) and the diversity and magnitude of associated benefits become the deciding factors for final selection of the NNBF options. Table 2.2 is an example of a table to further differentiate between alternatives. Use of such a second table can help visually depict, and in some instances quantify, subtle differences between preferred options.

Table 2.2. Example Evaluation Table

\begin{tabular}{|c|c|c|c|c|c|c|}
\hline Category & Metric & 苛 & 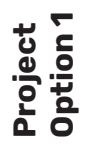 & 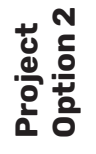 & 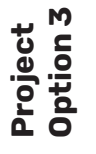 & 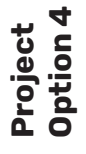 \\
\hline \multirow[t]{7}{*}{ Benefits } & Level of flood risk reduction & $\#$ & \# & \# & \# & \# \\
\hline & Level of sediment erosion reduction & & & & & \\
\hline & Improvements to habitat and fisheries & & & & & \\
\hline & Tourism and recreational opportunities & & & & & \\
\hline & Climate change mitigation & & & & & \\
\hline & Improvements to human health & & & & & \\
\hline & $\begin{array}{l}\text { Improvements to water quality and } \\
\text { sediment supply }\end{array}$ & & & & & \\
\hline \multirow[t]{5}{*}{ Environment } & $\begin{array}{l}\text { Presence of endangered species or other } \\
\text { key natural resources }\end{array}$ & & & & & \\
\hline & Long-term sustainability & & & & & \\
\hline & Resilient to climate change & & & & & \\
\hline & Water quality suitable for intended biota & & & & & \\
\hline & Substrate suitable for intended project & & & & & \\
\hline
\end{tabular}




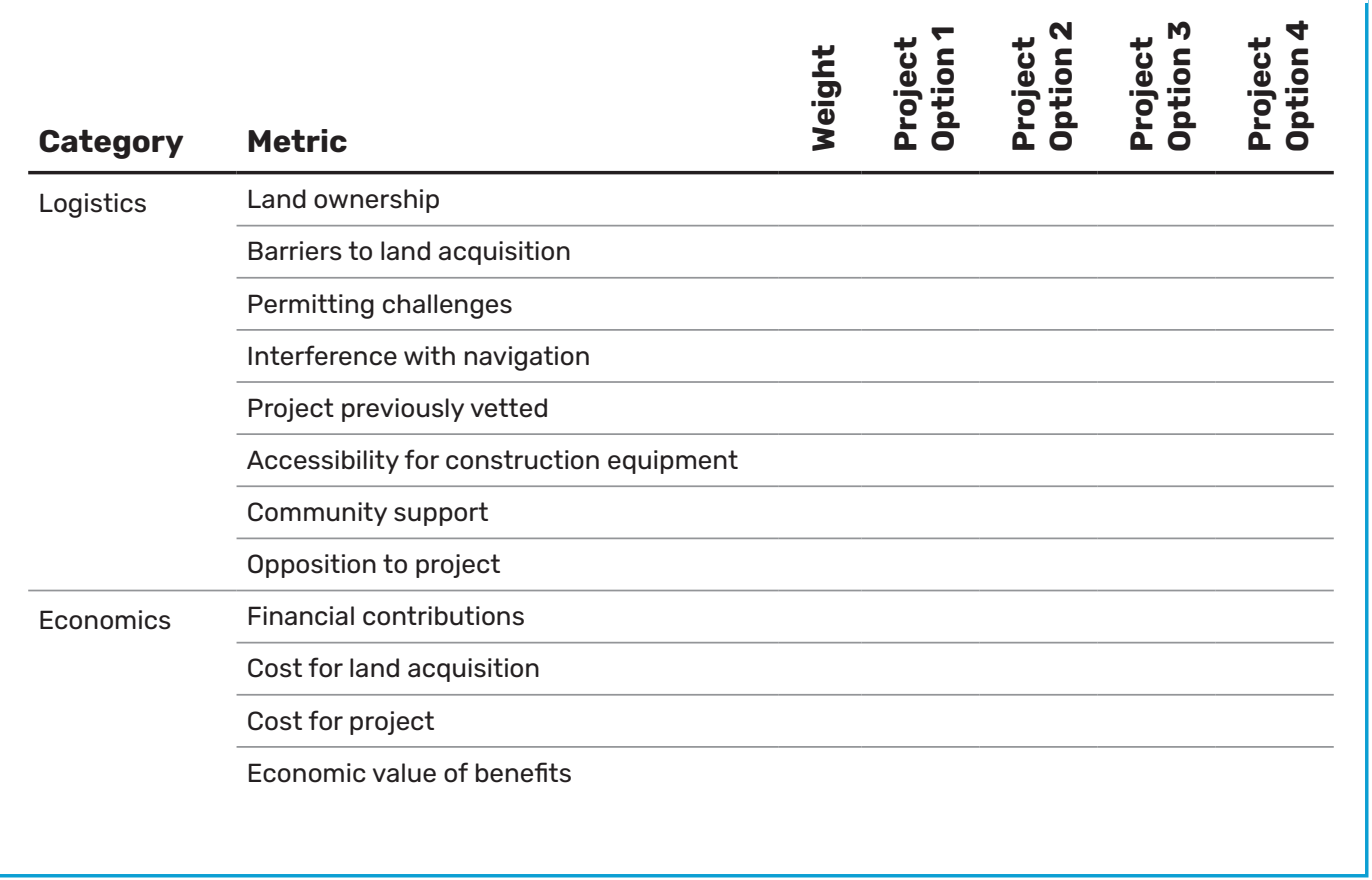

A key part of the process for selecting the preferred option is engagement with knowledgeable community members, stakeholders, and decision-makers who would likely have been involved in the development of a risk management strategy (e.g., floodplain managers, city or county planners, coastal planners, and resource agency representatives). This process includes reporting to partners, stakeholders, and the general public on both the findings of the NNBF options analysis and the anticipated benefits that integrate with existing risk management strategies.

\section{Decision-Making Phase Outcome}

\section{Outcome 5. Preferred NNBF option or options selected}

- Completion of project cost estimates for preferred NNBF options with confirmation of actual resources needs

- Completion of cost-benefit analysis to justify funding of preferred NNBF options

- Commitment and delivery of sufficient financial and in-kind resources to meet the eventual final cost

- Involvement of community members and stakeholders in selection of NNBF options 


\subsubsection{Implementation Phase (Steps 7 to 9)}

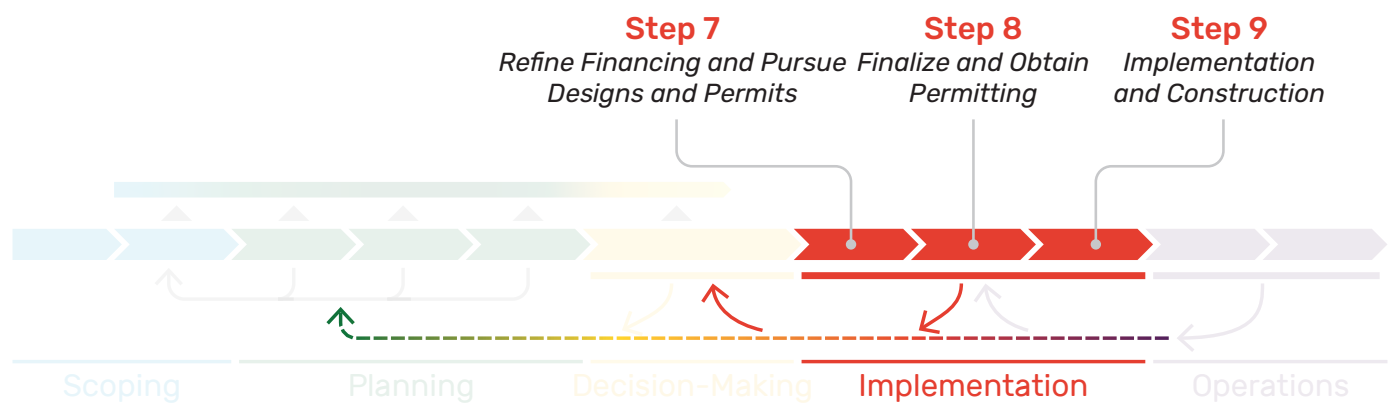

Once selected, the preferred NNBF option or options are further refined and finalized during the Implementation Phase, which puts into effect, and ultimately achieves, construction of the preferred NNBF options. This includes development of the actual FRM designs and procurement of contractor services prior to the start of construction. Efficient and timely progress during the Implementation Phase is founded on inclusive collaborations, deliberative preparation, and meticulous actions during the Scoping and Planning Phases. This avoids unnecessary reconsideration of the NNBF strategies, except where required to take account of unforeseen events, challenges, or changes in circumstances.

Entering into the Implementation Phase, project or system unknowns, which were carried forward and not fully resolved during the Scoping and Planning Phases, may require earlier steps (e.g., Steps 2 to 6) to be revisited (see Figure 2.3) to achieve greater clarity or to mitigate issues or concerns that may arise during construction. Step 7, Refine Financing and Pursue Designs and Permits, includes a number of initial activities of the Implementation Phase, as follows:

- Developing, for the selected option portfolio, outline design plans, drawings, materials, labor, and transport and hauling fees, together with an implementation (or construction) schedule

- Refining the estimated cost

- Refining the financing strategy

- Updating and finalizing regulatory and environmental applications based on the more detailed plans and assessments of impacts

- Identifying possible data gaps and the need for additional investigations 
Step 8, Finalize and Obtain Permitting, includes the following activities:

- Conducting necessary additional investigations, including any required constructability reviews by contractors

- Finalizing designs, plans, and specifications

- Obtaining regulatory and environmental permits required for construction

- Awarding construction and implementation contracts

In Step 9, Implementation and Construction, the technical team should provide oversight to verify the work and agree on any necessary field FRM engineering modifications made in a timely manner. Regular updates should also be provided by the technical team to partners, stakeholders, and all interested parties. At the conclusion of this step, as-built drawings should be prepared and notifications of completion sent to funding sources and regulators.

The setup, duration, and associated cost of the implementation and construction project may range from short-term, single-effort construction (e.g., constructing a wetland or beach that requires one mobilization of personnel and equipment) to a long-term, multiphase NNBF construction project (e.g., constructing a large wetland complex with many phases of actual construction) that may require several years to complete. Although short-term, single-effort projects may be attractive, overall cost savings (and greater benefits per unit cost) may be achieved by leveraging other activities or programs within the system. For example, sediment dredged during the maintenance of harbors and navigation channels could be used beneficially for the purpose of NNBF construction as part of a multiphase project.

\section{Implementation Phase Outcomes}

\section{Outcome 6. Approvals and authorities in place}

- Approvals obtained for proposed measures and interventions including landuse changes, design approvals, construction permits, and environmental impact assessment approvals and permits

- Agreement on the approach to governance to sustain NNBF intervention

- Approval of NNBF designs and FRM engineering specifications

- Approval of the construction timeline and milestones

- Approvals for the final cost of preferred NNBF options and finalization of methods of financing 


\section{Outcome 7. Overall solution portfolio delivered with NNBF elements optimized}

- Completion of design and implementation plan for measures with a focus on no-regret and lower cost strategies

- Completion of construction and implementation of NNBF options

- Delivery of updates on project status to partners, stakeholders, and community

- Verification of project completion delivered to regulatory authorities

- Development and approval of monitoring and maintenance and adaptive management plans

Chapters 8 to 14, which cover coastal projects, and Chapters 15 to 19, which cover fluvial projects, provide more information on recommended approaches for the construction of specific types of NNBF.

\subsubsection{Operations Phase (Steps 10 and 11)}

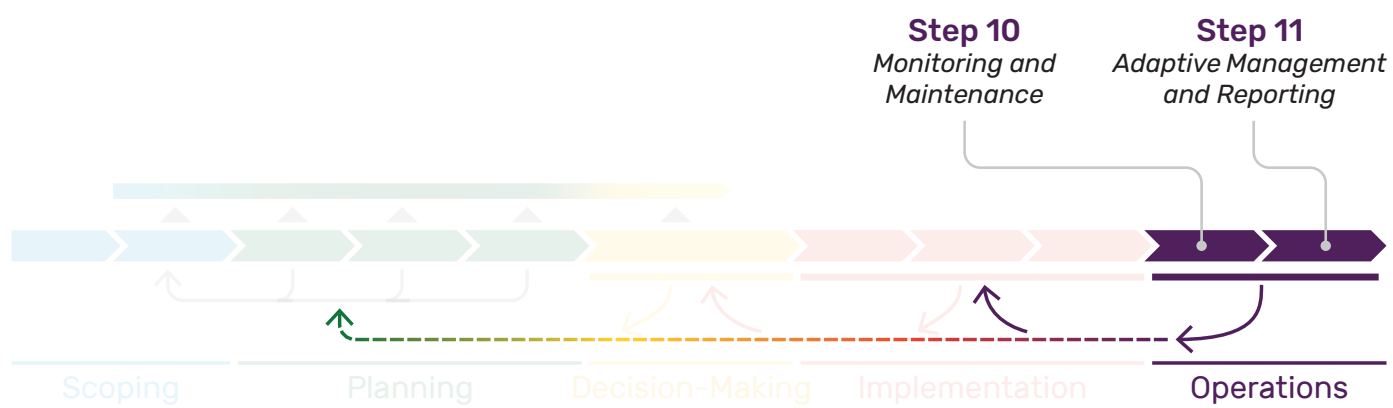

Completion of NNBF construction initiates the Operations Phase (Steps 10 and 11) of the project. Optimal performance of the NNBF requires well-developed monitoring, maintenance, and adaptive management plans that put in place actions that will promote the long-term performance of the project. The dynamic nature of NNBF and the anticipated future changes (e.g., natural or human-made) to the system in which it resides warrant the inclusion of another framework path that guides the team to another investigative review. Simply stated, operation of the project will provide information for adaptive management and future NNBF decision-making. Lessons learned during the Operations Phase may also offer valuable insights into future NNBF projects, and archiving that information for later use may also be another reason for revisiting earlier phases. 
Step 10, Monitoring and Maintenance, requires the team to initiate and follow protocols and procedures for monitoring and maintaining the actual NNBF and areas that make up the project sites. Ideally, the monitoring plan should be developed during the Planning and Implementation Phases and approved by the team during the Implementation Phase of the project. The magnitude and complexity of the project will influence the level of effort (and funding) to be invested in monitoring and, hence, the eventual monitoring plan and its approval, as follows (generally speaking):

- Smaller NNBF projects, which have historically demonstrated success within a well-characterized and stable system, will require less effort in terms of monitoring.

- Larger NNBF projects that are complex or new to a system or are highly dynamic will likely require a more comprehensive monitoring plan. Several iterations of the monitoring plan may be required before it is finalized.

Aside from implementing an adaptive management plan (Step 11), monitoring and maintenance of NNBF have traditionally been the most neglected activities associated with cumulative steps for realizing an NNBF project. Those interested in pursuing NNBF as part of a project would benefit from the establishment of well-crafted monitoring and maintenance plans.

Assuming that the objective is of a comprehensive resilience strategy, avoid the temptation to conduct only a cheap, cursory post-project evaluation of an NNBF project, neglecting a proper evaluation of critical parameters over time. This is because one-time reviews can only suggest limited corrective measures and only offer initial viability determinations for morphology and vegetation and habitat. As a result, they will restrict the maximum "return on investment" and inhibit the realization of the wider original performance goals.

Instead, adopt a well-crafted monitoring plan, which will do the following:

- Take into consideration the intended goals and benchmark success criteria for the project, along with information and data archived during the Planning and Implementation Phases (Figures 2.1 and 2.2), to develop success criteria for the NNBF project.

- Allow performance to be determined through an evaluation of predetermined and approved metrics (see Chapter 5 ) for assessing FRM benefits and ecosystem service co-benefits.

- Identify candidate corrective actions where the benchmark success criteria or performance metrics are not being achieved. In turn, this will inform how and when to activate an adaptive management plan (Step 11).

- Identify successful elements of the project and opportunities to expand on them (e.g., the size of an island or wetland) and the benefits they deliver.

Equivalent considerations for a maintenance plan should cover the following:

- How to maintain involvement among stakeholders so that they can contribute to maintenance decisions if monitoring shows the NNBF not performing as needed 
- How to fund maintenance activities

- How to proactively set up designs, permits, and property ownership to facilitate future maintenance

Reporting of monitoring and maintenance activities is also an important element of Step 10 because it is fundamental to retaining the engagement of communities, stakeholders, and decision-makers. Regular and accurate reporting of field data, updated model projections, and maintenance activities offer the following:

- A method to keep everyone involved aware of the project's viability

- The earliest opportunity to initiate an intervention, if warranted, including any necessary adaptive management (Step 11)

- Valuable information should it be necessary to revisit an earlier phase in the framework process (i.e., Scoping or Planning Phases) due to some unanticipated event or circumstances

Step 11, Adaptive Management and Reporting, includes specific activities that are undertaken either as corrective measures to ensure that the earlier defined project goals are achieved or, where possible, to expand elements of the project that have been particularly successful. Adaptive management by the multidisciplinary team should be based on an overall management plan for a system-wide, asset-management strategy (see Chapter 4). This plan should be formulated as part of the overall FRM strategy, with revisions, updates, and a fully defined strategy being realized during the Implementation Phase (see Chapter 7).

If project goals are not being achieved according to the success criteria, then decision-makers for the project should be ready to initiate protocols that were described, and agreed to, in the adaptive management plan. A well-structured adaptive management plan will offer the NNBF project team and the technical team information and recommended actions to pursue (see Chapter 7).

Although Step 11 is recognized as the last step in the framework, circumstances affecting the system or the project may require the team to re-examine and correspondingly update the NNBF project at any time after construction. Therefore, and to ensure the sustainability of the NNBF (see Figure 2.3), it may be necessary to cycle back to the applicable evaluation and design steps in the Scoping and Planning Phases to review the system, project alternatives, and funding options. This is particularly true if monitoring of the NNBF project (and surrounding system) indicates unanticipated inputs or perturbations. However, the level to which such a re-evaluation and correction should be conducted should be taken on a case-by-case basis. (For example, if an NNBF project is not achieving the targeted vegetation densities due to inconsistencies in post-construction design elevations, then targeted placement of additional sediment may be all that is required for future success.) 


\section{Operations Phase Outcomes}

\section{Outcome 8. Monitoring and adaptive management processes established}

- Administration of a monitoring plan that contains indicators, target values, roles and responsibilities, and monitoring method and duration

- Repair or maintenance activities occurring as prescribed by the specific triggers in the maintenance plan

- Monitoring reports being prepared and delivered

- Adaptive management plans being administered based on criteria for initiation

- Decision-making process established for sharing lessons learned and for agreeing on actions to change or improve the project, if required

\section{6 | References}

Bridges, T. S., K. A. Burks-Copes, M. E. Bates, Z. A. Collier, J. C. Fischenich, C. D. Piercy, E. J. Russo, et al. 2015. Use of Natural and Nature-Based Features (NNBF) for Coastal Resilience. ERDC SR-15-1. Vicksburg, MS: U.S. Army Engineer Research and Development Center, Environmental Laboratory, Coastal and Hydraulics Laboratory. http://hdl.handle.net/11681/19336.

Marchese, D., E. Reynolds, M. Bates, H. Morgan, S. Clarke, and I. Linkov. 2018. “Resilience and Sustainability: Similarities and Differences in Environmental Management Applications." Science of the Total Environment 613-614: 1275-1283.

Redman, C. L. 2014. "Should Sustainability and Resilience Be Combined or Remain Distinct Pursuits?" Ecology and Sociology 19 (2): 37. https://doi.org/10.5751/ES-06390190237.

Sayers, P., Y. Li, G. Galloway, E. Penning-Rowsell, F. Shen, K. Wen, Y. Chen, and T. Le Quesne. 2013. Flood Risk Management: A Strategic Approach. Paris: United Nations Educational, Scientific and Cultural Organization.

World Bank. 2017. Implementing Nature-Based Flood Protection: Principles and Implementation Guidance. Washington, DC: World Bank. 


\section{Acknowledgments}

\section{Lead Authors}

Jeffrey K. King, U.S. Army Corps of Engineers, United States

Jonathan D. Simm, HR Wallingford, United Kingdom

\section{Co-Author}

Todd S. Bridges, U.S. Army Corps of Engineers, United States

\section{Contributors}

Lead authors and co-author acknowledge the valuable contributions that have been offered by the broader project team during the compilation of this chapter. 


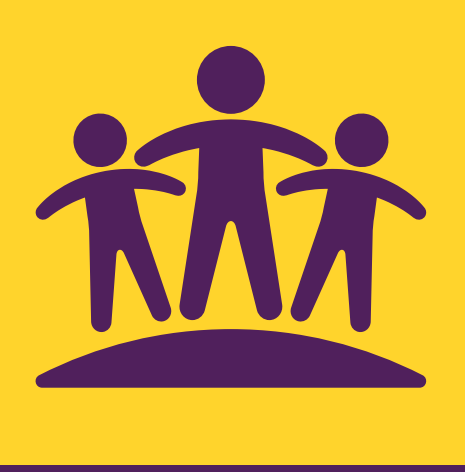

\section{Key Messages}

1. Stakeholders expect earlier, broader, and professional engagement.

2. Natural and nature-based features (NNBF) provide unique opportunities for engagement, including participation in defining the problem in scoping, developing and evaluating alternatives in the project design, maintenance, monitoring, and evaluation.

3. Engagement is important because of the increased likelihood of multiple benefits and, therefore, multiple beneficiaries, with NNBF projects.

4. Successful community and stakeholder engagement require that the engagement be integrated in all phases of NNBF projects.

5. NNBF projects should include an engagement plan and the resources to carry it out.

6. The tools and methods for engagement should reflect the type of engagement, either "light touch," "moderate," or "extensive" interaction. 


\section{1 | Introduction}

Engagement is an important and necessary part of all planning and decision-making for any infrastructure project. Engagement is included at each step of the natural and nature-based features (NNBF) framework (steps detailed in Chapter 2) because we assume an adaptive management approach to the project and, therefore, an iterative, flexible process using built-in feedback loops to inform all aspects of the project plan, including the engagement component. For example, at Step 1 of the NNBF framework, stakeholders can assist the project team in understanding the problem in the context of specific local circumstances. At Step 4 of the NNBF framework, when NNBF alternative formulation occurs, engagement can support the identification of alternatives not previously considered. There are several good example templates and case studies for incorporating early engagement into projects (coast.noaa.gov 2021a, 2021b, 2021c, 2021d, 2021e).

NNBF engagement is any interaction between the organization or agency responsible for delivering the NNBF project and relevant stakeholders, including communities where NNBF projects may be built. This interaction can include a wide range of different types of engagement, from one-way communication of information to consultation and collaborative discussion. Other terms used may include public participation, community engagement, and stakeholder engagement or stakeholder involvement; the term engagement is used throughout this chapter.

During the Scoping Phase (Steps 1 and 2 of the NNBF framework), the NNBF team members responsible for engagement will need to identify and reach out to the relevant stakeholders to develop an engagement plan. A well-planned process for engagement enables all those who have an interest in, have influence over, or will be potentially impacted by a project to be involved from an early stage to be kept informed, understand and add unique perspectives, and influence positive outcomes. Engagement processes should focus on the overarching objectives of the communities ${ }^{i}$ and agencies involved, which should generally require a neutral approach to any specific final solution. Good engagement minimizes the risk of project failure and project schedule delays and enhances opportunities for long-term, sustainable outcomes that benefit multiple parties.

It is important to acknowledge that genuine engagement is rarely easy. This chapter presents a simplified process with an understanding of the underlying complexity. Many projects come with some form of resistance, particularly in early stages. Stakeholders are often better than project staff at framing and successfully involving the press, politics, and the broader community. The manner and timing in which projects are communicated matter greatly to the success of the project. Projects will be better positioned to overcome any challenges if engagement is open, is transparent, and includes a genuine desire for stakeholder involvement. 
This chapter provides guidelines for engagement relevant to all projects, but in the specific context of NNBF projects, which often include stakeholders ${ }^{i i}$ with a complex mix of interests, backgrounds, and priorities. Building engagement into NNBF projects (particularly in project scoping, planning, and design, and potentially through maintenance and monitoring) offers unique opportunities for expanding the benefits that can be delivered and for expanding the pool of beneficiaries. The guidelines presented for engagement assume that NNBF is the selected (or likely to be selected) approach, while acknowledging that engagement is essential in reaching such a decision.

\subsubsection{Drivers for Engagement in NNBF Projects}

The impetus for stakeholder engagement in NNBF may come from any of the following:

- Societal drive to identify new options to manage flood risk, sea-level rise, and more extreme weather while improving resilience. NNBF is an approach to flood risk reduction that enables other benefits to be taken into account that improve adaptability and community resilience.

- Adaptive management strategies. NNBF projects can and very likely will involve ongoing engagement over a longer timescale, with the potential for more adaptability over time.

- The responsible organizations and agencies. An example of this is where there is a good or essential candidate site for deploying an NNBF project and stakeholders likely to be impacted by or influence potential solutions (e.g., local communities, landowners, or conservationists).

- Stakeholders themselves. An example of this is where there is local experience of flood impact and stakeholders would like new solutions to be implemented or want to explore the potential for an NNBF approach.

In several cases, NNBF options arise as a result of engagement with stakeholders. 


\section{Stakeholders Expect Earlier, Broader, and Better Engagement}

For many public- and private-sector bodies, traditional decision-making processes tended to include a decision being made, communicated with others, and then defended from external criticism or concern. This Decide, Announce, Defend (DAD) approach (Colbourne 2009a) may be perceived as a quick way of making and implementing decisions, but it is by its nature confrontational and often ineffective. Increasingly, early and ongoing engagement with stakeholders during the planning and decision-making process has become a more expected, popular, and successful alternative.

The Engage, Deliberate, Decide (EDD) approach (Colbourne 2009a) involves working with stakeholders at the earliest possible stages to understand their concerns, hopes, and motivations, and working with them to consider the way forward. Depending on the level of engagement, the ultimate decision may still be made by the responsible organization or authority but in the context of the following:

- A potentially enhanced stakeholder ownership of the decisions and decision-making, and this may substantially improve the legitimacy of, and the compliance with, management decisions

- A shared understanding of the rationale and context for the final decision, and the various issues that need to be taken into account during its implementation

- An increased likelihood that the final decision will be sustainable and deliver maximum benefit to a broader range of stakeholders

Engagement is frequently required by law; in these cases, the question becomes not whether to engage but how to engage. The modern EDD approach to engagement is of particular relevance for NNBF projects because partners are often required for co-funding or delivery of the nature-based aspects of the intervention. Beyond this, it represents a different attitude toward stakeholders when compared to traditional decision-making approaches. In an EDD process, stakeholders are more likely to be seen as enablers and partners, as opposed to blockers or adversaries.

The DAD approach presents a significant risk of the original decision having to be completely revisited, resulting in wasted time and resources and depleted levels of trust with relevant stakeholders. This approach is likely to be more appropriate in emergency situations (e.g., where there is imminent threat to safety and risk to life).

Ultimately, the attitude taken at the beginning of any decision-making process informs the way the whole process is managed and sets the context for the level of transparency and trust going forward. 


\subsubsection{Drivers for Engagement in NNBF Projects}

Engagement presents some specific considerations that should be taken into account throughout the life cycle of a project involving NNBF. These include the following:

- Projects involving NNBF offer the greater potential for multiple benefits, not only in terms of the benefits of reducing flood-related impacts for affected communities but also co-benefits in other areas such as recreation (improving a healthy environment and creating new business opportunities), conservation, visual impact, and environmental impact. This provides an opportunity to work with stakeholders to identify benefits, increase community resilience, and optimize benefit solutions, but it may present a challenge where the range of potential solutions offers different levels of benefit for different stakeholders (see Chapter 6).

- The delivery of projects involving NNBF may offer opportunities to involve stakeholders in new ways, such as engaging local volunteers to help with construction or monitoring.

- Projects involving NNBF require engagement with a diverse range of groups and individuals, including (but not restricted to) nongovernmental organizations, the insurance industry, contractors and engineers, environmental scientists, regional and local government, landowners, and many segments of the affected community. This requires the building of new relationships among and between stakeholders and potentially a process of collaboration and dialogue to enable multiple perspectives to be shared and genuinely understood.

- Where projects are taking place within specific local communities, engagement may be of particular importance because of the need to account for community values and their link to the NNBF approach being adopted (e.g., adoption of a particular NNBF approach could imply certain values such as harmony with nature or progressivism).

- Because of the relative newness of NNBF as an adaptive approach, these projects may be associated (whether appropriately or not) with greater uncertainty (see Chapter 7 for discussion of types of uncertainty). Uncertainty offers challenges to engagement processes because it can magnify the sense of risk and make shared agreement on a way forward difficult to reach. However, it also offers opportunities for stakeholders to work together to reduce this uncertainty, to define acceptable levels of uncertainty, and to be clear on how, by whom, and when a project will be monitored and maintained. 
CASE STUDY:

\section{South Padre Island Dune Volunteer Program (Gulf of Mexico, United States)}

South Padre Island, located on the southernmost end of Padre Island, Texas, is home to an estimated 5,000 inhabitants and, according to the Convention and Visitors Bureau, more than 5 million visitors. South Padre Island has an approximately 33-kilometer Gulf of Mexico beach within Cameron County, extending from 1.5 to 9 kilometers north of the Brazos Santiago Pass north jetty. South Padre Island experiences variable erosion rates; Gulf of Mexico shoreline ( 5 to 9 kilometers north of the jetties) erosion rates are increasing, averaging approximately 2 meters $(\mathrm{m})$ per year (or 1.5 to $3 \mathrm{~m}$ per year according to the University of Texas Bureau of Economic Geology historical erosion rate map).

The City of South Padre Island has implemented a successful dune restoration project along the entire length of its beach. The city will further identify low-lying areas and gaps in the dune line in efforts to complement the beach and dune plan, forming a continuous dune line that is 3 to $3.5 \mathrm{~m}$ above sea level and with a depth of $40 \mathrm{~m}$. Since 2008 , the city has been proactive in organizing numerous volunteer events to plant native vegetation in bare areas. Desired outcomes of this project include filling in gaps using native plants harvested from lots that are to be developed within city limits and planting native plants propagated by a contractor. The desired outcomes are two-fold: (1) a solidifying dune line that offers storm protection and (2) a reservoir of sand to replenish eroded beaches during high-energy wave events.

In late 2010 , the city developed an aggressive schedule for plantings in dunes, with the goal of 8,000 to 10,000 plants per event. The goal was to have approximately 50,000 plants transplanted along the most narrow and vulnerable areas along beaches on South Padre Island. In partnership with the University of Texas at Brownsville and Texas Southmost College, Surfrider Foundation, Texas Master Naturalist, and interested community members, they averaged more than 100 volunteers at each event. The city has hosted 11 events to date with its partners and they have successfully planted 106,000 native plants and recorded 2,770 volunteer hours (Figure 3.1).

Project success has been highly variable, with the location of the project being the main factor where the areas have not been established well enough and plants 
have been washed away by high-energy wave events. In project areas that are a considerable distance away from the water and have sand fences, the project has proved highly successful.

The next stage will last 18 months, with the completion of 14 volunteer planting events totaling 180,000 indigenous plants to add to the current plants, creating a solid continuous line and protection of the city's beach, infrastructure, and natural resources. Natural vegetation has been used in conjunction with sand fencing to speed up the accumulation of sand around the vegetation once it has been planted. Signs near each planting site are used to educate visitors to the beach as well as to protect the project area.

Project impacts include having larger dunes that are better able to diffuse wave energy in storms; the provision of habitat for shorebirds that nest on the seaward side; protection for coastal vegetation that grows on the landward side in the lee of the elements; and economic value for many including beach goers, surfers, and naturalists.

Figure 3.1. Volunteers Help with Plantings in Dunes (Padre Island, Texas, United States)

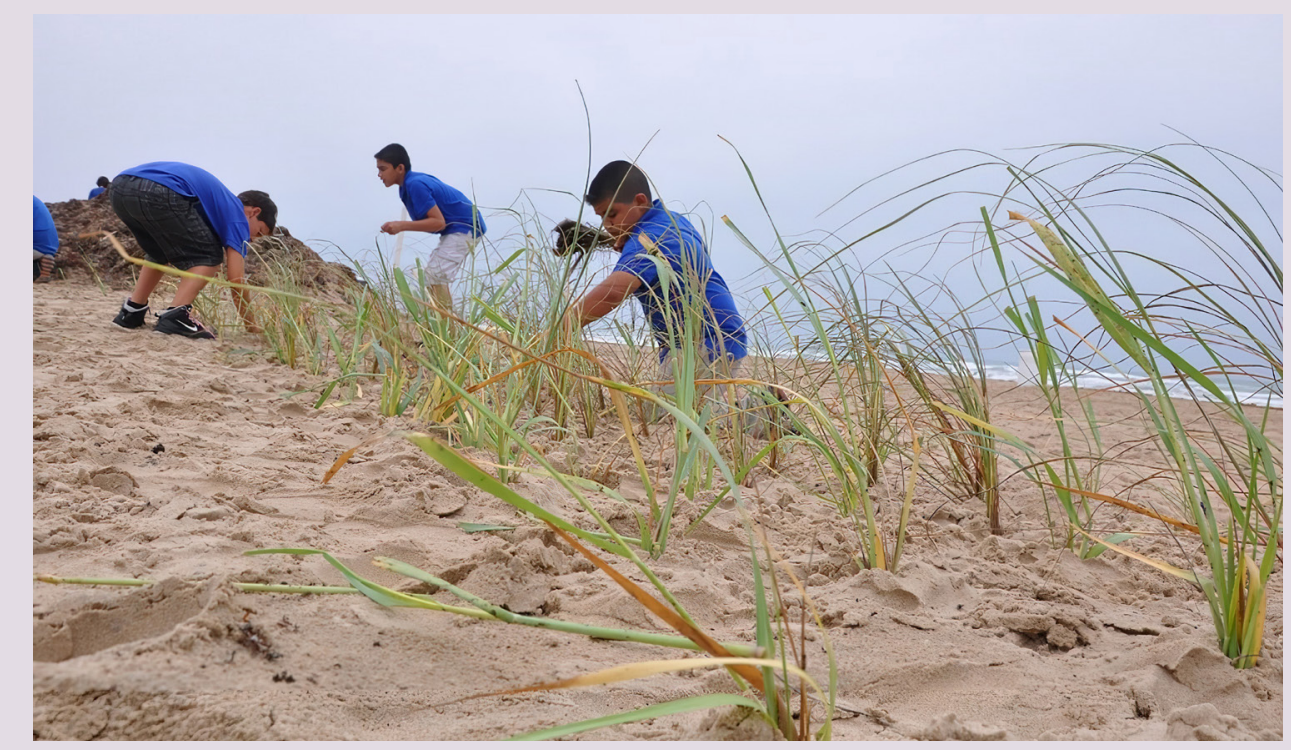

Source: Reuben Trevino, USACE

\section{NHIH}




\section{2 | Defining Engagement and Its Importance}

\section{Key Action}

Engagement is a process of meaningfully involving all those who may be directly impacted by a specific project or intervention. Engagement is of particular benefit to NNBF projects, given the complexity and length of these projects, the high levels of uncertainty, multiple interests, and diversity of co-benefits involved.

Engagement has strong links with social science, which offers a number of participatory approaches. ${ }^{\text {ii }}$ An underlying principle across all these approaches is to meaningfully involve all those who may be directly impacted by the project or intervention in question. Public participation will help jointly identify priorities, develop questions, design or co-create the project or intervention, and, in some cases, help implement the project (like the Texas dune project where volunteers participated). The social act of engaging in volunteer events creates opportunities to establish learning feedback, establishes a social network among participants (creating social circles that aid in free discussions and further improvements in process), and improves the trust between key stakeholders, which often includes balancing multiple viewpoints (e.g., environmental protection versus resource utilization).

A well-designed engagement plan will support the inclusion of a range of co-benefits and the increased likelihood of positive outcomes, including the following:

- Developing an enhanced and shared understanding about complex problems in the context of specific local circumstances

- Ensuring relevant information, expectations, interests, and needs are taken into account when making decisions

- Enabling and empowering stakeholders to take some form of ownership over the issue and take action themselves to become part of the solution

- Maximizing opportunities for a wide range of solutions to be considered by gaining a broader view of the relevant context (e.g., efficient or alternative financing options or innovative solutions)

- Laying longer term foundations for successful future projects by enhancing a mutual understanding across expert and layperson views, shifting mindsets, resolving conflict, and raising awareness or seeing the bigger picture

- Increasing commitment to agreed courses of action from a broad range of stakeholders

Beyond these overarching benefits, there are a range of potential benefits to the responsible organization (e.g., enhanced relationships, learning, and resource saving) and the stakeholders 
themselves (e.g., a sense of ownership and involvement in local decision-making, becoming more informed, and forming new connections). The benefits of engagement, collaboration, and conflict resolution are further documented in the Federal Forum on Environmental Collaboration and Conflict Resolution (2018).

\subsubsection{Engagement to Identify and Enhance NNBF Project Benefits}

Strengthening the holistic nature of the NNBF approach. Engagement builds understanding of the range of human activities and behavioral dynamics capable of enabling or impeding the successful implementation of an NNBF project, enabling socioeconomic aspects to be taken into account throughout project design (see Chapter 5 ).

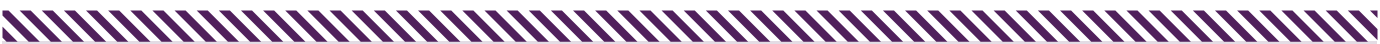

\section{CASE STUDY:}

\section{Collaborative Flooding and Erosion Protection (Chapel Island Shorelines, Canada)}

This case study provides an example of Type $C$ (extensive) (see Table 3.1) engagement and joint fact-finding; this case study also demonstrates the formal presentation of project options.

The objective of this project was to design a flooding and erosion protection solution for the shorelines at risk along Chapel Island. To support effective communication and a smooth progression throughout the project, several discussions with the local community, Potlotek First Nation representatives, and the Indigenous Services Canada were held before the start of the design. Regular meetings with Potlotek First Nation representatives were held during the design as well. These meetings encouraged a collaborative approach between Potlotek First Nation representatives and the consultants. Indigenous Services Canada's original request also noted the need for protection that is consistent with the intent and character of the island.

At the start of the project, the project team, with the support of the local school, organized a meeting to inform the community of the project objectives and build a basis of communication for their involvement in the later phases of the project, at the Implementation Phase and Operations Phase. 
Meetings with local community leaders, chief, council, and elders have been held to discuss the issues and local knowledge of the area and to suggest directions for further investigations.

During the meetings and preparation of conceptual options, the Potlotek First Nation community noted that the area sustains a very healthy oyster population. The community expressed an interest in involving students and researchers to maximize the possibility of incorporating oyster reefs as part of the coastal protection structure. The recommended proposed design option was aligned with the community's wishes-a living shoreline approach that is considered a hybrid solution to erosion protection, between hard infrastructure (rock) and natural features (salt marsh and oysters). This approach was believed to be effective for decreasing the wave energy on the shore (through the roughness of the oysters and the salt marsh), ensuring the sustainability of the protection system, and reducing maintenance and life-cycle cost of the project (oyster reefs are known to grow with sea-level rise and thereby continue to reduce wave heights under climate change conditions).

The following three preliminary erosion-protection design options were subsequently presented by Indigenous Services Canada:

1. A site-consistent, nature-based approach that included salt marsh and oyster bed restoration (Option 1)

2. An approach that maximizes ecosystem integration and benefits, with restoration of salt marsh, seagrass habitat, oyster beds, and an associated shellfish-supporting ecosystem (Option 2)

3. A somewhat standard engineering approach, with intermittent breakwaters and pocket beaches (Option 3)

The main outcome from the meetings was Potlotek First Nation's strong preference for the environmentally integrated option (Option 2). There was no interest in a site-consistent, nature-based approach (Option 1). However, Indigenous Services Canada developed some doubts as to the long-term effectiveness of Option 2. The funding agency's comfort level in the nature-based system was related to their level of understanding of NNBF designs. Additional communication at the outset of the project to better understand the funding agency's existing level of comfort may have helped in obtaining more immediate Indigenous Services Canada's buy-in. Conducting a presentation early in the project with the aim of introducing the living shorelines concept may have also been beneficial to gaining support. Neither Option 1 nor Option 2 has officially been selected at this time. 
Building trust, shared understanding, and objectives. Public understanding of the role of hard infrastructure in flood defense-and trust in the safety of these methods-varies depending on knowledge and experience, but it is likely to be higher across the board than understanding of nontraditional approaches such as NNBF. Building trust in NNBF and the organizations overseeing their delivery is, therefore, fundamental to successful implementation.

\section{NHINHIH}

CASE STUDY:

\section{Hosting Natural Flood Management Measures by Landowners at the Eddleston Water Project (Scotland, United Kingdom)}

This case study provides an example of Type $C$ (extensive) (see Table 3.1) engagement involving different types of governance structures and the benefits of participatory methods of engagement in which stakeholders are asked to share.

One of the aims of the Eddleston Water Project (see description in Chapter 19) for flood risk management in Scotland is to work with landowners and farmers in the local community to maximize the benefits of the work while sustaining farming livelihoods and practices.

Uptake of any changes in land management proposed by this project is a voluntary process. Landowners and land managers are not required to implement suggested measures, so recruiting willing participants to host natural flood management measures on their land requires close engagement and explanation of the aims, methods, and value of undertaking the study, combined with the means to avoid them becoming financially disadvantaged. It is essential to maintain this dialogue throughout the process as well as share results and keep local communities informed.

The extensive engagement process involved in the Eddleston Water Project spans every project stage and included the following:

- Strong governance structures comprising a trusted intermediary project managing the process (Tweed Forum), a project board to maintain engagement with key institutions, and a steering group providing wider engagement and advice 
- Ongoing one-to-one meetings on site with landowners, managers, and farmers

- Quarterly reports circulated to all institutions and researchers involved in the project, detailing engagement and dissemination activities and outcomes

- An annual science meeting to enable knowledge exchange and sharing from the project

- Presentations and field visits for stakeholders and interested parties

Learning from engagement processes to date includes the importance of using a trusted intermediary to build and maintain trust, tailoring engagement to specific stakeholders (e.g., using appropriate language and avoiding excessive paperwork), and reporting back regularly to institutions and key individuals.

\section{NHIHIHIH}

\section{Contributing to a paradigm shift through informing and raising awareness. NNBF} solutions address flood risk in the context of complex processes that vary in time and scale. Understanding this complexity as well as the capacity and limitations of flood risk management measures is a fundamental step for disaster mitigation and resilience building.

The successful implementation of NNBF, therefore, requires a paradigm shift from the traditional approach (see Chapter 5 ). Engagement provides an opportunity to catalyze this shift through the following:

- Sharing with stakeholders the limitations of strategies that rely on conventional infrastructure alone or treat flooding risk as an isolated issue and collaborating to develop more sustainable solutions

- Informing members of the community about the nonstatic nature of flooding risks and the need to implement solutions that allow adaptability while potentially creating additional benefits (see Chapter 7 )

- Providing data and information about the socioeconomic and environmental impacts of traditional approaches and the potential benefits of co-created (NNBF) solutions

- Raising stakeholders' awareness of their own role in aligning their needs and priorities with strategies for conservation and disaster mitigation

- Fostering the potential for local capacity building to support the future monitoring and maintenance of an NNBF solution through, for example, joint fact-finding

Strengthening the cost-benefit analysis of NNBF solutions. The participation of stakeholders in NNBF projects allows designers, authorities, and project teams to evaluate the perception and tolerance of risks and their variability within a community, and to tailor the design accordingly, avoiding unnecessary costs in the long term. 
Community members can provide information on potential additional co-benefits beyond

mitigating flooding risks so that multiple incentives for the implementation of NNBF solutions become apparent. Engagement will also enable the identification of strategies and phases for implementing the project that take into account seasonal variability in socioeconomic conditions and the priorities of the relevant stakeholders (see Chapter 6 ).

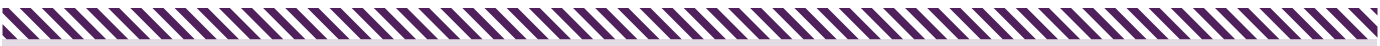

\section{CASE STUDY:}

\section{Coastal Flood Defense (the Netherlands)}

This case study is an example of Type C (extensive; Figure 3.2) engagement using a mutual gains approach.

Figure 3.2. Interactive Work Session with Stakeholders (Example of Type C [Extensive] Engagement) (the Netherlands)

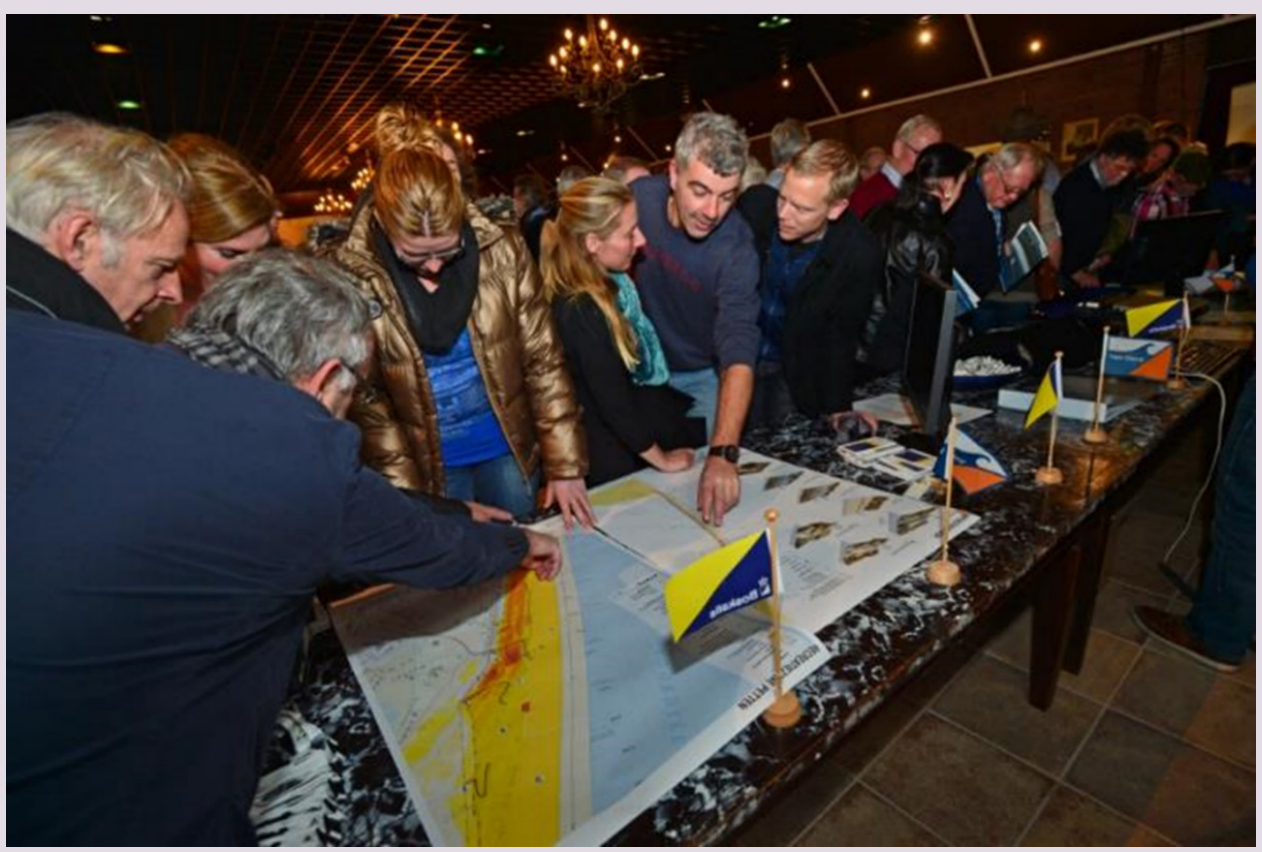

Source: Rijkswaterstaat 
Approximately 15 years ago, the flood defenses at the Town of Katwijk in the Netherlands were identified as a weak spot along the Dutch coastline. In response, the Dutch Flood Protection Program led a process to develop flood protection for the town and the surrounding low-lying countryside. As well as achieving compliance with Dutch legal safety standards, the aims were to create a better natural environment and stimulate tourism.

A series of meetings with local citizens enabled community members to discuss the pros and cons of a range of reinforcement options. Use of the mutual gains and strategic stakeholder management principles assisted in many of the 63 stakeholder views fed into the process being accommodated in the project design and delivery.

\section{Figure 3.3. Project Site Information for Beach and Foreshore Nourishment (the Netherlands)}

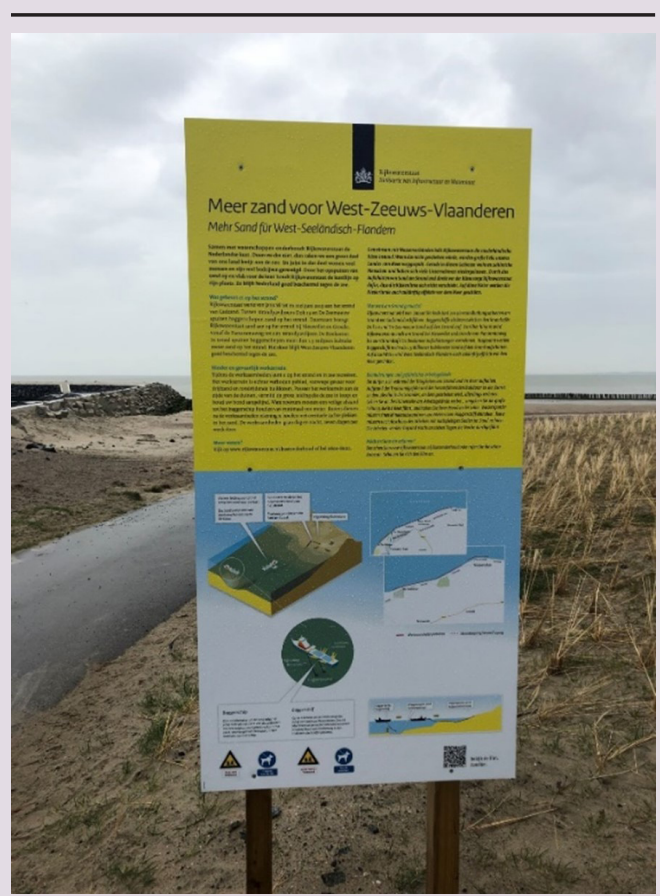

The final design involved a relatively small levee covered by a wide, artificial dune area and a new beach (all funded by the Dutch Flood Protection Program), alongside a parking garage (funded by the Town of Katwijk) to reduce local traffic congestion along the new beachfront (see also Chapter 9). Signage at the project site provides an opportunity to educate visitors about NNBF projects (see Figure 3.3).

The result is a high level of flood protection with relatively unspoiled views to the sea, new opportunities for small businesses along the beach, a notable increase in tourism boosting the local economy with visitor cars parked out of sight, and a dune habitat with native species (Figure 3.4). The project has won two prestigious architectural prizes.

Source: Rijkswaterstaat 
Figure 3.4. The Newly Constructed Dune and Beach Area with a Temporary Walkway for Visitors, during the Building Phase (the Netherlands)

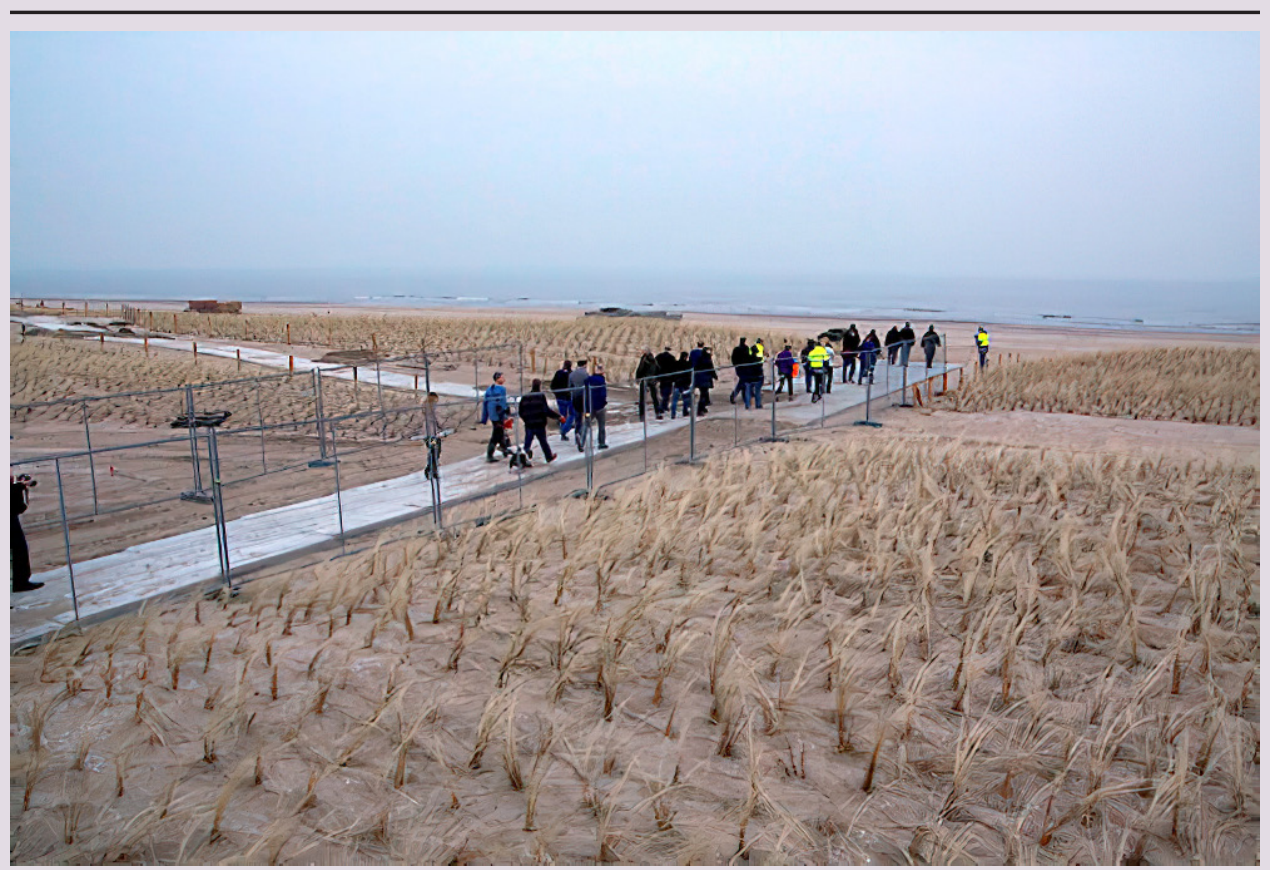

Source: Rijkswaterstaat

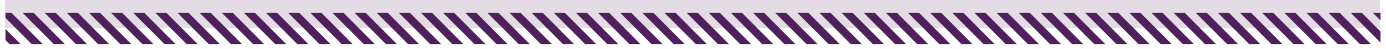

\subsubsection{Engagement to Address Potential Challenges in an NNBF Context}

For the purpose of providing guidance for those participating in engagement for NNBF specifically, this chapter begins with the assumption that NNBF has been selected or is likely to be selected as part of the project. However, low general awareness of the many benefits of NNBF can result in the tendency to perpetuate the use of more familiar, conventional infrastructure. The potential benefits of NNBF may be more likely to be realized more widely if the many advantages and costs were better understood by, and communicated to, stakeholders such as private landowners, contractors, and decision-makers. A thoughtful engagement process integrated into flood risk management projects at the earliest possible stage can, therefore, help to better communicate the full potential of NNBF solutions and avoid some of the potential challenges, such as public opposition to the project, delays, and additional financial risks. 
Managing opposition. The performance of NNBF solutions can vary in the short and long term, which may lead to the perception of high upfront costs and maintenance and significant alteration to the overall existing system and infrastructure. Some stakeholders may find it difficult to support new NNBF projects because of this, often resulting in resistance and sometimes rejection from stakeholders, including local communities. Although it is likely that there will always remain some form of opposition, successful engagement early in the project can mediate or even minimize potential public opposition or misconceptions.

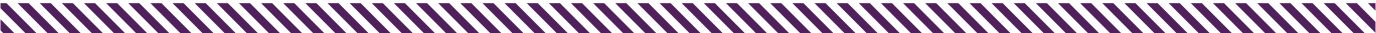

\section{CASE STUDY:}

\section{Avon River Local Ecosystem Enhancement (Nova Scotia, Canada)}

This case study provides an example of moving from Type A (light touch) engagement to Type $C$ (extensive) (see Table 3.1) engagement.

The design of the Avon River Aboiteau and Causeway Upgrades is part of a larger project that includes the construction, operation, and maintenance of 9.5 kilometers of twinned highway adjacent to the existing Nova Scotia Highway 101. The project involves the upgrade of an existing tidal gate structure on the Avon River causeway, which protects the Town of Windsor from the extreme tides of the Bay of Fundy. The causeway is integral with the local dike system, which protects approximately 2,100 hectares of land from tidal flooding. The construction of the causeway separates the Avon River in two parts, with different characteristics and ecosystems:

1. A freshwater-to-brackish lake upstream of the gate

2. A tidal estuary on the downstream side

It was clear that this project would be delicate given the scale of socioeconomic and environmental impacts. The community engagement plan was to meet with individual groups one at a time. This included First Nations, public representatives, public officials, farmers, fisheries association, university professors, and students. However, initial engagement did not include local business owners or recreational users of the lake upstream of the structure.

During the design phase of the project, an open house with a question-and-answer session was held where the public could learn about various options to replace the gate. One of the options included the partial restoration of the tidal flows along the river and consequently the restoration of a salt marsh upstream of the structure, 
partially infilling the current artificial freshwater lake. This lake is used for recreation, public events, and competitive canoeing. A series of posters also explained the design process, flooding risks, and technical considerations for all proposed options.

However, the recommended option for partial restoration (tidal exchange) caused significant concerns in the community, including a \#saveourlake social media campaign. As a result, a number of stakeholders pressured decision-makers (local politicians) to direct the design team to select an option that would keep the existing artificial freshwater lake as is (status quo).

The lesson learned from this situation is that it is more effective to engage with local business owners and recreational users throughout the design development process, as opposed to opening communication with them only after developing design options. Involving all affected parties from the start of the project would have allowed them to understand the complexity of the design considerations and their implications, as well as take part in the design process.

\section{NHIHก)}

Avoiding delays and extra costs. Project delays and unexpected costs can be an issue in any project, including NNBF projects. Addressing negative publicity and redesigning solutions can be time-consuming and costly, because delegating a portion of the project budget toward conflict mediation and resolution can impact the budget for the actual design processes and implementation of project tasks. To avoid these issues, there is a need to plan engagement well. A carefully designed engagement plan can reduce or even eliminate extra costs and delays associated with the response to public or stakeholder opposition in the later phases of a project, when most of the planning and design phases are complete and there is little opportunity for major modifications.

\section{3 | Engagement within the NNBF Project Framework}

Engagement is relevant at every stage of NNBF project development (Figure 3.5). Clarity of how, when, and by whom decisions will be made at each stage is vital to facilitate shared expectations of the process by all parties involved.

For project managers and team members to understand the alignment between the basic steps of engagement and the NNBF framework project phases, we present these within the same space. The main activities of the engagement process are presented at the phase where 
they should occur. However, it is important to maintain an iterative and adaptive engagement process throughout the project. Much like the overarching adaptive management approach, the engagement process should also include feedback and adaptation (see Chapter 7).

Figure 3.5. Community Engagement in the Context of the Phases of Project Development

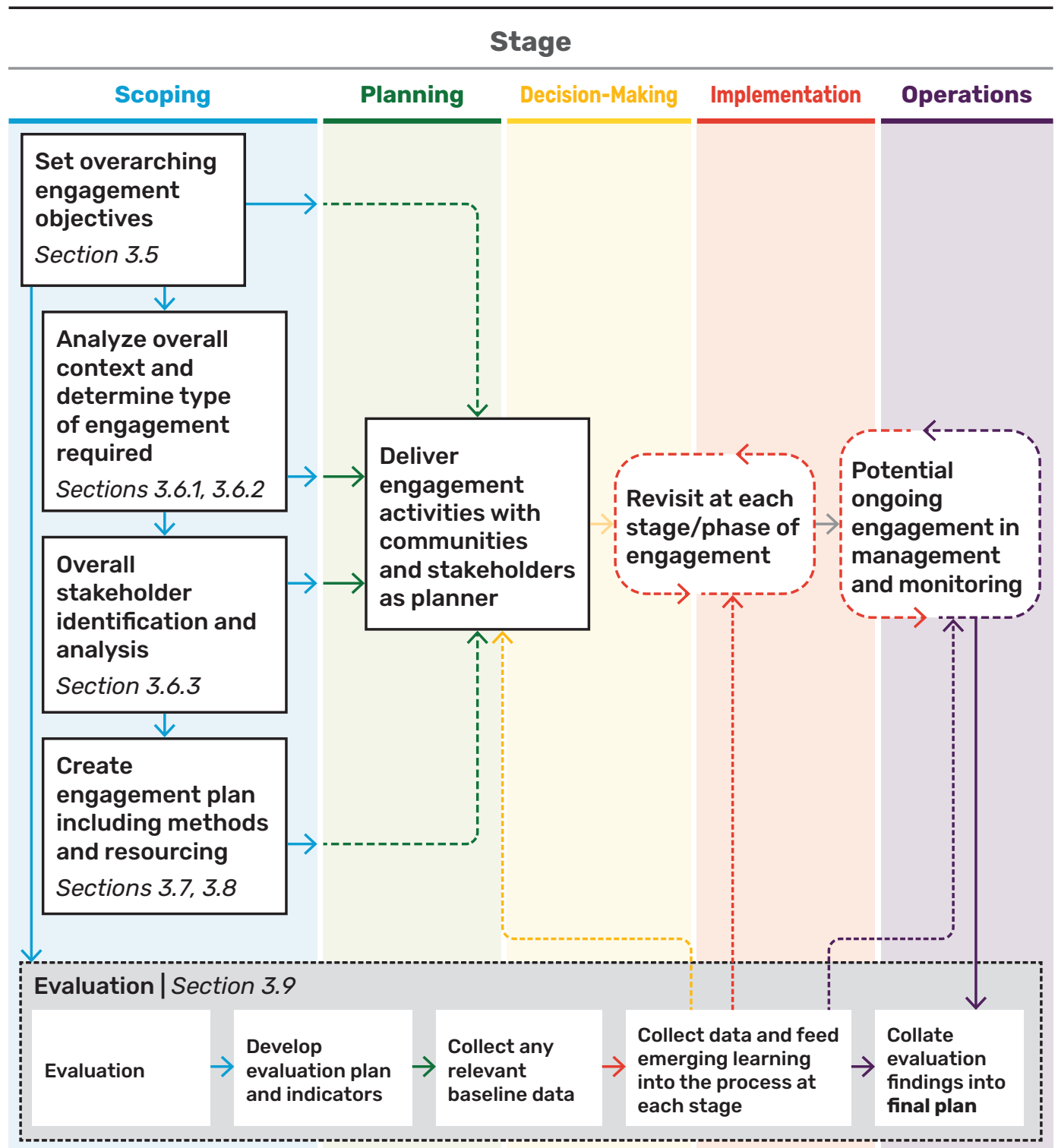




\section{4 | Develop an Engagement Plan}

A project plan is a formal, approved document used to guide both project execution and project control. The primary uses of the project plan are to document planning assumptions and decisions, facilitate communication among project stakeholders, and document approved scope, cost, and schedule baselines. An engagement plan is one component of the overall project plan.

An engagement plan documents the engagement principles and objectives, context, stakeholders, the appropriate intensity and methods for engagement, resources for engagement, and approach to evaluating engagement. The engagement plan pulls together the why, who, when, and how into a single framework, crucially linking to each major step in the NNBF project. To help with this detailed planning, Table 3.1 gives examples of the purpose and engagement actions at each project phase. We begin with the product-an engagement plan-and work backward to present the project team with best practices for the development of this plan.

Table 3.1. Examples of Engagement Actions for a Type A, Type B, and Type C NNBF Project

\begin{tabular}{|c|c|c|}
\hline \multicolumn{3}{|c|}{$\begin{array}{l}\text { PHASE 1: Scoping } \\
\text { (Initial planning and problem definition; funding strategy) }\end{array}$} \\
\hline Type A & Type B & Type C \\
\hline Light touch engagement & Moderate engagement & Extensive engagement \\
\hline \multirow{8}{*}{$\begin{array}{l}\text { Purpose of engagement } \\
\text { Develop engagement plan. } \\
\text { Inform stakeholders about } \\
\text { project and next steps. }\end{array}$} & Purpose of engagement & Purpose of engagement \\
\hline & Type A plus: & Type B plus: \\
\hline & $\begin{array}{l}\text { Understand the problem, the } \\
\text { evidence, and the local context, and } \\
\text { get stakeholder views and ideas. }\end{array}$ & $\begin{array}{l}\text { - Get community and } \\
\text { stakeholder feedback on draft } \\
\text { engagement plan in iterative }\end{array}$ \\
\hline & Raise awareness of the situation. & process. \\
\hline & $\begin{array}{l}\text { Understand the depth and range of } \\
\text { aspirations and concerns. }\end{array}$ & \\
\hline & $\begin{array}{l}\text { Form a collective vision of the } \\
\text { project (define problems and } \\
\text { opportunities; set objectives and } \\
\text { develop metrics) with internal and } \\
\text { external partners who are most } \\
\text { affected by or have most influence } \\
\text { over the project. }\end{array}$ & \\
\hline & $\begin{array}{l}\text { Describe the project governance } \\
\text { (how decisions are made). }\end{array}$ & \\
\hline & $\begin{array}{l}\text { Collectively develop engagement } \\
\text { plan with the project partners } \\
\text { (includes discussing what can and } \\
\text { cannot be influenced). }\end{array}$ & \\
\hline
\end{tabular}


PHASE 2: Planning

\begin{tabular}{|c|c|c|}
\hline $\begin{array}{c}\text { Type } \mathbf{A} \\
\text { Light touch engagement }\end{array}$ & $\begin{array}{c}\text { Tyре } \mathbf{B} \\
\text { Moderate engagement }\end{array}$ & $\begin{array}{c}\text { Type } \mathbf{C} \\
\text { Extensive engagement }\end{array}$ \\
\hline $\begin{array}{l}\text { Purpose of engagement } \\
\text { - Get feedback about the } \\
\text { planned specific activities to } \\
\text { improve the detail and quality. }\end{array}$ & $\begin{array}{l}\text { Purpose of engagement } \\
\text { Type A plus: } \\
\text { - Identify all possible options for } \\
\text { reducing flood risk and coastal } \\
\text { erosion. } \\
\text { - Identify all possible options for } \\
\text { additional environmental, economic, } \\
\text { and social benefits. } \\
\text { - Understand and analyze these } \\
\text { options and their implications. } \\
\text { - Inform public and stakeholders on } \\
\text { option selection. } \\
\text { - Consult on Environmental Impact } \\
\text { Assessment (as defined by } \\
\text { legislation). }\end{array}$ & $\begin{array}{l}\text { Purpose of engagement } \\
\text { Type B plus: } \\
\text { - Explain why the detailed } \\
\text { design looks like it does. } \\
\text { - Understand and consider } \\
\text { improvements to the final } \\
\text { design. } \\
\text { - Enable residents to have an } \\
\text { accurate understanding of } \\
\text { the scheme (correcting any } \\
\text { misinformation circulating). }\end{array}$ \\
\hline
\end{tabular}

PHASE 3: Decision-Making

\begin{tabular}{|c|c|c|}
\hline $\begin{array}{c}\text { Type A } \\
\text { Light touch engagement }\end{array}$ & $\begin{array}{c}\text { Type } \mathbf{B} \\
\text { Moderate engagement }\end{array}$ & $\begin{array}{c}\text { Type } \mathbf{C} \\
\text { Extensive engagement }\end{array}$ \\
\hline Purpose of engagement & Purpose of engagement & Purpose of engagement \\
\hline $\begin{array}{l}\text { Share the final plan or proposal } \\
\text { with affected stakeholders so } \\
\text { they know what is happening } \\
\text { and when, and who to contact } \\
\text { if they have concerns or } \\
\text { objections. }\end{array}$ & $\begin{array}{l}\text { Type A plus: } \\
\text { - Take into account advice from key } \\
\text { stakeholders. }\end{array}$ & $\begin{array}{l}\text { Type B plus: } \\
\text { - Update public on result } \\
\text { of public acceptability of } \\
\text { proposed option, changes } \\
\text { made, and planned way } \\
\text { forward. }\end{array}$ \\
\hline & & $\begin{array}{l}\text { - Report on the process in a } \\
\text { transparent way. }\end{array}$ \\
\hline
\end{tabular}

PHASE 4: Implementation

\begin{tabular}{|c|c|c|}
\hline $\begin{array}{c}\text { Type } \mathbf{A} \\
\text { Light touch engagement }\end{array}$ & $\begin{array}{c}\text { Tyре } \mathbf{B} \\
\text { Moderate engagement }\end{array}$ & $\begin{array}{c}\text { Type } \mathbf{C} \\
\text { Extensive engagement }\end{array}$ \\
\hline Purpose of engagement & Purpose of engagement & Purpose of engagement \\
\hline $\begin{array}{l}\text { Tell affected stakeholders } \\
\text { who to contact if they have } \\
\text { concerns or objections } \\
\text { about the construction and } \\
\text { monitoring activities. }\end{array}$ & $\begin{array}{l}\text { Type A plus: } \\
\text { - Consider involving key stakeholders } \\
\text { in monitoring. } \\
\text { - Inform all stakeholders frequently } \\
\text { by using a variety of communication } \\
\text { tools (e.g., websites). }\end{array}$ & $\begin{array}{l}\text { Type B plus: } \\
\text { - For large projects, build } \\
\text { an information center, } \\
\text { show stakeholders the } \\
\text { construction site, or organize } \\
\text { an open-house day to inform } \\
\text { the public. }\end{array}$ \\
\hline
\end{tabular}


PHASE 5: Operations

\begin{tabular}{|c|c|c|}
\hline $\begin{array}{c}\text { Type A } \\
\text { Light touch engagement }\end{array}$ & $\begin{array}{c}\text { Tyрe } \mathbf{B} \\
\text { Moderate engagement }\end{array}$ & $\begin{array}{c}\text { Type } \mathbf{C} \\
\text { Extensive engagement }\end{array}$ \\
\hline Purpose of engagement & Purpose of engagement & Purpose of engagement \\
\hline $\begin{array}{l}\text { Keep affected stakeholders } \\
\text { and wider public up to date } \\
\text { with ongoing management, } \\
\text { maintenance, and monitoring } \\
\text { activities. }\end{array}$ & $\begin{array}{l}\text { Type A plus: } \\
\text { - Offer opportunities for stakeholders } \\
\text { and wider community to play an } \\
\text { active role in ongoing management, } \\
\text { maintenance, and monitoring } \\
\text { activities. }\end{array}$ & $\begin{array}{l}\text { Type B plus: } \\
\text { - Encourage key stakeholders to } \\
\text { share their experience of being } \\
\text { involved in this NNBF project } \\
\text { through storytelling. }\end{array}$ \\
\hline
\end{tabular}

\section{METHODS OF ENGAGEMENT}

\begin{tabular}{|c|c|c|}
\hline $\begin{array}{c}\text { Type A } \\
\text { Light touch engagement }\end{array}$ & $\begin{array}{c}\text { Type } \mathbf{B} \\
\text { Moderate engagement }\end{array}$ & $\begin{array}{c}\text { Type } \mathbf{C} \\
\text { Extensive engagement }\end{array}$ \\
\hline $\begin{array}{l}\text { Likely to include: } \\
\text { - Provide ongoing information to } \\
\text { wider public at all stages, via } \\
\text { press release, social media, or } \\
\text { website. } \\
\text { - Direct correspondence to } \\
\text { interested and influential } \\
\text { stakeholders at key points (e.g., } \\
\text { by letter or email). } \\
\text { - Publish key documents online, } \\
\text { including draft and final plans. } \\
\text { - Provide online consultation on } \\
\text { key decisions. } \\
\text { - Create and post local signage } \\
\text { or poster explaining the } \\
\text { construction and monitoring } \\
\text { activities, including contact } \\
\text { details. }\end{array}$ & $\begin{array}{l}\text { Likely to include Type A plus: } \\
\text { - Hold regular meetings with } \\
\text { authorities who have a legal role in } \\
\text { flood or coastal risk management to } \\
\text { feed into each stage. } \\
\text { - Hold regular meetings with internal } \\
\text { and external partners who are } \\
\text { most affected by or have the most } \\
\text { influence over the project. } \\
\text { - Provide wider publicity to local } \\
\text { businesses and households, inviting } \\
\text { them to drop-in sessions to help } \\
\text { understand the problem, evidence, } \\
\text { and local context and to get their } \\
\text { views and ideas at key points in the } \\
\text { process, as well as keeping them } \\
\text { informed of the progress. } \\
\text { - Consult public (online and written } \\
\text { responses) at key points. }\end{array}$ & $\begin{array}{l}\text { Likely to include Type B plus: } \\
\text { - Create newsletter or other } \\
\text { communication tools to } \\
\text { keep local businesses and } \\
\text { households up to date from } \\
\text { scoping to management and } \\
\text { monitoring. } \\
\text { - Facilitate workshops with } \\
\text { local businesses, households, } \\
\text { schools, and universities to } \\
\text { help develop a collective vision } \\
\text { of the project, to find out how } \\
\text { they want to get involved (e.g., } \\
\text { be kept informed, comment } \\
\text { on plans, or join a working } \\
\text { group), and to get feedback on } \\
\text { options. } \\
\text { - Get community feedback on } \\
\text { draft engagement plan. } \\
\text { Make a public commitment } \\
\text { that the final proposed option } \\
\text { will be environmentally and } \\
\text { economically feasible and } \\
\text { publicly acceptable. }\end{array}$ \\
\hline
\end{tabular}




\begin{tabular}{|c|c|c|}
\hline $\begin{array}{c}\text { Type } \mathbf{A} \\
\text { Light touch engagement }\end{array}$ & $\begin{array}{c}\text { Type } \mathbf{B} \\
\text { Moderate engagement }\end{array}$ & $\begin{array}{c}\text { Type } \mathbf{C} \\
\text { Extensive engagement }\end{array}$ \\
\hline $\begin{array}{l}\text { Engage staff and partners in } \\
\text { construction and monitoring } \\
\text { engagement activities (e.g., } \\
\text { proactive information giving or } \\
\text { reactive responses). }\end{array}$ & $\begin{array}{l}\text { - Collate results of each stage of } \\
\text { engagement; publish summary and } \\
\text { response. } \\
\text { - Hold internal meetings (including } \\
\text { with partners) to reflect on } \\
\text { stakeholder input and agree on } \\
\text { amendments. } \\
\text { - Check major decisions with key } \\
\text { stakeholders. }\end{array}$ & $\begin{array}{l}\text { - Set up working groups } \\
\text { (with external stakeholders) } \\
\text { to understand and analyze } \\
\text { options and implications and } \\
\text { an advisory group who will } \\
\text { inform the option selection. } \\
\text { - Working groups and advisory } \\
\text { group share work with the } \\
\text { wider public for feedback. } \\
\text { - Provide public drop-in events } \\
\text { or other method to gage public } \\
\text { acceptance of the option } \\
\text { selection. } \\
\text { - Update public on result } \\
\text { of public acceptability of } \\
\text { proposed option, changes } \\
\text { made, and planned way } \\
\text { forward. } \\
\text { Build a project information } \\
\text { center to have a physical point } \\
\text { of contact for the project to } \\
\text { encourage wider stakeholder } \\
\text { interest. } \\
\text { - Involve children and teachers. } \\
\text { A child's world view is different } \\
\text { from that of adults. They often } \\
\text { view the world with a more } \\
\text { open mind, ask questions that } \\
\text { adults no longer dare to ask, } \\
\text { and come up with ideas that } \\
\text { no longer occur to us. }{ }^{1}\end{array}$ \\
\hline
\end{tabular}

Note:

1 For an example, see ConsultingKids (consultingkids.co.uk, n.d.) at https://consultingkids.com/.

\section{Key Action}

Early and iterative engagement planning is essential to the successful delivery of a credible process. 
Engagement planning is an iterative process and the engagement plan should be seen as a living document, which requires frequent discussion by the project team to reassess if the level of engagement is still fit for purpose (using the questions in Table 3.2). It is essential to remain flexible and open to change, including refreshing stakeholder input and revisiting aims and objectives at each stage in relation to the scope of the project. By following an iterative process, the project team will gain input to determine if and how the engagement plan should change, to take into account shifting needs and priorities. For example, a Type B (moderate) engagement project with a moderate level of engagement planned might become more publicly contentious and require a move to a more extensive engagement approach. In the sections that follow, the steps that lead to a successful engagement plan are presented and described. By the end of this chapter, any project team will be ready to develop and carry out an engagement plan.

Table 3.2. Assessment Tool for Different Decision Types*

\begin{tabular}{|c|c|c|c|}
\hline Decision type & $\begin{array}{l}\text { Type A } \\
\text { Light touch } \\
\text { engagement }\end{array}$ & $\begin{array}{c}\text { Type } \mathbf{B} \\
\text { Moderate } \\
\text { engagement }\end{array}$ & $\begin{array}{c}\text { Type C } \\
\text { Extensive } \\
\text { engagement }\end{array}$ \\
\hline $\begin{array}{l}\text { 1. How affected will others be by } \\
\text { the decision? }\end{array}$ & Very little & Some & Severe \\
\hline $\begin{array}{l}\text { The decision may have } 1 \text { effect } \\
\text { on (public interest, health, } \\
\text { livelihoods). }\end{array}$ & Few people & Some people & Many people \\
\hline $\begin{array}{l}\text { 2. How many different } \\
\text { perspectives, views, and politics } \\
\text { exist? }\end{array}$ & No significantly & A number of & A wide range of \\
\hline $\begin{array}{l}\text { There are likely to be }{ }_{\text {perspectives (to ours) on the issue }} \\
\text { and_politics. }\end{array}$ & No (or containable) & Some & Significant \\
\hline $\begin{array}{l}\text { 3. How much support or ownership } \\
\text { of the decision or implementation } \\
\text { by others is required? }\end{array}$ & $\begin{array}{l}\text { Known (project team } \\
\text { has strong opinion) }\end{array}$ & $\begin{array}{l}\text { Open to influence, but } \\
\text { limited options }\end{array}$ & $\begin{array}{l}\text { Unknown (or } \\
\text { project team has } \\
\text { no opinion) }\end{array}$ \\
\hline The best decision is & & & \\
\hline And we can implement & $\begin{array}{l}\text { Alone (with or without } \\
\text { support) }\end{array}$ & $\begin{array}{l}\text { More easily if others } \\
\text { work with us }\end{array}$ & $\begin{array}{l}\text { Only with sufficient } \\
\text { support, or only } \\
\text { with others }\end{array}$ \\
\hline $\begin{array}{l}\text { 4. How much risk and uncertainty } \\
\text { are involved? } \\
\text { Risk and uncertainty relevant to the } \\
\text { decision are }\end{array}$ & $\begin{array}{l}\text { Low and understood } \\
\text { by most }\end{array}$ & $\begin{array}{l}\text { Medium and } \\
\text { understood by us } \\
\text { (and some) but not by } \\
\text { others }\end{array}$ & $\begin{array}{l}\text { High and poorly } \\
\text { understood }\end{array}$ \\
\hline
\end{tabular}




\begin{tabular}{|l|c|c|c|}
\hline & Type A & Type B & Type C \\
& Light touch & Moderate & Extensive \\
\hline Decision type & engagement & engagement & engagement \\
\hline
\end{tabular}

5. When do actions and decisions have to be made?

Actions or decisions need to be made and implemented

Immediately or very quickly

Over months

Over years

Note:

*The type and scale of a project may dictate multiple types of engagement over time. For example, for a beach nourishment project, during initial design and construction, Type $C$ engagement may be optimal; however, for maintenance events in future years, Type A may be best.

Source: Adapted from Lindsey Colbourne Associates and Environment Agency 2008

\section{5 | Articulate Engagement Principles and Set Engagement Objectives}

\subsubsection{Engagement Principles}

Whatever the context and nature of an engagement process, certain values and principles underpin a good practice. At the heart of many of these values and principles are the ideas of transparency (of process, expectations, and outcomes), respect (for individuals and organizations, their views and values), and relevance (of the process to those involved and the overall aims of the project). The principles should be articulated in the engagement plan (Section 3.5) and shared with the stakeholders. It is important to remember that principles for engagement will be shaped by social and cultural context.

\section{Key Action}

If the organization does not have engagement principles, these may have to be created and agreed upon before developing a plan.

The International Association for Public Participation (IAP2) developed a set of core values for public participation. Created using a 2-year process with broad international input, the core values identify aspects of public participation that cross national, cultural, and religious boundaries, and are, therefore, relevant in multiple contexts. The values listed in "IAP2 Core Values for the Practice of Public Participation" provide a widely applicable set of principles that NNBF project managers and team members should consider and adopt. 


\section{IAP2 Core Values for the Practice of Public Participation}

1. Public participation is based on the belief that those who are affected by a decision have a right to be involved in the decision-making process.

2. Public participation includes the promise that the public's contribution will influence the decision.

3. Public participation promotes sustainable decisions by recognizing and communicating the needs and interests of all participants, including decision-makers.

4. Public participation seeks out and facilitates the involvement of those potentially affected by or interested in a decision.

5. Public participation seeks input from participants in designing how they participate.

6. Public participation provides participants with the information they need to participate in a meaningful way.

7. Public participation communicates to participants how their input affected the decision.

Source: iap2.org 2017

\section{N11111}

\section{CASE STUDY:}

\section{Examples of Engagement Principles}

Achieving mutual gains implies finding solutions that are supported by the involved parties. Issue management is used for continuously scanning the environment for new issues. An issue can be described as a development or event that might happen and forces stakeholders to take a position. Project management is used in the strategic stakeholder involvement approach to phase the process in clear steps and use typical project management instruments such as issue and risk lists, stakeholder matrices, road maps, and monitoring systems.

Over the last 20 years, the mutual gains approach (Fisher and Ury 1991) has been developed, refined, and applied into a strategic stakeholder involvement approach (Wesselink and Paul 2010). This approach has been a standard part of practice in the Netherlands for the last decade. Likewise, the U.S. government adopted a set of principles for environmental collaboration and conflict resolution in 2012 (OMB and CEQ 2012, page 7). The 12 principles featured in Table 3.3 provide another example of an approach to consider. 
Table 3.3. The 12 Principles of the Dutch Strategic Stakeholder Management (Strategisch Omgevings Management) Approach

\section{Principle}

1 Strive for mutual gains for all involved parties.

\section{Focus}

Look for a solution that is favored by all parties. Expand the possibilities for mutual gains that can compensate for losses.

2 Engage in the interests of stakeholders.

3 Distinguish between positions and interests.

4 Be trustworthy.

5 Prepare well and analyze thoroughly.

6 Scan issues first, then stakeholders.

7 Make transparent decisions and decisions transparent.

8 Spend most time on the most important stakeholders.

9 Distinguish between cooperation and conflict.

10 Make package deals.

11 Monitor mutual agreements.

Monitor and secure agreement on results and build trust.

12 Stay with the principles.
Understand the concerns of the stakeholders.

Look for solutions at the level of interest, not at the level of positions. Look for the interests associated with opinions.

Do what you promise. Internalize the approach, be modest in commitments, and admit mistakes.

Build a good understanding of the stakeholders interests, powers, and emotions.

Start with an overview and then focus on parts and details.

Be open. Provide information adjusted to participation and balanced with the project (expectation management).

By identifying and analyzing issues early, the dialogue with stakeholders can start early. Use dialogue and interaction to understand interests.

The first phase is to understand each other's opinions, interests, and worries about the impact of plans (constructive negotiations).

The second phase involves the conclusion of agreements on subjects with opposite interests that cannot be agreed to in the first phase.

Package deals prevent subsequent one-off negotiations and facilitate cooperation.

Beware of quick wins. Stay engaged.

Source: Translated and adapted from Wesselink and Paul (2010) Handboek Strategisch Omgevings Management (in Dutch). 
Based on these fundamentals, community engagement or strategic stakeholder involvement approaches in a project environment means that the project engages the stakeholders in a collaborative design process. The project organization respects and uses the expertise of the stakeholders in joint design and is open and transparent about all information necessary for the joint design, as are the stakeholders. The design is based on problem-specific interaction involving the interests of relevant stakeholders. Decision-making is based on the weighing of interests. The outcome of this process is a jointly agreed upon NNBF project.

\section{NIIIHINH}

\subsubsection{Engagement Objectives}

Guided by the overarching engagement principles (Section 3.5.1), the first step in identifying specific objectives for an engagement process is understanding the reasons for engaging. The examples provided in Section 3.2 can support this determination. Once the reasons have been established and principles have been selected, the process of setting engagement objectives begins.

Setting engagement aims and objectives in the context of overall project objectives is important to be able to do the following:

- Set a clear shared vision that can be communicated and shared internally and externally

- Measure success and impact

- Inform project planning and resourcing

- Open up opportunities for new partnerships, collaboration, and resourcing

- Link or integrate engagement inputs and outcomes with the overall project planning process

There may be aims and objectives relevant to the overall engagement process or to specific methods or phases of engagement. In both cases, where possible, these should be specific, measurable, achievable, relevant, and time-bound (also known as SMART goals). It is possible to have multiple objectives for even a seemingly simple engagement process. 


\section{Key Action}

It is essential to set engagement objectives upfront-so achievement goals are understood-and at each stage or phase of engagement.

Defining the level of influence stakeholders will have over the entire NNBF project or specific project decisions is a vital part of defining engagement objectives and setting realistic expectations. This may involve sharing constraints or clarifying decisions that have already been made. Once these boundaries are set, maintenance of trust relies on them being respected and adhered to or the rationale for any changes being clearly and transparently communicated.

\section{CASE STUDY: \\ Floodplain Reconnection Areas (the Netherlands)}

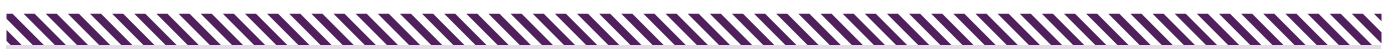

This case study is an example of Type $\mathrm{C}$ (extensive) engagement with co-designing compensation.

Room for the River was a Dutch government plan delivered between 2009 and 2016. Its aim was to address flood protection along the Rhine River and its tributaries, utilizing landscaping and environmental improvement.

In the Noordwaard project (see Figure 3.6) and Overdiepse Polder project, construction of floodways through agricultural areas was required to reduce peak discharge water levels upstream. This involved lowering existing levees to the original topography and geography (surveyed circa 1850), allowing the area to flood during very high river discharges (for technical details of the Noordwaard project, see Chapter 19).

Several farms and households had to be relocated during this process (either rebuilt on earth mounds behind a separate levee or relocated entirely), for which compensation mechanisms needed to be put in place. In the case of the Overdiepse Polder project, local farmers developed their own buyout and compensation plan. Many inhabitants had to move out of the area but in the context of a financial 
reparation scheme they had co-created, involving a combination of generic and tailored individual arrangements and legal interpretations. A solid social and economic outlook, together with a speedy project delivery, appeared to be the main driver for inhabitants to agree.

\section{Figure 3.6. Photograph of Noordwaard Project Floodplain Reconnection Area} (the Netherlands)

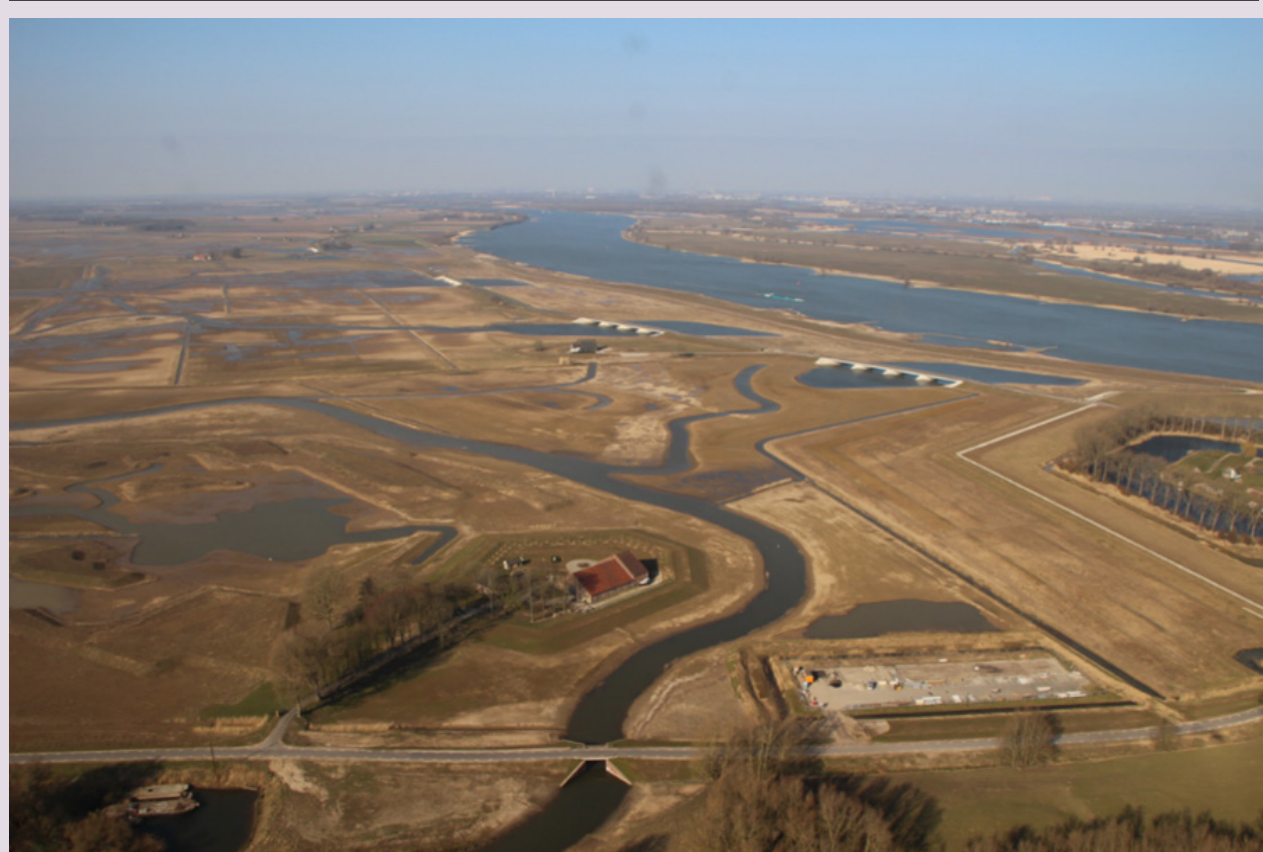

Note: This aerial photograph of the Noordwaard project shows the floodplain reconnection area with lowered levees, a newly built elevated road with bridges, and a farm rebuilt on an earth mound.

Source: Rijkswaterstaat

\section{NHIHINH}


Engagement objectives and wider project objectives should be informed by stakeholder input to enable them to take into account the range of views, to be jointly owned and understood, and to maximize opportunity for benefits to multiple parties. Where multiple agencies are involved in driving the project, there may be a broader range of project, and thus engagement, objectives to take into account.

Communicating the project objectives and rationale is a central part of the engagement process. Helping stakeholders understand the story in plain language may include answering simple questions such as the following:

- Why are we interested in this place, issue, or site now?

- What do we want to achieve?

- What are the likely benefits, risks, and challenges?

- Why are we asking stakeholders and the community to get involved and how?

- What benefits will involvement provide?

\section{Examples of Engagement Objectives}

\section{From Kounkuey Design Initiative, Kenya}

Outcomes for a productive public space focused on developing community ownership, mitigating disputes, and involving the community and stakeholders in the design process. The space provides the following benefits:

- Transforms an environmental liability into usable public space

- Is authored and operated by its end users collaborating with outside groups

- Integrates income-generating and socially empowering uses

- Adds value to a space without alienating the original community

- Meets expressed community priorities and links to larger improvement efforts

- Uses strong design concepts to create beautiful places

\section{From Rijkswaterstaat, the Netherlands}

A Public Participation Code was developed in 2014. It still has a status of "soft law" but will be legally embedded in the near future. The code centers on the following three key objectives:

- Contributions from society are taken on board throughout the entire planning process.

- Public initiatives receive the same careful consideration as government initiatives.

- Participation is transparent. 
Engagement objectives can also be more quantitative and highly focused on the engagement aspects of the overall project. For example, a project team doing flood resilience work at a business estate might set the following project goal: "We engage organizations and businesses within [area $\mathrm{X}$ ] to reduce the risk of flooding to their premises by [X date]." This goal would then be reached through the following objectives:

"At least [X\%] more people will:

- Accept that their premises and their staff, users, customers, and clients are at risk of flooding

- Take specific actions to reduce the risk of flooding to their organization and businesses

- Explain the flood risk and any flood plans to their staff, users, customers, and clients"

Both qualitative and quantitative objectives have benefits, depending on the project, the overarching goals, the context, and the stakeholders.

\section{6 | Assess the Context and Stakeholders}

\section{Key Action}

The type or intensity of engagement required and who to involve are important to clarify upfront, as well as for each engagement phase or activity.

\subsubsection{Contextual or Situational Analysis}

An upfront contextual analysis (also called situational analysis) can provide essential information for the entire engagement process, including identifying any potential issues at an early stage. Contextual or situational analysis is the analysis of the history, culture, and other social factors that may impact a project and related interactions. Contextual or situational analysis helps to highlight potential issues in project development and implementation. The local history of engagement, as well as physical, environmental, and legal considerations, should be included in the examination.

The analysis can draw upon hard information (statutory designations, definite, known facts) or soft information (perceptions, interpretations, often about the people side of a situation).

A contextual or situational analysis can be in depth (working carefully through a number of issues) or limited (reflecting on any really obvious or important contextual issues). The amount of effort put into this should be guided by the actual or potential level of conflict or disagreement within the project and its overall size and complexity. 
It is vital that any relevant legal requirements are built into the early design of the engagement process and revisited throughout the delivery process.

\subsubsection{Engagement Intensity}

Engagement can be viewed as a spectrum (Table 3.4). From left to right in Table 3.4, the different types of engagement (Type A [light touch], Type B [moderate], and Type C [extensive]) represent increasing levels of involvement and power for stakeholders. Multiple types of engagement may be used within a single project, whether at different project phases or with different groups of stakeholders. The simplified, three-pronged, Types A, B, and C model referenced in Table 3.4 is used throughout this chapter when discussing methodology and designing the engagement process. Industry standards such as the IAP2 Spectrum of Public Participation (IAP2 2018) provide an excellent foundation for a full spectrum of engagement. Here, a simplified spectrum has been adopted for the benefit of ensuring ease of application for all users. A range of factors is likely to influence the overall approach to engagement and require consideration early in the planning stage. These factors will be explored through the contextual or situational analysis and the stakeholder analysis.

Table 3.4. Types of Engagement

\begin{tabular}{|c|c|c|c|}
\hline & $\begin{array}{c}\text { Type } \mathbf{A} \\
\text { Light touch engagement }\end{array}$ & $\begin{array}{c}\text { Type } \mathbf{B} \\
\text { Moderate engagement }\end{array}$ & $\begin{array}{c}\text { Type } \mathbf{C} \\
\text { Extensive engagement }\end{array}$ \\
\hline Context & $\begin{array}{l}\text { Stakeholders recognize the } \\
\text { need for FRM/NNBF, and very } \\
\text { few stakeholders are affected. }\end{array}$ & $\begin{array}{l}\text { FRM/NNBF is not likely to } \\
\text { be controversial, but there } \\
\text { still needs to be stakeholder } \\
\text { buy-in. }\end{array}$ & $\begin{array}{l}\text { The role of FRM/NNBF } \\
\text { is unknown by some } \\
\text { stakeholders, and there } \\
\text { are likely to be different } \\
\text { perspectives about } \\
\text { the issues, with many } \\
\text { stakeholders affected. }\end{array}$ \\
\hline Goal & $\begin{array}{l}\text { Provide the stakeholders } \\
\text { with balanced and objective } \\
\text { information to assist them in } \\
\text { understanding the problems, } \\
\text { alternatives, and solutions. }\end{array}$ & $\begin{array}{l}\text { Obtain stakeholder feedback } \\
\text { on analysis, alternatives, and } \\
\text { decision. } \\
\text { Work directly with the public } \\
\text { and stakeholders throughout } \\
\text { the process to support } \\
\text { consistent understanding } \\
\text { and consideration of their } \\
\text { issues and concerns. }\end{array}$ & $\begin{array}{l}\text { Partner with the } \\
\text { stakeholders in each } \\
\text { aspect of the decision, } \\
\text { including the development } \\
\text { of alternatives and the } \\
\text { identification of the } \\
\text { preferred solution. }\end{array}$ \\
\hline
\end{tabular}




\begin{tabular}{|c|c|c|c|}
\hline & $\begin{array}{c}\text { Type A } \\
\text { Light touch engagement }\end{array}$ & $\begin{array}{c}\text { Type B } \\
\text { Moderate engagement }\end{array}$ & $\begin{array}{c}\text { Type } \mathbf{C} \\
\text { Extensive engagement }\end{array}$ \\
\hline $\begin{array}{l}\text { Overall shape } \\
\text { of engagement }\end{array}$ & $\begin{array}{l}\text { Likely to be regular informing } \\
\text { with wider stakeholders, some } \\
\text { targeted engagement of key } \\
\text { parties, and consultation on } \\
\text { any major decisions. Aligns } \\
\text { most closely to inform on the } \\
\text { IAP2 spectrum. }\end{array}$ & $\begin{array}{l}\text { Likely to require early } \\
\text { work to understand key } \\
\text { stakeholder interests and } \\
\text { concerns; close, ongoing } \\
\text { engagement with key } \\
\text { partners and stakeholders; } \\
\text { and broader consultation } \\
\text { and collaboration at major } \\
\text { decision points. Aligns most } \\
\text { closely to consult on the } \\
\text { IAP2 spectrum. }\end{array}$ & $\begin{array}{l}\text { Early and ongoing extensive } \\
\text { engagement is likely to be } \\
\text { required, including a mix } \\
\text { of informing, consulting, } \\
\text { and collaboration, to seek } \\
\text { collective ownership, build } \\
\text { relationships, and develop } \\
\text { an agreed way forward at } \\
\text { key points. Aligns most } \\
\text { closely to collaborate on the } \\
\text { IAP2 spectrum. }\end{array}$ \\
\hline Examples & $\begin{array}{l}\text { Case Study: Beach and } \\
\text { Shoreface Nourishment } \\
\text { (the Netherlands) }\end{array}$ & $\begin{array}{l}\text { Case Study: Living } \\
\text { Shoreline Flood Protection } \\
\text { (Ernst Brook, Mahone Bay, } \\
\text { Canada) }\end{array}$ & $\begin{array}{l}\text { Case Study: Flood } \\
\text { Mitigation Plan for } \\
\text { Coastal Communities } \\
\text { (Bay of Fundy's } \\
\text { Truro Area, Canada) }\end{array}$ \\
\hline
\end{tabular}

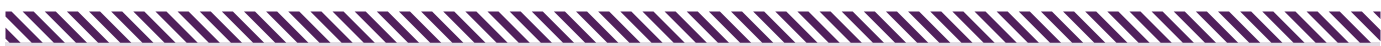

\section{CASE STUDY: \\ Beach and Shoreface Nourishment (the Netherlands)}

In the Netherlands, gradual coastal erosion is occurring due to sea-level rise, natural redistribution of sand, and human intervention. For longer timescales, this gradual erosion is anticipated to cause increased risk of flooding and erosion of dunes and dune infrastructure, together with the collective impacts on the natural environment, recreation, and potable water extraction. The Netherlands, therefore, has a coastal erosion management policy aimed at compensating the sediment losses by means of nourishment of the beach or the shoreface (Lodder et al. 2020). Its aim is to maintain the coastline dynamically at its 1990 position and to feed the coastline so it can grow with sea-level rise.

A scheme of monitoring, assessing, programming, and execution is in place, including annual bathymetry surveys and trend analysis of the coastline, reported online and in a map (see examples in Chapter 9). Every year, the nourishment scheme is updated on these monitoring results. 
Because the policy is already set by parliament for the whole nation, the annual nourishments only require light touch (Type A) engagement. The annual nourishment scheme is consulted with stakeholders each spring. Suggestions for adjustments to the program are weighted and, if feasible, included in the final scheme.

Before the start of nourishment work, a stakeholder meeting is scheduled to discuss operational aspects such as design detailing (e.g., beach height per section or phasing). For the general public, information is available on signposts at the beach entrance and online.

\section{1}

\section{N11)}

\section{CASE STUDY:}

\section{Living Shoreline Flood Protection (Ernst Brook, Mahone Bay, Canada)}

The primary objective of this project was to provide flood protection along the Ernst Brook and enhance the shoreline to mitigate the impact of sea-level rise and extreme weather events to protect businesses, private property, public spaces, retail, and tourism in the Town of Mahone Bay.

A living shoreline concept was found to be a viable alternative to the traditional armor rock. This concept made use of partial infilling in the harbor to create salt marsh habitat fronted by rock sills. The community was engaged through a series of three public meetings.

The first public meeting was to present the project to the public and identify their priorities, present ideas for flood protection measures, and gather local knowledge. The framework of the public meeting included a poster session with note-taking on which stakeholder's comments could be added in relation to flood and erosion observations.

The second public meeting included a presentation of the proposed design options, with a focus on how each feature addresses and solves a different issue. The presentation of these concept designs occurred in an open-house format where the 
community's feedback was collected and used to further adjust the proposed designs. During this event, an unexpected, informal consensus occurred when an attendee addressed the whole room, asking who was in favor of the living shorelines option; in response, all the attendees said they were in favor, and they were all in agreement.

The third public meeting included a presentation of the selected living shorelines option. This was also presented as an open house, with the aim of informing the community with the details of the chosen design and next steps. The only uncertainty from the public was the potential growth in mosquito population.

The three open-house meetings, designed to include the community before the project start and throughout the project, had a positive impact on the overall acceptance of the process and the proposed NNBF solution.

\section{NHINHก)}

\section{NHINHก)}

\section{CASE STUDY:}

Flood Mitigation Plan for Coastal Communities (Bay of Fundy's Truro Area,

\section{Canada)}

This project entailed the study of flooding risks and the development of a flood mitigation plan for the coastal communities along the Bay of Fundy's Truro area, which included the Municipality of Colchester, the Town of Truro, and the Millbrook First Nation. Residents of the community suffer repeated flooding damage at an alarming frequency.

Part of the recommendations that have been implemented as a result of the project was the realignment of dikes and salt marshes that have less than $8 \mathrm{~m}$ of foreshore. Dikes were realigned to restore as much of the natural floodplain as possible (up to $700 \mathrm{~m})$.

The first action taken in this project was to consult as many stakeholders as possible. Only through in-depth discussions during many meetings and workshops could the full depth of concerns, goals, objectives, and challenges be properly understood. 
From the outset of the project, the importance of working with the municipal council and staff, the public, and other stakeholder groups was recognized. A drop-in, public open house was held to gather information from the community on flooding experiences, concerns, and priorities.

Given the depth of historical and contemporary knowledge of the local area, the Nova Scotia Department of Agriculture, together with other stakeholders, was engaged through a workshop. Stakeholders included the flood advisory committee (the town, municipality, First Nations), the Department of Transportation, the Department of Environment, councilors, and emergency management organizations. The Nova Scotia Department of Natural Resources was consulted to discuss forestry activities that have historically taken place in the watershed and influenced surface runoff, potentially worsening flooding risks.

Continuous coordination with the Millbrook First Nation was held through a representative consultant, who was able to synthesize the needs, objectives, and priorities of the First Nation community throughout the project.

The discussions held early on in the design process with many of the stakeholders helped the local farm landowners be more receptive to selling their land when they understood that the project goal was to restore the natural floodplain and salt marsh, an essential part of a wider flood protection project.

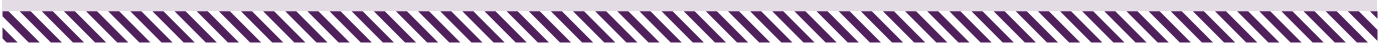

The level of influence and impact for each stakeholder will help to determine the level of intensity of engagement (discussed in detail in this section). Similarly, the nature of a specific decision may also impact the overall intensity of engagement required. Analyzing the situation aids decisions about how much effort and time to put into designing engagement and how soon to begin.

Tools such as that shown in Table 3.2 can help to assess specific decisions (either overarching the project or for key points in the project).

If responses to the questions in Table 3.2 are mostly in column $A$, the situation or decision is likely to only require a light touch engagement (Type $A$ ). If responses are mostly in column $B$, they suggest moderate engagement (Type B). And if responses are mostly in column $C$, they suggest extensive engagement (Type $\mathrm{C}$ ). 
Type A (light touch) engagement situations or decisions may be characterized by the following:

- Low conflict, controversy, or uncertainty

- Few or no options due to the decision being constrained by time, procedure, or resources

- Few stakeholders with an interest in changes resulting from the decision

Formal consultation may not be required at all. If it is required (e.g., legally), the scope may be constrained by time or procedure and available options. The resulting impact is likely to be limited in terms of the effect and the numbers of people and organizations affected, or the impact is well understood, predictable, and accepted. Any consultation is focused on getting details right. In these situations, more resources tend to be spent on communicating the results of decisions than on using engagement and consultation to inform decision-making. An example of such a project would be routine maintenance of existing flood defenses.

Type B (moderate) engagement situations or decisions may be characterized by the following:

- A relatively low level of controversy surrounding the issue

- The need for buy-in or understanding from a number of stakeholders to support well-informed decisions and to reduce risk of nondelivery through resistance or opposition

- The need for some degree of trade-off or compromise

Definition of the problem and generation of options may require close working with a limited number of experts or stakeholders that have relevant information or who will be affected. Different stakeholders may hold a range of preferences, and informal engagement that helps resolve conflicts may be essential. The results of informal engagement with stakeholders may need to be put to formal consultation to check that the results are supported or because it is required legally. Co-funding of the project may also be required, which involves close, early engagement with potential co-funders. An example of such a project would be the establishment of an NNBF project that is not likely to cause significant concern to many people.

Type C (extensive) engagement situations or decisions may be characterized by the following:

- High or potentially high levels of conflict, controversy, and uncertainty about the issue, with many potential options for the way forward

- Many stakeholders likely to be affected by decisions, potentially with some disproportionately affected, or some with apparently competing interests

- Significant risk of strong opposition unless the relevant people are involved in developing solutions 
There may be a need for shared ownership of a solution by multiple actors, each of whom has a role in delivering or funding it. As well as the informal engagement required for Type $B$ (moderate) engagement situations, significant efforts will need to be made to communicate more widely at all key stages of analysis and decision-making. A formalized consultation process will almost certainly be required to gain the mandate for the nature and extent of change being considered. In some cases, the formal consultation will be required more than once as options are developed and tested. An example of this type of project would be the establishment of an NNBF project that is likely to cause significant concern to many people.

Use Figure 3.7 to check that the outcome of the engagement type is in line with the anticipated overall level of influence stakeholders are likely to have over the decisions and the likely impact of the decisions (and implementation) upon them.

Figure 3.7. Typical Stakeholder Analysis Matrix, Indicating the Engagement Intensity Likely to Be Required

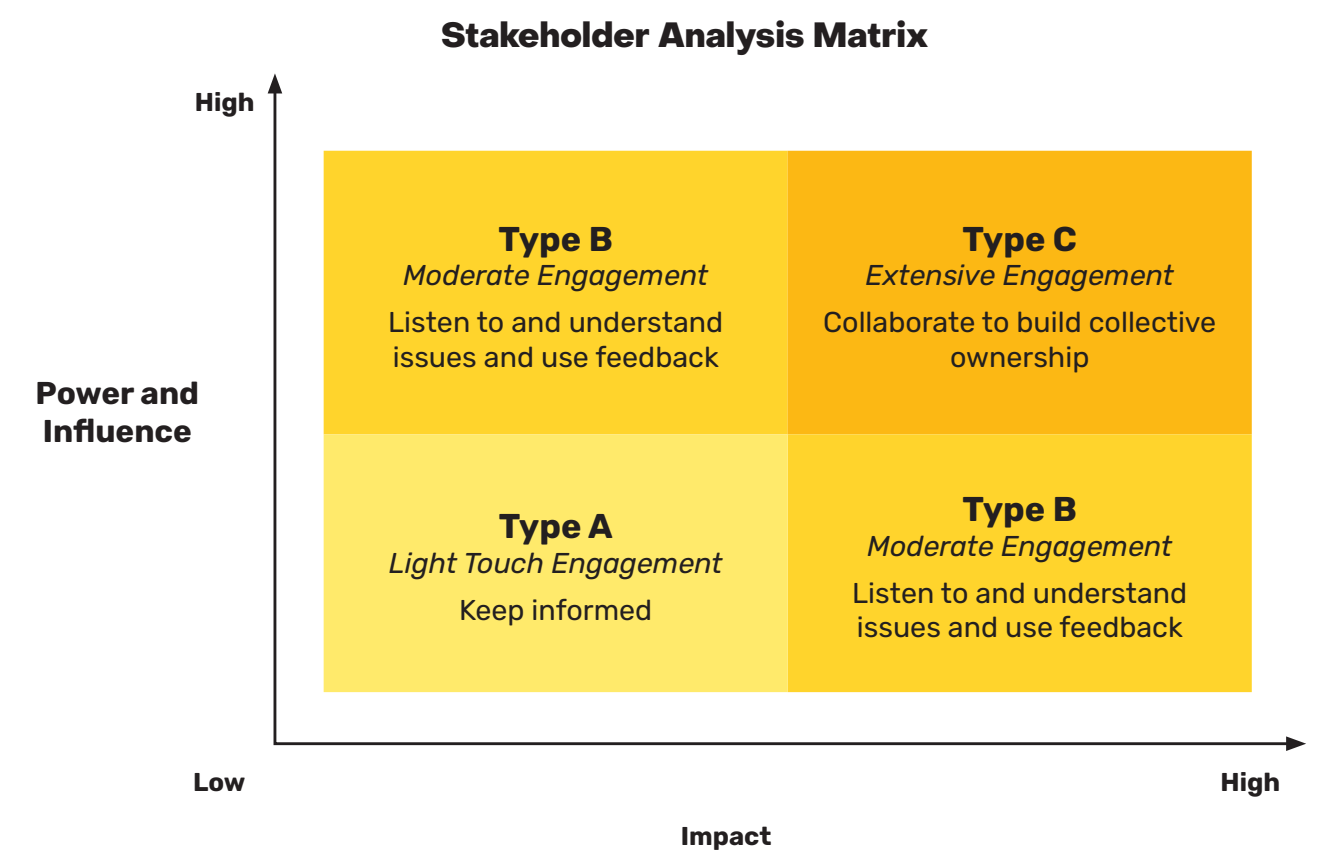

Source: Adapted from Lindsey Colbourne Associates and Environment Agency 2008

A third scale-level of interest-is often also taken into account, particularly when deciding how to engage with specific stakeholders, and for how long. For example, a stakeholder with significant influence but low interest may require proactive, persistent two-way engagement, whereas a group or organization with high interest but low influence or impact may appreciate information provision to keep them informed at specific points in the process. 


\subsubsection{Stakeholder Identification and Analysis}

Knowing where and how to involve stakeholders in the process is an essential part of the overall engagement plan. Defining the community involves a two-step process of stakeholder identification and stakeholder analysis. Even a simple level of identification and analysis enables the process not to always focus on the same subset of stakeholders and facilitates the inclusion of all stakeholders who may offer significant contributions-in positive or negative ways. Ultimately, a good stakeholder analysis process will help to avoid major issues later in the process and enable appropriate planning and resourcing.

\section{Key Action}

Identifying stakeholders early in the process is essential to planning whom to engage and how. Stakeholder analysis should be revisited at each stage to take into account potential shifts in impact, influence, and interest.

\subsubsection{Stakeholder Identification}

Stakeholder identification is the process of developing a long list of potential individuals, groups, or organizations that may or need to be engaged with as part of the project. It requires a systematic, reflective approach that moves beyond the obvious or usual groups. One way of approaching this process is to think through different categories and rationales for engaging, including the following:

- Sector: public, private, voluntary, or community

- Function: user, service provider, regulator, landowner, or decision-maker

- Geography: living within a specific postal district or flood risk area

- Socioeconomic: income, gender, age, disability, race and ethnicity, sexual orientation, religion or belief, or length of time living in area

- Impact: directly affected, indirectly affected, or able to influence the issue

- Understanding and experience of the issue: none, low, medium, or high

- Known or likely position: for or against the project or issue

The more that is known about people and their possible relationship to the project or issue, the easier it is to identify who should be involved, their needs, and their potential contribution to the process. 


\subsubsection{Stakeholder Analysis}

Stakeholder analysis is the process of reflecting on, analyzing, and deciding what the list of stakeholders communicates. It enables the grouping of stakeholders to plan engagement work, as well as a deeper understanding of the likely opportunities for and challenges of a collaborative approach.

A range of analysis approaches can be used, but most tend to involve a two-scale matrix based on the following scales:

- Likely influence they have over the decisions to be made (or their implementation)

- Likely impact of the decisions (and implementation) upon them

The process of stakeholder analysis is particularly useful when an integrated process to engagement is required, such as with NNBF projects, and is best carried out after the project and engagement aims have been agreed to but before any process planning is undertaken. Broad steps are as follows:

1. Using a matrix such as the one described previously and shown in Figure 3.7, categorize each stakeholder from the long list by level of influence and impact.

2. Consider the relationships (such as responsibilities, rights, or levels of conflict) within and between stakeholders in each area of the matrix. For example, there may be a responsibility for those in the top-right corner of the matrix (Type $C$ [extensive engagement]) to take into account, represent, or communicate with those in the bottom-right corner of the matrix (Type B [moderate engagement]).

3. Consider the intensity of engagement likely to be required for the different stakeholders based on the three categories shown in Figure 3.7 (light touch, moderate, or extensive).

The lines between the boxes in Figure 3.7 should not be taken as defined boundaries; they are for guidance only. The results should be considered as a continual draft and should be frequently updated.

A third level of interest is often also taken into account, particularly when deciding how to engage with specific stakeholders and for how long. For example, a stakeholder with significant influence but low interest may require proactive, persistent two-way engagement, whereas a group or organization with high interest but low influence or impact may appreciate information provision at specific points in the process. See Section 3.7 for more information on methodology. 


\section{Examples of Stakeholder Analysis Tools}

Some tools, such as the one produced by the U.S. National Oceanic and Atmospheric Administration Office for Coastal Management (coast.noaa.gov 2021f, 2021g), offer a step-by-step process for stakeholder or community needs assessment, which can add useful detail to the stakeholder identification and analysis process or help identify the most vulnerable areas or groups with whom to engage. A more formalized needs assessment may be advisable, particularly where there is limited knowledge about the range of relevant stakeholders (e.g., when working in a new geographic location).

An example of a tool used in the Netherlands and other European countries is the software Relatics (https://www.relatics.com/en/), which is used for all infrastructural projects, including NNBF projects. This tool offers a structured project approach to map stakeholder interests and interrelationships in a way that allows all the processes to be effectively monitored and to test whether everything is progressing within scope and budget.

\section{7 | Determine Engagement Methods}

There are multiple guides to the range of tools and methods available for community or stakeholder engagement. Table 3.1 shows a range of potential engagement action methods organized by the simplified, three-pronged, Types A, B, and C model (Table 3.4 provides further information on the types of engagement). These methods can range from basic information provision through newsletters or e-bulletins, to online surveys or consultations, and many forms of workshops and meetings. Consultations or public meetings (Figure 3.8) are effective methods to engage stakeholders in a timely manner.

\section{Key Action}

Once the engagement objectives, the intensity of engagement required, and the people to be engaged with are known, appropriate engagement methods must be decided on. Methods will change depending on the specific stage of the project and any shifts in objectives or stakeholder groups. 
Each method has different implications in terms of resourcing, coverage (e.g., number of stakeholders involved), aims, outcomes, and particular pros and cons. Some methods may be more appropriate for use with specific types of stakeholders, for specific levels or intensity of engagement, or during particular phases of the NNBF project cycle. Some methods work well in combination or in parallel, whereas others may be more appropriate in series, one after the other.

\section{Figure 3.8. Example Public Meeting for Early and Effective Stakeholder Engagement}

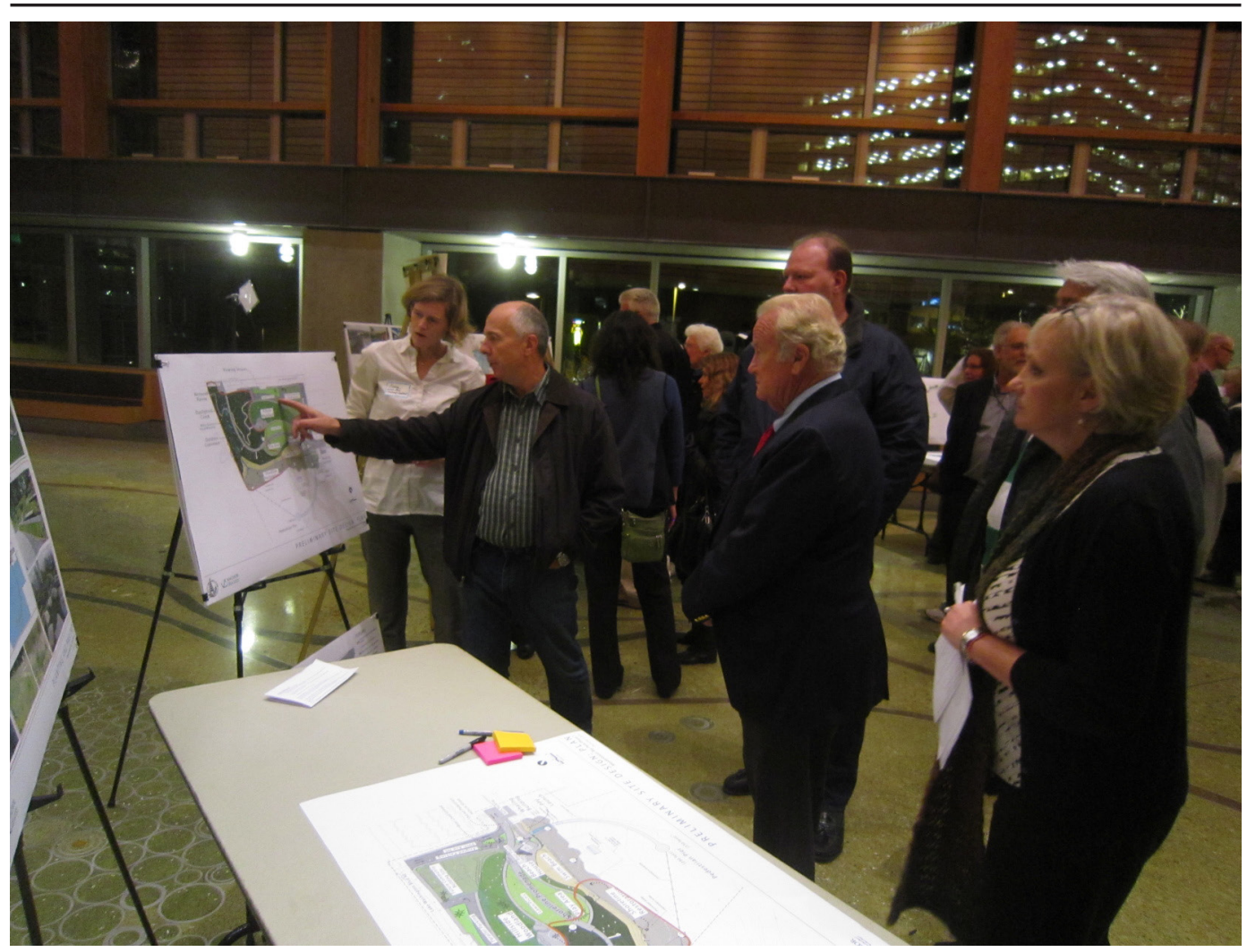

Source: Anchor QEA, LLC

The preceding steps of the engagement process should inform the specific choice and blend of engagement methods used in the project. Table 3.5 shows a range of typical engagement objectives, the main methods to consider in each case, and an example for illustration. $\mathrm{Be}$ aware that all projects will need a variety of methods over time, and sometimes in parallel, because the engagement objectives will change over time. 


\begin{tabular}{|c|c|c|}
\hline Engagement objectives & Main methods to consider & Examples \\
\hline $\begin{array}{l}\text { To provide ongoing support and } \\
\text { guidance to the engagement } \\
\text { on a project as it develops } \\
\text { throughout its life, building } \\
\text { ownership, and making the } \\
\text { most of local knowledge }\end{array}$ & $\begin{array}{l}\text { Steering and advisory groups, } \\
\text { and community liaison group (a } \\
\text { small group of committed local } \\
\text { stakeholders meeting regularly to } \\
\text { work with agencies and guide the } \\
\text { work) }\end{array}$ & \multirow{2}{*}{$\begin{array}{l}\text { A contentious project where a deep } \\
\text { level of stakeholder ownership } \\
\text { is needed for the project to be } \\
\text { successful, especially when difficult } \\
\text { choices will need to be made }\end{array}$} \\
\hline $\begin{array}{l}\text { To generate criteria by which } \\
\text { solutions should be assessed or } \\
\text { to generate possible solutions }\end{array}$ & $\begin{array}{l}\text { Facilitated workshops, } \\
\text { collaborative relationships, and } \\
\text { partnerships }\end{array}$ & \\
\hline $\begin{array}{l}\text { To gather feedback on specific } \\
\text { proposals }\end{array}$ & $\begin{array}{l}\text { Consultations (written or } \\
\text { meetings), focus groups, drop-in } \\
\text { meetings, social research, and } \\
\text { facilitated workshops }\end{array}$ & $\begin{array}{l}\text { Before a decision is made on a } \\
\text { scheme, to gain stakeholder feedback } \\
\text { on which options meet stakeholder } \\
\text { needs, which options do not, and } \\
\text { why, and how the options could be } \\
\text { improved }\end{array}$ \\
\hline $\begin{array}{l}\text { To build a picture of the } \\
\text { situation by gathering a wide } \\
\text { range of views and evidence }\end{array}$ & $\begin{array}{l}\text { Surveys, questionnaires, } \\
\text { interviews, focus groups, and } \\
\text { crowdsourcing }\end{array}$ & $\begin{array}{l}\text { During the early stage of an NNBF } \\
\text { project, helping to define what the } \\
\text { hopes and fears of the community } \\
\text { are regarding the risk of flooding }\end{array}$ \\
\hline $\begin{array}{l}\text { To inform stakeholders and } \\
\text { build their understanding }\end{array}$ & $\begin{array}{l}\text { Letters, emails, press releases, } \\
\text { newsletters, briefings (both } \\
\text { written and verbal), exhibitions, } \\
\text { advertising, and blog posts } \\
\text { Open-house days or site visits }\end{array}$ & $\begin{array}{l}\text { When initiating an NNBF project, } \\
\text { informing the community of a } \\
\text { problem that needs tackling } \\
\text { Demonstrating what an NNBF project } \\
\text { could look like }\end{array}$ \\
\hline $\begin{array}{l}\text { To enable stakeholders to keep } \\
\text { themselves in contact and up } \\
\text { to date }\end{array}$ & $\begin{array}{l}\text { Websites, e-bulletins, newsletters, } \\
\text { or social media } \\
\text { Allowing observation of project } \\
\text { meetings }\end{array}$ & $\begin{array}{l}\text { Any project that will last longer than a } \\
\text { few months where it would be useful } \\
\text { for stakeholders to have one place to } \\
\text { go to access information }\end{array}$ \\
\hline
\end{tabular}

Source: Adapted from Colbourne 2009b

As previously mentioned, there are many guides to the tools and methods for engagement. To become more familiar with this topic, the following resources are recommended:

- International Association of Facilitators Methods Database (2021)

- Involve Methods Database (2018)

- People and Participation: How to Put Citizens at the Heart of Decision-Making (Involve 2005)

- Community Planning Toolkit (Community Places 2014)

- National Co-ordinating Centre for Public Engagement method guide (publicengagement.ac.uk 2018a) 
As part of the overall methodology, data collection, analysis, and tools to address and reduce uncertainty should be considered. See "Data Collection and Analysis as Part of the Engagement Process" and "Methods and Tools for Addressing Uncertainty through Engagement" for more detail.

\section{Data Collection and Analysis as Part of the Engagement Process}

Many, if not all, of the methods will involve the collection of data by design (e.g., surveys and polls) or default (e.g., number and nature of attendees). Determining which data to collect is part of the upfront engagement and evaluation (Sections 3.4 and 3.9) planning process and should be linked as far as possible to the agreed engagement objectives (Section 3.5).

Varying degrees of data analysis are possible and necessary depending on the overall engagement process and range of methods used. For example, any formalized process of data collection such as a consultation or survey is likely to be followed by transparent analysis and presentation of results to demonstrate how responses were taken into account in the decision-making process.

Data analysis can be qualitative, quantitative or statistical, and spatial, depending on the type of data collected.

Secondary (usually publicly available) data can be used in support of engagement efforts. For example, in the United States, large datasets such as the U.S. Census provide sociodemographic data, and the U.S. Geological Survey provides geospatial datasets. These sources can be used as part of a needs assessment (Section 3.6) and can be combined with primary survey data to validate findings. 


\section{Methods and Tools for Addressing Uncertainty through Engagement}

NNBF projects are often characterized by high levels of uncertainty, which can exacerbate existing tensions and concerns among or between different groups of stakeholders. Uncertainties are typically related to the absence of empirical data and formal scientific knowledge (i.e., scientific uncertainties), and the inability to predict management success and outcomes (i.e., management uncertainties). Engagement is associated with the benefits of pooling local knowledge held by diverse groups of local stakeholders to overcome both types of uncertainties. Administrative and scientific communities should bring in inputs from local people and stakeholders to inform management decisions, to not only complement the knowledge developed by professional science but also overcome management uncertainties.

Some engagement methods enable levels of uncertainty to be reduced in a collaborative way so that there is a shared sense of ownership and understanding of any resulting assumptions and decisions. These methods include the following:

- Joint fact-finding. A fact-finding team, if formed, comprising a mix of stakeholders, decision-makers, and specialists, agrees on a process for gathering, analyzing, and interpreting information to help reduce uncertainty.

- Structured process. A structured process or framework is used to explore and assess options, agree on assumptions, reduce uncertainty, and plan contingencies. The framework is jointly owned and developed by a group of stakeholders representing the range of points of view on a particular issue.

\section{8 | Assess Resources}

\section{Key Action}

Plan engagement resourcing early, taking into account the people, tools, knowledge, time, budget, and practical resources required to deliver effective engagement over a potentially long period of time. Allow contingency to enable adaptation of the process to changes in circumstances or context.

When delivering any engagement program, it is essential to consider appropriate resourcing upfront, as part of the planning process. An extensive engagement process involving a wide range of stakeholders over a long period of time can be resource intensive but, as described 
in Section 3.2, ultimately leads to more sustainable outcomes and a reduced likelihood of additional, unexpected resources being required later down the line. Relevant resources for engagement include the following:

- People. This includes engagement professionals (internal and external), with roles potentially including skilled engagement leads or specialists, coordinators, evaluators, communicators, facilitators, analysts, and reporters (for smaller engagement processes, some of these roles may be combined). In some cases, the use of external specialists or experts may be considered, including using a neutral third-party convener or facilitator. Formation of specific engagement-focused groups may also be advisable, such as a steering group, which may include a mix of stakeholder interests. Ideally, one person with the appropriate social and communication skills, training, and experience should be responsible for the stakeholder and community engagement role within the NNBF project team. This might include someone with a background in facilitation, communications, or conflict resolution, with strong interpersonal skills and high levels of resilience.

- Tools and knowledge. The capacity to deliver engagement processes relies partially on the knowledge and experience of the people involved, and partially on the tools and techniques deployed. Some engagement methods require specific methodologies or processes to be used, and have particular requirements (e.g., in terms of digital or practical tools). This might involve social media communication experts, as well as technological tools and knowledge.

- Practical resources. This includes physical spaces or meeting places, administrative resources (paper, printing, and materials), digital resources, and any other practical considerations. Digital technology in the form of crowdsourcing, visualizations, spatial mapping, and other tools can be valuable resources, bearing in mind the need to enable equity of access and capacity for the stakeholders engaging with such tools.

- Time. Good engagement processes can take time, particularly where there is the need to build trust and relationships from scratch. The planning process should take into account the time required for each stage of engagement and the overall project timetable. Additionally, the time available from key staff members and stakeholders themselves is a critical factor to take into account, particularly if stakeholders are participating in their own time (in which case, thought should be given to covering expenses or potentially incentivizing participation).

- Budget. The budget should cover all the above resources and include a contingency budget to allow for a flexible program of engagement and adaptability to changing circumstances and needs (particularly for longer programs of engagement). Note that many communities will already have experience with previous engagement processes with varying degrees of resource and quality. The budget should allow for a better-than-average level of engagement for the duration of the project so that community expectations of quality can be set and met throughout. 


\section{$3.9 \mid$ Evaluate the Engagement}

\subsubsection{Evaluation Purpose and Principles}

A strategy to evaluate the effectiveness of engagement can yield many benefits and does not require great expenditure. Instead, evaluation can help save money and time, two of the most critical resources for any project. Evaluation tells us if we are communicating, involving our stakeholders, and achieving our goals. More specifically, evaluating engagement activity fulfils many purposes, including the following:

- Monitoring progress toward and achievement of engagement objectives

- Improving stakeholder engagement practice by gathering insight about what worked and what did not, and adjusting future activities accordingly to better meet the needs of the range of stakeholders involved, or to more effectively achieve objectives

- Raising awareness and understanding of the value of engagement and the story and impact of specific engagement activities

- Ensuring accountability and legitimacy of the engagement by demonstrating quality, value, and impact

Evaluation should be an ongoing process rather than something that is done solely at the completion of a project. A "look back" or summary report at the end of a project is valuable and can provide a fuller and deeper perspective than in the midst of activities. However, to gain the greatest value from an evaluation, it should be iterative throughout the project, or formative, with the methods and level of evaluation determined by nature and size of the project. Whatever the engagement process, evaluation should follow a consistent set of principles (Table 3.6).

\section{Key Action}

It is important for the team and particularly the project manager to support the need for evaluation of engagement. To support and enable the production of reliable, useful results, the evaluation should be implemented by an experienced social scientist or outreach specialist. 


\begin{tabular}{ll}
\hline Principles & Descriptions \\
\hline $\begin{array}{l}\text { Pragmatic, } \\
\text { proportionate, } \\
\text { and realistic }\end{array}$ & $\begin{array}{l}\text { Do the best with the resources available to evaluate progress. Focus on what is most } \\
\text { important for shaping future engagement and find simple ways to collect it. A simple } \\
\text { engagement process will require simple evaluation, and vice versa for a more complex } \\
\text { engagement process. }\end{array}$ \\
\hline $\begin{array}{l}\text { Objective and } \\
\text { open }\end{array}$ & $\begin{array}{l}\text { Do not fit the data around the desired answer. Even if the data do not show the desired } \\
\text { level of success, share the data with others so that everyone can learn to improve future } \\
\text { projects. }\end{array}$ \\
\hline Felevant & $\begin{array}{l}\text { Focus on the original engagement objectives as a framework for what to evaluate and how. } \\
\text { Fully integrated }\end{array}$ \\
\hline $\begin{array}{l}\text { Plan the engagement process and how it will be evaluated at the same time. This will bring } \\
\text { sharper focus to the overall project. }\end{array}$ \\
\hline $\begin{array}{l}\text { If requesting feedback, recognize that they have devoted time to the actual engagement. } \\
\text { Be aware of their time constraints. }\end{array}$
\end{tabular}

\subsubsection{Deciding What to Measure}

The data collected for the purposes of evaluation will vary by project. From the engagement objectives determined at the beginning of the planning process (Section 3.4), a number of evaluation indicators will emerge, such as level of stakeholder satisfaction, number and range of attendees at engagement events, social media activity, and quality of facilitation. The next step of evaluation planning is to decide how, when, where, and from whom specific data will be collected, bearing in mind the principles discussed previously.

\subsubsection{Collecting Data}

Some engagement evaluation measures are very simple to collect. For example, recording the number of attendees at events or the numbers of views of a website page. However, the value of these measures in evaluating engagement may be limited. Other evaluation measures may still be relatively simple to collect but more powerful in terms of demonstrating the impact of a particular activity on the understanding, attitudes, and actions of stakeholders. For example, methods testing understanding and attitudes include feedback questionnaires, graffiti walls at events, live online polling tools, surveys, and voting pads. Simple observation is also a useful tool to collect qualitative data on the attitudes and behaviors of individual stakeholders.

Collecting evaluation data once at the end of an engagement process will provide a picture of the situation (e.g., in terms of stakeholder views, experience, and level of engagement) at a given point in time. However, periodic data collection and analysis during the project enables different levels of analysis and understanding. For example, collecting baseline data at the beginning of an engagement process is essential to understanding what has changed. It may 
be appropriate to develop a set of tracker questions that are asked of stakeholders at the beginning of the process and at regular intervals throughout, to consistently measure change (e.g., questions about attitudes, awareness, preferences, hopes, and concerns). Similarly, there may be specific data points that are appropriate to track throughout the engagement process (e.g., number and diversity of stakeholders engaged at various points). In some cases, such as where there is a requirement to demonstrate social return on investment or economic impact, the collection of comparative data may be undertaken. This type of data attempts to identify and quantify the benefits of the broader engagement effort by comparing a set of before and after measures.

\subsubsection{Creating an Evaluation Plan}

Working from the original engagement objectives through to a set of evaluation indicators, measurement tools, and an understanding of how, when, where, and from whom specific data will be collected can feed into the development of an evaluation plan or framework. This can take many forms-from a simple spreadsheet to an additional project plan. As mentioned previously, regardless of the type of evaluation, it is vital to involve an experienced social scientist or outreach specialist in undertaking the evaluation of engagement. To become more familiar with this topic, the following resources are recommended:

- Evaluating Public Engagement (publicengagement.ac.uk 2018b)

- Evaluating Engagement Efforts (aese.psu.edu 2020)

- Evaluating Your Engagement Activities: Developing an Evaluation Plan (Spicer 2012)

\subsection{0 | Quick Reference}

Figure 3.9 is a quick reference to the engagement activities in the Scoping Phase shown in Figure 3.5 .

Figure 3.9. Community and Stakeholder Engagement Activities-Quick Reference

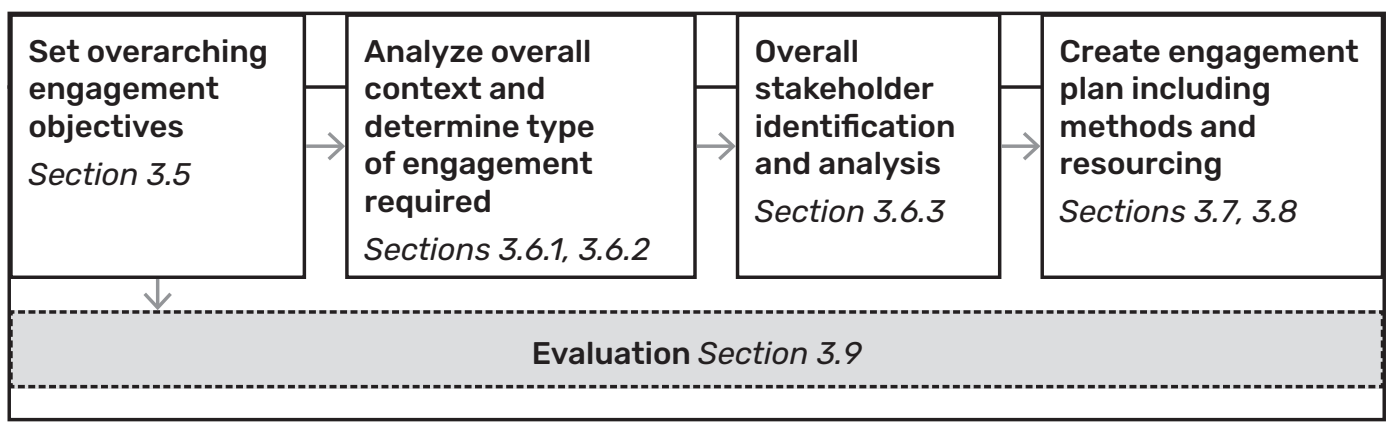

Source: Adapted from Environment Agency n.d.

O3 | Engaging Communities and Stakeholders in Implementing NNBF 
It is the hope that NNBF project teams will adopt a new paradigm that includes a deeper commitment to engagement than may have been the norm previously. The following reminders should serve as a quick reference to support the NNBF project engagement process:

- Deliver earlier, broader, and professional engagement at all NNBF project phases.

- Take advantage of the unique opportunities for engagement afforded by NNBF.

- Define the principles for engagement and set objectives early.

- Analyze the context and the stakeholders.

- Choose the tools and methods for engagement based on the type of engagement required: light touch, moderate, or extensive.

- Plan the engagement and assign the appropriate resources.

Evaluate the effectiveness and impact of the engagement. Be flexible and adaptive in the engagement plan.

Table 3.7 presents a summary of the products (or deliverables) for each step of the engagement process.

Table 3.7. Products by Engagement Step

\section{Engagement step Products}

1 Articulate the engagement Documented principles principles and objectives.

\section{Documented objectives}

2 Assess the context and stakeholders.

\section{Issue list}

The contextual analysis should result in a list of potential physical, environmental, legal, historical, cultural, and social issues that may be encountered in project development and implementation.

\section{Database of stakeholders}

The identification and analysis process should ultimately lead to a database of stakeholders, identifying who they are, their level of influence and impact in relation to the NNBF project, and the intensity of engagement they are likely to require, potentially with an additional consideration of the level of interest they are likely to have in the project.

\footnotetext{
3 Assess the resources.
}

\section{Resource matrix}

The matrix should include the identification of people, tools and knowledge, practical resources, time, and budget available for the engagement process.

4 Determine the engagement

Selected tools and methods methods. 
$5 \quad$ Plan the engagement.

Engagement plan

The plan should incorporate all products above; it may take the form of a spreadsheet, a text document, or a combination of the two, and should have a public-facing summary.

6 Deliver the engagement.

\section{Information materials}

These can include letters, posters, presentations, flyers, and other materials to provide information.

\section{Record of stakeholder input}

The records should include both in raw form and summary form; plan for how and when stakeholder input will be taken on board, and how stakeholders will be told about what change has occurred (or not) as a result.

7 Evaluate the engagement.

\section{Evaluation plan}

The plan should include the original engagement objectives, a set of evaluation indicators, measurement tools, and an understanding of how, when, where, and from whom specific data will be collected; this can feed into the development of an evaluation plan or framework; the plan may take many forms-from a simple spreadsheet to an additiona project plan.

\subsection{1 | References}

aese.psu.edu. 2020. Evaluating Engagement Efforts. Department of Agricultural Economics, Sociology, and Education, Penn State College of Agricultural Sciences. https://aese. psu.edu/research/centers/cecd/engagement-toolbox/evaluating-engagementefforts.

Cavalier, D., and E. B. Kennedy. 2016. The Rightful Place of Science: Citizen Science. Tempe, Arizona: Consortium for Science, Policy, and Outcomes.

coast.noaa.gov. 2021a. Connecting with Your Audience: Planning Your Next Interaction. Office of Coastal Management: DIGITALCOAST. https://coast.noaa.gov/digitalcoast/training/ audience.html.

coast.noaa.gov. 2021b. Nature-Based Solutions: Benefits, Costs, and Economic Assessments. Office of Coastal Management: DIGITALCOAST. https://coast_noaa.gov/digitalcoast/ training/gi-practices-and-benefits.html.

coast.noaa.gov. 2021c. Peer-to-Peer Case Study: Community Rain Gardens Are a Great Environmental Outreach Tool. Office of Coastal Management: DIGITALCOAST. https:/l coast.noaa.gov/digitalcoast/training/american-samoa.html.

coast.noaa.gov. 2021d. Peer-to-Peer Case Study: A Community Works Together to Restore the Floodplain and Reduce Damages. Office of Coastal Management: DIGITALCOAST. https://coast.noaa.gov/digitalcoast/training/walton-village.html. 
coast.noaa.gov. 2021e. Risk Communication Strategy Template. Office of Coastal Management: DIGITALCOAST. https://coast.noaa.gov/digitalcoast/training/risk-communicationstrategy.html.

coast.noaa.gov. 2021f. Needs Assessment Guide. Office of Coastal Management: DIGITALCOAST. https://coast.noaa.gov/digitalcoast/training/needs-assessmentguide.html.

coast.noaa.gov. 2021g. Stakeholder Analysis Worksheet. Office of Coastal Management: DIGITALCOAST. https://coast.noaa.gov/digitalcoast/training/stakeholder-analysisworksheet.html.

Colbourne, L. 2009a. Mainstreaming Collaboration with Communities and Stakeholders for FCERM. Improving Institutional and Social Responses to Flooding Science Report: SC060019 Work Package 4. Joint Defra/Environment Agency Flood and Coastal Erosion Risk Management R\&D Programme. Bristol: Environment Agency. https://assets.publishing.service.gov.uk/media/602e6d838fa8f5432d802fe6/ mainstreaming_collaboration_with_communities_and_stakeholders_for_FCERM_ WP4_technical_report.pdf.

Colbourne, L. 2009b. Collaboration with Civil Contingency Partners and Communities for Improved FCERM Outcomes. Improving Institutional and Social Responses to Flooding Science Report: SC060019 Work Package 3. Joint Defra/Environment Agency Flood and Coastal Erosion Risk Management R\&D Programme. Bristol: Environment Agency. https://assets.publishing.service.gov.uk/media/602e6d31e90e07660b5ab1f7/ Collaboration_with_civil_contingency_partners_and_communities_for_ improved_FCERM_outcomes_WP3_technical_report.pdf.

Community Places. 2014. Community Planning Toolkit: Community Engagement. Belfast: Community Places. https://www.communityplanningtoolkit.org/sites/default/files/ Engagement.pdf.

consultingkids.co.uk, n.d. ConsultingKids. https://www.consultingkids.co.uk/.

Environment Agency, n.d. Working with Others: Building Trust with Communities - A Guide for Staff. Bristol: Environment Agency. https://repository.tudelft.nl/islandora/object/ uuid:c3f55097-6365-42cb-89a5-2566f56c0f95/datastream/OBJ/download.

Federal Forum on Environmental Collaboration and Conflict Resolution. 2018. Environmental Collaboration and Conflict Resolution (ECCR): Enhancing Agency Efficiency and Making Government Accountable to the People. Washington, DC: Council on Environmental Quality. https://ceq.doe.gov/docs/nepa-practice/ECCR_Benefits_ Recommendations_Report_\%205-02-018.pdf.

Fisher, R., and W. Ury. 1991. Getting to Yes: Negotiating Agreement Without Giving In. Second Edition. New York: Penguin Group.

IAP2 (International Association for Public Participation). 2018. IAP2 Spectrum of Public Participation. IAP2 International Federation. https://cdn.ymaws.com/www.iap2.org/ resource/resmgr/pillars/Spectrum_8.5x11_Print.pdf. 
iap2.org. 2017. IAP2 Core Values. International Association for Public Participation. https:// www.iap2.org/page/corevalues.

International Association of Facilitators Methods Database. 2021. https://www.sessionlab. com/library/iafmethods.

Involve. 2005. People and Participation: How to Put Citizens at the Heart of DecisionMaking. London: Beacon Press. https://www.involve.org.uk/sites/default/files/field/ attachemnt/People-and-Participation.pdf.

Involve Methods Database. 2018. https://www.involve.org.uk/resources/methods.

Lindsey Colbourne Associates and Environment Agency. 2008. How Much Engagement? A Tool for Assessing Cost/Effective Approaches for the Environment Agency Working with Communities, Stakeholders, the Public and Others. https://static1.squarespace.com/ static/53f5e2eae4b0593b948c9e4c/t/56b9ebec859fd0159f26439e/1455025134867/ How\%2Bmuch\%2Bengagement.pdf.

Lodder, Q. L., J. L. Slinger, Z. B. Wang, and C. van Gelder. 2020. “Decision Making in Dutch Coastal Research based on Coastal Management Assumptions." In Proceedings ICE Coastal Management 2019. London: Thomas Telford.

MacKinnon, S., ed. 2018. Practising Community-Based Participatory Research: Stories of Engagement, Empowerment, and Mobilization. Vancouver: UBC Press Purich Books.

Molteberg, E. 1995. An Introduction to PRA: Participatory Rural Appraisal Training Notes. Ås, NO: International Environment and Development Studies, Noragric (Norwegian University of Life Sciences). https://www.participatorymethods.org/resource/ introduction-pra-participatory-rural-appraisal-training-notes.

OMB and CEQ (Office of Management and Budget and Council on Environmental Quality). 2012. Memorandum. Subject: Environmental Collaboration and Conflict Resolution. Washington, DC: Office of NEPA Policy and Compliance. https://ceq.doe.gov/docs/ceqregulations-and-guidance/OMB_CEQ_Env_Collab_Conflict_Resolution_20120907. pdf.

publicengagement.ac.uk. 2018a. Choose a Method. National Co-ordinating Centre for Public Engagement. https://www.publicengagement.ac.uk/do-engagement/choosemethod.

publicengagement.ac.uk. 2018b. Evaluating Public Engagement. National Co-ordinating Centre for Public Engagement.https://www.publicengagement.ac.uk/doengagement/evaluating-public-engagement.

Spicer, S. 2012. Evaluating Your Engagement Activities: Developing an Evaluation Plan. Manchester: The University of Manchester. http://www.engagement.manchester. ac.uk/resources/engagement/evaluating_public_enagement/Evaluating\%20 Your\%20Public\%20Engagement\%20Activities.pdf.

Wesselink, M., and R. Paul. 2010. Handboek Strategisch Omgevings Management. Amsterdam: Boom uitgevers Amsterdam. 


\title{
Acknowledgments
}

\author{
Lead Author
}

Maria Dillard, National Institute of Standards and Technology, United States

\section{Co-Authors}

Cath Brooks, Environment Agency, United Kingdom

Helen Fisher, 3KQ, United Kingdom

Hans Pietersen, Rijkswaterstaat, the Netherlands

Alwin Nijhuis, Rijkswaterstaat, the Netherlands

Anita van Breda, World Wildlife Fund, United States

Susan Durden, U.S. Army Corps of Engineers, United States

\section{Contributors}

Rhuari Bennett, 3KQ, United Kingdom

Marriah Abellera, U.S. Army Corps of Engineers, United States

Victoria Fernandez, CBCL Limited, Canada

Jennifer Rocard, Government of Nova Scotia, Canada

Alexander Wilson, CBCL Limited, Canada

Vincent Leys, CBCL Limited, Canada

Christopher Spray, University of Dundee, United Kingdom

Reuben Trevino, U.S. Army Corps of Engineers, United States

Lalini Pedris, World Wildlife Fund (formerly), United States

Sruthi Darbhamulla, World Wildlife Fund (formerly), United States 


\section{Endnotes}

i "Community" may be defined in a number of ways. Community boundaries may be based on legal, political, physical, or symbolic criteria. Most often for NNBF projects, the term "community" refers to a geographical and administrative designation in that there are physical boundaries around a place that operates with a governance structure (e.g., town, city, or county).

ii Stakeholders are individuals, groups, or organizations that have a relevant interest (e.g., political or legal) and that could impact, be impacted by, or influence the issue or project. Stakeholders include communities and members of the public, as well as charities, campaign or public interest groups, and public- and private-sector organizations. It is important to make a distinction between opinions and interests.

iii These include Participatory Rural Appraisal, Participatory Learning and Action, CommunityBased Participatory Research, Citizen Science, Mutual Gains Approach, or Strategic Stakeholder Management (Wesselink and Paul 2010 [in Dutch]). For examples, see An Introduction to PRA: Participatory Rural Appraisal Training Notes (Molteberg 1995), Practising Community-Based Participatory Research: Stories of Engagement, Empowerment, and Mobilization (MacKinnon 2018), and The Rightful Place of Science: Citizen Science (Cavalier and Kennedy 2016). 

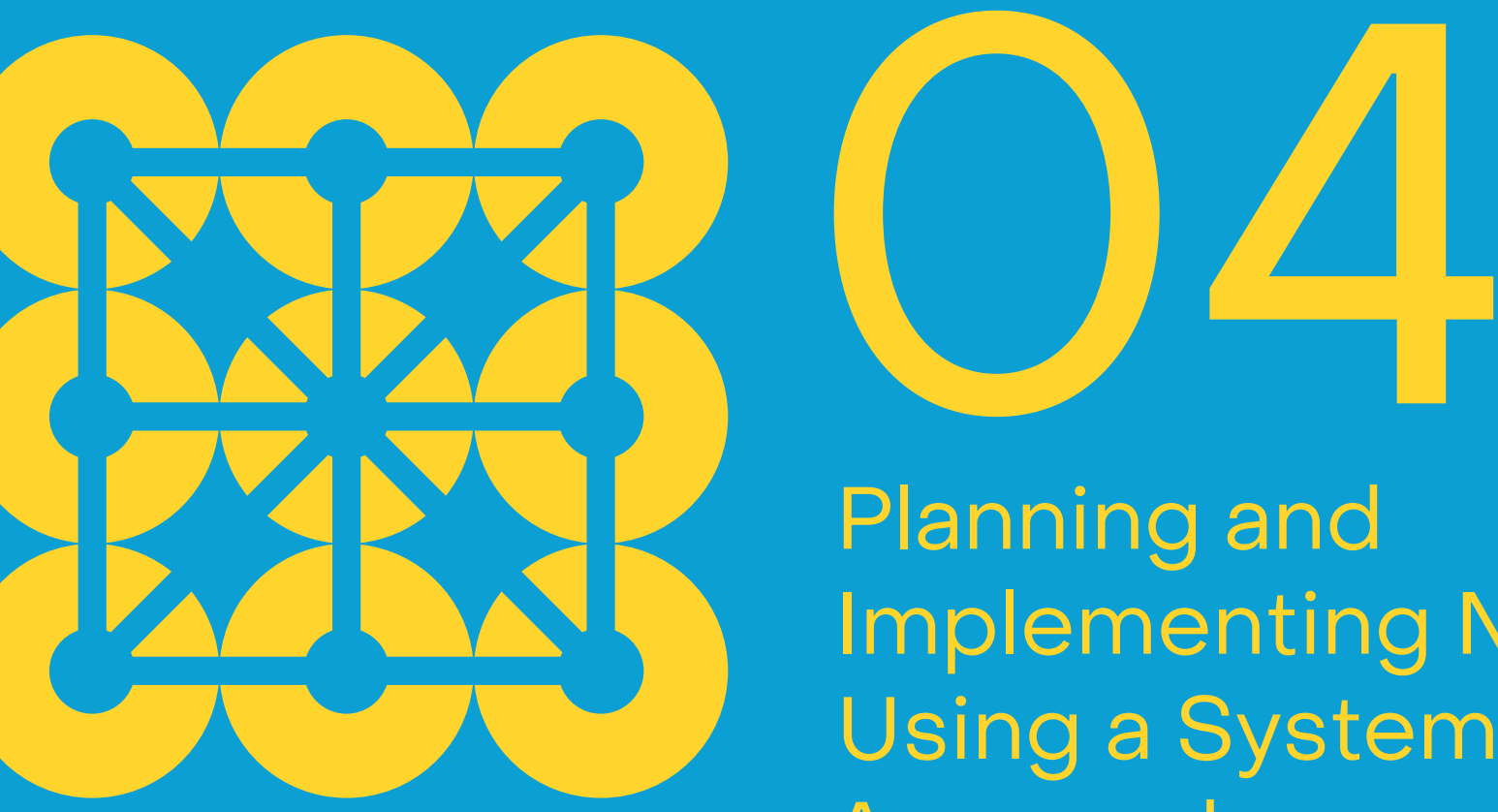

\section{Planning and} Implementing NNBF Using a Systems Approach

\section{Suggested Citation:}

de Vries, J., D. Reed, S. K. McKay, T. Bouma, S. E. Cunniff, B. Grasmeijer, P. Mason, A. Nicholson, P. Quinn, and J. M. Smith. 2021. "Chapter 4: Planning and Implementing NNBF Using a Systems Approach." In International Guidelines on Natural and NatureBased Features for Flood Risk Management. Edited by T. S. Bridges, J. K. King, J. D. Simm, M. W. Beck, G. Collins, Q. Lodder, and R. K. Mohan. Vicksburg, MS: U.S. Army Engineer Research and Development Center.

Full acknowledgments appear at the end of this chapter. 


\section{Key Messages}

1. Systems thinking means considering physical, biological, and social processes, and their interactions, in evaluating flood risk problems and solutions, and identifying ways to reduce conflict and maximize synergies to produce sustainable solutions.

2. Bringing people and different interests together is a way to explore holistic, system-wide issues, which can lead to innovative partnerships and potential leveraging of resources, accelerating identification and implementation of suitable, sustainable, and well-functioning solutions.

3. Natural and nature-based features (NNBF) solutions for flood risk reduction develop over time and space. A multidisciplinary team that creates an understanding of biogeophysical, socioeconomic, and governance system dynamics is essential for sustainable, long-term management and to verify performance criteria are met.

4. NNBF solutions can provide a variety of ecosystem benefits. Systems thinking enables the assessment of multiple potential outcomes, supports multifunctional design, and facilitates direct engagement with stakeholders and consideration of social benefits.

5. Systems thinking can be used to implement NNBF solutions on a large-system scale (think big), to integrate the effects of many small projects (start small), and either as standalone projects or as part of larger flood risk management efforts. 


\section{1 | Introduction}

A systems approach is essential for the successful implementation of flood risk reduction measures, including natural and nature-based features (NNBF), because it incorporates an early appreciation of the context and further enhances the breadth of perspective on the natural system by including the interplay of ecology, geomorphology, and hydrodynamics, as well as the interface with the social system (i.e., the engagement of local stakeholders). It results in tailor-made multifunctional and sustainable solutions (see Chapter 2). This chapter introduces the concept of a systems approach, identifies key principles that should be used to guide the application of a systems approach to NNBF, outlines essential aspects of a systems approach in project implementation using example case studies as illustrations, discusses gaps and future directions, and provides some concluding thoughts regarding the importance and benefits of using a systems approach.

Guidance on the mitigation and management of flood risk often recommends that a systems approach be used to define, characterize, and manage water resources (usace.army.mil 2002; APFM 2009; National Research Council 2013; WWF 2016; World Bank 2017; Burgess-Gamble et al. 2018). This chapter provides guidance on a systems approach for NNBF.

\subsubsection{Defining the Systems Approach}

One of the most fundamental features of a systems approach is that it emphasizes a broad view that looks beyond immediate events or local problems by identifying patterns and relationships within a system. This deeper and broader understanding provides the basis for more effective, multifunctional solutions with added value for both society and nature (see Chapter 2 and Chapter 6 ). Specific interpretations of a systems approach vary by discipline (see "Examples of Systems Approach Characterizations for Different Disciplines").

\section{Examples of Systems Approach Characterizations for Different Disciplines}

Chemistry (from Von Bertalanffy 1972): General System Theory is a logico-mathematical field whose task is the formulation and derivation of those general principles that are applicable to "systems" in general. In this way, exact formulations of terms such as wholeness and sum, differentiation, progressive mechanization, centralization, hierarchical order, finality and equifinality, etc., become possible, terms which occur in all sciences dealing with "systems" and imply their logical homology. 
Physical Geography (from Chorley and Kennedy 1971): A system is a structured set of objects and/or attributes. These objects and attributes consist of components or variables (i.e., phenomena which are free to assume variable magnitudes) that exhibit discernible relationships with one another and operate together as a complex whole, according to some observed pattern.

Ecology (from Watt 2013): An interlocking complex of processes characterized by many reciprocal cause-effect pathways.

Engineering (from Jenkins 1969): Systems Engineering is the science of designing complex systems, by the efficient use of resources in the form of men, money, machines and materials, so that the individual sub-systems making up the overall system can be designed, fitted together, checked and operated so as to achieve the overall objective in the most efficient way.

Sociology (from Bailey 1994): While the study of relationships is represented in sociology through network theory, there is a big difference between network theory and systems theory. The former abstracts relationships from the whole, while the latter studies not only the relationships themselves, but their systematic context, including the environment.

Common attributes of these interpretations include breadth, relationships, and feedback. Figure 4.1 shows several examples of interacting systems. In the context of NNBF, this implies a broad appreciation of the problems and an understanding of the natural, engineered, and social behavior of the system, as well as the effects, both negative and positive, of potential solutions. This requires that the dynamic physical, ecological, and relevant cultural aspects and processes within a system are considered-including feedback and causality. A systems approach provides understanding of the significant aspects of the system that generate, exacerbate, or are affected by the perceived problem. Because no one person can understand all aspects of such a system, systems thinking is also a tool for collective inquiry, knowledge exchange, coordinated action, and cooperation between different disciplines that can be critical for building support to solve a problem. 
Figure 4.1. Incremental Accumulation of Different Components, or Attributes, into a Bigger Picture

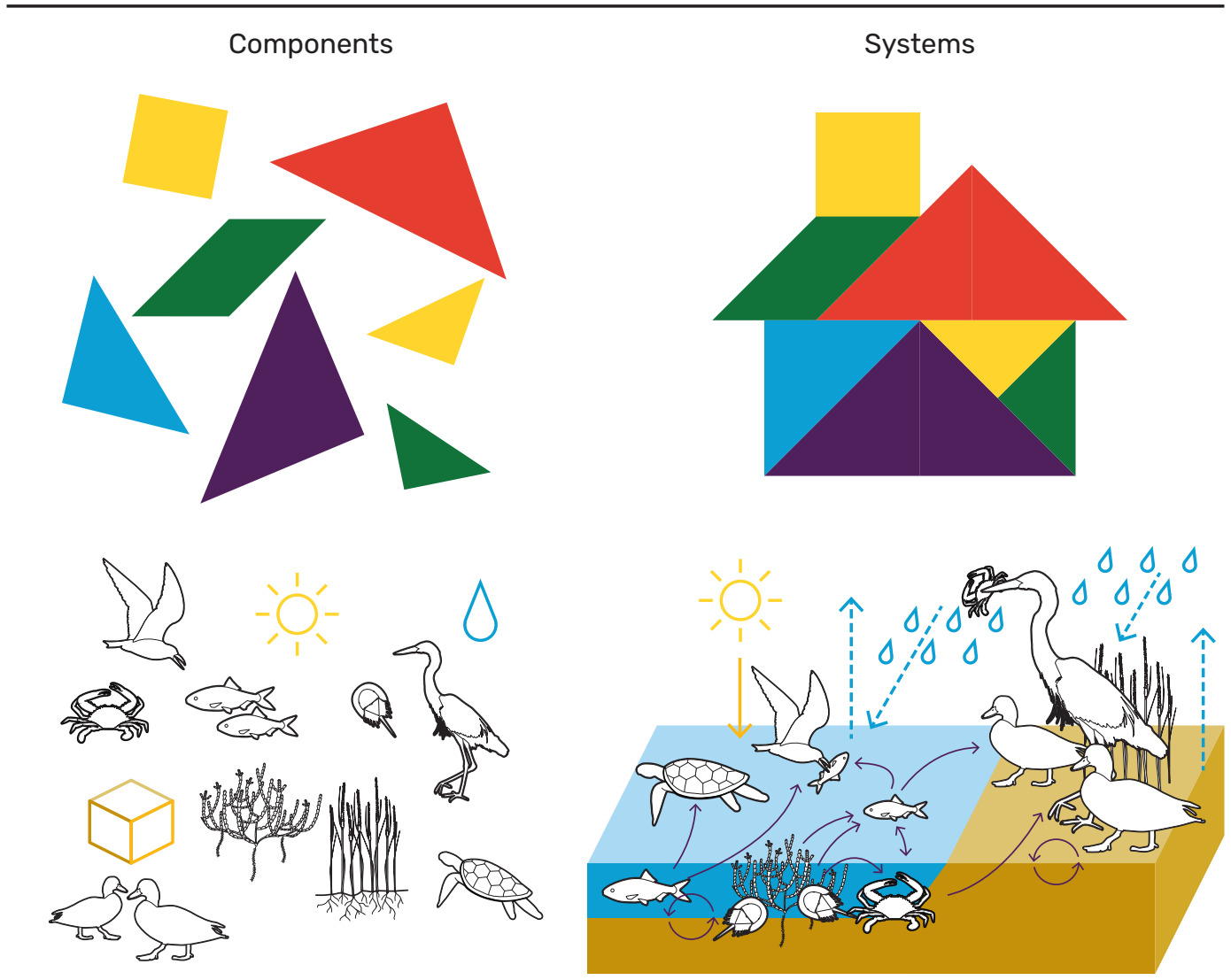

Source: Top graphics adapted from a tangram puzzle; bottom graphics adapted from ecological system graphics from the following website: http://ian.umces.edu/media-library 


\subsubsection{Incentives and Advantages of a Systems Approach}

A systems approach is particularly useful for flood risk management (FRM) systems because it promotes sustainable, long-term thinking that is essential to evaluating the near- and long-term effectiveness of interventions. Because systems thinking considers multiple aspects of a system, such as ecology, engineering, and social considerations, it can promote solutions that create added value by identifying multifunctional solutions (see Chapter 6 ). Systems thinking aids in identifying unintended costs and consequences, thereby optimizing potential benefits. This, in turn, can lead to greater societal support. Considering the inherent temporal changes of NNBF also leads to the possibility of including adaptive management (see Chapter 7).

From an implementation perspective, the broader the consideration of the problem or solution space, the greater potential there is to find feasible solutions that may address additional needs. This, in turn, may lead to cost-efficiency benefits and identify opportunities to leverage funding from multiple sources, some of which may be more interested in the co-benefits than in solving the immediate flood risk problem. By fostering learning and collaboration among interdisciplinary teams, a wider variety of mental models pertaining to performance of the system can be articulated, potentially leading to more innovative solutions or opportunities for leveraging resources.

Taking a systems approach has been found to be the key to making substantial progress in different circumstances. Sometimes this is driven by catastrophic events. In other areas, systems thinking has stimulated foresight and anticipation of problems and triggered taking actions to get ahead of increasing flood risk, while at the same time providing opportunities to address other social environmental needs.

\subsubsection{Limitations and Challenges of a Systems Approach}

Although the advantages are often clear, the utilization of a systems approach introduces complexities to risk reduction efforts that have additional consequences. The more factors considered in the analysis, the more uncertainties are introduced, and the analyses can become more complicated, time consuming, and costly. A systems approach will often entail working with, and achieving consensus among, a larger group of stakeholders than a narrower approach. This again takes time and resources but can lead to greater buy-in and acceptability of the solutions implemented, as well as a greater degree of understanding of the often large array of factors contributing to flood risk, some of which may be in the power of the stakeholders to resolve (see Chapter 3 ). Furthermore, because natural systems are not static and tend to evolve over time, a long-term commitment is necessary to evaluate whether the chosen solution evolves as expected within the system and meets the desired objectives. 


\subsubsection{Applying Systems Thinking for NNBF}

It is important to remember that using a systems approach does not necessarily imply an increase in the geographic scale considered. Rather, once a manageable systems context is defined, the focus needs to be on relationships among components. Moreover, a systems approach to risk reduction planning may not imply immediate implementation on a system-wide scale. Often planning, or the development of a long-term vision, can occur at the system scale, but individual elements of the solution identified can be incrementally implemented (assuming they have independent utility for flood risk reduction or other relevant benefits). A think big and start small approach enables implementation at any scale to be appropriately informed by understanding of the system. For NNBF in particular, one of the main requirements is that a multidisciplinary team is assembled that can bridge the biogeophysical, socioeconomic, and governance dynamics of the system and that the team commits to both long-term involvement and the necessary enabling resources.

\section{2 | Principles for Using a Systems Approach in Flood Risk Management}

This section defines a systems approach for FRM by articulating five principles drawn from literature on sustainability, participatory processes, and structured decision-making.

\subsubsection{Principle 1: Life Safety Is Where Flood Risk Management Begins but Not Where It Ends}

The primary motivation for all FRM systems is to reduce the loss of life and socioeconomic impacts from flooding. Expanding the scope of flood risk analyses using a systems approach does not diminish the focus on this primary objective; rather, it facilitates the consideration of additional socioeconomic and environmental effects. A systems approach requires management actions be viewed as multipurpose actions with a broad array of potential outcomes. For instance, NNBF such as coastal wetlands and oyster reefs have been promoted in the wake of Hurricane Sandy in the northeastern United States because of their capacity to both meet FRM objectives and provide valuable ecosystem goods and services.

Generally speaking, unsustainable actions have often been attributed to an incomplete accounting of the costs and benefits of decisions, where efficiency of life safety or economic outcomes have been overemphasized at the expense of ecological and social outcomes (Costanza et al. 1998; Odum 1998; Walker and Salt 2006; Poff et al. 2015). Many authors have thus suggested that sustainable actions address outcomes relative to the three pillars of 
economic prosperity, social equity, and ecological health, sometimes referred to as the triple bottom line of profit, people, and planet (Elkington 1997; Gibson 2006; Wu 2013; Bridges et al. 2014; Robertson 2014). This framework has promoted the concept that systems approaches "pay attention to what is important, not just what is quantifiable" (Meadows 2008), which requires planners, engineers, and decision-makers to expand their view beyond traditional life safety or economic damages objectives to include novel and emerging indicators of social and ecological outcomes (e.g., Hicks et al. 2016 and National Research Council 2000, respectively). The overarching goals of such a multiobjective approach (e.g., NNBF) are to encourage project teams and decision-makers to understand the effects of decisions more adequately beyond their single primary objectives, account for the social and ecological externalities associated with decisions, and optimize many, rather than a few, objectives (Kates et al. 2001).

\subsubsection{Principle 2: Flood Risk Management Is Nested in an Interconnected Socioecological Landscape}

Natural ecosystems, infrastructure, and social systems are not simply collections of discrete objects but include working parts embedded in complex networks that share their water, energy, resources, and environment. A holistic view of an FRM system explicitly acknowledges relationships between physical, ecological, and social processes and considers a nested suite of spatial frames from project to basin to regional scales. These socioecological systems (Ostrom 2009) are already complex to manage over short timescales, and effective management over longer timescales becomes increasingly more challenging.

Systems can be viewed in physical (e.g., a levee network), ecological (e.g., a wetland complex), informational (e.g., an emergency warning system), or social (e.g., a stakeholder group) terms, or combinations of these depending on the purpose under consideration. Regardless of the type, a system must have elements, interconnections, and functions (Meadows 2008). Elements describe the structure and composition of the system (i.e., its various parts) such as the assemblage of species in a wetland or the flood detention features in a city. Interconnections are the relationships between the components such as the effect of an upstream reservoir on a downstream port. System functions are the emergent properties of a system resulting from the elements and interconnections (Odum 1998). The emergent function of an FRM system is reducing loss of life and socioeconomic impacts. This can be challenging to quantify relative to individual elements of the system (e.g., a specific warning siren) or the interconnections (e.g., routing of urban floods through a system of small-scale rain gardens). Furthermore, a system often has more than one specific function. For example, the routing system of urban floods can have an important recreational function for fishing as well as providing natural habitat for a number of species. 
A landscape perspective that provides the total picture is required to understand how flood risk systems, and NNBF solutions, function. This can be implemented on different scales. Typically, FRM systems are nested and function over multiple spatial scales. For instance, a large regional rainfall event (e.g., due to a hurricane) could affect flood risk at a large spatial scale, while an associated flood warning system may only be applied within a single neighborhood. The same is true for NNBF solutions. A systems approach examines not only the interaction of multiple social, ecological, and technical processes but also their nested functioning across spatial scales.

\subsubsection{Principle 3: Sustainable Systems Are Resilient to Disturbances}

Disturbances challenge all systems to perform under variable and fluctuating conditions. In an ecological context (Lake 2000), disturbances are distinguished by timescale as follows: short, discrete events (e.g., flash floods); slow-onset, persistent, moderate-duration events (e.g., droughts); and long-term shifts in underlying conditions (e.g., sea-level rise). In the disaster management context, natural hazards are defined as "those elements of the physical environment, harmful to man and caused by forces extraneous to him" (Burton et al. 1978). Regardless of the disciplinary viewpoint, the resilience of a system to variability, disturbances, and hazards is consistently promoted as a crucial aspect of the long-term functionality and sustainability of system outcomes. For example, a component of system resiliency to a catastrophic event became evident during the Indian Ocean earthquake and tsunami in 2004, where mangroves provided substantial protection from the tsunami (see Patel et al. 2015).

The "Climate-Resilient International Development" Executive Order, signed by President Barack Obama on September 23, 2014, defines resilience as "the ability to anticipate, prepare for, and adapt to changing conditions and withstand, respond to, and recover rapidly from disruptions" (White House 2014). From this definition, four key components of resilience can be identified (Linkov et al. 2014; Rosati, Touzinsky, and Lillycrop 2015)-prepare (plan, anticipate, avoid), absorb (resist, withstand), recover (bounce back, return), and adapt (evolve, transform, bounce forward). Each of the four components of resilience provides opportunities to enhance system performance, but the degree to which adaptation is embraced is where large gains in long-term outcomes can be made (Wu 2013; Touzinsky et al., forthcoming). Sustainable systems use the four components of resilience not only to maintain but also to enhance long-term functionality under a variety of natural and anthropogenic disturbances.

The concept of resilience is integrally linked with the systems approach. For example, Walker and Salt (2006) propose that targeted analyses of resilience typically address the issues of what and to what. For FRM, of what defines the study system, articulates potential outcomes of interest, and bounds the problem, whereas to what defines the magnitude and frequency of flood events and the potential range of disturbances and hazards under consideration. 
Although purely conceptual, these simple prompts can provide important guidance for managers as they define a focal system and constrain what resilience means in the context of that system. By considering and encompassing natural system dynamics, NNBF solutions can be more resilient to disturbances than traditional and structural approaches to FRM.

\subsubsection{Principle 4: System-Wide Planning Is a Process Worth the Investment}

A systems approach not only takes into account the present-day outcomes of management but also balances the consequences of current actions for future stakeholders. Said differently, a systems approach to FRM is sustainable, which requires that it "meets the needs of the present without compromising the ability of future generations to meet their own needs" (WCED 1987). A sustainable FRM system should seek to reduce current life safety risks and socioeconomic damage, while providing for other additional benefits and value (Principle 1), as well as balance today's needs with a long-term vision for the system. Expanding the temporal horizon of outcomes requires that the intergenerational heritage and legacies of decisions play a prominent role in current decision-making. Legacies of NNBF projects can be positive effects such as reduced flood risk while creating or sustaining valuable ecosystems, or strong collaborative relationships, as well as negative impacts such as fiscal debt or loss of some specific habitats. In addition to legacy outcomes, intergenerational equity of decisions also requires incorporation of adaptability into designs, reversibility of decisions, and preservation of options for future decision-makers (Costanza et al. 1998). Revealing potentially hidden consequences in decisions is a widely recognized advantage of a systems approach, as characterized by the Iceberg Model shown in Figure 4.2. It is important to consider not only the obvious consequences of an event (the tip of the iceberg) but also underlying patterns, structures, and mental models (those that lie below the waterline). Looking beyond the obvious can lead to different approaches to solutions to flood risk problems that take into account underlying institutional structures and public perceptions. Furthermore, it promotes the possibility of connecting natural FRM to other problems in the system, such as dealing with pollution, restoring natural habitats, and safeguarding the freshwater supply. 


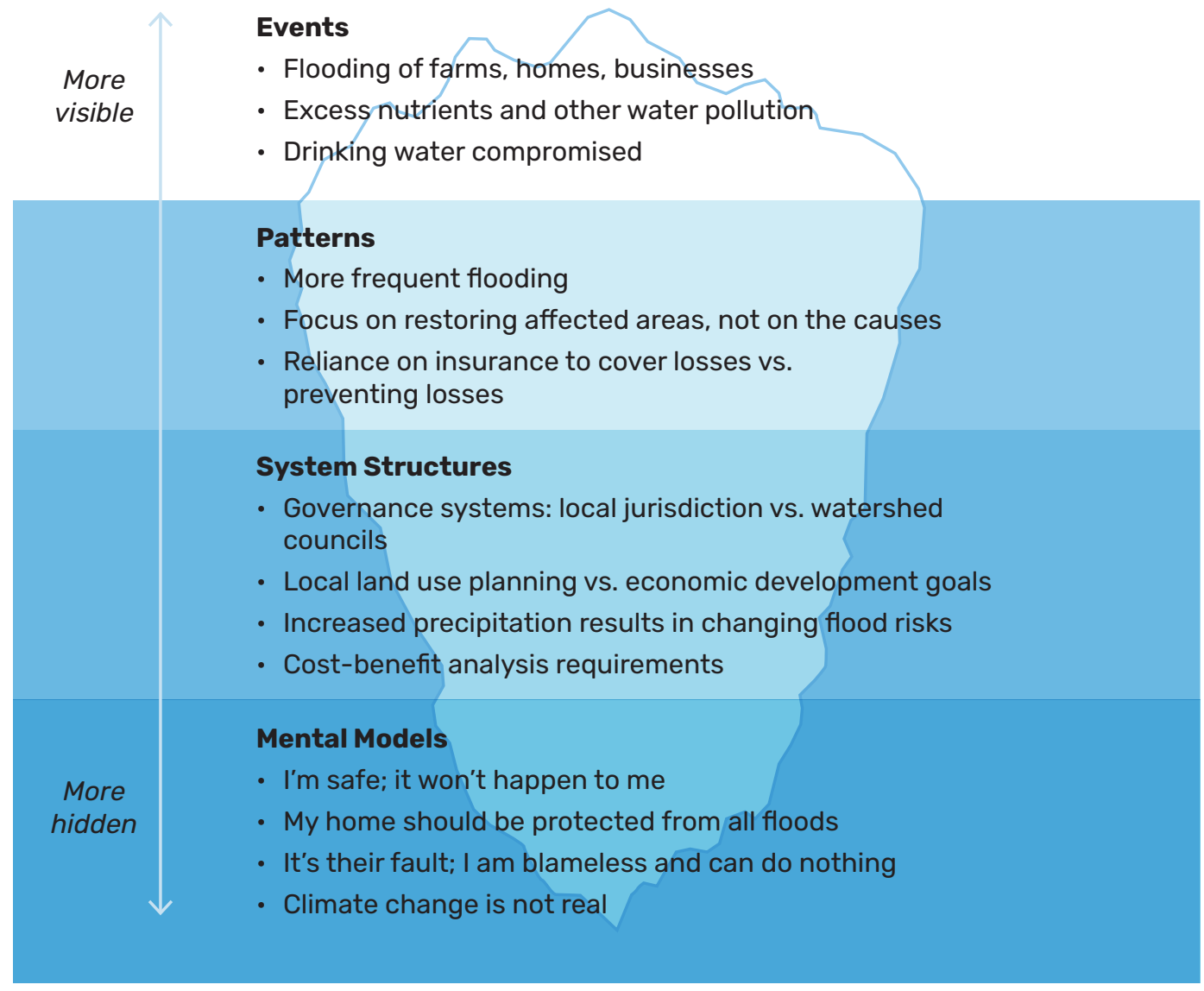

Over time, the trend has been that sustainable FRM systems pursue increasingly broader goals for long-term functionality, rather than unifunctional objectives. For instance, a systems approach decreases life safety risks while increasing co-benefits for ecosystems (e.g., functional floodplains), society (e.g., thermal regulation and parks), and the economy (e.g., reducing damages of storms). These systems pursue these goals proactively (Principle 1), as well as reactively in response to events (Principle 3). Short-term outcomes are typically more straightforward to quantify with a higher degree of certainty, and long-term outcomes are challenging to forecast due to greater uncertainty in predictive abilities (e.g., modeling), physical conditions (e.g., climate changes), and social values (e.g., attitudes about flood risk and the environment). Accordingly, monitoring and adaptive management are crucial components to practically balancing short- and long-term outcomes equitably (see Chapter 7). 


\subsubsection{Principle 5: Short-Term Benefits Are Balanced with Long-Term Outcomes}

Systems thinking is an investment (and commitment) in time, expertise, relationships, and resources. A systems approach may not always be simple with straightforward outcomes and solutions appearing rapidly. However, collective, multidisciplinary inquiry with a broad array of stakeholders and partners enhances information sharing, develops relationships, and is likely to lead to better decisions, more coordinated actions, added value, leveraged funding, and improved long-term trajectory of a system.

A broad multidisciplinary view of a flood risk problem is crucial to a systems approach and effective implementation of NNBF (Principle 1), but cross-disciplinary teams are often challenged by different technical language, embrace conflicting goals, and work at disparate time and space scales. Furthermore, the process of initiating stakeholder engagement can be challenging; however, there is a positive return on investment for doing so. Multiple disciplines and stakeholders can influence NNBF project visioning, objective setting, group investigation, and analysis, as well as the political and social capital brought by different groups and communities. Chapter 3 provides additional guidance on engaging stakeholders in the planning, design, operation, and adaptive management of NNBF solutions.

Importantly, a systems approach cannot be embraced with a single round of engagement and planning but instead should be considered an iterative and multistep process. The iterative nature of systems planning makes it a powerful tool for increasing understanding of complex processes, coping with uncertainty, adapting to change through time (e.g., climate change), and evolving the system to match society's shifting values.

\section{3 || Implementation}

As described in previous sections, there are many benefits of using a systems approach for any risk reduction project, especially those that consider NNBF. However, using a systems perspective in project implementation requires attention to several key issues. This section discusses approaches that can support such efforts through the following key steps: contextualize, analyze, decide, and manage (Sections 4.3.1, 4.3.2, 4.3.3, and 4.3.4, respectively). Each step includes case study examples from around the world to illustrate both challenges and potential solutions. This chapter provides a high-level overview. Generally, a more detailed approach is necessary for the design and construction phases, which are discussed in Chapter 2. 


\subsubsection{Contextualize}

Establishing the systems context for any project must occur early in the initiation and design process to develop a broad range of suitable solutions. Some funding sources for FRM may limit the extent to which a systems approach can be adopted. However, as this section will describe, this may lead to delays, limit the success of a project, or reduce the overall benefits. The systems context includes both the societal aspect (e.g., engaging stakeholders) and the natural system aspect (e.g., establishing the temporal and spatial scale of the natural system within which the project is set).

\subsubsection{Society}

The societal context is especially important because NNBF solutions generally provide a range of outcomes and benefits-flood risk reduction, ecosystem restoration, recreation, and other ecosystem services. Due to this multifunctionality, it is essential to conduct a thorough stakeholder analysis at the beginning of the project and determine the level of engagement most appropriate for the project (see Chapter 3). Understanding the needs of local citizens, businesses, and government agencies, among others, early in project development verifies that expectations for flood risk reduction are understood and residual risk is recognized. This early engagement also helps to ensure that the risk reduction project being implemented is balanced with the socioeconomic activities in the region.

Engagement is any interaction between the organization or agency responsible for delivering the NNBF project and relevant stakeholders, as well as communities where NNBF projects may be built. This interaction can include a wide range of different types of engagement, from one-way communication of information to consultation and collaborative discussion. Other terms used may include public participation, community engagement, stakeholder engagement, or involvement.

Stakeholder input, including opposition, can lead to an improved understanding of concerns and potential impacts of the project that may be incorporated into an improved design for the NNBF project. Similarly, this input can lead to the recognition that there are other problems within the system that additional projects may be required to address. The need for engagement reinforces the need to define the system scale early in project development; this scale will help to identify which stakeholders to involve. 
For NNBF projects, which may require more space to be effective than traditional structural approaches (e.g., seawall) to flood risk reduction, understanding current use of the foreshore or floodplain for economic or recreational use by the community is important to create local support. Understanding the socioeconomic system within which the project will be implemented often involves outreach to and engagement with businesses and residents. Stakeholder analysis will aid the definition of system boundaries and external forcing factors; the engagement of these stakeholders will support the identification of the potential range of interventions, the connections between the natural system and the societal context, and the potential project outcomes and associated benefits (Vreugdenhil et al. 2010a).

The following case study examples illustrate the importance of engagement for successfully implementing NNBF solutions and creating local support (Demak, Northern Java, Indonesia), as well as facilitating a platform for stakeholder discussion to bridge conflicting interests (Missouri River Recovery Implementation Committee [MRRIC], Missouri River, United States). Furthermore, the challenges with getting governmental entities to work together are also highlighted (Jamaica Bay, New York, United States).

\section{CASE STUDY:}

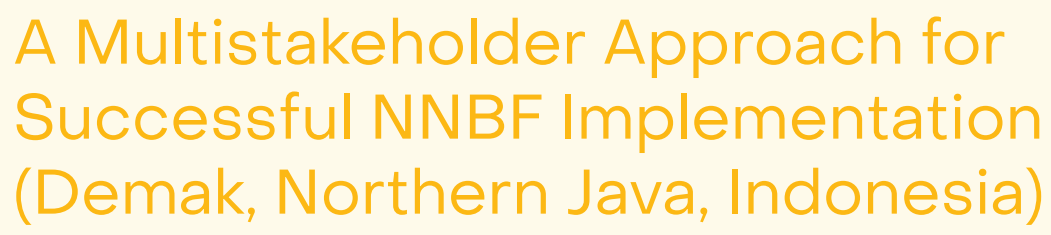

Communities in Northern Java, Indonesia, are suffering from coastal erosion affecting hundreds of kilometers of coastline. In the District of Demak, Indonesia, more than 3 kilometers of land including entire villages have already been lost to the sea (Figure 4.3). It is expected that sea-level rise will result in flooding 6 kilometers inland by 2100 , affecting more than 70,000 people and 6,000 hectares of aquaculture ponds. One successful flagship project in Demak has been used by the local authorities and the national government to bring the NNBF approach into mainstream coastal zone management across Northern Java, supporting increased resilience for $\mathbf{3 0}$ million people currently at risk from coastal hazards. 
Figure 4.3. Shoreline Change in the District of Demak, Northern Java, Indonesia

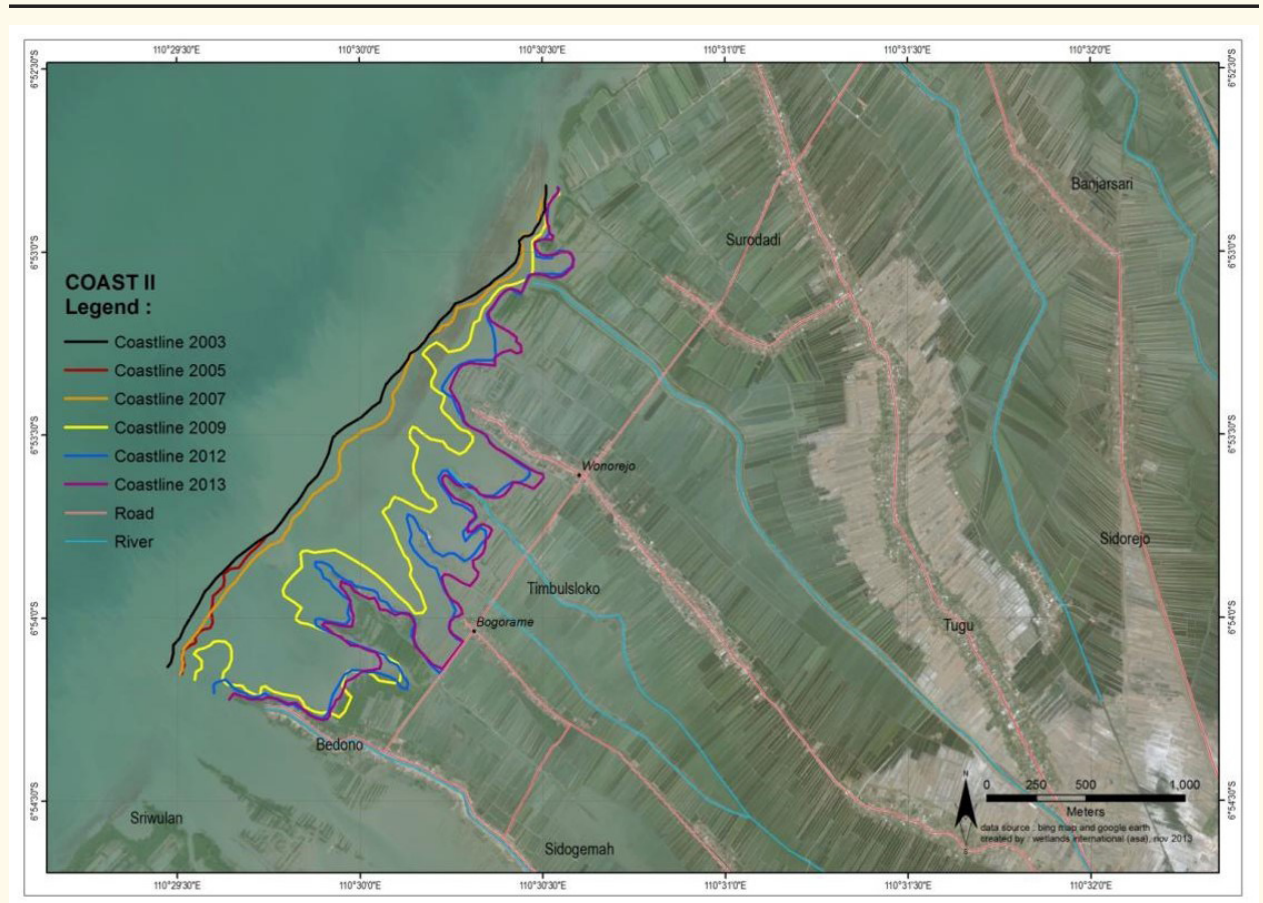

Source: Wetlands International

The main causes of the erosion problems in Demak are the removal of mangrove belts for aquaculture development, the construction of coastal infrastructure that disturbs sediment buildup from offshore sources, and groundwater extraction, which causes land subsidence and river canalization. Using only hard structures like dams and seawalls has proven to be ineffective as a single solution along rural mud coasts and often exacerbates erosion. Such structures also tend to be unstable (due to soft subsoils), expensive, limited in their capacity to adapt to climate change, and fail to provide the economic, environmental, and social services associated with healthy natural mangrove belts.

The Building with Nature (BwN) approach has been used to combine nature-based solutions, such as mangrove restoration, with techniques such as dams and seawalls, while taking into account the socioeconomic environment. In Demak, semipermeable barriers have been built from poles and brushwood to dampen the waves and capture sediment (Figure 4.4). Once the nearshore bed level rises enough, mangroves are 
expected to regenerate naturally, developing a natural defense that will protect the hinterland from further erosion. Where the coastline has not yet been eroded, the conversion of ponds into mangrove forests is encouraged in close collaboration with local communities. To read more about the BwN approach for this project, please visit the project website (https://www.ecoshape.org/en/pilots/building-with-natureindonesia/).

Figure 4.4. Construction of Permeable Dams in Demak, Indonesia

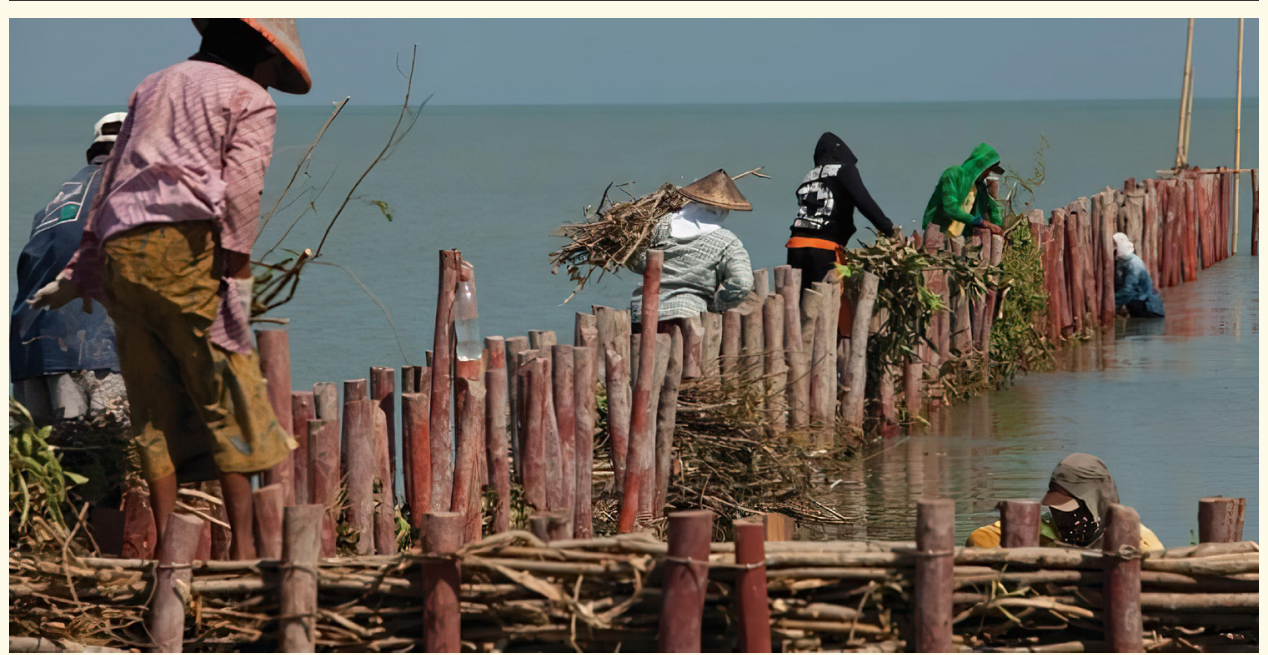

Source: Nanang Sujana

Local communities were involved through the Bio-Rights microcredit finance mechanism. Bio-Rights is an innovative financing mechanism for reconciling poverty alleviation and environmental conservation (Eijk and Kumar 2009). In return for active engagement in conservation and restoration measures, communities receive financial support to develop sustainable livelihoods that will generate income. In the case of Demak, this translates into coastal safety measures and sustainable aquaculture.

Bio-Rights agreements are conditional-payments to communities will only be provided subject to successful restoration. The approach covers the costs communities face to change their current unsustainable practice (degrading the very mangrove greenbelt that they rely on for coastal safety) into long-term sustainable livelihood strategies. Legal contractual agreements were set up with community groups, rather than with individuals, creating greater group cohesion and responsibility in implementing the agreement and collective motivation to accomplish 
both restoration and livelihood activities. This also increased project implementation efficiency, contributed to project sustainability, and reduced overhead costs. In addition, the implemented measures are controlled using community bylaws and are rooted in community development plans and government master planning for sustainable development. The integrated systems approach in Demak looked at the root causes of the coastal erosion problem and found a sustainable solution that halted coastal erosion through natural system understanding, while at the same time creating long-term benefits (and commitments) for the local community (i.e., the social system).

\section{CASE STUDY:}

\section{MRRIC - Forum to Facilitate Stakeholder Discussion and Collaboration (Missouri River, United States)}

The Missouri River system was significantly altered in the nineteenth and twentieth centuries, including the construction of six large reservoirs (Figure 4.5) that constitute the Missouri River Mainstem Reservoir System. The Missouri River Mainstem Reservoir System is operated by the U.S. Army Corps of Engineers for multiple purposes, including flood control, hydropower, navigation, water supply, irrigation, water quality, recreation, and fish and wildlife. Below the reservoirs, the river has been channelized, extensively covered with revetments, and trained to provide a self-scouring navigation channel. The ecosystem has been significantly altered, including the following:

- Three million acres of natural river habitat have been affected.

- Of 67 native fish species, 51 are now experiencing population decline.

- The reproduction of cottonwoods, historically the dominant floodplain tree, largely has ceased.

- Aquatic insects, a key link in the food chain, have been reduced by $70 \%$. 


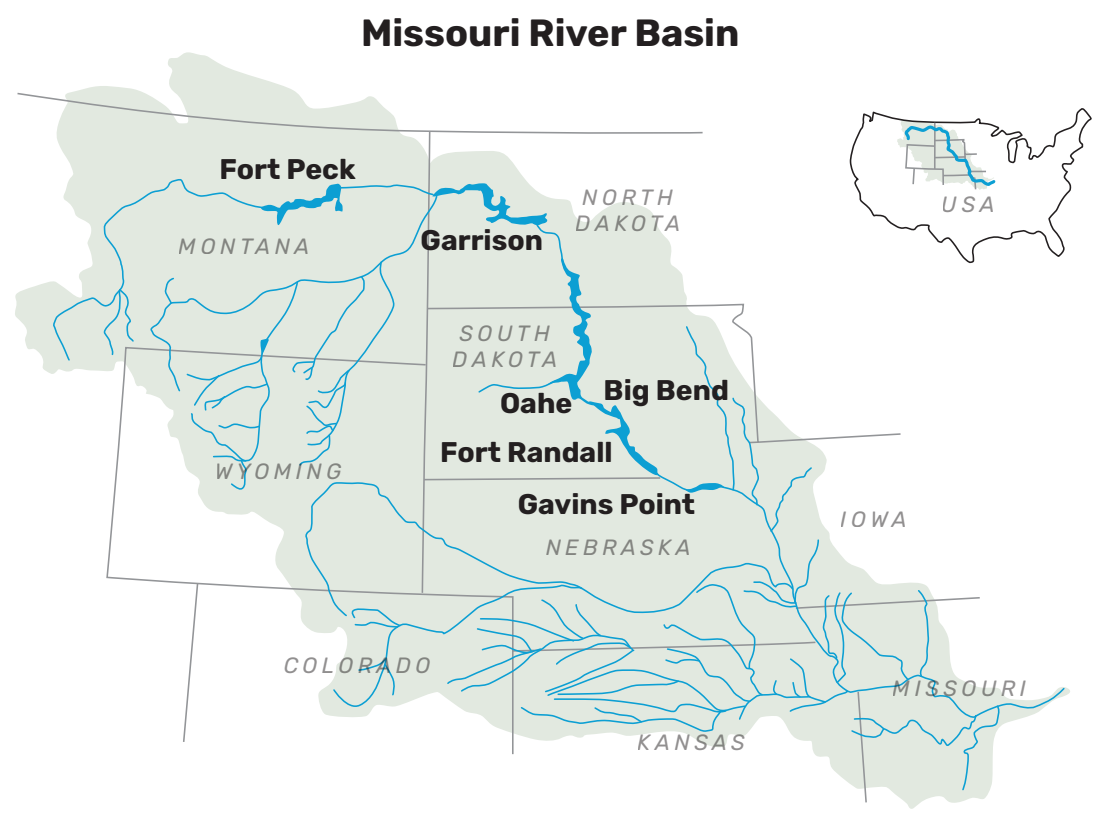

Note: Reservoir dams are indicated with bold text.

Source: Adapted from Missouri River Basin Gage Application (USACE 2021)

Multiple stakeholders play a role in the Missouri River Basin, and sometimes their interests conflict (e.g., commercial use interests of the Missouri River Mainstem Reservoir System and the navigation channel can conflict with tribal resources and other cultural interests). Because of the array of potentially competing interests, MRRIC was authorized by the U.S. Congress in 2007 to provide guidance to the study of the Missouri River and its tributaries. MRRIC provides a forum for stakeholders, tribes, and state and federal agencies to consider the needs of groups affected by management actions. Stakeholders include the 29 Native American tribes along the river, farmers, conservationists, and recreationists, all with different river interests. The MRRIC forum includes several working groups to address specific topics, and the forum is supported by an independent science advisory panel. 
MRRIC's work has been an integral part of reaching agreement on key aspects of river management. This is demonstrated by an April 2018 U.S. Fish and Wildlife Service Biological Opinion (USFWS 2018) that states the continued operation of the system was not considered to "jeopardize the continued existence of the pallid sturgeon, piping plover, and interior least tern." This shows that agencies have agreed on a set of actions to avoid conflict. Although U.S. Army Corps of Engineers operations on the Missouri River have only begun to consider NNBF as an integral part of floodplain management for flood risk reduction purposes, the established stakeholder progress provides an example of how very structured engagement processes, initiated by government, can reduce tension and provide a platform for agreement on diverse system-scale issues.

CASE STUDY:

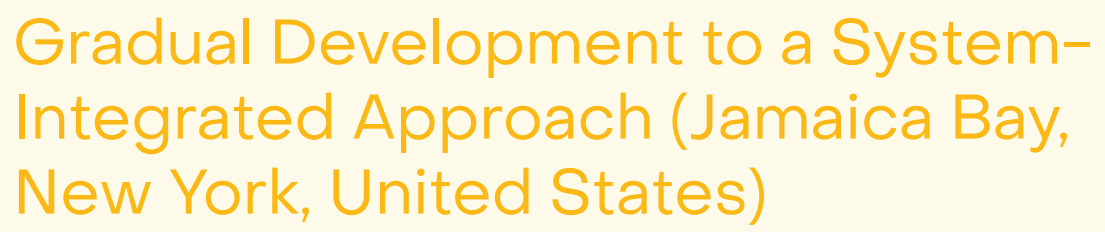

Jamaica Bay is a sheltered, shallow-water embayment of the Atlantic Ocean situated on the western end of Long Island in the New York City metropolitan area. The highly urbanized watershed is home to approximately 3 million residents and includes large-scale, highly valuable coastal infrastructure, one of the United States' most popular national parks, and an ecosystem supporting a diversity of fish and bird taxa. The physical and natural systems of the estuary have been transformed by centuries of development (Swanson and Wilson 2008; Handel et al. 2016; Peteet et al. 2018), including the following: filling of shallow waters and wetlands, dredging and channelization, altered freshwater and nutrient input, changes in tidal exchange and bay hydrodynamics, shoreline hardening, and reduction in mineral sediment inputs. Concerns over the sustainability of the system arose prior to, but were amplified by, the dramatic physical changes and infrastructure damage resulting from Hurricane Sandy in 2012. 
Systems integration in Jamaica Bay is being facilitated by a history of collective visioning, study, and action. A variety of plans and visions for the bay have been developed over time, build off different objectives (e.g., the water quality-focused watershed plans versus coastal storm risk management projects), were motivated by both short- and long-term goals (e.g., disposal of dredged material, overarching system resilience), and were led by separate entities (i.e., city, state, federal, private, and academic groups). These planning activities do not always result in identical recommendations, but the visioning process has led to an understanding of shared objectives, collaborative arrangements among groups (e.g., the City of New York and the National Park Service), prioritization of multipurpose projects, and relationships among local stakeholders. Similarly, scientific investigation, research, and analysis have provided points of collaboration for academic and government partners and filled key knowledge gaps surrounding management uncertainties. Relationships have been formalized not only between partners but also as a broad-reaching research consortium-the Science and Resilience Institute at Jamaica Bay. The final piece of systems integration in Jamaica Bay has been joint management actions contributing to large-scale outcomes. For instance, marsh islands are a unique, local ecosystem supporting biodiversity while also contributing to flood resilience and recreational objectives. From 2007 to 2018, marsh islands and wetlands have been restored through partners leveraging diverse resources such as mitigation funding, beneficial use of dredged material, community planting programs, large-scale ecosystem restoration initiatives (i.e., the Hudson-Raritan Estuary Program), and NNBF projects supporting FRM. Hurricane Sandy provided a focusing event that drew attention to multipurpose outcomes, but long-term collective visioning, inquiry, and action are also crucial elements to systems integration in Jamaica Bay. 


\subsubsection{Time and Space}

For a systems perspective, the temporal and spatial scales that are considered will have a profound influence on how the problem is approached. Understanding the scale of the system that needs to be considered is essential because any risk reduction project must involve both engagement with stakeholders (as discussed in Section 4.3.1.1) and an understanding of natural dynamics.

Stakeholders may think on a different scale than the scale at which scientists and engineers understand system dynamics (Karstens, Bots, and Slinger 2007). Sometimes stakeholders will try to solve their problem on their own scale, which for flood risk may be limited to the extent of damages from the previous storms, the area for which the stakeholder has responsibility or ownership, the obvious weak links or imminent threats, or the scale of a local political boundary (Vreugdenhil et al. 2010b; Slinger et al. 2013). NNBF measures targeted at the root causes of flooding at the scales at which they operate will be much more effective than measures sited in an isolated, nonstrategic manner. Accordingly, watershed modeling can be an important tool in strategic placement of NNBF in fluvial systems. Flood reduction measures, whether conventional, nature-based, or hybrid, can alter the timing of flood waves from different subbasins and tributaries of river systems (see also Chapter 16).

This is also illustrated by Slinger et al. (2013) in an integrated scale hierarchy for Dutch coastal policy (Figure 4.6). Whereas the natural scale of things might merit thinking in spatial scales of tens of kilometers, as is generally considered by a coastal morphologist or policy advisors, local coastal engineers might only look at the project scale of an individual beach nourishment project, generally being on the order of several hundred meters to several kilometers. Differences in policy implementation will lead to local differences, which might reduce total system efficiency. Constructing a hard structure or nourishing a local beach might be beneficial for a local stakeholder but may conflict or undermine policy objectives that are being implemented on a system scale. A system-wide master plan, or vision, can aid in reducing these differences in policy implementation. 
Figure 4.6. Integrated Scale Hierarchy for the Dutch Coast

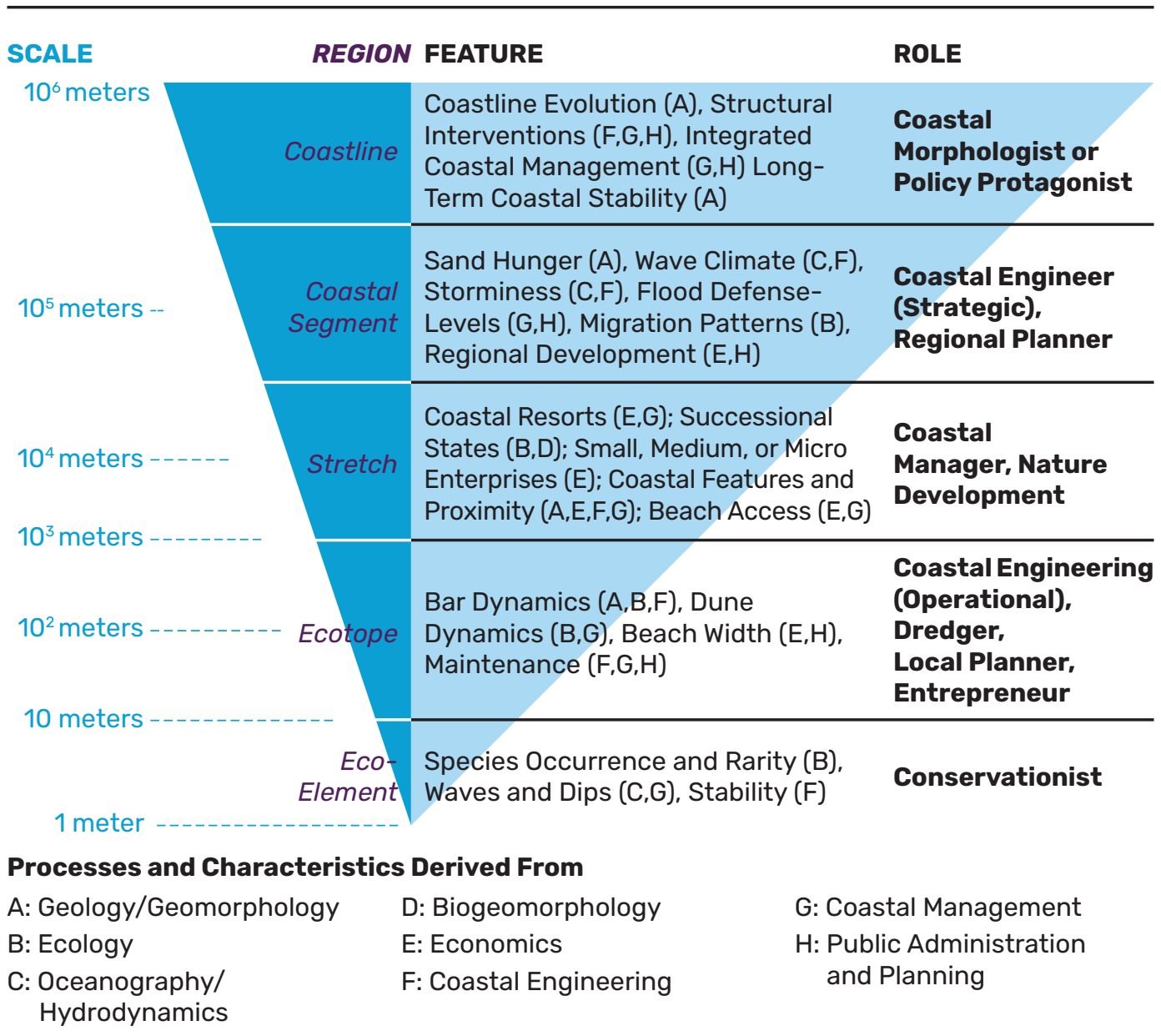

Source: Adapted from Slinger et al. 2013

NNBF projects are most effective when they take advantage of natural system dynamics influencing their immediate area of concern (e.g., sediment replenishment from updrift sources following storm damage to a beach). A study at the Beuningen/Ewijk River floodplain in the Netherlands showed that the management solutions chosen were less optimal from a systems perspective because upstream measures were not considered (Vreugdenhil et al. $2010 \mathrm{~b}$ ) due to the scale preference of the relevant stakeholder. In this case, increasing the scale of the system considered as context for the project (not the scale of the project) also increased complexity and the number of issues that needed to be considered. 
Often, flood risk reduction projects generate interest immediately after an event (e.g., Dutch North Sea flood in 1953, Hurricane Katrina [United States] in 2005, typhoon Haiyan [Philippines] in 2013), focusing attention on the current or recent past in terms of system state and a single event versus the range of possible flood risk scenarios. In addition, they are often focused on immediate action and outcomes, which may limit or constrain consideration of some solutions, such as NNBF.

Investments in risk reduction are most cost-effective if they focus on addressing the threat from events with a range of return intervals and will be more enduring in their effectiveness if they are planned and implemented with a long-term view of how flood risk could change in the future. This is particularly important not only in coastal systems where sea-level rise increases the potential for flooding, even without a flood event, but also in floodplains where precipitation regimes change toward more flashy events (Arnell and Gosling 2016). Many major cities lie on the coast and are also influenced by flooding from adjacent watersheds. The interaction of riverine flooding with coastal storms, as well as ongoing sea-level rise, is an important example of how a systems approach to FRM is crucial.

In addition, for NNBF that rely on the growth of organisms to reduce risk, the time-dependence of the biotic response must be considered in view of the flood threat. Thus, understanding the desired conditions for a number of target ecosystems is important. EcoShape has compiled a useful library on the use of target species and habitats for NNBF flood risk reduction projects (ecoshape.org 2021). Some NNBF solutions (e.g., mangrove forests) require years of maturation before they reach their full effect. However, other NNBF solutions can be effective soon after implementation (e.g., sand dune construction). It is possible that those which require time may be implemented intrinsically as hybrid projects, where an additional, perhaps sacrificial, traditional flood risk feature (e.g., a low earthen embankment) is used in conjunction with planting to increase the effectiveness of the project in the early years (Figure 4.7).

\section{Figure 4.7. Conceptual Representation of Changing Effectiveness of Features in a} Hybrid Project

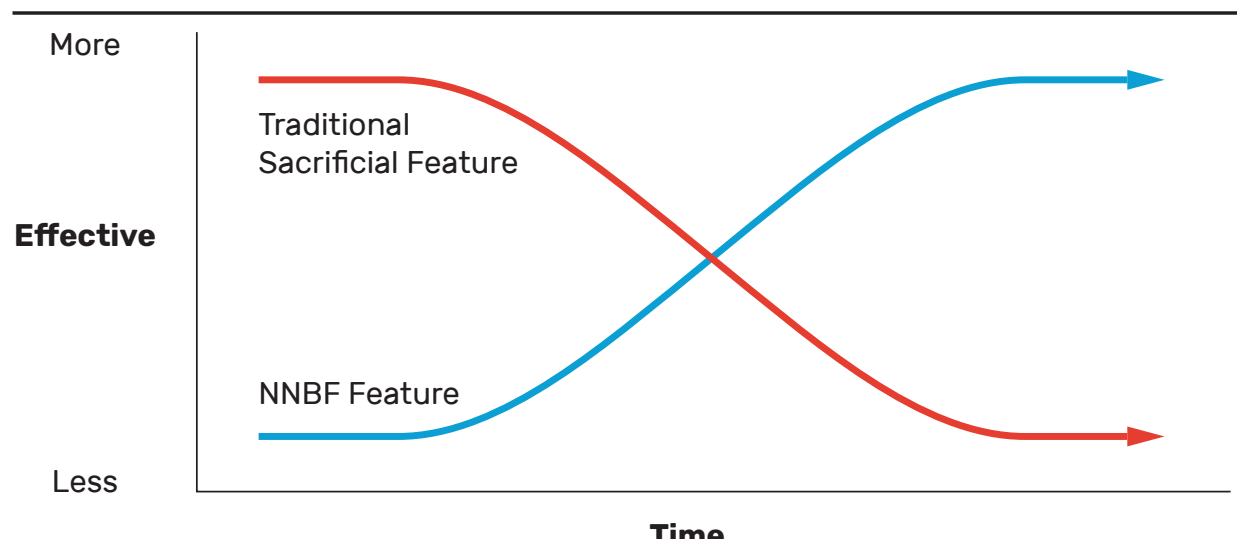


Deciding which natural scale to focus on may depend on issues such as financial resources, stakeholder interests, and long-term versus short-term benefit comparison. Gallop et al. (2015) show that different aspects should be considered depending on the scale that is addressed (also illustrated in Figure 4.8). The driving morphological as well as the ecological and biogeochemical feedback mechanisms might differ for different temporal and spatial scales. These different scales are also connected, and the knowledge transfer between different scales is not straightforward. For morphological change, Gallop et al. (2015) identify several major uncertainties in scale transfer, namely the uncertainty of different bedforms and ecological factors on sediment transport, the contribution of episodic and extreme events to morphological development, and the recovery period to equilibrium after such an event (see chapter 9). An understanding of the natural processes at different scales can be used to develop a vision on how best to implement an integrated flood risk program, either focusing on small-scale or larger scale interventions, or a combination of both.

Figure 4.8. Different Processes at Play on Different Spatial and Temporal Scales

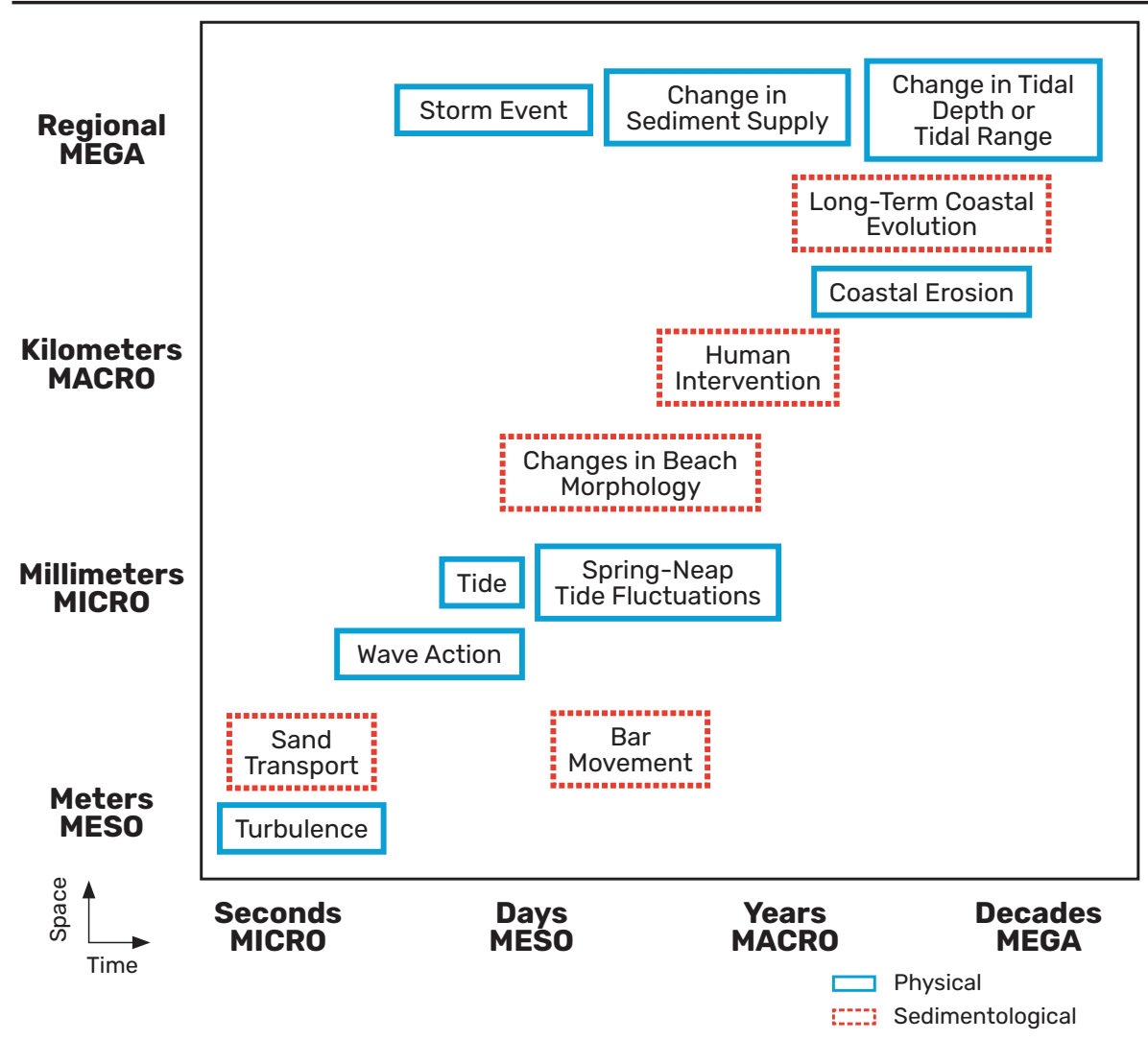

Source: Adapted from Gallop et al. 2015 and Larson and Kraus 1995 
The case study examples in Section 4.3.1.2 show that different projects can be effectively implemented on different scales within a single system as long as a clear vision and goal are set for the entire system (Dutch coast) and that simple principles based on natural processes can beneficially modify large-scale system dynamics (coastal Louisiana).

\section{CASE STUDY:}

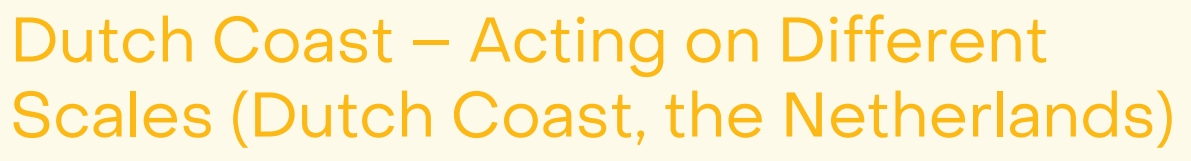

As a low-lying country, the Netherlands has a long history in its struggle against rising water. In the last centuries, the fight against rising water was mainly fought on a local level with local solutions. Over the last decades, the thinking has shifted to a more integrated, system-wide approach, including multiple governmental bodies, research institutes, and local stakeholders. In 1990, the foundation for this vision was established by the decision to maintain a stable coastline at the level of 1990 (the Basiskustlijn ["reference coastline"]) by means of sand nourishments. This political (and legal) decision enabled collaborative development of a dynamic coastal management approach based on sandy solutions, where natural processes play a key role. This vision also acknowledges that nourishments in the nearshore have an impact on the landward part of the coastal system (e.g., protected dune ecosystems), thereby connecting coastal defense to the management of several national and European Union nature reserves.

After the formation of this vision, the entire Dutch coastline has been aligned according to these standards, with NNBF and BwN projects such as the Sand Motor and Hondsbossche Dunes.

The application of a long-term vision for the entire Dutch coast can be seen as the overarching example of systems thinking. On a smaller spatial scale, a system-based approach is used to develop custom-made solutions that include other ecosystem services. NNBF solutions are preferred where possible and structural solutions are chosen when necessary (e.g., near coastal cities or in different natural systems). For example, the Dutch coast can be separated into the following three distinct subsystems: the Zeeuwse Delta/Scheldt-Meuse Estuary in the southwest, the closed Holland coast to the west, and the Wadden Sea barrier island system in the north (Figure 4.9). Each system requires different approaches and has different cost-benefit analyses and solutions. 
Figure 4.9. Overview of Dynamic Coastal Management Projects along the Dutch Coast

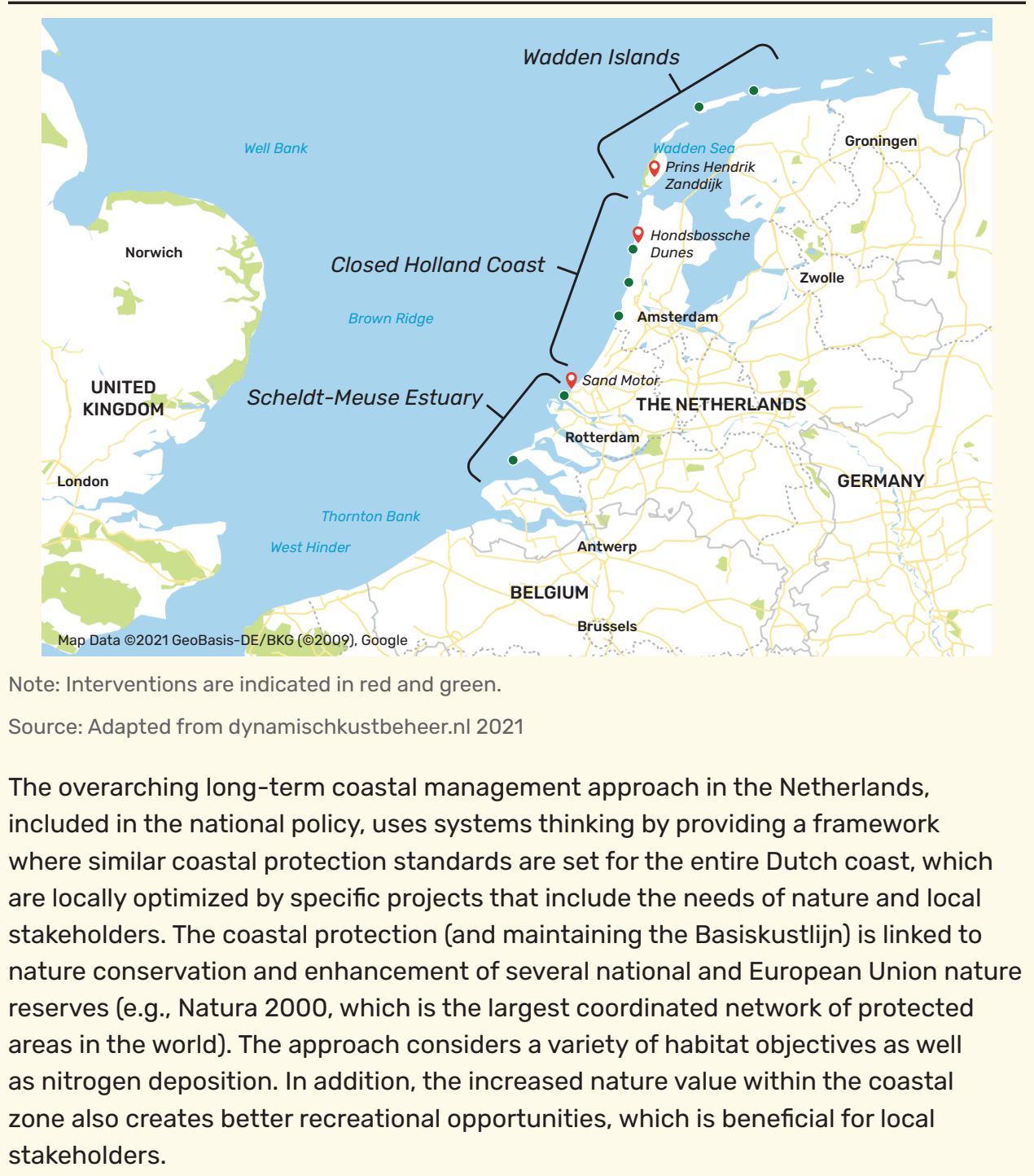




\section{CASE STUDY:}

\section{Natural System-Scale Thinking (Coastal Louisiana, United States)}

More than 1.2 million acres of Louisiana's coast has been lost to open water since the 1930s (Couvillion et al. 2017), increasing the exposure of local communities and cities like New Orleans to flood risk from hurricanes and tropical storms. To combat coastal land loss in the Mississippi River Delta, the State of Louisiana is proposing to construct in the levee system a series of strategically sited water-control gates to divert, during high river flows, some of the river's sediment-laden flows to re-establish connections between the river and its wetlands (Figure 4.10). Importantly, sediment in this system is seen as a valuable limited resource rather than a problem or a pollutant. These diversions will mimic the original land-building processes that created the delta system, providing a means to recover wetlands at a landscape scale and maintain them indefinitely in a manner that re-creates a dynamic deltaic ecosystem (Allison and Meselhe 2010), but the land building may take several decades to be manifest due to the large open-water areas that have to be filled. Although diversions involve the building of engineered structures, they represent a sustainable, nature-based, system-scale solution.

\section{Figure 4.10. Louisiana River Diversions}

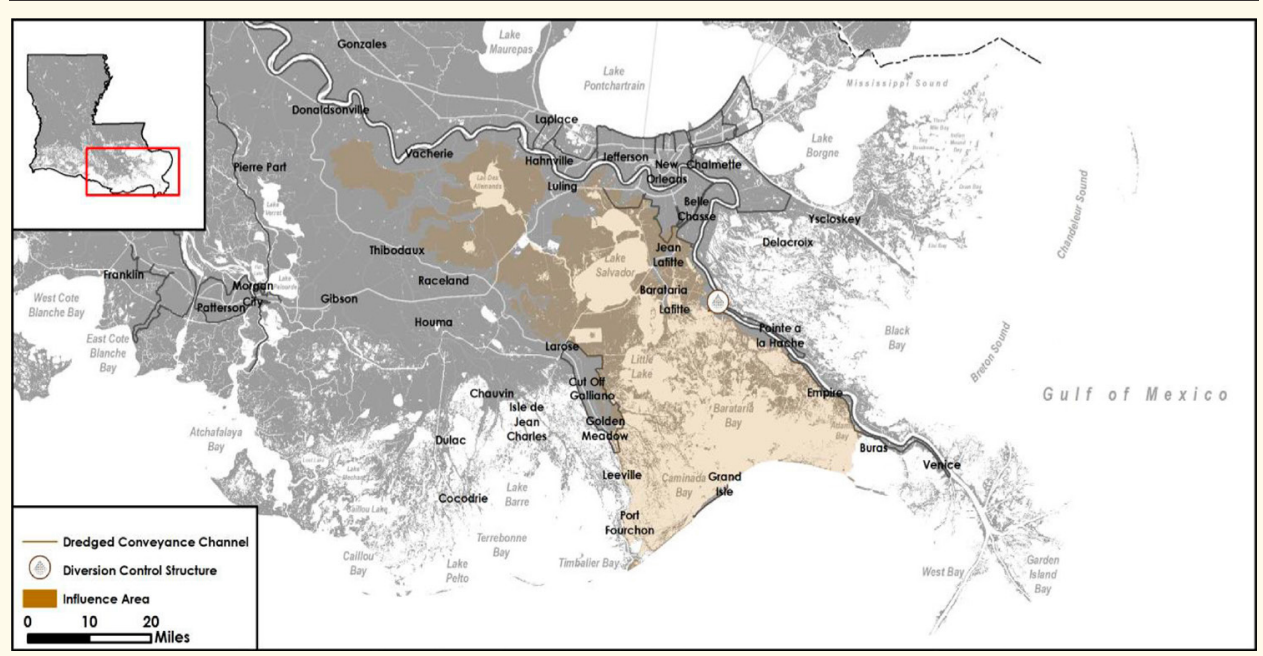

Source: Adapted from Peyronnin et al. 2017 
In addition, over the last century, the delta ecosystem has become increasingly influenced by saline gulf waters because riparian freshwater flows into the delta ceased due to construction of river levees for flood management. Flows through sediment diversions will deposit sediment and once more freshen the system and build and sustain wetlands on a large scale in the long term. This means local species distributions will change once the diversion is opened (de Mutsert et al. 2017). The effect on salinity will be more immediate than the effect on land building. Due to these changes, some fishers have raised concerns about the sediment diversions' near-term potential to affect resources they value and adversely affect their livelihoods. As local conditions change, fishing boats might need to travel farther to reach suitable habitat, and new gear might need to be purchased to catch different species close to home. Local fishers, looking at sediment diversions, see the impact in terms of annual loss of catch and the effect that has on their livelihoods. Coastal planners, looking at the coastal problem in Louisiana at the system scale, see re-establishing the delta-building processes as a linchpin approach.

Attempts to resolve or minimize conflicts were needed to provide a long-term solution to the massive land-loss problem. Scientific experts identified means to balance long-term ecosystem recovery with near-term community needs, using pulsed operational scenarios for sediment diversions (Peyronnin et al. 2017). These operational adjustments mean diversions can take advantage of the most sediment-laden river flows and minimize freshwater input to the wetlands.

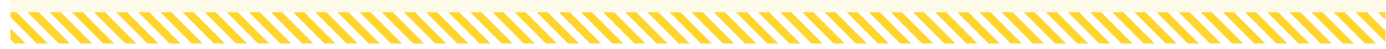

\subsubsection{Analyze}

The system analysis for developing NNBF solutions can occur in several ways. The type and scale of the system partly determines how the analysis during the design process proceeds. Small-scale problems with fewer interrelations can be approached differently than larger scale (spatial and temporal) interrelated problems. Furthermore, if an intervention has a long lifetime, the uncertainty of a predicted outcome will increase, and analysis techniques need to acknowledge and explore this.

During analysis, often the challenge is to create a model or assessment tool with the available knowledge that has an appropriate complexity, without making matters too complex (see French et al. 2016 as an example). These models usually require the expertise of several disciplines to obtain a system-wide assessment. Knowledge available on smaller temporal and spatial scales must be translated to larger scales, or vice versa, without losing reliability or essential process information (Gallop et al. 2015). 
It is also essential to identify current knowledge gaps about the (natural) system. The solution to the problem might also lie in gaining more knowledge and reducing uncertainties by conducting research through monitoring after the construction has been completed. This new knowledge might be essential to optimize or upscale similar NNBF solutions. For example, in the Netherlands, a number of pilot projects are executed to test the effectiveness of several NNBF implementations (see van Eekelen and Bouw 2020).

In addition to the natural setting, the history of structural interventions also determines the range of possibilities for NNBF implementation. In an already-altered environment, more effort may be required to bring the system back to natural conditions. Alternatively, a hybrid solution may be more readily implemented. In the Netherlands, for example, the Houtribdijk, a dike system along the lake Marken, did not meet legally mandated flood risk standards. Instead of opting for costly dike reinforcement, the construction of a cheaper vegetated sandy foreshore was preferred to bring the dike back to legal standards, which at the same time also created opportunities for nature (e.g., EcoShape's Houtribdijk project). However, at the Hondsbossche and Pettemer Zeewering, a dike not meeting legal standards was actually replaced by a fully natural solution-a sandy foreshore and dune habitat called the Hondsbossche Dunes project. Furthermore, in each system setting, efforts to optimize resource use can lead to opportunities to gain extra benefits. For example, siltation problems in a harbor or the overabundance of sediment at one location can make a resource available for use at another location (e.g., the creation of salt marsh for flood protection or tidal flat nourishment [van Eekelen et al. 2017]).

The approach for analysis must be tailored to the needs of the problem, the system, and the project. A number of examples are described in detail to illustrate different approaches that have been used for implementing NNBF solutions. The mangroves and northwest Europe salt marsh examples show that a knowledge of system dynamics, and its feedback and variability, is essential to develop a suitable NNBF solution. The Wadden Sea tidal inlet example shows that continued knowledge development is necessary to further optimize management strategies and for the optimal implementation of NNBF solutions. The Regional Sediment Management Master Plan (Parson, Khalil, and Waters 2012) in the Gulf of Mexico shows how the use of numerical modeling tools on a system scale can be used to create added value and optimize interventions. The installation of runoff attenuation features (RAFs) in Belford, United Kingdom, shows that the implementation of a multitude of small-scale features can have a beneficial impact on the entire system catchment scale as a whole. 


\section{CASE STUDY:}

\section{Considering System Connectivity, Mangroves}

The dependence of local communities in many areas on ecosystem services provided by natural features such as mangroves (see Chapter 6 ) reinforces the importance of understanding ecosystem connectivity for both effective FRM and community acceptance and support. To incorporate mangroves effectively into FRM systems, the system-level ecological connectivity needs to be considered in the analysis. For tropical coasts, it has been shown that mangroves, seagrass meadows, and corals can support each other in their persistence and ecosystem functioning. Gillis et al. (2014) conducted a review and found important connections (e.g., fluxes of sediments and nutrients) between ecosystems resulting in functionality at a system scale that could differ from that within a single ecosystem (Figure 4.11). Simultaneously, the combination of multiple habitats can provide additional flood reduction measures (e.g., by taking advantage of the wave-dampening effect of mangroves, submerged vegetation, and coral reefs).

Figure 4.11. Conceptualization of Connections between Land, Mangrove Forests, Submerged Vegetation, Coral Reefs, and Ocean Systems

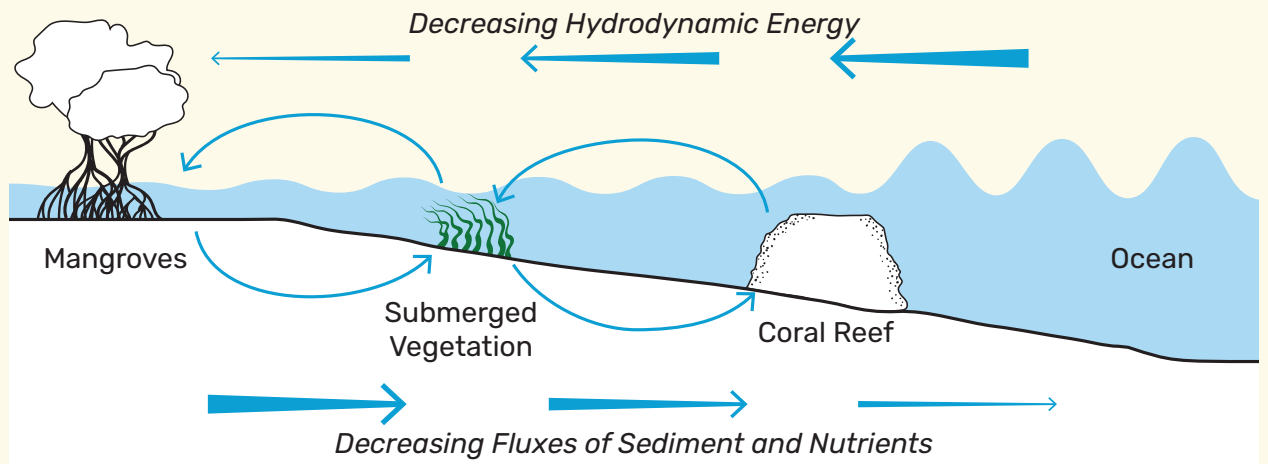

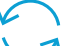
Biological Exchange

Source: Adapted from Gillis et al. 2014 
The consequence of this connectivity is that creating a sustainable, nature-based, coastal defense system may in some cases require restoring connectivity rather than directly restoring the target ecosystem (e.g., wave-attenuating mangroves). It is crucial, therefore, that analysis conducted to show the role of natural features in flood risk reduction consider these interactions and connections. Although this example is for tropical coasts, for salt marshes (see Section 4.3.2), considering the connectivity between the vegetated marsh and the adjacent tidal flat, as well as the surrounding sediment system, is essential.

CASE STUDY:

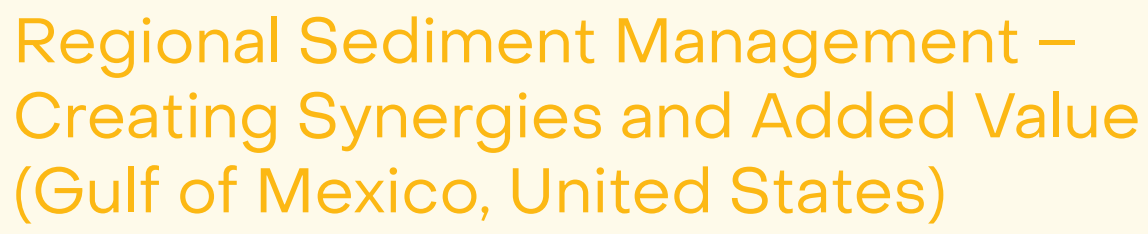

Historically, beach restoration projects in the United States have been managed on a project-by-project basis. Managing these projects outside the context of the larger sediment system adversely impacts adjacent projects (e.g., reduced downdrift sand supply). To address this issue, the U.S. Army Corps of Engineers implemented a regional sediment management demonstration project along 600 kilometers of shoreline from St. Marks River, Florida, to the Pearl River, Mississippi, in the northern Gulf of Mexico (Lillycrop et al. 2011; Parson and Rees 2005). The purpose was to evaluate managing sediments as a regional-scale resource to maximize the use of sediment, minimize environmental impacts, and optimize expenditures.

A comprehensive regional sediment budget was developed to understand the coastal processes and sediment transport on a system scale. The sediment budget was refined using a combination of regional- and local-scale numerical models and field measurements, the Sediment Budget Analysis System (Rosati and Kraus 1999), and GIS tools. Historical and newly collected data were garnered from study partners. In parallel, numerical models were applied to develop sediment transport potential over the region. Transport cells were created in the Sediment Budget Analysis System at the project scale and integrated to the regional scale. This sediment budget provided 
the regional context to develop engineering alternatives and assess potential regional impacts and identified data gaps. The models were focused at the subregional and project scales and evaluated project modifications to improve sediment management. A regional GIS was used to assess data and model results.

An example of an initiative within the regional sediment management demonstration project is Perdido Pass, a stabilized tidal inlet on the Alabama coast. Since 1971, more than 5.2 million cubic meters $\left(\mathrm{m}^{3}\right)$ of sediment has been dredged from the inlet and placed in disposal areas, resulting in the majority of sandy material being removed from the littoral system and leading to downdrift erosion (Parson and Rees 2005). The objectives of the Perdido Pass regional sediment management strategy were to reduce erosion and thus enhance storm protection along the shoreline, reduce rehandling of sediment, and optimize sand bypassing to reduce operation and maintenance costs. The benefits included reduced erosion of the downdrift beach, reduced dredging, improved habitat for sea turtles and shorebirds, and augmentation of natural dune creation (resulting in greater storm protection and habitat for dune-dwelling organisms; Lillycrop et al. 2011).

\section{CASE STUDY:}

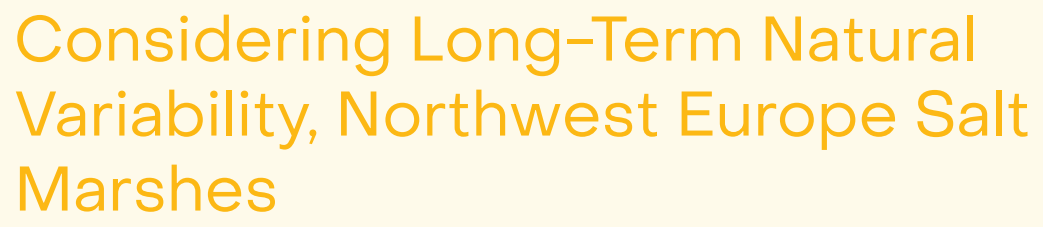

Although there is increasing interest in northwest Europe in integrating salt marshes as part of flood protection systems, analyzing their effectiveness faces many challenges. Processes influencing the morphological and ecological dynamics of coastal marshes operate across broad temporal and spatial scales (Figure 4.12). Salt marshes in northwest Europe often exhibit cyclic dynamics on a decadal timescale. The morphology of the marsh (e.g., shape, extent, presence of cliffs) is an important factor determining potential for wave attenuation (see Chapter 10). Morphological change can be driven by episodic- or decadal-scale external forcing superimposed on mobilization of sediments by waves and tides, mediated by vegetation effects in 
trapping sediment and binding soils. This means that the width of a marsh protecting a dike or levee will vary over time. This natural variation presents challenges to managers designing dikes and levees because the variability in marsh width may mean that there is uncertainty in the long-term defense value. Thus, to implement the marsh as part of the coastal defense system, several key issues must be resolved, including predicting and managing the marsh width, and using that knowledge to consider the effect on safety performance of the marsh and dike system.

Figure 4.12. Schematic Representation of How Processes on Different Spatial and Temporal Scales Influence Salt Marsh Dynamics

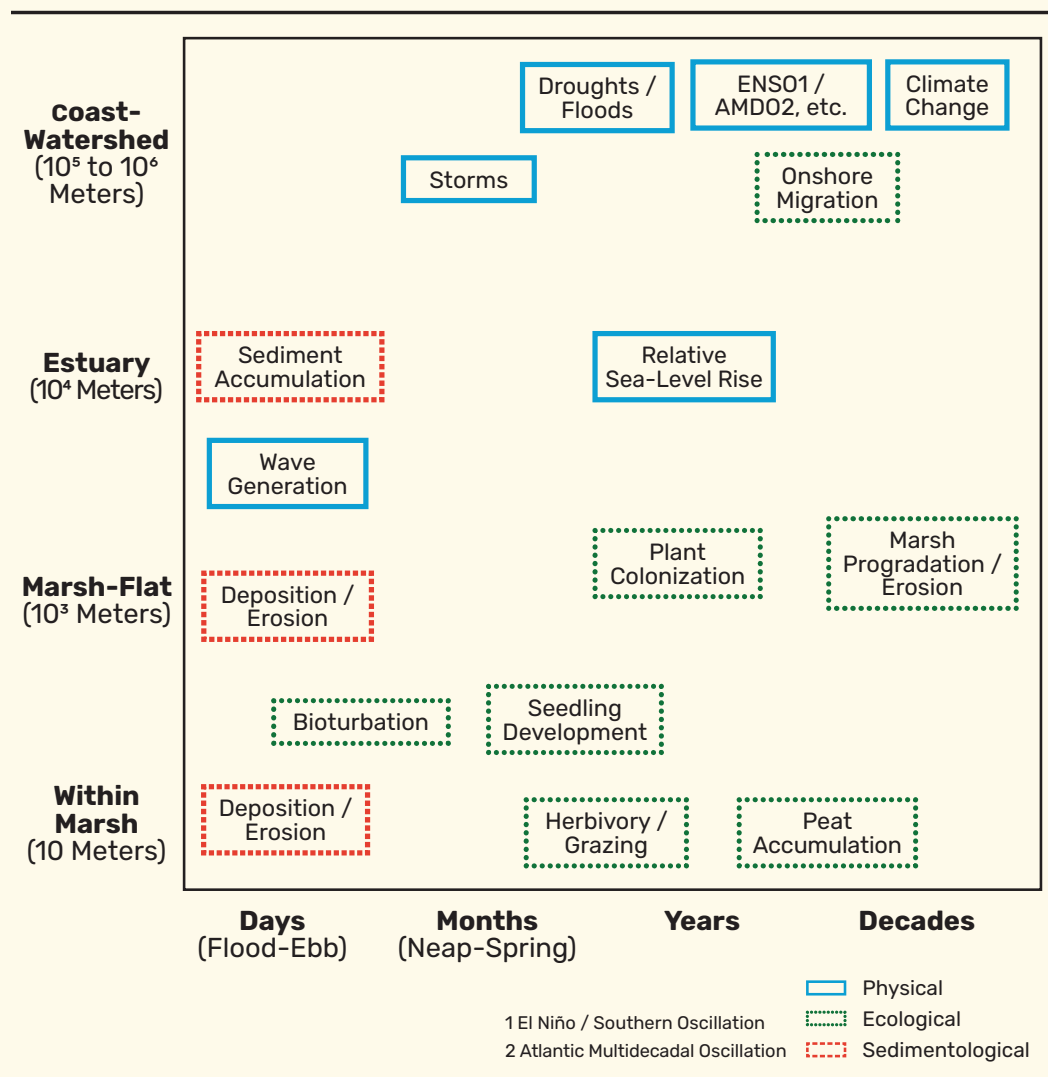

Being able to predict and manage the marsh width at any site requires detailed local information and an understanding of long-term change processes in a systems context. Experimental research may be needed to unravel processes underlying the initiation of marsh retreat (i.e., cliff initiation) and lateral marsh expansion (i.e., 
seedling establishment or rhizomal growth). Recent work has shown that tidal flats control the behavior of a marsh edge (Bouma et al. 2016). Understanding of processes controlling cliff formation is advancing (e.g., Bendoni et al. 2016; Wang et al. 2017). Understanding seed dispersal and seedling establishment and survival can be important controls on windows of opportunity in relation to sediment dynamics (e.g., Balke et al. 2011) and the marsh-tidal flat interface.

The developing knowledge base allows upscaling (i.e., the use of biogeomorphic models based on the process studies) and can inform the development of management measures by understanding how system-level changes in sediment supply interact with the marsh to change, over time, their effect in attenuating waves. Efforts have been made to include the effect of salt marsh vegetation in reducing wave height in the design criteria for dikes in the Netherlands (e.g., Vuik et al. 2016). However, the incorporation of morphological variation and uncertainty in marsh character into fully probabilistic assessments of flood risk (e.g., Vuik et al. 2017) requires additional research.

CASE STUDY:

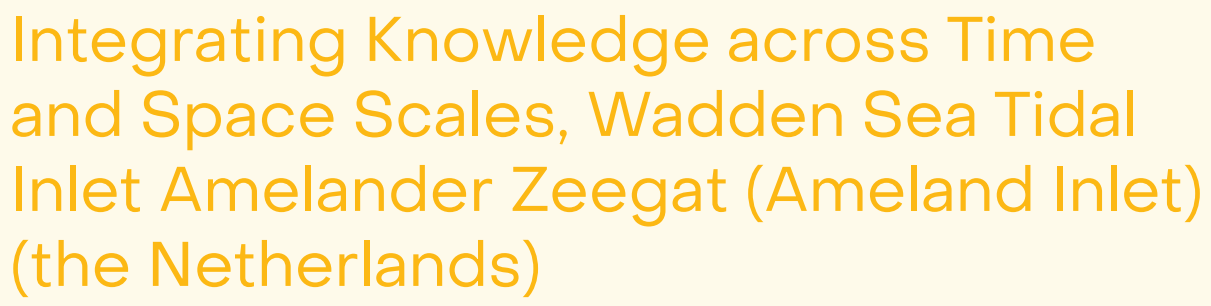

The goal of Dutch coastal policy is to create a safe, economically strong, and attractive coast (Ministry of Infrastructure and Environment and Ministry of Economic Affairs 2014). This is achieved by maintaining the part of the coast that supports these functions-the coastal foundation, defined as being the coastal sand body up to 20 meters below mean sea level. The coastal foundation is maintained by means of sand nourishments; the total nourishment volume is approximately 12 million $\mathrm{m}^{3}$ per year since 2000. The amount of sediment needed to achieve this goal requires determining not only how much sediment is needed to keep pace with sea-level rise but also how 
coastal processes, including waves and tides, can support nourishment programs. This led to the development of a coastal research program, Kustgenese 2.0. One of the major objectives of Kustgenese 2.0 is to further understand tidal inlet processes such that the effect of future coastal maintenance (e.g., nourishments) can be understood and predicted, requiring a long-term, system-level view of morphodynamics. To achieve this goal, Elias and Tonnon (2016) proposed a three-step approach (Figure 4.13).

Figure 4.13. Example Model Validation Steps and Associated Goals

\begin{tabular}{|c|c|c|}
\hline Step 1 & Step 2 & Step 3 \\
\hline $\begin{array}{l}\text { Present-State } \\
\text { Simulations }\end{array}$ & $\begin{array}{l}\text { Short-Term } \\
\text { Nourishment } \\
\text { Evaluation }\end{array}$ & $\begin{array}{l}\text { Long-Term } \\
\text { Nourishment } \\
\text { Evaluation }\end{array}$ \\
\hline Timescale: 1 year & Timescale: 5 years & Timescale: 5 to 25 years \\
\hline Goal: & Goal: & Goal: \\
\hline $\begin{array}{l}\text { Model and knowledge } \\
\text { development (calibra- } \\
\text { tion and validation with } \\
\text { data from field measure- } \\
\text { ment campaigns) }\end{array}$ & $\begin{array}{l}\text { Realistic computation of } \\
\text { nourishment behavior; } \\
\text { a single mega nourish- } \\
\text { ment on the ebb-tidal } \\
\text { delta }\end{array}$ & $\begin{array}{l}\text { Forecast studies, pre- } \\
\text { dict inlet behavior, and } \\
\text { evolution in relation } \\
\text { to the nourishment } \\
\text { strategy }\end{array}$ \\
\hline
\end{tabular}

The complexity of tidal inlets is illustrated by the Ameland Inlet case. Figure 4.14 shows the complex pattern of ebb and flood channels, secondary chutes, and shoal areas that form Ameland Inlet, as well as their connection to the tidal channels of the Wadden Sea. An understanding of the spatial and temporal evolution provides insight into the ebb-tidal delta dynamics, which can be used to optimize a nourishment strategy. For example, a former ebb-tidal delta shoal that attached to the coastline in approximately 1985 acts as a natural sand engine and has supplied the (downdrift) coastline with sand over the past decades. This motivated the large-scale field experiment in 2018 to place 5 million $\mathrm{m}^{3}$ of sand on the outer delta, which was then monitored over time. 
Figure 4.14. Overview of the Channels and Shoals That Form the Present-Day Ameland Inlet

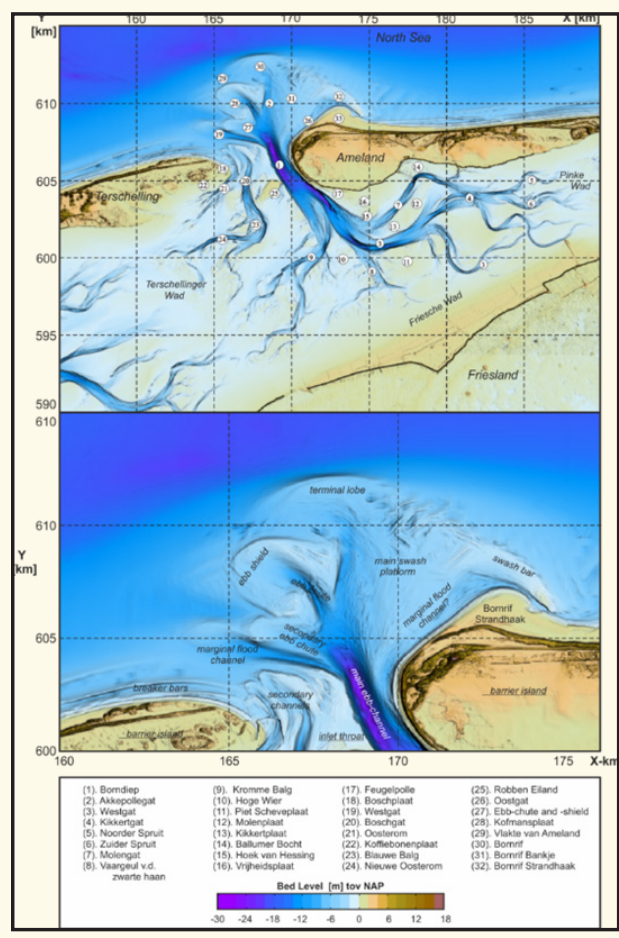

Note: This digital elevation model is based on measurements of the ebb-tidal delta and main channels in the basin in 2016 and date from 2011 for other areas.

Source: Bart Grasmeijer, Deltares
The dynamics of a tidal inlet depend on tidal exchange, itself influenced by changes in inshore lagoonal or estuarine environments, as well as ocean processes and shoreline sediment transport, the morphological effects of which must be integrated across a variety of timescales (Figure 4.8). Fundamental understanding of the physical processes underlying the inlet behavior and development can be obtained through numerical (process-based) modeling or the detailed analysis of field data. 


\section{CASE STUDY:}

\section{System-Scale Benefits of Small-Scale Implementations, 'Belford Burn Catchment (Belford, Northumberland, United Kingdom)}

A case study example from Belford, Northumberland, United Kingdom, demonstrates the potential for catchment-scale RAFs. The Belford Burn catchment was not suitable for a traditional flood management scheme. Although a single detention reservoir had been proposed, it was prohibitively expensive for the size of the town (Quinn et al. 2013).

The potential to regulate runoff rates through the slowing and temporary storage of floodwater using an NNBF-type RAF was investigated (Nicholson et al. 2012). An RAF is a soft-engineered landscape intervention that intercepts and attenuates surface hydrological flow pathways for flood management (Quinn et al. 2013). Additional benefits associated with flow interception may include improvement of water quality through sediment deposition (Barber and Quinn 2012) and ecological enhancement (Allot et al. 2015; Burgess-Gamble et al. 2018).

Through forensic observation of the RAF pond, it was possible to determine the impact of one pond on the channel flow. In Figure 4.15, the impact of one pond on the flow can be seen, and it is unsurprisingly small. However, there is a clear alteration to the rising limb of the storm and, hence, on the falling limb, and flow is temporarily stored. 
Figure 4.15. Example of a Runoff Attenuation Feature and Its Impact on Flow
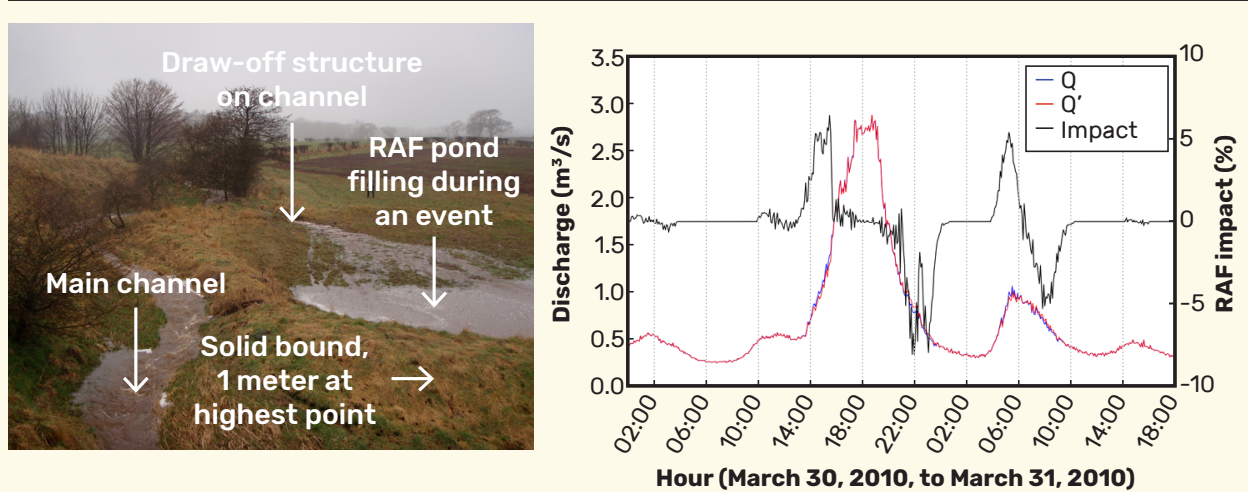

Note: The left panel shows an RAF in action. The right panel shows the observed impact of one pond on flow for a major storm event in March 2010, where Q is upstream flow and Q' is the downstream flow after the storage in the pond is removed.

Abbreviation:

$\mathrm{m}^{3} / \mathrm{s}$ : cubic meters per second

Source: Adapted from Nicholson et al. 2019

In Figure 4.16, the modeled discharge at the downstream of the reach is shown for incremental increases in the number of RAFs from 5 to 35 for March 2010 (5 RAFs provide a combined storage of approximately $2,500 \mathrm{~m}^{3}$ and 35 RAFs provide a combined storage of $17,500 \mathrm{~m}^{3}$ ). Essentially, each feature delays the onset of flow into the downstream through a reduction in the river levels resulting from the pond storage.
Figure 4.16. March 2010 Flood-Level Event and the Impact of Increasing the Pond Network by Five Ponds $\left(2,500 \mathrm{~m}^{3}\right)$

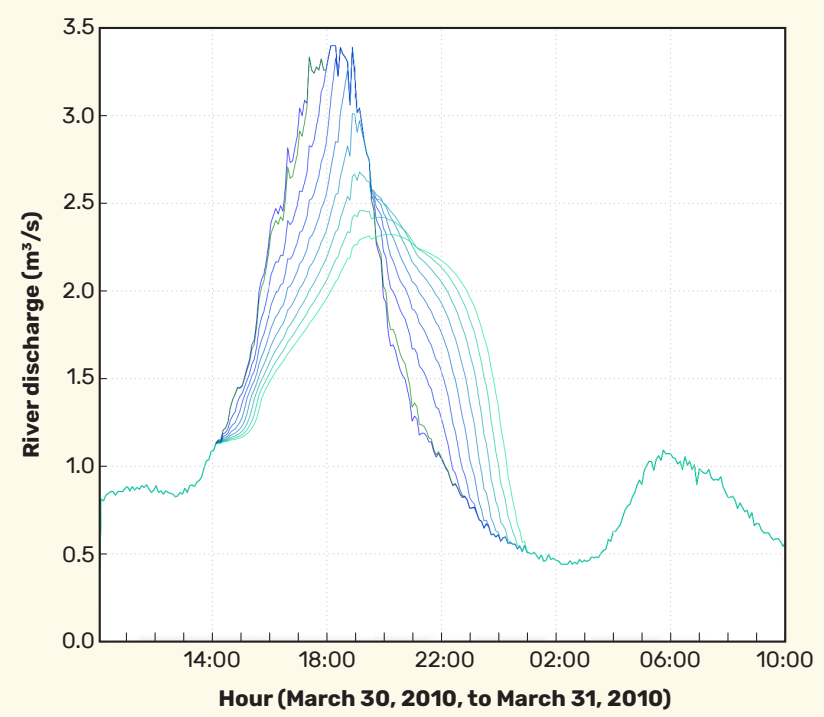


This example shows that the addition of new storage attenuation capacity to a catchment should give benefits downstream. However, to guarantee a significant impact, the addition of more RAFs is encouraged. The approach is not a replacement for traditional flood management methods that use storage as a primary defense strategy. It is an opportunity to augment the storage attenuation capacity to intensively farmed catchments. The measure can be implemented at many locations at relatively low cost and maintenance (Quinn et al. 2013). Given the uncertainty associated with the accuracy of models for flood impact, the case is made that new attenuation capacity (through velocity management or new storage) can give benefits to the catchment system. The metric of a storage attenuation capacity of $\mathrm{m}^{3}$ stored per 1 square kilometer may be a way forward for scaling up the method to larger catchments. The results may be indicative at this stage, but they point toward an approach that adding significant attenuation capacity to a river system is a useful way to mitigate floods as well as provide other benefits to water quality and ecology.

\subsubsection{Decide}

Deciding which approach to take to implement an NNBF solution can be complex given all the information generated and the different approaches that could be taken. How the many facets of project implementation using a systems approach are considered varies from system to system. For hazard mitigation and flood risk reduction projects in the United States, the standard approach for decision-making is a cost-benefit analysis using monetary approaches to quantify both costs and benefits. The concept of economic efficiency has been central in decisions for risk reduction projects. Ecosystem services are seen as one way of incorporating multiple project benefits into risk reduction decisions. For NNBF projects, the foundation in natural system characteristics makes this a potentially useful approach (Figure 4.17). By considering how people value the effects of a project, an ecosystem services approach also implicitly includes societal values in general, if not the opinion of all individual stakeholders. Multicriteria analysis and other approaches have been used to more directly consider stakeholder views (e.g., de Brito and Evers 2017; Hochrainer-Stigler and Lorant 2018). 
Figure 4.17. Simplified Representation of the Relationships between Natural Features and Ecosystem Service Benefits

\begin{tabular}{|c|c|c|c|c|}
\hline $\begin{array}{c}\text { Natural } \\
\text { Features }\end{array}$ & $\begin{array}{l}\text { Ecological } \\
\text { Production } \\
\text { Function }\end{array}$ & $\begin{array}{c}\text { Ecosystem } \\
\text { Goods and } \\
\text { Services }\end{array}$ & $\begin{array}{l}\text { Economic } \\
\text { Benefit } \\
\text { Function }\end{array}$ & $\begin{array}{c}\text { Ecosystem } \\
\text { Service } \\
\text { Benefits }\end{array}$ \\
\hline
\end{tabular}

Source: Adapted from Reed, Martin, and Cushing 2013

The potential multiple benefits of NNBF projects are often still assessed at the local scale of the project. In a system consideration, not all of the project effects may be defined in the same level of detail. This makes the incorporation of the many effects, positive and negative, into a single algorithm, as well as the inclusion of uncertainty of their development over time, more complex. Approaches to dealing with uncertainty in decision-making, such as robust decision-making and adaptation pathways (Kwakkel, Haasnoot, and Walker 2016) allow decision-makers to view multiple outcomes as part of their evaluation of alternatives. Shabman and Scodari (2012) suggest that decision-makers would be more conscious of the multiple implications of their decisions if information is displayed rather than combined, as stated in the following:

\section{To assure transparency and full recognition by decision participants of the different plan effects and the different parties that may realize them, all predicted effects for each plan, even if expressed in commensurate units (e.g., monetary units) should be left disaggregated (i.e., not summed or otherwise combined) for the purpose of plan display and comparison.}

They do, however, recommend that total cost be shown in an aggregated as well as disaggregated manner.

Using a systems approach to assess an array of potential solutions, including NNBF, introduces complexity to decisions. However, it has proved useful in many instances, including the following case study example. 


\section{CASE STUDY:}

\section{Mississippi Coastal Improvements Program - Multiple Lines of Defense (Mississippi, United States)}

The coast of Mississippi was devastated by the storm surges produced by Hurricanes Camille (1969) and Katrina (2005). Coastal Mississippi was inundated by storm surge during Hurricane Katrina, and essentially all coastal structures were destroyed. The Mississippi Coastal Improvements Program (MsCIP) project delivery team considered a combination of NNBF and structural measures as a part of a lines of defense concept that provides increasing levels of protection from the coast to the inland area. Four conceptual lines of defense were developed by a team that included engineers, environmentalists, planners, and geologists examining the landscape as a system, including environmental components and nonstructural solutions. The first line of defense identified was the offshore barrier islands. Ship Island (Figure 4.18) was breached during Hurricane Camille, and the breach was greatly enlarged during Hurricane Katrina, exposing the western coastline of Mississippi to greater waves and surge.

\section{Figure 4.18. Ship Island Restoration in Progress (MsCIP Project in 2018)}

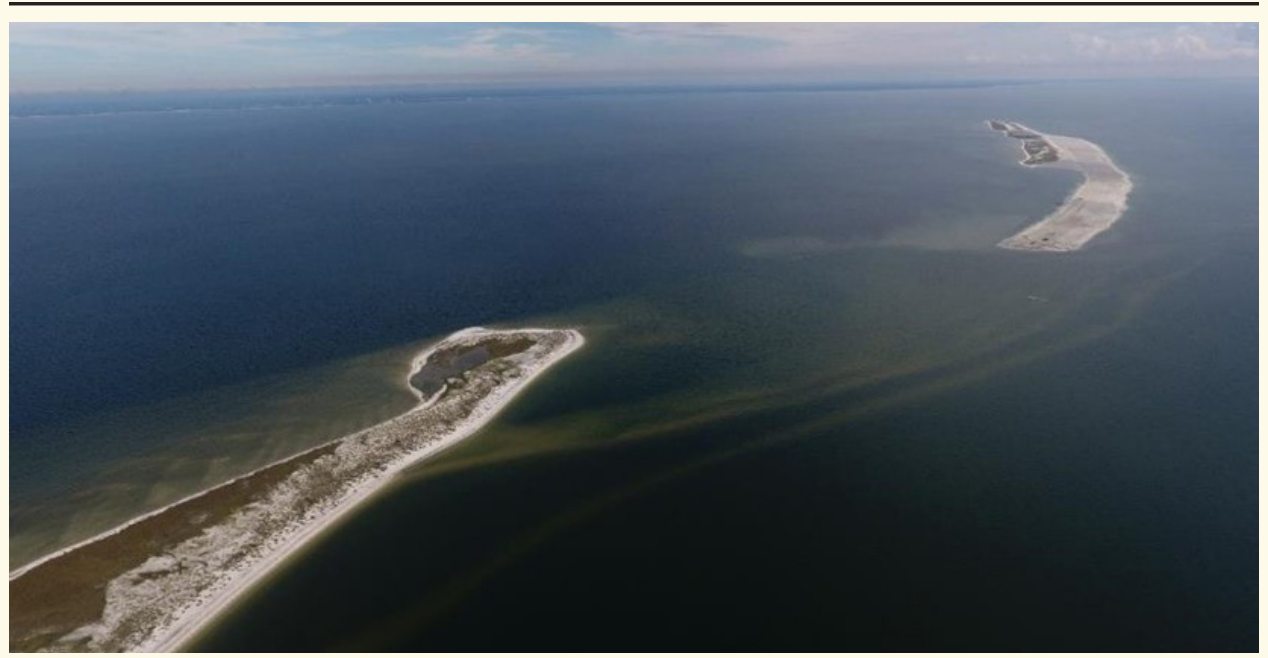

Source: Great Lakes Dredge \& Dock Company, LLC 
The second line of defense was the human-made beaches along the coast, including restoration with higher dunes or dune vegetation. The third line of defense was elevating roadways along the coastline to provide a hardened barrier to surge damage. The beaches, dunes, and elevated roads would be overtopped in large events but would be beneficial for smaller, more frequent storms. Coastal areas without beaches and roadways were considered for standalone projects, such as ring levees with consideration of interior drainage, pumping station, and gates. Surge gates were also considered to block surge from entering the coastal bays as part of the third line of defense. Further inland, a high-ground alignment barrier that followed the railroad line was considered as the fourth line of defense. A number of options along each of the lines of defense were evaluated. Twelve elements of the plan were recommended for construction and included, in general, restoring protective beaches, restoring native habitats, and raising an existing levee, along with nonstructural elements of removing and raising structures (Figure 4.19).

Figure 4.19. Main Elements of the MsCIP Comprehensive Plan

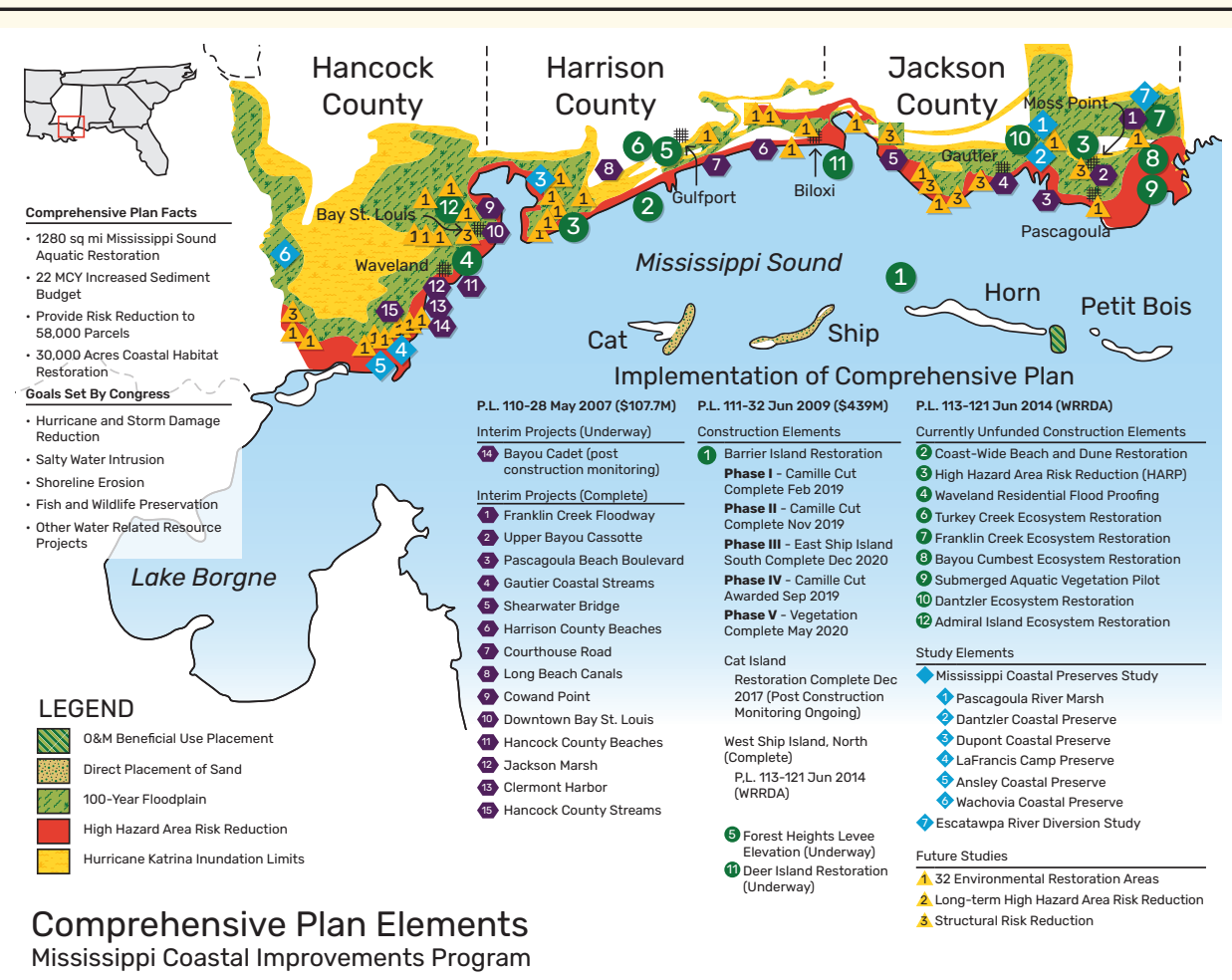

Source: Adapted from sam.usace.army.mil 2021 
The MsCIP Comprehensive Plan outlined systems-based solutions and recommendations that addressed hurricane and storm damage reduction, ecosystem restoration and fish and wildlife preservation, reduction of damaging saltwater intrusion, and reduction of coastal erosion (USACE 2009). Additional future studies will consider further improvements identified in the MsCIP Comprehensive Plan.

\subsubsection{Manage}

Following project implementation, it is important to link on-the-ground outcomes, detected through monitoring, with the original objectives for the system. This is especially important for decisions for FRM and, in particular, NNBF projects because they are made in the face of many uncertainties (e.g., how the ecosystem will respond, damage caused by conditions more extreme than expected).

Adaptive management was first proposed nearly four decades ago to develop more resilient policies for managing ecosystems using techniques that reduce uncertainty (Holling 1978) and that provide a way of moving forward (see Chapter 7). The premise for adaptive management suggests using the best available knowledge to design and implement management plans, while establishing an institutional structure that enables learning from outcomes to adjust and improve decision-making (McLain and Lee 1996).

The adaptive management process involves a series of activities to define the problem and identify current understanding to implement beneficial actions that improve the system, while allowing for continued learning through monitoring and assessment.

In the Netherlands, the Dutch coastal management strategy of hold the line has been developed from a system perspective. This strategy aims to keep the coastline at the same location as 1990, while at the same time creating space for nature where possible. The frame of reference method (van Koningsveld and Mulder 2004) is a means to test and improve objectives that have been defined at the beginning of a project through monitoring several key performance indicators (conscience-eu.net, n.d.) (Figure 4.20). 


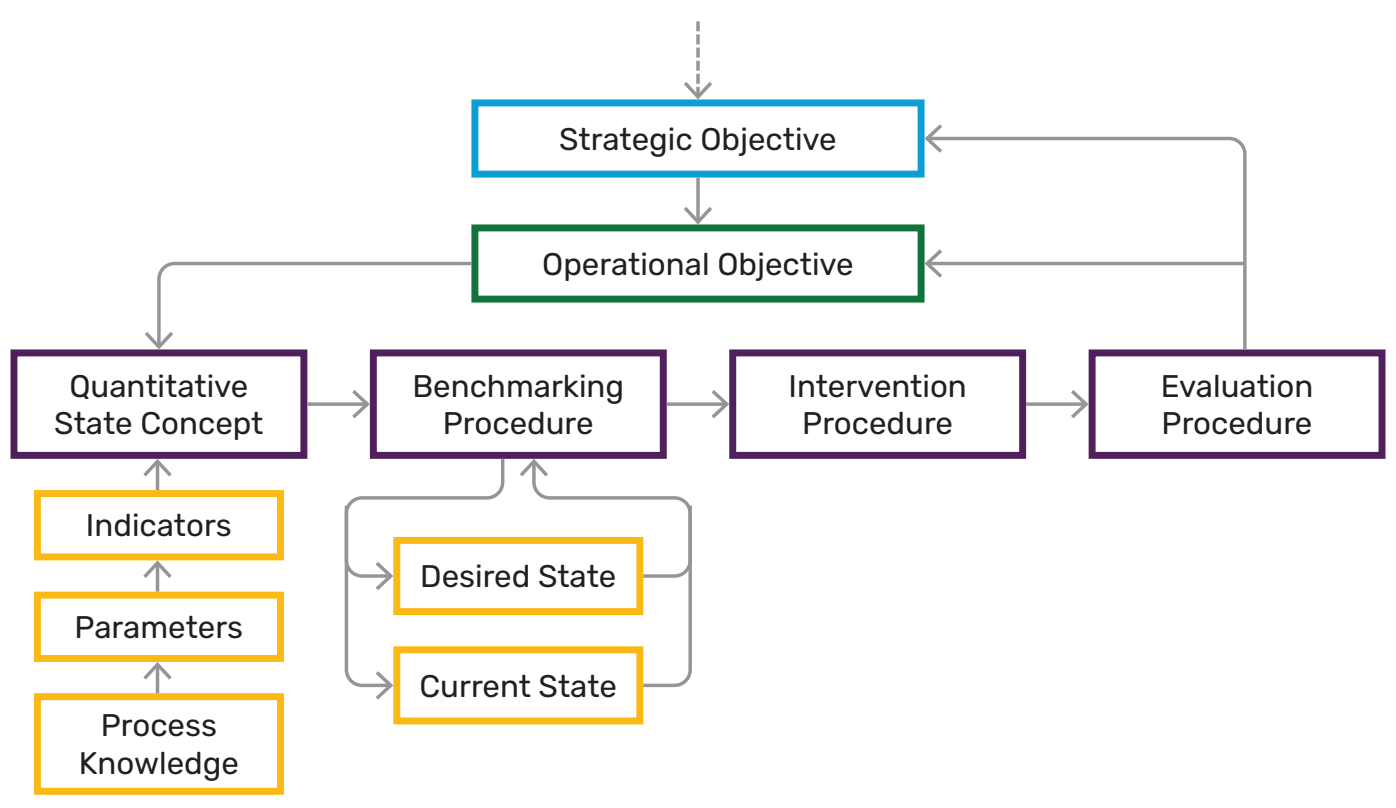

Source: Adapted from van Koningsveld and Mulder 2004

As illustrated in this chapter, effective stakeholder engagement is essential for achieving common understanding, reaching consensus, and reducing conflicts. Stakeholder engagement also provides an opportunity to disseminate information about project progress and for dialogue regarding any adjustments that are needed (see Chapter 3 ). A fundamental aspect of adaptive management is the progressive nature of the process in which assessment of outcomes leads to improved decision-making and adjustment of management actions (Murray and Marmorek 2003).

The key to adaptive management is the understanding that not all outcomes may be anticipated, but opportunities exist for learning even from undesirable results. Adaptive management requires a systems view recognizing that factors external to the project footprint can have effects, either positive or negative, on project-level flood risk outcomes. Understanding why responses are occurring after projects are built and developing effective responses require thinking outside the project box, long-term commitment, and knowledge of the systems context and its dynamics. Closing the loop, in terms of assessing actions and revising actions or policies, using what has been learned is often thought to be most critical in the process, although it has rarely been achieved in restoration (Westgate, Likens, and Lindenmayer 2013). 
The following case study examples illustrate the necessity to involve local stakeholders in the decision-making process (La Poza, Chile) and the advantages that an integrated adaptive management approach based on a long-term vision brings as a resilient solution for flood risk problems (Fort Collins, Colorado, United States).

CASE STUDY:

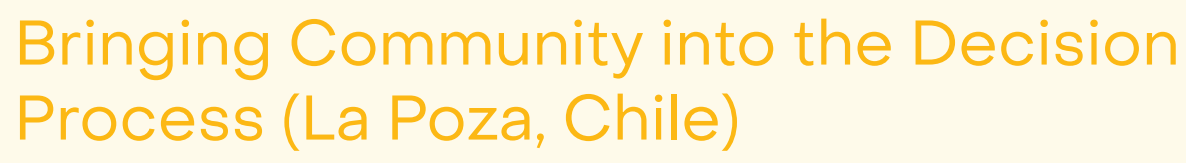

In 2010, an 8.8-magnitude earthquake followed by a tsunami devastated the City of Constitución, Chile, which is located at the mouth of the Maule River. In the aftermath, a rapid reconstruction effort was initiated, and one of the most challenging areas to address was the area called La Poza, which had been home to 100 families (Long 2015). Some wanted to rebuild, some wanted to move if they could sell their land, and some lived there informally with no title to the land.

Initially, two alternatives were developed-a \$30-million U.S. dollars (USD) land buyout with deed restrictions and a large USD\$42-million seawall-which were met with public anger and mistrust. The buyout alternative was considered unrealistic and undesirable. The seawall was seen as cutting the city off from the coast and the river. Through a participatory process, which is a key component of the systems approach, it was determined that citizens were more concerned about frequent flooding due to rainfall, the lack of open public space, and access to the town's river and waterfront. Based on this dialogue, the design team developed a third alternative-creating a forest between new housing and the coast. The forest would attenuate floodwaters-dissipating between $40 \%$ and $70 \%$ of the power of a future tsunami-and provide public recreational space and access to the river. 


\section{CASE STUDY:}

\section{Integrated Flood Risk Management (Fort Collins, Colorado, United States)}

Fort Collins, Colorado, is a rapidly growing small city in the semiarid western United States, with a population of less than 15,000 in 1950 and more than 160,000 in 2015. As is the case with growing urban areas elsewhere, floodplain real estate is a valuable commodity in Fort Collins and a potential risk. On July 28,1997 , the city experienced an extreme rainfall event (a greater than 500-year return interval in locations), which resulted in five deaths, 62 injuries, and more than USD\$250 million in property damage (Weaver, Gruntfest, and Levy 2000).

This tragic event led the city to invest heavily in comprehensive floodplain management and to adaptively manage flood losses over the course of the subsequent 20 years. Multiple flood modeling studies were undertaken by numerous entities to better understand and quantify flood risk (FEMA 2013). Fort Collins invested in a multipronged, integrated FRM system involving strong floodplain regulation and building requirements, integrated open space, acquisition of at-risk structures, capital projects, public education, and flood warning systems (Weaver, Gruntfest, and Levy 2000; Hilmes-Robinson and Lochra 2014). The open-space program and associated nature-based floodway was a prominent component of the program, with more than $66 \%$ of the 100-year floodplain preserved as open space (Hilmes-Robinson and Lochra 2014). Some of the community's most popular parks are part of this open-space network. The system has operated better than anticipated in numerous storms (Hilmes-Robinson and Lochra 2014). The Federal Emergency Management Agency (FEMA) has acknowledged this proactive approach to floodplain management, designating Fort Collins one of seven communities nationwide (out of 1,444 eligible) to receive one of the two top ratings in its community rating system (FEMA 2017).

The long-term investment in progressively stringent, integrated floodplain management has been a success and source of pride for local elected officials. However, the adaptive learning from this project had a broader systemic effect on understanding extreme rainfall. The 1997 events led researchers and meteorologists to partner with citizen scientists to measure local rainfall. The nonprofit Community Collaborative Rain, Hail and Snow Network (cocorahs.org 2020) has since been expanded to include thousands of gauges run by citizen scientists throughout the United States. 


\section{4 || Summary}

Systems thinking is essential in developing a sustainable, long-term approach for FRM in any setting. It requires consideration of the interactions and feedback mechanisms that influence flood risk and how different interventions might shape short-term and long-term outcomes. Furthermore, systems thinking identifies opportunities to create value over and above that which might have been provided if a narrow, problem-solving approach were adopted. Different FRM approaches can be implemented within a system, provided their relations and feedback are taken into account. The Dutch coast may be one of the best-known examples of how individual projects are seen in a systems context for overall FRM, but the lessons and approaches described here can be of broad application. A long-term vision and the setting of strategic objectives provide a direction to evaluate whether different measures applied throughout the system align or oppose each other, and how they work together to provide the expected benefits.

Systems thinking requires the realization that ideas can develop over time with progressing insights. This is especially important in the implementation of NNBF solutions, which are rarely static but rather are dynamic, continuously evolving. Long-term thinking also supports the implementation of NNBF solutions as their benefits evolve and change over time, often increasing (see Chapter 10). The coastal Louisiana example considers how taking an action provides effects over large spatial scales, as well as how they develop and change over time. Using a system-inclusive framework as context for project planning can provide guidance on how NNBF options fit best in the system and whether they can best be implemented on a large (think big) or small (start small) scale, or a combination of both.

In addition to the initial boundary conditions, the temporal and spatial scales are two important features of systems thinking. The scale of the coastal system or watershed determines which local stakeholders should be involved; the inclusion of multiple stakeholders throughout the design process can create additional support for the implementation of new measures and guide the analyses applied to develop an NNBF solution. This chapter provides several examples of where stakeholder engagement was critical to project success, including Demak in Northern Java, Indonesia, where stakeholders had direct engagement with project construction, and the Missouri River, where a concerted, organized effort to engage widely diverse stakeholders has been foundational in moving toward agreement on actions to be taken. Although thinking at too small a scale might lead to missing essential system parameters and missed added-value opportunities, a very broad scale might lead to a loss of focus. The regional sediment management approach is a good example of where regional sediment budgets are used to set the scale of consideration. In other cases, the scale may be set by social or economic considerations, as well as the physical system. The broad perspective that systems thinking introduces leads to consideration of a wide array of flood 
risk circumstances and may allow NNBF approaches to be effectively used to address more frequent, lower-level flooding issues where they could be more effective than with large storm events.

Decision-making in a systems context, no matter the spatial or economic scale of the project, is not easy because, by definition, it introduces an array of project implications, either positive or negative, which in a narrower, project-specific view may not be recognized. This can make analyses more complex, and for some long-term flood risk problems, it will require additional research or data collection (e.g., northwest Europe salt marshes, as described in Section 4.3.2). However, the efficiencies in project implementation that can result from such understanding justify the effort. The systems approach also creates more support and commitment with the local stakeholders and aims to provide more resilient and flexible solutions in the long term. These benefits can be realized if the systems approach is used in planning, even if there are insufficient resources to immediately implement all the components. Just focusing on the projects for which funds are available can lead to unintended consequences as later projects come online, or limit the synergy among projects, which is one of the most important benefits of the systems approach.

Taking a systems approach has been found to be the key to making real progress in several systems. Sometimes this is driven by catastrophic events, as in Fort Collins (see Section 4.3.4) or Jamaica Bay (see Section 4.3.1.1). Events often spur action. However, although disasters can reveal the scope of the issues, the complexity introduced by the systems perspective can lead to roadblocks as funds are not available to address the multiple complex issues, or the scale of the problem becomes clearer and organizations are not equipped to cope. In the Missouri River, the matching of a governance approach to the system at the scale of the problem through MRRIC (see Section 4.3.1.1), which is not constrained by existing political and jurisdictional boundaries, seems to have provided an opportunity to move forward.

In other areas, foresight and anticipation of problems can stimulate a different kind of thinking and provide opportunities. A revenue-generating measure passed by nine California counties in 2016 established a 20-year, USD\$12 parcel tax to raise approximately USD\$25 million annually, or USD\$500 million over 20 years, to fund restoration projects in San Francisco Bay. The money will be used for projects that have the greatest long-term, positive impact on the bay. Similarly, in the low-lying Netherlands, concerns about future sea-level rise have resulted in the establishment of the national Deltaprogramma, where yearly $€ 1.3$ billion euros (USD\$1.5 billion) is available for flood risk reduction measures until 2032, providing long-term flood protection, including the implementation of NNBF solutions.

These programs exemplify ways that NNBF can be implemented on a large scale. However, it should not be forgotten that smaller scale implementation can also provide a variety of benefits, as long as a comprehensive system understanding is used as the starting point for problem solving. 


\section{5 | Gaps and Future Directions}

Different aspects of a systems approach have been used in NNBF and other FRM projects around the world. However, there are few examples that have considered all aspects of the systems approach described here, including the dynamic physical, ecological, and relevant cultural aspects and processes within a system, and feedback among them. This means there are few comprehensive case studies on which new applications can build. The lessons learned that are available from the existing use of the systems approach may be difficult to translate to other settings. Further, because the use of NNBF in FRM is relatively new, there are few mature examples of its application using a systems approach. This is particularly the case for the role of systems thinking in the long-term development and adaptive management of NNBF under changing (climate) conditions, which is relatively uncharted territory. Further expanding the evidence base will help the mainstreaming of systems thinking and NNBF, resulting in more optimized, sustainable solutions focused on long-term benefits.

The relatively small evidence base compared to traditional flood risk mitigation projects contributes to a gap in the experience of those planning, designing, and managing NNBF projects, and limits the application of the systems approach. As shown in this chapter, setting the context is an important step in systems thinking and is especially important as a way to find common ground between different stakeholders. However, the best approach to find common ground is always location-specific and requires local experience. Acting on multiple spatial and temporal scales can further complicate the contextualization of a flood risk problem. Consideration of relevant processes and feedback mechanism operating on different scales introduces additional knowledge gaps and uncertainties. These should be considered in the planning and design of NNBF but may also require further investigation and monitoring once an NNBF project has been built. Filling these knowledge gaps and sharing the lessons learned will be beneficial for future NNBF projects.

The assessment of the suitability of NNBF through a systems approach is characterized by the inclusion of multidisciplinary knowledge of physical and ecological processes. The potential to include the wide-ranging benefits of NNBF can lead to more expansive consideration of how the project influences the system than might occur in traditional FRM. Such a comprehensive view requires consideration of these co-benefits in the evaluation of alternatives (and the willingness to pay for them), and additional effort will be required to develop best practices that enable the co-benefits of NNBF to be considered by decision-makers.

As more information is developed on the long-term evolution and performance of NNBF projects, future management to ensure continued effectiveness will benefit from the systems approach. Future development and land-use modifications, as well as changes in flood risk, will alter the systems' context for any project, and as gaps in knowledge are filled, new ones will arise. Using a systems approach from the start will enable stakeholders, planners, and managers to work together on common goals and be better prepared for what the long term brings. 


\section{6 || References}

Allison, M. A., and E. A. Meselhe. 2010. “The Use of Large Water and Sediment Diversions in the Lower Mississippi River (Louisiana) for Coastal Restoration." Journal of Hydrology 387 (3): 346-360.

Allot, T., E. Shuttleworth, M. Evans, C. Agnew, M. Pilkington, T. Spencer, D. Milledge, et al. 2015. "Annex 5: Flood Risk." In Restoration of Blanket Bogs: Flood Risk Reduction and Other Ecosystem Benefits. Edited by M.G. Pilkington, et al. Derbyshire: Moors for the Future Partnership. https://www.moorsforthefuture.org.uk/__ data/assets/pdf file/0014/91211/Annex-5.Flood-Risk_0.pdf.

APFM (Associated Programme on Flood Management). 2009. Integrated Flood Management: Concept Paper. WMO-No. 1047. Geneva: World Meteorological Organization.

Arnell, N. W., and S. N. Gosling. 2016. “The Impacts of Climate Change on River Flood Risk at the Global Scale." Climatic Change 134 (3): 387-401.

Bailey, K. D. 1994. Sociology and the New Systems Theory: Toward a Theoretical Synthesis. Albany, NY: SUNY Press.

Balke, T., T. J. Bouma, E. M. Horstman, E. L. Webb, P. L. Erftemeijer, and P. M. Herman. 2011. “Windows of Opportunity: Thresholds to Mangrove Seedling Establishment on Tidal Flats." Marine Ecology Progress Series 440: 1-9.

Barber, N. J., and P. F. Quinn. 2012. "Mitigating Diffuse Water Pollution from Agriculture Using Soft-Engineered Runoff Attenuation Features." Area 44 (4): 454-462.

Bendoni, M., R. Mel, L. Solari, S. Lanzoni, S. Francalanci, and H. Oumeraci. 2016. "Insights into Lateral Marsh Retreat Mechanism through Localized Field Measurements." Water Resources Research 52 (2): 1446-1464. doi:10.1002/2015WR017966.

Bouma, T. J., J. van Belzen, T. Balke, J. van Dalen, P. Klaassen, A. M. Hartog, D. P. Callaghan, et al. 2016. "Short-Term Mudflat Dynamics Drive Long-Term Cyclic Salt Marsh Dynamics." Limnology and Oceanography 61 (6): 2261-2275.

Bridges, T. S., J. Lillycrop, J. R. Wilson, T. J. Fredette, B. Suedel, C. J. Banks, and E. J. Russo. 2014. "'Engineering with Nature' Promotes Triple-Win Outcomes." Terra et Agua 135: 17-23.

Burgess-Gamble, L., R. Ngai, M. Wilkinson, T. Nisbet, N. Pontee, R. Harvey, K. Kipling, et al. 2018. Working with Natural Processes - Evidence Directory. SC150005. Bristol: Environment Agency.

Burton, I., R. W. Kates, and G. F. White. 1978. The Environment as Hazard. New York: Oxford University Press.

Chorley, R. J., and B. A. Kennedy. 1971. Physical Geography: A Systems Approach. Upper Saddle River, NJ: Prentice Hall. 
cocorahs.org. 2020. Community Collaborative Rain, Hail and Snow Network. https://www. cocorahs.org/.

conscience-eu.net, n.d. Holland Coast (Between Den Helder and Cadzand) (NL). Conscience: Concepts and Science for Coastal Erosion Management. http://www.conscience-eu. net/dutch_coast/.

Costanza R., F. Andrade, P. Antunes, M. van den Belt, D. Boersma, D. F. Boesch, F. Catarino, et al. 1998. "Principles for Sustainable Governance of the Oceans." Science 281 (5374): 198-199.

Couvillion, B. R., H. Beck, D. Schoolmaster, and M. Fischer. 2017. Land Area Change in Coastal Louisiana (1932 to 2016). Scientific Investigations Map 3381, 16 p. pamphlet. Lafayette, Louisiana: U.S. Geological Survey. https://doi.org/10.3133/sim3381.

de Brito, M. M., and M. Evers. 2016. "Multi-Criteria Decision-Making for Flood Risk Management: A Survey of the Current State of the Art." Natural Hazards and Earth System Sciences 16 (4): 1019-1033.

de Mutsert, K., K. Lewis, S. Milroy, J. Buszowski, and J. Steenbeek. 2017. “Using Ecosystem Modeling to Evaluate Trade-Offs in Coastal Management: Effects of Large-Scale River Diversions on Fish and Fisheries." Ecological Modelling 360: 14-26.

dynamischkustbeheer.nl. 2021. Voorbeelden. Dynamisch Kustbeheer. http://www. dynamischkustbeheer.nl/content/kaart.asp?menu=10060000_000000.

ecoshape.org. 2021. Concepts. EcoShape. https://www.ecoshape.org/en/concepts/.

Eijk, P., and R. Kumar. 2009. Bio-Rights in Theory and Practice: A Financing Mechanism for Linking Poverty Alleviation and Environmental Conservation. Wageningen, NL: Wetlands International.

Elias, E., and P. K. Tonnon. 2016. Beschrijving Kennisbasis Modellering van Zeegaten t.v.b. Kustgenese2. 1230381-000. Delft, NL: Deltares.

Elkington, J. 1997. Cannibals with Forks: The Triple Bottom Line of 21st Century Business. Oxford: Capstone Publishing Ltd.

FEMA (Federal Emergency Management Agency). 2013. Flood Insurance Study: Larimer County, Colorado and Incorporated Areas. Volume 1 of 4 . Flood Insurance Study No. 08069CV001D.

FEMA. 2017. Coordinator's Manual. National Flood Insurance Program Community Rating System. FIA-15/2017. Washington, DC: Federal Emergency Management Agency.

French, J., A. Payo, B. Murray, J. Orford, M. Eliot, and P. Cowell. 2016. "Appropriate Complexity for the Prediction of Coastal and Estuarine Geomorphic Behaviour at Decadal to Centennial Scales." Geomorphology 256: 3-16. 
Gallop, S. L., M. Collins, C. B. Pattiaratchi, M. J. Eliot, C. Bosserelle, M. Ghisalberti, M. Ghisalberti, et al. 2015. "Challenges in Transferring Knowledge between Scales in Coastal Sediment Dynamics." Frontiers in Marine Science 2: 82.

Gibson, R. B. 2006. “Beyond the Pillars: Sustainability Assessment as a Framework for Effective Integration of Social, Economic, and Ecological Considerations in Significant Decision Making." Journal of Environmental Assessment Policy and Management 8 (3): 259-280.

Gillis, L. G., T. J. Bouma, C. G. Jones, M. M. Van Katwijk, I. Nagelkerken, C. J. L. Jeuken, P. M. J. Herman, and A. D. Ziegler. 2014. "Potential for Landscape-Scale Positive Interactions among Tropical Marine Ecosystems." Marine Ecology Progress Series 503: 289-303.

Handel, S. N., J. Marra, C. M. K. Kaunzinger, V. M. Bricelji, J. Burger, R. L. Burke, M. Camhi, et al. 2016. "Ecology of Jamaica Bay: History, Status, and Resilience." In Prospects for Resilience: Insights from New York City's Jamaica Bay. Edited by E. W. Sanderson, W. D. Solecki, J. R. Waldman, and A. S. Parris, 91-116. Washington, DC: Island Press.

Hicks, C. C., A. Levine, A. Agrawal, X. Basurto, S. J. Breslow, C. Carothers, S. Charnley, et al. 2016. “Engage Key Social Concepts for Sustainability." Science 352 (6281): 38-40.

Hilmes-Robinson, M., and C. Lochra. 2014. "Fort Collins Floodplain Management Program: Success Stories from the September 2013 Flood." Colorado Water: Newsletter of the Water Center of Colorado State University 31 (2): 14-19.

Hochrainer-Stigler, S., and A. Lorant. 2018. "Evaluating Partnerships to Enhance Disaster Risk Management Using Multi-Criteria Analysis: An Application at the Pan-European Level." Environmental Management 61 (1): 24-33.

Holling, C. S., ed. 1978. Adaptive Environmental Assessment and Management. Chichester, UK: John Wiley and Sons.

Jenkins, G. M. 1969. “The Systems Approach.” Journal of Systems Engineering, 1 (1): 3-49.

Karstens, S. A., P. W. Bots, and J. H. Slinger. 2007. "Spatial Boundary Choice and the Views of Different Actors." Environmental Impact Assessment Review 27 (5): 386-407.

Kates, R. W., W. C. Clark, R. Corell, J. M. Hall, C. C. Jaeger, I. Lowe, J. J. McCarthy, et al. 2001. “Sustainability Science." Science 292 (5517): 641-642.

Kwakkel, J. H., M. Haasnoot, and W. E. Walker. 2016. “Comparing Robust Decision-Making and Dynamic Adaptive Policy Pathways for Model-Based Decision Support under Deep Uncertainty." Environmental Modelling \& Software 86: 168-183.

Lake, P. S. 2000. "Disturbance, Patchiness, and Diversity in Streams." Journal of the North American Benthological Society 19 (4): 573-592.

Larson, M., and N. C. Kraus. 1995. "Prediction of Cross-Shore Sediment Transport at Different Spatial and Temporal Scales." Marine Geology 126 (1-4): 111-127. 
Lillycrop, L. S., J. W. McCormick, L. E. Parson, and M. A. Chasten. 2011. "Adaptive Management through Regional Sediment Management." Paper presented at the Proceedings of the Western Dredging Association (WEDA XXXI) Technical Conference and Texas A\&M University (TAMU 42) Dredging Seminar, Nashville, TN, June 2011.

Linkov, I., T. Bridges, F. Creutzig, J. Decker, C. Fox-Lent, W. Kröger, J. H. Lambert, et al. 2014. "Changing the Resilience Paradigm." Nature Climate Change 4 (6): 407-409.

Long, G. 2015. "The Rebuilding of Chile's Constitución: How a 'Dead City' Was Brought Back to Life." The Guardian. Cities. February 23, 2015. https://www.theguardian.com/ cities/2015/feb/23/rebuilding-chile-constitucion-earthquake-tsunami.

McLain, R. J., and R. G. Lee. 1996. "Adaptive Management: Promises and Pitfalls." Environmental Management 20: 437-448.

Meadows, D. H. 2008. Thinking in Systems: A Primer. White River Junction, VT: Chelsea Green Publishing.

Ministry of Infrastructure and Environment and Ministry of Economic Affairs. 2014. “Deltaprogramma 2015." Werk aan de delta, de beslissingen om Nederland veilig en leefbaar te houden, the Hague, the Netherlands. https://www.deltacommissaris.nl/ documenten/publicaties/2014/09/16/deltaprogramma-2015.

Murray, C., and D. Marmorek. 2003. "Adaptive Management and Ecological Restoration." In Ecological Restoration of Southwestern Ponderosa Pine Forests. Washington, DC: Island Press.

National Research Council. 2000. Ecological Indicators for the Nation. Washington, DC: National Academies Press.

National Research Council. 2013. Sustainability for the Nation: Resource Connections and Governance Linkages. Washington, DC: National Academies Press.

Nicholson, A. R., G. M. O'Donnell, M. E. Wilkinson, and P. F. Quinn. 2019. "The Potential of Runoff Attenuation Features as Natural Flood Management Approach." Journal of Flood Risk Management 13 (S1): 1-14.

Nicholson, A. R., M. E. Wilkinson, G. M. O'Donnell, and P. F. Quinn. 2012. “Runoff Attenuation Features: A Sustainable Flood Mitigation Strategy in the Belford catchment, UK." Area 44 (4): 463-469.

Odum, E. P. 1998. Ecological Vignettes: Ecological Approaches to Dealing with Human Predicaments. Amsterdam: Harwood Academic Publishers.

Ostrom, E. 2009. "A General Framework for Analyzing Sustainability of Social-Ecological Systems." Science 325 (5939): 419-422.

Parson, L. E., and S. I. Rees. 2005. Northern Gulf of Mexico (NGOM) Regional Sediment Management Demonstration Program Initiatives. ERDC/CHL CHETN-XIV-17. Vicksburg, MS: U.S. Army Engineer Research and Development Center. 
Parson, L., S. M. Khalil, and J. P. Waters. 2012. "An Introduction to the Technical Framework for the Gulf Regional Sediment Management Master Plan." Journal of Coastal Research 60 (sp1): 1-5.

Patel, D. M., V. M. Patel, A. P. Singh, and B. Katariya. 2015. "Resilience of Tsunami in Coastal Regions of Kachchh by Use of Mangrove Belt and Numerical Modelling." International Journal of Earth and Atmospheric Science 2 (4): 149-159.

Peteet, D. M., J. Nichols, T. Kenna, C. Chang, J. Browne, M. Reza, S. Kovari, L. Liberman, and S. Stern-Protz. 2018. “Sediment Starvation Destroys New York City Marshes' Resistance to Sea Level Rise." Proceedings of the National Academy of Sciences 115 (41): 1028110286. https://doi.org/10.1073/pnas.1715392115.

Peyronnin, N. S., R. H. Caffey, J. H. Cowan, D. Justic, A. S. Kolker, S. B. Laska, A. McCorquodale, et al. 2017. “Optimizing Sediment Diversion Operations: Working Group Recommendations for Integrating Complex Ecological and Social Landscape Interactions." Water 9 (6): 368.

Poff, N. L., C. M. Brown, T. E. Grantham, J. H. Matthews, M. A. Palmer, C. M. Spence, R. L. Wilby, et al. 2015. "Sustainable Water Management under Future Uncertainty with Eco-Engineering Decision Scaling." Nature Climate Change 6: 25-34. doi:10.1038/ NCLIMATE2765.

Quinn, P., G. O'Donnell, A. Nicholson, M. Wilkinson, G. Owen, J. Jonczyk, N. Barber, M. Hardwick, and G. Davies. 2013. Potential Use of Runoff Attenuation Features in Small Rural Catchments for Flood Mitigation. Newcastle: School of Civil Engineering and Geosciences, Newcastle University. https://research.ncl.ac.uk/proactive/belford/ newcastlenfmrafreport/.

Reed, D., L. Martin, and J. A. Cushing. 2013. Using Information on Ecosystem Goods and Services in Corps Planning: An Examination of Authorities, Policies, Guidance, and Practices. Fort Belvoir, VA: U.S. Army Corps of Engineers, Institute of Water Resources.

Robertson, M. 2014. Sustainability Principles and Practices. New York: Routledge, Taylor \& Francis Group.

Rosati, J. D., and N. C. Kraus. 1999. Sediment Budget Analysis System (SBAS). Coastal and Hydraulics Engineering Technical Note CHETN-IV-20. Vicksburg, MS: U.S. Army Engineer Research and Development Center.

Rosati, J. D., K. F. Touzinsky, and W. J. Lillycrop. 2015. "Quantifying Coastal System Resilience for the U.S. Army Corps of Engineers." Environmental Systems and Decisions 35: 196-208.

sam.usace.army.mil. 2021. Mississippi Coastal Improvements Program. U.S. Army Corps of Engineers Mobile District Website. https://www.sam.usace.army.mil/Missions/ Program-and-Project-Management/Civil-Projects/MsCIP/. 
Shabman, L., and P. Scodari. 2012. Towards Integrated Water Resources Management: A Conceptual Framework for U.S. Army Corps of Engineers Water and Related Land Resources Implementation Studies. 2012-VSP-01. Alexandria, VA: U.S. Army Corps of Engineers, Institute for Water Resources.

Slinger, J., H. Vreugdenhil, L. Hermans, S. Cunningham, A. Bruens, J. Mulder, and M. Menke. 2013. “Drawing Lines in the Sand: The Evolution of Dutch Coastal Policy." Poster presented at the Planet Under Pressure Conference, London, March 2013. http:// resolver.tudelft.nl/uuid:853c9166-a369-4174-b0e0-d8084f6797b8.

Swanson, R. L., and R. E. Wilson. 2008. “Increased Tidal Ranges Coinciding with Jamaica Bay Development Contribute to Marsh Flooding." Journal of Coastal Research 24 (6): $1565-1569$.

Touzinsky, K., A. C. Baker, H. M. Morgan, and S. K. McKay. Forthcoming. Sustainability and Resilience: Complementary Concepts for Managing Systems. ERDC TR-EMRRP-\#\#. Vicksburg, MS: U.S. Army Engineer Research and Development Center.

USACE (U.S. Army Corps of Engineers). 2009. Comprehensive Plan and Integrated Environmental Impact Statement, Mississippi Coastal Improvements Program (MSCiP) Hancock, Harrison and Jackson Counties, Mississippi. Washington, DC: U.S. Army Corps of Engineers.

USACE. 2021. Missouri River Basin Gage Application. Accessed April 1, 2021. https://www.nwdmr.usace.army.mil/rccl.

usace.army.mil. 2002. Environmental Operating Principles. U.S. Army Corps of Engineers Headquarters. http://www.usace.army.mil/Missions/Environmental/EnvironmentalOperating-Principles/.

USFWS (U.S. Fish and Wildlife Service). 2018. Final Biological Opinion for the Operation of the Missouri River Mainstem Reservoir System, the Operation and Maintenance of the Bank Stabilization and Navigation Project, the Operation of Kansas River Reservoir System, and the Implementation of the Missouri River Recovery Management Plan. TAILS No. 06E00000-2018-F-0001. Mountain Prairie Region. Denver, CO: U.S. Fish and Wildlife Service.

van Eekelen, E. M., M. L. Sittoni, F. van der Goot, H. E. Nieboer, M. J. Baptist, J. Boer, and F. H. Tonneijck. 2017. "The Living Lab for Mud: Integrated Sediment Management Based on Building with Nature Concepts." Paper presented at Central Dredging Association (CEDA) Dredging Days, Rotterdam, NL, November 2017. https://www.ecoshape.org/ uploads/sites/2/2017/11/Ceda-2017-paper-Van-Eekelen-Sittoni-et-al-THE-LIVINGLAB-FOR-MUD-INTEGRATED-SEDIMENT-MANAGEMENT-BASED-ON-BUILDING-WITHNATURE-CONCEPTS.pdf.

van Eekelen, E., and M. Bouw. 2020, Building with Nature: Creating, Implementing and Upscaling Nature-Based Solutions. Rotterdam, NL: nai010 publishers.

van Koningsveld, M., and J. P. M. Mulder. 2004. "Sustainable Coastal Policy Developments in the Netherlands. A Systematic Approach Revealed." Journal of Coastal Research 20: 375-385. 
Von Bertalanffy, L. 1972. "The History and Status of General Systems Theory." Academy of Management Journal 15 (4): 407-426.

Vreugdenhil, H., J. Slinger, W. Thissen, and P. K. Rault. 2010a. “Pilot Projects in Water Management." Ecology and Society 15 (3): 13.

Vreugdenhil, H., J. Slinger, E. Kater, and W. Thissen. 2010b. “The Influence of Scale Preferences on the Design of a Water Innovation: A Case in Dutch River Management." Environmental Management 46: 29-43. doi:10.1007/s00267-010-9524-0.

Vuik, V., S. N. Jonkman, B. W. Borsje, and T. Suzuki. 2016. "Nature-Based Flood Protection: The Efficiency of Vegetated Foreshores for Reducing Wave Loads on Coastal Dikes." Coastal Engineering 116: 42-56.

Vuik, V., W. van Balen, and S. van Vuren. 2017. “Fully Probabilistic Assessment of Safety Against Flooding along the Dutch Coast." Journal of Flood Risk Management 10 (3): 349-360.

Walker, B., and D. Salt. 2006. Resilience Thinking: Sustaining Ecosystems and People in a Changing World. Washington, DC: Island Press.

Wang, H., D. van der Wal, X. Li, J. van Belzen, P. M. J. Herman, Z. Hu, Z. Ge, L. Zhang, and T. J. Bouma. 2017. "Zooming In and Out: Scale Dependence of Extrinsic and Intrinsic Factors Affecting Salt Marsh Erosion." Journal of Geophysical Research: Earth Surface 122 (7): 1455-1470. doi:10.1002/2016JF004193.

Watt, K. E., ed. 2013. Systems Analysis in Ecology. New York: Elsevier.

WCED (World Commission on Environment and Development). 1987. Our Common Future. Oxford: Oxford University Press.

Weaver, J. F., E. Gruntfest, and G. M. Levy. 2000. "Two Floods in Fort Collins, Colorado: Learning from a Natural Disaster." Bulletin of the American Meteorological Society 81 (10): 2359-2366.

Westgate, M. J., G. E. Likens, and D. B. Lindenmayer. 2013. “Adaptive Management of Biological Systems: A Review." Biological Conservation 158: 128-139.

White House, The. 2014. Climate-Resilient International Development. EO 13677. Federal Register 79 (187): 58229-58236. https://www.federalregister.gov/ documents/2014/09/26/2014-23228/climate-resilient-international-development.

World Bank. 2017. Implementing Nature-Based Flood Protection: Principles and Implementation Guidance. Washington, DC: World Bank.

Wu, J. 2013. "Landscape Sustainability Science: Ecosystem Services and Human Well-Being in Changing Landscapes." Landscape Ecology 28: 999-1023.

WWF (World Wildlife Fund). 2016. Natural and Nature-Based Flood Management: A Green Guide. Washington, DC: World Wildlife Fund. https://www.worldwildlife.org/publications/ natural-and-nature-based-flood-management-a-green-guide. 


\section{Acknowledgments}

\section{Lead Authors}

Jurre de Vries, Rijkswaterstaat, the Netherlands

Denise Reed, University of New Orleans, United States

\section{Co-Authors}

S. Kyle McKay, U.S. Army Corps of Engineers, United States

Tjeerd Bouma, Royal Netherlands Institute for Sea Research; Utrecht University; HZ University of Applied Sciences, the Netherlands

Shannon E. Cunniff, Environmental Defense Fund, United States

Bart Grasmeijer, Deltares, the Netherlands

Pamela Mason, College of William \& Mary, United States

Alex Nicholson, Arup, United Kingdom

Paul Quinn, Newcastle University, United Kingdom

Jane McKee Smith, U.S. Army Corps of Engineers, United States 


\section{Endnote}

' This material is taken largely from Nicholson et al. (2019). 

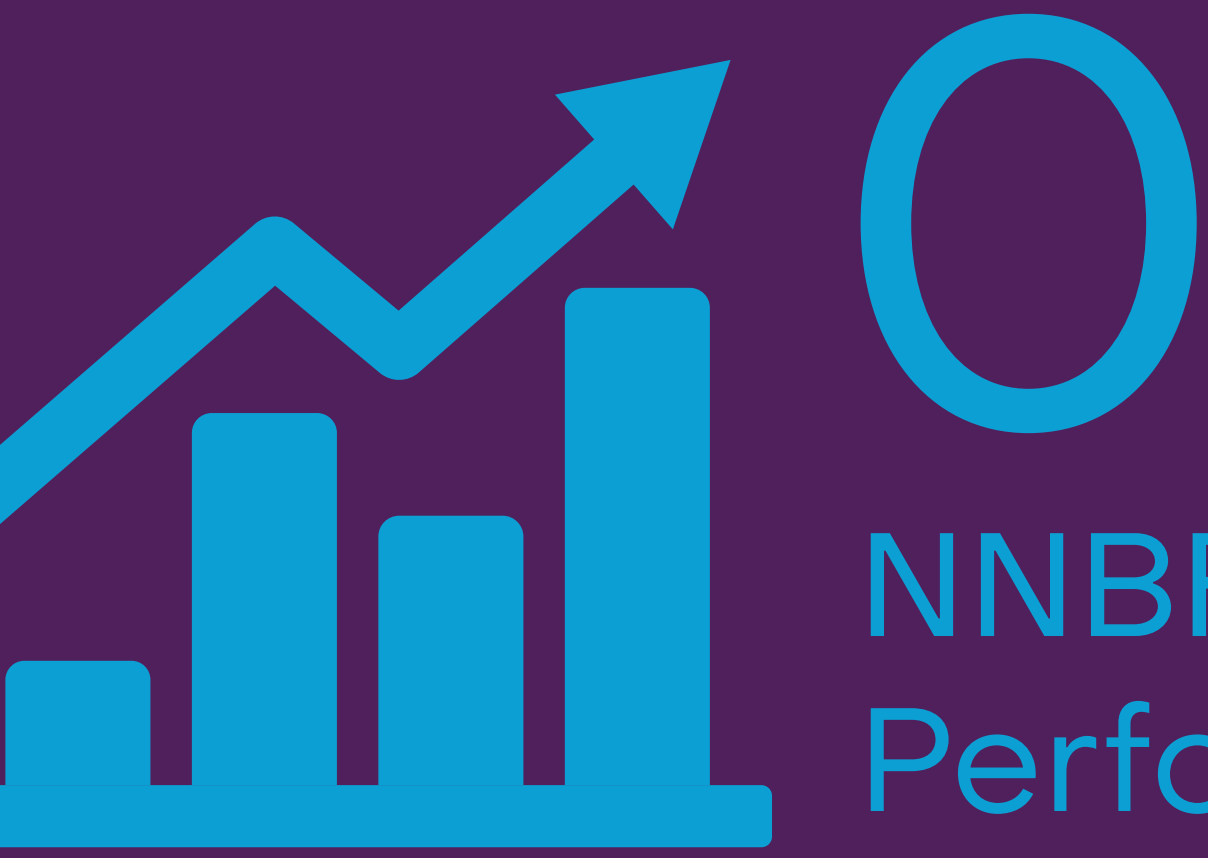

NNBF

Performance

\section{Suggested Citation:}

Piercy, C. D., J. D. Simm, T. S. Bridges, M. Hettiarachchi, and Q. Lodder. 2021. “Chapter 5: NNBF Performance." In International Guidelines on Natural and Nature-Based Features for Flood Risk Management. Edited by T. S. Bridges, J. K. King, J. D. Simm, M. W. Beck, G. Collins, Q. Lodder, and R. K. Mohan. Vicksburg, MS: U.S. Army Engineer Research and Development Center.

Full acknowledgments appear at the end of this chapter. 


\section{Key Messages}

1. Natural and nature-based features (NNBF) flood risk management (FRM) performance and aspects of social and economic performance are examined using a source-pathway-receptor-consequence conceptual model commonly used for FRM.

2. Performance metrics include direct and indirect measurements, modeled parameters, or outputs and should be assessed based on predetermined performance criteria.

3. Sources of uncertainty in NNBF performance are largely similar to those of structural measures, although natural variability of NNBF may be greater than that of structural measures.

4. Because monitoring budgets are usually limited, monitoring metrics should be chosen carefully to capture the most critical aspects of the project (typically those related to the objectives), and metrics that can inform multiple types of performance should be used when possible.

5. Performance of NNBF over a project life cycle requires periodic assessment at a frequency commensurate with the natural dynamism of the NNBF and the location.

6. For NNBF and structural measures in a world with increasing disturbance events, there is a real need to get better values on long-term rates of failure (fragility) and the associated maintenance costs.

7. FRM and the ecological, social, and economic performance of NNBF are interrelated, and proper ecological function of NNBF is critical to ensuring proper FRM, social, and economic functions. 


\section{1 | Introduction}

The goal of the International Guidelines on Natural and Nature-Based Features for Flood Risk Management (NNBF Guidelines) is to inform the use of natural and nature-based features (NNBF) to provide functions relevant to flood risk management (FRM) while also producing economic, environmental, and social co-benefits. Performance is the ability of a system to meet one or more desired and declared objectives. Performance is measured using a set of predetermined metrics designed to ascertain whether the NNBF is producing the desired benefits. Metrics are specific parameters or properties of the NNBF, typically quantifiable, that are associated with some desired aspect of performance.

Multiple interrelated categories of performance relate to NNBF and include the following:

- FRM performance, in the context of NNBF, is the reduction in physical forces that produce flooding or damages or that otherwise contribute to FRM for the full range of possible events over a project's life. Erosion reduction is included as a component of FRM performance because future FRM performance can be compromised by persistent erosion. The two aspects of FRM performance are the system performance, which is the effect of the system of measures including NNBF on the hazard, and the structural performance, which is the effect of the hazard on the NNBF and other measures.

- Ecological performance is the production of the desired ecological functions by the NNBF. Ecological performance includes the production of desired ecosystem goods and services such as water quality.

- Social performance refers to the desired social co-benefits produced by the NNBF, including human health, well-being, and equity, as well as recreational, cultural, and educational co-benefits.

- Economic performance pertains to the reduction in economic damages, as well as the economic value related to other FRM, ecological, and social co-benefits produced by the feature.

Performance should be considered over an entire project life cycle and should consider the full array of possible environmental conditions that drive performance for present and future conditions alone and in combination with each other (e.g., future sea-level rise coupled with a full range of storm events). Performance should be estimated for both robust and deteriorated or otherwise suboptimal NNBF conditions (e.g., if two flood events occur consecutively). Like structural measures, NNBF performance may deteriorate over time, requiring routine maintenance to sustain performance over the course of an entire project lifetime. However, unlike structural measures, many NNBF are able to adapt to future conditions and performance may even improve over time (e.g., wetlands migration in response to sea-level change). 
Performance concepts and analyses are applicable to existing NNBF, not just NNBF solutions that require active construction or modifications. Conservation and maintenance of existing NNBF are both valuable to FRM goals. If existing NNBF are providing FRM functions-especially if new NNBF, structural measures, or nonstructural measures rely on those functions to perform-the performance of those existing FRM functions should be quantified. For example, if a levee is fronted by a wetland, the levee toe is protected by the wetland, and the benefit of that wetland should be quantified in the analysis of the levee's performance and reliability. If these benefits are not quantified, the only provisions for their continued conservation and maintenance are related to avoiding adverse environmental impacts, which may not be adequate to ensure their long-term sustainability. Note that the nature and quantification of NNBF benefits are discussed in detail in Chapter 6 of this NNBF Guidelines-and benefits associated with FRM are distinguished from co-benefits, meaning benefits other than those related to FRM such as improved ecological or social functioning.

Optimizing NNBF performance and determining best NNBF practices for specific locations or stressor scenarios require clear conceptualization of project actions and outcomes. Performance measurements are a key component of an effective adaptive management strategy. More detail on addressing performance using a life-cycle approach is found in Section 5.6, and more detail on developing and implementing NNBF adaptive management approaches is found in $\underline{\text { Chapter } 7 .}$

\section{2 | Describing NNBF Performance}

System performance is described in this NNBF Guidelines using a source-pathway-receptorconsequence (SPRC) conceptual model (also described as a hazard-performance-exposureconsequences model) to determine system performance (Figure 5.1). This approach was developed to describe risk associated with environmental contaminants and has since been adopted by the Environment Agency in the United Kingdom and applied globally in flood risk assessments (Narayan et al. 2012; Grilli et al. 2017). The U.S. Army Corps of Engineers adopted a similar approach to describing flood risk hazards in current engineer regulations (USACE 2019). 


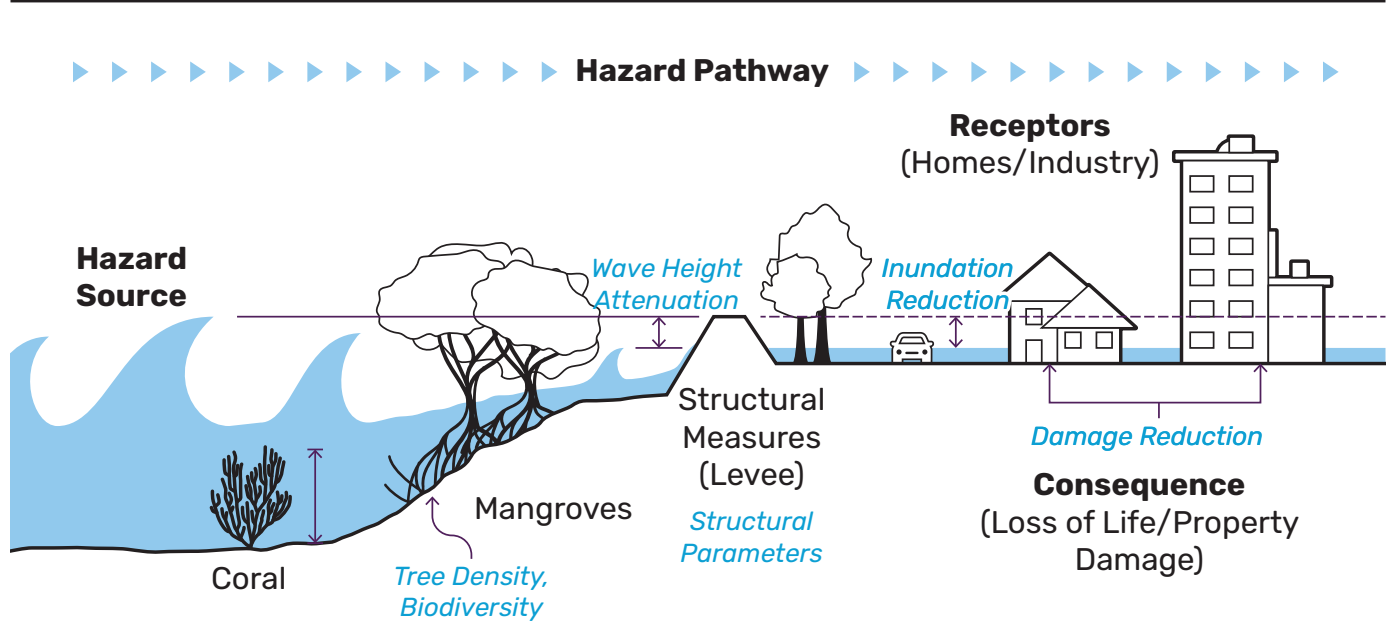

The first step in describing NNBF performance using the SPRC model is to clearly identify and quantify all relevant hazard sources. Hazard sources may be acute or chronic. Typically, FRM risk assessments focus on acute hazards such as coastal storms, but chronic hazards such as unaddressed erosion can undermine a system's ability to perform effectively over a period of years. Coastal hazard sources include acute storm-related hazards such as wind, surge, and waves, as well as chronic hazards such as sea-level rise, tides, waves from wind and boat wakes, and bank failure processes. Coastal hazards may also include precipitation and runoff associated with coastal storms. Fluvial hazard sources include precipitation, runoff, currents, and inundation related to overbank flow from rivers and streams. Coastal and fluvial hazards may combine in rivers along coasts and lead to compound flooding. Quantification of these hazards involves assessing from data the statistical distributions of the physical parameter or parameters associated with each hazard and the correlations between them. It also involves assessing how these parameters will change with time, either directly (e.g., relative mean sea-level rise) or indirectly (e.g., increased wave heights as a result of sea-level rise).

Determining how the NNBF or structural measure alters the hazard pathway is the second step in describing performance. The pathway is the movement of the water through the system and includes how measures alter those pathways. Understanding the pathways absent the NNBF or structural measure is critical to determining how the hazard propagates through the system and what measures can address the hazard. How the implemented NNBF measures alter the hazard pathway by reducing the duration of flood peaks or slowing flood waves contributes to 
the overall engineering system performance, even when the NNBF is not the primary measure providing FRM performance. An analysis of hazard pathways should include inundation modeling when the hazard exceeds the capacity of the measure to perform, such as in the case of overtopping and breaching. Static inundation mapping based on peak water levels may overpredict inundation and mask the effects of NNBF measures that limit the volume of water entering hinterlands. For example, a wetland in combination with a levee reduces flooding in the event of levee breach because the wetland limits the size of the breach and slows the flow of water into the hinterlands (Zhu et al. 2020).

The third step in describing performance is to identify the receptors that may be affected by the hazard. Typically, the receptors are structures, infrastructure, people, and ecosystems that are affected by the hazard and may be conceptualized as the system's exposure to the hazard. However, in some cases, the receptors may be other components of the FRM system itself that are protected from harm by another component. Nonstructural FRM measures (i.e., elevation of structures, comprehensive evacuation plans, and buyouts) seek to remove the receptors from the hazard area, thereby reducing exposure to the hazard even though the hazard pathway remains.

Finally, the consequences are the harm or damages that could occur if the receptors are affected by the hazard. Consequences include damages to structures, property, or ecosystems; stress; loss of life; or any other negative physical, ecological, social, or economic damage attributable to the hazard. Consequences can be determined by examining the relationships with the (modeled) hazards at any location. (The best-known examples of these are depth-damage relationships, which provide the economic or financial damage associated with a given water depth in a building.) The SPRC model of project performance ultimately guides efforts to minimize consequences by not only addressing the hazard pathway (through use of NNBF or structural measures) but also by reducing (through the use of nonstructural measures) the number of receptors at risk from the hazard.

The following subsections illustrate how this conceptual model applies to two systems of NNBF, structural and nonstructural measures, the first for a typical acute coastal storm hazard and the second for a typical chronic fluvial hazard.

\subsubsection{NNBF Performance for Acute Hazards}

Figure 5.1 illustrates how this conceptual model applies to a system of NNBF, structural, and nonstructural measures for a typical coastal storm hazard. A similar presentation could be made for individual alternatives. 
In the case of Figure 5.1, the NNBF (the coral reef and the mangroves) and the structural measures (the coastal levee) together modify the hazard pathway. The coral reef attenuates storm wave energy transmitted to the mangroves; the mangroves, in turn, reduce total water levels experienced at the levee via wave and surge attenuation. (Note that the two NNBF measures alter different hazard sources. The coral reef primarily reduces storm wave energy and height, and the mangroves reduce surge, as well as wave energy and height.) Finally, the levee prevents the transmission of water to the receptors (e.g., the homes, people, and infrastructure landward of the coral reef-mangrove-levee system), thereby reducing adverse consequences such as damages to property, harm to people, or loss of life.

\subsubsection{NNBF Performance for Chronic Hazards}

The SPRC model can also be applied to chronic hazards. In some cases, NNBF may be implemented in combination with structural measures to address chronic hazards, such as erosion, which affect the structural performance of the measure over the project life cycle. In the case illustrated in Figure 5.2, the hazard addressed by the NNBF is waves induced by boat wakes. The marsh alters the pathway of the boat wake waves (and wind waves) at low-to-moderate water levels by reducing the wave energy exerted on the levee, which in this case is the receptor. The consequences of leaving the hazard unaddressed are increased maintenance costs due to erosion of the levee or reduced structural performance of the levee during storm events if erosion is allowed to continue unabated.

Figure 5.2. SPRC Model for NNBF Used to Prevent Structural Damage to Levee from Ship Wake

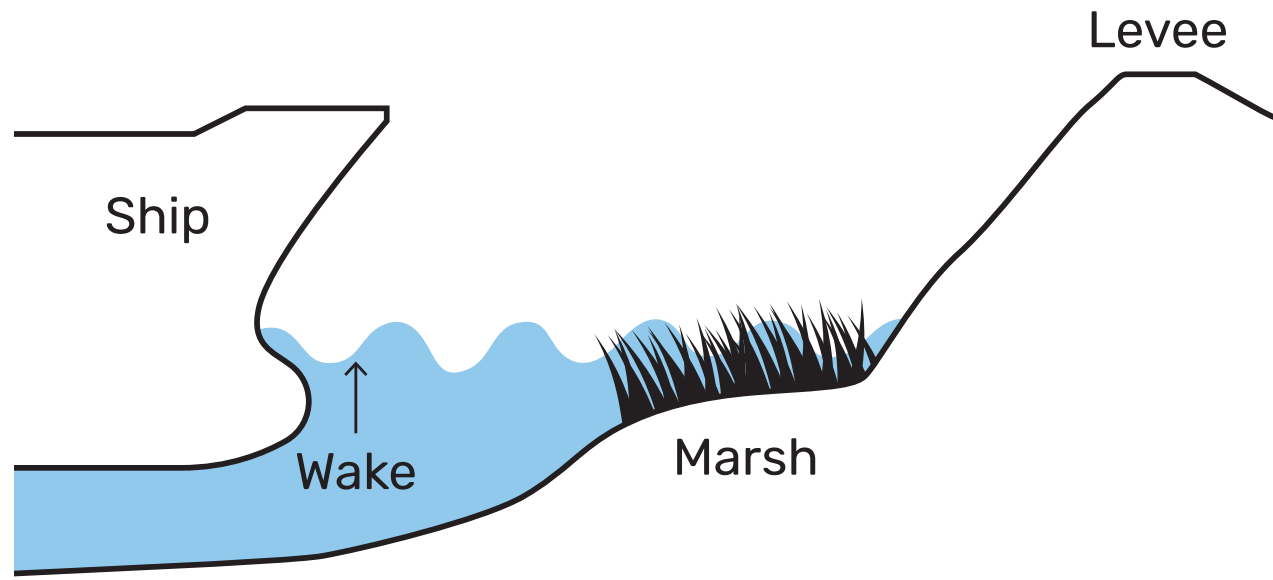




\subsubsection{NNBF Performance with Respect to Co-Benefit Production}

Given the variety of co-benefits NNBF can offer, performance is not limited to the FRM benefits of reducing the impact of flood hazards. Production of co-benefits should also be assessed using the performance concept. The NNBF or system performance with respect to co-benefits is described by the ecological, social, or economic outputs related to project objectives, such as habitat provisioning, increased carbon sequestration, or recreation. (As mentioned in Section 5.1, the range of benefits and co-benefits and their quantification are discussed in Chapter 6.)

Different aspects of performance are interrelated and often interdependent; although categorizing types of performance is useful to determine whether specific project objectives are met, assessing FRM performance requires assessing ecological performance because NNBF rely on ecological functions to produce FRM benefits. For example, robust plant communities on dunes facilitate sand trapping, which enhances natural dune growth, thereby increasing potential FRM performance. Sustained social and economic performance may also provide incentives or targets for financial investment for communities to maintain NNBF so FRM performance is also maintained into the future.

Even though all aspects of ecological, social, or economic performance are not necessarily related to FRM outputs, all performance assessment should relate to specific project objectives. For example, oyster reefs can increase water clarity through the removal of material suspended in the water column; however, the improvement in water quality due to the presence of the oyster reef would only be assessed if increased water clarity is a desired objective. Likewise, NNBF may provide ecological co-benefits to fish populations through maintenance of critical juvenile habitats, which, in turn, support improved social performance of fishing-related recreation, as well as economic performance through support of commercial or recreational fisheries. Although these benefits may be qualitatively described, the degree to which they are quantified and their performance assessed depends on project objectives defined as a part of project scoping or planning. More detail on measuring co-benefit performance is found in Section 5.3 . 


\section{3 | Assessing NNBF Performance}

NNBF performance should be assessed through the application of a clear methodology to determine whether the project goals and objectives are being met. In the case of FRM performance, an accepted risk assessment methodology can be applied depending on the needs of the project-and indeed may be required (see USACE 2019). However, use of risk assessment methods may not be relevant to all aspects of NNBF performance, especially ecological or social performance. Other methods from ecosystem restoration practice and ecosystem goods and services approaches can also be used to assess NNBF performance. The performance assessment method chosen based on the needs and requirements of the project should be used to inform the monitoring program set out in the adaptive management plan (see Chapter 7).

Regardless of the method used and the project phase, all methods assess performance through the measurement of performance metrics as related to defined performance criteria. The performance criteria are the standards NNBF performance is evaluated against, and the performance metrics are the measurements that determine whether the performance criteria are fulfilled. Performance metrics and criteria should be clearly linked to the NNBF objectives to determine whether the project meets expectations. Performance criteria and metrics should reflect project efficacy, efficiency, and effectiveness (Checkland and Poulter 2006), as follows:

- In the context of NNBF performance, efficacy is the ability of the measure to transform the hazard pathway to the extent required to meet project FRM objectives.

- Efficiency is the ability of the system of measures to meet project objectives with the least expense-monetary, environmental, or otherwise.

- Effectiveness is the ability of the system of measures to achieve the broader project objectives (e.g., co-benefit production or flood consequence minimization).

Although efficacy and effectiveness may seem duplicative, they should be distinguished. The efficacy of a particular measure can be described by whether the measure reduces water levels to a prescribed level, whereas effectiveness is a more holistic concept. If the measure encourages development in an area that will always have some residual risk of flooding, it may have efficacy but not effectiveness because it enhances flood risk rather than minimizes it. 


\section{Use Project Objectives to Define Design Criteria and Performance Metrics}

Performance metrics and criteria selected should directly relate to the project objectives and, in turn, inform the criteria and constraints used to design NNBF, especially in projects intended to meet multiple objectives. The project objectives will dictate the performance criteria that will be used to assess project performance and should be linked to corresponding design criteria (Figure 5.3). Most NNBF are constrained by the environmental requirements for the biotic component (i.e., elevation for wetlands, water depth, and clarity for submerged aquatic vegetation) and will dictate how the project is designed and how the project is monitored once constructed.

\section{Figure 5.3. Using Project Objectives to Determine NNBF Performance Metrics and Design Criteria}

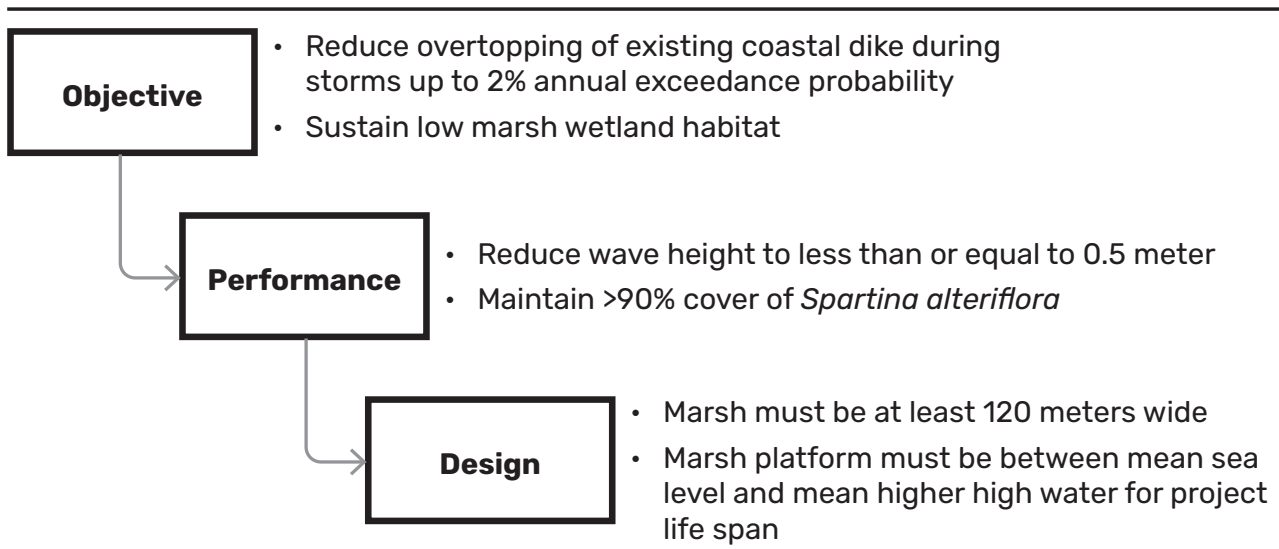

Although biotic requirements may constrain aspects of NNBF design, there are aspects that can be manipulated to maximize performance to achieve the project objectives. For example, tidal channels in coastal wetlands can be designed to prevent surge from easily propagating deep into the wetland by creating branched and sinuous channel networks with the channel mouths oriented away from the predominant storm path direction. Dunes can be designed to provide interdune swale habitats important to many shorebirds while still meeting the required standards. 
Performance assessment is considered differently based on the phase of the project. Table 5.1 and Figure 5.4 show how performance assessment changes during a project. In the Planning Phase and the Decision-Making Phase (the five phases of the project development framework-Scoping, Planning, Decision-Making, Implementation, and Operations-are described in detail in Chapter 2; see Figure 5.4), the full SPRC framework must be analyzed to determine how concepts of FRM and ecological, social, and economic performance align to meet the project objectives. Consequently, performance assessment in the Planning Phase and the Decision-Making Phase relies on composite metrics that most directly relate to the project objectives. For example, using a strict damage reduction cost-benefit analysis as part of project justification (during the Decision-Making Phase) requires the cost of the project to be less than or equal to the expected reduction in damages due to coastal storms over the project life. Including other types of economic benefits besides damage reduction, such as business disruption avoided or recreational revenue generated, and even benefits that cannot be monetized, such as life safety and well-being benefits, can drastically alter project cost-benefit and may result in the selection of different project alternatives. As part of project planning, performance criteria specific to individual NNBF measures are defined by the characteristics necessary to meet the project objectives, such as the volume of water detained by a leaky dam for a certain rainfall event.

Table 5.1. Performance Assessment Requirements during NNBF Project Phases

\begin{tabular}{llll}
\hline \multicolumn{1}{c}{ Phase } & \multicolumn{1}{c}{$\begin{array}{c}\text { Performance } \\
\text { criteria }\end{array}$} & \multicolumn{1}{c}{ Metric type required } & \multicolumn{1}{c}{ Data required } \\
\hline Scoping & $\begin{array}{l}\text { Performance criteria } \\
\text { are suggested by the } \\
\text { project objectives }\end{array}$ & $\begin{array}{l}\text { Indirect - Scientific evidence, } \\
\text { case studies, and expert } \\
\text { knowledge }\end{array}$ & $\begin{array}{l}\text { Existing data on system } \\
\text { Planning }\end{array}$ \\
$\begin{array}{llll}\text { Performance criteria } \\
\text { are with respect } \\
\text { to project efficacy, } \\
\text { efficiency, and } \\
\text { effectiveness, which } \\
\text { will indicate potential } \\
\text { location and size of } \\
\text { measures }\end{array}$ & $\begin{array}{l}\text { Computational - Apply simple } \\
\text { representations of measures } \\
\text { into models }\end{array}$ & $\begin{array}{l}\text { Existing data on system, } \\
\text { some new data on system } \\
\text { (i.e., current bathymetry, } \\
\text { parameter sets for NNBF, } \\
\text { structure inventory) }\end{array}$ \\
\hline Decision-making & $\begin{array}{l}\text { The extent to which } \\
\text { each combination of } \\
\text { measures meets the } \\
\text { project performance } \\
\text { criteria with respect to } \\
\text { efficacy, efficiency, and } \\
\text { effectiveness }\end{array}$ & $\begin{array}{l}\text { Computational - } \\
\text { Hydrodynamic, engineering, } \\
\text { ecological, social, and } \\
\text { provide complete assessment } \\
\text { of all project objectives }\end{array}$ & $\begin{array}{l}\text { No new data required; use } \\
\text { inform decision }\end{array}$ \\
\hline
\end{tabular}




\section{Phase}

\section{Implementation}

Operations

Use adaptive

management

plan as guide

\section{Performance} criteria

Maximization of the efficacy, efficiency, and effectiveness of performance criteria both in design and after implementation

The extent to which NNBF are performing as designed using agreed efficacy, efficiency, and effectiveness criteria

\section{Metric type required}

Computational - Higher resolution modeling of individual measures to finalize design

Direct - Use methods in contract to determine whether project meets specifications

Direct - Metrics that directly quantify performance such as shoreline erosion rate

Indirect - Proxy or semiquantitative metrics that indicate function

Computational - Define characteristics of NNBF that provide minimum acceptable function

\section{Data required}

Some new data may be required at higher resolution in proposed project areas

As-built project data as detailed in design and contract specifications

Periodic and after-event measurement of the metrics

Periodic or after-event measurements of proxy or index-based metrics

Periodic and after-event measurement of NNBF characteristics (i.e. dune crest elevation or vegetation density) that affect measure performance

Figure 5.4. Performance Assessment Requirements during the Course of an NNBF Project

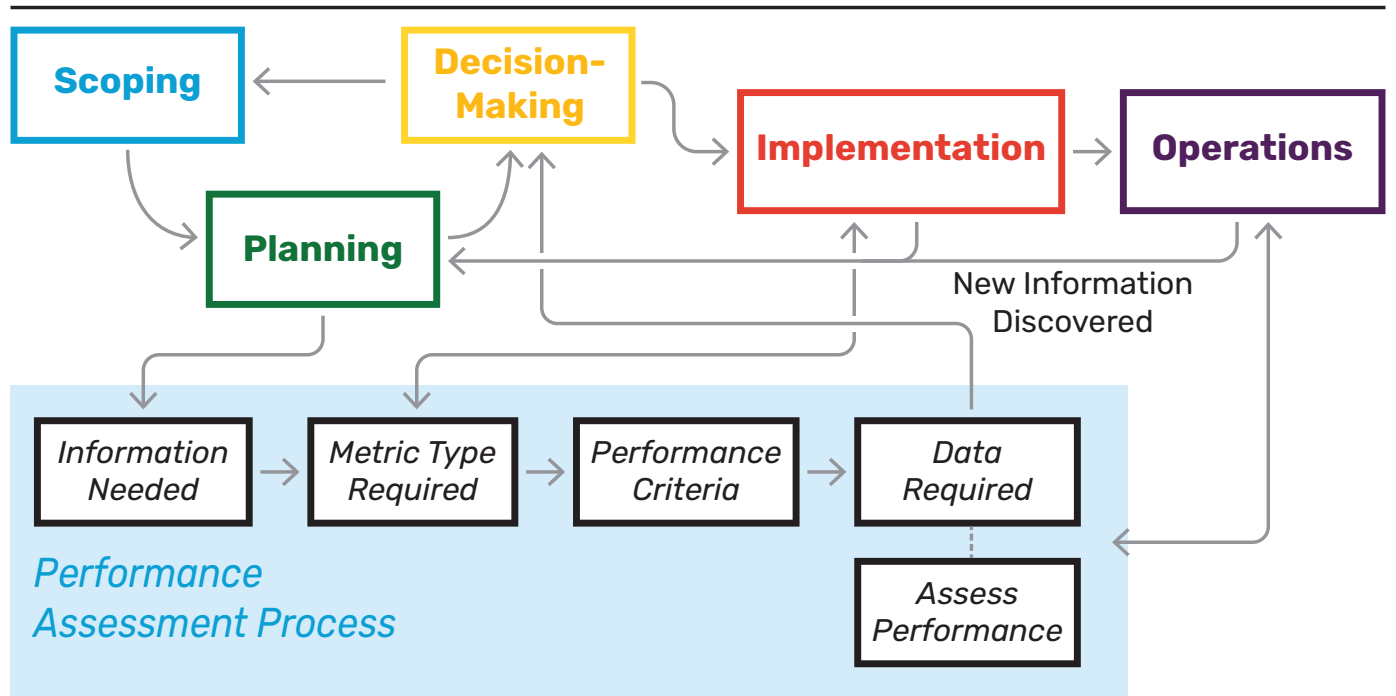


Once a project is implemented, however, the focus shifts to monitoring and management where the individual NNBF elements of the FRM system must be assessed periodically to ensure the overall project objectives continue to be met. The metrics used to assess performance in the Implementation Phase are readily measurable characteristics of the system, such as dune crest elevation or vegetation cover, and directly relate to the defined performance criteria developed in the Planning Phase. Monitoring metrics do not necessarily inform flood risk objectives directly; instead, they intend to capture the condition of the NNBF and determine whether it continues to meet the defined performance criteria. The performance criteria developed for the Operations Phase are based on measurable limit states, which are the NNBF properties that provide the minimum acceptable function with respect to a given objective. For instance, to achieve required wave attenuation functions, wetland width should be greater than or equal to some precalculated value, and monitoring requires routine measurement of the wetland width rather than direct measurement of the wave attenuation. If the NNBF condition does not meet the defined performance criteria, then management actions are taken to ensure the project continues to deliver the required level of performance.

Because monitoring budgets are almost always limited, monitoring metrics should be chosen carefully to capture the most critical aspects of the project (typically those related to the objectives). The interdependency between FRM, ecological, social, and economic performance can be used to identify common performance metrics. For example, beaches and dunes provide critical FRM functions, but they are also recreation areas between storms and may provide additional economic co-benefits through production of tourism and associated revenues. FRM and recreation performance can both be assessed roughly using a simple metric such as beach width.

Performance of NNBF alone or in combination with other measures should be assessed as a system, not as distinct elements. Combinations of NNBF, structural, and nonstructural measures are typically used when not all hazard sources can be addressed with one solution or additional co-benefits are desired that one measure alone cannot provide. Isolating individual elements neglects any potentially synergistic (or antagonistic) effects between the elements of the system of measures. In some cases, this can lead to the overdesign of structural elements of a combined system of measures or inaccurately capture the performance of the NNBF elements.

Although this chapter focuses on project-scale performance, individual projects are often implemented within broader coastal and fluvial systems to produce benefits (e.g., related to FRM or otherwise) for a broader geographic region. To obtain system-wide benefits, performance must be understood not only at the project level but also at the regional system level (i.e., watershed scale). To assess performance at a regional scale, a broader strategy that assesses multiple projects across the region using a common set of metrics and criteria may be needed. More information on developing performance assessment at a regional or programmatic level is in "Programmatic Approaches to Performance Monitoring." 


\section{Programmatic Approaches to Performance Monitoring}

Effective planning, design, implementation, and management of NNBF require interdisciplinary information, including measurements of the interacting physical, biological, biogeochemical, and socioeconomic forces that will influence project success. However, extensive monitoring of each NNBF and the system drivers affecting NNBF performance is not feasible in every case. A cost-effective solution is to develop a collaborative measurement approach across systems of NNBF projects, using a network of stakeholders to collect established sets of performance metrics, which should include a combination of simple and high-precision direct and indirect performance metrics, as well as computational performance assessments. By enabling comparison of performance across projects, best practices can be established to determine how NNBF location relates to the larger area, how design relates to performance, how NNBF respond to disturbances, and when maintenance actions should be initiated to ensure continued performance. Integrating science with engineering design and implementation will provide landscape decision-support information and tools for scientifically defendable management strategies that both accelerate and improve our responsiveness to resource management and policy needs.

\subsubsection{NNBF Performance Measurement}

Performance metrics can be measured directly, indirectly, or computationally. The method used to measure performance depends on the metric itself, the characteristics of the NNBF, the funds available to monitor performance, policy directives, and a number of logistical factors. If NNBF performance is to be assessed as part of a broader regional or programmatic assessment, generally common measurement techniques should be applied to ensure the metrics are comparable. Methods used to measure performance, as well as the measurement frequency and the parties responsible for carrying out monitoring plans, should be defined in the adaptive management plan (Chapter 7 ). Community-based monitoring may be a useful approach, both in terms of physical measurements and observations and in understanding and assessing NNBF social and economic co-benefits (see Chapter 3, Section 3.1.2).

Costs and logistics associated with the selection of performance metrics should be carefully considered. It is impossible to measure everything, even if metrics are measured computationally using predictive models. Metrics should be selected with affordability and ease of measurement and interpretation in mind, especially for projects with few monetary and personnel resources. If the burden of NNBF performance monitoring is perceived as too 
great or too complex, structural measures alone may be selected. Fewer carefully selected metrics that can inform multiple aspects of performance, including project efficacy, efficiency, and effectiveness, even coarsely, are preferred over tens of metrics, even if more metrics may produce more precise data on specific aspects of NNBF performance.

\subsubsection{Direct Performance Measurement}

Direct performance measurement is simply the direct measurement of a defined metric at an NNBF site. Direct measurement techniques are most applicable to aspects of ecological and social performance and include visitor numbers, vegetation aboveground biomass, and infaunal diversity. Generally, direct measurement of FRM system performance can only occur for chronic hazard sources and may include measurements such as accretion rates or multiannual erosion rates. Other aspects of structural performance, however, can be measured directly, such as dune scarping or bank erosion after storm or flood events.

Direct measurements can occur locally through on-the-ground measurement techniques or remotely through the use of airborne or satellite imaging and measurement techniques. Acceptable direct measurement techniques should be defined by the adaptive management plan.

Not all metrics can be measured directly. Direct measurement of FRM performance is typically not feasible for the following four main reasons:

1. Some assurance of performance prior to a flood event is required.

2. Decoupling the effects of each hazard source (i.e., the proportion of the total water level attributable to tides, surge, and waves) is not feasible in almost all cases.

3. Direct measurement of hazard pathways during storm events is not common due to the dangers to personnel and equipment.

4. Large storm events are relatively infrequent, especially for recurrence probabilities less than $1 \%$ annual exceedance probability.

Direct measurement of economic performance is often not feasible because economic systems are complex and fluctuations in metrics related to community and regional economics can be related to a number of external and internal drivers unrelated to the FRM system or a particular measure, such as NNBF.

\subsubsection{Indirect Performance Measurement}

As previously mentioned, direct measurements are not always feasible for a number of reasons. In some cases, indirect measurements can be used as proxies, approximations of direct metrics, or qualitative descriptions related to preferred direct measurements. Examples of indirect measurements include the following: 
- Using proxies such as water marks on buildings or silt marks on vegetation in place of actual inundation level measurements during a flood

- Using correlations or relationships between metrics to reduce number of metrics or to use metrics that are simpler and cheaper to measure

- Using semiquantitative, index-based socioeconomic or ecological metrics such as habitat suitability indices

- Providing qualitative evidence using methods such as case studies, logic, prior experience, and expert elicitation

Indirect evidence of performance through qualitative observations is very useful in resource-stressed contexts or in areas with sparse direct monitoring.

\subsubsection{Computational Modeling for Performance Measurement}

Computational models are frequently required to assess engineering or economic performance. Even when performance is directly measured, identifying the magnitude of the effect of FRM measures can be difficult because of the variation in performance due to storm characteristics or system noise and complexity. Because storm characteristics strongly influence the structural performance of some NNBF, computational models allow engineering and economic performance estimates to be conducted for a variety of storm events without requiring direct measurement of consequences for an entire suite of storms. Models can be used to provide information about NNBF effects due to specific hazard sources (e.g., waves versus surge).

Computational performance measurement must use direct and indirect measurements of NNBF characteristics related to parameters that drive the models. In the case of reefs, direct measurement of reef height, crest width, and rugosity are used to define hydrodynamic model parameters that calculate the effect of the reef on a variety of storm conditions. In addition, these direct metrics describing NNBF geometry also frequently correlate with ecological function and, in some cases, may serve to inform ecological performance as well.

For complex FRM systems that include multiple measures, some level of computational modeling is always advised because any measure may have unpredictable effects, such as prolonging flood duration or even increasing water levels in some areas. Different flood and storm characteristics may increase the likelihood of observing unpredictable or undesirable effects, so modeling should include a variety of storm typologies. Computational modeling capabilities for NNBF are rapidly expanding as more model developers and practitioners incorporate the effects of NNBF into existing hydrodynamic models. Tools are under development to easily insert proposed NNBF into existing coastal hydrodynamic model geometry, allowing multiple configurations of NNBF alone or in combination with structural measures to be simulated and compared relatively quickly. 
Ideally, model estimates of performance should be checked against real conditions after construction to determine whether the NNBF perform as designed. This is especially true if NNBF are implemented as a pilot or demonstration project. However, as NNBF use expands and model estimates of performance gain acceptance, performance can be more reliably predicted, as it is for structural features such as levees or rubble-mound breakwaters.

\subsubsection{Selecting NNBF Performance Metrics}

NNBF performance metric selection is critical because the metrics selected influence decisions and actions throughout a project and can affect not only the array of measures implemented but also whether investments are made at all. Performance metrics should be carefully selected to ensure all project objectives are represented, and where applicable, performance metrics should be informed by the SPRC framework with respect to system efficacy, efficiency, and effectiveness. The suite of metrics selected should not lead to the selection of NNBF or other measures that result in adverse ecological impacts or unequitable investment decisions due to a heavy emphasis on prioritizing FRM performance. For instance, prioritizing tangible structure damages and neglecting intangible social effects can lead to investment decisions that prioritize protection from larger flood events that, if unchecked, would lead to more structure damages over smaller flood events. However, these smaller events may lead to greater cumulative intangible social effects affecting more people over a project life cycle (ten Veldhuis 2011).

NNBF and conventional measures are adopted to address inherent risks associated with flood hazards, but even with measures in place, residual risk remains. Performance metrics should also address the residual risk associated with individual measures as well as systems of measures. Risk metrics should quantify or describe the overall performance of a system of FRM measures with respect to both risk and residual risk. In cases where NNBF alone are insufficient to achieve required performance, NNBF may be combined with conventional measures to reduce residual risks from structural failure. Although risk metrics are typically associated with FRM performance, ecological, social, and economic risks should also be considered because some potential measures may perform well with respect to FRM objectives but may introduce additional ecological, social, or economic risks. Although storm surge barrier construction may address inherent risks from coastal storms, frequent operation of the barrier may ultimately increase residual social and economic risks by facilitating development in locations that may eventually be unsustainable to protect.

Performance metrics and the method of assessment will change throughout a project. (Table 5.2 shows an example for FRM metrics, but the same principle applies to all types of performance.) Metrics should be selected carefully to suit the project phase as well as the level of information on performance required at each phase. For the Scoping Phase and the 
Planning Phase, information from scientific literature and scenario analysis using a suite of simplified assumptions related to NNBF characteristics may be sufficient, whereas more detailed modeling is required in design phases to develop full plans and specifications.

Table 5.2. Sample Performance Metrics Used during a Fringing Coral Reef NNBF Project

\begin{tabular}{|c|c|c|}
\hline Phase & Performance criteria and metrics & Data required \\
\hline Scoping & $\begin{array}{l}\text { Fringing coral reefs may reduce storm wave } \\
\text { heights by up to } X \%\end{array}$ & Existing data on system \\
\hline \multirow[t]{3}{*}{ Planning } & $\begin{array}{l}\text { Modeled maximum water level for an event } \\
\text { with and without reef }\end{array}$ & \multirow{3}{*}{$\begin{array}{l}\text { Hydrodynamic model of system } \\
\text { Model parameterization of typical } \\
\text { constructed reef } \\
\text { Set of likely storm conditions for } \\
\text { a range of intensities, durations, } \\
\text { directions, and so on }\end{array}$} \\
\hline & $\begin{array}{l}\text { Annual exceedance probability of a modeled } \\
\text { water level with and without reef }\end{array}$ & \\
\hline & $\begin{array}{l}\text { Duration of overtopping waves with and } \\
\text { without reef }\end{array}$ & \\
\hline \multirow{3}{*}{$\begin{array}{l}\text { Decision-making } \\
\text { (design) }\end{array}$} & Expected damages with and without reef & FRM and economic model outputs \\
\hline & $\begin{array}{l}\text { Number of individuals affected by flooding } \\
\text { with and without reef }\end{array}$ & $\begin{array}{l}\text { FRM model outputs and } \\
\text { socioeconomic data }\end{array}$ \\
\hline & $\begin{array}{l}\text { Duration and extent of road flooding with } \\
\text { and without reef }\end{array}$ & $\begin{array}{l}\text { FRM model outputs and asset } \\
\text { inventory }\end{array}$ \\
\hline \multirow[t]{3}{*}{ Implementation } & $\begin{array}{l}\text { Modeled maximum water level with different } \\
\text { reef shapes and configurations }\end{array}$ & $\begin{array}{l}\text { Measured current and wave data in } \\
\text { vicinity of proposed reef }\end{array}$ \\
\hline & $\begin{array}{l}\text { Design and contract specifications defining } \\
\text { reef geometry }\end{array}$ & $\begin{array}{l}\text { Measured reef substrate crest height } \\
\text { and width }\end{array}$ \\
\hline & & Reef substrate base width \\
\hline \multirow[t]{3}{*}{ Operations } & Reef height, crest width, rugosity & $\begin{array}{l}\text { Periodic surveys of reef height, crest } \\
\text { width, rugosity }\end{array}$ \\
\hline & Debris lines after storm event & $\begin{array}{l}\text { Periodic or after-event } \\
\text { measurements of proxy or } \\
\text { index based metrics }\end{array}$ \\
\hline & $\begin{array}{l}\text { Modeled maximum water level for reef } \\
\text { damaged after major storm event }\end{array}$ & $\begin{array}{l}\text { Periodic and after-event } \\
\text { measurement of NNBF } \\
\text { characteristics (i.e., dune crest } \\
\text { elevation, vegetation density) that } \\
\text { affect measure performance }\end{array}$ \\
\hline
\end{tabular}




\subsubsection{FRM Performance}

Because NNBF are distinguished from typical ecosystem restoration projects by their ability to produce FRM benefits, selecting FRM metrics should be considered carefully. FRM performance requires metrics and criteria that characterize the hazard (i.e., the source in the SPRC framework) as well as the pathway (i.e., how the measure affects the transmission of the hazard to the receptors). The performance metrics and criteria should clearly examine how NNBF alter the pathway of one or several hazard sources, whether the hazards are waves, currents, erosion, or total water level. The metrics used at each phase of the project should also reflect the level of information required to make decisions on what NNBF to use, where they should be located, and what their characteristics such as size and elevation should be.

Common system performance metrics used in the Planning Phase and the Decision-Making Phase include the following:

- The annual exceedance probability (e.g., the chance of a hazard source of a given magnitude at a location occurring in any given year without and with project) ${ }^{i}$

- The long-term exceedance probability (e.g., the chance of a hazard source occurring over a given number of years without and with project, taking into account nonstationarity of hazard parameters)

These two metrics can be applied as source loading terms to characterize the likelihood of a particular water level or flood or storm event occurring. For instance, water-level events of a given annual exceedance probability may have regulatory significance, as is the case for the Federal Emergency Management Agency (FEMA) under the U.S. National Flood Insurance Program. The same metrics can also be applied to determine how FRM measures affect the hazard (source plus pathway) by determining the difference in the metric values with and without project. Exceedance probabilities can be used at a systems scale to determine how all measures affect the pathway of several hazard sources (e.g., surge, currents, and waves). To get a full picture of the system response, these composite metrics ideally should be calculated for a suite of events of various magnitudes, directions, and durations because system responses vary greatly for different storm and flood event characteristics.

However, exceedance probabilities alone are insufficient to fully understand how the FRM measures may respond under a full range of loadings. To understand system function, exceedance probability metrics should be combined with fragility curves to obtain a more realistic understanding of the function of the FRM system by use of the following:

- The annual failure probability (e.g., the likelihood a measure or system of measures will not meet system or structural performance requirements in a given year)

- The system assurance (e.g., the chance of a hazard source not exceeding the capacity of the FRM system over a given number of years) 
Incorporating fragility also allows FRM structural performance to be considered more explicitly. Structural performance is largely dependent on NNBF type and should be informed by NNBF modes of performance and failure (see "On the Concept of Failure" and "Considering Hazards beyond Water Levels" for more information). If the NNBF do not structurally perform (e.g., they are damaged during a flood and do not reduce water levels as designed), system performance will likewise be compromised. However, because NNBF are complex systems reliant on physical and ecological components to provide function, damage of one component may result in no or only partial loss of performance. If NNBF continue to meet the project objectives, even damaged NNBF would not be considered a "failure." For example, beaches and dunes erode during the course of storms, perhaps with no loss of system performance relative to surge reduction during storms until the dune is breached, allowing flooding of the hinterlands.

\section{On the Concept of Failure}

The terms performance and failure are related. Performance relates to some kind of measure of the ability to meet one or more desired and declared objectives. Failure relates to the inability to meet one or more of those desired and declared objectives. Therefore, the concept of failure is predicated on the definition of performance objectives. More specifically, failure can be defined as the inability to achieve a defined performance criterion (e.g., response to a given loading; Morris et al. 2008) or performance metric for a given function.

Because uncertainties exist in both the loading (e.g., the magnitude or duration of an event) and the system response, each FRM measure has a probability of failure via a number of modes across a range of plausible loading events and NNBF conditions. The resulting distribution of the failure probability (conditional on the loading) is often described as a fragility curve (see Figure 5.5 ). It is often best to capture fragility based on the assumption of stationarity of the state of the system being assessed and to deal separately with the change of system state with time. To decrease fragility and the probability of system failure, structural measures must be improved through replacement or repair. However, NNBF may become decreasingly likely to fail through time due to natural or aided growth via management actions. Many NNBF also offer some residual performance, which is performance of a measure in a degraded or damaged state, so the probability of failure may not reach $100 \%$, even under extreme loading. 
Figure 5.5. Conceptual Fragility Curves for Structural and NNBF Measures

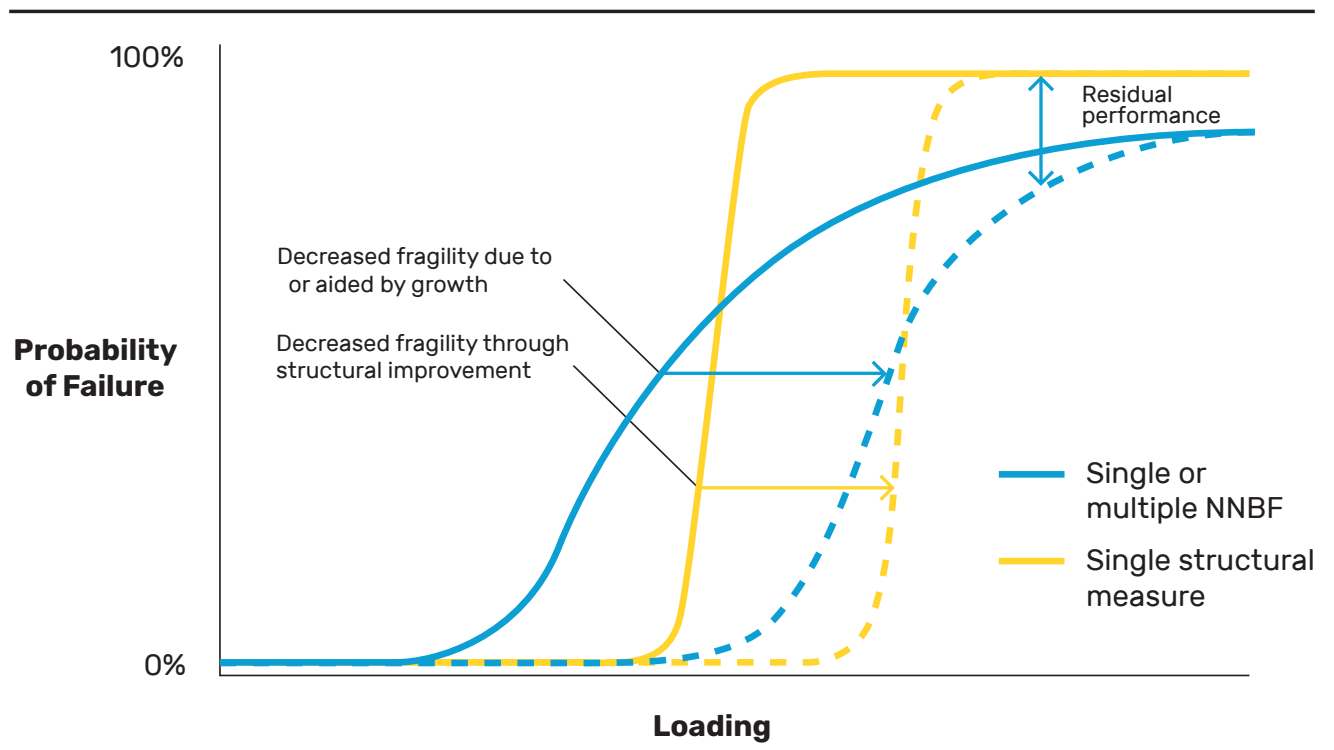

Note: Decreasing fragility of structural measures requires structural improvements such as adding rock armor, whereas NNBF measures can decrease fragility through natural growth or recovery, such as natural dune growth via eolian processes.

Failure should not be confused with specific process mechanisms, where it is better to use alternative terminology, such as the following:

- Deterioration. The slow physical degradation of the state of a physical measure, leading to reduced physical performance

- Damage. The rapid physical degradation of a physical measure during a single loading event

- Breach. The substantial loss of barrier or protection to the ingress of water 


\section{Considering Hazards beyond Water Levels}

Maximum water level is not the sole metric that explains flood severity. Given the same water level, floods with high current velocity will inflict more damages than those that come on more gradually. Sudden inundation, whether through flash flooding or catastrophic failure of protective FRM measures, also poses a greater risk to life safety, giving residents little time to move to higher ground. Flood duration or peak water-level timing may be just as critical to determining flood severity and associated structural damages and risks to life safety, as well. In the case of levee overtopping, the number of receptors affected (such as structures or roads) depends on flood depth and extent, which is a function of the duration and extent of overtopping and not just the maximum water level. If FRM options are screened using metrics that use only the maximum water level, measures that decrease the duration of flooding may be eliminated from consideration even when reducing flood severity may be more economically viable than measures that eliminate flooding altogether.

Although annual failure probabilities and system assurance metrics provide a more complete view of FRM system performance, note that they only relate to the source and pathway parts of the SPRC framework; reductions in exceedance or failure probabilities or increases in system assurance do not necessarily translate to benefits. To understand benefits, the relationship between the preceding metrics and the receptors and consequences must be quantified using a different set of metrics (e.g., relating flood depth to damages; see Sections 5.3.2.3 and 5.3.2.4). As FRM performance facilitates the production of benefits that would otherwise be at risk from flood impacts, reduction of inherent and residual flood risks are also benefits and should be captured in planning scenario analyses.

For proposed projects, FRM metrics are computationally derived from a combination of hydrodynamic and statistical models rather than solely relying on historical records. Ideally, probabilistic methods should be used to account for variations in storm and flood characteristics, as well as variations in the system and NNBF characteristics. Deterministic methods that use a single design storm to calculate FRM performance metrics may not adequately represent NNBF or structural measure performance across the full array of source loadings and may lead to underestimation or overestimation of NNBF performance. Additionally, hydrodynamic models used to calculate FRM performance metrics should simulate the hazard source the NNBF is designed to address. For example, reef NNBF performance should use hydrodynamic models that include the effects of waves. The models should also allow for aspects of reef performance such as reef height, crest width, and rugosity (which affects the hydrodynamic friction) to be adequately parameterized at a spatial scale that adequately represents the NNBF, which may require refinement of model geometry to accurately capture key characteristics of the NNBF. 
Additional FRM performance metrics may be required to determine NNBF performance in cases where NNBF is designed to address only chronic hazard sources such as erosion. In cases where NNBF are primarily designed to address chronic hazard sources, their system performance during storms may not be the primary driver of benefits. Chronic hazard sources are by nature lower in magnitude so any effect the NNBF have during larger events may be very small and may not be reflected in the calculation of composite performance metrics such as the annual exceedance probability. However, chronic hazards occur over many years and can lead to degradation of structures and shoreline retreat that may manifest on the order of decades, ultimately increasing future flood risk or increasing shoreline and structure maintenance costs. Scenario analysis can be used to determine how future flood risk would be affected if the NNBF were not present by projecting historical erosion rates into the future or by calculating the cost associated with the maintenance of shorelines, structures, or other NNBF with and without the NNBF intervention. See "Beach and Dune NNBF System Mitigates Chronic Erosion and Increases Long-Term NNBF Performance" for an example of how addressing chronic erosion can increase NNBF performance.

\section{NHINHIH}

\section{CASE STUDY:}

\section{Beach and Dune NNBF System Mitigates Chronic Erosion and Increases Long-Term NNBF Performance (City of Den Helder, the Netherlands)}

Ongoing erosion was documented since the 1960s south of the City of Den Helder in the Netherlands. The erosion led to the shoreline receding beyond the minimum reference coastline position and caused an increase in the probability of breaching of the beach and dune that protect the hinterlands from flooding. In 1993, routine sand nourishment was initiated in accordance with the coastal flood risk policy aimed at stopping coastal retreat. Since the nourishment (represented by shaded vertical bars in Figure 5.6) started, shoreline position stabilized, and the long-term erosion trend reversed after a large nearshore and shoreface nourishment in 2007. This action effectively halted the ongoing erosion, and the probability of beach and dune breaching stabilized. Figure 5.6 gives an example of the effects of 30 years of sequential nourishment. The left y axis shows the cross-shore position with positive values in the seaward direction, and the right $y$ axis shows the corresponding failure 
probability in green. The blue line shows a cubic spline fit of repeated estimates (+) of the low-water mark shoreline position for one transect. The purple horizontal line represents the minimum acceptable coastline position (basal coastline) required to keep flood risk at a socially acceptable level.

Figure 5.6. Repeated Beach Nourishment Reverses Chronic Beach-Dune System Erosion

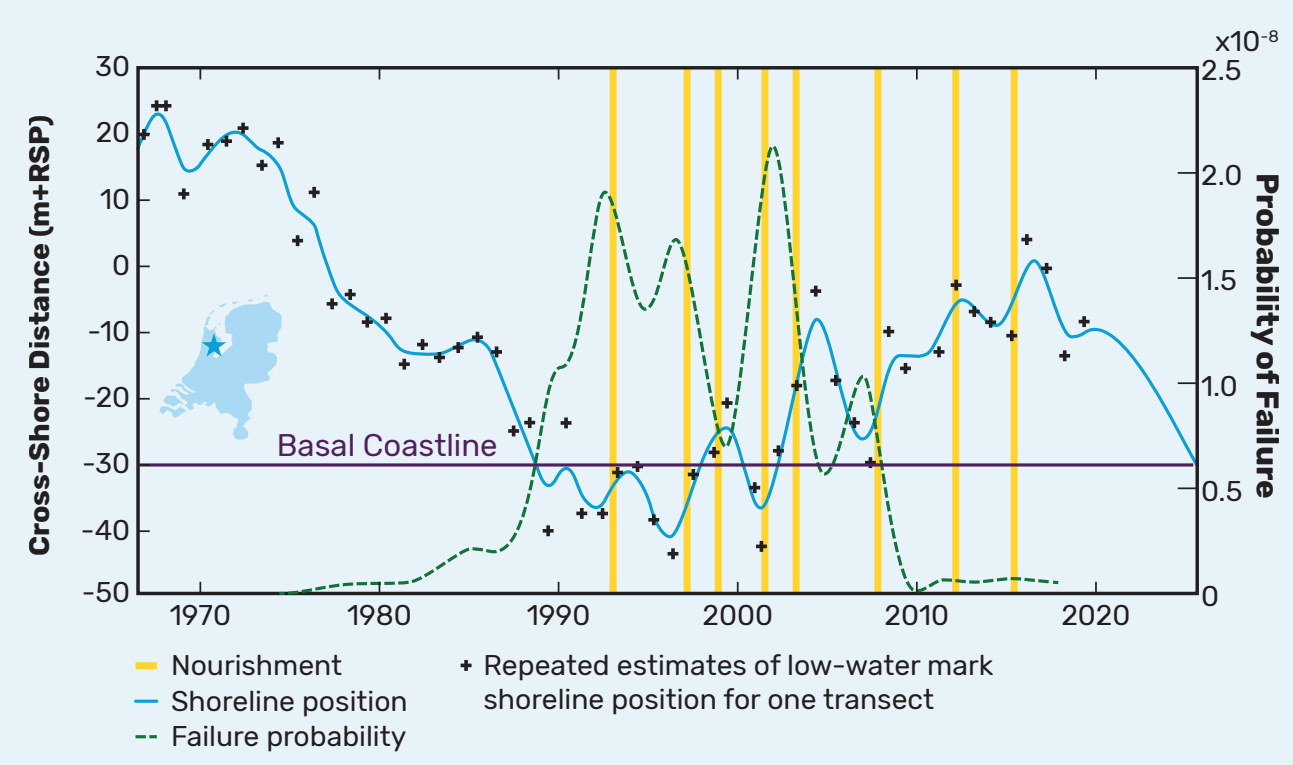

Abbreviation:

$\mathrm{m}+\mathrm{RSP}=$ meters RijksStrandPalen lijn, which is a Dutch reference for monitoring

\subsubsection{Ecological Performance}

Ecological performance metrics are used to determine how NNBF function ecologically and can be considered as part of the FRM performance assessment or assessed on their own merit for projects with ecological objectives. Because many NNBF rely on a biological component to provide some degree of FRM performance, ecological performance should be assessed even in cases where no specific ecological objective is stated. In the Planning Phase, ecological performance metrics are selected to determine whether the NNBF will meet stated ecological and FRM objectives. In the Operations Phase, when the project is adaptively managed, 
ecological performance metrics may be measured to assess aspects of FRM performance, even for projects with no explicit ecological objective. For example, many NNBF use vegetation to attenuate waves and flow, and the efficacy of the vegetation in performing that function depends on the density and height of the stems, which can be presumed from simple ecological measurements of vegetation cover estimates and species composition.

Some aspects of ecological performance may only be qualitatively described, especially during the Planning Phase of projects or if ecological objectives are secondary or tertiary to other objectives. However, the ecological co-benefits associated with the NNBF should be acknowledged during all project phases. Including ecological co-benefits in the alternatives analysis may make an NNBF solution more favorable than a structural solution, even if the co-benefits are not explicitly quantified. If NNBF is adequately maintained, ecological co-benefits of NNBF, such as enhanced fisheries production, climate change mitigation, and water quality improvements, are reliably produced throughout the project life, diversifying the portfolio of benefits and co-benefits of FRM measures.

Other aspects of ecological performance must be assessed computationally. Ecological models of the relevant processes that drive the delivery of those benefits may be used to quantify ecological performance. The types of models used will vary with NNBF type and the desired FRM functions and co-benefits. Some ecological co-benefits-and even some FRM benefits in cases where slow-growing biota (i.e., floodplain forests) provide FRM function such as carbon sequestration-are expected to develop and accrue over long time periods and require models that can use aspects of the NNBF design or condition to extrapolate how the NNBF will function into the future. In other cases, ecological co-benefits attributable to the NNBF may be accrued elsewhere in the system. For example, oyster reefs can enhance fish production and sustain wildlife populations through reduced degradation of habitat. However, quantifying that effect may not be possible without models that can discretize the effect of the reef on larger scale population dynamics, so those benefits may instead be qualitatively or indirectly described through the citation of scientific studies.

\subsubsection{Social Performance}

The social value of NNBF should be captured as a co-benefit and its performance assessed in the same manner as FRM and ecological performance. Social performance is linked to aspects of the engineering and ecological performance of the system and to the values of the community itself (Arkema et al. 2017). Social co-benefits commonly quantified as part of FRM studies include aspects of human health and safety such as loss of life. Quantifying tangible aspects of social performance, such as the population at risk (e.g., receptors and consequences if evacuation is not possible), in the SPRC framework is common practice in many FRM studies. However, social performance FRM benefits include other intangible aspects of well-being and quality of life, such as psychological stress associated with the flood event 
and the aftermath (e.g., securing temporary housing and filing insurance claims), increased commute time due to flooded roadways, and business or supply chain disruptions. Some of these quality-of-life aspects, such as commute time impacts, can be directly quantified, but other aspects, such as psychological stress, may only be qualitatively described or indirectly described through metrics such as willingness-to-pay to avoid health impacts associated with flooding (Defra and EA 2004). Although quantifying social performance of NNBF and other measures is not always as straightforward as quantifying damages to structures, neglecting social performance may affect investment decisions that ultimately favor protecting structures, which can exacerbate issues of equity in communities (ten Veldhuis 2011).

NNBF also provide social co-benefits outside of flood events and recovery, unlike most structural measures. Tourism and recreation, enhanced fisheries production, climate change mitigation, and water quality improvements are examples of other aspects of social performance. Recreation and educational opportunities are also examples of other aspects of social performance, and they are often described using tangible and directly measurable metrics such as visitor numbers, trail lengths, and number of educational trip visits. The performance of each of these co-benefits should be identified in the Planning Phase and monitored throughout the project life cycle. Refer to $\underline{\text { Chapter } 6}$ for more detailed information on NNBF benefits and co-benefits.

Even if social performance is not the primary stated objective of a project, social performance is critical to a project's success because the system of measures implemented to manage flood risk must be socially acceptable to the community for it to proceed, especially when local governments provide some of the funding for project planning and implementation. Just as ecological performance can support FRM benefits, social commitment to NNBF can ensure continued FRM performance. For example, in the Bahamas, community involvement in the development of FRM measures for the master plan for Andros Island was strong (Arkema et al. 2017; Natural Capital Project et al. 2017; see Andros Island case study in Chapter 6). Similarly, the City of South Padre Island, Texas, organized several volunteer dune planting events beginning in 2008 to restore dune vegetation cover damaged by storms, reinforcing the commitment of the community to the dune system (Bessette 2016; see South Padre Island case study in Chapter 3 ).

\subsubsection{Economic Performance}

FRM, ecological, and social performance of NNBF systems can ultimately be described in terms of economic performance (Beck et al. 2018; Beltrán, Maddison, and Elliott 2018). Quantifying economic performance of NNBF measures is crucial if cost-benefit analysis is used to develop projects. The most common economic metric for flood risk studies is the expected damage function (Kunreuther and Sheaffer 1970), which uses the change in avoided expected damages from an FRM project as a measurement of its value. Expected damages can be calculated on 
a per-event or annual basis for the period of analysis. Expected damages may be calculated using depth-damage curves; in some cases, more advanced inundation modeling may also be required to understand how flood depths vary across the landscape and what receptors will be impacted and for how long.

However, as mentioned previously, a focus solely on structural damages is inadequate and neglects other economic consequences of flooding, such as disruptions to businesses and supply chains and loss of income. These impacts do not affect all segments of the community equally, and the ability to recover from economic impacts related to flood events is not the same. Frequently, lower income households are disproportionally affected to a greater extent than higher income households. Consequently, economic performance assessments that focus on the value of the structures lost due to storms may not only neglect aspects of social and ecological performance but also can lead to inequitable decisions related to FRM (Beck et al. 2018; Reguero et al. 2019; Storlazzi et al. 2019). In addition, social and ecological performance metrics can be used in an ecosystem goods and services approach to develop additional economic performance metrics (Olander et al. 2015, 2018), as described in detail in Chapter 6. Recreation opportunities can be translated into potential value to the tourism industry. Likewise, NNBF that may provide habitat to juveniles or prey of commercial fisheries can potentially increase the value of the fishery.

Cumulative and synergistic co-benefits to the broader population, economy, and landscape by the complementary individual performance of different NNBF in a network should also be captured or described (e.g., the larger socioeconomic impact of a beach, dune, and reef restoration program on fishing communities). These co-benefits can be measured or evaluated using approaches described in $\underline{\text { Chapter } 6 .}$.

In some cases, economic performance cannot or is not readily able to be monetized. Although in some cases the need to monetize economic co-benefits is dictated by policy, nonmonetized economic co-benefits of NNBF should still be considered in decision-making. Several approaches that can quantify these nonmonetized economic co-benefits are presented in Table 6.7 in $\underline{\text { Chapter } 6 .}$

\section{4 | NNBF Performance Dynamism}

NNBF performance is dynamic at multiple temporal scales. Over a storm or flood event, NNBF performance may vary more than that of structural measures as the NNBF condition and geometry changes in response to the forces exerted upon it. Performance also changes over years and decades due to recovery from disturbances; in response to changes in physical forces driven by changes in climate, sea level, or landscape alteration; or in response to management actions. However, unlike structural measures, NNBF can adapt to changing 
conditions, allowing performance to be maintained or even improved over time as the biotic components of NNBF grow and mature. Coastal marshes can accrete in response to increasing inundation from sea-level rise, and oyster reefs can accrete shell and recruit new larvae that can increase the reef elevation and strengthen the reef structure. Conversely, performance and reliability of structural measures are greatest immediately after construction, with performance declining over time as the measure degrades.

NNBF performance assessment should reflect the dynamic nature of the NNBF, the physical drivers acting on it, and the assets the NNBF is meant to protect. Because NNBF rely on services provided by ecosystems to provide benefits and deliver performance, performance should be expected to reflect the natural ecosystem dynamics. For example, performance may change seasonally as vegetation moves from active to dormant growth stages. Following site management or construction activities, NNBF functions develop at different rates, and performance expectations should reflect the required maturation time for various NNBF functions to develop (see Figure 5.7). At sites that require earthwork and planting, functions that rely on the physical form of the NNBF (e.g., elevation) may be realized immediately or develop over the space of a year or two, whereas other elements of ecological performance, such as biodiversity, may take much longer.

Figure 5.7. Conceptualized Example of Performance Dynamics of a New NNBF

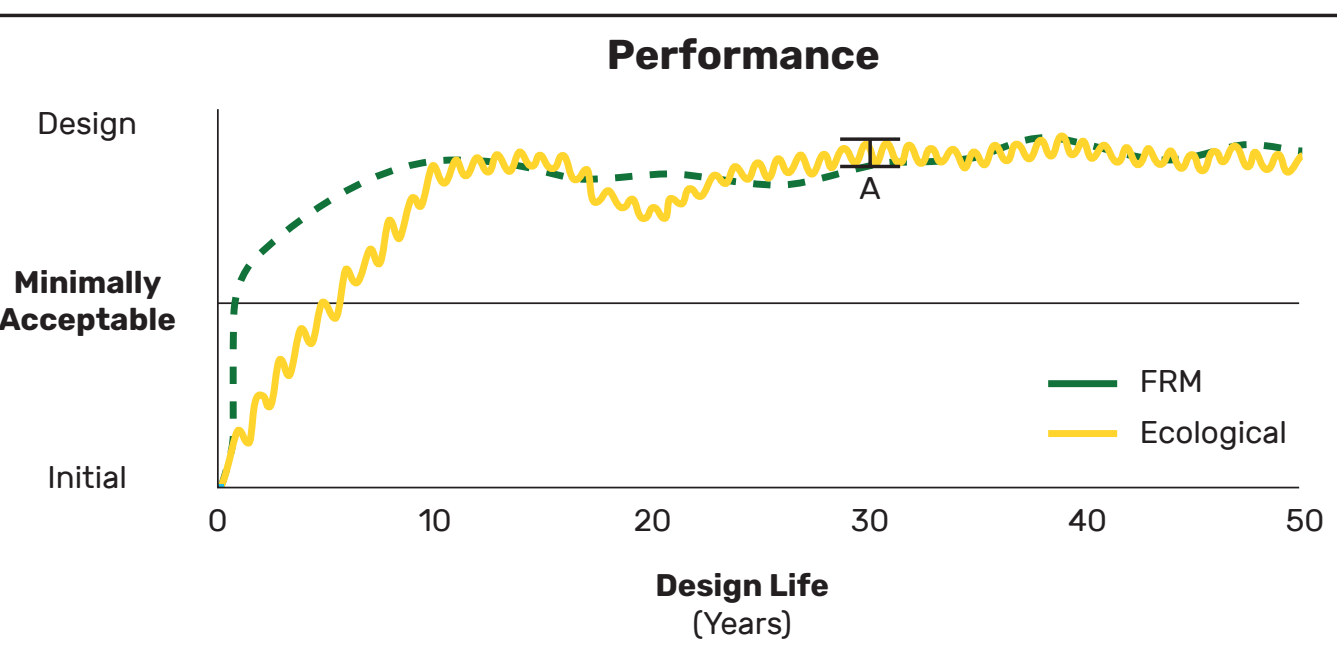

Notes: Green dashed line represents FRM performance, and yellow solid line represents ecological performance. Minimally acceptable FRM performance is immediately achieved, whereas full engineering and ecological performance takes 10 years to reach full design level. Value A represents typical seasonal variation in ecological performance. 
Although some NNBF performance dynamics can be incorporated into models, full integrated modeling of NNBF condition is not necessarily required to determine NNBF performance variability or the time required for NNBF to achieve full design performance levels. The resilience of NNBF means NNBF condition is influenced by the history of environmental conditions at the site, including storms, floods, and droughts. Similarly, the time for NNBF to reach full design performance will vary from site to site based on environmental conditions in the years immediately after implementation. Instead of trying to model every possible combination of NNBF and environmental condition, another approach is to model limiting conditions where the ideal and minimally acceptable are defined. For example, performance variability due to seasonal vegetation changes can be assessed by determining performance for the limiting conditions (e.g., peak biomass and dormant conditions). A similar approach can be used to assess performance as NNBF develops after construction, using the as-built specifications to determine performance immediately after construction and the expected performance once the biotic component of the NNBF has fully developed. Routine monitoring can also help inform how NNBF are responding to the unique combination of conditions that affect performance. In the stages after initial construction or restoration of NNBF, the trajectory of change in performance (either positive due to natural adaptation, as well as restoration and maintenance actions, or negative due to degradation) can help determine how quickly a particular NNBF may achieve full performance.

Environmental conditions can lead to degradation and an accompanying loss of performance of NNBF and structural measures, especially in the absence of maintenance. However, maintenance actions for degraded NNBF can restore or even increase performance, whereas maintenance of structural measures is unlikely to increase performance without a significant rehabilitation effort. In the case of beaches, degradation is counteracted with routine nourishment via dredging and placement of sand resources directly on the beach or in the nearshore and shoreface. Degradation rates are variable based on the frequency of extreme events but can be estimated using knowledge of the system and past projects.

Long-term changes in the physical environment and NNBF condition may require significant adaptation to the project design and performance criteria, either planned or in response to unanticipated changes in the system. NNBF can be implemented and constructed incrementally to address long-term changes in the environment, such as sea-level rise. In some cases, NNBF measures may be easier than structural measures to modify to meet the new performance criteria. For example, increasing island area and elevation to increase surge attenuation performance can be conducted relatively easily in comparison to retrofitting a floodwall to increase its height. 


\section{5 | NNBF Resilience}

Many NNBF measures are pursued to increase resilience, which, as the term is applied to critical infrastructure and risk management, refers to the ability of a system to prepare for, absorb, and recover from or adapt to adverse events (NAS 2012). However, this definition of resilience is not universal because resilience is a descriptive term that can mean different things depending on the context. Four common uses of resilience as it pertains to NNBF are FRM, ecological, community, and institutional resilience.

FRM resilience is a measurement of how well an FRM system can resist and recover from a disturbance, with a focus on system stability with some permissible oscillation around a stable equilibrium condition (Holling 1996). For highly engineered systems, FRM system condition may be quite fixed up until the point of failure. Although NNBF are designed to confer FRM function and should be considered in an FRM context, consideration of FRM resilience alone is insufficient for NNBF because they also rely on biotic components to function.

Ecological resilience is a property of persistence of an ecological system in the face of disturbances or other perturbations of system variables that may disrupt a system's stability (Holling 1973) and should be used to assess biotic components of NNBF. The persistence associated with resilient ecological systems is a key motivation for the use of NNBF over structural measures, which always require intervention to recover to a desirable state. NNBF should balance ecological resilience with ecological stability. Large disturbances can permanently alter highly stable ecological systems, especially when coupled with chronic stressors such as human development. Conversely, highly resilient ecological systems may oscillate, sometimes wildly, between at least two states (e.g., fluvial sandbars that are periodically colonized by vegetation). Although the vegetation may slow flows under moderate flow conditions, sandbars and the vegetation that colonizes them are ephemeral features that disappear and reappear along river systems; ecologically speaking, they are highly resilient features, but they would not reliably produce FRM benefits at a particular location due to their ephemeral nature. If NNBF performance depends on one ecological state, high ecological resilience would lead to unreliable performance.

Community resilience refers to the ability of a community to persist and recover from a disturbance. Highly resilient communities are able to rapidly and fully recover following a flood event and are able to withstand flood events of greater magnitude than are those that are less resilient through a combination of FRM and other infrastructure interventions, strong nonstructural measures such as emergency response, risk communication, and mitigation (Koliou et al. 2018). High community resilience is critical not only to the persistence of a community but also to the continued functioning of the FRM system, especially in cases where routine maintenance is required for function. 
Institutional resilience in the context of FRM is the ability of governments and institutional organizations to plan for, anticipate, and operate in advance of and during-and to respond and adapt to-flood events. Institutional resilience requires institutions to effectively manage and maintain FRM infrastructure including NNBF; to maintain critical functions such as emergency communications in advance of, during, and after a flood event; and to rapidly make decisions in advance of, during, and immediately after a flood event to reduce potential harm (Curt and Tacnet 2018). Institutional resilience enables and fortifies FRM, ecological, and community resilience.

To assess system resilience, the concept should be further discerned into individual components that can be measured using four aspects of resilience (preparedness, absorptive capacity, recoverability, and adaptive capacity). Resilient NNBF (or FRM systems in general) can be assessed using the four concepts shown in Figure 5.8 (prepare, absorb, recover, and adapt) (Francis and Bekara 2014; NAS 2012; Curt and Tacnet 2018). Although metrics have been proposed to measure each of these components, no universal or accepted set of metrics describes FRM systems, let alone those that include NNBF, which may increase the resilience of other co-benefits to flood-related hazards. If resilience is a project objective, the type of resilience should be specified, as well as the type of disturbance to which the project is to be resilient. Metrics used to assess project resilience should also reflect the four aspects of resilience. Examples of these four aspects of resilience as it pertains to FRM, ecological, community, and institutional resilience are shown in Figure 5.8.

Figure 5.8. Examples of Four Aspects of Resilience for FRM, Ecological, Community, and Institutional Resilience

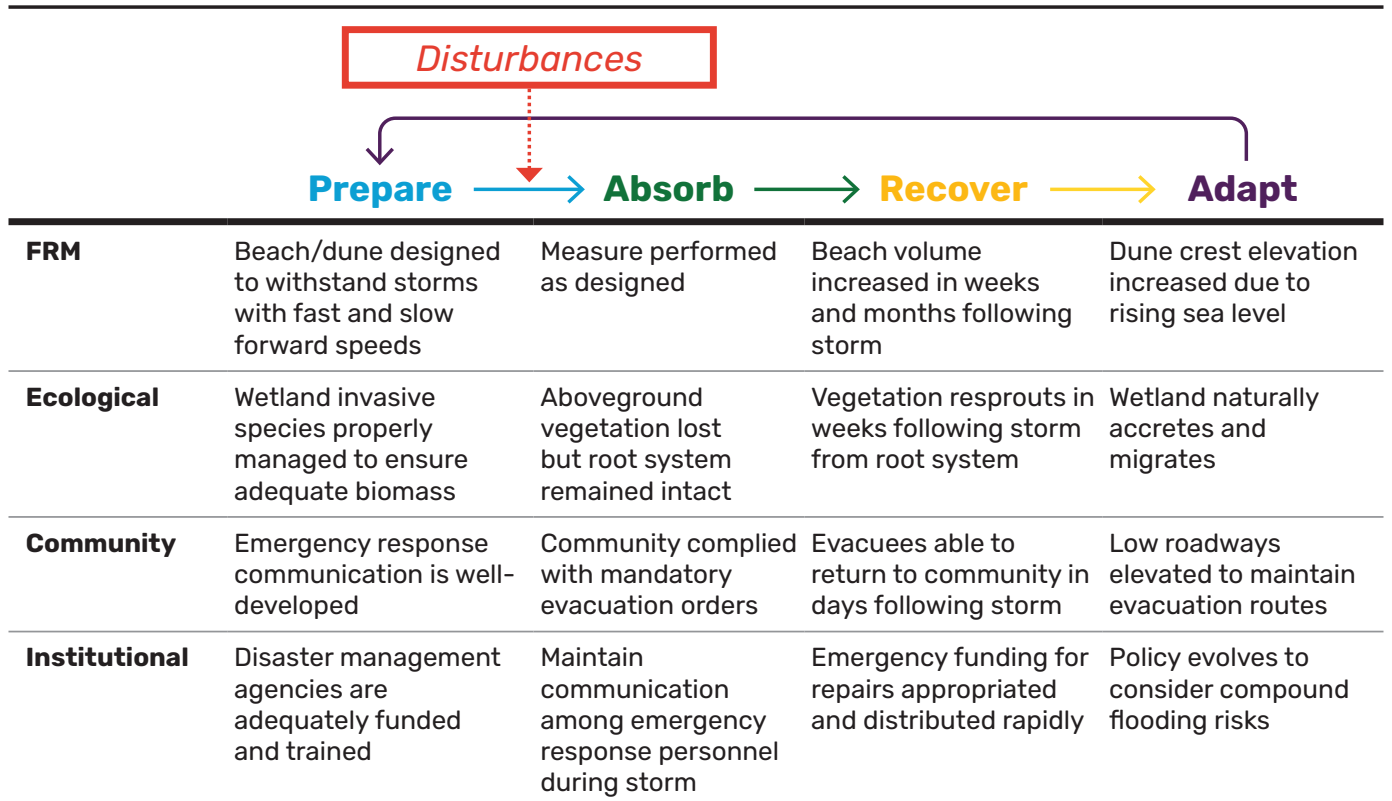


Preparedness encompasses anything done in advance of a flood that affects the ability of a system to absorb, recover, and adapt from the flood event. Preparedness includes aspects of FRM planning, which includes application of the NNBF framework and risk assessment techniques such as the SPRC model. However, preparedness can also include maintenance of existing infrastructure, including NNBF, through appropriate monitoring and management actions, actions taken to increase community resilience, and actions taken to increase institutional resilience so systems can better absorb, recover, and adapt to flood events.

Absorptive capacity is the loading a system can absorb without changing state and for which NNBF and other forms of flood infrastructure can be easily captured using typical FRM assessment approaches. However, in some cases, exceeding an NNBF absorptive capacity may not cause failure but may simply change its state. For instance, a storm event that erodes a dune system has exceeded the absorptive capacity of the dune, but the dune system still performed its FRM function and did not lead to system failure. In ecological contexts, the absorptive capacity can be quantified by the magnitude of disturbance required to change the ecological state (e.g., altering a dune's predominant vegetation from a shrub such as wax myrtle to a stabilizing grass such as salt hay). Once the condition of the dune is altered, its ability to absorb the next disturbance is altered unless the state of the dune changes either through maintenance actions or natural processes, which leads to the next concept of resilience: recoverability.

Recoverability. Resilient NNBF are recoverable; that is, they are able to recover function after a disturbance. NNBF, unlike other structural measures, have some capacity to self-repair. Recoverability can be assessed based on the degree to which function returns without rehabilitation, as well as the rate at which the function returns. During major storm events, beaches and dunes can erode significantly. However, the beach can recover relatively quickly, with portions of the beach morphology recovering over the course of months (Morton et al. 1994). Although complete recovery of the beach and dune can take longer (sometimes on the order of a decade or more), the dune system has the capacity to self-heal, and the process can be enhanced through the addition of simple actions such as the installation of fencing or nearshore (beachface) nourishment. Although NNBF are not a substitute for investment in and development of community resilience, NNBF may provide communities that lack strong community resilience with a means to recover some FRM function without expensive recovery efforts, allowing resources to be invested in the recovery of other critical components of the community rather than replacing FRM infrastructure.

Adaptive capacity, the ability of a system to evolve under changing conditions, is the final concept of resilience. NNBF have a high adaptive capacity by nature, whereas structural measures have little-to-no adaptive capacity without expensive retrofitting or construction activities. As physical, ecological, social, or economic conditions change over time, an adaptive FRM system can ideally continue providing performance as designed. In some cases, system changes or new information may indicate the FRM system is inadequate to provide the level 
of performance required, or other forces are leading to the premature loss of performance (e.g., subsidence rates in Louisiana were higher than predicted, leading to levees that did not provide the level of protection as designed). NNBF are by nature more adaptable because additional sediment can be added to features to make them larger or higher as needed without requiring retrofits or complete redesign, as is the case for some structural measures.

\section{6 | Life-Cycle Approach for NNBF Performance Assessment}

Generally, investment decisions are made-or should be made-using a life-cycle approach considering the full expected project life of a system of FRM measures including NNBF. The aim is to optimize performance for both FRM and the desired co-benefits while minimizing whole-life costs. To achieve this, the performance of NNBF-and other FRM measuresmust be projected over an entire project life cycle-and so must the maintenance actions necessary to achieve the required performance. Maintenance activities are triggered once NNBF reach a defined limiting condition, which is caused by NNBF deterioration, damage, or breach. The NNBF deterioration rate and the likelihood of damage or breach is a function of disturbance conditions at the site, how that site is influenced by regional conditions and how those conditions vary, how human use of the location will evolve, and how natural and human disturbance will change over the life of the NNBF. Not all NNBF damages require repair because some natural recovery can be expected. Depending on the expected project life, the ease to which these future conditions can be predicted will vary. Although projections of future conditions will always carry a greater uncertainty than current or past conditions, likely future changes should be examined.

Understanding the dynamics of the site and the NNBF itself will inform how the NNBF performance may change over time in response to typical conditions as well as storms. Flood and storm statistics can inform how likely a particular disturbance that may lead to damage or breach is to be experienced over a project life cycle and provide a rough estimate of the likelihood that costs for significant repair may be incurred. However, even in the absence of damaging flood or storm events, site changes and deterioration leading to insufficient performance can occur. Rates of deterioration can be predicted using modeling tools, although modeling the full range of expected future conditions is impossible. Instead, Environment Agency in the United Kingdom (Defra and EA 2013) uses standard condition-grade deterioration curves for common flood defense assets, which include NNBF such as dune and shingle beaches and wetlands. This approach uses required maintenance regime categories based on local conditions to estimate maintenance requirements and likely deterioration curves to aid in planning. Depending on the site conditions and acceptable condition grade, the life cycle of these NNBF can be relatively short or long, requiring no or 
several significant restoration or rehabilitation actions over a project life cycle. Although each site and circumstance are unique and prevent deterioration and associated maintenance from being predictable, these tools are useful for comparing alternatives to determine the relative life-cycle costs associated with NNBF maintenance. Figure 5.9 provides a conceptualized example of the performance of two FRM alternatives-one using a single structural measure and one using NNBF in combination with a structural measure over a full life cycle in a setting where chronic degradation is occurring. Note that NNBF do not need to be very large to reduce chronic degradations of associated structural measures (see Chapter 14).

\section{Figure 5.9. Conceptualized Example of the Performance of Two FRM Alternatives over a} 50-Year Life

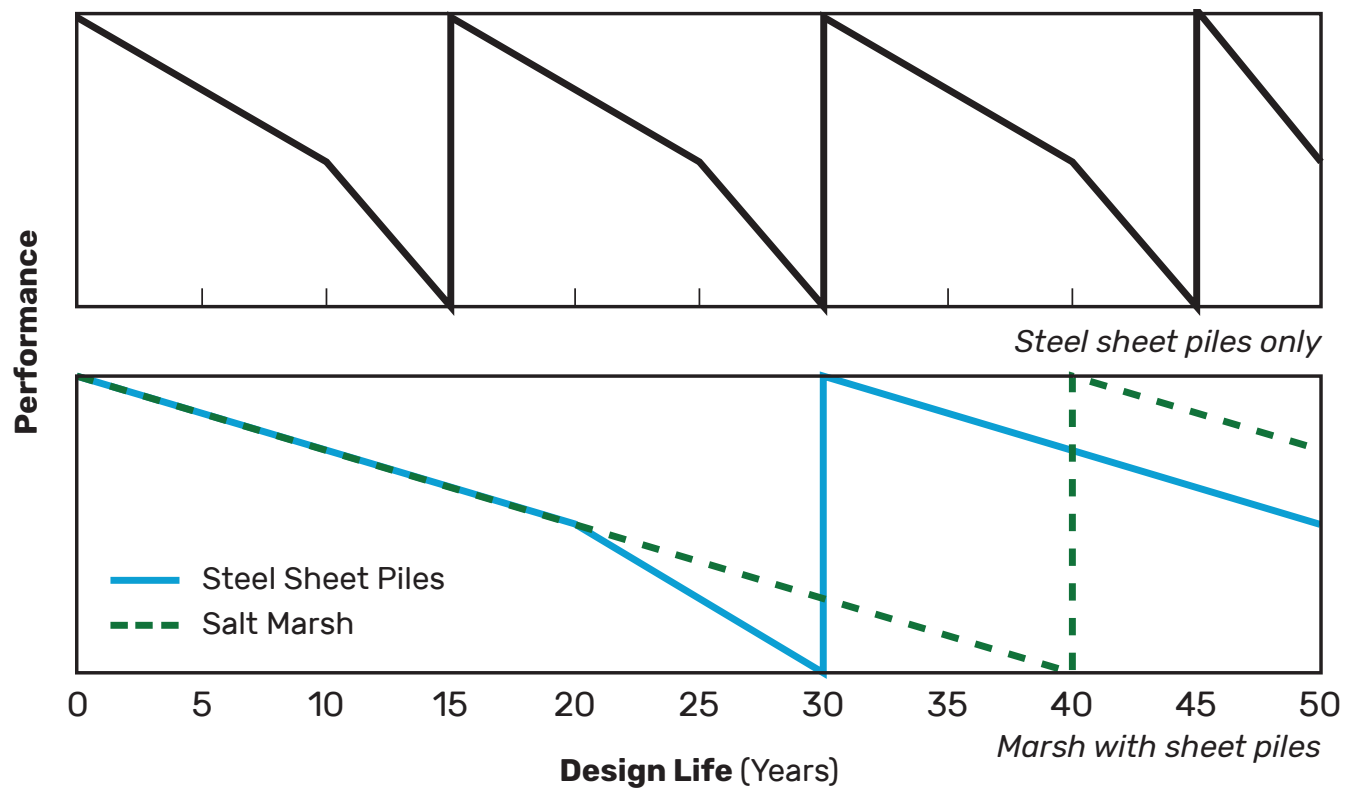

Notes: The first alternative shows steel sheet piles only; it has an estimated lifetime of 15 years and, therefore, needs to be reinstalled or rehabilitated three times during the full life cycle. The second alternative shows a marsh NNBF measure combined with sheet piles. The presence of the marsh extends the sheet pile's estimated life, so the sheet pile only needs to be reinstalled or rehabilitated once. Similarly, the marsh will require rehabilitation or restoration once during the life cycle to maintain desired performance levels.

Regular performance assessments are required during the expected lifetime of FRM projects to assess whether all measures are performing according to plan and whether adaptive measures are needed. Performance assessments for NNBF measures should be conducted at a frequency that is reflective of the dynamism of the feature and may need to occur at 
a frequency greater than that for structural measures that may change at a slower rate. Performance assessment should also consider the time horizon over which the projected benefits are expected to develop and be fully delivered. This time horizon may be longer than the expected maintenance interval of an individual NNBF measure (e.g., nourishment, leaky dam, or riparian side channel). In these cases, multiple NNBF maintenance actions are required to deliver the projected benefits during the entire project lifetime.

Projects built to provide greater FRM performance provide more FRM benefits; however, they may not produce a comparable increase in co-benefits and are also likely to cost more for both construction and maintenance. The incremental increase in FRM performance may not provide a comparable increase in co-benefit performance to justify the increase in cost. Refer to Chapters 6 and $\underline{7}$ for a more detailed discussion on the concept of the life-cycle approach.

\section{7 | Uncertainty and NNBF Performance Assessment}

Any risk-based approach to FRM must address uncertainty in performance estimates and the source of that uncertainty. Decisions regarding NNBF adoption, design, and adaptive management also require consideration of uncertainty regarding performance, especially in comparison to other alternatives. Uncertainty regarding FRM comes from two sources: the natural variability of a system (i.e., aleatory sources) and the "unknown unknowns" of a system (i.e., epistemic sources). Natural system variability can be quantified and includes the random nature of storm event characteristics, as well as random errors in data used to characterize the system and the NNBF. The unknown unknowns of the system can relate to a number of things but could include, for example, incomplete characterization of the system, changes in system state due to climate or sea-level change, model error, sample size, and measurement error. The unknown unknowns related to NNBF may or may not be greater than those associated with structural measures because many of the potential sources (especially aspects relating to proper characterization of the flood hazard) are the same for both structural and NNBF measures. Although not exhaustive, uncertainty in NNBF performance assessments would be improved by addressing these four issues: (1) proper incorporation of NNBF into models of FRM performance, (2) understanding and quantifying NNBF dynamism, (3) understanding long-term evolution and maintenance requirements of NNBF, and (4) fully accounting for NNBF benefits and co-benefits. All four of these issues have elements of both sources of uncertainty and are not exclusive to NNBF.

Incorporation of NNBF into models of FRM performance has been limited and standard model characterizations have not been established for all NNBF. NNBF condition may change during the duration of a storm or flood in ways that are not always well understood. Uncertainty 
related to modeling of NNBF can be reduced through proper conceptualization of the FRM system, proper application of numerical models, improved numerical models, improved data describing NNBF response to hazards, and measurement of aspects of FRM performance across a greater range of conditions.

Because NNBF initial condition (e.g., whether vegetation is growing or dormant and initial soil moisture) can affect NNBF performance, models of FRM performance should similarly be able to simulate performance under a range of likely conditions. Fragility curves (see "On the Concept of Failure" in Section 5.3.2.1) are commonly used to quantify the uncertainty in the response of structural measures in different condition states to different types of flood loading, but their application in FRM is often limited to one type of loading, and there are few examples of their application to NNBF (Jane et al. 2018; Gruhn et al. 2012). Accurate representation of fragility requires extensive modeling of a full range of possible condition states of the measure, as well as explicit characterization of all types of loading that can lead to failure (Jane et al. 2018). Because NNBF may have a larger range of possible condition states than structural measures due to natural variability, additional modeling scenarios may be required to fully represent NNBF fragility. Future work should focus on understanding the fragility of different common NNBF under different types of loadings to determine how performance varies.

The dynamism of NNBF increases uncertainty of expected performance because the condition of the NNBF is not fixed and does not necessarily follow a monotonic trajectory of degradation like structural measures. As mentioned in Section 5.4, full integrated modeling of dynamic NNBF processes is not required, but the range of likely states should be described. Although NNBF are by definition dynamic, the natural variability related to the biotic components of NNBF is constrained by the habitat requirements of the biotic component and can be quantified. As mentioned previously, understanding the limiting conditions that constrain NNBF performance and modeling those boundaries can be used to determine a range of expected performance across a range of possible conditions. For example, beaches naturally vary in width and volume in response to seasonal changes and storm events. Rather than require each new project model performance for every possible beach and dune condition, Environment Agency in the United Kingdom defines several condition states for common beach-dune profiles that describe the expected performance of the system (Defra and EA 2013). A similar approach can be applied to other common NNBF types to provide more tools that can be used in project planning and monitoring.

Adaptive management including routine maintenance can be used to further constrain NNBF natural variability and reduce the risk of FRM system failure to achieve performance standards. If some naturally occurring beach states are not able to deliver the required performance, then maintenance actions such as nearshore (shoreface) nourishment are taken to change the state to a condition able to provide the required performance. However, the maintenance 
schedule for some NNBF is not always well known or understood. There is increasing evidence of short- or long-term vulnerabilities and risks for communities along coasts and within watersheds, but future site conditions are not well understood because future development patterns, sea-level rise, and climate change all may affect the future performance of all FRM measures. Use of NNBF within an adaptive management context can reduce potential harm from these unknown risks regarding future conditions without having to rely on highly uncertain model projections that could lead to over- or under-design of FRM projects. Adaptive management can be used in a phased implementation approach where demonstration projects are used to better understand and reduce sources of uncertainty related to NNBF performance dynamics. Lessons learned as part of demonstration projects can be immediately applied to the later Implementation Phase to reduce uncertainty. For more information on adaptive management, see $\underline{\text { Chapter } 7 .}$

Uncertainty associated with NNBF FRM performance may not be the greatest uncertainty for an FRM project. Uncertainty related to ecological and social co-benefit quantification is high, and these co-benefits are frequently ignored in many FRM studies regardless of the measures examined. Because NNBF have a greater potential to deliver ecological and social co-benefits, neglect of these types of co-benefits can lead to decisions that do not maximize benefit to communities. However, categories of benefits should not be neglected simply because of high actual or perceived levels of uncertainty. Estimates of consequences, especially economic consequences, are often the greatest source of uncertainty in FRM, so relative differences in uncertainty regarding NNBF or structural FRM performance may be small when compared to uncertainties regarding social or economic performance. Instead, consistent frameworks for inclusion of all benefit streams should be developed to manage uncertainty related to decision-making and investment in a transparent manner.

\section{8 | Gaps and Future Directions}

Improving characterization of performance. Although uncertainty in performance is commonly cited as a potential barrier to NNBF implementation (Piercy et al., forthcoming), evidence of performance of various NNBF is growing (see the second and third major sections of this NNBF Guidelines-coastal applications of NNBF [including open coast and estuarine environments] and NNBF applications in fluvial or riverine environments, respectively). However, NNBF performance in many cases is not as simple to characterize and quantify as performance of structural measures; many structural measures serve as barriers to floodwater, typically providing a consistent measurement of FRM performance up to the point of failure. Methods and tools are needed that can better capture the dynamic nature of NNBF performance. Similarly, performance of structural measures should not be treated as static, allowing better consideration of measure deterioration processes and resulting fragility. 
Development and selection of performance metrics. Although risk assessment methodologies are more widely adopted for FRM projects, additional research is needed on how to develop and select performance metrics that describe how individual measures and the FRM system as a whole serve to reduce inherent and residual risks associated with flood hazards.

Risk evaluation across the project life cycle. Additional research is needed on how to consider risk across project life cycles, especially in cases where future conditions may be changing. For instance, in low-elevation coastal areas, development patterns and population centers may potentially shift in response to changing sea levels, potentially affecting how risk is distributed even if acute flood hazards are managed.

\section{Holistic quantification and consideration of benefits and co-benefits of NNBF}

performance. Methods are required to enable consideration and quantification, when possible, of the multiple facets of NNBF performance with respect to benefit and co-benefit production. Governance and policies should also be revised to allow consideration of benefits and co-benefits of FRM projects in a holistic manner as opposed to the narrow focus with which many FRM projects are currently justified. As resilience is commonly cited as an advantage of NNBF measures over structural measures, future work should focus on developing methodologies and metrics to better quantify resilience for all FRM projects.

\section{9| References}

Arkema, K., R. Griffin, S. Maldonado, J. Silver, J. Suckale, and A. Guerry. 2017. “Linking Social, Ecological, and Physical Science to Advance Natural and Nature-Based Protection for Coastal Communities." Annals of the New York Academy of Sciences 1399 (1): 5-26. doi:10.1111/nyas.13322.

Beck, M. W., I. J. Losada, P. Menéndez, B. G. Reguero, P. Díaz-Simal, and F. Fernández. 2018. "The Global Flood Protection Savings Provided by Coral Reefs." Nature Communications 9 (1): 2186.

Beltrán, A., D. Maddison, and R. J. Elliott. 2018. "Is Flood Risk Capitalised into Property Values?" Ecological Economics 146: 668-685.

Bessette, S. R. 2016. South Padre Island Beach Management: Assessment of Dune Restoration. PowerPoint Presentation. Edinburg, TX: University of Texas Rio Grande Valley.

Checkland, P., and J. Poulter. 2006. Learning for Action: A Short Definitive Account of Soft Systems Methodology and Its Use for Practitioner, Teachers, and Students. Vol. 26. Chichester, UK: Wiley.

Curt, C., and J. M. Tacnet. 2018. "Resilience of Critical Infrastructures: Review and Analysis of Current Approaches." Risk Analysis 38 (11): 2441-2458. 
Defra and EA (Department for Environment, Food, and Rural Affairs and Environment Agency). 2004. The Appraisal of Human Related Intangible Impacts of Flooding. Technical Report FD2005/TR. London: Defra Flood Management Division.

Defra and EA. 2013. Practical Guidance on Determining Asset Deterioration and the Use of Condition Grade Deterioration Curves. Revision 1. Report SC060078/R1. Bristol: Environment Agency.

Francis, R., and B. Bekera. 2014. "A Metric and Frameworks for Resilience Analysis of Engineered and Infrastructure Systems." Reliability Engineering \& System Safety 121: 90-103.

Grilli, A., M. L. Spaulding, B. A. Oakley, and C. Damon. 2017. "Mapping the Coastal Risk for the Next Century, Including Sea Level Rise and Changes in the Coastline: Application to Charlestown RI, USA." Natural Hazards 88 (1): 389-414.

Gruhn, A., D. Salecker, P. Fröhle, H. Schüttrumpf, and F. Thorenz. 2012. "Assessment of Hydraulic Loads and Derivation of Failure Probabilities as a Basis for the Determination of Fragility Curves for Flood Defence Dunes." Paper presented at the 6th ChineseGerman Joint Symposium on Hydraulic and Ocean Engineering (CGJOINT2012), Keelung, TW. September 2012.

Holling, C. S. 1973. "Resilience and Stability of Ecological Systems." Annual Review of Ecology and Systematics 4 (1): 1-23.

Holling, C. S. 1996. "Engineering Resilience versus Ecological Resilience." In Engineering Within Ecological Constraints. Edited by P. Schulze. Washington, DC: National Academies Press.

Jane, R. A., D. J. Simmonds, B. P. Gouldby, J. D. Simm, L. Dalla Valle, and A. C. Raby. 2018. “Exploring the Potential for Multivariate Fragility Representations to Alter Flood Risk Estimates." Risk Analysis 38 (9): 1847-1870.

Koliou, M., J. W. van de Lindt, T. P. McAllister, B. R. Ellingwood, M. Dillard, and H. Cutler. 2018. "State of the Research in Community Resilience: Progress and Challenges." Sustainable and Resilient Infrastructure 5 (4): 131-151.

Kunreuther, H., and J. R. Sheaffer. 1970. "An Economically Meaningful and Workable System for Calculating Flood Insurance Rates." Water Resources Research 6 (2): 659-667.

Morris, M., W. Allsop, F. Buijs, A. Kortenhaus, N. Doorn, and D. Lesniewska. 2008. “Failure Modes and Mechanisms for Flood Defence Structures." In Flood Risk Management: Research and Practice. Edited by P. Samuels, S. Huntington, W. Allsop, and J. Harrop. London: Taylor \& Francis Group.

Morton, R. A., J. G. Paine, and J. C. Gibeaut. 1994. "Stages and Durations of Post-Storm Beach Recovery, Southeastern Texas Coast, USA." Journal of Coastal Research 10 (4): 884-908. 
Narayan, S., S. Hanson, R. J. Nicholls, D. Clarke, P. Willems, V. Ntegeka, and J. Monbaliu. 2012. "A Holistic Model for Coastal Flooding Using System Diagrams and the SourcePathway-Receptor (SPR) Concept." Natural Hazards and Earth System Science 12 (5): 1431-1439.

NAS (National Academy of Sciences). 2012. Disaster Resilience: A National Imperative. Washington, DC: National Academies Press.

Natural Capital Project, Office of the Prime Minister, Inter-American Development Bank, BRL Ingénierie, and Blue Engineering Ltd. 2017. Sustainable Development Master Plan for Andros Island. Stanford: Natural Capital Project, Stanford University.

Olander, L., R. J. Johnston, H. Tallis, J. Kagan, L. Maguire, S. Polasky, D. Urban, J. Boyd, L. Wainger, and M. Palmer. 2015. Best Practices for Integrating Ecosystem Services into Federal Decision Making. Durham, NC: National Ecosystem Services Partnership, Duke University.

Olander, L. P., R. J. Johnston, H. Tallis, J. Kagan, L. A. Maguire, S. Polasky, D. Urban, J. Boyd, L. Wainger, and M. Palmer. 2018. "Benefit Relevant Indicators: Ecosystem Services Measures That Link Ecological and Social Outcomes." Ecological Indicators 85: 1262-1272.

Piercy, C. D., S. Altman, T. M. Swannack, C. C. Carrillo, E. Russ, and J. Winkelman. Forthcoming. Expert Elicitation Workshop for Planning Wetland and Reef NNBF Futures EMRRP Technical Notes Collection. Vicksburg, MS: U.S. Army Engineer Research and Development Center. http://cw-environment.usace.army.mil/eba/.

Reguero, B. G., F. Secaira, A. Toimil, M. Escudero, P. Diaz-Simal, M. W. Beck, R. Silva, C. Storlazzi, and I. J. Losada. 2019. "The Risk Reduction Benefits of the Mesoamerican Reef in Mexico." Frontiers in Earth Science 7: 125.

Storlazzi, C. D., B. G. Reguero, A. D. Cole, E. Lowe, J. B. Shope, A. E. Gibbs, B. A. Nickel, R. T. McCall, A. R. van Dongeren, and M. W. Beck. 2019. Rigorously Valuing the Role of U.S. Coral Reefs in Coastal Hazard Risk Reduction. Open-File Report 2019-1027. Reston, VA: U.S. Department of the Interior and U.S. Geological Survey.

ten Veldhuis, J. A. E. 2011. "How the Choice of Flood Damage Metrics Influences Urban Flood Risk Assessment." Journal of Flood Risk Management 4 (4): 281-287.

USACE (U.S. Army Corps of Engineers). 2019. Risk Assessment for Flood Risk Management Studies. ER 1105-2-101. Washington, DC: Department of the Army.

Zhu, Z., V. Vuik, P. J. Visser, T. Soens, B. van Wesenbeeck, J. van de Koppel, S. N. Jonkman, S. Temmerman, and T. J. Bouma. 2020. "Historic Storms and the Hidden Value of Coastal Wetlands for Nature-Based Flood Defence." Nature Sustainability 3: 853-862. 


\section{Acknowledgments}

\section{Lead Authors}

Candice D. Piercy, U.S. Army Corps of Engineers, United States

Jonathan D. Simm, HR Wallingford, United Kingdom

\section{Co-Authors}

Todd S. Bridges, U.S. Army Corps of Engineers, United States

Missaka Hettiarachchi, World Wildlife Fund, Australia and Sri Lanka

Quirijn Lodder, Rijkswaterstaat, the Netherlands

\section{Contributors}

Todd Swannack, U.S. Army Corps of Engineers, United States

Peter Murdoch, U.S. Geological Survey, United States 


\section{Endnotes}

' Note that return intervals have often been used in FRM studies to describe the likelihood that a flood event would occur (e.g., 100-year flood event). However, for the lay person, this may be misinterpreted that a 100-year flood event will occur only once every 100 years. Annual exceedance probabilities, which are the inverse of return intervals, are generally preferred because the probability that a flood event of a given magnitude would occur in any given year is the same regardless of when the last major flood event of that magnitude occurred. 

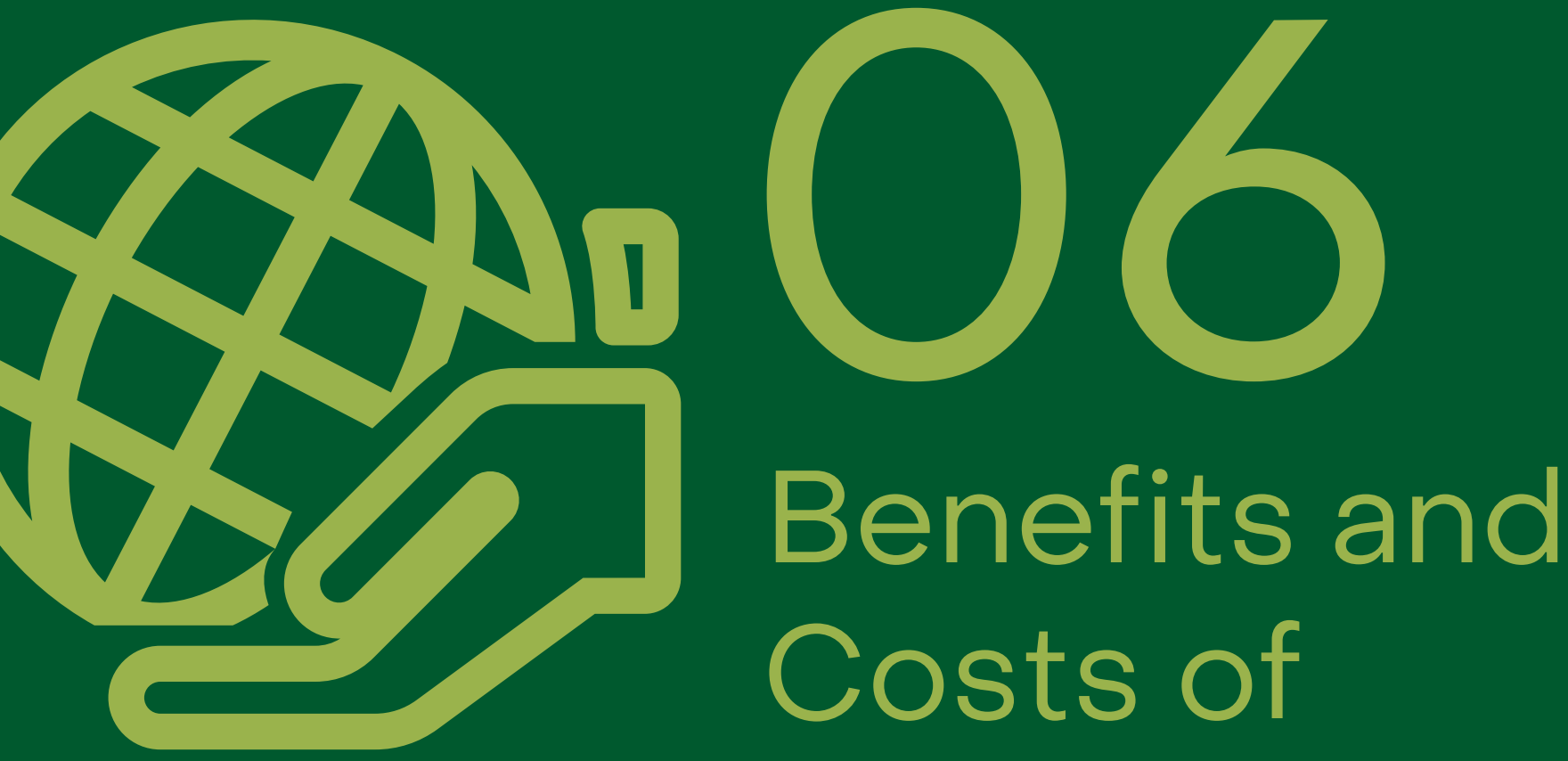

\section{NNBF}

\section{Suggested Citation:}

van Zanten, B., K. Arkema, T. Swannack, R. Griffin, S. Narayan, K. Penn, B. G. Reguero, G. Samonte, S. Scyphers, E. Codner-Smith, S. IJff, M. Kress, and M. Lemay. 2021. "Chapter 6: Benefits and Costs of NNBF." In International Guidelines on Natural and Nature-Based Features for Flood Risk Management. Edited by T. S. Bridges, J. K. King, J. D. Simm, M. W. Beck, G. Collins, Q. Lodder, and R. K. Mohan. Vicksburg, MS: U.S. Army Engineer Research and Development Center.

Full acknowledgments appear at the end of this chapter. 


\section{Key Messages}

1. Natural and nature-based features (NNBF) provide risk reduction benefits as well as additional co-benefits that are all highly valued by society.

2. Benefits should be considered in each phase of the project cycle.

3. Benefits often take time to accrue until the NNBF becomes fully functional.

4. Multiple valuation approaches and metrics can be used to qualitatively and quantitatively assess benefits and social vulnerability outcomes.

5. Different metrics and related decision-support tools (e.g., cost-benefit analysis, multicriteria analysis) may be suitable for different stakeholders and audiences.

6. Measuring and quantifying benefits and costs are important when comparing NNBF and structural measure alternatives for consideration in management strategies and designs, as well as for the identification of project funding and financing.

7. Monitoring and evaluating benefits, as well as ecological and physical changes, are important for ensuring NNBF meet the multiple needs of coastal communities and for communicating the benefits of NNBF to stakeholders.

8. In data-poor environments, benefit assessment can adopt participatory and qualitative approaches, as well as utilize secondary and Earth observation data for quantitative assessment and monitoring. 


\section{1 | Introduction}

Flooding and erosion affect vulnerable communities around the globe. Each year from 2016 to 2018 , an average of 3,400 lives were lost and more than $\$ 30$ billion U.S. dollars (USD) in damages resulted from floods (EM-DAT 2019). Without the presence of NNBF, annual losses are expected to increase dramatically; for example, the global annual avoided damages due to the presence of mangroves and coral reefs have been estimated at USD\$65 billion and USD\$4 billion, respectively (Beck et al. 2018; Menéndez et al. 2020). The primary goals of protecting and restoring natural and nature-based features (NNBF) are to reduce the risk of flooding and erosion, adapt to climate change, and build coastal resilience. In addition to reducing disaster risk and building resilience, NNBF can provide co-benefits that support the development of the blue economy and address specific societal challenges such as water security, food security, and human health (World Bank 2017; IPCC 2019; GCA 2019; IUCN 2020). These co-benefits help to support the positioning of NNBF in relation to alternative structural measures. Recovery from the Coronavirus Disease 2019 (COVID-19) pandemic provides a strong additional rationale for investing in NNBF because investing in nature has proven to be an effective way to create jobs, while enhancing our natural environment, with estimates in the United States of up to 17 jobs per USD\$1 million invested in the United States (Edwards, Sutton-Grier, and Coyle 2013).

Unlike those of gray infrastructure (e.g., seawalls, breakwaters, groins, and jetties), the risk reduction benefits of NNBF historically have not been estimated in metrics that relate to human well-being-such as the amount of property damage prevented or the number of people protected-so NNBF are often not considered on the same terms in decision-making processes. Comparing NNBF with structural alternatives requires an understanding of their relative costs and benefits, including both disaster risk reduction and co-benefits. Appropriate methods for achieving that understanding are discussed in this chapter.

This chapter provides guidance on assessing risk reduction benefits for NNBF in social and economic terms, such as damages to coastal and fluvial infrastructure and properties avoided due to flood protection and shoreline stabilization (see also Chapters 8 to 14, which address coastal systems, and Chapters 15 to 19, which address fluvial systems). Flooding and erosion risk reduction by NNBF can be achieved via different processes depending on the type of NNBF, including trapping sediments, dampening waves, and storing water, as described in more detail in the coastal and fluvial systems chapters of these guidelines. Advances in modeling have increased the capacity to value the risk reduction benefits of NNBF. For example, recent analyses estimate that coral reefs in the United States provide more than USD\$1.8 billion per year in flood risk reduction benefits (Storlazzi et al. 2019). In addition, salt marsh and mangrove wetlands reduce annual flood risks to properties by $15 \%$ to $25 \%$ in regions across the United States (Narayan et al. 2017; Narayan, Bitterwolf, and Beck 2019). Recently, global benefit-cost ratios (BCRs) for protecting mangroves were estimated at more than five to one (GCA 2019). 
This chapter also describes approaches to assess the co-benefits provided by NNBF. These include habitat for fisheries, opportunities for tourism and recreation, carbon storage and sequestration, and human health benefits (Barbier et al. 2011). Guidance is needed to help practitioners better incorporate co-benefits of NNBF into the assessment of design alternatives for risk reduction (see Chapter 2 ) and into other decision-making contexts such as habitat restoration and coastal management. Assessing co-benefits is also important for anticipating trade-offs and potential impacts to target resources, and for establishing a vernacular through which multiple agencies and stakeholders can define shared objectives and support the development of performance standards that capture economic, social, and ecological outcomes of implementing NNBF (NSTC 2015; also see Chapter 5).

This chapter aims to improve understanding and application of benefits information with guidance on (1) economic approaches for quantifying risk reduction benefits by NNBF and (2) approaches for assessing co-benefits in economic and social terms. In the introductory sections that follow, risk reduction benefits and co-benefits are defined in Section 6.1.1. The basic NNBF benefits assessment is outlined in Section 6.1.2, followed by a discussion of how to integrate NNBF benefits assessment in different project phases in Section 6.1.3, as described in the framework chapter of these guidelines (Chapter 2). The contents of the subsequent sections in this chapter are listed at the end of this section.

\subsubsection{Definition of Benefits}

In these guidelines, benefits are divided into the following two categories (Figure 6.1):

- Risk reduction and resilience benefits. These are the risk reduction properties of NNBF, specifically flood protection and erosion control. Flood protection is achieved through (storm) water absorption through infiltration, flood storage, or wave and surge attenuation. NNBF can help to build and stabilize shorelines and riverbanks, thus reducing erosion. NNBF are often a more resilient solution because they are able to adapt to changing conditions such as sea-level rise or land subsidence.

- Co-benefits. These are defined as any other relevant benefit derived from NNBF. For example, the co-benefits of NNBF include habitat for fisheries, nature-based tourism and recreational opportunities, carbon storage and sequestration, and human health benefits. Co-benefits are highly specific to each type of NNBF; the main categories of co-benefits adopted in these guidelines are described in Section 6.2.2. 


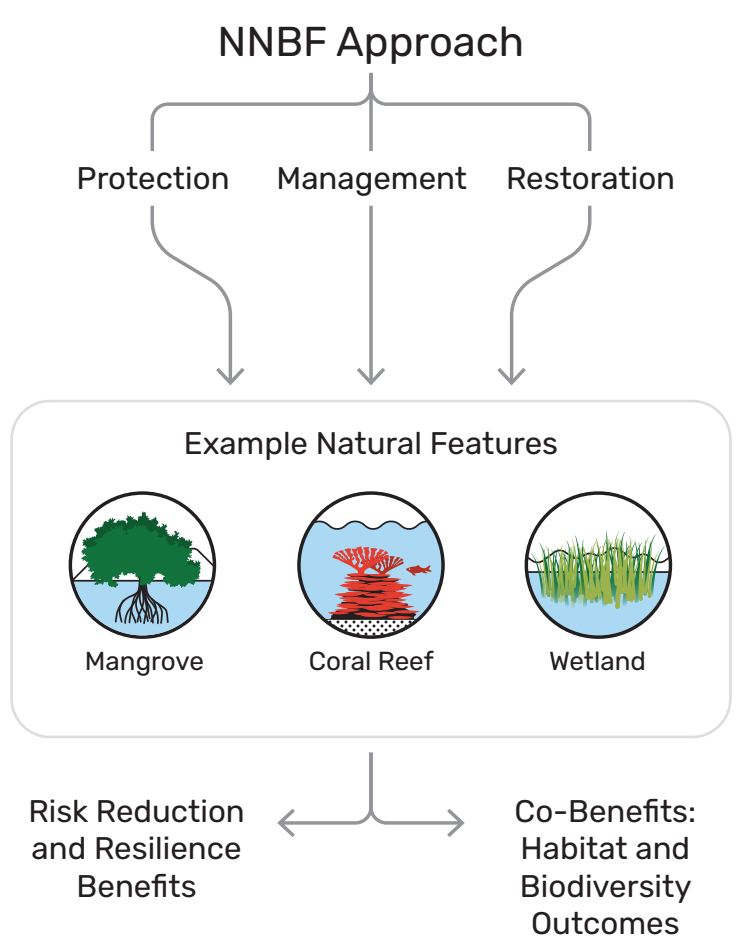

The definition of benefits used in this chapter builds on the concept of ecosystem services, popularized originally by the Millennium Ecosystem Assessment (MEA 2005) and advanced over the past two decades by scholars and practitioners around the world (Daily 1997; Costanza 1997; Guerry et al. 2015; Diaz et al. 2018). This chapter adopts the most recent broadly accepted definition of ecosystem services-the contribution of nature to peoplewhich comes from the Intergovernmental Science-Policy Platform on Biodiversity and Ecosystem Services (Diaz et al. 2018). By encompassing natural components, NNBF have the potential to contribute to human well-being in diverse ways.

\subsubsection{NNBF Benefits Assessment in a Nutshell}

The first and most fundamental step of assessing risk reduction benefits and co-benefits of NNBF is explicitly recognizing and assessing how changes in natural features lead to changes in the provision of benefits (Figure 6.2). For example, wetland restoration can lead to changes in wave heights through the frictional effects of vegetation blades, stems, and branches on water flow, and influence patterns of overtopping berms and other coastal structures, which, 
in turn, can influence damages and maintenance costs (Figure 6.2 [A]). Similar relationships exist for other co-benefits, such as fisheries. These same wetlands provide habitat for fish refuge and recruitment, which, in turn, can lead to greater stock biomass, catch, and nutritional benefits and can support fisheries-related livelihoods (Figure 6.2 [B]). During the last two decades, much research has been dedicated to understanding and quantifying relationships between changes in ecosystems and changes in outcomes that matter to people (Barbier et al. 2011; Costanza et al. 2017; Guerry et al. 2015; Maes et al. 2016; Diaz et al. 2018; Olander et al. 2018).

This chapter adopts the framing and terminology of foundational studies that applied this approach to NNBF (specifically, Beck and Lange 2016; Arkema et al. 2017; Olander et al. 2018). The resulting conceptual model for assessing benefits is shown in Figure 6.2. The conceptual model in Figure 6.2 links changes in NNBF that result from a management action or policy (red boxes) to changes in the structure and function of the NNBF (yellow boxes) and how those changes, in turn, influence ecosystem services (green boxes) and societal benefits (blue boxes; Arkema et al. 2017). This conceptual model can be integrated with different types of costs to assess both benefits and costs of a specific intervention and more fully explore trade-offs of alternative designs.

Figure 6.2. Conceptual Model for Assessing Benefits of NNBF and Application to Risk Reduction and Co-Benefits

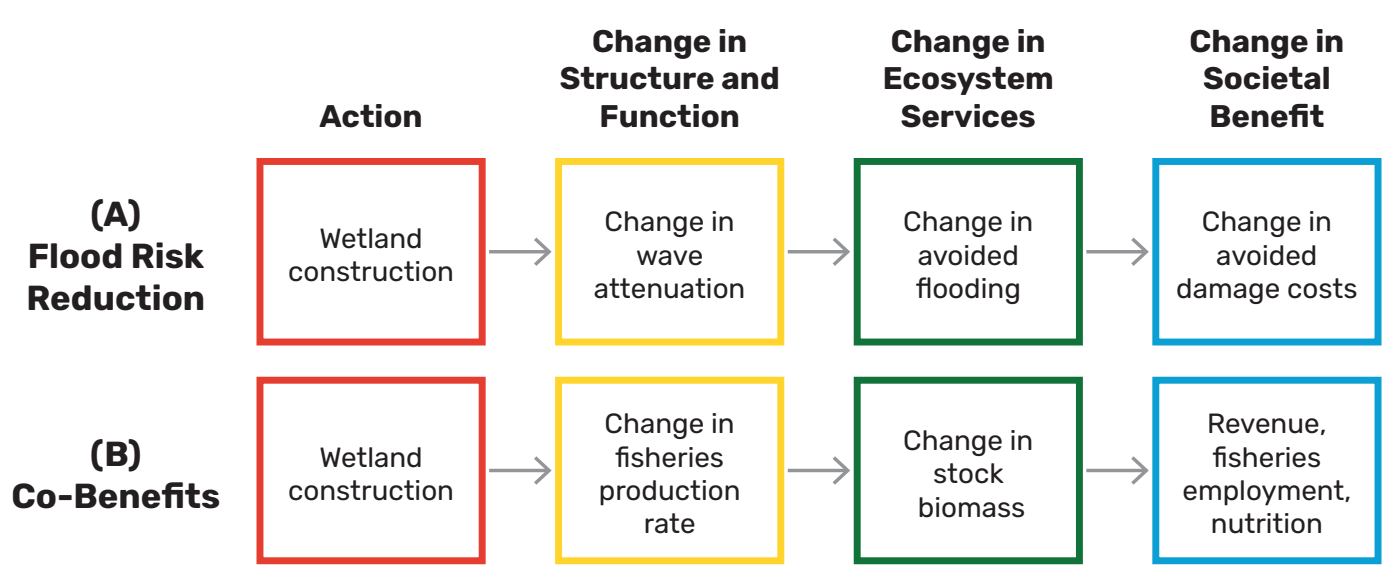

Notes: This example uses wetland construction to show the application of the framework to (A) flood risk reduction and (B) co-benefits. Red indicates the action taken, yellow indicates the change in the structure and function of the NNBF, green indicates the change in ecosystem services, and blue indicates the change in the societal benefit. The general framework builds on the ecosystem services literature and is adapted from Beck and Lange (2016), Arkema et al. (2017), and Olander et al. (2018). For the purposes of illustration, we have excluded the many possible ecological and socioeconomic feedbacks that may occur among steps in this framework. 
A second important step is comparing the benefits of project alternatives. For this step, it is important to understand the strategic priorities and policy mechanisms of the agency developing the NNBF project. Different organizations will prioritize different types of benefits, and, as a result, different decision-support frameworks and conceptual models can be applied to compare these benefits. For some conservation groups or regulatory agencies, habitat restoration or water quality improvements may be objectives in themselves, whereas other institutions, such as emergency management and risk reduction agencies, insurance companies, and businesses, may focus on risk reduction benefits first and on co-benefits that can be monetized second.

Project alternatives that include NNBF can be compared using different decision-support tools. For projects or organizations that focus exclusively on monetized benefits, a cost-benefit analysis (CBA) may be used to compare alternatives. Projects and organizations that value cultural benefits (e.g., aesthetic quality), "intermediate" ecosystem services without a direct benefit to people (e.g., biodiversity and habitat outcomes, preventing erosion in an uninhabited area), nonmonetized indicators of societal value (e.g., count of families below the poverty line within the flood zone), or a mixture of monetized and nonmonetized benefits may use a variety of other decision-support tools, including multicriteria analysis (MCA), cost-effectiveness analysis (CEA), or other less structured approaches to analyze trade-offs.

The effect of considering a wider range of benefits and co-benefits is to raise the possibility of drawing multiple types of stakeholders into a project's development and longevity (each interested in different types of co-benefits). A diversity of stakeholders can help identify a suite of co-benefits that can be monetized, rather than relying on a single project sponsor interested primarily in flood risk reduction, for example. In addition, stakeholders may serve as potential sources for project financing and provide capacity and support for implementation and maintenance. The enhanced perspectives and financial resources gained from a large stakeholder group should permit a more holistic, robust, and imaginative approach to the NNBF project.

\subsubsection{Guidance Format for Assessing Costs and Benefits in the NNBF Framework}

NNBF benefits should be considered in each phase of the project and should be an integral part of project design. Each phase of the NNBF project development framework requires a different approach to benefits assessment (see Section 2.5 and Figure 2.3 in Chapter 2 and Figure 6.3 in this chapter), as follows: 
- Scoping Phase. During the NNBF Scoping Phase (see discussion in Chapter 2 , Section 2.5.1), flood and erosion risk reduction benefits and co-benefits are identified and assessed on a qualitative or semiqualitative level. It is useful to determine whether project proponents will be required to quantitatively assess co-benefits in addition to flood reduction to get project approval.

- Planning Phase. During the Planning Phase (see discussion in Chapter 2, Section 2.5.2), these flood reduction benefits and potential co-benefits should be quantitatively assessed.

- Decision-Making Phase. Using decision-support tools, such estimates of risk reduction benefits and potential co-benefits are included in the Decision-Making Phase (see discussion in Chapter 2, Section 2.5.3).

- Implementation Phase. The project should be implemented (see discussion of Implementation Phase in Chapter 2, Section 2.5.4) based on the outcomes of the benefits assessment to ensure delivery of the risk reduction benefits and co-benefits.

- Operations Phase. Benefits and co-benefits should be monitored in the Operations Phase (see discussion in Chapter 2, Section 2.5.5). This monitoring stage should include regular assessments of risk reduction performance and co-benefit accrual. If the NNBF is not achieving its intended objectives, then the feature should be adaptively managed (refer to Chapter 7 for more details).

Figure 6.3. Phases in the NNBF Project Development Framework

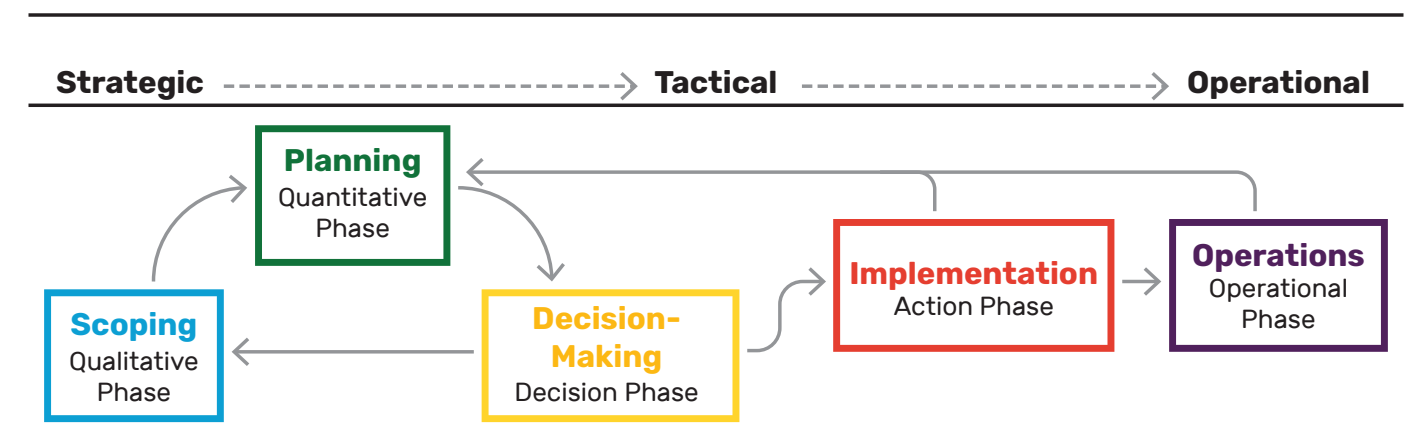

This framework for assessing NNBF, linked to the overall framework in Chapter 2 , will be returned to throughout this chapter. The assessment and evaluation of benefits during the Scoping Phase, Planning Phase, Decision-Making Phase, and Implementation Phase is often an iterative process. For example, in the Decision-Making Phase, a project might be adapted, which may involve returning to portions of the Scoping Phase and the Planning Phase to estimate changes in expected delivery of benefits. On a longer timescale, monitoring and evaluation during the Operations Phase could reveal deficiencies in the project design for delivery of risk reduction and co-benefits; if this is the case, then adaptive management would be required (refer to $\underline{\text { Chapter } 7 \text { ). }}$ 
The following sections of this chapter discuss the different levels of detail of benefit assessment throughout this iterative framework:

- Section 6.2 focuses on describing risk reduction and co-benefits of NNBF to give readers examples of the types of benefits that could be included in a project assessment and to highlight the evidence and importance of these benefits for addressing societal challenges.

- Section 6.3 provides guidance on scoping and qualitatively assessing NNBF benefits. The Scoping Phase (which includes the qualitative assessment) often defines the selection of site, scale, time horizon, type of NNBF, and risk reduction and co-benefits to be assessed in the next stages of the project. Stakeholder engagement (see Chapter 3 ) is an important element in this phase.

- Section 6.4 provides guidance on the quantitative assessment of NNBF benefits to inform the Planning Phase and Decision-Making Phase of a project. The section presents approaches for monetary valuation as well as nonmonetary quantification of benefits using indirect measures.

- Section 6.5 provides guidance and examples on the use of MCA, CBA, and CEA to compare solutions. It also describes options for handling the uncertainty in costs and benefits in a decision-support framework.

- Section 6.6 discusses monitoring and managing the performance and benefits of NNBF.

- Section 6.7 discusses gaps and future directions.

\section{2 | The Benefits and Costs of NNBF}

\subsubsection{Risk Reduction Benefits of NNBF}

NNBF provide flood risk management and erosion control by taking advantage of biophysical properties of natural systems. For example, the sloping nearshore bottom of beaches (see Chapter 9) causes waves to break and dissipates wave energy across the surf zone. Similarly, dune fields are physical barriers that reduce inundation and wave attack on the inward side of the dune (Bridges et al. 2015). In river systems, restored floodplains can store and convey water, and upland forests can help slow and retain runoff (World Bank 2018). These features, either alone or in conjunction with other NNBF and gray infrastructure, can reduce risk from river floods, coastal storms, and sea-level rise (Borsje et al. 2011; Gedan et al. 2011; Guannel et al. 2016). In general, coastal NNBF reduce flooding and erosion as a result of wave and surge attenuation, water storage, or both (Arkema et al. 2017; World Bank 2017). Fluvial NNBF reduce flooding by storage, by slowing or infiltrating water in upper and middle watersheds, and by improving conveyance in the lower watersheds. 
However, not every type of NNBF functions in the same way. For example, biogenic reefs and beaches attenuate waves but do not store water, whereas upland forests store water but generally have no function in dissipating wave energy. Table 6.1 summarizes the disaster risk reduction functions provided by each NNBF type. Although the mechanisms by which each NNBF provides risk reduction benefits may differ (see respective feature chapters in the coastal section [Chapters 8 to 14] and fluvial section [Chapters 15 to 19] of these guidelines), the valuation approach for them is consistent across features (e.g., Whelchel et al. 2018). It is important to keep in mind that flood risk is not only a function of the hazard itself; it also depends on the magnitude and vulnerability of exposed people, property, valuable land, and other valued assets within the hazard zone. Through attenuation of waves and water levels, stabilization of shorelines, and other effects on coastal and fluvial processes (see coastal section [Chapters 8 to 14] and fluvial section [Chapters 15 to 19] of these guidelines), NNBF can reduce the vulnerable populations at risk from coastal and fluvial hazards (Das and Vincent 2009; Arkema et al. 2013; Menéndez et al. 2019; Losada et al. 2018), prevent loss of property and economic damages (Beck et al. 2018; Reguero et al. 2019), reduce business interruption, and substitute or complement seawalls and structural measures. Refer to Chapter 5 for approaches on quantifying risk reduction performance for types of NNBF.

\section{Table 6.1. Example NNBF Functions that Contribute to Risk Reduction Benefits*}

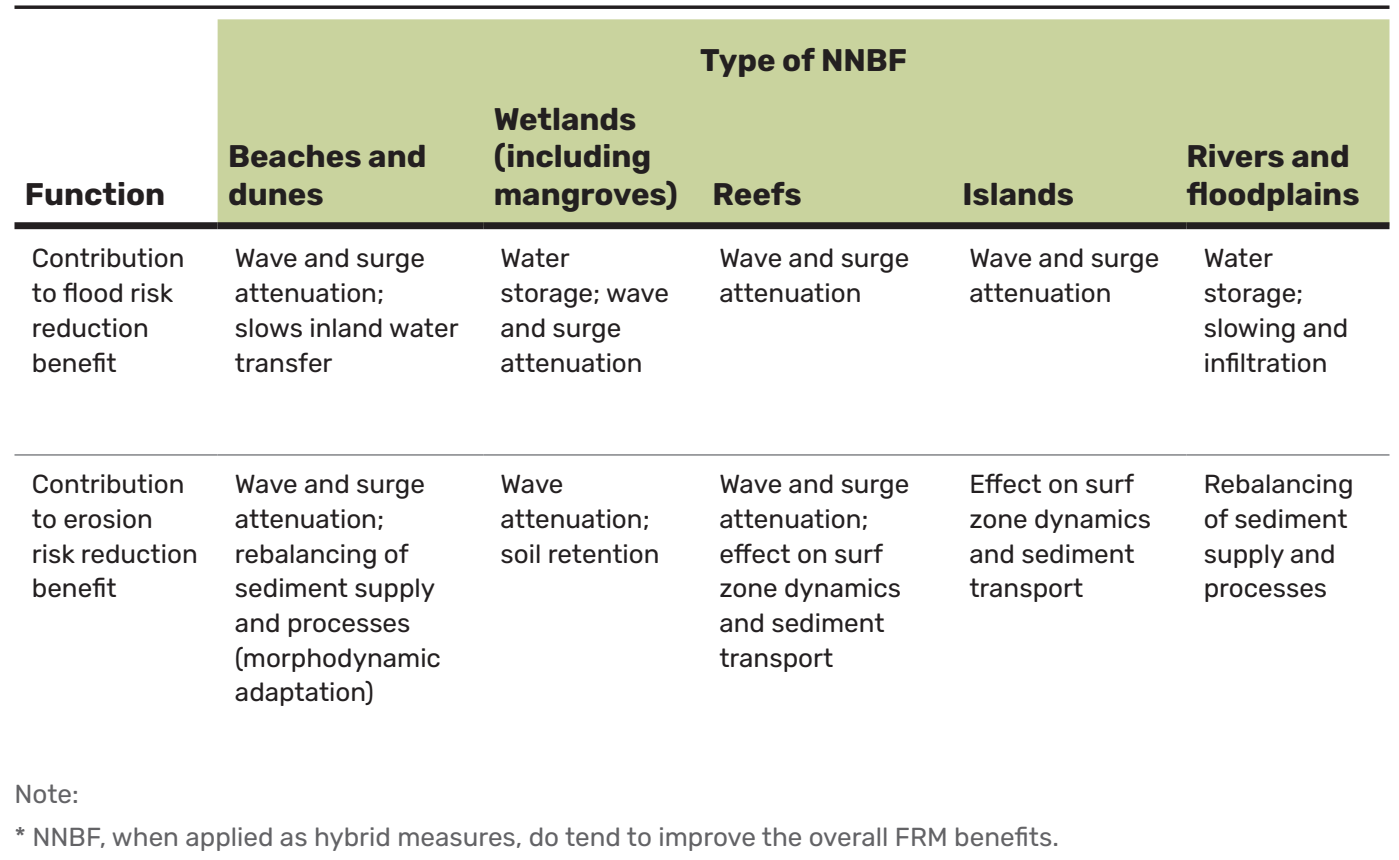




\subsubsection{Co-Benefits of NNBF}

NNBF not only have the ability to reduce flooding and erosion but they also offer diverse co-benefits to communities (for an overview, see Morris et al. 2018). Whereas gray infrastructure may result in ecological impacts and losses of ecosystem services, NNBF will often-but not always-result in significant net gains in co-benefits.

In some cases, these co-benefits can be expressed as intermediate services; they do not describe the actual use by people but rather describe the state of an NNBF. Examples of intermediate services are increases in fish populations or habitat (yellow box in Figure 6.2 $[B])$. These intermediate services can be very important to assess because, for some project developers, the main co-benefit of NNBF for risk reduction is habitat and species conservation or restoration. Co-benefits can also be expressed as final services, such as revenue from fish sold on the market, revenue from nature-based tourism, or improved water quality for communities (Arkema, Scyphers, and Shephard 2017). The functions of the co-benefits and their links to benefits and human well-being are a continuum, as identified in the conceptual model (Figure 6.2). The conceptual model highlights the interconnected function of co-benefits with natural and nature-based coastal and fluvial ecosystems-a dynamic biophysical feedback loop where habitat affects and is affected by the broader coastal and fluvial systems (Keeler et al. 2012; Olander et al. 2018). Table 6.2 describes six important types of co-benefits of NNBF; it is not an exhaustive list but provides examples of the wide range of co-benefits that are often assessed or could be assessed for NNBF.

Table 6.2. Examples of Co-Benefits Provided by NNBF

\section{Habitat}

NNBF create habitats replete with benefits. These benefits span aquatic, plant, and human life, including providing critical nursery, spawning, or transition habitat for species (Gilliers et al. 2006); increasing local biodiversity (Christie et al. 2006); serving as critical corridors and stopover habitat for pollinator networks and migratory species (Tonietto and Larkin 2018); increasing energy flow through the system (Palmer, Ambrose, and Poff 1997); improving aesthetics and viewsheds, which can lead to increases in tourism; and improving water quality, which extends to human consumption (e.g., drinking water, fisheries). Importantly, habitats and their associated species provide more co-benefits to people than can realistically be addressed in any single project and have conservation value beyond their societal benefits. For this reason, conservation of natural features is often the number one co-benefit in an NNBF project after risk reduction values.

\section{Fisheries}

By enhancing fisheries production, NNBF projects can provide food resources and support livelihoods. Diverse assemblages of finfish and of shrimp, crab, lobster, and other shellifish rely on NNBF such as conserved and restored salt marshes, mangrove forests, seagrass, and oyster reefs for essential habitat and feeding grounds (Beck et al. 2011; Peterson, Grabowski, and Powers 2003; Jordan, Stoffer, and Nestlerode 2011; Arkema et al. 2019). For example, mangroves have been shown to enhance local fisheries' catches around the globe (Carrasquilla-Henao and Juanes 2017). A growing number of empirical field studies have shown that the complex 
habitat (i.e., high rugosity) provided by NNBF supports higher levels of biodiversity and fisheries production than degraded or hardened shorelines (e.g., Scyphers et al. 2011; Humphries and La Peyre 2015; Gittman et al. 2016). For instance, experimental studies in the Gulf of Mexico found that, compared to degraded natural shorelines, oyster reef breakwaters strongly enhanced abundance of blue crab (Callinectes sapidus) and several highly desirable finfish species, such as red drum (Sciaenops ocellatus) and spotted seatrout (Cynoscion nebulosus; Scyphers et al. 2011, 2015). Conservative assessments of the economic value of enhanced fish production have estimated a hectare of oyster reef will yield approximately USD $\$ 5,500$ to USD $\$ 99,000$ in commercial landings (Grabowski et al. 2012). In addition, many of these fisheries species are key components of identity and culture in coastal communities (Dyer and Leard 1994); thus, NNBF play a role in supporting not only commercial and recreational fishing but also the cultural benefits that fisheries provide.

\section{Climate change mitigation}

NNBF that involve vegetation or organic material in soils can help regulate Earth's climate by removing carbon dioxide from the atmosphere. For example, the degradation and conversion of seagrasses and mangrove systems globally release 0.3 to 1.02 petagrams (billion tons) of carbon dioxide annually (Pendleton et al. 2012; Hamilton and Friess 2018). These emissions, which are equivalent to $3 \%$ to $19 \%$ of those from deforestation globally, result in economic damages of USD\$6 billion to USD\$42 billion annually (Pendleton et al. 2012). Protection and restoration of seagrasses and mangrove forests are important to storage and sequestration of carbon. Restored seagrass beds and marshes can accumulate carbon in their soils and through in situ production (Donato et al. 2011; Mcleod et al. 2011; Davis et al. 2015). Rates vary depending on the age of the plots and the density of vegetation (Davis et al. 2015). Functional plant diversity has also proven to have a positive effect on carbon sequestration when restoring floating fen ecosystems (van Zuidam et al. 2019). In contrast to other benefits of NNBF, which are often provided to communities relatively near the ecosystems that generate them (e.g., coastal risk reduction), increases in carbon storage and sequestration resulting from habitat restoration benefit the global community due to atmospheric circulation (Mandle et al. 2015).

\section{Tourism and recreation}

NNBF also provide opportunities for tourism and recreation, including wildlife viewing and sportfishing, which, in turn, support local livelihoods and the economies of coastal states and countries worldwide. In the United States alone, ocean-related recreation accounted for 1.2 billion visitor days across nearly 50 million visitors in 2012 (Kildow et al. 2014; Kosaka and Steinbeck 2018). Fishing, swimming, beach-going, and boating are among the top recreational uses of coastlines and fluvial systems for both residents and tourists (Pendleton, Martin, and Webster 2001; Pendleton, Kildow, and Rote 2006). NNBF support these activities by drawing visitors (Arkema et al. 2015; Spalding et al. 2017) and maintaining overall ecosystem health (e.g., through water quality services). For example, $30 \%$ of the world's reefs are of value in the tourism sector, with an estimated value of USD\$36 billion, or more than $9 \%$ of all coastal tourism value in the world's coral reef countries (Spalding et al. 2017). Both the number of acres and quality of habitat are key components in consumer preferences (and values) for tourism and recreation (Spalding et al. 2017; Bauer, Cyr, and Swallow 2004; Loomis 2000). Commonly used indicators to identify the relative benefits of NNBF for tourism and recreation include contribution to state or country gross domestic product, number of jobs supported, and number of visitors. Willingness to pay for habitat improvement resulting in improved benefits and travel cost analysis are two other appropriate methodologies (Brander and van Beukering 2013).

\section{Human health}

Based on growing evidence that nature positively influences people's mental and physical health, NNBF have the potential to benefit human health and well-being (Depledge and Bird 2009; Bratman, Hamilton, and Daily 2012; Cracknell et al. 2018; Sandifer, Sutton-Grier, and Ward 2015). Recent research shows that walking in the woods lowers rumination (a known risk factor for mental illness; Bratman et al. 2015), watching marine life reduces both 
heart rate and blood pressure (Cracknell et al. 2018), and exercising outdoors has greater psychological benefits than the same level of physical activity indoors (Depledge and Bird 2009). Water features appear to be particularly restorative, with access to coastal areas reducing stress, increasing physical activity, and resulting in stronger communities (Depledge and Bird 2009). NNBF can improve the health of communities that they protect. Flood storage areas with park-like features, such as recreation fields and walking trails, encourage physical activity and store water during rain or flood events. Coastal dunes provide protection from storm surges or high winds, while also providing materials for beaches as they evolve and shift (Casarin et al. 2012) and supporting a variety of outdoor recreation activities.

\section{Water quality and sediment supply}

The functions of NNBF that help reduce flooding and erosion also provide mechanisms for sediment processes that result in improvement of water quality. For example, reconnection of wetlands, including floodplain forests and intertidal marshes, can be effective in managing high nutrient loads and increases in sediment deposition inland, thus reducing downstream sediment loadings. Water quality benefits can also flow from nearshore NNBF. For example, oysters are suspension feeders that feed on particulate organic matter, such as detritus and phytoplankton. By pulling these particulates out of the water column, oyster reefs can improve light availability for other ecosystems (e.g., seagrass in Chesapeake Bay) and water quality for people and fish.

\subsubsection{The Costs of NNBF}

All interventions and structural measures, both hybrid and NNBF, involve analyzing costs and trade-offs throughout the project life cycle. For NNBF to be considered as alternatives to, or in combination with, structural measures such as seawalls, bulkheads, and levees, it is necessary to also analyze their costs and potential trade-offs. The following are the main costs in the total life cycle of a typical NNBF project (adapted from Bilkovic et al. 2016):

- Planning costs

- Design and permitting costs

- Costs of the land (or space) required for the project, including opportunity costs

- Costs of creation, protection, or restoration

- Costs of maintenance and monitoring

The cost of land may be a major component of these costs for some NNBF, especially in urban areas and narrow coastal margins. After cost of land, the other key components of NNBF costs are design, permitting, creation, protection, and restoration. However, an advantage of well-designed NNBF is the ability to "self-maintain" using natural processes-for example, by retaining soil and keeping pace with sea-level rise (Temmerman and Kirwan 2015), which can significantly reduce long-term maintenance costs and the need for infrastructure upgrades. In some contexts, NNBF can be more cost-effective than structural measures due to the limited maintenance cost. The costs of creation are highly variable, depending in part on geographic location, type of NNBF, and intervention (e.g., restoration through planting versus hydrological intervention). 
In some cases, NNBF projects can have trade-offs or unanticipated negative impacts. These could include the monetary and social costs of losing certain benefits when an NNBF project results in the conversion of one type of habitat into another, or in unanticipated damage to an adjacent habitat or service due to a poorly designed NNBF. For example, if the design of an oyster reef NNBF is not properly scoped with adjacent communities, it could block easy access to nearby recreational fishing locations, which could, in turn, lead to the loss of local support for the NNBF.

Once the implementation costs and potential trade-offs are scoped and evaluated, they can be combined with evaluations of their co-benefits to assess the overall viability of the NNBF.

\section{3 | Scoping and Qualitative Assessment of Benefits}

An NNBF project starts with the Scoping Phase, as shown in Figure 6.4. A primary goal of the Scoping Phase is to identify which co-benefits will be assessed and which NNBF will be the primary focus of the project. In this first phase, a project idea evolves informed by high-level estimates of NNBF benefits and costs, before a more detailed quantitative assessment of benefits is conducted in the Planning Phase and the Decision-Making Phase. Risk reduction benefits and co-benefits play a role in the site selection of a project, the type of intervention, the area over which to evaluate a project, and the timing for planning and evaluation.

Figure 6.4. Scoping Phase

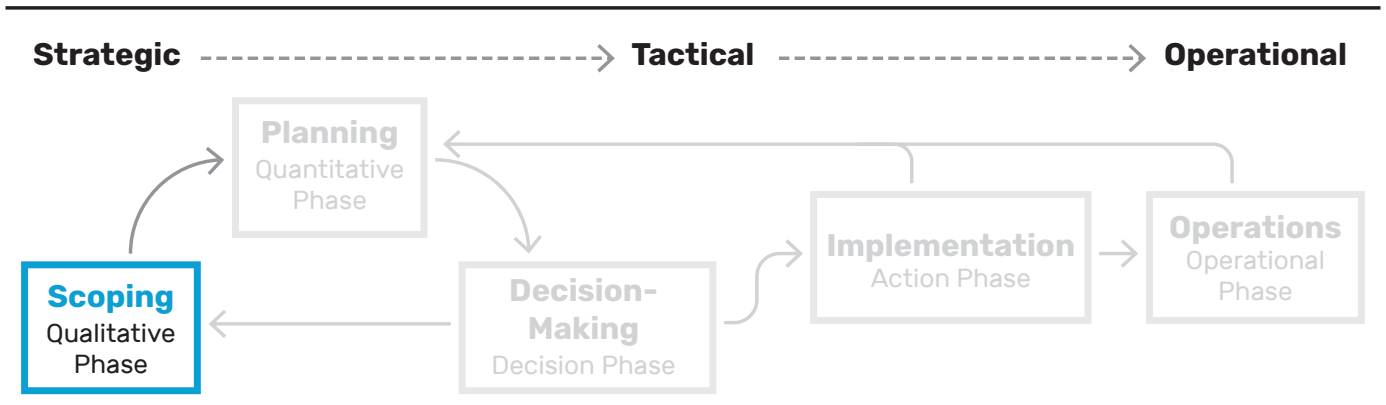

Another important part of the Scoping Phase is to explore approaches for assessing the benefits of NNBF in subsequent phases. The approach to benefits assessment needs to be tailored to the strategic priorities of the implementing and funding organizations, policy and legislative requirements, and other contextual factors. Consider the three examples in Table 6.3. 
Table 6.3. Types of NNBF Projects and the Approach of the Economic Analysis

\begin{tabular}{|c|c|c|}
\hline $\begin{array}{l}\text { Primary project } \\
\text { outcome }\end{array}$ & Description & Approach \\
\hline $\begin{array}{l}\text { Coastal or fluvial flood } \\
\text { risk reduction }\end{array}$ & $\begin{array}{l}\text { This is an NNBF project in which the primary } \\
\text { objective is to reduce coastal or fluvial flood risk } \\
\text { for communities. This may leverage public- or } \\
\text { private-sector financing for its implementation. It } \\
\text { will require a detailed monetary evaluation of the } \\
\text { damages avoided and co-benefits generated that are } \\
\text { relevant to its investors and stakeholders. }\end{array}$ & $\begin{array}{l}\text { The project team recognizes } \\
\text { it is important for investors } \\
\text { to obtain a BCR on both } \\
\text { the risk reduction and the } \\
\text { co-benefits; thus, CBA is the } \\
\text { right approach. }\end{array}$ \\
\hline $\begin{array}{l}\text { Habitat conservation } \\
\text { or restoration }\end{array}$ & $\begin{array}{l}\text { This is an NNBF project in which the primary } \\
\text { objective is to restore a specific type of habitat while } \\
\text { also reducing riverbank erosion; this project values } \\
\text { habitat as an intermediate service (Figure 6.2). In } \\
\text { such a case, the benefit of creating more habitat can } \\
\text { be expressed as the area of new habitat restored or, } \\
\text { perhaps, in carrying capacity for a particular species, } \\
\text { but not in monetary terms. }\end{array}$ & $\begin{array}{l}\text { It is more appropriate } \\
\text { to quantify benefits as } \\
\text { intermediate services and } \\
\text { use an MCA or CEA (see } \\
\text { Section 6.4) to compare } \\
\text { NNBF project alternatives. }\end{array}$ \\
\hline $\begin{array}{l}\text { Integrated coastal } \\
\text { or watershed } \\
\text { management }\end{array}$ & $\begin{array}{l}\text { This is an NNBF project in which risk reduction } \\
\text { benefits are one of several social and economic } \\
\text { outcomes of an integrated watershed or coastal } \\
\text { management program or development planning } \\
\text { process. In this case, co-benefits, such as fisheries } \\
\text { or tourism, that relate to local livelihoods could be } \\
\text { of equal or greater importance than risk reduction } \\
\text { benefits and thus tip the scale in favor of NNBF }\end{array}$ & $\begin{array}{l}\text { The assessment will need to } \\
\text { involve a trade-off analysis } \\
\text { of benefits that reflect the } \\
\text { diversity of participants and } \\
\text { stakeholders involved in } \\
\text { integrated management and } \\
\text { what they value. }\end{array}$ \\
\hline
\end{tabular}
options over structural measures.

Under all circumstances, it is essential for the project teams to define the approach for the NNBF benefits assessment in the Scoping Phase (which includes the qualitative assessment) and the suite of benefits that will be included in the assessment.

Six core steps are presented here for scoping the benefits assessment for NNBF. These steps or questions do not need to be addressed sequentially; however, the earlier steps generally inform the later ones. These steps help identify the highest priority benefits to assess. Identifying which benefits to evaluate is important because it is unrealistic and cost- and time-prohibitive to assess all possible benefits from an NNBF project.

Step 1. Identify the relevant participants involved in the NNBF project or planning process. Who are the decision-makers and stakeholders most likely to be affected by the project and what benefits provided by NNBF do they most care about? (Refer to Chapter 3.) 
Step 2. Identify the main issues, challenges, and opportunities facing these participants, including the primary decision-makers and stakeholders. What potential benefits of NNBF are most likely to be influenced by scenarios related to these issues, challenges, and opportunities? (Refer to Chapter 3 .)

Step 3. What types of NNBF already exist in the system and where? (Refer to Chapters 8 to 14 , which address coastal systems, and Chapters 15 to 19 , which address fluvial systems.) What types of NNBF are under consideration for project implementation, and which benefits of NNBF are most likely to be provided by these features?

Step 4. Given the answers to the previous questions, over what area of interest should benefits be assessed and over what time period?

Step 5. What data, tools, and technical capacity are available for assessing benefits?

Step 6. What are the roles and responsibilities of the project partners?

The following sections show how to apply several of these steps to risk reduction benefits (Section 6.3.1) and co-benefits of NNBF (Section 6.3.2) during the Scoping Phase (which includes the qualitative assessment).

\subsubsection{Scoping and Qualitative Assessment of NNBF Risk Reduction Benefits}

All six steps described in the previous section are useful when scoping risk reduction benefits of NNBF. However, two of the most important factors are understanding the main hazards (e.g., erosion, flooding, wave impacts, and storm surges) and the spatial scope where NNBF could be conserved or implemented (Steps 2 and 3). The scope of these project objectives requires moving from a qualitative assessment to a quantitative framework that can forecast potential project futures. To answer the questions posed in these steps, it is often fruitful to use both data-driven and local knowledge-based approaches. This section highlights a data-driven approach, and the section on co-benefits that follows highlights a participatory approach. These approaches are not mutually exclusive; ideally, elements of both would be used in most projects to ensure the work is informed by the best available science and the science is salient, credible, and legitimate (Posner, McKenzie, and Ricketts 2016; Arkema and Ruckelshaus 2017).

A variety of data on coastal and river floodplains can be used to inform flood management and the potential benefits of NNBF. Sites at risk and where NNBF have high (potential) benefits can be identified qualitatively by overlaying hazard, exposure, and vulnerability information with different potential NNBF development sites. This exercise can be conducted at different scales, ranging from global to local. 
Scoping risk reduction benefits can be supported by information on the following:

- Hazards. Identify coastal and fluvial hazards, including historical flood and erosion data (e.g., from satellite imagery), to explain the causes of observed impacts, shoreline changes, and ecosystem loss. For example, the severity of coastal flooding can be assessed by estimating total water levels from the combination of tides, surges, and wave run-up (e.g., Losada et al. 2013; Beck and Lange 2016).

- Exposure and vulnerability mapping is the value exposed to flooding or erosion, both in terms of properties and infrastructure (anthropogenic capital), people, buildings, and ecosystems (natural capital and ecosystem services), and other assets. A pragmatic approach can be identifying these assets by using topographic information, satellite or aerial imagery, and geospatial analysis (Arkema et al. 2013; Hoppler and Meixler 2016; Silver et al. 2019). An example is shown in Figure 6.5, where different buildings, roads, and coastal landforms are represented against the topographic ground-height contour lines in a coastal section of Seychelles (World Bank and Ministry of Environment, Energy and Climate Change of Seychelles 2019).

- Identification of sites with potential to restore, protect, or develop NNBF. Identify coastal or fluvial ecosystems and landforms, their historical change, and their relationship with the coastal or fluvial impacts. For example, coral reefs play a critical role in the propagation and breaking of waves, but their effect goes beyond wave attenuation because they also configure surf zone currents and sediment transport, which are the main factors determining the position of the shoreline (Reguero et al. 2018a).

\section{NHINHNH}

\section{CASE STUDY:}

\section{Example of Scoping Phase and Qualitative Assessment of NNBF Risk Reduction (Mahé, Seychelles)}

An example of scoping risk reduction benefits of coral reefs is shown in Figure 6.5, a map of a section of the coastline of Mahé, Seychelles. The map shows the coral reef system (i.e., the NNBF) and contour lines depicting low-lying areas (i.e., flood-prone area or hazard mapping). The offshore reefs critically influence the propagation and breaking of waves, flooding, and sediment transport. Interruptions in the reef system, as well as other coastal landforms such as points, shoreline shapes, or anthropogenic structures (e.g., the landfill on the east side of the image), can also represent 
important features to understand flood and erosion risk. Coastal topography can also provide critical information to infer areas at risk. Run-up from waves for Mahé has been estimated at approximately 3.5 meters ( $\mathrm{m}$; World Bank and Ministry of Environment, Energy and Climate Change of Seychelles 2019). Topographic contour lines at $3 \mathrm{~m}$ and $5 \mathrm{~m}$ above mean sea level are able to provide qualitative information about the flood-prone area. Buildings, roads, and other coastal assets such as hotels can be identified from public aerial and satellite imagery (e.g., Google Earth). Furthermore, historical impacts, such as the Indian Ocean tsunami, showed that these below 3-m, low-lying areas were subjected to the highest impact from flooding. These low-lying areas, in addition to river outlets and freshwater streams, are indicative of potential impact from rainfall and runoff flooding.

Figure 6.5. Coastline of Mahé, Seychelles

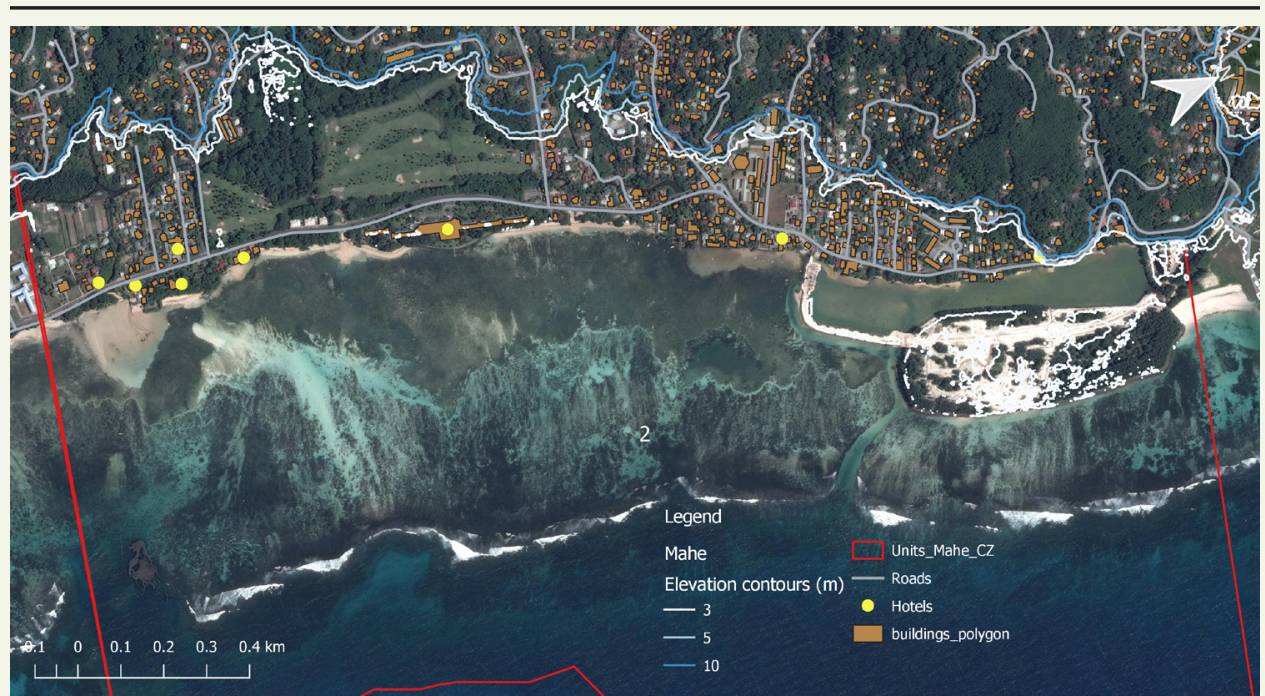

Note: A section of the coastline of Mahé, Seychelles, showing coral reefs protecting beaches and coastal dwellings.

Source: Seychelles Coastal Management Plan, Government of Seychelles 
Effective solutions can be found by assessing and understanding coastal and fluvial processes and the main factors influencing them. Existing ecosystems and new NNBF (as well as historical ecosystem loss) can influence these processes, as engineered structures do. For example, where reef systems once provided effective coastal protection but have been degraded, restoring their natural functioning can provide effective coastal protection (e.g., Reguero et al. 2018a). In other cases, introducing new NNBF to shift or change geophysical processes can provide risk reduction. The observation of historical impacts, and the role of NNBF in past events (e.g., historical cyclones), could also serve as a valuable insight into potential benefits of NNBF.

These preliminary risk reduction benefits can be compared with representative costs from similar projects in other regions, as a first estimate of costs and benefits. For example, in the U.S. Gulf Coast, different adaptation strategies, structural and NNBF, are compared in terms of the benefits of flood risk reduction from hurricanes and sea-level rise, as well as the cost of implementation and maintenance of each feature (Reguero et al. 2018b). The analysis of different scenarios of costs and benefits can also provide insight into the range of variation and uncertainty before conducting quantitative valuations. Even when information on hazards, exposure and vulnerability, and restoration potential is not readily available, or if there is limited time, a scoping exercise for risk reduction benefits and qualitative assessment that is more hypothesis-based can be useful for thinking about which NNBF or combination of NNBF (e.g., seagrass, coral, and dunes) may be most useful in different locations.

\subsubsection{Scoping and Qualitative Assessment of NNBF Co-Benefits}

Decision-makers need to address societal challenges such as food security, urbanization, and habitat and biodiversity conservation. In the Scoping Phase, potential co-benefits of NNBF are identified by connecting the need (societal challenges) with the potential co-benefits that NNBF could provide. A practical way to do this is to analyze which benefits or ecosystem services can be provided by present, restored, or constructed ecosystems and how these interact with the policy objectives. Besides decision-makers, stakeholders have a large role in identifying (potential) benefits (see Chapter 3). Any societal problem or issue is likely to be affected by or have effects on several groups of stakeholders.

A scoping exercise and qualitative assessment of co-benefits starts with exploring expected and desired co-benefits. Stakeholder interviews or facilitated workshops can be used to identify the benefits that should be taken into account (World Bank 2017; see "NNBF as a Component of Sustainable Development Planning (Andros Island, the Bahamas)"; Arkema and Ruckelshaus 2017). The questions outlined in Steps 1 to 6 above are as applicable to co-benefits as they are to risk reduction benefits. This process is illustrated in Figure 6.6. 
If possible, quantification of (the key) benefits is desired as input for the decision-making process (Section 6.4). Otherwise, the co-benefits should be described in qualitative narratives and included in the decision-making process (World Bank 2017). The uneven distribution of benefits among stakeholders-often stakeholders across spatial scales-could raise a barrier for acceptance of the project and implementation. The Scoping Phase should address not only local but also regional, national, and global issues and potential benefits (EcoShape 2020). To compare project alternatives in the Scoping Phase (which includes the qualitative assessment), MCA is often applied (see Section 6.5.1).

Figure 6.6. The Scoping and Identifying of Key Co-Benefits for an NNBF Project through Engaging with Stakeholders

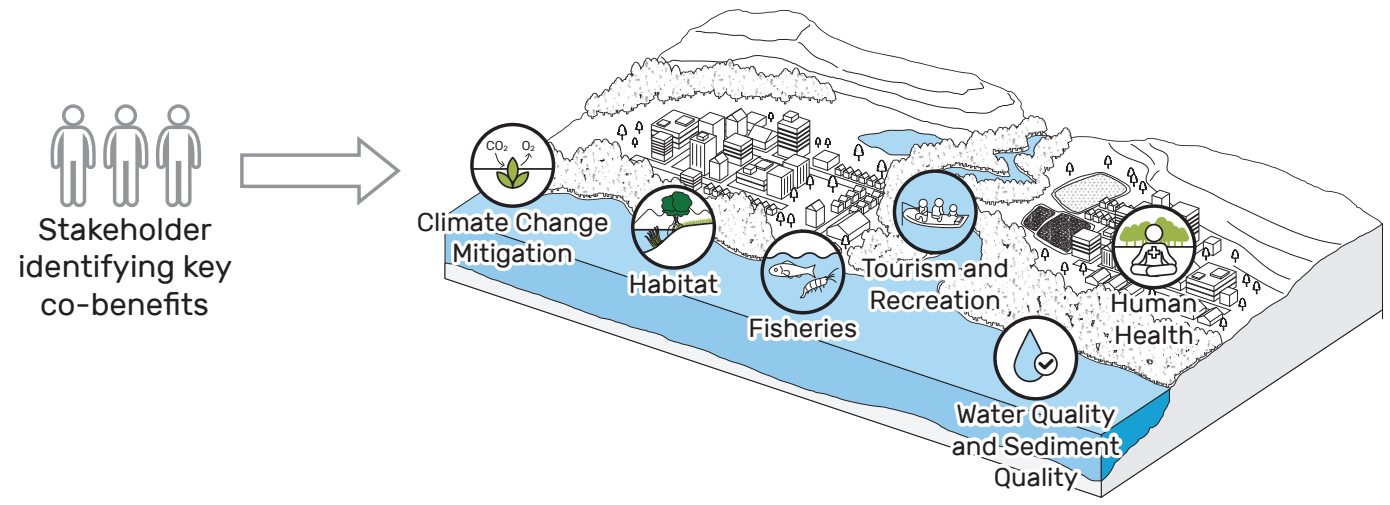

All

CASE STUDY:

NNBF as a Component of Sustainable Development Planning (Andros Island, the Bahamas)

The central challenge confronting the Government of The Bahamas is to make investments in sustainable economic development without sacrificing the ecosystems that underlie the economy and sustain the well-being of its citizens. To address this challenge, a Sustainable Development Master Plan was designed for Andros Island to identify public and private investment opportunities, policy recommendations, zoning guidelines, and other management actions to guide the sustainable development 
of the island over the next 25 years (OPM 2017). The process involved extensive consultation with communities (Scoping Phase, see Section 6.3) and quantitative assessment of fisheries, tourism, and coastal protection benefits provided by NNBF (Planning Phase, see Section 6.4). The assessment of multiple benefits provided by coastal and marine ecosystems as part of a sustainable development planning process paved the way for a loan from the Inter-American Development Bank to the Government of The Bahamas to invest in NNBF (e.g., mangrove restoration) for coastal resilience (Lemay et al. 2017; Decision-Making Phase, see Section 6.5). Through public meetings, site visits, and one-on-one conversations in homes and workplaces, the Office of the Prime Minister of The Bahamas and its partners (i.e., the University of The Bahamas, Natural Capital Project, and The Nature Conservancy) worked with stakeholders to identify a set of benefits that reflect the shared values of Androsians and could be used to compare alternative development plans. These benefits were thriving fisheries (measured in terms of catch and revenue from the spiny lobster fishery); a vibrant tourism industry (measured by visitation, expenditures, and jobs); resilient coastal communities from coastal risk reduction due to NNBF (measured in terms of total population, numbers of elderly and young people, and income at highest risk); and area of functioning coastal, marine, and freshwater ecosystems (measured in acres; Hargreaves-Allen 2010; Arkema and Ruckelshaus 2017; Arkema et al. 2019; Silver et al. 2019; Ruckelshaus et al. 2020; Arkema et al. 2021).

Key benefits on Andros Island include recreation and tourism, fisheries, species habitat, and coastal protection from storms (see Figure 6.7).

Figure 6.7. Key Benefits on Andros Island, the Bahamas

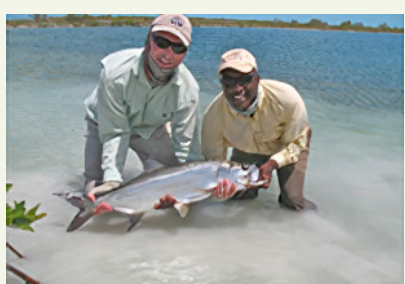

Tourism and Habitat

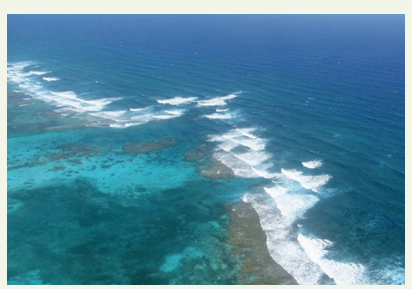

Coastal Storm Protection

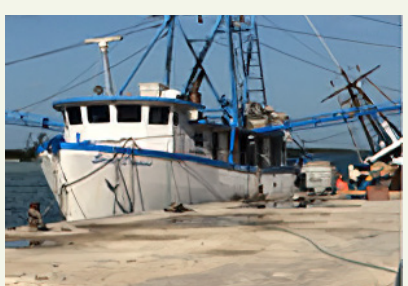

Fisheries 


\section{4 | Quantitative Assessment of Benefits and Costs}

During the Planning Phase of an NNBF project (Figure 6.8), benefits and costs should be assessed quantitatively to, later on, support the decision-making process. As described in Table 6.3, the way benefits are measured and quantified depends on the priorities of the project stakeholders and, of course, methodological and data constraints. In this section, we present index-based approaches for valuing risk reduction and co-benefits as well as monetary valuation approaches for risk reduction and co-benefits. Finally, Section 6.4.4 describes cost structures of NNBF.

Figure 6.8. Planning Phase

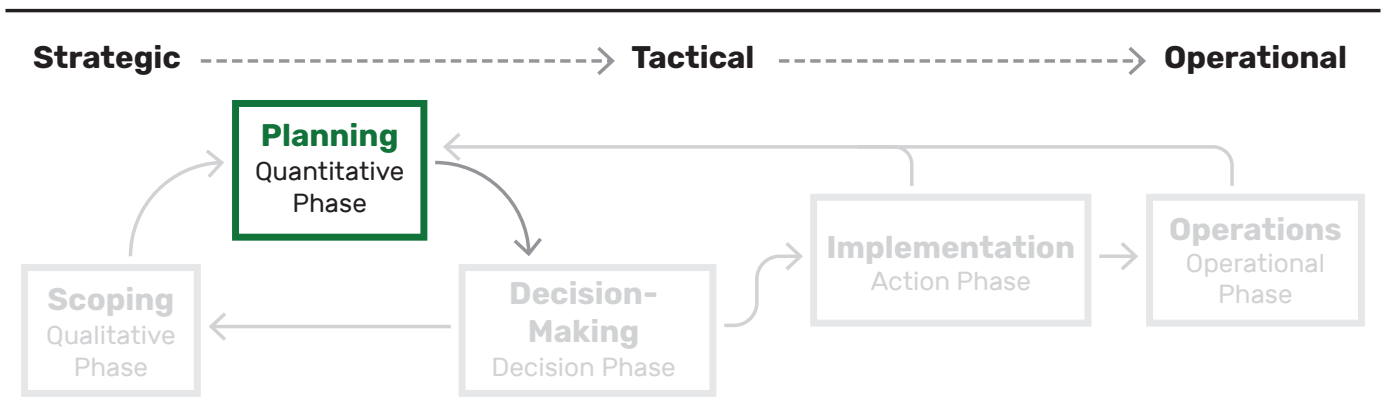

\subsubsection{Index-Based Approaches for Valuing Risk Reduction and Co-Benefits}

Although there have been considerable advances in the methods and tools to monetarily value flood risk reduction benefits from NNBF (see next section), in many locations and contexts, it is difficult to obtain data on public preferences for risk reduction or an adequate characterization of people and communities at risk. Even in cases with adequate data and resources to monetize risk reduction benefits, values, and costs, there are cases when different approaches are necessary. For example, when social justice and equity issues are a priority, indicators of social vulnerability can provide valuable additional information as alternative quantitative metrics that link NNBF to risk reduction values held by affected populations (Olander et al. 2018). Demographic factors that influence the ability of populations to prepare for, respond to, and recover from coastal hazards (e.g., age, wealth, literacy, access to vehicles) help to identify which populations may benefit the most from interventions related to NNBF (reviewed for NNBF in Arkema et al. 2017). 
Indicators of social vulnerability can be used to measure societal value of NNBF for risk reduction by linking biophysical changes from NNBF to valued outcomes that are not easily monetized, such as the number of people no longer within the 100 -year flood zone, the extent of critical infrastructure (e.g., area, count) protected, the count of socially vulnerable households within a flood zone, or the potential change in subjective well-being from a change in flood exposure (Luechinger and Raschky 2009). When evaluating the benefits and costs of NNBF, decision-relevant and standardized indicators are critically important because they provide a tool to compare benefit streams among different potential alternatives, including traditional risk reduction approaches. Indicators of societal benefits can be used with quantitative hydrodynamic modeling or with indices that describe exposure to hazards such as flooding or erosion. They can also be used with biophysical modeling of coastal and fluvial co-benefits such as water quality (Keeler et al. 2012), air quality, ecological change, and nature-based recreation. In the ecosystem services literature, these indicators are sometimes referred to as benefit-relevant indicators (Olander et al. 2018). This section describes approaches for combining indicators of social vulnerability with an index-based hydrodynamic approach for data poor regions.

\section{Indicator-Based Approach to Assessing Societal Benefits}

There are four core steps to an indicator-based approach to assessing societal risk reduction and co-benefits provided by NNBF, as follows:

Step 1. Choose a set of societal indicators. Examples of indicators are key infrastructure (e.g., roads, schools, and hospitals) that stakeholders would want to benefit from risk reduction, as well as ecosystems and demographic groups that may be particularly vulnerable to coastal or fluvial hazards. The following are some important questions to ask:

- Does the indicator reflect the changes in NNBF ecological condition in units that are relevant to the benefit and beneficiaries of interest?

- Does the indicator capture relevant physical and institutional access constraints on the flow of the benefit from the NNBF?

Step 2. Develop a causal chain linking the influence of an action or scenario with its impact on the NNBF, the function of the NNBF, and the change in societal benefit (e.g., Figure 6.2; Olander et al. 2018; Arkema et al. 2017).

Step 3. Apply a coastal or fluvial hazard index that includes (Sharp et al. 2020) or could be modified to include (Wamsley et al. 2015) the role of NNBF, along with other key variables 
that influence risk from flooding and erosion, including shoreline geomorphology, wave power and direction, sea-level rise, storm surge, and elevation. Use the hazard index to identify areas most at risk from coastal or fluvial flooding and erosion. Then estimate the influence of NNBF on exposure from coastal or fluvial hazards by calculating exposure to those hazards with and without the protective role of NNBF included in the hazard index (Arkema et al. 2013; Hoppler and Meixler 2016; Cabral et al. 2017; Silver et al. 2019; and see the Andros Island, Bahamas, case study).

Step 4. Combine results from the coastal or fluvial hazard analysis with maps of social indicators (e.g., critical infrastructure and vulnerable populations) to estimate the number of people and amount of critical infrastructure at risk from coastal or fluvial hazards with, compared to without, the risk reduction benefits from NNBF (Arkema et al. 2013; Silver et al. 2019; and see Table 1 in Arkema et al. 2017 for literature review).

\subsubsection{Monetary Assessment of Flood Risk Reduction Benefits}

\subsubsection{Expected Damage Function and Exposure to Monetize Avoided Damage}

This approach for valuing the risk reduction benefits of NNBF borrows directly from the convention of using expected damage functions for quantifying flood risk (Kunreuther and Sheaffer 1970). The expected damage function approach uses the change in avoided expected damages from a flood defense project as a measure of the value, or benefit, of that project. This approach is consistent with the concept of social welfare for risk-neutral property owners (Barbier 2015) in that it reflects willingness to pay (WTP) for risk reduction at a price consistent with the expected reduction in property damages associated with the project.

The history of using expected damage functions goes back to the 1940s (White 1945), and the method has been formalized into various policies governing CBA for hazard mitigation (see Cannon, Phelan, and Passaro 1995 for theoretical and applied rationale used by the U.S. Army Corps of Engineers; and see Penning-Rowsell et al. 2013 for the equivalent approach adopted in the United Kingdom). The expected damage function method has increasingly been applied to NNBF as process-based predictive models have begun integrating NNBF (e.g., coastal vegetation in Barbier and Enchelmeyer 2014; Beck and Lange 2016; Reddy et al. 2016; Narayan et al. 2017; Menendez et al. 2018; coral reefs in Beck et al. 2018; Reguero et al. 2019; Storlazzi et al. 2019; and combination of gray and ecosystem-based adaptation strategies in Reguero et al. 2018a). 
To apply this method and assess the risk reduction benefits of NNBF, there are four core steps for estimating protection benefits from NNBF (Beck and Lange 2016). An example of this method applied to a coastal environment is as follows:

Step 1: Estimate coastal and fluvial hydrodynamics. Hydrodynamic conditions are the starting point for assessing flood risk and the risk reduction benefits of an NNBF project. In coastal areas, this involves modeling waves, wind, sea level, and tides in the offshore and nearshore environments. In the fluvial environment, hydrodynamic models should include velocity, flow, and inundation stage. Modeling should be conducted to quantify how hydrodynamic forces change throughout their propagation from deep to shallow waters due to interactions with the bathymetry and coastal geometry (although other factors such as wind transfer can also affect the waves). In addition, models can predict how runoff produces flooding in a watershed. Different datasets and models provide information on hydrodynamic and input conditions (Reguero et al. 2012; Vousdoukas et al. 2018). There are also different models, tools, and approximations for estimating these conditions (e.g., see a summary in Kroeker et al. 2016 and in Beck and Lange 2016).

Step 2: Estimate effects of NNBF on hydrodynamics. This step evaluates the effect on the hydrodynamics induced by the NNBF (e.g., wave attenuation by coral reefs or surge attenuation by wetlands), which vary depending on the NNBF and the hydrodynamic context and thus require different approaches to quantify. For instance, biogenic reefs can attenuate short waves (e.g., wind waves) mainly through wave breaking and wave energy dissipation, depending on relative depth, rugosity, and reef geometry (Monismith 2007). In contrast, mangrove forests and wetlands can attenuate both short wave energy and long waves (e.g., storm surges), provided their extension is sufficient to create enough frictional dissipation. Moreover, biogenic reefs can persist in high wave energy environments, whereas other NNBF are found in areas more protected from intense wave action. Similarly, specific processes affect freshwater flooding, including rainfall, the properties of the watershed, and human infrastructure. These processes can be modeled in a variety of ways depending on the scale, scope, and resolution needed (e.g., see Whelchel et al. 2018).

Step 3: Estimate flooding and erosion with and without NNBF. For example, in coastal flooding, water levels along coastal shorelines vary depending on tides and incident wave conditions. As a first-order estimate, these water levels can be defined by the total water level (Losada et al. 2013), as follows: (1) average sea level (including mean water level), astronomical tides, storm surges, and wave setup; and (2) fluctuating surf beat from the individual waves at the shoreline, usually referred to as wave run-up (i.e., height above mean water elevation).

The total water level defines the potential flood height at the coast. The output of Step 3 is a set of maps of the extent and maximum depth of total flood level for each scenario, with and without the NNBF project or projects in place. As in Step 2, in Step 3 the effect of the NNBF of flooding and erosion can be modeled in a variety of ways depending on the scale, scope, and resolution of the study. 
If the analysis intends to measure the long-term value of the project, either as net present value (NPV) or annual value of risk reduction, then this step will need to produce flood maps for all relevant storm return periods in the study area, with and without the NNBF project.

\section{Steps 1, 2, and 3 for Fluvial Flooding}

Although the analysis is different, the risk reduction benefits of NNBF for fluvial flooding can similarly be determined by modeling river stage, velocity, and runoff, accounting for factors such as geomorphic setting of the watershed, channel morphology, and catchment capacity and retention.

The result of flood risk assessments should be flood maps associated with probability of occurrence. For example, the 100-year flood zone is associated with a flood event that has 1 in 100 chance (i.e., a 1\% probability) of being equaled or exceeded in any given year. The floodwater level can be mapped as an area of inundation for each probability of occurrence. The resulting map is referred to as, for example, the 100 -year flood zone.

Step 4: Assess expected damages with and without NNBF. The final step is calculating the socioeconomic impacts of both scenarios-with and without the project. This may include damage to buildings, infrastructure, and agricultural land in terms of their repair or replacement cost. Damage may also be expressed as the impact on other relevant risk reduction indicators, such as the number of people affected. Damage to structures and land is generally calculated using depth-damage functions that relate flood depth to a repair or replacement cost for each asset type (Simpson et al. 2014). For example, such a function would typically indicate that a structure flooded by $0.5 \mathrm{~m}$ of water will have a lower damage percentage than a structure flooded by $2 \mathrm{~m}$ of water (e.g., Scawthorn et al. 2006). For each asset class, these functions generally calculate either the total repair cost or the repair cost as a fraction of asset value. Intersecting a spatial inventory of assets with the flood depths estimated in Step 3 provides a flood level for each asset in the flood zone; using the respective depth-damage function for each asset provides a damage value for each asset that can be aggregated to calculate the total damage level from a given flood event.

The final value of the protection benefit for a single storm is then the difference of the aggregate total damages across assets estimated with and without NNBF. 
The change in expected damages from an NNBF project can be represented in a variety of ways depending on the interests of the decision-maker, as follows in order of least analysis effort to most:

- Expected change in damages from a single storm. This is the basic process described in Steps 1 through 4 above in this section. It provides a measure of the change in damages from an NNBF project by comparing total damages with and without the project for a single storm (e.g., Narayan et al. 2017). Assessments like these are often useful in demonstrating the value of new technologies (proof of concept), or in indemnity valuations (post-storm), and require less effort than the following metrics.

- Annual change in expected damages. Building off the single-storm damage assessment, this incorporates information about event frequency (often defined by return periods, such as a 100-year storm) to estimate the expected annual change in damages from an NNBF (e.g., Menendez et al. 2019; Storlazzi et al. 2019) or through a probabilistic simulation of all possible storms (Reguero et al. 2019). The expected annual damage for any given year is the weighted sum, across all storm probabilities, of the damages multiplied by the probability of each loss. Calculating the annual risk reduction benefit of an NNBF project requires conducting this assessment with and without the project in place and taking the net difference. See Olsen et al. (2015) for further details on estimating annual expected damages.

- Net present value of change in expected damages. A life-cycle CBA of NNBF requires knowing the NPV of benefits (and costs) across the lifetime of the project, including all potential storm types and their expected probabilities. This also extends beyond the annual change in expected damages by incorporating information about the time preference for money (discount rate or weighted average cost of capital) and any relevant dynamic social, engineering, and environmental factors. Examples of these include changes in exposed infrastructure composition or value through time and changes (deterioration or improvement) in the performance or reliability of the flood mitigation measures (structural or NNBF), as well as sea-level rise and other changing climatic factors. An example can be found for the U.S. Gulf Coast, where costs and benefits of NNBF adaptation strategies are compared with other measures to reduce future flood risk in 20- and 40-year life cycles, accounting for (1) the effect of relative sea-level rise and future storms and (2) changes in population and economic exposure, and using different discount rates (e.g., Reddy et al. 2016; Reguero et al. 2018b).

Finally, if depth-damage functions are unavailable or unreliable, the information gathered in Steps 1 through 4 can still be used to measure the value of assets exposed to flooding, as well as the change in exposure due to an NNBF project. This change in exposure is the difference in total exposed assets or people within the flood zone from Step 3, with and without the NNBF project. This represents the upper bound of potential damages from a flood event. Although not readily used in a CBA in a monetary form, this is a commonly reported metric that requires less data and effort but can provide an upper bound to the potential risk reduction value of an NNBF project. 
These four steps allow for an assessment of the protection and risk reduction benefits offered by NNBF. Tools and models for solving each step of the valuation approach are described in the respective features chapters. The models and tools are described in $\underline{\text { Chapter } 5}$.

\subsubsection{Other Approaches to Value Risk Reduction Benefits}

The expected damage function approach is the most well-established approach to valuing risk reduction benefits of NNBF based on site-specific conditions, but other approaches have been used in the literature and are under further development. These approaches can lead to useful information and insights about the value of NNBF, even if they are less applicable at this stage for quantifying the potential risk reduction benefits of proposed projects, as follows:

- Regression analysis and value transfer. Value transfer places a value on risk reduction benefits by transferring values estimated from other locations. Transferring flood or erosion protection values from a different location is generally less reliable and less preferred than other valuation methods unless the comparison location is very similar in its social, economic, and environmental characteristics (Ruckelshaus et al. 2016). Value transfer can be improved by applying regression analysis on this dataset of case studies to produce a predictive function of the value of NNBF that can be applied in other sites while controlling for differences in site and hazard attributes. This is a common convention for improving the validity of value transfer estimates of ecosystem service value when site-specific analysis is not possible (Nelson and Kennedy 2009). Meta-regression value transfer is mainly applied for quantifying co-benefits. The only study that has done this for risk reduction benefits of NNBF (Rao et al. 2015) applied function-based value transfer to assess the coastal protection value of mangroves, coral reefs, and wetlands.

- Hedonic analysis. Hedonic analysis is an approach for valuing environmental public goods' effects on marketed goods, such as real estate. Risk reduction from coastal and fluvial flood mitigation projects generally falls into this category as a public good that benefits multiple parties and is nonexcludable, regardless of whether it is privately or publicly provided. Like meta-regression value transfer, hedonic analysis employs regressions to estimate how various house amenities and disamenities affect sale prices, allowing isolation of flood risk and risk reduction by NNBF. The impact of flood risk on house values is a well-studied topic; a recent meta-analysis found more than 36 published studies since 1987 (Beltrán, Maddison, and Elliott 2018). In addition to the hedonic analysis regression, this approach will require the researcher to conduct the flood modeling required to assess changes in the floodplain from NNBF projects, namely Steps 1 through 3 of the expected damage function method described previously to locate properties in flood-prone areas. Hedonic analysis will also enable researchers to control for other potential positive amenities of NNBF for property owners, such as recreational and aesthetic values. 
- Stated preference approaches. Contingent choice and contingent valuation are two stated preference approaches used by economists to directly solicit WTP for goods and services that are not exchanged in markets. In the context of valuing NNBF risk reduction services, contingent valuation directly asks people their WTP for flood risk reduction using surveys; contingent choice similarly asks for respondents to state their risk reduction preferences but uses a series of hypothetical choices between alternatives to derive these values. Rather than observing the effect of NNBF on prices of marketed goods (i.e., real estate) like with hedonic analysis, these approaches rely on survey respondents directly stating their preferences. A common problem with stated preference valuation approaches is that respondents often overstate their WTP, which has been attributed to the hypothetical nature of such surveys. The advantage of stated preferences approaches is the ability to investigate values of planned large-scale NNBF for which reliable market data are not available and that-specifically contingent choice valuation-allows researchers to address risk reduction and co-benefits in the same valuation framework.

Other approaches. The following approaches merit attention because they have either been used previously to value risk reduction or may have some appeal for valuation of this service:

- Replacement cost uses the cost of a substitute project to value the risk reduction service being provided by an existing NNBF project, assuming that the substitute provides the same service level. In the case of NNBF, an example would be using the cost of a similarly protective levee or breakwater to estimate the value of dune loss. This approach has the advantage of being easily applicable in an area where costs are available from previously implemented projects and project alternatives. Yet, as summarized in Barbier (2015), this is generally unadvised for valuing the risk reduction benefits of NNBF, or the value of ecosystem services in general, because (1) built infrastructure may not necessarily be the best way to replace the existing or lost service and as a result may overestimate values and (2) this method estimates a benefit using a cost estimate-these will not generally coincide.

- Defensive expenditures and averting behavior at the household level may also be used as a value proxy for changes in risk. Households may increase their expenditures on goods and services designed to compensate for losses in environmental flood risk reduction; examples include costs related to elevating structures, purchasing a sump pump, or buying insurance. General guidance suggests that replacements of the appropriate degree and type may often be hard to achieve, and like replacement costs, the measures taken may not be the most cost-efficient to achieve the chosen level of risk reduction (Turner, Morse-Jones, and Fisher 2010). This type of assessment has only limited research in the context of NNBF (Mahmud and Barbier 2016) and is not currently recommended until methods are formalized with more study. 


\subsubsection{Comparison between Approaches for Monetizing Risk Reduction Benefits}

A comparison of the approaches to valuing risk reduction benefits-expected damage function, hedonic analysis, and contingent choice and contingent valuation-has suggested that all three, although theoretically appropriate measures of changes in welfare, may produce different results (Shabman and Stephenson 1996). Over the last decade, the expected damage function approach has been mainstreamed to value risk reduction benefits of NNBF (van Zanten, Van Beukering, and Wagtendonk 2014; Reguero et al. 2018b; Beck et al. 2019; Menendez et al. 2020) for good reasons: (1) it is the standard method to assess expected flood damage and flood risk and thus enables direct comparison with the risk reduction benefits associated with structural measures such as dikes and dams; (2) the expected damage function approach is formalized into various policies governing CBA for flood risk mitigation; and (3) in contrast to contingent valuation, the method actually relies on hydrological and hydrodynamic modeling to estimate flood hazard areas. However, under certain circumstances, there might be merit in using the other valuation approaches for risk reduction benefits. Some of the key trade-offs are as follows:

- The expected damage function approach and hedonic analysis require flood modeling to produce estimates of the change in risk reduction benefits. Contingent choice and contingent valuation do not necessarily require flood modeling; however, that leaves the survey respondent in a position to individually determine their own change in flood risk from project alternatives. Limited individual experience with flood protection by NNBF (Cameron and Englin 1997) and complexity of the flood protection process have been shown to lead to biases and high variation in estimated values.

- Hedonic analysis and contingent choice provide opportunities to measure co-benefits simultaneously with flood risk reduction and erosion reduction. Hedonic analysis is less flexible than contingent choice in this regard in that it can only monetize co-benefits that affect house values. Contingent choice can capture a broader array of use values.

- In terms of effort, expense, and specialized skills, the expected damage function approach, although data intensive, can be done without the costly acquisition of new data in many locations. Hedonic analysis generally requires purchasing databases of sales transactions, and stated preference surveys can be costly to design and administer. Expected damage function analysis does not require specialized skills in regression analysis, whereas contingent valuation and contingent choice may not require as much GIS analysis as the other approaches. Stated preference approaches are costly because they require primary quantitative data collection using a survey. 


\subsubsection{Monetary Assessment of Co-Benefits}

Fully covering the variety of potential co-benefits from NNBF and the assessment approaches to monetize them is beyond the scope of this chapter. Some of these benefits and relevant measurement techniques are well established, whereas others are still developing. The general approach for valuing co-benefits, a process that closely mirrors the approach taken to measure risk reduction benefits in concept, is discussed in this section.

The first step when assessing co-benefits is to characterize the relationships between NNBF implementation and changes in the environmental condition and benefits to people (Figure 6.2; Arkema, Scyphers, Shepard et al. 2017; Olander et al. 2018). Like all valuation assessments, this is a change assessment that requires an explicit comparison of the benefits from the NNBF project against benefits from existing conditions. For both the project situation and the existing conditions, the same methods can be used as those that link NNBF to benefits. Depending on the type of benefit that is being considered, the assessment will generally require modeling to link NNBF to a change in environmental conditions and additional modeling to link those changes to changes in human well-being. Table 6.4 summarizes methods appropriate for a range of co-benefits associated with NNBF. In an NNBF benefit assessment study that assigns a monetary value to risk reduction benefits and co-benefits, one should be aware of the risk of double counting benefits. For example, it is possible that hedonic analysis (see Table 6.4) also captures a part of the risk reduction benefits that have been also quantified using the expected damage function approach.

Table 6.4. Relevant Valuation Approaches for NNBF Co-Benefits

\begin{tabular}{|c|c|c|}
\hline $\begin{array}{l}\text { Valuation } \\
\text { approach }\end{array}$ & Description & $\begin{array}{l}\text { NNBF benefit } \\
\text { measurement }\end{array}$ \\
\hline $\begin{array}{l}\text { Production function } \\
\text { approach }\end{array}$ & $\begin{array}{l}\text { This approach recognizes that ecosystems may be inputs } \\
\text { into benefit assessments of other marketed goods or } \\
\text { services (i.e., salt marsh and mangroves acting as habitat } \\
\text { for commercial fisheries; Johnston et al. 2002; Arkema et } \\
\text { al. 2019). The value they contribute can be estimated by } \\
\text { evaluating the marginal contribution of the ecosystem to } \\
\text { the production of the marketed good. }\end{array}$ & $\begin{array}{l}\text { Change in commercial } \\
\text { and recreational fishing } \\
\text { opportunities; climate } \\
\text { regulation; water quality }\end{array}$ \\
\hline Avoided damages & $\begin{array}{l}\text { This approach assesses the potential costs due to lost } \\
\text { benefits provided by ecosystems (e.g., climate change } \\
\text { effects on individual and societal welfare if coastal } \\
\text { wetlands no longer stored and sequestered carbon } \\
\text { [Fisher, Bateman, and Turner 2011; Reddy et al. 2016]). } \\
\text { Can include market values or social costs. }\end{array}$ & $\begin{array}{l}\text { Change in social cost of } \\
\text { carbon through carbon } \\
\text { storage and sequestration; } \\
\text { water quality }\end{array}$ \\
\hline
\end{tabular}


Valuation approach

Hedonic analysis

\section{Description}

This approach uses housing markets to demonstrate WTP for different levels of nearby natural amenities (e.g., higher versus lower water quality). The WTP for changes in natural amenities can be revealed by comparing the market value of homes with different levels of associated natural amenities, holding all else constant (Poor, Pessagno, and Paul 2007).

Travel cost method This approach estimates benefits based on observed recreational behavior. Information on travel expenses and trip frequency is used to estimate a trip demand function to estimate net gains from the NNBF. Common survey data used include individual visitation frequency, travel costs and other expenditures, environmental quality measures, and demographic information.

Contingent
valuation and
contingent choice

These stated preference methods use survey techniques to elicit values for co-benefits of NNBF and to assess individuals' willingness to make trade-offs among these benefits. Contingent valuation asks respondents to value alternatives directly, whereas contingent choice asks respondents to choose between a series of alternatives with given prices to derive respondents' WTP. Survey data should include detailed descriptions of the change in benefits resulting from NNBF and a mechanism for eliciting value. See Johnston et al. (2018) for an example for NNBF.

Benefits (value) This approach extrapolates values of NNBF co-benefits transfer from one site where data are available (reference site)

\section{NNBF benefit} measurement

Change in recreational opportunities and tourism; change in aesthetic landscape quality

Change in recreational opportunities and tourism

\section{All co-benefits}

to another site (project site), potentially using a value function or correction factor (e.g., see Reddy et al. [2016] for recreation example). Although this method has the advantage of being inexpensive and rapid, benefits transfer may lead to transfer errors due to differences between the benefit transferred from the reference site and the true value of the co-benefits of NNBF at the project site. Transfer errors are expected to be lower when two sites are similar and are minimized with intraregion rather than interregion transfers. Matching site, contextual, institutional, quantity, and quality characteristics between the policy and the reference sites will all decrease the benefit transfer error (Rao et al. 2013). Expected benefits should be similar in magnitude and type in the studies being used (Dubgaard 2003; Cesar and van Beukering 2004).

\section{All benefits}




\subsubsection{Assessing Costs of NNBF}

The Planning Phase and Decision-Making Phase for NNBF require knowing the costs over the life cycle of the project. The costs of an NNBF project can be broadly considered in four phases, similar to the costs of a project involving coastal or fluvial structures (Table 6.5).

The NNBF in Table 6.5-mangroves and reefs-serve as examples. Similar cost components apply to other NNBF.

Table 6.5. Major Cost Components Comparison: NNBF versus a Conventional Structure

\begin{tabular}{|c|c|c|c|c|}
\hline $\begin{array}{c}\text { Cost } \\
\text { component }\end{array}$ & $\begin{array}{l}\text { Land and } \\
\text { permitting }\end{array}$ & $\begin{array}{l}\text { NNBF co } \\
\text { Sourcing and } \\
\text { transporting } \\
\text { material }\end{array}$ & $\begin{array}{c}\text { Design and } \\
\text { creation }\end{array}$ & $\begin{array}{c}\text { Maintenance } \\
\text { and monitoring }\end{array}$ \\
\hline Mangroves & $\begin{array}{l}\text { - } \text { Cost of land } \\
\text { - Permits for } \\
\text { intertidal } \\
\text { modification }\end{array}$ & $\begin{array}{l}\text { - } \text { Nursery costs for } \\
\text { planting } \\
\text { - Sediment } \\
\text { delivery costs }\end{array}$ & $\begin{array}{l}\text { - } \text { Design costs } \\
\text { - } \text { Site access } \\
\text { - Labor for planting } \\
\text { - Engineering costs } \\
\text { for protecting } \\
\text { saplings } \\
\text { - Engineering costs } \\
\text { for hydrological } \\
\text { restoration }\end{array}$ & $\begin{array}{l}\text { - Labor } \\
\text { - } \text { Monitoring } \\
\text { equipment } \\
\text { - Regular } \\
\text { maintenance } \\
\text { and upkeep }\end{array}$ \\
\hline Reefs & $\begin{array}{l}\text { - Permits for } \\
\text { offshore } \\
\text { modification } \\
\text { - Cost of ocean } \\
\text { space }\end{array}$ & $\begin{array}{l}\text { - Cost of sourcing } \\
\text { fragments } \\
\text { - Reef nursery } \\
\text { costs } \\
\text { - Delivery of } \\
\text { fragments to site }\end{array}$ & $\begin{array}{l}\text { - } \text { Design costs } \\
\text { - } \text { Site access } \\
\text { - Labor for } \\
\text { outplanting } \\
\text { Engineering } \\
\text { equipment } \\
\text { for structural } \\
\text { components }\end{array}$ & $\begin{array}{l}\text { - Labor } \\
\text { - } \text { Monitoring } \\
\text { equipment } \\
\text { - } \text { Regular } \\
\text { maintenance } \\
\text { and upkeep }\end{array}$ \\
\hline Structures & $\begin{array}{l}\text { - Cost of land } \\
\text { - Permits } \\
\text { for coastal } \\
\text { structures }\end{array}$ & $\begin{array}{l}\text { Costs of } \\
\text { construction } \\
\text { material (e.g., } \\
\text { sand, rock, } \\
\text { armoring, and } \\
\text { concrete) }\end{array}$ & $\begin{array}{l}\text { - Design costs } \\
\text { - Site access } \\
\text { - Labor and } \\
\text { engineering } \\
\text { equipment for } \\
\text { construction }\end{array}$ & $\begin{array}{l}\text { - Labor } \\
\text { - } \text { Monitoring } \\
\text { equipment } \\
\text { - } \text { Regular } \\
\text { maintenance } \\
\text { and upkeep }\end{array}$ \\
\hline
\end{tabular}


The major components of life-cycle costs to consider when designing an NNBF project are land and permitting, sourcing and transporting material, design and creation (or restoration), and maintenance and monitoring costs. Unless implemented in offshore environments (i.e., coral or oyster reefs) or used to advance the coastline by afforestation (e.g., Chung 2006), the NNBF will need land, incurring real estate and opportunity costs associated with the use of the land. In situations where new coastal land becomes available through other adaptation strategies such as managed realignment or managed retreat, this land can be used to create NNBF, potentially reducing this cost (Turner et al. 2007).

Permitting costs should be included in NNBF project cost evaluations, though these can be highly variable across and even within countries. In countries like the United States where there are strict regulations on modifications to the intertidal environment, it is usually harder (and costlier) to obtain construction permits for wetland NNBF than for structures such as seawalls or levees that are typically situated above the high-tide line. It is also worth noting that difficult permitting processes can result in longer wait times, delaying the execution of the NNBF project and consequently resulting in higher capital costs.

Appropriate design and planning are necessary when creating an NNBF to ensure that it achieves the intended outcomes, and design and planning come with associated costs. Like for any other coastal or fluvial project, this will require detailed analysis, modeling and design, and construction planning, whether the project is to enhance a coastal marsh or to restore a mangrove forest or an offshore reef. This component can be expected to be similar in magnitude to typical engineering projects, although potentially requiring different kinds of analyses, such as of the hydrodynamics of breaching an inlet to create new tidal marsh, or different techniques, such as the creation of special reef blocks for coral reef restoration.

There is limited but important guidance on the costs of creating NNBF projects (Table 6.6). In general, NNBF creation costs can be expected to vary considerably by NNBF type, location, size, technique, and, in the case of tidal wetland NNBF, the availability of sediment. Mangrove NNBF projects are significantly cheaper (approximately thousands of USD per hectare [ha]) to restore than salt marshes and coral reefs (greater than hundreds of thousands of USD per ha), which require operations in higher energy environments (Bayraktarov et al. 2017; Narayan et al. 2016; Ortega et al. 2019). In the U.S. Gulf Coast, oyster reef restoration costs can vary from USD $\$ 12,000$ per ha to more than USD $\$ 1,000,000$ per ha (La Peyre et al. 2014). Some factors and techniques can reduce these costs; for example, restoration becomes much cheaper when labor is available at low cost, either as a result of voluntary contributions of effort from local communities or simply due to low capital costs of labor. Another technique that can be used to reduce creation costs is to design the project to create the conditions for natural establishment and growth of the NNBF habitats. This method is also preferable from an ecological standpoint relative to, for example, manual planting of saplings that may not follow appropriate techniques (Primavera and Esteban 2008). However, the trade-off 
associated with this method is the longer time for establishment of the NNBF, which will mean longer wait times for the NNBF's benefits to be apparent. For salt marsh restoration projects, emerging techniques such as thin-layer placement can help reduce creation costs. Leveraging navigation dredging projects and beneficially using sediment from the project over time can also significantly reduce creation costs of intertidal NNBF.

Table 6.6. Unit Costs of Different NNBF Types

\begin{tabular}{|c|c|c|}
\hline NNBF type & Global median capital costs (USD\$) & $\begin{array}{l}\text { Maintenance } \\
\text { costs (USD\$) }\end{array}$ \\
\hline Mangrove forests & $\begin{array}{l}\text { 1,000 to } \mathbf{9 , 0 0 0} \text { per ha } \\
\text { (Bayraktarov et al. 2016; Narayan et al. 2016) }\end{array}$ & $\begin{array}{l}7 \text { to } 85 \text { per ha per year } \\
\text { (Global) (Aerts 2018) }\end{array}$ \\
\hline Coastal marshes & $\begin{array}{l}\text { 11,000 to } 230,000 \text { per ha } \\
\text { (Aerts 2018; Bayraktarov et al. 2016; Narayan } \\
\text { et al. 2016) }\end{array}$ & $\begin{array}{l}\text { Wadden Sea } \\
25 \text { per m per year } \\
\text { (Vuik et al. 2019) }\end{array}$ \\
\hline $\begin{array}{l}\text { Coral reefs } \\
\text { (per ha costs assumed as per } \\
\text { kilometer costs for a } 10-m \text {-wide reef) }\end{array}$ & $\begin{array}{l}165,600 \text { to } 1,300,000 \text { per kilometer } \\
\text { (Bayraktarov et al. 2016; Narayan et al. 2016; } \\
\text { Ferrario et al. 2014) }\end{array}$ & Not available \\
\hline $\begin{array}{l}\text { Oyster reefs and artificial reefs } \\
\text { (per ha costs assumed as per } \\
\text { kilometer costs for a } 10-\text { m-wide reef) }\end{array}$ & $\begin{array}{l}\text { Oyster reefs: } \\
\mathbf{6 6 , 8 0 0} \text { per kilometer } \\
\text { (Bayraktarov et al. } 2016 \text { ) } \\
\text { Artificial reefs in the United Kingdom: } \\
\mathbf{3 0 0 , 0 0 0} \text { to } \mathbf{9 0 0 , 0 0 0} \text { per kilometer (range) } \\
\text { (Aerts 2018) }\end{array}$ & Not available \\
\hline
\end{tabular}

Source: Adapted from Oppenheimer et al. 2019 and sources within

The costs of maintenance, monitoring, and adaptive management of an NNBF once it is put in place should not be overlooked. A well-designed NNBF should, under the right conditions, be able to "self-maintain" by, for example, building sediment or growing to keep pace with sea-level rise or recovering after storm damage. This capacity will reduce maintenance costs and is a significant benefit of NNBF over structural alternatives such as seawalls, bulkheads, and levees (e.g., Gittman et al. 2016). However, site and landscape conditions can change for the worse, and NNBF will need to be regularly monitored and, when needed, managed to ensure they remain functional in terms of providing the intended benefits. 


\section{5 | Comparing Costs and Benefits of Project Alternatives Using Decision-Support Frameworks}

\section{Figure 6.9. Decision-Making Phase}

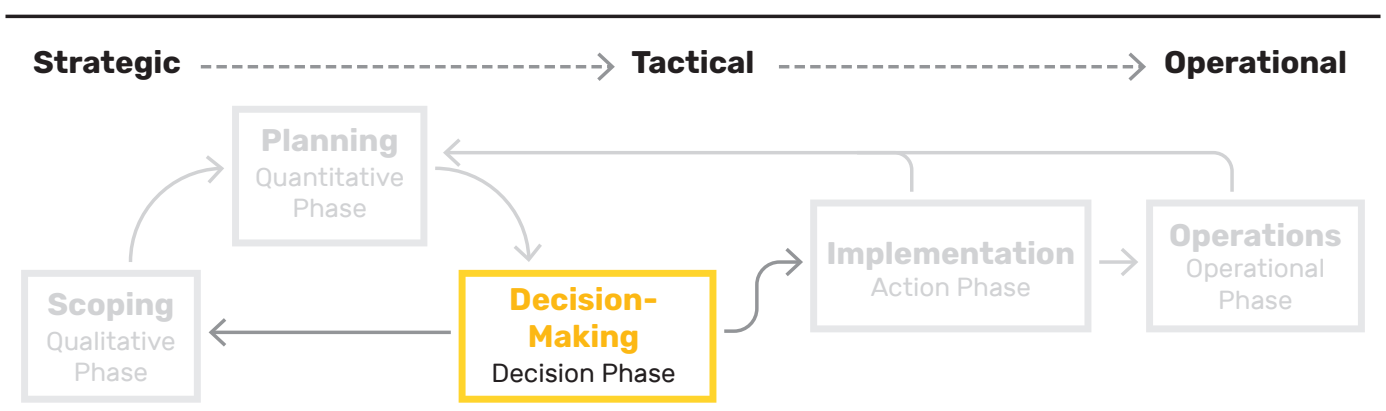

The Decision-Making Phase (Figure 6.9) of planning for infrastructure projects, whether purely structural, hybrid, or NNBF, usually involves developing several different project alternatives, and evaluating and comparing these alternatives based on their collective costs, benefits, and trade-offs among the different types of benefits and their beneficiaries. Each alternative has its own benefits and trade-offs that should be considered. The combined assessment of costs and benefits is important when evaluating the viability of NNBF projects alongside other alternatives for risk reduction and co-benefits. Commonly applied decision-support frameworks by which such a combined assessment of NNBF benefits, costs, and trade-offs can be performed include MCA, CEA, CBA, and robust decision-making (RDM) approaches. Table 6.7 shows the applicability of decision-support tools to compare NNBF project alternatives.

Table 6.7. Features and Comparisons of Different Decision-Support Frameworks

\begin{tabular}{llll} 
Tool & Opportunities & Challenges & Typical application \\
\hline MCA & $\begin{array}{l}\text { Consideration of multiple } \\
\text { objectives and plural values }\end{array}$ & $\begin{array}{l}\text { Value-based weighting of } \\
\text { objectives required, which } \\
\text { hinders replication }\end{array}$ & $\begin{array}{l}\text { NNBF interventions involving } \\
\text { benefits that are hard to } \\
\text { monetize, such as habitat } \\
\text { or species richness (i.e., } \\
\text { intermediate services) }\end{array}$ \\
\hline
\end{tabular}




\begin{tabular}{llll} 
Tool & Opportunities & Challenges & Typical application \\
\hline CEA & $\begin{array}{l}\text { Ambition level fixed } \\
\text { and only costs to be } \\
\text { compared (benefits of } \\
\text { NNBF are assumed fixed for } \\
\text { alternatives) }\end{array}$ & $\begin{array}{l}\text { Ambition level needs to be fixed } \\
\text { and agreed upon }\end{array}$ & $\begin{array}{l}\text { Well-specified NNBF project with } \\
\text { important intangible effects, } \\
\text { which should not be exceeded } \\
\text { (e.g., loss of life, protection } \\
\text { standards) }\end{array}$ \\
\hline CBA & $\begin{array}{l}\text { Rigorous frameworks for } \\
\text { comparing cost to benefits }\end{array}$ & $\begin{array}{l}\text { Need to monetize all benefits, } \\
\text { difficulty incorporating intangible } \\
\text { effects }\end{array}$ & $\begin{array}{l}\text { Well-specified NNBF project with } \\
\text { monetizable economic benefits } \\
\text { and cost }\end{array}$ \\
\hline RDM & $\begin{array}{l}\text { Address uncertainty and } \\
\text { robustness }\end{array}$ & $\begin{array}{l}\text { Technical and computing skills } \\
\text { required }\end{array}$ & $\begin{array}{l}\text { Projects with large uncertainties } \\
\text { and long time frames (context } \\
\text { of climate change where flood } \\
\text { return periods may become more } \\
\text { uncertain) }\end{array}$
\end{tabular}

Source: Adapted from Mechler 2014

The particular approach used to evaluate these costs, benefits, and trade-offs will depend on several factors, including the following:

- Policy directives or constraints, as well as the magnitude of potential investment

- The nature of the stakeholder partnerships and the objectives of each stakeholder group

- The governance structure of the project (e.g., the extent to which stakeholders' objectives will be considered as a part of the decision-making)

- The technical team's collective experience and familiarity with a particular method

As indicated in previous sections, NNBF projects can have broad-ranging direct and indirect benefits and costs. For example, Figure 6.10 compares benefit accrual for different structural measures and NNBF types. To evaluate these simultaneously and relative to other potential coastal or fluvial flood mitigation options, synthesizing these benefits for decision-making and visualizing them for broader engagement is an important step. 
Figure 6.10. Comparison of Benefits of Structural Measure and NNBF Types by Both Space Required and Time to Be Fully Operational in Terms of Risk Reduction

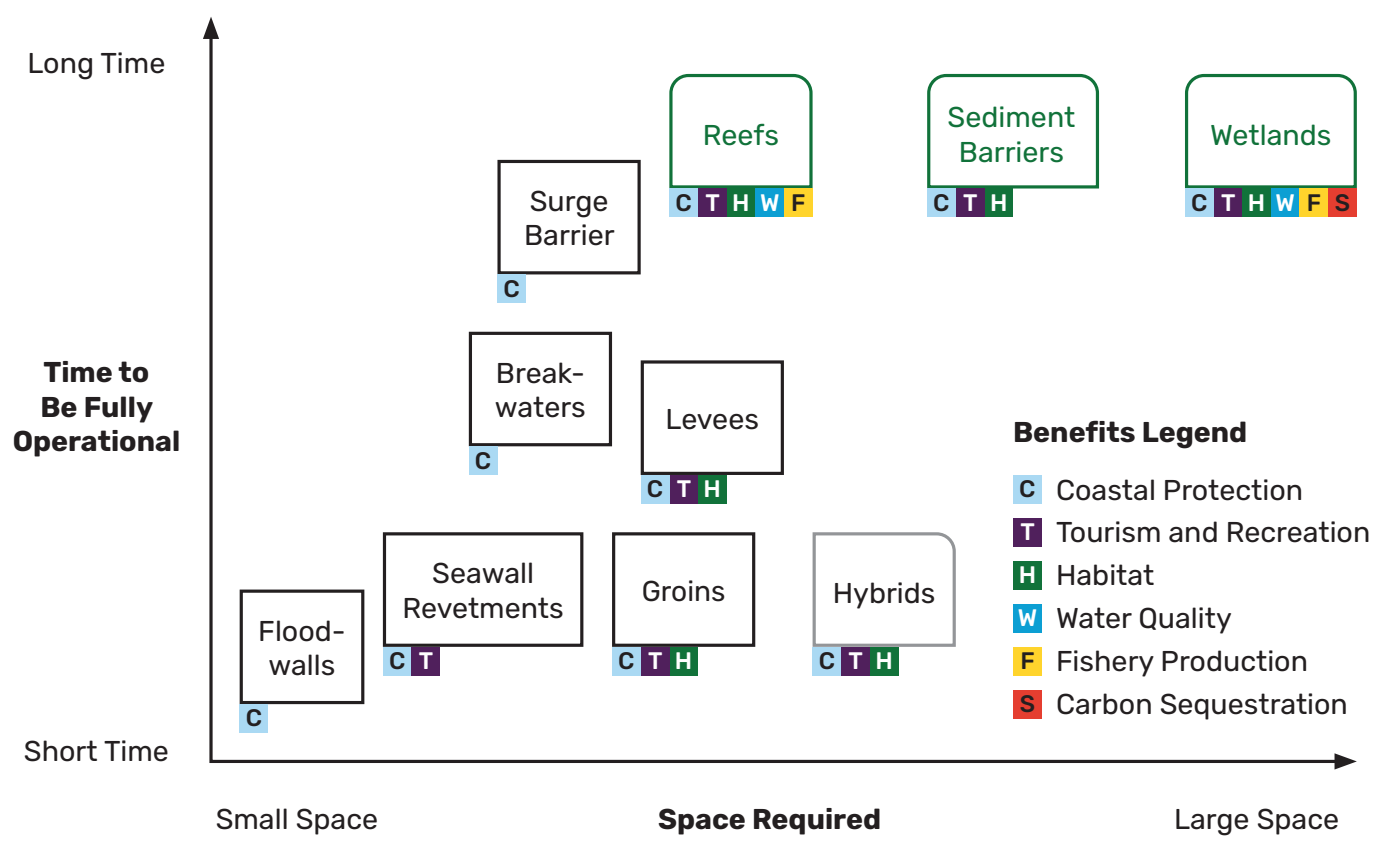

Choosing from among a suite of potential solutions to flood risk includes trade-offs. For NNBF, the trade-offs may be the costs or the type or amount of benefits, as well as who is experiencing the changes. Single benefits should not be used as a proxy for all benefits; it is not only the balance sheet that is underrepresented, but it may not be apparent where increasing one function will diminish another, and it is unlikely to adequately identify how many and who are at risk. Every strategy or potential solution will have benefits and impacts, and it is critical to clearly document both. Even NNBF projects can have negative impacts on the coastal or fluvial environment and coastal or fluvial habitats if poorly designed, placed, or managed, although these impacts are less than the negative consequences of structural measures. For example, projects that plant mangroves or include marsh on extant mudflats will have to pay careful attention to unintended negative consequences such as the loss of valuable biodiversity (Erftemeijer and Lewis 1999). Offshore reefs can, in some cases, aggravate coastal erosion or storm surges (e.g., Roeber and Bricker 2015), and careful attention should be paid to the proper location of restoration efforts to avoid unintended impacts on nearby coastlines. 
Table 6.8 illustrates the differences between MCA, CEA, and CBA using a project example. Suppose, for example, that two fictional project alternatives have been developed for the coastal area presented in Table 6.8-(1) a coral reef restoration and submerged breakwater and (2) a seawall-and that the cost and benefit examples have been assessed quantitatively. Table 6.8 shows what an MCA, CEA, and CBA for this project could look like. As described in Table 6.7, MCA compares the weighted nonmonetary scores of project alternatives, CEA assesses the total present cost over a project lifetime to achieve a policy goal (i.e., protection against a 50-year return period flooding event in Table 6.8), and CBA adds up all present costs and benefits over a project lifetime. As can be seen in the results table, a different approach can lead to a different outcome. In this example, the decision-support frameworks that value the change in co-benefits (MCA, CBA) evaluate the NNBF alternative more positively.

Table 6.8. Comparison of MCA, CEA, and CBA Using a Fictional Project with Two Alternative Interventions

\section{Project alternative 1: Coral reef restoration and submerged breakwater}

\begin{tabular}{|c|c|c|c|c|c|}
\hline \multirow{2}{*}{$\begin{array}{l}\text { Cost and } \\
\text { benefit } \\
\text { Cost }\end{array}$} & \multirow{2}{*}{$\begin{array}{l}\text { Effect } \\
\text { Up-front investment }\end{array}$} & \multicolumn{2}{|c|}{$\begin{array}{c}\text { MCA } \\
\text { Score and } \\
\text { weight }\end{array}$} & \multirow{2}{*}{$\begin{array}{c}\text { CEA } \\
\text { Present values* } \\
\text { (USD) } \\
\$ 2.8 \text { million }\end{array}$} & \multirow{2}{*}{$\begin{array}{c}\text { CBA } \\
\text { Present values* } \\
\text { (USD) }\end{array}$} \\
\hline & & 75 & 1 & & \\
\hline & Maintenance & 20 & 1 & $\$ 785,000$ & $\$ 785,000$ \\
\hline \multirow{5}{*}{$\begin{array}{l}\text { Benefit } \\
\text { (compared to } \\
\text { no action) }\end{array}$} & Coastal flood protection & 70 & 1 & $\begin{array}{l}50 \text {-year return } \\
\text { period protection }\end{array}$ & \$1.3 million \\
\hline & $\begin{array}{l}\text { Beach erosion } \\
\text { prevention }\end{array}$ & 80 & 0.75 & - & $\$ 471,000$ \\
\hline & Nature-based tourism & 90 & 0.50 & - & $\$ 2.4$ million \\
\hline & Fisheries & 75 & 0.75 & - & $\$ 471,000$ \\
\hline & Recreation residents & 90 & 0.75 & - & $\$ 785,000$ \\
\hline
\end{tabular}


Project alternative 2: Seawall

\begin{tabular}{|c|c|c|c|c|c|}
\hline \multirow{2}{*}{$\begin{array}{l}\text { Cost and } \\
\text { benefit } \\
\text { Cost }\end{array}$} & \multirow{2}{*}{$\begin{array}{l}\text { Effect } \\
\text { Up-front investment }\end{array}$} & \multicolumn{2}{|c|}{$\begin{array}{l}\text { MCA } \\
\text { Score and } \\
\text { weight }\end{array}$} & \multirow{2}{*}{$\begin{array}{c}\text { CEA } \\
\text { Present values* } \\
\text { (USD) } \\
\$ 1.5 \text { million }\end{array}$} & \multirow{2}{*}{$\begin{array}{c}\text { CBA } \\
\begin{array}{c}\text { Present values* } \\
\text { (USD) }\end{array} \\
\text { \$1.5 million }\end{array}$} \\
\hline & & 100 & 1 & & \\
\hline & Maintenance & 50 & 1 & $\$ 157,000$ & $\$ 157,000$ \\
\hline \multirow{5}{*}{$\begin{array}{l}\text { Benefit } \\
\text { (compared to } \\
\text { no action) }\end{array}$} & Coastal flood protection & 100 & 1 & $\begin{array}{l}50 \text {-year return } \\
\text { period protection }\end{array}$ & $\$ 1.6$ million \\
\hline & $\begin{array}{l}\text { Beach erosion } \\
\text { prevention }\end{array}$ & 0 & 0.75 & - & \$o \\
\hline & Nature-based tourism & 30 & 0.50 & - & $\$ 785,000$ \\
\hline & Fisheries & 0 & 0.75 & - & $\$ 0$ \\
\hline & Recreation residents & 45 & 0.75 & - & $\$ 393,000$ \\
\hline
\end{tabular}

\section{Results:}

\begin{tabular}{lccc}
\hline Alternative & MCA & CEA* (USD) & CBA* (USD) \\
\hline $\begin{array}{l}\text { Project alternative 1: Coral reef } \\
\text { restoration and submerged breakwater }\end{array}$ & 394 & $\begin{array}{c}\text { \$3.6 million } \\
\text { (present costs) }\end{array}$ & $\begin{array}{c}\text { \$1.8 million (NPV) } \\
1.49 \text { (BCR) }\end{array}$ \\
\hline Project alternative 2: Seawall & 299 & $\begin{array}{c}\text { \$1.7 million } \\
\text { (present costs) }\end{array}$ & $\$ 1.66$ (BCR)
\end{tabular}

Notes:

Table shows a fictional project example to illustrate comparative cost evaluation.

* With a discount rate of $5 \%$ and a project lifetime of 30 years

The top part of the table shows the present costs and benefits of Project Alternative 1 and Project Alternative 2. For the MCA, costs and benefits are expressed using a qualitative score and a weight per effect. For the CEA and CBA, cost and benefits (CBA) are expressed in U.S. dollars. The bottom part of the table shows the results of the three decision-support tools. Project Alternative 1 scores best using the MCA (394 points) and CBA (\$1.8 million [NPV]), whereas Project Alternative 2 scores best using CEA, achieving protection against a 50-year return period event with the lowest cost. 
Because the outcome can vary with the approach used to compare benefits and with the co-benefits included in the analysis, it can be useful to include the breakdown of results for all benefits. Transparent and detailed accounting of benefits is especially important when the Decision-Making Phase involves consultation with diverse stakeholders who may be interested in specific co-benefits of the project.

\subsubsection{Comparing Project Alternatives Using Multicriteria Analysis}

Because many of the co-benefits derived from NNBF are so-called nonmarket services that are difficult, expensive, or controversial to monetize for a CBA, other approaches are necessary. MCA is a useful approach to capture indirect co-benefits that cannot otherwise be captured completely in a CBA, or when costs and benefits cannot be measured in the same terms (i.e., a "dollar value"). An MCA is an analysis where the alternative plans or measures are scored against multiple criteria related to the explicit objectives established for the project using quantitative measures of performance, expert judgment, or a combination of approaches. Project alternatives can be ranked by weighting (see Table 6.8) the objectives and associated input criteria from the decision-makers and stakeholders, as determined by the governance process of the project. This approach is best applied when a project considers multiple objectives and plural values. It is also a tool to increase stakeholder engagement and support to inform an early dialogue in the Scoping Phase (which includes the qualitative assessment) of an NNBF project.

\subsubsection{Comparing Project Alternatives Using Cost-Benefit Analysis}

In a CBA, the costs and benefits of project alternatives are compared to a situation without project intervention (EcoShape 2019). Although a variety of CBA approaches exist, the following principles are applied in most applications:

- Comparisons of a number of different alternatives for a specified project timeline (e.g., 30 or 50 years); generally, a "no action" scenario is compared to one or multiple project alternative scenarios to select the best project alternative

- Analysis of the relevant and monetizable costs and benefits through a societal lens, including nonmarketed and public benefits

In CBAs, future costs and benefits are discounted based on a predefined discount rate (5\% in Table 6.8). The discount rate represents the annual depreciation of costs and benefits because people place a higher value on the present than on the future. This phenomenon can 
be explained by general uncertainties about the future and by opportunity costs associated with the project-the potential return on investment of capital in other projects. In CBA for NNBF, the discount rate is often determined by the regulator or funding agency (see Table 6.7). Project alternatives in a CBA can be evaluated using four different indicators: (1) the BCR, (2) the NPV (i.e., the discounted benefits minus discounted costs over the project lifetime), (3) the economic rate of return (i.e., the broad welfare economic rate of return), and (4) the internal rate of return of the project.

It is important to note that if the costs or benefits cannot be monetized, they will not be included in the analysis.

\subsubsection{Accounting for Uncertainty: Comparing Project}

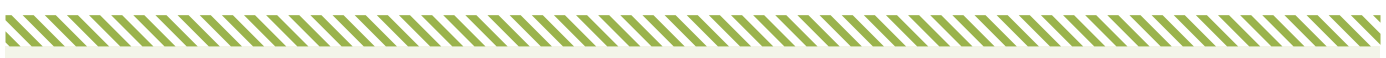

CASE STUDY:

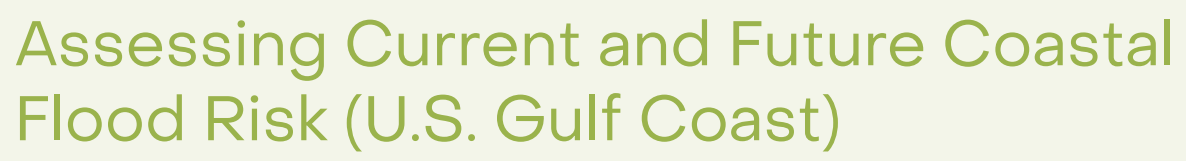

This case study applied the Economics of Climate Adaptation principles (ECA 2009) to assess the cost-effectiveness of various adaptation measures of current and future coastal flood risk along the U.S. Gulf Coast. By assessing the economic damages of current and future coastal flood risk, the study calculated the benefits of implementing different adaptation measures and compared them with the costs of implementing and maintaining them. Using a CBA for the Gulf Coast, this study found that NNBF could avert more than $40 \%$ of the future coastal risk from the combined impacts of climate change, land subsidence, and coastal development. On average, the BCRs of NNBF projects were estimated at just above 3.5 (Reguero et al. 2018b). The result is a CBA where the different options are represented by decreasing order of BCRs, and the total cumulative flood protection benefit of each measure is represented in the horizontal axis (see Figure 6.11). 
Figure 6.11. Cumulative Benefit-Cost Ratio Curve for NNBF in the U.S. Gulf Coast

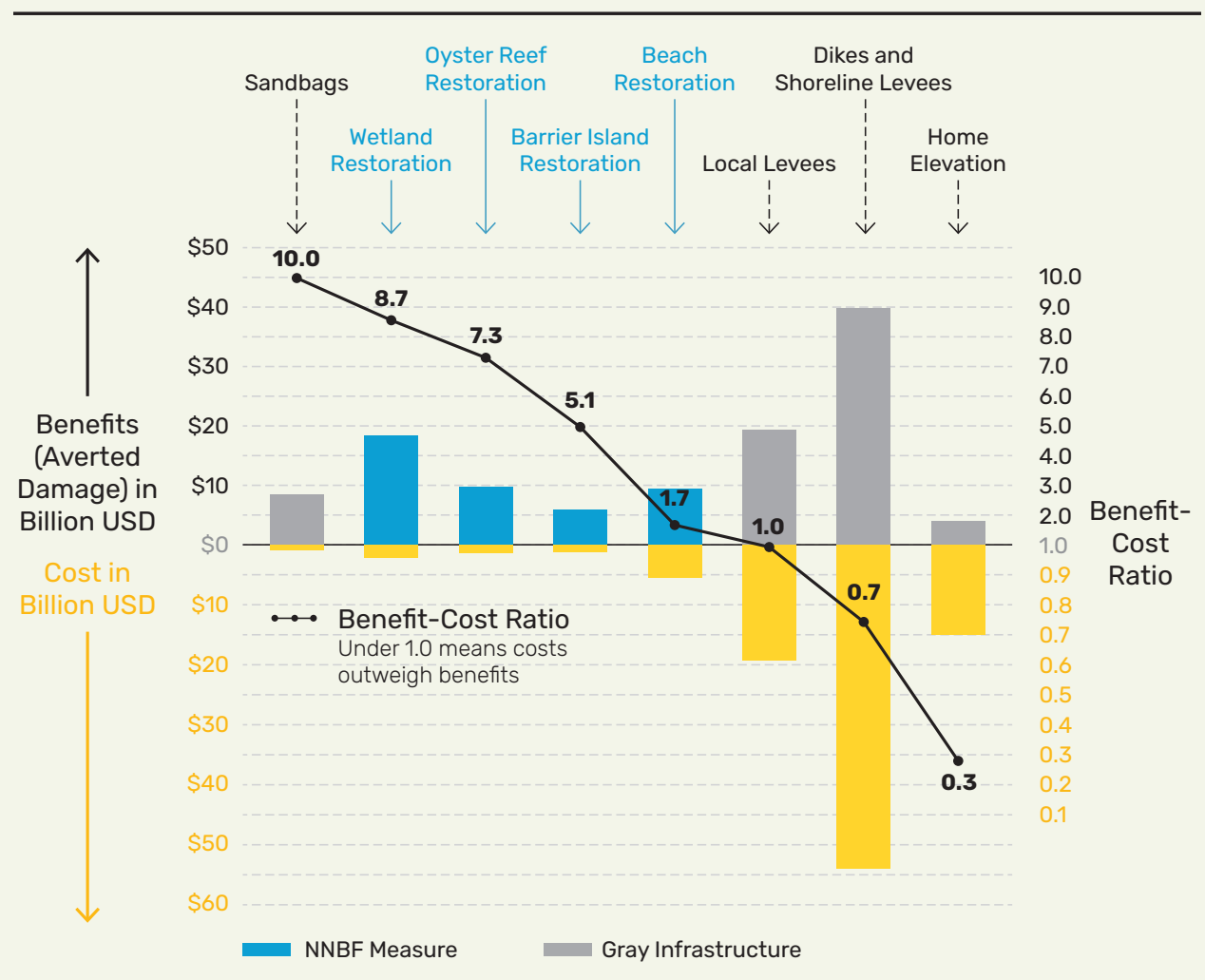

\section{Alternatives Using Robust Decision-Making Approaches}

Investment decisions for infrastructure projects often face significant uncertainties about future costs and benefits. Variability in natural processes is a particularly relevant source of uncertainty for NNBF because of the relative dynamic nature of these measures (Wang, Feng, and Swail 2015). That is, their structure and function are subject to change over time as the feature matures. Further, it is not (yet) possible to obtain precisely all the information and knowledge about the natural system. And in the social system, changing interests, preferences, values, perceptions, and behaviors may lead to additional uncertainties about future benefits. For example, a co-benefit such as nature-based tourism is highly dependent on the costs of transportation and political stability in a region. Also, the appreciation of 
certain benefits might change over time as a result of global priorities (e.g., the value of carbon credits fluctuates, as well as global funding available for coastal or fluvial flood mitigation and biodiversity protection). When appraising an investment decision in gray infrastructure, hybrid infrastructure, or NNBF, it is helpful to realize that there are different types of uncertainty. Hallegatte et al. (2012) identify three types. Translated to an NNBF context, these types of uncertainty emerge from (1) uncertain future policy that affects the costs and benefits of NNBF, (2) the lack of scientific understanding of the functioning and fragility of NNBF, and (3) the variability of natural systems. There are multiple methods for capturing uncertainty. The two most common approaches are sensitivity analysis and RDM.

\subsubsection{Sensitivity Analysis Standard Cost-Benefit Analysis Framework}

In a probabilistic CBA framework, sensitivity analysis will test the effect of assumptions and uncertainties on modeling result indicators, such as the BCR or the NPV of a specific project alternative. Sensitivity analysis is often applied as a stress test to verify the robustness of CBA outcomes under different scenarios of future economic development, climate change, or variations of the assumed discount rate. Analysis of different scenarios can also serve to assess uncertainty related to CBA of different options (e.g., Reguero et al. 2018b).

\subsubsection{Robust Decision-Making}

Recognizing different types of uncertainty, RDM promotes a decision-making under (deep) uncertainty approach to assess the costs and benefits of infrastructure project alternatives. Hallegatte et al. (2012) define deep uncertainty as a situation in which one or more of the following types of uncertainties are present:

- Different and equally valid worldviews or multiple knowledge frames, including factors that define success of the project

- Unquantifiable risk due to unpredictability of complex systems and incomplete knowledge

- Adaptive decision-making over time that is not independent of the project decision context

Building on the presumption that risk and uncertainty can be quantified, a traditional probabilistic CBA seeks to find an optimal investment decision based on the likely future outcome. Decision-making under (deep) uncertainty takes a different approach-it aims to answer the question, "Under which conditions is the decision or project considered a good investment?" Thus, acknowledging that not all uncertainties or risks can be quantified (i.e., for certain factors there is no reliable probability distribution), a wide range of plausible future conditions is considered to explore a range of possible outcomes. An important step in the decision-making under (deep) uncertainty approach is to scope key uncertainties that will determine whether a project will reach its objectives. This scoping exercise is a collaborative effort of stakeholders and analysts working on the project. Depending on the project, 
this exercise will yield a set of uncertainties that can be classified accordingly, enabling assessment whether there is deep uncertainty or not. This process involves a number of basic steps (Bonzanigo and Kalra 2014).

\section{Steps Involved in Robust Decision-Making}

1. Decision-makers structure the decision problem to identify their potential options, the metrics and performance thresholds they will use to evaluate whether their options meet or fail to meet their goals, and the uncertainties that could affect the performance of the policy option according to the metrics. Analysts use models to relate these factors.

2. Analysts statistically generate hundreds of futures and evaluate the performance of their options in each of those futures. This generates a large table of inputs (the uncertain future conditions) and outputs (the metrics) for each option.

3. Analysts identify which input conditions best explain when each option meets or fails to meet decision-makers' performance thresholds. These conditions describe scenarios to which each option is vulnerable.

4. Analysts and decision-makers together compare the scenarios with available evidence to determine whether they are sufficiently plausible to hedge against. They compare trade-offs between robustness, feasibility, cost, and other factors and select those options that best balance their needs.

\section{CASE STUDY: \\ Viability of Wetland Restoration (Colombo, Sri Lanka)}

All

To evaluate the viability of using wetland restoration as NNBF in the flood-prone City of Colombo, Sri Lanka, the World Bank and partners applied a decision-making under (deep) uncertainty approach to assess the economic desirability of wetland conservation despite uncertainties in climate change factors in relation to extreme events. (The case study features in Browder et al. 2019.) The results indicate that wetland conservation is the most desirable option from a welfare economic 
perspective, considering trade-offs between urban development and wetland protection scenarios. Figure 6.12 depicts an analysis of the trade-offs between urban development and wetland protection in the near future, comparing five scenarios: conservation of $0 \%, 30 \%, 50 \%, 90 \%$, and $100 \%$ of the wetlands by 2030 .

Figure 6.12. Trade-Offs between Wetland Conservation and Land Development in 2030

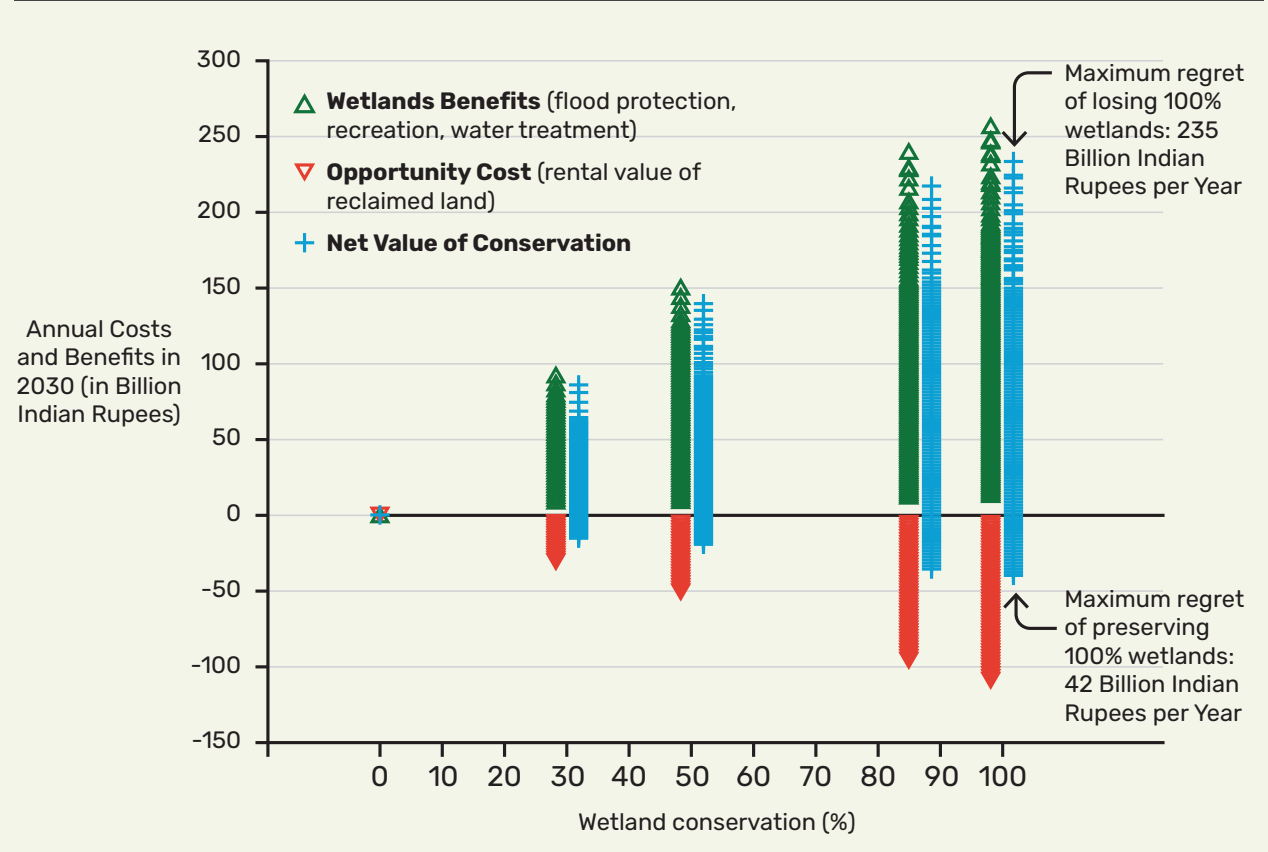

Wetland conservation generates a decisively positive impact, even when considering the lost revenue from forgone rental property development. Regardless of the magnitude of wetland conservation, wetland benefits (green upward arrow in Figure 6.12) are expected to far outweigh the opportunity costs of not developing the land (red downward arrow in Figure 6.12). The more wetlands are conserved, the greater the payoff in the form of wetland benefits such as flood protection, recreation, carbon sequestration, and wastewater treatment (Browder et al. 2019). 


\section{6 | Monitoring and Managing the Performance and Benefits of NNBF}

During the Implementation Phase and the Operations Phase of an NNBF project (Figure 6.13), all interventions, structural or nonstructural, require monitoring. This is done with varying degrees of success. The benefits of NNBF are expected to change over time because of natural ecosystem processes and management. Without monitoring the performance of the benefits, maintenance needs, project improvements, and social and economic benefits of the project to stakeholders will remain unknown. Unlike structural measures, monitoring NNBF requires monitoring the performance of the NNBF for flood or erosion reduction and the co-benefits. The former is discussed in Chapter 5 . This section focuses on monitoring the suite of benefits from an NNBF. The dynamic nature of NNBF requires a defined adaptive management plan explicitly designed to monitor biophysical, environmental, and socioeconomic benefits (refer to $\underline{\text { Chapter } 7}$ for more details on developing adaptive management plans). The monitoring plan should be reflective of the interests of the project authority and the stakeholders, consistent with the overall project objectives, and determined by priorities established by public policy and the investing organizations. Monitoring benefits provides a means for maintaining involvement of key stakeholders.

Figure 6.13. Implementation Phase and Operations Phase

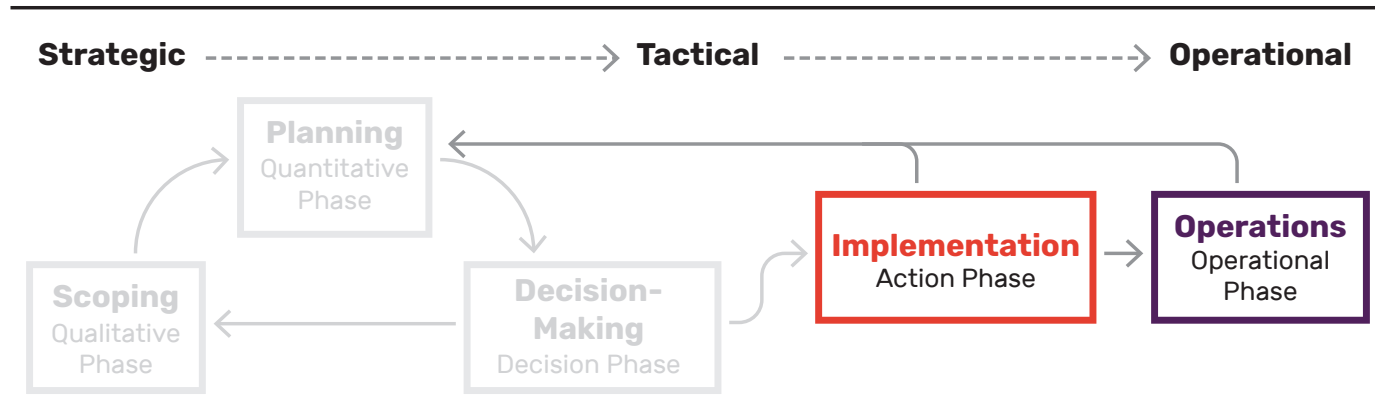

Consider the following example, which presents some of the complexities of benefits monitoring. A particular NNBF project could be functioning well a decade after it was implemented, but if property values decreased, the economic damages avoided could also decrease. Conversely, from a biophysical perspective, engineering function might be poor due to plantings that have failed or reefs that are not recruiting at expected levels, but if demand for coastal property increased, then the value of the service could actually increase, justifying more investment in the NNBF measure. This example illustrates the importance of reporting both biophysical and socioeconomic metrics of co-benefits. The conceptual model for relationships between change in ecosystem structure and function and change in societal benefits (Figure 6.2) may be useful in identifying metrics to monitor. 
Metric identification for benefit management should occur early in the planning process so that it can be incorporated into the adaptive management plan. Not every co-benefit will be able to be monitored, so the stakeholder groups and project authority should identify metrics that provide critical information on the co-benefit of interest. Further, the metrics for monitoring should be limited to a reasonable number that balances level of effort with monitoring objectives. Not all benefits will change at the same rate-the benefits of NNBF rely on its structure and functions, which occur at multiple temporal scales ranging from days (e.g., a storm or flooding event) to months (e.g., seasonally as vegetation shifts from active to dormant growth stages) to years or decades (e.g., ecological succession). Metrics should be developed for each benefit of interest in such a way that the temporal resolution of benefit evolution is captured.

Benefit evaluation should occur throughout the project life cycle, and performance should be assessed based on the trajectory of change while acknowledging that some functions will not be attained for many years after construction (see Figure 6.14 for an example of benefit accrual). In coastal marshes, for example, increasing elevation to avoid inundation is realized after several years once marsh vegetation has time to establish and trap sediment. Similarly, co-benefits such as tourism and nutrient sequestration may not occur until the habitat is fully developed.

\section{Figure 6.14. Dynamism in Benefit Streams}

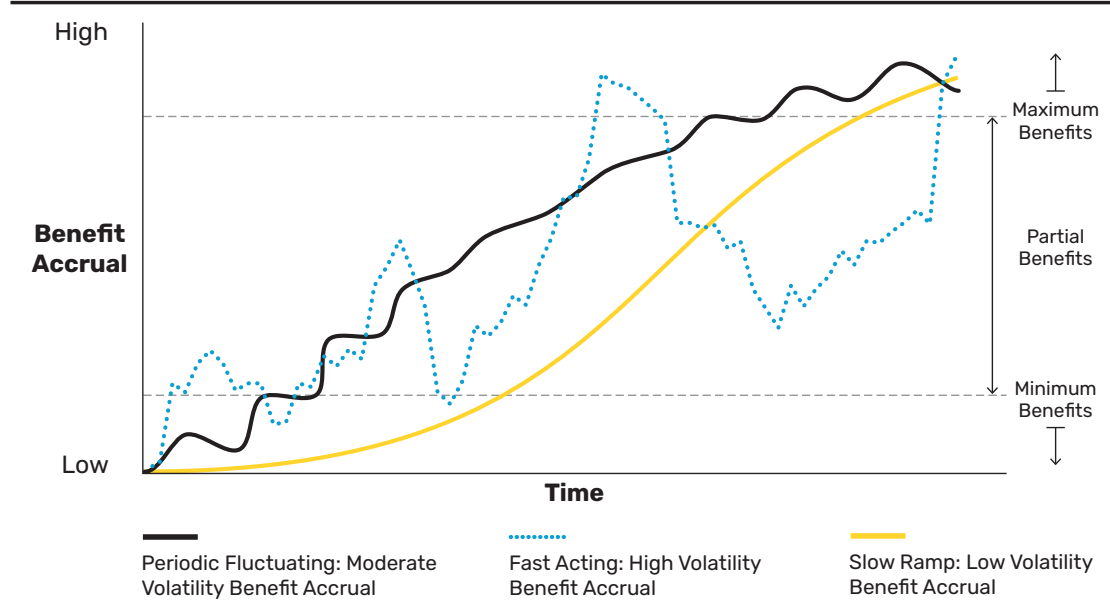

Notes: The area between the dashed lines represents partial benefits, and the areas above and below represent maximum and minimum benefits, respectively. The solid black line represents a benefit that fluctuates due to environmental variability but increases over time, reaching a partial benefit quickly and taking longer to reach its maximum. The dotted blue line represents a benefit that reaches a partial benefit quickly, then fluctuates due to perturbations in the environment as it approaches its maximum, where it then experiences consecutive perturbations that significantly decrease the benefits (e.g., an oyster reef that is exposed to multiple stressors in a short period of time but then rebounds when the conditions stabilize). Finally, the yellow line represents a benefit that does not begin to accrue until after the NNBF is established. 
Benefits should be estimated for both robust and deteriorated conditions. For example, in the case of a reef NNBF, benefits should be considered for reef growth both exceeding and not reaching expected wave attenuation and recruitment goals. Management plans should also include strategies for dealing with events that vary in frequency and duration (e.g., floods that occur consecutively or last for an extended time; see blue dotted line in Figure 6.14 where consecutive events occur).

The dynamism of NNBF benefits requires careful and deliberate monitoring throughout the project life. It is important to match monitoring events with the timescale of processes that generate the benefits-metrics may need to be monitored at different times. For example, at sites that require construction and planting, functions that rely on the physical form of the NNBF may develop over a few years, whereas other elements of ecological performance such as biodiversity may take much longer to occur, so the monitoring efforts should reflect those processes. This process is rarely, if ever, done for structural measures.

NNBF are complex systems that rely on the interactions of physical, ecological, and social components to provide function. Damage or failure of one component may not result in a complete loss of performance or benefit. For example, in vegetated features such as wetlands or dunes, storm conditions may damage vegetation, resulting in a reduction of performance. Beaches and dunes likewise erode during storms, perhaps with no loss of performance relative to surge reduction until the dune is breached. Management actions should first determine if the feature will recover its flood reduction benefit naturally or if active intervention is required to regain this function. These changes in benefit quality should not be regarded as failures but as a part of the dynamic nature of the feature itself.

\section{7 | Gaps and Future Directions}

Recent years have brought growing interest, research, and case studies related to NNBF for flood risk reduction and co-benefits, bridging the gap between environmental economics, hydrology and hydrodynamic modeling, and sustainability science. Yet quantifying the social and economic benefits of NNBF continues to be an active area for research and an opportunity to test new strategies for implementation and monitoring. The following is an outline of these opportunities and priorities for future work:

\section{- Hydrological and physical models for the assessment of NNBF are being advanced rapidly and the accuracy of models that assess expected and averted damages will increase, and the uncertainty and error propagation of models will be reduced. One area that demands further attention is accounting for the fragility of NNBF to the fluvial or coastal hazard in a quantitative way (i.e., development of fragility curves).}


- Learning from a growing body of practice of NNBF projects, a better alignment between financing models for NNBF and benefit assessment methodologies is a priority. The funding and financing models should account for both market and nonmarket values of NNBF. NNBF can be financed or co-financed through bonds, insurance, publicprivate partnerships engaging the tourism sector, carbon offsets, and global funding streams for climate mitigation and adaptation. Bringing these approaches to scale will go hand-in-hand with the development of improved benefit assessment methodologies to unlock funding and financing.

- There is a growing global momentum for bringing the application of ecologic-economic models and natural capital accounting to scale (Dasgupta 2021; Johnson et al. 2021). NNBF will make up a significant contribution to natural capital stocks. New methodologies need be to be developed to accurately reflect the risk reduction and co-benefits of NNBF in coastal, fluvial, and island natural capital accounts.

- Combined field and modeling studies are needed to monitor the social and economic outcomes of NNBF. Monitoring of ecosystem restoration projects typically focuses on ecological outcomes, which provide little data on the flood risk reduction and co-benefits policymakers, communities, and other stakeholders hope to achieve. Long-term monitoring of natural and restored NNBF sites, including the collection of social vulnerability and economic data, will help practitioners understand and communicate about the benefits of NNBF and thus harness support for project sustainability. Integrating economic, ecological, and physical models and data will help to improve predictive tools for understanding the benefits of NNBF over time.

- Advancing Earth observation technologies will drive innovation of approaches for assessing and monitoring the benefits of NNBF. Increasingly, open and commercial high-resolution Earth observation data are available to NNBF project teams and academics. For example, high-resolution radar will become available for flood and erosion detection and hazard mapping (Rosen 2021), and high-resolution imagery will be increasingly used in applications monitoring the extent, condition, and functioning of NNBF. 


\section{$6.8 \mid$ References}

Aerts, J. 2018. “A Review of Cost Estimates for Flood Adaptation." Water 10 (11): 1646.

Arkema K., S. Scychers, and C. Shephard. 2017. "Living Shorelines for Nature and People." In Living Shorelines: The Science and Management of Nature-Based Coastal Protection. Edited by D. M. Bilkovic, M. M. Mitchell, M. K. La Peyre, and J. D. Toft. Boca Raton, FL: Taylor \& Francis Group and CRC Press, CRC Press Marine Science Series.

Arkema, K., and M. Ruckelshaus. 2017. "Transdisciplinary Research for Conservation and Sustainable Development Planning in the Caribbean." In Conservation for the Anthropocene Ocean: Interdisciplinary Science in Support of Nature and People. Edited by P. Levin and M. Poe. San Diego, CA: Elsevier.

Arkema, K., D. Fisher, K. Wyatt, S. A. Wood, and H. Payne. 2021. "Advancing Sustainable Development and Protected Area Planning with Social Media-Based Tourism Data." Sustainability 13 (5), 2427. https://doi.org/10.3390/su13052427.

Arkema, K., G. Guannel, G. Verutes, S. Wood, A. Guerry, M. Ruckelshaus, P. Kareiva., M. Lacayo, and J. Silver. 2013. "Coastal Habitats Protect People and Property from Sea Level Rise and Storms." Nature Climate Change 3: 913-918.

Arkema, K., G. Verutes, S. Wood, C. Clarke, M. Canto, S. Rosado, A. Rosenthal, et al. 2015. "Embedding Ecosystem Services in Coastal Planning Leads to Better Outcomes for People and Nature." Proceedings of the National Academy of Sciences 112 (24): 7390-7395.

Arkema, K., L. Rogers, J. Toft, A. Mesher, K. Wyatt, S. Albury-Smith, S. Moultrie, M. Ruckelshaus, and J. Samhouri. 2019. "Integrating Fisheries Management into Sustainable Development Planning." Ecology and Society 24 (2): 1. https://doi.org/10.5751/ES10630-240201.

Arkema, K., R. Griffin, S. Maldonado, J. Silver, J. Suckale, and A. Guerry. 2017. "Linking Social, Ecological and Physical Science to Advance Natural and Nature-Based Protection for Coastal Communities." Annals of the New York Academy of Sciences 1399 (1): 5-26. doi:10.1111/nyas.13322.

Barbier, E. B. 2015. "Valuing the Storm Protection Service of Estuarine and Coastal Ecosystems." Ecosystem Services 11: 32-38.

Barbier, E. B., and B. S. Enchelmeyer. 2014. "Valuing the Storm Surge Protection Service of U.S. Gulf Coast Wetlands." Journal of Environmental Economics and Policy 3 (2): 167-185.

Barbier, E. B., S. D. Hacker, C. Kennedy, E. W. Koch, A. C. Stier, and B. R. Silliman. 2011. "The Value of Estuarine and Coastal Ecosystem Services." Ecological Monographs 81 (2): 169-183.

Bauer, D. M., N. A. Cyr, and S. K. Swallow. 2004. "Public Preferences for Compensatory Mitigation of Salt Marsh Losses: A Contingent Choice of Alternatives." Conservation Biology 18 (2): 401-411. 
Bayraktarov, E., M. I. Saunders, P. J. Mumby, H. P. Possingham, S. Abdullah, and C. E. Lovelock. 2017. "Response to 'Rebutting the Inclined Analyses on the Cost-Effectiveness and Feasibility of Coral Reef Restoration."' Ecological Applications 27 (6): 1974-1980.

Bayraktarov, E., M. I. Saunders, S. Abdullah, M. Mills, J. Beher, H. P. Possingham, P. J. Mumby, C. E. Lovelock. 2016. "The Cost and Feasibility of Marine Coastal Restoration." Ecological Applications 26 (4): 1055-1074. https://esajournals.onlinelibrary.wiley.com/doi/ full/10.1890/15-1077.

Beck, M. W., and G-M. Lange, eds. 2016. Managing Coasts with Natural Solutions: Guidelines for Measuring and Valuing the Coastal Protection Services of Mangroves and Coral Reefs. Washington, DC: Wealth Accounting and the Valuation of Ecosystem Services Partnership (WAVES), World Bank. http://documents.worldbank.org/curated/ en/995341467995379786/Managing-coasts-with-natural-solutions-guidelines-formeasuring-and-valuing-the-coastal-protection-services-of-mangroves-and-coralreefs.

Beck, M. W., I. J. Losada, P. Menéndez, B. G. Reguero, P. Díaz-Simal, and F. Fernández. 2018. "The Global Flood Protection Savings Provided by Coral Reefs." Nature Communications 9 (1): 2186.

Beck, M. W., R. D. Brumbaugh, L. Airoldi, A. Carranza, L. D. Coen, C. Crawford, O. Defeo, et al. 2011. "Oyster Reefs at Risk and Recommendations for Conservation, Restoration, and Management." BioScience 61 (2): 107-116.

Beltrán, A., D. Maddison, and R. J. Elliott. 2018. "Is Flood Risk Capitalised into Property Values?" Ecological Economics 146: 668-685.

Bilkovic, D. M., M. M. Mitchell, P. Mason, and K. Duhring. 2016. “The Role of Living Shorelines as Estuarine Habitat Conservation Strategies." Coastal Management Journal 44 (3): 161-174.

Bonzanigo, L., and N. Kalra. 2014. Making Informed Investment Decisions in an Uncertain World: A Short Demonstration. Policy Research Working Paper 6765. Washington, DC: The World Bank.

Borsje, B. W., B. K. van Wesenbeeck, F. Dekker, P. Paalvast, T. J. Bouma, M. M. van Katwijk, and M. B. de Vries. 2011. "How Ecological Engineering Can Serve in Coastal Protection." Ecological Engineering 37 (2): 113-122.

Brander, L., and P. van Beukering. 2013. The Total Economic Value of U.S. Coral Reefs: A Review of the Literature. Silver Spring, MD: National Oceanic and Atmospheric Administration Coral Reef Conservation Program.

Bratman, G. N., J. P. Hamilton, and G. C. Daily. 2012. “The Impacts of Nature Experience on Human Cognitive Function and Mental Health." Annals of the New York Academy of Sciences 1249 (1): 118-136. doi:10.1111/j.1749-6632.2011.06400.x. 
Bridges, T. S., K. A. Burks-Copes, M. E. Bates, Z. A. Collier, J. C. Fischenich, C. D. Piercy, E. J. Russo, et al. 2015. Use of Natural and Nature-Based Features (NNBF) for Coastal Resilience. ERDC SR-15-1. Vicksburg, MS: U.S. Army Engineer Research and Development Center, Environmental Laboratory, Coastal and Hydraulics Laboratory. https://hdl.handle.net/11681/19336.

Browder, G., S. Ozment, I. Rehberger-Bescos, T. Gartner, and G. M. Lange. 2019. Integrating Green and Gray: Creating Next Generation Infrastructure. Flagship Report. Washington, DC: World Bank and World Resources Institute. https://files.wri.org/s3fspublic/integrating-green-gray-executive-summary.pdf.

Cabral, P., G. Augusto, A. Akande, A. Costa, N. Amade, S. Niquisse, A. Atumane, et al. 2017. "Assessing Mozambique's Exposure to Coastal Climate Hazards and Erosion." International Journal of Disaster Risk Reduction 23: 45-52. doi:10.1016/j. ijdrr.2017.04.002.

Cameron, T. A., and J. Englin. 1997. "Respondent Experience and Contingent Valuation of Environmental Goods." Journal of Environmental Economics and Management 33 (3): 296-313.

Cannon, M. G., J. M. Phelan, and M. A. Passaro. 1995. Procedural Guidelines for Estimating Residential and Business Structure Value for Use in Flood Damage Estimations. IWR 95 R 9. Alexandria, VA: U.S. Army Corps of Engineers, Water Resources Support Center, Institute for Water Resources.

Carrasquilla-Henao, M., and F. Juanes. 2017. “Mangroves Enhance Local Fisheries Catches: A Global Meta-Analysis." Fish and Fisheries 18 (1): 79-93.

Casarin, R. S., G. R. Martinez, I. Mariño-Tapia, G. P. Vanegas, E. M. Baldwin, and E. E. Mancera. 2012. "Manmade Vulnerability of the Cancun Beach System: The Case of Hurricane Wilma." CLEAN: Soil, Air, Water 40 (9): 911-919.

Cesar, H. S., and P. van Beukering. 2004. "Economic Valuation of the Coral Reefs of Hawai'i." Pacific Science 58 (2): 231-242.

Christie, M., N. Hanley, J. Warren, K. Murphy, R. Wright, and T. Hyde. 2006. "Valuing the Diversity of Biodiversity." Ecological Economics 58 (2): 304-317.

Chung, C. H., 2006. Forty Years of Ecological Engineering with Spartina Plantations in China. Ecological Engineering 27 (1): 49-57.

Costanza, R., R. d'Arge, R. De Groot, S. Farber, M. Grasso, B. Hannon, K. Limburg, et al. 1997. "The Value of the World's Ecosystem Services and Natural Capital." Nature 387 (6630): 253.

Costanza, R., R. de Groot, L. Braat, I. Kubiszewski, L. Fioramonti, P. Sutton, S. Farber, and M. Grasso. 2017. "Twenty Years of Ecosystem Services: How Far Have We Come and How Far Do We Still Need to Go?" Ecosystem Services 28 (A): 1-16. 
Cracknell, D. L., S. Pahl, M. P. White, and M. H. Depledge. 2018. “Reviewing the Role of Aquaria as Restorative Settings: How Subaquatic Diversity in Public Aquaria Can Influence Preferences, and Human Health and Well-Being." Human Dimensions of Wildlife 23 (5): 446-460.

Daily, G. C., ed. 1997. Nature's Services: Societal Dependence on Natural Ecosystems. Washington, DC: Island Press.

Danielsen, F., M. K. Serensen, M. F. Olwig, V. Selvam, F. Parish, N. D. Burgess, T. Hiraishi, et al. 2005. "The Asian Tsunami: A Protective Role for Coastal Vegetation." Science 310 (5748): 643.

Das, S., and J. R. Vincent. 2009. "Mangroves Protected Villages and Reduced Death Toll during Indian Super Cyclone." Proceedings of the National Academy of Sciences 106 (18): 7357-7360.

Dasgupta, P. 2021. The Economics of Biodiversity: The Dasgupta Review. London: HM Treasury.

Davis, J. L., C. A. Currin, C. O'Brien, C. Raffenburg, and A. Davis. 2015. “Living Shorelines: Coastal Resilience with a Blue Carbon Benefit." PLOS ONE 10 (11): e0142595.

Depledge, M. H., and W. J. Bird. 2009. "The Blue Gym: Health and Wellbeing from Our Coasts." Marine Pollution Bulletin 58 (7): 947.

Díaz, S., U. Pascual, M. Stenseke, B. Martín-López, R.T. Watson, Z. Molnár, R. Hill, et al. 2018. "Assessing Nature's Contributions to People." Science 359 (6373): 270-272.

Donato, D. C., J. B. Kauffman, D. Murdiyarso, S. Kurnianto, M. Stidham, and M. Kanninen. 2011. "Mangroves among the Most Carbon-Rich Forests in the Tropics." Nature Geoscience 4 (5): 293-297.

Dubgaard, A., M. F. Kallesee, J. Ladenburg, and M. L. Petersen. 2003. “Cost-Benefit Analysis of the Skjern River Restoration in Denmark." In Cost-Benefit Analysis and Water Resource Management. Edited by R. Brouwer and D. Pearce. Cheltenham, UK: Edward Elgar Publishing.

Dyer, C. L., and R. L. Leard. 1994. "Folk Management in the Oyster Fishery of the U.S. Gulf of Mexico." In Folk Management in the World's Fisheries: Lessons for Modern Fisheries Management. Niwot, CO: University Press of Colorado.

ECA (Economics of Climate Adaptation). 2009. Shaping Climate-Resilient Development: $A$ Framework for Decision-Making. San Francisco, CA: ClimateWorks Foundation.

EcoShape 2020. Making a (Business) Case for Building with Nature: Guidance and Lessons from the Interreg North Sea Region Project. North Sea Region Interreg Building with Nature Project. https://northsearegion.eu/media/15183/deliverable-5-2-businesscase-guidance-document-final.pdf. 
Edwards, P. E. T., A. E. Sutton-Grier, and G. E. Coyle. 2013. "Investing in Nature: Restoring Coastal Habitat Blue Infrastructure and Green Job Creation." Marine Policy 38: 65-71. https://www.sciencedirect.com/science/article/abs/pii/S0308597X12001182. https:// doi.org/10.1016/j.marpol.2012.05.020.

EM-DAT (The International Disaster Database). 2019. (Centre for Research on the Epidemiology of Disasters [CRED], Université catholique de Louvain, Brussels, Belgium).

Erftemeijer, P. L. A., and R. R. Lewis. 1999. Migratory Shorebirds and Their Habitats in the Inner Gulf of Thailand. Publication No. 13. Thailand: Wetlands International, Thailand Programme and Bird Conservation Society.

Ferrario, F., M. W. Beck, C. D. Storlazzi, F. Micheli, C. C. Shepard, and L. Airoldi. 2014. "The Effectiveness of Coral Reefs for Coastal Hazard Risk Reduction and Adaptation." Nature Communications 5: 1-9. https://doi.org/10.1038/ncomms4794.

Fisher, B., I. Bateman, and R. K. Turner. 2011. Valuing Ecosystem Services: Benefits, Values, Space and Time. Working Paper No. 3. Nairobi, Kenya: UNEP. https://docplayer. net/21102380-Valuing-ecosystem-services-benefits-values-space-and-time.html.

GCA (Global Commission on Adaptation). 2019. Adapt Now: A Global Call for Leadership on Climate Resilience. Washington, DC: World Resources Institute. https:// openknowledge.worldbank.org/handle/10986/32362.

Gedan, K. B., M. L. Kirwan, E. Wolanski, E. B. Barbier, and B. R. Silliman. 2011. “The Present and Future Role of Coastal Wetland Vegetation in Protecting Shorelines: Answering Recent Challenges to the Paradigm." Climatic Change 106 (1): 7-29.

Gilliers, C., O. Le Pape, Y. Desaunay, J. P. Bergeron, N. Schreiber, D. Guerault, and R. Amara. 2006. "Growth and Condition of Juvenile Sole (Solea L.) as Indicators of Habitat Quality in Coastal and Estuarine Nurseries in the Bay of Biscay with a Focus on Sites Exposed to Erika Oil Spill." Scientia Marina 70 (S1): 183-192.

Gilman, E., and J. Ellison. 2007: "Efficacy of Alternative Low-Cost Approaches to Mangrove Restoration, American Samoa." Estuaries and Coasts 30 (4): 641-651.

Gittman, R. K., S. B. Scyphers, C. S. Smith, I. P. Neylan, and J. H. Grabowski. 2016. “Ecological Consequences of Shoreline Hardening: A Meta-Analysis." BioScience 66 (9): 763-773. doi:10.1093/biosci/biw091.

Grabowski, J. H., R. D. Brumbaugh, R. F. Conrad, A. G. Keeler, J. J. Opaluch, C. H. Peterson, M. F. Piehler, S. P. Powers, and A. R. Smyth. 2012. “Economic Valuation of Ecosystem Services Provided by Oyster Reefs." BioScience, 62 (10): 900-909. https://doi. org/10.1525/bio.2012.62.10.10.

Guannel G., K. Arkema, P. Ruggiero, and G. Verutes. 2016. “The Power of Three: Coral Reefs, Seagrasses and Mangroves Protect Coastal Regions and Increase their Resilience." PLOS ONE 11:e0158094. 
Guerry, A. D., S. Polasky, J. Lubchenco, R. Chaplin-Kramer, G. C. Daily, R. Griffin, M. Ruckelshaus, et al. 2015. "Natural Capital and Ecosystem Services Informing Decisions: From Promise to Practice." Proceedings of the National Academy of Sciences 112 (24): 7348-7355.

Hallegatte, S., A. Shah, R. Lempert, C. Brown, and S. Gill. 2012. Investment Decision Making Under Deep Uncertainty: Application to Climate Change. Policy Research Working Paper No. 6193. Washington, DC: The World Bank.

Hallegatte, S., and V. Przyluski. 2012. The Economics of Natural Disasters: Concepts and Methods. Policy Research Working Paper No. 5507. Washington, DC: The World Bank.

Hamilton, S. E., and D. A. Friess. 2018. "Global Carbon Stocks and Potential Emissions Due to Mangrove Deforestation from 2000 to 2012." Nature Climate Change 8 (3): 240-244.

Hargreaves-Allen, V. 2010. An Economic Valuation of the Natural Resources of Andros Islands, Bahamas. Washington, DC: Conservation Strategy Fund. https://www.conservationstrategy.org/sites/default/files/field-file/Andros_Exec_summary_Il.pdf.

Hoppler, T., and M. S. Meixler. 2016. "Modeling Coastal Vulnerability through Space and Time." PLOS ONE 11 (10): e0163495. https://doi.org/10.1371/journal.pone.0163495.

Humphries, A. T., and M. K. La Peyre. 2015. “Oyster Reef Restoration Supports Increased Nekton Biomass and Potential Commercial Fishery Value." PeerJ 3 (12): e1111.

IPCC (Intergovernmental Panel on Climate Change). 2019. "Summary for Policymakers." In IPCC Special Report on the Ocean and Cryosphere in a Changing Climate. Edited by H. O. Pörtner, D. C. Roberts, V. Masson-Delmotte, P. Zhai, M. Tignor, E. Poloczanska, K. Mintenbeck, et al. Principality of Monaco: IPCC. https://www.ipcc.ch/site/assets/ uploads/sites/3/2019/11/03_SROCC_SPM_FINAL.pdf.

IUCN (International Union for Conservation of Nature). 2020. IUCN Global Standard for NatureBased Solutions: A User-Friendly Framework for the Verification, Design and Scaling Up of NbS. First Edition. Gland, CH: International Union for Conservation of Nature.

Johnson, J. A., G. Ruta, U. Baldos, R. Cervigni, S. Chonabayashi, E. Corong, O. Gavryliuk, J. Gerber, T. Hertel, C. Nootenboom, and S. Polasky. 2021. The Economic Case for Nature: A Global Earth-Economy Model to Assess Development Policy Pathways. Washington, DC: World Bank. https://openknowledge.worldbank.org/handle/10986/35882.

Johnston, R. J., T. A. Grigalunas, J. J. Opaluch, M. Mazzotta, and J. Diamantedes. 2002. "Valuing Estuarine Resource Services Using Economic and Ecological Models: The Peconic Estuary System Study." Coastal Management 30 (1): 47-65.

Johnston, R. J., C. Makriyannis, and A. W. Whelchel. 2018. "Using Ecosystem Service Values to Evaluate Tradeoffs in Coastal Hazard Adaptation." Coastal Management (46) 4: 259277. https://doi.org/10.1080/08920753.2018.1474067.

Jordan, S. J., J. Stoffer, and J. A. Nestlerode. 2011. “Wetlands as Sinks for Reactive Nitrogen at Continental and Global Scales: A Meta-Analysis." Ecosystems 14 (1): 144-155. http:// dx.doi.org/10.1007/s10021-010-9400-z. 
Keeler, B. L., S. Polasky, K. A. Brauman, K. A. Johnson, J. C. Finlay, A. O'Neill, K. Kovacs, and B. Dalzell. 2012. "Linking Water Quality and Well-Being for Improved Assessment and Valuation of Ecosystem Services." Proceedings of the National Academy of Sciences 109 (45): 18619-18624.

Kildow, J. T., C. S. Colgan, J. D. Scorse, P. Johnston, and M. Nichols. 2014. State of the U.S. Ocean and Coastal Economies 2014. Monterey, CA: Center for the Blue Economy. https://cbe.miis.edu/noep_publications/1.

Kosaka, R., and S. Steinback. 2018. 2012 National Ocean Recreation Expenditure Survey. NOAA Technical Memorandum NMFS-F/SPO-185. Silver Spring, MD: Economics and Social Analysis Division, Office of Science and Technology, National Marine Fisheries Service.

Kroeker, K. J., B. G. Reguero, P. Rittelmeyer, and M. W. Beck. 2016. "Ecosystem Service and Coastal Engineering Tools for Coastal Protection and Risk Reduction." In Managing Coasts with Natural Solutions: Guidelines for Measuring and Valuing the Coastal Protection Services of Mangroves and Coral Reefs. Edited by M. W. Beck and G-M. Lange. Washington, DC: Wealth Accounting and the Valuation of Ecosystem Services Partnership (WAVES), World Bank.

Kunreuther, H., and J. R. Sheaffer. 1970. "An Economically Meaningful and Workable System for Calculating Flood Insurance Rates." Water Resources Research 6 (2): 659-667.

La Peyre, M., J. Furlong, L. A. Brown, B. P. Piazza, and K. Brown. 2014. “Oyster Reef Restoration in the Northern Gulf of Mexico: Extent, Methods and Outcomes." Ocean \& Coastal Management 89: 20-28.

Lemay, M., H. Tsuneki, R. Guerrero, M. Argimon, K. Schueler, E. Chavez, G. Alleng, P. Jimenez de Arechaga, et al. 2017. A Proposal for a Loan for the "Climate Resilient Coastal Management and Infrastructure Program." Washington, DC: Inter-American Development Bank (IDB).

Loomis, J. B. 2000. "Environmental Valuation Techniques in Water Resource Decision Making." Journal of Water Resources Planning and Management 126 (6): 339-344.

Losada, I. J., B. G. Reguero, F. J. Méndez, S. Castanedo, A. J. Abascal, and R. Mínguez. 2013. "Long-Term Changes in Sea-Level Components in Latin America and the Caribbean." Global and Planetary Change 104: 34-50.

Losada, I. J., P. Menéndez, A. Espejo, S. Torres, P. Díaz-Simal, S. Abad, M. W. Beck, et al. 2018. The Global Value of Mangroves for Risk Reduction. Technical Report. Berlin: Nature Conservancy.

Luechinger, S., and P. A. Raschky. 2009. "Valuing Flood Disasters Using the Life Satisfaction Approach." Journal of Public Economics 93 (3-4): 620-633.

Maes, J., C. Liquete, A. Teller, M. Erhard, M. L. Paracchini, J. I. Barredo, B. Grizzetti, et al. 2016. "An Indicator Framework for Assessing Ecosystem Services in Support of the EU Biodiversity Strategy to 2020." Ecosystem Services 17: 14-23. https://doi. org/10.1016/j.ecoser.2015.10.023. 
Mahmud, S., and E. B. Barbier. 2016. "Are Private Defensive Expenditures Against Storm Damages Affected by Public Programs and Natural Barriers? Evidence from the Coastal Areas of Bangladesh." Environment and Development Economics 21 (6): 767-788.

Mandle, L., H. Tallis, L. Sotomayor, and A. L. Vogl. 2015. “Who Loses? Tracking Ecosystem Service Redistribution from Road Development and Mitigation in the Peruvian Amazon." Frontiers in Ecology and the Environment 13 (6): 309-315.

Mcleod, E., G. L. Chmura, S. Bouillon, R. Salm, M. Björk, C. M. Duarte, C. E. Lovelock, W.H. Schlesinger, and B.R. Silliman. 2011. "A Blueprint for Blue Carbon: Toward an Improved Understanding of the Role of Vegetated Coastal Habitats in Sequestering C02." Frontiers in Ecology and the Environment 9 (10): 552-560.

MEA (Millennium Ecosystem Assessment). 2005. Ecosystems and Human Well-Being: Synthesis. Washington, DC: Island Press.

Mechler, R. 2016. "Reviewing Estimates of the Economic Efficiency of Disaster Risk Management: Opportunities and Limitations of Using Risk-Based Cost-Benefit Analysis." Natural Hazards 81 (3): 2121-2147.

Mechler, R., J. Czajkowski, H. Kunreuther, E. Michel-Kerjan, W. Botzen, A. Keating, C. McQuistan, N. Cooper, and I. O'Donnell. 2014. Making Communities More Flood Resilient: The Role of Cost-Benefit Analysis and Other Decision-Support Tools. Zurich: Zurich Flood Resilience Alliance. http://pure.iiasa.ac.at/id/eprint/11193/.

Menéndez, P., I. J. Losada, S. Torres-Ortega, S. Narayan, and M. W. Beck. 2020. “The Global Flood Protection Benefits of Mangroves." Scientific Reports 10 (1): 1-11. https://doi. org/10.1038/s41598-020-61136-6.

Monismith, S. G. 2007. "Hydrodynamics of Coral Reefs." Annual Review of Fluid Mechanics 39: 37-55.

Morris, R. L., T. M. Konlechner, M. Ghisalberti, and S. E. Swearer. 2018. “From Grey to Green: Efficacy of Eco-Engineering Solutions for Nature-Based Coastal Defence." Global Change Biology 24 (5): 1354-1013. https://doi.org/10.1111/gcb.14063.

Narayan, S., M. W. Beck, P. Wilson, C. J. Thomas, A. Guerrero, C. C. Shepard, B. G. Reguero, G. Franco. J. C. Ingram, and D. Trespalacios. 2017. "The Value of Coastal Wetlands for Flood Damage Reduction in the Northeastern USA." Scientific Reports 7 (1): 9463. https://doi.org/10.1038/s41598-017-09269-z.

Narayan, S., M. W. Beck, B. G. Reguero, I. J. Losada, B. Van Wesenbeeck, N. Pontee, J. N. Sanchirico, J. C. Ingram, G. M. Lange, and K. A. Burks-Copes. 2016. “The Effectiveness, Costs and Coastal Protection Benefits of Natural and Nature-Based Defences." PLOS ONE 11 (5): e0154735.

Narayan, S., S. Bitterwolf, and M. W. Beck. 2019. The Costs of Mangrove and Reef Restoration Relative to Coastal Protection Structures in the Caribbean. Policy Brief. Arlington, VA: Nature Conservancy. 
Natural Capital Project, Office of the Prime Minister, Inter-American Development Bank, BRL Ingénierie, and Blue Engineering Ltd. 2017. Sustainable Development Master Plan for Andros Island. Stanford: Natural Capital Project, Stanford University.

Nelson, J. P., and P. E. Kennedy. 2009. "The Use (and Abuse) of Meta-Analysis in Environmental and Natural Resource Economics: An Assessment." Environmental and Resource Economics 42 (3): 345-377.

NSTC (National Science and Technology Council). 2015. Ecosystem Service Assessment: Research Needs for Coastal Green Infrastructure. Washington, DC: White House Office of Science and Technology Policy. https://obamawhitehouse.archives.gov/sites/ default/files/microsites/ostp/cgies_research_agenda_final_082515.pdf.

Olander, L. P., R. J. Johnston, H. Tallis, J. Kagan, L. A. Maguire, S. Polasky, D. Urban, J. Boyd, L. Wainger, and M. Palmer. 2018. "Benefit Relevant Indicators: Ecosystem Services Measures that Link Ecological and Social Outcomes." Ecological Indicators 85: 1262-1272.

Olander, L., R. J. Johnson, H. Tallis, J. Kagan, L. Maguire, S. Polasky, D. Urban, J. Boyd, L. Wainger, and M. Palmer. 2015. Best Practices for Integrating Ecosystem Services into Federal Decision Making. Durham, NC: National Ecosystem Services Partnership, Duke University.

Olsen, A., Q. Zhou, J. Linde, and K. Arnbjerg-Nielsen. 2015. "Comparing Methods of Calculating Expected Annual Damage in Urban Pluvial Flood Risk Assessments." Water 7 (1): 255-270.

OPM (Office of the Prime Minister of the Commonwealth of the Bahamas). 2017. Sustainable Development Master Plan for Andros Island. With support from Inter-American Development Bank, BRL Ingénierie, and Blue Engineering Ltd. Washington, DC: InterAmerican Development Bank. February 2017.

Oppenheimer, M., B. Glavovic, J. Hinkel, R. van de Wal, A. K. Magnan, A. Abd-Elgawad, R. Cai, et al. 2019. "Chapter 4: Sea Level Rise and Implications for Low Lying Islands, Coasts and Communities." In Special Report on the Ocean and Cryosphere in a Changing Climate. Edited by H. Pörtner, D. C. Roberts, and V. Masson-Delmotte. Monaco: Intergovernmental Panel on Climate Change. https://www.ipcc.ch/site/assets/ uploads/sites/3/2019/11/08_SROCC_Ch04_FINAL.pdf.

Ortega, S. T., I. J. Losada, A. Espejo, S. Abad, S. Narayan, and M. W. Beck. 2019. "The Flood Protection Benefits and Restoration Costs for Mangroves in Jamaica." Forces of Nature. Washington, DC: World Bank. https://openknowledge.worldbank.org/ handle/10986/35166.

Palmer, M. A., R. F. Ambrose, and N. L. Poff. 1997. “Ecological Theory and Community Restoration Ecology." Restoration Ecology 5 (4): 291-300.

Pendleton, L., D. C. Donato, B. C. Murray, S. Crooks, W. A. Jenkins, S. Sifleet, S., Craft, et al. 2012. "Estimating Global 'Blue Carbon' Emissions from Conversion and Degradation of Vegetated Coastal Ecosystems." PLOS ONE 7 (9): e43542. 
Pendleton, L., J. Kildow, and J. W. Rote. 2006. “The Non-Market Value of Beach Recreation in California." Shore and Beach 74 (2): 34-37.

Pendleton, L., N. Martin, and D. G. Webster. 2001. "Public Perceptions of Environmental Quality: A Survey Study of Beach Use and Perceptions in Los Angeles County." Marine Pollution Bulletin 42 (11): 1155-1160.

Penning-Rowsell, E., S. Priest, D. Parker, J. Morris, S. Tunstall, C. Viavattene, J. Chatterton, and D. Owen. 2013. Flood and Coastal Erosion Risk Management: A Manual for Economic Appraisal. London: Routledge.

Peterson, C. H., J. H. Grabowski, and S. P. Powers. 2003. "Estimated Enhancement of Fish Production Resulting from Restoring Oyster Reef Habitat: Quantitative Valuation." Marine Ecology Progress Series 264: 249-264.

Poor, J., K. L. Pessagno, and R. W. Paul. 2007. "Exploring the Hedonic Value of Ambient Water Quality: A Local Watershed-Based Study." Ecological Economics 60 (4): 797-806. https://doi.org/10.1016/j.ecolecon.2006.02.013.

Posner, S. M., E. McKenzie, and T. H. Ricketts. 2016. "Policy Impacts of Ecosystem Services Knowledge." Proceedings of the National Academy of Sciences 113 (7): 1760-1765.

Primavera, J. H., and J. M. A. Esteban. 2008. "A Review of Mangrove Rehabilitation in the Philippines: Successes, Failures and Future Prospects." Wetlands Ecology and Management 16 (5): 345-358.

Rao, N. S., A. Ghermandi, R. Portela, and X. Wang. 2015. “Global Values of Coastal Ecosystem Services: A Spatial Economic Analysis of Shoreline Protection Values." Ecosystem Services 11: 95-105.

Rao, S., S. Pachauri, F. Dentener, P. Kinney, Z. Klimont, K. Riahi, and W. Schoepp. 2013. "Better Air for Better Health: Forging Synergies in Policies for Energy Access, Climate Change and Air Pollution." Global Environmental Change 23 (5): 1122-1130.

Reddy, S. M., G. Guannel, R. Griffin, J. Faries, T. Boucher, M. Thompson, J. Brenner, et al. 2016. "Evaluating the Role of Coastal Habitats and Sea-Level Rise in Hurricane Risk Mitigation: An Ecological Economic Assessment Method and Application to a Business Decision." Integrated Environmental Assessment and Management 12 (2): 328-344.

Reguero, B. G., F. Secaira, A. Toimil, M. Escudero, P. Diaz-Simal, M. W. Beck, R. Silva, C. D. Storlazzi, and I. J. Losada. 2019. "The Risk Reduction Benefits of the Mesoamerican Reef in Mexico." Frontiers in Earth Science 7: 125.

Reguero, B. G., M. Menéndez, F. J. Méndez, R. Mínguez, and I. J. Losada. 2012. “A Global Ocean Wave (GOW) Calibrated Reanalysis from 1948 Onwards." Coastal Engineering 65: 38-55.

Reguero, B. G., M. W. Beck, V. N. Agostini, P. Kramer, and B. Hancock. 2018a. "Coral Reefs for Coastal Protection: A New Methodological Approach and Engineering Case Study in Grenada." Journal of Environmental Management 210: 146-161. 
Reguero, B. G., M. W. Beck, D. N. Bresch, J. Calil, and I. Meliane. 2018b. “Comparing the Cost Effectiveness of Nature-Based and Coastal Adaptation: A Case Study from the Gulf Coast of the United States." PLOS ONE 13 (4): e0192132.

Roeber, V., and J. D. Bricker. 2015. “Destructive Tsunami-Like Wave Generated by Surf Beat over a Coral Reef during Typhoon Haiyan." Nature Communications 6: 7854.

Rosen, J. 2021. “Shifting Ground.” Science 371 (6532): 876-880. doi:10.1126/ science.371.6532.876.

Ruckelshaus, M., B. G. Reguero, K. Arkema, R. Guerrero-Compeán, K. Wheeks, A. Bailey, and J. Silver. 2020. "Harnessing New Data Technologies for Nature-Based Solutions in Assessing and Mapping Risk in Coastal Zones." International Journal of Disaster Risk Reduction 51: 101795. https://doi.org/10.1016/j.ijdrr.2020.101795.

Ruckelshaus, M., G. Guannel, K. Arkema, G. Verutes, R. Griffin, A. Guerry, J. Silver, J. Ferries, J. Brenner, and A. Rosenthal. 2016. "Evaluating the Benefits of Green Infrastructure for Coastal Areas: Location, Location, Location." Coastal Management 44 (5): 504-516.

Sandifer, P. A., A. E. Sutton-Grier, and B. P. Ward. 2015. "Exploring Connections among Nature, Biodiversity, Ecosystem Services, and Human Health and Well-Being: Opportunities to Enhance Health and Biodiversity Conservation." Ecosystem Services 12: 1-15.

Scawthorn, C., P. Flores, N. Blais, H. Seligson, E. Tate, S. Chang, E. Mifflin, et al. 2006. “HAZUSMH Flood Loss Estimation Methodology. II. Damage and Loss Assessment." Natural Hazards Review 7 (2): 72-81.

Scyphers, S. B., S. P. Powers, K. L. Heck Jr., and D. Byron. 2011. “Oyster Reefs as Natural Breakwaters Mitigate Shoreline Loss and Facilitate Fisheries." PLOS ONE 6 (8): e22396.

Scyphers, S. B., T. C. Gouhier, J. H. Grabowski, M. W. Beck, J. Mareska, and S. P. Powers. 2015. "Natural Shorelines Promote the Stability of Fish Communities in an Urbanized Coastal System." PLOS ONE 10 (6): e0118580.

Shabman, L., and K. Stephenson. 1996. "Searching for the Correct Benefit Estimate: Empirical Evidence for an Alternative Perspective." Land Economics 72 (4): 433-449.

Sharp, R., J. Douglass, S. Wolny, K. Arkema, J. Bernhardt, W. Bierbower, N. Chaumont, et al. 2020. "InVEST User's Guide." The Natural Capital Project, Stanford University, University of Minnesota, Nature Conservancy, and World Wildlife Fund.

Silver, J. M., K. K. Arkema, R. M. Griffin, B. Lashley, M. Lemay, S. Maldonado, S. H. Moultrie, et al. 2019. "Advancing Coastal Risk Reduction Science and Implementation by Accounting for Climate, Ecosystems, and People." Frontiers in Marine Science 6: 566.

Simpson, A., R. Murnane, K. Saito, E. Phillips, R. Reid, and A. Himmelfarb. 2014. Understanding Risk in an Evolving World: Emerging Best Practices in Natural Disaster Risk Assessment. Washington, DC: Global Facility for Disaster Reduction and Recovery, World Bank, UN International Strategy for Disaster Reduction. 
Spalding, M., L. Burke, S. A. Wood, J. Ashpole, J. Hutchinson, P. Ermgassen. 2017. “Mapping the Global Value and Distribution of Coral Reef Tourism." Marine Policy 82: 104-113. https://doi.org/10.1016/j.marpol.2017.05.014.

Storlazzi, C. D., B. G. Reguero, A. D. Cole, E. Lowe, J. B. Shope, A. E. Gibbs, B. A. Nickel, R. T. McCall, A. R. van Dongeren, and M. W. Beck. 2019. Rigorously Valuing the Role of U.S. Coral Reefs in Coastal Hazard Risk Reduction. U.S. Geological Survey Open-File Report 2019-1027. Reston, VA: U.S. Department of the Interior and U.S. Geological Survey. https://doi.org/10.3133/ofr20191027.

Temmerman, S., and M. L. Kirwan. 2015. “Building Land with a Rising Sea." Science 349 (6248): 588-589. doi:10.1126/science.aac8312.

Tonietto, R. K., and D. J. Larkin. 2018. "Habitat Restoration Benefits Wild Bees: A Meta-Analysis." Journal of Applied Ecology 55 (2): 582-590.

Turner, R. K., D. Burgess, D. Hadley, E. Coombes, and N. Jackson. 2007. "A Cost-Benefit Appraisal of Coastal Managed Realignment Policy." Global Environmental Change 7 (3-4): 397-407. https://doi.org/10.1016/j.gloenvcha.2007.05.006.

Turner, R. K., S. Morse-Jones, and B. Fisher. 2010. “Ecosystem Valuation: A Sequential Decision Support System and Quality Assessment Issues." Annals of the New York Academy of Sciences 1185 (1): 79-101.

van Zanten, B. T., P. J. H. Van Beukering, and A. J. Wagtendonk. 2014. “Coastal Protection by Coral Reefs: A Framework for Spatial Assessment and Economic Valuation. Ocean and Coastal Management 96: 94-103. doi:10.1016/j.ocecoaman.2014.05.001.

van Zuidam, J. P., C. H. van Leeuwen, E. S. Bakker, J. T. Verhoeven, S. ljff, E. T. Peeters, B. G. van Zuidam, and M. B. Soons. 2019. "Plant Functional Diversity and Nutrient Availability Can Improve Restoration of Floating Fens via Facilitation, Complementarity and Selection Effects." Journal of Applied Ecology 56 (1): 235-245. https://doi. org/10.1111/1365-2664.13256.

Vousdoukas, M. I., L. Mentaschi, E. Voukouvalas, M. Verlaan, S. Jevrejeva, L. P. Jackson, and L. Feyen. 2018. "Global Probabilistic Projections of Extreme Sea Levels Show Intensification of Coastal Flood Hazard." Nature Communications 9 (1): 2360.

Vuik, V., B. W. Borsje, P. W. Willemsen, and S. N. Jonkman. 2019. "Salt Marshes for Flood Risk Reduction: Quantifying Long-Term Effectiveness and Life-Cycle Costs." Ocean and Coastal Management 171: 96-110.

Wamsley, T. V., Z. A. Collier, K. Brodie, L. M. Dunkin, D. Raff, and J. D. Rosati. 2015. "Guidance for Developing Coastal Vulnerability Metrics." Journal of Coastal Research 31 (6): 15211530.

Wang, X. L., Y. Feng, and V. R. Swail. 2015. "Climate Change Signal and Uncertainty in CMIP5Based Projections of Global Ocean Surface Wave Heights." Journal of Geophysical Research: Oceans 120 (5): 3859-3871. 
Whelchel, A. W., B. G. Reguero, B. van Wesenbeeck, and F. G. Renaud. 2018. "Advancing Disaster Risk Reduction through the Integration of Science, Design, and Policy into EcoEngineering and Several Global Resource Management Processes." International Journal of Disaster Risk Reduction 32: 29-41.

White, G. F. 1945. Human Adjustment to Floods: A Geographical Approach to the Flood Problems in the United States. Research Paper No. 29. Chicago: Department of Geography, University of Chicago.

World Bank and Ministry of Environment, Energy and Climate Change of Seychelles. 2019. Seychelles Coastal Management Plan: 2019-2024. Washington, DC: World Bank; and Victoria, Seychelles: Ministry of Environment, Energy and Climate Change of Seychelles.

World Bank. 2017. Implementing Nature-Based Flood Protection: Principles and Implementation Guidance. Washington, DC: World Bank.

World Bank. 2018. The World Bank Annual Report 2018 (English). Washington, DC: World Bank Group. http://documents.worldbank.org/curated/en/630671538158537244/TheWorld-Bank-Annual-Report-2018.

\section{Works Consulted}

Barbier, E. B. 2007. "Valuing Ecosystem Services as Productive Inputs." Economic Policy 22 (49): 177-229.

Bilkovic, D. M., M. M. Mitchell, M. K. La Peyre, and J. D. Toft. 2017. Living Shorelines: The Science and Management of Nature-Based Coastal Protection. First Edition. Boca Raton, FL: CRC Press.

Bin, O., T. W. Crawford, J. B. Kruse, and C. E. Landry. 2008. “Viewscapes and Flood Hazard: Coastal Housing Market Response to Amenities and Risk." Land Economics 84 (3): 434-448.

Bos, F., and P. Zwaneveld. 2017. Cost-Benefit Analysis for Flood Risk Management and Water Governance in the Netherlands: An Overview of One Country. CPB Background Document. The Hague, NL: CPB Netherlands Bureau for Economic Policy Analysis.

Botzen, W. W., and J. C. van den Bergh. 2012. "Risk Attitudes to Low-Probability Climate Change Risks: WTP for Flood Insurance." Journal of Economic Behavior \& Organization 82 (1): 151-166.

Boutwell, J. L., and J. V. Westra. 2016. "The Role of Wetlands for Mitigating Economic Damage from Hurricanes." JAWRA Journal of the American Water Resources Association 52 (6): 1472-1481.

Costanza, R., O. Perez-Maqueo, M. L. Martinez, P. Sutton, S. J. Anderson, and K. Mulder. 2008. "The Value of Coastal Wetlands for Hurricane Protection." Ambio 37 (4): 241-248. 
Currin, C. A., J. Davis, and A. Malhotra. 2017. "Response of Salt Marshes to Wave Energy Provides Guidance for Successful Living Shoreline Implementation." In Living Shorelines: The Science and Management of Nature-Based Coastal Protection. Edited by D. M. Bilkovic, M. M. Mitchell, M. K. LaPeyre, and J. D. Toft. Boca Raton, FL: CRC Press.

de Vries, M., D. van der Wal, I. Möller, B. van Wesenbeeck, G. Peralta, and A. Stanica. 2018. Earth Observation and the Coastal Zone: From Global Images to Local Information. FP7 FAST Project Syntesis Report. Bucharest: GeoEcoMar. http://doi.org/10.5281/ zenodo.1158437.

DePiper, G. S., D. W. Lipton, and R. N. Lipcius. 2016. “Valuing Ecosystem Services: Oysters, Denitrification, and Nutrient Trading Programs." Marine Resource Economics 32 (1): 1-20. https://www.journals.uchicago.edu/doi/10.1086/688976.

Dundas, S. J. 2017. "Benefits and Ancillary Costs of Natural Infrastructure: Evidence from the New Jersey Coast." Journal of Environmental Economics and Management 85: 62-80.

Environment Agency. 2010. Flood and Coastal Erosion Risk Management Appraisal Guidance. FCERM-AG. Bristol, UK: Environment Agency.

FEMA (Federal Emergency Management Agency). 2009. BCA Reference Guide. Washington, DC: Department of Homeland Security. https://www.fema.gov/sites/default/ files/2020-04/fema_bca_reference-guide.pdf.

Guannel G., P. Ruggiero, K. Arkema, J. Faries, M. Pinsky, A. Guerry, and G. Gelfenbaum. 2015. “Integrated Modeling Framework to Quantify Coastal Protection Services Provided by Vegetation." Journal of Geophysical Research-Oceans 120 (1): 324-345.

Haasnoot, M., J. H. Kwakkel, W. E. Walker, and J. ter Maat. 2013. "Dynamic Adaptive Policy Pathways: A Method for Crafting Robust Decisions for a Deeply Uncertain World." Global Environmental Change 23 (2): 485-498.

HM Treasury. 2003. The Green Book: Appraisal and Evaluation in Central Government. London: HM Treasury and Government Finance Function.

IEC (Industrial Economics, Inc.). 2012. Enhanced Ecosystem Services and Associated Values: Restoration of the Huntington Beach Wetlands, quoted in Socioeconomic Benefits of Habitat Restoration. Edited by G. Samonte, P. Edwards, J. Royster, and V. Ramenzoni. 2017. NOAA Tech. Memo. NMFS-OHC-1. Silver Spring, MD: Office of Habitat Conservation, National Oceanic and Atmospheric Administration.

Johnston, C. A. 1991. "Sediment and Nutrient Retention by Freshwater Wetlands: Effects on Surface Water Quality." Critical Reviews in Environmental Science and Technology 21 (5-6): 491-565.

Kull, D., R. Mechler, and S. Hochrainer-Stigler. 2013. “Probabilistic Cost-Benefit Analysis of Disaster Risk Management in a Development Context." Disasters 37 (3): 374-400. https://doi.org/10.1111/disa.12002. 
Lathrop Jr., R. G., W. Irving, J. J. Seneca, J. Trimble, and R. M. Sacatelli. 2019. “The Limited Role Salt Marshes May Have in Buffering Extreme Storm Surge Events: Case Study on the New Jersey Shore." Ocean \& Coastal Management 178: 104803.

Lipton, D., D. K. Lew, K. Wallmo, P. Wiley, and A. Dvarskas. 2014. “The Evolution of Non-Market Valuation of U.S. Coastal and Marine Resources." Journal of Ocean and Coastal Economics 2014 (1): 6.

Loerzel, J., M. Gorstein, A. M. Rezaie, S. B. Gonyo, C. S. Fleming, and A. Orthmeyer. 2017. Economic Valuation of Shoreline Protection Within the Jacques Cousteau National Estuarine Research Reserve. NOAA Technical Memorandum NOS NCCOS 234. Silver Spring, MD: NOAA National Centers for Coastal Ocean Science, Marine Spatial Ecology. https://doi.org/10.7289/V5/TM-NOS-NCCOS-234.

Loomis, J., and L. Santiago. 2013. “Economic Valuation of Beach Quality Improvements: Comparing Incremental Attribute Values Estimated from Two Stated Preference Valuation Methods." Coastal Management 41 (1): 75-86. https://doi.org/10.1080/0892 0753.2012 .749754$.

Losada, I. J., M. Beck, P. Menéndez, A. Espejo, S. Torres, P. Diaz-Simal, F. Fernandez, et al. 2017. Valuing Protective Services of Mangroves in the Philippines: Technical Report. Washington, DC: World Bank.

Menéndez, P., I. J. Losada, S. Torres-Ortega, S. Narayan, and M. W. Beck. 2020. “The Global Flood Protection Benefits of Mangroves." Scientific Reports 10: 4404. https://doi. org/10.1038/s41598-020-61136-6.

Murphy, J. J., P. G. Allen, T. H. Stevens, and D. Weatherhead. 2005. “A Meta-Analysis of Hypothetical Bias in Stated Preference Valuation." Environmental and Resource Economics 30 (3): 313-325.

Palmer, M. A., D. Lettenmeier, N. L. Poff, S. Postel, B. Richter, and R. Warner. 2008. “Wild and Scenic Rivers." Preliminary Review of Adaptation Options for Climate-Sensitive Ecosystems and Resources. Edited by S. H. Julius and J.M. West. Washington, DC: U.S. Climate Change Science Program.

Patil, P. G., J. Virdin, S. M Diez, J. Roberts, and A. Singh. 2016. Toward a Blue Economy: A Promise for Sustainable Growth in the Caribbean. Washington, DC: World Bank. https://openknowledge.worldbank.org/handle/10986/25061.

Parsons, G. R., Z. Chen, M. K. Hidrue, N. Standing, and J. Lilley. 2013. "Valuing Beach Width for Recreational Use: Combining Revealed and Stated Preference Data." Marine Resource Economics 28 (3): 221-241.

Restore America's Estuaries. 2015. Living Shorelines: From Barriers to Opportunities. Arlington, VA: Restore America's Estuaries.

Sartori, D., G. Catalano, M. Genco, C. Pancotti, E. Sirtori, S. Vignetti, and C. Del Bo. 2015. Guide to Cost-Benefit Analysis of Investment Projects: Economic Appraisal Tool for Cohesion Policy 2014-2020. Brussels, BE: European Commission Directorate-General for Regional and Urban Policy. 
Shreve, C. M., and I. Kelman. 2014. "Does Mitigation Save? Reviewing Cost-Benefit Analyses of Disaster Risk Reduction." International Journal of Disaster Risk Reduction 10 (A): 213-235.

Stive, M. J. 2004. “How Important Is Global Warming for Coastal Erosion?" Climatic Change 64 (1): 27-39.

Tallis, H., H. Mooney, S. Andelman, P. Balvanera, W. Cramer, D. Karp, S. Polasky, et al. 2012. “A Global System for Monitoring Ecosystem Service Change." Bioscience 62: 977-986.

Tallis, H., S. E. Lester, M. Ruckelshaus, M. Plummer, K. McLeod, A. Guerry, S. Andelman, et al. 2011. "New Metrics for Managing and Sustaining the Ocean's Bounty." Marine Policy 36 (1): 303-306. doi:10.1016/j.marpol.2011.03.013.

van den Hoek, R. E., M. Brugnach, J. P. Mulder, and A. Y. Hoekstra. 2014. "Analysing the Cascades of Uncertainty in Flood Defence Projects: How 'Not Knowing Enough' Is Related to 'Knowing Differently.'" Global Environmental Change 24: 373-388.

Wainger, L., and M. Mazzotta. 2011. “Realizing the Potential of Ecosystem Services: A Framework for Relating Ecological Changes to Economic Benefits." Environmental Management 48: 710-733.

Whitehead, J. C., C. F. Dumas, J. Herstine, J. Hill, and B. Buerger. 2008. "Valuing Beach Access and Width Revealed and Stated Preference Data." Marine Resource Economics 23 (2): 119-135.

Withycombe, G. 2016. The Sydney Coastal Councils Group Experience: Prioritising Coastal Adaptation Options at the Local Level. Case Study for CoastAdapt. Southport, AU: National Climate Change Adaptation Research Facility, Gold Coast.

Zhai, G., T. Sato, T. Fukuzono, S. Ikeda, and K. Yoshida 2006. "Willingness to Pay for Flood Risk Reduction and Its Determinants in Japan." JAWRA Journal of the American Water Resources Association 42 (4): 927-940. 


\section{Acknowledgments}

\section{Lead Authors}

Boris van Zanten, World Bank, United States

Katie Arkema, Stanford University; Pacific Northwest National Laboratory, United States

Todd Swannack, U.S. Army Corps of Engineers, United States

\section{Co-Authors}

Rob Griffin, University of Massachusetts-Dartmouth, United States

Siddharth Narayan, East Carolina University, United States

Kim Penn, National Oceanic and Atmospheric Administration, United States

Borja G. Reguero, University of California, Santa Cruz, United States

Giselle Samonte, National Oceanic and Atmospheric Administration, United States

Steven Scyphers, Northeastern University, United States

Elizabeth Codner-Smith, The Nature Conservancy, United States

Stéphanie IJff, Deltares, the Netherlands

Marin Kress, U.S. Army Corps of Engineers, United States

Michele Lemay, Inter-American Development Bank, United States

\section{Contributors}

Glenn-Marie Lange, World Bank, United States

Brenden Jongman, World Bank, United States

Natural Capital Project, United States 

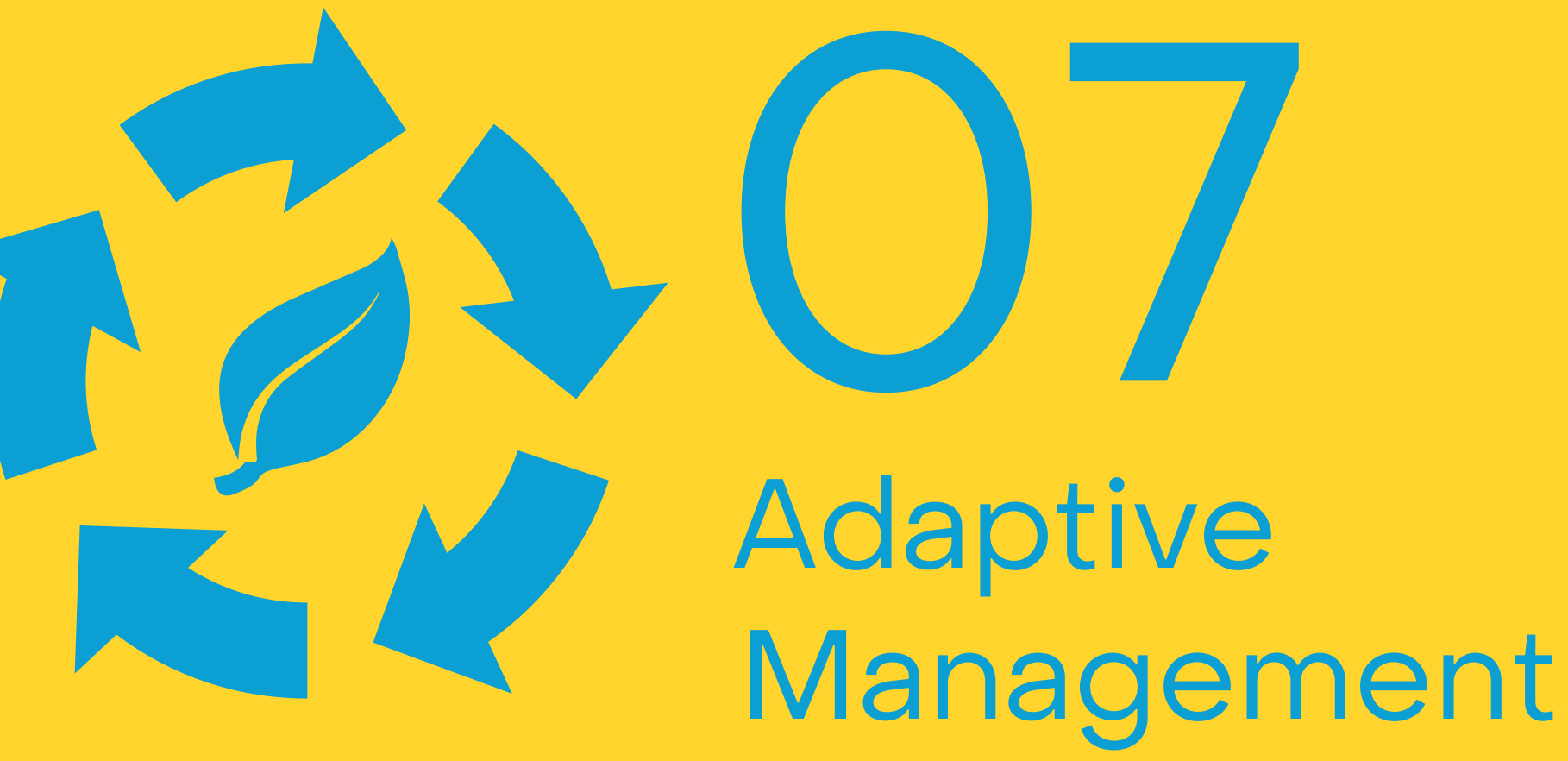

\section{Suggested Citation:}

de Looff, H., T. Welp, N. Snider, and R. Wilmink. 2021. "Chapter 7: Adaptive Management." In International Guidelines on Natural and Nature-Based Features for Flood Risk Management. Edited by T. S. Bridges, J. K. King, J. D. Simm, M. W. Beck, G. Collins, Q. Lodder, and R. K. Mohan. Vicksburg, MS: U.S. Army Engineer Research and Development Center.

Full acknowledgments appear at the end of this chapter. 


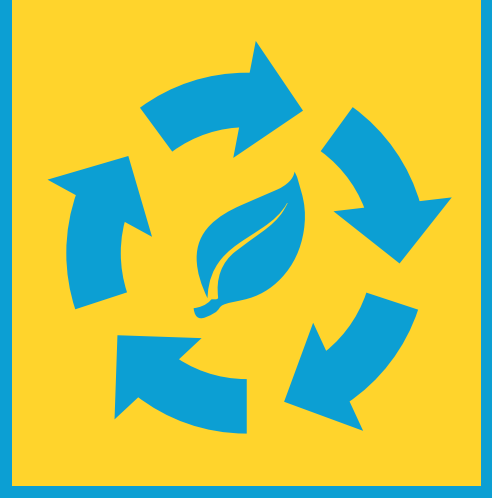

\section{Key Messages}

1. Adaptive Management (AM): This is an essential process for addressing and reducing uncertainties in structural and natural and nature-based features (NNBF) projects in a phased implementation. NNBF involve complex, dynamic environmental and social processes with varying uncertainties. AM addresses these uncertainties to optimize risk management while taking advantage of the flexibility of NNBF.

2. Improved Outcomes: By reducing uncertainties over time, AM can modify NNBF to improve their performance and facilitate attainment of the desired benefits.

3. Flexibility: While acknowledging factors that cannot be controlled, AM focuses on those project aspects that can be controlled or adapted to increase flexibility in project design over time to achieve desired project performance.

4. Reflect and Adapt: AM provides a structured and informed decision-making process that is critical to manage unexpected and unintended outcomes and that enables managers and stakeholders to take timely corrective or adaptive actions. AM should be used throughout the planning, design, construction, and post-construction project phases. 


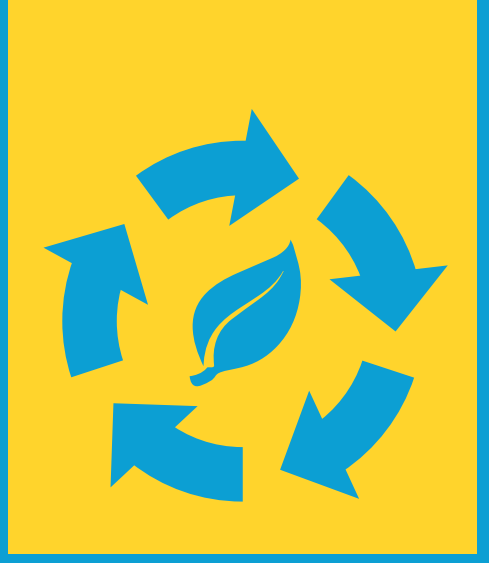

\section{Key Messages (Continued)}

5. Continuous Improvement: AM has the ability to make adjustments to the project throughout its life cycle to meet or improve expected outcomes and benefits at either the project or system level and to inform future projects for the benefit of the social and environmental systems.

6. Communication and Commitment: Leadership and stakeholder groups play a critical role throughout the entire AM process through commitment to long-term monitoring and assessment and a transparent and responsive process. 


\section{1 | Introduction}

Adaptive management (AM) is an iterative decision-making method that can be used to reduce levels of uncertainty and risk in predicting and achieving desired results by using natural and nature-based features (NNBF) or structural solutions. This iteration can aid project optimization by enabling designers to avoid, in the initial stages, "overbuilding" to account for uncertainty because the adaptive steps (measure and monitor, refine and adapt) facilitate future adjustments or enhancements, as necessary. Although AM is generally discussed in this chapter as a programmatic approach, it can also be applied on a project-specific basis to deal with design uncertainties and actual performance post-construction, to adapt with real-time data as they are being gathered.

Coastal and fluvial systems (see Chapter 4) are flexible and dynamic systems. The use of NNBF couples the physical and ecological systems with the social system, thereby capturing the complexity of interactions between the systems. Future uncertainties, as well as existing data and knowledge gaps, can limit the ability to predict the functions and response to management actions of both systems. Specifically, interactions among and between the various aspects of the hydrodynamic, morphologic, ecological, economic, and social landscape currently and in the future of a dynamic and ever-changing environment (e.g., sea-level rise) become more variable. This increased uncertainty in outcomes reduces levels of certainty in making science and flood risk management (FRM) predictions for both NNBF projects and more traditional (structural) flood risk reduction projects.

\subsubsection{Chapter Overview}

This chapter presents the principles of AM relative to its application in the life cycle of an NNBF project. It is not an extensive examination of $A M$ but rather is structured to aid practitioners and stakeholders in determining when and how to implement AM on NNBF projects and to provide guidance to optimize the results of its use. In this chapter, AM is defined and its applicability and reasons why it should be a critical component of NNBF projects are presented. Guidance for developing an AM plan is presented in the context of the NNBF project development framework flowchart (Chapter 2, Figure 2.1). Actions to create an AM plan include the following:

- Clearly defining the AM scope and objectives

- Engaging stakeholders with AM (see Chapter 3 ) and developing a governance structure

- Securing funding for implementing AM

- Identifying critical project uncertainties and performance metrics, with particular consideration given to the inherent dynamic nature of the socioecological systems involved

- Using conceptual and numerical models to predict outcomes 
- Formulating the AM monitoring plan and subsequent data synthesis to evaluate outcomes

- Adapting through the planning, designing, construction, and post-construction phases

- Implementing lessons learned into subsequent project phases

The challenges of implementing AM for NNBF projects to optimize risk management are also discussed in relation to shifting social and environmental factors.

\subsubsection{What Is Adaptive Management?}

AM is a structured decision-making process that has been around for decades with various and widely ranging definitions and applications (Williams and Brown 2014; Williams, Szaro, and Shapiro 2009; Canter and Atkinson 2010; Stankey, Clark, and Bormann 2005). Various forms of AM have been widely embraced by the natural resource and environmental communities, but different definitions and variations of $A M$ have created considerable ambiguity about what AM is and how it should be implemented (Ruhl and Fischman 2010; Fujitani et al. 2017; Gregory, Ohlson, and Arvai 2006). Because NNBF managers and stakeholders can initially lack experience to fully appreciate or effectively use AM, it is important to create a tight, concise, meaningful definition of AM (preferably at the beginning of the project) to facilitate buy-in among those involved. This also helps prevent the use of AM as an excuse for poor management.

For the purposes of this guidance, the following comprehensive definition, slightly modified from Craig and Ruhl (2014), is used:

\section{Adaptive management is a structured decision-making method, the core of which is a multi-step, iterative process for adjusting management measures to changing circumstances or new information about the effectiveness of NNBF projects or the system being managed.}

AM provides a structured process that enables managers and stakeholders to address risks and uncertainties that result in changing circumstances throughout a project life cycle. AM reduces uncertainties regarding project performance by developing and using new information, gathered by monitoring, and evaluating key uncertainties. This can facilitate the ability to make adjustments to the project during its life cycle to meet or improve expected outcomes and benefits at either project or system scales and to inform future projects (Williams and Brown 2014; Williams, Szaro, and Shapiro 2009; Canter and Atkinson 2010; Stankey et al. 2005). Discussion of these different spatial and temporal scales is presented in Chapter 4.

Effective and efficient communication among all stakeholders is critical to ensuring that anticipated and achieved project outcomes, in addition to adjustments being made over time, are clearly understood. Chapter 3 defines stakeholders and provides an overview of good practice in engagement in the specific context of NNBF projects. 
Although AM has been associated primarily with natural resources management, it can be used to manage other types of systems, including flood damage reduction and navigation infrastructure (NRC 2004). AM can be applied to projects involving structural measures, NNBF, or a combination of the two. Components of the AM process have been well defined in the literature and various graphics employed to illustrate the flow of its implementation (Chades et al. 2017; Holling 1978; McFadden, Hiller, and Tyre 2011; Walters and Holling 1990; Williams 2011; Williams and Brown 2014). Figure 7.1 illustrates the fluid and continuous nature of how the six key components of AM (plan, design, build, monitor, evaluate, and adapt) interact.

The central component, adapt, emphasizes the point that informed feedback at any stage can be iteratively applied to promote adaptation (or change) anywhere in the sequence of plan, design, build, monitor, and evaluate to optimize the project.

Figure 7.1. Conceptual Process Flow Model of the Six Key Components of Adaptive Management

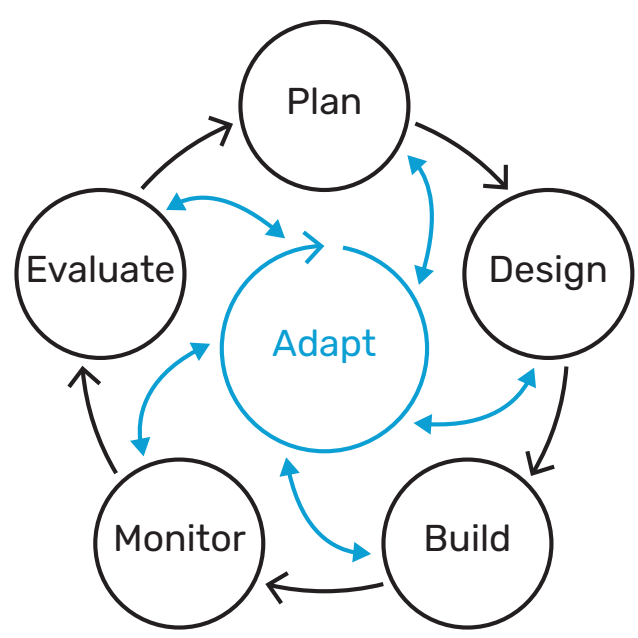

The two primary types of AM, passive and active, encompass the spectrum of $A M$ that can be applied to an NNBF project. Passive AM involves relatively limited monitoring efforts to try to understand whether a specific management action is achieving the desired performance level. Active AM involves a more rigorous approach where the management action is conducted in the context of an explicit hypothesis and associated monitoring protocol aimed at determining whether the proposed management action produces a given result (Gold 2006).

Source: Adapted from Greig et al. 2013

\subsubsection{NNBF in the Context of the Socioecological System}

Applying AM to NNBF and structural projects to facilitate achieving project objectives and attaining flood risk reduction and a suite of societal co-benefits (as discussed in Chapter 6 ) requires consideration of the dynamic interactions between the social and ecological systems. Figure 7.2 illustrates these various interactions and emphasizes the pivotal role that AM plays in achieving desired goods and services-the social system uses and manages the resources of the ecological system, whereas the ecological system provides goods and services, including flood risk reduction, to the social system. 


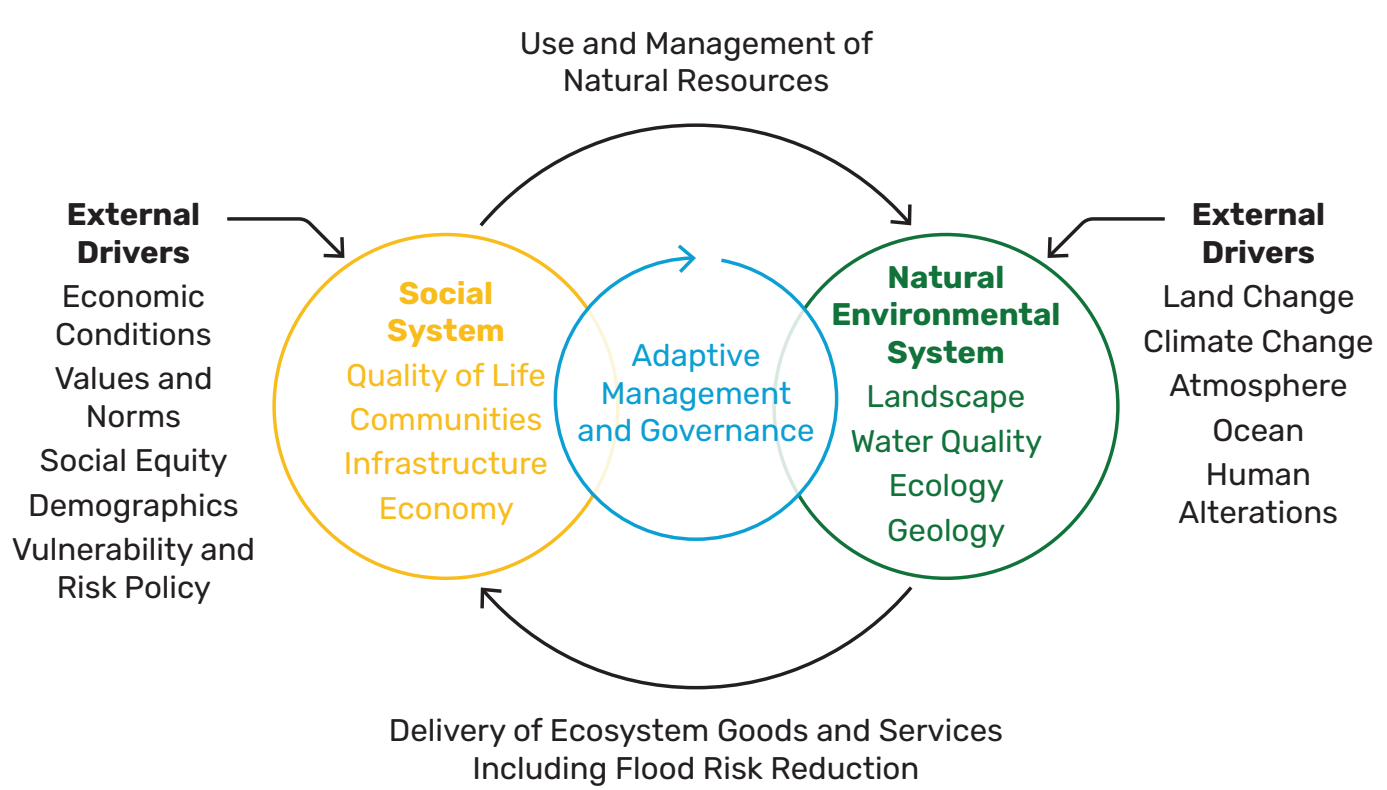

Source: Adapted from Goulburn Broken Catchment Management Authority 2013

The ecological system components are atmosphere, land, water, flora, and fauna. The social system consists of factors at various levels, such as individuals, communities, and institutions, as well as elements of the system (e.g., economics, livelihoods, and transportation). Each of these entities has specific characteristics that influence behaviors and contribute to their ability to be resilient, such as agency or self-efficacy (Berkes and Ross 2013).

A wide range of social, economic, and physical external drivers can introduce uncertainties by changing social and ecological systems on a project or wider system scale during the project's life cycle. For example, social drivers can include cross-culture differences, demographics, land-use change, political structure, and attitudes. Economic factors include available budgets, flood damages, market costs, tax bases, and employment rates. As described in Chapters 9 and 10 , coastal and fluvial physical drivers consist of factors primarily related to atmospheric, hydrodynamic, and geomorphological regimes in conjunction with respective ecological states.

As shown in Figure 7.2, the ecological system produces goods and services, including flood risk reduction, that are used and managed by the social system. The goal of AM in NNBF projects is to account for the dynamic coupling between the social and ecological systems in a way that meets project performance during its life cycle while both systems are being simultaneously influenced by the project and external drivers. This goal is achieved by adjusting management 
measures to changing circumstances or to new information about the effectiveness of the NNBF projects or the system being managed. Without effective AM and governance, the coupled social and ecological systems can become off-balanced, where the use and management of natural resources by the social system reduces the quantity and quality of goods and services provided, thereby increasing aspects, such as flood risk, over time.

\subsubsection{Benefits of Adaptive Management in NNBF}

AM applied to NNBF projects can increase the likelihood of achieving the desired goals and objectives by providing a structured decision-making method that allows management flexibility when dealing with interactions between dynamic social and ecological systems. Overall, the process can reduce life-cycle project costs, reduce the risk of failure, improve outcomes, and allow an expansion of the knowledge base for decision-making.

\section{Benefits of Investing in Adaptive Management}

\section{Reducing Life-Cycle Project Costs}

- Reduces up-front costs by allowing management of unknowns over time

- Saves cost by not overdesigning up front, while providing the ability to adapt the design over time, as needed, sustaining project life span and benefits

- Optimizes operations and maintenance costs over time

\section{Reducing Risk and Improving Outcomes}

- Improves outcomes and robustness by using adaptive actions over time

- Allows phasing of projects, instead of needing to minimize uncertainties up front

- Provides flexibility to change direction or adapt overall strategy

- Allows acceptance of risk to innovate with confidence where uncertainty and risk are addressed over time

- Facilitates environmental permitting, acknowledging uncertainties regarding impacts

- Enhances ability to meet multiple objectives and benefits over time

- Improves design life via asset resilience

\section{Adapting to Improve Knowledge}

- Improves future work through lessons learned from ongoing projects

- Enhances knowledge about performance of features through monitoring and evaluation 
- Quickly builds knowledge of system functionality and performance by accepting risks early during planning and design phases

- Leads to more innovative design by evaluating new technologies in the field

\section{2 | Applicability of Adaptive Management for NNBF}

Given the dynamic natures and inherent uncertainties of coastal and fluvial environmental systems, AM can be quite beneficial for NNBF projects because it provides a certain degree of flexibility to respond to changes. Technical and economic management actions can be taken as more is learned about the systems, as understanding about specific NNBF performance metrics through monitoring increases over time, and as the needs of society shift and change.

To maximize benefits derived by AM, its applicability to specific project conditions and needs should be considered. During the Scoping Phase of the NNBF project development framework (discussed in Chapter 2), managers should consider the applicability of AM based on the following three conditions (Williams, Szaro, and Shapiro 2009; Rist et al. 2013):

- There are relevant and measurable uncertainties in the outcomes of management actions or the system being managed.

- The project is controllable, allowing for future modifications in management actions.

- There is a low risk of irreversible harm to the environment or society (compared to no action).

Williams, Szaro, and Shapiro (2009) also reported that the successful application of AM is usually associated with the following five conditions:

- Timely management actions are important and required, despite uncertainty (also known as the ability to act without complete knowledge).

- Clear and measurable objectives, with associated metrics, have been defined to inform project performance and iterative decision-making.

- Management and decision-making are flexible over time to allow for learning and adjustments over time, supported by a range of alternative actions and funding justifications.

- Uncertainties can be reduced over time with the use of effective and targeted monitoring and regular synthesis of system responses to inform subsequent management adjustments. 
- There is a commitment to active and sustained engagement of diverse stakeholders throughout the AM process to facilitate dialogue around various perspectives and encourage collaboration in decision-making.

Although AM has been used and documented in many geographically extensive and complex ecosystem management applications that involve many of the elements of the socioecological system shown in Figure 7.2, it has also been applied to suitable smaller local projects (Williams, Szaro, and Shapiro 2009). AM can be implemented at different scales of effort depending on needs and opportunities within a project and system. There are probably more potential applications of AM at smaller (local) scale because of the prevalence of small projects and because small projects can usually be framed more easily, uncertainties identified more readily, and stakeholder involvement facilitated more directly (McConnaha and Paquet 1996).

Although AM processes can be developed at any point in the project life cycle, it is most desirable to start at the beginning of an unconstructed project in the Planning Phase of the NNBF project development framework (discussed in Chapter 2). This can have certain advantages, such as involving stakeholders and establishing funding required for monitoring up front. But AM can also be applied to projects that are either in the later phases of design and implementation or that have already been constructed.

\section{3 | Development of an Adaptive Management Plan}

\subsubsection{Overview}

Adaptation can occur at every stage of the project, as depicted in Table 7.1. Adaptation occurs often and naturally and is not always recognized as AM. For instance, during construction, the design may be altered due to soil conditions on site. It is important to recognize these adaptations to learn lessons for future projects and increase efficiency in project implementation.

The setup of an AM plan ideally follows the phases in the project as elaborated in Chapter 2. This specific approach has been worked out in this chapter with defined AM steps. For each step, a short description is given, and key actions are identified.

Table 7.1 presents the specific steps to AM in respect to each phase of the project (Scoping Phase, Planning Phase, Decision-Making Phase, Implementation Phase, and Operations Phase-discussed in Chapter 2). The specific steps to AM are explained in Sections 7.3.2 through 7.3.13, and key actions are identified in the table and at the beginning of each of those sections. 


\begin{tabular}{|c|c|c|c|}
\hline Stage & $\begin{array}{l}\text { Step } \\
\text { in AM } \\
\text { plan }\end{array}$ & Description & Key actions \\
\hline \multirow[t]{3}{*}{ Scoping } & 1 & $\begin{array}{l}\text { Identify the scope of } \\
\text { AM program, including } \\
\text { prioritizing multiple } \\
\text { objectives to be evalu- } \\
\text { ated over time. }\end{array}$ & $\begin{array}{l}\text { Identify scale and scope of AM application. } \\
\text { - Identify and prioritize clear and measurable } \\
\text { (specific, measurable, achievable, relevant, and } \\
\text { time-bound; SMART) objectives. } \\
\text { - Identify design life of feature and AM program. }\end{array}$ \\
\hline & 2 & $\begin{array}{l}\text { Define stakeholder } \\
\text { roles in AM, including } \\
\text { governance. }\end{array}$ & $\begin{array}{l}\text { - Identify communities and stakeholders (see } \\
\text { Chapter 3). } \\
\text { - Through effective leadership, define roles and } \\
\text { responsibilities for stakeholders and decision- } \\
\text { makers. } \\
\text { - Prepare engagement plan to involve stakeholders } \\
\text { throughout entire AM process in collaborative } \\
\text { decision-making. } \\
\text { - Define AM governance structure (with governance } \\
\text { structure and decision-making process). }\end{array}$ \\
\hline & 3 & $\begin{array}{l}\text { Develop funding } \\
\text { strategy for } \\
\text { implementation of AM } \\
\text { program, including } \\
\text { monitoring, evaluation, } \\
\text { and subsequent } \\
\text { adaptive actions. }\end{array}$ & $\begin{array}{l}\text { - Identify funding needs for monitoring, evaluation, } \\
\text { and subsequent adaptive actions, including funding } \\
\text { to engage stakeholders. } \\
\text { - Develop funding strategy and assess potential } \\
\text { sources. } \\
\text { - Ensure that funding for AM is included in overall } \\
\text { project budget. } \\
\text { - Identify potential funding sources for future needs, } \\
\text { such as additional funding for adaptive actions. }\end{array}$ \\
\hline \multirow[t]{3}{*}{ Planning } & 4 & $\begin{array}{l}\text { Identify performance } \\
\text { metrics for objectives } \\
\text { and uncertainties to } \\
\text { be monitored over } \\
\text { time. }\end{array}$ & $\begin{array}{l}\text { - Identify uncertainties relevant to the project. } \\
\text { - Prioritize critical management uncertainties. } \\
\text { - Identify acceptable range of risk for critical } \\
\text { uncertainties. } \\
\text { - Identify and prioritize performance metrics for } \\
\text { objectives and critical uncertainties. }\end{array}$ \\
\hline & 5 & $\begin{array}{l}\text { Develop scientific } \\
\text { approach through the } \\
\text { use of conceptual or } \\
\text { numerical models. }\end{array}$ & $\begin{array}{l}\text { - Investigate the necessity to use conceptual models, } \\
\text { numerical models, or other analytical tools. } \\
\text { - If using models, decide which methods to use and } \\
\text { how to use the results. }\end{array}$ \\
\hline & 6 & $\begin{array}{l}\text { Design monitoring } \\
\text { plan. }\end{array}$ & $\begin{array}{l}\text { Determine which parties (experts and stakeholders) } \\
\text { will design the monitoring plan. } \\
\text { - Determine the type of monitoring suitable for each } \\
\text { performance metric. } \\
\text { - Make inventory of existing monitoring networks. } \\
\text { - Evaluate existing monitoring networks for gaps } \\
\text { specific to the project. } \\
\text { - Determine what additional monitoring is needed } \\
\text { (spatially and temporally). } \\
\text { - Establish data collection and data management } \\
\text { protocols. } \\
\text { - Specify how monitoring data and information will be } \\
\text { collected and shared. }\end{array}$ \\
\hline
\end{tabular}




\begin{tabular}{|c|c|c|c|}
\hline Stage & $\begin{array}{l}\text { Step } \\
\text { in AM } \\
\text { plan }\end{array}$ & Description & Key actions \\
\hline \multirow[t]{2}{*}{ Planning } & 7 & $\begin{array}{l}\text { Plan for data } \\
\text { synthesis and set } \\
\text { decision thresholds. }\end{array}$ & $\begin{array}{l}\text { - Set performance benchmarks and thresholds for } \\
\text { each metric by which an AM assessment would be } \\
\text { triggered. } \\
\text { - Plan for the regular assessment of monitoring data. } \\
\text { - Use tools to integrate complex information and } \\
\text { inform decisions. } \\
\text { - Establish clear plans and resources for monitoring } \\
\text { data analyses and synthesis to support } \\
\text { decision-making. }\end{array}$ \\
\hline & 8 & $\begin{array}{l}\text { Identify possible } \\
\text { adaptive actions } \\
\text { and scenarios for } \\
\text { implementation over } \\
\text { time. }\end{array}$ & $\begin{array}{l}\text { - Identify the list of potential adaptation actions that } \\
\text { could be needed in the future. } \\
\text { - Assess whether adaptation measures are needed } \\
\text { and at what phase of the framework. } \\
\text { - Establish connections between program- and } \\
\text { project-scale decisions. }\end{array}$ \\
\hline Decision-Making & 9 & $\begin{array}{l}\text { Select preferred } \\
\text { options. }\end{array}$ & $\begin{array}{l}\text { Decide on the final monitoring plan, decision } \\
\text { thresholds, and adaptive actions to be included } \\
\text { in the AM plan, as well as the timeline for } \\
\text { reassessment and future decision-making. }\end{array}$ \\
\hline \multirow[t]{2}{*}{ Implementation } & 10 & Adapt during design. & $\begin{array}{l}\text { - Incorporate lessons learned from previously } \\
\text { designed similar projects into subsequent design } \\
\text { modifications. }\end{array}$ \\
\hline & 11 & $\begin{array}{l}\text { Adapt during } \\
\text { construction. }\end{array}$ & $\begin{array}{l}\text { - Identify opportunities for a more proactive and } \\
\text { collaborative approach to changes identified during } \\
\text { construction. } \\
\text { - Develop a communication and data plan to support } \\
\text { construction. } \\
\text { - Conduct regular surveys and inspections to collect } \\
\text { data and have regular meetings with project team } \\
\text { and contractor; adapt surveying and construction } \\
\text { during construction phase. }\end{array}$ \\
\hline Operations & 12 & $\begin{array}{l}\text { Adapt } \\
\text { post-construction } \\
\text { (operational). }\end{array}$ & $\begin{array}{l}\text { - Provide for periodic monitoring and evaluation of } \\
\text { results. } \\
\text { - Implement feedback loop of framework flow chart. }\end{array}$ \\
\hline
\end{tabular}

\subsubsection{Identify Scope of Adaptive Management Program, Including Multiple Objectives (Step 1)}

\section{Key Actions}

- Identify scale and scope of AM application.

- Identify design life of feature and AM program.

- Identify and prioritize clear and measurable (SMART) objectives. 


\subsubsection{Identify Scale and Scope of Adaptive Management Application}

The scope of the AM plan can encompass an individual NNBF on an individual project-level scale or on a larger system scale, likely involving a collection of NNBF projects. The dynamic nature of the socioecological system requires an understanding of the functions and processes to develop an AM plan. System-scale AM should consider broad objectives of the entire system and can look at collective outcomes of multiple projects, which could include both NNBF and structural solutions.

Both the project and system scales should be considered before converging on a delineated scope, goals, and objectives for the design of the intended AM plan. It should be noted that AM can occur at multiple phases of a project, as well as multiple scales (Rist et al. 2013; Rist, Campbell, and Frost 2012; McFadden, Hiller, and Tyre 2011). Adaptive planning uses new knowledge about the system, as well as changing societal perspectives, to re-evaluate goals, objectives, criteria, and strategies. The planning stage can consist of multiple goals with changing emphases over time.

\section{NHIH}

CASE STUDY:

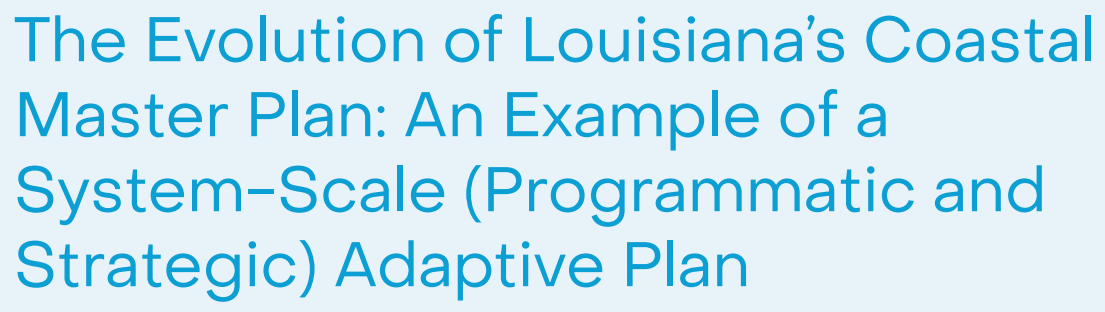

Planning for coastal resilience is an iterative and evolutionary process that requires a long-term commitment by the state and lead agencies. The State of Louisiana in the United States has had decades of experience in coastal planning. The Louisiana Coastal Master Plan is an internationally renowned coastal resilience plan that uses highly sophisticated models and decision-making processes to meet future challenges in sustaining coastal Louisiana (CPRA 2017). After Hurricanes Katrina and Rita in 2005, the Louisiana legislature mandated that the state update the coastal master plan every 5 years (recently changed to every 6 years). With each iteration of the Louisiana Coastal Master Plan, the process becomes more detailed, the public engagement more extensive, the decision-making more transparent, and the modeling more sophisticated, thereby improving understanding about the system and what management actions are needed. 
Adaptive design can integrate lessons learned during and after FRM design and implementation into current and future NNBF. Monitoring during construction and regular assessment of data can lead to adaptation of the project during the construction phase. The AM processes in the Planning Phase and the Implementation Phase of the NNBF project development framework are usually not as well documented by implementing entities as the post-construction $A M$ process that most people associate with $A M$, which involves monitoring, assessment, and adaptive actions.

As discussed in Section 7.1.2, it is important to create a tight, concise, meaningful definition of AM for each agency or region to facilitate buy-in among stakeholders and to avoid the use of AM to justify politically driven management decisions being made without a scientific basis or an evaluation of options. The definition should also include the goals and purpose to express the situation's needs and significance. Natural resource AM could have multiple goals with changing emphasis over time, which should be clarified early in the process. The flexibility of management goals should be aimed at making the system more resilient overall. The management of Glen Canyon Dam in the State of Arizona in the United States is a good example of strictly defining what it means to actively adapt the resources involved. In this case, the well-defined AM strategy emphasized a focus on active AM with the use of experimentation. Defining $A M$ in the beginning and setting clear goals that were practical and achievable in the near term helped establish the AM program quickly (usbr.gov 2020). Another option is to hire AM experts to work internally with other resource managers to facilitate the use of $A M$ and provide guidance and an agency-specific definition and framework for AM.

\section{NHINHก)}

\section{CASE STUDY:}

\section{Glen Canyon Dam (Arizona, United States)}

The significant levels of uncertainty surrounding the resources of the Colorado River ecosystem and the effects of dam operations on those resources led to the creation and implementation of the Glen Canyon Dam Adaptive Management Program. From its inception, the Glen Canyon Dam Adaptive Management Program has developed and implemented research and monitoring to analyze impacts and build a knowledge base of dam operations on the Colorado River and its downstream resources. This emphasis on active AM via scientific experimentation has enabled the program to measure and monitor resource responses in the Colorado River ecosystem. With time and maturity, these experiments have grown from a single focus on dam releases to also looking at flow and nonflow action. A variety of stakeholders have 
interests in the ecosystem, including federal and state agencies, Native American tribes, the Colorado River Basin states, electrical utilities, and recreational and environmental groups. Stakeholder representatives participate in the official federal advisory committee-the Glen Canyon Adaptive Management Work Group-and develop operations recommendations for the Secretary of the U.S. Department of the Interior on how to best protect the resources and meet legal requirements. A subgroup comprising technical representatives-the Glen Canyon Technical Working Group-develops research questions, criteria, and standards for monitoring and research. Independent review panels comprising individuals not participating in long-term monitoring assess the quality of science conducted by the Glen Canyon Dam Adaptive Management Program and make recommendations for improvement.

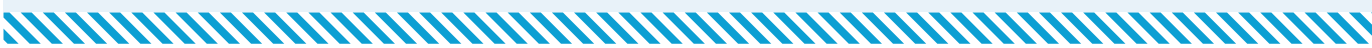

\subsubsection{Identify Design Life of Feature and Adaptive Management Program}

The scope of the project, as defined in the project goals and objectives, should take into account the period of service and the natural dynamics of the NNBF. As applied to structural measures, period of service is a defined period over which benefits are quantified for a benefit-cost analysis. In some aspects, NNBF can be viewed in perpetuity because some features, such as beaches, islands, and wetlands, have existed for hundreds or thousands of years. A common approach to design is to incorporate safety factors or margins to provide assurance and reliability (e.g., freeboard on a levee). The flexibility of NNBF can be capitalized upon when designing features in conjunction with the incorporation of AM because designers may be able to reduce this factor of safety (i.e., minimize overdesign) and attendant cost if they know that the NNBF design can be modified if not performing as expected (as determined by post-construction monitoring and data synthesis). Reduction of any safety factor must take into account the consequences that could be incurred by design failure.

How long the AM program is implemented will depend on factors such as type and scale of the project, level of uncertainties, stakeholder composition and objectives, and available funding. The AM program does not necessarily have to extend the full lifetime of the project, but when considered at a system scale, some form of AM may extend beyond the lifetime of an individual project. Some key uncertainties can be resolved in the beginning of the project; however, future unknowns can arise that would warrant re-establishing an AM program (Figure 7.3). Uncertainties can never be completely eliminated; thus, managers should establish a range of acceptable risk under which they are confident that the objectives of the project can be met through deliberation with stakeholders. Changes to the environment, such as those caused by 
climate change, or to the social system, such as a change of objectives based on stakeholder values, can occur in the future and increase the uncertainties of project performance beyond the acceptable range. When this occurs, managers (in close dialogue and deliberation with stakeholders) should evaluate whether the AM program needs to be re-established to ensure long-term performance of the NNBF.

\section{Figure 7.3. Adaptive Management and Risk over Time}

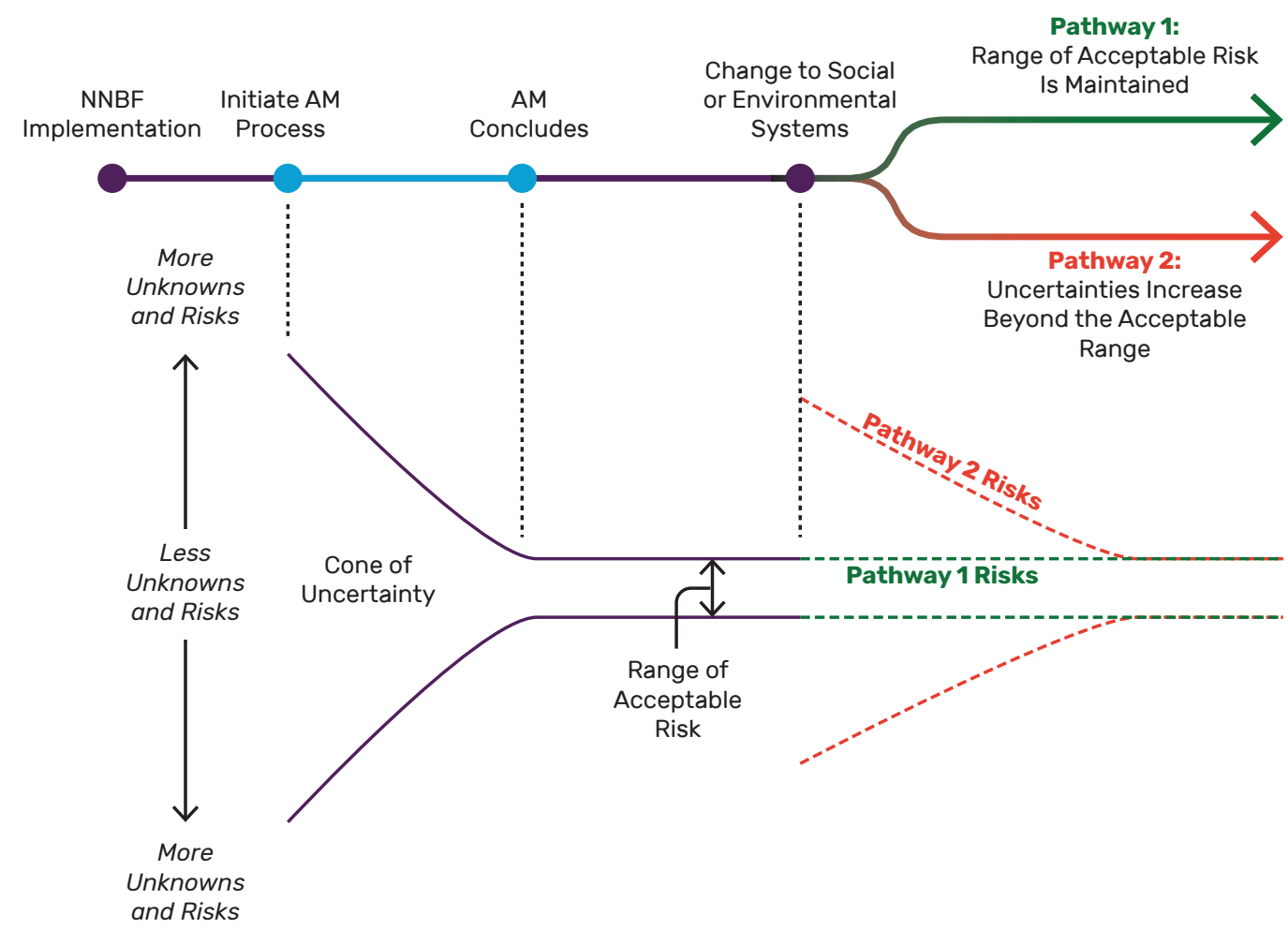

Note: Over time, AM will reduce uncertainties potentially to a time of acceptable risk in which the AM program is no longer necessary. However, future changes in the social or environmental systems may extend uncertainties outside the acceptable range, warranting a re-establishing of the AM program.

Because AM is a multistep, iterative process for structured decision-making, if and when the level of uncertainty is sufficiently reduced and adjustment of management actions no longer required, the AM approach can be replaced by other management approaches for the remaining design life of the project. 


\subsubsection{Identify and Prioritize Clear and Measurable (SMART) Objectives}

Goals are important to establish the ultimate desired outcomes of any project; however, goals tend to be broad, abstract, and indicative of the general intention of the project. Objectives are narrow, precise, and concrete, and they define details of how goals will be accomplished. The establishment of clear and measurable objectives can help ensure that the various stakeholders (with often different perspectives) understand and agree on the performance criteria. Establishing clear objectives is especially important on large, multipurpose NNBF projects that can affect many stakeholders often with conflicting expectations. AM can provide a systematic means for stakeholders to identify and discuss these differences (see discussion of stakeholder engagement processes in Chapter 3 ). If common ground can be negotiated between stakeholders on even relatively small initial matters on an operational level, the pattern can be set to address future larger issues. The earlier stakeholders are engaged openly with a readily accessible, inclusive, and transparent decision-making process, the better the outcome of the AM process and the NNBF. By establishing "the operating environment of an AM project, stakeholders directly influence both decision-making and learning" (Williams and Brown 2014).

One of the key purposes of using NNBF approaches is to provide multifunctional benefits to the FRM, natural environmental, and social systems; thus, each project will have multiple goals and objectives of varying spatial and temporal scales. As discussed previously, goals are simply what we want to accomplish, and objectives are how goals are going to be met. Chapter 6 discusses how important it is to recognize and assess these benefits in understanding the cost-effectiveness and trade-offs of alternative management strategies and design options. Chapter 5 discusses aspects that should be considered when selecting and prioritizing FRM, ecological, social, and economic performance metrics in regard to performance dynamism to account for the dynamic nature of NNBF at multiple scales. In many cases, these multiple objectives can be incompatible with each other. This may warrant the need for managers and stakeholders to develop an objective hierarchy that can be managed through the AM program.

An objective hierarchy (Figure 7.4) provides a structured way for AM to prioritize objectives based on stakeholders' values and demonstrates the relationships between various objectives, thereby reducing conflict and uncertainty among objectives over time. Objective hierarchies can demonstrate a difference in the level of importance of the various objectives.

The fundamental objective for NNBF is mostly to reduce flood risks. However, secondary and tertiary objectives include ecological enhancement and economic development. Objective hierarchies can also be used to demonstrate varying levels of detail, as shown in Figure 7.4. In this example, the fundamental (or primary) objective is broad and visionary and measured through status and trend monitoring that many times cannot be directly attributed to the 
NNBF but instead provides a general status of the environment. The secondary and tertiary objectives become more concrete and measurable and can be directly linked to the NNBF contributions to the primary objective.

\section{Figure 7.4. Adaptive Management Objective Hierarchy}

\begin{tabular}{|c|c|}
\hline $\begin{array}{l}\text { Fundamental Objective } \\
\text { - Improve ecosystem services and } \\
\text { reduce flood risk by restoring a barrier } \\
\text { island complex }\end{array}$ & $\begin{array}{l}\text { Status and Trend Monitoring } \\
\text { - Vulnerability } \\
\text { - Habitat use } \\
\text { - Sea-level rise }\end{array}$ \\
\hline $\begin{array}{l}\text { Secondary Objective } \\
\text { - Reduce storm surge and waves on } \\
\text { adjacent community } \\
\text { - Increase quality and quantity of } \\
\text { habitat for wildlife }\end{array}$ & $\begin{array}{l}\text { Effectiveness Monitoring } \\
\text { - Surge and wave height } \\
\text { - Overwash } \\
\text { - Island breaching and recovery } \\
\text { - Shoreline and marsh erosion rates } \\
\text { - Vegetation diversity and cover }\end{array}$ \\
\hline $\begin{array}{l}\text { Tertiary Objective } \\
\text { - Establish dune to resist } 3 \text { meters of } \\
\text { surge for } 10 \text { hours } \\
\text { - Enhance ecological habitat and } \\
\text { erosion resistance by establishing } \\
\text { beach grass vegetation cover }\end{array}$ & $\begin{array}{l}\text { Implementation Monitoring } \\
\text { - Sediment source and characteristics } \\
\text { - Settlement } \\
\text { - Vegetation establishment and } \\
\text { survival rates }\end{array}$ \\
\hline
\end{tabular}

Note: This objective hierarchy structure illustrates how AM can prioritize objectives based on stakeholders' valued components and shows the relationships between various objectives. Examples of performance metrics are included along with the type of monitoring to be conducted to determine performance for each objective.

With regard to $A M$, the objectives should, foremost, be relevant to the decision-making process and possess a number of attributes that render them useful as guides to management (Adamcik et al. 2004). To be useful for decision-making and evaluation, objectives of a natural resource management project, with slight modification for the structural system aspects, need to exhibit the following specific, measurable, achievable, relevant, and time-bound (SMART) technical features (modified after Williams, Szaro, and Shapiro 2009). These objectives are typically set in the planning process but can be refined over time in the AM program.

- Specific. Objectives should be unambiguous, with specific metrics and specific target conditions. Specificity can be encouraged by articulating objectives with who, what, why, and where phrases.

- Measurable. Objectives should contain elements that can be readily measured to promote the evaluation of management actions and recognize their contributions to successful management. 
- Achievable. Objectives should be based on the capacities of the systems being managed and the political or social system within which management occurs.

- Relevant. Objectives should contain endpoints or conditions representing their achievement. For example, a relevant habitat objective might describe the habitat conditions expected when the objective is achieved or flood protection level of service provided.

- Time-bound. Objectives should indicate the time frame for achievement, consistent with the duration of the project. Project implementation may be in stages, but the overall time frame should be clear.

\section{NHIH}

\section{CASE STUDY: The Houtribdijk (the Netherlands)}

The Houtribdijk (Figure 7.5) is a dam that separates Lake Marken from Lake IJssel in the Netherlands and is part of the Netherlands' primary water defenses system. The dam protects the hinterland of Flevoland and areas around Amsterdam from flooding. An assessment determined that the dam did not meet required levels of service established by law, and it had to be upgraded.

Half the length of the dam was reinforced using an innovative beach NNBF that consisted of adding sandy shores to the existing dam in a nontidal freshwater system. In total, approximately 10 million cubic meters of sand were added to both sides of a 10-kilometer section of the dam.

Figure 7.5. The Houtribdijk

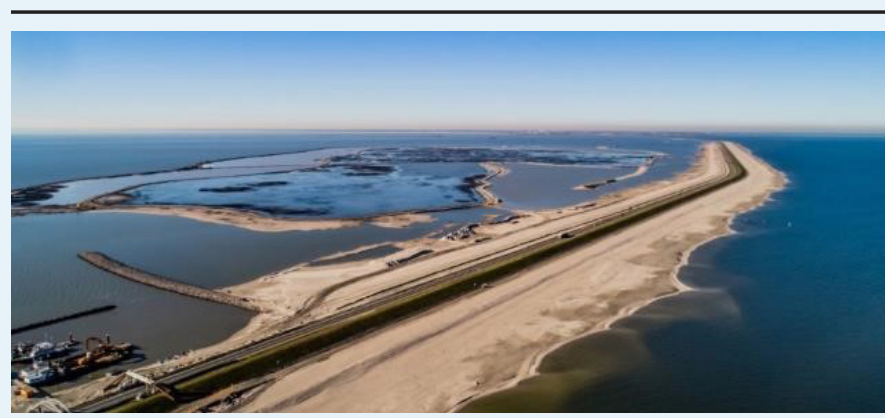

Note: Newly constructed sandy shores (including nature area Trintelzand); location: Houtribdijk, dam connecting the provinces of Noord-Holland and Flevoland, the Netherlands

Source: Courtesy of Frank Janssens, Rijkswaterstaat 
Because of limited knowledge and modeling capabilities to predict how the sandy shores will develop over time and uncertainties regarding an appropriate methodology for assessing the safety of these sandy shores, the project is being monitored as part of an AM plan. The driving processes for the morphologic development of the beach were not understood well enough to make a good estimate of the lifetime and decay of the sandy shores (and, therefore, the need for subsequent maintenance nourishment works).

To handle these scientific and managerial uncertainties over time, Rijkswaterstaat, the Directorate-General for Public Works and Water Management (responsible for FRM and daily maintenance of the levee), implemented an AM strategy for this dam. It includes scientific research and a monitoring program that is designed to expand knowledge about the morphological driving processes and improve predictive capabilities to inform managerial actions regarding maintenance requirements to keep the dam's level of engineering performance in conformance with the law.

As part of the AM plan, the dam is being intensely monitored for at least 5 years. After year 4, data and knowledge acquired by monitoring will be used to evaluate the maintenance requirement hypothesis, set scientifically proven intervention thresholds where possible, and decide whether these thresholds are within acceptable uncertainty ranges. The answers to these questions will determine how to continue monitoring in the following years. Funding of the first 5 years of the AM strategy was secured from the construction budget.

The AM strategy's most important objective is to comply with FRM standards. To do that, timely maintenance works (renourishing) are required. To plan these works, the morphodynamic processes need to be better understood. A key uncertainty is the erosion rate of the sandy shores due to hydraulic impact (waves and currents). Therefore, a monitoring scheme was implemented to measure these parameters with a high temporal frequency over time. The data will be used (1) to assess the current status of the dam with respect to the temporally defined intervention criteria (see Figure 7.6) and (2) for scientific research with regard to the driving processes and numerical model improvements (XBeach) for these sandy shores. By incorporating these new data and improved understanding gained by monitoring, management actions will include definition of new thresholds and adaptation of the overall management strategy if needed. 
Figure 7.6. Data Analysis of Current Dam Intervention Criteria

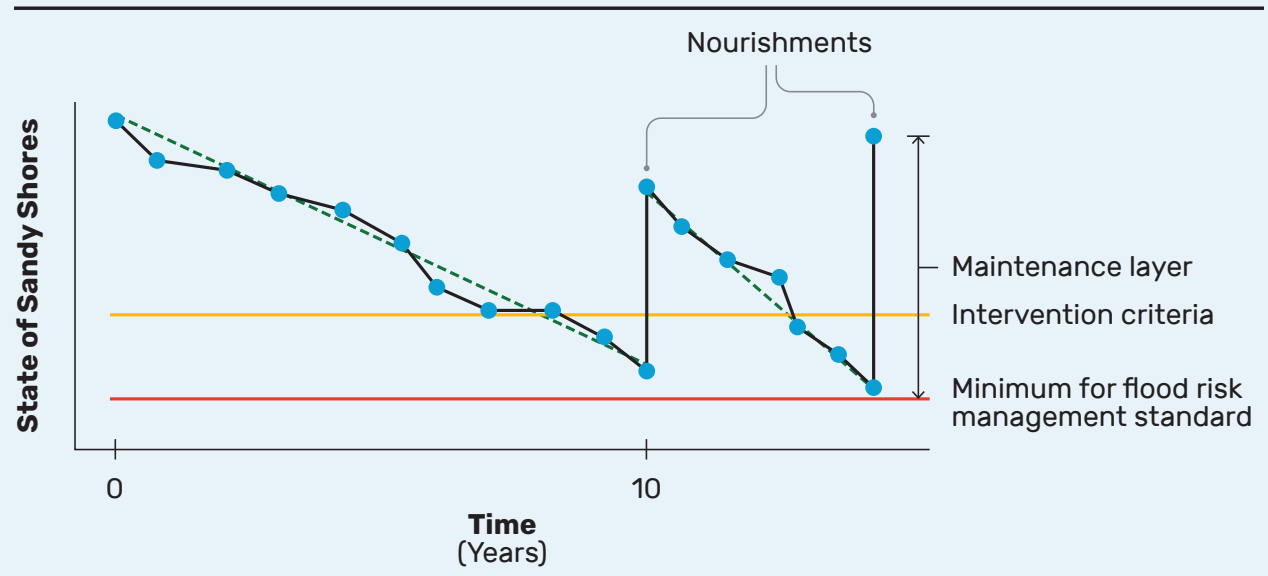

\subsubsection{Define Stakeholder Roles in Adaptive Management, Including Governance (Step 2)}

\section{Key Actions}

- Identify communities and stakeholders.

- Through effective leadership, define roles and responsibilities for stakeholders and decision-makers.

- Prepare engagement plan to involve stakeholders in collaborative decision-making throughout the entire AM process.

- Define AM governance plan (with governance structure and decision-making process).

A number of catalysts drive interest in NNBF projects and bring stakeholders together, as described in Chapter 3 . They include threatening situations such as natural hazard events and climate change. As is true for all project phases, stakeholders are a critical component of effective AM and should be identified and engaged with as early as possible. The AM plan should be developed and elaborated on by stakeholders in phases. During early scoping, the overarching structure and process should be determined and more details added with time and in subsequent iterative AM steps. This requires a commitment to long-term communication and outreach throughout the entire AM process. 
Because NNBF produce multifunctional benefits, the number and types of stakeholders can be diverse. Stakeholder group size, composition, and level of participation will depend on a number of factors including NNBF project parameters such as type (e.g., fluvial or coastal), objectives, location, relative size and cost, funding sources, and timing (see chapter 3 for how to conduct stakeholder analysis and assess the level of engagement). Some projects will involve more high-level governmental participation than others that may comprise more local, smaller entities. Larger NNBF system-based projects generally involve more national stakeholder involvement due to increased complexity and cost.

Although stakeholder input is necessary and imperative to the AM process, it can add time and complexity to the situation if managers struggle to find consensus between scientists and stakeholders. Communicating the risks involved in $\mathrm{AM}$ to stakeholders and agencies poses another challenge because such risks are often not well understood and are, therefore, difficult to discuss in detail. Rather than disregarding change, uncertainty needs to be normalized in future predictions to allow for actions based on imperfect predictions and information. AM can be used as a tool to reduce uncertainty and act on those predictions. Communication regarding risks and uncertainty should also place emphasis on the risk of inaction, because deciding not to include AM in a project may pose a much greater risk to the system than if AM is implemented.

Managers should focus on getting the right stakeholders involved in the AM development process and increasing consensus across all groups (see Chapter 3 for stakeholder analysis). Effective engagement is especially important because it can both increase stakeholder interest in AM and help reduce political unwillingness to use AM for NNBF projects.

Effective leadership is needed to communicate between scientists, managers, and stakeholders. Leadership needs to understand and champion AM best practices and secure funding. Leadership should have a sense of the science and the ability to communicate with stakeholders, scientists, and upper-level management in a credible way. One reason for the successful implementation of AM in Glen Canyon Dam was the Secretary of the U.S. Department of the Interior's full support for the AM program and its management, resulting in clear charters and operating procedures for collaboration (USBR 2017; AMWG 2011).

To develop good relationships between scientists and managers, professionally led facilitation is often needed. Leadership should ensure scientific independence and peer review for AM plan development, while also promoting conceptual ecological models with simple decision triggers to prioritize relevant experiments that managers can support. 
In the AM plan, roles and responsibilities are delegated in a governance plan to respective organizations and personnel. The objective of this AM governance structure is to convert growing knowledge into improved management through inclusive and transparent decision-making. Composition of the governance plan roster is based on consideration of authority, administration, decision-making, and accountability (Fischenich et al. 2018).

Governance of the AM processes is important to define early and can include the governance structure and decision-making process. The governance structure will define the roles and responsibilities of all relevant entities, including the authorized agencies, technical and management staff, independent external review, and stakeholders. The decision-making process includes principles of governance and standard operating procedures that define how decisions will be made (e.g., consensus, quorum, or sole authority), timelines for decisions, conflict resolution procedures, financial management, and communication structure with clear channels between all entities.

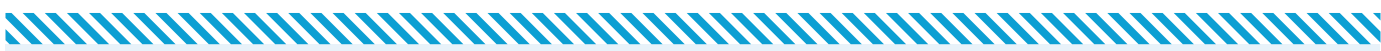

\section{CASE STUDY:}

\section{Platte River Governance: Get the People Right First (United States)}

The Platte River Adaptive Management Program in Colorado, Wyoming, and Nebraska is built around an Applied Science Strategy to achieve multiple river basin functions, including various water uses and habitat for threatened and endangered species (Smith 2011). The Governance Committee was formed to manage decisions and includes voting representation of federal and state agencies, upstream and downstream water users, and conservation groups. Although it took nearly 10 years of negotiations to build a fully functioning collaborative structure, the Governance Committee has come to agreement on water, land, and AM plans.

An independent executive director and staff manage the Governance Committee and the overall AM process, thereby reducing bias and building trust between various stakeholders. The Governance Committee appoints six members to an Independent Science Advisory Committee that provides important external technical guidance and scientific review to the Governance Committee (Smith 2011). 


\subsubsection{Develop Funding Strategy for Implementation of Adaptive Management (Step 3)}

\section{Key Actions}

- Identify funding needs for monitoring, evaluation, and subsequent adaptive actions, including funding to engage stakeholders.

- Develop funding strategy and assess potential sources.

- Ensure that funding for AM is included in overall project budget.

- Identify potential funding sources for future needs, such as additional funding for adaptive actions.

AM should be budgeted into the project in the Scoping Phase of the NNBF project development framework when managers are developing budgets and identifying funding mechanisms. To be effectively implemented, AM must be included in the overall project budget and funding requests. The AM funding considerations could include funding for monitoring and assessment over many years, as well as identified or realistic future funding for any subsequent $A M$ actions that may be needed if the project needs to be adjusted. These budgets will be developed and elaborated upon as details of the AM plan are refined. Funding sources can include government, stakeholders, national programs, nongovernmental organizations, universities, and local communities.

In many cases, the commitment to monitoring and AM can be included as a permit or legal requirement, thereby ensuring funding is available for implementation. It may be that funding can also become available at some other project life-cycle phase (e.g., funding made available after a major emergency such as that authorized in the United States after Hurricane Sandy). Implementation agencies could also develop a funding stream at an agency-wide or programmatic (strategic) level, thereby providing AM funding across multiple projects or regions. 


\subsubsection{Identify Performance Metrics for Objectives and Uncertainties (Step 4)}

\section{Key Actions}

- Identify uncertainties relevant to the project.

- Prioritize critical management uncertainties.

- Identify acceptable range of risk for critical uncertainties.

- Identify and prioritize performance metrics for objectives and critical uncertainties.

\subsubsection{Uncertainties}

As part of the NNBF framework, risks and uncertainties associated with achieving the project objectives are identified during the planning of an NNBF project.

Because risk is based on uncertainty, AM should be considered in all these key actions because it provides a structured process that enables managers to address risks and uncertainties during the initial and ongoing stages of a project. Establishment of the risk management strategy will inform decision-making on the applicability of implementing AM regarding the evaluation of whether the risks associated with learning-based decision-making are too high or not. This includes establishing an acceptable range of risk from uncertainties, as depicted in Figure 7.3 .

Uncertainties are prevalent in all coastal and fluvial systems, specifically with a climate change future. Uncertainties should be clearly stated to be valuable assessments of the current state of knowledge and to provide opportunities for learning that characterize the AM approach (Murray and Marmorek 2003). As discussed in Chapter 5 , any risk-based approach to FRM must address aleatory and epistemic uncertainty when estimating performance.

The critical uncertainties will need to be prioritized. Managers can ask themselves multiple questions to narrow a long list of uncertainties into those that would actually impact their decision-making process. What is the management action affected by this uncertainty? How is this uncertainty related to achieving an objective? How would potential outcomes of this uncertainty change a manager's actions (Murray and Marmorek 2003; Greig et al. 2013)? 
Depending on program and project requirements, the AM plan can be framed in the context of explicit hypotheses or questions about the performance of the NNBF. Conceptual models, numerical models, or other analytical tools can be used to illustrate the management actions and expected responses, as well as the aspects of the physical, biological, or social system that are highly uncertain. Then, as the project is implemented and monitored, subsequent management actions are based on performance metric results that, to varying degrees, either test these hypotheses or answer the questions.

\subsubsection{Performance Metrics}

Once objectives and uncertainties are identified and prioritized, performance metrics for each objective should be identified. As described in Chapter 5 , FRM, ecological, social, and economic performance is the measure of how well NNBF achieve FRM while also producing economic, environmental, and social benefits. Chapter 6 emphasizes the importance of benefit performance metrics because they resonate with different stakeholders and the economic and societal value depends in part on demand for the service.

Performance metrics are quantitative and qualitative criteria, based on anticipated physical, biological, or social responses, to evaluate the success of the NNBF in achieving the project's objectives. When selecting relevant performance metrics, the following items should be considered: (1) scientific link to the management action, (2) relevance to decision-makers and stakeholders, (3) availability and ready accessibility, (4) cost-effectiveness (especially for long-term monitoring), and (5) appropriate spatial and temporal scale. Performance metrics should be scientifically valid and demonstrate a relatively high "signal-to-noise" ratio that allows clear correlations to be made. Once all relevant performance metrics are identified, there may be a need to prioritize metrics based on funding. These metrics will provide the following: (1) long-term information on how well the project achieved its intended outcomes, (2) a reduction in uncertainties, and (3) insights into any unintended positive or negative outcomes.

\subsubsection{Develop Scientific Approach through the Use of Conceptual or Numerical Models (Step 5)}

\section{Key Actions}

- Investigate the necessity to use conceptual models, numerical models, or other analytical tools.

- If using models, decide which methods to use and how to use the results. 
AM uses many different types of models to achieve a wide variety of objectives and goals. "A model represents and simplifies reality by showing relationships between the objects of a theory, causal interactions, and the states of a system" (NRC 2004; Pickett, Kolasa, and Jones 1994). Models can range from relatively simple logic schematic diagrams of conceptual models to complex numerical models used to describe systems in terms of inputs, processes, relationships, and outputs, and are important tools in AM decision-making. They can, to varying degrees of accuracy, provide information on the existing conditions of the project and evidence about outcomes that enable decision-makers and stakeholders to evaluate the effects of the NNBF on the system and the effects of the system on the NNBF. It is important to note that communication between decision-makers, stakeholders, and modelers on the respective model's capabilities (e.g., capacities, limitations, and uncertainties) is required for productive, successful use of models.

Models are tools to organize and analyze data, visualize information, and identify uncertainties. Conceptual models demonstrate inputs and outputs, as well as relationships between various elements of the socioecological system (i.e., as a flow diagram; see Figure 7.7).

\section{Figure 7.7. Example Conceptual Model}

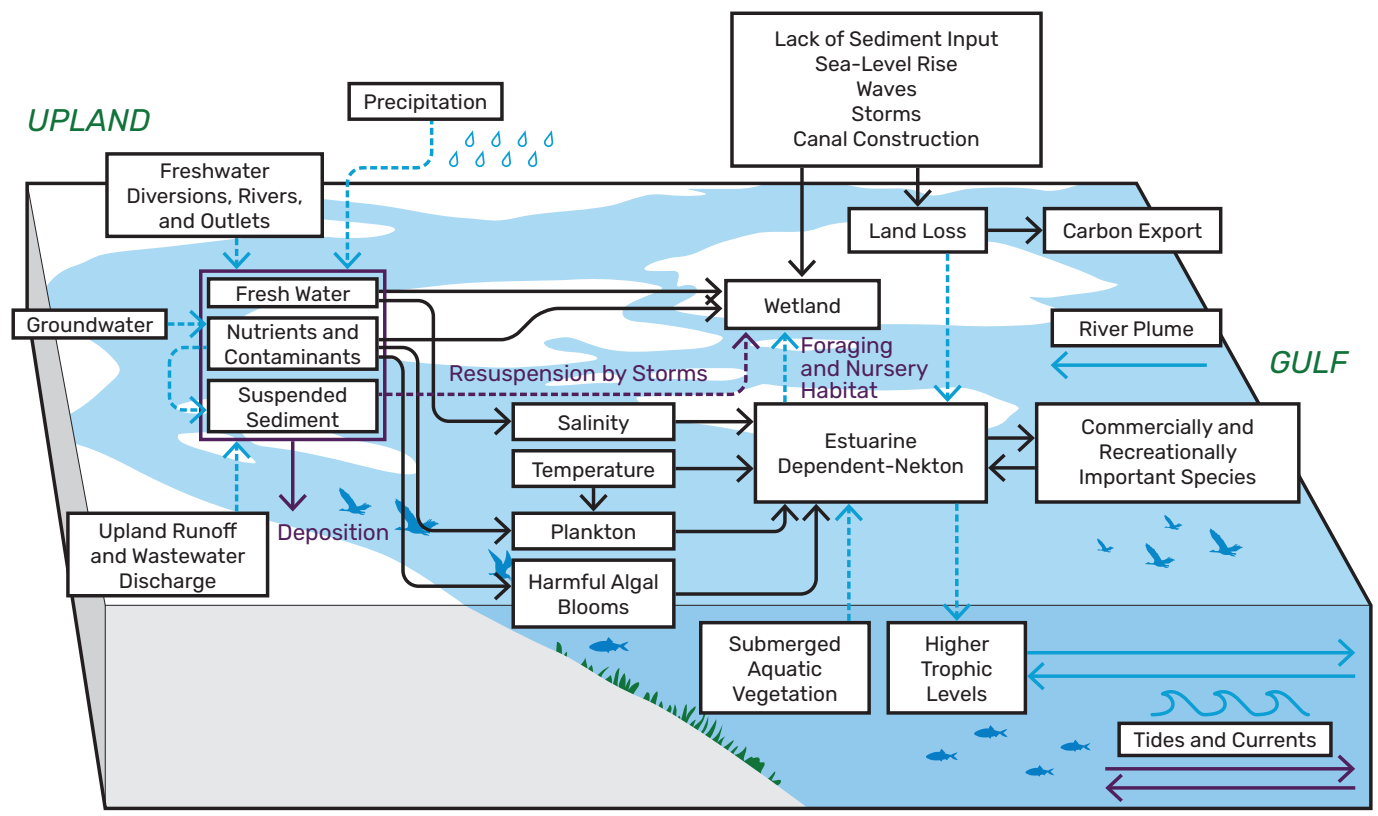

Note: This example of the conceptual model for the Mississippi River estuarine wetlands demonstrates the connections and relationships between various aspects of the ecosystem that may be measured to evaluate performance.

Source: Adapted from mississippiriverdelta.org 2019 
Numerical models are mathematical tools that establish relationships between variables that can provide predictions of current and future conditions. Numerical models can also provide an opportunity to test and evaluate the sensitivity of a system to uncertainty (CPRA 2017). With existing data, these models can be used to establish baseline conditions and gain an understanding of how the current system is being managed. They can also be used as a framework to compare design or future management alternatives and predict how the environment will respond. As described in later sections, subsequent monitoring and evaluation of the constructed NNBF's impacts and performance will be compared to respective modeling results to judge and possibly improve that model's capabilities to optimize future management actions.

To address the wide variety of aspects related to the social and ecological systems illustrated in Figure 7.2, models used in NNBF projects are not to be restricted to one particular kind. The variety of different types of models used in NNBF projects is highlighted by the numerous descriptions of their uses throughout this document. (For example: Chapter 9 describes how the conceptual physical system model for beaches and dunes is used to identify essential morphological elements, general sediment pathways, sediment sources and sinks, human interventions, and how associated drivers and processes link together; Chapter 5 describes how a hazard-performance-exposure-consequences model is used to determine system performance.) Modeling approaches will need to take into account climate change, which is an ever-present reality in natural resource management. Climate change is rapidly changing baseline conditions and adding never-before-seen levels of uncertainty and risk in environmental predictions (Rist, Campbell, and Frost 2012).

\subsubsection{Design Monitoring Plan (Step 6)}

\section{Key Actions}

- Determine which parties (experts and stakeholders) will design the monitoring plan.

- Determine the type of monitoring suitable for each performance metric.

- Make an inventory of existing monitoring networks.

- Evaluate existing monitoring networks for gaps specific to the project.

- Determine what additional monitoring is needed (spatially and temporally).

- Establish data collection and data management protocols.

- Specify how monitoring data and information will be collected and shared. 
Monitoring is essential for AM as a source of data with which to measure progress toward accomplishing management objectives and to validate and calibrate numerical models. Or more simply put, AM is not possible without effective monitoring (CPRA 2017). Monitoring provides the data needed to fill known information gaps about uncertainties, demonstrate success, and provide lessons learned from the success or failure of a project that can be applied to both existing and future projects. Chapter 5 discusses how direct and indirect measurements are taken to assess feature performance levels, and Chapter 6 describes monitoring aspects that are critical to evaluating benefits delivered. All these monitoring aspects stress consideration of the dynamic nature of NNBF.

As noted in Step 3, it is important that the AM plan is budgeted for the life span of the feature or of the AM plan (because not all AM plans are needed to last the entire life cycle of the project). If critical uncertainties are resolved, the AM plan could be altered in response to these resolutions, or even possibly discontinued.

Once the performance metrics for objectives and critical uncertainties are identified, a monitoring design and plan can be developed. This monitoring plan must establish clear goals and objectives. The type of monitoring deployed depends on the performance metrics involved, the relevance of the performance metric to management decisions, the feasibility of collecting the information required, and the funding available to do so. Whether it is in situ monitoring, remote sensing, citizen science, or periodic measurement, there are four categories of monitoring that can be deployed (Murray and Marmorek 2003), as follows:

- Validation and research monitoring focuses on general understanding of the system to reduce scientific uncertainties directly related to the project.

- Implementation and compliance monitoring evaluates whether the project was constructed as intended, typically referred to as post-construction monitoring, and reduces implementation uncertainty.

- Effectiveness monitoring refers to monitoring to evaluate whether the management action had the expected effect and typically includes a comparison to baseline or reference data.

- Status and trend monitoring evaluates broader objectives that could be influenced by other external factors and could be paired with a causal relationship evaluation.

There is an important temporal aspect of implementing these different categories of monitoring for achieving respective goals and objectives. Monitoring also occurs in various stages of project development, as follows:

- Monitoring is conducted before construction (implementation) starts to establish baseline conditions for subsequent comparative purposes.

- Monitoring can also occur during construction and tie into AM that may modify the construction process (i.e., change design or technique during construction). 
- Post-construction (implementation and compliance) monitoring occurs immediately after construction is complete and typically focuses on whether the project was built as intended. If the project differs drastically from the original design, adjustments may be needed to achieve the expected performance outcomes.

- Long-term monitoring (appropriate to life span and objectives of the project) focuses on performance over time, benefits and impacts of the project, reduction of uncertainties, and provision of data to understand the influence of gradual natural deterioration and to test the precision of numerical models and improve accuracy of predictions over time.

- Event-based monitoring (e.g., data collected before and after a storm) can be important to understanding how the NNBF responded to the extreme event.

It is recommended to work with a range of different experts (e.g., academia, agencies, nongovernmental organizations, and stakeholders) to develop a monitoring plan that helps to assess the impacts of the NNBF project or feature from a range of different perspectives. Collaboration with stakeholders should be considered a two-way communication, where the monitoring data inform and engage local communities, partners, and funders on how the project works. Stakeholders can provide ecological knowledge from researchers or other professionals, or citizen science in which data are collected by (usually unpaid) citizens to inform the AM process. In some instances, the long-term monitoring may be transferred from the construction or funding agency to a local community. Involving these entities and stakeholders from the beginning can build ownership in the feature and avoid tensions when evaluating the results. Stakeholders who actively contribute to the results help to build a collaborative environment.

Formalizing the monitoring design should include an inventory of existing monitoring networks, such as water levels, wave characteristics, and meteorological data operating in the region or location of the project. If programmatic (strategic) AM efforts exist in the area, the data collected for this level of AM should also be evaluated. The existing networks should be evaluated for gaps specific to the project. Once the level of effort is known, the monitoring plan and budget can be developed. The sampling design can include the following:

- Statistical design or methodology

- Monitoring technologies and sampling schemes

- Data management equipment, software, standards, and protocols

- Communication protocols (how, where, and when data will be shared)

A statistical analysis, such as a power analysis, can be conducted to inform the spatial and temporal frequency needed to detect the level of change expected. A power analysis is usually conducted before the study to answer the question about how big of a sample size is required to achieve the desired results (Ellis 2010). The monitoring design must balance statistical power (scientific viability) with management considerations (budgets and decision time frame). 
Where feasible, reference sites can be integrated into a before-after-control-impact (BACI) design. Evaluating innovative monitoring technologies, such as digital ecological maps and the use of satellites or drones, can reduce costs while increasing the geographical scale of the monitoring area.

The level of community and stakeholder engagement (as discussed in Chapter 3 ) will shape development and execution of data sharing-related aspects. It is recommended to make monitoring data and the information and interpretation derived from them as easily accessible as possible (e.g., through apps and interactive websites; see Figure 7.8). Where applicable, data on the performance of international NNBF should also be included. For example, data collected from regular monitoring of creation and maintenance costs, particularly for wetlands, are necessary to fill crucial gaps in our knowledge of NNBF life-cycle costs (see Chapter 10).

Figure 7.8. Example of Citizen Beach Science

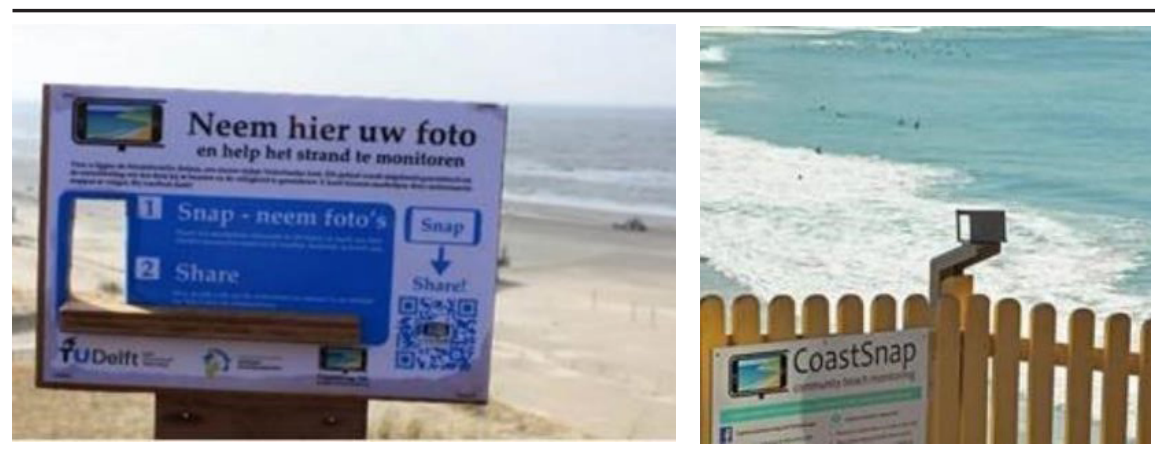

Source: Water Research Laboratory, University of New South Wales Sydney (environment.nsw.gov.au 2020)

Notes: The photograph on the left is a sign on the Hondsbossche and Pettemer Dunes (the Netherlands) that reads "Take your picture here and help us monitor the beach." The photograph on the right is of the CoastSnap beach monitoring.

\subsubsection{Plan for Data Synthesis and Set Decision Thresholds (Step 7)}

\section{Key Actions}

- Set performance benchmarks or thresholds for each metric by which an AM assessment would be triggered.

- Plan for the regular assessment of monitoring data.

- Use tools to integrate complex information and inform decisions.

- Establish clear plans and resources for monitoring data analyses and synthesis to support decision-making. 
Raw monitoring data must be reduced to decision-relevant information. Problems in this step have been a weakness in many AM plans. For example, monitoring data have been collected but not synthesized or evaluated in a way that informs future decision-making. Regular assessment of monitoring data should be part of the monitoring plan to include adequate funding for data synthesis, identification of who will conduct the assessment (internal or external experts), the time frame needed to inform decision-making (e.g., every year or every 5 years), and conditions for irregular assessments (i.e., storms). The data synthesis will compare the on-the-ground monitoring data to proposed benchmarks or thresholds for performance.

Setting benchmarks and thresholds can be based on some baseline historical condition, a desired range of environmental conditions (e.g., marsh elevation and water depth), or a maximum and minimum value of tolerance beyond which actions must be taken (risk tolerance). Defining thresholds can be a complex task, specifically in dynamic environments being affected by climate change. Thresholds should be science-based, statistically sound, and related to management actions and could be modified over time. These thresholds should be specific and delineated, such as the following simple examples:

- If natural recruitment does not achieve $X$ by year $Y$, then implement planting protocols.

- If restoration area falls below $X$ acres per hectare, then implement sediment renourishment protocols.

- If population density of specified bird species falls below $X$, evaluate habitat expansion alternatives.

The thresholds may be established through the use of decision-support tools (see the case study "Using Tools to Inform Adaptive Decisions [Okanagan River Basin, British Columbia, Canada]").

\section{N11)}

\section{CASE STUDY:}

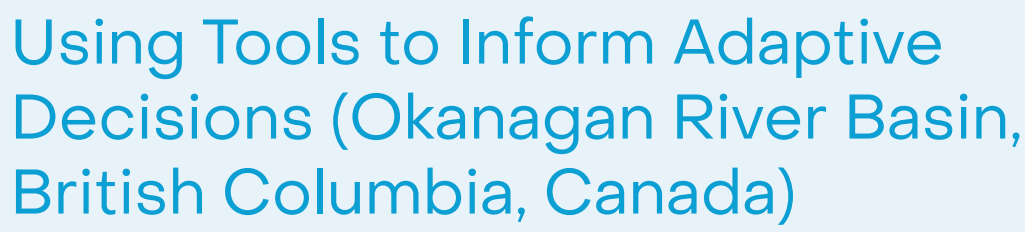

The Okanagan River Basin, in the State of Washington in the United States and the Canadian province of British Columbia, is the site of a system of dams and reservoirs managed for multiple objectives including flood protection, water use, fish habitat, recreation, and tourism. To better manage the uncertainty and natural variability 
of spring floods to meet multiple and sometimes competing objectives, managers use a Fish-Water Management Tool (Figure 7.9) to predict and analyze trade-offs in outcomes. The management tool incorporates real-time data and models, as well as thresholds for key performance metrics, to allow gaming or scenario analysis to occur rapidly and inform decision-making. Basic stop-light characterization of thresholds allows managers to quickly assess how various flow release strategies will meet or fail to meet the desired outcomes (Hyatt, Alexander, and Stockwell 2015).

\section{Figure 7.9. Okanagan Lake Fish-Water Management Tool Output Example}

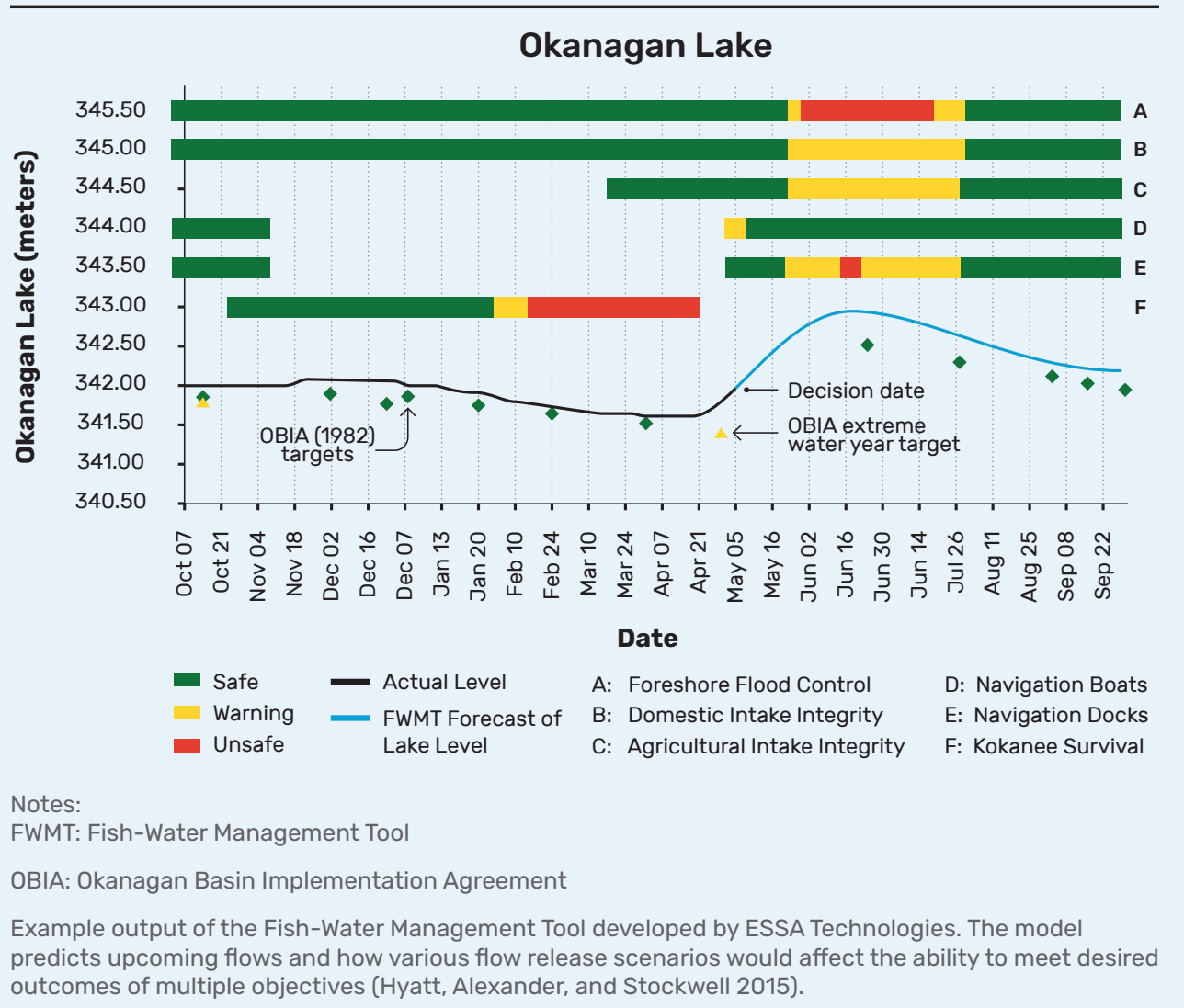




\subsubsection{Identify Possible Adaptive Actions (Step 8)}

\section{Key Actions}

- List potential adaptation actions that could be needed in the future.

- Assess whether adaptation actions are needed and at what phase of the framework.

- Establish connections between program- and project-scale decisions.

The regular synthesis of monitoring data should provide decision-makers and stakeholders with an indication of project performance relative to the established objectives. Typically, a list of potential adaptive actions will be developed during the project planning and engineering and design phases and included up front in the AM plan. If the systems do not perform as planned (i.e., a threshold is crossed), then change is initiated. Project managers or operators should evaluate each adaptive measure for its suitability to address the issue at hand. In some cases, conditions are unforeseen and require solutions that were not originally included in the AM plan. Flexibility and innovation are key to identifying the appropriate adaptive action. Although most adaptive measures are formulated to improve performance to address a lagging threshold value, it is also possible that project performance could exceed expectations and call for measures including expansion or replication.

Ideally, changes can be made to the project on the ground that improve its overall performance, but in some cases, the adaptation will occur in the Planning Phase for the next project (i.e., lessons learned on an earlier project are incorporated into the design of following projects to improve their performance). This can occur when the adaptive actions are too costly and not effective in reversing the threshold that was crossed. Where possible, funding should be set aside or designated for the implementation of cost-effective adaptive actions; however, this is a challenge for many agencies (discussed further in Section 7.4).

Regardless of the scale of system planning being used (large-scale or project-level, see Chapter 4), the planning process itself should be learning and improving over time, especially with the engagement of stakeholders. Large-scale system plans can be complex and intensive to develop; thus, there is a reluctance to revisit or adapt these types of plans over time. However, it is imperative in this drastically changing environment that large-scale system plans are updated regularly-intervals of 5 to 10 years are recommended (see the case study “The Evolution of Louisiana's Coastal Master Plan: An Example of a System-Scale (Programmatic and Strategic) Adaptive Plan"). This allows the planning process to incorporate new scientific understanding, changing stakeholder values, and updated objectives. This also allows the planning process to stay abreast of the latest on-the-ground conditions and best available science and to incorporate lessons learned from implemented projects. 
With large-scale system plans, projects may be selected for implementation but not funded for more than 10 years; thus, reassessing the on-the-ground conditions will ensure that the best project is selected when funding is secured.

Project-level plans can be adapted to lessons learned through previous planning processes. This learning can happen at any stage of the planning process-from project objectives, modeling assumptions, types of NNBF considered, and storm conditions. Stakeholder involvement during the planning process is a continuous learning experience in which managers and decision-makers should be experimenting with ways to better engage the public and learning what methods are most effective.

\subsubsection{Select Preferred Options (Step 9)}

\section{Key Action}

- Decide on the final monitoring plan, decision thresholds, and adaptive actions to be included in the AM plan, as well as the timeline for reassessment and future decision-making.

In the Decision-Making Phase (Step 6) of the NNBF project development framework, preferred NNBF options have been selected. Once the preferred NNBF options have been finalized, the final monitoring plan, decision thresholds, and preferred adaptive actions can be narrowed or adjusted to fit the preferred options. In addition, the future decision-making process and timelines can be defined to provide details on when and how often future decisions will be evaluated.

\subsubsection{Adapt during Design (Step 10)}

\section{Key Action}

- Incorporate lessons learned from previously designed similar projects into subsequent design modifications.

As the planning process improves over time by learning from experience, project design should, in turn, evolve to achieve the respective planning objectives. In broad terms, the civil engineering design practice is evolving from simplicity to complexity because, in the past, "most major civil investments were traditionally designed and implemented primarily in terms of single investments, for single purposes, on the basis of a single forecast of future events, and with a narrow focus on construction" (NRC 2004). As these design practices 
evolve, they are becoming more sophisticated, emphasizing consideration of a system-based approach versus that of just a single project and, increasingly, recognizing and addressing uncertainty. During the design process, engineers are constantly adapting as new information is provided about the on-the-ground conditions (see the case study "Thin-Layer Placement of Dredged Material on Wetlands Adaptive Designs [Ring Island, Avalon, and Fortescue, New Jersey, United States]"). This adaptation is especially pertinent to designs of NNBF that are implemented to deliver a range of diverse (single to multifunctional) benefits. Design optimization of these features involves the consideration and balancing of associated tradeoffs. The dynamic but flexible nature of NNBF also influences how adaptation during design is practiced. Design innovation, coupled with risk-informed decision-making in the context of the iterative AM plan, can be implemented to capitalize on the adoptability of NNBF because they can allow the opportunity to more readily (compared to structural measures) modify the design over time.

In particular, lessons learned from previously designed projects should be incorporated into subsequent design modifications (see the case study "Thin-Layer Placement of Dredged Material on Wetlands Adaptive Designs [Ring Island, Avalon, and Fortescue, New Jersey, United States]"). This could vary the timing of the AM monitoring. For instance, monitoring the design effectiveness of a project may not occur until right before the initiation of the next project to ensure lessons learned are incorporated into that project.

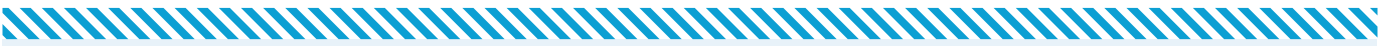

CASE STUDY:

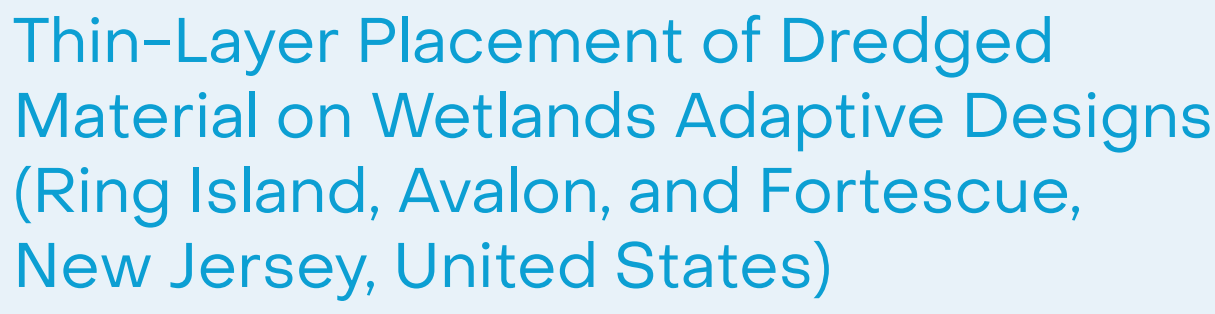

There has been increasing interest and effort recently in the United States in a sediment placement method called thin-layer placement (TLP; see Figure 7.10). TLP involves placing dredged sediments in thin layers to provide opportunities for sediment management, beneficial use of dredged material, and ecological enhancement. The application of thin layers has advantages over more traditional, thicker sediment placement in environments where thicker layers pose potential challenges to natural resources, infrastructure, navigation, or other assets. Various reports document the benefits of NNBF wetland TLP, including increased marsh 
elevation, improved soil stability, and enhancement of wetland functions while maintaining characteristic plant communities (DeLaune et al. 1990; Mendelssohn and Kuhn 2003). Interest in wetland TLP has increased, in part, due to wetland degradation from sea level rise, subsidence, and severe storms. The U.S. Army Corps of Engineers TLP website (erdc.dren.mil 2020) is a source of information, knowledge, and experience regarding sediment TLP.

Figure 7.10. Example of Thin-Layer Placement

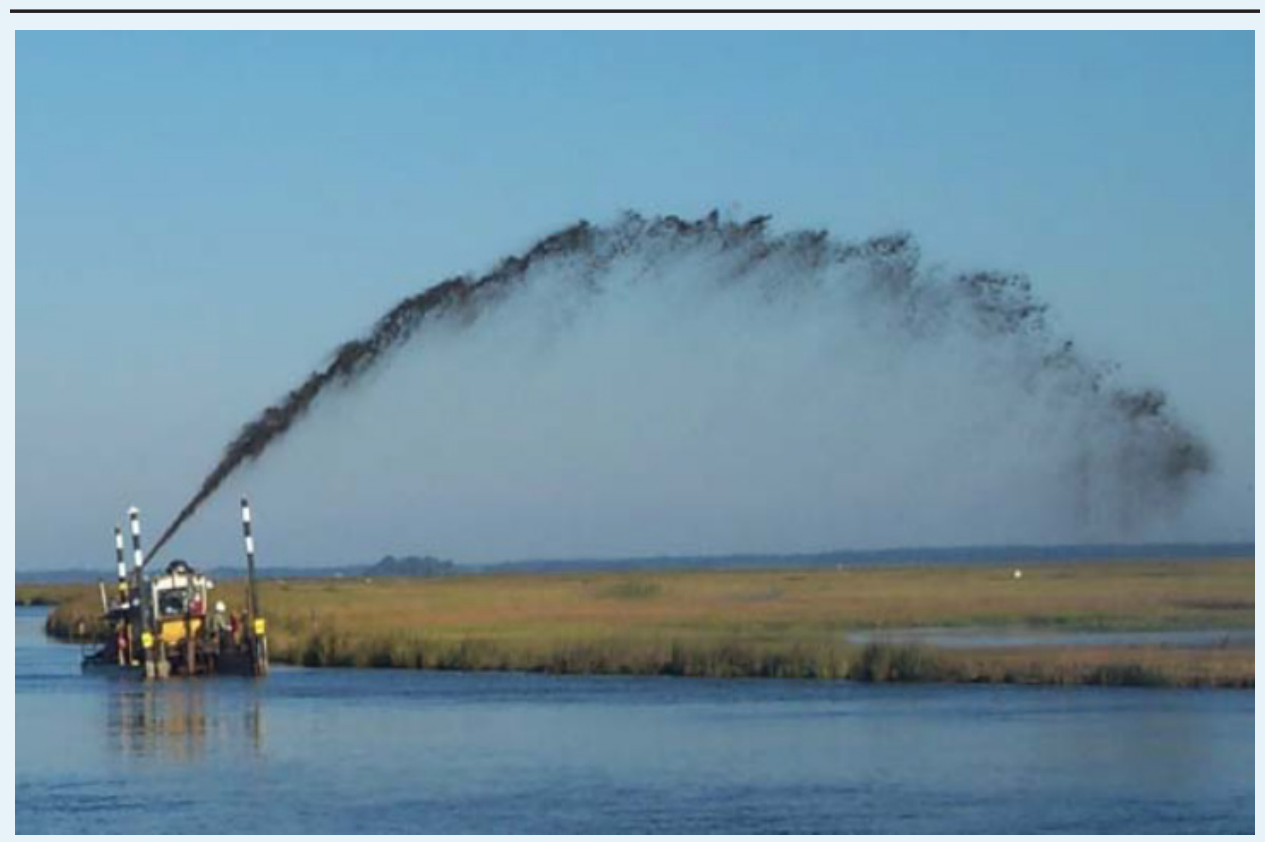

Note: This photograph is an example of a high-pressure TLP discharge.

Source: Courtesy of Bob Blama

The first documented TLP of dredged material in the United States occurred in the Louisiana wetlands in the late 1970s. Petroleum-related canals constructed with mechanical and hydraulic pipeline dredges since the late 1930s had created high "spoil banks" alongside the canals that were determined to cause adverse environmental and ecological impacts. During construction of the canal in the 1970s, the dredged material was sprayed from a high-pressure nozzle installed on the stern of the cutterhead suction pipeline dredge (similar to the dredge shown in Figure 7.10) to place sediment in thin layers, unconfined along the channel flanks. 
Although these types of projects were conducted several decades ago, most TLP projects today are conducted further into the wetlands-beyond the onboard, high-pressure spraying distance-and the engineering design and construction knowledge base is relatively limited. Through the use of AM, new techniques and experience are improving aspects of TLP, such as the design and construction of sediment containment structures and pipeline discharge placement methodologies to place dredged material at target elevations.

Between August 2014 and April 2017, three TLP projects were sequentially constructed at Ring Island in Middle Township, New Jersey; the Cape May Wetlands Wildlife Management Area in Avalon, New Jersey (Figures 7.11 and 7.12); and the Fortescue Wildlife Management Area in Fortescue, New Jersey. A large variety of stakeholders were involved with each project, but all three were fundamentally planned, designed, and constructed by the same project team that consisted of the New Jersey Department of Environmental Protection, U.S. Army Corps of Engineers Philadelphia District, the New Jersey Department of Transportation, and The Nature Conservancy.

These three projects provide an example of AM. Lessons learned by the team in earlier pilot projects were applied to these later projects to optimize design aspects, as follows:

- The lessons learned provided a better understanding of what the minimum practical sediment placement area (surface area and thickness of placed sediment) could be, with regard to dredge slurry (sediment and water) production rates, for the project to be constructible. As these projects progressed, an appreciation of the relative importance of design needs evolved (e.g., to more accurately measure the sediment volume holding capacities of wetland pannes and pools).

- As understanding of how coarse- and fine-grained sediment flowed and settled in the slurry matrix over the wetlands increased, the design of the containment structure used to keep sediment on the wetlands was modified to optimize retention while reducing cost. 
Figure 7.11. Avalon, New Jersey, Phase II Dredged Material Thin-Layer Placement Site with Coir Log Lateral Confinement

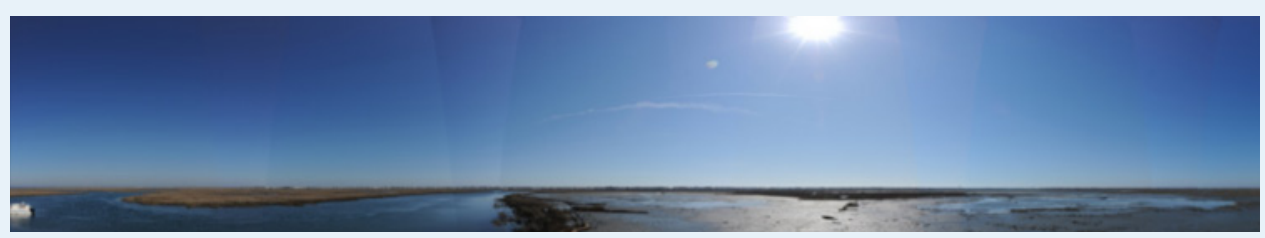

Source: Courtesy of Tim Welp, U.S. Army Corps of Engineers

Figure 7.12. Pipeline High-Pressure Discharge at Avalon, New Jersey, Thin-Layer Placement Project

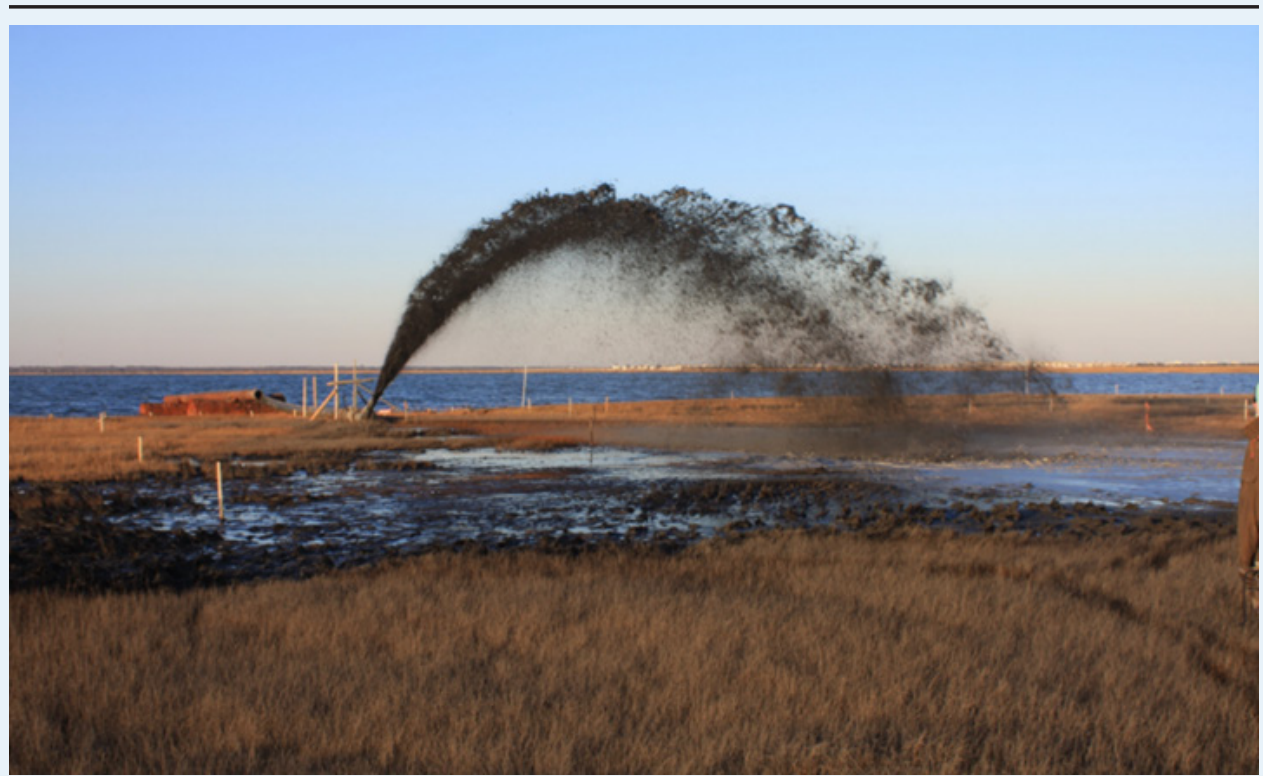

Source: Courtesy of Tim Welp, U.S. Army Corps of Engineers

The project team's report documents the lessons learned from implementing the three marsh enhancement and dredged material beneficial use pilot projects (The Nature Conservancy and New Jersey Department of Environmental Protection, forthcoming) that included planning, permitting, contracting, construction, and monitoring, in addition to design. 


\subsubsection{Adapt during Construction (Step 11)}

\section{Key Actions}

- Identify opportunities for a more proactive and collaborative approach to changes identified during construction.

- Develop a communication and data plan to support construction.

- Conduct regular surveys and inspections to collect data and have regular meetings with project team and contractor; adapt surveying and construction during construction phase.

AM during construction largely takes the form of real-time collaboration to respond to conditions encountered during construction operations. The degree to which AM can be implemented during construction will depend on project specifics, such as the type of NNBF being built, the spatial and temporal scales of its fabrication, and associated considerations that include project contracting and construction management practices. Manoliadis and Oustadakis (2014) note that because construction project management issues continually change over time, an adaptive process is needed to provide opportunities for a more proactive and collaborative approach during changes caused by construction problems (i.e., field changes and delays).

With larger, longer term NNBF construction projects, more extensive AM practices might be applied. An example of adaptation during construction is the Rijkswaterstaat Ameland Ebb-Tidal Delta Nourishment Project (see the case study "Adaptation during Construction [the Netherlands]"). The key to prudent adaptation is to have regular surveys or inspections to collect data, to have regular meetings with the project team and contractor, and to adapt surveying and construction during the construction phase.

Because AM is based on a learning process, it improves long-run management outcomes, but a challenge in effectively using it lies in finding the correct balance between gaining knowledge to improve management in the future and achieving the best short-term outcome based on current knowledge (Allan and Stankey 2009). This balancing act can also be applied to the NNBF construction phase and associated considerations previously listed.

Construction teams should incorporate lessons learned from past projects. For small, short-term NNBF construction projects, implementation of AM might just consist of documenting how the project was constructed. Lessons learned during construction should be documented and made accessible so that this knowledge can be used to optimize the next project's design, construction, and subsequent system benefits. When applicable, 
accurate as-built drawings should be collected upon completion of a construction project to document any changes made during construction that deviated from the original design. As-built drawings (also known as record drawings) include all changes made in the contract specifications and working drawings during the construction process and show the measured dimensions, geometry, and location of all work components completed under the contract. As-built drawings help define the baseline conditions that are later used as the basis for comparison with data collected by subsequent monitoring efforts.

\section{N11}

\section{CASE STUDY:}

\section{Adaptation during Construction (the Netherlands)}

The Dutch Wadden Sea is separated from the North Sea by barrier islands. Exchange of water and sediments takes place through six tidal inlets. Due to closure works in the past century (Afsluitdijk) and ongoing sea-level rise, the Wadden Sea Basin is a sediment depositional system.

It is estimated that over the last 80 years, the Wadden Sea Basin has gained approximately 600 million cubic meters of sediment. This process has diminished the volume of sand in respective ebb-tidal deltas, which, in turn, has decreased the level of flood protection the Wadden Islands provide to the Netherlands. In a nourishment pilot system initiated in 2018, sand dredged from the deeper part of the North Sea (at the 20-meter depth contour) was placed closer to shore to restore the sediment budget in the ebb-tidal delta system (Figure 7.13).

Figure 7.13. Ebb-Tidal Delta Inlet of the Dutch Wadden Sea

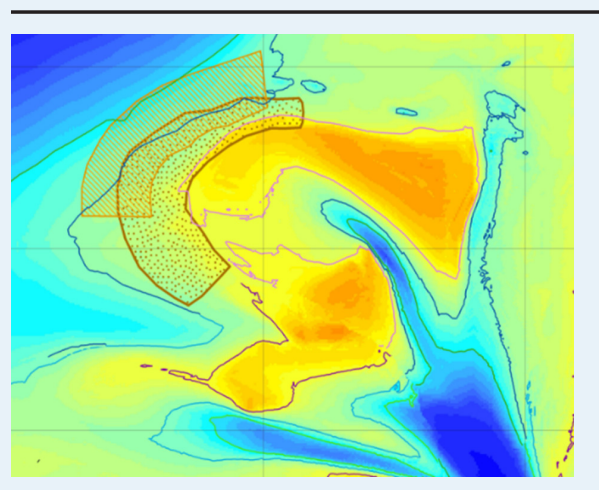

Note: The graphic shows the ebb-tidal delta inlet of the Dutch Wadden Sea. The dotted area is the initial design of sand nourishment, and the striped area is the adapted design during construction.

Source: Courtesy of Harry de Looff, Rijkswaterstaat 


\section{Design of Nourishment}

The initial plan was to place 5 million cubic meters of sand directly seaward of the ebb chute of the ebb-tidal delta (dotted area in Figure 7.13) at a depth of -5 to -8 meters mean sea level. But during the early stages of construction, two circumstances were encountered that required a significant change in the original plan. The following two alterations were implemented, leading to an altered design (striped area in Figure 7.13):

- An ecological survey showed that the area northeast of the original nourishment area was a nursery for juvenile sand eels, so the nourishment area was shifted westward. This was considered a change in design.

- A large flat area at approximately -6.5 meters mean sea level was encountered in the southwest portion of the original nourishment area. Ground seas and swells meant sand could not be placed there safely, so the design was shifted to the northwest.

\section{Survey during Construction}

A bathymetric survey was conducted every 6 weeks during the 10 -month construction phase. Following each survey, the contractor and Rijkswaterstaat met to evaluate the different maps and discuss issues in execution. Aspects such as where to start, how to proceed, and how to finish were discussed and altered in these meetings.

\subsubsection{Adapt Post-Construction (Step 12)}

\section{Key Actions}

- Provide for periodic monitoring and evaluation of results.

- Implement feedback loop of framework flowchart.

Following completion of construction, monitoring will be conducted in accordance with the AM plan to reduce uncertainties and to gain information to optimize subsequent future actions, including project design, management actions, testing of alternative hypotheses, and model development. The return (feedback) loop from the Operations Phase to the Planning Phase in the NNBF project development framework flowchart (Chapter 2, Figure 2.1) 
illustrates this iterative process that is so vital for maximizing the benefits of AM. It is critical that this feedback be efficient and effective. The post-construction monitoring effort will not necessarily be evenly distributed over time because the level of effort will depend on the specific performance metrics being measured and on the management decisions made after evaluating the results of post-construction monitoring.

\section{4 | Gaps and Future Directions}

A number of gaps exist that can pose challenges when implementing AM, which has led to some successes and some failures. Some of the overarching challenges are AM definitions and frameworks, leadership and stakeholder acceptance, shifting baselines, risk management (including regulatory constraints and desire for front-loaded analysis), and funding.

\subsubsection{Adaptive Management Definitions and Frameworks}

As previously described, the various and widely ranging definitions and applications of AM have created considerable ambiguity about what $A M$ is and how it should be implemented. Effective and efficient communications among all project stakeholders is critical to eliminate or reduce this ambiguity.

\subsubsection{Leadership and Stakeholder Acceptance}

In general, decision-makers and stakeholders seek certainty in achieving desired project performance requirements. A major objective of AM is to enhance scientific and FRM knowledge to reduce uncertainties. Risk management involves advance identification and analysis of potential risks so that actions can be implemented to reduce it, but the degree of risk accepted by organizations can vary significantly. This degree of accepted risk (or, conversely, degree of risk aversion) can depend on a variety of internal and external factors, including corporate mindset; organizational structure; budget and financial issues; cultural, political, and governance norms; litigation considerations; and environmental regulations (Doremus et al. 2011; Murray and Marmorek 2003). Changes may be required to one or more factors before meaningful AM can be implemented. Management characteristics that can indicate an organization's potential to successfully implement $A M$ as a mechanism for risk management include its history of meaningful collaboration with stakeholders, cost sharing of these collaborative efforts, and a demonstrated commitment to evaluation and scientific rigor (Williams, Szaro, and Shapiro 2009; Cosens et al. 2017). 


\subsubsection{Shifting Baselines}

Historical conditions and trends in natural variability, such as in freshwater flows, may not capture current or future conditions of a system. In particular, large projects that influence the natural environment in complex ways at a landscape scale, such as water resource projects, can benefit from the use of AM strategies as a way to adjust actions based on the conditions experienced at any given point in time (Thom et al. 2016; Fujitano et al. 2017). Natural variability poses challenges to the planning and implementation of natural resource management, including the regulatory and permitting decision-making processes that typically rely on reasonable estimates of future conditions. Many agencies do not have clear guidance on how to incorporate changing baselines into their planning and implementation processes, thus leading to an underrepresentation of uncertainties and the future without action conditions. In some instances, laws and guidance are written to maintain a current condition or achieve some historical condition, which may not be possible in all cases. There is a growing need for flexibility in our laws and policy guidance that will require policy-makers and lawmakers to have an appreciation for the shifting baseline.

\subsubsection{Risk Management}

Agencies tend to front-load project data analysis, which does not easily facilitate the integration of AM into the process. Front-loaded analysis refers to conducting all the analysis during the planning of a project with little or no analysis after the project is constructed. This is evident in how many agencies may construct projects and walk away. There are three main reasons an agency needs to complete all analysis before construction: (1) aversion to the risks of project failures or litigation, (2) lack of long-term funding, and (3) regulatory compliance. In a front-loaded analysis, models or other analytical tools are used to estimate performance while the ability to influence changes in a design is relatively high and the cost to make those changes is relatively low. But whether those anticipated benefits were ever achieved or whether adjustments could have been made along the way is rarely documented. Given variations in the performance of different NNBF over time and the fact that they can lend themselves to a higher degree of flexibility compared to traditional structural projects, front-loaded analysis does not provide the implementation agency or stakeholders with information on how the project performed over time, specifically in comparison to model predictions of outcomes.

Regulatory compliance tends to include inherently front-loaded statutes that place restrictions on potentially environmentally harmful actions with a deterministic and static view of future conditions. Agencies are reluctant to leave themselves vulnerable to a reassessment of the regulatory requirements (Doremus et al. 2011; Murray and Marmorek 2003). One solution could be to make the AM process an enforceable action of the permit or regulatory process, thus requiring agencies to designate funds for future needs. 


\subsubsection{Funding}

Step 3 of the Scoping Phase of the project development framework (Chapter 2) discusses the importance of establishing the funding strategy and estimating project cost to include identification of funding mechanisms and preliminary cost estimates for NNBF projects. These planning and engineering costs are required to arrive at a selected plan that includes monitoring and AM. Schrass and Mehta (2017) reported that stakeholders from various coastal states in the United States suggested that the creation of statewide programs such as low-interest loans, tax credits, or cost sharing to encourage the adoption of nature-based approaches to coastal resilience would reduce lifetime project costs and "incentivize private landowners to adopt NNBF practices." The World Association for Waterborne Transport Infrastructure (PIANC 2021) Working Group 230 is currently preparing a document titled "How to Attract Green Funding for Nature-Based Navigation Infrastructure" that will describe options and practical steps to take to attract funding from institutional investors for nature-based infrastructure projects.

Although many NNBF projects may include funding to monitor project performance for a set number of years, they are unlikely to include funding to implement adaptive actions. Funding for data sharing and universal monitoring protocols is also lacking. Identification of long-term funding streams for AM and adaptive actions is needed. One option could be to have an agency-wide rotating fund that could be applied for, depending on the results of the AM analysis, to increase project performance.

\section{5 | References}

Adamcik, R. S., E. S. Bellantoni, D. C. DeLong Jr., J. H. Schomaker, D. B. Hamilton, M. K. Lauban, and R. L. Schroeder. 2004. Writing Refuge Management Goals and Objectives: A Handbook. Washington, DC: U.S. Fish and Wildlife Service.

Allan, C., and G. Stankey. 2009. Adaptive Environmental Management: A Practitioner's Guide. Dordrecht, NL: Springer.

AMWG (Glen Canyon Dam Adaptive Management Work Group). 2011. Operating Procedures. Phoenix, AZ: AMWG. https://usbr.gov/uc/progact/amp/pdfs/OpProced020911.pdf.

Berkes, F., and H. Ross. 2013. "Community Resilience: Toward an Integrated Approach." Society and Natural Resources 26 (1): 5-20.

Canter, L. W., and S. F. Atkinson. 2010. "Multiple Uses of Indicators and Indices in Cumulative Effects Assessment and Management." Environmental Impact Assessment Review 31 (5): 491-501.

Chades, I., S. Nicol, T. M. Rout, M. Peron, Y. Dujardin, J. B. Pichancourt, A. Hastings, and C. Hauser. 2017. "Optimization Methods to Solve Adaptive Management Problems." Theoretical Ecology 10 (1): 1-20. 
Cosens, B. A., R. K. Craig, S. L. Hirsch, C. A. T. Arnold, M. H. Benson, D. A. DeCaro, A. S. Garmestani, H. Gosnell, J. B. Ruhl, and E. Schlager. 2017. “The Role of Law in Adaptive Governance." Ecology and Society 22 (1): 30.

CPRA (Coastal Protection and Restoration Authority of Louisiana). 2017. "Appendix F: Adaptive Management." In Louisiana's Comprehensive Master Plan for a Sustainable Coast. Baton Rouge, LA: Coastal Protection and Restoration Authority of Louisiana. June 2, 2017.

Craig, R. K., and J. B. Ruhl. 2014. “Designing Administrative Law for Adaptive Management." Vanderbilt Law Review 67 (1): 1-87. https://ssrn.com/abstract=2222009.

DeLaune, R. D., R. P. Gambrell, J. H. Pardue, and W. H. Patrick. 1990. "Fate and Effect of Petroleum Hydrocarbons and Toxic Organics in Louisiana Coastal Environments." Estuaries 13: 72-80. doi:10.2307/1351434.

Doremus, H., W. L. Andreen, A. Camacho, D. A. Faber, R. L. Glicksam, D. D. Goble, B. C. Karkkainen, et al. 2011. Making Good Use of Adaptive Management. Center for Progressive Reform White Paper No. 1104. Washington, DC: Center for Progressive Reform.

Ellis, P. D. 2010. The Essential Guide to Effect Sizes: Statistical Power, Meta-Analysis, and the Interpretation of Research Results. New York: Cambridge University Press.

environment.nsw.gov.au. 2020. CoastSnap Beach Monitoring. NSW Department of Planning, Industry and Environment. https://www.environment.nsw.gov.au/research-andpublications/your-research/citizen-science/get-involved/coastsnap.

erdc.dren.mil. 2020. Thin Layer Placement. Thin-Layer Placement of Dredged Material. https://tlp.el.erdc.dren.mil/.

Fischenich, C. J., K. E. Buenau, J. L. Bonneau, C. A. Fleming, D. R. Marmorek, M. A. Nelitz, C. L. Murray, B. O. Ma, G. Long, and C. J. Schwarz. 2018. Science and Adaptive Management Plan: Missouri River Recovery Program. Technical Report TR-18-XX. Vicksburg, MS: U.S. Army Engineer Research and Development Center Environmental Laboratory. https://usace.contentdm.oclc.org/utils/getfile/collection/p16021coll7/id/8070.

Fujitani, M., A. McFall, C. Randler, and R. Arlinghaus. 2017. "Participatory Adaptive Management Leads to Environmental Learning Outcomes Extending Beyond the Sphere of Science." Science Advances 3 (6): e1602516.

Gold, B. 2006. "Active vs. Passive Adaptive Management." Adaptive Management: Summer Solstice IV (2). https://www.biohabitats.com/newsletter/adaptive-management-2/ active-vs-passive-adaptive-management/.

Goulburn Broken Catchment Management Authority. 2013. Goulburn Broken Regional Catchment Strategy 2013-2019. Victoria, AU: Goulburn Broken Catchment Management Authority.

Gregory, R., D. Ohlson, and J. Arvai. 2006. “Deconstructing Adaptive Management: Criteria for Applications to Environmental Management." Ecological Applications 16 (6): 24112425. 
Greig, L. A., D. R. Marmorek, C. Murray, and D. C. E. Robinson. 2013. “Insight into Enabling Adaptive Management." Ecology and Society 18 (3): 24.

Hart, S., R. Glicksman, and N. P. Snider. 2018. Adaptive Management and NEPA in the Courts. https://www.edf.org/sites/default/files/documents/Case\%20Law\%20Review\%20 of\%20AM\%20and\%20NEPA\%20Final\%20Memo\%2003-26-18.pdf.

Holling, C. S, ed. 1978. Adaptive Environmental Assessment and Management. Chichester, UK: John Wiley and Sons.

Hyatt, K. D., C. A. Alexander, and M. M. Stockwell. 2015. “A Decision Support System for Improving 'Fish Friendly' Flow Compliance in the Regulated Okanagan Lake and River System of British Columbia." Canadian Water Resources Journal 40 (1): 87-110.

Manoliadis, O., and D. Oustadakis. 2014. "Application of Adaptive Process in Construction Project Management." Paper presented at the 9th MIBES International Conference, Thessaloniki, Greece.

McConnaha, W. E., and P. J. Paquet. 1996. "Adaptive Strategies for the Management of Ecosystems: The Columbia River Experience." American Fisheries Science Symposium 16: $410-421$.

McFadden, J. E., T. L. Hiller, and A. J. Tyre. 2011. “Evaluating the Efficacy of Adaptive Management Approaches: Is There a Formula for Success?" Journal of Environmental Management 92 (5): 1354-1359.

Mendelssohn, I. A., and N. L. Kuhn. 2003. "Sediment Subsidy: Effects on Soil-Plant Responses in a Rapidly Submerging Coastal Salt Marsh." Ecological Engineering 21 (2-3): 115-128.

mississippiriverdelta.org. 2019. The Impacts of the Mississippi River on the Gulf of Mexico Ecosystem. Restore: The Mississippi River Delta. http://mississippiriverdelta.org/ learning/impacts-of-the-mississippi-river/.

Murray, C., and D. Marmorek. 2003. "Adaptive Management: A Science-Based Approach to Managing Ecosystems in the Face of Uncertainty." Paper presented at the Fifth International Conference on Science and Management of Protected Areas: Making Ecosystem Based Management Work, Victoria, BC, May 2003.

NRC (National Research Council). 2004. Adaptive Management for Water Resources Project Planning. Washington, DC: National Academies Press.

PIANC (The World Association for Waterborne Transport Infrastructure). 2021. "How to Attract Green Funding for Nature-Based Navigation Infrastructure." EnviCom 230 Working Group Terms of Reference. https://www.pianc.org/uploads/files/EnviCom/ToR/ToREnviCom-WG-230-How-to-Attract-Green-Funding-for-Nature-Based-NavigationInfrastructure.pdf.

Pickett, S. T., J. Kolasa, and C. G. Jones. 1994. Ecological Understanding: The Nature of Theory and the Theory of Nature. San Diego, CA: Academic Press. 
Rist, L., A. Felton, L. Samuelsson, C. Sandström, and O. Rosvall. 2013. "A New Paradigm for Adaptive Management." Ecology and Society 18 (4): 63.

Rist, L., B. M. Campbell, and P. Frost. 2012. "Adaptive Management: Where Are We Now?" Environmental Conservation 40 (1): 5-18.

Ruhl, J. B., and R. L. Fischman. 2010. "Adaptive Management in the Courts." Minnesota Law Review 139: 424-484.

Schrass, K. and A. V. Mehta. 2017. Improved Use and Understanding of NNBF in the MidAtlantic. Annapolis, MD: National Wildlife Federation. https://www.midatlanticocean.org/wpcontent/uploads/2017/03/Improved-Use-and-Understanding-of-NNBF-in-the-MidAtlantic.pdf.

Smith, C. B. 2011. "Adaptive Management on the Central Platte River - Science, Engineering and Decision Analysis to Assist in the Recovery of Four Species." Journal of Environmental Management 92 (5): 1414-1419.

Stankey, G. H., R. N. Clark, and B. T. Bormann. 2005. Adaptive Management of Natural Resource: Theory, Concepts, and Management Institutions. Washington, DC: U.S. Department of Agriculture.

The Nature Conservancy and New Jersey Department of Environmental Protection. Forthcoming. Beneficial Use of Dredged Material to Enhance Salt Marsh Habitat in New Jersey: Project Summary and Lessons Learned on Project Development and Implementation.

Thom, R., T. St. Clair, R. Burns, and M. Anderson. 2016. "Adaptive Management of Large Aquatic Ecosystem Recovery Programs in the United States." Journal of Environmental Management 183 (2): 424-430.

USBR (U.S. Bureau of Reclamation). 2017. Glen Canyon Dam Adaptive Management Work Group Charter. Washington, DC: U.S. Department of the Interior, Bureau of Reclamation. https://www.usbr.gov/uc/progact/amp/pdfs/20190916-AMWGCharter-508-UCRO. pdf.

usbr.gov. 2020. Glen Canyon Dam Adaptive Management Program. Bureau of Reclamation. https://usbr.gov/uc/progact/amp/index.html.

Walters, C. J., and C. S. Holling. 1990. “Large-Scale Management Experiments and Learning by Doing." Ecology 71: 2060-2068.

Williams, B. K. 2011. "Adaptive Management of Natural Resources: Framework and Issues." Journal of Environmental Management 92 (5): 1346-1353.

Williams, B. K., and E. D. Brown. 2014. "Adaptive Management: From More Talk to Real Action." Environmental Management 53 (2): 465-479.

Williams, B. K., R. C. Szaro, and C. D. Shapiro. 2009. Adaptive Management: the U.S. Department of the Interior Technical Guide. Washington, DC: U.S. Department of the Interior. 


\section{Acknowledgments}

\section{Lead Authors}

Harry de Looff, Rijkswaterstaat, the Netherlands

Tim Welp, U.S. Army Corps of Engineers, United States

\section{Co-Authors}

Natalie Snider, Environmental Defense Fund, United States

Rinse Wilmink, Rijkswaterstaat, the Netherlands

\section{Contributors}

Stan Rogers, National Oceanic and Atmospheric Administration, United States

David M. Kidwell, National Oceanic and Atmospheric Administration, United States 

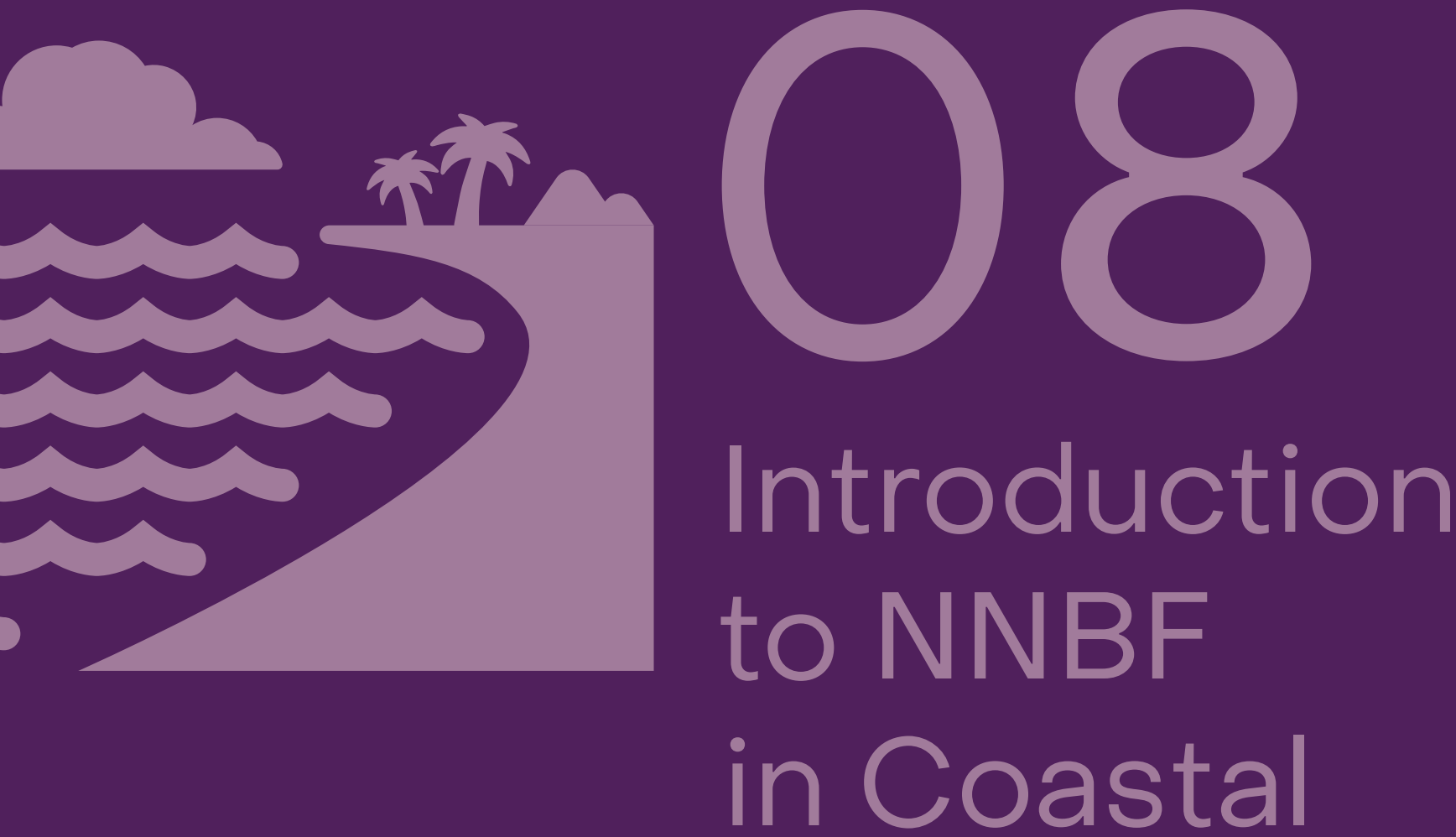

Systems

\section{Suggested Citation:}

Simm, J. D. 2021. "Chapter 8: Introduction to NNBF in Coastal Systems." In International Guidelines on Natural and Nature-Based Features for Flood Risk Management. Edited by T. S. Bridges, J. K. King, J. D. Simm, M. W. Beck, G. Collins, Q. Lodder, and R. K. Mohan Vicksburg, MS: U.S. Army Engineer Research and Development Center.

Full acknowledgments appear at the end of this chapter. 


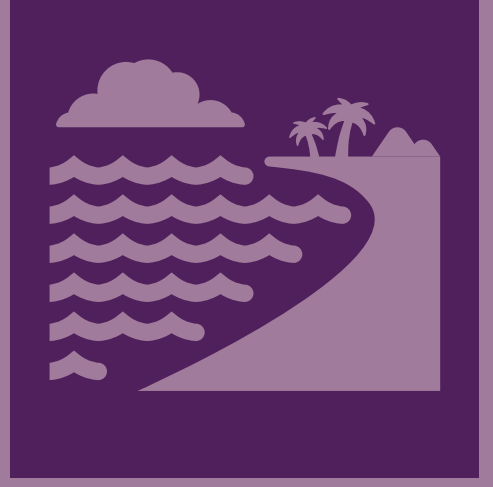

\section{Introduction}

This chapter provides a brief overview of the use of natural and nature-based features (NNBF) in a coastal context and serves as an introduction to the coastal applications of NNBF (including open coast and estuarine environments) discussed in Chapters 8 to 14.

Coastal NNBF encompass a variety of approaches, including the creation or re-creation of natural habitats (e.g., salt marshes, mangrove forests, reefs, beaches, and dunes), the enhancement of existing habitats (e.g., foreshore recharge of beaches), the use of more-organic materials for structures (e.g., wood rather than stone), and the ecological enhancement of existing hard infrastructure (e.g., the creation of rock pools within seawalls or the use of textured concrete to improve colonization by marine organisms). Coastal NNBF elements can also be combined with hard structures in a multilayered approach to flood risk management (FRM; e.g., foreshore recharge or marsh restoration combined with levees).

Coastal NNBF deliver FRM benefits in various ways, including the following:

- Attenuate the energy, and height, of incoming waves

- Attenuate storm surge water levels along the shoreline

- Provide storage of floodwater in the upper tidal reaches of estuaries

- Reduce erosion of sediments and soils

- Attract and stabilize sediments

- Attract and sustain flora and fauna, which can stabilize structures such as dikes 


\section{1 | Context for the Use of NNBF in the Coastal Zone}

The coastal zone constitutes only 3\% of the Earth's surface, but it contains a disproportionately large amount of its assets (Schultz 2001; Huntington, Burgess, and Townend 2002). Coastal zones accommodate $60 \%$ of the world's population, a figure expected to increase to $80 \%$ by 2050 . Two-thirds of the world's cities with populations of more than 1.6 million are found in coastal areas. The coastal zone contains ports and harbors for international trade and a major portion of the world's prime agricultural land, together accounting for $25 \%$ of global primary productivity. Coastal areas have great ecological value, offer recreation and tourism value, provide habitat for many endangered species, and are the source of $90 \%$ of the world's catch of fish (Park, Simm, and Ritzema 2009).

Due to the large amount of assets in the coastal zone, average global flood losses in 2005 were estimated to be approximately $\$ 6$ billion U.S. dollars (USD) and are estimated to increase to USD $\$ 52$ billion by 2050 with projected socioeconomic change alone. Even if adaptation investments maintain constant flood probability, subsidence and sea-level rise are projected to increase annual global flood losses to between USD\$60 billion and USD\$63 billion in 2050 (Hallegatte et al. 2013).

Key considerations for the development of FRM systems (structural, nonstructural, and NNBF) within the coastal zone include the following:

- The wider context for FRM. There is a need to support and manage the coastal landscape that provides the foundation for FRM. This landscape physically provides a risk mitigation function in its own right, supports the maintenance of structural measures, or limits the impact of waves or storm surge on those measures. Management of the associated sediment and ecology should reflect the relevant ecological or sediment system (see Chapter 4), commonly divided for the purposes of management and analysis into a nested or hierarchical set of units. For example, when considering coastal morphology, the concept of coastal sediment cells and subcells may be used (see Motyka and Brampton 1993 and Pontee and Parsons 2010 for examples from the United Kingdom). These cells are units of coastline within which the natural processes are relatively self-confined and there are distinct inputs (sources), throughputs (sediment transport), and outputs (sinks or stores) of noncohesive sediment.

- Cross-shore focus. The immediate focus of FRM tends to be either side of the coastline, normally defined in relation to mean high water level, with a concern to limit the risk to the people and property in the hinterland from flooding and coastal erosion. This often involves maintenance of an FRM system that could either be a single-line system (e.g., a wall or a levee) or a multizoned, cross-shore system with both structural and NNBF elements. 
- Management considerations. The coastal environment is subject to continual change, which may be cyclical or continuous, including, in particular, the following:

- Wave and water level forcing are known to be nonstationary (e.g., relative sea-level rise and fall, changes in storminess).

- Profile and condition of the defense line may deteriorate or improve.

- Number of people and amount of development of property behind the defense line are frequently growing.

In addition, common activities to maintain the FRM system in a particular location, rather than allow natural rollback of the morphological and ecological system, frequently lead to compression of the zone seaward of the defense line, often described as coastal squeeze.

\section{2 | Identifying Appropriate Locations for NNBF and Associated Longshore Alignment of the Risk Management Interventions}

Chapters 9 to 14 examine a range of possible responses in relation to the longshore alignment of the risk management interventions. The starting point for this thinking follows the commonly accepted idea of deciding whether to advance the line, hold the line, or retreat, rollback, or managed realignment from the current alignment of structural measures (Nicholls et al. 2008; Linham and Nicholls 2012; Wong et al. 2014) as opposed to policies relating to wider coastal management.

\subsubsection{Advance the Line}

Advance the line involves creating new land by building seaward or upward. This may involve combinations of the following activities:

- Land reclamation above sea level by land filling with pumped sand or other fill material or by retaining beach sediment by wave- or beach-control structures

- Planting vegetation to support natural accretion of land

- Surrounding low areas with levees, termed polderization, which also involves a drainage and possibly a pumping system 


\subsubsection{Hold the Line}

Hold the line involves improving the quality of the structural measures or raising their crest elevation or cross-shore profile to maintain or improve the standard of protection.

\subsubsection{Retreat, Rollback, or Managed Realignment}

Retreat, rollback, or managed realignment involves moving the alignment of the structural measures backward or removing them entirely in the case of retreat to high-ground measures. The drivers behind such a change may be a combination of managing the increased forcing on the structural measures and creating or providing substitute intertidal habitat.

This alignment of structural measures has in the past been described as the defense line, a line commonly associated with the seaward alignment of the crest of the measures on artificially defended coasts such as those found widely in northwest Europe. With internationally widespread moves away from flood defense and toward FRM and the need to apply this thinking on more natural and undefended coasts, the use of the term defense line is best avoided. There is no internationally accepted alternative terminology, but a working definition must relate to the crest alignment of the principal measure, whether that principal measure is structural or NNBF. Here, the principal measure is understood to be that measure that provides the physical method of last resort or backstop during the more severe events.

Coastal NNBF can be used in all these contexts, either as the principal measure or as a supporting measure (most likely located seaward of the principal measure). For example, beach-dune systems are accepted as principal measures in their own right, being able to directly deliver a standard of protection that can be estimated in advance. Other measures may be more suitable for use as supporting measures (e.g., in combination with levees and seawalls, a coastal strategy often referred to as multiple lines of defense). For example, wetlands or reefs are able to reduce the energy of incoming waves, but they may still require a conventional principal measure such as a levee or floodwall to deliver the desired level of flood risk reduction.

Chapters 9 to 14 discuss the implications of the alternative alignment policies discussed previously for the use of NNBF as a principal measure or as a supporting measure in a multilayered system. 


\section{3 | NNBF Geometry and Structure}

\subsubsection{NNBF Structural Profile}

To deliver functionality in relation to the purposes listed in the first section of this chapter, coastal NNBF require an appropriate cross-shore profile in terms of crest level and cross section and in terms of roughness. Both are associated with the capacity of NNBF to absorb storm surge and wave energy. Any design or assessment of the profile or roughness needs to take into account how this may change with time due to morphological change (erosion or accretion) or the growth and decay of vegetation.

\subsubsection{NNBF Resilience and Sustainability}

Any design or assessment of NNBF must also consider their resilience (especially functional robustness and speed of recovery) given the effect of the biophysico-chemical environment in which they are situated. Allowance is required for both short-term extreme events (storms) and chronic changes in the environment (e.g., mean sea-level rise or changes in salinity or temperature). NNBF that rely on sediment must consider the sustainability of maintaining sufficient quantities of material via either natural morphological processes or artificial importation (e.g., beach nourishment). NNBF that rely on vegetation must consider the sustainability of the ecological system given the various physical, temperature, and water quality stressors. In the right environment, coastal NNBF have the potential to be self-sustaining; however, their performance may take some time to mature, and they may be vulnerable to damage by extreme events while maturing. Even when they are mature, it may be necessary to assist natural healing processes by suitable maintenance and repair.

\section{4 | Success Factors for Coastal NNBF}

The key success factors for coastal NNBF used for FRM include the following:

- Raising the cross-shore profile and offering greater frictional resistance to the movement of water, both of which can reduce waves and water levels. Reductions depend on a number of factors such as topography, sediment and vegetation characteristics, and the characteristics of the incoming events (e.g., water level, wave height, and wave period). Reducing water levels requires more extensive widths than reduction of waves. Any cross-shore adjustments should consider combining NNBF approaches with other structural measures, especially when considering flood and coastal erosion risk for urban environments. 
- Making use of the extensive experience in the restoration of habitats gained worldwide over the past few decades, including conservation of existing habitats, restoration of degrading or degraded habitats, or creation of new habitats. In this regard, it will be important to place coastal NNBF within regional contexts or settings and to mimic any available natural analogs (e.g., as determined by tidal range, foreshore gradients, sediment supply, or temperature climate).

- Planning for NNBF to be self-sustaining, given the physical environment, available sediment supply, and ecological setting, but recognizing the need for maintenance and adaptive management especially in the early years while the NNBF system is becoming established.

- Making use of the additional value offered by NNBF in terms of multifunctional co-benefits when compared with conventional structural and nonstructural measures.

- Recognizing the practical limits to facilitating NNBF processes within the reality of a coastline that is already engineered. For example, NNBF may well be able to display desired characteristics of recoverability to storms and adaptability to sea-level rise following a disturbance. But recovery or adaptation may only be able to take place if there are appropriate sediment supplies and sufficient space (e.g., for gravel or dune barriers to move landward while retaining their longshore integrity).

\section{5 | Measures Covered in the Coastal Section of These NNBF Guidelines}

The following coastal NNBF are discussed in the following chapters:

- Beaches and dunes (Chapter 9)

- Coastal wetlands (Chapter 10)

- Islands (Chapter 11)

- Reefs (Chapter 12)

- Submerged aquatic vegetation (Chapter 13)

These chapters cover many of the NNBF currently in use or under consideration. Coastal forests (particularly mangroves) are covered under wetlands, the landform they are most associated with. In addition, Chapter 14 covers environmental enhancements to conventional infrastructure. 
The following aspects of each NNBF are discussed:

- The feature itself, its benefits, and contexts for application

- Conceptual system understanding

- Objectives, performance, and metrics

- Design considerations

- Construction considerations and methods

- Monitoring, operations, maintenance, and management

- Gaps and future directions

Throughout the chapters, cross-references are made to the relevant parts of the more general guidance in the earlier chapters of these guidelines (Chapters 1 to 7 ).

In seeking to apply any of these measures for flood and coastal risk reduction, it should be recognized that there is a spectrum in the maturity of knowledge and understanding about their application. An example of a mature and well-accepted measure is beaches and dunes, which have provided protection to coasts (whether managed or not) for many years in ways that are relatively well understood. An example of a less-mature measure in terms of the understanding of its coastal risk reduction is submerged aquatic vegetation.

\section{6| References}

Hallegatte, S., C. Green, R. J. Nicholls, and J. Corfee-Morlot. 2013. "Future Flood Losses in Major Coastal Cities." Nature Climate Change 3 (9): 802.

Huntington, S., K. Burgess, and I. Townend. 2002. "Coastal Engineering Science to Policy and Practice: Keynote Address." In Proceedings of the 28th International Conference on Coastal Engineering. Volume 1. Edited by J. M. Smith. Cardiff, Wales: U.S. Army Engineer Research and Development Center.

Linham, M. M., and R. J. Nicholls. 2012. “Adaptation Technologies for Coastal Erosion and Flooding: A Review." Proceedings of the Institution of Civil Engineers - Maritime Engineering 165 (3): 95-112.

Motyka, G., and A. Brampton. 1993. Coastal Management: Mapping of Coastal Cells. Report SR328. Wallingford, UK: HR Wallingford.

Nicholls, R. J., P. P. Wong, V. Burkett, C. D. Woodroffe, and J. Hay. 2008. “Climate Change and Coastal Vulnerability Assessment: Scenarios for Integrated Assessment." Sustainability Science 3 (1): 89-102. doi:10.1007/s11625-008-0050-4. 
Park, S. H., J. Simm, and H. Ritzema. 2009. "Development of Tidal Areas: Some Principles and Issues Towards Sustainability." Irrigation and Drainage 58 (S1): S52-S59.

Pontee, N., and A. Parsons. 2010. "A Review of Coastal Risk Management in the UK." Proceedings of the Institution of Civil Engineers: Maritime Engineering 163 (1): 31-42.

Shultz, B. 2001. "Development of Tidal Swamps and Estuaries." Keynote Address at 1st Asian Regional Conference at 52nd IEC Meeting of International Commission on Irrigation and Drainage (ICID), Seoul, KR, September 2001.

Wong, P. P., I. J. Losada, J. P. Gattuso, J. Hinkel, A. Khattabi, K. L. McInnes, Y. Saito, and A. Sallenger. 2014. "Coastal Systems and Low-Lying Areas." In Climate Change 2014: Impacts, Adaptation, and Vulnerability. Part A: Global and Sectoral Aspects. Edited by C. B. Field, V. R. Barros, D. J. Dokken, K. J. Mach, M. D. Mastrandrea, T. E. Bilir, M. Chatterjee, K. L. Ebi, Y. O. Estrada, R. C. Genova, et al. Contribution of Working Group II to the Fifth Assessment Report of the Intergovernmental Panel on Climate Change. Cambridge: Cambridge University Press. 


\title{
Acknowledgments
}

\author{
Lead Author
}

Jonathan D. Simm, HR Wallingford, United Kingdom

\section{Contributors}

Nigel Pontee, Jacobs, United Kingdom

Todd S. Bridges, U.S. Army Corps of Engineers, United States

Quirijn Lodder, Rijkswaterstaat, the Netherlands

Enda Murphy, National Research Council Canada, Canada 

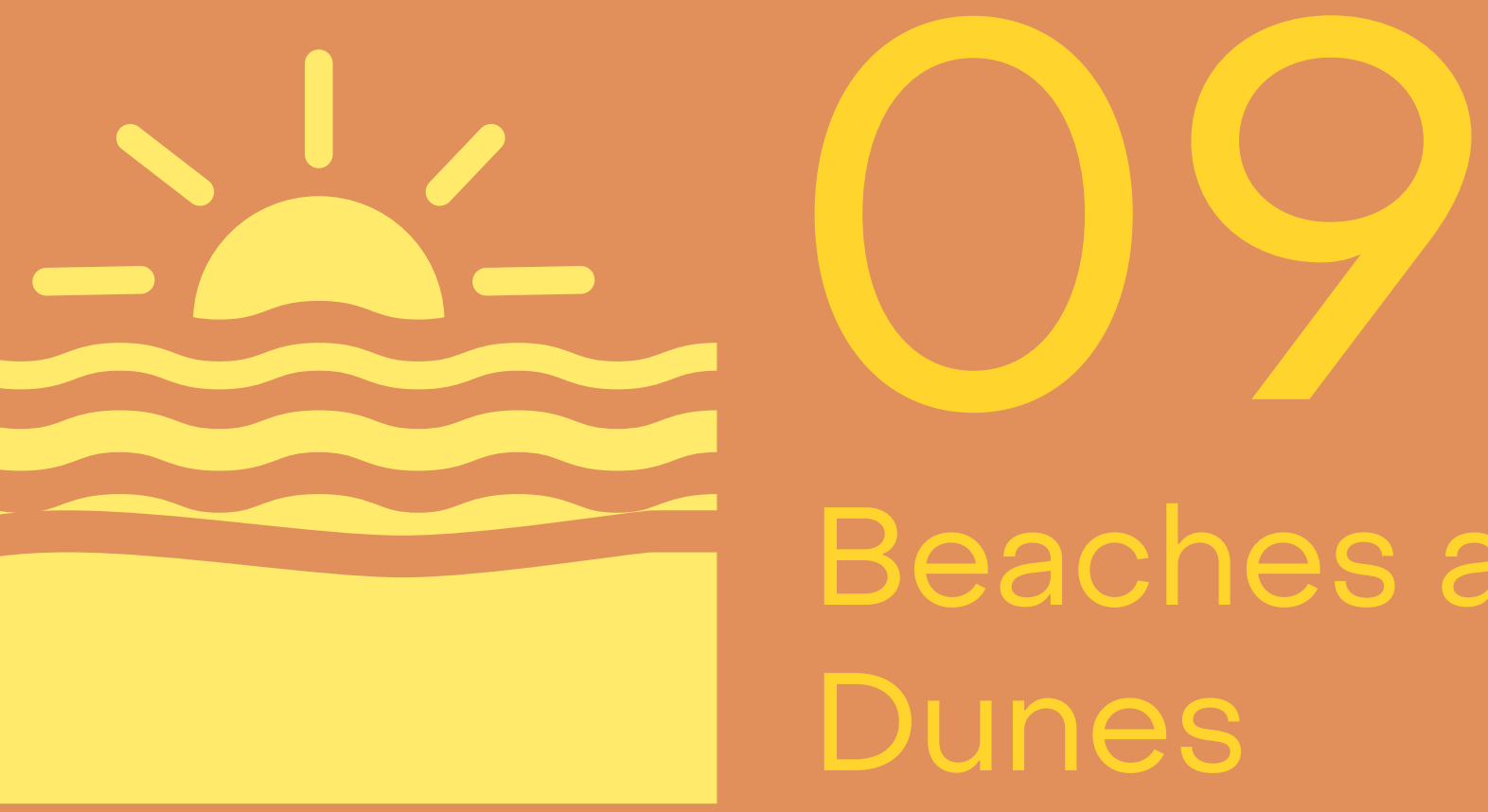

\section{Beaches and}

\section{Dunes}

\section{Suggested Citation:}

Lodder, Q., C. Jeuken, R. Reinen-Hamill, O. Burns, R. Ramsdell, III, J. de Vries, B. McFall, S. IJff, C. Maglio, and R. Wilmink. 2021. "Chapter 9: Beaches and Dunes." In Natural and Nature-Based Features Guidelines. Edited by T. S. Bridges, J. K. King, J. D. Simm, M. W. Beck, G. Collins, Q. Lodder, and R. K. Mohan. Vicksburg, MS: U.S. Army Engineer Research and Development Center.

Full acknowledgments appear at the end of this chapter. 


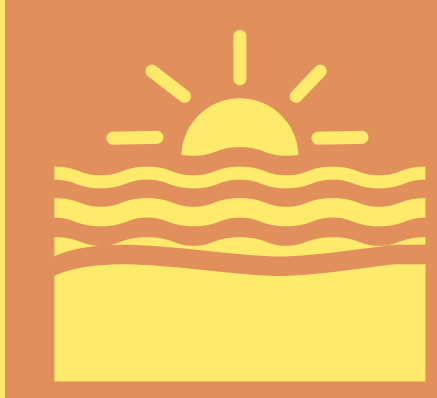

\section{Key Messages}

1. Beaches and dunes are inherently dynamic systems that reduce land loss and inundation risk of the hinterland while providing high amenity and environmental benefits.

2. The development of sustainable and cost-effective beach and dune measures requires a cross-disciplinary approach. Essential disciplines include engineering, coastal geomorphology, ecology, and governance.

3. Understanding the past, present, and possible future physical system dynamics-more specifically, sediment budgets, associated hydrodynamics, sediment dynamics, and interactions with ecological systems-is critical for determining the scale and feasibility of a given project.

4. It is essential to consider past and future scenarios, notably the effects of socioeconomic developments and climate change impacts, such as sea-level rise and possible changes to frequency and intensity of storms, when designing beaches and dunes.

5. The design of beach and dune natural and nature-based features (NNBF) should include management requirements, strategies, and associated monitoring needs.

6. Plan to let nature do most of the work when managing or implementing a beach and dune system as NNBF for coastal resilience. Consider the following: 


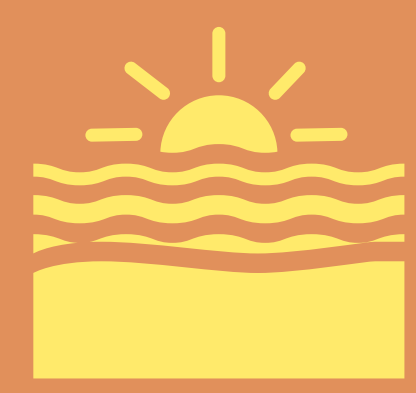

\section{Key Messages (Continued)}

a. For beach and dune systems, the design should align with the original beach and dune as much as possible. Mimic or re-create as far as possible the natural conditions of the location in question to let nature do most of the work and reduce maintenance requirements.

b. Place sediments where winds, waves, and tides can assist in transport for beach and dune building.

c. Whenever feasible, the design of beaches should allow a degree of profile dynamism by focusing on beach slope, volume, and width as primary design parameters, rather than attempting to create a static system.

d. Ecologically sustainable beach and dune systems require healthy habitat conditions and supporting processes to be in place. Once these conditions exist, colonization by appropriate flora and fauna is likely. Additional dune-specific considerations include the following:

i. Natural regeneration of vegetation will be encouraged and augmented as needed with appropriate native pioneer species seeding and planting.

ii. The implementation of a beach and dune project will result in distress to the existing ecosystem. The long-term impact on the ecosystem depends on the speed of recovery versus the frequency of disturbance.

iii. Dunes are often different types, each having its values and specific requirements, but generally, dune ecosystems cannot sustainably flourish without a feeding (dry) beach and foreshore. 


\section{9. || Introduction}

Coastal beaches and dunes are valuable to flood risk management (FRM) because they can dissipate wave energy, can trap sediments, and have the potential to grow with rising sea levels-they are vital natural and nature-based features (NNBF). This chapter explains not only how and where beaches and dunes can be used to help manage erosion and flood risk but also how they provide co-benefits such as habitat and recreation. The chapter does not consider shores where habitats such as wetlands are naturally present or constructed as an NNBF measure. For these types of habitats, refer to Chapter 10.

\section{2 || Defining the Feature, Its Benefits, and the Context for Its Application}

\subsubsection{Beaches and Dunes}

Beaches are one of the most dynamic coastal geomorphic landforms. They constitute a natural transition zone between land and sea, are an amenity and an economic resource, and provide habitat for diverse species.

Beaches are accumulations of unconsolidated and noncohesive sediment. They are situated on the interface between dry land and the sea and are actively affected by hydrodynamic processes and wind (CIRIA 2010). Their spatial limits are not fixed and will change at a range of different timescales. One possible set of spatial extents, according to Davis (1985), is the uppermost limit of wave action and the low tide mark, comprising the backshore and foreshore of the coastal profile (Figure 9.1). The foreshore usually has a steep slope and is the most active part of the beach. The development and width of beaches are largely controlled by the slope of the inner shelf and coastal area, abundance and composition of sediments, tidal range, and wave energy (Wright and Short 1984).

The zone immediately landward of the beach (the hinterland, Figure 9.1) should be considered along with the beach when designing NNBF. When present or planned for, dunes are an integral part of a sandy coastal system. Dunes are accumulations of windblown sand starting on the backshore, usually in the form of small hills or ridges, stabilized by vegetation or control structures (CIRIA 2010). They occur where sand from the beach dries out at low tide and is transported inland by wind and deposited in the hinterland, where specialized vegetation may subsequently colonize the sandy deposits. Dunes form a necessary temporary store of sediment that can be reclaimed by the sea during extreme events, helping to buffer against the erosion of the beach naturally. The size and shape of dunes are a function of climate, geology and geomorphology, wind and wave regime, and tidal range (Davidson-Arnott 2010). 
Just seaward of the beach (Figure 9.1), the incoming waves transform over the seabed bathymetry of the nearshore zone, often characterized on sandy coasts by bar and trough systems; however, the nearshore zone seaward of coarse sediment (gravel, cobble, boulder) beaches can be very steep, offering no, or limited, wave transformation function. The nearshore and foreshore are naturally dynamic and inhabited by fauna able to withstand high energy and changing conditions.

Figure 9.1. Typical Cross-Shore Profile of a Sandy Beach and Dune System

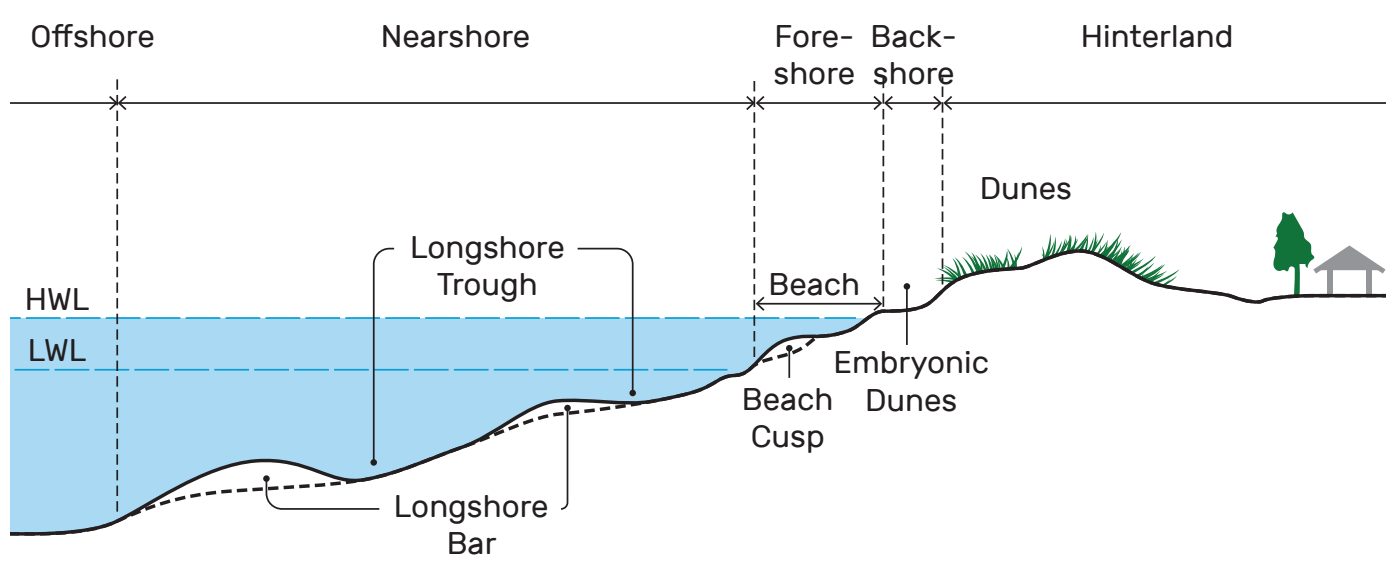

Abbreviations:

HWL: high water level, LWL: low water level

Notes: The backshore is the area from the normal high tide level to the landward margin of the beach, sometimes also referred to as the dry beach. This zone is important for eolian sediment transport to dunes. The foreshore is the intertidal beach zone. The nearshore represents the rather wide zone between the low tide level and the seaward limit of the bar and trough system.

Physical, biological, geological, and chemical processes create natural beach and dune systems. These natural systems evolve and commonly provide multiple benefits to human settlements and infrastructure. Nature-based beach and dune systems mimic the characteristics of natural systems but are created by human design, engineering, and construction to provide specific services (Bridges et al. 2015). These nature-based systems may also include hybrid solutions with structural controls or other features.

These guidelines differentiate beach and dune features based on geology and sedimentology and morphological elements present (beach, beach and dune), as follows:

- Sandy beach and dune systems (see "Sandy Beach and Dune Systems")

- Sand-gravel (mixed sediment) and gravel beach systems (see "Mixed Sand and Gravel and Gravel Beaches") 
Cliffs are treated as a sediment source component of a beach system (i.e., an element of a coastal sediment budget analysis or a receptor that beaches and dunes might be designed to protect, rather than a standalone system). NNBF methods for managing cliff erosion do exist but are beyond the scope of this chapter. For more information on the management of cliffs, refer to Lee and Clark (2002).

\section{Sandy Beach and Dune Systems}

Sandy beach and dune systems (Figure 9.2) have sediment ranging in size across the sand spectrum ( 0.62 to 2 millimeters [mm]). Many sand beaches will also have a minor gravel fraction, depending on the local geology and wave energy conditions, but they will be dominated by sand-sized particles. Sand beaches are characterized by gently sloping (wave dissipative) gradients across the intertidal zone. Beach cusps may form between the foreshore and backshore (Brenninkmeyer 1982), whereas berms, ridges, runnels, ripples, and washovers may characterize the morphology of the backshore (the latter four features are typical for sandy beaches). Compared with gravel beaches, the lower gradient of sandy beaches means the surf zone tends to be wider and sediment is transported both as bedload and in suspension by waves and tidal currents.

\section{Figure 9.2. Example of a Sandy Beach with Dunes (Callantsoog in the Netherlands)}

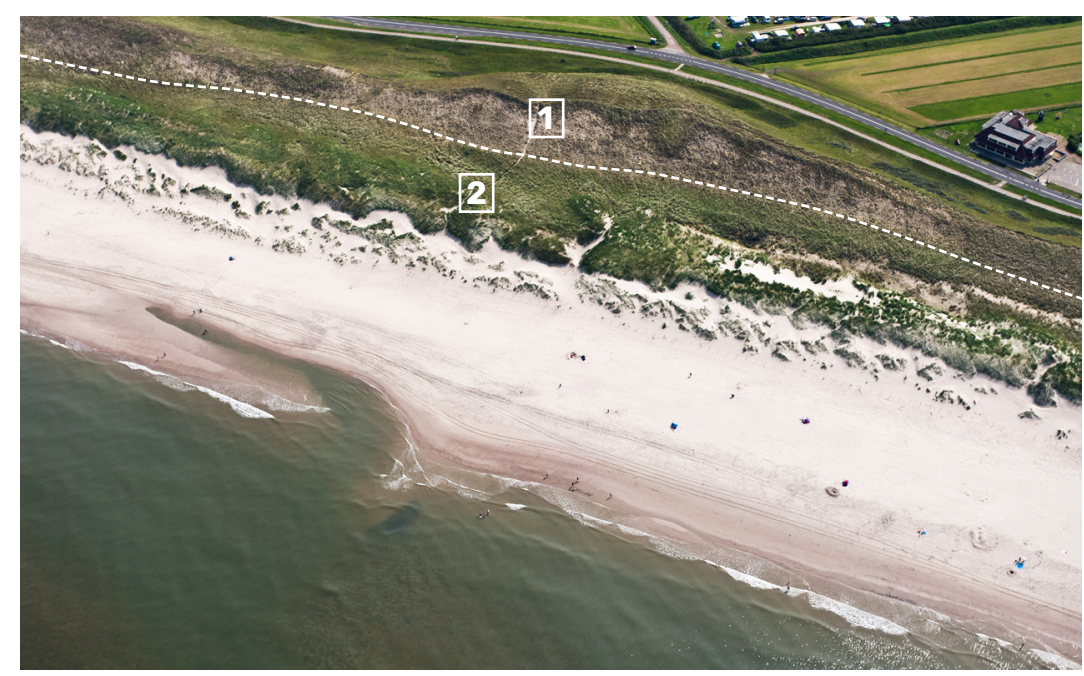

Source: https://beeldbank.rws.nl, Rijkswaterstaat, Joop van Houdt

Notes:

1: Indicates the dune face before structural nourishments

2: Indicates the dune field that evolved since nourishments started around 1990 


\section{Mixed Sand and Gravel and Gravel Beaches}

Mixed sand and gravel beaches have sediment in sizes ranging more than four orders of magnitude-from fine sand ( 100 microns) to gravels (2 to $64 \mathrm{~mm}$ ) to small boulders (greater than $256 \mathrm{~mm}$ ); gravel beaches have the larger sizes and no or negligible amounts of sand. Sediment distribution may vary with time and across the beach profile (e.g., discrete coarse sediment on the upper beach and a fine-sediment low tide terrace) along the shore and below the beachface. Mixed sand and gravel and gravel beaches are found in many places around the world, characterized by historical (quaternary) or modern ice cover and mountain ranges in proximity to the coast or hard geology, including some of the United States, United Kingdom, and New Zealand coastlines featured in case studies in this chapter (see Section 9.5.4) and many South Atlantic coasts (San Roman Blanco 2003; Curoy 2010; Pontee, Pye, and Blott 2004; Polidoro et al. 2018; Dornbusch 2017). Mixed sand and gravel and gravel beaches are typically characterized by steep beach slopes and multiple steps (see Figure 9.3). Beach slopes are generally steeper than 1 vertical to 20 horizontal, with a narrow swash zone ranging from a few meters $(\mathrm{m})$ to less than $100 \mathrm{~m}$ wide.

\section{Figure 9.3. Examples of Sedimentary Zones on Mixed Sand and Gravel and Gravel Beaches}
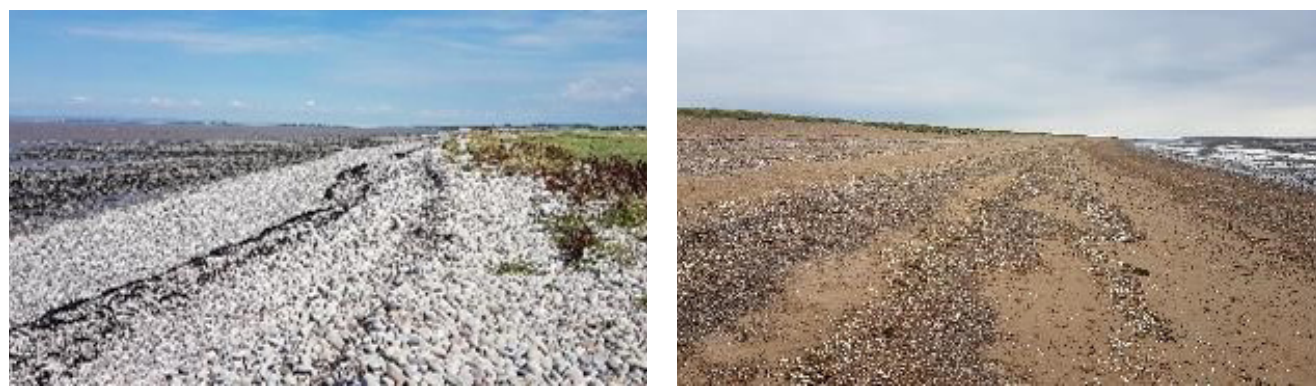

Notes: The left photograph is a gravel beach at Stolford, and the right photograph is a mixed sand and gravel beach at Heacham, both in the United Kingdom. The photographs were taken at low tide and show the underlying shore platforms.

Source: Courtesy of the Environment Agency in the United Kingdom 


\subsubsection{The Occurrence of Beaches and Dunes}

Recent analyses by Luijendijk et al. (2018) indicate that approximately $30 \%$ of the world's ice-free shorelines comprise sand or gravel (see also Figure 9.4). Sandy shorelines are most abundant in the subtropics and lower midlatitudes. They have the lowest occurrence in the tropics, where mud and mangrove coasts are most abundant (see Chapter 10). Approximately half these shorelines were relatively stable during the period 1984 to 2016 (with change rates between -0.5 and $0.5 \mathrm{~m}$ per year); roughly a quarter were eroding, and an approximately similar amount were accreting (see Luijendijk et al. [2018] for details). Crucially, these trends are subject to variations on a range of temporal scales, with seasonal-, annual-, decadal-, and centennial-scale changes of most relevance to engineering considerations. Climate change will exert considerable influence in the future on global shorelines and the risk faced by coastal communities, with rising sea levels and changes in storm conditions likely to affect beaches and dunes.

\section{Figure 9.4. Global Distribution of Sandy and Gravely Shorelines}

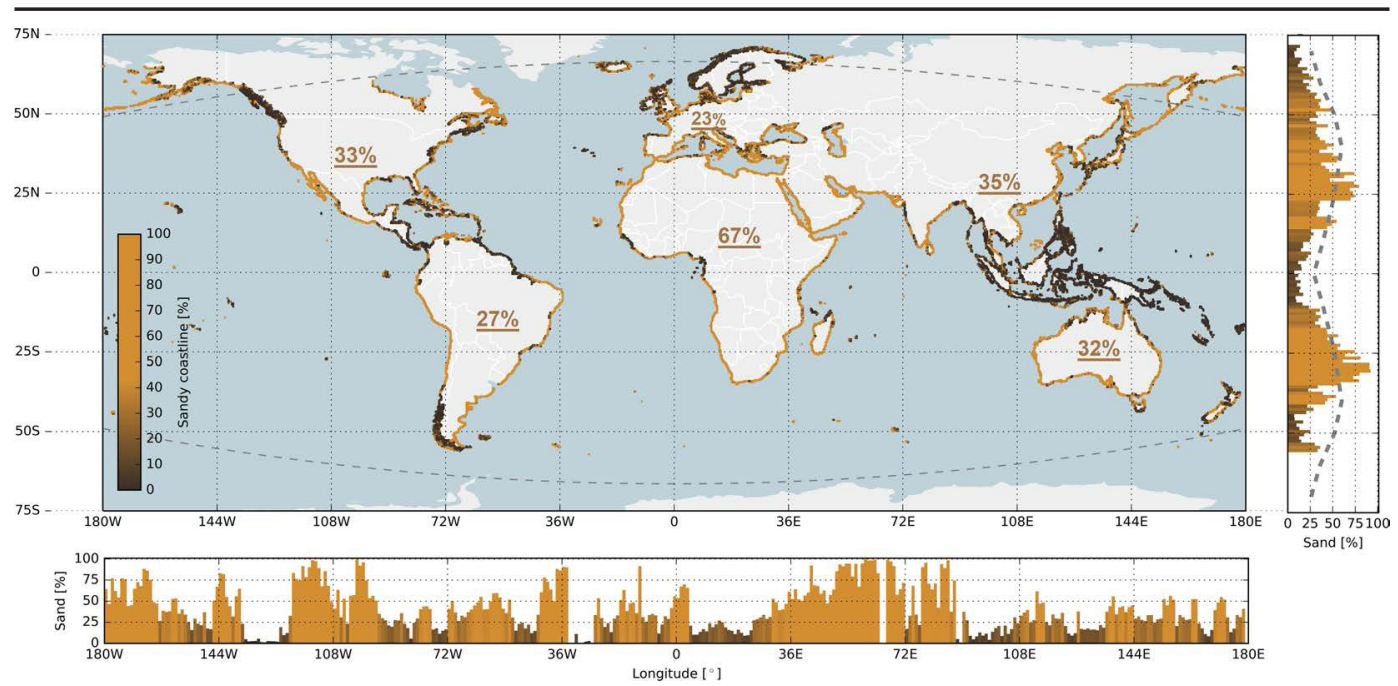

Notes: The colored shorelines represent the local percentage of sandy and gravely shorelines (light brown is sand or gravel; dark brown is nonsand). The graph to the right summarizes the relative occurrence of sandy shorelines per degree of latitude, and the graph below the map shows the same information per degree of longitude. The underlined percentages in the map are the percentage of sandy or gravely shorelines per continent.

Source: Luijendijk et al. 2018

Beaches and dunes can form anywhere land and water meet and enough sediment is available and can accumulate (Davis 1985). Consequently, they occur in a variety of geomorphological settings (Figure 9.5). These settings can be in low, intermediate, or high energy environments (i.e., from sheltered to exposed) and can be wave-dominated, mixed, or tide-dominated. 
Dominant wind direction and frequency, fetch, and bathymetry, which all control wave energy, are additional factors controlling the energy environment of a coast.

Figure 9.5. Overview of Beach and Dune Examples as a Function of Solutions, Setting, and Type

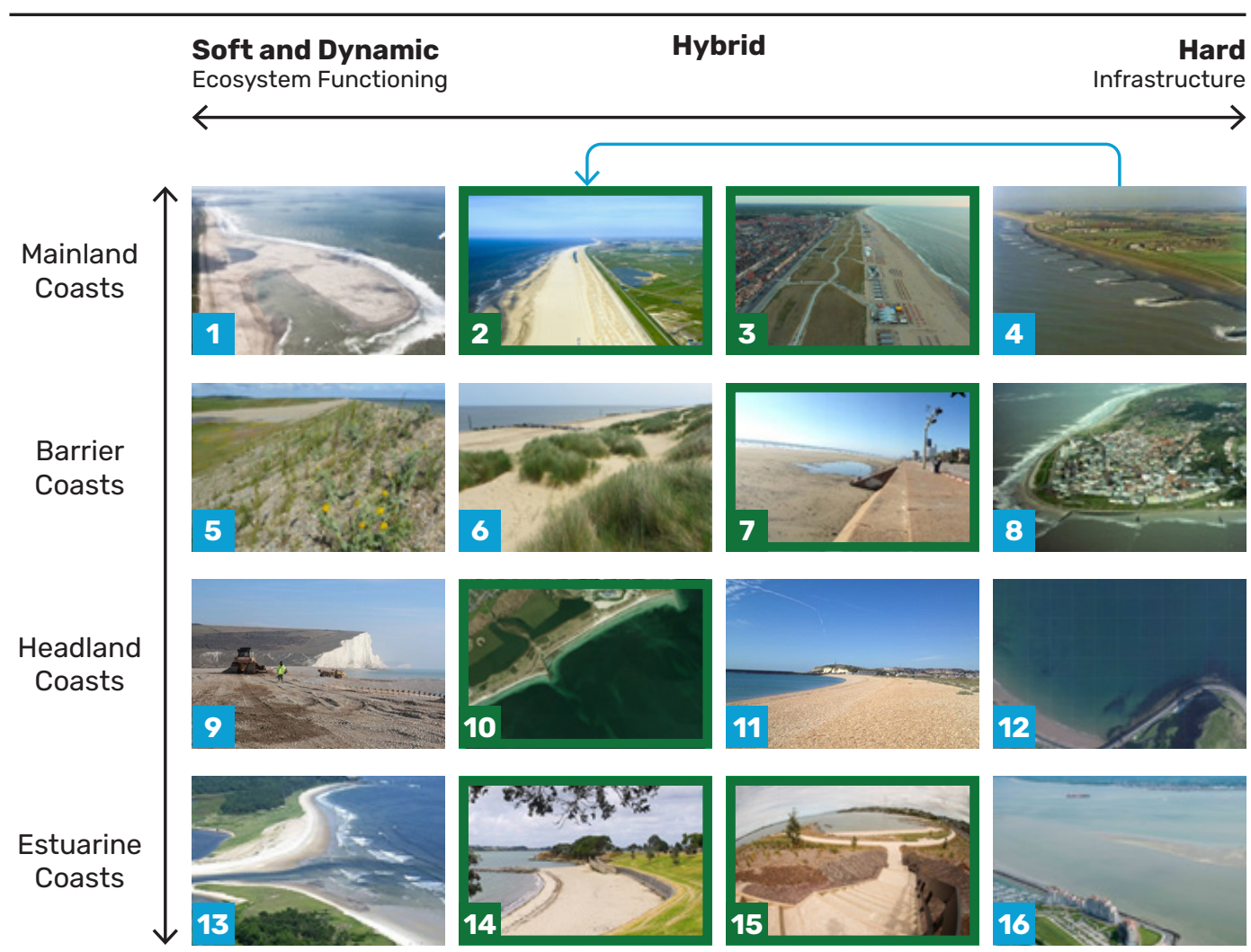

Notes: The green boxes indicate nature-based beach and dune projects. A thin, blue arrow shows how the Hondsbossche sea defense transitioned from hard to soft and dynamic.

\section{Locations}

1: Ter Heijde, the Netherlands

2: Camperduin, the Netherlands

3: Katwijk, the Netherlands

4: Camperduin, the Netherlands

5: Blakeney Point, United Kingdom

6: Blakeney Point, United Kingdom

7: Galveston, United States

8: Norderney, Germany
9: Seaford Head, United Kingdom
10: Krege bugt, Denmark
11: Bulverhythe, United Kingdom
12: Scarborough, United Kingdom
13: Cadzand, the Netherlands
14: Point England, Tamaki River, New Zealand
15: Onehunga, Manukau Harbor, New Zealand
16: Breskens, the Netherlands

Source: Rijkswaterstaat, except Locations 9 and 11 - Environment Agency 


\subsubsection{Values and Contexts for Application}

\subsubsection{Ecosystem Services of Beaches and Dunes}

Beaches and dunes are generally the first line of defense from coastal erosion and flooding (see Section 9.2.1) and can deliver these regulating services in the following ways (see Chapter 5):

- Beaches and the nearshore zone attenuate the energy of incoming waves, reducing wave height and wave overtopping.

- Dunes protect against certain storm surge levels.

- Dune vegetation reduces erosion rates by trapping and stabilizing sediments and increases coastal resiliency by dissipating wave energy and increasing the integrity of underlying sediment through root integration.

- Quasicyclic exchanges of sediments between dunes, beaches, and nearshore zone reduce the impact of erosive events, as follows:

- Dunes can buffer the effects of erosive events by providing material that is a source of sediment for the beach.

- Beaches and dunes increase in elevation over time if natural processes and management interventions (e.g., recharge and recycling) supply enough sediment.

Beaches and dunes also play a crucial role in providing societal and ecological services (e.g., Everard, Jones, and Watts 2010; Barbier et al. 2011; Rodríguez-Revelo et al. 2018; also see Chapter 6), including the following:

- Cultural services including recreation and tourism, education, and aesthetic (landscape) benefits

- Supportive services including habitat provision, refuge and forage areas, and water cycling

- Provisioning services including fresh water, food, construction materials, alternative energy resources, and landing for fishing boats

\subsubsection{Contexts for Application of Beach and Dune NNBF}

Where natural beaches and dunes are present, restoring, maintaining, or enhancing processes, features, and dynamics should be the first goal of managers seeking to reduce flood and erosion risk, given the benefits provided by naturally functioning systems. Management considerations for natural systems are associated with matching sediment types and desired geometry and volume. Whether a beach is stable, eroding, or accreting, adding sediment increases beach and shoreface volumes that enhance the existing buffer against erosion and reduce inundation risk (see the case studies in Section 9.5.4 and Figure 9.5). 
Where further engineered interventions or nature-based beaches or dunes are required to achieve the desired outcome, it is advisable to mimic natural processes and dynamics as much as possible. Nature-based solutions require similar considerations of physical drivers but likely with less available information such as natural berm elevation, grain size, and dune configuration, which means these projects will require greater flexibility of design and maintenance. The latter can be critical and challenging, especially in densely populated areas where urbanization encroaches the shoreline, such as along the East Coast of the United States. And there are other factors to consider, including different ecological effects and the resulting changes that may occur due to habitat transformation (e.g., hard bottom to sandy bottom, subtidal to intertidal or subaerial areas).

The following are examples of further engineered interventions or nature-based systems:

- Installing one terminal groin to improve the retention of beach sediment within a subcell rather than installing a full groin field

- Installing a fence or thatching to support an increase in the size and volume of dunes (e.g., coastal-management.eu 2021)

- Restoring or creating a fronting beach to reduce wave energy as part of a seawall maintenance or construction project could be considered a hybrid nature-based beach

- Recharging the rear (landward face) of an eroding barrier beach to mimic natural rollback and achieve a design volume rather than placing sediment on the erosive beachface; this could be considered a nature-based enhancement

Generally, a careful assessment of the effects of the engineering options is required because there may be impacts on the adjacent structures or to downstream navigation infrastructure (e.g., increased sedimentation in an access channel or port).

For all management approaches, whether for natural or nature-based systems, where possible and feasible, reserving space landward of these features to support migration and rollback will strengthen the resilience of the coast and its communities.

\section{3 | Conceptual System Understanding}

\subsubsection{Physical System}

Understanding the dynamics of the physical system, including its ecological components, existing engineering structures, and human interventions, is essential to assessing the feasibility and maintenance requirements of coastal beach and dune systems. A proven way to obtain this system understanding involves the following: (1) developing a conceptual model of the physical system of the area of interest, (2) performing a sediment budget analysis 
for the coastal system under consideration, and (3) assessing existing dune and beach habitats supporting the ecology of the envisaged beach and dune system. Sections 9.3.1.1, 9.3.1.2, and 9.3.1.3 elaborate on these three aspects by providing definitions, key issues, and concise descriptions and references for methods (illustrative case studies are provided in Section 9.5.4).

\subsubsection{Conceptual Physical System Model}

A conceptual model of the physical system qualitatively identifies essential morphological elements, general sediment pathways, sediment sources and sinks, human interventions, and how associated drivers and processes link together. Usually, such a system understanding involves analyzing readily available data, studies, and literature and leveraging available expertise. French et al. (2016a) developed a conceptual framework referred to as coastal and estuarine system mapping and an open-source GIS tool to derive conceptual system models. Figure 9.6 shows an example of a hypothetical beach and dune system. Relative sea-level rise acts as a sediment sink to a coastal system; the gradual increase in water level or land subsidence creates accommodation space for sediments to settle (e.g., Jervey 1988). Other aspects of climate change may also change the potential for sediment supply (e.g., changes in rainfall intensity within catchments or offshore wave intensities).

\section{Figure 9.6. Conceptual Model of Physical Processes for a Hypothetical Beach and Dune System}

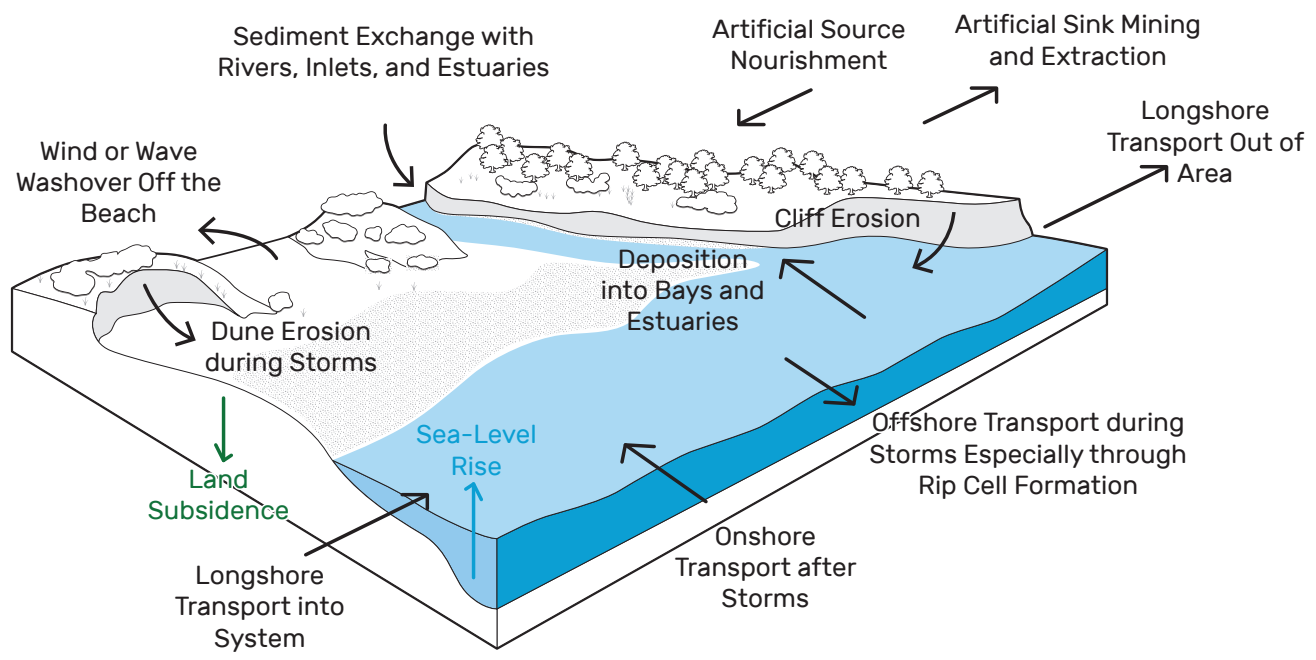

Source: Adapted from DSE 2012, Figure 5-4 


\subsubsection{Sediment Budget Analysis}

The conceptual physical system model (see Section 9.3.1.1) provides the basis to perform a quantitative sediment budget analysis of the coastal system under consideration, detailing the conceptual model and system understanding. A sediment budget analysis quantifies the sediment inputs (sources) and outputs (sinks), including human sediment interventions (dredging, nourishments), and the resulting, or net balance, defined coastal system and time interval (Figure 9.7). A sediment budget analysis serves as a common framework to evaluate sediment transport pathways and exchanges to determine whether a coastal system and its functional elements (e.g., the beach or dune) are accreting, eroding, or stable. Whether the beach-dune system is accreting, eroding, or stable informs coastal management planning and associated evaluations of alternative project designs. For example, implementing a beach and dune system for flood and erosion risk mitigation along an eroding coast will likely require more sediment resources and sediment recharging than a stable or accreting coast.

\section{Figure 9.7. Concept to Quantify the Sediment Budget Analysis of a Coastal System in Terms of Sediment Volume Changes and Estimating Associated Sediment Fluxes and Human Interventions}
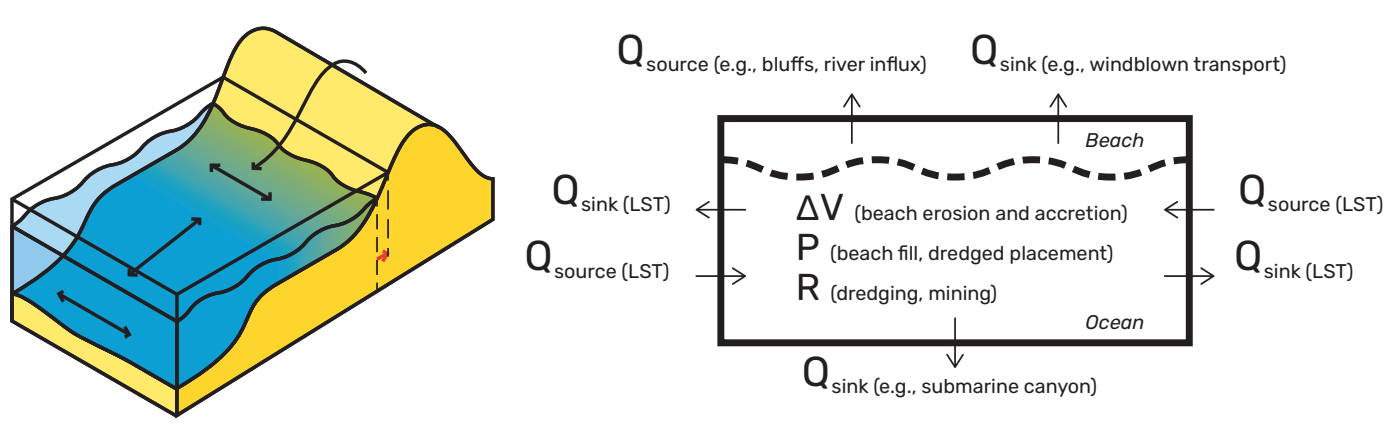

Abbreviation:

LST: longshore transport

Notes: The 3D schematic profile (left figure) shows directions of typical sediment fluxes. The red arrow in the 3D cross section indicates the rollback effect related to (relative) sea-level rise and insufficient sediment supply. The right figure schematically details typical sediment budget analysis components that form part of the following sediment budget analysis equation:

$$
\sum \text { source }-\mathrm{Q} \operatorname{sink}-\Delta \mathrm{V}+\mathrm{P}-\mathrm{R}=\text { Residual }
$$

Herein, the residual indicates to what extent the system is stable, eroding, or accreting.

Source: Adapted from Rosati 2005 (reproduced with permission from the Coastal Education and Research Foundation, Inc.) 
Bowen and Inman (1966) were among the first to develop and apply the concept of sediment budget analysis for a coastal system. Since then, the method has been refined by many others using it (e.g., Jarrett 1977; Dolan et al. 1987; Kana and Stevens 1992; Komar 1996; Rosati and Kraus 1999; Rosati 2005; Elias, Van der Spek, and Lazar 2016). Roberts and Brooks (2018) recently developed a comprehensive guide on the need for and best practice of sediment budget analyses, targeting coastal FRM practitioners. French et al. (2016a) also provide relevant guidance to perform such analyses. Sections 9.3.1.2.1 through 9.3.1.2.3 briefly address three selected critical issues in performing a sediment budget analysis: (1) definition and identification of the relevant spatial and temporal scales, (2) understanding sediment budget analyses and dynamics, and (3) long-term trends and natural variability observed in coastal state indicators.

For a complete overview of how to undertake a sediment budget analysis, see, for example, Rosati (2005) or Roberts and Brooke (2018). For peer-reviewed sediment budget analysis case studies in a data-rich and a data-poor environment, see, for example, Elias and Van der Spek (2017) regarding the former and Hobgen et al. (2014) regarding the latter.

\subsection{Definition of the spatial and temporal scales}

Temporal and spatial scales for establishing sediment budgets and informing coastal management and project design should align as much as possible (e.g., Rosati 2005; Cowell et al. 2003; French et al. 2016b). Defining the relevant spatial and temporal scales of the coastal system under consideration is, therefore, a critical issue in developing a sediment budget and adopting a systems approach (see also chapter 4 ).

The coastal system should contain all functional elements, hierarchy, and interactions between these elements, to explain the system behavior (Roberts and Brook 2018; French et al. 2016a, 2016b). For beaches and dunes, as specific landforms within a larger-scale coastal system, this would ideally imply that the system is a clearly defined unit of the coast, in which the sediments are mostly self-contained (a closed system). Coastal systems are, however, seldom fully closed systems. In practice, these boundaries are, therefore, primarily defined based on geomorphological considerations. 
At the highest level, the spatial scale of the coastal system strongly links to its geomorphological setting. For example, for a headland, pocket beach coast, the spatial scales are generally smaller than for a more open barrier coast and a mainland coast. The identification of natural features or landforms (e.g., the beaches, dunes, and cliffs, [sandy] bars and troughs, and depths of closure [see also Section 9.5]) within the coastal system is essential for defining the hierarchy and subboundaries of interacting elements of a system that share and exchange sediments within the system. Furthermore, engineering structures like groins or shipping channels play a role in the definition of the boundaries of the various functional elements of the coastal systems. When available, information on residual flow and sediment transport patterns obtained from measurements and modeling studies can support these steps to identify system boundaries.

Although spatial and temporal scales of the morphological change of a coastal system are site specific, timescales of morphological change generally tend to increase with spatial scale (see Figure 9.17). The time interval for quantifying sediment budgets, however, also depends on practical considerations, such as the availability and accuracy of data.

\subsection{Understanding sediment budgets and dynamics of a coastal system}

Hydrodynamic and eolian processes and conditions, at generally much shorter timescales, drive the changes in sediment budget and coastal morphology. Understanding these conditions and processes and obtaining quantitative estimates of the sources, sinks, and associated sediment pathways imply answering questions such as the following:

- What are the primary forces driving coastal change?

- What are the contributions of tides, average waves and swells, storm surges, and relative sea-level rise?

- What are the orders of magnitude of the associated gross and net longshore and cross-shore sediment transport rates?

- What quasicyclic morphologic behavior is relevant?

Section 9.5.5 describes modeling tools to support an analysis addressing these questions. Figure 9.8 shows an example of a detailed sediment budget analysis for a data-rich case in the Dutch Wadden Sea. These results informed the nourishment strategy for the area and the design of individual nourishment schemes (see also Section 9.2 and Figure 9.8). Morang (2016) describes an elaborate sediment budget analysis for an example on the coast of Maine in the United States. 
Figure 9.8. Synthesis of Sediment Budget Analysis Undertaken for the Texel Inlet (in the Netherlands) and Bordering Coasts in the Dutch Wadden Sea, from 1985 to 2015

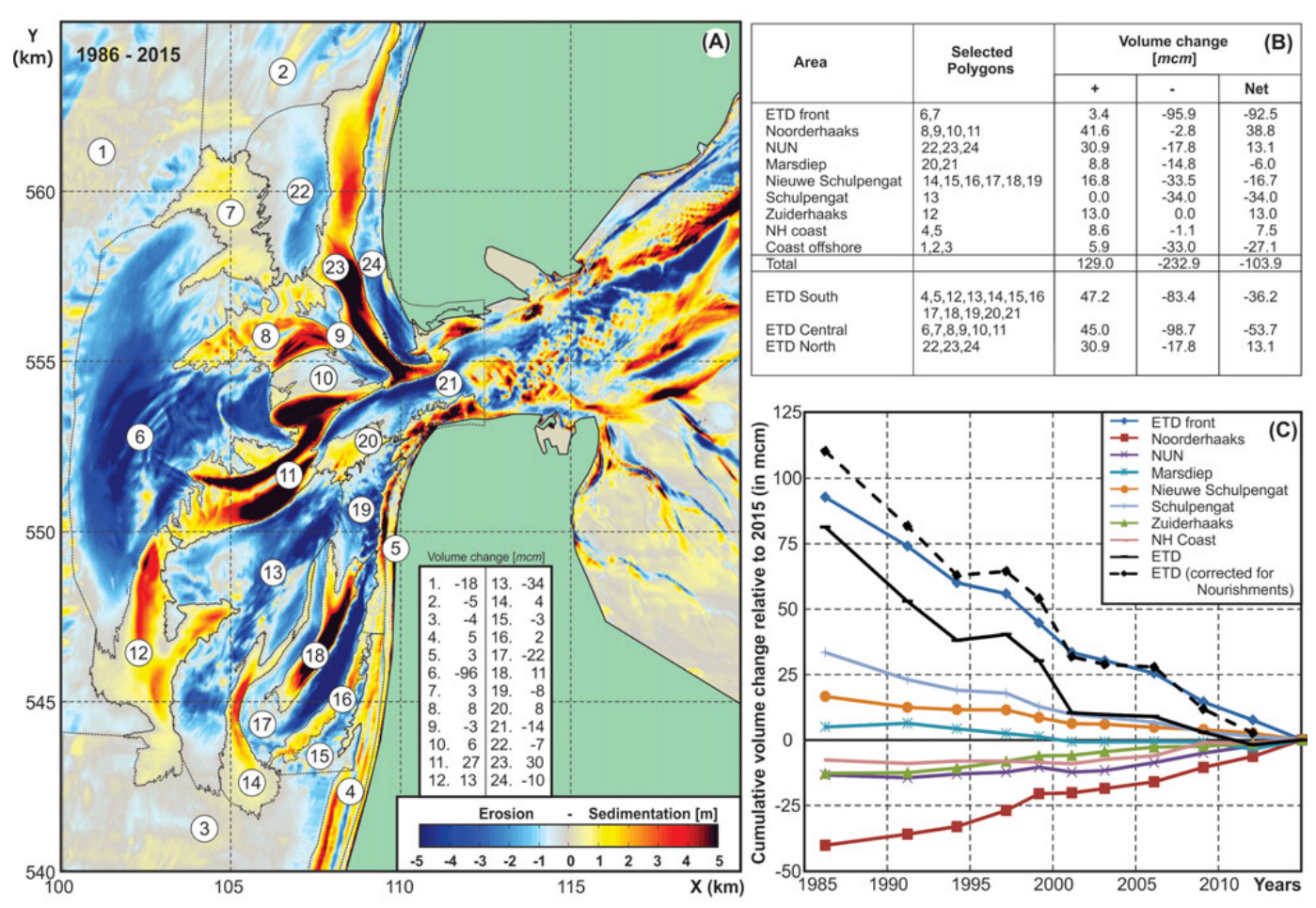

Figure continues on next page. 


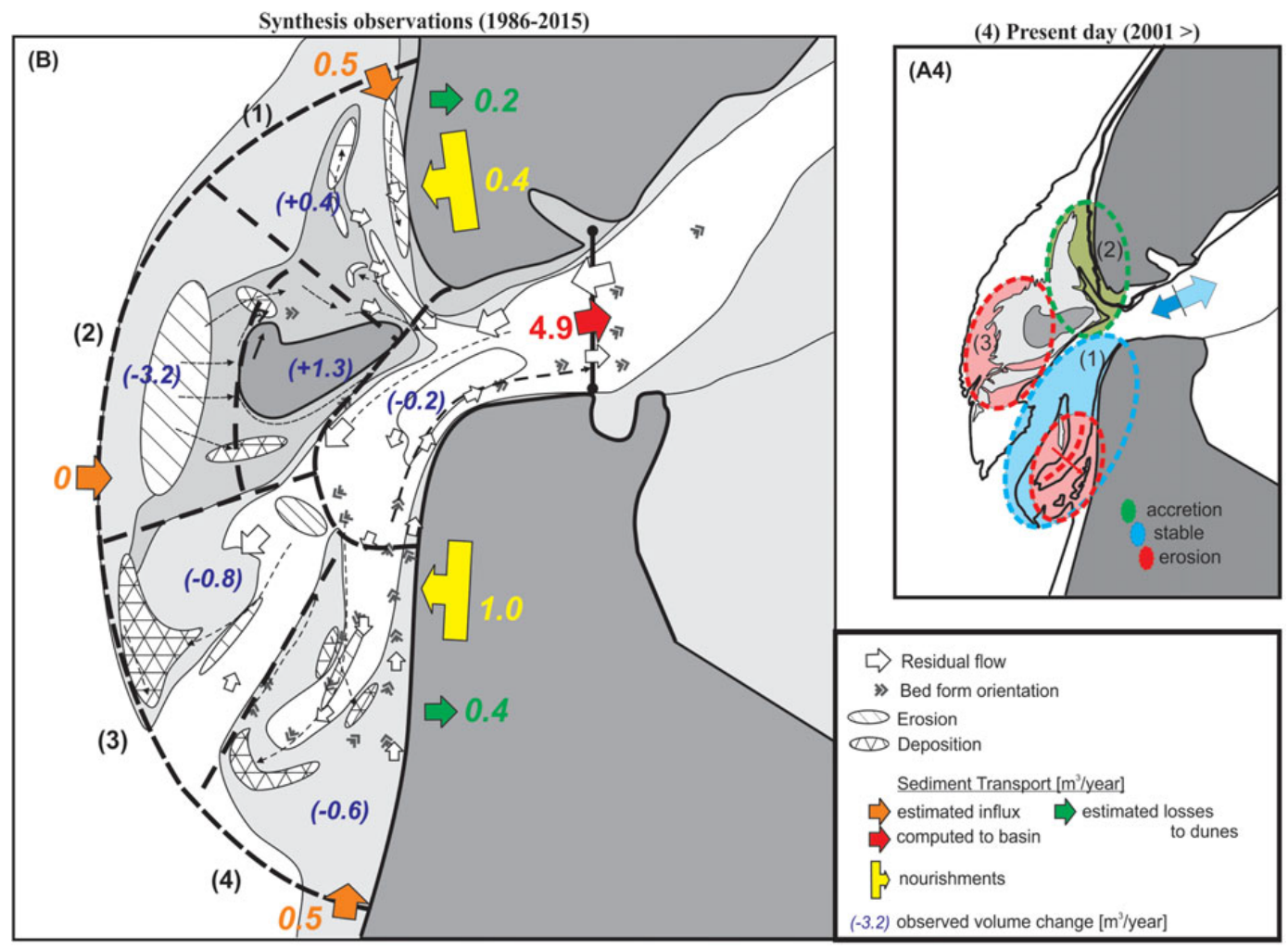

Abbreviations:

mcm: million $\mathrm{m}^{3}$ or million cubic meters

ETD: ebb-tidal delta front

$\mathrm{NH}$ : North-Holland coast

NUN: Noorderlijke Uitlopers van de Noorderhaaks (translates as "the northern extension of Noorderhaaks shoal")

Notes:

(A): erosion sedimentation map indicating various functional elements

(B): budget changes of the various elements and the system as a whole

Bottom (B) and (A4): synthesis of the sediment budget analysis

The obtained budget understanding was used to define the nourishment strategy for the area and design individual nourishment schemes.

Source: Elias and Van der Spek 2017 
The phenomenon of scale interaction (see also Chapter 4) is related to the behavior of and interactions between functional elements in a coastal system. Larger-scale processes influence smaller-scale processes and vice versa (e.g., De Vriend 1991; Cowell et al. 2003; French et al. 2016b). Using the example of Figure 9.8, the tidal inlet dynamics interact with the ebb-tidal delta. The ebb-tidal delta influences the beaches and dunes at the tip of the barrier island. Likewise, a smaller-scale evolution can affect the sediment requirement and budget of a larger area. A typical example of this is the formation of quasicyclic shortcut channels (bend cutoff) in the mouth of inlet systems affecting the sediment budget of (larger parts) of the ebb-tidal delta (see numbers 23 and 24 in Figure 9.8 [A]), revealing a landward migration of a tidal channel causing erosion of nearshore zone. Channel bank nourishments may be used to slow down this process (see also Figure 9.17).

\subsection{Long-term trends and natural variability}

Understanding the past, present, and future sediment budgets of a coastal system and its functional elements requires an assessment of the short-term (months, years) fluctuations and longer-term (years, decades, centuries) trends. This can be challenging for inherently dynamic system elements, such as beaches and dunes. Even in dynamic equilibrium, the sediment volume and other coastal state indicators, such as shoreline position, may display considerable short-term fluctuations superimposed on a long-term trend.

Generally, the first step to quantify natural fluctuations in sediment budgets is to analyze a time series of bathymetric maps, if available, and other sources such as aerial and satellite images (e.g., see Luijendijk et al. 2018). When plotting a time series of derived coastal indicators such as beach volume or shoreline position, any longer-term trends and superimposed fluctuations in the system behavior become visible. Figure 9.9 gives a conceptual example of a stable and accreting morphological feature with its associated natural dynamics and a structurally degrading feature also with its associated natural dynamics. Statistical analyses can support an objective identification of trends and superimposed fluctuations, because both the start and end year and time intervals affect the quantification of trends and the characterization of natural variability. See, for example, Zeileis et al. (2003), Bai and Perron (1998), and Kass and Raftery (1995) for useful methods, and an application in a data-rich estuarine system in Jeuken et al. (2014). Where data are scarce, a range of techniques, including comparative assessment and modeling, can support similar analyses (see Section 9.5.5 for modeling tools). Generally, the net changes in a sediment budget determined by a sediment budget analysis have inherent uncertainties that are related to, for example, measurement accuracy, and the impact of human interventions on sediment volume changes. Because of the large areas for which these analyses are typically made, relatively small, systematic vertical measurement errors can result in errors in the total sediment budgets of $50 \%$ to $100 \%$. Multiple and long-term observations and appropriate analyses methods help to narrow uncertainties in the sediment budget by lessening the influence and weighting of proven systematic errors. 
Figure 9.9. Conceptual Time Series of Beach Volume, as Coastal State Indicator, Displaying Short Variations and Long-Term Trends in Sediment Volume Changes

\section{Coastal State Indicator (Beach Volume $\left.\left[\mathrm{m}^{3} / \mathrm{m}\right]\right)$}

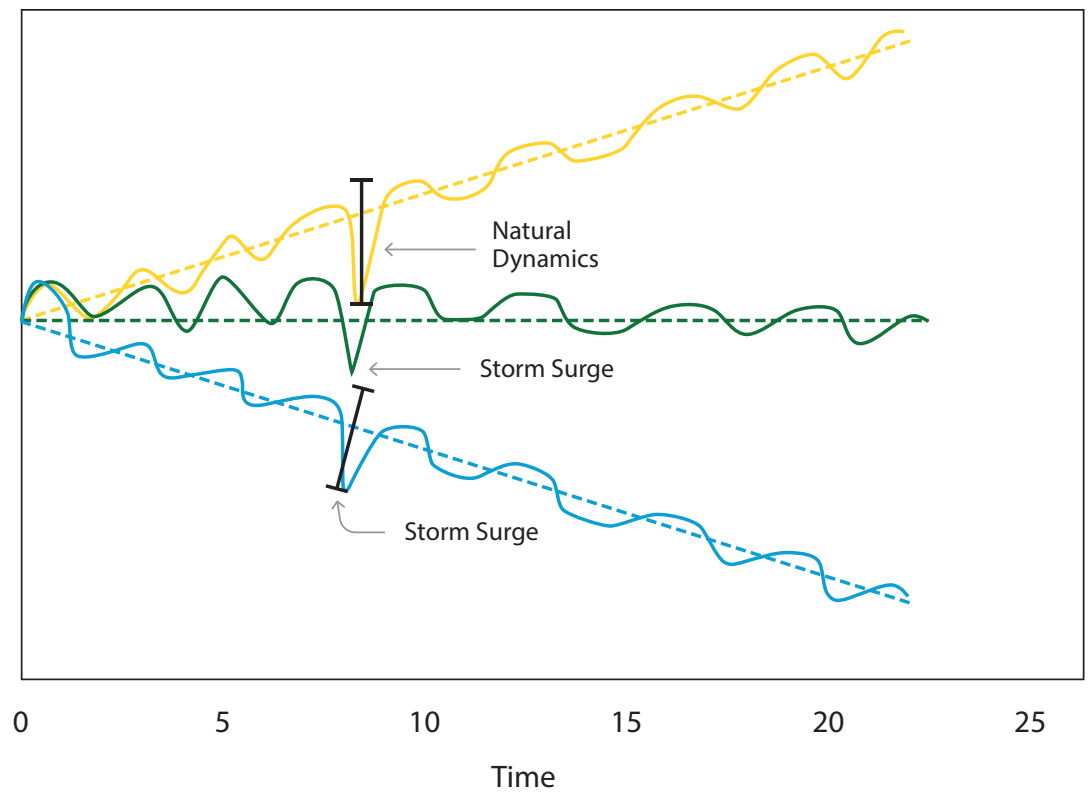

Abbreviation:

$\mathrm{m}^{3} / \mathrm{m}$ : cubic meters per meter

\section{Example of the Annual Assessment of Sedimentation and Erosion Trends along the Dutch Beaches and Dunes Coast}

Rijkswaterstaat (the agency responsible for the design, construction, management, and maintenance of the main infrastructure facilities in the Netherlands) carries out regular assessments of the Dutch beaches and dunes coast to support the dynamic maintenance of the Dutch coast. Every year, the sedimentation and erosion trends for each coastal transect are determined. Large-scale and long-term sedimentation and erosion trends are assessed every few years for the coastal system and its subsystems (e.g., Elias et al. 2012; Elias, Van der Spek, and Lazar 2016; Van der Spek and Lodder 2015).

Most parts of the Dutch sandy coastline are surveyed annually with single-beam echosounders and lidar equipment. The surveys result in an annual dataset with harmonized transect profile data from approximately $10 \mathrm{~m}$ below to $10 \mathrm{~m}$ above mean sea level (MSL). The Dutch coastal monitoring database JARKUS (JAaRlijkse KUStmetingen, Dutch for "annual coastal measurements") contains yearly surveys since 1965. 
Each year, the current volume trend between approximately $5 \mathrm{~m}$ below and $3 \mathrm{~m}$ above MSL is calculated and assessed to a reference coastline (see Figures 9.10 and 9.11). The result of this assessment forms the basis for the Dutch national beach and shoreface nourishment scheme. An online map and book (Rijkswaterstaat Coastline Map Database; Rijkswaterstaat Kustlijnkaarten 1992-2020) provide the results of this assessment. Please refer to Chapter 7 and to Section 9.7 for more information.

\section{Figure 9.10. Sedimentation and Erosion Trends near The Hague}

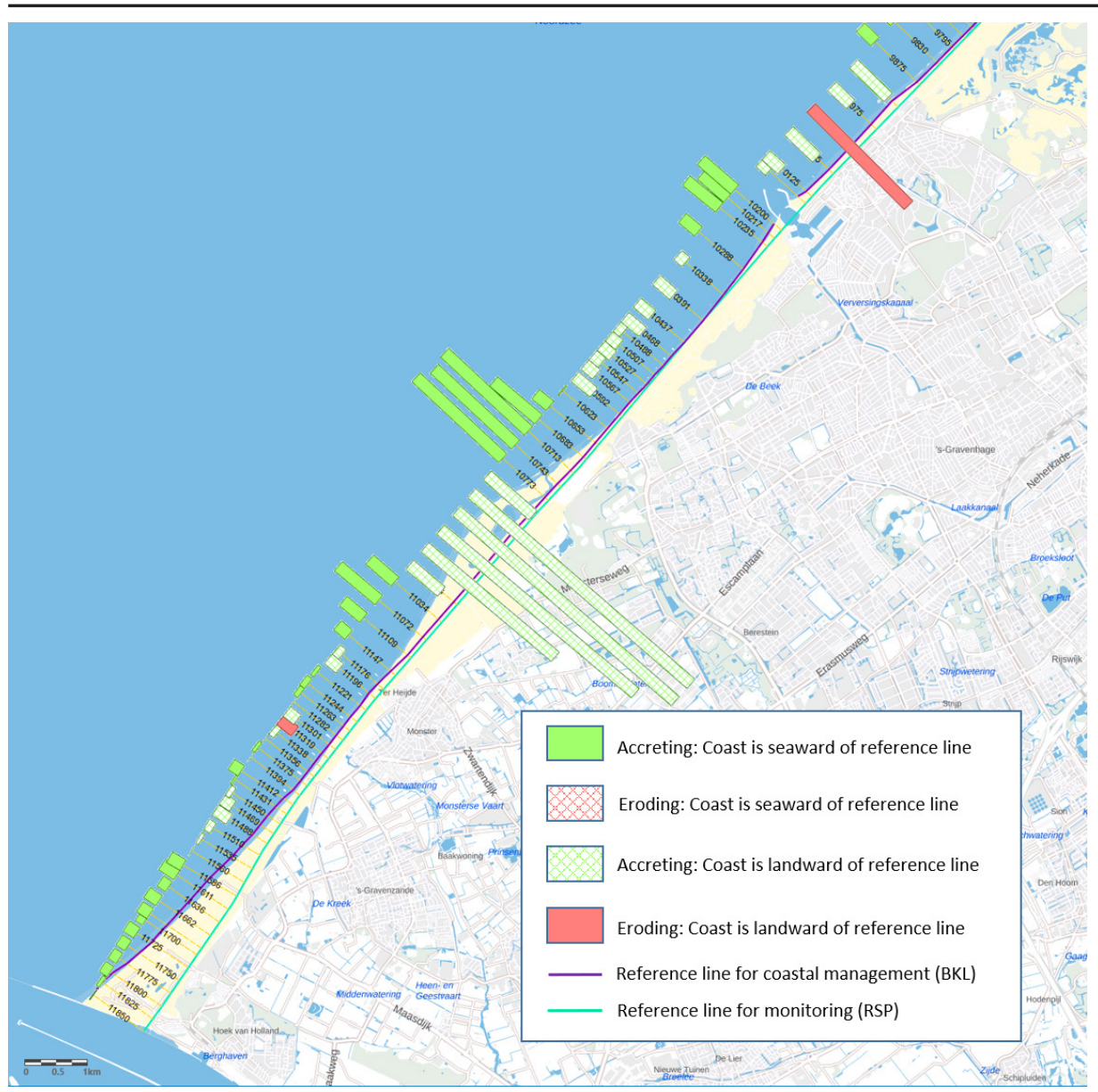

Notes: These trends are calculated for each transect along the Dutch coast. The hatched red pattern is not present in this stretch of coast.

Abbreviations:

BKL: Basis KustLijn, which is the reference line for coastal management in reference to the RSP RSP: RijksStrandPalen lijn, which is a Dutch reference for monitoring 
Figure 9.11. Officially Calculated (Annual Assessment) Coastline Positions and Trends for the Coastal Town of Scheveningen in the Netherlands

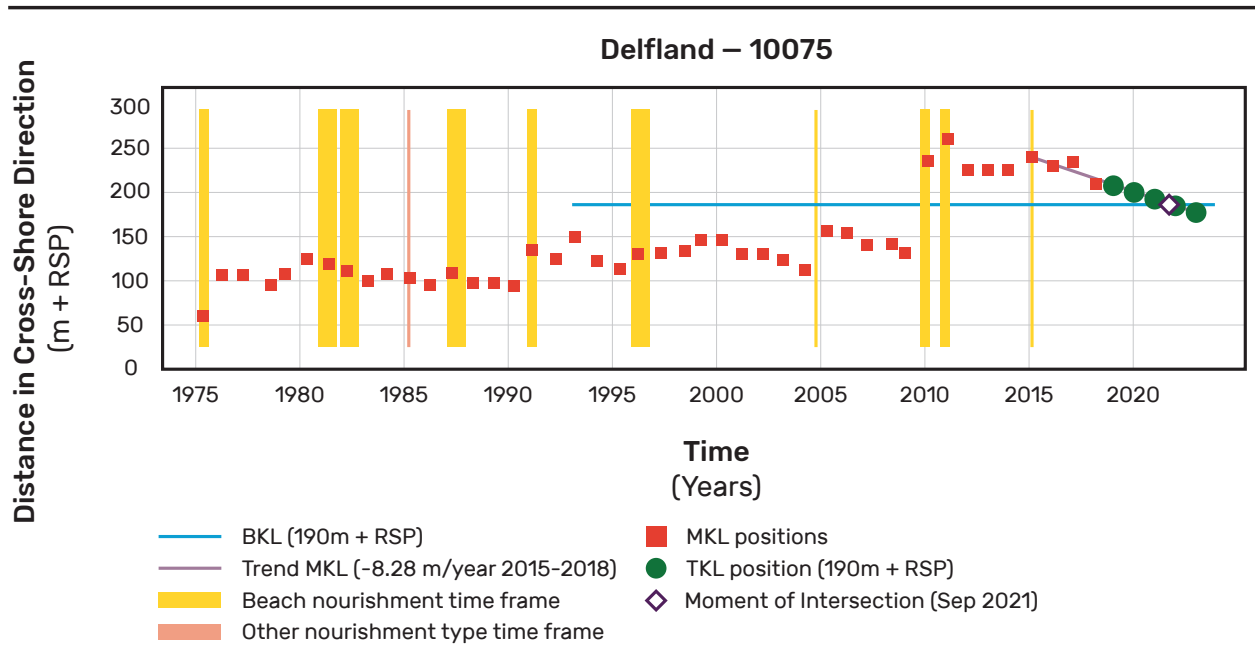

Notes: This graph provides the basis of the map in Figure 9.10. "Delfland - 10075" defines the location of this transect, which is at the Delfland part of the coast at transect near 10075.

Abbreviations:

BKL: Basis KustLijn, which is the reference line for coastal management in reference to the RSP MKL: Momentane KustLijn, which is the current coastline position in reference to the RSP $m+R S P$ : meters RijksStrandPalen lijn, which is a Dutch reference for monitoring

TKL: Toekomstige KustLijn, which is the expected future coastline position in reference to the RSP

Legend:

$\mathrm{Y}$ axis: cross-shore position; positive is seaward

Red squares: approximate (weighted) low watermark

Vertical bars: nourishment time frames

Blue horizontal line: minimum reference coastline position and volume needed to keep flood risk at a societally acceptable level

\subsubsection{Beach and Dune Habitat Assessments}

When assessing the feasibility of a beach and dune NNBF, it is essential to identify the ecosystem and the ecological functions and services of the proposed area of interest, as well as the proposed borrow area (if any). The ecosystem consists of the habitat and the species that are there or that might be found there in the future. Beaches, dunes, and borrow sites can provide habitat for a wide range of marine and terrestrial flora and fauna. Figure 9.12 shows the components of a typical beach and dune ecosystem in a temperate region. 


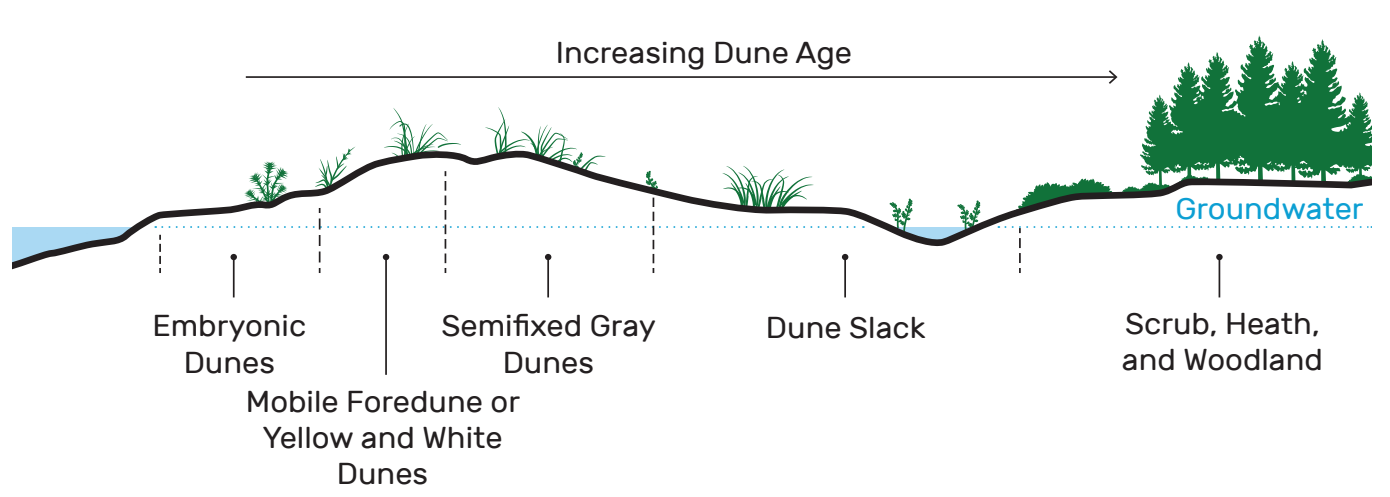

Nearshore waters are productive ecosystems where phytoplankton and zooplankton make use of turbulence for their production. High concentrations of plankton attract other species such as shellfish (that can form big reefs) and fish. Conversely, on the beach, the conditions are too harsh for most plant and animal species. Only some burrowing organisms, such as mollusks, populate sand beach ecosystems (Carter 1988). There is only slight primary production, although some diatom populations may survive there.

Farther away from the influence of the sea, pioneer plant species such as sea rocket or prickly saltwort can establish. When accompanied by sea couch grass and marram grass, sand is trapped, and embryonic dunes start to grow. If not eroded during storms, these embryonic dunes may grow meters high and form a foredune, which can become very stable and protect the hinterland against flooding. Rainwater is captured and creates a sizeable freshwater lens below the dune landscape. Where the ground level meets the groundwater level, dune slacks occur with their characteristic biodiverse plant communities.

Over time, organic matter accumulates, increasing the nutrient content and allowing more seral species to settle. Especially in the fixed older backdunes (gray dunes), the conditions are less harsh and grassland communities occur (often grazed by rabbits or domesticated animals). If no grazing occurs, shrubs (e.g., brambles or hawthorn) and eventually trees (e.g., alder or oak) will replace the grass species.

Physical processes that determine where and in what form these habitats arise include sand transport, salt spray, chemical conditions of the sediment and groundwater (e.g., calcium content), the relative influence of seawater and groundwater, and nutrient availability (see also Section 9.5.2.7).

Sustainable beach and dune ecosystems require healthy habitats and natural processes. Once a healthy habitat exists, the appropriate mix of species will usually follow. To support thriving ecosystems, the following are recommended: 
- Avoid high nutrient levels.

- Allow natural dune dynamics (e.g., reactivation of sand in blowouts).

- Promote the ecological connectivity needed to provide suitable habitats for early succession stages.

When planning and constructing a nature-based beach and dune system, the requirements from a societal perspective generally determine whether the establishment of fauna and flora should be supported by, for example, planting, seeding, or aided recolonization with species.

\subsubsection{Socioeconomic and Governance Aspects}

Beaches and dunes are generally part of a large-scale coastal system or coastal tract that contains a hierarchy of sediment-sharing morphological units or landforms (Cowell et al. 2003 in French et al. 2016a). This system often has multiple stakeholders and governing agencies affecting the realization of benefits and the governance of the project.

The benefits of NNBF projects will be realized over time, which may cause funding and permitting challenges. It is, therefore, essential to assess and be aware of the spatial and temporal scales of the socioeconomic and governance systems, how they differ from the physical system scales, and their implications for implementing and managing beach and dune systems. For example, a nourished beach will feed downdrift beaches due to longshore net sediment transport. This sediment transport, for example from Community A to Community $B$, will most likely be perceived as a loss in Community $A$ and as a gain in Community B. In the long term, both communities benefit from nourishing updrift beaches, but the timescale at which they benefit is different. The same applies to any intended or unintended adverse effects of beach and dune NNBF projects that could increase windblown sand landward, the requirement to extend coastal outfalls, or the requirement for increased dredging downdrift to maintain safe navigation. For more generic aspects of governance and stakeholder engagement, see $\underline{\text { Chapter } 3 \text {. }}$

\section{4 | Objectives and Metrics}

For any NNBF project for coastal resilience to floods and erosion, it is essential to identify the strategic and operational or tactical goals for the project (see Chapter 4; Lodder et al. 2020; Marchand et al. 2011).

Generally, strategic objectives reflect a long-term vision about the desired development of the coast. Often this vision is based on general ideas about sustainable development, and, ideally, it demonstrates the interdependency of the natural and socioeconomic systems. Examples of strategic goals include the following: 
- Sustainably maintained flood protection and other functions of the dune and beach system

- Societally acceptable flood risk

- A fully functional, self-supporting ecosystem

- Increased or maintained recreational values

- A resilient coastal community

The following are some reasons why a strategic goal may not be achieved and may require the application of an NNBF: (1) chronic erosion of a beach and dune system, (2) dune degeneration due to invasive species, and (3) lack of sediment input from the beach.

Operational objectives describe in more detail what to do to achieve the strategic goals. Often this implies a choice between different tactics; therefore, operational objectives are also sometimes referred to as tactical objectives (Marchand et al. 2011; Garel et al. 2014). The operational objectives need to allow for SMART (specific, measurable, achievable, relevant, and time-bound) assessments, using performance metrics (or coastal state indicators) and a benchmarking and evaluation procedure to support operational decision-making and adaptive management. The following are examples of operational objectives for beach and dune systems:

- Preserve dune strength (i.e., a design event that each dune transect should be able to resist).

- Dynamically maintain specific dune habitats.

- Dynamically maintain the cross-shore beach and dune volumes.

- Specify the risk threshold or reduction goal (e.g., estimated annual damage in dollars per year is a commonly used risk metric).

- Maintain a specified area of recreational beach.

- Optimize coastal storm damage risk reduction (the plan that provides the most economical return over a project life).

Section 9.5.4 summarizes strategic and operational objectives for four selected case studies.

\subsubsection{From Objectives to a Management Strategy}

Once the goals for an NNBF beach and dune project are set, a management strategy must be identified to meet the defined objectives (see the NNBF Planning Phase, Steps 3 to 5, and options analysis in Chapter 2; also see Section 9.7.2). The most appropriate management strategy will likely be one of the following four most common types for coastal beach and dune systems, as identified from more than 20 case studies in the United States, northwest Europe, and New Zealand:

- Advance the line. New defenses are planned to extend the land area seaward.

- Hold the line. The current alignment of the defense is maintained. 
- Retreat, rollback, or managed realignment. The shoreline can move landward to an agreed position.

- Do nothing. No active intervention is planned.

Management strategies can differ geographically and change over time depending on many factors, including (changing) objectives, changing financial budgets, and future conditions. As an example, the map of Poole Bay and Christchurch Bay, on the south coast of England, shown in Figure 9.13, displays spatially varying coastal management strategies based on short-, mid-, and long-term considerations. The strategies range between managed realignment (active retreat) and advance the line, with the two extremes occurring next to each other in one policy unit around Christchurch Bay.

\section{Figure 9.13. Map of Poole Bay and Christchurch Bay on the South Coast of England Displaying Spatially Varying Management Strategies for the Area}

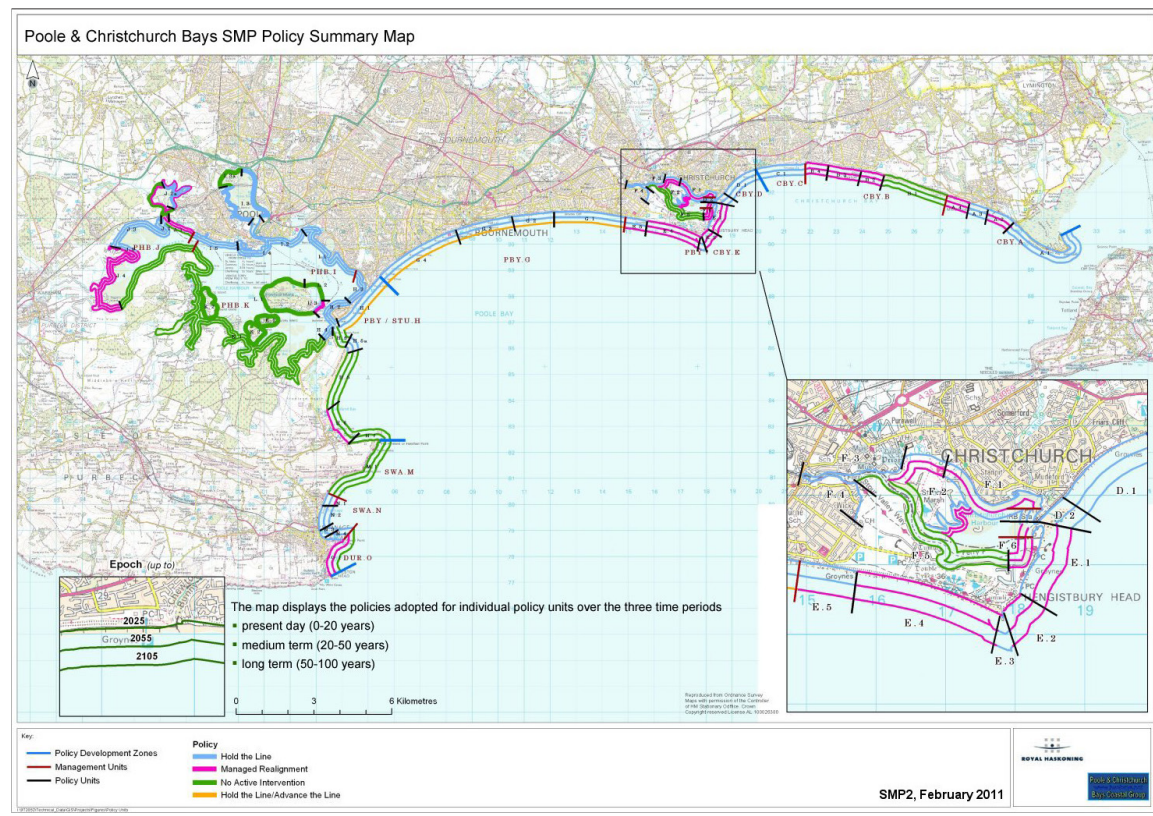

Source: Adapted from Royal Haskoning 2011

In addition, there may be a need to adjust strategies over time. Ideally, an adaptive and robust coastal plan identifies such adjustments (see Chapter 6 ). An adaptive plan aids decision-makers in the identification of proactive, short-term actions while also establishing a flexible framework to guide future actions that allow for adaptation over time as the uncertain future unfolds. Adaptive planning and adaptive management are critical to the successful implementation of flood risk and erosion mitigation strategies and associated measures (see Chapter 7; see also Section 9.7). 


\section{Adaptive Planning Using Dynamic Adaptive Policy Pathways}

The Dynamic Adaptive Policy Pathways (DAPP) approach (Haasnoot et al. 2013; deltares.nl 2019) is a proven method for planning under uncertainty in future conditions of climate and socioeconomics. The essence of DAPP is to plan proactively in the short term and respond dynamically in the mid to long term as the future unfolds. DAPP shows possible sequences of actions or measures over time, meeting the policy objectives as we move into an uncertain future. The timing of future measures is assessed continuously by monitoring climate and socioeconomic trends. Multiple pathways can achieve the objectives, and together these are visualized in a transit map infographic (see Figure 9.14), which shows the shelf life of measures as conditions (e.g., sea level) change. A preferred pathway is selected with substantial stakeholder involvement and a suite of additional considerations.

Figure 9.14. Adaptation Pathways Map and Scorecard Presenting Costs and Benefits

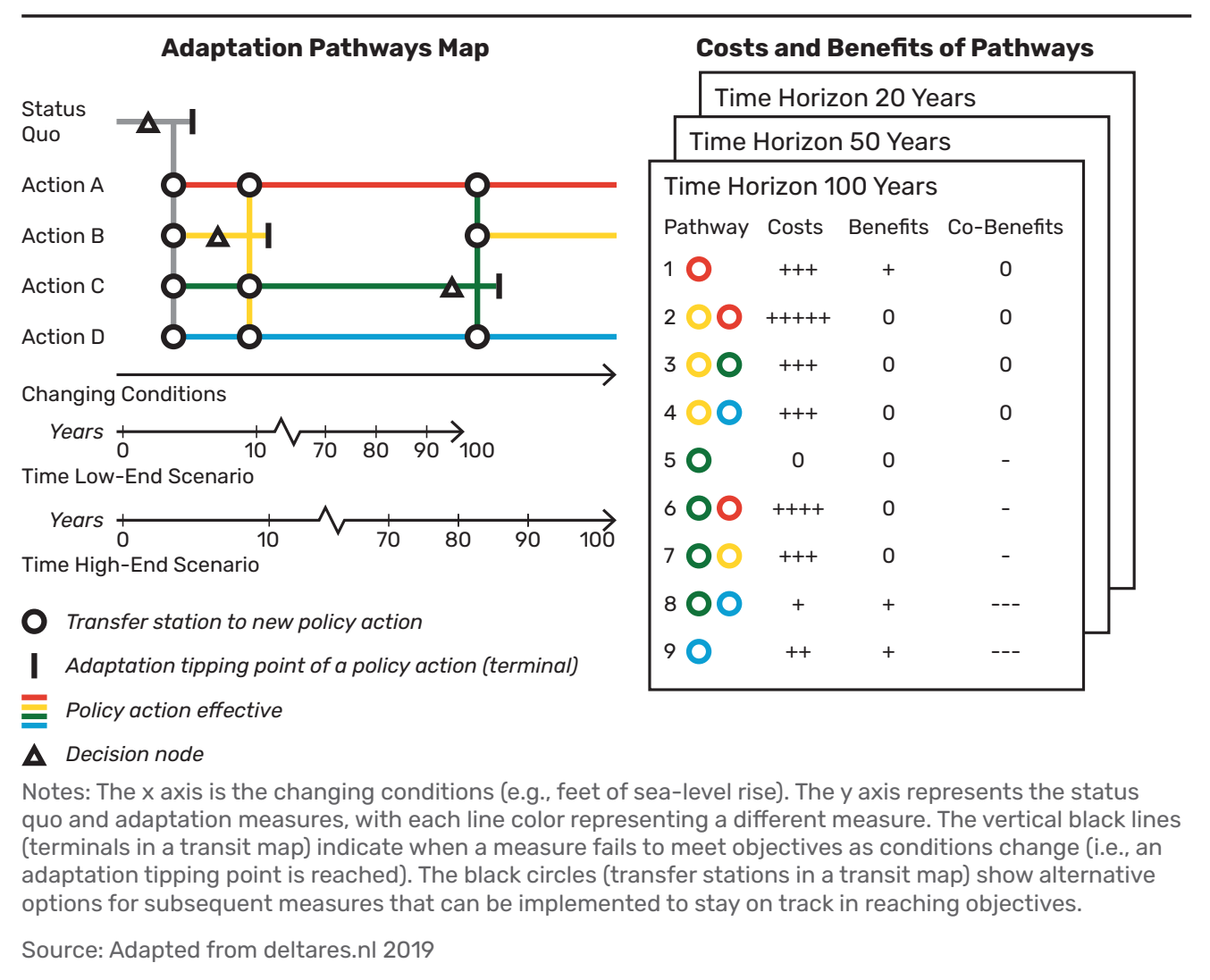


DAPP is a structured method comprising the following seven steps (see also Haasnoot, Warren, and Kwakkel 2019):

1. In the decision context, assess the uncertainties that are relevant for the planning process and identify with decision-makers and stakeholders the objectives of the plan.

2. Assess vulnerabilities now and as conditions change in the future. Identify adaptation tipping points and adaptation opportunities.

3. With stakeholder involvement, identify all potential adaptation actions to achieve objectives as conditions (e.g., sea level) change in the future. Use expert knowledge and, if available, quick-scan models to narrow this set to a selection of high-potential actions. Use detailed models for identifying flood risk to determine the adaptation tipping points of individual actions and combinations of actions.

4. Develop adaptation pathways using the results. Use these tipping points to develop the adaptation pathways, with each pathway representing a viable sequence of actions that will meet objectives under changing conditions.

5. Design an adaptive plan. The pathways are evaluated in a multicriteria analysis using a suite of tailor-made criteria typically involving cost, co-benefits, feasibility, community acceptance, and ecological impacts. This evaluation results in a preferred pathway.

6. Implement the plan. Once a preferred pathway is selected, commence the financial and policy requirements for implementation and the implementation and design of short-term, no-regret actions.

7. Design a monitoring system. Monitoring signals of changing conditions is a key aspect of the DAPP approach because it triggers decision-makers when they need to begin the process of implementing the next action in the pathway.

An adaptive planning approach such as DAPP has considerable advantages over more traditional planning approaches. The adaptation pathways are almost independent of future scenarios (scenario neutral), which alleviates the paralysis surrounding which scenario to consider in the planning. DAPP works with adaptation tipping points; these are the shelf lives of actions in terms of how much change in conditions (e.g., sea-level rise) they can accommodate and still reach community objectives. Climate scenarios inform the timing of the tipping points, which is when a new or additional action in the plan should be implemented. New climate scenarios affect only the estimated timing in the adaptive plan. DAPP looks beyond a design event by working with community objectives such as a tolerable risk level and assessing how that objective can be met as sea level rises, up to and beyond design values. The adaptation pathways help lead to no regret actions, by illuminating dependencies between actions and identifying locked in situations. DAPP creates adaptive plans that are robust and sufficiently flexible to ensure 
a community is prepared to respond to changing conditions as the future unfolds. DAPP does not plan for one specific future but rather accepts the uncertainty in the future and plans for changing conditions, monitoring climate signals carefully to determine when the next step in the plan will be needed. Participatory stakeholder engagement is built into the approach and supported by methods and tools that can be tailored.

\section{Dynamic Adaptive Policy Pathways for a Coastal Area in New Zealand}

New Zealand's Clifton to Tangoio Coastal Hazard Strategy 2120 (hbcoast.co.nz 2020) represents a coordinated approach to identifying and responding to coastal hazards and the influence of sea-level rise over the next 100 years along a 22-kilometer $(\mathrm{km})$ stretch of mixed sand and gravel coast backed by a town and several smaller coastal communities. It provides a platform for long-term planning and decision-making.

The vision of the strategy (strategic objective) is that coastal communities, businesses, and critical infrastructure are resilient to the effects of coastal hazards. The objective is to take a long-term (100-plus-year) approach and identify the choice, or series of choices, that provide the most cost-effective outcome for the community while addressing economic, environmental, cultural, and social issues.

Following a comprehensive study of the natural systems, coastal erosion, and inundation hazards and a risk assessment, the stakeholders used the DAPP approach and pathway generator tool (deltares.nl 2019) to derive a societally acceptable pathway.

The example presented in Figure 9.15 shows that due to relatively high rates of shoreline erosion, maintaining the status quo is not acceptable. A possible pathway begins with beach nourishment. This is likely to be sustainable until sea-level rise reaches $0.2 \mathrm{~m}$ above present levels. Currently, nourishment is likely to require control structures to remain cost-effective, balancing the cost of importing sediment with the cost of the structures. Beyond $0.4 \mathrm{~m}$ of sea-level rise, the preferred strategy is managed retreat, removing land-based assets from the coastal edge. However, it could be that beach nourishment or seawall structures can be engineered to address at least $0.95 \mathrm{~m}$ of sea-level rise. The use of NNBF provides time to initiate the required plan changes and responses to facilitate a progressive retreat from the coastal edge while maintaining communities and their values. The blue-shaded pathway represents the recommended pathway for the Clifton area, comprising a seawall, protecting this region in the near term ( 0 to 20 years) and midterm (20 to 50 years), followed by managed retreat in the long term. 
Figure 9.15. Sea-Level Trigger-Based Policy Actions Matched to Representative Concentration Pathways Scenarios

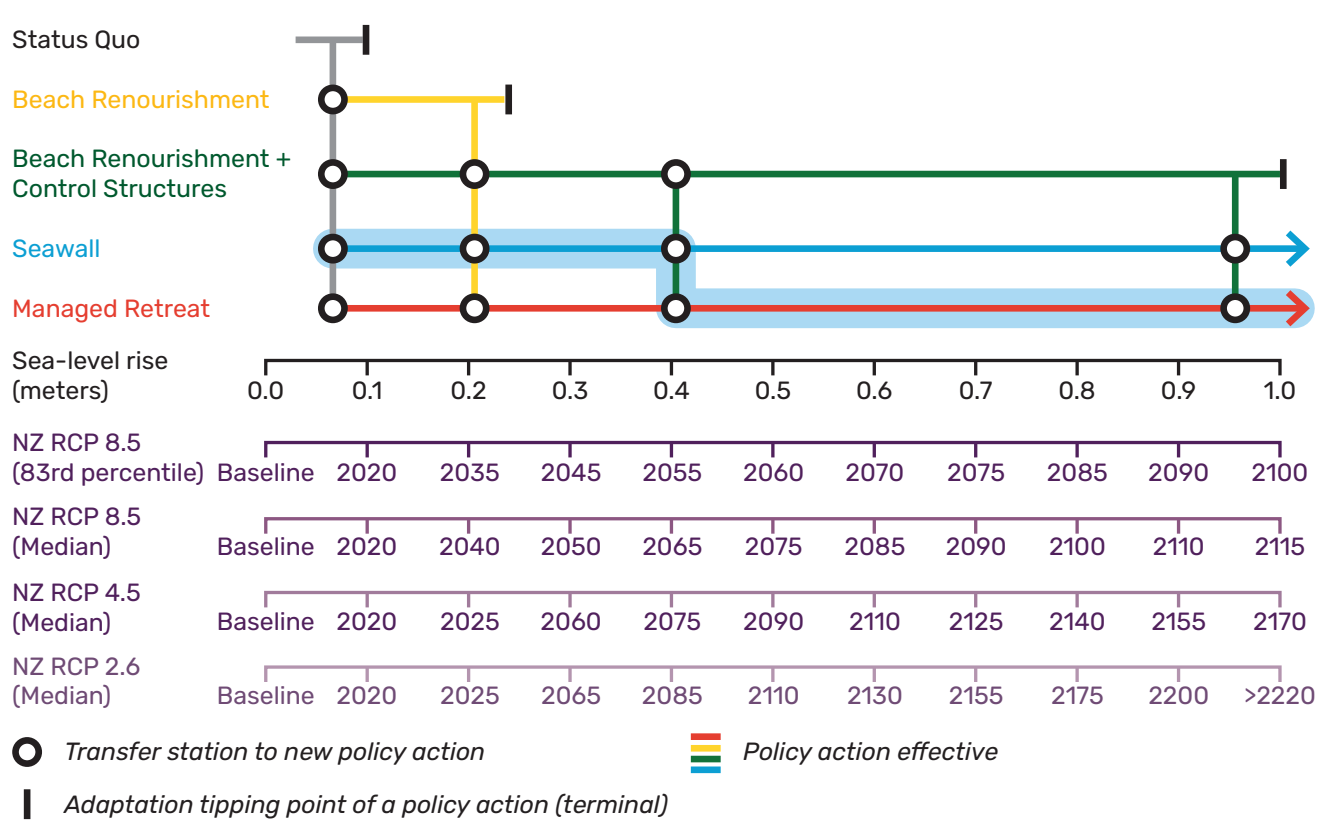

Note:

NZ RCP: New Zealand representative concentration pathways

Source: Adapted from deltares.nl 2019

\section{5 | Design}

\subsubsection{Developing Designs}

Once strategic goals and operational objectives are in place, the next step is to develop and evaluate the different combinations of possible solutions. This step enables effective integration of the various purposes and outcomes formulated by the varied stakeholders, thereby also facilitating the decision process (see $\underline{\text { Chapter } 3 \text { ). }}$. 
The existing conditions of the project setting and the desired functionality of the solution primarily determine which design options are feasible. The design of a beach or dune differs depending on the intended function (e.g., when beaches and dunes are used as a primary defense [standalone] or as an additional flood defense [hybrid solution]). The conceptual design stage should identify the solution space and potentially conflicting interests. For example, a beach system with a relatively large grain size, which is beneficial for flood defense, will probably not be as suitable for dune formation, beach habitat, and recreation.

Figure 9.16 identifies the following three general conceptual designs for the management of beach and dune systems, reflecting different strategies (see discussion in Section 9.4.1):

- Retreat, rollback, or managed realignment would allow the beach system to migrate landward. Nourishments, as part of this strategy, often aim to slow the landward migration of the beach and dune system.

- Hold the line would nourish the beach system to maintain the location of the beach and shoreline.

- Advance the line would nourish the beach with enough sediment volume to move the beach system and shoreline seaward.

The selected design largely depends on the cross-shore distance between the resources and infrastructure of interest and the waterline, the health of the beach and dune system, and the intended use of the area. The selected design can transition over time with both increasing and reduced intervention. For example, a project may start with retreat (Figure 9.16) but transition into hold the line once the shoreline position reaches a threshold (Figure 9.16). When hold the line is not sustainable, or if the resources behind the beach and dune are relocated or are considered less valuable, the retreat design-or perhaps a do-nothing strategy-can be adopted. A rigid backstop structure made of a nonerodible material such as concrete, geotubes, or stone can be part of the initial nourishment scheme or implemented over time as needed (Figure 9.16). The hard backstop feature is a final line of defense during a storm event and ideally should only be engaged during a relatively severe storm. In addition, for the advance the line design, progression seaward can be completed through time with successive nourishments and does not necessarily have to be built to full width during one construction project.

Figure 9.16 shows dunes in all three designs. Dunes are an integral part of a natural beach and dune system, and they operate together for both coastal storm damage reduction and as an ecosystem. If an existing system does not have dunes, or they are in a reduced state compared to historical or natural conditions, strong consideration should be given to enhancing or adding dune features (as shown in Figure 9.16). 
The various components of each design can be nourished individually or in combination. For example, for hold the line, it may be viable only to feed the dry beach and dune (or perhaps only nourish or build a dune). Equally, it may be feasible to sustain the system using only nearshore nourishment below the waterline. These variations are system and goal dependent. Larger-scale nourishments could include delta and mega nourishments such as the Dutch sand motor (also known as sand engine) project (Figure 9.17).

Figure 9.16. Three General Conceptual Designs for Beach and Dune Systems

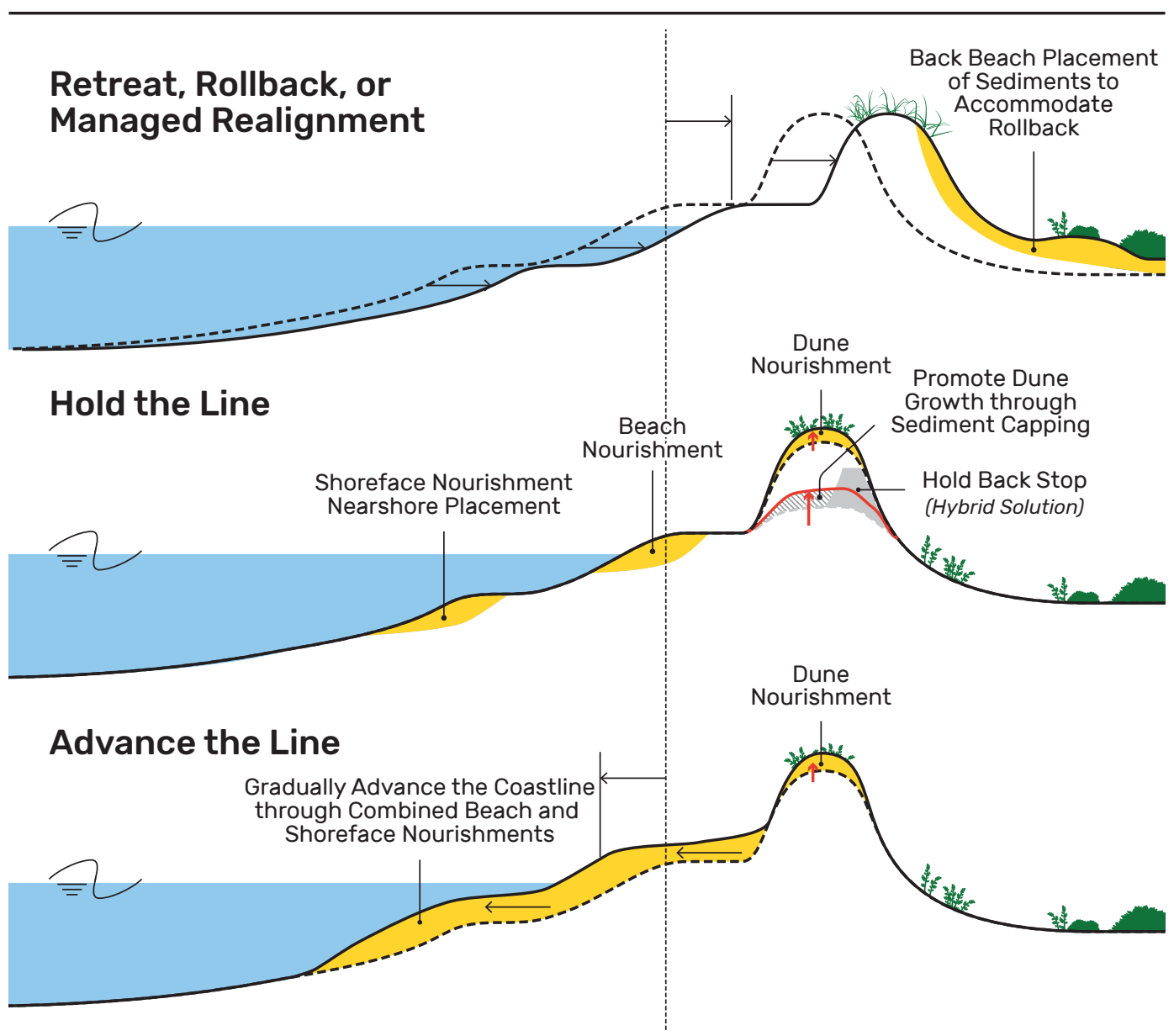


Figure 9.17. Different Spatial and Temporal Scales of Nourishment Schemes

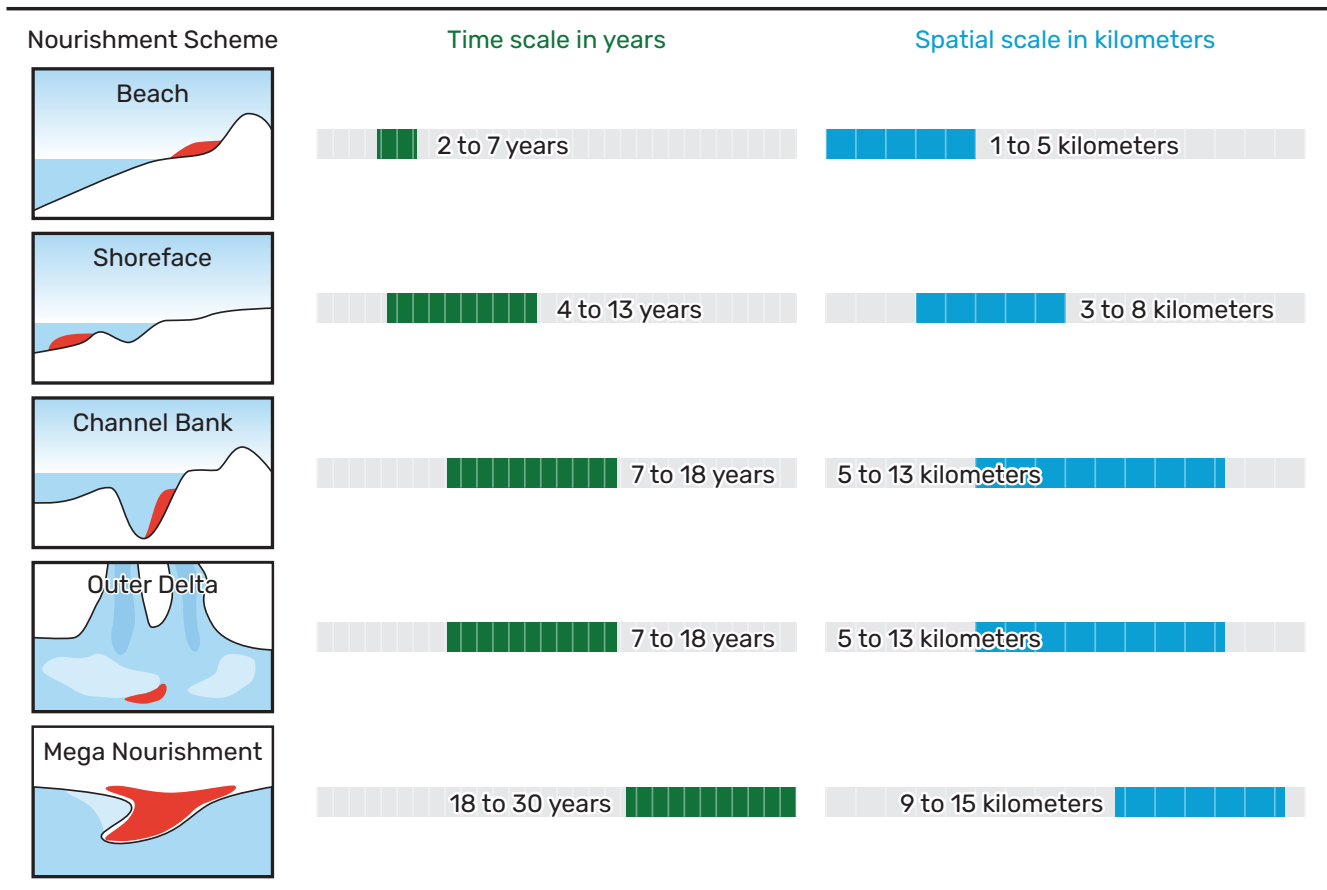

\subsubsection{Design Principles and Parameters}

The geometry of beaches and dunes fundamentally controls the nature of their interaction with coastal processes and, therefore, their FRM capacity.

It is recommended to mimic or re-create as far as possible the natural conditions of the location in question and to work with natural processes and reduce maintenance requirements by adopting the following two principles:

- Avoid building beaches with unnaturally high crests. Unless the beach width also increases, raising crest elevation will increase the gradient of the beach profile, which, in turn, will reduce the wave-attenuating quality of the beach and lead to impacts such as beach scarping and cliffing and enhanced movement of sediment offshore during storms.

- Design beaches to allow a degree of profile dynamism rather than attempting to create a static system. This degree of freedom will build in adaptability to pressures such as storms and climate change, and thus resilience, and focus on beach slope, volume, and width as primary design concerns, while allowing crest height to develop naturally. This approach will mean that some overtopping may occur during storms. In certain situations, overtopping may be unacceptable, but where suitable conditions exist, this approach will facilitate processes critical to beach evolution and adaptation, such as crest buildup and rollback, 
and will promote natural recovery. Allowing the development of more extensive profiles without artificially raised crests, and if necessary, removing any artificial constraints, can also improve connectivity between beach and dune complexes. Improved connectivity enhances the resilience of both beach and dune and creates a more sustainable system that provides more FRM, ecological, and socioeconomic benefits.

Building on the established conceptual system understanding, discussed in Section 9.3, and typical objectives and metrics, discussed in Section 9.4, the following key design parameters should be considered when including beaches and dunes as NNBF measures for coastal flood and erosion risk reduction and resilience:

- Grain size

- Beach slope

- Active profile height

- In situ volume
- Width

- Control structures

- Habitat types

Other requirements, such as conservation and environmental enhancement and recreation, need additional considerations. Sections 9.5.2.1 through 9.5.2.7 outline approaches to determining the above-mentioned design parameters for NNBF beach and dune systems. It may be necessary to deviate from these approaches to meet critical performance objectives (e.g., by adding an engineered core within a dune complex to act as a backstop to achieve the hold the line policy or by installing a terminal groin to aid retention of beach sediment within the system).

\subsubsection{Grain Size}

The geology and native sedimentology of coastlines, especially the sediment grain sizes, exert considerable influence on the morphology of beaches and dunes and should, therefore, inform scheme design, particularly of nourishments and the selection of borrow areas. Gravel beaches have profiles with discrete berms and ridges and steep slopes, whereas sandy systems generally have shallower gradients (e.g., CIRIA 2010). This understanding allows engineers to mimic natural conditions in their designs and, if necessary, identify appropriate borrow areas.

A beach and dune design that mimics natural sediment grain sizes, sorting, and density supports recovery of the coastal ecosystem after implementation (e.g., Van Tomme 2013; Winnard 2012). For sandy beach and dune systems, placement of significantly finer sediment may result in quick loss of nourished sand (see also Section 9.5.2.4). Overly coarse sediments may result in the formation of a steeper beach (i.e., a change in beach state; Wright and Short 1984), which is often unwanted due to negative impacts on recreation, safety, and the environment (e.g., Hearin 2014). 
The grain size distribution of nourished sediments can also affect sandy beach ecosystems, with overly coarse sediments causing adverse impacts on benthic communities (Van Tomme 2013). Placement of too coarse or fine sediments (less than 75 microns) on the intertidal beach may also reduce the eolian sediment transport capacity and thus sediment deposition in the dunes. Changes in eolian sediment transport and deposition may cause changes in the species composition of the dune vegetation, altering the dune ecosystem as well. For sandy beaches inhabited by hatching sea turtles, additional sediment properties in the borrow area (e.g., color and percentage of fines less than 5\%) need to match the naturally occurring sediments on the beach (Koch, Forrest, and Brantly 2011) to avoid unwanted changes in success rates and gender of turtle reproduction. Such additional conditions apply, for example, to the shores of Florida. Priestas, Berkowitz, and Vanzomeren (2019) studied the changes in sediment color and the percentage of fines during the dredging and placement process using a hopper dredger. The results indicate that the dredging process of hopper dredgers changes the color and reduces the volume of fine sediments in such a way that the requirement for the sediment properties in the borrow areas could be less stringent.

A potential benefit of using less mobile (coarser) sediment is that it typically remains in the project area longer and performs better during storms (less cross-shore erosion). This benefit could be a design consideration for nature-based beach and dune systems (see also Section 9.5.2.4), although excessively increasing the grain size may also increase permeability and, therefore, flow through the beach.

\subsubsection{Beach Slope}

The profile of beach nourishments is a geometric shape typically consisting of a possible dune, a dry beach berm, and a beach (foreshore) slope. When considering the nourishment of existing beach and dune systems, the aim is to establish a relatively stable equilibrium cross-shore profile, with the gradient of the cross-shore profile dependent on grain size, wave, and tide conditions. The equilibrium profile can be temporally dynamic, where it varies in morphology over the seasons, as illustrated in the beach classification scheme of Wright and Short (1984). It is unrealistic to expect a static or uniform profile because variation in morphology is natural for beaches.

The type of available sediment combined with hydrodynamic forcing can be used to determine the expected beach slope. The connection between the beach slope in the intertidal zone and the sediment grain size has been observed in previous studies. The relationship described by Bascom (1951) and Wiegel (1964), which found the beach slope to be a function of sediment grain size and beach exposure, has been extended to include additional data from around the world in Figure 9.18 (McFall 2019). Using wave height and direction, beach exposure can be quantified and categorized as exposed, moderately protected, or protected (Mangor et al. 2017). 
Figure 9.18. Grain Size-Slope Relationships of Sandy Beaches in the Intertidal Zone (with Data from around the World)

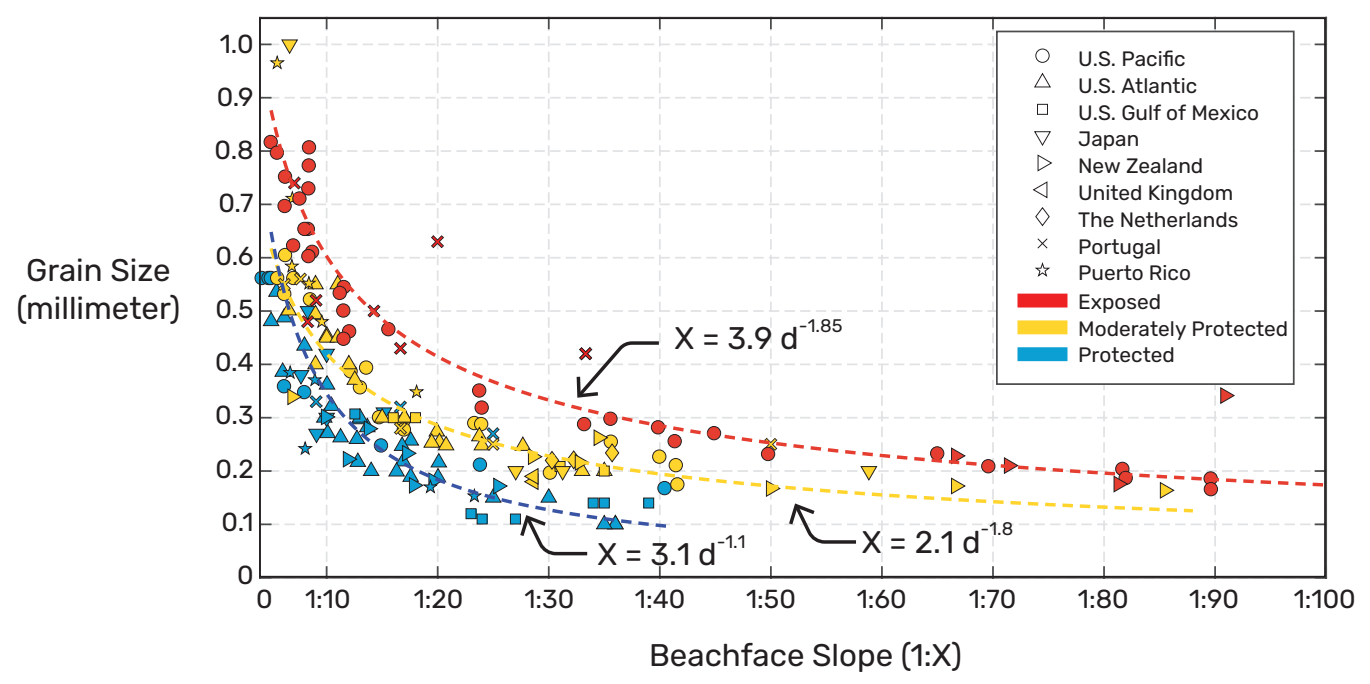

Source: Based on original graph by Wiegel 1964 with additional data from case study sites in this chapter and other readily available case study information (adapted from McFall 2019). Reproduced with permission from the Coastal Education and Research Foundation, Inc.

\subsubsection{Active Profile Height}

The active profile height is the vertical distance from the crest of the beach-or dune, if present-to the depth of closure. The beach crest typically varies between 0.5 and $1.5 \mathrm{~m}$ above the highest astronomic tide, depending on the exposure of the beach to wave energy and swash height. Dune height can range from one to tens of meters, depending on various location-specific conditions. The depth of closure is the depth beyond which no significant profile fluctuation takes place due to coastal processes (namely wave action). Insight into the location of the depth of closure is valuable because any sediment imported or relocated as part of an NNBF design scheme may redistribute in the active profile. In contrast, any material moved beyond this point (seaward) is no longer part of the dynamic coastal system.

When available, historical beach profile information should be used to inform the dimensions and extent of the active beach profile. However, in many areas, information is limited, and alternative empirical methods are available to assess the equilibrium profile and depth of closure. The Hallermeier method is commonly used (Hallermeier 1981) to determine the closure depth based solely on wave data. "Establishing the Closure Depth for the Dutch Coast" and "Estimating the Depth of Closure for the United States" illustrate both ways of establishing closure depth. The obtained values can display significant spatial and temporal variability. 


\section{Establishing the Closure Depth for the Dutch Coast}

The closure depth for the coast of the Dutch mainland has been investigated for decades. The depth of closure ranges from 6 to $7 \mathrm{~m}$ below MSL over several years (Marsh et al. 1998) to between 10 and $20 \mathrm{~m}$ below MSL at timescales greater than 50 years (Kleinhans 2002).

Based on visual assessments from more than 50 years of annual surveys (Figure 9.19), the profiles converge to a depth of closure of approximately $9 \mathrm{~m}$ below MSL (Normaal Amsterdams Peil [NAP], or Normal Amsterdam Datum). However, it is also clear that the structural lowering of the shoreface is also happening to at least $15 \mathrm{~m}$ below MSL.

Using Hallermeier (1981) and Birkemeier (1985), the depth of closure ranges from 12.2 to $12.9 \mathrm{~m}$ and from 9.3 to $9.8 \mathrm{~m}$, respectively.

Figure 9.19. Spatial Variability of the Depth of Closure along the Dutch Coast Using Annual Transect Observations (JARKUS)

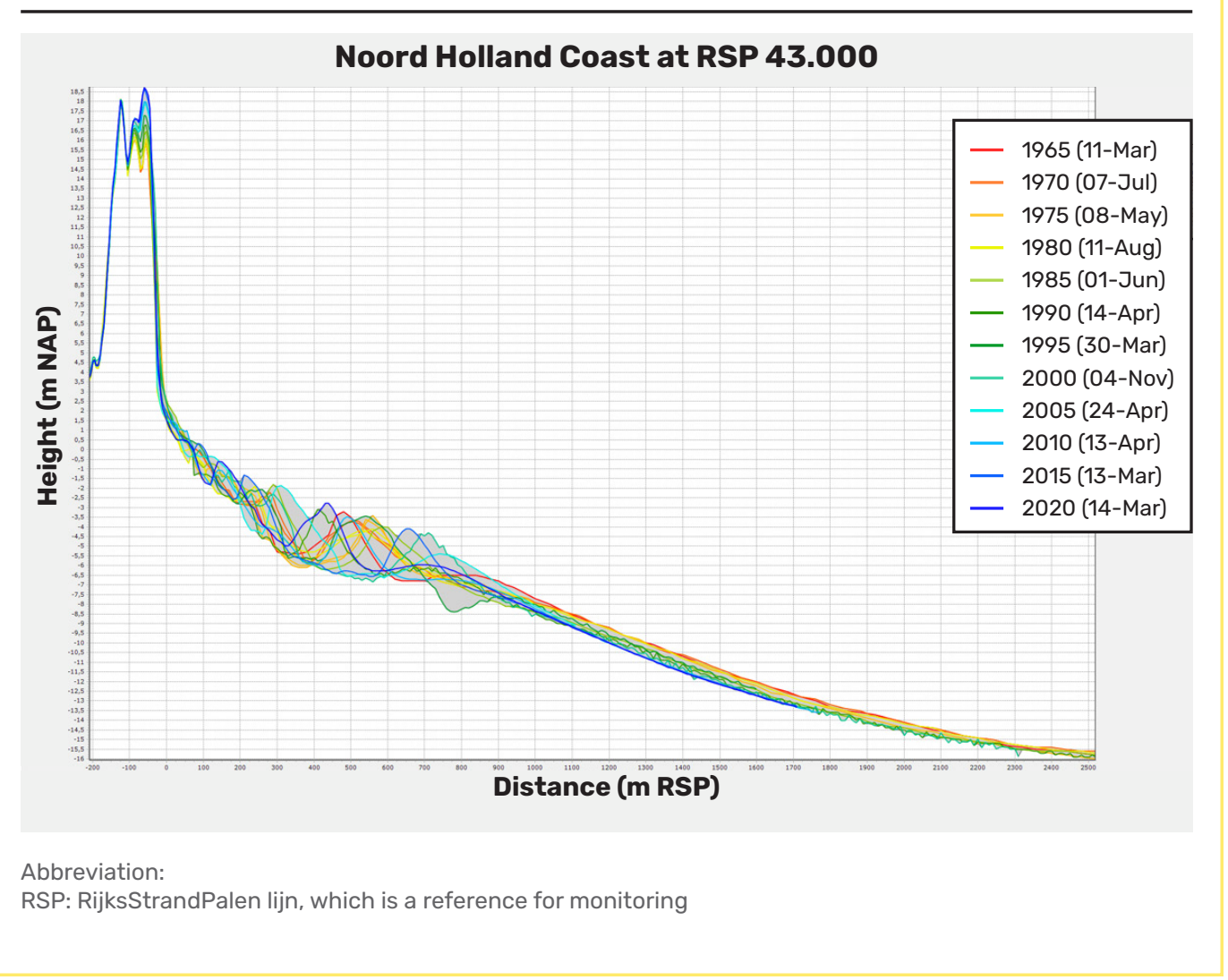




\section{Estimating the Depth of Closure for the United States}

The depth of closure for the entire United States coastline was estimated by Brutsché et al. (2016) using historical wave hindcast data and the empirical equations derived by Hallermeier (1981) and Birkemeier (1985). Figure 9.20 presents the spatial variability of the depth of closure using Hallermeier's equation and shows that the more exposed beach systems have a greater depth of closure.

Figure 9.20. Spatial Variability of the Depth of Closure along the Gulf of Mexico and the Florida Coast Using Hallermeier's Equation Showing More Exposed Beach Systems Having a Greater Depth of Closure

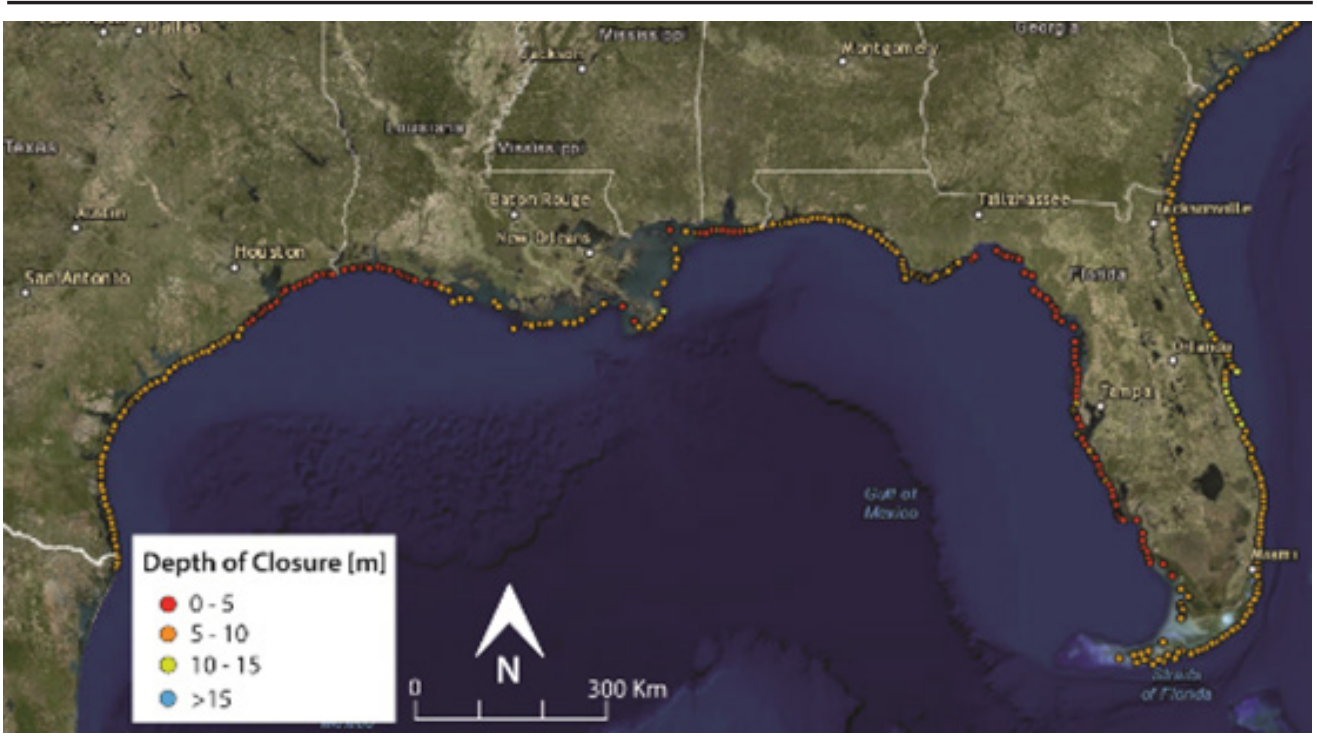

Source: Brian McFall, U.S. Army Corps of Engineers 


\subsubsection{In Situ Volume}

For nourishments of existing beaches, the required in situ beach volume must be examined, considering not only the past, present, and future sediment budgets for the (envisioned) beach and dune system at stake but also the performance of the beach during storms. Beach volume is known to be a critical factor in beach performance during storms if the berm and dune elevations replicate the natural system.

When a long-term erosional trend is present, without changes to management or coastal processes, this trend is likely to continue and possibly increase with the effects of climate change. For a sustainable beach-dune system, a negative sediment budget needs to be compensated or slowed. In most cases, maintaining beach volumes requires ongoing sediment placement if the strategy is to hold the line. However, it may be possible to enhance sediment budgets in vulnerable locations by addressing the causes of sediment deprivation (e.g., removing or modifying updrift groin fields or harbor arms). The period between adding nourishments and determining the volumes required will depend on the losses experienced. However, it is also important not to overfill the system because this could result in excessive initial erosion and loss of sediment (van Rijn 2014). "Natural Beach and Dune Systems, Nourishment Design" gives general guidance determining nourishment volumes based on practices in the Netherlands. Many other countries use similar principles. In some instances, it may be preferable to allow or even actively promote rollback of eroding beaches as an NNBF. An example is when rollback results in a change in planform that reduces longshore wave energy (e.g., switching from drift to swash alignment) and the landward movement activates new sediment sources such as stable dunes, cliffs and bluffs, or relict beach deposits.

The required sediment volume for beach nourishment and construction of nature-based beaches also depends on the properties of the sediments in the borrow area. Ideally, these are similar (see Section 9.5.2.1), but if not, corrections in fill volume and beach profile should be anticipated (see "Volume Corrections"). 


\section{Natural Beach and Dune Systems, Nourishment Desigr}

The required volume of sand for nourishment is a function of the specified design requirements for a certain period or a lifetime considering the various loss mechanisms, such as seaward and longshore sediment transport. The sediment volume and beach slope are generally determined as follows:

- Determine the volume of sand eroded annually in the active zone along the considered coastal section for approximately 3 to 10 years using suitable trend analysis methods (see Section 9.3.1). Preferably, data from a longer period is used, but this is not always possible due to earlier nourishments.

- Multiply the annual volume by the required lifetime to obtain the total in situ nourishment volume to be placed in the coastal section under consideration. Generally, the contracted gross sediment volume is 1.15 times the in situ design volume, on average suitable for soft-medium sands (bulking factor for fine-medium sands; e.g., Bray et al. 1997).

- Determine the volume per running meter in consultation with the contractor. Sediment volume per running meter should match both the longshore distribution of the projected erosion and the minimum and maximum volume placement per meter on the nourishment location (beach or shoreface).

- For beach nourishments, place the sand between the dune toe level and the low water level, aiming for a sandy beach slope similar to the natural beach slope (e.g., approximately 1 vertical to 30 horizontal in the Netherlands). Strict requirements for the beach slope are often not necessary because the sea will adjust it. Strict slope requirements may imply risks for the contractor, which transfer to costs.

- For shoreface nourishments, place the sand seaward from the outer breaker bar, aiming for a crest height that matches the existing breaker bars. No strict requirements are needed for the exact shape of the nourishment because the sea will adjust the profile form quickly. Strict requirements may imply risks for the contractor, which transfer to costs. 


\section{Volume Corrections}

Placement of coarser sediment can result in a steeper beach profile and change the morphology and habitat of the existing system. An overfill factor model (e.g., in the Shore Protection Manual [USACE 1984]) can be used to adjust the required fill based on the difference between the in situ and source sediments to understand the potential consequences of different sand gradings.

The potential for rapid sand loss due to weathering should be considered for landbased sand sources because these sources tend to have a higher percentage of fines susceptible to marine weathering. Sand loss means that either additional volumes will be required to achieve the in situ design amount or processing will be required to reduce the content of fines susceptible to weathering. The fill factor method in the Shore Protection Manual (USACE 1984) does not consider the weathering process and is an additional factor to consider for land-based sources.

Mixed sand and gravel or gravel beaches can have a wider grading, and the distribution varies along with the beach profile (Schulmeister and Rouse 2003). Depending on local requirements, this might present more freedom in sorting the source sediments, although it requires a similar assessment of potential sediment losses along the profile.

\subsubsection{Width}

The cross-sectional profile width of a sediment placement is a function of the nourishment volume and existing profile characteristics. The beach width, an essential parameter for eolian transport into the dunes and recreation, can be derived using observations and the updated relationship between beach slope and grain size (Figure 9.18), and accounting for tidal low and high water levels.

\subsubsection{Consideration of Control Structures}

For nature-based beach and dune projects, it is advisable to design the beach orientation normal to the dominant incident wave direction to reduce the longshore transport losses from the system. Controls, such as headlands and groins, might also be used to mitigate longshore sediment losses. Because groins block the longshore sediment transport, downdrift sediment deficits may develop. Control structures can also support natural beach and dune systems experiencing long-term erosion, and where nourishment is not a viable or sufficiently effective option (e.g., Simm et al. 2020). 


\subsubsection{Dune Habitat Types (Vegetation)}

In the case of dunes, the stabilizing influence of vegetation can be a critical control on engineering performance (see Section 9.4.1 for a characterization of dunes and recommendations for management). Consultation with dune ecologists will, therefore, be essential to help maximize the efficacy, for both flood risk and habitat management, of the NNBF measure. The involvement of dune ecologists is also necessary to avoid unintended negative consequences associated with, for example, the introduction of inappropriate non-native, invasive species to an area or the interruption of nutrient dispersion. Another consideration is whether to plant vegetation or let dune vegetation develop through natural regeneration or establishment. Both options require an investigation of habitat suitability. For example, "Description of Habitat Conditions and Processes for Embryonic and White Dunes in the Westerschelde Estuary" provides some guidance for assessing habitat suitability and developing conceptual designs to support suitable dune habitat. The values for certain conditions in this example are appropriate to determine the feasibility of nature-based embryonic and white dunes along the estuarine shore of the Westerschelde Estuary in the Netherlands (Deltares et al. 2005). From an NNBF design perspective, general critical habitat conditions include the following: (1) sufficient development space, (2) a sandy beach wide enough to enable eolian sediment transport, and (3) minimum required sediment deposition in the dunes to maintain the base elevation requirement (see "Description of Habitat Conditions and Processes for Embryonic and White Dunes in the Westerschelde Estuary"). The estimated values for elevation, beach width, wind conditions, climate, and eolian transport and development space are all location specific. They were and can be derived for other locations, using historical data pertaining to the area and nearby beach and dune systems, calculations, and expert judgment. For nature-based beach and dune systems with limited data availability and reference areas, the flowchart in Figure 9.21 and the beach slope graph (Figure 9.18) can be used as a starting point to assess the feasibility of a beach and dune system and to develop site-specific conceptual designs. 


\section{Description of Habitat Conditions and Processes for Embryonic and White Dunes in the Westerschelde Estuary}

Figure 9.21. Flowchart of Conditions and Processes for Embryonic and White Dune Habitats as Established for a Case Study in the Westerschelde Estuary, the Netherlands

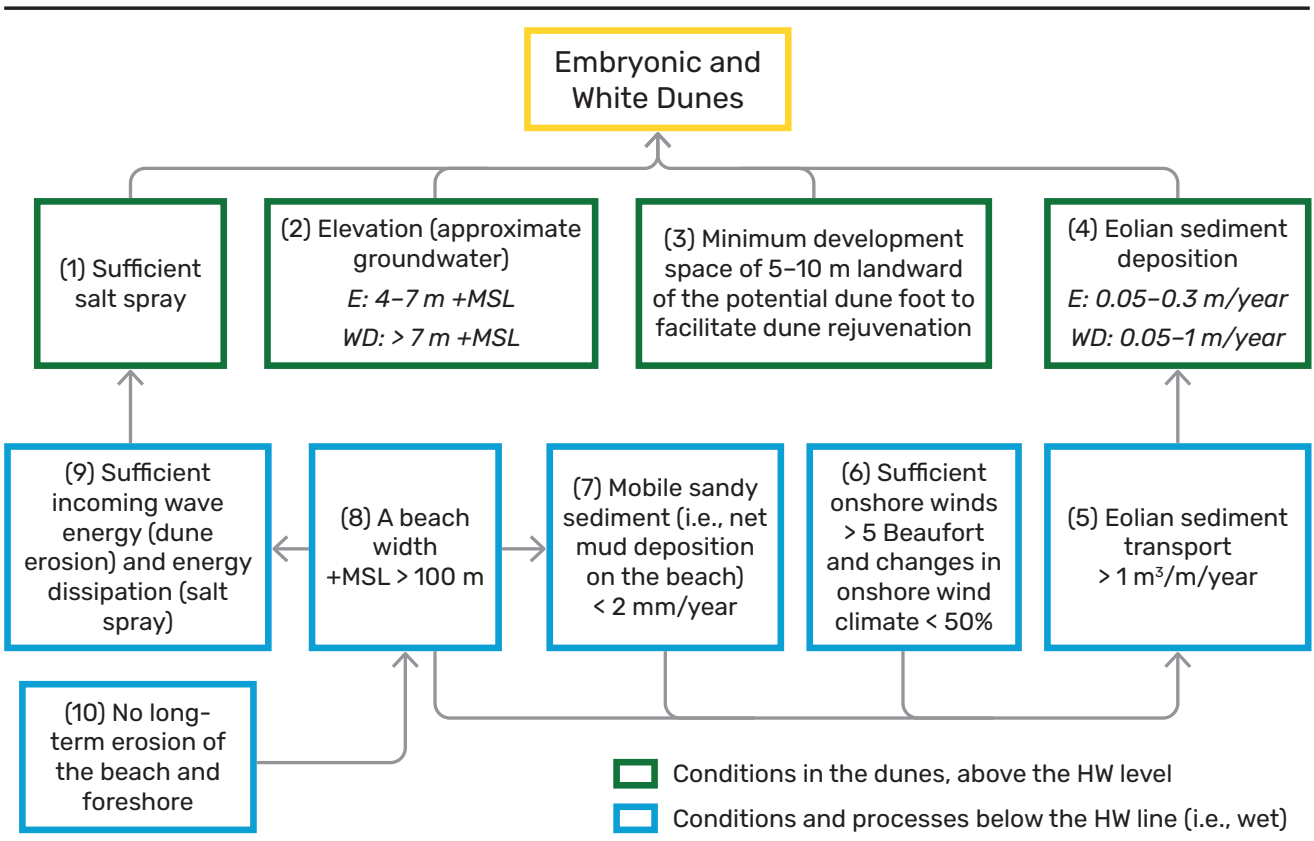

Abbreviations:

+MSL: above mean sea level

E: embryonic

HW: high water

WD: white dunes

Source: Adapted from Deltares et al. 2005

The following abiotic conditions and processes are critical for the formation of embryonic and white dunes (the numbers correspond to the numbered boxes in Figure 9.21):

1. Salt spray. If the salt spray is too low, dunes will become grassland or sea buckthorn habitat. Salt spray correlates with wave energy (exposure, 9) and wind (6). The effect of salt spray generally decreases rapidly in dunes-salt-tolerant species typically occur in the first $50 \mathrm{~m}$ of dunes. 
2. Dune elevation. Elevation strongly relates to eolian sediment deposition (5) and the processes responsible for the minimum required development space. For the estuarine case study example, the transition between embryonic and white dunes occurs at an elevation of $7 \mathrm{~m}$ above MSL. Embryonic dunes prefer salty groundwater and can occur at elevations between 4 and $7 \mathrm{~m}$ above MSL. White dunes prefer fresh infiltration water at elevations greater than $7 \mathrm{~m}$ above MSL.

3. Development space. The horizontal area between the dune foot and any limit or barrier landward of the dune area-the development space-should allow for dune erosion during storms and seaward growth of the dunes during mild conditions. For the estuarine case study example, this space is approximately 5 to $10 \mathrm{~m}$ wide.

4. Sediment deposition. This condition is fulfilled when net sediment deposition is 0.05 to $0.3 \mathrm{~m}$ per year for embryonic dunes and 0.05 to $1.0 \mathrm{~m}$ per year for white dunes.

5. Eolian sediment transport rate. Conditions 3 and 4 in the case study example imply a minimum eolian sediment transport of 1 cubic meter $\left(\mathrm{m}^{3}\right)$ per meter per year on the beach above MSL. This process suggests the next three requirements.

6. Wind conditions and climate. Onshore wind conditions are five and more on the Beaufort wind force scale and no changes in the wind climate of more than $50 \%$ due to future constructions.

7. Availability of mobile sand (no silting up of the beach). This condition is fulfilled if regular resuspension by waves and tides occurs. For the case study example, this is the case under the following conditions:

- The simulated net annual deposition of silt and clay on the beach is less than $2 \mathrm{~mm}$.

- The simulated reference concentration of sand averaged over the representative hydrometeorological conditions exceeds 0 grams per liter.

8. Beach width. The beach width above MSL up to the dune foot is more than $100 \mathrm{~m}$.

9. Wave energy and dissipation. Incoming wave energy directly affects beach width, availability of mobile sandy sediments, development space (through erosion), and salt spray. Exact minimum required values are not known. Wave energy is likely to be most critical to mobile, sandy sediment availability. When deposition of mud is absent, it is plausible that salt spray and seasonal dune erosion will occur.

10. No long-term erosion of beach and foreshore. For sustainable dune maintenance, the foreshore should not experience long-term net erosion if the coast is not allowed to roll back. Structural loss of sediment after a beach and dune erosion event supports a sustainable dune development process, provided that the eroded sediment remains available for regrowth (i.e., dune rejuvenation). If this is not the case and structural erosion occurs, erosion should be mitigated with nourishment to let beach and dune habitats thrive. 
Designers should consider the type of habitat they want to create, the complexity necessary to restore natural ecological functions and services, and the target species to inhabit it. If a particular assemblage of species is desired (e.g., species with denser root networks to maximize sediment stabilization), the design of the measure should include them. Stabilization of dune vegetation implies the creation of a static dune system, which might not be optimal for ecology. Many dune species thrive best with relatively large sand dynamics in the dunes. Stabilization might, however, provide additional flood safety. For example, in some locations along the Dutch coast (at Meijendel north of The Hague and at Terschelling, for instance), manually initiated blowouts (lowered dune crest elevation) have been created to promote natural sand dynamics to increase the sediment volume in the backdunes and to increase biodiversity through resetting the ecological succession.

The implementation of an NNBF beach and dune project may cause an initial disturbance to the existing ecosystem. Renourishments may result in recurring disturbances. These disturbances (e.g., changes in the sediment volume of the beach) are not necessarily a problem because of the large-scale natural variability that occurs seasonally and more dramatically during storms. The long-term impact on beach and dune ecosystems depends on the speed of recovery versus the frequency of disturbance (Palumbi, McLeod, and Grünbaum 2008). When disturbance and recovery are in balance, long-term ecosystem impacts might be limited. Figure 9.22 provides a conceptualized example.

\section{Figure 9.22. Recovery versus Disturbance}

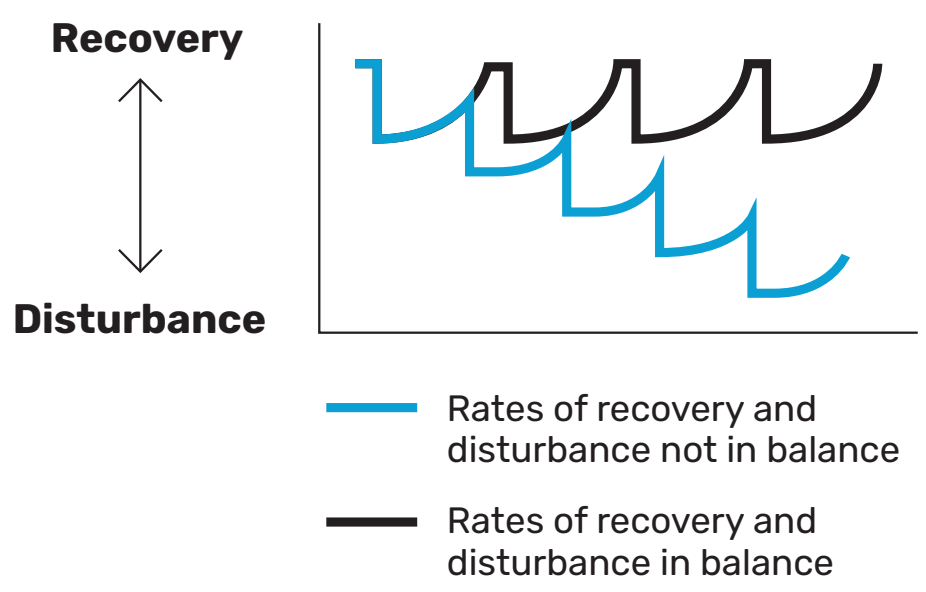

Note: When disturbance happens more frequently than the time needed for recovery, a negative trend will result. Note that other factors can also influence the patterns in ecosystem functioning (e.g., sea-level rise, pollution). 


\subsubsection{Costs and Benefits}

This section focuses on identifying the main factors affecting the costs and benefits of beach and dune NNBF projects rather than quantifying them because they are design, location, and governance setting specific. As explained in detail in the discussions on benefit and benefit evaluation in $\underline{\text { Chapter } 6}$, indirect benefits (such as avoided costs or losses), direct benefits (reduced flood risk), and co-benefits (e.g., habitat creation and recreation) are considered. The decision on whether to go ahead with a project should also consider nonmonetized (intangible) benefits such as visitor enjoyment and aesthetic and habitat values. The case studies in Section 9.5.4 show the role benefit and cost assessments play in the decision-making process of different countries. For example, the emphasis in the United Kingdom and the United States is on the monetized life-cycle costs and benefits per project. In the Netherlands and Denmark, this is less the case. The costs and benefits of Dutch FRM are analyzed at a broad national scale rather than project by project. The flood risk standards are set based on the analysis for the country (ENW 2016).

\subsubsection{Benefits}

As outlined in Section 9.2.3, beaches and dunes can offer flood and erosion risk reduction services by (1) attenuating incoming waves and, in some cases, storm surge water levels; and (2) trapping and stabilizing sediments. Besides these flood and erosion risk services, beaches and dunes are valuable coastal habitats. Maintaining or creating these habitats through the implementation of beach and dune NNBF are considered essential societal benefits, even though monetization of these benefits is sometimes tricky. Table 9.1 provides examples of beach and dune NNBF benefits and co-benefits derived from various case studies. "Example of Cost-Benefit and Multicriteria Analyses for the Katwijk Nature-Based Beach and Dune Reinforcement (the Netherlands)" provides examples of how the different benefits and costs were measured and included in the identified case studies.

Table 9.1. Examples of Beach and Dune NNBF Benefits and Co-Benefits

\begin{tabular}{lll}
\hline \multicolumn{1}{c}{ Broad category } & \multicolumn{1}{c}{$\begin{array}{c}\text { Beach and dune } \\
\text { functions }\end{array}$} \\
\hline Engineering & Wave attenuation & $\cdot$ Reduction in flood and erosion risk \\
\cline { 2 - 3 } & Surge attenuation & $\cdot$ Reduction in flood and erosion risk \\
\cline { 2 - 3 } & $\begin{array}{l}\text { Sediment trapping and } \\
\text { land building }\end{array}$ & $\begin{array}{l}\text { - Increase in land elevation, resulting in, for example, } \\
\text { resilience to sea-level rise }\end{array}$ \\
& - Reduction in erosion risk \\
\hline
\end{tabular}




\begin{tabular}{|c|c|c|}
\hline Broad category & $\begin{array}{l}\text { Beach and dune } \\
\text { functions }\end{array}$ & Benefits \\
\hline \multirow[t]{4}{*}{ Environmental } & $\begin{array}{l}\text { Habitat provision for } \\
\text { beach and dune species }\end{array}$ & $\begin{array}{l}\text { - Contribution to healthy and resilient coastal } \\
\text { ecosystems (and assistance in meeting legal nature } \\
\text { conservation targets) }\end{array}$ \\
\hline & $\begin{array}{l}\text { Diversity and density of } \\
\text { fauna and flora }\end{array}$ & $\begin{array}{l}\text { Increased opportunities for wildlife-viewing } \\
\text { recreation }\end{array}$ \\
\hline & & $\begin{array}{l}\text { - Contribution to healthy and resilient coastal } \\
\text { ecosystems }\end{array}$ \\
\hline & $\begin{array}{l}\text { Nursery habitat } \\
\text { for fish }\end{array}$ & $\begin{array}{l}\text { Increased or maintained fish populations (value for } \\
\text { both nature and commercial fishing) }\end{array}$ \\
\hline \multirow[t]{3}{*}{ Socioeconomic } & Recreation & $\begin{array}{l}\text { Increased or maintained possibilities for beach } \\
\text { activities }\end{array}$ \\
\hline & & - Attractive landscape for visitors and inhabitants \\
\hline & Education & $\begin{array}{l}\text { Education facilities and possibilities to show the } \\
\text { benefits of NNBF solutions to society, especially the } \\
\text { next generation }\end{array}$ \\
\hline
\end{tabular}

\subsection{Flora and fauna (biodiversity and wildlife)}

Land-use change, and interruption of beach and dune systems, may have a substantial adverse effect on biodiversity. The associated negative factors may include habitat loss, genetic erosion, reduction in ecological connectivity, decrease in species vigor, and loss of species richness. The enhancement of beach and dune systems through nature-based systems can serve to increase biodiversity through the targeted increase of site-specific flora and the reattraction of indigenous fauna (Straatsma et al. 2017), thus helping to restore, enhance, and protect myriad ecological functions and services. One possible method to evaluate the relative effectiveness of various nature-based approaches is through a net environmental cost-benefit analysis (see Chapter 6).

\subsubsection{Costs}

Project costs consist of capital costs (the cost to deliver the project initially) and maintenance costs (the cost of subsequent work to repair, maintain, and monitor the project). Capital costs include design services, construction, land purchases (if needed), required mitigation (e.g., creation of additional compensatory habitat), stakeholder engagement, licensing, and permitting. Maintenance costs occur throughout the lifetime of a project and include costs related to the impacts of climate change and sea-level rise, as well as, in some instances, decommissioning. 
The costs of creating, restoring, and maintaining beach and dune systems are highly variable across sites, so it is not easy to draw general conclusions. However, it is possible to identify and compare cost drivers semiquantitatively. Table 9.2 provides an overview of cost drivers for NNBF systems.

Table 9.2. Overview of Cost Drivers for the Management of Natural Systems and Construction of Nature-Based Systems

\begin{tabular}{|c|c|c|c|c|c|c|}
\hline \multirow[b]{2}{*}{$\begin{array}{c}\text { Cost } \\
\text { drivers }\end{array}$} & \multirow[b]{2}{*}{$\begin{array}{c}\text { Beach } \\
\text { nourishment }\end{array}$} & \multicolumn{2}{|c|}{ Natural systems } & \multicolumn{2}{|c|}{ Nature-based systems } & \multirow[b]{2}{*}{$\begin{array}{l}\text { Impact } \\
\text { on costs }\end{array}$} \\
\hline & & $\begin{array}{c}\text { Shoreface } \\
\text { nourishment }\end{array}$ & $\begin{array}{l}\text { Sediment } \\
\text { trapping to let } \\
\text { dunes form } \\
\text { naturally }\end{array}$ & $\begin{array}{l}\text { Complete } \\
\text { beach } \\
\text { and dune } \\
\text { system }\end{array}$ & $\begin{array}{l}\text { Beach with } \\
\text { control } \\
\text { structures }\end{array}$ & \\
\hline $\begin{array}{l}\text { Availability } \\
\text { of sand }\end{array}$ & $x$ & $x$ & & $\mathrm{x}$ & $x$ & +++ \\
\hline $\begin{array}{l}\text { Distance to } \\
\text { borrow site }\end{array}$ & $x$ & $x$ & & $x$ & $x$ & +++ \\
\hline $\begin{array}{l}\text { Available time } \\
\text { frame for } \\
\text { placement }^{1}\end{array}$ & $x$ & $x$ & & $x$ & $x$ & ++ \\
\hline $\begin{array}{l}\text { Beach equipment } \\
\text { (dumpers and } \\
\text { bulldozers) }\end{array}$ & $\mathrm{x}$ & & & $x$ & $x$ & ++ \\
\hline $\begin{array}{l}\text { Water depth } \\
\text { in proximity to } \\
\text { target site }\end{array}$ & $x$ & $x$ & & $x$ & $x$ & ++ \\
\hline $\begin{array}{l}\text { Sand trapping } \\
\text { (e.g., natural } \\
\text { vegetation, fences) }\end{array}$ & $x$ & $x$ & $x$ & $x$ & $x$ & + \\
\hline $\begin{array}{l}\text { Initial planting for } \\
\text { habitat creation }\end{array}$ & $x$ & & & $x$ & $x$ & ++ \\
\hline $\begin{array}{l}\text { Hard control } \\
\text { structures (for } \\
\text { hybrid solutions) }\end{array}$ & $x$ & & & $x$ & $x$ & +++ \\
\hline
\end{tabular}




Cost
$\begin{aligned} & \text { drivers } \\ & \text { nourishment }\end{aligned}$
$\begin{aligned} & \text { Beach } \\ & \text { Planning, } \\ & \text { permitting, and } \\ & \text { engineering }\end{aligned}$
$\begin{aligned} & \text { Shourishment } \\ & \text { nonitoring }\end{aligned}$

\section{Example of Cost-Benefit and Multicriteria Analyses for the Katwijk Nature-Based Beach and Dune Reinforcement (the Netherlands)}

Some benefits of NNBF are difficult to monetize. The effort put into monetizing benefits varies per country and heavily depends on the governance setting. The following table is an example of the multicriteria analysis used for the nature-based beach and dune FRM project at Katwijk in the Netherlands. For this project, multiple solutions were considered. For decision-making, only the costs were monetized, and the benefits were qualitatively evaluated. It should be noted that this is possible because the project was designed to deliver a fixed flood risk reduction mandated by law. The legal flood standard was derived on the economic optimization of cost and avoided flood damages. The sand in front of the boulevard (7.5 m NAP) option, shown in Table 9.3, was chosen as the preferred solution. 
Table 9.3. Example of Multicriteria Analysis Applied to Katwijk, the Netherlands

\begin{tabular}{|c|c|c|c|c|c|c|c|}
\hline \multirow[b]{2}{*}{ Criterion } & \multirow[b]{2}{*}{$\begin{array}{l}\text { Reference } \\
\text { situation }\end{array}$} & \multirow[b]{2}{*}{$\begin{array}{c}7.5 \\
\text { meters } \\
\text { NAP }\end{array}$} & \multicolumn{3}{|c|}{ Sand in front of boulevard } & \multicolumn{2}{|c|}{$\begin{array}{c}\text { Construction in } \\
\text { dune in front of } \\
\text { boulevard }\end{array}$} \\
\hline & & & $\begin{array}{c}10.5 \\
\text { meters } \\
\text { NAP }\end{array}$ & $\begin{array}{l}7.5 \text { meters } \\
\text { NAP, no } \\
\text { change legal } \\
\text { position }\end{array}$ & $\begin{array}{c}10.5 \text { meters } \\
\text { NAP, no } \\
\text { change legal } \\
\text { position }\end{array}$ & $\begin{array}{c}7.5 \\
\text { meters } \\
\text { NAP }\end{array}$ & $\begin{array}{c}10.5 \\
\text { meters } \\
\text { NAP }\end{array}$ \\
\hline \multicolumn{8}{|l|}{ Safety and design } \\
\hline $\begin{array}{l}\text { Ensure safety in } \\
\text { hinterland }\end{array}$ & 0 & ++ & ++ & ++ & ++ & ++ & ++ \\
\hline Expandability & 0 & ++ & ++ & ++ & ++ & + & + \\
\hline Robustness & 0 & ++ & ++ & ++ & ++ & + & + \\
\hline Sustainability & 0 & ++ & ++ & ++ & ++ & + & + \\
\hline \multicolumn{8}{|l|}{$\begin{array}{l}\text { Construction and } \\
\text { maintenance }\end{array}$} \\
\hline Construction & 0 & + & + & + & + & + & + \\
\hline $\begin{array}{l}\text { Management and } \\
\text { inspectability }\end{array}$ & 0 & ++ & ++ & ++ & ++ & - & - \\
\hline Need for maintenance & 0 & -- & - & -- & - & - & $0 /-$ \\
\hline \multicolumn{8}{|l|}{ Risk management } \\
\hline Magnitude of erosion & 0 & $0 /+$ & $0 /+$ & $0 /+$ & $0 /+$ & ++ & ++ \\
\hline $\begin{array}{l}\text { Area that floods at } \\
\text { normative water levels }\end{array}$ & 0 & 0 & 0 & 0 & 0 & ++ & ++ \\
\hline \multicolumn{8}{|l|}{ Use of space } \\
\hline $\begin{array}{l}\text { Influence on living and } \\
\text { working }\end{array}$ & 0 & - & - & - & - & - & - \\
\hline $\begin{array}{l}\text { Influence on } \\
\text { infrastructure }\end{array}$ & 0 & - & - & - & - & $0 /-$ & 0/- \\
\hline $\begin{array}{l}\text { Nuisance during } \\
\text { construction }\end{array}$ & 0 & - & - & - & - & - & - \\
\hline \multicolumn{8}{|l|}{ Spatial quality } \\
\hline $\begin{array}{l}\text { Effect on view from } \\
\text { houses at boulevard }\end{array}$ & 0 & -- & -- & -- & -- & $0 /-$ & - \\
\hline $\begin{array}{l}\text { Effect on identity of } \\
\text { Katwijk }\end{array}$ & 0 & -- & -- & -- & -- & - & - \\
\hline $\begin{array}{l}\text { Effect on spatial } \\
\text { quality and landscape }\end{array}$ & 0 & $0 /-$ & 0/- & $0 /-$ & $0 /-$ & 0 & 0 \\
\hline
\end{tabular}




\begin{tabular}{|c|c|c|c|c|c|c|c|}
\hline \multirow[b]{2}{*}{ Criterion } & \multirow[b]{2}{*}{$\begin{array}{l}\text { Reference } \\
\text { situation }\end{array}$} & \multicolumn{4}{|c|}{ Sand in front of boulevard } & \multicolumn{2}{|c|}{$\begin{array}{c}\text { Construction in } \\
\text { dune in front of } \\
\text { boulevard }\end{array}$} \\
\hline & & $\begin{array}{c}7.5 \\
\text { meters } \\
\text { NAP }\end{array}$ & $\begin{array}{c}10.5 \\
\text { meters } \\
\text { NAP }\end{array}$ & $\begin{array}{c}7.5 \text { meters } \\
\text { NAP, no } \\
\text { change legal } \\
\text { position }\end{array}$ & $\begin{array}{c}10.5 \text { meters } \\
\text { NAP, no } \\
\text { change legal } \\
\text { position }\end{array}$ & $\begin{array}{c}7.5 \\
\text { meters } \\
\text { NAP }\end{array}$ & $\begin{array}{c}10.5 \\
\text { meters } \\
\text { NAP }\end{array}$ \\
\hline $\begin{array}{l}\text { Potential of } \\
\text { reinforcement } \\
\text { for spatial quality } \\
\text { and economic } \\
\text { development }\end{array}$ & 0 & $0 /+$ & $0 /+$ & ++ & ++ & ++ & ++ \\
\hline
\end{tabular}

\begin{tabular}{llllllll}
\hline Social Impact & 0 & - & - & - & - & - & - \\
\hline $\begin{array}{l}\text { Costs } \times \mathbf{6 1} \text { million } \\
\text { euros (\$1.2 million }\end{array}$ & & 40.5 & 30.45 & 42.35 & 33.2 & 32.0 & 37.3 \\
$\begin{array}{l}\text { U.S. dollars) } \\
\text { ( }\end{array}$ & & & & & & &
\end{tabular}

Notes:

,+- , and 0 indicate relative effects on criterion with + being positive, - being negative, and 0 being neutral. $0 /+$ and $0 /-$ mean neutral or positive and neutral or negative.

The maximum rating is +++ for greatest positive effect and --- for greatest negative effect.

\subsubsection{Preferred Approach, Design Detailing, and Specifications for Case Study Examples}

There is no one size fits all when it comes to identifying a preferred approach, design details, and specifications (see iterative processes and steps in Chapter 2). The identification process needs to be tailored to the local physical, socioeconomic, and governance situation. This section systematically outlines these aspects for the following four implementation case studies, which are introduced in the Engineering with Nature Atlas (Bridges et al. 2018) and cover the range of strategies (advance the line, hold the line, retreat), solutions (natural, nature based, soft, and hybrid), and beaches (sandy, mixed, and gravel):

- A natural sandy beach and dune system in the United States (Galveston Beach, Texas)

- A natural shingle and mixed beach system in the United Kingdom (North Norfolk)

- A nature-based sandy beach and dune system in the Netherlands (Hondsbossche and Pettemer sea dike)

- A nature-based shingle and mixed beach system in New Zealand (Tamanau Reserve) 


\section{CASE STUDY:}

\section{Natural System - Galveston Beach (Texas, United States)}

Galveston Island is one of Texas's most urbanized beach areas. Due to their proximity to the greater Houston metropolitan area, Galveston's beaches are under everincreasing pressure to provide the desired beach experience to more than 6 million visitors per year. Galveston Island, however, is a sediment-deficit system. Narrow beaches along the central and western portions of the island are eroding $2.5 \mathrm{~m}$ to $3 \mathrm{~m}$ per year, whereas beaches at the eastern and western ends of the Island are rapidly accreting up to $3.5 \mathrm{~m}$ per year.

A storm in 1900 prompted the construction of a series of coastal protection works. Elevation grades of the entire city were raised between 1903 and 1928. Between 1901 and 1963, a seawall was built on top of the existing 2- to 2.5-m-high natural dune system (see Figure 9.23). A series of 15 stone groins were constructed in front of the seawall, from 10th to 61st Streets in Galveston, to protect the seawall from undermining and to retain the beaches seaward of the seawall.

During fall and winter 2015 , more than $490,000 \mathrm{~m}^{3}$ of sediments dredged from the Galveston Bay Entrance Channel were placed on a severely eroded beach on Galveston Island. This beneficial use project functions as a sediment bypass effort keeping sediments in the system. Although there were concerns about the quality of the placed material, the placement was closely monitored. Construction practices allowed the sediment to contain silt and clay (approximately $38 \%$ of the dredged material), which was immediately lost into the swash zone where it quickly dispersed outside of the active beach zone. Water quality is not a significant concern in this area because background turbidity rates are highly variable due to frequent episodic naturogenic runoff discharges from Galveston Bay and the Brazos River, which bracket this area.

The local community and the state funded the incremental cost of approximately $\$ 10$ U.S. dollars (USD) per cubic yard to have this material pumped to the beach instead of placed at an offshore location. Previous truck haul projects have cost the local community more than USD\$40 per cubic yard. 
This beneficial use project was repeated in fall 2019 and will be repeated in summer 2021. It is the intention of the local and state partners that every future Galveston Bay Entrance Channel dredging event will include beneficial use. Future placements may be performed further west along the seawall in areas that do not have a beach present to increase long-term stability and resilience in these areas. Table 9.4 provides a summary of the design detailing aspects of Galveston Beach.

Figure 9.23. Area West of 61st Street (Babes Beach) before and after the 2015 Beneficial Use Project
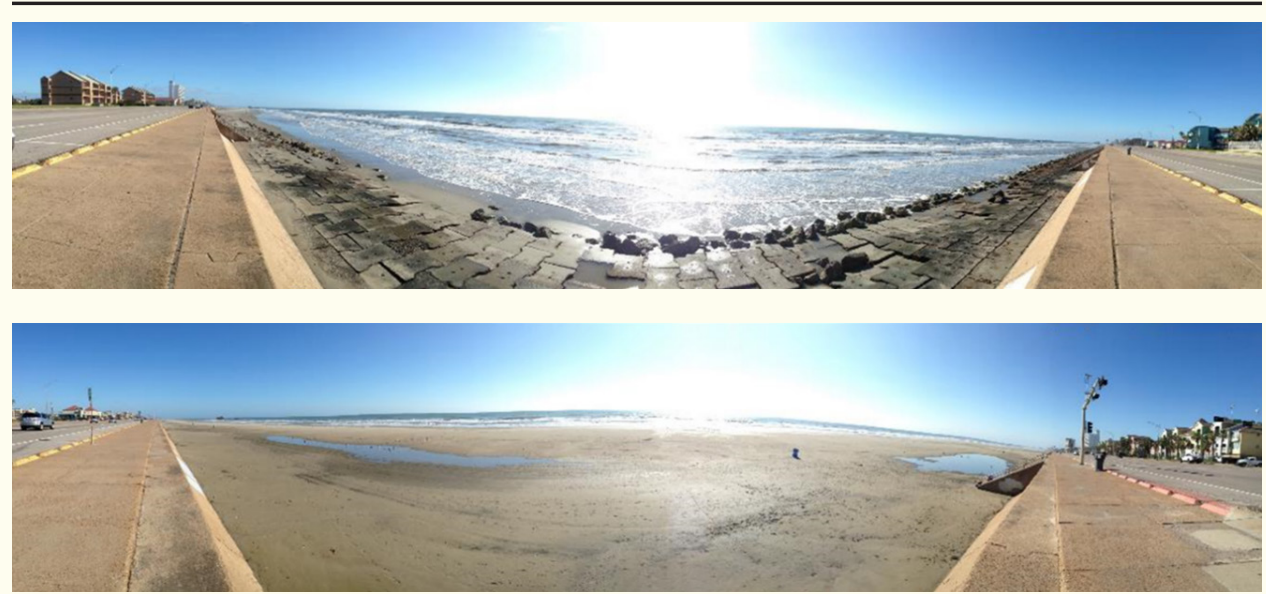

Note: The top photograph was taken before the beneficial use project, and the bottom photograph was taken after.

Source: Courtesy of Coraggio Maglio

Table 9.4. Summary of the Design Detailing Aspects of Galveston Beach

\section{STRATEGY}

Advance the line, followed by hold the line

\section{TYPE OF CONTRACT}

Invitation for bid, build-only contract

\section{TYPE OF SOLUTION}

Natural, hybrid

\section{PROJECT COSTS}

USD $\$ 8,040,000$ for the community and state, plus USD $\$ 15,000,000$ for the navigation dredging 


\section{OBJECTIVES}

\section{Strategic}

Add resiliency to coastal storm damage reduction efforts.

\section{Operational}

Leverage federal navigational dredging projects and allow local stakeholders to pay the incremental cost to pump material to the beach instead of the less costly offshore disposal alternative.

Keep sediments in the active coastal system.

\section{DESIGN REQUIREMENTS}

\section{Engineering}

The beach in front of Babes Beach protects the Galveston seawall from being undermined in a significant storm event. The potential for undermining was further mitigated by scour protection riprap installed at the toe of the seawall, thus rendering the beach a nonproject feature.

\section{Environmental}

Native dune species are now established near the seawall in the areas of the 2015 beneficial use project.

\section{Socioeconomic}

Provides economic development west of 61st Street and enhanced recreational opportunities for residents and visitors.

\section{Performance monitoring}

The local community performs annual beach profile monitoring.

\section{Specifications}

The dredging contractor is required to collect sediment samples for scientific monitoring from each load of material they pump to the beach.

The local community annually updates the sand management plan. 
CASE STUDY:

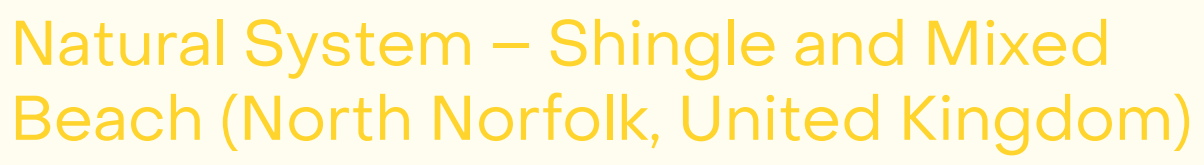

The Environment Agency in the United Kingdom historically managed the gravel barrier beach that forms the Cley to Salthouse section of Blakeney Point via reprofiling to provide the first line of flood defense to Cley and Salthouse villages and to internationally essential marsh habitats in the hinterland. Over time, the steep face and artificially raised crest meant that the beach underwent a gradual reduction in volume because sediment was unable to pass naturally onto and over the crest and instead moved alongshore. This increased the threat of overwashing and breaching during storms. To address these issues, a mutually beneficial approach incorporating traditional engineering elements and natural features was developed by a group of key stakeholders (Figure 9.24). Table 9.5 provides a summary of the design detailing aspects of the mixed beach of North Norfolk.

Figure 9.24. Aerial Photographs of the Western Extent of the Cley to Salthouse Barrier and Tidal Reach of the River Glaven before and after Scheme Completion

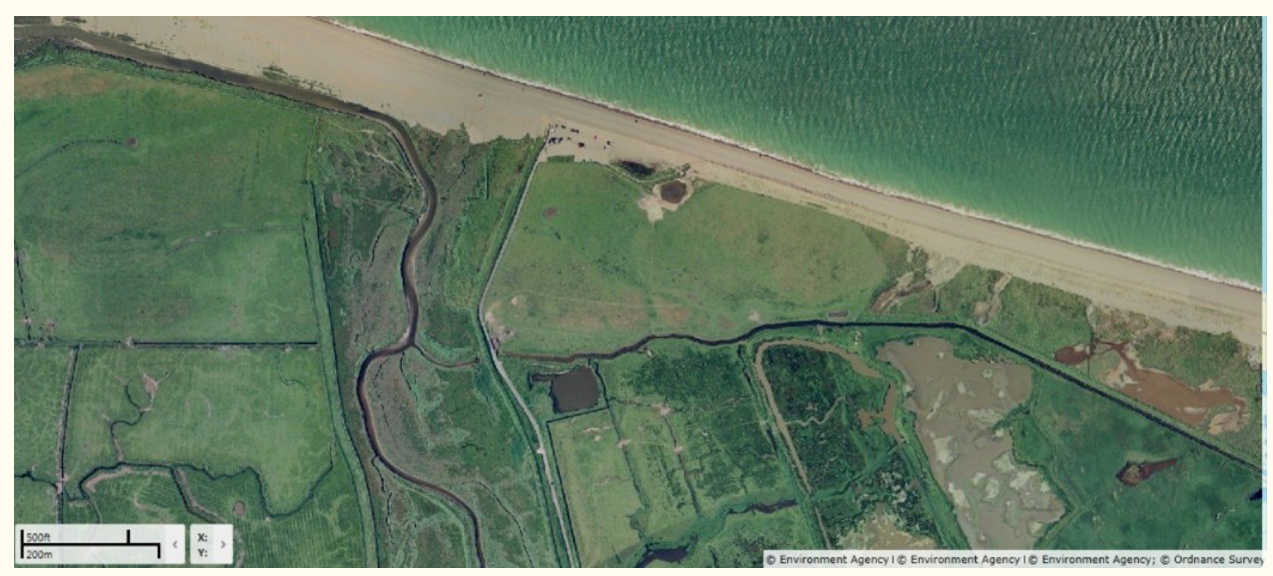

Figure continues on next page. 


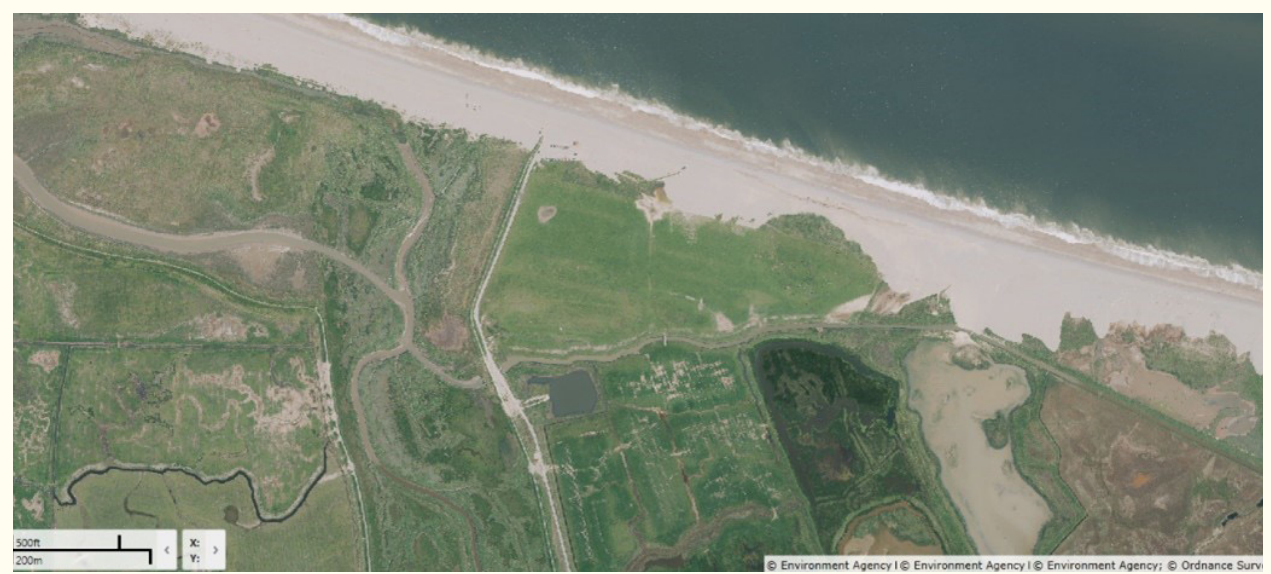

Notes: The top photograph was taken of the River Glaven before scheme completion (1999), and the bottom photograph was taken after scheme completion (2014). The bottom photograph shows the landward realignment of the River Glaven visible to the left and the reactivated gravel barrier (with overwash fans) following the cessation of annual reprofiling works.

Source: Courtesy of the Environment Agency in the United Kingdom

Table 9.5. Summary of the Design Detailing Aspects of the Mixed Beach of North Norfolk (United Kingdom)

\section{STRATEGY}

Retreat (managed realignment)

TYPE OF CONTRACT

Design and build

\section{TYPE OF SOLUTION}

Natural, soft for the beach, hybrid in hinterland

\section{PROJECT COSTS}

$£ 2.4$ million Great Britain pounds (GBP) (USD\$3.3 million) (all on works in the hinterland)

\section{OBJECTIVES}

\section{Strategic}

Provide flood risk reduction to the hinterland and maintain the ecological integrity of designated habitats. 


\section{Operational}

Implement the following drainage improvements in the hinterland to increase the speed with which the Cley and Salthouse marshes drain during flooding:

- Realign the tidal River Glaven landward to prevent blocking by the overwashed shingle beach

- Widen the channel to accommodate larger discharges

- Replace Cley sluice with a larger structure to improve drainage capacity

- Cease beach management activities (reprofiling) and allow the beach to return to natural processes and morphology (via wave action)

- Install ultrasonic gauges to improve telemetry and the flood warning system

\section{DESIGN REQUIREMENTS}

\section{Engineering}

The following improvements were focused on the hinterland:

- Cut new channel for tidal River Glaven 250 m landward of old alignment, increasing bed width from 2 to $8 \mathrm{~m}$; the resulting spoil material $\left(1,600 \mathrm{~m}^{3}\right)$ was used to fill in the old channel

- In the drainage infrastructure, replaced existing Cley sluice (single, 1.5-m-diameter pipe) with a new structure with improved discharge capacity (four 1.5-m-by-1.25-m rectangular pipes), and lowered Cley East Bank from $2 \mathrm{~m}$ to $0.8 \mathrm{~m}$ to improve drainage within the marshes during major inundations

- Installed three ultrasonic gauges to measure flows and salinity for the flood warning system

\section{Environmental}

- Beach. No design specifications were initiated; beach management was ceased to reinstate natural processes and allow gradual relaxation of barrier beach profile, and ultimately rollback

- Hinterland. Maintained the ecological integrity of the European-designated North Norfolk coast Special Protection Area and Special Area of Conservation (mix of saline, brackish, and freshwater habitats)

\section{Socioeconomic}

The marshes and beach are important economic assets to the area, attracting numerous visitors each year. A new visitor center was built to further enhance the draw for tourists, with associated benefits to the area. 


\section{Performance monitoring}

General monitoring is undertaken as part of Environment Agency-led Anglian Coastal Monitoring Program, including beach profile surveys and aerial photography. The scheme-specific monitoring focuses on the following:

- The development of the salt marsh habitat in the infilled channel of the River Glaven estuary

- The effects of construction and operation on suspended solids and fecal coliform concentrations in Blakeney estuary

- The effects of construction and subsequent operation on several birds in the Cley and Salthouse marshes

- The successful in situ protection of plants and re-establishment of lost plants after construction

- Salinity in the ditch network of Cley and Salthouse marshes

\section{Specifications}

Design criteria for drainage infrastructure to accommodate high flows during tidal inundation events were prescribed in the tender documents.

\section{CASE STUDY:}

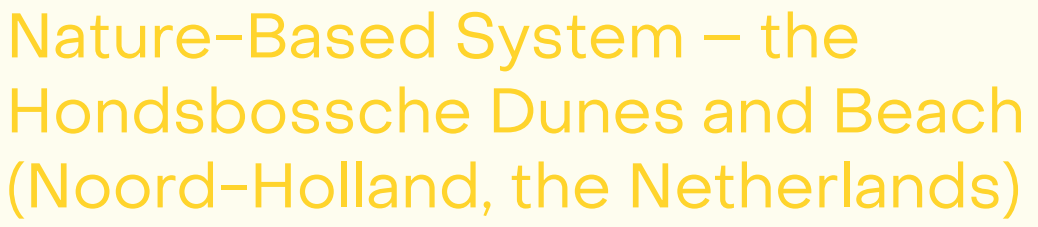

Because the Hondsbossche and Pettemer sea dike no longer met safety standards, the dike was reinforced in 2015 with a soft, natural barrier of 30 million $\mathrm{m}^{3}$ of sand on the seaside of the dike. The resulting area was renamed Hondsbossche dunes (Figure 9.25). The information in this section is from EcoShape 2019, ecoshape.org 2021, and Arcadis 2013. 
Figure 9.25. Hondsbossche Sea Defense and Hondsbossche Dunes

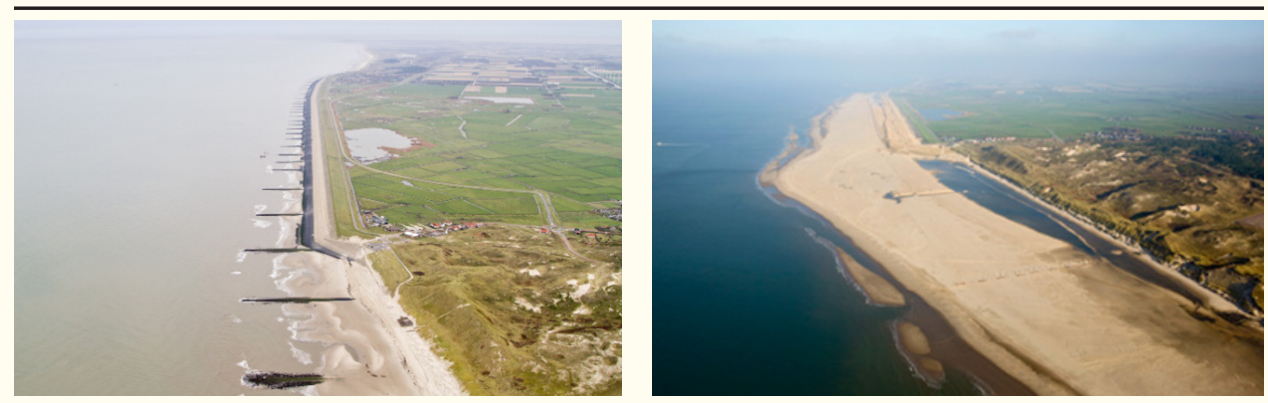

Note: Hondsbossche sea defense is on the left (before), and Hondsbossche dunes is on the right (after). Source: Courtesy of Rijkswaterstaat

The adopted strategy for coastal management in the Netherlands is hold the line. The Dutch coast is retreating in most places, but by sand nourishment, the coastline is dynamically maintained (hold the line). Along the north Holland coast, the 5.5-km-long Hondsbossche and Pettemer sea dike (a traditional design) no longer met the safety standards. The following four possible solutions were considered. Three were a traditional approach, and one was a natural (sandy) approach (Figure 9.26):

1. Raise the crest of the dike (traditional approach)

2. Add nourishment to the foreshore (traditional approach)

3. Make the dike resistant to overtopping (traditional approach)

4. Construct dune, beach, and foreshore (natural [sandy] approach)

All four alternatives met the required safety standard. The natural (sandy) solution was selected for the following reasons:

- Safety. It was the alternative that could be implemented most quickly. Also, sand is a flexible solution that can be adapted in the future, and it gives a high feeling of safety (buildings are far from the sea).

- Environment. The design gave the least hindrance to the environment (no interference to the landside of the dike). It created chances for nature and economic development, and it was possible to mitigate effects on nature.

- Execution. The sandy approach fits well with other projects in the area to improve spatial quality (for nature and recreation).

- Cost-benefit. From the social cost-benefits analysis, this solution turned out not to be the cheapest, but it did deliver the highest benefits (tourism and recreation) compared to the other alternatives. 
One argument for selecting the sandy design is that it is a flexible solution that can easily be modified in the future. The current design is made to last 50 years, even with sea-level rise (Figures 9.27 and 9.28); after that time, it can be adapted to changing conditions if necessary. Table 9.6 summarizes the main design detailing aspects of this case study.

Table 9.6. Summary of the Design Detailing Aspects of the Hondsbossche Dunes

\section{STRATEGY}

Advance the line, followed by hold the line

\section{TYPE OF CONTRACT}

Design, build, and maintain approximately 9 miles of coast for a period of 20 years

\section{TYPE OF SOLUTION}

Nature-based, soft

\section{PROJECT COSTS}

$€ 230$ million euros (USD\$271 million)

\section{OBJECTIVES}

\section{Strategic}

Helps ensure safety (no flooding) and improve the spatial quality in the region

\section{Operational}

- Safety. Withstand 10,000-year storm conditions; the defense should be designed for 50 years, taking sea-level rise into account

- Spatial quality. Comply with the safety quality standards as described by the regional government (province)

Financial criteria from the ministry for coastal management are "sober, robust, and effective." This means not only that the financial input should contribute to increased safety against the lowest costs but also that the measure should have a long lifetime (be robust).

\section{DESIGN REQUIREMENTS}

\section{Engineering}

- The sand and coast profile should meet the safety requirements for 50 years, which is being able to withstand a 10,000-year storm (including sea-level rise and subsidence, not including changing wave conditions).

- There will be a safety dune for the full length of the dike. The width is at least $75 \mathrm{~m}$ and a maximum of $100 \mathrm{~m}$. Dune height is at least $7 \mathrm{~m}$ and not higher than the dike (12 $m+$ NAP). The safety dune is placed seaward of the dike. 
- The coastline must be smooth, and the dune, beach, and nearshore should fit to the other coastal stretches. The dunes should be connected so that no water can pass.

\section{Environmental}

- The dunes in the central part of the design have a nature function. Mitigation measures were taken to reduce or restore negative effects on natural values. These mitigation measures included compensation for the lost foraging habitat of the ruddy turnstone and the Eurasian oystercatcher.

- The sand used should have physical and chemical characteristics and grain size comparable to the sand in natural, nearby dune systems.

\section{Socioeconomic}

- The beach should be wide enough to walk on.

- Hindrance by sand transport should be minimized by taking measures to trap the sand in the area and prevent sand transport over the dike.

- The existing dike should be maintained as cultural heritage. The dunes should be lower than the dike so that the view from the hinterland is not changed.

- Dunes close to the villages get a recreational function, which includes creating a cycling path, entrances to the beach, and (re)placement of beach pavilions and restaurants.

\section{Performance monitoring}

1. Safety. In the Netherlands, monitoring of coastal safety and the dynamics of the coastline are organized nationally by Rijkswaterstaat. Parameters to monitor coastal safety function are the position of the coastline compared to a fixed reference line (Ministerie van Infrastructuur en Waterstaat 2018) and the sand volume in the whole coastal segment (including nearshore, beach, and dunes).

2. Design. Because the design is a new concept, EcoShape initiated an innovation project to learn more about efficient sand nourishment with added value for nature and leisure. In this project, EcoShape and its partners researched the following three themes:

- Improving predictability in the development of engineered habitats

- Optimizing design and morphological evolution

- Perception of local community and visitors 
The results have been used for guidelines providing new knowledge about the following: (1) where soft approaches deliver added value, (2) how to optimize the design, and (3) possible financial benefits by comparison with hard solutions (see ecoshape.org 2021).

\section{Specifications}

- Requested tender scope: design, build, and maintain for 20 years.

- See design requirements.

Figure 9.26. Alternative Designs to Improve Coastal Safety at the Hondsbossche and Pettemer Sea Dike

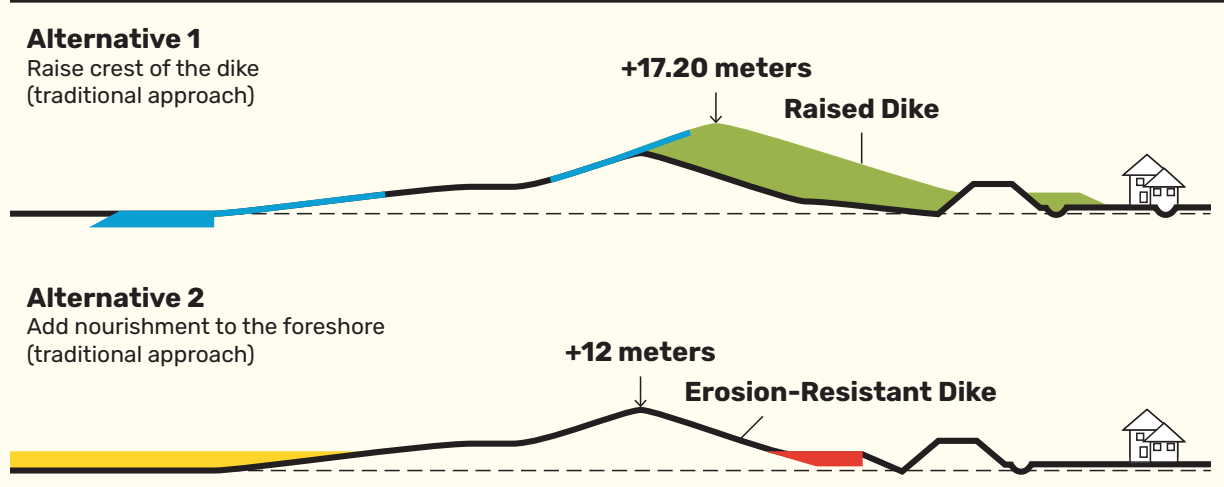

\section{Alternative 3}

Make dike overtopping-resistant (traditional approach)

+13.50 meters Erosion-Resistant Dike

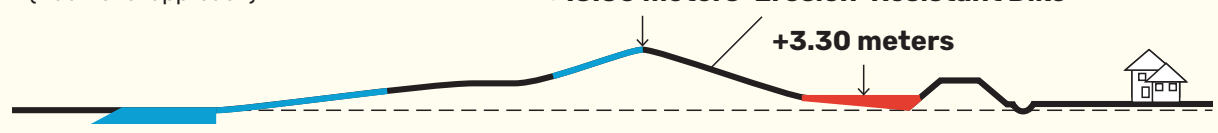

\section{Alternative 4}

Construct dune, beach, and foreshore (natural [sandy] approach)

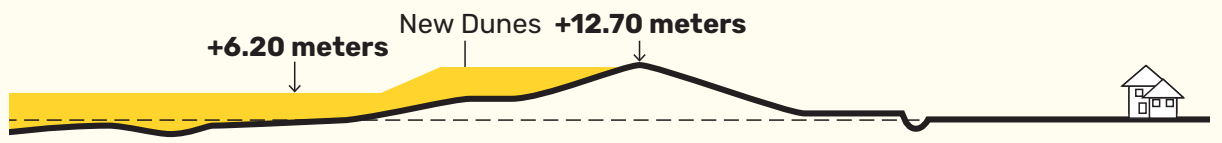

Structural measures
Earth to heighten and widen the dike
Sand
Erosion protection at base of dike

Note: Alternative 4 was selected as the preferred design.

Source: Ecoshape.org 2021 
Figure 9.27. Hondsbossche Dunes Design with Different Zones for Nature Development and Recreation

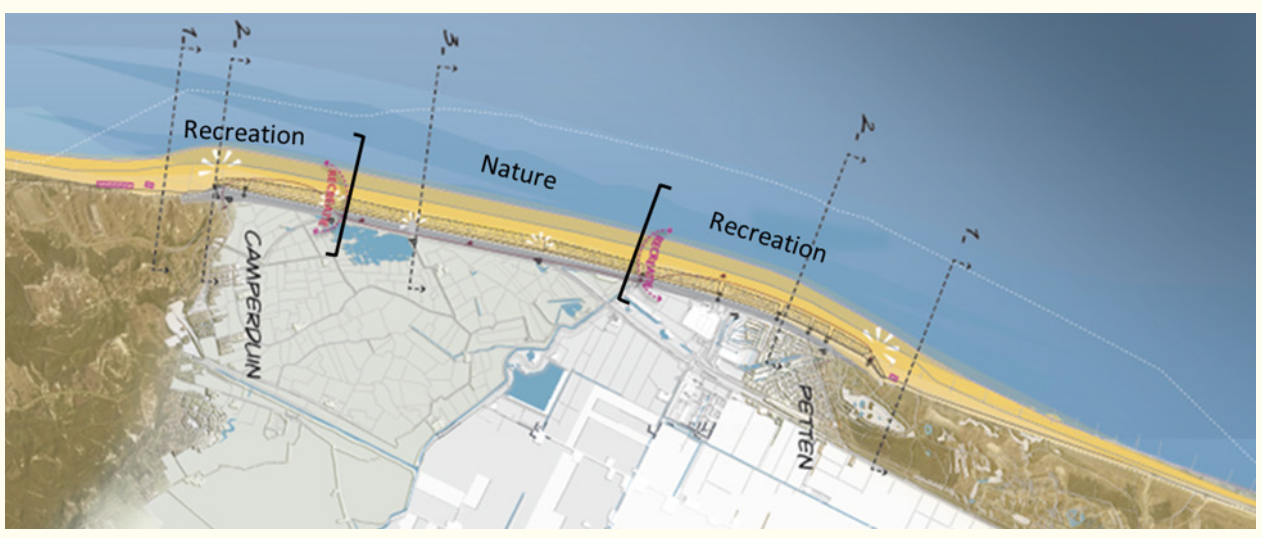

Source: Courtesy of Rijkswaterstaat

Figure 9.28. Habitat Types within the Central Nature Zone of the Constructed Hondsbossche Dunes

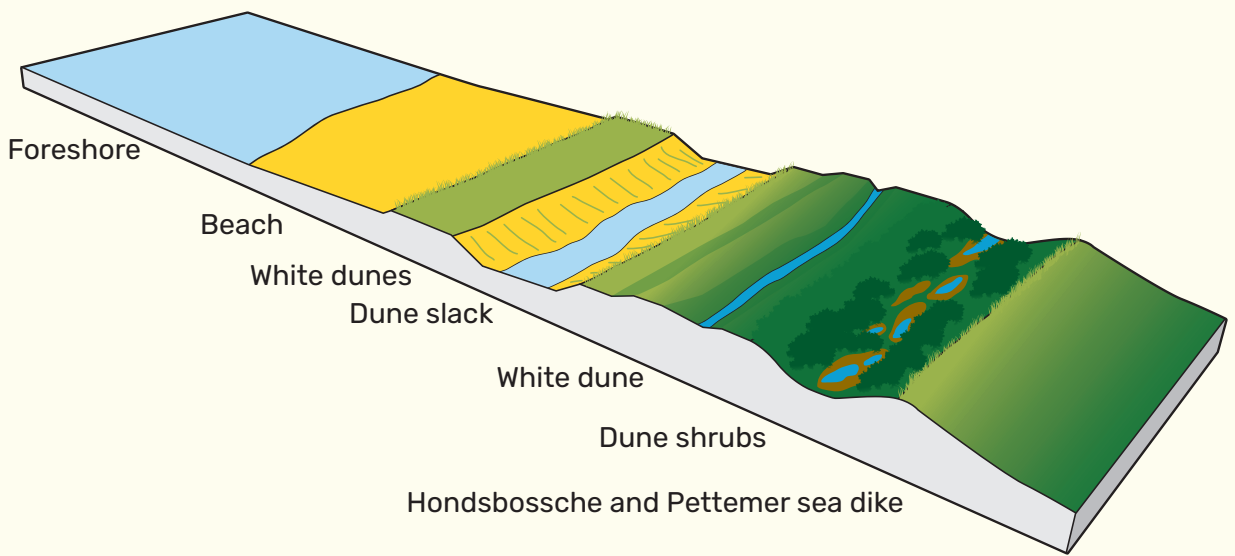

Source: ZSHN combination Van Oord/Boskalis VOF (joint venture company of Van Oord and Boskalis) 


\section{CASE STUDY:}

\section{Nature-Based System - Shingle and Mixed Beach Park, Taumanu Reserve (Auckland, New Zealand)}

Taumanu Reserve is a new coastal park in Auckland, New Zealand, created between 2011 and 2015 as part of the Onehunga Foreshore Restoration Project (Figure 9.29). The project re-establishes access to an inner Manukau coastal environment and restores an amenity that was lost to the community of Onehunga through the establishment of State Highway 20 in the 1970s. Taumanu comprises a 6.8-hectare park formed on reclaimed coastal land and provides $1.4 \mathrm{~km}$ of new coastline with sandy and gravely beaches, a boat ramp and turning bay, picnic areas, and open space. Walking and cycling paths extend through the park and traverse State Highway 20 across a feature gateway bridge to the existing Onehunga Bay Reserve. Taumanu has been sensitively designed to fit within both cultural and physical landscapes and has been recognized nationally and internationally for its design response.

The project team's commitment to using a nature-based framework for design required them to understand, coordinate, and layer the input of many technical and subject matter experts, including those outside of engineering, such as landscape architects, flora and fauna experts, and contractors with expertise in efficient construction. The result was increased resilience and decreased costs through effective stakeholder engagement throughout the project life cycle and efficient construction programming.

Figure 9.29. A Before (June 2011) and After (November 2015) Look at the Coastal Edge for the Taumanu Reserve Foreshore, Replacing a Linear Rock Armor Revetment with Undulating Soft Shores and Control Structures
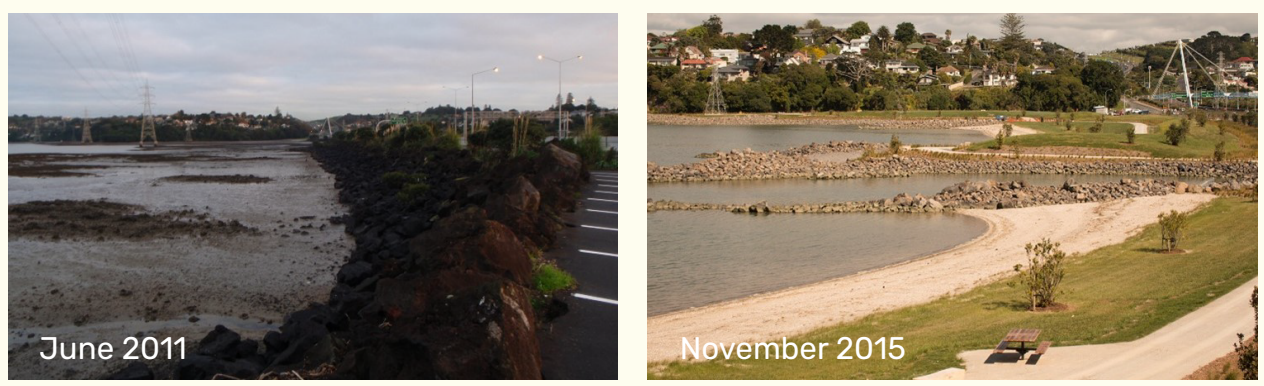

Source: Courtesy of Tonkin + Taylor 
The team adopted an approach they termed layering. The layering approach started with nature and involved the following three steps:

1. Use the natural environment to determine the starting point for each design element.

2. Apply technical engineering to design a functional piece of infrastructure.

3. Overlay the functional infrastructure with multiple layers of enhancements that would improve the aesthetical, ecological, cultural, and social outcomes that the infrastructure would achieve.

The focus was restoring natural character because this was one of the core design philosophies. Table 9.7 provides a summary of the design detailing aspects of the Beach Park of Taumanu Reserve.

An example of the layered development approach used in this project is the creation of lava-flow headlands in lieu of rock groins (Figure 9.30). These lava-flow headlands reflect the adjacent environment and have a natural appearance, and their ecological function is enhanced. The headlands enabled the creation of nine beaches formed from either sand or gravel. Taumanu's beaches were based on the processes observed and modeled from around the wider Manukau Harbor's coastline (Figures 9.31 and 9.32).

Figure 9.30. A Schematic Illustrating the Design Process for the Lava-Flow Headlands Using a Collaborative and Layered Approach

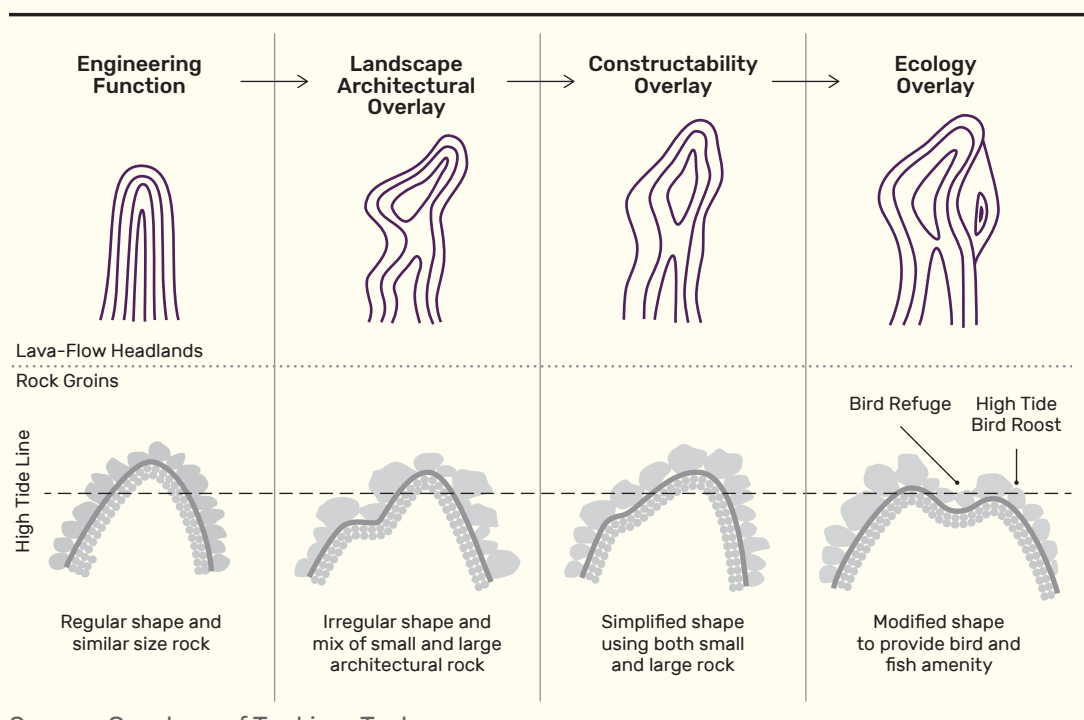

Source: Courtesy of Tonkin + Taylor 
Table 9.7. Summary of the Design Detailing Aspects of the Beach Park of Taumanu Reserve, Auckland, New Zealand

\section{STRATEGY}

Advance the line, followed by hold the line

\section{TYPE OF CONTRACT}

Design, consent, and build of $1.5 \mathrm{~km}$ of coast

\section{TYPE OF SOLUTION}

Nature-based, hybrid

\section{PROJECT COSTS}

\$28 million New Zealand dollars (USD\$19.6 million)

\section{OBJECTIVES}

\section{Strategic}

- Restore the environmental character of Onehunga Bay and enhance the integrity and function of its landscapes, coastal processes, habitats, and intrinsic biodiversity values.

- Restore and enhance the public access to the coastal edge and coastal waters and provide a wide range of new recreational opportunities for the whole community.

- Acknowledge the cultural connections and heritage values of tangata whenua ("people of the land").

- Restore the connectivity of the site to the Onehunga community and enhance the important public access corridors and connections.

\section{Operational}

Create 6.8 hectares of contoured coastal reserve, edged by nine beaches formed from either sand or gravel, with access provided by $1.5-\mathrm{km}$ shared-use paths connecting to a gateway pedestrian footbridge over a motorway integrating reserves on both sides and boat ramp access, parking, and amenity buildings.

\section{DESIGN REQUIREMENTS}

\section{Engineering}

- The site is complex, with geology being a mixture of soft estuarine sediments and basalt lava flows, an intertidal foreshore-facing predominant-wind direction with tidal channels to the lagoon, and significant existing infrastructure through the project area (motorway, national gas, and power reticulation).

- Reclamation was formed from $350,000 \mathrm{~m}^{3}$ of fill, with minimum levels of $0.9 \mathrm{~m}$ above extreme high water levels, with increased elevations to provide natural slopes and access to the bridge, $15,000 \mathrm{~m}^{3}$ of headland rock, and $25,000 \mathrm{~m}^{3}$ of sand and cobbles. 
- Beach orientation and grain size were based on creating dynamically stable sandy beaches for public access and cobble beaches as headland controls.

\section{Environmental}

- Of the entire coastal reserve, 35\% (the western end of the foreshore) is designed as a low-activity area. The space fosters passive recreation and environmental amenities through dense planting, contours, and limited space or resources for active recreational activities.

- Two of the park's nine beaches were designed specifically for coastal birds. There are no physical access points to these beaches-they are completely cut off by strategic native planting and natural barriers. Provision of a large expanse of gravel between the path and the top of the beaches provides roosting habitat, although features such as wood logs, architectural rocks, and native New Zealand plants make both human and dog access difficult. The birds' sight line to the beach is maintained, which gives them an added feeling of security.

- To encourage the growth of native fauna, specific invertebrate habitats were created using native plants, logs, and rocks throughout the entire foreshore.

- Significant water quality improvements to Onehunga Bay were achieved, which reduced $E$. coli and brought the water up to safe swimming standards.

\section{Socioeconomic}

The project delivered on a long-overdue promise to restore access to the community lost because of the motorway construction in the 1970s. Public support for the project during the approval was significant, and since its completion, the project has achieved significant awards for public engagement and development of parks and open spaces.

\section{Performance monitoring}

The beaches, reserves, and plantings are regularly monitored through a designated monitoring program. The number of birds spotted bathing and feeding on site has significantly increased since the beaches and new roosting and feeding habitats were constructed. Many native birds, including the New Zealand dotterel, are regularly present on the limited-access beaches.

\section{Specifications}

According to design requirements 
Figure 9.31. Completed Taumanu Reserve Project (Auckland, New Zealand), View of Sandy Bay from Constructed Hill

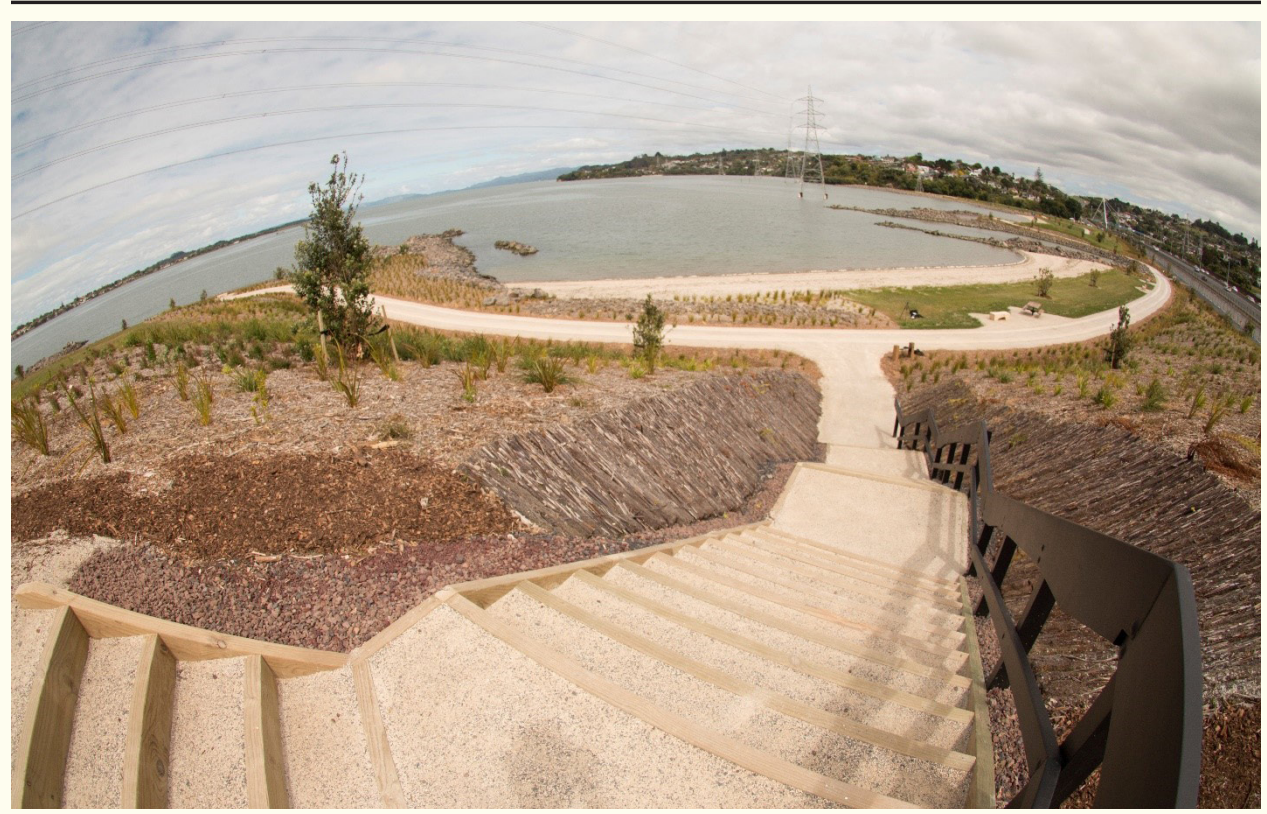

Source: Courtesy of Tonkin + Taylor

Figure 9.32. Taumanu Reserve Project Layout

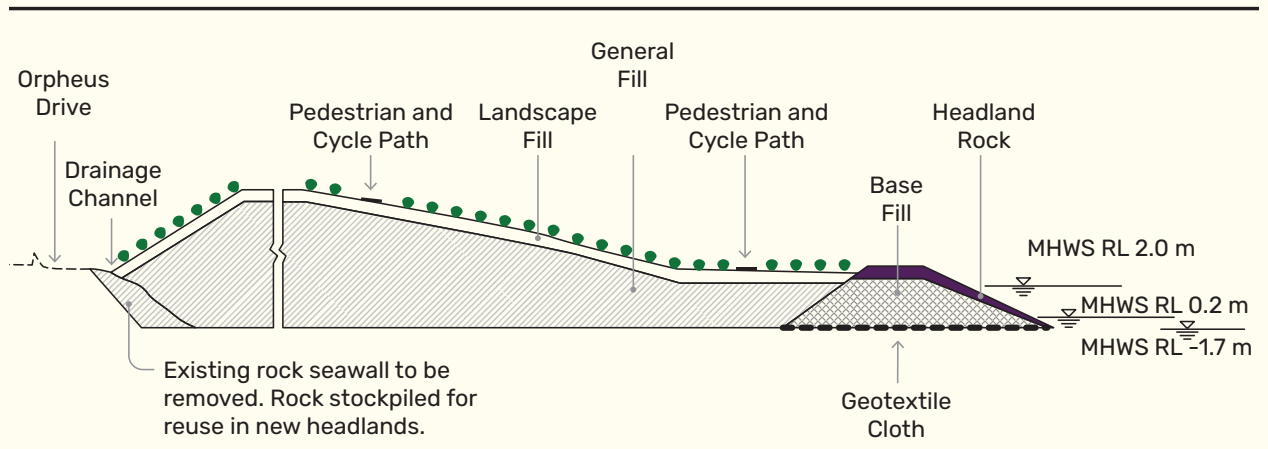

Abbreviation:

MHWS RL: mean high water springs AVD-46 (Auckland 1946) datum

Source: Courtesy of Tonkin + Taylor 


\subsubsection{Tools and Existing Design Guidance}

Using tailored modeling tools and design guidance is integral to a successful project.

Tools to assist in the design of beach-dune nourishment projects include web applications, numerical models, analytical models, and physical models. Web applications can be used to provide a rapid preliminary assessment of existing coastal conditions based on global data or analytical models. For example, the Shoreline Monitor provides satellite-based estimates of shoreline position to give insight in long-term shoreline changes, whereas other platforms such as MI-SAFE"iindicate potential flood risk reduction effect of (vegetated) foreshores based on global data. Analytical models are also available. For example, the Sediment Mobility Tool iii displays the depth of closure and sediment mobility data for the U.S. coastline, and SimpleCoastiv gives a collection of diverse simple tools for a preliminary assessment of coastal problems and solutions in coastal areas.

Numerical models can be used to assess the expected engineering performance of beach and dune projects. Different models are used for eolian sediment transport (e.g., AeoLiS; Hoonhout and de Vries 2016), which is more critical for dune development than hydrodynamic-driven beach sediment transport. A range of process-based models exists for hydrodynamic-driven beach sediment transport. Models include the following:

- Long-term 1D shoreline change models using gradients in longshore transport to compute changes in shoreline position possibly in combination with data assimilation, cross-shore, storm-driven processes on either a fixed cross-shore reference frame or completely vector based. Examples include, among others, GENESIS (Hanson 1989), LITPACK (Kristensen et al. 2016), UNIBEST (Tonnon et al. 2018), CoSMoS COAST (Vitousek et al. 2017), and Shorelines (Roelvink et al. 2020).

- Long-term domain models, either 2D horizontal (2DH) (depth-averaged) or 3D, via the simulations of hydrodynamic flow, waves (parametric or spectral), and sediment transport. Examples include Coastal Modeling System (CMS; cirp.usace.army.mil 2021), ADCIRC (Luettich and Westerink 1991), and Delft3D (Lesser et al. 2004).

- Storm-driven models to compute the response of the beach and dune during episodic events such as hurricanes via either analytical or resolving relevant processes, either in transect (1D) or domain mode (2DH; depth-averaged). Examples include, among others, DUROS (Vellinga 1986), SBeach (Larson et al. 2004), and XBeach (Roelvink et al. 2009, 2017).

Physical models and field observations may be used in combination with analytical numerical models for validation or to quantify input parameters. In addition, observations can be particularly useful to estimate sediment transport in complex bathymetric scenarios. Guidance on the use of various morphological modeling techniques is available in an 
Environment Agency guide (Blanco et al. 2019). For lessons learned on the use of tools in the development and implementation of the sand motor (also known as sand engine) NNBF in the Netherlands, see, for example, Tonnon et al. 2018, Roelvink et al. 2020, and Bridges et al. 2018.

Available technical design guidance manuals for beach design and management include the following:

- The Coastal Engineering Manual (also known as the Shore Protection Manual; USACE 1977, 1984, 2002)

- The Construction Industry Research and Information Association Beach Management Manual (CIRIA 2010) and Groynes in Coastal Engineering (Simm et al. 2020)

- Design guidance for dune management includes Sand Dune Processes and Management for Flood and Coastal Defense (Pye, Saye, and Blott 2007) and Advice on Options for Sand Dune Management for Flood and Coastal Defense (Pye, Blott, and Guthrie 2017)

\section{6 | | Implementation}

\subsubsection{Tendering}

To deliver a given NNBF, the owner will have to select and manage a party (generally a contractor) to do the work (see Implementation Phase discussed in Chapter 2). Discussions between the client and contractor before and throughout the tender process are opportunities for knowledge exchange and further testing of project assumptions and bottlenecks that arose during the initiation and design stage. The timeliness and cost of the construction are risk items that can be mitigated by following these general principles:

- Place risk on the party (owner or contractor) best able to understand and control it (see also Simm and Cruickshank 1998).

- Consider mobilization, temporary works, and short-term environmental impacts, as well as monitoring and adaptive management, when planning and pricing.

- Involve potential contractors early in the process. They can help identify contract language or requirements that may lack internal consistency or that conflict with local standards or industry best practices.

- The focus in the contract should be with functional specifications. Leave room for the contractor to determine the how. The more the method is set at the preliminary design stage, the more difficult it is for a contractor to develop project (and cost) optimizations. 
- NNBF solutions are dynamic-the as-built design evolves over time. This should be reflected in the contract and functional specifications and tolerances. Because NNBF solutions are dynamic, they require different functional specifications and tolerances than hard designs. The natural variability should be considered in these specifications and tolerances.

- Consider these two interface management questions: Are there other efforts underway that will affect the construction? How are they to be coordinated?

The relative risk profile for a project is heavily influenced by the form of the contract. The "best" contracting method will be driven by several factors, including the complexity of the project, funding model, prevailing contracting methods in the host country, and relative sophistication of the owner and contractor (Table 9.8).

Table 9.8. Relative Risks for Different Forms of Contracts

\begin{tabular}{|c|c|c|c|c|c|c|}
\hline \multicolumn{3}{|c|}{ Contract Components } & \multirow[b]{2}{*}{ Common names } & \multirow[b]{2}{*}{$\begin{array}{l}\text { Time frame } \\
\text { relative to } \\
\text { NNBF life }\end{array}$} & \multirow[b]{2}{*}{$\begin{array}{l}\text { Contractor } \\
\text { risk }\end{array}$} & \multirow[b]{2}{*}{ Owner risk } \\
\hline$\frac{5}{5}$ & 을 & $\begin{array}{c}\text { Operations } \\
\text { and } \\
\text { maintenance }\end{array}$ & & & & \\
\hline No & Yes & No & $\begin{array}{l}\text { - Open bid } \\
\text { - Request for } \\
\text { proposal } \\
\text { - Request for } \\
\text { qualifications }\end{array}$ & $\begin{array}{l}\text { Short, in } \\
\text { middle of NNBF } \\
\text { life }\end{array}$ & $\begin{array}{l}\text { Performance, } \\
\text { cost, weather, } \\
\text { compliance }\end{array}$ & $\begin{array}{l}\text { Permitting, } \\
\text { design } \\
\text { suitability, } \\
\text { resilience }\end{array}$ \\
\hline Yes & Yes & No & - Design and build & $\begin{array}{l}\text { Medium, at } \\
\text { start of NNBF } \\
\text { life }\end{array}$ & $\begin{array}{l}\text { Permitting, } \\
\text { design, } \\
\text { performance, } \\
\text { cost }\end{array}$ & $\begin{array}{l}\text { Suitability, } \\
\text { resilience }\end{array}$ \\
\hline No & Yes & Yes & $\begin{array}{l}\text { Build, operate, } \\
\text { maintain, and } \\
\text { transfer }\end{array}$ & $\begin{array}{l}\text { Medium, to } \\
\text { NNBF life }\end{array}$ & $\begin{array}{l}\text { Permitting, } \\
\text { performance, } \\
\text { cost }\end{array}$ & $\begin{array}{l}\text { Suitability, } \\
\text { resilience }\end{array}$ \\
\hline Yes & Yes & Yes & $\begin{array}{l}\text { Design, build, } \\
\text { operate, and } \\
\text { transfer } \\
\text { - Engineering, } \\
\text { procurement, and } \\
\text { construction }\end{array}$ & $\begin{array}{l}\text { Long, } \\
\text { throughout } \\
\text { major part of } \\
\text { NNBF life }\end{array}$ & $\begin{array}{l}\text { Permitting, } \\
\text { design, } \\
\text { performance, } \\
\text { cost, suitability, } \\
\text { resilience }\end{array}$ & $\begin{array}{l}\text { Suitability, } \\
\text { contractor } \\
\text { competence }\end{array}$ \\
\hline
\end{tabular}




\begin{tabular}{|c|c|c|c|c|c|c|}
\hline \multicolumn{3}{|c|}{ Contract Components } & \multirow[b]{2}{*}{ Common names } & \multirow[b]{2}{*}{$\begin{array}{c}\text { Time frame } \\
\text { relative to } \\
\text { NNBF life }\end{array}$} & \multirow[b]{2}{*}{$\begin{array}{c}\text { Contractor } \\
\text { risk }\end{array}$} & \multirow[b]{2}{*}{ Owner risk } \\
\hline$\frac{5}{\frac{5}{5}}$ & 흑 & $\begin{array}{c}\text { Operations } \\
\text { and } \\
\text { maintenance }\end{array}$ & & & & \\
\hline Yes & Yes & Yes & $\begin{array}{l}\text { Design, build, } \\
\text { finance, and } \\
\text { operate and } \\
\text { maintain }\end{array}$ & $\begin{array}{l}\text { Long, } \\
\text { throughout } \\
\text { major part of } \\
\text { NNBF life }\end{array}$ & $\begin{array}{l}\text { Permitting, } \\
\text { design, financing, } \\
\text { performance, } \\
\text { cost, suitability, } \\
\text { resilience }\end{array}$ & $\begin{array}{l}\text { Suitability, } \\
\text { contractor } \\
\text { competence }\end{array}$ \\
\hline
\end{tabular}

Notes:

The contract valuation that incorporates some measure of technical assessment is preferred to the lowest price, but the right mix of technical versus price in the final evaluation will be subject to the same factors as the form of the contract.

Provide tenderers with ample time to ask questions, and provide feedback on any unclear or inconsistent requirements.

\subsubsection{Sediment Sourcing}

Projects to maintain or rehabilitate beach and dune systems will generally require a sediment source. The distance and accessibility of the sediment source will determine available working methods.

Land-based sources of sand and gravel are only going to be useful for small to medium quantities (less than 1 million $\mathrm{m}^{3}$ ). Truck haul can only offer a limited rate of sediment delivery and affects communities between the project and the borrow source. In principle, it is easier to examine and control the characteristics of the sediment (because it can be inspected or even processed by the truck load), but this might limit the available quantity. In addition, upland sources may be less suitable for amenity use being more angular than marine sands.

Offshore sources of sediment are most common for large-scale projects. Dredging can provide for the delivery of sediments at a high rate (10,000 to $100,000 \mathrm{~m}^{3}$ per day), even over long transport distances. The challenge is finding sediments and characterizing them in detail because offshore site investigations are costly and may be difficult (e.g., in deep water, rough seas, or fast-moving currents). Regardless of the source, observe the following principles when sourcing sediments:

- Know the desired grain size distribution and color profile. In some localities, there may be laws or regulations regarding this (e.g., the Florida sand law and color restrictions for beach sand due to turtle nesting).

- Perform a thorough soil campaign. See Johnson and Sraders (2003) and PIANC (2016) for details on executing such a campaign. 
- Provide the tenderers with all relevant details from the investigations. Although potential contractors are expected to competently interpret results using industry or company standards, overly broad disclaimers concerning variations on soil do little to protect the owner in the case of erroneous or inadequate data.

\subsubsection{Sediment Delivery}

Working methods should as far as possible be left to the contractor to decide. However, the contract needs to include tools to help ensure that the NNBF as delivered meets the tactical and operational objectives (see Section 9.4), as in the following:

- Include in the contract high standards of safety and environmental conditions for employees, subcontractors, and the public.

- In the contract, address any permit conditions specific to the work (not including generally applicable laws).

- Provide the contractor with clear and realistic time frames, remembering that tighter, more detailed schedules may drive up the cost or rule out certain contractors.

- Clearly identify potential internal and external threats that might affect the critical path, resulting in project delays.

- Make sure the required tolerances are appropriate to both the goal of the NNBF and the available working methods. Consider tolerances to manage risk and that they may have both a payment and an acceptance component.

- Specify in the contract how the quality of the work will be checked. Tie these checks to acceptance and payment.

\subsubsection{Habitat Creation and Planting}

Multiple nature-based techniques exist to restore or reconnect beach and dune systems. These include the reintroduction or enhancement of grasses, graminoids, forbs (flowering monocots and flowering dicots), shrubs, and trees through seeding, divisions, or placement of containerized plantings. Additional restoration can be provided through enhancement of microbia by reintroduction of beneficial species via soil amendment use of, for example, blue-green algae, mycorrhizae, and bacteria, and adding ecological complexity through land shaping and creation of microsites.

Consideration of site-specific revegetation, whether by containerized plant, division, or seed, should be made at the planning and design stage to allow for proper timing and budget considerations. In addition, plant materials (seed, divisions, or containers) should be ordered from purveying nurseries and seedsmen early in the project process and reserved through deposit to guarantee the most reasonable pricing and help ensure availability. 


\section{7 || Adaptive Management, Monitoring, and Operation and Maintenance}

As with conventional features, NNBF beaches and dunes require maintenance over time. Therefore, adaptive management, monitoring, and operation and maintenance measures are needed and need to be built into the process from the start. Generally, adaptive management of NNBF focuses on management actions during the lifetime of the project after implementation. The acquirement of the data is essential to check whether performance objectives are met so that ultimately the strategic goals will be achieved (e.g., see Section 9.5.4 for the beach and dune case studies). Chapter 7 provides a comprehensive overview of generic adaptive management technical and managerial principles.

\subsubsection{Technical}

It is essential to describe in the adaptive management plan the monitoring needed to assess the performance indicators and determine whether the beaches and dunes are delivering the expected FRM, socioeconomic, and ecological performance. The geometry of the beach and dune system is a typical monitoring need for such an assessment. This monitoring need can be met by surveying the bathymetry of the shoreface, beaches, and dunes. Typical methods are lidar or echosounding. Other examples of monitoring needs and performance indicators are habitat types, habitat acreage, and biodiversity (see Section 9.5 for other examples).

In addition to defining the data required, the procedure for assessing data (for reporting on the performance indicators) should be included in the adaptive management plan (i.e., the method to calculate a coastline position using the monitoring data with respect to a reference coastline set as a performance indicator). The procedure needs to be developed for every objective (see Chapters 5 and 7 ).

\subsubsection{Managerial}

The managerial side of the adaptive management strategy needs to be developed in parallel with the technical side. Procedures need to be established for how the assessment results will be shared and with whom, and what, when, and by whom decisions can be made. The method and frequency of reporting results also need to be established.

Given the inherently dynamic nature of beaches and dunes and the partly stochastic nature of natural morphodynamics and biodynamics, freedom should be left to manage knowns and unknowns. The development of a beach and dune system can be quite different than initially anticipated. This may not be a problem because it is possible that the objectives are

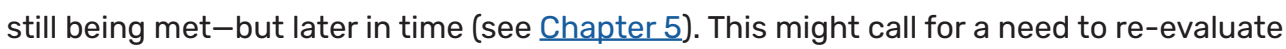


the performance objectives. It is advised to plan for this and allow for re-evaluation of performance objectives in a predefined schedule. Lessons learned based on earlier adaptive management cycles for similar beaches and dunes or other NNBF measures can also be used to inform re-evaluating objectives.

In addition, it is strongly recommended to log management actions. It is also recommended to compose a risk register in which the risk of not meeting the performance objectives is assessed. The choice of whether only management actions should be taken or performance objectives need to be adjusted depends on the current strategic and tactical goals for the NNBF beach and dune project. Over time, both the boundary conditions for an NNBF project and the requirements to be met might change.

\section{8 | Gaps and Future Directions}

The examples in this chapter show that beaches and dunes are coastal landscapes that can gradually adapt to, for example, sea-level rise when supplied with enough sediments and given space to adjust. In locations where this accommodation of space is limited and NNBF are maintained within a narrow spatial envelope, the approach is effectively prolonging the time before conversion to hybrid and, eventually, hard defenses or coastal retreat and relocation of vulnerable receptors is necessary.

Methods such as the DAPP approach (see Section 9.4 and "Adaptive Planning Using Dynamic Adaptive Policy Pathways"), communities of practices such as Climate Risk Informed Decision Analysis, and adaptive management of beach and dune projects support decision-making and adaptation over time as the uncertain future unfolds. In locations where cost-benefit analysis indicates that maintaining the beach and dune feature in situ is no longer a viable option, it will be necessary to explore options to relocate vulnerable people, properties, and infrastructure inland. Integration with existing spatial and land-use planning tools will be essential in this endeavor. For example, the United Kingdom's National Planning Policy Framework includes a mechanism that allows local authorities to designate particularly vulnerable locations as Coastal Change Management Areas to prevent further development and facilitate discussions about adaptation and relocation. Relocation has the benefit of enabling managers to restore natural functioning to beach and dune systems and realize the benefits of a natural feature approach both locally and elsewhere within the coastal system (e.g., restored longshore sediment movement downdrift). Insights into long-term performance of NNBF and the associated risk reduction benefits and costs are essential for implementing these features as a multifunctional flood risk reduction strategy. Such insights should be combined with policies including a long-term (decades to a century) planning horizon. 
Continued research and collaboration across disciplines is, therefore, recommended and should include the following:

- Extending the evidence base on the long-term performance of beach and dune NNBF for coastal resilience under a wide range of conditions and environmental settings

- Enhancing the understanding, uptake and upscaling, and improved implementation of beach and dune NNBF in coastal resilience projects

- Developing and implementing long-term strategies for sustainable coastlines in relation to long-term processes such as climate change and socioeconomic developments

\section{9 | References}

Arcadis. 2013. Zwakke schakels Noord-Holland projectplan. Amersfoort, NL: Hoogheemraadschap Hollands Noorderkwartier.

Bai, J., and P. Perron. 1998. "Estimating and Testing Linear Models with Multiple Structural Changes." Econometrica 66 (1): 47-78. doi:10.2307/2998540.

Barbier, E. B., S. D. Hacker, C. Kennedy, E. W. Koch, A. C. Stier, and B. R. Silliman. 2011. “The Value of Estuarine and Coastal Ecosystem Services." Ecological Monographs 81 (2): 169-183. doi:10.1890/10-1510.1.

Bascom, W. N. 1951. "The Relationship between Sand Size and Beach-Face Slope." Eos: Transactions American Geophysical Union 32 (6): 866-874.

Birkemeier, W. A. 1985. "Field Data on Seaward Limit of Profile Change." Journal of Waterway, Port, Coastal, and Ocean Engineering 111 (3): 598-602.

Blanco, B., B. Woods Ballard, J. Simm, A. Brampton, J. Sutherland, B. Gouldby, and K. Rossington. 2019. Coastal Morphological Modelling for Decision-Makers. Report SC090036/R. Bristol: Environment Agency.

Bowen, A. J., and D. L. Inman. 1966. Budget of Littoral Sands in the Vicinity of Point Arguello, California. Technical Memorandum No 19. Vicksburg, MA: U.S. Army Coastal Engineering Research Center.

Bray, N., A. Bates, and J. Land. 1997. Dredging: A Handbook for Engineers. Second Edition. London: Butterworth-Heinemann.

Brenninkmeyer, B. 1982. "Major Beach Features." In Beaches and Coastal Geology. Edited by M. Schwartz. Boston: Springer.

Bridges, T. S., E. M. Bourne, J. K. King, H. K. Kuzmitski, E. B. Moynihan, and B. C. Suedel. 2018. Engineering with Nature: An Atlas. ERDC/EL SR-18-8. Vicksburg, MS: U.S. Army Engineer Research and Development Center. http://dx.doi.org/10.21079/11681/27929. 
Bridges, T. S., K. A. Burks-Copes, M. E. Bates, Z. A. Collier, J. C. Fischenich, C. D. Piercy, E. J. Russo, et al. 2015. Use of Natural and Nature-Based Features (NNBF) for Coastal Resilience. ERDC SR-15-1. Vicksburg, MS: U.S. Army Engineer Research and Development Center, Environmental Laboratory, Coastal and Hydraulics Laboratory. http://hdl.handle.net/11681/19336.

Brutsché, K. E., J. Rosati, C. E. Pollock, and B. C. McFall. 2016. Calculating Depth of Closure Using WIS Hindcast Data. ERDC/CHL CHETN-VI-45. Vicksburg, MS: U.S. Army Corps of Engineers.

Carter, R. W. G. 1988. Coastal Environments: An Introduction to the Physical, Ecological and Cultural Systems of Coastlines. Cambridge, MA: Academic Press.

CIRIA (Construction Industry Research and Information Association). 2010. Beach Management Manual. Second Edition. London: Construction Industry Research and Information Association.

cirp.usace.army.mil. 2021. Coastal Inlets Research Program. Coastal Modeling System (CMS). https://cirp.usace.army.mil/products/cms.php.

coastal-management.eu. 2021. Dune Strengthening, Rehabilitation and Restoration. RISC-KIT. https://coastal-management.eu/measure/dune-strengthening-rehabilitation-andrestoration.

Cowell, P. J., M. J. F. Stive, A. W. Niedoroda, H. J. de Vriend, D. J. P. Swift, G. M. Kaminsky, and M. Capobianco. 2003. "The Coastal-Tract (Part 1): A Conceptual Approach to Aggregated Modeling to Lower-Order Coastal Change." Journal of Coastal Research 19 (4): 812-827.

Curoy, J. 2010. “Morphological and Longshore Sediment Transport Processes on Mixed Beaches." PhD thesis, University of Sussex. http://sro.sussex.ac.uk/39655/1/ Curoy._J\%C3\%A9r\%C3\%B4me.pdf.

Davidson-Arnott, R. 2010. Introduction to Coastal Processes and Geomorphology. Cambridge: Cambridge University Press.

Davis, R. A. 1985. Coastal Sedimentary Environments. New York: Springer. https://doi. org/10.1007/978-1-4612-5078-4.

De Vriend, H. J. 1991. "Mathematical Modelling and Large-Scale Coastal Behaviour." Journal of Hydraulic Research 29 (6): 727-740. doi:10.1080/00221689109498955.

Deltares, Arens bureau voor strand en duinonderzoek, ecologisch adviesbureau B. Kruijser, Savesk Hydraulics and Royal Haskoning. 2005. Westerschelde Container terminal en het behoud van jonge duinvorming. Report (Dutch) for Zeeland Seaports.

deltares.nl. 2019. Dynamic Adaptive Policy Pathways: Supporting Decision Making Under Uncertainty Using Adaptation Tipping Points and Adaptation Pathways in Policy Analysis. Deltares. Accessed 2019. https://www.deltares.nl/en/adaptive-pathways/. 
Dolan, T. J., P. G. Castens, C. J. Sonu, and A. K. Egense. 1987. “Review of Sediment Budget Methodology: Oceanside Littoral Cell, California." In Coastal Sediments. Edited by N. C. Kraus. New York: American Society of Civil Engineers.

Dornbusch, U. 2017. “Design Requirement for Mixed Sand and Gravel Beach Defences under Scenarios of Sea Level Rise." Coastal Engineering 124: 12-24. doi:10.1016/j. coastaleng.2017.03.006.

DSE (Department of Sustainability and Environment). 2012. Victorian Coastal Hazard Guide. Melbourne, AU: Victorian Government Department of Sustainability and Environment. https://www.marineandcoasts.vic.gov.au/__data/assets/pdf_file/0032/405995/ Victorian-Coastal-Hazard-Guide.pdf.

EcoShape. 2019. Innovatieproject Hondsbossche Duinen: Eindrapportage definitief 0.1. Dordrecht: EcoShape. https://www.ecoshape.org/nl/projecten/hondsbossche-enpettemer-zeewering/.

ecoshape.org. 2021. Sand Nourishment - Hondsbossche Dunes, NL. Building with Nature. https://www.ecoshape.org/en/cases/sand-nourishment-hondsbossche-dunes-nl/.

Elias, E. P. L., A. J. F. Van der Spek, and M. Lazar. 2016. “The 'Voordelta,' the Contiguous EbbTidal Deltas in the SW Netherlands: Large-Scale Morphological Changes and Sediment Budget 1965-2013; Impacts of Large-Scale Engineering." Netherlands Journal of Geosciences 96 (3): 27. doi:10.1017/njg.2016.37.

Elias, E., A. J. F. Van der Spek, Z. B. Wang, and J. de Ronde. 2012. “Morphodynamic Development and Sediment Budget of the Dutch Wadden Sea over the Last Century." Netherlands Journal of Geosciences 91 (3): 293-310. doi:10.1017/ S0016774600000457.

Elias, E., and A. Van der Spek. 2017. “Dynamic Preservation of Texel Inlet, the Netherlands: Understanding the Interaction of an Ebb-Tidal Delta with Its Adjacent Coast." Netherlands Journal of Geosciences 96 (4): 293-317. doi:10.1017/njg.2017.34.

ENW (Expertise Netwerk Waterveiligheid). 2016. Fundamentals of Flood Protection. Rijkswaterstaat: Lelystad Ministerie van Infrastructuur en Milieu.

Everard, M., L. Jones, and B. Watts. 2010. "Have We Neglected the Societal Importance of Sand Dunes? An Ecosystem Services Perspective." Aquatic Conservation: Marine and Freshwater Ecosystems 20 (4): 476-487.

French, J. R., H. Burningham, G. Thornhill, R. Whitehouse, and R. J. Nicholls. 2016 a. "Conceptualizing and Mapping Coupled Estuary, Coast and Inner Shelf Sediment Systems." Geomorphology 256: 17-35.

French, J., A. Payo, B. Murray, J. Orford, M. Eliot, and P. Cowell. 2016b. "Appropriate Complexity for the Prediction of Coastal and Estuarine Geomorphic Behaviour at Decadal to Centennial Scales." Geomorphology 256: 3-16. 
Garel, E., C. C. Rey, O. Ferreira, and M. van Koningsveld. 2014. "Applicability of the 'Frame of Reference' Approach for Environmental Monitoring of Offshore Renewable Energy Projects." Journal of Environmental Management 141: 16-28. http://dx.doi. org/10.1016/j.jenvman.2014.02.037.

Haasnoot, M. 2013. "Anticipating Change. Sustainable Water Policy Pathways for an Uncertain Future." PhD thesis, University of Twente. doi:10.3990/1.9789036535595.

Haasnoot, M., A. Warren, and J. H. Kwakkel. 2019. "Dynamic Adaptive Policy Pathways (DAPP)." In Decision Making Under Deep Uncertainty. Edited by V. Marchau, W. Walker, P. Bloemen, and S. Popper. Cham, CH: Springer. https://doi.org/10.1007/978-3-03005252-2_4.

Haasnoot, M., J. H. Kwakkel, W. E. Walker, and J. ter Maat. 2013. “Dynamic Adaptive Policy Pathways: A Method for Crafting Robust Decisions for a Deeply Uncertain World." Global Environmental Change 23 (2): 485-498.

Hallermeier, R. J. 1981. "A Profile Zonation for Seasonal Sand Beaches from Wave Climate." Coastal Engineering 4: 253-277.

Hanson, H. 1989. "Genesis: A Generalized Shoreline Change Numerical Model." Journal of Coastal Research 5: 1-27.

hbcoast.co.nz. 2020. Clifton to Tangoio Coastal Hazards Strategy 2120. Hawke's Bay Regional Council. https://hbcoast.co.nz/.

Hearin, J. 2014. "Historical Analysis of Beach Nourishment and Its Impact on the Morphological Modal Beach State in the North Reach of Brevard County, Florida." Coastal and Marine Research 2: 37-53. doi:10.12966/cmr.10.01.2014.

Hobgen, S., B. Myers, R. Fisher, and R. Wasson. 2014. "Creating a Sediment Budget in a Data Poor Context: An Example from Eastern Indonesia." Geografiska Annaler: Series A, Physical Geography 96 (4). doi:10.1111/geoa.12076.

Hoonhout, B. M., and S. de Vries. 2016. "A Process-Based Model for Aeolian Sediment Transport and Spatiotemporal Varying Sediment Availability." Journal of Geophysical Research: Earth Surface 121 (8): 1555-1575.

Jarrett, J. T. 1977. "Sediment Budget Analysis Wrightsville Beach to Kure Beach, NC." In Coastal Sediments. New York: American Society of Civil Engineers.

Jervey, M. T. 1988. “Quantitative Geological Modeling of Siliciclastic Rock Sequences and Their Seismic Expression." In Sea-Level Changes: An Integrated Approach, Special Publication No. 42. Edited by C. K. Wilgus, B. S. Hastings, C. G. S. C. Kendall, H. W. Posamentier, C. A. Ross, and J. C. Van Wagoner. Tulsa, OK: Society of Economic Paleontologists and Mineralogists.

Jeuken, C. J., Z. B. Vroom, D. Wang, G. Depreiter, G. van Holland, S. Dam, J. Poortman, and J. Cleveringa. 2014. Advies flexibel storten. Verbeteren van het criterium neuvengeulen - voorstel voor het afleiden van koerslijnen en ondergrenzen voor het watervolume van nevengeulen. Deltares Report 1209395. Delft: Deltares. 
Johnson, K. D., and G. A. Sraders. 2003. "Geotechnical Investigations for Dredging Projects: A Contractor's Perspective." Paper presented at the Proceedings of the Western Dredging Association 23rd Technical Conference, Oakbrook, IL.

Kana, T. W., and F. D. Stevens. 1992. “Coastal Geomorphology and Sand Budgets Applied to Beach Nourishment." In Coastal Engineering Practice. Edited by S. A. Hughes. New York: American Society of Civil Engineers.

Kass, R. E., and A. E. Raftery. 1995. "Bayes Factors." Journal of the American Statistical Association 90 (430): 773-795. doi:10.1080/01621459.1995.10476572.

Kleinhans, M. 2002. Sediment Dynamics on the Shoreface and Upper Continental Shelf, $A$ Review. EC MAST Project No. MAS3-CT97-0086. Utrecht, NL: Universiteit Utrecht, Physical Geography.

Koch, J. L., B. M. Forrest, and R. M. Brantly. 2011. Sand Search and Fill Material QA/QC Plans for Beach Nourishment Projects in Florida. Tallahassee, FL: Florida Department of Environmental Protection, Bureau of Beaches and Coastal Systems.

Komar, P. D. 1996. "The Budget of Littoral Sediments, Concepts and Applications." Shore and Beach 64 (3): 18-26.

Kristensen, S. E., N. Drenen, R. Deigaard, and J. Fredsoe. 2016. "Impact of Groyne Fields on the Littoral Drift: A Hybrid Morphological Modelling Study." Coastal Engineering 111: 13-22. doi:10.1016/j.coastaleng.2016.01.009.

Larson, M., L. Erikson, and H. Hanson. 2004. "An Analytical Model to Predict Dune Erosion Due to Wave Impact." Coastal Engineering 51: 675-696.

Lee, E., and A. Clark. 2002. Investigation and Management of Soft Rock Cliffs. London: Thomas Telford Ltd. doi:10.1680/iamosrc.29859.

Lesser, G. R., J. A. Roelvink, J. A. T. M. van Kester, and G. S. Stelling. 2004. “Development and Validation of a Three-Dimensional Morphological Model." Coastal Engineering 51: 883-915. doi:10.1016/j.coastaleng.2004.07.014.

Lodder, Q. J., J. L. Slinger, Z. B. Wang, and C. van Gelder. 2020. “Decision Making in Dutch Coastal Research based on Coastal Management Assumptions." In Proceedings ICE Coastal Management 2019. Edited by N. Hardman. London: Thomas Telford Ltd.

Luijendijk, A., G. Hagenaars, R. Ranasinghe, F. Baart, G. Donchyts, and S. Aarninkhof. 2018. "The State of the World's Beaches." Scientific Reports 8: 6641. https://doi.org/10.1038/ s41598-018-24630-6.

Luettich, R. A., and J. J. Westerink. 1991. "A Solution for the Vertical Variation of Stress, Rather Than Velocity, in a Three-Dimensional Circulation Model." International Journal for Numerical Methods in Fluids 12: 911-928.

Mangor, K., N. K. Drnen, K. H. Kærgaard, and S. E. Kristensen. 2017. Shoreline Management Guidelines. Hrsholm, Denmark: DHI. 
Marchand, M., A. Sanchez-Arcilla, M. Ferreira, J. Gault, J. A. Jimnez, M. Markovic, J. P. M. Mulder, et al. 2011. "Concepts and Science for Coastal Erosion Management - An Introduction to the Conscience Framework." Ocean and Coastal Management 54 (12): 859-866. http://dx.doi.org/10.1016/j.ocecoaman.2011.06.005.

Marsh, S. W., R. J. Nicholls, A. Kroon, and P. Hoekstra. 1998. "Assessment of Depth of Closure on a Nourished Beach: Terschelling, The Netherlands." In Coastal Engineering 1998. Edited by B. L. Edge. Reston, VA: American Society of Civil Engineers. doi:10.1061/9780784404119.236.

McFall, B. C. 2019. “The Relationship between Beach Grain Size and Intertidal Beach Face Slope." Journal of Coastal Research 35 (5): 1080-1086. doi:10.2112/ JCOASTRES-D-19-00004.1.

Ministerie van Infrastructuur en Waterstaat. 2018. Basiskustlijn 2017. The Hague, NL: Ministerie van Infrastructuur en Waterstaat.

Morang, A. 2016. Saco Bay, Maine: Sediment Budget for Late Twentieth Century to Present. ERDC/CHL CHETN-XIV-40. Vicksburg, MS: U.S. Army Engineer Research and Development Center, U.S. Army Corps of Engineers. February 2016.

Palumbi, S. R., K. L. McLeod, and D. Grünbaum. 2008. “Ecosystems in Action: Lessons from Marine Ecology about Recovery, Resistance, and Reversibility." Bioscience 58 (1): 33-42.

PIANC (The World Association for Waterborne Transport Infrastructure). 2016. Classification of Soils and Rocks for the Maritime Dredging Process. WG Report No. 144-2017. Brussels: PIANC Secrétariat Général.

Polidoro, A., T. Pullen, J. Eade, T. Mason, B. Blanco, and D. Wyncoll. 2018. “Gravel Beach Profile Response Allowing for Bimodal Sea States." In Proceedings of the Institution of Civil Engineers - Maritime Engineering 171 (4): 145-166.

Pontee, N., K. Pye, and S. J. Blott. 2004. "Morphodynamic Behaviour and Sedimentary Variation of Mixed Sand and Gravel Beaches, Suffolk, UK." Journal of Coastal Research 20 (1): 256-276.

Priestas, A., J. Berkowitz, and C. Vanzomeren. 2019. “Predicting Color Change of Dredge Sediment from Fine Sediment Losses and Mixing through Hobber Dredging and Beach Placement." Paper presented at the International Conference on Coastal Sediments, St. Petersburg, FL, May 2019.

Pye, K., S. J. Blott, and G. Guthrie. 2017. Advice on Options for Sand Dune Management for Flood and Coastal Defence. NRW Evidence Report, Report No. 207. Wales: Natural Resources Wales, Bangor.

Pye, K., S. Saye, and S. J. Blott. 2007. Sand Dune Processes and Management for Flood and Coastal Defence. R\&D Technical Report FD1302/TR. London: Department for Environment, Food and Rural Affairs, Flood Management Division. 
Rijkswaterstaat Kustlijnkaarten. 1992-2020. Rijkswaterstaat Coastline Map Database. https:// puc.overheid.nl/doc/PUC_48455_31/1/\#ee75d980-305a-4ff9-b002-b163f27da19f.

Roberts, H., and T. Brooks. 2018. Sediment Budget Analysis: Practitioner Guide. No. SC150011. Bristol: Environment Agency.

Rodríguez-Revelo, N., I. Espejel, C. A. García, L. Ojeda-Revah, and M. A. S. Vazquez. 2018. "Environmental Services of Beaches and Coastal Sand Dunes as a Tool for Their Conservation." In Beach Management Tools - Concepts, Methodologies, and Case Studies. Edited by C. M. Botero, O. D. Cervantes, and C. W. Finkl. doi:10.1007/978-3319-58304-4_5.

Roelvink, J. A., A. J. M. Reniers, A. R. van Dongeren, J. S. M. van Thiel de Vries, R. T. McCall, and J. Lescinski. 2009. "Modelling Storm Impacts on Beaches, Dunes and Barrier Islands." Coastal Engineering 56 (11-12): 1133-1152. https://doi.org/10.1016/j. coastaleng.2009.08.006.

Roelvink, D., R. T. McCall, S. Mehvar, K. Nederhoff, and A. Dastgheib. 2017. “Improving Predictions of Swash Dynamics in XBeach: The Role of Groupiness and IncidentBand Runup." Coastal Engineering 134: 103-123. https://doi.org/10.1016/j. coastaleng.2017.07.004.

Roelvink, D., B. Huisman, A. Elghandour, M. Ghonim, and J. Reyns. 2020. “Efficient Modeling of Complex Sandy Coastal Evolution at Monthly to Century Time Scales." Frontiers in Marine Science 7: 535. https://www.frontiersin.org/article/10.3389/ fmars.2020.00535. doi:10.3389/fmars.2020.00535.

Rosati, J. D. 2005. “Concepts in Sediment Budgets." Journal of Coastal Research 21 (2): 307-322. doi:10.2112/02-475A.1.

Rosati, J. D., and N. C. Kraus. 1999. Formulation of Sediment Budgets at Inlets. Coastal Engineering Technical Note CETN-IV-15 (rev. version September 1999). Vicksburg, MS: U.S. Army Research and Development Center.

Royal Haskoning. 2011. Poole and Christchurch Bays Shoreline Management Plan 2. Review Sub-cell $5 f$ Hurst Spit to Durlston Head. http://twobays.net/smp2.htm.

Shulmeister, J., and H. Rouse. 2003. "Gravel and Mixed Sand and Gravel Systems." In The New Zealand Coast: Te tai o Aotearoa. Edited by J. R. Goff, S. L. Nichol, and H. L. Rouse. Palmerston North, NZ: Dunmore Press.

Simm and Cruickshank. 1998. Construction Risk in Coastal Engineering. London: Thomas Telford.

Simm, J., O. Orsini, B. Blanco, A. Lee, P. Sands, A. Williams, A. Camilleri, and R. Spencer. 2020. Groynes in Coastal Engineering: Guide to Design, Monitoring and Maintenance of Narrow Footprint Groynes. Report C793. London: Construction Industry Research and Information Association. 
Straatsma, M., A. Bloecker, H. Lenders, R. S. E. V. Leuven, and M. Kleinhans. 2017. "Biodiversity Recovery Following Delta-Wide Measures for Flood Risk Reduction." Science Advances 3 (11). doi:10.1126/sciadv.1602762.

Tonkin + Taylor. 2011. Onehunga Foreshore Project: Assessment of Environmental Effects. T+T Project No. 22967. Unpublished Report for Auckland Council. August 2011.

Tonnon, P. K., B. J. A. Huisman, G. N. Stam, and L. C. van Rijn. 2018. “Numerical Modelling of Erosion Rates, Life Span and Maintenance Volumes of Mega Nourishments." Coastal Engineering 131: 51-69. doi:10.1016/J.COASTALENG.2017.10.001.

USACE (U.S. Army Corps of Engineers). 1977. Shore Protection Manual. 3d ed. Fort Belvoir, VA: U.S. Army Coastal Engineering Research Center.

USACE. 1984. Shore Protection Manual. OCLC No. 11285141. Vicksburg, MS: Coastal Engineering Research Center, Department of the Army.

USACE. 2002. Coastal Engineering Manual. EM 1110-2-1100. Vicksburg, MS: USACE, Engineer Research and Development Center.

Van der Spek, A., and Q. Lodder. 2015. "A New Sediment Budget for the Netherlands: The Effects of 15 Years of Nourishing (1991-2005)." Paper presented at the Coastal Sediments 2015 Conference, San Diego, CA, May 2015. doi:10.1142/9789814689977_0074.

van Rijn, L. C. 2014. Beach Nourishment. Blokzijl, NL: www.leovanrijn-sediment.com.

Van Tomme, J. 2013. "Biotic Interactions within Sandy Beach Ecosystems, with Implications for an Ecologically-Sound Beach Nourishment." PhD thesis, Ghent University Faculty of Sciences.

Vitousek, S., P. L. Barnard, P. Limber, L. Erikson, and B. Cole. 2017. “A Model Integrating Longshore and Cross-Shore Processes for Predicting Long-Term Shoreline Response to Climate Change. Journal of Geophysical Research: Earth Surface 122: 782-806. doi:10.1002/2016JF004065.

Wiegel, R. L. 1964. Oceanographical Engineering. Englewood Cliffs, NJ: Prentice Hall.

Winnard, K. 2012. Ecological Effects of Re-Building Beaches on Intertidal Habitats in Wales. CCW Science Report No. 997. Bangor: Countryside Council for Wales.

Wright, L., and A. Short. 1984. "Morphodynamic Variability of Beaches and Surf Zones, A Synthesis." Marine Geology 56 (1-4): 92-118. https://doi.org/10.1016/00253227(84)90008-2.

Zeileis, A., C. Kleiber, W. Krämer, and K. Hornik. 2003. “Testing and Dating of Structural Changes in Practice." Computational Statistics \& Data Analysis 44 (1-2): 109-123. doi:10.1016/ S0167-9473(03)00030-6. 


\section{Acknowledgments}

\section{Lead Authors}

Quirijn Lodder, Rijkswaterstaat, the Netherlands

Claire Jeuken, Deltares USA Inc., United States

\section{Co-Authors}

Richard Reinen-Hamill, Tonkin + Taylor, New Zealand

Oli Burns, Environment Agency, United Kingdom

Robert Ramsdell, III, Dredging Consultant, United States

Jurre de Vries, Rijkswaterstaat, the Netherlands

Brian McFall, U.S. Army Corps of Engineers, United States

Stéphanie IJff, Deltares, the Netherlands

Corragio Maglio, U.S. Army Corps of Engineers, United States

Rinse Wilmink, Rijkswaterstaat, the Netherlands

\section{Contributors}

Uwe Dornbusch, Environment Agency, United Kingdom

John Winkelman, U.S. Army Corps of Engineers, United States

Per Sorensen, Danish Coastal Authority, Denmark

Randy Mandel, Ramboll, United States

Kees Nederhoff, Deltares USA Inc., United States 


\section{Endnotes}

i https://aqua-monitor.appspot.com/?datasets=shoreline

ii https://www.deltares.nl/en/software/mi-safe-viewer/

iii https://navigation.usace.army.mil/SEM/SedimentMobility

iv https://www.simplecoast.com/toolstutorials/ 

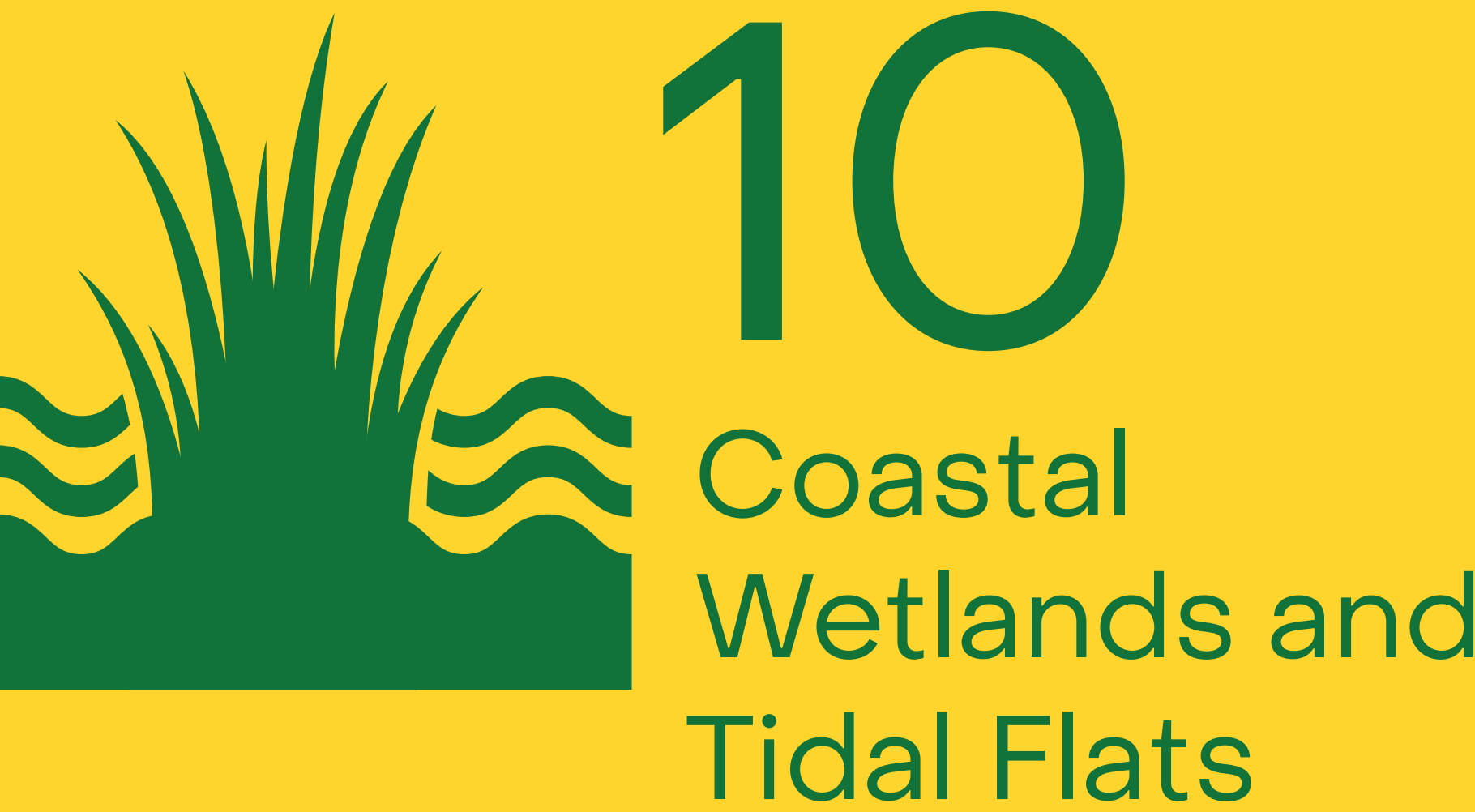

\section{Suggested Citation:}

Piercy, C. D., N. Pontee, S. Narayan, J. Davis, and T. Meckley. 2021. “Chapter 10: Coastal Wetlands and Tidal Flats." In International Guidelines on Natural and Nature-Based Features for Flood Risk Management. Edited by T. S. Bridges, J. K. King, J. D. Simm, M. W. Beck, G. Collins, Q. Lodder, and R. K. Mohan. Vicksburg, MS: U.S. Army Engineer Research and Development Center.

Full acknowledgments appear at the end of this chapter. 


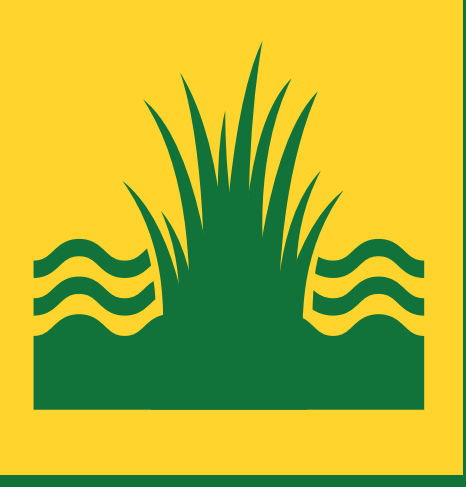

\section{Key Messages}

1. Coastal wetlands and tidal flats can reduce flood and erosion risks in coastal environments. They do this by raising bed levels and offering greater frictional resistance to the movement of water, which can reduce both waves and surge.

2. Coastal wetland and tidal flat natural and nature-based features (NNBF) projects can include the conservation of existing wetlands, restoration of degrading or degraded wetlands, or construction of new wetlands. In urban environments where there is limited space, wetland NNBF may involve creating more limited extents of features (e.g., using terracing) to reduce erosion and partially attenuate waves. Wetland NNBF approaches may also be combined with other structural (e.g., nearshore breakwaters, levees) or NNBF measures (e.g., reefs, upland vegetation communities).

3. Wetland NNBF performance is largely controlled by location, coastline geometry, and storm characteristics.

4. The ability of salt and brackish marshes and mangroves to reduce wave heights is particularly well documented through modeling, laboratory, and field studies. Significant wave reduction can occur within relatively narrow feature widths. Wave reduction depends on several factors such as topography, vegetation characteristics, and characteristics of the storm events (e.g., water level, wave height, wave period).

5. The reduction of surge water levels requires greater wetland size and extent. These reductions occur at both local (across the width of the features) and wider (e.g., along the length of an estuary) scales. 


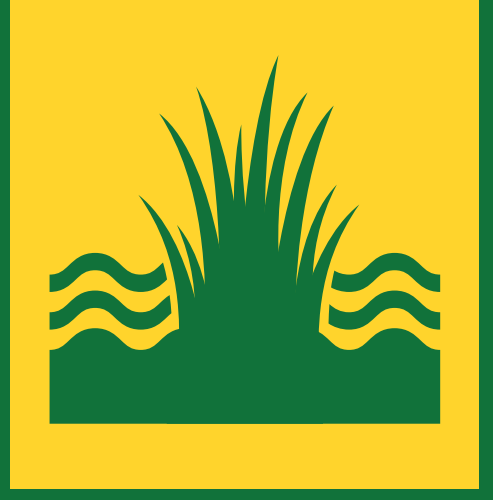

\section{Key Messages (Continued)}

6. Coastal wetlands can also be used as flood storage areas to reduce water levels in estuarine environments, but their efficacy depends on the location and design. There are multiple examples of coastal wetlands used for flood storage across Europe.

7. Coastal wetland and tidal flat NNBF projects can draw upon the extensive experience in the restoration of marshes and mangroves, which has led to the creation of thousands of hectares of features worldwide over the last few decades. Wetland NNBF are a subset of wetland restoration, which aims to achieve primary goals in flood and erosion risk management.

8. In the correct setting, coastal wetland and tidal flat NNBF have the potential to be self-maintaining over time. For example, with sufficient sediment supply, mangroves and marsh features may accrete vertically with sea-level rise. Wetland NNBF also require other suitable environmental parameters to be met (e.g., salinity, tidal inundation).

9. Wetland NNBF projects should consider where they are expected to persist now and into the future, in addition to where they were located in the past. As coastal conditions change, historical wetland locations may be or become unsuitable for wetlands.

10. The performance of wetland and tidal flat NNBF projects may vary over time as vegetation establishes and develops. Designs should consider likely storm damage, recovery, and maintenance requirements. 


\section{1 | Introduction}

This chapter explains how and where coastal wetlands and tidal flats can be used to provide flood risk management (FRM) functions in coastal areas. Coastal wetlands include salt marshes, brackish marshes, mangrove forests, and tidal freshwater marshes; tidal flats are intertidal areas largely void of vegetation, comprising mud or sand, and frequently associated with coastal wetlands. For the purposes of this chapter, the term coastal wetland covers both the vegetated area and any adjacent or interspersed intertidal flats because the unvegetated tidal flats are critical to the function and performance of coastal wetlands. But coastal wetlands exclude wave-dominated shores such as beaches and dunes, which are covered in Chapter 9 . For wetlands associated with fluvial settings, refer to Chapter 14.

Coastal wetlands and intertidal areas are valuable because they can dampen wave, surge, and current energy, trap sediments, and, in the correct settings, be self-sustaining under rising sea levels and other pressures. This chapter also shows how these features provide co-benefits-benefits other than those related to FRM-such as fish production, filtration of pollutants from upland runoff, water quality mediation, recreation, and carbon sequestration.

This chapter is not intended to be a comprehensive reference on wetland conservation and restoration. Indeed, numerous references already exist on wetland function, value, restoration design, and monitoring (UNEP-Nairobi Convention/USAID/WIOMSA 2020; Broome and Craft 2019; Roman and Burdick 2012; Barbier 2011; Zedler 2000; Pôle-Relais Zones Humides Tropicales 2018). This chapter outlines the key aspects of coastal wetlands as natural and nature-based features (NNBF) with a focus on FRM functions and includes conservation of existing wetlands. The intent of this chapter is to provide the reader with an understanding of the range of options, potential benefits, and factors that should be considered for the successful use of wetlands for coastal FRM. FRM is what distinguishes wetland NNBF from typical wetland projects.

\section{2 | Defining the Feature, Its Values, and Contexts for Application}

Role. Historically, wetlands have long been present on coastlines in the absence of adverse human impacts and are dynamic and effective builders of land in coastal margins (Kemp et al. 2013; Kirwan and Megonigal 2013; Gehrels 2000), although their distribution is projected to change as sea levels continue to rise in most parts of the world (Mitchell et al. 2017). Coastal wetlands and tidal flats offer a cost-effective and resilient approach to protecting coastal communities from flooding and erosion and provide a broad spectrum of benefits in addition to shoreline protection. Existing features already reduce flood and erosion risks and, hence, there is benefit in maintaining and enhancing these features into the future. In some cases, 
features have been built exclusively of natural components; in others, they are a combination of natural and conventional measures. In all cases, the design is site specific and driven by the desired outcomes and physical environment. For this reason, the use of wetlands as standalone features or in combination with conventional measures should be considered a part of developing comprehensive FRM strategies.

How they work. Coastal wetlands defend coastlines by providing resistance to the movement of water. As tidal waters flood a coastal wetland, the shallow bathymetry and aboveground vegetation function as a semipermeable barrier, slowing down and reducing the energy of the water, ultimately attenuating inland progression of floodwaters and waves before they meet the upland shoreline.

Form of NNBF. NNBF solutions that incorporate wetlands can take a wide variety of forms and serve a range of purposes (Figure 10.1). Wetland NNBF approaches include (1) conserving existing wetlands, (2) creating relatively narrow fringes of wetland along shorelines to mitigate erosion (sometimes referred to in the United States as living shorelines; see "Wetland Living Shorelines"), (3) improving the condition (e.g., height, density, area) of existing wetlands through restoration, (4) restoring previously reclaimed estuarine wetlands for flood control (i.e., managed realignment), and (5) constructing new wetlands where none previously existed.

\section{Figure 10.1. Wetland NNBF Projects of All Types Can Be Implemented at the Scale of an Estuary}

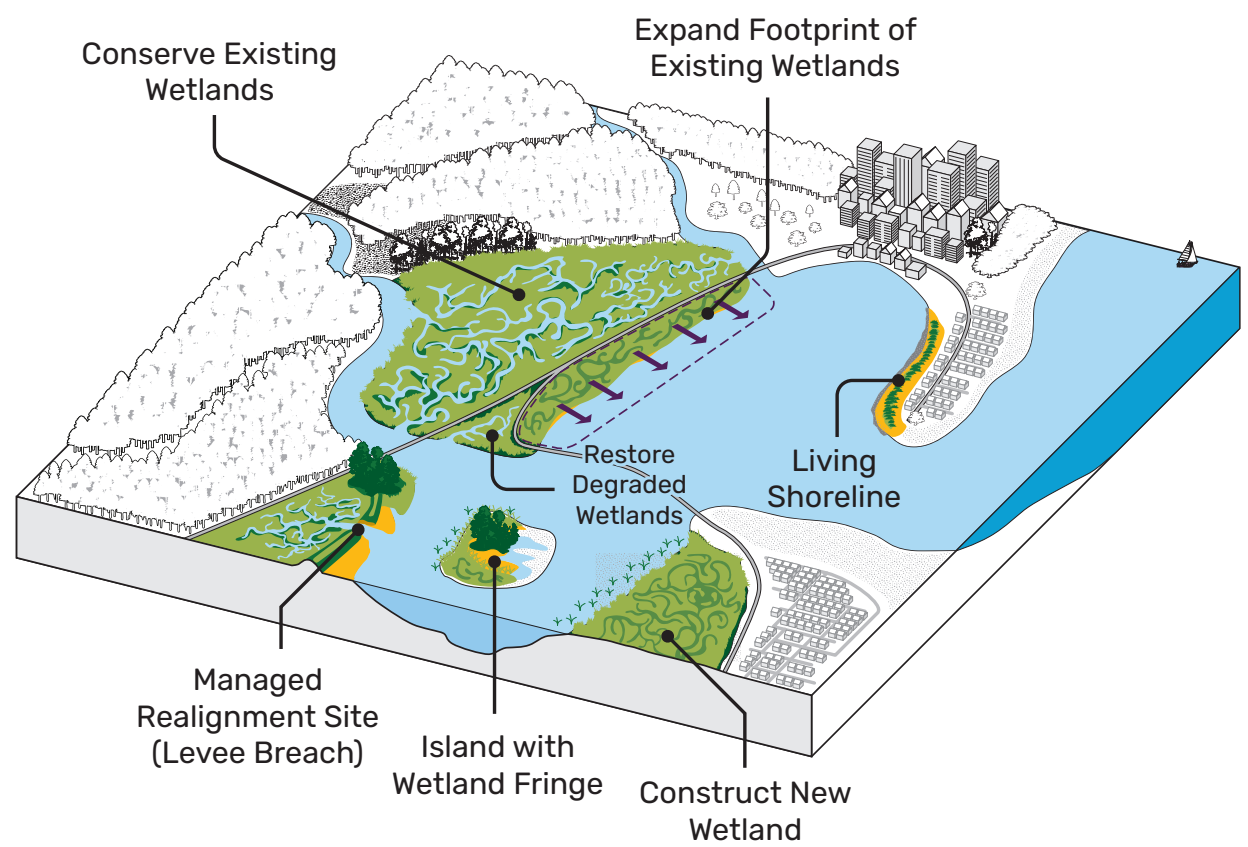




\section{Wetland Living Shorelines}

Living shoreline is a term commonly used in the United States to describe a type of NNBF that involves the use of native vegetation to protect against shoreline erosion. Living shorelines have a footprint that is dominated by native elements such as tidal flats, seagrass beds, intertidal marshes, or mangroves (or a combination of these). In exposed locations, living shorelines often include a structure parallel to and along the waterward edge of the shore to buffer it against incoming wave energy. In low wave-energy settings, these structures may comprise natural elements such as oyster reefs; higher wave-energy settings may require wooden or rock sills or breakwaters (see Figure 10.2).

The term hybrid living shoreline refers to designs that include both natural elements and engineered features. It should be noted that the structural elements of both natural and hybrid living shorelines may alter water and sediment exchange in the vegetated habitat. Therefore, designs for these features must permit adequate exchange processes and should minimize disruptions to the free movement of fauna within the system. Additional living shorelines literature can provide more details on the conditions that necessitate the introduction of hardened structures to marsh edges to dampen waves (Currin, Davis, and Malhotra 2017; NOAA 2015).

\section{Figure 10.2. Two Living Shorelines on Pivers Island in Beaufort, North Carolina, United States}

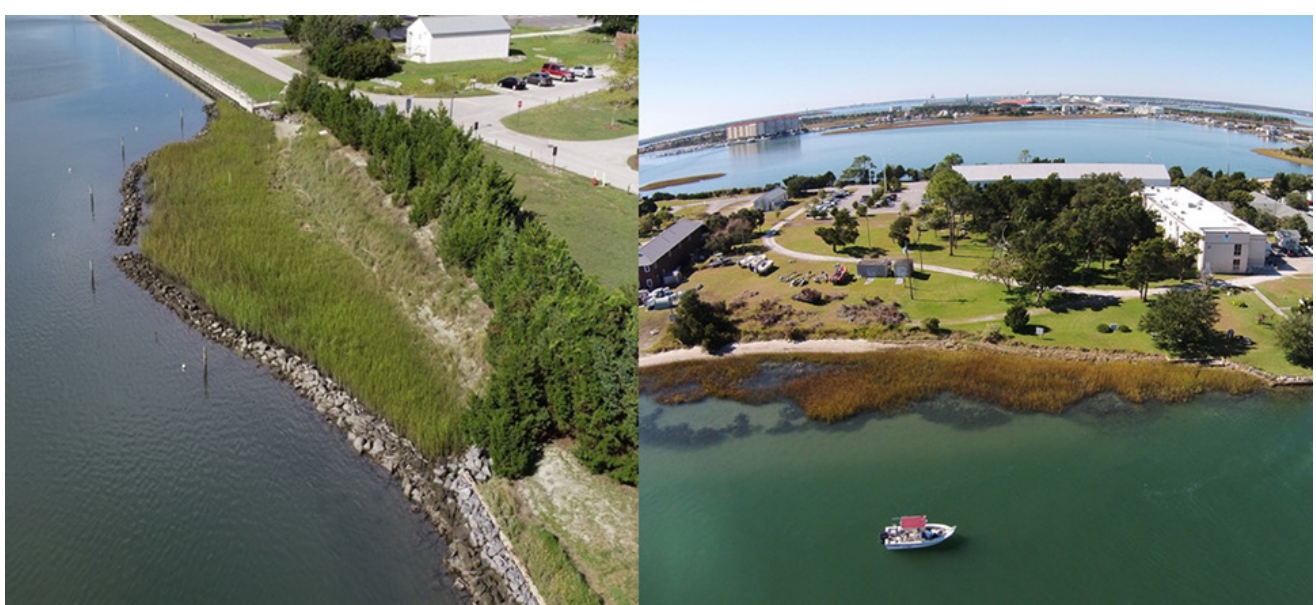

Left photograph: Duke University Marine Lab living shoreline. Right photograph: National Oceanic and Atmospheric Administration (NOAA) Beaufort Laboratory living shoreline. Features in the Duke University living shoreline include a rock sill with a notch to promote proper tidal exchange, a transition zone to the upland, and a shrub and tree buffer. Features in the NOAA living shoreline include vegetation plantings with oyster reefs to reduce wave energy. 
Benefits. Although the magnitude of the benefits varies by locale, wetland characteristics, and nature of the event, there is ample evidence that the presence of coastal wetlands confers significant protection to adjacent upland regions. In an analysis of the economic losses caused by 34 major hurricanes in the United States (Costanza et al. 2008), increased wetland presence was correlated with lower storm-related losses. Observational evidence from the 2012 Hurricane Sandy in the northeast United States and the 2004 Indian Ocean tsunami indicates that shorelines with intact coastal wetlands fared better during these extreme events than those without (Bayas et al. 2011). "Value of Existing Coastal Wetlands in FRM" describes the economic value of coastal wetlands with respect to FRM function. In addition to their role in coastal protection, coastal wetlands are highly valued for the following co-benefits: (1) providing essential habitat for a wide range of marine and estuarine organisms, (2) enhancing nearshore water quality by filtering pollutants from upland runoff and trapping suspended sediments, and (3) creating recreational opportunities for outdoor enthusiasts. For these reasons, there is growing interest in incorporating coastal wetland ecosystems into comprehensive coastal risk reduction strategies.

\section{Value of Existing Coastal Wetlands in FRM}

Although FRM functions of coastal wetlands are often cited as a benefit of wetland restoration, relatively few studies systematically quantify costs, benefits, and co-benefits of existing and restored coastal wetlands. A regional assessment of the value of wetlands across the eastern and Gulf coasts of the United States provides \$3,200 U.S. dollars (USD; 2004) per hectare in avoided damages annually (Costanza et al. 2008). A more recent study of marsh and mangrove wetlands found a $1 \%$ loss in coastal wetland coverage resulted in a $0.6 \%$ increase in property damages, including increased damages from wind (Sun and Carson 2020). Over a 30-year period, the expected value of storm protection from coastal wetlands is on average (the mean value) USD\$36 million per square kilometer, with a median value of USD\$2 million per square kilometer. The difference in the mean and median values indicates wetlands in some locations may provide a large marginal value, emphasizing the role of location on coastal wetland function with respect to FRM.

Other studies used insurance industry models to quantify the value of coastal wetlands for FRM. Narayan et al. (2017) showed that the presence of coastal marshes in Ocean City, New Jersey, United States, on average reduced flood damages by $16 \%$ annually.

Regionally, the effects of wetlands for a single storm, Hurricane Sandy, were mixed, with wetlands reducing damages on average by $11 \%$ in zip codes that were flooded, although wetlands increased damages in some areas and provided little benefit in urban areas with very little remaining wetland area. Generally, states with the greatest wetland cover (i.e., Virginia, Maryland, Delaware, and New Jersey) within the model domain observed the 
greatest reduction (approximately $20 \%$ to $30 \%$ ) in damages from Hurricane Sandy. Using similar modeling approaches, mangroves were found to reduce flood damages by $25.5 \%$ annually in Collier County, Florida, United States (Narayan et al. 2019). During Hurricane Irma in 2017, mangroves reduced damages an average of USD\$7,500 per hectare. Where existing wetlands are insufficient in area or quality to provide the desired FRM function, wetland restoration or creation projects are required.

Status and sustainability. Coastal wetlands have been disappearing at an alarming rate over the past century. Modeled estimates indicate that as much as $50 \%$ of the global extent of mangroves and $25 \%$ of the global extent of salt marshes have been lost since 1940 (Nelleman et al. 2009; MA 2005), with losses of up to $80 \%$ in some regions (Bromberg and Bertness 2005; Airoldi and Beck 2007), due to a combination of factors but mainly conversion to developed land. Fortunately, these rates of loss have slowed and, in some places, even reversed in some cases, particularly for mangroves in developing countries. However, coastal wetlands are still at risk from both new coastal development and the combination of rising sea levels and human-made barriers preventing the natural inland migration of coastal habitats-the latter process being known as coastal squeeze (Doody 2013; Pontee 2013).

Impacts of and adaptation to climate change. Climate-induced changes in sea level are predicted to result in further reductions in coastal wetland area due to increasing wetland inundation, with additional losses of up to $50 \%$ by 2100 under moderate sea-level rise scenarios (Spencer et al. 2016). At the same time, the frequency and intensity of extreme weather events are predicted to increase under future climate conditions (Knutson et al. 2010). Given the important role that wetlands play in coastal protection, further losses of wetlands should be avoided, and wetland restoration should be pursued wherever possible. With sufficient sediment supply, wetlands can maintain their position in the tidal frame despite rising sea levels through vertical accretion or landward transgression. This ability to adapt to a changing environment renders wetlands more resilient to long-term changes in sea level than conventional structures such as bulkheads, and they may be less likely to sustain damages from some storms (Gittman et al. 2014).

\subsubsection{Types and Setting of Coastal Wetlands and Intertidal Areas}

Coastal wetlands are vegetated ecosystems that occur in the intertidal zones of every continent except Antarctica. Salt marshes are the dominant form of coastal wetland in temperate regions, but they are replaced by mangrove forests in the tropics and subtropics. Salt marshes are replaced inland by brackish and tidal freshwater wetlands. Coastal wetlands develop in low-to-moderate wave-energy settings with relatively low slope, and, as a result, 
are common along inland coasts and estuarine shorelines. Coastal wetlands predominantly occur on soft and relatively unconsolidated sediments (i.e., sand, silt, and clay) because vegetation facilitates the trapping of finer sediment particles and prevents resuspension. Wetland grain size also tends to decrease in the landward direction because of decreases in tidal energy over the land surface.

Mangrove forests and salt marshes comprise vegetated areas dissected by tidal creeks, interspersed with unvegetated pools and tidal flats, which are critical to achieving habitat diversity and maintaining water and sediment exchange with the wider estuary, and typically bordered by shallow, unvegetated tidal flats. Vegetated areas are populated by a mixture of species with varying tolerances for flooding and salinity and typically exhibit strong zonation with the more flood-tolerant species growing at lower elevations. Within a given geography, the distribution and growth of salt marsh plants and mangroves are controlled by nutrient availability, shoreline energy regimes (waves and tides), competition with other species, and other factors.

Brackish and freshwater wetlands occur in the upper reaches of tidal influence where the average annual salinity ranges from mesohaline to fresh. Compared to salt marshes and mangrove forests, brackish and freshwater tidal wetlands are comparatively diverse, although species diversity varies by location.

Unvegetated intertidal regions, commonly referred to as tidal flats, are often associated with coastal wetlands. Tidal flats adjacent to salt marshes and mangrove forests often comprise predominately fine-grained sediments and are referred to as mudflats. They are important in dissipating wave energy, and there can be exchanges of sediment between wetlands and fronting mudflats (e.g., during storms when sediment may be resuspended by waves and carried into the wetland).

\subsubsection{Values and Contexts for Application}

Wetlands provide a range of ecosystem services. This document is principally concerned with flood and coastal erosion risk reduction services and benefits, but the range of co-benefits that wetlands can provide can be important in choosing nature-based defenses over more conventional infrastructure or in demonstrating the economic viability of nature-based solutions. 


\subsubsection{Flood and Coastal Erosion Risk Benefits}

Wetlands and intertidal flats can deliver FRM benefits in the following five ways (Table 10.1):

1. By reducing long-term shoreline erosion, which exacerbates future flood risk

2. By trapping and stabilizing coastal sediments, which contributes to coastal wetland surface elevation and consequently reduces future flood risk

3. By attenuating the energy, and hence the height, of incoming waves, which reduces the component of total water levels attributable to waves or the wave energy transmitted to habitats or structures landward of the wetland

4. By attenuating storm surge, which reduces the component of total water levels attributable to surge

5. By providing flood storage, which redistributes the total flood volume, thereby reducing flood damages in adjacent areas (Mclvor et al. 2012a, 2012b, 2013, 2016; Cunniff and Schwartz 2015; Pollard, Spencer, and Brooks 2019), or storing runoff caused by precipitation associated with storms

Generally, the best documented co-benefits are erosion reduction, sediment trapping, and wave attenuation, although evidence exists for all five categories of FRM benefits (Table 10.1).

Table 10.1. Modes of FRM from Wetland and Intertidal Flats and Some Examples

\begin{tabular}{ll}
\hline $\begin{array}{l}\text { Erosion } \\
\text { reduction }\end{array}$ & Required space scale: 1 to 10 s of meters \\
& Potential benefits: \\
- & Moderates increase in future flood risk by lowering shoreline recession rate \\
- & Can take the place of structural measures such as bulkheads \\
- & Can prevent erosion of toe of landward structural features \\
- & Reduces maintenance costs of protected structures \\
- Increases life span of protected structures \\
Examples: \\
- A 5-meter strip of marsh vegetation was planted along the shoreline of Pivers Island, North \\
Carolina, United States, in 2000 to reduce erosion. The narrow marsh fringe has eliminated \\
erosion and has survived multiple storms without damage (Currin 2012). \\
- Mangroves in India's Sundarban region regulate the erosion rate of the muddy delta, with \\
increased density of mangroves associated with lower erosion rates (Mitra 2020).
\end{tabular}




\author{
Sediment Required space scale: 1 to 1,000 s of meters \\ trapping \\ Potential benefits: \\ - Maintenance of current flood risk level into the future by maintaining or increasing wetland \\ elevation and extent \\ - Can take place of structural measures such as bulkheads \\ - Can prevent erosion of toe of landward structural measures \\ - Reduces maintenance costs and increases life span of protected structures
}

\title{
Examples:
}

- Semipermeable dams were used to trap soft sediment and restore mangroves in Semarang Indonesia (Wetlands International 2015, 2016).

- The Netherlands mud motor uses muddy sediment dredged from the nearby Port of Harlingen to increase sedimentation in the Koehoal Salt Marsh, allowing it to accrete more rapidly (van Eekelen et al. 2017; ecoshape.org 2019).

\section{Wave Required space scale: $>10$ s of meters}

\section{attenuation}

\section{Potential benefits:}

- Reduces flooding by wave overtopping and run-up

- Reduces required height of structural measures used in combination with wetlands

- Reduces damage to protected assets during extreme events

- Reduces maintenance costs of protected structures

- Lengthens life span of adjacent infrastructure

\section{Examples:}

- Seventeen years of mangrove reforestation in Vietnam was found to reduce wave damages to dikes during typhoons and effectively manage risks to surrounding low-lying communities (Bolte et al. 2011).

- The Sturgeon Bank brackish foreshore marsh in the Fraser River delta of British Columbia, Canada, accounts for one-third of the wave-energy dissipation during the winter and two-thirds of the dissipation during the summer (Forysinski 2019). This marsh and other area foreshore marshes provide protection to the dikes surrounding the City of Richmond, so ongoing marsh recession is increasing the flood risk to the city (City of Richmond 2019).

\section{Surge Required space scale: $>100$ s to 1,000 s of meters}

attenuation

Wetland must occupy large proportion of total flow area to provide measurable benefit.

\section{Potential benefits:}

- Reduces flooding from storm surge

- Reduces required height of structural measures used in combination with wetlands

- Reduces frequency of surge-barrier operation

\section{Examples:}

- Setback of levees (depoldering) of the Hedwige and Prosper Polders in the Netherlands provides room for water during tidal surges, thereby reducing the risk of floods along the Western Scheldt Estuary and re-establishing an estuarine natural area (climate-adapt.eea. europa.eu 2016; EEA 2018).

- In Florida, United States, mangroves reduced the area flooded from Hurricane Irma by 3,200 hectares. The reduction in flooding extent and height resulted in USD\$1.5 billion in avoided property damages, with most avoided damages in Lee and Collier Counties where surge was the greatest (Narayan et al. 2019). 


$\begin{array}{ll}\begin{array}{l}\text { Flood and } \\ \text { surge } \\ \text { storage }\end{array} & \text { Required space scale: Storage volume }>1,000 \text { s of cubic meters } \\ & \begin{array}{l}\text { Flood storage is a function of volumetric storage capacity rather than area; storage capacity } \\ \text { must be a significant proportion of total flow volume or large enough to capture design } \\ \text { precipitation event. }\end{array} \\ & \text { Potential benefits: } \\ \text { - Reduces water level } \\ \text { - Provides flood and surge storage } \\ \text { - Stores runoff during coastal storms } \\ \text { Examples: } \\ \text { - The Alkborough Flats managed realignment project at the confluence of the Rivers Trent } \\ \text { and Ouse in the Humber Estuary, United Kingdom, provides additional flood storage } \\ \text { capacity during extreme high-water events, lowering water levels in the upper estuary by } \\ \text { 15 centimeters at a } 1 \text { in-200 flood event (Cali et al. 2008). } \\ \text { - Near Tillamook, Oregon, United States, 179 hectares of wetland and associated features were } \\ \text { opened to tidal action to provide valuable salmon habitat while storing excess floodwaters } \\ \text { from the Wilson, Trask, and Tillamook Rivers at the mouth to Tillamook Bay. The project } \\ \text { reduced water levels in the Town of Tillamook by approximately } 21 \text { centimeters following a } \\ \text { heavy rain event in } 2017 \text { (Northwest Hydraulic Consultants 2018). }\end{array}$

Erosion reduction and sediment trapping. Wetlands effectively reduce erosion rates due to the combined effect of aboveground and belowground biomass (Gedan et al. 2011; Shepard, Crain, and Beck 2011). Wetland aboveground biomass (e.g., stems and leaves) reduces the velocity of incoming water during high tide, allowing sediment to fall out of suspension, effectively trapping sediments and promoting accretion of the wetland surface. Aboveground biomass also dissipates energy from locally generated wind waves, reducing energy exerted on shorelines. At the same time, the belowground vegetative material (e.g., roots and rhizomes) forms a binding matrix that holds soil particles in place, reinforcing shorelines against wave- and current-induced erosion. Belowground biomass further adds to surface elevation through the production of belowground roots and rhizomes, which contribute to soil volume (Gedan et al. 2011). Erosion reduction and sediment trapping benefits are realized during both everyday conditions and extreme weather events. Even relatively narrow strips of wetland can reduce erosion rates (see Table 10.1) and trap sediments, creating shore protection benefits that may be resilient to the effects of sea-level rise.

Wave attenuation. Numerous scientific studies over the past three to four decades have observed and recorded the capacity of coastal mangrove forests, salt marshes, and reed beds to attenuate wave energy and height during storm events (e.g., Gedan et al. 2011; Shepard, Crain, and Beck 2011; NRC 2014). A synthesis of more than 69 studies shows that salt marshes are particularly effective at wave attenuation, reducing incoming wave heights by nearly $70 \%$ on average across all observations (Narayan et al. 2016). Mangrove forests are also fairly effective barriers to incoming waves, reducing wave heights by approximately $33 \%$ on average 
(Narayan et al. 2016). Generally, greater wetland widths are required to attenuate larger waves so attenuation of storm waves will require larger wetland areas than those required to reduce erosion, which is typically driven by locally generated wind waves.

Across-wetland surge attenuation. Wetland vegetation and bathymetry together can lead to lower water levels at the rear of a wetland than at the front (sometimes referred to as within-wetland attenuation or across-wetland attenuation; see Figure 10.3). However, relatively large wetland areas are required to achieve meaningful reductions in water levels, with reported surge-attenuation rates ranging from 0 to 70 centimeters per kilometer $(\mathrm{cm} / \mathrm{km})$ over marsh widths greater than 10 meters $(\mathrm{m})$, depending on storm characteristics and location, with most estimates ranging between 1.7 and $25 \mathrm{~cm} / \mathrm{km}$ (Paquier et al. 2017; Leonardi et al. 2018). The proportion of the surge-attenuation capacity attributable to vegetation varies from essentially negligible to the dominant frictional elements, accounting for up to approximately $60 \%$ of the attenuation capacity in some cases (Loder et al. 2009). As the base water level increases, the relative contribution of vegetation friction decreases with little-to-no effect at extreme water levels. Note that some of the estimates of surge attenuation included in the reviews by Paquier et al. (2017) and Leonardi et al. (2018) were produced from modeling studies that simulated the removal or addition of wetlands by removing or adding only the frictional elements (e.g., vegetation) from the model and not by modifying the topography (Sheng, Lapetina, and Ma 2012; Zhang et al. 2012; Marsooli et al. 2016). Because wetland topography is maintained by the vegetation, model estimates of surge-attenuation rates that include only the effects of vegetation friction may not accurately represent the effect of losing existing wetlands on storm-surge propagation.

\section{Figure 10.3. Across versus Along Surge Attenuation through Wetlands}

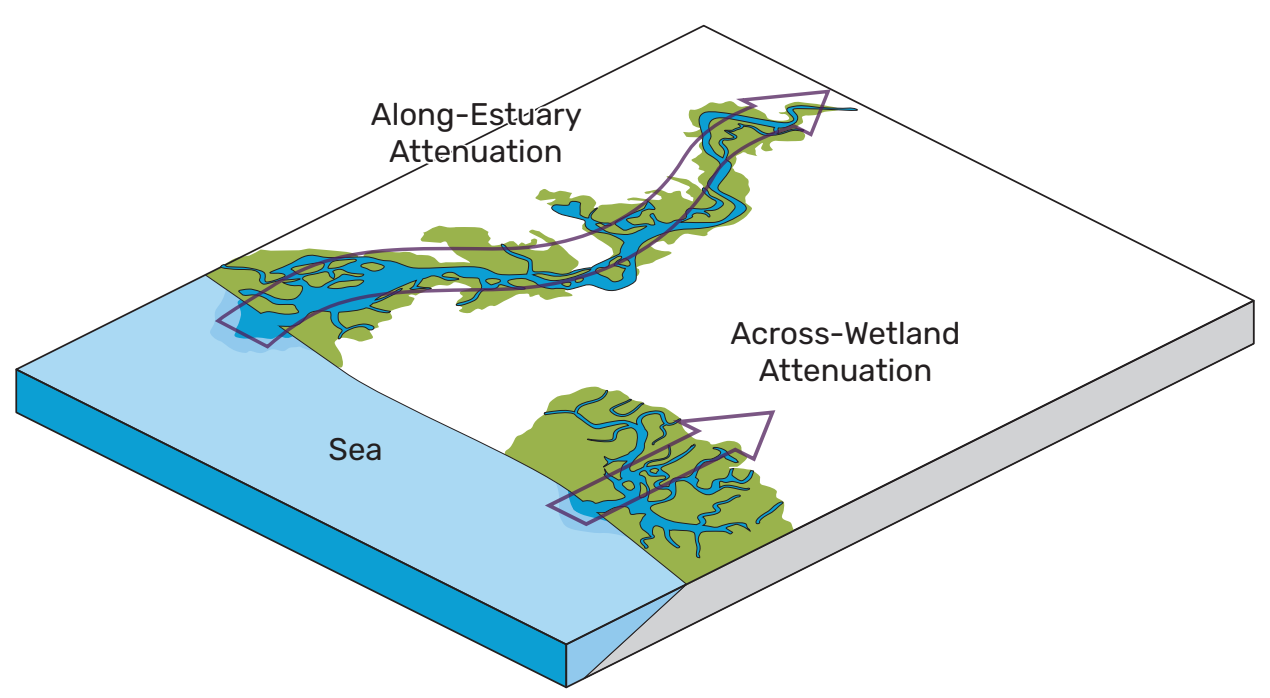


The surge-attenuation capacity of mangrove forests is greater than that of salt marshes because of the additional height and complex plant geometry. Although total mangrove widths on the order of 7 to 8 kilometers $(\mathrm{km})$ or greater reduced surge height for a Category 3 hurricane by approximately $80 \%$ (Zhang et al. 2012), narrower mangrove buffer widths, on the order of $30 \mathrm{~m}$ to $1.6 \mathrm{~km}$, are not without merit, resulting in significant reduction in inundation volume (between $66 \%$ and $69 \%$ depending on mangrove characteristics) associated with intense hurricanes such as Hurricane Andrew (Sheng and Zou 2017). Some measurable surge reduction, on the order of 4 to 6 centimeters $(\mathrm{cm})$, has also been reported for sites with mangrove buffers as narrow as $50 \mathrm{~m}$ (Dasgupta et al. 2019).

Along-estuary surge attenuation. Networks of coastal wetlands can also reduce water levels across entire estuaries by decreasing the rate at which storm surge propagates into and across the estuary (see the portion of Figure 10.3 labeled "Along-Estuary Attenuation"). Modeling studies have demonstrated how wetlands along the length of an estuary can affect surge and tidal propagation. Surge-attenuation effects of wetlands vary depending on the landscape, with the greatest effects documented for broad deltaic wetlands and wetlands within funnel-shaped estuaries such as the Mississippi River delta in the United States and the Humber Estuary in the United Kingdom, respectively, with moderate and limited effects documented for wetlands within embayments and lagoonal estuaries such as the Chesapeake and Jamaica Bays in the United States, respectively (Leonardi et al. 2018). For example, Stark et al. (2015) found that storm tides that exceeded marsh elevations along the edges of a 4-km tidal channel could attenuate water levels by $5 \mathrm{~cm} / \mathrm{km}$. For temperate salt marshes along confined estuaries, significant surge attenuation does not occur until $20 \%$ to $40 \%$ of the total flow volume passes over the salt marsh (Stark et al. 2016). However, any surge-attenuation effects decrease again as water levels begin to exceed the plant height.

Flood storage. The conversion of upland areas to new intertidal areas within estuaries can be used to create flood storage areas-areas that periodically inundate under flood events-and in doing so reduce water levels in the wider estuary. The successful functioning of flood storage areas depends on a number of design factors, including location within the estuary, size of the area, and form of connectivity (e.g., culverts, weirs, breaches) with the wider estuary. Flood storage projects are commonly located in the upper parts of estuaries rather than near the estuary mouths (Figure 10.4; Pontee 2015). In the Scheldt Estuary, a series of wetland flood storage schemes known as the Sigma Plan (sigmaplan.be 2020) located $100 \mathrm{~km}$ or more upstream of the estuary mouth and used to reduce water levels under storm-surge tides, reduced water levels by up to $50 \mathrm{~cm}$ during a storm-surge event on December 6, 2013 (Smolders et al. 2020). 
Figure 10.4. Effects of Wetland Flood Storage Area Location on Estuarine Water Levels
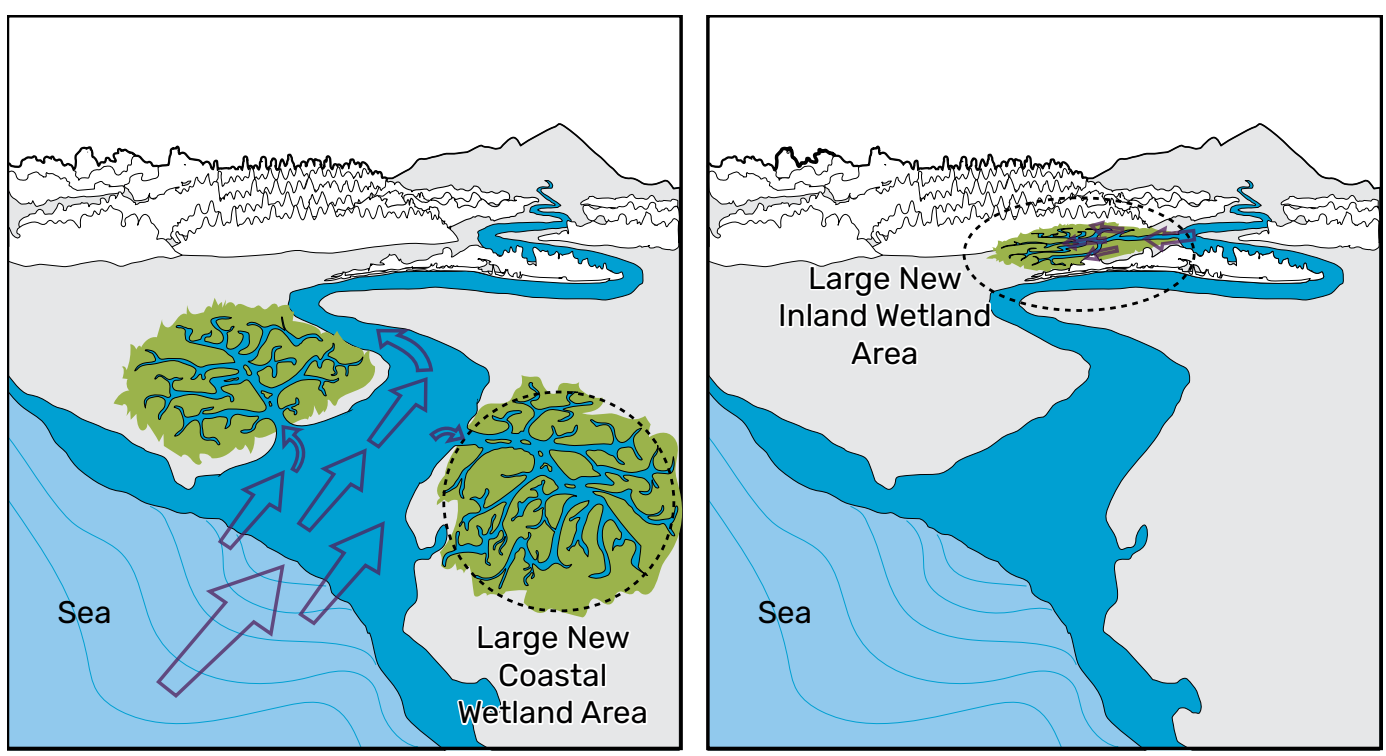

Left panel: Creating large new areas of intertidal habitat near estuary mouths can draw more water into the estuary, leading to an increase in water levels in the estuary. Right panel: Creating new areas of intertidal habitat in the inner estuary does not draw extra water into the estuary and can provide a wider area for water to spread, thus reducing water levels.

\subsubsection{Coastal Wetland Co-Benefits}

One of the main attractions of wetland NNBF is that in addition to providing FRM benefits, they can provide a range of co-benefits, including the following:

- Enhancing fisheries production (Hutchison et al. 2014)

- Sequestering carbon within plant biomass and soil (Alongi 2014; Davis et al. 2015; Doughty et al. 2015; Howard et al. 2017)

- Improving water quality (Breux, Farber, and Day 1995; Zedler 2003)

- Reducing maintenance dredging requirements in nearby ship channels, by trapping sediment

- Supporting ecotourism (Lee and Hsieh 2016)

- Providing material for fuel, construction, and medicinal uses (Bandaranayake 1998; Barbier 2011) 
The provision of each of these co-benefits depends on a host of ecosystem and environmental characteristics and may or may not overlap spatially (Atkinson et al. 2016). That is, a wetland that provides high fisheries or species richness value may not provide much coastal protection or vice versa, requiring careful consideration of the trade-offs between ecological and FRM functions, for example. It is important to understand the distribution of each of these co-benefits when making decisions on where, how, and for what purpose to manage or restore a wetland. The realization of some of the potential co-benefits might depend on local or national regulatory frameworks. For example, in some parts of the world, wetlands may be grazed by cattle, whereas in other parts of the world, wetlands may be protected by conservation regulations that prevent grazing. Refer to the benefits chapter (Chapter 6) for a detailed description of how to identify, assess, and quantify the suite of NNBF benefits.

\section{3 | Conceptual System Understanding}

To implement successful wetland NNBF solutions, it is necessary to consider a number of key aspects of the physical, socioeconomic, and governance systems. The physical system includes both the typical aspects of the physical system (such as the hydrodynamics) and the ecological system (including the vegetation). When new wetlands or the expansion of existing wetlands is proposed, the effect of the actions on hydrodynamics and ecosystem function should also be considered. Depending on governance issues, changing subtidal or intertidal unvegetated areas to wetlands may require additional permits or actions to ensure ecological functions of the system are not degraded. As with all proposed FRM actions, early engagement with regulatory agencies and stakeholders is critical not only to gain support and buy-in for proposed wetlands but also to discourage any rumors or false assumptions about the nature of the project.

\subsubsection{Physical System}

Key aspects of the physical system influencing wetlands include (1) site landscape position (see Section 10.5.1) and geomorphology (e.g., site elevation, site shape, tidal creek density, proximity to inlets); (2) hydrology, hydrodynamics, and sediment transport (e.g., tidal range, groundwater inflow, and wave energy); (3) soils; (4) vegetation; and, in some cases, (5) fauna (Figure 10.5). 
Figure 10.5. Coastal Wetland Biophysical Processes That Control Elevation and Erosion Dynamics as Part of an Estuarine System

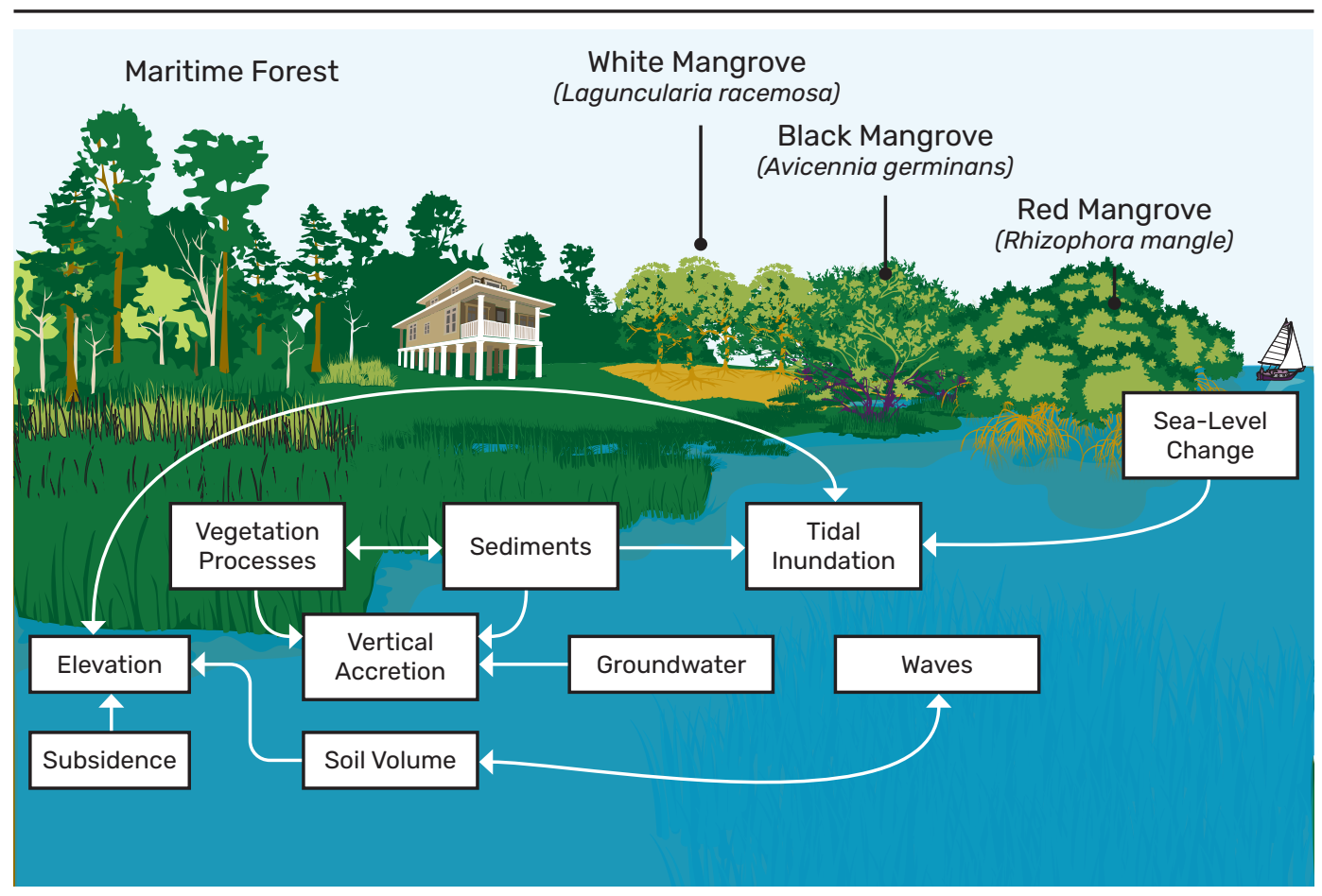

Hydrodynamic controls on wetlands. Shoreline energy is a strong determinant of wetland distribution; wave and current energy must be sufficiently low so the wetland substrate is not eroded and vegetation can establish and maintain itself. Shoreline energy, in turn, is strongly controlled by site landscape position. Wetland edge erosion is linearly correlated with wave power, so although storm events can significantly erode wetland shorelines, more frequent, less energetic conditions are responsible for the majority of the long-term erosion (Leonardi and Fagherazzi 2015). Observational study of smooth cordgrass (Spartina alterniflora)-dominated marsh shorelines in Alabama, United States, indicates noneroding wetlands occur in environments where the median significant wave height is $0.1 \mathrm{~m}$ and $80 \%$ of all shoreline waves are less than or equal to $0.2 \mathrm{~m}$ (Roland and Douglass 2005); however, such rules of thumb are site specific. Measurements of representative wave energy or wave power factor capture site-specific variation and can better delineate conditions conducive to wetland vegetation. Currin, Davis, and Malhotra (2017) found stable, relatively wide swathes of Spartina alterniflora persisted in the New River Estuary of North Carolina, United States, at representative wave energy during the top $20 \%$ of wind events of up to 250 joules per meter (corresponding to a wave power of 170 joules per meter per second). Wetlands can persist in more energetic conditions, but some engineered structure such as a sill or breakwater is required to prevent erosion. 
Evidence indicates stable salt marshes can survive storms with relatively little damage; however, brackish and freshwater marshes with a higher proportion of organic sediments can be more susceptible to storm damage (Leonardi et al. 2018). Degraded salt marshes, which are characterized by reduced soil shear strength, are likewise susceptible to storm damage (Day et al. 2011; Deegan et al. 2010). Coastal wetlands adjacent to structures or abrupt elevation changes, such as ditches or embankments, where concentrated flows or wave reflection can occur during extreme events, may be more susceptible to storm damages than unaltered wetlands (Morton and Barras 2011).

Mangroves may be susceptible to wind damage during strong storms. Recovery times range from 18 months to 4 years, demonstrating that natural recovery can occur even after devastating storm damages, although permanent habitat conversion can occur (Smith, Knapp, and Collins 2009; Barr et al. 2012; Long, Primavera, and Trivedi 2016).

Resilience to sea-level rise. The ability of marshes to build in place is dependent on the rate of relative sea-level rise, tidal range, and suspended sediment concentrations. In regions with typical ambient suspended sediment concentrations on the order of 20 to 50 milligrams per liter, salt marshes are predicted to be resilient to 10 to 50 millimeters per year of sea-level rise (Kirwan et al. 2016a). In contrast, model results suggest that in microtidal regions with low suspended sediment concentrations, elevated rates of sea-level rise may outpace elevation gain, ultimately leading to wetland loss by drowning (Kirwan et al. 2010). Once wetland vegetation is lost due to excessive inundation, restoration is not possible without the addition of sediment to restore intertidal elevations (Day et al. 2011; Mariotti 2016). Denser aboveground biomass can enhance rates of sediment accumulation (Davis, Currin, and Morris 2017), especially for mineral sediments. Barriers to sediment transport can lead to sediment starvation of downstream wetland ecosystems, further impeding the ability of coastal wetlands to maintain elevation (Kemp et al. 2016). Long-term degradation of wetlands will affect their capacity to produce FRM benefits (Bouma et al. 2014).

Coastal wetlands can adapt to elevated rates of sea-level rise by migrating landward. However, this migration is dependent on the presence of undeveloped migration corridors for wetland inland migration (Enwright, Griffith, and Osland 2016; Anderson and Barnett 2017). Therefore, to ensure future coastal wetland area, current upland ecosystems behind existing tidal marshes and mangrove forests should be protected from urban development to ensure migration opportunities. If the slope abruptly increases near the upland margins of wetland systems either due to natural topography or anthropogenic alterations such as bulkheads, retaining walls, or conventional levees, the ability of the wetland communities to migrate is blocked or hindered and the wetland is less resilient to changes in water level. The term managed realignment is often used to describe the process whereby flood infrastructure (e.g., levees) is relocated landward to re-create coastal wetlands (Pontee 2007). 


\subsubsection{Socioeconomic System}

Coastal wetlands provide a number of ecological services and co-benefits that are valued by humans in a socioeconomic context. If coastal wetlands are used as part of a comprehensive FRM plan or scheme, the social and economic values associated with those systems should be maintained. For example, if a salt marsh requires a structural measure to prevent erosion and reduction of the FRM benefit obtained from the wetland, that structure should be designed in such a way as to still allow fish to readily access the marsh creeks and vegetated areas. For circumstances where competing interests are difficult to reconcile, a formal community engagement process will likely be necessary (see Chapter 3 ).

\subsubsection{Governance System}

Although the specifics of wetlands governance vary internationally, wetlands are subject to a variety of international, national, and local treaties, laws, and other regulations. These special provisions will require additional levels of coordination and review beyond the additional recommended engagement for all NNBF projects and may necessitate additional consultation or time to attain the required approvals. Although permitting requirements typically require a near-final design, best practices for developing wetland NNBF projects should engage regulatory agencies during the early stages of project conceptualization and design so any requirements can be incorporated more easily into progressively more detailed designs.

Likewise, the adjacent aquatic habitats are subject to any number of regulations controlling their use and development. If wetland NNBF are likely to adversely impact or alter those habitats through conversion, additional coordination will be required. Although issues associated with habitat conversion are often not avoidable, especially in cases where coastal wetlands are being created, early engagement with regulators and stakeholder groups can help prevent costly delays by integrating design elements to enhance impacted aquatic habitats, such as the incorporation of reef structures or sheltered pool areas along wetland edges to enhance shallow-water habitat quality.

\section{4 | Objectives, Performance, and Metrics}

\subsubsection{Setting Objectives}

The design team should identify key goals and objectives for each project. The primary goals and objectives for NNBF projects will relate to FRM (Table 10.2). A range of additional objectives can also be delivered by the other ecosystem services that wetlands and tidal flats provide (Section 10.2.2). 
Table 10.2. Examples of Wetland Functions, Objectives, Metrics, and Performance Factors

\begin{tabular}{|c|c|c|c|c|}
\hline Functions & $\begin{array}{c}\text { Example } \\
\text { objectives }\end{array}$ & $\begin{array}{c}\text { Example } \\
\text { performance } \\
\text { metrics }\end{array}$ & $\begin{array}{c}\text { Example } \\
\text { performance } \\
\text { criteria }\end{array}$ & $\begin{array}{l}\text { Applicable } \\
\text { evaluation } \\
\text { techniques }\end{array}$ \\
\hline $\begin{array}{l}\text { Erosion } \\
\text { reduction }\end{array}$ & $\begin{array}{l}\text { Reduce sediment } \\
\text { loss from shoreline }\end{array}$ & $\begin{array}{l}\text { Shoreline change } \\
\text { rate }\end{array}$ & $\begin{array}{l}\text { Rate of shoreline } \\
\text { loss reduced by } 20 \%\end{array}$ & $\begin{array}{l}\text { Directly or remotely } \\
\text { measured }\end{array}$ \\
\hline $\begin{array}{l}\text { Sediment } \\
\text { trapping and } \\
\text { land building }\end{array}$ & $\begin{array}{l}\text { Maintain elevation of } \\
\text { wetlands }\end{array}$ & $\begin{array}{l}\text { Wetland elevation, } \\
\text { accretion rate }\end{array}$ & $\begin{array}{l}\text { Accretion rate to } \\
\text { meet or exceed local } \\
\text { rate of sea-level rise }\end{array}$ & $\begin{array}{l}\text { Directly or remotely } \\
\text { measured, indirectly } \\
\text { measured }\end{array}$ \\
\hline \multirow{2}{*}{$\begin{array}{l}\text { Wave } \\
\text { attenuation }\end{array}$} & $\begin{array}{l}\text { Reduce maintenance } \\
\text { of structure } \\
\text { landward of wetland }\end{array}$ & $\begin{array}{l}\text { Wave thrust, rate } \\
\text { of degradation of } \\
\text { structure condition }\end{array}$ & $\begin{array}{l}\text { Wave thrust on } \\
\text { structure reduced } \\
\text { by } 50 \% \text { during windy } \\
\text { conditions }\end{array}$ & $\begin{array}{l}\text { Computed or directly } \\
\text { measured }\end{array}$ \\
\hline & $\begin{array}{l}\text { Reduce component } \\
\text { of total water level } \\
\text { attributable to } \\
\text { waves during storm } \\
\text { conditions }\end{array}$ & Wave height & $\begin{array}{l}>20-\mathrm{cm} \text { reduction in } \\
\text { wave height during } \\
\text { storm conditions }\end{array}$ & $\begin{array}{l}\text { Computed or directly } \\
\text { measured }\end{array}$ \\
\hline $\begin{array}{l}\text { Surge } \\
\text { attenuation }\end{array}$ & $\begin{array}{l}\text { Reduce water } \\
\text { level up-estuary } \\
\text { of wetland during } \\
\text { storm conditions }\end{array}$ & $\begin{array}{l}\text { Change in surge } \\
\text { component of total } \\
\text { water level beyond } \\
\text { wetland location }\end{array}$ & $\begin{array}{l}>30-\mathrm{cm} \text { surge } \\
\text { water-level } \\
\text { reduction during } \\
\text { storm events } \\
\text { up to } 2 \% \text { annual } \\
\text { exceedance } \\
\text { probability }\end{array}$ & Computed \\
\hline Flood storage & $\begin{array}{l}\text { Reduce water } \\
\text { level up-estuary } \\
\text { of wetland during } \\
\text { storm conditions; } \\
\text { store precipitation- } \\
\text { driven runoff }\end{array}$ & $\begin{array}{l}\text { Volume of water } \\
\text { stored in wetland } \\
\text { during storm event }\end{array}$ & $\begin{array}{l}\text { Store } 4,000,000 \\
\text { cubic meters of } \\
\text { floodwater when } \\
\text { flood levels exceed } \\
2.75 \text { meters; reduce } \\
\text { total water levels } \\
\text { up-estuary of flood } \\
\text { storage area }\end{array}$ & $\begin{array}{l}\text { Computed or indirectly } \\
\text { measured }\end{array}$ \\
\hline
\end{tabular}

The choice of objectives will inform the location, size, and structure of the wetland NNBF required. However, the type of wetland NNBF that can be implemented will also depend on the characteristics of the local site. For example, if space is limited, it may not be possible to create an expansive feature with which to deliver significant reductions in surge or wave height. In such circumstances, it might be necessary to use a wetland combined with conventional measures (e.g., a levee) or another NNBF (e.g., an oyster reef). 


\subsubsection{Performance}

Wetland NNBF performance is largely controlled by the following two aspects that can be manipulated in design: (1) the underlying geomorphology of the vegetated wetland surface and intersecting channels, ephemeral salt pannes, and permanent pools and (2) the vegetation. To assess performance, the effects of both aspects should be quantified and used to estimate performance. The landscape (e.g., space constraints) and the biophysical requirements for wetland vegetation (e.g., elevation constraints) limit the degree to which wetland geomorphology and vegetation can produce FRM benefits.

Storm characteristics also strongly influence wetland performance with respect to FRM objectives; and the variation in performance due to variation in storm characteristics, such as direction and forward speed, should also be considered. Note that other NNBF and structural measures also exhibit variation in performance under different storm conditions, so some consideration of common storm patterns should be part of the planning and design process to ensure the FRM measures selected address the storm patterns linked to problematic flooding.

Reported values for wetland wave and water-level attenuation tend to show a greater variation than those for conventional measures due to variations in vegetation in and between wetlands. Generally, previous studies have documented the greatest attenuation benefits coming from relatively frequent storm events that are greater than the elevation of the underlying sedimentary platform but that do not greatly exceed the top of the wetland vegetation (Lawler, Haddad, and Ferreira 2016; Leonardi et al. 2018). Performance may also be highly nonlinear, so simple relationships describing benefit per unit length or area of wetland are not realistic. For instance, once the vegetation becomes submerged, wave-attenuation benefits drop off steeply (see Section 10.6.3).

Dynamics. Because coastal wetlands are dynamic, their performance is likely to change over time. Natural inter- and intra-annual variation results in variation in reported performance estimates for wave and surge attenuation. For instance, seasonal changes in vegetation influence standing aboveground biomass and biophysical properties, with greater performance expected during the peak of the growing season and a greater likelihood of stem breakage during the dormant season (Schulze et al. 2019). Over a longer temporal scale, wetland vertical accretion can help maintain or increase performance as wetland elevation keeps pace with or even exceeds sea-level rise (see Section 10.3.1).

Some changes in the coastal environment may exceed the ability of wetland NNBF to sustain required performance levels, necessitating periodic performance evaluations and targeted management interventions. Routine management actions may be initiated if the wetland reaches a defined limit state (i.e., the wetland state that provides a minimum level of acceptable performance) or if the wetland sustains irrecoverable damages due to severe storms. Typical management actions may include replanting or replacing sediment 
(see Chapter 7). Such interventions can be considered analogous to maintenance schedules for conventional measures and should be part of an adaptive management plan that describes required maintenance actions and the limit states that would initiate repair and rehabilitation of the wetland.

Wetland performance will evolve after initial project construction. Some degree of FRM performance can be expected immediately because the bathymetry changes associated with wetland creation or restoration provide wave- and surge-attenuation benefits. As the site develops ecologically and vegetation is established, FRM and ecological performance are expected to increase. Expected performance should be associated with timelines based on project initiation (such as 0 to 5,5 to 20,20 to 50 , and 50 to 100+ years). For instance, vegetation may be expected to establish in the first few years, providing FRM benefits. But some ecosystem features (e.g., floral diversity, belowground biomass) may take longer to achieve full compatibility with natural sites (Mossman, Davy, and Grant 2012).

Damage. Wetland NNBF performance may be temporarily reduced in response to storm events, especially if the wetland endures damages (see Section 10.3.1). Wetland vegetation can be damaged through vegetation deformation, flattening, breakage, uprooting, and scour of the soil and substrate. Wetland NNBF may be more susceptible to damage from storms immediately after construction, when vegetation is developing or sediments are consolidating.

Significant erosion and scour from storms in wetland environments are not common, however, and are more likely in highly organic brackish and freshwater wetlands where soil strength is lower (Leonardi et al. 2018). The probability of complete wetland loss due to storm events has not been extensively quantified. Vuik et al. (2019) quantified the probability that a dike combined with a vegetated foreshore (i.e., a coastal wetland) would fail but considered stem breakage as the only damage mode, using models developed for two northern European salt marsh species (Vuik et al. 2018). Shear stresses associated with stem breakage and uprooting have been quantified for some wetland species, but erosion and scour of wetland substrates are not commonly modeled, although models of wetland edge erosion have been proposed (Kirwan et al. 2016b).

\subsubsection{Selecting Metrics}

NNBF project objectives should be linked to qualitative, or preferably quantitative, metrics that describe the project performance. These performance metrics should be considered in the initial planning phases and should directly inform the design of the monitoring and adaptive management plan. As mentioned in Section 10.3.1, wetland NNBF performance relies on physical and ecological factors, so ecologically based metrics are required even in the absence of an explicit ecological objective. 
FRM performance metrics for most coastal protection, whether NNBF or conventional, are generally calculated and evaluated with wave or hydrodynamic models (see Chapter 5). The key wetland model parameters are well studied (Mendez and Losada 2004) and incorporated in many models, including those used by industry and government (e.g., Narayan et al. 2016; see Section 10.6.9 Design Tools for detail on models). Using Table 10.2 as an example, wetland NNBF can be used to reduce both wave height and wave energy, measured using peak wave height or wave thrust (i.e., the wave energy exerted on the wetland edge) metrics. The objective of the wetland NNBF project determines which metric is applicable; reductions in wave energy are more appropriate when the wetland is used to reduce wave attack on an asset or structure, and wave height is more appropriate if the wetland is used to reduce total water levels or prevent wave overtopping of associated structures such as levees. More information on performance and metrics is found in $\underline{\text { Chapter } 5 .}$

\section{5 | Conceptual Design Considerations}

As mentioned previously in Section 10.2.1, wetland NNBF projects can range in size from small-scale interventions such as narrow lengths (on the order of tens of meters) of wetland-designed to reduce shoreline erosion-to system-wide networks of wetland features on the order of hundreds or thousands of hectares of wetland distributed throughout an estuary (e.g., Belgian Sigma Plan)-designed to reduce stormwater levels through surge attenuation or flood storage (see Figures 10.3 and 10.4 in Section 10.2.2). Each of these scales of intervention may confer different types and scales of benefits depending on the configuration and location and will require different levels of design consideration.

Wetland NNBF projects can draw upon an extensive amount of existing knowledge and guidance developed for wetland restoration. The geomorphological, hydrological and hydraulic, and biological components of coastal wetlands are relatively well understood, and there are multiple examples of restoring tidal flats, salt marshes, and mangroves. The design team should comprise experts able to address the interdependence of these components (Zeff 2011). However, as existing resources are designed for habitat restoration projects, FRM objectives may introduce additional design considerations.

If wetlands formerly existed in an area, then there is a good chance that conditions will be suitable for wetland establishment or re-establishment. Engineering interventions can be used to alter some aspects of the natural system (e.g., raising or lowering bed levels, installing tidal exchange structures to control water levels). Where adequate sediment supply does not exist naturally, periodic maintenance in the form of sediment placement may be needed. 


\subsubsection{Project Footprint and Area of Influence}

Landscape-scale controls on wetland NNBF function, such as location in the landscape and coastline configuration, should be accounted for in design because the efficacy of coastal wetlands in an FRM context is often controlled by larger landscape processes such as wave energy and sediment supply. Examples of the role of landscape-scale controls in coastal wetland NNBF performance include the following:

- The position of new wetland areas in an estuary is an important factor in determining the impacts on water levels (see Section 10.3.1).

- In lagoonal environments, the configuration and location of coastal inlets have more of a role in the propagation of storm surge through a wetland than do the specific attributes of the wetland itself such as tidal creek configuration (Lawler, Haddad, and Ferreira 2016).

- Regional sediment dynamics can affect the long-term morphology and viability of coastal wetlands, causing a deterioration of future FRM benefits if those systems are unable to maintain wetland elevation or extent as sea level increases (Mariotti 2016, 2018).

In addition, global processes such as sea-level rise and climate change coupled with local anthropogenic activities, such as shoreline modification, land-use change, water or sediment impoundment, and vessel activity, alter physical conditions that may result in significant changes to wetland NNBF function (e.g., changes in plant species) or even loss of the entire resource.

Conversely, wetland NNBF may have an area of influence well beyond the immediate project footprint. Wetland NNBF may potentially affect water levels thousands of meters or more from the wetland site (Smolders et al. 2015, 2020; Stark et al. 2016). Wetland loss at an estuary scale can affect the tidal hydrodynamics and sediment storage capacity of the entire estuary (Donatelli et al. 2018). Traditional coastal engineering projects rarely examine regional consequences of local actions beyond considering environmental impacts (Saldago and Martínez 2017); similarly, most wetland restoration literature focuses on the wetland and adjacent environments. However, wetland NNBF effects on the broader landscape, even if subtle, should be considered to ensure the full range of benefits and co-benefits is captured (for more information, see Chapter 14).

Understanding how wetland NNBF link to the larger landscape is critical to understanding how wetlands will perform now and into the future. Sea-level rise is expected to cause changes in the position of coastal wetlands in the landscape as increasing inundation of coastal wetlands shifts optimal growth zones higher in elevation and deeper into estuarine fringes (Mitchell et al. 2017). Development of wetland NNBF should use modern restoration planning techniques 
and consider the larger landscape and mosaic of coastal landscape features by including metrics such as feature size (sometimes referred to as habitat patch sizes in the restoration literature) and continuity with other features (Thorslund et al. 2017). For example, larger patches of a coastal wetland with a range of elevations that gradually slope into the uplands will have greater ability to adapt to rising sea levels than narrow patches of a coastal wetland located against conventional structures or steep uplands. An example of continuity with other features is pairing coastal wetland NNBF located along estuarine fringes with transitional wetlands and coastal shrub-scrub and forest communities, providing a migration corridor for plants and biota as sea levels increase (see example from Blackwater National Wildlife Refuge in "Historical Wetland Footprints" for more information on wetland migration corridor planning).

\section{Historical Wetland Footprints}

Wetland NNBF should be located where they will likely thrive in the future, not where they were in the past. However, regulatory concerns often limit restoration and wetland construction activities to areas where wetlands previously existed. In some cases, this is not preferable because environmental conditions may have changed and wetlands may not be able to survive in those areas. For projects in coastal areas experiencing rising sea levels, wetland NNBF footprints should include not only historical wetland areas but also areas immediately upland to allow for migration as seaward edges erode and wetland-upland boundaries shift (Scheurch et al. 2018). In areas undergoing rapid rates of sea-level rise and reduced sediment loading, wetland areas within a basin may shift dramatically from historical footprints. Projections of wetland change within small tributaries of the Chesapeake Bay indicate wetlands near the mouth of the bay will likely convert to open water and new wetland areas will form farther upstream (Mitchell et al. 2017). In the United States, National Wildlife Refuges that manage significant tracts of coastal wetlands, such as Blackwater National Wildlife Refuge (see Figure 10.6), are preparing for future migration of wetland areas through targeted management actions as well as conservation of undeveloped lands in migration corridors. 
Figure 10.6. Blackwater National Wildlife Refuge Marsh Migration Corridors with Future Habitat Projections

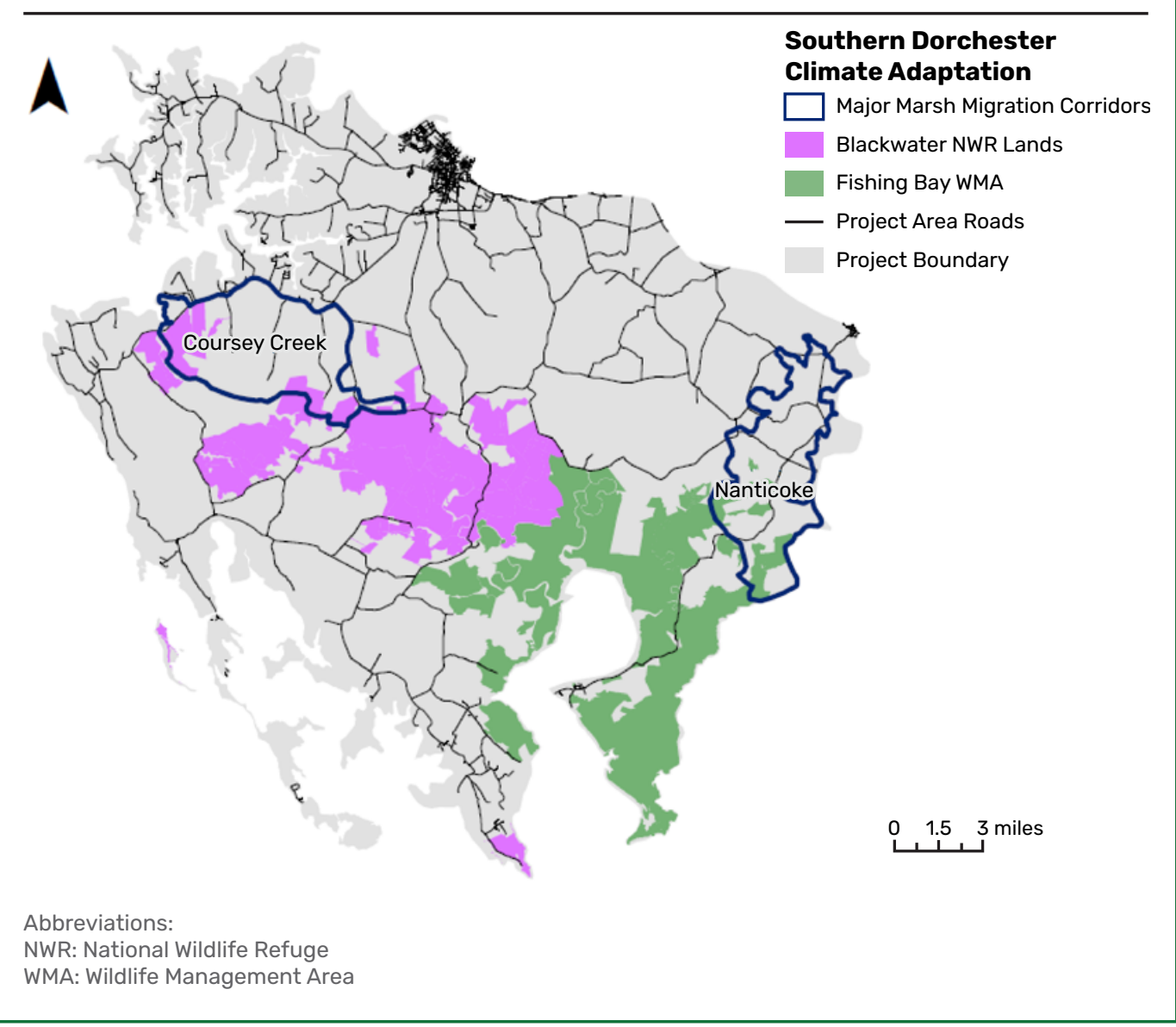




\subsubsection{Baseline Conditions}

This section describes physical, ecological, and biogeochemical conditions as described in Section 10.3.1 that must be considered when designing wetland NNBF. Analyses of these conditions need to cover both the project footprint and the area of influence, as described in Section 10.5.1. Each individual design consideration will influence other design considerations and must be accounted for when developing a holistic approach to wetland development. Existing data should be incorporated with site-specific data to inform the design process. The nature of the project will determine the level of detail required to produce the design, but each of the following design aspects should be considered in some capacity.

Site landscape position and geomorphology. Site landscape position dictates exposure of the site to physical drivers such as waves, currents, winds, freshwater inflows, and groundwater. Wetland geomorphology controls water and sediment distribution, which, in turn, controls biotic productivity and distribution. Descriptions of wetland geomorphology should include the wetland location and typical elevations of vegetated features, as well as the elevation, distribution, and configuration of tidal channels, ephemeral salt pannes, and permanent pools in the wetland area. The elevation and slope of adjacent environments such as tidal flats and uplands should also be described. Large wetland restoration projects will require channel and open-water feature design. For larger-scale wetland restoration projects that include morphologic design components (including channels), see Table 10.3.

\section{Table 10.3. Range of Coastal Wetland NNBF Techniques}

\begin{tabular}{|c|c|c|c|c|c|}
\hline Technique & 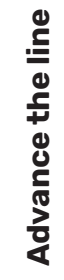 & 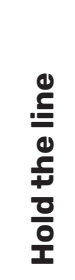 & 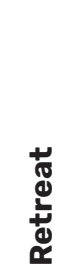 & Appropriate application & $\begin{array}{l}\text { Required } \\
\text { effort }\end{array}$ \\
\hline $\begin{array}{l}\text { Species control (e.g., invasive } \\
\text { removal, diversity planting) }\end{array}$ & Yes & Yes & Yes & $\begin{array}{l}\text { Removal of non-native vegetation } \\
\text { species from a wetland area to allow } \\
\text { native species to establish or better } \\
\text { compete }\end{array}$ & Low \\
\hline Vegetation seeding or planting & Yes & Yes & Yes & $\begin{array}{l}\text { Introduction of a mixture of } \\
\text { native seeds or plugs to a poorly } \\
\text { vegetated or unvegetated wetland } \\
\text { area }\end{array}$ & Low \\
\hline $\begin{array}{l}\text { Living shoreline with or without } \\
\text { a sill (see NOAA } 2015 \text { for more } \\
\text { information on living shorelines) }\end{array}$ & Yes & Yes & No & $\begin{array}{l}\text { Shoreline protection measure that } \\
\text { relies on natural elements including } \\
\text { wetlands to stabilize eroding or } \\
\text { otherwise unstable shorelines }\end{array}$ & Medium \\
\hline
\end{tabular}




\begin{tabular}{|c|c|c|c|c|c|}
\hline Technique & 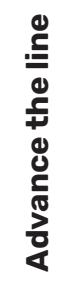 & 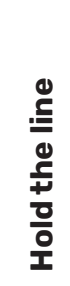 & 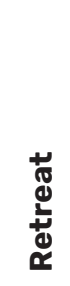 & Appropriate application & $\begin{array}{l}\text { Required } \\
\text { effort }\end{array}$ \\
\hline $\begin{array}{l}\text { Enhanced tidal exchange (e.g., } \\
\text { culvert enlargement) }\end{array}$ & No & Yes & Yes & $\begin{array}{l}\text { Re-establishment of complete } \\
\text { or more complete tidal exchange } \\
\text { through a coastal structure such } \\
\text { as a culvert, tide gate, or other } \\
\text { human-made barrier }\end{array}$ & Medium \\
\hline $\begin{array}{l}\text { Retention structures (e.g., berms } \\
\text { or bunds for wave reduction) }\end{array}$ & Yes & Yes & Yes & $\begin{array}{l}\text { Low breakwater-like structures } \\
\text { designed to reduce wave energy } \\
\text { and encourage accretion in wetland } \\
\text { or shallow-water environments } \\
\text { behind structure }\end{array}$ & Medium \\
\hline $\begin{array}{l}\text { Thin-layer placement (direct } \\
\text { placement of sediment on site) }\end{array}$ & Yes & Yes & Yes & $\begin{array}{l}\text { Application of a relatively thin (on } \\
\text { the order of centimeters or } 10 \text { s } \\
\text { of centimeters) layer of sediment } \\
\text { directly to a wetland to a prescribed } \\
\text { target elevation (costs vary widely } \\
\text { with distance from sediment } \\
\text { source, sediment depth, and area) }\end{array}$ & Medium to High \\
\hline $\begin{array}{l}\text { Strategic sediment placement } \\
\text { (i.e., mud motor) }\end{array}$ & Yes & Yes & Yes & $\begin{array}{l}\text { Introduction of sediment to tidal } \\
\text { flat or nearshore environment to } \\
\text { increase the sediment loading to } \\
\text { wetlands }\end{array}$ & Medium to High \\
\hline Sediment diversions & Yes & Yes & Yes & $\begin{array}{l}\text { Introduction of sediment into } \\
\text { estuarine environment via } \\
\text { river diversions to increase the } \\
\text { sediment loading to wetlands }\end{array}$ & High \\
\hline Wetland creation & Yes & Yes & Yes & $\begin{array}{l}\text { Engineered placement of } \\
\text { sediments to shallow open water } \\
\text { to create emergent wetland } \\
\text { feature }\end{array}$ & High \\
\hline Regrading & No & No & Yes & $\begin{array}{l}\text { Construction of proper elevation, } \\
\text { slope, and contour of a formerly } \\
\text { upland area to establish wetland }\end{array}$ & Medium to High \\
\hline Terracing & Yes & Yes & No & $\begin{array}{l}\text { Creation of elevation zones in } \\
\text { new or existing wetlands to allow } \\
\text { different vegetation communities } \\
\text { to establish }\end{array}$ & High \\
\hline
\end{tabular}




\begin{tabular}{|c|c|c|c|c|c|}
\hline Technique & 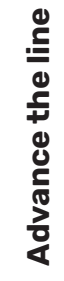 & 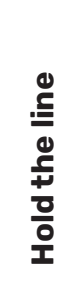 & 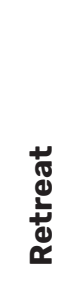 & Appropriate application & $\begin{array}{l}\text { Required } \\
\text { effort }\end{array}$ \\
\hline $\begin{array}{l}\text { Managed realignment, tidal flow } \\
\text { restoration, and depolderization }\end{array}$ & No & Yes & Yes & $\begin{array}{l}\text { Restoration of tidal flow to } \\
\text { previously protected and possibly } \\
\text { drained area that may once have } \\
\text { been wetland }\end{array}$ & Medium to High \\
\hline Flood storage areas & No & No & Yes & $\begin{array}{l}\text { Upland or formerly protected } \\
\text { areas designed to flood at high } \\
\text { water levels, storing floodwater } \\
\text { and creating temporarily flooded } \\
\text { wetlands }\end{array}$ & High \\
\hline
\end{tabular}

Hydrology, hydrodynamics, and sediment transport. The relative importance of hydrological and hydrodynamic processes to wetland function is highly site specific. Wetlands that are well connected to coastal waterbodies are typically controlled by surface water hydrodynamics and are driven by tides, waves, and currents. However, wetlands that are only intermittently connected to coastal waterbodies (e.g., during storms or the highest of high tides) may be driven more strongly by hydrological processes such as precipitation, groundwater, and upland runoff.

Inundation affects wetland vegetation and biogeochemical processes in the wetland and is described by the hydroperiod, which describes the inundation frequency, magnitude, and duration at a range of temporal scales ranging from days to years and including episodic storm events. Episodic storm events are of particular interest for FRM functions, whereas ecological functions depend on more typical conditions. Hydrodynamic characteristics of a full range of storm events, including the response from and effect on the wetland, should be characterized. Lower intensity but potentially damaging hydrodynamic conditions such as boat wake waves should also be described.

Wetlands require sediment accumulation to compensate for compaction, organic matter decomposition, and episodic erosion of the sediment bed surface layer (Morris et al. 2016). Therefore, important design considerations include sediment supply, accretion rates, erosion rates, and distribution of incoming sediment throughout the wetland. At many locations, short-term events (e.g., high river discharge or storm surge) provide a significant portion of the annual mineral sediment supply to wetlands, and the cumulative effects of these deposition events should be characterized. 
Soils. Wetland soils serve as the biological interface for macroinvertebrates, microinvertebrates, microbial populations, and plants. Common influential soil parameters include bulk density, grain size distribution, organic matter composition, and salinity, although other aspects of wetland soils such as oxidation-reduction potential, sulfide concentration, or nutrient content may be of interest depending on project objectives. Geotechnical aspects of wetland soils or of sediments used for wetland construction should be described for projects that require significant earthwork to assess trafficability of construction equipment, as well as the ability of the wetland to resist erosive forces. Sediment sources for constructing wetlands are limited (e.g., navigation dredged material or borrow sites) and will not replicate conditions at surrounding wetlands. However, the composition of sediment from these sources should be compared to typical wetland substrate to determine whether the constructed substrate will remain in place under expected hydrodynamic conditions and support desired wetland habitat and function. More information on soil physical and biogeochemical properties that may influence design are discussed in Section 10.6.8.

Vegetation. Vegetation is a critical component of the biophysical feedback that sustains coastal wetlands and is a primary ecological goal of most wetland restorations. As the primary frictional element in wetland environments, vegetation is also a critical driver of FRM functions. Vegetation species distribution, abundance, and aboveground and belowground physical form should be described as related to wetland geomorphology because elevation and inundation gradients drive plant distribution. Vegetation should be compared to expected and typical regional benchmarks for species composition, diversity, and abundance, although wetland NNBF projects may ultimately prioritize vegetation communities that produce the greatest FRM benefits (see Section 10.6 .6 for more information on vegetation design considerations). Non-native and invasive species should be documented and considerations for their management should be considered in the wetland design.

Fauna. These guidelines are aimed at wetland NNBF for FRM, and faunal use is not as important as it is in traditional wetland restoration-although some fauna have the ability to affect FRM functions. Herbivorous fauna such as snails and waterfowl may need to be controlled to establish or re-establish vegetation, whereas crabs and other benthic macroinvertebrates may play important roles in soil formation and the stabilization of freshly deposited sediments through bioturbation. 


\subsubsection{Developing Conceptual Designs}

Coastal wetland NNBF options range from conservation of existing wetlands to creation of new wetlands where none previously existed. The array of wetland NNBF options, from least to most invasive and costly, is as follows: (1) conservation of existing wetlands, (2) restoration of degraded wetlands, (3) expansion of existing wetlands, and (4) creation of new wetlands where none existed previously. Although conservation of existing wetlands is the most efficient option, interventions such as sediment thin-layer placement or wetland edge protection may be required to produce or to continue to produce FRM functions in systems that are altered by humans or where wetlands are degraded or lost. Existing wetlands may be degraded due to a number of reasons, including invasive species, drought, sediment starvation, alterations to site hydrology, or increased inundation due to rising sea levels. In some cases, desired FRM functions may require the expansion of existing wetlands, the creation of new coastal wetlands, or the re-establishment of historical wetlands that were completely lost. Regardless of the scope of intervention required, the conceptual design should identify what, if any, interventions may be required to establish or re-establish proper geomorphological and biophysical conditions for the desired coastal wetland type.

Wetlands function very well in most intertidal areas, but the areas where wetlands could make the greatest contribution to FRM are often in environments most heavily degraded by past management choices. Therefore, the most difficult part of conceptual design is often figuring out how to repair enough of the environmental conditions (e.g., topography, water quality, or sedimentation) to enable the wetland to be re-established. Similarly, the areas where coastal wetlands can provide the greatest economic co-benefits (i.e., developed areas) are the areas with the least amount of available land for coastal wetland development (van Coppenolle and Temmerman 2019). Because FRM function is related to wetland size, constraints on land availability will limit the FRM function a coastal wetland NNBF can achieve.

Project objectives. Project objectives must inform the conceptual design for coastal wetland solutions, dictating not only the required FRM benefits but also the co-benefits required of the solution. Design conceptualization should analyze whether the location is compatible with the environmental requirements of coastal wetlands and whether all the required benefits and co-benefits can be delivered by coastal wetland NNBF alone or in combination with structural measures. The conceptual design should also identify the logistical and environmental constraints and a suite of possible design solutions to be analyzed in the detailed design phase. 
Design alternatives. The various ways to achieve the desired FRM function in coastal wetlands require varying levels of engineering effort and cost (see Table 10.3). They range from relatively simple, low-cost approaches such as reseeding and tidal flow restoration to active and more costly approaches involving sediment application and tidal channel construction. These techniques can be used in various combinations to achieve the project goals and objectives and meet the needs of the selected site using the funds available. Solutions can be categorized on their location relative to the present lines of defense, which are hold the line (located in the same position), retreat (located inland), and advance the line (located further seaward). Some techniques can be deployed in various locations (e.g., planting). Not all projects will require equal levels of engineering; in fact, wetland NNBF projects typically work best when engineering is minimized and reliance on the system's natural ability to adapt over time is maximized (Mohan 2001; Mitch 2006). Adherence to this principle will also serve to minimize unnecessary costs.

Care should be taken to avoid overdesign (e.g., requiring small elevation tolerances or designing intricate networks of tidal creeks and pools) because wetlands are dynamic systems and biophysical feedbacks will lead to shifts from the prescribed design. In addition, active construction on existing wetland sites, as well as newly created wetlands, can cause damages that may inhibit recovery of the site. Understanding the geomorphological and biophysical conditions at the site will enable designers to determine whether natural processes alone are sufficient to develop the full array of wetland functions. For example, not every project will require planting instead of allowing natural colonization to take place. However, in heavily altered coastal landscapes, there are limits on the ability of natural processes to facilitate the adaptation and maintenance of proper wetland geometry that enables FRM benefit production, and additional management or maintenance actions may be required to sustain required FRM benefits.

Funding availability will largely dictate the scope of possible engineering interventions. For example, if funds do not allow construction of a wetland large enough to attain appreciable storm-surge reduction or wave-attenuation benefits, project requirements may need to be readdressed. In some cases, construction may be phased and the wetland constructed over multiple years. This is a realistic option when maintenance dredging is the likely sediment source and full FRM performance is not immediately required. In some cases, a smaller coastal wetland in combination with additional measures may be the most cost-effective way to produce the required FRM benefits.

Addressing wetland degradation in design. Engineering interventions should also address the underlying causes of site degradation to ensure the wetland NNBF is sustainable, even if the solution is to prescribe rigorous maintenance. Common symptoms of wetland degradation, such as ongoing erosion, fragmentation, or failure to "keep up" with rising sea levels, are attributable, in part, to changes in physical condition and processes such as morphology, inundation, water exchange, wave climate, currents, salinity, turbidity, and 
sediment supply. Only when appropriate physical conditions and processes have been partly or fully re-established can restoration of native plant species occur through natural colonization, planting, or recruitment. For example, increased wave action due to nearby navigation channels or increased erosion can lead to rapid loss of wetlands, and engineering interventions should be designed to reduce the wave energy. Many wetlands may degrade and subside due to reduced tidal exchange from improperly sized culverts or similar restrictions, and interventions should be designed to improve tidal exchange. In areas of reduced sediment loading or high levels of subsidence, interventions such as thin-layer placement or locally increasing suspended sediment concentrations by placing sediment in the nearshore (referred to as strategic placement or a sand motor or mud motor concept in the United States and the Netherlands, respectively, see Table 10.1 for more information) can directly or indirectly increase elevations in wetland environments. Even where full restoration of physical conditions is not possible (e.g., if full tidal exchange cannot be restored to a formerly impounded area), incremental improvements in condition may still be desirable to improve FRM function even if optimal conditions cannot be achieved.

Dynamics and uncertainty. As discussed in Section 10.4.2, design and management of sustainable wetlands must consider the dynamic interrelationships between vegetation, hydraulics, and substrate within and outside a designated restoration site (Zeff 2011). Because vegetation and topography control the FRM benefits conferred by wetlands, these dynamics ultimately affect the ability of wetlands to produce FRM benefits. Designs must also consider wetland health, function, and sustainability during day-to-day conditions, not just performance under extreme events.

Natural variability and uncertainty can be managed by using conservative performance estimates to calculate performance using the minimal marginal condition of the wetland, such as during the dormant season when biomass is at its nadir and stem breakage is the most likely. Although typical factor-of-safety approaches for dealing with performance uncertainty in structural measures, such as increasing structure height, are not directly transferrable, requiring additional wetland width or pairing wetland NNBF with structural measures are ways to account for variability and uncertainty. "Horizontal Levee Design Concept" describes an approach to combining a coastal wetland with a levee so that both can better adapt to future sea levels using a horizontal levee concept (Figure 10.7). Other options may include pairing lower coastal wetland NNBF communities with higher elevation shrub-scrub wetland communities that may confer FRM benefits at higher water levels (as well as facilitate connectivity between the wetland and the upland). Adaptive management also reduces uncertainty because routine maintenance is integrated into the project design. 


\section{Horizontal Levee Design Concept}

Wetland restoration is of particular interest in the San Francisco Bay area of California, United States, where $94 \%$ of all wetland areas have been lost, largely from development. In addition, the low lying South Bay region is at risk of flooding due to sea-level rise. Restoration and FRM goals in this region potentially conflict because new levee standards threaten to further disconnect existing and restored wetlands from natural freshwater seepage characteristic of tidal wetlands in the region. Moreover, newly restored wetlands would be pinned between the rising waters of the bay and the flood-control levee in a classic case of coastal squeeze. To combat this potential issue, the concept of a horizontal levee was proposed (see Figure 10.7). The horizontal levee comprises a traditional flood-control levee core with a seaward ecotone slope on the order of 10 to 1 (horizontal to vertical) to 30 to 1 , grading smoothly to a low marsh elevation. The slope is planted with native wetland and transitional species, restoring habitats that have largely been lost in the region, as well as providing adaptive capacity allowing wetlands to adjust landward as sea levels rise. Some designs allow the ecotone slope to undulate slightly, creating microhabitats within the slope that can increase overall habitat diversity.

Horizontal levees may have limited application in some areas due to the larger area required. If levees are expanded seaward, the levee may encroach on existing intertidal and subtidal habitats. However, setting back horizontal levees may not be possible or may be prohibitively expensive due to development and issues with real estate acquisition.

Due to the climate of the San Francisco Bay region, many of the proposed horizontal levees are paired with freshwater discharge points from wastewater treatment facilities. Clean wastewater is discharged along an infiltration trench near the top of the slope, re-establishing the lost freshwater seepage that many wetlands in the region rely on. A full-scale pilot of the horizontal levee concept implemented at Oro Loma, California, United States, used a broad ecotone area to connect the levee to the wetland surface using a 30-to-1 slope (Oro Loma Sanitary District 2015). The demonstration project has shown removal of metals, pharmaceuticals, and nutrients from the wastewater effluent transmitted through the ecotone slope. 


\section{Figure 10.7. Illustration of Horizontal Levee Design Concept}

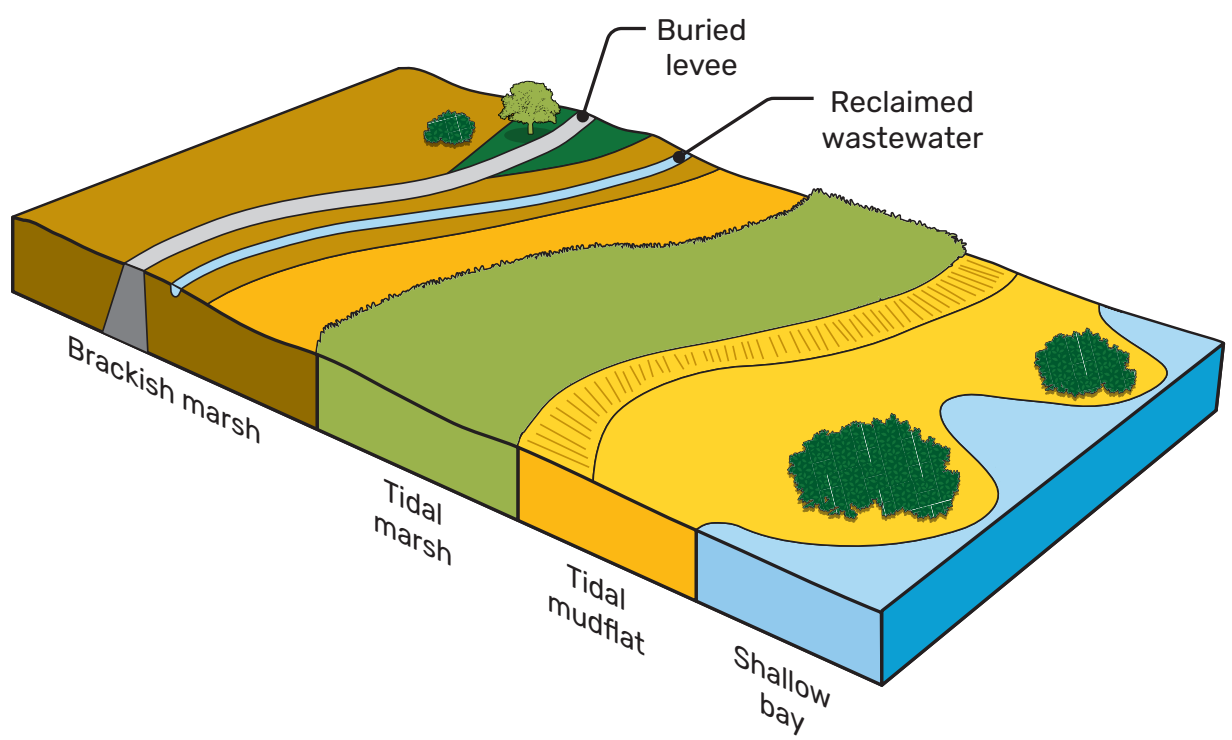

Source: Adapted from Battalio, Holmes, and Lowe 2013

Design constraints. Wetland NNBF design may have different constraints than traditional coastal engineering design, and those differences should be considered early in the design process. Constraints related to the biophysical requirements of the wetland environment (e.g., elevation and wave-energy tolerances) are described in Section 10.3. Reference wetland approaches can be helpful for defining these constraints in some cases, but designers should consider if the reference approach is applicable to the project site (see "Applicability of Reference Area Wetland Approaches to Wetland NNBF Projects"). Depending on other design requirements or planned management, restoration, or creation methods, additional design constraints may apply. For instance, projects that use dredged material or slurried sediment may need to consider dredged material consolidation, dredging project schedules, or turbidity of discharge water leaving the site, among other constraints. Projects occurring in wetlands or habitats associated with wetlands may attract interest from other stakeholder groups; early engagement with these groups may allow the project design to accommodate special considerations that could potentially increase co-benefits, gain project advocates, or even gain additional funding. 
Any work in wetland environments will also require compliance with various regulatory requirements. Those requirements should be identified early, and engagement with regulators ideally would begin early in the project conceptualization. Although some special permit conditions, such as the U.S. Army Corps of Engineers (USACE) nationwide living shoreline permit, can expedite permitting for small projects conducted by non-USACE entities, other similar considerations have not been universally implemented by all regulatory entities in the United States or other countries. As mentioned previously, early engagement with regulators is one way to avoid costly delays late in the design process, but future wetland NNBF projects would benefit from implementation of regulatory flexibility.

\section{Applicability of Reference Area Wetland Approaches to Wetland NNBF Projects}

Coastal wetland restoration frequently requires designers to define an acceptable range of elevations. The reference area approach in which adjacent intact habitats serve as ecological benchmarks is frequently used through determination of key aspects of design, such as species composition, elevation gradients, and tidal inundation (Shisler 1990), and to ensure the design fulfills the appropriate environmental requirements. This is best practice in areas with functioning wetlands nearby that are subject to similar environmental conditions. However, reference areas may have developed under different environmental conditions (e.g., lower sea levels) or may not be analogous to the desired wetland. In addition, reference area structure (e.g., elevation range and species) may not provide the desired FRM benefits that the wetland NNBF requires. In these cases, local tidal elevations such as mean sea level, mean high water, mean higher high water, and the highest extent of astronomical tide can be used to define appropriate design elevations because wetland vegetation community zones are strongly correlated with tidal elevations. In strongly microtidal environments, such as coastal Louisiana or Venice Lagoon, meteorological events such as sustained onshore winds may have a larger impact on water levels than do tides, and appropriate wetland elevations should be adjusted to account for the contribution of those events to the wetland hydroperiod.

Size constraints. As noted in Section 10.5.1, the design of wetland NNBF needs to consider the available space, which might limit the type of project that can be implemented (see various scales of measures indicated in Table 10.1). Generally, FRM benefits from coastal wetland NNBF scale with size; however, size limitations do not preclude the use of wetland NNBF. Small wetlands on the order of tens of meters (measured from the wetland edge to upland) can still provide erosion-reduction co-benefits, protecting shorelines and assets close to shore from erosion that occurs during lower-intensity waves caused by winds and boat wakes (Currin et 
al. 2015). Evidence indicates fringes of marsh, sometimes paired with rock sills, may survive lower-intensity hurricanes better than traditional shoreline protection such as bulkheads, potentially reducing long-term maintenance costs for shoreline protection (Gittman et al. 2014). Smaller wetland sites are generally more exposed to physical forces from the estuarine environment, which might prevent the successful establishment and development of vegetation (see Section 10.4.2).

Where space permits, large wetlands, on the order of hundreds or thousands of hectares, may provide a wider range of FRM benefits, reducing shoreline erosion, attenuating waves, reducing storm surges, and, in some cases, storing floodwater. Larger wetlands will alter hydrodynamics in a wider area than smaller wetlands (Section 10.3.1) and may require more study to determine how water levels in the broader estuary respond to the restoration or creation of the wetland. Larger wetland areas may require additional considerations for vegetation establishment because relying solely on colonization, which depending on local climatic conditions can take several years, may not be feasible from an FRM, ecological, or social perspective.

Combining wetland NNBF with structural measures. Wetlands may be combined with structural measures, in what are sometimes referred to as hybrid solutions, to increase their engineering performance over that of a wetland NNBF or structural measure alone. To deal with space constraints in highly developed locations, a wetland may be paired with a traditional coastal structure such as a bulkhead, levee, or revetment to increase the FRM benefits and co-benefits beyond the benefits of either measure alone. See Chapter 14 for examples of how NNBF can be used to increase the co-benefits of structural measures.

Structural measures are typically located landward of the wetland, and the wetland may be used to provide FRM benefits to assets, populations, or infrastructure behind the structural measure or to the structural measure itself. For example, the wetland can be used to reduce wave or surge height before reaching the structural measure, reducing the required design dimensions of the measure or reducing the risk of overtopping. In other cases, the area of wetland may be constrained, and wave and surge attenuation may not be very significant, but the wetland reduces erosion, slowing or preventing deterioration of or damage to the structural measure. Wetland NNBF in combination with structural measures can reduce the likelihood of failure of the structural measure under extreme loading; and in the event of structural measure failure, the wetland reduces the associated extent of flooding and its consequences. During the historical 1953 North Sea flood in the Netherlands, levee breaches in areas with wetlands (i.e., vegetated foreshores) were smaller, and the resulting hinterland flooding was reduced compared to levees fronted by bare mudflats (Zhu et al. 2020). Combining wetland NNBF with structural measures can minimize the negative environmental impacts of the structure and may also reduce the maintenance requirements of those structures (USACE 1995). The wetland may increase the reliability of the structural measure, increase the useful life of the measure, or reduce the maintenance costs of the measure (Vuik et al. 2019). 
When considering the use of wetlands in combination with structural measures, interactions between the wetland and the structural measure should be closely analyzed because the resulting performance may not be additive and, in some cases, the interactions could be antagonistic. The effects of wetland NNBF in combination with structural measures can be complex and require detailed computational modeling of project design configurations under a wide range of storm conditions. Examples of some documented effects of structural elements on NNBF performance and function include the following:

- Structures such as seawalls that are located adjacent to or landward of wetland NNBF should be designed in a way to minimize erosion and scour resulting from reflecting waves (Mattheus et al. 2010).

- The number, width, sill elevation, and location of breaches of the fronting levee of flood storage areas affect the performance of the flood storage area (Kiesel et al. 2020).

- If structural elements such as levees dissect and significantly reduce the wetland NNBF area, performance is reduced (Stark et al. 2016).

- The location and orientation of structures such as levees within wetland NNBF areas can lead to localized areas of water-level amplification due to set up, reflection, or blocking of flow (Wamsley et al. 2010; Stark et al. 2016).

The results of many of these studies on wetland NNBF combined with structural elements are nuanced and site specific and should not be viewed as universally applicable. However, the same factors that affect wetland NNBF performance also apply when combined with structural measures, such as site location, size, and shape, as well as the storm characteristics.

When considering combinations of wetlands and structural measures, abrupt changes in elevation should also be avoided whenever possible because, as noted in Section 10.3.1, abrupt increases in slope can lead to water-level amplification. Although typically used to promote wetland resilience to rising sea levels, the horizontal levee concept, which uses gradual slopes (less than 10 to 1) on the seaward side of levees (ESA PWA 2013), can be used to minimize slope change between the wetland and the levee, as well as any associated water-level amplification. More information on the horizontal levee design concept is provided in "Horizontal Levee Design Concept."

\section{6 | Developing Detailed Designs and Specifications}

Detailed design should focus on aspects of performance that can be controlled within design (e.g., vegetation types, surface elevations) and on optimizing the FRM functions of the wetland given the setting and design storm characteristics. It is important to realize that some aspects of wetland performance are dependent on environmental conditions 
(e.g., nearshore bathymetry, wave height, water levels) and are less able to be "designed" per se, whereas other aspects (e.g., wetland platform elevation, configuration of tidal channel inlets) are more easily controlled. Performance of wetlands for wave and surge attenuation, erosion prevention, and flow reduction is highly dependent on storm characteristics and the geomorphic setting. The aspects of the wetland itself that are linked to FRM functions and can be prescribed in a design are summarized in Table 10.4 and are then described in more detail in the following subsections.

Table 10.4. Wetland Design Parameters and Performance Factors

\begin{tabular}{|c|c|c|c|}
\hline $\begin{array}{l}\text { Design } \\
\text { parameter }\end{array}$ & $\begin{array}{l}\text { Affected } \\
\text { function }\end{array}$ & $\begin{array}{l}\text { Performance factors } \\
\text { and considerations }\end{array}$ & Performance guidelines \\
\hline Wetland location & $\begin{array}{l}\text { - Erosion } \\
\text { protection } \\
\text { - Accretion } \\
\text { - Wave } \\
\text { attenuation } \\
\text { - Surge } \\
\text { attenuation } \\
\text { - Flood storage }\end{array}$ & $\begin{array}{l}\text { - Location relative to } \\
\text { assets } \\
\text { - Position in estuary (e.g., } \\
\text { close to mouth, inlets) } \\
\text { - Exposure (e.g., fetch, } \\
\text { proximity to navigation } \\
\text { channels) } \\
\text { - Proximity to structural } \\
\text { measures (e.g., levees, } \\
\text { bulkheads) }\end{array}$ & $\begin{array}{l}\text { Properties behind marshes and } \\
\text { mangroves have lower flood damages } \\
\text { than those with no wetlands (Narayan } \\
\text { et al. 2017, 2019). } \\
\text { - Proximity to and configuration of } \\
\text { inlets and exposure to ocean surge are } \\
\text { dominant factors affecting wetland } \\
\text { surge-attenuation capacity (Lawler, } \\
\text { Haddad, and Ferreira 2016). } \\
\text { - Hardened structure design can lead to } \\
\text { wave reflection and scour of wetland } \\
\text { (Morton and Barras 2011). }\end{array}$ \\
\hline $\begin{array}{l}\text { Wetland shape } \\
\text { and size }\end{array}$ & $\begin{array}{l}\text { - Erosion } \\
\text { protection } \\
\text { - Wave } \\
\text { attenuation } \\
\text { - Surge } \\
\text { attenuation } \\
\text { - Flood storage }\end{array}$ & $\begin{array}{l}\text { Distance from shoreline } \\
\text { to upland or structure } \\
\text { - Size relative to estuary } \\
\text { - Storage volume }\end{array}$ & $\begin{array}{l}\text { - Greatest wave attenuation occurs in } \\
\text { first tens of meters of wetland (Garzon } \\
\text { et al. 2019; Bao 2011). } \\
\text { - Typical surge-attenuation rates are } \\
\text { a function of wetland size; typical } \\
\text { surge-attenuation rates for marsh } \\
1.7 \text { to } 25 \mathrm{~cm} / \mathrm{km} \text { (Leonardi et al. } 2018 \text { ) } \\
\text { and mangroves } 4.2 \text { to } 48 \mathrm{~cm} / \mathrm{km} \\
\text { (Narayan et al. } 2019 \text { ) reported. } \\
\text { - Storage volume should be } 20 \% \text { to } 40 \% \\
\text { of total volume of estuarine reach to } \\
\text { store significant floodwater (Stark et al. } \\
\text { 2016). }\end{array}$ \\
\hline $\begin{array}{l}\text { Wetland } \\
\text { elevation }\end{array}$ & $\begin{array}{l}\text { - Accretion } \\
\text { - Wave } \\
\text { attenuation } \\
\text { - Surge } \\
\text { attenuation }\end{array}$ & $\begin{array}{l}\text { Elevation relative to tidal } \\
\text { datum and tide range } \\
\text { (upper intertidal range } \\
\text { most conducive to } \\
\text { primary productivity) } \\
\text { - Elevation relative to } \\
\text { protected assets and } \\
\text { structural measures }\end{array}$ & $\begin{array}{l}\text { - Greater elevation provides greater flood } \\
\text { protection (Loder et al. 2009). } \\
\text { - Platform elevation can be manipulated } \\
\text { to create multiple wetland vegetation } \\
\text { zones to provide FRM benefits at range } \\
\text { of water levels (Horstman et al. 2015). }\end{array}$ \\
\hline
\end{tabular}




\begin{tabular}{|c|c|c|c|}
\hline $\begin{array}{l}\text { Design } \\
\text { parameter }\end{array}$ & $\begin{array}{l}\text { Affected } \\
\text { function }\end{array}$ & $\begin{array}{l}\text { Performance factors } \\
\text { and considerations }\end{array}$ & Performance guidelines \\
\hline $\begin{array}{l}\text { Nearshore } \\
\text { bathymetry }\end{array}$ & $\begin{array}{l}\text { - Erosion } \\
\text { protection } \\
\text { - Accretion } \\
\text { - Wave } \\
\text { attenuation } \\
\text { - Surge } \\
\text { attenuation }\end{array}$ & $\begin{array}{l}\text { Bottom elevation } \\
\text { adjacent to wetland } \\
\text { - Bottom geometry } \\
\text { adjacent to wetland }\end{array}$ & $\begin{array}{l}\text { Shallow tidal flats are associated with } \\
\text { less wetland erosion and help dissipate } \\
\text { wave energy (Bouma et al. 2016). } \\
\text { Wide mudflats may help supply } \\
\text { sediment to wetland features during } \\
\text { storms, allowing them to accrete } \\
\text { vertically (Ganju 2019; Schuerch, } \\
\text { Spencer, and Evans 2019). }\end{array}$ \\
\hline $\begin{array}{l}\text { Connectivity to } \\
\text { other features }\end{array}$ & $\begin{array}{l}\text { - Wave } \\
\text { attenuation } \\
\text { - Surge } \\
\text { attenuation }\end{array}$ & $\begin{array}{l}\text { Distance to mudflat, } \\
\text { transitional and upland } \\
\text { plant communities } \\
\text { - Slope between wetland } \\
\text { and adjacent features }\end{array}$ & $\begin{array}{l}\text { Deep water adjacent to wetlands can } \\
\text { exacerbate wetland edge erosion } \\
\text { (Ganju 2019). } \\
\text { - Levees that reduce wetland width can } \\
\text { lead to amplified surge by reducing } \\
\text { available flow area (Stark et al. 2016). }\end{array}$ \\
\hline $\begin{array}{l}\text { Tidal channels } \\
\text { and open-water } \\
\text { elements }\end{array}$ & $\begin{array}{l}\text { - Erosion } \\
\text { protection } \\
\text { - Accretion } \\
\text { - Wave } \\
\text { attenuation } \\
\text { - Surge } \\
\text { attenuation } \\
\text { - Flood storage }\end{array}$ & $\begin{array}{l}\text { - Channel width, depth } \\
\text { - Channel orientation } \\
\text { - Marsh edge area ratio } \\
\text { - Proportion of } \\
\text { unvegetated to } \\
\text { vegetated area }\end{array}$ & $\begin{array}{l}\text { Deeper and wider wetland channels } \\
\text { allow surge and waves to propagate } \\
\text { further into the wetland than do } \\
\text { shallow, narrow channels (Stark et } \\
\text { al. 2015, 2016; Lawler, Haddad, and } \\
\text { Ferreira 2016). } \\
\text { - Greater proportion of channels and } \\
\text { ponds reduces wave- and surge- } \\
\text { attenuation capacity (Barbier et al. } \\
\text { 2013). }\end{array}$ \\
\hline $\begin{array}{l}\text { - Vegetation } \\
\text { type } \\
\text { - Height } \\
\text { - Density } \\
\text { - Diameter } \\
\text { - Complexity } \\
\text { - Flexibility } \\
\text { - Roots }\end{array}$ & $\begin{array}{l}\text { - Erosion } \\
\text { protection } \\
\text { - Accretion } \\
\text { - Wave } \\
\text { attenuation } \\
\text { - Surge } \\
\text { attenuation }\end{array}$ & $\begin{array}{l}\text { Height: typical height } \\
\text { above wetland platform } \\
\text { - Density (as a function } \\
\text { of height): proportion } \\
\text { of flow area blocked per } \\
\text { unit area, number of } \\
\text { vertical elements (i.e., } \\
\text { stems) per unit area, } \\
\text { leaf area index } \\
\text { - Flexibility: qualitative } \\
\text { description (flexible } \\
\text { versus rigid), } \\
\text { quantitative (modulus } \\
\text { of elasticity, moment of } \\
\text { inertia) } \\
\text { - Roots: mass per unit } \\
\text { volume of soil of live } \\
\text { plant roots, depth above } \\
\text { which } 95 \% \text { of live root } \\
\text { mass occurs }\end{array}$ & $\begin{array}{l}\text { - Height: taller vegetation provides } \\
\text { greater resistance to flow and waves } \\
\text { over a greater range of water levels } \\
\text { (Beudin et al. 2017). } \\
\text { - Density: greater vegetation density } \\
\text { blocks more flow and exerts more } \\
\text { friction than less dense vegetation } \\
\text { (Loder et al. 2009); distribution of } \\
\text { aboveground biomass affects velocity } \\
\text { profile and scour potential (Horstman } \\
\text { et al. 2015). } \\
\text { - Flexibility: rigid vegetation provides } \\
\text { greater attenuation benefits than } \\
\text { flexible vegetation (Beudin et al. } 2017 \text { ) } \\
\text { but may be more prone to breakage or } \\
\text { uprooting, whereas flexible vegetation } \\
\text { may lay prone and protect soil from } \\
\text { scour (Vuik et al. 2019). } \\
\text { Roots: greater rooting depth and large } \\
\text { density of roots will provide erosion } \\
\text { resistance at greater depth along marsh } \\
\text { edges (Howes et al. 2010; Silliman et al. } \\
\text { 2019). }\end{array}$ \\
\hline
\end{tabular}




\begin{tabular}{|c|c|c|c|}
\hline $\begin{array}{c}\text { Design } \\
\text { parameter }\end{array}$ & $\begin{array}{l}\text { Affected } \\
\text { function }\end{array}$ & $\begin{array}{l}\text { Performance factors } \\
\text { and considerations }\end{array}$ & Performance guidelines \\
\hline $\begin{array}{l}\text { Structural } \\
\text { elements }\end{array}$ & $\begin{array}{l}\text { - Erosion } \\
\text { protection } \\
\text { - Accretion } \\
\text { - Wave } \\
\text { attenuation } \\
\text { - Surge } \\
\text { attenuation } \\
\text { - Flood storage }\end{array}$ & $\begin{array}{l}\text { - Structure type } \\
\text { - Temporary or } \\
\text { permanent } \\
\text { - Structure location } \\
\text { - Structure function }\end{array}$ & $\begin{array}{l}\text { Structures should only be used where } \\
\text { necessary and should enhance wetland } \\
\text { function. } \\
\text { - Structures designed to prevent } \\
\text { erosion should be sized appropriately } \\
\text { to address erosion issues (Melby et al. } \\
\text { 2005). }\end{array}$ \\
\hline $\begin{array}{l}\text { Sediment } \\
\text { properties }\end{array}$ & $\begin{array}{l}\text { Erosion } \\
\text { protection }\end{array}$ & $\begin{array}{l}\text { - Bulk density, organic } \\
\text { matter }\end{array}$ & $\begin{array}{l}\text { Low bulk density, higher organic matter, } \\
\text { and lower percent sand are associated } \\
\text { with lower erosion rates (also } \\
\text { associated with well-developed marsh } \\
\text { environments; Feagin et al. 2009). }\end{array}$ \\
\hline
\end{tabular}

\subsubsection{Wetland Location}

Wetland location is one of the primary determinants of wetland FRM function. Wetlands exposed to stronger storm energy such as those adjacent to tidal inlets are less able to attenuate waves or surge than those located in more sheltered areas (Lawler, Haddad, and Ferreira 2016). Because the greatest storm damage reduction benefits also occur in areas immediately adjacent to wetlands (Narayan et al. 2017, 2019), it follows that wetland projects located near assets will provide more FRM benefits than a similarly sized wetland project located further away. Wetland areas should be located forward of assets because wave and surge attenuation can lead to local water-level increases near the leading edge of the wetland, resulting in increased damages to assets in front of the wetland (Stark et al. 2016; Smolders et al. 2015; Zhang et al. 2012). The predominate direction of storms and floods should also be considered so the wetland is positioned between the assets and hazard. In some areas, wetlands may lead to increased water-level elevation, flood duration, and damages, especially where assets are located in landscape positions formerly occupied by wetlands and characterized by low elevations and near the shore (Lathrop et al. 2019).

\subsubsection{Wetland Shape and Size}

Wetland shape and size are the most basic aspects of design geometry and greatly determine the degree of FRM benefit the wetland can provide (see Sections 10.3.1 and 10.4.2). The dimensions are often controlled by the landscape and limited by the extent of deep water and the upland boundaries. For wave attenuation, the wetland distance between the shore and upland should be maximized. 
The primary direction of damaging wave conditions should be examined. This should consider the wave conditions for a range of wind directions and water-level conditions, bearing in mind the fetch lengths, water depths, and storm tracking (Duvall, Wiberg, and Kirwan 2019). To obtain benefits such as surge attenuation or flood storage, the wetland should be significantly large in comparison to the size of the estuary so the resulting reductions in water levels are measurable. Practically speaking, wetland areas should be sufficiently large enough so that $20 \%$ to $40 \%$ of the total surge volume in an estuarine reach will pass over a wetland area, following modeling studies from the Western Scheldt Estuary (Stark et al. 2016). This is easiest to achieve in upper reaches of the estuary, where total flow volumes are smaller than they are close to the estuary mouth.

In urban areas, where existing defenses may be vertical, steel, sheet pile walls or bulkheads, there is likely to be little horizontal space for wetland creation. In such settings, terraces can be created at different elevations to create narrow platforms for vegetation development. Although their FRM benefits are limited, space-constrained wetlands such as this may provide some ecological benefit and some reduction in degradation of structural elements due to wave action (Willemsen et al. 2020). Proximity to structural measures can alter the composition of the wetland vegetation community by altering the hydrodynamics of the wetland and limiting the ability of the wetland to migrate landward with changes in sea level (Heatherington and Bishop 2012). This may limit the long-term viability of wetland terraces if bed levels relative to the local tidal frame are unable to be maintained.

\subsubsection{Wetland Elevation and Nearshore Bathymetry}

Wetland elevation and nearshore bathymetry are other critical aspects of wetland design geometry. Wetland design elevation is largely dictated by the desired wetland type and species composition. Most coastal wetlands occur in the upper intertidal zone. The species composition is determined by the inundation duration, which somewhat limits the extent to which wetland elevation can be manipulated, although areas with greater tide ranges allow greater freedom with this aspect of design than do areas with small tide ranges.

Wave- and surge-attenuation benefits are maximized when water levels are higher than the vegetated marsh surface but lower than the vegetation height (i.e., emergent conditions) (Figure 10.8). The greatest wave reduction occurs when the water levels are at or just below the vegetation canopy (Mazda et al. 2006; Quartel et al. 2007). Typically, wetland flood storage areas with lower elevations can store more water than those higher in elevation, but the breach or culvert opening should prevent the site from filling up and diminishing the storage capacity when water levels are lower (Pontee 2015; Smolders et al. 2020). 


\section{Wave Attenuation}

- Wave length "through" marsh vegetation

- Maximum wave attenuation

- $80 \%$ of attenuation within first 160 meters of width (Möller and Spencer 2002)

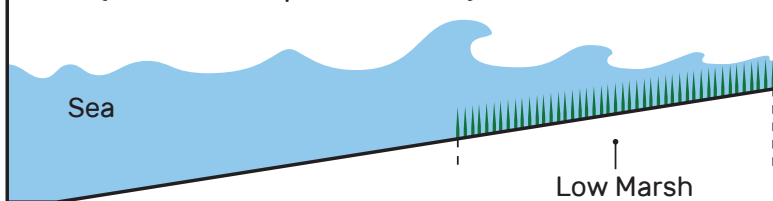

Vegetation factors: density, height, stiffness

\section{Wave Attenuation}

- Wave length high (above vegetation)

- More-limited attenuation

Storm Surge

Sea
Levee

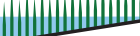

High Marsh

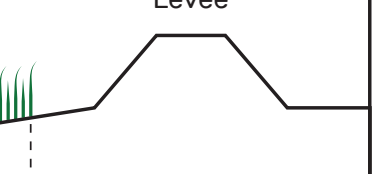




\subsubsection{Connectivity to Other Features}

Just as designing wetlands with topographic variability can increase both FRM and ecological function of wetland NNBF, smoothly linking wetland elevations to subtidal areas and uplands can also increase FRM benefits and ecological and social co-benefits as well. The bathymetry near wetland edges strongly affects the translation of wave energy, with steep or concave wetland edges subject to greater forces from wave impact than terraced or convex wetland edges where the waves may break away from the wetland edge (Tonelli, Fagherazzi, and Petti 2010). If adjacent mudflat or sand flats are too deep, wave breaking may occur directly on the wetland edge, leading to higher long-term erosion rates. Deep water adjacent to wetlands can also exacerbate erosion or preferentially accrete sediments that would otherwise deposit on the wetland surface (Ganju 2019). Thin-layer or strategic sediment placement can be used to increase the elevation of adjacent mudflats and sand flats in the same way these techniques can be used to increase the elevation of the vegetated wetland area (see Table 10.5).

Table 10.5. Engineered Elements That May Be Incorporated into a Coastal Wetland Design

\begin{tabular}{|c|c|c|}
\hline Structural element & Purpose & Design considerations \\
\hline $\begin{array}{l}\text { - Vegetation planting } \\
\text { - Geotextiles (temporary) }\end{array}$ & $\begin{array}{l}\text { Stabilize } \\
\text { sediment }\end{array}$ & $\begin{array}{l}\text { - Choice of plant species (should be } \\
\text { native) } \\
\text { - Seedlings damage or removal by large } \\
\text { waves or strong currents }\end{array}$ \\
\hline $\begin{array}{l}\text { - } \text { Brushwood fencing (temporary) } \\
\text { - } \text { Coir logs (temporary) } \\
\text { - Oyster reefs } \\
\text { - Geotextile containers } \\
\text { - } \text { Nearshore breakwaters-wood or rock } \\
\text { - Gabions } \\
\text { - } \text { Concrete or flexible mattresses } \\
\text { - } \text { Rock } \\
\text { - Open-stone asphalt }\end{array}$ & $\begin{array}{l}\text { Erosion } \\
\text { protection }\end{array}$ & $\begin{array}{l}\text { - Wave or current energy } \\
\text { - Water depth } \\
\text { - Durability of element } \\
\text { - Size of element or fill components } \\
\text { - Source of element or fill components } \\
\text { - Bearing capacity of substrate } \\
\text { - Salinity (for oysters) }\end{array}$ \\
\hline $\begin{array}{l}\text { - Brushwood fencing (temporary) } \\
\text { - Coir logs (temporary) } \\
\text { - Wooden palisades } \\
\text { - Rock or sediment berm or bund } \\
\text { - Vegetation planting } \\
\text { - Groins }\end{array}$ & $\begin{array}{l}\text { Retain or } \\
\text { accrete } \\
\text { sediment }\end{array}$ & $\begin{array}{l}\text { - Wave or current energy } \\
\text { - Water depth } \\
\text { - Permeability of element } \\
\text { - Geometry of element (e.g., height, } \\
\text { length, spacing) }\end{array}$ \\
\hline
\end{tabular}




\begin{tabular}{|c|c|c|}
\hline Structural element & Purpose & Design considerations \\
\hline $\begin{array}{l}\text { - Tide gates } \\
\text { - Geotextile containers } \\
\text { - Wooden palisades }\end{array}$ & Reduce flows & $\begin{array}{l}\text { - Wave or current energy } \\
\text { - Source of fill } \\
\text { - Stability on soft sediments } \\
\text { - Permeability }\end{array}$ \\
\hline $\begin{array}{l}\text { - Sediment placement } \\
\text { - Terracing }\end{array}$ & $\begin{array}{l}\text { Raise surface } \\
\text { elevation }\end{array}$ & $\begin{array}{l}\text { - Particle size characteristics } \\
\text { - Method of delivery (e.g., vessel, dump } \\
\text { truck) } \\
\text { - Space available } \\
\text { - Desired elevations }\end{array}$ \\
\hline - Earthen embankments or levees & $\begin{array}{l}\text { Prevent } \\
\text { flooding }\end{array}$ & $\begin{array}{l}\text { - Wave or current energy } \\
\text { - Water levels in extreme events } \\
\text { - Bearing capacity of substrate } \\
\text { - Source of fill }\end{array}$ \\
\hline
\end{tabular}

Transitional wetland and associated upland plant communities such as maritime forests that occur at higher elevations at the upland extent of wetlands may confer additional FRM benefits because many transitional marsh species are typically taller and woodier than predominantly herbaceous marsh species. In mangrove systems, the transitional zones also host species with different growth habits, often shorter and shrubbier than the trunks of intertidal mangrove species, providing frictional elements such as branches or stems at moderate water levels. Including explicit transitional zones into uplands provides additional resilience in areas of rising sea levels, guaranteeing some wetland function will exist into the future. Additional economic and social co-benefits may be derived by maintaining the connectivity between wetlands and uplands because many biota, especially birds, may use both habitat types. The relatively higher elevation transitional zone also allows space to include recreational trailways for people to exercise or bird-watch, for example.

\subsubsection{Tidal Channels and Open-Water Elements}

Wetland geometry design should also explicitly consider open-water elements such as tidal channels, shallow-water pannes, and deeper pools. These elements are naturally occurring components of wetland complexes and are critical to the correct hydrological and ecological function of the system. Although design of tidal channels and other open-water elements is not always required or recommended, the geometry of tidal channels can affect how waves 
and surge propagate through a wetland (see Table 10.4). Results from a handful of field, laboratory, and modeling studies suggest that wider, denser, and less channelized wetlands are better at reducing long waves and tsunamis and that this capacity for surge reduction is less effective for slow-moving, longer-duration storms where there is more time for the storm surge to penetrate this barrier (Stark et al. 2015; Yao et al. 2015; Zhang et al. 2012).

To avoid overdesigning wetland sites by constructing every part of the tidal channel network, channels in newly created wetlands may be allowed to self-form by strategically notching containment levees in a few areas (van Proosdij et al. 2010). However, tidal currents in microtidal environments may not be strong enough to erode the sediments, leading to waterlogging in the wetland interior and ultimately requiring additional earthwork to excavate pilot channels. Predicted shear stress during flood and ebb tides and the erodibility of the soil should be examined to determine whether tidal channels can be allowed to form on their own or if earthwork will be required.

If channels are being created or restored or if levees of formerly impounded or poldered areas are to be breached, channels should be sinuous and branched so surge is not quickly directed deep into a wetland, effectively bypassing the vegetated zones and reducing the attenuation effects of the vegetation. Channel density should be great enough to provide adequate tidal exchange and sediment transport to maintain the wetland, although optimizing potential wave- and surge-attenuation channels and open-water elements of wetlands should not dominate the wetland complex. Regional relationships between tidal channel dimensions (e.g., width, depth, density, and sinuosity) are commonly used to plan wetland restoration and creation projects (Hood 2015; Odell, Hall, and Brooks 2008).

\subsubsection{Vegetation}

Selection of the dominant vegetation is typically predetermined by the target wetland type and design elevations but can be manipulated to optimize FRM benefits by designing for a range of wetland elevations. Generally, the more saline the wetland, the less diverse the plant community and the more limited the ability to select plants to maximize the desired benefits. In brackish to freshwater environments or higher in the tidal prism, greater species diversity occurs and plants can be selected based on their ability to attenuate waves or prevent erosion.

Growth form. Plant growth form and physical properties (e.g., stem density, height, stiffness) affect how effectively the vegetation captures sediment or attenuates waves and surge. Several field studies in mangrove and salt marsh wetlands show that wave reduction capacity increases at greater vegetation widths, vegetative densities, and heights, and it decreases at higher water levels when the water surface exceeds the vegetation height 
(Brinkman 2006; Möller et al. 1999; Narra 2012; Vuik et al. 2015). Other species-specific vegetation characteristics such as plant stiffness, porosity, and state of dormancy, as well as site geometry and current velocity, also affect the wave-attenuation capacity of wetlands (Bouma, De Vries, and Herman 2010; Ysebaert et al. 2011; Vuik et al. 2018; Armanini, Righetti, and Grisenti 2005; Maza, Lara, and Losada 2015; Losada et al. 2016). Creating conditions that support taller and stiffer plants can maximize wave-attenuation functions. Wetland plants with deep, dense root networks are more resistant to erosion and scour during storm events (Howes et al. 2010; Silliman et al. 2019), so deeply and densely rooted species should be selected in areas prone to more energetic wave conditions.

Although plant species in many coastal wetlands are restricted based on the conditions, the wetland elevation and topography can be designed to favor some species over others. Certain species of mangroves, such as Rhizophora sp., are characterized by dense stilt roots and have greater wave-attenuation capacity than species such as Avicennia sp. and Sonneratia sp., which are characterized by pneumatophores (Horstman et al. 2015), so creating conditions that favor Rhizophora sp. would result in a wetland with greater wave-attenuation function. In salt marshes, selection of plant species may require trade-offs between tall, aboveground biomass and dense, deep, belowground biomass. For example, in eastern North American salt marshes, the low marsh is dominated by smooth cordgrass (Spartina alterniflora), which can take on short or tall growth forms. Although the tall form of Spartina alterniflora, with a height of up to $1.5 \mathrm{~m}$, would result in greater wave-attenuation capacity, it has lower belowground biomass than the short form and may be more prone to scour and erosion during storms.

Sites should be constructed to provide small-scale and site-scale variation in topography that facilitates a variety of wetland vegetation niches. Designing wetlands that can be inhabited by a variety of species is desirable ecologically for biotic use, and greater species diversity may also provide a wider variety of plant growth habits with varied biomechanical properties that can provide FRM benefits for a range of water levels and conditions. During and immediately after storm events, flexible species lay prone, protecting the soil surface from scour, whereas more rigid stems remain upright, attenuating waves despite the greater risk of breakage or uprooting (Vuik et al. 2019).

Vegetation design considerations. Planting should be minimized in favor of natural colonization where practical to minimize costs. If the project site is relatively small, a natural seed bank is sufficiently present, and biophysical conditions are suitable, monitored natural colonization is usually acceptable. The revegetation process will be substantially slower, however, and it will take longer to generate the same FRM benefits or ecological co-benefits as a planted site. Natural colonization may not be feasible for rare species (Mossman, Davy, and Grant 2012) in areas prone to colonization by invasive species, latitudes with short growing seasons, very large sites, or newly constructed sites with limited natural seed bank. 
If the site requires some level of planting, detailed planting plans should include on-center spacing and row spacing for monotypic planting of marsh or mangrove species, as well as the required conditions for planting such as time of year, soil conditions, salinity, water level, and groundwater hydrology. Wetlands with more diverse plant communities may require more complex plans that take advantage of the synergistic and competitive relationships among species and individual plants. The as-built site conditions should dictate the final plant selection, rather than the original design, because the as-built conditions may deviate from the original design. Because planting typically occurs sometime after construction (months to years after depending on site conditions), the planting design can be adjusted to accommodate any changes.

Planting design best practices. Elements of vegetation design include not only the plant stock (seed or plugs) of the desired species but also the means to protect them from grazing, such as goose netting or tree shelters for taller species. Temporary structures such as brushwood or bamboo fences or straw bales may be required to protect young plants from storms during establishment phases, or submerged breakwaters may be required to protect new plantings from wave energy; all would add to the project costs (Kamali and Hashim 2011). Likewise, temporary cover plantings of annual species may be used to promote conditions conducive to the establishment of new plantings. Native plant stock sources may be limited, so species selection should reflect not only the desired species assemblages but also the availability of plant stocks.

Proactive consideration of planting requirements during the design phase can greatly assist with availability and long-term success and trajectory. Very often, improper planting techniques, site selection, and species or genotype selection can result in the failure of wetland projects (Kodikara et al. 2017). Including a botanist, wetland scientist, or other experienced wetland restoration practitioner on the design team is recommended. Having a wetland scientist or similar professional on site during planting is also recommended to ensure plants are properly cared for.

If seeding and planting are to be used in a project, these materials must be included in the budget and design criteria from the onset of the project because they are often not available in the diversity, genetics, and number required without prior reservation, deposit, and increase through reputable nurseries and dealer. More details on planting techniques appropriate in a variety of wetland environments can be found in other sources (Zedler 2000; Broome, Craft, and Burchell 2019). 


\subsubsection{Structural Elements for Wetland Protection}

Additional aspects of coastal wetland design may include structural elements to prevent erosion of wetland edges, prevent damage as a wetland site becomes established, reduce wave action for vegetation persistence, or address altered physical processes that affect wetland function, as described in Section 10.5.3. Note that structural elements included as part of wetland design are distinguished from coastal wetland NNBF in combination with another structural measure because they serve a different purpose (see discussion on combining wetland NNBF with structural measures in Section 10.5.3).

Because structural elements can be expensive and may interfere with some natural wetland processes, they are typically recommended only in areas where the wetland position needs to be maintained due to upland development. Hardening a wetland shoreline to prevent movement inhibits the inherent resiliency gained from the use of nature-based FRM approaches. Likewise, edge erosion contributes some sediment back to the wetland platform, so preventing erosion may limit deposition in other areas, potentially affecting the wetland's ability to maintain elevation relative to sea level.

These structural elements are typically engineered to less stringent design criteria than coastal engineering structures designed to protect assets during less frequent, larger magnitude events. In many situations, the conditions that cause ongoing wetland erosion are not rare or particularly extreme. For example, Leonardi et al. (2016) found the 2.5-month frequency wind event (corresponding to wind speeds between 10 and $40 \mathrm{~km}$ per hour) is responsible for the long-term deterioration of salt marsh, with extreme storm events only responsible for approximately $1 \%$ of the long-term rate. For larger wetland NNBF projects, life-cycle cost analysis approaches may be warranted to determine the optimal protection level required for wetland projects (Melby et al. 2005). When evaluating the wave energy that a shoreline is likely to experience on a regular basis, it is also important to consider the proximity of the site to navigation channels because boat wake waves can be a strong driver of coastal erosion (Bilkovic et al. 2017).

Structural elements can be designed to be permanent or temporary and are described in Table 10.5. Examples of temporary structural elements include straw bales, coir logs, coconut fiber matting, and sacrificial sediment bunds or berms that may be eroded over time. More permanent elements include shell bags, rock, cast-concrete structures such as Reef Balls, and gabion baskets; they may be designed to encourage colonization of bivalves such as oysters or mussels. Generally, "soft" and biological materials are preferred over hard engineered structures such as rock or cast concrete (although rock may be considered a natural material along rocky coastlines). Earthen structures such as berms, levees, and islands can be used to control waves, flow, or water elevation and can be designed to erode or to dissipate wave energy instead of reflecting it. 


\subsubsection{Sediment Properties}

If wetland NNBF is to be created or sediments are used to build elevation or expand the footprint of existing wetlands, the properties of the sediment should be considered. Wetlands have been constructed from sediment sizes ranging from sand to silts and clays. Although gravely and rocky sediments should be avoided at least for the topmost layers, the use of sand or mud will not necessarily affect the success of the created wetland (Campbell et al. 2017).

Sandy and muddy sediments also behave differently during and after construction and require different design considerations. Sandy sediments tend to stack and build elevation relatively easily, especially using hydraulic placement because sand quickly settles out of suspension. Muddy sediments may be more suitable for thinner placements (e.g., on wetlands or in shallow water) because the elevation builds slowly and the hydraulic slurry can flow for tens of meters. More information on thin-layer placement can be found at the USACE thin-layer placement website (tlp.el.erdc.dren.mil 2020).

After construction, fine-grained, muddy sediments tend to consolidate more than sandy sediments and may require a longer period of stabilization prior to seeding or planting. Temporary containment structures should be removed relatively soon after construction to allow tidal exchange to re-establish. If earthen dikes or levees are used, they should be notched before the sediment is fully consolidated so tidal creeks can begin to form. For more information on wetland creation, see the Louisiana Coastal Protection and Restoration Authority's Marsh Creation Design Guidelines (2017).

\subsubsection{Design Tools}

A number of tools can be used in the development of wetland NNBF designs. Numerous models characterize the hydrodynamic forcing conditions and estimate sediment and vegetation response. This section focuses on classes of models relevant to wetland NNBF design and provides examples of those models (Table 10.6) but does not provide an exhaustive listing. Tools vary in complexity and cost, so the level of modeling effort should be commensurate with the size and complexity of the project. 
Table 10.6. Representative Models for Use in the Development of Coastal Wetland NNBF Measures

\section{Wave models}

\section{When to use:}

- Assessment of degree of wave reduction over wetland feature

- Fringe erosion during wave events

- Effect of boat wake on wetland erosion

\section{Examples:}

- FUNWAVE (fengyashi.github.io 2019)

- STWAVE (xmswiki.com 2019)

- SWAN (swanmodel.sourceforge.net, n.d.)

\section{Hydrodynamic models}

When to use:

- Assessment of flood storage function

- Assessment of surge reduction

- Assessment of currents

- Hydrologic residence time

- Time-varying salinity

\section{Examples:}

- ADCIRC (adcirc.org, n.d.)

- Delft3D (oss.deltares.nl 2020)

- HEC-RAS (hec.usace.army.mil, n.d.)

- MIKE 21/3 (mikepoweredbydhi.com, n.d.)

- ROMS (myroms.org 2020)

- Telemac (opentelemac.org 2020)

\section{Sediment transport models}

When to use:

- Assessment of short-term erosion

- Assessment of long-term mineral accretion trends

- Shoreline morphology

\section{Examples:}

- COAWST (usgs.gov 2019)

- Delft3D (oss.deltares.nl 2020)

\section{Wetland biophysical models}

\section{When to use:}

- Prediction of long-term evolution of feature with respect to elevation, vegetation density, size

- Response of wetlands to sea-level change

Examples:

- MARSED (Temmerman et al. 2004)

- Marsh Equilibrium Model (MEM) (Morris et al. 2002)

- Sea Level Affecting Marshes Model (SLAMM) (coast. noaa.gov 2020)

- Wetland Accretion Rate Model for Ecosystem Resilience (WARMER) (Swanson et al. 2014)

\section{Hybrid models}

\section{When to use:}

- Advanced applications that combine wetland elevation and hydrodynamic models

\section{Examples:}

- Delft3D+vegetation module (Best et al. 2018)

- Hydro-MEM (Alizad et al. 2016)

- Marsh Transect Model (Kirwan et al. 2016b)

\section{Vegetation models}

\section{When to use:}

- Determining appropriate vegetation communities based on marsh elevation and tidal data

\section{Examples:}

- Marsh Analysis and Planning Tool Incorporating Tides and Elevations (MAPTITE; NOAA 2014) 
Wetland NNBF models vary in temporal scale based on their intended purpose. Wetland NNBF engineering performance is usually determined at a storm-event scale using similar modeling tools as other structural measures, whereas long-term performance uses models that operate at seasonal or even annual timescales for decades or centuries. Applicable spatial scales for wetland NNBF modeling also varies and is a function of the size of the wetland and the intended purpose of the modeling. Some models represent wetlands as uniform blocks, whereas others resolve to the scale of creek networks and vegetation communities.

Wave models. Wave models can be used in wetland design in the following two capacities: (1) to assess wetland NNBF performance in attenuating waves and (2) to assess the effect of waves on the wetland itself. The type of wave model selected and the manner in which it is applied depend on which aspects of wave-wetland interaction are of interest. Wave model output can be coupled to hydrodynamic and sediment models as a driving force for assessing how waves interact with storm surge or drive sediment transport processes.

Phase-averaged spectral wave models, which simulate wave generation and transformation including dissipation due to vegetation, are most commonly used to determine wetland performance and to examine the effects of waves on wetland conditions. Phase-averaged models represent waves as a spectrum (distribution of energy with wave frequency and direction). Waves grow over a fetch (open water in the upwind direction) and are dissipated by vegetation, bottom roughness, and breaking. If wetland waves are sufficiently long (with respect to water depth), wave refraction and shoaling may be important factors focusing wave energy on shallow features. Typical wave model inputs include wetland bathymetry and topography, vegetation cover (spatial extent and vegetation properties [diameter, density, plant height]), winds, and water levels.

Phase-averaged wave models should be forced with the expected ranges of winds and water levels for the site. Because wind waves are a key driving force for transporting sediment and eroding shorelines, simulating wave conditions during typical and windy conditions at normal water levels is useful for assessing the effect of waves on wetland shoreline erosion and predicting erosional hot spots. Forcing the models with storm conditions where both wind and water levels are greater allows the performance with respect to wave attenuation to be assessed and design alternatives to be compared.

Boat wakes may also cause erosion within wetlands, requiring phase-resolving boat wake models that resolve individual wave crests and troughs generated by a passing vessel. Boat wake parameters typically are available in manuals such as the USACE Coastal Engineering Manual (USACE 2002) or can be modeled with Boussinesq or shallow-water equation models that include a boat wake source term. 
Hydrodynamic models. Hydrodynamics, especially the hydroperiod, are important processes for wetlands because site hydrology controls biogeochemical and ecological functioning to a great extent. Hydrodynamic models are also used to assess wetland NNBF function with respect to surge-attenuation and flood storage capacity. Hydrodynamic models range in degree of complexity as well as applicable temporal and spatial scales, and the hydrodynamic model selected depends on the intended purpose of the modeling. Small wetland projects designed to attenuate waves or prevent erosion may not require much hydrodynamic modeling, if any, but larger and more complex wetlands designed to attenuate surge or store floodwater will require modeling to assess both engineering and ecological function. Hydrodynamic models typically used to assess wetland performance will use shorter temporal scales, whereas models used to assess design for ecological function will use longer scales.

Most 2D and 3D hydrodynamic models used routinely in FRM studies have the ability to simulate the effects of wetland NNBF. They include TELEMAC (Hervouet 2007), Delft3D (oss.deltares.nl 2020), ADvanced CIRCulation (ADCIRC; Luettich and Westerlink 2004, 2012), and Regional Ocean Modeling System (ROMS; Shchepetkin and McWilliams 2005). However, the way wetlands are represented in those models varies in complexity, with some using simple parameters to capture the changes in bathymetry and friction associated with wetlands and others using time-varying parameterization of the vegetation form drag, including associated flexing and bending of stems. Typically, only large wetland NNBF projects (on the order of tens of thousands of square meters or larger) are simulated using these sorts of hydrodynamic models because the effects of smaller projects are unlikely to be detectable in the results. In addition, implementation of created or significantly restored wetlands in the model domains may not be trivial, sometimes requiring time-consuming alterations in the model grid or mesh to attain the required spatial resolution to represent the wetland.

Wetland restoration literature describes how hydrodynamic models can be used to design sites that function ecologically. Models used in this capacity are typically 1D or 2D, depending on the complexity of the site. Precipitation and groundwater may be included if they are significant components of the water budget, which is more common for brackish and transitional parts of coastal wetlands that are only infrequently inundated by tides. MacBroom and Schiff (2012) cover a variety of applicable hydrodynamic modeling approaches that can be used to design restoration projects in salt marsh environments. Simple hydrodynamic models have been used similarly to design mangrove restoration projects (Marois and Mitsch 2017).

Sediment transport models. Although an adequate sediment supply is critical to maintaining coastal wetlands, especially in regions with rising sea levels, sediment transport models are not routinely used to assess wetland NNBF FRM or ecological function. However, sediment transport modeling may be warranted in some types of wetland NNBF projects, especially those that use strategic sediment placement to restore or maintain wetlands. Sediment 
transport models require implementation of hydrodynamic models over months or years (as opposed to over days or weeks associated with storm events) and, therefore, may be relatively costly to develop and run. Sediment transport models were used to understand strategic sediment placement in the Wadden Sea in the Netherlands and Mobile Bay in Alabama, United States (Baptist et al. 2019; Parson et al. 2015).

Biophysical models. Biophysical wetland models should be used in design to determine the long-term effects of altered sea level, sediment supply, or other environmental state changes on wetland properties (e.g., vegetation density, elevation). Wetlands, especially salt marshes and mangrove forests, have complex biophysical feedbacks with their environments whereby they are able to accrete through both sediment deposition and belowground biomass accumulation in response to increasing (or decreasing) inundation associated with tidal epochs and changing sea levels. These feedbacks can be complex and vary with species, so simple estimations of accretion rates may be inadequate to understand wetland properties across a project life cycle.

Several models with a range of complexity have been developed to describe these feedbacks, from zeroth-order models that only describe vertical accretion at one point to fully 3D, coupled biophysical and hydrodynamic models, which are characterized as hybrid models in Table 10.6. Hydro-MEM, which couples a point model of marsh accretion (Marsh Equilibrium Model; Morris et al. 2002) with ADCIRC, a hydrodynamic ocean circulation model often used to simulate storm surge, has been used to predict future marsh conditions under rising sea levels and how the changes in marsh condition relate to changes in storm-surge propagation in various marsh systems (Alizad et al. 2016). The current literature on the topic reveals various hybrid biophysical models that couple various processes such as accretion, edge erosion, pond dynamics, and creek incision together (e.g., Mariotti 2020 and references within; Nunez et al. 2020; Best et al. 2018), but their use for wetland NNBF design has not been assessed.

Vegetation models. Although vegetation dynamics are implicitly or explicitly modeled in most biophysical models, simpler models can also be used to predict wetland species distributions based on site topography and hydroperiod. But the representation of wetland vegetation dynamics in these models is often simplistic, limiting their use in understanding how changes in wetland vegetation growth and distribution may affect wetland NNBF performance over many decades. Simple habitat suitability models and tools such as the Marsh Analysis and Planning Tool Incorporating Tides and Elevations (MAPTITE; NOAA 2014) implemented in GIS software can be used to develop site planting plans or to determine the range of species likely to develop at a created or restored site so estimates of vegetation height and density can be used to parameterize hydrodynamic or wave models. 


\subsubsection{Estimating Costs and Benefits}

Financial costs and benefits are usually considered to help inform whether projects should go ahead or to compare different options. Such analysis is termed cost-benefit analysis, and the resulting ratio of costs to benefits is termed the benefit-cost ratio. It is common practice that, to go ahead, the analysis must demonstrate the costs of the project are less than the benefits, sometimes by a set amount. The decision on project go-ahead may also take into account other costs and benefits that are not readily expressed in monetary values, such as visitor enjoyment or aesthetic value. Chapter 6 explores the costs and benefits of NNBF solutions more generally. This section concentrates on costs and benefits as they relate to wetland NNBF solutions.

Costs and benefits associated with wetland NNBF may be more complex than those associated with structural measures, especially if there are multiple sources of funding tied to specific objectives. However, wetland NNBF may be able to access more potential funding sources than structural measures. Wetland NNBF can also be supported by conservation and restoration funds, green adaptation funds, blue carbon sequestration funds, and many other sources (Colgan 2017).

Flood and erosion risk benefits. As outlined in Section 10.3.1, wetlands can offer FRM benefits by attenuating incoming waves and, in some cases, storm-surge water levels; storing floodwater; trapping and stabilizing sediments; and reducing erosion. These services turn into financial benefits in terms of directly avoided flood or erosion damages and through indirectly avoided disruptions to business. For example, projects documenting the aftereffects of mangrove restoration projects in India, Vietnam, and elsewhere have observed considerable avoided damages to lives, coastal structures, and inland assets such as houses and farms during tropical cyclones (Vuik et al. 2015; Krauss et al. 2009; Wamsley et al. 2009; Zhang et al. 2012; Das and Vincent 2009).

The decision whether to include a coastal wetland project as part of a portfolio of FRM measures should be taken based on a full accounting of FRM benefits and other co-benefits, but FRM benefits are critical because FRM is what distinguishes wetland NNBF from typical wetland projects. Appropriate data on coastal populations and properties, coupled with numerical models for wave attenuation and flooding such as those described in Section 10.6.9, enable estimates to be made of the economic benefits of coastal wetlands in reducing flooding and flood damages. The variation in documented performance in coastal wetlands, especially in early scoping stages of a project, can propagate significant uncertainty into estimates of avoided economic damages, which can potentially affect the decision on whether to use coastal wetlands for FRM. But because the performance of coastal wetlands has been documented only relatively recently, the evidence base is actively growing, and it is anticipated that the true variation in coastal wetland performance under a range of conditions will be better captured in the near future. 
Under certain storm conditions, the predicted reductions in water levels and waves attributable to coastal wetlands may not be particularly large in magnitude, sometimes on the order of tens of centimeters. However, the relationship between total water level and FRM-related economic benefits is not linear, so small reductions in water levels can still result in relatively large economic benefits. This can lead to large differences in the reported economic benefits of coastal wetland projects. Recent studies of salt marsh and mangrove wetlands in the United States and mangroves in the Philippines suggest damage reduction benefits from these features of anywhere between USD\$2 and USD\$7,500 per hectare for individual extreme events and annual flood damages (Narayan et al. 2017, 2019; Barbier et al. 2013; Losada et al. 2017). It is to be noted that these values reflect only the coastal protection services from these ecosystems. Because indirect benefits such as interruptions to commerce and co-benefits such as aesthetic quality of wetland NNBF may not be easily monetized, or are intentionally not monetized (and, therefore, cannot be incorporated into a traditional cost-benefit calculation), the full array of benefits and co-benefits may be underestimated. Efforts to account for indirect economic benefits, whether or not they are monetized, will provide a more complete accounting of the benefits of coastal wetlands.

\subsubsection{Wetland Unit Costs}

The evidence base of costs associated with NNBF wetland measures is not yet as well developed as for structural measures. There are numerous studies and reviews of the costs and benefits of coastal habitat restoration as well as the co-benefits (Bayraktarov et al. 2016; Edwards, Sutton-Grier, and Coyle 2013; NOAA 2014, 2020), but there is often less guidance on projects designed to provide FRM benefits. Wetland restoration costs cannot be assumed to be equivalent to wetland NNBF costs given the different project objectives, requirements, and scales. However, the elements of a wetland restoration cost estimate and the project elements that contribute to variability in costs will be similar to those of a wetland NNBF project.

Typically, unit costs of wetland restoration and creation vary by habitat and by region. Mangrove restoration, common in developing countries, has the cheapest restoration costs per hectare (USD $\$ 1,000$ to USD $\$ 5,000$ ). Salt marsh restoration is most common along temperate coastlines of developed countries, and the costs of this restoration are relatively higher, often double or more in magnitude (median cost per hectare USD\$11,100) (Narayan et al. 2016). Although mangrove restoration projects tend to be much larger in total extent, there is no clear evidence that project costs are influenced by their size. In general, the more structural elements (e.g., rock sills or levees) a wetland NNBF contains, the more expensive it is. As mentioned in Section 10.6.7, structural elements should be avoided unless absolutely necessary because they not only unnecessarily increase costs but also may interfere with the natural dynamism of coastal wetlands. 
At present, there is little knowledge of how costs of wetland creation, restoration, and conservation compare against the costs of equivalent structural measures (but see Reguero et al. 2018). A few comparisons of breakwater costs with the costs of restoration in mangrove forests and marsh wetlands suggest that, under low wave-energy conditions, habitat restoration is several times more cost-effective than breakwater construction, especially as water depth increases (Narayan et al. 2016). Results from China indicate that reduction in storm damages attributable to wetlands is approximately $¥ 11.9$ million Chinese yuan (CNY) (USD\$1.8 million) per square kilometer compared to CNY $¥ 4.8$ million (USD\$742,000) per km of seawall (Liu et al. 2019).

Conserving and maintaining existing wetlands to preserve the coastal protection benefits they already provide can be a cost-effective strategy, especially for vegetated coastlines exposed to multiple hazards from waves and storm surges. Maintenance of existing wetlands to support the production of future FRM benefits may not require extensive actions. If the wetland begins to degrade due to changes in environmental conditions such as rising sea levels, maintenance actions should be pursued that interrupt the degradation cycle enough to allow the natural biophysical processes that typically maintain the wetland function to re-establish. The benefits from wetlands in terms of avoided damages, other FRM benefits, or co-benefit production need to be weighed against the costs of keeping these wetlands healthy and the opportunity costs of preventing their conversion to other, competing land uses such as urban development, agriculture, or aquaculture (Barbier 1994). In locations with high rates of sea-level rise, the costs to maintain some coastal wetlands may eventually outweigh the benefits and active maintenance may no longer be economically justified. However, as populations respond to rising sea levels and relocate, maintenance of coastal wetlands in other locations may become economically justified.

Projects that require little engineering and construction, such as those requiring only vegetation restoration or re-establishment of tidal exchange through removal or replacement of structures such as culverts or tide gates, are similarly cost-effective. Restoration by planting, such as is common with mangroves, can be relatively cheap and easy to implement (less than USD\$500 per hectare in some cases), although several factors determine the project's feasibility and success, including the availability of the local genotype seedlings and propagules, the involvement of the local community, effective training, and appropriate site selection (Primavera and Esteban 2008). Costs associated with re-establishment of tidal exchange may only involve removal or replacement of the structure, allowing natural re-establishment of the wetland to occur provided adequate sediment and seed-bank availability.

The costs of creating, restoring, and maintaining wetlands are highly variable across sites, habitat types, project conditions, and standard of protection to be provided. The costs should extend over the lifetime of the project and include the impact of climate change, sea-level rise, and, in some instances, decommissioning costs. Decommissioning of coastal wetlands 
is rarely required, but in cases where future conditions are likely to make a wetland site unsustainable and the wetland will no longer be maintained, structural elements associated with the wetland such as rock sills may need to be removed. Costs also vary around the world due to the availability of materials and labor. Table 10.7 shows elements of wetland NNBF costs that should be considered when constructing a cost estimate divided into capital and maintenance costs. Some components of capital costs, particularly some aspects of planning, design, and permitting, are likely to be delegated to consultants that have particular expertise and those fees should also be estimated. Likewise, construction, except for very small projects, is typically contracted out, and any additional costs associated with soliciting bids and issuing contracts should be estimated.

\section{Table 10.7. Elements of Wetland NNBF Costs}

\begin{tabular}{|c|c|c|c|}
\hline Capital costs & $\begin{array}{l}\text { Relative cost } \\
\text { magnitude }\end{array}$ & Maintenance costs & $\begin{array}{l}\text { Relative cost } \\
\text { magnitude }\end{array}$ \\
\hline $\begin{array}{l}\text { Planning costs, including site } \\
\text { investigation data collection }\end{array}$ & Low to Medium & $\begin{array}{l}\text { Routine monitoring as prescribed } \\
\text { in the adaptive management plan }\end{array}$ & Low \\
\hline Design costs & Medium & Mowing & Low \\
\hline Land purchases & High & $\begin{array}{l}\text { Routine maintenance of } \\
\text { structural elements or water }\end{array}$ & Low \\
\hline Mitigation (if required) & Low to High & control structures & \\
\hline Stakeholder engagement & Low & Invasive species control & Low \\
\hline License and permitting fees & Low & $\begin{array}{l}\text { Monitoring and repair associated } \\
\text { with storm damages }\end{array}$ & Low to Medium \\
\hline Construction costs ${ }^{1}$ & Medium to High & Sediment renourishment & Medium to High \\
\hline Planting costs ${ }^{2}$ & Low & Decommissioning & Low to Medium \\
\hline Site access elements ${ }^{3}$ & Low & & \\
\hline
\end{tabular}

Notes:

${ }^{1}$ Site preparation, earthwork, sediment movement and acquisition, erosion and sediment control, temporary construction access, specialty equipment rental, water control structures, temporary or permanent erosion protection

${ }^{2}$ To include cost of plants, bird netting, labor, and short-term monitoring over the period of performance

${ }^{3}$ Signage, paths, boardwalks, viewing platforms, fencing 
Elements of costs. Aspects of wetland NNBF capital costs that are particularly difficult to estimate are land acquisition costs, permitting costs, and time associated with permitting. Unless used to advance the coastline by reclaiming lost land (Chung 2006), NNBF involving coastal wetlands will sometimes need to acquire land or use land already owned by the involved organizations. Because some NNBF solutions are relatively new, additional efforts and costs may be incurred at the permitting stage. Especially in the United States, it can be more difficult to obtain construction permits for wetland NNBF than for structural measures (Currin, Chappell, and Deaton 2010). This can result in longer project wait times for NNBF and, consequently, significantly higher capital costs, although multiple high-level efforts at federal and state levels are seeking to change this. Best practices indicate this barrier can be overcome through active stakeholder and regulator engagement early in project conceptualization so that regulators understand that the project objectives and concerns are addressed during design. For more information on engagement of stakeholders and regulators, refer to Chapter 3 .

Like other structural measures, wetland NNBF will require periodic maintenance and upkeep to preserve their health and hence their coastal protection function. Monitoring and maintenance costs, like other costs associated with wetland NNBF, are not well documented but can be estimated based on the costs and estimated frequency of specific adaptive management actions. Maintenance activities may be required in the immediate aftermath of storms, when mangrove or marsh forests can be affected by tree debris and excessive sedimentation due to high winds, waves, and surges (Smith, Knapp, and Collins 2009). However, not all storm damages will require active repair because wetlands are well adapted to periodic storm impacts. For example, vegetation may be allowed to naturally recover from storm damages with an expected reduction in performance. However, extensive damage to the underlying wetland platform, although unlikely unless the wetland condition was already compromised, may require engineering intervention because natural recovery (if possible) may take years or decades. Wetlands used for FRM will also require periodic monitoring as part of a comprehensive adaptive management approach to ensure the FRM functions are sustained under future conditions.

Under the right conditions, however, coastal wetlands can offer a degree of adaptability to-and recovery from-changing environmental conditions, including sea-level rise, that structural measures such as seawalls typically do not (van Wesenbeeck et al. 2016), ultimately providing a cost savings across a project lifetime. This characteristic could potentially eliminate or reduce the cost of upgrading defenses to keep pace with changing load conditions. 


\section{7 | Construction Considerations and Methods}

Construction methods and equipment selections will vary from project to project depending on individual designs and site characteristics. Foremost, all construction plans should place safety first. Construction in coastal wetland environments presents a special suite of risks, including working in or near water, unstable ground conditions, and even the potential risk of unexploded ordnance from previous military operations. Site access may be limited, and evacuation could be difficult.

Project complexity also varies widely, and construction plans and specifications likewise vary. Sites that simply require planting or seeding may only need a detailed planting plan, and quality assurance requirements may be limited to percentage survival over the first growing season, for example. Sites that require significant earthwork will require far more detailed plans and specifications. Despite the variation in required construction considerations, most projects should have a professional wetland scientist or environmental advisor on site during construction to help provide guidance when unforeseen conditions are encountered or when a degree of interpretation is required to implement designs. Other key considerations and best practices that commonly apply are discussed in the following subsections.

\section{Construction Considerations and Recommendations}

- Construction specifications should focus on what the contractor should not do and should not prescribe means and methods.

- Final wetland elevation is a critical design criteria and should be addressed explicitly in quality assurance and quality control plans. For projects that manipulate elevation, sediment compression and consolidation should be considered.

- Construction permitting and certification may require additional time and consultation, especially for projects that are located near other valued ecological resources.

- Pilot construction phases may be advised for large projects and projects that utilize new design and construction techniques.

- Adaptive management during construction can improve outcomes if regulatory entities are amenable.

- If required, planting activities should be timed based on site conditions (e.g., consolidation, salinity, temperature), rather than being determined by a project schedule. 


\subsubsection{Construction Permitting and Certification}

Wetlands are sensitive habitats that are likely to be protected by multiple national and international conservation designations. Construction work is, therefore, likely to require consents or permits prior to taking place. As mentioned in Section 10.6.10, permitting and certification for some wetland NNBF projects, especially in the United States, may be more difficult than for structural measures due to some regulators' unfamiliarity with wetland NNBF. Although efforts are underway to improve the process, early consultation with permitting authorities is recommended so regulators are familiar with the project purpose and objectives, plans and specifications can be developed with permit requirements and constraints in mind, and timelines can be met.

\subsubsection{Construction Plans, Specifications, and Schedule}

There are no remarkable differences between wetland NNBF project plans and specifications and those of other types of restoration projects. Construction plans and specifications should reflect the complexity of the project, with more detailed plans required for projects that include more elements. Construction plans should include a timeline and the order of work to be executed, which are critical for projects that may involve multiple stages. For wetland projects involving hydraulic sediment placement, the construction schedule may be of critical importance to allow sufficient time for dewatering between construction phases. Wetland projects frequently are subject to time of year restrictions as part of permitting and certification and for logistical reasons, and those restrictions should be clearly stated.

Wetland NNBF construction plans should cover each project phase (e.g., grading and planting). Additional plan details are required for critical elements or engineered features, with more detail required for wetland edges, tidal channels, transitional areas to uplands or adjacent features, areas where structures such as culverts or tide gates interface with the wetland, any unique habitat features such as designed pools, and any other special design feature.

Once a contractor is selected, the contractor work plan should be provided and should contain the items summarized in Table 10.8 . 
Table 10.8. Elements of Contractor Work Plan for Wetland Projects

\begin{tabular}{|c|c|}
\hline Item & Description \\
\hline $\begin{array}{l}\text { Project management and } \\
\text { organization }\end{array}$ & Project management structure including key positions and responsibilities \\
\hline Health and safety plan & $\begin{array}{l}\text { Plan detailing elements required for safe execution of work, with details on } \\
\text { how to cope with hazards specific to wetland environments }\end{array}$ \\
\hline $\begin{array}{l}\text { Mobilization and demobilization } \\
\text { plan }\end{array}$ & $\begin{array}{l}\text { Plan for staging and breakdown of equipment on site-should include plan } \\
\text { for access for equipment and personnel, especially in difficult-to-access } \\
\text { locations }\end{array}$ \\
\hline Construction equipment & $\begin{array}{l}\text { Specifications of all equipment and details concerning access, staging, and } \\
\text { where individual pieces of equipment are permitted }\end{array}$ \\
\hline Staging areas & $\begin{array}{l}\text { Identification of support areas off immediate project site in adjacent or } \\
\text { nearby upland site }\end{array}$ \\
\hline Environmental controls & $\begin{array}{l}\text { Any controls for minimizing adverse construction impacts to surrounding } \\
\text { areas (e.g., noise, sediment discharge) }\end{array}$ \\
\hline Permit compliance & $\begin{array}{l}\text { Details on how compliance with permit requirements will be attained, with } \\
\text { additional details required for special provisions }\end{array}$ \\
\hline Submittals & Anticipated submittals to organization responsible for project \\
\hline Schedule of work & Work days, shifts, work hours, contingency plans \\
\hline Construction quality control plan & Methods for determining compliance with design specifications \\
\hline Site restoration & Plan to restore site to required condition upon project completion \\
\hline \multicolumn{2}{|c|}{ For projects with sediment placement: } \\
\hline Borrow source & Details on borrow source material transport \\
\hline Containment plans & $\begin{array}{l}\text { If not specified, contractor plans to create containment areas for sediment } \\
\text { placement }\end{array}$ \\
\hline Pipeline corridor & $\begin{array}{l}\text { Locations and layout of hydraulic pipeline for projects utilizing sediment } \\
\text { slurry }\end{array}$ \\
\hline
\end{tabular}

\subsubsection{Quality Assurance Plans}

Quality assurance plans for construction stages should be compatible with the success criteria and metrics determined earlier in the design process. Best practices should avoid specifying means and methods for construction, focusing instead on performance-based criteria. Note that the metrics used to determine whether construction was successful are different from the metrics used to determine project performance. The quality assurance plan should 
prescribe how the constructed site will be assessed based on the design specifications and should include some allowance for deviation from the specifications. The methods by which the project will be assessed after construction (e.g., survey methods and success criteria) and the party responsible for that assessment should be determined.

The quality assurance plan should also prescribe best management practices to minimize damages to the wetland and a method to assess and quantify damages. Any prohibited actions should be explicitly stated; required repair of damages should be prescribed as well. Other common components of a contractor work plan (discussed in Section 10.7.2, also see Table 10.8) include access, mobilization, and demobilization plans; a spill prevention plan; invasive species control plans; and a communication plan.

\subsubsection{Earthwork in Wetland Environments}

Wetland sites by their nature are likely to be low lying, formed of sediments with poor load-bearing capacity, and waterlogged or subject to periodic tidal inundation. Such conditions may require the use of specialist long-reach excavators and tracked vehicles. In some scenarios, amphibious excavators may be needed. Low- and ultra-low ground-pressure equipment may be specified at sites with low weight-bearing capacity. Restrictions on travel pathways and the number of transits across one location may also be necessary. Wherever possible, the preference would be for construction work to take place in the dry (e.g., behind an existing defense levee before it is removed) rather than in a tidal environment. For some projects, it may be necessary to use marine-based equipment such as jack-up barges, barge-based excavators, or split-bottom barges to deliver sediment.

Of critical importance to wetland design is creation of the correct elevations relative to the local tidal frame to produce the proper hydroperiod. Wetland design may also involve breaching existing structural measures such as levees to allow tidal waters into the project area and the creation of channels to allow the area to flood and drain. Areas outside of channels may need to be graded toward creeks to improve drainage or to form low depressions or low mounds to facilitate habitat heterogeneity. GPS controlled planting can be used to ensure design specifications are met.

Some projects may involve raising site elevations. New material may be delivered by rail or road, but many wetland restoration projects involve the placement of dredged material. Dredged material may be placed in several ways, including mechanical placement (e.g., where dredged material is placed from clamshell dredgers) or pumping (e.g., where sediment is moved by a cutterhead hydraulic dredging operation). Fine-grained, muddy sediments require some sort of semipermanent or permanent perimeter structure such as containment cells or baffles to contain the sediments while the wetland substrate dewaters and consolidates. 
Containment cells may be created from earthen levees constructed from well-consolidated, on-site borrow material or, in some cases, from biodegradable materials such as straw bales. Baffles may be created from brushwood panels, or specialized spreaders can be used to slow and distribute the slurry as it exits the pipeline. Confining the site too tightly during construction, however, can interfere with site dewatering and increase costs.

Given the importance of achieving the correct elevations for vegetation development, it is important to consider sediment settlement processes and the requirement for repeated phases of sediment placement. Several lessons learned can be gleaned from past studies of constructed or restored wetlands (e.g., Coastal America 1996; Mohan 2001; Mohan and Palermo 1998; Mohan and Urso 1997). For mechanically placed sediment, it may be necessary to regrade the material to ensure the correct site topography. For some intertidal marsh projects, overcompaction of sediments, due to either past agricultural practices or the use of heavy equipment during construction, can impede future sediment drainage and vegetation establishment. Ways to avoid this include the use of low-ground-pressure equipment, temporary haul roads, or deep ploughing of sediments after construction.

\subsubsection{Wetland Planting Considerations}

Planting plans are frequently included as part of wetland specifications; however, not all sites require planting nor are they ready for planting immediately after construction concludes. If planting is required or desired, the condition of the site should dictate when planting should occur, especially when dredged sediments are used. Such sediments require time to consolidate and equilibrate with the new environmental conditions before plants can successfully establish.

Sites with a high risk of erosion may require temporary cover to prevent erosion and sediment losses. That can be accomplished by seeding a fast-growing annual species (preferably a native species adapted to wetland conditions) or by covering the site with a biodegradable material such as straw or coir geotextile. If the project contains new levees, they will need to be constructed early enough to stabilize and vegetate before being subject to tidal conditions.

Seed mixes are commercially available for many areas of the world, or seeds may be harvested locally from surrounding habitats. If plant stock is to be used, best practice is to inspect plant materials upon delivery for species correctness, local genotype, vigor or disease, and proper planting number so that only acceptable stock are planted. Seedlings should be sufficiently acclimated (sometimes referred to as hardening off) to the conditions, including salinity, in which they are to be planted to minimize mortality. 


\subsubsection{Construction of Structural Elements}

As noted in Section 10.6.7, wetland NNBF projects may include structural elements (e.g., revetments or levees). The construction of these elements is well covered in existing literature (e.g., USACE 1984; USACE 2002; CIRIA, CUR, and CETMEF 2007; CIRIA 2013) and will not be repeated here. However, the design specification should explicitly state how the wetland and structure will interface and the order in which work should proceed.

\section{8 | Monitoring, Maintenance, Evaluation, and Adaptive Management}

Post-construction monitoring and maintenance are required to assess whether project objectives are being met and to facilitate evaluation of the need for corrective action when objectives are not achieved. Adaptive management of coastal wetland NNBF is required to ensure they are performing as designed (see Chapter 7).

In NNBF designs that incorporate structural elements for wave protection or water control (e.g., flood gates, weirs, breakwaters), those structures must be periodically inspected and maintained as they would in any other location. For wetlands suffering from chronic sediment deficits, routine maintenance may require periodic nourishment through thin-layer placement of sediment. Use of coastal wetlands as part of an FRM system may require repair of damages caused by storms if natural recovery processes are expected to be too slow.

Because each NNBF wetland is uniquely tailored to its site and desired project goals, there is no one-size-fits-all maintenance and monitoring plan. The six steps of a well-designed adaptive management program (plan, design, build, monitor, evaluate, and adapt) are described in detail in Chapter 7 . We focus here on general guidelines for monitoring and maintenance, evaluation, and adaptative management of wetland systems used as part of a nature-based FRM plan or scheme.

\subsubsection{Monitoring and Maintenance}

A monitoring plan designed to detect changes in the site over time is necessary to ensure the NNBF continues to produce the desired management benefits as the site matures. Although many sources exist for general wetland monitoring protocols (Neckles et al. 2002; Baldwin, Barendregt, and Whigham 2009; Buchsbaum and Wigand 2012; Zhao et al. 2016, among others), monitoring wetlands for NNBF performance should focus on aspects of the wetland that contribute to the stated project objectives and be used to inform the performance 
metrics developed as part of the design. Consequently, wetland NNBF monitoring should be constrained compared to the typical monitoring protocols set up for wetland restoration. However, some ecological parameters should still be monitored for all wetland NNBF projects-even those implemented primarily for FRM benefits because FRM performance relies on maintenance of healthy vegetation.

Table 10.9 presents a simple set of potential monitoring parameters and metrics to assess wetland NNBF performance. At a minimum, the monitoring plan should evaluate the geomorphology and condition of the vegetative community because these are the core characteristics that influence a wetland's ability to manage flood risk. The secondary measures are not directly related to a site's performance in flood and erosion control, but they are key drivers of success of the vegetative community and are, therefore, valuable for evaluating overall site performance and for selecting appropriate adaptation strategies when core performance criteria are not being met.

Table 10.9. Performance Criteria for Wetland NNBF

\begin{tabular}{|c|c|c|c|c|}
\hline \multicolumn{2}{|c|}{ Types of measures } & $\begin{array}{l}\text { Monitoring } \\
\text { parameters }\end{array}$ & $\begin{array}{c}\text { Example monitoring } \\
\text { metrics }\end{array}$ & $\begin{array}{c}\text { Example } \\
\text { monitoring criteria }\end{array}$ \\
\hline \multirow[t]{7}{*}{$\begin{array}{l}\text { Core } \\
\text { measures }\end{array}$} & \multirow[t]{5}{*}{ Geomorphology } & $\begin{array}{l}\text { - Spatial } \\
\text { area and } \\
\text { configuration }\end{array}$ & $\begin{array}{l}\text { Total wetland length } \\
\text { perpendicular to } \\
\text { shoreline }\end{array}$ & $\begin{array}{l}\text { - Should exceed } \\
\text { minimum acceptable } \\
\text { design criteria. }\end{array}$ \\
\hline & & $\begin{array}{l}\text { - Creek and } \\
\text { panne area } \\
\text {. Flevation }\end{array}$ & $\begin{array}{l}\text { Ratio of unvegetated } \\
\text { to vegetated wetland } \\
\text { surface }\end{array}$ & \multirow{4}{*}{$\begin{array}{l}\text { - Should be stable or } \\
\text { decreasing relative to } \\
\text { reference sites. } \\
\text { - Should be stable or } \\
\text { changing at a rate } \\
\text { commensurate with } \\
\text { local change in sea } \\
\text { level. } \\
\text { - Should be stable or } \\
\text { aggrading. }\end{array}$} \\
\hline & & \multirow[t]{3}{*}{$\begin{array}{l}\text { Shoreline } \\
\text { position }\end{array}$} & $\begin{array}{l}\text { Elevation of wetland } \\
\text { surface relative to } \\
\text { defined datum }\end{array}$ & \\
\hline & & & \multirow[t]{2}{*}{$\begin{array}{l}\text { - Change in position over } \\
\text { time }\end{array}$} & \\
\hline & & & & \\
\hline & Vegetation & $\begin{array}{l}\text { - Abundance } \\
\text { - Structure }\end{array}$ & $\begin{array}{l}\text { - Aboveground biomass } \\
\text { or percent cover }\end{array}$ & \multirow{2}{*}{$\begin{array}{l}\text { Biomass should be } \\
\text { similar to reference } \\
\text { sites of same } \\
\text { elevation relative to } \\
\text { tide. }\end{array}$} \\
\hline & & - Structure & $\begin{array}{l}\text { Stem and tree density } \\
\text { and height }\end{array}$ & \\
\hline
\end{tabular}




\begin{tabular}{|c|c|c|c|c|}
\hline \multicolumn{2}{|c|}{ Types of measures } & $\begin{array}{l}\text { Monitoring } \\
\text { parameters }\end{array}$ & $\begin{array}{c}\text { Example monitoring } \\
\text { metrics }\end{array}$ & $\begin{array}{c}\text { Example } \\
\text { monitoring criteria }\end{array}$ \\
\hline \multirow[t]{4}{*}{$\begin{array}{l}\text { Secondary } \\
\text { measures }\end{array}$} & Hydrology & $\begin{array}{l}\text { - Water levels at } \\
\text { project site }\end{array}$ & $\begin{array}{l}\text { Proportion of time } \\
\text { inundated }\end{array}$ & $\begin{array}{l}\text { Inundation trends } \\
\text { should match those } \\
\text { required by the } \\
\text { desired vegetative } \\
\text { community. }\end{array}$ \\
\hline & $\begin{array}{l}\text { Soil physical } \\
\text { properties }\end{array}$ & $\begin{array}{l}\text { - Texture and } \\
\text { structure }\end{array}$ & $\begin{array}{l}\text { Bulk density, grain } \\
\text { size, percent organic } \\
\text { content }\end{array}$ & *See note below. \\
\hline & $\begin{array}{l}\text { Soil } \\
\text { biogeochemical } \\
\text { properties }\end{array}$ & $\begin{array}{l}\text { - Porewater } \\
\text { chemistry } \\
\text { - Nutrient } \\
\text { availability }\end{array}$ & $\begin{array}{l}\text { - Salinity, sulfide, } \mathrm{pH} \\
\text { - Inorganic nutrients }\end{array}$ & *See note below. \\
\hline & Vegetation & - Abundance & $\begin{array}{l}\text { Belowground biomass, } \\
\text { rooting depth }\end{array}$ & $\begin{array}{l}\text { Biomass should be } \\
\text { similar to reference } \\
\text { sites of same relative } \\
\text { elevation within tide } \\
\text { frames. }\end{array}$ \\
\hline \multirow[t]{4}{*}{$\begin{array}{l}\text { Co-benefit } \\
\text { measures }\end{array}$} & $\begin{array}{l}\text { Biotic use } \\
\text { (Ecological) }\end{array}$ & $\begin{array}{l}\text { - Benthic } \\
\text { abundance }\end{array}$ & - Biomass of infauna & $\begin{array}{l}\text { Biomass should be } \\
\text { similar to reference } \\
\text { sites. }\end{array}$ \\
\hline & $\begin{array}{l}\text { Vegetation } \\
\text { (Ecological) }\end{array}$ & - Diversity & $\begin{array}{l}\text { - Simpson's biodiversity } \\
\text { index }\end{array}$ & $\begin{array}{l}\text { Diversity should be } \\
\text { similar to reference } \\
\text { sites. }\end{array}$ \\
\hline & $\begin{array}{l}\text { Recreation } \\
\text { (Social) }\end{array}$ & - Visitor use & $\begin{array}{l}\text { - Number of visitors per } \\
\text { month }\end{array}$ & $\begin{array}{l}\text { Increase from number } \\
\text { of pre-project visitors } \\
\text { per month. }\end{array}$ \\
\hline & $\begin{array}{l}\text { Fishery value } \\
\text { (Economic) }\end{array}$ & $\begin{array}{l}\text { - Shrimp } \\
\text { production }\end{array}$ & $\begin{array}{l}\text { Salt marsh edge } \\
\text { area (as proxy for } \\
\text { production) }\end{array}$ & $\begin{array}{l}\text { Increase salt marsh } \\
\text { edge area by } 25 \% \text {. }\end{array}$ \\
\hline
\end{tabular}

Note: *No specific performance criteria are associated with these factors; rather, they are valuable as diagnostics of vegetative community performance. For example, high sulfide concentrations, $\mathrm{pH}$ values less than 5.8 or greater than 7.5, and low organic matter content are all indicators of nutrient limitation, which may inhibit plant growth. Fine-textured soils or those with very high organic matter content may have limited porewater exchange capacity, which can result in poor vegetative growth.

The frequency and timing of monitoring should consider both the time frames over which parameters are likely to change and the expected seasonal cycles in parameter response. Vegetative structure, for example, is not likely to change rapidly so annual monitoring is likely sufficient, but because vegetative characteristics tend to change dramatically over the course of a growing season, it is important to schedule annual monitoring of vegetation for the same time each year. Wetland performance during extreme events is critical to evaluating the success of the wetland as an NNBF measure; therefore, monitoring plans will require some flexibility to be able to capture the feature's performance during these stochastic events, as well as under everyday conditions. 


\subsubsection{Evaluation}

As discussed in Chapter 5 , performance may be evaluated directly, indirectly, or computationally, and the method used to evaluate performance will determine the monitoring parameters. For wetlands, direct measurement of shoreline erosion is relatively simple and can be easily conducted through periodic field or remote-sensing measurements. Direct measurements of surge attenuation, however, are not appropriate because (1) surge water levels vary from storm to storm, (2) changes in water levels before and after project implementation cannot be easily attributed to the project construction, and (3) the greatest magnitude design storm events may not occur during a project's life span. Instead, computational methods are preferred, so the monitoring plan should measure the parameters relevant to the simulation of the wetland effects in the hydrodynamic model, such as wetland size, shape, and vegetation structure. If performance is evaluated indirectly, the monitoring parameters selected will be simple measurements that are related to or correlate with the identified performance metric. For example, the aboveground abundance of wetland vegetation can be measured as a simple estimate of percent cover because previous studies have indicated that vegetation density is positively correlated with wave-attenuation capacity.

Performance criteria should be temporally explicit, acknowledging that coastal wetlands that have undergone extensive restoration or were recently created will not be capable of achieving performance criteria immediately after construction. It may take several years for the vegetative community to develop the characteristics of the reference site, so not meeting these objectives in the early years may not be a reason to take adaptive actions as long as the metric in question appears to be on an acceptable trajectory. Likewise, an existing wetland that is squeezed between rising seas and a permanent structure may not be able to meet the same performance criteria late in the project life span.

\subsubsection{Adaptive Management}

The complexity and uniqueness of each project site coupled with uncertainty regarding future conditions (e.g., sea level) may require reassessment of the initial design and possible adjustments or modifications to the site over time. Although potential modifications to design due to unknown future conditions are not unique to coastal wetlands or NNBF in general, modifications to wetland NNBF can be comparatively simpler and potentially cheaper than modifications to structural measure design. 
Adaptation measures or interventions should be implemented only if the evaluation of the wetland reveals with a reasonable degree of certainty the cause of the lack of performance. Because wetlands are naturally dynamic, change is not only expected but also desired. However, some changes may exceed the capacity of the wetland to naturally adapt, or the trajectory of change over multiple monitoring cycles may indicate the wetland may soon be unable to provide the required level of performance and continue to meet the project objectives. Therefore, temporary environmental impacts due to disturbances such as drought, storm damage, or ice rafting, among others, can cause poor vigor in wetland vegetation, but they should not warrant adaptive management actions unless the poor condition persists.

Monitoring metrics, such as vegetation cover, that may be highly variable across time and space should not trigger adaptation measures unless the metrics do not meet performance criteria over large areas of the wetland or for several monitoring events. For unexplained poor ecological performance, the adaptive management action may be more robust monitoring and evaluation to determine the cause of the decline. However, if a critical aspect of wetland performance, such as marsh elevation, is found to be significantly different from the intended range, even for a single monitoring event, an immediate adaptive action may be required because proper elevation is fundamental to vegetative community establishment.

In situations caused by changes in a wetland enabling environmental conditions, such as wave climate and hydroperiod, adaptation measures should directly address ameliorating these conditions if possible. Under accelerating sea-level rise rates, maintenance of coastal wetlands may not be feasible in some locations, so adaptive management plans may require provisions for allowing landward migration of wetland features through the acquisition of adjacent uplands combined with removal or relocation of structural defenses. In areas where upland migration is blocked, some wetland projects may have provisions for replacing the FRM function provided by the wetland by the addition of additional structural measures once the wetland's condition deteriorates to a point where it cannot be mitigated.

\section{9 | Gaps and Future Directions}

Although the number of studies of wetland NNBF benefits and implementation examples is growing, some questions still remain. These issues are not insurmountable and should not preclude consideration of wetlands as part of a comprehensive FRM approach. However, use of wetland NNBF should consider how these knowledge gaps may affect the project and whether robust adaptive management can be used to minimize residual risk from these knowledge gaps. 
More field and modeling studies should address the long-term stability and, thus, the cost-effectiveness of restoration projects compared to other nonstructural and structural measures. Monitoring of wetland restoration projects typically focuses on ecological outcomes, which provides little data on how effectively wetlands deliver FRM benefits and often stops at the conclusion of initial funding or when regulatory requirements are met. When projects are monitored and results reported, frequently only successful results are highlighted, limiting the ability to synthesize guidance from lessons learned. Most long-term work has been conducted on near-pristine wetlands such as National Estuarine Research Reserves and Long-Term Ecological Research sites in the United States and equivalent sites in Europe, with limited consideration of wetland response during and immediately after storms. More long-term monitoring of natural and restored wetland sites will help practitioners understand the natural variation in and sustainability of wetland NNBF performance and how restored and created wetland sites respond to changes in environmental conditions. Responses may be positive (e.g., adaptability) or negative (e.g., pollution).

\section{Future studies should use a consistent cost-benefit framework that accounts for the full array of benefits, co-benefits, and life-cycle costs so studies can be compared and replicated. Although there are many rigorous assessments of the benefits of wetlands in reducing damages, few studies systematically evaluate NNBF side by side other engineering alternatives, such as seawalls, breakwaters, and levees. The uncertainties associated with estimates of the costs and benefits of wetland NNBF, as well as structural and nonstructural measures, should also be clearly communicated so practitioners can more easily assess whether wetland NNBF can reliably and cost-effectively provide the required FRM benefits at a particular site.}

Costs should also be better categorized so they can be better used in economic models because creation, opportunity, and maintenance costs are accounted for very differently. Although there is substantial information on the costs of wetland restoration, most projects combine multiple objectives and, as such, are difficult to evaluate purely in terms of coastal protection benefits. Despite some large-scale estimates of the overall value of wetlands for coastal protection, relatively few studies document the costs and benefits of specific NNBF projects at a level of detail required for developing wetland NNBF cost estimates (Barbier 2007; Pontee et al. 2016).

These limitations apply to a number of NNBF (see $\underline{\text { Chapter } 6}$ for more information).

The knowledge base of wetland NNBF performance should be further developed so potential efficacy of wetland NNBF projects under different conditions can be better understood. Determining the appropriate size and location of a wetland NNBF project required to achieve the desired benefits and co-benefits are difficult to determine without dedicated computational modeling. Because the characteristics of storms and the 
site-specific characteristics of wetlands strongly control their performance with respect to FRM, available wetland NNBF performance data reveal considerable variation in reported efficacy, so determining whether wetland NNBF are viable options at a site can be difficult at early project stages.

\section{Methods and tools are needed to quantify the system-scale benefits and co-benefits of wetland NNBF and the linkages between wetland NNBF and other measures.}

Understanding how benefits and co-benefits of individual wetland NNBF projects scale to larger system benefits can be challenging, so it is often neglected in cost-benefit analyses. The reverse is also true with respect to adverse impacts at project scales; the system-wide changes caused by shoreline hardening may not be accounted for at the scale of an individual project, so any avoided impacts from implementation of a wetland NNBF may be similarly neglected. The same approach, including the inclusion of co-benefits, should be applied to both wetland NNBF and structural measures so NNBF and structural measures are evaluated using equivalent analyses.

Wetland NNBF also act in concert with other NNBF and structural measures in the system, potentially enhancing production of benefits and co-benefits. The linkages with other NNBF affect the performance of wetland NNBF and the ability of coastal wetlands to adapt in the face of changing coastal environments. Cost-benefit analysis methods should include mechanisms to capture the value of the interconnectedness between coastal wetlands and other NNBF.

\section{Improvements in the implementation of coastal wetlands in hydrodynamic models are needed to more accurately and efficiently include wetland NNBF in modeling scenarios.} Although wetland NNBF have been incorporated into many hydrodynamic models and models used by the insurance industry, current implementations do not optimally represent the frictional effects from wetland vegetation, and they neglect vegetation growth, aging, stem breakage, uprooting, and erosion dynamics. Dozens of vegetation drag coefficient formulations are presented in the literature and may produce very different results depending on the parameterization. A consensus approach is needed to determine how best to formulate and parameterize vegetation frictional effects for both marsh and mangrove systems. Models should also include mechanisms to simulate during-storm processes such as stem breakage, uprooting, erosion, and scour, and to incorporate long-term changes in wetlands so storm response can be understood under possible future conditions. Despite the shortcomings of wetland modeling formulations, existing models can easily be improved incrementally as more pilot studies and monitoring efforts focus on wetland ecohydraulics. Data collection efforts should be informed by the needs of the modeling community for better data related to wetland biophysical processes. 


\section{9 | References}

adcirc.org. n.d. ADCIRC. https://adcirc.org/.

Airoldi, L., and M. W. Beck. 2007. “Loss, Status and Trends for Coastal Marine Habitats of Europe." Oceanography and Marine Biology: An Annual Review 45: 345-405.

Alizad, K., S. C. Hagen, J. T. Morris, P. Bacopoulos, M. V. Bilskie, J. F. Weishampel, and S. C. Medeiros. 2016. "A Coupled, Two-Dimensional Hydrodynamic-Marsh Model with Biological Feedback." Ecological Modelling 327: 29-43.

Alongi, D. M. 2014. "Carbon Cycling and Storage in Mangrove Forests." Annual Review of Marine Science 6: 195-219.

Anderson, M. G., and A. Barnett. 2017. Resilient Coastal Sites for Conservation in the Northeast and Mid-Atlantic U.S. Arlington, VA: The Nature Conservancy, Eastern Conservation Science.

Armanini, A., M. Righetti, and P. Grisenti. 2005. "Direct Measurement of Vegetation Resistance in Prototype Scale." Journal of Hydraulic Research 43 (5): 481-487.

Atkinson, S. C., S. D. Jupiter, V. M. Adams, J. C. Ingram, S. Narayan, C. J. Klein, and H. P. Possingham. 2016. "Prioritising Mangrove Ecosystem Services Results in Spatially Variable Management Priorities." PLOS ONE 11 (3): e0151992. https://journals.plos.org/ plosone/article?id=10.1371/journal.pone.0151992.

Bandaranayake, W. M. 1998. "Traditional and Medicinal Use of Mangroves." Mangroves and Salt Marshes 2 (3): 133-148.

Bao, T. Q. 2011. Effect of Mangrove Forest Structures on Wave Attenuation in Coastal Vietnam. Oceanologia 53 (3): 807-818.

Baldwin, A. H., A. Barendregt, and D. F. Whigham. 2009. “Tidal Freshwater Wetlands: An Introduction to the Ecosystem." In Tidal Freshwater Wetlands. Leiden: Backhuys Publishers.

Baptist, M. J., T. Gerkema, B. C. van Prooijen, D. S. van Maren, M. van Regteren, K. Schulz, I. Colosimo, et al. 2019. "Beneficial Use of Dredged Sediment to Enhance Salt Marsh Development by Applying a 'Mud Motor.'" Ecological Engineering 127: 312-323.

Barbier, E. B. 1994. "Valuing Environmental Functions: Tropical Wetlands." Land Economics 70 (2): 155-173.

Barbier, E. B. 2007. "Valuing Ecosystem Services as Productive Inputs." Economic Policy 22 (49): 178-229.

Barbier, E. B. 2011. “Wetlands as Natural Assets." Hydrological Sciences Journal 56 (8): 13601373. 
Barbier, E. B., I. Y. Georgiou, B. Enchelmeyer, and D. J. Reed. 2013. "The Value of Wetlands in Protecting Southeast Louisiana from Hurricane Storm Surges." PLOS ONE 8 (3): e58715.

Barr, J. G., V. Engel, T. J. Smith, and J. D. Fuentes. 2012. “Hurricane Disturbance and Recovery of Energy Balance, $\mathrm{CO} 2$ Fluxes and Canopy Structure in a Mangrove Forest of the Florida Everglades." Agricultural and Forest Meteorology 153: 54-66. https:// digitalcommons.unl.edu/cgi/viewcontent.cgi?article=1921\&context=usgsstaffpub.

Battalio B., M. Holmes, and J. Lowe. 2013. "Up or Out? The Laid Back Levee." Estuary News 22 (2): 10. https://www.sfestuary.org/wp-content/uploads/2013/03/EstApr2013FINALweb.pdf.

Bayas, J. C. L., C. Marohn, G. Dercon, S. Dewi, P. H. Piepho, L. Joshi, M. Noordwijk, and G. Cadisch. 2011. "Influence of Coastal Vegetation on the 2004 Tsunami Wave Impact in West Aceh." In Proceedings of the National Academy of Sciences USA 108 (46): $18612-18617$.

Bayraktarov, E., M. I. Saunders, S. Abdullah, M. Mills, J. Beher, H. P. Possingham, P. J. Mumby, and C. E. Lovelock. 2016. "The Cost and Feasibility of Marine Coastal Restoration." Ecological Applications 26 (4): 1055-1074.

Best, Ü., M. Van der Wegen, J. Dijkstra, P. W. J. M. Willemsen, B. W. Borsje, and D. J. A. Roelvink. 2018. "Do Salt Marshes Survive Sea Level Rise? Modelling Wave Action, Morphodynamics and Vegetation Dynamics." Environmental Modelling and Software 109: 152-166.

Beudin, A., T. S. Kalra, N. K. Ganju, and J. C. Warner. 2017. “Development of a Coupled WaveFlow-Vegetation Interaction Model." Computers \& Geosciences 100: 76-86. https:// www.sciencedirect.com/science/article/pii/S0098300416308184.

Bilkovic, D. M., M. M. Mitchell, M. K. La Peyre, and J. D. Toft, eds. 2017. Living Shorelines: The Science and Management of Nature-Based Coastal Protection. 1st ed. New York: CRC Press.

Bolte, P., F. Barnaby, M. Rahmadana, and N. Cuc. 2011. Planting Projection: Evaluation of Community-Based Mangrove Reforestation and Disaster Preparedness Programme, 2006-2010. Geneva: International Federation of Red Cross and Red Crescent Societies. https://www.ifrc.org/docs/Appeals/annual11/MAAVN00111myr-PlantingProtection-April-2011-EN.pdf.

Bouma, T. J., J. van Belzen, T. Balke, Z. Zhu, L. Airoldi, A. J. Blight, A. J. Davies, et al. 2014. "Identifying Knowledge Gaps Hampering Application of Intertidal Habitats in Coastal Protection: Opportunities and Steps to Take." Coastal Engineering 87: 147-157.

Bouma, T. J., M. B. De Vries, and P. M. J. Herman. 2010. “Comparing Ecosystem Engineering Efficiency of Two Plant Species with Contrasting Growth Strategies." Ecology 91 (9): 2696-2704. 
Bouma, T. J., J. van Belzen, T. Balke, J. van Dalen, P. Klaassen, A. M. Hartog, D. P. Callaghan, et al. 2016. "Short-Term Mudflat Dynamics Drive Long-Term Cyclic Salt Marsh Dynamics." Limnology and Oceanography 61 (6): 2261-2275.

Breaux, A., S. Farber, and J. Day. 1995. "Using Natural Coastal Wetlands Systems for Wastewater Treatment: An Economic Benefit Analysis." Journal of Environmental Management 44 (3): 285-291.

Brinkman, R. M. 2006. "Wave Attenuation in Mangrove Forests: An Investigation Through Field and Theoretical Studies." PhD diss., James Cook University.

Bromberg, K. D., and M. D. Bertness. 2005. "Reconstructing New England Salt Marsh Losses Using Historical Maps." Estuaries 28: 823-832.

Broome, S. W., C. B. Craft, and M. R. Burchell. 2019. "Tidal Marsh Creation." In Coastal Wetlands. Edited by G. M. E. Perillo, E. Wolanski, D. R. Cahoon, and C. S. Hopkinson. Amsterdam: Elsevier.

Buchsbaum, R. N., and C. Wigand. 2012. "Adaptive Management and Monitoring as Fundamental Tools to Effective Salt Marsh Restoration." In Tidal Marsh Restoration: A Synthesis of Science and Management. Edited by C. T. Roman and D. M. Burdick. New York: Springer, 213-231.

Cali, M., A. Parsons, L. Batty, S. Duggan, P. Miller, N. Pontee, and P. Miller. 2008. “Managing Coastal Change: Walberswick to Dunwich." Paper presented at FLOODrisk 2008: The European Conference on Flood Risk Management Research into Practice, Oxford, UK, October 2008.

Campbell, A., Y. Wang, M. Christiano, and S. Stevens. 2017. "Salt Marsh Monitoring in Jamaica Bay, New York, from 2003 to 2013: A Decade of Change from Restoration to Hurricane Sandy." Remote Sensing 9 (2): 131.

climate-adapt.eea.europa.eu. 2016. A Transboundary Depoldered Area for Flood Protection and Nature: Hedwige and Prosper Polders. Climate Adapt. https://climate-adapt.eea. europa.eu/metadata/case-studies/a-transboundary-depoldered-area-for-floodprotection-and-nature-hedwige-and-prosper-polders.

Chung, C.-H. 2006. "Forty Years of Ecological Engineering with Spartina Plantations in China." Ecological Engineering 27 (1): 49-57.

CIRIA, CUR, and CETMEF (Construction Industry Research and Information Association; the Netherlands Centre for Civil Engineering Research and Codes; and Centre d'Etudes Techniques Maritimes et Fluviales). 2007. The Rock Manual: The Use of Rock in Hydraulic Engineering. Second Edition. Report C683. London: CIRIA.

CIRIA (Construction Industry Research and Information Association). 2013. The International Levee Handbook. Report C731. London: CIRIA.

City of Richmond. 2019. Flood Protection Management Strategy 2019 - Public and Stakeholder Engagement. Richmond, CA: City of Richmond. https://www.richmond.ca/__shared/ assets/19_Flood_Protection_Management_Strategy_CNCL_03251953137.pdf. 
coast.noaa.gov. 2020. Sea Level Affecting Mashes Model. NOAA Office for Coastal Management. https://coast.noaa.gov/digitalcoast/tools/slamm.html.

Coastal America. 1996. Coastal Restoration and Protection - Lessons Learned. Technology Transfer Report. Silver Spring, MD: Coastal America.

Coastal Protection and Restoration Authority. 2017. Marsh Creation Design Guidelines. Report Version MCDG1.0. Baton Rouge, LA: Coastal Protection and Restoration Authority.

Colgan, C. S. 2017. "The Blue Economy of the Indian Ocean: Context and Challenge." Journal of Indian Ocean Rim Studies 1: 7-37.

Costanza, R., O. Perez-Maqueo, M. L. Martinez, P. Sutton, S. J. Anderson, and K. Mulder. 2008. "The Value of Coastal Wetlands for Hurricane Protection." Ambio 37 (4): 241-248.

Cunniff, S., and A. Schwartz. 2015. Performance of Natural Infrastructure and Nature-Based Measures as Coastal Risk Reduction Features. New York: Environmental Defense Fund.

Currin, C. A., W. S. Chappell, and A. Deaton. 2010. “Developing Alternative Shoreline Armoring Strategies: The Living Shoreline Approach in North Carolina." In Puget Sound Shorelines and the Impacts of Armoring - Proceedings of a State of the Science Workshop. Edited by H. Shipman, M. N. Dethier, G. Gelfenbaum, K. L. Fresh, and R. S. Dinicola. U.S. Geological Survey Scientific Investigations Report 2010-5254. Reston, VA: U.S. Geological Survey.

Currin, C. 2012. Impact of Hurricane Irene on Pivers Island Shorelines. Washington, DC: NOAA Center for Coastal Fisheries and Habitat Research. https://files.nc.gov/ncdeq/ document-library/HurricanelmpactsPiverslsland.pdf.

Currin, C., J. Davis, L. C. Baron, A. Malhotra, and M. Fonseca. 2015. "Shoreline Change in the New River Estuary, North Carolina: Rates and Consequences." Journal of Coastal Research 31 (5): 1069-1077.

Currin, C. A., J. Davis, and A. Malhotra. 2017. "Response of Salt Marshes to Wave Energy Provides Guidance for Successful Living Shoreline Implementation." Living Shorelines: The Science and Management of Nature-Based Coastal Protection. Oxfordshire, UK: CRC Press, Taylor \& Francis Group.

Das, S., and J. R. Vincent. 2009. "Mangroves Protected Villages and Reduced Death Toll during Indian Super Cyclone." Proceedings of the National Academy of Sciences 106 (18): 7357-7360.

Dasgupta, S., M. S. Islam, M. Huq, Z. Huque Khan, and M. R. Hasib. 2019. "Quantifying the Protective Capacity of Mangroves from Storm Surges in Coastal Bangladesh." PLOS ONE 14 (3): e0214079.

Davis, J. L., C. A. Currin, C. O'Brien, C. Raffenburg, and A. Davis. 2015. “Living Shorelines: Coastal Resilience with a Blue Carbon Benefit." PLOS ONE 10 (11): e0142595. 
Davis, J., C. Currin, and J. T. Morris. 2017. "Impacts of Fertilization and Tidal Inundation on Elevation Change in Microtidal, Low Relief Salt Marshes." Estuaries and Coasts 40 (6): 1677-1687.

Day, J. W., G. P. Kemp, D. J. Reed, D. R. Cahoon, R. M. Boumans, J. M. Suhayda, and R. Gambrell. 2011. "Vegetation Death and Rapid Loss of Surface Elevation in Two Contrasting Mississippi Delta Salt Marshes: The Role of Sedimentation, Autocompaction and SeaLevel Rise." Ecological Engineering 37 (2): 229-240.

Deegan, L. A., D. S. Johnson, R. S. Warren, B. J. Peterson, J. W. Fleeger, S. Fagherazzi, and W. M. Wollheim. 2010. "Coastal Eutrophication as a Driver of Salt Marsh Loss." Nature 490 (7420): 388-392.

Donatelli, C., N. K. Ganju, X. Zhang, S. Fagherazzi, and N. Leonardi. 2018. “Salt Marsh Loss Affects Tides and the Sediment Budget in Shallow Bays." Journal of Geophysical Research: Earth Surface 123 (10): 2647-2662.

Doody, J. P. 2013. “Coastal Squeeze and Managed Realignment in Southeast England: Does It Tell Us Anything about the Future?" Ocean and Coastal Management 79: 34-41.

Doughty, C. L., J. A. Langley, W. S. Walker, I. C. Feller, R. Schaub, and S. K. Chapman. 2015. "Mangrove Range Expansion Rapidly Increases Coastal Wetland Carbon Storage." Estuaries and Coasts 39: 385-396.

Duvall, M. S., P. L. Wiberg, and M. L. Kirwan. 2019. “Controls on Sediment Suspension, Flux, and Marsh Deposition near a Bay-Marsh Boundary." Estuaries and Coasts 42 (2): 403-424.

ecoshape.org. 2019. Living Lab for Mud. EcoShape. https://www.ecoshape.org/en/projects/ living-lab-mud/.

Edwards, P. E. T., A. E. Sutton-Grier, and G. E. Coyle. 2013. "Investing in Nature: Restoring Coastal Habitat Blue Infrastructure and Green Job Creation." Marine Policy 38: 65-71.

EEA (European Environment Agency). 2018. Climate-ADAPT 10 Case Studies: How Europe Is Adapting to Climate Change. Luxembourg: Publications Office of the European Union. https://climate-adapt.eea.europa.eu/about/climate-adapt-10-case-studies-online. pdf.

Enwright, N. M., K. T. Griffith, and M. J. Osland. 2016. “Barriers to and Opportunities for Landward Migration of Coastal Wetlands with Sea-Level Rise." Frontiers in Ecology and the Environment 14 (6): 307-316.

ESA PWA (Environmental Science Associates and Philp Williams \& Associates). 2013. Analysis of the Costs and Benefit of Using Tidal Marsh Restoration as a Sea Level Rise Adaptation Strategy in San Francisco Bay. Report prepared for The Bay Institute. San Francisco, CA: ESA PWA.

Feagin, R. A., S. M. Lozada-Bernard, T. M. Ravens, I. Möller, K. M. Yeager, and A. H. Baird. 2009. "Does Vegetation Prevent Wave Erosion of Salt Marsh Edges?" Proceedings of the National Academy of Sciences 106 (25): 10109-10113. 
fengyashi.github.io. 2019. FUNWAVE-TVD. FUNWAVE. https://fengyanshi.github.io/.

Forysinski, K. 2019. "Nature-Based Flood Protection: The Contribution of Tidal Marsh Vegetation to Wave Attenuation at Sturgeon Bank." Master's thesis, University of British Columbia.

Ganju, N. K. 2019. “Marshes are the New Beaches: Integrating Sediment Transport into Restoration Planning." Estuaries and Coasts 42 (4): 917-926.

Garzon, J. L., M. Maza, C. M. Ferreira, J. L. Lara, and I. J. Losada. 2019. “Wave Attenuation by Spartina Saltmarshes in the Chesapeake Bay under Storm Surge Conditions." Journal of Geophysical Research: Oceans 124 (7): 5220-5243.

Gedan, K. B., M. L. Kirwan, E. Wolanski, E. B. Barbier, and B. R. Silliman. 2011. “The Present and Future Role of Coastal Wetland Vegetation in Protecting Shorelines: Answering Recent Challenges to the Paradigm." Climatic Change 106 (1): 7-29.

Gehrels, W. R. 2000. “Using Foraminiferal Transfers Functions to Produce High-Resolution SeaLevel Records from Salt-Marsh Deposits, Maine, USA." The Holocene 10 (3): 367-376.

Gittman, R. K., A. M. Popowich, J. F. Bruno, and C. H. Peterson. 2014. “Marshes with and without Sills Protect Estuarine Shorelines from Erosion Better than Bulkheads during a Category 1 Hurricane." Ocean Coast Management 102 (A): 94-102.

Heatherington, C., and M. J. Bishop. 2012. "Spatial Variation in the Structure of Mangrove Forests with Respect to Seawalls." Marine and Freshwater Research 63 (10): 926-933.

hec.usace.army.mil. n.d. HEC-RAS. U.S. Army Corps of Engineers Hydrologic Engineering Center. https://www.hec.usace.army.mil/software/hec-ras/.

Hervouet, J.-M. 2007. Hydrodynamics of Free Surface Flows: Modelling with the Finite Element Method. Hoboken, NJ: John Wiley \& Sons, Ltd.

Hood, W. G. 2015. "Geographic Variation in Puget Sound Tidal Channel Planform Geometry." Geomorphology 230: 98-108.

Horstman, E. M., C. M. Dohmen-Janssen, T. J. Bouma, and S. J. Hulscher. 2015. “Tidal-Scale Flow Routing and Sedimentation in Mangrove Forests: Combining Field Data and Numerical Modelling." Geomorphology 228: 244-262.

Howard, J., A. Sutton-Grier, D. Herr, J. Kleypas, E. Landis, E. Mcleod, E. Pidgeon, and S. Simpson. 2017. "Clarifying the Role of Coastal and Marine Systems in Climate Mitigation." Frontiers in Ecology and the Environment 15 (1): 42-50.

Howes N. C., D. M. FitzGerald, Z. J. Hughes, I. Y. Georgiou, M. A. Kulp, M. D. Miner, J. M. Smith, and J. A. Barras. 2010. "Hurricane-Induced Failure of Low Salinity Wetlands." Proceedings of the National Academy of Sciences 107 (32): 14014-14019.

Hutchison J., A. Manica, R. Swetnam, A. Balmford, and M. Spalding. 2014. "Predicting Global Patterns in Mangrove Forest Biomass." Conservation Letters 7 (3): 233-240. 
Kamali, B., and R. Hashim. 2011. "Mangrove Restoration without Planting." Ecological Engineering 37 (2): 387-391.

Kemp, A. C., B. P. Horton, C. H. Vane, C. E. Bernhardt, D. R. Corbett, S. E. Engelhart, S. C. Anisfeld, A. C. Parnell, and N. Cahill. 2013. "Sea-Level Change during the Last 2,500 Years in New Jersey, USA." Quaternary Science Reviews 81: 90-104.

Kemp, G. P., J. W. Day, J. D. Rogers, L. Giosan, and N. Peyronnin. 2016. “Enhancing Mud Supply from the Lower Missouri River to the Mississippi River Delta USA: Dam Bypassing and Coastal Restoration." Estuarine, Coastal and Shelf Science 183: 304-313.

Kiesel, J., M. Schuerch, I. Möller, T. Spencer, and A. Vafeidis. 2019. "Attenuation of High Water Levels over Restored Saltmarshes Can Be Limited: Insights from Freiston Shore, Lincolnshire, UK." Ecological Engineering 136: 89-100.

Kirwan, M. L., G. R. Guntenspergen, A. D'Alpaos, J. T. Morris, S. M. Mudd, and S. Temmerman. 2010. "Limits on the Adaptability of Coastal Marshes to Rising Sea Level." Geophysical Research Letters 37 (23).

Kirwan, M. L., and J. P. Megonigal. 2013. “Tidal Wetland Stability in the Face of Human Impacts and Sea-Level Rise." Nature 504: 53-60.

Kirwan, M. L., S. Temmerman, E. E. Skeehan, G. R. Guntenspergen, and S. Fagherazzi. 2016a. "Overestimation of Marsh Vulnerability to Sea Level Rise." Nature Climate Change 6 (3): 253-260.

Kirwan, M. L., D. C. Walters, W. G. Reay, and J. A. Carr. 2016b. "Sea Level Driven Marsh Expansion in a Coupled Model of Marsh Erosion and Migration." Geophysical Research Letters 43 (9): 4366-4373.

Knutson, T. R., J. L. McBride, J. Chan, K. Emanuel, G. Holland, C. Landsea, I. Held, J. P. Kossin, A. K. Srivastava, and M. Sugi. 2010. "Tropical Cyclones and Climate Change." Nature Geoscience 3 (3): 157-163.

Kodikara, K. A. S., N. Mukherjee, L. P. Jayatissa, F. Dahdouh-Guebas, and N. Koedam. 2017. "Have Mangrove Restoration Projects Worked? An In-Depth Study in Sri Lanka." Restoration Ecology 25 (5): 705-716.

Krauss, K. W., T. W. Doyle, T. J. Doyle, C. M. Swarzenski, A. S. From, R. H. Day, and W. H. Conner. 2009. "Water Level Observations in Mangrove Swamps during Two Hurricanes in Florida." Wetlands 29 (1): 142.

Lathrop Jr., R. G., W. Irving, J. J. Seneca, J. Trimble, and R. M. Sacatelli. 2019. “The Limited Role Salt Marshes May Have in Buffering Extreme Storm Surge Events: Case Study on the New Jersey Shore." Ocean \& Coastal Management 178: 104803.

Lawler, S., J. Haddad, and C. M. Ferreira. 2016. "Sensitivity Considerations and the Impact of Spatial Scaling for Storm Surge Modeling in Wetlands of the Mid-Atlantic Region." Ocean Coastal Management 134: 226-238. 
Lee, T. H., and H. P. Hsieh. 2016. “Indicators of Sustainable Tourism: A Case Study from a Taiwan's Wetland." Ecological Indicators 67: 779-787.

Leonardi, N., I. Carnacina, C. Donatelli, N. K. Ganju, A. J. Plater, M. Schuerch, and S. Temmerman. 2018. "Dynamic Interactions between Coastal Storms and Salt Marshes: A Review." Geomorphology 301: 92-107.

Leonardi, N., and S. Fagherazzi. 2015. "Effect of Local Variability in Erosional Resistance on Large-Scale Morphodynamic Response of Salt Marshes to Wind Waves and Extreme Events." Geophysical Research Letters 42 (14): 5872-5879.

Leonardi, N., N. K. Ganju, and S. Fagherazzi. 2016. "A Linear Relationship between Wave Power and Erosion Determines Salt-Marsh Resilience to Violent Storms and Hurricanes." Proceedings of the National Academy of Sciences of the United States of America 113 (1): 64-68.

Liu, X., Y. Wang, R. Costanza, I. Kubiszewski, N. Xu, M. Yuan, and R. Geng. 2019. "The Value of China's Coastal Wetlands and Seawalls for Storm Protection." Ecosystem Services 36 : 100905.

Loder, N. M., J. L. Irish, M. A. Cialone, and T. V. Wamsley. 2009. “Sensitivity of Hurricane Surge to Morphological Parameters of Coastal Wetlands." Estuarine, Coastal and Shelf Science 84 (4): 625-636.

Long, J., C. Giri, J. Primavera, and M. Trivedi. 2016. “Damage and Recovery Assessment of the Philippines' Mangroves Following Super Typhoon Haiyan." Marine Pollution Bulletin 109 (2): 734-743.

Losada, I. J., M. Maza, and J. L. Lara. 2016. “A New Formulation for Vegetation-Induced Damping under Combined Waves and Currents." Coastal Engineering 107: 1-13.

Losada, I. J., M. Beck, P. Menendez, A. Espejo, S. Torres, P. Diaz-Simal, F. Fernandez, et al. 2017. Valuing Protective Services of Mangroves in the Philippines: Technical Report. Washington, DC: World Bank.

Luettich, R. A., and J. J. Westerink. 2004. Formulation and Numerical Implementation of the 2D/3D ADCIRC Finite Element Model Version 44.XX. Morehead City, NC: University of North Carolina at Chapel Hill, Institute of Marine Sciences.

Luettich, R. A., and J. J. Westerink. 2012. ADCIRC: A Parallel Advanced Circulation Model for Oceanic, Coastal and Estuarine Waters. User's Manual for Version 50.99. Morehead City, NC: University of North Carolina at Chapel Hill, Institute of Marine Sciences.

MA (Millennium Ecosystem Assessment). 2005. Ecosystems and Human Well-Being: Synthesis. Washington, DC: Island Press.

MacBroom, J. G., and R. Schiff. 2012. "Predicting the Hydrologic Response of Salt Marshes to Tidal Restoration." In Tidal Marsh Restoration. Edited by C. T. Roman and D. M. Burdick. Washington, DC: Island Press. 
Mariotti, G. 2016. “Revisiting Salt Marsh Resilience to Sea Level Rise: Are Ponds Responsible for Permanent Land Loss?" Journal of Geophysical Research: Earth Surface 121 (7): 1391-1407.

Mariotti, G. 2018. "Marsh Channel Morphological Response to Sea Level Rise and Sediment Supply." Estuarine, Coastal and Shelf Science 209: 89-101.

Mariotti, G., T. Elsey-Quirk, G. Bruno, and K. Valentine. 2020. “Mud-Associated Organic Matter and Its Direct and Indirect Role in Marsh Organic Matter Accumulation and Vertical Accretion." Limnology and Oceanography 65 (11): 2627-2641.

Marois, D. E., and W. J. Mitsch. 2017. “A Mangrove Creek Restoration Plan Utilizing Hydraulic Modeling." Ecological Engineering 108 (B): 537-546.

Marsooli, R., P. M. Orton, N. Georgas, and A. F. Blumberg. 2016. “Three-Dimensional Hydrodynamic Modeling of Coastal Flood Mitigation by Wetlands." Coastal Engineering 111: 83-94.

Mattheus, C. R., A. B. Rodriguez, B. A. McKee, and C. A. Currin. 2010. "Impact of Land-Use Change and Hard Structures on the Evolution of Fringing Marsh Shorelines." Estuarine, Coastal and Shelf Science 88 (3): 365-376.

Maza, M., J. L. Lara, and I. J. Losada. 2015. “Tsunami Wave Interaction with Mangrove Forests: A 3-D Numerical Approach." Coastal Engineering 98: 33-54.

Mazda, Y., M. Magi, Y. Ikeda, T. Kurokawa, and T. Asano. 2006. "Wave Reduction in a Mangrove Forest Dominated by Sonneratia sp." Wetlands Ecology and Management 14: 365-378.

Mclvor, A. L., I. Möller, T. Spencer, and M. Spalding. 2012a. Reduction of Wind and Swell Waves by Mangroves. Natural Coastal Protection Series: Report 1. Cambridge Coastal Research Unit Working Paper 40. Arlington, VA: The Nature Conservancy and Wetlands International.

Mclvor, A. L., T. Spencer, I. Möller, and M. Spalding. 2012b. Storm Surge Reduction by Mangroves. Natural Coastal Protection Series: Report 2. Cambridge Coastal Research Unit Working Paper 41. Arlington, VA: The Nature Conservancy and Wetlands International.

Mclvor, A. L., T. Spencer, I. Möller, and M. Spalding. 2013. The Response of Mangrove Soil Surface Elevation to Sea Level Rise. Natural Coastal Protection Series: Report 3. Cambridge Coastal Research Unit Working Paper 42. Arlington, VA: The Nature Conservancy and Wetlands International.

Mclvor, A., T. Spencer, I. Möller, and M. Spalding. 2016. “Coastal Defence Services Provided by Mangroves." In Managing Coasts with Natural Solutions: Guidelines for Measuring and Valuing the Coastal Protection Services of Mangroves and Coral Reefs. Edited by M. W. Beck and G. M. Lange. Washington, DC: World Bank. http://documents1.worldbank.org/ curated/en/995341467995379786/pdf/Managing-coasts-with-natural-solutionsguidelines-for-measuring-and-valuing-the-coastal-protection-services-ofmangroves-and-coral-reefs.pdf. 
Melby, J. A., E. F. Thompson, M. A. Cialone, J. M. Smith, L. E. Borgman, Z. Demirbilek, J. L. Hanson, and L. Lin. 2005. Life-Cycle Analysis of Mid-Bay and Poplar Island Projects, Chesapeake Bay, Maryland. Coastal and Hydraulics Laboratory Technical Report ERDC/CHL-TR-05-12. Vicksburg, MS: U.S. Army Engineer Research and Development Center.

Mendez, F. J., and I. J. Losada. 2004. "An Empirical Model to Estimate the Propagation of Random Breaking and Nonbreaking Waves over Vegetation Fields." Coastal Engineering 51 (2): 103-118.

mikepoweredbydhi.com. n.d. MIKE Powered by DHI. https://www.mikepoweredbydhi.com/.

Mitch, W. J. 2006. "Why a Natural Systems Approach to Estuarine Restoration Works." Paper presented at the 3rd National Conference on Coastal and Estuarine Habitat Restoration. New Orleans, LA, December 2006.

Mitchell, M., J. Herman, D. M. Bilkovic, and C. Hershner. 2017. “Marsh Persistence under SeaLevel Rise is Controlled by Multiple, Geologically Variable Stressors." Ecosystem Health and Sustainability 3 (10): 1379888. doi:10.1080/20964129.2017.1396009.

Mitra, A. 2020. “Mangroves: A Barrier Against Erosion." In Mangrove Forests in India. Cham, CH: Springer.

Mohan, R. K. 2001. "Design and Construction of Coastal Wetlands Using Dredged Material." In Handbook of Dredging Engineering. Edited by J. B. Herbich. New York: McGraw Hill Company.

Mohan, R. K., and D. C. Urso. 1997. "Design and Construction Aspects of Creating Artificial Islands Using Dredged Material. Proceedings," WEDA -XVIII Conference, Charleston, SC.

Mohan, R. K., and M. R. Palermo. 1998. “Bottoms up." Civil Engineering 68 (12): 56.

Möller, I., and Spencer, T. 2002. “Wave Dissipation over Macro-Tidal Saltmarshes: Effects of Marsh Edge Typology and Vegetation Change." Journal of Coastal Research 36: 506-521.

Möller, I., T. Spencer, J. R. French, D. J. Leggett, and M. Dixon. 1999. “Wave Transformation over Salt Marshes: A Field and Numerical Modelling Study from North Norfolk, England." Estuarine, Coastal and Shelf Science 49 (3): 411-426.

Morris, J. T., P. V. Sundareshwar, C. T. Nietch, B. Kjerfve, and D. R. Cahoon. 2002. “Responses of Coastal Wetlands to Rising Sea Level." Ecology 83 (10): 2869-2877.

Morris, J. T., D. C. Barber, J. C. Callaway, R. Chambers, S. C. Hagen, C. S. Hopkinson, B. J. Johnson, et al. 2016. "Contributions of Organic and Inorganic Matter to Sediment Volume and Accretion in Tidal Wetlands at Steady State." Earth's Future 4 (4): 110-121.

Morton, R. A., and J. A. Barras. 2011. "Hurricane Impacts on Coastal Wetlands: A Half-Century Record of Storm-Generated Features from Southern Louisiana." Journal of Coastal Research 27 (6A): 27-43. 
Mossman, H., A. Davy, and A. Grant. 2012. "Does Managed Coastal Realignment Create Saltmarshes with 'Equivalent Biological Characteristics' to Natural Reference Sites?" Journal of Applied Ecology 49 (6).

myroms.org. 2020. Regional Ocean Modeling System (ROMS). https://www.myroms.org/.

Narayan, S., M. W. Beck, B. G. Reguero, I. J. Losada, B. Van Wesenbeeck, N. Pontee, and K. A. Burks-Copes. 2016. "The Effectiveness, Costs and Coastal Protection Benefits of Natural and Nature-Based Defences." PLOS ONE 11 (5): e0154735.

Narayan, S., M. W. Beck, P. Wilson, C. J. Thomas, A. Guerrero, C. C. Shepard, B. G. Reguero, G. Franco, J. C. Ingram, and D. Trespalacios. 2017. "The Value of Coastal Wetlands for Flood Damage Reduction in the Northeastern USA." Scientific Reports 7: 9463. doi:10.1038/s41598-017-09269-z.

Narayan, S., C. J. Thomas, J. Matthewman, C. C. Shepard, L. Geselbracht, K. Nzerem, and M. W. Beck. 2019. Valuing the Flood Risk Reduction Benefits of Florida's Mangroves. University of California, Santa Cruz and The Nature Conservancy. http://www. conservationgateway.org/SiteAssets/Pages/floridamangroves/Mangrove_Report_ digital_FINAL.pdf.

Narra, P. M. F. 2012. "Attenuation of Wave Energy in Mangrove Forests." Master's thesis, Universidade de Aveiro Departamento de Engenharia Civil.

Neckles, H. A., M. Dionne, D. M. Burdick, C. T. Roman, R. Buchsbaum, and E. Hutchins. 2002. "A Monitoring Protocol to Assess Tidal Restoration of Salt Marshes on Local and Regional Scales." Restoration Ecology 10 (3): 556-563.

Nellemann, C., M. MacDevette, T. Manders, B. Eickhout, B. Svihus, A. Prins, and B. Kaltenborn. 2009. The Environmental Food Crisis: The Environment's Role in Averting Future Food Crises. A UNEP Rapid Response Assessment. Arendal, NO: United Nations Environment Programme.

NOAA (National Oceanic and Atmospheric Administration). 2014. A User Guide for Marsh Analysis and Planning Tool Incorporating Tides and Elevations (MAPTITE): A GIS Application for Marsh Restoration. NOS 2014. Silver Spring, MD: National Oceanic and Atmospheric Administration (NOAA), U.S. Department of Commerce.

NOAA. 2015. Guidance for Considering the Use of Living Shorelines. Accessed December 2020. https://www.habitatblueprint.noaa.gov/wp-content/uploads/2018/01/NOAAGuidance-for-Considering-the-Use-of-Living-Shorelines_2015.pdf.

NOAA. 2020. Restoration Atlas. Accessed August 11, 2020. https://www.habitat.noaa.gov/ apps/restoration-atlas/.

Northwest Hydraulic Consultant, Inc. 2018. Southern Flow Corridor: As-Built Project Validation of Peak Water Level Reduction during the October 2017 Flood. Tillamook, OR: Northwest Hydraulic Consultants, Inc. https://ossfc. files.wordpress.com/2019/02/sfcoctober-2017-flood-modeling-report-final-r3c.pdf. 
NRC (National Research Council). 2014. Reducing Coastal Risk on the East and Gulf Coasts. Washington, DC: National Academy of Sciences. https://www.nap.edu/ resource/18811/coastal-risk-brief-final.pdf.

Nunez, K., Y. J. Zhang, J. Herman, W. Reay, and C. Hershner. 2020. "A Multi-Scale Approach for Simulating Tidal Marsh Evolution." Ocean Dynamics 70 (9): 1187-1209.

Odell, R. E., B. R. Hall, and P. C. Brooks. 2008. “Conceptual Design and Modeling of Restored Coastal Wetlands." International Journal of River Basin Management 6 (3): 283-295.

opentelemac.org. 2020. Open TELEMAC-MASCARET: The Mathematically Superior Suite of Solvers. TELEMAC-MASCARET. http://www.opentelemac.org/.

Oro Loma Sanitary District. 2015. Oro Loma and Castro Valley Sanitary Districts to Test Experimental Levee. San Lorenzo, CA: Oro Loma Sanitary District.

oss.deltares.nl. 2020. Delft3D Open Source Community. Delft3D. https://oss.deltares.nl/web/ delft3d.

Paquier, A. E., J. Haddad, S. Lawler, and C. M. Ferreira. 2017. "Quantification of the Attenuation of Storm Surge Components by a Coastal Wetland of the U.S. Mid Atlantic." Estuaries and Coasts 40 (4): 930-946.

Parson, L., N. Lovelace, E. Godsey, K. Reine, and J. Gailani. 2015. Regional Sediment Management (RSM) Strategy for Mobile Bay, Alabama. ERDC/CHL CHETN-XIV-41. Vicksburg, MS: U.S. Army Engineer Research and Development Center, U.S. Army Corps of Engineers.

Pôle-Relais Zones Humides Tropicales. 2018. Mangrove Restoration: Summary of the Key Elements to be Considered in any Restoration Project. Technical Guide. https:// www.icriforum.org/wp-content/uploads/2020/05/restoration-guide-eng-WEBsecured\%20(1).pdf.

Pollard, J. A., T. Spencer, and S. M. Brooks. 2019. “The Interactive Relationship between Coastal Erosion and Flood Risk." Progress in Physical Geography: Earth and Environment 43 (4): 574-585.

Pontee, N. I. 2007. "Realignment in Low-Lying Coastal Areas: UK Experiences." Proceedings of the Institution of Civil Engineers - Maritime Engineering 160 (4): 155-166.

Pontee, N. 2013. “Defining Coastal Squeeze: A Discussion." Ocean and Coastal Management 84: 204-207.

Pontee, N. I. 2015. "Impact of Managed Realignment Design on Estuarine Water Levels." Proceedings of the Institute of Civil Engineers - Maritime Engineering 168 (2): 48-61.

Pontee, N. I., S. Narayan, M. W. Beck, and A. H. Hosking. 2016. “Nature-Based Solutions: Lessons from around the World." Proceedings of the Institution of Civil Engineers - Maritime Engineering 169 (1): 29-36. 
Primavera, J. H., and J. M. A. Esteban. 2008. "A Review of Mangrove Rehabilitation in the Philippines: Successes, Failures and Future Prospects." Wetlands Ecology and Management 16 (5): 345-358.

Quartel, S., A. Kroon, P. G. E. F. Augustinus, P. Van Santen, and N. H. Tri. 2007. “Wave Attenuation in Coastal Mangroves in the Red River Delta, Vietnam." Journal of Asian Earth Sciences 29 (4): 576-584.

Reguero, B. G., M. W. Beck, D. N. Bresch, J. Calil, and I. Meliane. 2018. “Comparing the Cost Effectiveness of Nature-Based and Coastal Adaptation: A Case Study from the Gulf Coast of the United States." PLOS ONE 13 (4): e0192132.

Roland, R. M., and S. L. Douglass. 2005. "Estimating Wave Tolerance of Spartina alterniflora in Coastal Alabama." Journal of Coastal Research 21 (3): 453-463.

Roman, C. T., and D. M. Burdick. 2012. Tidal Marsh Restoration: A Synthesis of Science and Management. Island Press.

Salgado, K., and M. Martínez. 2017. “Is Ecosystem-Based Coastal Defense a Realistic Alternative? Exploring the Evidence." Journal of Coastal Conservation 21: 837-848. doi:10.1007/s11852-017-0545-1.

Schuerch, M., T. Spencer, S. Temmerman, M. L. Kirwan, C. Wolff, D. Lincke, C. J. McOwen, et al. 2018. "Future Response of Global Coastal Wetlands to Sea-Level Rise." Nature 561 (7722): 231-234.

Schuerch, M., T. Spencer, and B. Evans. 2019. "Coupling between Tidal Mudflats and Salt Marshes Affects Marsh Morphology." Marine Geology 412: 95-106.

Schulze, D., F. Rupprecht, S. Nolte, and K. Jensen. 2019. “Seasonal and Spatial within-Marsh Differences of Biophysical Plant Properties: Implications for Wave Attenuation Capacity of Salt Marshes." Aquatic Sciences 81 (4): 65.

Shchepetkin, A. F., and J. C. McWilliams. 2005. "The Regional Oceanic Modeling System (ROMS): A Split-Explicit, Free-Surface, Topography-Following-Coordinate Oceanic Model." Ocean Modelling 9 (4): 347-404.

Sheng, Y. P., A. Lapetina, and G. Ma. 2012. “The Reduction of Storm Surge by Vegetation Canopies: Three-Dimensional Simulations." Geophysical Research Letters 39: 1-5.

Sheng, Y. P., and R. Zou. 2017. "Assessing the Role of Mangrove Forest in Reducing Coastal Inundation during Major Hurricanes." Hydrobiologia 803 (1): 87-103.

Shepard, C. C., C. M. Crain, and M. W. Beck. 2011. "The Protective Role of Coastal Marshes: A Systematic Review and Meta-Analysis." PLOS ONE 6: e27374.

Shisler, J. K. 1990. "Creation and Restoration of Coastal Wetlands of the Northeastern United States." In Wetland Creation and Restoration: The Status of the Science. Edited by J. A. Kusler and M. E. Kentula. Washington, DC: Island Press.

sigmaplan.be. 2020. What Is the Sigma Plan? Sigmaplan. https://www.sigmaplan.be/en/. 
Silliman, B. R., Q. He, C. Angelini, C. S. Smith, M. L. Kirwan, P. Daleo, J. J. Renzi, et al. 2019. “Field Experiments and Meta-Analysis Reveal Wetland Vegetation as a Crucial Element in the Coastal Protection Paradigm." Current Biology 29 (11): 1800-1806.

Smith, M. D., A. K. Knapp, and S. L. Collins. 2009. "A Framework for Assessing Ecosystem Dynamics in Response to Chronic Resource Alterations Induced by Global Change." Ecology 90 (12): 3279-3289.

Smolders, S., Y. Plancke, S. Ides, P. Meire, and S. Temmerman. 2015. "Role of Intertidal Wetlands for Tidal and Storm Tide Attenuation along a Confined Estuary: A Model Study." Natural Hazards and Earth System Sciences Discussions 15 (7): 1659-1675.

Smolders, S., M. João Teles, A. Leroy, T. Maximova, P. Meire, and S. Temmerman. 2020. "Modeling Storm Surge Attenuation by an Integrated Nature-Based and Engineered Flood Defense System in the Scheldt Estuary (Belgium)." Journal of Marine Science and Engineering 8 (1): 27.

Spencer, T., I. Möller, F. Rupprecht, T. J. Bouma, B. K. van Wesenbeeck, M. Kudella, M. Paul, et al. 2016. "Salt Marsh Surface Survives True-to-Scale Simulated Storm Surges." Earth Surface Processes and Landforms 41 (4): 543-552.

Stark, J., T. Van Oyen, P. Meire, and S. Temmerman. 2015. "Observations of Tidal and Storm Surge Attenuation in a Large Tidal Marsh." Limnology and Oceanography 60 (4): 1371-1381.

Stark, J., Y. Plancke, S. Ideas, P. Meire, and S. Temmerman. 2016. “Coastal Flood Protection by a Combined Nature-Based and Engineering Approach: Modeling the Effects of Marsh Geometry and Surrounding Dikes." Estuarine, Coastal and Shelf Science 175: 34-45.

Sun, F., and R. T. Carson. 2020. “Coastal Wetlands Reduce Property Damage during Tropical Cyclones." Proceedings of the National Academy of Sciences 117 (11): 5719-5725.

swanmodel.sourceforge.net. n.d. SWAN. http://swanmodel.sourceforge.net/.

Swanson, K. M., J. Z. Drexler, D. H. Schoellhamer, K. M. Thorne, M. L. Casazza, C. T. Overton, J. C. Callaway, and J. Y. Takekawa. 2014. "Wetland Accretion Rate Model of Ecosystem Resilience (WARMER) and Its Application to Habitat Sustainability for Endangered Species in the San Francisco Estuary." Estuaries and Coasts 37 (2): 476-492.

Temmerman, S., G. Govers, S. Wartel, and P. Meire. 2004. "Modelling Estuarine Variations in Tidal Marsh Sedimentation: Response to Changing Sea Level and Suspended Sediment Concentrations." Marine Geology 212 (1-4): 1-19.

Thorslund, J., J. Jarsjo, F. Jaramillo, J. W. Jawitz, S. Manzoni, N. B. Basu, S. R. Chalov, et al. 2017. "Wetlands as Large-Scale Nature-Based Solutions: Status and Challenges for Research, Engineering and Management." Ecological Engineering 108 (B): 489-497.

tlp.el.erdc.dren.mil. 2020. Thin-Layer Placement. https://tlp.el.erdc.dren.mil/.

Tonelli, M., S. Fagherazzi, and M. Petti. 2010. "Modeling Wave Impact on Salt Marsh Boundaries." Journal of Geophysical Research: Oceans 115 (C9). 
UNEP-Nairobi Convention/USAID/WIOMSA. 2020. Guidelines on Mangrove Ecosystem Restoration for the Western Indian Ocean Region. Nairobi: UNEP. https:// www.nairobiconvention.org/CHM\%20Documents/WIOSAP/guidelines/ GuidelinesonMangroveRestorationForTheWIO.pdf.

USACE (U.S. Army Corps of Engineers). 1984. Shore Protection Manual. Volumes I and II, 4th Edition. Washington, DC: U.S. Government Printing Office.

USACE. 1995. Design of Coastal Revetments, Seawalls, and Bulkheads. EM 1110-2-1614. Washington, DC: U.S. Army Corps of Engineers.

USACE. 2002. Coastal Engineering Manual. EM 1110-2-1100. Washington, DC: U.S. Army Corps of Engineers.

usgs.gov. 2019. Coupled-Ocean-Atmosphere-Wave-Sediment-Transport (COAWST) Modeling System. USGS. https://www.usgs.gov/software/coupled-ocean-atmosphere-wavesediment-transport-coawst-modeling-system.

van Coppenolle, R., and S. Temmerman. 2019. "A Global Exploration of Tidal Wetland Creation for Nature-Based Flood Risk Mitigation in Coastal Cities." Estuarine, Coastal and Shelf Science 226: 106262.

van Eekelen, E. M. M., L. Sittoni, F. van der Goot, H. E. Nieboer, M. J. Baptist, J. Boer, and F. H. Tonneijck. 2017. "The Living Lab for Mud: Integrated Sediment Management based on Building with Nature Concepts." Paper presented at the Central Dredging Association Dredging Days 2017, Rotterdam, The Netherlands, November 2017. https://www. ecoshape.org/uploads/sites/2/2017/11/Ceda-2017-paper-Van-Eekelen-Sittoni-etal-THE-LIVING-LAB-FOR-MUD-INTEGRATED-SEDIMENT-MANAGEMENT-BASED-ONBUILDING-WITH-NATURE-CONCEPTS.pdf.

van Proosdij, D., J. Lundholm, N. Neatt, T. Bowron, and J. Graham. 2010. “Ecological ReEngineering of a Freshwater Impoundment for Salt Marsh Restoration in a Hypertidal System." Ecological Engineering 36 (10): 1314-1332.

van Wesenbeeck, B. K., M. D. van der Meulen, C. Pesch, H. de Vriend, and M. B. de Vries. 2016. "Nature-Based Approaches in Coastal Flood Risk Management: Physical Restrictions and Engineering Challenges." In Ecosystem-Based Disaster Risk Reduction and Adaptation in Practice. Part of the Book Series Advances in Natural and Technological Hazards Research. Edited by F. Renaud, K. Sudmeier-Rieux, M. Estrella, and U. Nehren. Springer, Cham. https://doi.org/10.1007/978-3-319-43633-3_8.

Vuik, V., B. W. Borsje, T. Suzuki, I. Kratzer, S. N. Jonkman, and T. Bouma. 2015. "Nature-Based Flood Protection: The Efficiency of Vegetated Foreshores in Reducing Wave Run-Up." Paper presented at the 36th IAHR World Congress, The Hague, The Netherlands, June 2015.

Vuik, V., H. Y. S. Heo, Z. Zhu, B. W. Borsje, and S. N. Jonkman. 2018. “Stem Breakage of Salt Marsh Vegetation under Wave Forcing: A Field and Model Study." Estuarine, Coastal and Shelf Science 200: 41-58. 
Vuik, V., B. W. Borsje, P. W. Willemsen, and S. N. Jonkman. 2019. “Salt Marshes for Flood Risk Reduction: Quantifying Long-Term Effectiveness and Life-Cycle Costs." Ocean \& Coastal Management 171: 96-110.

Wamsley, T. V., M. A. Cialone, J. M. Smith, J. H. Atkinson, and J. D. Rosati. 2010. “The Potential of Wetlands in Reducing Storm Surge." Ocean Engineering 37 (1): 59-68.

Wetlands International. 2015. Building with Nature Indonesia - Reaching Scale for Coastal Resilience. Ede, The Netherlands: Wetlands International. https://www.wetlands.org/ publications/building-with-nature-in-indonesia/.

Wetlands International. 2016. Mangrove Restoration: to Plant or Not to Plant? Ede, The Netherlands: Wetlands International. https://www.wetlands.org/publications/ mangrove-restoration-to-plant-or-not-to-plant/.

Willemsen, P. W., B. W. Borsje, V. Vuik, T. J. Bouma, and S. J. Hulscher. 2020. “Field-Based Decadal Wave Attenuating Capacity of Combined Tidal Flats and Salt Marshes." Coastal Engineering 156: 103628.

xmswiki.com. 2019. SMS:STWAVE. AQUAVEO. https://www.xmswiki.com/wiki/SMS:STWAVE.

Yao, Y., R. Du, C. Jiang, Z. Tang, and W. Yuan. 2015. “Experimental Study of Reduction of Solitary Wave Run-Up by Emergent Rigid Vegetation on a Beach." Journal of Earthquake and Tsunami 9 (5): 1540003.

Ysebaert, T., S. L. Yang, L. Zhang, Q. He, T. J. Bouma, and P. M. Herman. 2011. "Wave Attenuation by Two Contrasting Ecosystem Engineering Salt Marsh Macrophytes in the Intertidal Pioneer Zone." Wetlands 31 (6): 1043-1054.

Zedler, J. B. 2003. "Wetlands at Your Service: Reducing Impacts of Agriculture at the Watershed Scale." Frontiers in Ecology and the Environment 1 (2): 65-72.

Zedler, J. B., ed. 2000. Handbook for Restoring Tidal Wetlands. Boca Raton, FL: CRC Press.

Zeff, M. L. 2011. “The Necessity for Multidisciplinary Approaches to Wetland Design and Adaptive Management: The Case of Wetland Channels." In Wetlands: Integrating Multidisciplinary Concepts. Edited by B. A. LePage. Dordrecht, The Netherlands: Springer.

Zhang, K. Q., H. Q. Liu, Y. P. Li, H. Z. Xu, J. Shen, J. Rhome, and T. J. Smith. 2012. "The Role of Mangroves in Attenuating Storm Surges." Estuarine, Coastal and Shelf Science 102-103: 11-23.

Zhao, Q., J. Bai, L. Huang, B. Gu, Q. Lu, and Z. Gao. 2016. "A Review of Methodologies and Success Indicators for Coastal Wetland Restoration." Ecological Indicators 60: 442452. doi:10.1016/j.ecolind.2015.07.003.

Zhu, Z., V. Vuik, P. J. Visser, T. Soens, B. van Wesenbeeck, J. van de Koppel, S. N. Jonkman, S. Temmerman, and T. J. Bouma. 2020. "Historic Storms and the Hidden Value of Coastal Wetlands for Nature-Based Flood Defence." Nature Sustainability 3: 853-862. 


\section{Acknowledgments}

\section{Lead Authors}

Candice D. Piercy, U.S. Army Corps of Engineers, United States

Nigel Pontee, Jacobs, United Kingdom

\section{Co-Authors}

Siddharth Narayan, East Carolina University, United States

Jenny Davis, National Oceanic and Atmospheric Administration, United States

Trevor Meckley, National Oceanic and Atmospheric Administration, United States

\section{Contributors}

Bregje van Wesenbeeck, Deltares, the Netherlands

Mike Beck, University of California, Santa Cruz, United States

Janine Harris, National Oceanic and Atmospheric Administration, United States

Stéphanie IJff, Deltares, the Netherlands

Emily Russ, U.S. Army Corps of Engineers, United States

Joseph Gailani, U.S. Army Corps of Engineers, United States

Mindert de Vries, Deltares, the Netherlands

Denise Reed, University of New Orleans, United States 


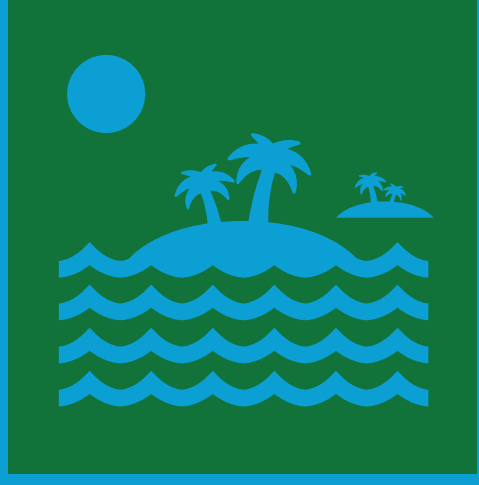

\section{Key Messages}

1. Islands are proven to deliver coastal resilience benefits, especially as part of a multiple-lines-of-defense strategy. Islands can be effective in areas where other, land-based natural and nature-based features (NNBF) are not feasible (e.g., urban areas).

2. Islands can simultaneously provide multiple services, including storm surge reduction, wave dissipation, erosion control, dredged material management, safe navigation and safe harbor, ecosystem diversity, recreation, and commercial opportunities.

3. Island features may have a regional influence and, therefore, must be placed in the regional context. For example, islands that provide coastal resilience benefits will significantly influence circulation, sediment transport, water quality, waves, and habitat within their domain of influence.

4. Habitat trade-offs are inevitable-island construction almost always involves changing habitat types from subtidal to intertidal and supratidal. Short-term impacts must be considered within the context of long-term ecosystem co-benefits, especially within the context of sea-level rise.

5. Islands may be multihabitat features; therefore, guidance from previous feature chapters may apply here. For example, large islands often include beach and dune, wetland, and upland plant community components. 


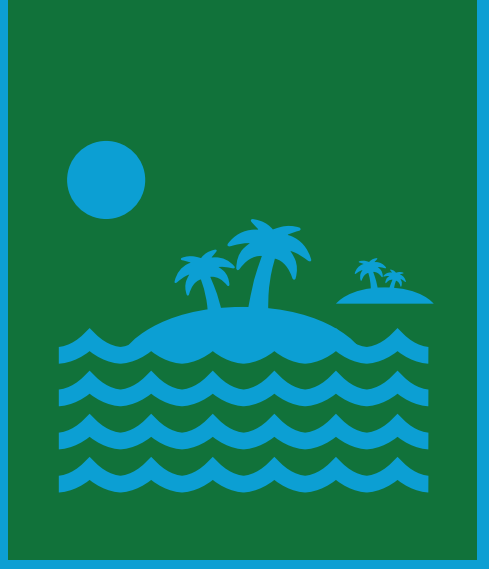

\section{Key Messages (Continued)}

6. The complexity of physical processes at island NNBF settings, coupled with limited case studies for some conditions, results in significant uncertainty and risk during the construction process. Experienced contractors, capable of adaptively managing construction, are required to reduce risk and meet project goals within cost, regulations, and schedule.

7. Islands are typically dynamic features, and therefore, their success in achieving predefined objectives and observed metrics may fluctuate or change over time. 


\section{1 | Introduction}

Islands in estuaries, major river deltas, and open-coast environments reduce the severity of hazards, including erosion and flooding from wind-driven waves and extreme water levels, on the nearby habitats and shorelines. Islands may also provide critical ecosystem function for threatened and endangered species and migratory birds while providing access to recreational opportunities and navigation co-benefits. This chapter will focus on islands as natural and nature-based features (NNBF) that support coastal resilience. Three types of islands will be discussed in this chapter-barrier islands, deltaic islands (including spits), and in-bay or in-lake islands. These islands may be new construction or, as in most cases, the restoration of island remnants. The degradation and loss of islands through combined processes such as sea-level rise, subsidence, and inadequate sediment input (e.g., upstream impoundments, navigation channels, evolving natural processes) are reducing the coastal resilience benefits of these features. This chapter does not include discussions of island reclamation solely for purposes of urban or agricultural development.

\subsubsection{Background}

Islands exist throughout coastal regions but are more common under specific conditions, including moderate tidal range and gentle foreshore slope. These islands can be a legacy of earlier geological and hydrological processes or sustained through ongoing processes. The latter are sustained through a combination of fluvial and marine processes that continually erode, nourish, and shape islands. Sediment transport, waves, river and coastal hydrology, littoral processes, climatology, episodic events, and vegetation are integral to island formation and sustenance. Although islands range in size from less than a hectare to millions of hectares, islands restored or created as NNBF are typically less than 20 kilometers $(\mathrm{km})$ in length (shore parallel direction) and are relatively narrow (less than $1 \mathrm{~km}$ ).

Islands are dynamic landscape features, constantly moving in response to both short-term and long-term regional circulation patterns, wave climate, habitat evolution, changes in sediment supply, subsidence, sea-level rise, and storm events. Islands are typically exposed to these processes from a broader range of directions than other NNBF. These characteristics result in special design requirements, discussed in Section 11.5. Further, changes in sediment supply due to natural or anthropogenic influences will influence island dynamics and resilience benefits. Additional details for the three island types (barrier, deltaic, in-bay and in-lake) are provided in the sections that follow. This classification system is broad, and island features may fall under more than one classification. 


\subsubsection{Types and Setting}

\subsubsection{Barrier Islands}

Barrier islands are defined as "typically elongate, narrow land formations, composed of unconsolidated materials, lying parallel to the shoreline, and separated from the mainland coast by lagoons and/or bays" (Oertel 1985). Barrier islands are often the first line of defense, protecting the mainland coast from inundation (Figures 11.1 and 11.2) by waves, erosion, and the full force of the open-ocean environment. They have the capacity to alter surge pathways and attenuate waves in a wide variety of settings (Wamsley et al. 2009; Grzegorzewski, Cialone, and Wamsley 2011). Recent surveys based on satellite imagery indicate that there are more than 2,000 barrier islands in the world, with more than $20,000 \mathrm{~km}$ of shoreline (Stutz and Pilkey 2011). Although typically less than $100 \mathrm{~km}$, barrier island length ranges over several orders of magnitude, with an average length of $15 \mathrm{~km}$ outside the Arctic (Stutz and Pilkey 2011) and a maximum length of $200 \mathrm{~km}$ (Garrison et al. 2010). There are extensive barrier island systems present in the United States, Mexico, Russia, and Australia, with smaller barrier island chains in equatorial Brazil, the North Sea (i.e., the Netherlands, Germany, Denmark), Canada, Mozambique, India, Madagascar, Columbia, and Nigeria (see Figure 11.1 and Stutz and Pilkey 2011) and less extensive islands in many other countries.

\section{Figure 11.1. Barrier Island Setting and Features}

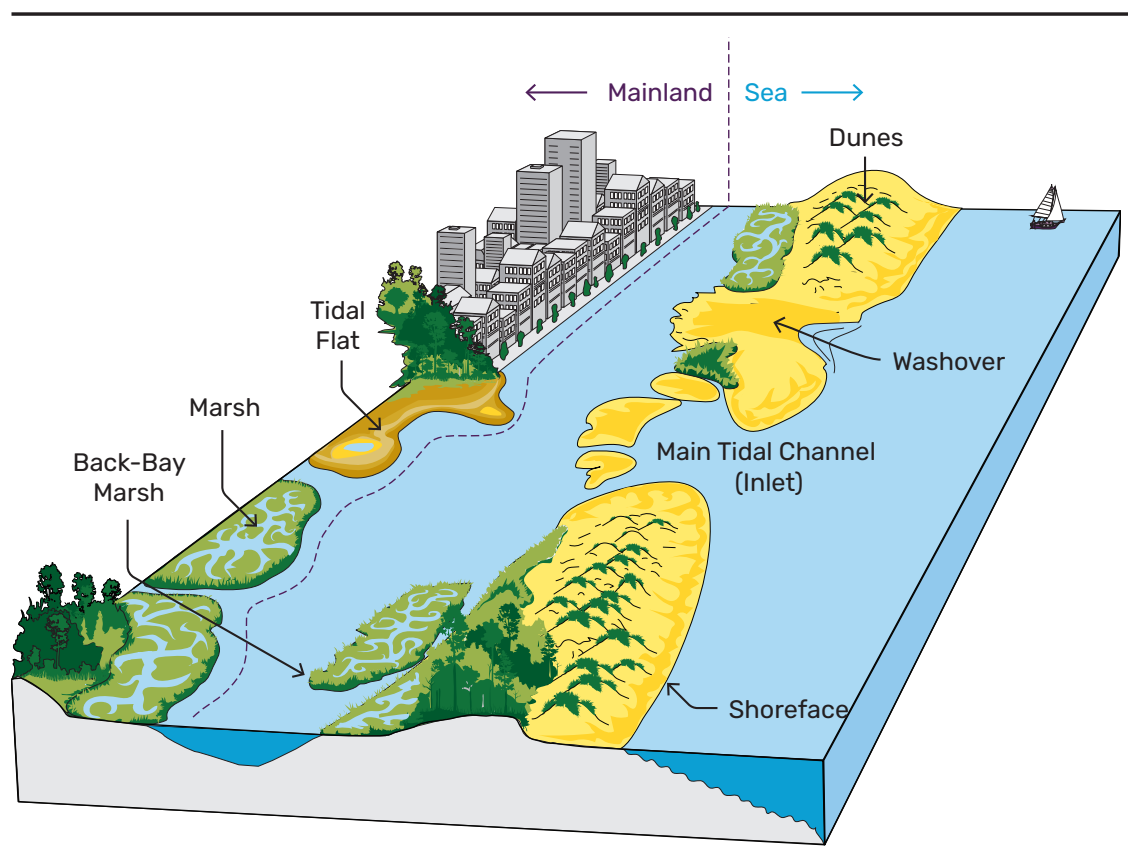




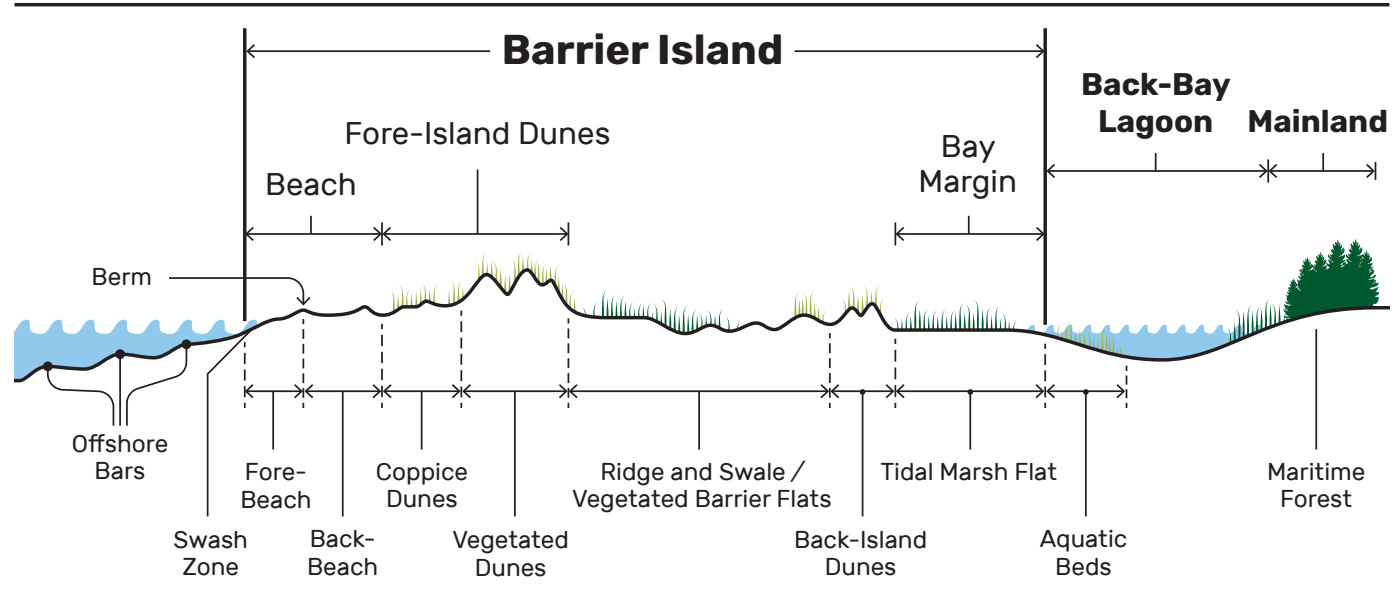

\subsubsection{Deltaic Islands}

Deltaic islands are formed at the mouths of rivers, where fast-moving waters slow as the river meets a sea or lake, and the sediment carried by the river is deposited on the seabed or lakebed (Figure 11.3). Large river deltas (e.g., Danube, Niger, Nile, Rhine, Ganges, Mississippi, Mekong, Fraser, Saskatchewan, Mackenzie, Peace-Athabasca, Sacramento-San Joaquin, and Patía) consist of networks of islands and distributary channels, which can incorporate sensitive and biologically diverse habitats such as salt marshes, tidal mudflats, wetlands, and beaches. Stutz and Pilkey (2002) identified three essential requirements for deltaic island formation-adequate sediment supply, low foreshore slope, and sufficient wave energy to support island building. Tidal range is another factor affecting deltaic island formation, with very large tidal ranges unfavorable for island formation. Deltaic island morphology is highly variable and depends on interactions between fluvial and coastal processes, and sediment characteristics (Stutz and Pilkey 2002, 2011). Deltaic sediments deposited at the mouth of a river naturally consolidate and subside over time, and the exposure of islands to flood and erosion hazards is often governed by balances between rates of subsidence and sediment supply, as well as relative sea- and lake-level changes and vegetation establishment and survival. Stutz and Pilkey (2002) point out that the stability of deltaic islands is critically dependent on a stable supply of fluvial sediment, and that many existing deltaic islands are threatened by interruptions of the natural sediment pathways (e.g., hydropower dams, dredging for navigation, channelization, and levee building). Deltaic channels (active or abandoned) and islands provide flood risk management (FRM) function through flood storage and by acting as barriers to attenuate waves and storm surges. Deltaic islands and deltaic systems may also be a source of sediment supply to downdrift coastal barrier islands, and so they may indirectly influence coastal resilience and ecosystem function over significant distances. 
Figure 11.3. Deltaic Island Conceptual Figure

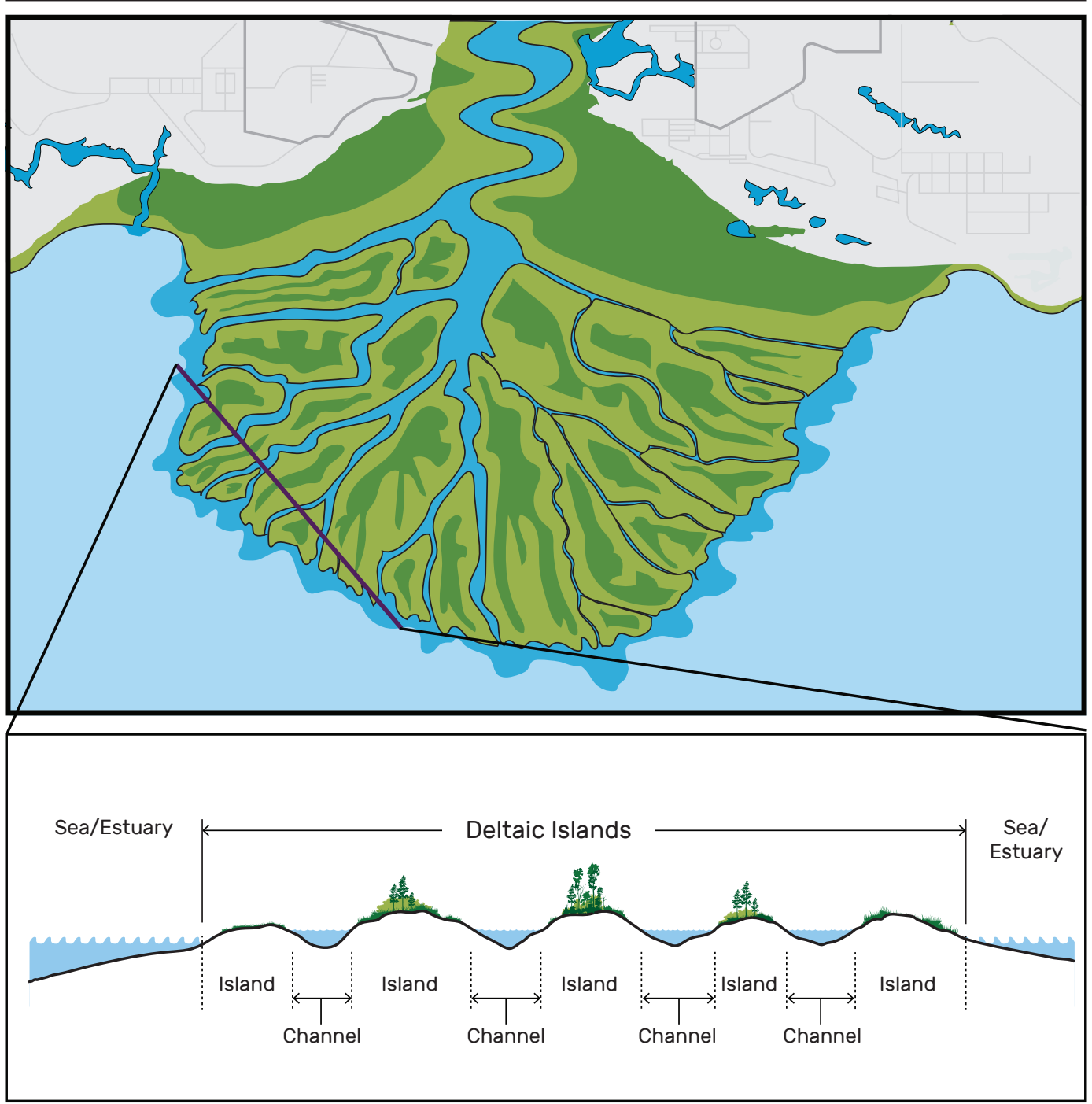




\subsubsection{In-Bay or In-Lake Islands}

In-bay or in-lake islands differ from their barrier and deltaic counterparts in that the processes they are exposed to are constrained by the scale of the waterbody. Also referred to as fetch-limited islands, they typically exist outside the deltaic and barrier island network in more protected areas and are formed by lagoon, bay, estuary, or lake hydrodynamics and sediment dynamics (Lewis, Cooper, and Pilkey 2005). Globally there are approximately 7,500 islands within lagoons, bays, and other waterbodies, making them more abundant than open-ocean barrier islands. However, they are usually much shorter, typically less than $1 \mathrm{~km}$ long. In the Chesapeake and Delaware Bays of the United States, more than 300 fetch-limited islands have been identified (Lewis, Cooper, and Pilkey 2005). These vegetation-dominated islands protect the mainland from erosion and direct wave attack by attenuating short waves and providing greater shore and bank stabilization.

\subsubsection{Values and Contexts for Application}

Islands serve multiple functions, including storm surge reduction, wave dissipation, erosion control, dredged material management, safe navigation and safe haven, ecosystem diversity, wildlife habitat, recreation, and commercial opportunities (e.g., tourism and fisheries). Islands often comprise multiple habitat types (e.g., reef, beach, dune, upland plant community, wetland, and submerged aquatic vegetation [SAV] bed) and have a hydrodynamic footprint that influences the formation and protection of adjacent coastal habitats. Islands are a critical element in the multiple-lines-of-defense strategy (Lopez 2009). This strategy describes how multiple features in a sequence, from offshore to onshore, provide greater coastal resilience benefits than a single feature (Lopez 2009; Guannel et al. 2016; Arkema et al. 2017). For example, overwash and windblown sand can nourish dunes and marshes on the back side of islands, and the protective environment in back bays can facilitate the formation of beds of SAV (see Chapter 13), salt marsh (see Chapter 10), and other habitat that requires protection from large waves (Walters et al. 2014; Harkers Island in North Carolina is an example). In turn, SAV beds, salt marsh, and dune vegetation interact with, and can exert a strong influence on, the hydrodynamics and morphology of barrier islands and back-bay systems through biostabilization of sediment and wave attenuation (Duck and da Silva 2012; Stallins 2005; Rupprecht et al. 2017). Back-bay marsh subsequently reduces loss of beach and dune sediment during overtopping or high wind events. However, most studies focus on the benefits (e.g., wave and storm protection benefits) of single habitat types like wetlands, coral reefs, or mangroves (Narayan et al. 2016, 2017; Arkema et al. 2017).

Islands may be an efficient and cost-effective FRM measure, where other shore-based solutions are not feasible or are ineffective (e.g., high-energy areas or urbanized shorelines), especially in areas near navigation channels, where clean dredged sediments are available for construction and maintenance. Many islands are at risk due to sea-level rise, subsidence, and 
inadequate sediment supply such as in the Chesapeake Bay (Wray, Leatherman, and Nicholls 1995), eastern Canada (Carter et al. 1989; Forbes et al. 2004), and the Isles Dernières island chain in Louisiana, United States (CECI 2013). If evolving conditions are captured in design and maintenance, considering processes such as sediment budget (source and net transport), expected sea-level rise, and island nourishment requirements, resilient island features can be created.

Habitat trade-offs when restoring and creating island features are inevitable. The process typically requires switching from subtidal to intertidal and supratidal habitat and may replace a single habitat with multiple habitats, simultaneously increasing diversity and resilience (Figure 11.4). Therefore, short-term changes to the ecosystem must be considered and communicated within the context of historical conditions, long-term benefits, biodiversity trends, and system trajectories such as sea-level rise (see Sections 11.2.4 and 11.4).

\section{Figure 11.4. Conceptual Illustration of Habitat Switching Components}

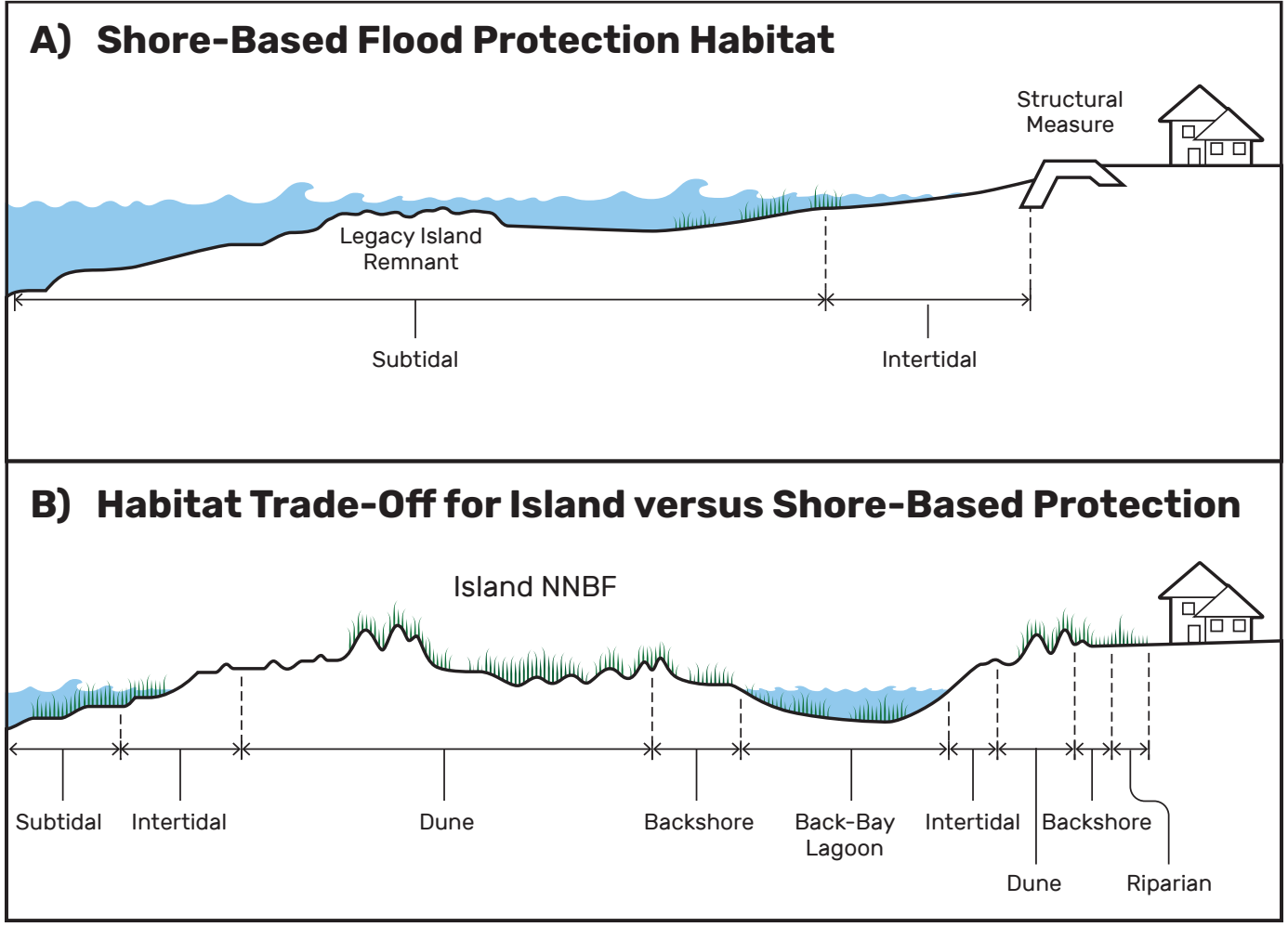


Given the relatively narrow set of conditions that support sustainable island features (e.g., sediment budget, tidal range, and foreshore slope), there is limited context under which islands are preferred to shore-based NNBF. Islands might be used to stabilize shorelines in locations where transport gradients are significant or longshore sediment transport dominates, where the foreshore slope is gentle and water depths small (making island construction or restoration feasible), or where appropriate material is available; otherwise, reefs or other alternatives may be appropriate. Island construction usually requires an existing platform to manage costs and optimize sediment capture. These platforms are typically remnants of islands that have either subsided or eroded over time due to changing climatic and sediment loading conditions. However, there are conditions where dynamic shorelines result in legacy platforms outside the present sediment transport system. In these cases, island creation on legacy platforms may be infeasible (due to lack of sediment source) or ill-advised. Under these conditions, other options that locate the island closer to the new shoreline (where benefits are maximized) should be evaluated.

\section{2 | Conceptual System Understanding}

\subsubsection{Introduction}

In addition to diverse habitat on the island, changing circulation and wave climate within the island's domain of influence may permit establishment or construction of additional aquatic habitats, such as reefs, fish spawning grounds, or SAV, which are not part of the island but provide additional resilience and ecosystem co-benefits. Like other coastal features, they are often at risk from degradation due to sea-level rise, lack of sediment sources, and erosion from storm events. A conceptual understanding of the regional system processes that influence or will be affected by the island feature is required for successful implementation. This begins with an understanding of the coastal classification and physical processes that govern the type of naturally occurring islands within an area; this understanding can be obtained from surveying local analogous features. Examining existing, local and regional, and natural analogues to support assessments of what can and cannot work at a given site is critical to successful restoration or construction of islands. Besides analogues, proper understanding of local circulation, wave climate, and predominant sediment transport patterns are critical to evaluating sustainability and maintenance requirements. An intensive survey of available system data (e.g., morphology, bathymetry, reports) can help understand historical conditions (what the system used to be) and system evolution. 


\subsubsection{Natural System}

Island features can play important roles in healthy ecological systems, in part due to the variety and diversity of habitats that they support (Figure 11.4). Barrier island-lagoon ecosystems exhibit significant biotic diversity (Gilmore 1995), deltaic islands are common features of estuarine wetland systems that encompass some of the world's most productive ecosystems (Elliott et al. 2019), and in-bay and in-lake islands can provide similarly diverse habitat, including beach and dune, upland plant community, high marsh, and low marsh. Islands may also provide predator-free habitat for nesting birds depending on their distance from the mainland and their size (Erwin et al. 2011) and may also protect local, diverse aquatic habitat such as SAV and fish spawning grounds (see Swan Island Restoration Project case study in Section 11.2.2.3) (Fullarton et al. 2006). Steep gradients and temporal disturbances or changes in environmental parameters tend to occur in the vicinity of island features, such as variations in wave and current exposure, water temperature and salinity, topography (elevation and aspect), light and shade, sediment characteristics and dynamics, and habitat. The primary factors influencing island development, migration, and erosion and accretion dynamics are the relict lithology, hydrodynamics, wave energy, sediment availability, sediment type and source, slope, and drainage of the mainland (Oertel 1985; Riggs et al. 2008). In addition, subsidence and sea-level rise are factors that increase susceptibility to loss of island features and associated coastal resilience function (Carter et al. 1989).

These processes, in turn, govern the feature characteristics that form or can be constructed or adaptively managed on an island. Islands may be a combination of beaches and dunes, high and low wetlands (marshes and mangroves), or upland vegetation and forest, suggesting that all these features can be used in isolation or combined to form the island features. Subtidal and intertidal features such as oyster reefs or SAV may also be part of the seascape that surrounds the island. These features increase ecosystem diversity, increase sediment retention, and support wave attenuation. Both sediment supply and sediment stabilization benefits of island vegetation are required to sustain the island as a system that provides coastal resilience benefits.

\subsubsection{Barrier Islands}

Geological and morphological origins of barrier islands are diverse. Some are glacial remnants from drowned river valleys (Long Island Sound and Cape Cod on the U.S. Northeast Coast), some are continuously being nourished by ongoing river discharge (Mississippi and Alabama on the U.S. Gulf Coast), and others are a combination of both (the Outer Banks in North Carolina, on the U.S. East Coast). Independent of the origin, islands provide coastal resilience benefits by trapping sediments, reducing storm surge, and protecting open coasts from waves. 
Five environments generally characterize the island system-beach and dune, barrier island, inlet and inlet deltas, back-bay lagoon, and mainland (Figures 11.1 and 11.2). The lithology, sediment type and supply, slope, and drainage of the mainland all influence barrier island dynamics (Oertel 1985; Hequette and Ruz 1991; Riggs et al. 2008). For example, on the sediment-rich northern stretch of the Outer Banks in North Carolina, United States, the barrier islands are longer, wider, and with higher elevation, and the back-barrier lagoon is also wider and forms a somewhat deeper embayment than the sediment-limited southern portion (Riggs et al. 2008).

The Outer Banks example illustrates the physical processes that lead to a variety of barrier island forms. During storm events, overwash removes sediment from the shoreface and deposits it on the back side of the island. This process erodes the front side and supports accretion on the back side; it is referred to as rolling over, a process of island migration, usually in the landward direction. Post-storm, long-term littoral and eolian transport may permit renourishment of the shoreface. Islands that have sufficient sediment supply may roll over and migrate intermittently during storm events instead of narrowing on the front and back sides. However, this process can be highly variable in response to individual storms, which can cause local, rapid erosion. Over longer time periods, rates of relative sea-level change exert considerable influence on the evolution and sustainability of barrier island systems (Carter et al. 1989). To understand the natural system and develop sustainable island features, it is critical to understand the role of vegetation in trapping sediments, both during events (trapping in the back bay) and during recovery of the shoreface (stabilization benefits of dune vegetation). Therefore, there is a feedback loop between healthy sediment transport and vegetation processes. Sediment supplied to island backshore wetlands (Figure 11.4 [B]) during overwash is critical to maintaining intertidal elevation for healthy wetland growth. This is complemented by the demonstrated efficient trapping of sediments from open water by wetland vegetation during storms and flood tide (Kirwan et al. 2016). Similarly, dune and upland plant communities are critical to trapping sediment from eolian transport and storm surge. In addition, vegetation creates biomass, as described in Chapter 10. Without this island and wetland vegetation, barrier islands would quickly dissipate during storms as sediment is transported beyond the island platform. Similarly, sediment supply is critical to maintaining backshore wetland and dune elevation. Barrier island systems are susceptible to sediment deficits caused by natural and anthropogenic changes or interruptions in sediment supply (e.g., shoreline armoring, navigation channels acting as sediment traps, and reduced river sediment load).

Depending on rates of sediment supply, recovery of overwash beaches and shoreface (including beach and dune) can take many years or decades, such that islands can be more vulnerable to subsequent storm events or relative sea-level rise (Carter et al. 1989). Storm clustering over timescales of weeks to years can affect barrier island resilience (Forbes et al. 
2004). The potential effects of climate change on storm clustering are, therefore, a concern for barrier island systems such as those on the coasts of the southern Gulf of Saint Lawrence, where sea-level rise and subsidence are already significant factors driving shoreline recession.

\subsubsection{Deltaic Islands}

Deltaic systems, which may include islands, occur where a river enters the sea. Deltaic systems often include a network of islands, wetlands, and both abandoned and active distributaries. Deltaic islands form and degrade through a combination of fluvial and coastal processes as well as subsidence. There are approximately 30 to 35 major deltas (i.e., with land areas exceeding 1,000 square kilometers) in the world (Well and Coleman 1985), and numerous smaller deltas.

Deltaic islands fronting the coast, where coastal processes are dominant, may have more in common with barrier islands than islands further upstream in the delta, and these islands are often defined as either deltaic or barrier, or both (e.g., the Nile River and Mississippi River deltas). High river discharge events both erode islands and nourish island platforms with sediment critical to compensate for subsidence. These events continually rework deltaic systems, creating new distributaries while cutting off others (Figure 11.3) and altering local processes that sustain and degrade islands and wetlands. Storm events in the open ocean have similar effects on the near-coast portion of the delta. Sediment from the river and coastal islands in the delta often help to sustain barrier islands downdrift. Anthropogenic activity has significantly reduced or diverted sediment into and within many of the world's deltas. Decreases in sediment load can deprive deltaic islands of material needed to rebuild them following storm-driven erosion events.

Deltaic islands and the nearby land are prime locations for agriculture due to rich soil sustained by episodic flooding, as well as convenient locations for cities engaged in commerce and trade. In addition to global sea-level rise, sediment deficits and the subsequent impact on delta evolution have made cities and cropland more vulnerable to flooding from both the sea and river. As humans intervene to sustain islands that are critical to resilience, these activities must account for the reduced sediment loads that sustained the original deltaic island systems. Over time, deltaic island formation or erosion can be affected by the following:

- River hydrology and hydraulics (and related climate change influences)

- Sediment availability in river watersheds

- Tidal range

- Waves and coastal sediment transport processes 
- Land use changes and anthropogenic activities (e.g., dredging, channelization, levee and dike construction, deforestation, and urbanization)

- Relative sea- and lake-level change (including climate change-related sea-level rise and uplift or subsidence)

- Density differences between river water and receiving waters (e.g., due to salinity or temperature differences)

\subsubsection{In-Bay or In-Lake Islands}

In-bay or in-lake islands respond to similar physical processes as their barrier and deltaic island counterparts. For example, Lewis, Cooper, and Pilkey (2005) found dominantly landward migration of these islands as a result of shoreface erosion on the open-water side and accretion along the back side (i.e., mainland side), a result of similar rollover processes that occur in open-ocean barrier islands. However, there are key morphological differences-in-bay and in-lake islands are usually much shorter, narrower, and lower elevation and are strongly controlled by intertidal and upland vegetation dynamics (Pilkey, Cooper, and Lewis 2009). Islands within the Chesapeake Bay are examples of in-bay islands that fit these criteria. These islands are degrading and at risk of erosion into submerged shoals (Erwin et al. 2011; Wray, Leatherman, and Nicholls 1995). Their relatively small size and proximity to maintained navigation channels makes them prime candidates for restoration through beneficial use of dredged sediments (see Swan Island Restoration Project case study). In-bay and in-lake islands have been classified by Lewis, Cooper, and Pilkey (2005) into the following three main categories:

1. Classic islands. These islands undergo similar processes as open-ocean barrier islands, such as overwashing, cross-shore migration, and longshore migration, to form recurved spits and inlets.

2. Marsh fringe islands. The most common type, these islands are created by sediment trapping on existing high marsh. The high marsh acts as an anchor point for additional sediment accretion and subsequent island formation. They often exhibit a crescent-shaped sandy beach that is oriented concave to the primary flow of water and are backed by a fringe marsh.

3. Two-sided islands. These islands experience similar physical processes on both the lagoon and the open-water side. Tangier Island located in the Chesapeake Bay is a good example of a two-sided island type. There is considerable variability among and within these island types, and although they are often dominated by intertidal and upland vegetation, they may also have beach and dune features. 


\section{Swan Island Restoration Project (Maryland, United States)}

Chesapeake Bay islands reduce erosion and wave run-up to adjacent habitats and communities while providing habitat for migratory birds and other wildlife (Erwin et al. 2011). These islands are disappearing at an alarming rate. Use of dredged sediment from navigation channels is one method applied by the U.S. Army Corps of Engineers (USACE) Baltimore District to restore the physical features of Chesapeake Bay islands (Blama 2012).To restore one such island, the USACE Baltimore District employed beneficial use of dredged sediments from a nearby navigation channel as a cost-effective way to build resilience for nearby coastal communities and maintain shallow-water channels. From October 2018 to April 2019, the USACE Baltimore District placed approximately 61,000 cubic yards of dredged sediment on Swan Island, a natural wave break for the Town of Ewell on Smith Island, within Chesapeake Bay. This area has been experiencing erosion rates of up to 3 meters per year over the past 75 years. In June and July 2019, approximately 200,000 high and low marsh and dune plants were installed (see Figure 11.5).

The restoration of Swan Island is expected to produce significant benefits in terms of ecosystem services, increased resilience to future sea-level rise, and abatement of erosive losses for adjacent communities and habitats. The pre- and post-restoration monitoring and integrated hydrodynamic and ecological model development by project partners will serve to quantify the benefits and efficacy of the island restoration and inform adaptive management actions (Herman et al. 2020).

Figure 11.5. 2018 Pre-Placement and 2019 Post-Placement Photographs
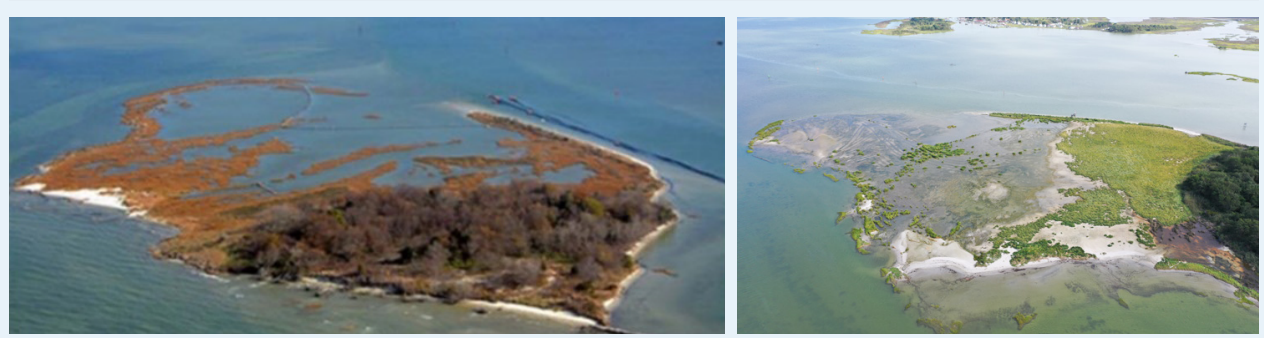

Note: The photograph on the left shows pre-placement in 2018, and the photograph on the right shows post-placement in 2019.

Source: Left photograph courtesy of U.S. Fish and Wildlife Service; right photograph courtesy of National Oceanic and Atmospheric Administration 


\subsubsection{Socioeconomic System}

Island features provide services that protect people, property, and coastlines from the destructive power of storms (Costanza et al. 2008; Arkema et al. 2013; Bridges et al. 2015; Narayan et al. 2016; Guannel et al. 2016; Narayan et al. 2017). Whether formed within bays, as barrier islands, or as a result of deltaic processes, islands have the potential to deliver diverse socioeconomic services that benefit both people and wildlife (marine and terrestrial) (Arkema et al. 2017; Reguero et al. 2018). Island resilience benefits that protect people and property are derived, in part, because islands comprise multiple complementary habitats that, in combination, are well suited to resist and recover during and after storm events. These habitats provide socioeconomic co-benefits such as coastal protection (including wave dampening, storm surge reduction, and erosion control), recreation, commercial opportunities (fisheries, agriculture, shipping, and ecotourism), and habitat for threatened and endangered species (Arkema et al. 2017). However, the exact socioeconomic co-benefits depend on the location, size (width and length), elevation, and distance from shore, among other island attributes.

The benefits of barrier island restoration in the Gulf of Mexico as measured by averted or avoided damages (a standard insurance industry risk modeling approach) and cost-benefit analysis are estimated to be valued at $\$ 5.9$ million U.S. dollars (USD) and with a 5.1 benefit-cost ratio (BCR), respectively (Reguero et al. 2018). This is lower than the damages avoided and a lower BCR than other natural features in the Gulf of Mexico such as oyster reefs (USD\$9.7 million and 7.3 BCR) and wetlands in high-risk areas (USD\$18.2 million and $8.7 \mathrm{BCR}$ ), which are cheaper to construct and often more extensive in size but similar to the damages averted for wetlands in conservation areas (USD\$5.9 million). However, islands have a greater overall BCR (5.1 BCR) than wetlands in conservation areas (1.9 BCR) and beach nourishment in the eastern (1.7 BCR) and western Gulf of Mexico (0.2 BCR). This is likely due to the lower property values or the relatively high cost of beach nourishment projects, or both (Reguero et al. 2018). However, as stated previously, island features may be an option in regions where mainland-adjacent NNBF are not feasible due, for example, to mainland urbanization or other factors. Under these conditions, islands can also provide diverse habitat co-benefits to replace those lost to urbanization or other anthropogenic land use on the mainland.

Although studies such as Reguero et al. 2018 generally take a single-habitat approach to assessing coastal protective services, this ignores the potential combined, complementary effect of integrated offshore to onshore habitat types in terms of short-term and long-term protective benefits (Lopez 2009; Guannel et al. 2016; Arkema et al. 2017). Further, as large natural features encompassing many habitat types, islands may be designed and adaptively managed to provide multiple socioeconomic co-benefits (also see CPRA 2007; Lopez 2009; Guannel et al. 2016; Grouthes and Able 2016). 
Islands and their interconnected waterways are essential to the livelihoods and cultural heritage of Indigenous people and historical working waterfronts worldwide (Jones and Garza 1998). Similarly, depending on their location, islands have the potential to significantly alter waterfront recreation, access, and visual appearance for adjacent communities. Therefore, considering these socioeconomic aspects during the Scoping Phase and Planning Phase (discussed in Section 11.2.4) may be critical to community advocacy and overall project success.

\subsubsection{Governance Context}

The governance context has a significant bearing on the feasibility and success of island NNBF projects, decision-making, and the processes by which islands are restored, constructed, and maintained. Jurisdiction and permitting requirements often depend on island and sediment borrow area location and scale; the landowner (island and borrow area); locally applicable regulatory frameworks; and interested or affected parties (e.g., users of the site and surrounding areas). Given these potential variables, the governance process necessarily includes numerous stakeholders from government, nonprofits, and private sectors.

Island construction generally involves dredging of sediments from a borrow area and placement of that material to form or restore an island in another area that may or may not have been present historically. Typically, this introduces regulatory and permitting considerations applicable to both the borrow area and placement sites. The former may be eliminated or streamlined in cases where sediment dredged for navigation (or other) purposes provides opportunities for beneficial use in island construction. Construction or restoration of an island generally requires placing sediment within a subtidal area to raise the elevation above the mean high tide mark. The process of replacing one habitat type for another, such as when subtidal seafloor is converted to intertidal marsh, is often referred to as habitat switching. Due to the well-recognized value of most subtidal areas as habitat (e.g., seagrasses, reefs, and mudflats) critical to the maintenance of fisheries' productivity, most developed countries have legal requirements that must be completed prior to initiation of dredge and placement operations. The amount and type of existing habitat proposed to be switched may be part of the regulatory framework, depending on the location, and should be addressed early in the planning and stakeholder engagement process, prior to the development of final planning and environmental assessment documents for the regulatory agency review.

For example, in the United States, Section 404 of the Clean Water Act, the Essential Fish Habitat provisions of the Magnuson-Stevens Act, the Endangered Species Act, and the Fish and Wildlife Coordination Act (among others) govern activities that may impact U.S. waters and wildlife. In Canada, the Fisheries Act requires that projects near water avoid harmful alteration, disruption, or destruction of fish habitat unless authorized by the minister 
of Fisheries and Oceans Canada (DFO). In Bahrain, there is environmental legislation pertaining to dredging and island-building activities that typically culminates in the requirement for an environmental impact assessment (Deltares and Delft Hydraulics 2008). Although the laws governing these activities vary by country, the process generally involves coordination across multiple stakeholders, jurisdictions, and agencies to gain approvals and obtain the required permits.

The most relevant steps in the process for gaining final approvals and permits are outlined in Phases 1 through 4 (i.e., Scoping Phase, Planning Phase, Decision-Making Phase, and Implementation Phase) of the five phases (note that Phase 5 is the Operations Phase) of the NNBF project development framework (described in detail in Chapter 2). However, the following list adds details relevant to governance, permitting, and approvals for island construction projects (this list is also adapted from Deltares and Delft Hydraulics [2008]):

1. Scoping Phase. The Scoping Phase includes problem identification and identification and organization of stakeholders and applicable regulatory requirements. The Scoping Phase usually begins with the identification of a site or a problem that requires an action to resolve (e.g., an eroding island in front of a waterfront community). Next, ownership of the island site and surrounding areas, including borrow areas, where construction will occur, should be identified along with the potential regulatory requirements and stakeholders. Stakeholder engagement allows all regulatory agencies and local communities who live and work in the project area to provide input. This improves system understanding and supports refinement of objectives and methods. Local stakeholders, in particular, should be involved throughout subsequent phases to improve design and implementation and increase community awareness and advocacy. Stakeholders may include the following:
a. Landowners
b. Government bodies (federal, state, provincial, and local municipalities)
c. Financial institutions
d. Other partners (e.g., nonprofits, commercial interests, local community groups)

2. Planning Phase. During this phase, a preliminary project description and design are developed to determine the regional environmental, cultural, and socioeconomic co-benefits and impacts. Preliminary description and design alternatives should be shared with regulators and stakeholders to identify and address relevant issues such as endangered species, essential fish habitat, and cultural resources. This will help to facilitate project approvals through the regulatory process.

3. Decision-Making Phase. During the Decision-Making Phase, a final project description with alternatives is presented and reviewed by the relevant stakeholders. Criteria and basis for the selected alternatives should be clearly presented to justify recommendations and typically include relevant information such as cost, habitat trade-offs, technical performance, and benefits for each alternative. 
4. Implementation Phase (specific to permit and license regulatory approvals). As part of project implementation, the regulatory approval process and permits must be completed. At this stage, decisions on the final project design and implementation strategy, along with associated adaptive management or monitoring procedures, are documented (in country- and region-specific format) for final approval and issuance of permits. Depending on the regulatory framework, permits or licenses could take the following forms and may include mitigation actions or conservation recommendations prescribed by the regulatory entities:

a. Dredging or extraction permits from the borrow area

b. Island construction or reclamation permit (sediment placement)

\section{Environmental Permits and Authorizations in Canada}

In Canada, the Fisheries Act requires that projects near water avoid harmful alteration, disruption, or destruction of fish habitat and prohibits activities, other than fishing, that cause the death of fish. The Fisheries Act recently underwent a significant overhaul, with potentially significant implications for permitting and authorization of island NNBF projects. For example, the updated act contains new provisions for the development of regulations for permitting of larger-scale ("designated") projects, and codes of practice for smaller, more routine projects; habitat restoration; preservation of marine biodiversity; and participation of Indigenous peoples in project reviews. DFO publishes recommended measures to protect fish and fish habitat. However, these measures include avoiding work in water, or placing fill below the high water mark, which are inevitably involved in island NNBF construction. Thus, island projects will almost always require, at a minimum, the proponent to submit a request for review to DFO's Fish and Fish Habitat Protection Program. The review determines the following: (1) if the project would impact an aquatic species at risk; ( 2 ) if the activity could result in the death of fish and the harmful alteration, disruption, or destruction of fish habitat; and (3) if the project will need ministerial authorization under the Fisheries Act. If a Fisheries Act authorization is applied for, and granted, it will include terms and conditions that the proponent must follow to avoid, mitigate, offset (counterbalance impacts), and monitor the impacts to fish and fish habitat resulting from the project. 


\section{3 | Objectives and Metrics}

An NNBF island can be a potential solution for meeting an overall project objective or strategic goal (see Chapters 2 and 9 ). This section seeks to define objectives that may be addressed by NNBF island solutions within the context of an overall coastal resilience or shoreline management strategy (see Chapter 9 ). Due to the complexity and dynamic nature of island ecosystems and the limited number of case studies, a certain degree of flexibility is often desired when setting environmental objectives and metrics, and planning for adaptive management of island NNBF. Nevertheless, it is possible (and desirable) to establish quantitative objectives and performance metrics (Table 11.1).

Objectives and metrics should be defined to enable unbiased assessment of project performance and to support adaptive management (i.e., specific, measurable, achievable, relevant, and time-bound [SMART] objectives-see chapter 9). Project objectives are defined as the project goals (Table 11.1), and performance metrics are measures of success in achieving project objectives. Performance metrics should be aligned with stakeholder risk mitigation objectives and risk tolerances (e.g., island feature is dynamically stable and provides acceptable flood protection for design events with specified probabilities). The objectives established for a project will guide the monitoring, maintenance, and adaptive management of the island NNBF (Section 11.6). For example, Davis et al. (forthcoming) identified specific goal statements and performance metrics that reflect the primary project objective of quantifying coastal resilience performance of Swan Island, in Chesapeake Bay (see Swan Island Restoration Project case study in Section 11.2.2.3); this includes goals such as determine how the restoration actions have influenced the capacity of Swan Island to provide protection from wave energy to the Town of Ewell, Maryland, United States, and a performance measure of "maintain or increase relative to designed elevations." One potential scenario, then, is that decreased designed elevations over time may be cause for an adaptive management action, such as placement of more sediment or planting vegetation to stabilize elevations (Davis et al., forthcoming; see "Simplified Resilience Conceptual Model for Swan Island Restoration Project [Maryland, United States]" in Section 11.6). Therefore, the selection of monitoring parameters, maintenance, and adaptive management of the island NNBF will naturally stem from the project objectives and performance metrics identified to evaluate project success. 
Table 11.1. Potential Project Objectives Satisfied by Islands and Associated Performance Metrics

\begin{tabular}{|c|c|c|c|}
\hline $\begin{array}{c}\text { Range of } \\
\text { project } \\
\text { objectives }\end{array}$ & $\begin{array}{l}\text { Island } \\
\text { function }\end{array}$ & Example objective & $\begin{array}{c}\text { Example performance } \\
\text { metric or measure } \\
\text { of success }\end{array}$ \\
\hline \multirow[t]{6}{*}{ Engineering } & Wave attenuation & $\begin{array}{l}\text { - Reduce storm wave } \\
\text { exposure and associated } \\
\text { risk } \\
\text { - Reduce erosion risk }\end{array}$ & $\begin{array}{l}\text { - Wave energy and height } \\
\text { reduction during a storm } \\
\text { - Reduction in erosion rate } \\
\text { - Wave run-up elevations } \\
\text { - Mean wave overtopping } \\
\text { discharges } \\
\text { - Survival of vegetation }\end{array}$ \\
\hline & Surge attenuation & $\begin{array}{l}\text { Reduce flood risk } \\
\text { associated with inundation }\end{array}$ & $\begin{array}{l}\text { - Surge reduction during a storm } \\
\text { - Reduction in inundated land } \\
\text { area during a storm } \\
\text { - Survival of vegetation }\end{array}$ \\
\hline & $\begin{array}{l}\text { Sediment trapping } \\
\text { and land building }\end{array}$ & $\begin{array}{l}\text { - Increase land elevation } \\
\text { - Increase acreage } \\
\text { - Reduce erosion } \\
\text { - Stabilize shoreline in lee of } \\
\text { island }\end{array}$ & $\begin{array}{l}\text { - Temporal increase in surface } \\
\text { elevation } \\
\text { - Temporal reduction in erosion } \\
\text { or accretion } \\
\text { - Beach profiles that are stable } \\
\text { over time }\end{array}$ \\
\hline & $\begin{array}{l}\text { Mainland shore } \\
\text { stabilization }\end{array}$ & $\begin{array}{l}\text { Protect infrastructure and } \\
\text { land-based natural features } \\
\text { (wetlands, for example) }\end{array}$ & - Shoreline position \\
\hline & $\begin{array}{l}\text { Beneficial } \\
\text { placement of } \\
\text { sediment }\end{array}$ & $\begin{array}{l}\text { Provide cost-effective } \\
\text { disposal option for } \\
\text { sediment dredged for other } \\
\text { purposes } \\
\text { - Reduce other maintenance } \\
\text { requirements (nourishment } \\
\text { with mined material) }\end{array}$ & $\begin{array}{l}\text { - Savings in dredging cost } \\
\text { - Measured reduction in } \\
\text { frequency and magnitude } \\
\text { of other construction and } \\
\text { nourishment activities }\end{array}$ \\
\hline & $\begin{array}{l}\text { Provide physical } \\
\text { conditions } \\
\text { consistent with } \\
\text { environmental } \\
\text { objectives }\end{array}$ & $\begin{array}{l}\text { Provide required land area } \\
\text { and range of elevations to } \\
\text { support colonization by } \\
\text { flora and fauna } \\
\text { - Provide appropriate } \\
\text { exposure to fresh- and } \\
\text { saltwater conditions } \\
\text { (overwash), waves, and } \\
\text { currents } \\
\text { - Provide for appropriate } \\
\text { supply of natural sediment } \\
\text { and nutrients } \\
\text { - Provide appropriate } \\
\text { water renewal or flushing, } \\
\text { drainage, and water quality } \\
\text { Control exposure to } \\
\text { waterborne debris }\end{array}$ & $\begin{array}{l}\text { - Land area at different } \\
\text { elevations } \\
\text { - Changes in land area at } \\
\text { different elevations } \\
\text { - Island crest elevations } \\
\text { - Observed frequency and } \\
\text { duration of overwash events } \\
\text { - Wave and current speeds at } \\
\text { locations near the island } \\
\text { - Water residence times } \\
\text { - Water quality parameters } \\
\text { (temperature, salinity, } \\
\text { suspended sediment } \\
\text { concentrations) } \\
\text { - Quantities and distribution of } \\
\text { debris }\end{array}$ \\
\hline
\end{tabular}




\section{Range of project objectives}

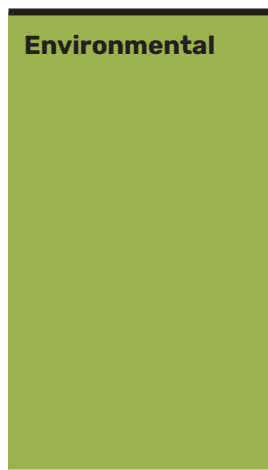

\section{Island} function

\section{Example objective}

- Provide range of habitat types (flora and fauna)

- Provide space for migratory bird resting and nesting

\section{Example performance metric or measure of success}

\begin{tabular}{|c|c|c|}
\hline $\begin{array}{l}\text { Provide habitat } \\
\text { diversity }\end{array}$ & $\begin{array}{l}\text { Provide range of habitat } \\
\text { types (flora and fauna) } \\
\text { - Provide space for migratory } \\
\text { bird resting and nesting }\end{array}$ & $\begin{array}{l}\text { - Habitat ranges } \\
\text { - Species utilization } \\
\text { - Presence or rate of protected } \\
\text { species } \\
\text { - Migratory bird seasonal } \\
\text { population }\end{array}$ \\
\hline $\begin{array}{l}\text { Provide habitat } \\
\text { area }\end{array}$ & $\begin{array}{l}\text { - Provide habitat for species } \\
\text { of interest }\end{array}$ & $\begin{array}{l}\text { - Habitat area or type } \\
\text { - Inundation period }\end{array}$ \\
\hline $\begin{array}{l}\text { Provide sustainable, } \\
\text { self-sustaining } \\
\text { habitat }\end{array}$ & $\begin{array}{l}\text { - Provide stability or growth } \\
\text { of vegetation }\end{array}$ & $\begin{array}{l}\text { - Area covered by vegetation } \\
\text { - Vegetation density, percent } \\
\text { survival }\end{array}$ \\
\hline Education & $\begin{array}{l}\text { - Increase education } \\
\text { facilities }\end{array}$ & $\begin{array}{l}\text { Number of visitors to visitor } \\
\text { centers } \\
\text { - Number of signs installed } \\
\text { - Number of presentations given } \\
\text { to local community }\end{array}$ \\
\hline Tourism & - Attract visitors & $\begin{array}{l}\text { - Business transactions } \\
\text { - Number of visitors }\end{array}$ \\
\hline Navigation & $\begin{array}{l}\text { - Provide safe harbor } \\
\text { - Provide sustainable and } \\
\text { cost-effective dredged } \\
\text { sediment management }\end{array}$ & $\begin{array}{l}\text { - Use by small vessels during } \\
\text { non-events } \\
\text { - Damage to vessels during } \\
\text { events } \\
\text { - Risk reduction to large ships } \\
\text { entering ports } \\
\text { - Quantity of dredged sediment } \\
\text { used beneficially } \\
\text { - Island sediment budget }\end{array}$ \\
\hline Recreational & $\begin{array}{l}\text { Provide recreational } \\
\text { opportunities } \\
\text { - Increase public well-being }\end{array}$ & $\begin{array}{l}\text { - Usage levels } \\
\text { - Concession levels } \\
\text { - Social science metrics } \\
\text { - Recreational fish populations }\end{array}$ \\
\hline Fisheries & $\begin{array}{l}\text { - Increase commercial } \\
\text { fishing productivity }\end{array}$ & $\begin{array}{l}\text { - Commercial species population } \\
\text { - Commercial fishing take }\end{array}$ \\
\hline $\begin{array}{l}\text { Avoided } \\
\text { damages }\end{array}$ & $\begin{array}{l}\text { Protect area from flood } \\
\text { hazards } \\
\text { - Reduce flood risk to } \\
\text { communities }\end{array}$ & $\begin{array}{l}\text { Stabilization or decrease } \\
\text { in damage to buildings in } \\
\text { infrastructure over time } \\
\text { - Measured reduction in injuries } \\
\text { or fatalities due to extreme } \\
\text { events } \\
\text { - Decrease in flood insurance } \\
\text { premiums or emergency } \\
\text { response costs }\end{array}$ \\
\hline
\end{tabular}

response costs 
Islands are dynamic features; therefore, their success in achieving predefined objectives and observed metrics may fluctuate. Changes in performance may be gradual, may be sudden and dramatic (e.g., in response to tipping points or storm events that exceed design criteria), or may change over time. In particular, islands are naturally exposed to waves and hydrodynamic processes from a broader range of directions than shore-based NNBF, and, therefore, may experience higher susceptibility to changes in climate variables (e.g., direction of wave incidence). Also, overwash may reduce dune height, which temporarily reduces storm surge mitigation benefits to the mainland. However, natural accretion of dunes post-storm (recovery) may reinstate coastal resilience performance. These processes must be considered when establishing performance objectives and metrics, and monitoring may be required to re-evaluate performance after post-storm recovery.

Island features can be designed to help achieve multiple environmental objectives related to the provision of habitat and species diversity. The complex feedback and interactions between physical and biological processes determine island ecosystem function (Brantley et al. 2014) and the extent to which environmental objectives and metrics for island NNBF can be satisfied. Positive correlations between island area and species richness have been widely documented (Ricklefs and Lovette 1999, and references therein).

As stated previously, construction of island features typically requires placement of sediment in subtidal or intertidal areas, resulting in habitat switching. This trade-off inevitably leads to short-term losses of marine habitat (see discussion of recovery versus disturbance in Chapter 9, Section 9.5.3.7), which must be balanced against longer-term objectives (e.g., increased habitat diversity with greater coastal protection capacity; Figure 11.4).

Objectives, metrics, and performance can be expected to change over time, or have temporal components. For example, tighter control on wave exposure may be required during the initial stages following construction or restoration of an island feature to allow time for vegetation to establish. Beyond this initial period, objectives for wave exposure may be relaxed. Similarly, periods of strong habitat and ecosystem growth and establishment may be interspersed with periods of stagnation or decline, depending on system-wide changes and natural (e.g., seasonal or decadal) fluctuations.

\section{4 | Design Considerations}

The design process for island features generally follows established frameworks for coastal engineering design (e.g., Part V of USACE 2002; CIRIA 2010) and other coastal NNBF (Chapter 2). Design considerations for islands will necessarily draw on those for other coastal features (e.g., beaches, dunes, and wetlands), because islands are typically composite features. However, there are some unique design considerations for islands, particularly with 
respect to the physical processes in an open-water setting, habitat diversity, and interactions with surrounding areas and other processes (e.g., vegetation and sediment dynamics). The design team should be multidisciplinary, consisting of engineers, ecologists, oceanographers, dredgers, and others. Furthermore, there are a limited number of case studies for island NNBF that capture the wide range of conditions (e.g., hydrology, wave, climatology, vegetation, geomorphology) in which island NNBF will be constructed. This section identifies some key considerations for island NNBF at each of the following five identified design phases:

- Establishing design criteria

- Site characterization

- Conceptual design

- Evaluation and analysis of design alternatives

- Detailed design development

\subsubsection{Design Criteria}

Similar to other NNBF, the design process for island features typically begins with establishing basic design criteria to meet and confirm the overall project objectives (see Section 11.3).

These criteria may include but are not limited to the following:

- Regulatory criteria and project constraints

- Project coordinate systems and datums

- Design life, design return period, or acceptable risk of design storm encounter

- Role of the island feature within the overall resilient system (because islands are often key components of multiple-lines-of-defense systems) and areas where the island is intended to provide FRM benefits

- Geotechnical and seismic design criteria

- Island and shore stability criteria

- Wave, water level (including relative sea-level change considerations), current, and wave overtopping criteria

- Water quality and circulation and renewal criteria, both from the perspective of providing for healthy island ecosystems and avoiding negative impacts by altering circulation patterns in surrounding waters

- Habitat criteria (shade, aspect, exposure, substrate, vegetation types, woody debris, water velocities, depths, and habitat suitability) 
- Vegetation ecology criteria (elevations, salt tolerance, aspect, tolerable slopes, frequency and duration of inundation, wave exposure, and control of invasive species)

- Beach quality criteria (if applicable), including wave exposure, stability, safety, debris, materials, and tolerances

- Ability of the system to recover from events through natural processes

- Monitoring and maintenance criteria

- Navigation criteria, if applicable (i.e., preserving minimum fairway widths and exposure to ship wake)

- Criteria for engineered control structures (if applicable)

- Approaches to short- and long-term phasing and adaptation (e.g., sequencing to align with overall coastal resilience strategy and flexibility in the design for adaptation to sea-level rise)

- Life-cycle cost considerations (e.g., preference for capital versus maintenance investment)

Establishing design criteria may involve multiple iterations and discussion among the owner, designer, regulators, subject matter specialists, and stakeholders (see Chapters 2 and $\underline{3}$ ). This step also serves to identify requirements and details for studies, field data collection, and analysis conducted at later design stages.

Design criteria for island NNBF can differ in a number of ways from those for conventional offshore structures (e.g., breakwaters) and shore-based NNBF. For example, key objectives of barrier island NNBF are typically to attenuate waves and storm surges or stabilize mainland shorelines. However, it is also recognized that some overwash and inundation of barrier islands is needed to replicate the natural processes that contribute to island building (Leatherman 1976) and sustainable backshore wetland growth and survival (Walters et al. 2014; Schupp et al. 2013). Careful consideration should, therefore, be given to balance competing objectives when establishing design wave and water level criteria, and wave overtopping and transmission criteria for an island NNBF. Balancing these competing objectives directly influences island design profiles (crest levels and widths, seaward slope), the sediment characteristics required to meet stability criteria, and the types of habitats and ecosystems that can be supported. For example, the design criteria for beach crest elevations of the Deltaport East Causeway barrier islands (see Deltaport East Causeway Barrier Island Features case study) were set by considering local wave and water level conditions, as well as local, natural barrier beach analogues. 


\section{CASE STUDY:}

\section{Deltaport East Causeway Barrier Island Features (British Columbia, Canada)}

Deltaport East Causeway is on the west shore of the Fraser River delta (Figure 11.6) and is the road and rail link connecting the Port of Vancouver's largest container terminal to mainland British Columbia, Canada. In 2010, Vancouver Fraser Port Authority constructed habitat features along the shore of the causeway as a condition of the Fisheries Act authorization for a port expansion. The features were integrated with the causeway shore protection structures that provide FRM functions to this critical transportation corridor. Post-construction, compliance monitoring of physical and biological metrics indicated that wave and wind exposure was inhibiting habitat function. Performance deficiencies were primarily related to salt marsh productivity and retention of sediment.

Figure 11.6. Location of Deltaport Causeway Site

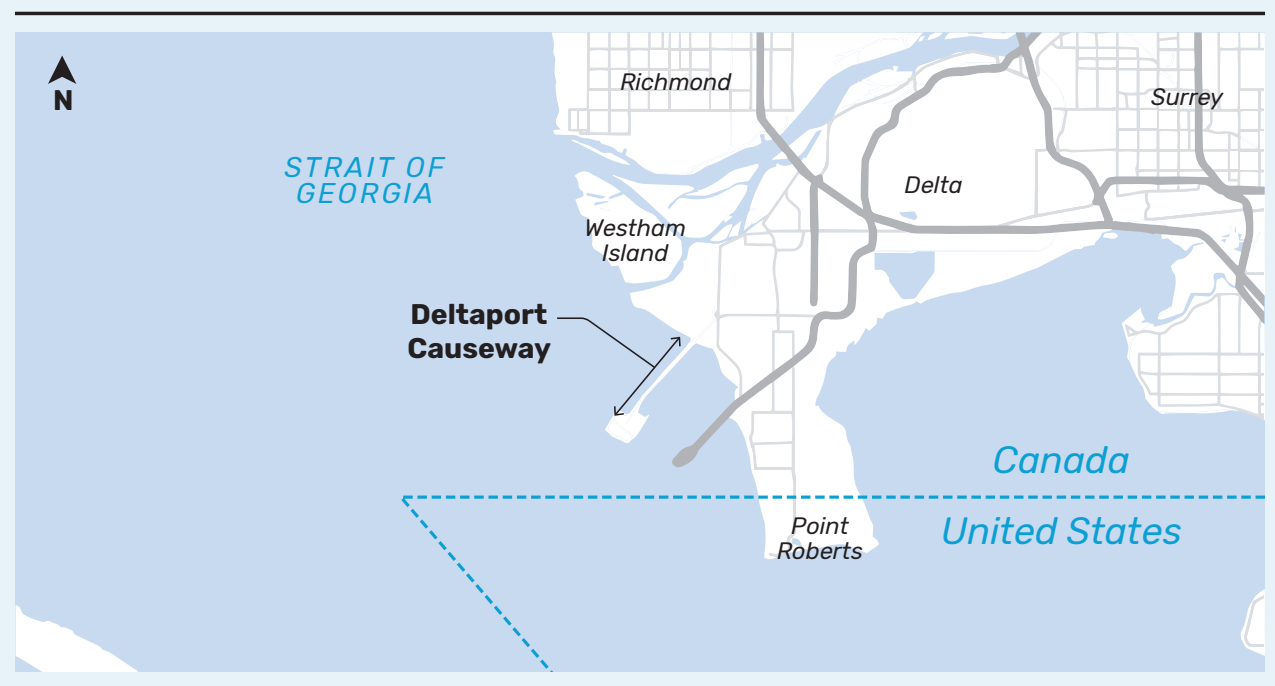

In 2016, a remedial concept was developed to address these performance deficiencies. Several barrier beach and back-beach marsh features were constructed, making use of on-site materials, to create and enhance habitat. The barrier islands now provide FRM functions for sections of the causeway where rock armoring is not present. 
The barrier island feature designs were developed considering the local wave climate and geomorphological principles applicable to crenulate beaches, and by drawing on observations from several local, natural analogues. The barrier beaches and artificial headlands provide a dynamically stable framework on which to support diverse habitat, even under conditions where sediment supply has been interrupted. One year following construction, the beaches and marshes had performed well morphodynamically (see Figure 11.7). Establishment of new salt marsh has required adaptive management due to challenges including accumulation of eelgrass wrack from adjacent subtidal flats and large woody material (logs), and scour of back-beach marshes during strong southeasterly winter storms. Field monitoring has demonstrated the need for adaptive management and provided the following valuable insights:

- Salt marsh establishment takes time. Even small waves generated along short, nearshore fetches can have significant impacts on substrate stability and vegetation survival during the initial stages of marsh establishment. This is a key consideration for island NNBF, which are exposed to waves from a broader range of directions than other features. Cluster plantings offer some resistance to wave action.

- Wrack and large woody material accumulation can inhibit drainage and vegetation survival in the early stages of marsh establishment. Floating barriers can be effective but must be designed to withstand wrack, debris, and hydrodynamic loads.

Figure 11.7. Salt Marsh Vegetation Establishment on Leeward Side of the Barrier Islands

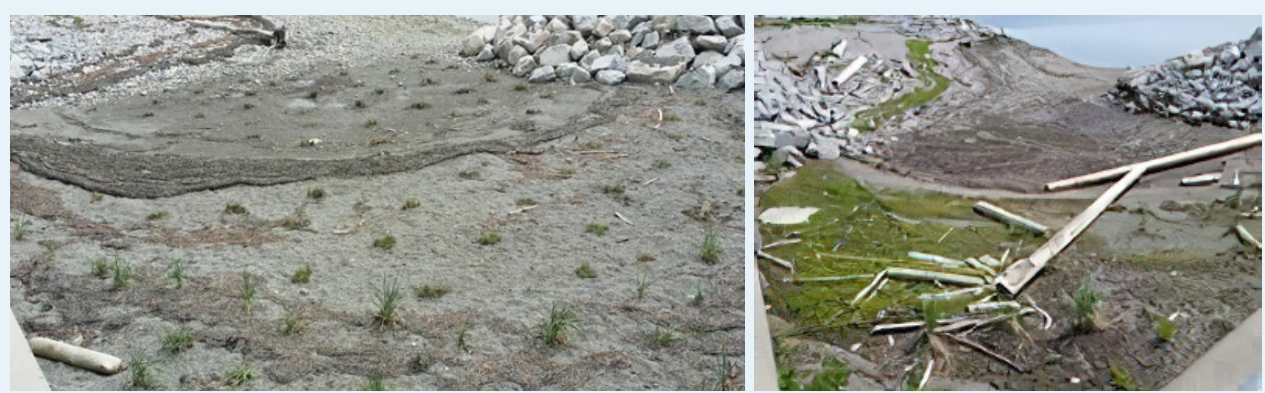

Note: The left photograph is immediately after construction, and the right photograph is approximately 1 year after construction.

Source: Courtesy of Phil Osborne, Golder Associates 
On marine coasts, setting appropriate design criteria to accommodate relative sea-level change is an important consideration for any coastal engineering project but requires special considerations for island NNBF. For offshore structural measures (e.g., breakwaters) providing resilience functions, elevating the crest may be an acceptable approach to accommodating projected sea-level rise over the design life, and this could be reflected in the design criteria. However, overbuilding may not be appropriate for an island NNBF because of the requirements to facilitate some overwash at the beginning of the design life to support habitat establishment, as described in the Deltaport East Causeway example (see Deltaport East Causeway Barrier Island Features case study). Island NNBF are, therefore, more likely to involve, and are generally more amenable to, solutions incorporating adaptive management (see Chapter 7), and this should typically be reflected in the design criteria.

Particularly for islands, the regulatory and governance regime often plays an important role in establishing design criteria, because island NNBF almost always involve placement of material below the waterline, which can trigger design requirements for preventing or minimizing adverse impacts on subtidal habitats, navigation, fisheries, and other marine-based activities. Obtaining an early indication of the design implications is important to guide the design process and stakeholder engagement.

\subsubsection{Site Characterization}

Characterizing existing or baseline system conditions and projected future changes in the natural system encompassing a proposed island NNBF site are crucial prerequisites for developing a design that works with natural system processes (see Section 11.2.2). The open-water environment at island sites is often subject to harsher conditions and more temporal and spatial variability than comparable shore-based NNBF sites, which elevates the importance of adequately characterizing site conditions to ensure a robust design.

Adequate field data are required to support the effective design of islands to support FRM. The availability of baseline field measurements and observations to characterize key physical processes at the project site is critical for the development of concepts that are robust and sustainable, to support model verification, and to guide and inform construction operations. Data needs and sources, as well as methods and approaches for characterizing conditions at coastal and offshore sites, are provided in several established guidance documents (e.g., USACE 2002; CIRIA, CUR, and CETMEF 2002; CIRIA 2010), and may involve field measurements or modeling (numerical or physical). At a minimum, it is important to characterize the following:

- Bathymetry (and topography if applicable)

- Hydrodynamic conditions (water levels, circulation, waves-ambient and extreme) 
- Sediment transport patterns (ambient and extreme) and geomorphology (sediment characteristics, lithology, sediment sources and sinks, sediment mobility, sediment budgets, longshore drift, storm-induced changes)

- Geotechnical conditions

- Environmental conditions (inundation, water quality, native habitat types, flora and fauna-abundance and diversity)

Often, the creation of island NNBF may involve re-establishing or restoring relict or degraded island features to enhance coastal resilience functions. This requires developing an understanding of historical geological conditions at the site that led to the existing state and the existing coastal resilience function provided, so that future changes can be anticipated.

Depending on regional or site-specific considerations and known hazards, it may be important to characterize the potential exposure of the site to meteorological and hydrological extremes, ice, waterborne debris (e.g., logs), crustal uplift and subsidence, tsunami, and seismic loading. For example, liquefaction of sediment during an earthquake could potentially cause settlement and subsidence of an island NNBF and loss of resilience function. If such an event were to coincide with a storm surge, flooding could occur. It should be noted that these types of considerations are not unique to island NNBF; similar considerations (i.e., the need for multihazard assessments) are relevant to the design of any FRM measures, and in line with established disaster risk reduction principles such as those identified in the United Nations Sendai Framework (United Nations 2015).

The extent of field data and levels of analysis required to adequately characterize an island site will depend on a number of considerations including project scale and location, risks and risk tolerances, criticality of the proposed NNBF within the overall FRM strategy (e.g., whether the island is part of a multiple-lines-of-defense system), overall project cost, acceptable uncertainty, and adaptive management strategies. However, system and process understanding typically supports more accurate appraisals of design alternatives, facilitates robust and cost-effective design, and reduces project risks during all stages of a project life cycle (design, construction, maintenance, and adaptive management).

\subsubsection{Conceptual Design}

Once design criteria have been established, the process of developing (and later evaluating) conceptual (preliminary) design options can begin. The level of effort and analysis involved in developing and evaluating options and the types of tools used for the analysis will typically depend on the size of the project, perceived project risks, and the number of potentially viable options. 
Key considerations when identifying and developing island NNBF conceptual designs include the following:

- Identifying the potential role of an island NNBF within the context of broader FRM strategies (e.g., as part of a multiple-lines-of-defense approach)

- Assessing (at a conceptual level) how the island could potentially address specific project objectives and provide specific FRM functions, such as wave attenuation (see Section 11.3)

- Understanding how existing natural conditions at the site have implications for the design, as follows:

- Meteorological (wind), hydrodynamic (waves, water levels, currents, and circulation), and geomorphological processes often place constraints on the orientation, shape, and water depths where island construction or restoration is feasible.

- Local water depths and bathymetric features frequently limit where island construction or restoration will be economically feasible (deep waters require larger volumes of material for construction, whereas shallow waters create challenges for construction access).

- Geotechnical conditions can affect the viability and cost of island creation or restoration (e.g., excessive settlement and consolidation, the presence of fine or soft sediments, or containment requirements may be limiters).

- Consider availability of materials for island construction and shore stabilization, and compatibility with native materials (e.g., coarser materials may allow for steeper cross-shore profiles and, therefore, reduced island footprints, but may not be compatible with existing beach materials; different soil types may be required to support establishment of different types of vegetation and habitat). Due to the unique biogeography of island ecosystems, the use of locally sourced, ecotypic plant materials is even more important for ensuring success in the revegetation of native plants.

- Existing uses of coastal waters may determine acceptable areas for island encroachment (such as fisheries, navigation, subsea pipelines, and utilities).

- Understanding the project footprint and impacts on the surrounding environment: The range of directions and severity of processes to which the site is exposed affect the project footprint, the extent of mainland areas where coastal resilience benefits can reliably be provided, and considerations for island and habitat stability. When analyzing design wave conditions, processes such as wave blocking and wave diffraction effects should be considered (Figure 11.8).

- Identifying natural analogues, preferably near the site or at least in similar environments, can help to provide confidence in the viability of an island NNBF solution at a particular site. However, the existence of local, natural analogues does not in itself guarantee the feasibility of island NNBF solutions. In areas where existing barrier beaches are threatened by significant erosion, relative sea-level rise, disruption of transport patterns, subsidence, or other natural processes, island NNBF may be challenging to implement and require significant adaptive management to maintain. 
- Integration with other natural and human-made coastal and offshore features

- The potential to adopt hybrid solutions that incorporate structural measures to enhance coastal resilience benefits, improve island NNBF longevity, or reduce maintenance requirements

- Assessing order-of-magnitude project construction costs to provide an indication of whether cost objectives or budgetary constraints are consistent with project technical objectives, and to support with evaluation of alternatives: A first order approximation of costs developed at the conceptual design stage should typically be refined and updated throughout the course of the design process.

Key features of an island NNBF, and associated considerations, to be established through the design process, are listed in Table 11.2.

Table 11.2. Island Components and Design Considerations

\section{Feature or component of island NNBF}

Island plan form and layout

\section{Design considerations}

- Footprint and area of influence

- FRM function

- Stability (e.g., orientation with respect to dominant waves, response to hydrodynamic forcing, allowances for seasonal adjustments, dynamic stability, and sediment budgets)

- Materials: layout affects quantities (e.g., fill) and associated project cost; local availability may constrain design options

Island profile

- Crest elevations (linked to local water level variability and desired inundation regimes for various habitat types, controls wave overtopping discharges and wave transmission into leeward areas, and affects frequency of overwash events needed to sustain back-bay habitat)

- Slopes (linked to stability criteria and sediment characteristics, drainage, and vegetation)

- Stability (profile response to storms)

- Materials: profile affects quantities (e.g., fill) and associated project cost; local availability may constrain design options

Control structures (e.g., groins, toe berms, breakwaters, and buried seawalls)
- May help to stabilize or prolong life of NNBF, minimize maintenance, or exert additional control on island response to storms

- Effectiveness of different control structures depends on dominant physical processes and local and regional conditions (e.g., groins are most effective where sediment transport processes are dominated by longshore drift; toe berms may be less effective or counterproductive in macrotidal areas)

- Beyond physical effects, control structures may incorporate features to promote ecosystem function (e.g., Vertipools and textured concrete armor units)-see Chapter 14 for details on enhancing structural measures 
Feature or component of island NNBF

\section{Design considerations}

Materials

- Sediment characteristics (affect stability response to wave and current action, and ability to support different vegetation or habitat types)

- Compatibility with native materials (sediment, vegetation)

- Vegetation tolerance to environment (salt, wave, and current exposure)

- Local availability of ecotypic plant materials

- Natural supply of material (sediment budgets)

Target habitats

- Inundation regime (elevation)

- Sensitivity and tolerance to environmental conditions (waves, currents, wind, and salt)

- Local, natural analogues

Figure 11.8. Project Footprint and Area of Influence

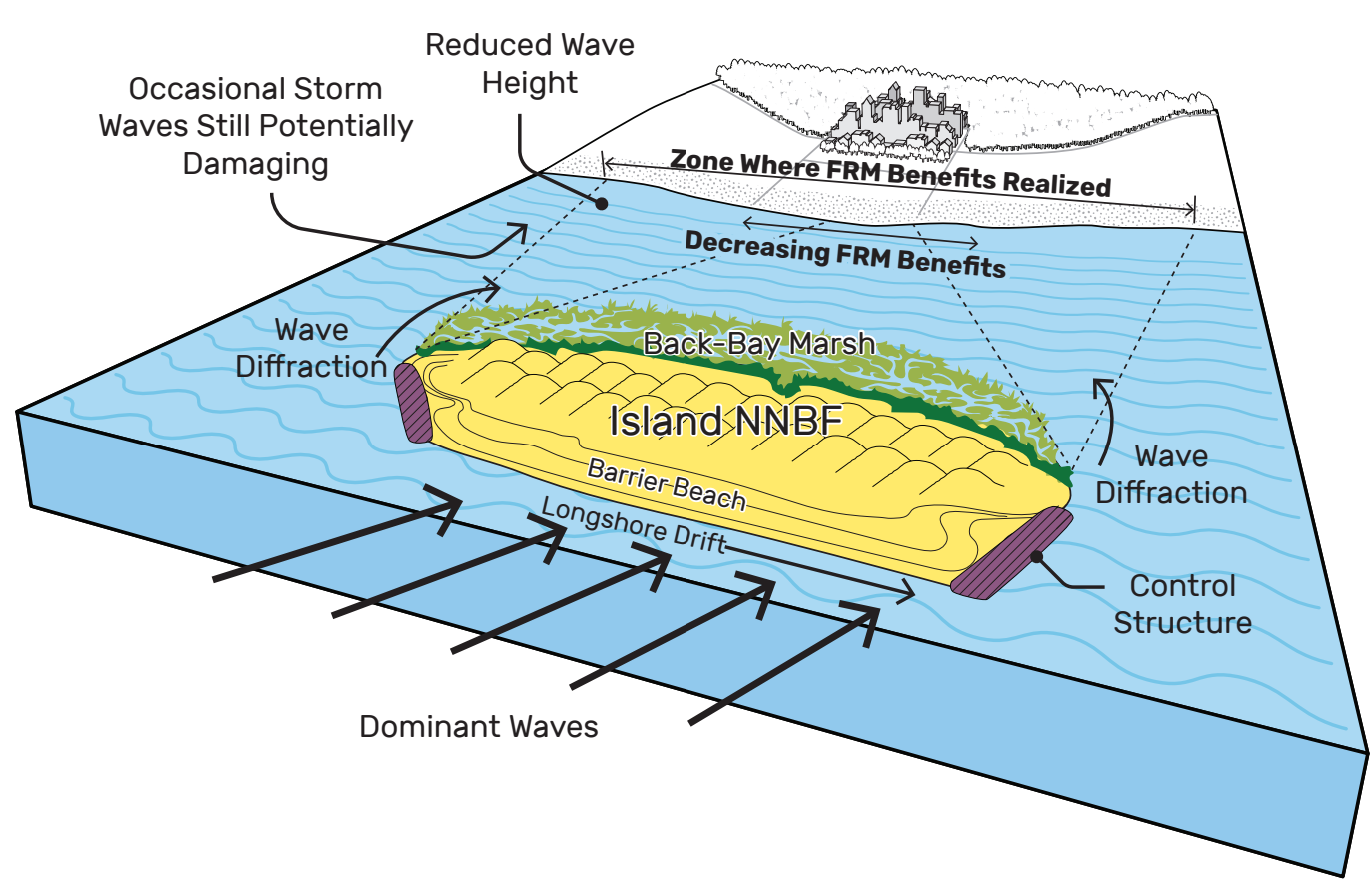

In addition to the positive impacts associated with coastal resilience and ecosystem health, the potential negative impacts of an island NNBF on the surrounding environment and downdrift coastlines is a key consideration at the conceptual design phase. The potential for 
an island NNBF to temporarily or permanently affect sediment transport gradients, circulation, water quality, and existing habitats in surrounding areas should be considered in light of observations and lessons learned with respect to the negative effects of island reclamation on marine environments (e.g., Smith et al. 2019). Potential adverse impacts include but are not limited to the following:

- Modification of wave and current conditions in leeward and downdrift regions, potentially leading to unwanted erosion and accretion

- Damage to sea, lake, or riverbed habitat and ecosystems at the island site and surrounding areas as a consequence of construction

- Unwanted habitat switching as a result of changes to physical and chemical system

- Impacts on water quality (e.g., impoundment of water between islands and mainland or creation of stagnant zones)

- Impacts on fisheries and navigation associated with changes in bathymetry, channel widths, currents, and wave exposure due to the presence of an island

In-depth analyses may be required or desired to better assess or constrain the risk of adverse impacts, and design modifications or adaptive management approaches may be needed to mitigate risks.

Much of the analysis performed in conceptual design will support evaluation and analysis of design alternatives (Section 11.4.4).

\subsubsection{Evaluation and Analysis of Design Alternatives}

Evaluation of conceptual design options should take into account technical, economic, environmental, and sociocultural criteria and can be mostly qualitative or may involve detailed multicriteria analysis and complex economic modeling (see Chapter 6). Stakeholder involvement in the evaluation is typically required (see Chapter 3 ). The evaluation is typically based on a comparison to a baseline "do nothing" scenario, which may include projected future system changes (e.g., climate change effects or urbanization).

When comparing and evaluating design alternatives involving island NNBF, it is important to recognize that there can be socioeconomic trade-offs in the costs and benefits of island construction and restoration. In some instances, beneficial use of dredged material from navigation channels is a cost-effective method to build and restore islands (see Swan Island Restoration Project case study in Section 11.2.2.3). Following a multicriteria analysis of seven different dredging management strategies, Bros (2007) recommended that sediment dredged from the Fraser River delta navigation channels in British Columbia, Canada, be used to provide habitat and FRM benefits on deltaic islands as the preferred strategy. 
During the evaluation stage, analytical tools should be applied to refine the initial design. Analytical tools include general rules of thumb or simple equations provided in design manuals and textbooks (e.g., USACE 2002; Kamphuis 2010), as well as more sophisticated numerical modeling or physical modeling tools. In some cases, selected field experimentation can also provide valuable insight to project performance at larger scales. Selecting appropriate analytical tools to support island design applications depends on a number of considerations, which may include the characteristics of a particular site (e.g., tidal range, wave exposure, geomorphological regime, and availability of field data), the design phase (e.g., preliminary planning or detailed design), the level of project risk and stakeholder risk tolerances, the levels of uncertainty and complexity associated with the tools, and selected trade-offs or preferences for reducing design uncertainty versus adaptive management approaches.

Numerical models for storm surge and wave attenuation are one method for a priori evaluation of FRM benefits for alternative island designs. Model predictions are particularly well suited for evaluation in complex domains that typically surround island features. The following considerations for selecting and applying numerical modeling tools are specific to islands:

- Waves. A key effect of islands on waves is diffraction (bending) of waves into the leeward region of the island. The capability of, and need for, analytical tools (such as numerical wave models) to capture this process should be carefully assessed. For example, phase-resolving numerical wave models (such as Boussinesq wave models) tend to be better suited to capturing diffraction effects than phase-averaged (spectral) wave models (such as SWAN, MIKE21 SW). However, in cases where predicting the wave field in the lee region of the island is not a primary concern, the parametric treatment of diffraction in spectral wave models may be adequate (and computationally less expensive). Simple diffraction diagrams (Goda, Takayama, and Suzuki 1978) may even be used to characterize diffracted wave conditions in some circumstances.

- Hydrodynamics. Deltaic islands are often located in areas with significant water density gradients (e.g., where fresh water from a river meets the sea). The capability of hydrodynamic models to capture 3D baroclinic effects and include advection and dispersion of temperature and salinity should, therefore, be considered for these types of applications. For shallow, gently sloping sites where baroclinic effects are not significant, 2D (depth-averaged) hydrodynamic models may be adequate for capturing water circulation patterns and storm surges.

- Storm impacts. The capability, or lack thereof, of numerical morphological models to predict island beach and dune erosion, overwash, and breaching (i.e., the formation of a channel through a barrier island during an inundation event) is an important consideration. Even the most advanced numerical morphological modeling tools (e.g., Roelvink et al. 2009) typically require extensive field datasets to support model calibration and validation for application to shore-based settings. The design team must understand the limitations of these models, including the empirical data upon which they are based. A rigorous 
evaluation of model processes and input data (which are site specific) should be performed before model application. For islands, there are many additional complicating factors. For example, storm events can induce a water level differential across barrier island features (McCall et al. 2015), which can drive groundwater flow, and impact wave overtopping and morphological response.

- Potential for long-term morphological change or sea-level change. For projects with a design life spanning multiple decades, longer-term morphological or sea-level change may be an important consideration. This typically requires the use of long-term historical records or hindcasts of waves and water levels in combination with sediment transport and shoreline change calculations or morphological models (e.g., 2D morphologic change models driven by coupled $2 \mathrm{D}$ or $3 \mathrm{D}$ hydrodynamic models and wave models such as DELFT-3D, MIKE ST/MT, and SISYPHE; or 1D shoreline evolution models such as LITPACK, GenCade). More recently, efforts have been made to incorporate the effects of future climate change on waves and water levels in such analyses, by forcing wave and hydrodynamic models with downscaled climate model predictions. Future projections of global sea-level change may be adapted to provide regional or local estimates of relative sea-level rise, by taking into account measured uplift or subsidence rates (e.g., James et al. 2014).

Extensive guidance and considerations for selecting and applying empirical formulae and numerical modeling tools are provided in USACE (2002), Federal Emergency Management Agency (FEMA; 2005, 2016); CIRIA, CUR, and CETMEF (2007); Barnard et al. (2014); and Resio and Westerink (2008).

Where justified by project risks and scale, laboratory physical model testing can sometimes provide a reliable option for analyzing island interactions with physical processes and FRM benefits. Particularly for offshore island sites where the costs of adaptive management and ongoing maintenance can be high compared to shore-based sites (e.g., due to the logistics and cost of mobilization), up-front investment in physical model testing can be beneficial in helping to de-risk designs and reduce project life-cycle costs. Scale physical models constructed in 2D wave flumes or 3D wave basins can be used to assess wave run-up, overtopping, transmission, and penetration into downdrift areas, wave-driven current patterns, wave-structure-beach interactions (for hybrid features), and morphological change for island NNBF (e.g., Baker et al. 2016; Knox and Rayner 2016). Care and experience are needed when designing physical model test programs to make sure the important hydrodynamic model parameters are scaled and assessed correctly, and to ensure limitations are recognized. Guidance on scale effects, model effects, and other considerations for physical model testing are provided in Hughes (1993). In some cases, selective physical model testing can be used to calibrate or validate empirical formulae and numerical models.

Following the options evaluation, one or several concepts may be brought forward for more detailed testing and analysis in subsequent design phases. 


\subsubsection{Developing Detailed Design for Selected Alternatives}

Once the preferred conceptual design or designs are selected, the design is finalized, typically through an iterative process and leading to the development of detailed drawings, construction specifications, and cost analysis. Detailed design phase considerations are not unique to island NNBF. The level of detail and extent to which construction-related issues and methods are considered or prescribed at the detailed design phase will depend largely on the procurement and contracting approach adopted (e.g., standard, design-build, or turnkey), and the local availability of experienced contractors. The following issues and constraints may affect the detailed design development:

- Constructability

- Availability of experienced contractors

- Local availability of equipment

- Local availability and cost of suitable construction materials

- Site access (potentially including seasonal)

- Availability of locally sourced plant materials (e.g., species and seed sources)

- Restrictions on construction windows (see "Restrictions in Time Frame for Construction" in Section 11.5.2) and navigation and traffic control

- Site preparation (e.g., availability of areas for lay-down establishment, clearing, stockpiling, and control of invasive species)

- Surveying and methods of measurement (e.g., pre- and post-construction bathymetric surveys to quantify fill volumes, local benchmarks for surveying, survey tolerances, and trial sections)

- Environmental risks and management during construction (e.g., turbidity control, control of invasive species, spill prevention and emergency management, waste management, noise control, air quality, and dust control)

- Acceptable construction tolerances

- Planning for post-construction monitoring, maintenance and adaptive management (including control of invasive species)

Most island NNBF projects will require fill material to be imported and placed on the island platform to enhance, restore, or create the island and associated coastal resilience benefits. Identification and characterization of suitable sources of available fill material, and incorporation in the final design, is, therefore, a critical element of a successful island NNBF project. The fill needs to be located and characterized to understand its performance in the system. Defining characteristics may include particle size distribution (gradation curve, mean or median grain size, uniformity or sorting coefficients, percentage of fines, and maximum size), grain density (specific gravity), mineralogical composition (e.g., carbonate content), 
organic content, color, and other geotechnical properties. The design process will typically be iterative, considering the characteristics of available fill and the expected performance with respect to overall performance objectives. Depending on available material and priorities (e.g., FRM, habitat function, or minimizing maintenance), some trade-offs or adjustment of performance objectives and metrics may be appropriate at the detailed design phase. For example, in the Deltaport East Causeway barrier islands project (see Deltaport East Causeway Barrier Island Features case study in Section 11.4.1), material used to construct the barrier beaches (predominantly gravel with some coarse sand) was slightly coarser than grain sizes typically required for the target forage fish habitat (coarse sand to pea gravel). Using coarser material provided greater confidence that the beach would remain dynamically stable under storm wave action and maintain FRM function, with some compromise in habitat suitability.

\section{5 | Implementation}

After tendering is completed and a contract awarded (see Chapter 9, Section 9.6), project preparation and execution begin. Implementation of island construction differs from other previously addressed NNBF because the island is surrounded by water, and this adds an additional component to staging. This section describes the issues and processes that are unique to island features.

\subsubsection{Environmental Considerations and Logistical Issues}

Island NNBF typically exist in dynamic environments where forces on all sides can erode the feature. Often, the site cannot be isolated from surrounding hydrodynamic conditions (e.g., by dikes) without significant added cost. Depending on energy at the site, sediment losses may need to be factored into the implementation. Effects of multiple processes that degrade the feature may need to be evaluated, including river discharge, tidal currents, storm surge, waves, wind, and vessel wake. In addition, hydraulic conditions will change during the construction process, and the effects of these changes must be considered during the construction phase. For example, restoration of a barrier island will increase tidal currents over the island platform and around the island edges, thus eroding sediment as it is being placed. Therefore, significant room must be permitted for adaptive management during construction, monitoring, and maintenance phases. An experienced contractor is required to manage this type of project, identify change in conditions, and implement proper adaptation to achieve project goals.

Island creation and restoration include a number of construction and logistical challenges. Work often occurs in a highly dynamic and energetic environment, where an island is built from the seabed upward. Knowledge of proper and effective methods is required and includes an extensive risk assessment of the factors that might delay the project or lead to additional 
costs. Furthermore, relatively simple operations such as transporting land-based equipment or conducting progress surveys become more challenging when working in an unsheltered environment. Here, an understanding of the risks that might affect the planning is critical to successfully construct an island. Also, in addition to knowledge of the handling of sand, an understanding of muddy (e.g., fine or mixed) material, as well as how to create the most suitable habitat conditions, is essential to create the most optimal island that fulfills multiple benefits and truly creates additional value.

\subsubsection{Managing Risks and Uncertainties}

There is generally less experience with planning and construction of island features compared to other NNBF, such as beaches and dunes and wetlands. The physical and ecological environments are more diverse and variable than most land-based NNBF. This potentially poses increased uncertainty and risk.

These are the main risks and challenges during the construction phase:

1. Changing and unexpected wave, circulation, and sediment transport patterns

2. Managing impacts to ecologically sensitive habitats near the construction site

3. Changes in elevation due to sediment consolidation and compaction

4. Sediment loss due to erosion from the island platform

5. Controlling invasive species

6. Greater potential downtime because of multiple conditions that may stop or slow operations

a. Do not work in wet season if river discharge is a potential issue.

b. Do not work during seasons with frequent high-energy storms.

c. Work in wintertime and cold weather may have added safety impacts and restrictions to personnel as well as impacts due to ice restricting access to the site.

d. Predetermine environmental windows for all seasons (e.g., prevent harm to birds, fish spawning, sea turtles, and marine mammals) (see "Restrictions in Time Frame for Construction").

7. Managing delays due to greater number and interdependency of phases during island construction (compared to other NNBF)

8. Site conditions not matching initial assumptions (sediment loss rates during excavation and placement, sediment quality and availability, wave climate, and ecological evolution) 


\section{Restrictions in Time Frame for Construction}

In the United States, the National Oceanic and Atmospheric Administration's National Marine Fisheries Service has issued regional biological opinions, which state that beach nourishment activities are prohibited along the southeast Atlantic coast from May 1 through October 30 to protect nesting sea turtles.

In Canada, DFO recommends timing windows that depend on regional considerations for projects in or around water as a measure to protect fish and fish habitat and to aid compliance with the Fisheries Act and Species at Risk Act.

\subsubsection{Preparation and Equipment Selection}

The construction of an island feature is a complex operation in which a number of aspects and risks need to be considered to successfully execute such a project. The following parameters require consideration to achieve the most cost-efficient solution:

- Equipment selection

- Availability and location of the borrow area (e.g., sediment, other building material, and other design aspects)

- Working restrictions (logistic bottlenecks)

The effort and the relative cost per unit volume of island construction are largely related to the type and amount of dredging equipment required and the distance of the borrow area (sediment source) from the island project. For example, if the building material is located near the planned island location, a cutter suction dredger might be most cost-effective-if located in relatively sheltered conditions. Alternatively, if the source of the material is located far away from the project site, a trailing suction hopper dredger would be more efficient. Furthermore, the availability and distance of suitable material will partly influence the duration of the execution time as reflected in the time that it takes a dredger to sail there and back with one load of sand. In addition, other aspects of the material source location can influence the choice of equipment (e.g., dredging in deeper or more unsheltered locations imposes another requirement on the dredging equipment).

Compared to beach nourishments, the logistics of constructing an island are typically more complex. For example, on an island there may not be a suitable transport mechanism or lay-down area to transport and stage land-based equipment. Therefore, as shown in Figure 11.3, the first step in construction of an island is to create a body of sand, from which 
land-based equipment can assist in the construction process. Often, rainbowing, which is the propelling of sand in a high arc, is an efficient way of creating the first part of an island, if the legal framework permits (see Section 11.2.4). Another alternative is to use sediment dredged for navigation purposes. For example, island construction at Round Island in Mississippi, United States, exclusively used material dredged from the adjacent navigation channel, thus significantly reducing costs because excavation costs are covered by the navigation channel maintenance program. However, coordinating navigation dredging projects with NNBF construction projects adds another layer of complexity to sequencing, which may require program managers to investigate beneficial use opportunities.

\subsubsection{Sediment Source Considerations}

Additional considerations are the sediment volumes, sediment sources (borrow areas), types of sediments, and other materials to be used in the island construction. Placement and building with sand is a process that is reasonably well understood, and it has been applied in a number of projects. The process is more complex if the design of an island also includes the placement of muddy and silty material or rocks. Therefore, islands constructed from sand are more straightforward than those of mixed or muddy and silty material. Finer-grained material is often required for construction of back-bay marshes on islands. Because NNBF islands not only serve as a coastal resilience measure but also create specific habitats, it is essential that the requirements of the various habitats are met (e.g., sediment size and composition or inundation regimes). For example, the compaction of a silt layer after placement can lead to an undesired lowering of the elevation, which alters the inundation period, creating other habitats than expected. Insight into the main design parameters that are required to create these habitat types is essential for successful construction.

The Marker Wadden in the Netherlands is a good example of the construction of a partly muddy island (Figure 11.9) (ecoshape.org 2020). This island group is being dredged by a cutter suction dredger with material from a nearby borrow pit. First, sand-containment berms were constructed, as well as a small marina with a rock revetment. Afterward, the compartments were filled with muddy material until a desired height. The islands are constructed in a freshwater lake environment for the purpose of creating swamp and marsh habitat, functioning as a foraging area for a number of (migratory) bird species. 


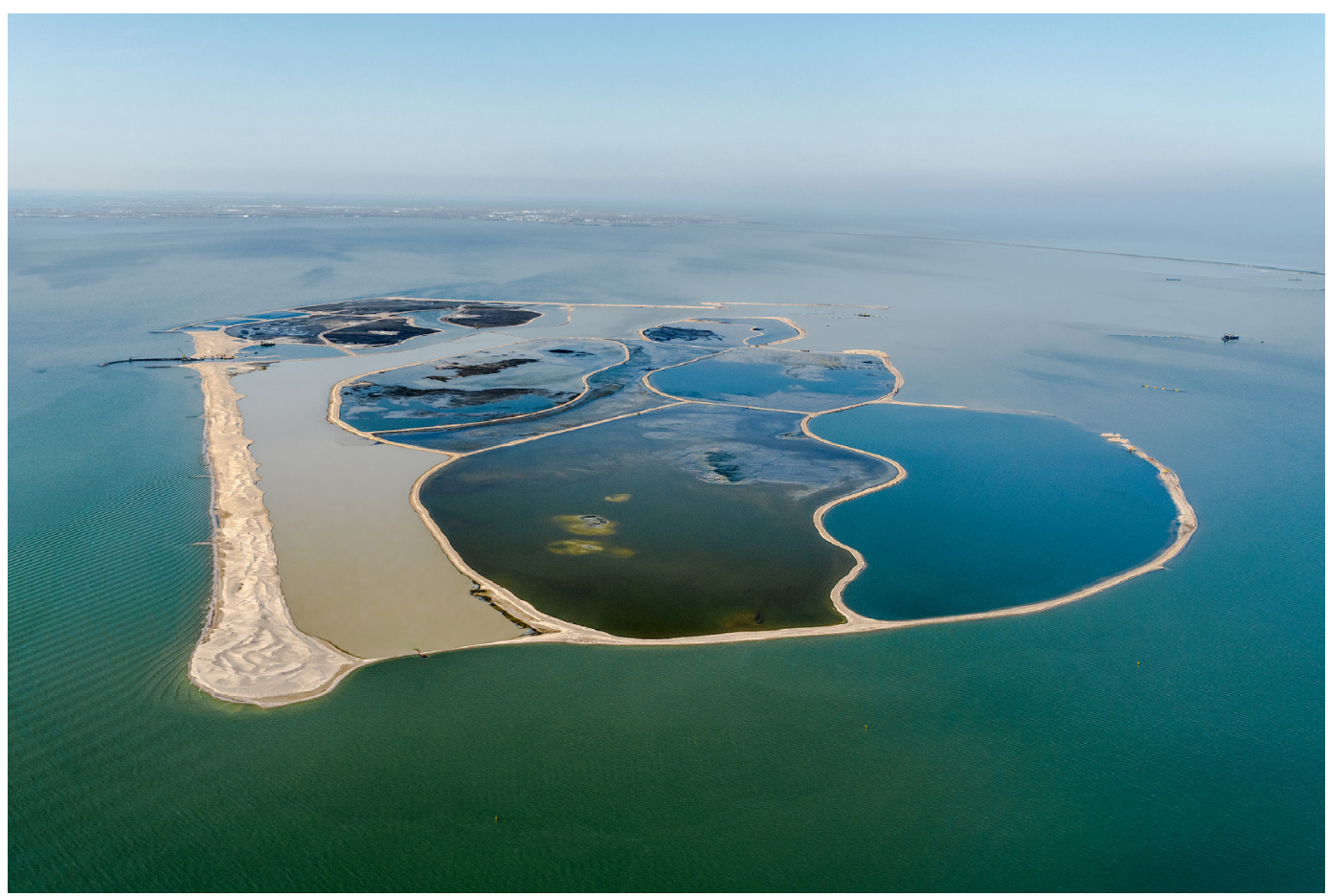

Source: Courtesy of Natuurmonumenten (Dutch Nature Conservancy)

\subsubsection{Sequencing Considerations}

Depending on the design requirements and the hydrodynamic conditions, additional protective measures may need to be implemented to prevent erosion during (and after) the construction phase. However, the ability to contain the site during construction may be limited due to significant hydraulic forces that can damage containment structures. In addition, any containment will influence stability of surrounding features and associated habitats.

The placement of material in a high-energy environment can create an obstruction of the flow, which promotes erosion (Figures 11.10 and 11.11, Table 11.3), and standard mitigation tools, such as silt curtains, may not be applicable in high-energy systems. This may lead to erosion of the island under construction or change the erosion sedimentation patterns in the vicinity. Additional mitigation efforts to manage this risk, such as temporary structures or permanent but buried hard structures, may be employed to balance sediment loss with rate of infilling. Numerical modeling can be used to quantify the effect prior to construction (e.g., hydraulic conditions and wave climate). 
Figure 11.10. Example Construction Phasing

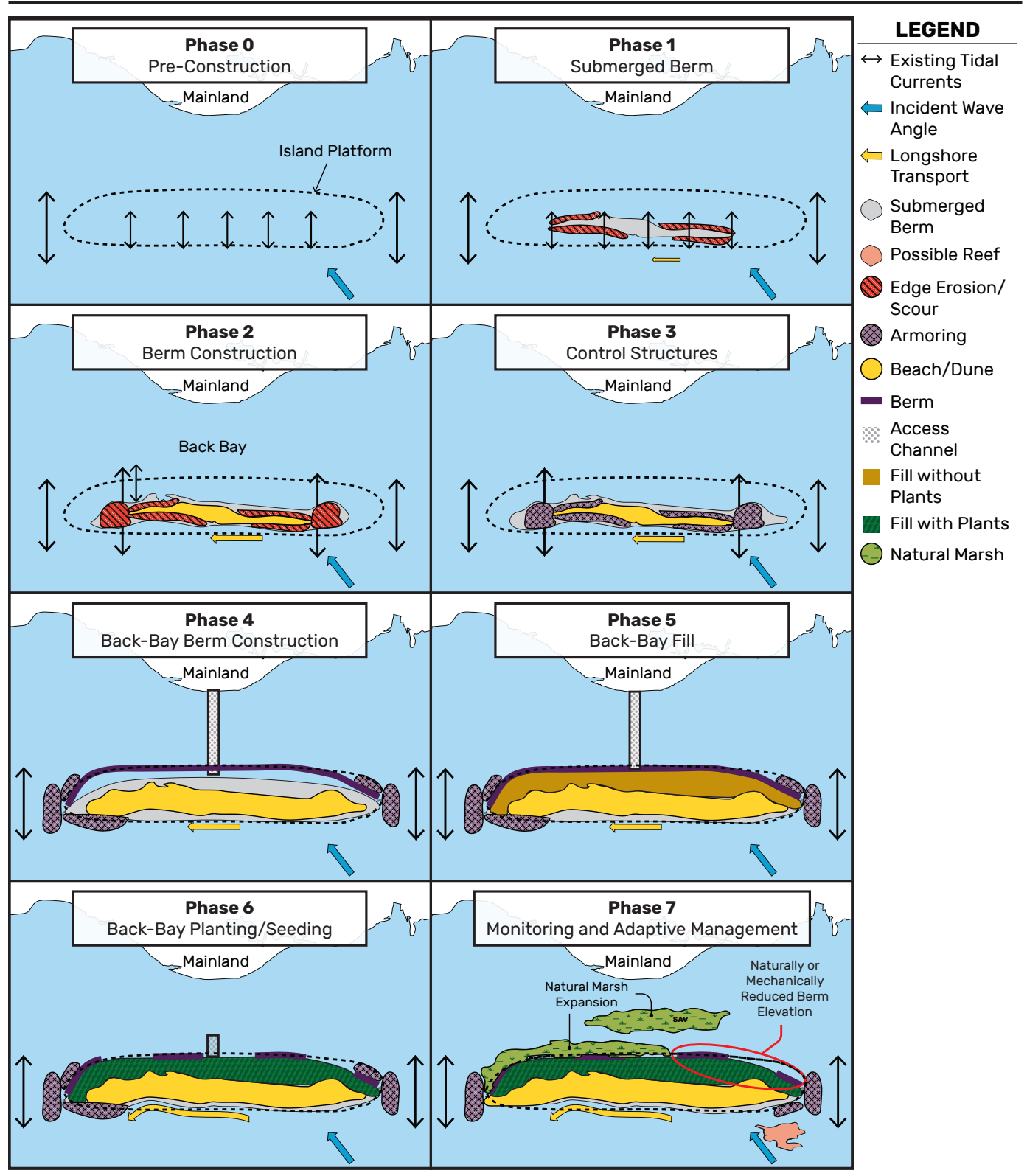


Table 11.3. Description of Example Construction Phasing in Figure 11.10

\begin{tabular}{|c|c|}
\hline Phase & Action \\
\hline $\begin{array}{l}\text { Phase 0: } \\
\text { Pre-construction }\end{array}$ & $\begin{array}{l}\text { - Baseline monitoring (e.g., waves, bathymetry, circulation) } \\
\text { - Baseline habitat evaluation }\end{array}$ \\
\hline $\begin{array}{l}\text { Phase 1: } \\
\text { Submerged berm }\end{array}$ & $\begin{array}{l}\text { - Initial underwater sediment placement on the existing shoal } \\
\text { - Monitor hydrodynamic changes } \\
\text { - Quantify sediment loss } \\
\text { - Monitor surrounding habitat }\end{array}$ \\
\hline $\begin{array}{l}\text { Phase 2: } \\
\text { Berm (foreshore) } \\
\text { construction }\end{array}$ & $\begin{array}{l}\text { - Construction of foreshore berm } \\
\text { - Create back-bay sheltered environment } \\
\text { - Monitor hydrodynamic changes } \\
\text { - Monitor sediment transport patterns }\end{array}$ \\
\hline $\begin{array}{l}\text { Phase 3: } \\
\text { Control structures }\end{array}$ & $\begin{array}{l}\text { Based on sediment loss, evaluate alternatives for temporary control } \\
\text { measures to stabilize the site during construction }\end{array}$ \\
\hline $\begin{array}{l}\text { Phase 4: } \\
\text { Back-bay berm } \\
\text { construction }\end{array}$ & $\begin{array}{l}\text { - Retention structures to hold fine-grained sediment during back-bay } \\
\text { infilling } \\
\text { - Create back-bay access, if needed }\end{array}$ \\
\hline $\begin{array}{l}\text { Phase 5: } \\
\text { Back-bay fill }\end{array}$ & $\begin{array}{l}\text { - Deliver mixed sand, silt, and clay to back bay } \\
\text { - Monitor consolidation } \\
\text { - Meet consolidation requirements } \\
\text { - Grade for high marsh, low marsh, etc. } \\
\text { - Breach berm to permit tidal exchange }\end{array}$ \\
\hline $\begin{array}{l}\text { Phase 6: } \\
\text { Planting }\end{array}$ & $\begin{array}{l}\text { - Evaluate water and sediment quality } \\
\text { - Assess benefits of planting versus natural colonization } \\
\text { - Establish and monitor wetland, upland, and dune plant communities } \\
\text { - Evaluate need for protective measures such as wind fence }\end{array}$ \\
\hline $\begin{array}{l}\text { Phase 7: } \\
\text { Monitoring and adaptive } \\
\text { management }\end{array}$ & $\begin{array}{l}\text { Based on sediment loss, evaluate alternatives for sustained control } \\
\text { measures to stabilize erosion-prone parts of the island } \\
\text { - Monitor to develop adaptive management plan focusing on morphology, } \\
\text { sustainability, and habitat }\end{array}$ \\
\hline
\end{tabular}




\section{Restoring Barrier Islands}

The natural barrier island has eroded away into the form of a sandbar. The protective dunes have disappeared and lack vegetation.

New Beach and Dunes

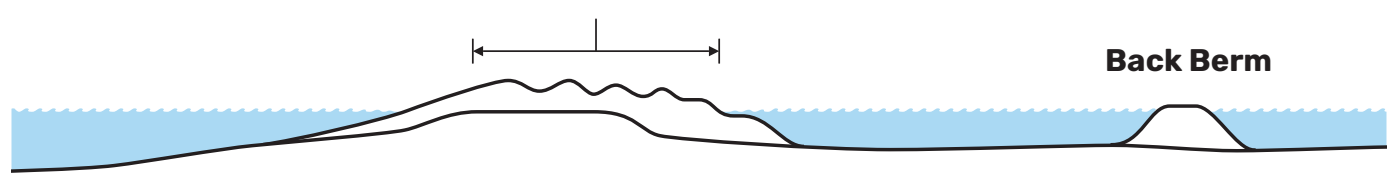

A new beach and dunes are created by placing sand on top of the eroded barrier island. A temporary back berm is installed to contain the back-bay marsh.

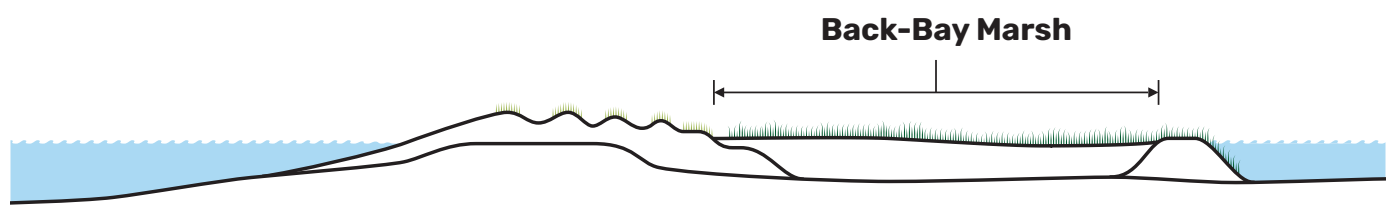

The back-bay marsh is created by placing muddy sediment between the barrier island and the back berm. Marsh vegetation and SAV are planted to stabilize the soil.

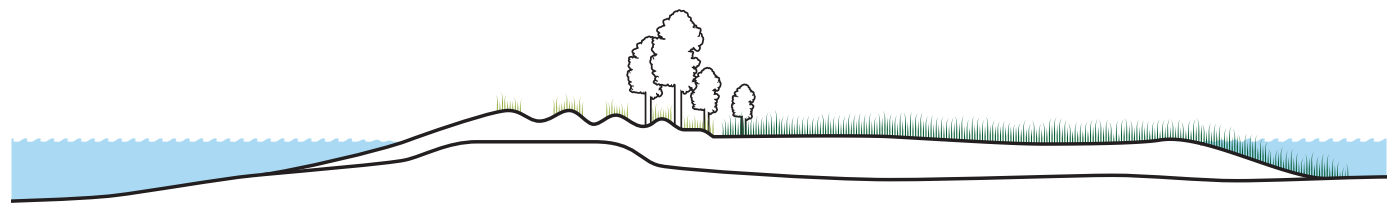

Mature dunes and mature vegetation stabilize the new barrier island ecosystem, which attracts flora and fauna. The back berm is either removed or erodes naturally. 
The occurrence of large storm events can also cause severe damage to the island under construction, leading to project delays and additional costs. A wave climate analysis during the design phase can reduce this risk. Planning critical construction activities during seasons with less storm activity can further reduce the risk of erosion. Also, placing relatively coarse sandy material in the areas where erosion is expected to be most severe is a way to reduce or prevent erosion from occurring. The placement of hard structures is another way of preventing erosion from occurring during and after the construction phase. However, the exact definition of the requirements with respect to the stability of the island is the main driver in determining the mitigation measures to prevent erosion. For example, allowing for a dynamic or gradual erosion of the island may be part of the project design objectives. In this case, less effort is needed to mitigate the risk.

If construction occurs in a sensitive environment, an outward berm can be constructed first to contain or reduce the spreading of fine sediment into the environment, as has been done in the tidal flat construction at the Galgeplaat, the Netherlands (see Figure 11.12) (publicwiki.deltares.nl, n.d.).

\section{Figure 11.12. Construction at the Galgeplaat (the Netherlands)}

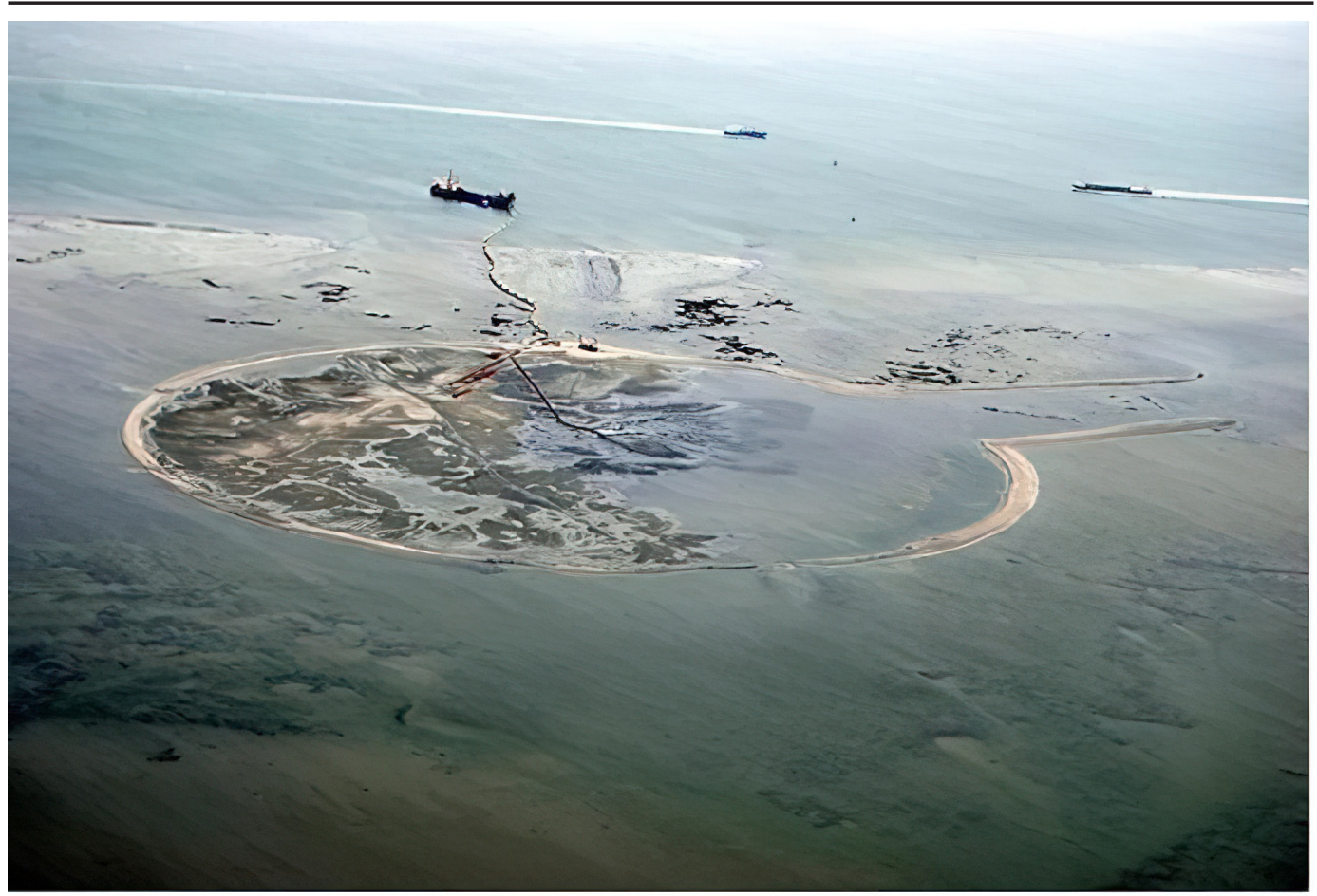

Source: Courtesy of EcoShape/Van Oord 


\subsubsection{Construction Monitoring and Adaptive Management}

Uncertainties associated with island construction are typically greater than those associated with other NNBF because of the numerous, interdependent variables that influence processes in these exposed, high-energy environments. Therefore, monitoring and adaptive management during construction are generally required to ensure that the island is constructed according to design, meets the specifications, and maintains future functionality. Two of the most significant uncertainties during island construction that may require adaptive management are loss of (noncohesive) sediment and the behavior and consolidation of cohesive sediments. A third source of uncertainty that must be addressed in adaptive management but is beyond the scope of these guidelines is construction safety in dynamic open-water locations. Typically, experienced contractors can manage risks to workers and equipment.

A comprehensive monitoring plan should be developed that addresses these and other risks and uncertainties during construction. Bathymetric and elevation surveys can be used to identify the magnitude and location of sediment losses. Current and wave data can identify potential areas of scour. Surveying compaction and consolidation of cohesive sediment can be used during construction to evaluate if the sediment behaves as expected, and if adjustments to design and execution are necessary. For example, if compaction and consolidation are greater than expected, elevations and inundation regimes will be different than design criteria, complicating establishment of vegetation. Additional sediment may be required to ensure the elevation meets design specifications. Similarly, sediment loss due to erosion around the island perimeter during construction may be greater than expected. In both these situations, potential mitigation efforts should be identified a priori in the design phase to ensure rapid response to any unexpected changes. For example, sources for additional sediment or materials for temporary control structures should be identified. As part of the design and contracting processes, responsibilities associated with potential increased costs and schedule changes should also be identified.

Circulation and wave climate will change gradually in response to construction, and these changes may require modifications to subsequent construction phases. Although robust hydrodynamic models may be used as a screening-level approach to support construction planning and sequencing for large projects, model fidelity is often insufficient to quantify changes during construction. Therefore, monitoring data are required to quantify actual conditions and identify any unacceptable sediment losses, risk to ecosystem, or risk to construction staff or equipment. For these conditions, mitigation measures should be undertaken in the field using an iterative monitoring and adaptive management approach. 
Islands are particularly vulnerable to erosion after sediment placement but before vegetation is established. Island features are exposed to wind, waves, and currents, which can rapidly move or undermine sediment. One factor that reduces loss of sediment is successful establishment of vegetation as part of the final construction phase. However, issues related to sediment loss from lack of vegetation is an uncertainty that is generally managed post-construction (see Section 11.6).

Monitoring of the island profile elevations and vegetation development should continue before, during, and after planting. Adaptive measures may be required to reduce sediment transport from the island platform. These measures may include fencing or ground cover to reduce eolian transport. Similarly, submerged structural measures may be required to reduce platform sediment loss until SAV or reefs are established.

Construction monitoring and adaptive management are key components to ensure timely and cost-effective completion. In addition, the surrounding environment should be monitored. If sensitive habitats are located near the construction site, turbidity, hydrodynamic conditions, and ecosystem health are typically monitored to manage risks. Protective measures (such as berms to minimize turbidity in back-bay marsh or SAV) can be implemented as part of an adaptive management approach.

\section{6 | Monitoring, Maintenance, and Adaptive Management after Construction}

Monitoring the island after construction is required to verify performance and develop post-construction adaptive management strategies (see Chapter 7) to maintain ecological and FRM functions. Ongoing monitoring allows iterative modifications to the adaptive management plan to optimize performance. By evaluating and addressing uncertainties, iterative adjustments can be made to the island NNBF to evaluate intended outcomes and inform future island projects.

Monitoring and management strategies will be site specific and depend on environmental conditions, objectives, and resources. Depending on monitoring budget, the challenges of monitoring island sites (which may be remote), project objectives, and performance metrics, managers may have to develop monitoring priorities. For example, to evaluate coastal resilience function of an island, a suite of hydrodynamic, ecological, and topographic parameters may be required (see Figure 11.13 in "Simplified Resilience Conceptual Model for Swan Island Restoration Project"). Monitoring for other objectives, such as island benefits for migratory birds and other wildlife, will require information about the variety and density of flora and fauna. 
As another example, if the island is eroding at an unacceptable rate, additional monitoring may be required to identify the root causes. Once the causes are identified, alternative solutions can be identified and evaluated. For example, armoring or temporary hard structures may be implemented (Figure 11.10 and Table 11.3). The Deltaport East Causeway (see Deltaport East Causeway Barrier Island Features case study in Section 11.4.1) also demonstrates adaptive solutions that are based on site monitoring. Similar monitoring and adaptive management approaches are applied to evaluate and maintain ecosystem function. For example, elevations change over time, and unwanted vegetation may be introduced because inundation or other processes are not properly balanced. Therefore, regrading and replanting may be required. Experimental approaches (such as pilot studies) may be beneficial to determining proper long-term habitat maintenance strategies. Finally, adaptive management and maintenance requires responsible parties to be identified up front in contracts or other planning documents (e.g., monitoring and adaptive management plans).

\section{Simplified Resilience Conceptual Model for Swan Island Restoration Project (Maryland, United States)}

To evaluate the coastal resilience performance of Swan Island in Chesapeake Bay, an understanding of the hydrodynamic processes, sediment movement processes, and ecological responses are required. Through a series of iterative group-mediated workshops, the project team identified a simplified conceptual model that represents the required parameters to understand and quantify island resilience performance. Called the simplified resilience conceptual model, these parameters and the relationships between them are shown in Figure 11.13. Water movement (waves and currents), plant biomass, elevation (island profile and nearshore bathymetry), and sediment supply represent the measured system parameters collected by the project team (Davis et al., forthcoming; Herman et al. 2020). Further, a monitoring and adaptive management plan developed to track progress will ensure project goals are met. This living document serves as a blueprint for the project team and codifies all aspects of the monitoring approach (what, how, and how often data are collected), reporting and data management, roles and responsibilities, performance metrics, and decision thresholds for adaptive management action (Herman et al., forthcoming). 


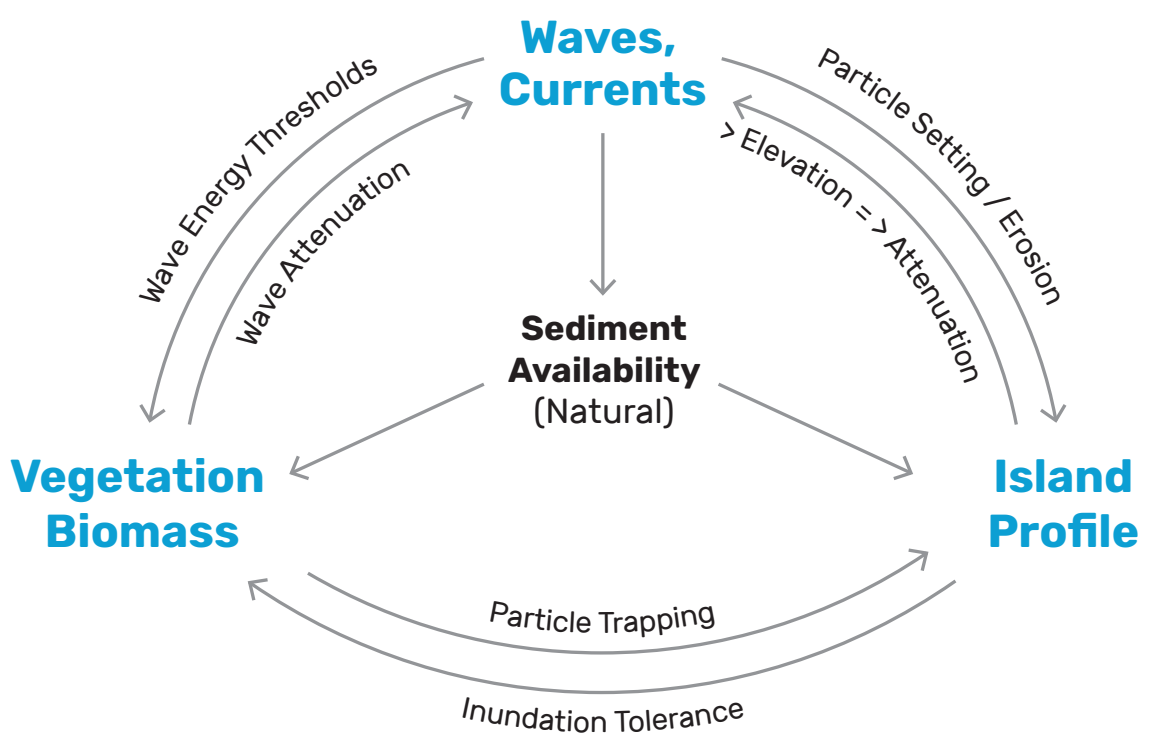

Note: This model was developed to capture important system-level components that drive the response to restoration and will capture the overall resilience of the system.

Source: Adapted from Herman et al. 2020

\section{7 | Gaps and Future Directions}

The following gaps and corresponding proposed future directions would support broader application of island NNBF:

- Use of multiple habitat types. Research on the potential combined, complementary effect of multiple habitat types from offshore to onshore in terms of both short-term and long-term protective benefits (Lopez 2009; Guannel et al. 2016; Arkema et al. 2017) is required to justify larger NNBF projects such as islands. This would emphasize a systems approach to implementing NNBF, rather than a single-habitat approach.

- Island area of influence. Quantitative studies on island areas of influence are required to address habitat switching issues and potential impacts of island restoration. Short-term impacts should be balanced against long-term outcomes and consider a systems approach. This issue is presently one of the primary regulatory hurdles to NNBF implementation. 
- Innovation. Innovative practices and field experimentation (learning by doing) should be encouraged. Risks can be managed to assure that experiments will not cause irreparable damage. Therefore, innovative practices can be tested and demonstrated. Successful practices can then be broadly applied at other sites. The concept of living laboratories (de Groot and van Duin 2013; van Eekelen et al. 2017) provides an ideal means to improve understanding of island systems while pushing innovation and implementation that improve coastal resilience and ecosystem diversity.

- Regional case studies to inform island feasibility. Although the basic dynamics of island evolution are understood, the highly variable conditions in which island NNBF can provide coastal resilience benefits require more regional case studies in a variety of environmental conditions (e.g., circulation, climate, waves, tidal range, sediment type, geomorphology, dimensions, native habitats). With a broad range of case studies, design teams can select relevant analogues for their site. These case studies will illustrate when island features are feasible and support optimization of design, implementation, and maintenance approaches.

\section{8 | References}

Arkema, K. K., G. Guannel, G. Verutes, S. A. Wood, A. Guerry, M. Ruckelshaus, P. Kareiva, M. Lacayo, and J. M. Silver. 2013. "Coastal Habitats Shield People and Property from Sea-Level Rise and Storms." Nature Climate Change 3 (10): 913-918.

Arkema, K., R. Griffin, S. Maldonado, J. Silver, J. Suckale, and A. D. Guerry. 2017. “Linking Social, Ecological, and Physical Science to Advance Natural and Nature-Based Protection for Coastal Communities." Annals of the New York Academy of Sciences 1399 (1): 5-26. doi:10.1111/nyas.13322.

Baker, S., M. Sturm, B. Pinchin, and A. Cornett. 2016. “Physical Modelling of the Lakeview Waterfront Connection Project." Paper presented at 6th International Conference on the Application of Physical Modelling in Coastal and Port Engineering and Science, Ottawa, ON, May 2016.

Barnard, P. L., M. van Ormondt, L. H. Erikson, J. Eshleman, C. Hapke, P. Ruggiero, P. N. Adams, and A. C. Foxgrover. 2014. "Development of the Coastal Storm Modeling System (CoSMoS) for Predicting the Impact of Storms on High-Energy, Active-Margin Coasts." Natural Hazards 74 (2): 1095-1125.

Blama, R. N. 2012. Barren Island Dredged Material Placement for Regional Sediment Management. ERDC/CHL CHETN-XIV-21. Vicksburg, MS: U.S. Army Corp of Engineers.

Brantley, S. T., S. N. Bissett, D. R. Young, C. W. Wolner, and L. J. Moore. 2014. “Barrier Island Morphology and Sediment Characteristics Affect the Recovery of Dune Building Grasses Following Storm-Induced Overwash." PLOS ONE 9 (8): e104747. 
Bridges, T. S., K. A. Burks-Copes, M. E. Bates, Z. A. Collier, J. C. Fischenich, C. D. Piercy, E. J. Russo, et al. 2015. Use of Natural and Nature-Based Features (NNBF) for Coastal Resilience. ERDC SR-15-1. Vicksburg, MS: U.S. Army Engineer Research and Development Center, Environmental Laboratory, Coastal and Hydraulics Laboratory. http://hdl.handle.net/11681/19336.

Bros, W. 2007. "Sustainable Dredging Program on the Lower Fraser River." MBA thesis, Simon Fraser University.

Carter, R. W. G., D. L. Forbes, S. C. Jennings, J. D. Orford, J. Shaw, and R. B. Taylor. 1989. “Barrier and Lagoon Coast Evolution under Differing Relative Sea-Level Regimes: Examples from Ireland and Nova Scotia." Marine Geology 88 (3-4): 221-242.

CECI (Coastal Engineering Consultants Inc.). 2013. NRDA Caillou Lake Headlands Beach and Dune Restoration (TE-100) Final Design Report. Prepared for Coastal Protection and Restoration Authority of Louisiana. Baton Rouge, LA: Coastal Engineering Consultants.

CIRIA (Construction Industry Research and Information Association). 2010. Beach Management Manual. Second Edition. London: Construction Industry Research and Information Association.

CIRIA, CUR, and CETMEF (Construction Industry Research and Information Association, CUR, and CETMEF). 2007. The Rock Manual: The Use of Rock in Hydraulic Engineering. Second Edition. Report C683. London: CIRIA.

Costanza, R., O. Pe'rez-Maqueo, M. L. Martinez, P. Sutton, S. J Anderson, K. Mulder, 2008. “The Value of Coastal Wetlands for Hurricane Protection." AMBIO: A Journal of the Human Environment 37 (4): 241-248.

CPRA (Coastal Protection and Restoration Authority). 2007. Integrated Ecosystem Restoration and Hurricane Protection: Louisiana's Comprehensive Master Plan for a Sustainable Coast. Baton Rouge, LA: Coastal Protection and Restoration Authority.

Davis, J., P. Whitfield, D. Szimanski, B. R. Golden, M. Whitbeck, J. Gailani, B. Herman, A. Tritinger, S. C. Dillion, and J. King. Forthcoming. "A Framework for Evaluating Island Restoration Performance: A Case Study from the Chesapeake Bay." In Integrated Environmental Assessment and Management. Special Series: Incorporating Nature-Based Solutions to the Built Environment. https://doi.org/10.1002/ieam.4437.

de Groot, A. V., and W. E. van Duin. 2013. Best Practices for Creating New Salt Marshes in a Saline Estuarine Setting, a Literature Review. IMARES Report No. C145/12. Wageningen: IMARES. https://edepot.wur.nl/248715.

Deltares and Delft Hydraulics. 2008. Dredging and Land Reclamation Technical Manual. Prepared for Strategic Projects Directorate, Ministry of Works, Kingdom of Bahrain. Delft, NL: Deltares.

Duck, R. W., and J. F. da Silva. 2012. "Coastal Lagoons and Their Evolution: A Hydromorphological Perspective." Estuarine, Coastal and Shelf Science 110: 2-14. 
ecoshape.org. 2020. Marker Wadden KIMA. EcoShape. https://www.ecoshape.org/en/projects/ marker-wadden/.

Elliott, M., J. W. Day, R. Ramachandran, and E. Wolanski. 2019. "A Synthesis: What Is the Future for Coasts, Estuaries, Deltas and Other Transitional Habitats in 2050 and Beyond?" Coasts and Estuaries: The Future. Edited by E. Wolanski, J. Day, M. Elliott, and R. Ramesh. Cambridge: Elsevier.

Erwin, M. E., D. F. Brinker, B. D. Watts, G. R. Costanzo, and D. D. Morton. 2011. "Islands at Bay: Rising Seas, Eroding Islands, and Waterbird Habitat Loss in Chesapeake Bay (USA)." Journal of Coastal Conservation 15: 51-60. https://doi.org/10.1007/s11852-0100119-y.

FEMA (Federal Emergency Management Agency). 2005. Final Draft Guidelines for Coastal Flood Hazard Analysis and Mapping for the Pacific Coast of the United States. A Joint Project by FEMA Region IX, FEMA Region X, FEMA Headquarters. West Sacramento, CA: Northwest Hydraulic Consultants.

FEMA. 2016. Guidance for Flood Risk Analysis and Mapping: Coastal General Study Considerations. Washington, DC: Federal Emergency Management Agency.

Forbes, D., G. Parkes, G. Manson, and L. Ketch. 2004. "Storms and Shoreline Retreat in the Southern Gulf of St. Lawrence." Marine Geology 210 (1-4): 169-204.

Fullarton, M., R. B. Nairn, C. J. Petykowski, J. P. Selegean, and L. T. Barber. 2006. "Cat Island Restoration, Green Bay." Paper presented at Coastal Engineering 2006 - Proceedings of the 30th International Conference, San Diego, CA, September 2006.

Garrison, J. R., J. Williams, S. P. Miller, E. T. Weber, G. McMechan, and X. Zeng. 2010. “GroundPenetrating Radar Study of North Padre Island: Implications for Barrier Island Internal Architecture, Model for Growth of Progradational Microtidal Barrier Islands, and Gulf of Mexico Sea-Level Cyclicity." Journal of Sedimentary Research 80 (4): 303-319.

Gilmore, G. R. 1995. “Environmental and Biogeographic Factors Influencing Ichthyofaunal Diversity: Indian River Lagoon." Bulletin of Marine Science 57(1):153-170.

Goda, Y., T. Takayama, and T. Suzuki. 1978. "Diffraction Diagrams for Directional Random Waves." Coastal Engineering Proceedings 1 (16): 35.

Grouthes, T. M., and K. W. Able. 2016. Assessment of Dredge Material Island Shorelines as Habitat for Juvenile Summer Flounder and Other Fishes. Final Report to the U.S. Army Corp of Engineers Navigation Section, Baltimore District. Baltimore: U.S. Army Corps of Engineers.

Grzegorzewski, A. S., M. A. Cialone, and T. V. Wamsley. 2011. “Interaction of Barrier Islands and Storms: Implications for Flood Risk Reduction in Louisiana and Mississippi." Journal of Coastal Research 59 (59): 156-164.

Guannel, G., K. Arkema, P. Ruggiero, and G. Verutes. 2016. “The Power of Three: Coral Reefs, Seagrasses and Mangroves Protect Coastal Regions and Increase Their Resilience." PLOS ONE 11 (7): e0158094. https://doi.org/10.1371/journal.pone.0158094. 
Hequette, A., and M. Ruz. 1991. "Spit and Barrier Island Migration in the Southeastern Canadian Beaufort Sea." Journal of Coastal Research 7 (3): 677-698.

Herman, B., P.E. Whitfield, J. Davis, D. Szimanski, R. Raves Golden, A. Tritinger, J. Gailani, T. M. Swannack, and J. K. King. Forthcoming. Swan Island Ecosystem Restoration Monitoring and Adaptive Management Plan.

Herman, B., T. M. Swannack, J. K. King, P. E. Whitfield, J. Davis, D. Szimanski, D. Bryant, and J. Gailani. 2020. "Ecological Habitat Modeling Workshop." ERDC/EL SR-20-1. Paper presented at the Proceedings from the U.S. Army Corps of Engineers and the National Oceanic and Atmospheric Administration - National Ocean Service, Cambridge, MD, April 2019.

Hughes, S. A. 1993. Physical Models and Laboratory Techniques in Coastal Engineering. Advanced Series on Ocean Engineering: Volume 7. Singapore: World Scientific. https:/l doi.org/10.1142/2154.

James, T. S., J. A. Henton, L. J. Leonard, A. Darlington, D. L. Forbes, and M. Craymer. 2014. Relative Sea-Level Projections in Canada and the Adjacent Mainland United States. Geological Survey of Canada Open File 7737. Ottawa, ON: Natural Resources Canada.

Jones, R. R., and D. A. Garza. 1998. “Co-Management of the Razor Clam (Siliqua patula) Fishery at Haida Gwaii, British Columbia, Canada." In Proceedings of the North Pacific Symposium on Invertebrate Stock Assessment and Management. Edited by G. S. Jamieson and A. Campbell. Canadian Special Publication of Fisheries and Aquatic Sciences 125: 385-391.

Kamphuis, J. W. 2010. Introduction to Coastal Engineering and Management. Second Edition. Advanced Series on Ocean Engineering: Volume 30. Singapore: World Scientific.

Kirwan, M. L., D. C. Walters, W. G. Reay, and J. A. Carr. 2016. “Sea Level Driven Marsh Expansion in a Coupled Model of Marsh Erosion and Migration." Journal of Geophysical Research 43 (9): 4366-4373.

Knox, P., and A. Rayner. 2016. 3D Physical Model Study of a Shoreline Improvement Scheme for Euclid, Ohio, USA. Technical Report OCRE-TR-2016-012. Ottawa, ON: National Research Council Canada.

Leatherman, S. P. 1976. "Barrier Island Dynamics: Overwash Processes and Eolian Transport." Paper presented at the 15th International Conference on Coastal Engineering, Honolulu, HI, July 1976.

Lewis, D. A., J. A. G. Cooper, and O. H. Pilkey. 2005. “Fetch Limited Barrier Islands of Chesapeake Bay and Delaware Bay." Southeastern Geology 44 (1): 1-17.

Lopez, J. A. 2009. "The Multiple Lines of Defense Strategy to Sustain Coastal Louisiana." Journal of Coastal Research 54 (10054): 186-197. https://doi.org/10.2112/SI54-020.1.

McCall, R., G. Masselink, T. Poate, J. Roelvink, and L. Almeida. 2015. “Modelling the Morphodynamics of Gravel Beaches During Storms with XBeach-G." Coastal Engineering 103: 52-66. 
Narayan, S., M. W. Beck, P. Wilson, C. J. Thomas, A. Guerrero, C. C. Shepard, B. G. Reguero, G. Franco. J. C. Ingram, and D. Trespalacios. 2017. "The Value of Coastal Wetlands for Flood Damage Reduction in the Northeastern USA." Scientific Reports 7(1):9463. https://doi.org/10.1038/s41598-017-09269-z.

Narayan, S., M. W. Beck, B. G. Reguero, I. J. Losada, B. van Wesenbeeck, N. Pontee, J. N. Sanchirico, J. C. Ingram, G. M. Lange, and K. A. Burkes-Copes. 2016. "Effectiveness, Costs and Coastal Protection Benefits of Natural and Nature-Based Defences." PLOS ONE 11 (5): e0154735. https://doi.org/10.1371/journal.pone.0154735.

Oertel, G. F. 1985. “The Barrier Island System.” Marine Geology 63: 1-18.

Pilkey, O. H., J. A. G. Cooper, and D. A. Lewis. 2009. “Global Distribution and Geomorphology of Fetch-Limited Barrier Islands." Journal of Coastal Research 25 (4): 819-837.

publicwiki.deltares.nl. n.d. Tidal Flat Nourishment - Galgeplatt, NL. Building with Nature Guideline. https://publicwiki.deltares.nl/display/BTG/Tidal+flat+nourishment++ Galgeplaat $\% 2 \mathrm{C}+\mathrm{NL}$.

Reguero, B. G., M. W. Beck, D. N. Bresch, J. Calil, and I. Meliane. 2018. “Comparing the Cost Effectiveness of Nature Based and Coastal Adaptation: A Case Study from the Gulf Coast of the United States." PLOS ONE 13 (4): e0192132. https://doi.org/10.1371/ journal.pone.0192132.

Resio, D. T., and J. J. Westerink. 2008. Modeling the Physics of Storm Surges." Physics Today $61(9): 33$.

Ricklefs, R. E., and I. J. Lovette. 1999. "The Roles of Island Area per se and Habitat Diversity in the Species-Area Relationships of Four Lesser Antillean Faunal Groups." Journal of Animal Ecology 68 (6): 1142-1160.

Riggs, S. R., S. J. Culver, D. V. Ames, D. J. Mallison, D. R. Corbett, and J. P. Walsh. 2008. North Carolina's Coasts in Crisis: A Vision for the Future. A White Paper by the Members of the North Carolina Coastal Geology Cooperative Research Program. Greenville, NC: East Carolina University.

Roelvink, D., A. Reniers, A. P. Van Dongeren, J. V. T. de Vries, R. McCall, and J. Lescinski. 2009. "Modelling Storm Impacts on Beaches, Dunes and Barrier Islands." Coastal Engineering 56 (11-12): 1133-1152.

Rupprecht, F., I. Möller, M. Paul, M. Kudella, T. Spencer, B. K. Van Wesenbeeck, G. Wolters, et al. 2017. "Vegetation-Wave Interactions in Salt Marshes under Storm Surge Conditions." Ecological Engineering 100: 301-315.

Schupp, C. A., N. T. Winn, T. L. Pearl, J. P. Kumer, T. J. Carruthers, and C. S. Zimmerman. 2013. "Restoration of Overwash Processes Creates Piping Plover (Charadrius melodus) habitat on a barrier island (Assateague Island, Maryland)." Estuarine, Coastal and Shelf Science 116: 11-20. 
Smith, L., P. Cornillon, D. Rudnickas, and C. B. Mouw. 2019. “Evidence of Environmental Changes Caused by Chinese Island-Building." Scientific Reports 9 (1): 5295. https:// doi.org/10.1038/s41598-019-41659-3.

Stallins, J. A. 2005. "Stability Domains in Barrier Island Dune Systems." Ecological Complexity 2 (4): 410-430. https://doi.org/10.1016/i.ecocom.2005.04.011.

Stutz, M. L., and O. H. Pilkey. 2002. “Global Distribution and Morphology of Deltaic Barrier Island Systems." Journal of Coastal Research 36 (10036): 694-707. https://doi. org/10.2112/1551-5036-36.sp1.694.

Stutz, M. L., and O. H. Pilkey. 2011. ““Open-Ocean Barrier Islands: Global Influence of Climatic Oceanographic and Depositional Settings." Journal of Coastal Research 27 (2): 207-222. https://doi.org/10.2112/09-1190.1.

United Nations. 2015. Sendai Index for Disaster Risk Reduction 2015-2030. Geneva: The United Nations for Disaster Risk Reduction.

USACE (U.S. Army Corps of Engineers). 2002. Coastal Engineering Manual. EM 1110-2-1100. Vicksburg, MS: U.S. Army Corps of Engineers, Engineer Research and Development Center.

van Eekelen, E. M. M., L. Sittoni, F. van der Goot, H. E. Nieboer, M. J. Baptist, J. Boer, and F. H. Tonneijck. 2017. "The Living Lab for Mud: Integrated Sediment Management based on Building with Nature Concepts." Paper presented at Central Dredging Association (CEDA) Dredging Days, Rotterdam, NL, November 2017. https://www.ecoshape. org/app/uploads/sites/2/2017/11/Ceda-2017-paper-Van-Eekelen-Sittoni-et-alTHE-LIVING-LAB-FOR-MUD-INTEGRATED-SEDIMENT-MANAGEMENT-BASED-ONBUILDING-WITH-NATURE-CONCEPTS.pdf.

Walters, D., L. J. Moore, O. D. Vinent, S. Fagherazzi, and G. Mariotti. 2014. "Interactions between Barrier Islands and Backbarrier Marshes Affect Island System Response to Sea Level Rise: Insights from a Coupled Model." Journal of Geophysical Research: Earth Surface 119 (9): 2013-2031.

Wamsley, T. V., M. A. Cialone, J. M. Smith, B. Z. Ebersole, and A. S. Grzegorzewski. 2009. "Influence of Landscape Restoration and Degradation on Storm Surge and Waves in Southern Louisiana." Natural Hazards 51: 207-224.

Well, J. T., and J. M. Coleman. 1985. Deltaic Morphology and Sedimentology with Special Reference to the Indus River Delta. Technical Report Number 424. Baton Rouge, LA: Coastal Studies Institute, Louisiana State University.

Wray, R. D., S. P. Leatherman, and R. J. Nicholls. 1995. “Historic and Future Land Loss for Upland and Marsh Islands in the Chesapeake Bay, Maryland, USA." Journal of Coastal Research 11 (4): 1195-1203. 


\section{Works Consulted}

Adams, M. A., and I. W. Whyte. 1990. Fish Habitat Enhancement: A Manual for Freshwater, Estuarine, and Marine Habitats. Department of Fisheries and Oceans, Canada and Envirowest Environmental Consultants. Vancouver, BC: Minister of Supply and Services.

Barbosa, S. M., and M. E. Silva. 2009. “Low-Frequency Sea-Level Change in Chesapeake Bay: Changing Seasonality and Long-Term Trends." Estuarine, Coastal Shelf Science 83 (1): 30-38.

Caro, R. A. 1974. The Power Broker: Robert Moses and the Fall of New York. New York: Knopf.

Environmental Assessment Maintenance Dredging Sinepuxent Bay and Isle of Wight Bay Federal Navigation Channel Project. January 2014. Ocean City, Worcestor County MD.

Environmental Assessment Maintenance Dredging Susquehanna River Federal Navigation Channel Project. January 2013, Havre de Grace, Harford County, MD.

Environmental Assessment Maintenance Dredging Twitch Cove and Big Thorofare Federal Navigation Channel Project. December 2015. Somerset County, MD.

EWN (Engineering with Nature). 2018. Strategic Plan 2018-2023: Expanding Implementation. Vicksburg, MS: U.S. Army Corps of Engineers.

Farley, P. 1923. "Coney Island Public Beach and Boardwalk Improvements." Paper 136. The Municipal Engineers Journal 9 (4).

Grossman, D. H. 1998. International Classification of Ecological Communities: Terrestrial Vegetation of the United States. Arlington, VA: Nature Conservancy.

Kearney, M. S., and J. C. Stevenson. 1991. "Island Land Loss and Marsh Vertical Accretion Rate Evidence for Historical Sea-Level Changes in Chesapeake Bay." Journal of Coastal Research 7 (2): 403-415.

Kraus, N. C., and K. Hayashi. 2004. "Numerical Morphologic Model of Barrier Island Breaching." Paper presented at Coastal Engineering 2004 - Proceedings of the 29th International Conference, National Civil Engineering Laboratory, Lisbon, PT, September 2004.

Laczo, T. D., M. L. Gomez, and R. N. Blama. 2013. Regional Sediment Management for Atlantic Coast of Maryland and Assateague Island Seashore (Assateague By-Pass Project). ERDC/CHL CHETN-XIV-35. Vicksburg, MS: U.S. Army Corps of Engineers.

Mangor, K., I. Broker, and D. Haslov. 2008. "Waterfront Developments in Harmony with Nature." Terra et Aqua 111: 21-30.

MDE (Maryland Department of the Environment). 2017. Innovative Reuse and Beneficial Use of Dredged Material Guidance Document. Baltimore: MDE. 
National Research Council. 1995. Beach Nourishment and Design. Washington, DC: National Academy of Sciences.

Shepard, F. P. 1937. “Revised Classification of Marine Shorelines." The Journal of Geology 45 (6): 602-624.

Shepard, F. P. 1948. Submarine Geology. New York: Harper.

Shepard, F. P. 1973. Submarine Geology. New York: Harper.

Simpson, D., M. Wray, J. Houghton, and J. Klekotka. 2007. “Mixed Sand and Gravel Beach Design and Construction for Habitat Restoration." Paper presented at the Coastal Sediments 2007 Conference, New Orleans, LA, May 2007. 


\section{Acknowledgments}

\section{Lead Authors}

Joseph Gailani, U.S. Army Corps of Engineers, United States

Paula Whitfield, National Oceanic and Atmospheric Administration, United States

Enda Murphy, National Research Council Canada, Canada

\section{Co-Authors}

Jurre de Vries, Rijkswaterstaat, the Netherlands

Gordon Thomson, Baird, United States

Wendell Mears, Anchor QEA, LLC, United States

Danielle Szimanski, U.S. Army Corps of Engineers, United States

\section{Contributors}

Monica Chasten, U.S. Army Corps of Engineers, United States

Per Serensen, Danish Coastal Authority, Denmark

Phil Osborne, Golder Associates, Canada

Jessica Cohn, Massachusetts Division of Ecological Restoration, United States 

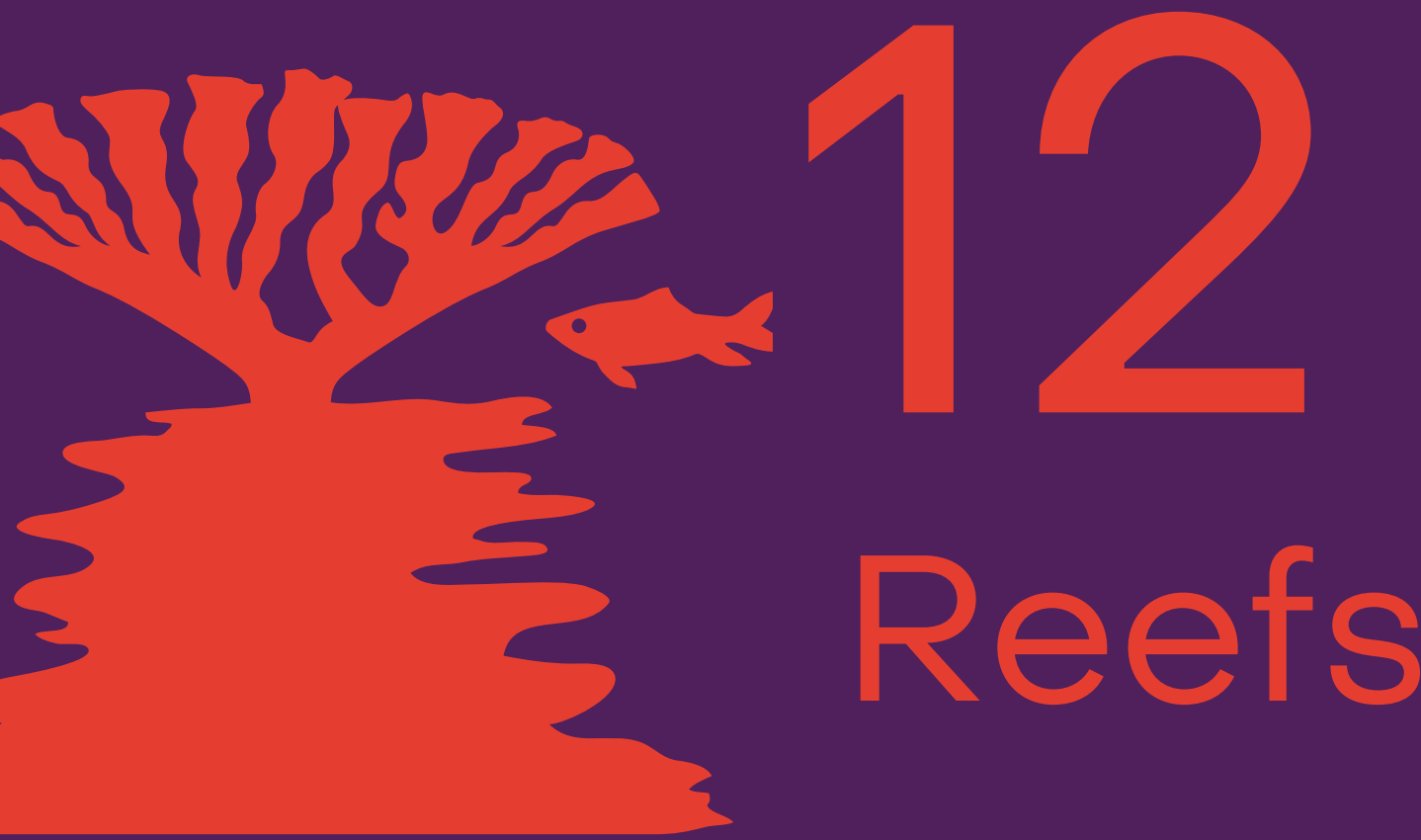

\section{Suggested Citation:}

Lowe, R. J., E. McLeod, B. G. Reguero, S. Altman, J. Harris, B. Hancock, R. ter Hofstede, E. Rendle, E. Shaver, and J. M. Smith. 2021. "Chapter 12: Reefs." In International Guidelines on Natural and Nature-Based Features for Flood Risk Management. Edited by T. S. Bridges, J. K. King, J. D. Simm, M. W. Beck, G. Collins, Q. Lodder, and R. K. Mohan Vicksburg, MS: U.S. Army Engineer Research and Development Center.

Full acknowledgments appear at the end of this chapter. 


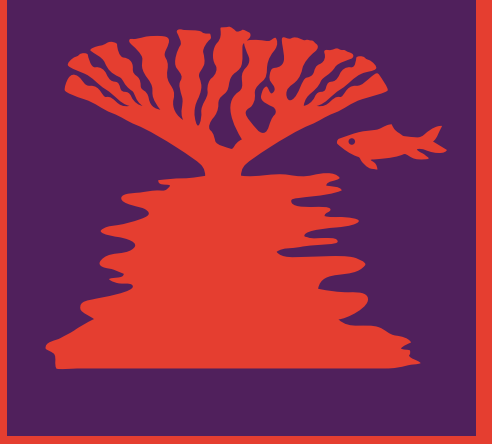

\section{Key Messages}

1. Reefs provide many ecosystem services, such as fisheries, recreation, and tourism. One of the most important services is protection from coastal flooding and erosion.

2. By protecting coastlines from wave energy, natural coral and shelliish reefs can provide similar levels of coastal protection to artificial submerged coastal engineering structures.

3. Healthy reef ecosystems provide greater benefits to coastlines than simply reducing wave energy because reef organisms also produce calcium carbonate material that can eventually be a source of sand nourishment.

4. In contrast to engineered coastal structures, natural and engineered reefs can be self-sustaining ecosystems, meaning that healthy reefs can, in some cases, continue to grow and maintain a structure that can protect shorelines without assistance from humans and keep pace with sea-level rise.

5. The geometry and placement of a reef governs its capacity for flood and erosion reduction by determining how it modifies nearshore wave and current fields, and shoreline responses.

6. There is significant engineering knowledge on the design of submerged breakwaters and artificial reefs, as well as understanding the physical processes along natural coral reef coastlines, which provides a foundation to help guide the design of natural and nature-based features (NNBF) for coastal protection. 


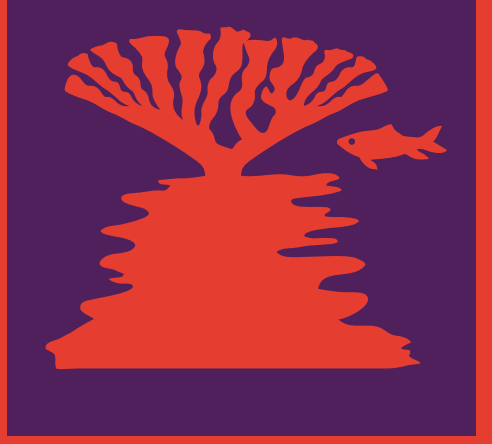

\section{Key Messages (Continued)}

7. Historically, there has also been significant experience with shellfish reef restoration for coastal risk reduction (coral reef restoration could adopt elements of this).

8. To date, there are only limited field applications using coral reef restoration for the purpose of reducing coastal flooding and erosion risk.

9. NNBF should be designed with multiple objectives (in addition to coastal protection) including both ecological and socioeconomic elements.

10. The design and construction of a reef NNBF should aim to mimic the natural geomorphology of a pre-existing or existing reef platform to favor biological growth, and materials used should be similar to those present in the surrounding environment.

11. Quantifying and maintaining the role of reefs in reducing coastal flooding and erosion should be factored into long-term coastal development and management strategies.

12. Maintaining the structural and biological benefits of reefs can be challenging in the context of global environmental change; thus, adaptive management is needed to support reef resilience and responsive decision-making. 


\section{1 | Introduction}

Coral and shellish reefs can reduce flooding and erosion in coastal areas, but not all reefs provide significant coastal protection benefits. This chapter provides an overview of the coastal protection benefits of reefs (e.g., reducing flooding, storm damage, and erosion) and discusses the suite of co-benefits that reefs can also provide (e.g., fisheries production, habitat and biodiversity, recreation and tourism revenue, and improved water quality).

For many reef-lined coasts around the world, reefs act as the first line of defense against flooding, storm damage, and erosion. However, the various ways in which reefs provide coastal protection are not always fully recognized and accounted for, in part, due to the historical focus on understanding and predicting flooding and erosion impacts for certain open-coast sandy shorelines lacking reefs. Yet, understanding the coastal protection services of reefs and assessing how they can reduce risk are critical because reefs will need to be effectively incorporated into climate adaptation programs, hazard mitigation strategies, and coastal development and management decisions (see Chapter 6).

This chapter is not intended to be a comprehensive reference on reef restoration, which in many cases can be closely related to the use of reefs for coastal defense. There are other sources that provide detailed information (e.g., reefresilience.org 2020a; public.tableau.com, n.d.). Instead, this chapter focuses on describing the key aspects relevant to the use of reefs for flood and erosion risk management.

\section{2 | Defining the Feature, Its Values, and Contexts for Application}

\subsubsection{Introduction}

Reef is a general term that describes shallow, submerged structures in the ocean. Natural reefs are formed by a variety of marine organisms, and often have a profound influence on coastal hydrodynamics, sediment transport, and morphological changes. The shallow nature and morphological complexity of reefs support some of the world's most productive marine ecosystems and provide habitats for large portions of marine species. As such, the broad ecosystem services that reefs provide worldwide are widely recognized and valued.

Reef ecosystems are influenced by environmental characteristics (e.g., sea surface temperature, nutrients, and turbidity) that define the habitat requirements that govern their geographic distributions. Coral reefs mostly occur within warm (i.e., $20^{\circ} \mathrm{C}$ to $30^{\circ} \mathrm{C}$ ), oligotrophic, clear waters that are optimal for coral growth. Organisms living within coral reefs 
form large-scale structures that can span hundreds of meters to hundreds of thousands of square kilometers within the world's tropical oceans. Reefs provide not only many ecosystem services such as fisheries, recreation, and tourism (Barbier et al. 2011; Grabowski et al. 2012; Spalding et al. 2017) but also substantial coastal protection and risk reduction (Beck et al. 2018; Reguero et al. 2019; Reguero et al. 2021; Ysebaert et al. 2019) to nearby populations, including the 850 million people living within 100 kilometers $(\mathrm{km})$ of a reef (Burke et al. 2011). Although coral reefs are arguably the most well-known class of reefs, other types of reefs are prevalent throughout the world's oceans, ranging from temperate rocky reefs (Wernberg et al. 2012) to shellfish reefs (Grabowski and Peterson 2007). These other classes of reefs are physically analogous to coral reefs but can be smaller (e.g., tens to hundreds of meters) and thus may have different effects on local coastal processes.

Shelliish reefs are formed by aggregations of bivalve mollusks, mostly species of oysters and mussels. Shellfish reefs can be found in sheltered temperate and tropical areas of bays, estuaries, and nearshore coastal environments, with different species requiring specific temperature and salinity regimes. Given they comprise filter-feeding organisms, shellfish reefs also need adequate food sources in the water column (e.g., phytoplankton and detritus) for optimal growth. Once established, shellfish reefs have the capacity to provide substantial coastal protection benefits (Scyphers et al. 2011; Chowdhury et al. 2019). However, shellfish reefs may affect shorelines differently than coral reefs because shelliish reefs are formed in sheltered waters and thus typically exist in low wind-wave energy environments. Shellfish reefs also can have a substantial indirect influence on flood reduction by supporting salt marsh growth and expansion behind shellfish reefs, which can further enhance coastal protection (see Chapter 10).

The effectiveness of a reef in reducing coastal flooding depends on complex interactions and feedbacks between waves, water levels, reef morphology, roughness, and habitat properties, among other factors. Natural reefs provide flood reduction benefits by dissipating incident wave energy (Lowe et al. 2005; Quataert et al. 2015; Buckley et al. 2018). Reefs often reduce wave energy reaching coastlines by more than $90 \%$ (Ferrario et al. 2014), which, in turn, can reduce wave-driven coastal flooding and risk (Beck et al. 2018; Reguero et al. 2019; Reguero et al. 2021). Studies have demonstrated the capacity of reefs to significantly reduce the coastal impacts of extreme storm events (e.g., tropical cyclones; Cuttler et al. 2018). Reefs dissipate incident wind-wave energy (sea-swell waves with periods approximately 5 to 25 seconds) through both depth-limited wave breaking and friction (drag) associated with the large bottom roughness and porosity that is typical of reefs (Lowe et al. 2005). Yet, when incident wind waves are dissipated by reefs, some of this energy is converted into other forms, namely through the generation of mean wave-driven currents, mean water levels via wave setup, and low-frequency waves (periods greater than 25 seconds) (Monismith 2007; Pomeroy et al. 2012; Lowe and Falter 2015; Quataert et al. 2015), which can become a primary driver of coastal flooding and erosion behind reefs (Buckley et al. 2018). 
Healthy reef ecosystems offer far greater benefits to coastlines than simply reducing coastal flooding and erosion risk. Coral reefs enhance the resilience and sustainability of coastlines by providing multiple services, including a natural source of sand nourishment, albeit over long timescales (e.g., decades and longer). In addition to directly protecting shorelines by stabilizing the shoreline, reducing erosion (e.g., Reguero et al. 2018a; Cuttler et al. 2018; Baldock et al. 2020), and supporting beach accretion, natural reefs can provide extra benefits for shoreline habitat expansion (e.g., protecting other ecosystems and natural and nature-based features [NNBF] such as beach and dune systems, wetlands, and mangroves). Shoreline changes behind reefs driven by waves can be partially explained by how waves are transformed and mean currents are generated over reefs, which alter sediment transport patterns and coastal morphology over time (e.g., Ranasinghe, Larson, and Savioli 2010). Predicting long-term changes to beaches fronted by natural reef ecosystems can also often be highly complicated by the need to resolve the contributions to coastal sediment budgets, including sediment supply, which is often directly linked to organisms living within a reef. Reef organisms produce calcium carbonate skeletal material, which when broken down over time, produces new carbonate sediment (see also Chapter 9). In many coastlines with reefs, reef-derived sediment is the primary source of sand that supplies and maintains beaches over time. The strong coupling between the ecological state of a reef and beaches is particularly visible at low-lying coral reef islands. In these areas, the sediment that forms beaches, supports their recovery after storms, and allows reef islands to adapt to historical sea-level rise is entirely sourced from carbonate sediments produced by organisms living within the reef (e.g., Perry, Spencer, and Kench 2008).

\subsubsection{Types of Reefs}

There are many types of reefs around the world, ranging from natural reefs such as coral reefs and shellfish reefs (e.g., oysters or mussels) to engineered artificial reef structures. Coral reefs cover approximately 285,000 square kilometers of the earth's surface in tropical ocean regions and at various depths from shallow areas to the deep sea (Spalding, Ravilious, and Green 2001). Coral reefs consist of hard corals and other reef-building organisms (e.g., coralline algae) that produce the calcium carbonate that build reef structures. Smaller colonies of hard corals also live in cold and deep waters, but warm-water corals in the tropics are responsible for building the large-scale morphological structures commonly associated with coral reefs. Corals in tropical regions have a symbiotic relationship with photosynthetic algae that produce energy for corals and facilitate coral skeletal deposition (Pearse and Muscatine 1971). Healthy coral reefs are among the most biologically diverse, productive, and economically valuable ecosystems on the planet. They support $25 \%$ of the ocean's biodiversity (Burke et al. 2011); provide food, spawning, and nursery grounds for commercially important fish populations; support millions of jobs through tourism (Spalding et al. 2017), fishing, and recreational activities; and are an integral part of the cultural values of coastal communities. 
Shellfish reefs also act as natural breakwaters by reducing wave energy, and thus provide coastal protection and reduced erosion risk for both coastal populations and other habitats (e.g., salt marshes and submerged aquatic vegetation; Grabowski et al. 2012). Large shellfish reefs are primarily formed by oysters, although other taxa have created reef structures in some situations (Gillies et al. 2018). Oysters are a type of bivalve that attach to other oysters or hard substrate to form reefs. Oyster reefs are submerged habitats that occur in both intertidal and subtidal areas. Oysters occupy both marine and brackish waters in temperate and some tropical regions, and they are primarily found along the Pacific and Atlantic coasts of the United States, Gulf of Mexico, Australia, Japan, China, Europe, and the United Kingdom. Oyster reefs once dominated many shorelines, much like coral reefs do today. In some areas, such as the east coasts of the United States and China, oyster reefs historically formed structures that were meters high and often treated as navigational hazards. Such reefs would have offered substantial protection to shorelines, people, and property. No such oyster reefs exist naturally today at such a scale (Beck et al. 2011). Oyster reefs provide many benefits, including shoreline stabilization; water quality improvement by filtering out pollutants, excess nutrients, microalgae, and suspended organic matter in the water column; and food and habitat for commercially important fishes and crustaceans.

In addition to shellfish reefs and coral reefs, other types of natural reefs include rocky reefs, which comprise subtidal rock formations (e.g., granite, limestone, and basalt) and are frequently found in temperate coastal waters, and sponge reefs, made from hexactinellid sponges with skeletons made of silica (e.g., such as those found off the coast of British Columbia, Canada).

Artificial reefs are submerged engineered structures constructed using a variety of designs and materials (Baine 2001; Broughton 2012). Artificial reefs differ from traditional low-crested submerged breakwaters because they are usually designed to serve additional functions, which primarily include providing habitat for a range of marine life (Lokesha, Sundar, and Sannasirai 2013) but occasionally may include other functions (e.g., to enhance or create surf breaks) (Rendle and Rodwell 2014; Rendle 2016). Artificial reefs have been implemented to support recreational fisheries, species conservation, and habitat replacement (Bohnsack and Sutherland 1985; Baine 2001; Broughton 2012; Komyakova et al. 2019). Artificial reefs are often used to add structure to otherwise open or bare areas of the seafloor, and thus can provide the critical hard substrate for marine life to colonize, such as corals. They also can support shelter for marine species at various life stages, such as fish and crustaceans. Due to this increase in habitat space for marine life, artificial reefs are also often used to attract fish for tourism opportunities including recreational fishing and diving (Leeworthy, Maher, and Stone 2006; Komyakova et al. 2019). Artificial reefs typically have been designed for the aforementioned 
ecosystem service benefits (e.g., habitat creation, which enhances the production of reef-associated species including macroalgae, invertebrates, and fishes). However, they can also be designed to reduce wave energy and shoreline erosion (e.g., Reguero et al. 2018a). Figure 12.1 summarizes some of the different options for protecting coastlines, ranging from green to gray approaches (i.e., natural reefs to artificial reefs to breakwaters).

Figure 12.1. Different Methods to Attenuate Wave Energy Using Green (Coral Reef) to Gray (Breakwater) Approaches
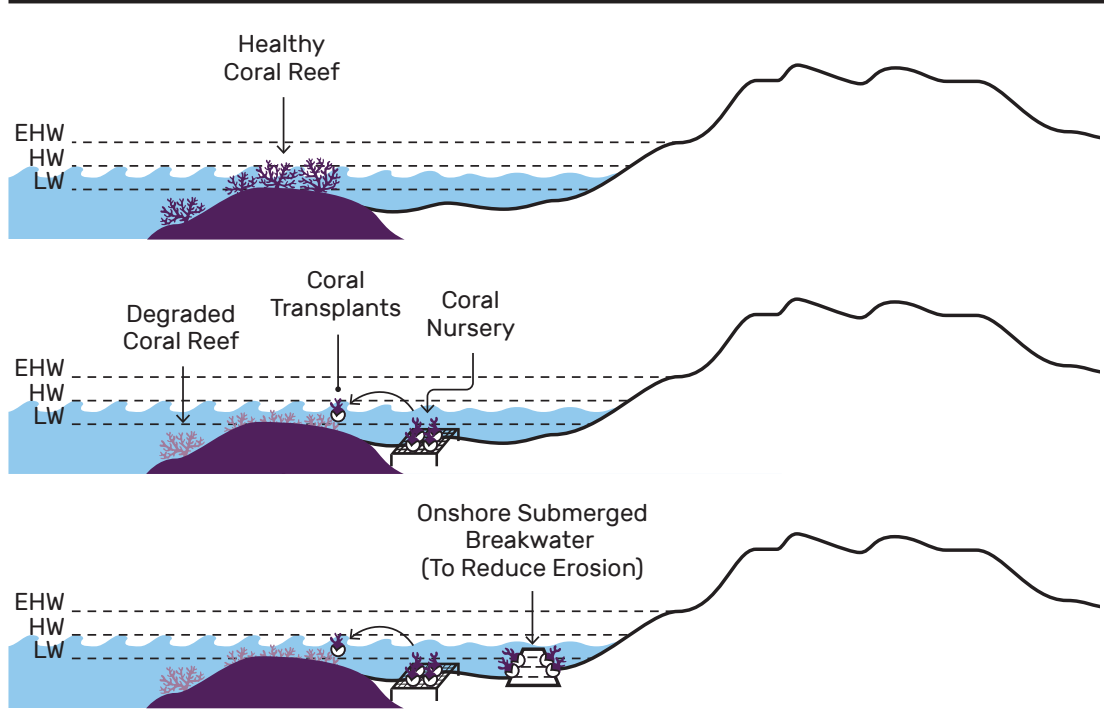

(To Reduce Erosion)
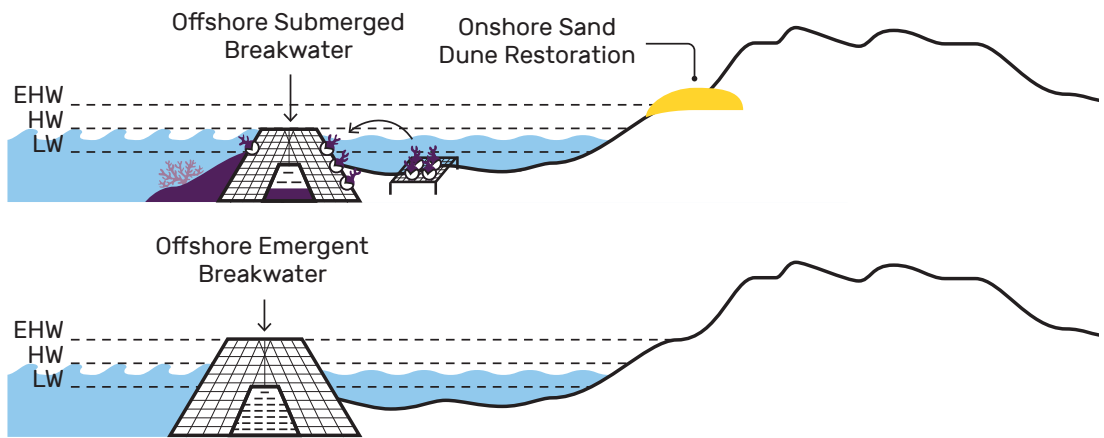

Less

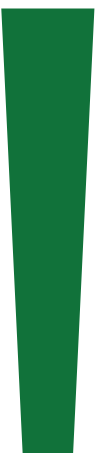

Natural

\section{Cost}

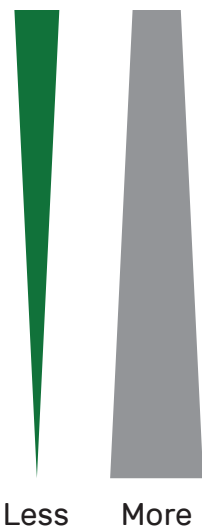

$\mathrm{LW}=$ low water; $\mathrm{HW}=$ high water; $\mathrm{EHW}=$ extreme high water

Source: Adapted from Kramer 2016 


\subsubsection{Global and Local Threats Facing Coral and Shellfish Reefs}

Natural reefs are subject to a range of local- to global-scale environmental stressors that have the potential to reduce their long-term sustainability, and thus effectiveness as NNBF. For example, coral reefs globally are being degraded and destroyed by a combination of local human impacts (overfishing, destructive fishing, sedimentation, and nutrient pollution) and harmful conditions caused by climate change (e.g., increasing sea temperatures and ocean acidification) (Hoegh-Guldberg et al. 2007; Hughes et al. 2017; Hughes et al. 2018). Large storms, such as tropical cyclones and hurricanes, can also produce high losses of coral cover (Puotinen et al. 2020); for example, prior to recent global bleaching events, some of the greatest impacts to the Great Barrier Reefs were from tropical cyclones (De'ath et al. 2012). Tropical reef building corals often live within relatively narrow environmental limits that define habitat requirements; consequently, local degradation of water quality beyond these limits has led to significant losses of coral reefs in many parts of the world (e.g., De'ath and Fabricius 2010; Hughes et al. 2018). Climate change ultimately poses the greatest long-term threat to coral reefs worldwide by increasing sea temperatures and by ocean acidification (Wong et al. 2014). For example, during the long-lasting and severe El Niño conditions during 2014 to 2017 , the persistent marine heat-wave conditions across many tropical regions led to the worst coral bleaching on record, with such events forecast to become more frequent and severe in the future (van Hooidonk et al. 2016; Hughes et al. 2018).

Similar to coral reefs, oyster reefs are also experiencing significant global declines, with the majority of the destruction having been thought to be inflicted in the second half of the nineteenth century. An estimated $85 \%$ of oyster reefs have been lost globally (Beck et al. 2011) due to a combination of overharvesting, habitat destruction, and reduced water quality. Loss of oyster reefs is often driven by dredging and trawling combined with sedimentation, anoxia, and disease (Lenihan et al. 1999). Oyster disease is often associated with the introduction of non-native species due to ballast water or transfers of non-native oysters for aquaculture (NRC 2004). Additionally, coastal development, freshwater inflows, and increased sediments, nutrients, and other pollutants have also further contributed to oyster reef decline (NRC 2004).

Despite the global losses of reefs, there are some positive signs. A growing number of studies show successful examples of oyster and coral reef restoration (Beck et al. 2011; Young, Schopmeyer, and Lirman 2012; Reguero et al. 2018a). Oyster reefs have the potential to keep pace with present rates of sea-level rise (Rodriguez et al. 2014), and some corals have been observed to thrive in extreme conditions (e.g., extreme temperatures [Palumbi et al. 2014; Dandan et al. 2015]) and low pH waters (Shamberger et al. 2014). These observations provide hope that corals in some locations may have some capacity to adapt to certain future environmental changes when adequately managed. Human interventions, such as assisted evolution, translocation of species, reef restoration, manipulation of symbiotic algae within 
corals, and engineering solutions such as shading and cooling during bleaching events, are also being explored to support reef survival (van Oppen et al. 2017; McLeod et al. 2019; NAS 2019). Reducing local threats facing coral and shellfish reefs (e.g., eliminating overfishing, improving water quality, and implementing marine protected areas) can improve reef health to help reefs maintain their coastal protection benefits. Improved methods of reef restoration can also help restore the structure and function of damaged reefs if the underlying causes of decline are addressed and managed. Indeed, research suggests that reef restoration projects may be more cost effective and may provide more sustained coastal protection than traditional submerged breakwaters when all costs and benefits are considered (Ferrario et al. 2014).

\subsubsection{Values and Contexts for Application}

Natural and artificial reefs provide coastal protection and risk reduction services by dissipating wind waves originating from the open ocean as the waves propagate over shallow and rough reef structures (Gourlay 1994, 1996a, 1996b; Hardy and Young 1996; Wolanski 1994; Sheppard et al. 2005; Lowe et al. 2005). Healthy coral reefs, for example, often dissipate most incident wave energy before the waves reach the shore (Ferrario et al. 2014). This wave-energy buffering reduces risk to coastal communities by wave-driven coastal flooding and associated losses (Storlazzi et al. 2018, 2019; Beck et al. 2018; Reguero et al. 2019). Recent research shows that the cost of annual damages from flooding would likely double without coral reefs (Beck et al. 2018).

The effectiveness of reefs to attenuate wave energy and protect coastlines depends on their size, orientation, elevation, and location relative to shore, as well as tidal range, among other characteristics. One of the most important characteristics that governs coastal protection is the elevation of the reef crest (the shallowest part of a reef) relative to sea level. The capacity of a reef to dissipate wave energy decreases as the elevation of the reef crest becomes deeper. For instance, for subtidal shelliish reefs found in deep water, their coastal protection services are often less, because most of the wave energy is transmitted to the shoreline. Tidal variations and other sources of sea-level variability (see Section 12.3.4) can also greatly diminish the effectiveness of reefs to dissipate wave energy when water levels are high. For natural coral and shellfish reefs, reef degradation can also reduce the elevation and roughness of a reef structure over time (i.e., due to human impacts and climate change), and thus also reduces their ability to protect shorelines.

Conventional approaches to mitigate coastal erosion rely on constructing engineering structures, yet natural coral and shellfish reefs can often provide comparable protection. Furthermore, the effect of reefs on sediment transport can also have similar effects to other natural and engineered structures that promote the stability of shorelines. For example, healthy coral reefs can maintain shorelines in a stable equilibrium, similar to natural headlands and engineered breakwaters in many pocket beaches around the world (Hsu et al. 2010), 
whereas the degradation of reefs can alter wave and current patterns, leading to areas of chronic coastal erosion and enhanced flooding (Reguero et al. 2018a). In contrast to engineered coastal structures, natural and artificial reefs can be self-sustaining ecosystems, meaning that healthy reefs can, in many cases, continue to grow and maintain a structure that can protect shorelines without human intervention (as observed in Reguero et al. [2018a] using a coastline stability model). For example, research indicates that the vertical growth rates of unharvested oyster reefs are faster than predicted rates of sea-level rise (Rodriguez et al. 2014), meaning that they could maintain their coastal protection benefits in the face of climate change and adapt to sea-level rise in contrast to conventional engineering structures (Grabowski et al. 2012). However, reef degradation may reduce their ability to keep up with sea-level rise (Perry et al. 2018); for example, for coral reefs to maintain their coastal protection benefits, they must continue to accrete calcium carbonate structures by maintaining the health of calcifying reef organisms that build reefs.

In addition to directly reducing wave energy, both coral reefs and shellfish reefs often play less recognized critical roles in protecting and facilitating the establishment of other coastal habitats. For example, wave attenuation by coral reefs often allows tropical seagrass beds to form in protected lagoons, mangrove forests to form along coastlines, and beach and dune systems to be established. Because seagrass meadows and mangroves also attenuate wave energy and trap sediments (Duarte et al. 2013) (see also Chapters 10 and 13 ), reefs may also act synergistically with other forms of NNBF to further mitigate risks of coastal flooding and erosion (Guannel et al. 2016). Similarly, by buffering waves and improving water quality, shellfish reefs can provide suitable conditions for salt marshes and temperate seagrass beds. These associated benefits of reefs greatly increase overall protection services of other ecosystems in their lee (Alongi 2008; Christianen et al. 2013). Thus, multiple layers of natural protection may be the most effective strategy when habitats are healthy, interconnected, and working together to maximize benefits to coastal communities (Guannel et al. 2016). Table 12.1 provides a summary of the various key functions of reefs, their performance aspects, and benefits.

Table 12.1. Ways in Which Reefs Deliver Flood and Coastal Erosion Risk Reduction

\begin{tabular}{llll}
\hline \multicolumn{1}{c}{ Effects } & \multicolumn{1}{c}{ Performance factors } & \multicolumn{1}{c}{ Potential benefit } & \multicolumn{1}{c}{ Example } \\
\hline $\begin{array}{l}\text { Wave-energy } \\
\text { dissipation (flood } \\
\text { defense) }\end{array}$ & $\begin{array}{l}\text { Elevation relative to mean } \\
\text { sea level, proximity of reef to } \\
\text { shore, width and height of reef, } \\
\text { reef roughness, and porosity } \\
\text { characteristics }\end{array}$ & $\begin{array}{l}\text { Reduced coastal flooding, } \\
\text { reduced erosion, reduced } \\
\text { damage to coastal } \\
\text { infrastructure during } \\
\text { storms }\end{array}$ & $\begin{array}{l}\text { Fringing coral reefs in } \\
\text { the tropical Indo-Pacific } \\
\text { and Caribbean }\end{array}$ \\
& & & \\
\hline
\end{tabular}




\begin{tabular}{|c|c|c|c|}
\hline Effects & Performance factors & Potential benefit & Example \\
\hline Shoreline creation & $\begin{array}{l}\text { Production of sand by calcifying } \\
\text { organisms and bioerosion, sand } \\
\text { and sediment trapping }\end{array}$ & $\begin{array}{l}\text { Beach formation and } \\
\text { maintenance }\end{array}$ & $\begin{array}{l}\text { Formation of coral reef } \\
\text { islands }\end{array}$ \\
\hline $\begin{array}{l}\text { Wetland } \\
\text { enhancement and } \\
\text { growth }\end{array}$ & $\begin{array}{l}\text { Erosion reduction and shoreline } \\
\text { stabilization creating suitable } \\
\text { conditions for wetlands and } \\
\text { promoting growth }\end{array}$ & $\begin{array}{l}\text { Surge reduction, further } \\
\text { wave reduction and } \\
\text { shoreline stabilization }\end{array}$ & $\begin{array}{l}\text { Oyster reefs in front } \\
\text { of salt marshes and } \\
\text { coral reefs in front of } \\
\text { mangroves }\end{array}$ \\
\hline $\begin{array}{l}\text { Long-term shoreline } \\
\text { stabilization (erosion } \\
\text { control) }\end{array}$ & $\begin{array}{l}\text { Bathymetric configuration and } \\
\text { influence on wave propagation, } \\
\text { surf zone currents, and } \\
\text { sediment transport patterns }\end{array}$ & $\begin{array}{l}\text { Shoreline maintenance } \\
\text { and preservation }\end{array}$ & $\begin{array}{l}\text { Oyster reefs adjacent to } \\
\text { coastlines }\end{array}$ \\
\hline $\begin{array}{l}\text { Storm impact } \\
\text { mitigation }\end{array}$ & $\begin{array}{l}\text { Ability to reduce coastal waves } \\
\text { and water levels during extreme } \\
\text { storms }\end{array}$ & $\begin{array}{l}\text { Reduced damage to } \\
\text { coastal infrastructure } \\
\text { during storms }\end{array}$ & $\begin{array}{l}\text { Coastal flooding and } \\
\text { erosion reduction } \\
\text { behind reefs during } \\
\text { tropical cyclones }\end{array}$ \\
\hline
\end{tabular}

\section{3 | Conceptual Understanding}

\subsubsection{Reef Morphology and Characteristics}

The morphological characteristics of coral reefs influence their capacity to protect coastlines, with these reefs often classified into three main categories: fringing, barrier, and atolls; however, more than a dozen types have been described (Andréfouët et al. 2006). A reef is further divided into the following zones (moving from the shore to the sea): backreef or reef flat, reef crest or algal ridge, and seaward slope or fore reef (Figure 12.2). However, these zones differ based on reef type and are shaped by several physical and biological processes (e.g., organisms present, depths, wave energy, temperature, and light).

Shellfish reefs are built by bivalve mollusks over successive generations and consist of a top layer of live animals that reside over a 3D structure of accumulated dead shells. Because they form complex structures, shellish reefs enhance near-bed turbulence and vertical mixing in the lower water column and slow down current velocities through increased bed roughness (Ysebaert et al. 2019). Shellfish reefs create spatially and topographically complex habitats and are present across a range of spatial scales, from small clumps to large patches to extensive beds and reefs that cover thousands of square meters and extend kilometers in length 
(Gutiérrez et al. 2003, 2011). Shellifish reefs are different from shellifish beds, where the latter comprises only a single layer of live animals (hence low relief). Shellfish reefs appear in distinct reef morphologies and spatial patterns, thought to arise from feedback mechanisms between shellfish and local hydrodynamics (different morphologies include string reefs, fringe reefs, and patch reefs) (Ysebaert et al. 2019). Shellfish reefs can be highly variable due to available substrate, sediment type, sea-level variations, salinity, tidal range, and flow conditions.

\section{Figure 12.2. Typical Coral Reef Zones}

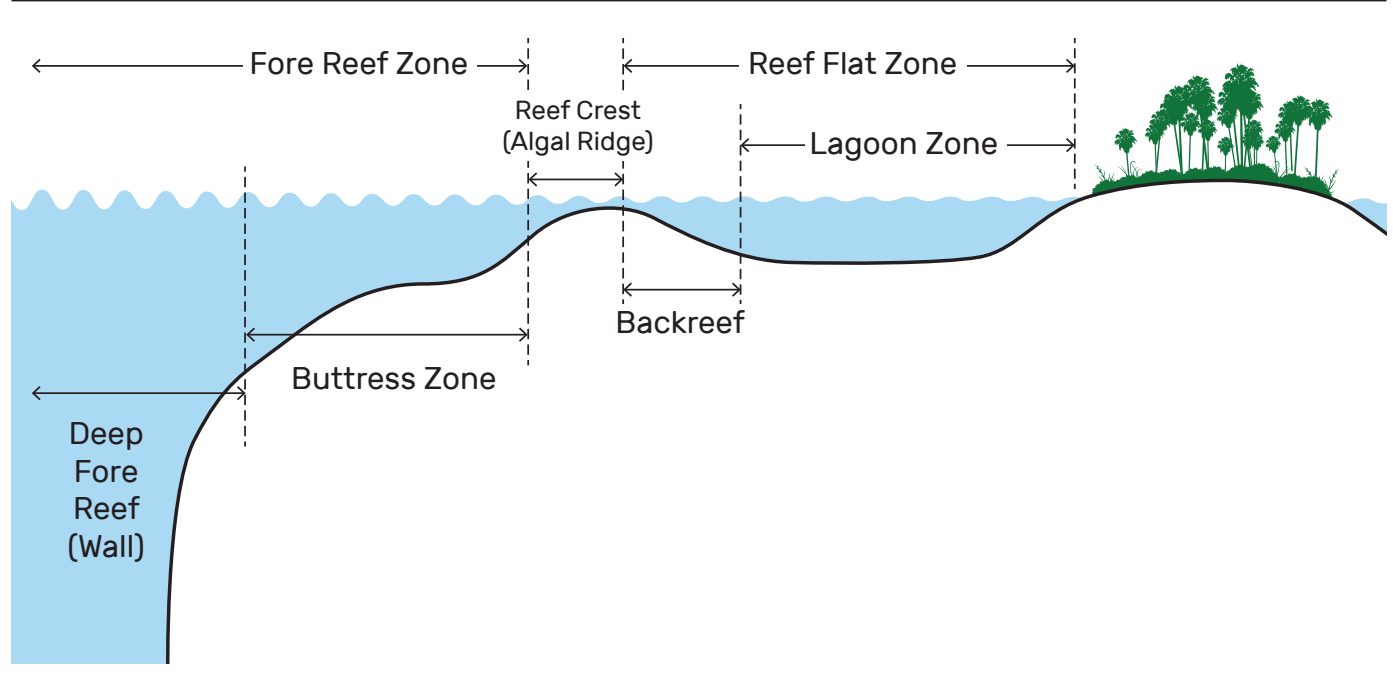

Source: Adapted from coris.noaa.gov 2021

The configuration of reefs plays a critical role in their flood risk reduction and erosion-control performance (see Section 12.5). For a fringing reef, the reef flat zone (including the back reef and a deeper lagoon if present) is partially sheltered from offshore wave energy. This zone can range from tens of meters to kilometers wide and may range from tens of centimeters to several meters deep (which may also become exposed at low tide). The reef crest (algal ridge) generally experiences strong wave action and is also often exposed at low tide; therefore, coral cover in this zone may be limited or absent altogether. The reef crest often varies from several to tens of meters wide. The height of the reef crest and the length and width of the reef flat are primary variables determining wave attenuation (Ferrario et al. 2014). Any breaks (gaps) in the reef crest may reduce some of the capacity of a reef to attenuate wave energy. For example, in the Caribbean, discontinuous and semicontinuous reef crests attenuate much less wave energy than those with continuous reef crests (Roberts 1980; Kramer 2016). 
Shallow reef crests with wide reef flats achieve the largest reduction in wave energy (i.e., reduced wave height at the shoreline; Figure 12.3 Case $A$ ). Wider reef flats dissipate more wave energy, which is usually most pronounced within the initial 100 meters $(\mathrm{m})$ of reef when waves initially break in the surf zone, after which wave-energy reduction becomes more gradual (Ferrario et al. 2014). The additional presence of patch reefs and shallow lagoon sediment banks can further attenuate wave energy. When a reef crest becomes deeper and narrower, more energy reaches the shoreline (Figure 12.3 Case B and Case C; Zepeda-Centeno et al. 2018).

Differences in reef organism composition can be an important factor in the coastal protection service of reefs. Coral growth rates differ among species (e.g., large branching corals contribute significantly more calcium carbonate accumulation in Caribbean reefs than smaller weedy species [Perry et al. 2013]). For reefs to accrete vertically, more calcium carbonate must be produced than is removed through bioerosion, dissolution, and storm export (Perry et al. 2014). On most coral reefs, the processes of accretion and erosion are nearly balanced, with a slightly higher rate of net reef accretion. Studies reveal that reef accretion is commonly 3.5 millimeters per year, although it can be as high as 14 millimeters per year (Buddemeier and Smith 1988).

Shellfish reefs have the capacity to grow vertically at exceptional rates; for example, the vertical growth rate of young oyster reefs can exceed 10 centimeters per year, thus far exceeding even worst-case sea-level rise scenarios (Rodrigues et al. 2014). These vertical accretion rates of oyster reefs are thought to have the potential to exceed all other common ecosystem engineers, including salt marsh, seagrass, and mangrove ecosystems (Rodrigues et al. 2014). However, growth rates of shellifish are highly variable across reef elevation gradients due to stress from submergence (e.g., from competition and predation) and exposure (desiccation) (Ridge et al. 2015). 
Figure 12.3. Schematic of the Effects of the Bathymetry Profile of a Reef on Wave Attenuation that Determines Wave Heights Reaching a Beach

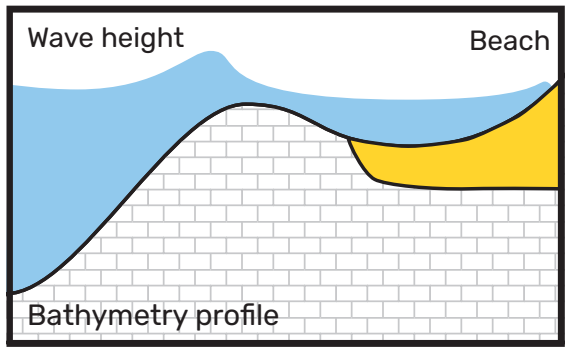

Wave height
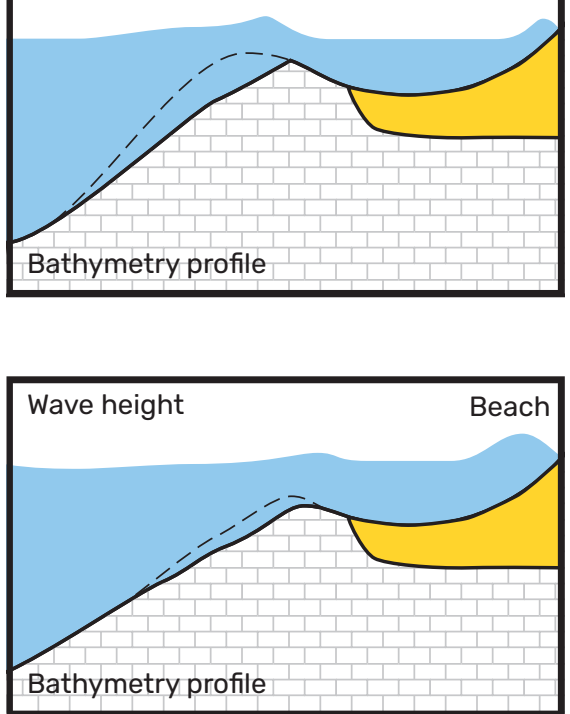

\section{Case A: High Beach Protection}

The shallow reef crest dissipates a large portion of incident wave energy (wave heights immediately are reduced to 0.4 to 0.6 times the reef crest water depth). Further wave energy is dissipated over the reef flat prior to reaching the shoreline.

Beaches are likely to be stable.

\section{Case B: Medium Beach Protection}

The deeper reef crest allows for greater wave heights across the reef.

Higher wave energy reaches the beach compared to Case A.

Beaches are more dynamic but still protected.

\section{Case C: Sporadic Beach Protection}

Waves rarely break on the deep reef crest (only large waves may break).

Beaches are more dynamic and prone to erosion, especially during storms.

Note: This does not consider longshore variability in reef morphology that may also be important.

Source: Zepeda-Centeno et al. 2018 


\subsubsection{Water Depth}

For both coral and shellfish reefs, the water depth over the shallowest part of a reef greatly affects the capacity of the reef to attenuate wave energy (Monismith 2007). For larger-scale coral reefs, water depths are usually shallowest on the outermost reef crest or algal ridge (approximately $\pm 0.5 \mathrm{~m}$ relative to mean sea level [MSL]) (Kramer 2016). For narrower shellfish reefs, maximum wave attenuation is achieved when the reef crest depth is at or above MSL. When depths are large over both types of reefs (e.g., during high tides or storm surges), larger waves can be transmitted past the reef crest and travel toward the coastline (Lugo-Fernandez et al. 1998). When water depths are small, incident waves are dissipated at a greater rate by enhanced wave breaking and bottom friction (Kramer 2016). For sites that experience relatively large tides, water depths over a reef vary substantially over each tidal cycle (timescales of 12 or 24 hours); in this case, waves are attenuated at greater rates at low phases of the tide (low rates at high tide), causing wave heights transmitted to coastlines behind reefs to vary substantially during each tidal cycle (Lugo-Fernandez et al. 1998; Lowe et al. 2005; Taebi et al. 2011). As a consequence, for sites with large tides (e.g., macrotidal regimes), a reef would only provide substantial coastal protection over a portion of the tidal cycle, which may undermine the suitability of a reef NNBF for coastal hazard risk reduction at a site.

\subsubsection{Reef Surface Roughness}

The coastal protection capacity of coral reefs is greater than many other marine systems because of the combined effect of waves breaking at the reef crest and the high frictional dissipation of wave energy across the reef, thus modifying wave run-up at the shoreline (Quataert et al. 2015; Buckley et al. 2018). Although rates of frictional dissipation of wave energy across a reef tend to be more gradual than the concentrated rates of wave-breaking dissipation in the surf zone, given the large widths of reefs, the total amount of frictional dissipation can be large (comparable to breaking dissipation) (Lowe et al. 2005). The 3D structure of a coral reef plays an important role in reducing wave energy and protecting coastlines (Harris et al. 2018). Structural complexity is often assessed using a measure of reef rugosity that relates to the physical scales of the reef bottom roughness. As waves move across a reef, reef roughness exerts drag forces on the oscillatory flow motions that cause wave energy to be dissipated (Lowe et al. 2007). The type of substrate affects the amount of energy loss by drag (e.g., sand and pavement results in less drag than large corals); thus, surfaces with greater rugosity (i.e., high physical roughness) are more effective at reducing wave energy. Rates of frictional dissipation over coral reef flats can be more than 10 times greater than that over sand (Lugo-Fernandez et al. 1998; Lowe et al. 2005), and as water level decreases, rates of frictional dissipation can be further enhanced (Huang et al. 2012; Pomeroy et al. 2012). 
The surfaces of shellfish reefs similarly function to reduce wave energy and affect flow patterns due to the drag forces created by the shellfish roughness (Styles 2015). A recent study found that shelliish reefs can increase drag coefficients by up to five times over that for a bare mud bed (Whitman and Reidenbach 2012). Although shellfish reefs can be effective at attenuating wave energy, their effect is greatest when water depths are no more than a few tens of centimeters above the reef crest (Wiberg et al. 2019). In addition, the health of a shellifish reef can affect the structure and long-term wave-attenuation capacity of the reef. Degraded reefs contain fewer live oyster clusters and thus have different bed roughness; such morphological differences can result in different impacts to hydrodynamic function, flow fields, and sediment transport. For example, a study compared a degraded and a reference-condition oyster reef and assessed how differences in reef morphology and roughness affected near-bed hydrodynamic function and found that the drag coefficient at the reference healthy reef was almost twice that at the degraded reef (Kitsikoudis, Kibler, and Walters 2020).

\subsubsection{Hydrodynamic Processes - Wave-Driven Contributions to Coastal Flooding}

Coastal flooding is caused by extreme water levels that may be driven by different hydrodynamic processes. The total water level at a coastline is usually assumed to comprise five primary components (e.g., Vitousek et al. 2017) (Figure 12.4): (1) MSL variability, (2) tides, (3) storm surges (wind and pressure driven), (4) wave setup, and (5) swash excursions. MSL variability includes long-term sea-level rise, as well as shorter-term seasonal and interannual variations (Losada et al. 2013; Lowe, Cuttler, and Hansen 2021), such as the El Niño-Southern Oscillation variability and other climate-driven processes that can represent significant variation in certain reef regions. Sea-level variability driven by the first three components (MSL, tides, and surges) originates from large-scale ocean processes that occur offshore of reefs (i.e., at a scale much greater than an individual reef). As a consequence, reefs generally have minimal ability to alter these slowly varying contributions to offshore water levels; in other words, the water levels at a coastline fronted by a reef tend to closely follow offshore water-level variations induced by MSL, tides, and surges. 


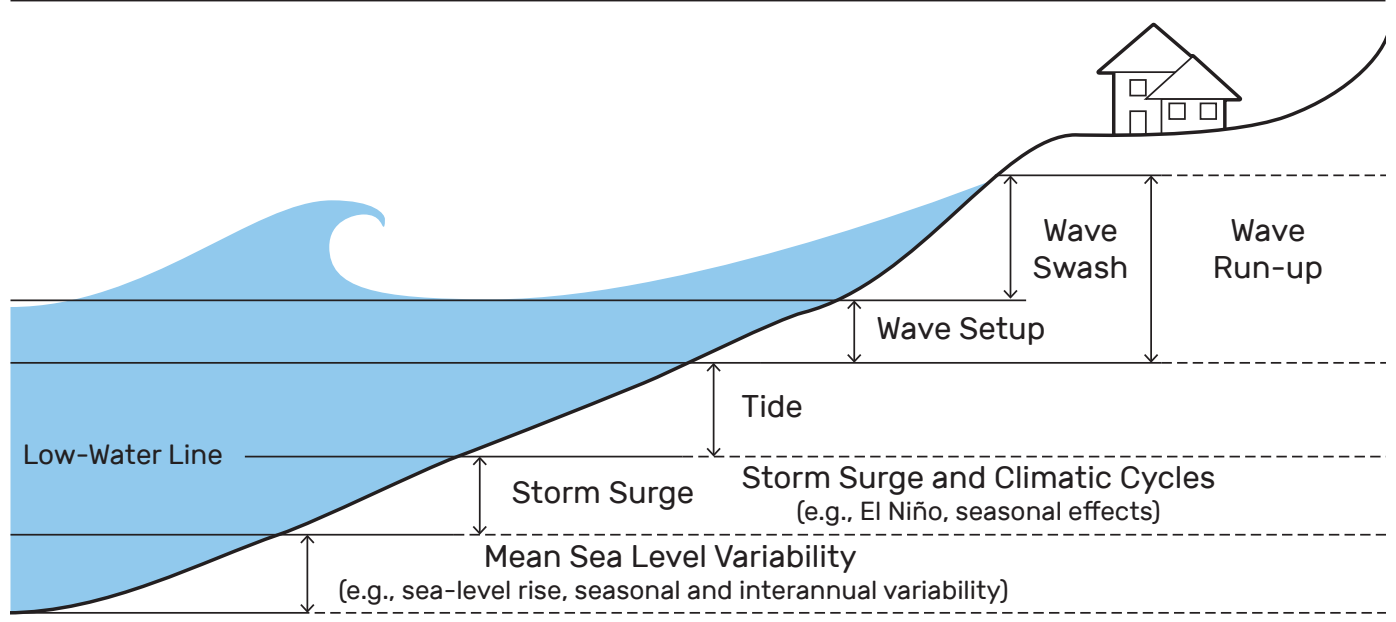

Source: Adapted from Vitousek et al. 2017

In contrast, wave-driven contribution to coastal flooding can be substantially reduced by reef structures by dissipating incident wave energy, with the amount of dissipation dependent on the depth of the reef, its cross-shore width, and its bottom roughness characteristics (Figure 12.3). Wave dissipation over reefs affects both a wave setup and swash contribution to coastal flooding (collectively, these setup and swash contributions are referred to as wave run-up; Stockdon et al. 2006). Wave setup describes an elevation of mean water level relative to offshore, which occurs due to wave forces (gradients in wave radiation stresses) that are generated by wave dissipation during breaking (and to a lesser extent by bottom friction). Because wave setup is generated more efficiently when waves break on the steep fore reef slopes typical of reefs (Buckley et al. 2015), wave setup at coastlines fronted by longshore uniform reefs can be much larger (e.g., up to $25 \%$ of the incident wave height or even larger; Gourlay et al. 1996a; Taebi et al. 2011) than for mild-sloping sandy beaches (Bowen, Inman, and Simmons 1968). This wave setup contribution at reef coastlines can often be of similar magnitude or larger than the storm surge. For example, in Hawaii during Hurricane Iniki, Kennedy et al. (2012) found that wave setup accounted for more than two-thirds of the increase in the mean water level at the shoreline (wind and barometric setup contributing the other one-third). For cases with longshore variable reefs (i.e., for reefs broken periodically by channels), as well as reefs with relatively deep coastal lagoons, wave setup at a coastline can also be reduced when water is able to return to the ocean via wave-driven flows that prevent the accumulation of wave setup within the reef (Figure 12.5) (Lowe, Hart, and Pattiaratchi 2010; Rijnsdorp et al. 2021). Overall, wave setup tends to be strongly dependent on the broader morphological properties of a reef, and to a lesser extent on the bottom roughness characteristics (Buckley et al. 2016). 
Figure 12.5. Wave-Driven Circulation Patterns Generated behind Reefs that Influence Whether Shoreline Erosion or Accretion Will Occur

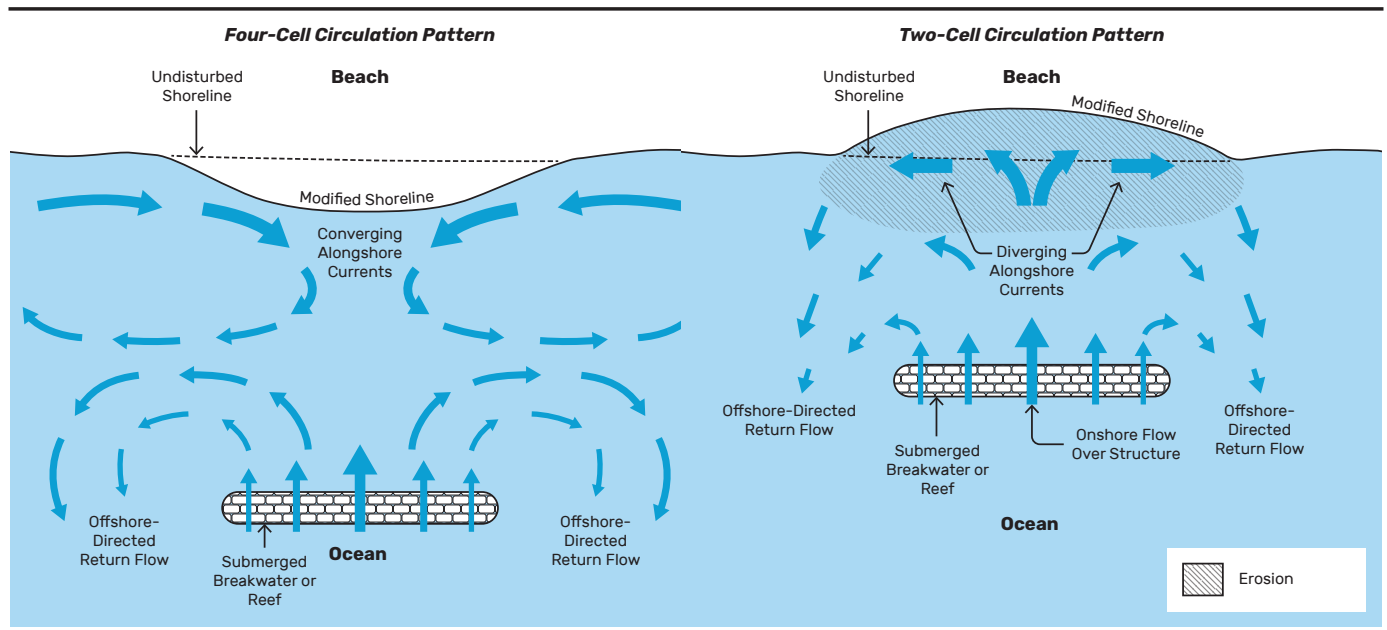

Notes: This graphic depicts how mean wave-driven flow patterns behind reefs can determine whether shoreline erosion or accretion will occur based on whether the mean wave-driven flows generated by waves breaking over the structure are diverging or converging.

Source: Adapted from Ranasinghe, Larson, and Savioli 2010

The swash contribution to wave run-up is driven by wave motions incident to the shoreline, which is due to a combination of any sea-swell wave energy that is transmitted across the reef, as well as low-frequency (infragravity) wave motions that are generated at the crest by breaking sea-swell wave groups (Péquignet et al. 2009; Pomeroy et al. 2012). However, for shallow reefs, the contribution of sea-swell waves to swash motions is often smaller than the contribution from low-frequency waves (Buckley et al. 2018). This is because shallow reefs are usually highly efficient at dissipating incident sea-swell wave energy (Ferrario et al. 2014), by causing waves larger than a critical depth to break and rapidly lose energy (Hardy and Young 1996). As a consequence, only small residual waves (smaller than the critical depth) are transmitted shoreward past a shallow reef crest, where they can be further dissipated by bottom friction (Lowe et al. 2005).

Low-frequency wave contributions to swash motions are often a major contributor to wave-driven coastal flooding over shallow reefs, which can trigger especially large wave run-up events when these low-frequency waves become amplified at natural resonant frequencies over a reef (e.g., Péquignet et al. 2009). Low-frequency waves originate from sea-swell waves that in the open ocean propagate in groups (or sets) (Longuet-Higgins and Stewart 1962). When these sea-swell wave groups break on a reef, low-frequency (infragravity) waves are generated at the same frequency as the wave groups, which then propagate across 
a reef. These low-frequency waves can be dissipated by bottom friction, but this tends to be at a lower rate than sea-swell waves (Pomeroy et al. 2012). As a consequence, studies of natural reefs have found these low-frequency waves often dominate at the shoreline behind reefs (Pomeroy et al. 2012; Winter et al. 2017). These low-frequency waves also tend to reflect at shorelines and can create cross-shore standing wave patterns occurring at the natural frequencies of a reef system that depend on the reef morphology (Buckley et al. 2018). When the period of incident wave groups matches these natural frequencies, resonance can occur and standing low-frequency wave motions across a reef can be substantially amplified (Gawehn et al. 2016; Nwogu and Demirbilek 2010; Pearson et al. 2017). A growing number of studies of reefs have revealed how the occurrence of low-frequency wave resonance can drive extreme water-level variations and flooding at reef-fronted coastlines (Péquignet et al. 2009; Roeber and Bricker 2015).

\subsubsection{Shoreline Response to Reefs and Submerged Structures}

The shoreline response behind reefs can be complex, and if all relevant processes are not fully understood or resolved, unexpected responses of a shoreline may occur. Reefs are usually assumed to have a stabilizing effect on adjacent beaches by reducing the sea-swell wave energy that reaches a shoreline. Indeed, studies have revealed how reefs can substantially reduce beach erosion, including during extreme storms such as tropical cyclones (de Alegria-Arzaburu et al. 2013; Cuttler et al. 2018). Over longer timescales, reefs can alter the equilibrium position of a shoreline by inducing beach accretion behind reefs. For example, Black and Andrews (2001) analyzed a large database of measured equilibrium shoreline position behind submerged and emergent coastal structures (including both natural and artificial reefs) and proposed a simple empirical model to predict the offshore extent of a shoreline as a function of the basic geometric properties of a reef (i.e., length and width) and its distance from shore. These and other studies have suggested that reefs should consistently favor beach accretion. However, Ranasinghe and Turner (2006) reviewed a number of case studies and noted, "Although natural submerged reefs are often associated with shoreline salients, suggesting that submerged structures may provide beach protection (Black and Andrews 2001), the relatively few reported investigations of shoreline response to submerged structures are inconsistent." In fact, in several of the cases they examined where submerged structures were constructed along a coastline (including both artificial reefs and analogous submerged breakwaters), they observed areas of erosion rather than accretion (the opposite to the intended design function). 
A range of different hydrodynamic processes drive both cross-shore and longshore gradients in sediment transport processes behind reefs that determine the behavior of shorelines behind reefs. These shoreline responses cannot generally be reproduced by simple empirical design formulations but instead generally require using process-based hydrodynamic-morphodynamic models to predict shoreline variability behind reefs. One useful framework has been developed for coastal structures (and is adaptable to reefs) to determine whether shorelines behind the structure will likely accrete or erode, based on whether mean wave-driven currents generated by wave breaking either converge (causing accretion) or diverge (causing erosion) (Ranasinghe, Larson, and Savioli 2010; Figure 12.5). This approach assumes that sediment transport behind reefs is primarily shaped by suspended transport that is explained by the mean flow patterns. When such structures are located sufficiently close to a shoreline, mean wave-driven currents generated by breaking drive cross-shore flows that diverge at the shoreline and then return to the ocean (i.e., creating a "two-cell" circulation pattern; see right panel of Figure 12.5), which produces beach erosion. Conversely, when the induced breaking occurs sufficiently far offshore, wave-driven currents generated over a reef no longer interact with the shoreline. Instead, gradients in wave energy along the shoreline (due to wave shadowing by the reef) cause gradients in wave breaking (and hence wave setup) along the shoreline that can drive converging mean flows that favor beach accretion (i.e., a four-cell circulation pattern; see left panel of Figure 12.5). Another mechanism that can cause shoreline accretion behind reefs can be drawn from responses to analogous offshore (detached) breakwaters (Figure 12.6). Oblique wave breaking along a coast drives longshore sediment transport (i.e., longshore drift) that can be interrupted within the wave shadow behind reefs. Due to smaller waves breaking behind reefs, longshore sediment transport can be locally reduced, causing accumulation of sediment behind the reef leading to beach accretion. Overall, these two mechanisms emphasize the importance of properly resolving the dominant hydrodynamic processes (wave breaking and wave-driven current circulation) responsible for sediment transport along reef-lined coasts, to ensure they have positive or neutral effects on adjacent beaches. However, it is important to emphasize that these two mechanisms of sediment transport also do not reflect the full range of sediment transport processes that may occur behind reefs. For example, in the low-energy backreef and back-lagoon regions of coral reefs, sediment transport by bed load (sediment moving in regular contact with the bed) can dominate over suspended transport, leading to entirely different patterns of sediment transport (Cuttler et al. 2019). 


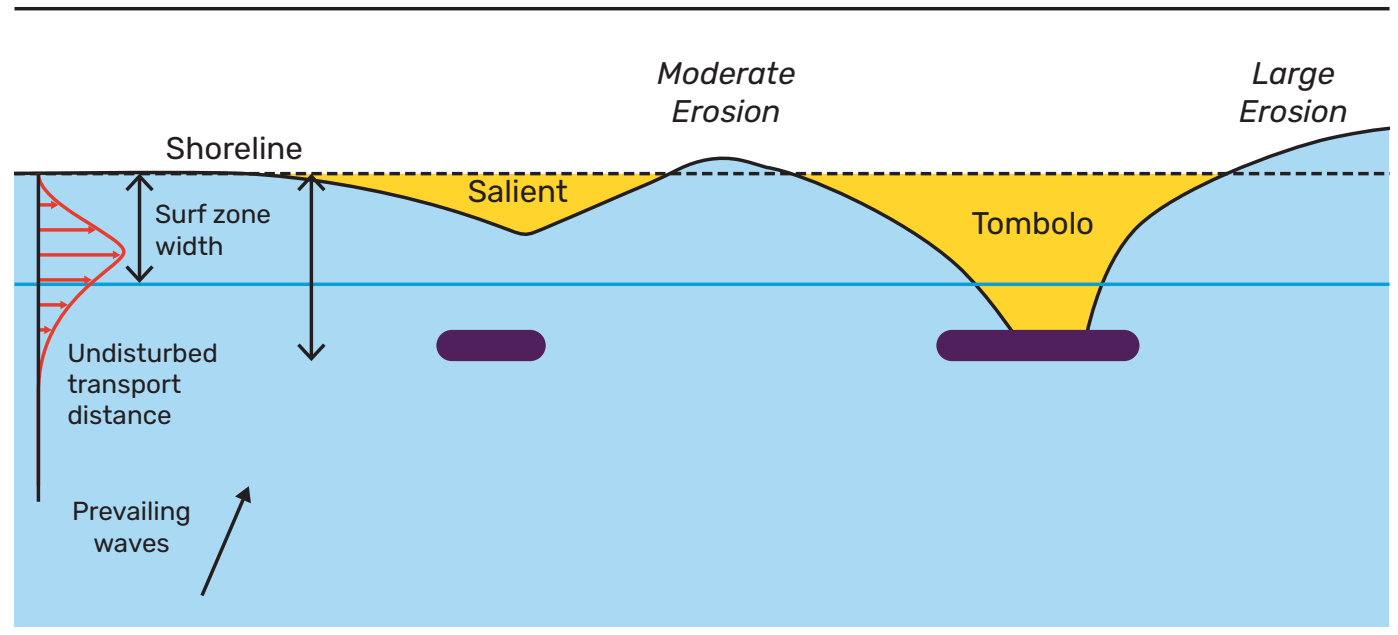

Source: Adapted from coastalwiki.org 2020

\subsubsection{Human Factors Affecting Coastal Protection Capacity of Reefs}

Human impacts (e.g., increased sedimentation, coral disease, nutrients, thermal stress, sea-level rise, storm impacts, and ocean acidification) can degrade reefs and reduce their coastal protection function (Quataert et al. 2015; Reguero et al. 2018a). When coral cover decreases (e.g., due to mass coral bleaching or extreme storm damage), the structural complexity and the ability to reduce wave energy by bottom friction are reduced (Quataert et al. 2015). Furthermore, if the vertical growth rate of a reef cannot keep pace with sea-level rise over time, then the ability of a reef to dissipate wave energy is reduced and larger waves can be transmitted into backreef environments and reach the shoreline (Figure 12.5; Baldock et al. 2014; Quataert et al. 2015; Albert et al. 2016; Harris et al. 2018). For example, a study of Caribbean reefs demonstrated that losses of reef-building corals resulted in reduced reef accretion (Perry et al. 2013). In recent decades, Caribbean reefs are becoming flatter and more structurally homogeneous, likely due to loss of branching corals and mass bleaching events (Alvarez-Filip et al. 2009). Projections suggest that Caribbean reefs need at least $10 \%$ of live coral cover to maintain the reef surface under current rates of erosion (Perry et al. 2013).

The ability of humans to effectively manage existing threats to reefs will determine future reef health and how effective they will be at providing coastal protection services into the future. Poorly managed reefs are more susceptible to reef flattening, but human interventions may also support the coastal protection services that reefs provide. Adequate reef management 
through, for example, marine protected areas and recognizing them as natural infrastructure in coastal zone management frameworks (e.g., World Bank and Ministry of Environment, Energy and Climate Change of Seychelles 2019) can be an effective mechanism for reducing local threats to reefs and supporting reef recovery following disturbances (Mumby and Harborne 2010). Notably, the current coverage of marine protected areas worldwide is insufficient, with many reefs not effectively managed; so, increased efforts globally are needed to secure reefs and the benefits that they provide (Mora and Sale 2011), in addition to the urgent reduction of global greenhouse gas emissions to slow global climate change.

\section{4 | Project Objectives and Guiding Principles}

\subsubsection{Objectives and Metrics}

Different reef types (coral, shellfish, and artificial reefs) can be used and designed for coastal protection (flood and erosion reduction). However, as for any coastal protection project, it is necessary to identify which services are the most important for a given area. The process of defining objectives can help to clarify what methods of intervention are most appropriate (e.g., using active restoration versus other management actions), costs, stakeholder preferences, and the timeline and scale of the project. Project objectives should be identified and agreed upon by all project partners. This can help to build consensus and avoid potential conflicts or risks to project success. Ensuring that stakeholders have realistic expectations of what a project can achieve over what timescales is also important. Objectives should be SMART (specific, measurable, achievable, relevant, and time-bound).

Adopting reefs for NNBF should have multiple objectives beyond simply coastal protection and should aim to deliver co-benefits via additional biological or socioeconomic objectives (and generally a combination of both). Socioeconomic objectives may include increasing coastal protection services of a reef, raising public awareness of the importance of reef ecosystems, increasing fisheries production, increasing tourism revenue, or developing alternative livelihoods to reduce dependence on reef resources. Examples of biological objectives include promoting marine biodiversity, increasing biomass and productivity of commercially important reef species, assisting recovery of key reef species (e.g., reef-building corals or shellfish) or ecosystem processes (e.g., coral or oyster recruitment), and mitigation of damage to the reef framework (reefresilience.org 2020b). 
Defining clear project goals and objectives is a critical step in project planning because it will become the foundation for defining the future success of a project. A set of quantitative or measurable metrics should, therefore, be established to assess whether the objectives are being achieved or the approach in an adaptive management cycle needs to be adjusted. A reef design engineered for coastal protection also must address coastal engineering requirements and standards (see Section 12.5). Table 12.2 provides some examples of metrics that may be used to evaluate project objectives.

Table 12.2. Examples of Metrics to Evaluate Coastal Protection Projects

\begin{tabular}{ll}
\hline \multicolumn{1}{c}{ Objective } & \\
\hline Coastal protection performance & Metric \\
& - Reef depth profile \\
& $\cdot$ Wave attenuation \\
& - Reef width and distance to shore \\
& - Shoreline change (erosion and accretion) \\
\hline Ecological performance & Coral and shellfish cover (richness and diversity) \\
& - Coral and shellfish growth and reproduction \\
& - Fisheries production
\end{tabular}

The main considerations for designs that meet these objectives are outlined in the following section, together with a process to help guide design and implementation of reefs for coastal protection.

\subsubsection{Guiding Principles}

Despite their obvious coastal protection services, engineering with reefs is a nontraditional approach. Reefs can function similar to breakwaters, but they can also provide many other services, which can give them advantages but also make them more challenging to design. The following principles are important to consider when designing reefs for coastal protection:

- Principle 1: Choose a site that considers the suitability of all key reef ecosystem components based on local environmental conditions. An NNBF reef project will likely not succeed if the various organisms chosen for a site are not optimal for the local environmental conditions, which are needed to support growth and reproduction (see Section 12.2). For example, species of corals, shellfish, and other reef-building organisms often live within narrow ranges of environmental conditions (e.g., temperature, salinity, wave exposure, nutrients, light availability). Reef design should target species that are 
endemic to the region, either present in neighboring sites or previously present at the site. It may also be possible that suitable environmental conditions are not present, but once a reef is established, it will eventually establish suitable conditions. For example, different species of corals and shellfish require some sheltering from large waves and may be most likely to survive initially with temporary protection until the reefs become well established.

- Principle 2: Consider the hydrodynamic and sediment transport patterns generated by the reef. The addition of a reef off a coast can generate complex hydrodynamic and sediment transport responses, which if not properly designed, can have unintentional negative impacts on the existing shoreline. Field measurements and numerical modeling (with validation) are critical to first fully understand the existing hydrodynamic and sediment transport processes at a site, and then how the presence of a reef will alter these processes. Detailed numerical models (not simple empirical models) to predict how a reef modifies waves, water levels, and circulation should be viewed as best practice (see overview in Sections 12.3.4 and 12.3.5). The complexity of the reef structure (coral, rock, or shellfish) can make detailed modeling of a reef system more challenging compared to simpler coastal systems such as open-coast sandy beaches, but new methods and advances in models enable these processes to be much more accurately predicted. Variation in the crest elevation and the presence of channels can affect wave dissipation and circulation patterns, but similar models to those applied to design coastal structures can be applied for reefs (e.g., Reguero et al. 2018a). It is also important to consider the response of hydrodynamic and sediment transport processes to a range of probable extreme conditions (i.e., extreme wave and water levels), as well as the responses to longer-term changes (e.g., sea-level rise).

- Principle 3: Address any underlying causes of reef degradation prior to project implementation. Addressing reef degradation is a key mechanism to achieving the broader goal of restoring coral and shellfish reef structure and function, while also helping support provision of multiple services by reefs. Projects designed to restore reefs to support coastal protection should be located in coastal environments where reefs would normally naturally be found. Thus, projects must first address any of the local causes of ongoing reef degradation (e.g., water quality, nutrients, temperature, coral or shellfish disease, and predation must be considered in the project design to be able to create or restore a viable reef community).

- Principle 4: Engage stakeholders from project conception to implementation. Quantifying and balancing the benefits, impacts, and potential trade-offs requires stakeholder participation and collaboration with social scientists (e.g., resource economists) who can help to provide cost-benefit analyses to inform project design. Before a project is implemented, it is important to engage local stakeholders (e.g., community leaders, government officials, and tourism agencies) early and throughout 
the planning process, including fully understanding all relevant policy and legislation in a region that could influence the success of the project. Engaging stakeholders can increase local support for a project, increase local relevance, and enhance the benefits of a project for all stakeholders. Further, different stakeholders may have competing interests, making it important to reconcile such differences to avoid potential conflicts. Potential risks need to be clearly articulated to manage expectations. Chapter 3 provides more insight on how the stakeholder engagement process should be conducted through design, construction, and operations and maintenance. There should also be recognition of how the project will impact the socioeconomic system in the future. Benefits may include flood risk reduction, shoreline protection, enhanced tourism, and improved fisheries. In addition, there could be negative impacts to these same services.

- Principle 5: Consider how climate change and other future environmental pressures may affect coastal protection services. A significant benefit of coral and shellfish reefs is their ability to grow and potentially adapt to some climate change stressors (e.g., sea-level change or increased storminess). As for other coastal projects, the design should include evaluation of potential changes in the environment (e.g., water levels, waves, and temperature) and the required natural or human-assisted adaptation strategies to maintain the physical and ecological functions of the reef. Given that the effectiveness of reefs to dissipate wave energy is highly correlated with water depth over the reef (dissipation decreases when water level increases), sea-level rise is a key parameter when considering future flood risk scenarios. Furthermore, coral bleaching events from increasing sea surface temperature combined with storm impacts may result in increased coral mortality and structural damage to the reef. There should be an attempt to quantify uncertainty in the temporal and spatial impacts of stressors. Scenario planning can be a helpful tool to explore how climate change could affect the viability of reefs and management of effectiveness in response to changing conditions (McLeod et al. 2019). Results from such efforts are critical to inform adaptive management (refer to Chapter 7), along with monitoring the physical and ecological functions of the reef and interaction with stakeholders.

\subsubsection{Site Selection}

Prior to committing to designing and implementing a reef NNBF project, an initial site assessment should be implemented that helps to formulate the problem and verify that use of a reef will likely deliver the intended project outcomes (e.g., through a desktop review). This would include an initial review of historical literature describing the anticipated causes of coastal flooding and erosion at the site (see Section 12.3.4), and then confirmation that a reef is a reasonable candidate to adopt for mitigation. A review of local environmental conditions (e.g., water quality, flow temperature, salinity) is equally fundamental to build confidence that 
the key organisms that will build and maintain the reef are appropriate for use at the site (i.e., the intended species of coral or shellfish will likely survive, grow, and successfully reproduce in the environment). This can most simply be identified by any evidence that these organisms are already thriving nearby under similar environmental conditions. For coral reefs, a site should have sufficient light conditions and water quality comparable to those at nearby thriving reefs, taking into account the nutrient and turbidity levels, water temperature, depth, and flow conditions (Edwards and Gomez 2007). Also, it is important to consider the distance to adjacent healthy reefs to support larval replenishment to facilitate recovery and colonization of the restored reefs (Abelson 2006). Furthermore, the sites selected for establishing new reefs should have sufficient settlement space for outplanted corals or shellfish that includes barren and stable reef rock areas that lack excessive algal growth, or a sandy seabed that is sufficiently stable to place artificial structures without the risk of being smothered from the movement of itself or the sand. An example of an oyster reef pilot project is described in "Shellfish Reef as Shoreline Protection."

\section{Shellfish Reef as Shoreline Protection}

The oyster reef pilot project in the Eastern Scheldt in the Netherlands (Figure 12.7) aimed to prevent erosion by using reef-forming Pacific oysters. This oyster builds 3D reef structures that can be effective in dissipating wave energy and thus protecting adjacent shorelines from erosion.

To grow the reefs, a substrate of oyster shells was placed on the tidal flat. To prevent the shells being washed away with the tide or during storms, they were stowed in boxes made of steel wire known as gabions. In the summer, oyster larvae, which need a hard substrate on which to grow, attach themselves to the shells and gradually build up a solid reef structure that can withstand winds and waves. Once the oysters have established, the steel wires of the gabion corrode away, after which the reef will have to survive on its own, constantly renewing itself by settlement of new larvae.

During the past decade, the experiments in the Eastern Scheldt have demonstrated that the use of oysters as ecosystem engineers for erosion prevention is technically and biologically feasible and socially acceptable. The projects in the Eastern Scheldt have shown that highly dynamic environments such as estuaries, where interlinked physical processes are at work, offer exciting opportunities to build with nature. 
Figure 12.7. Shellfish Reef as Shoreline Protection (Eastern Scheldt, the Netherlands)

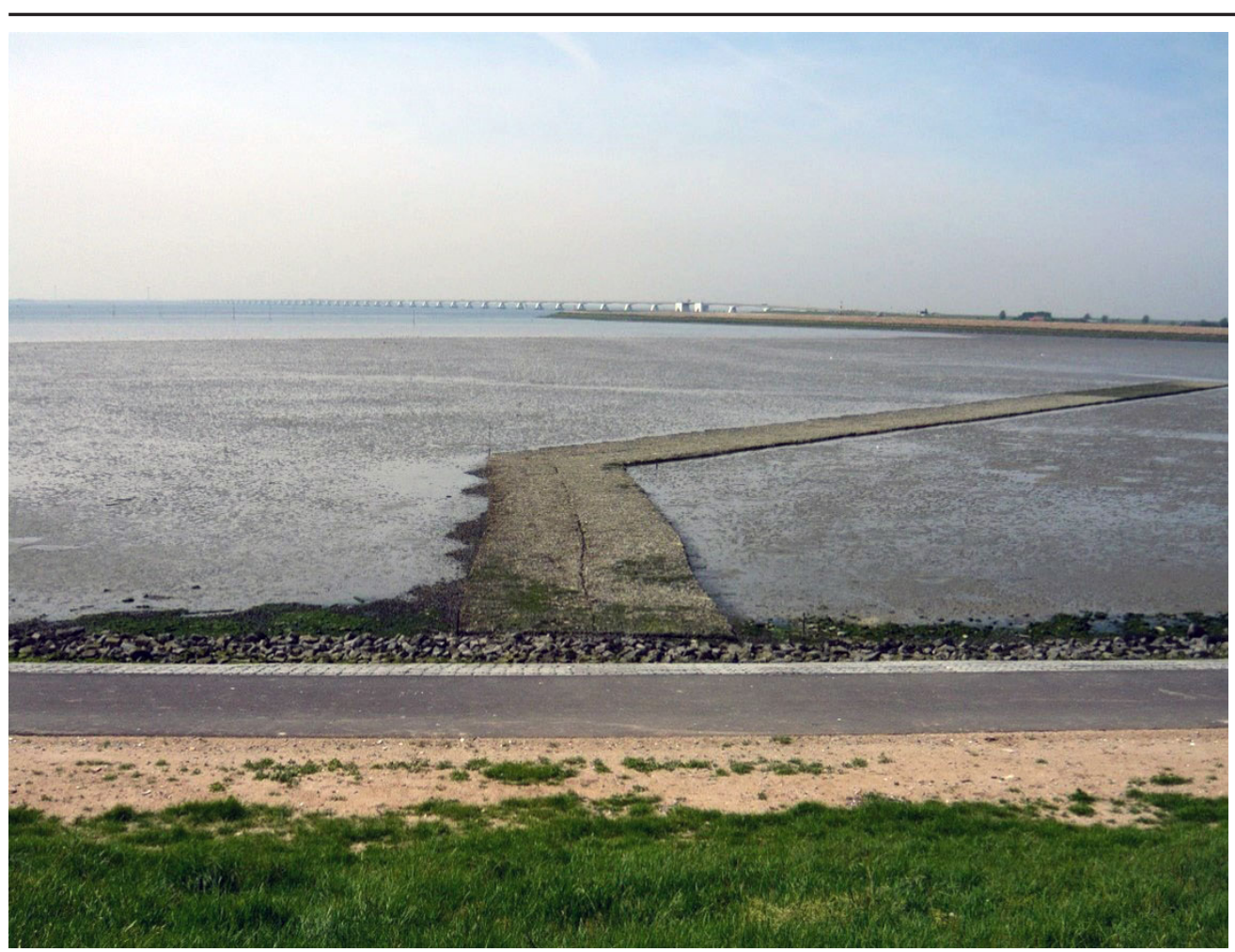

Source: T. Ysebaert, Wageningen Marine Research

If organisms were once present at the site, further investigation would be needed to understand the likely causes of historical decline and whether restoration is a viable option. The historical evolution, any prior natural reef, and any historical degradation (including the causes of degradation) are critical to (1) link reef degradation with environmental conditions, (2) understand the need of an intervention, and (3) inform effective designs and interventions. Thus, before attempting to restore a degraded reef, it is important to assess the environmental stressors responsible for damaging the reef in the first place and confirm that they can be brought under control if needed. Such stressors may include fishery activities, coastal infrastructure, habitat limitations (e.g., lack of suitable substrate for settlement), and recruitment limitations (e.g., insufficient offspring supply or overabundance of predators to maintain a population; Brumbaugh et al. 2006). 
If the seafloor is not sufficiently stable (e.g., in silty areas), a low-lying base should be constructed that would act as the footprint upon which the new reef would sit. Such a base could be built of small quarried stone (e.g., 10 to 200 millimeters) up to a certain height (e.g., $0.5 \mathrm{~m}$ ) above the surrounding sediment and extending several meters away from the perimeter of the main reef structure. Such a filter layer has the following benefits: (1) prevents the new reef structure from sinking into the soil, (2) prevents sediment overtopping and scouring from occurring on the main artificial reef, (3) elevates the main artificial reef into a depth that is conducive to the development of a reef building ecosystem, and (4) provides substantial 3D habitat complexity that is attractive to marine life.

In the case of coral transplantation, it is also critical to select a recipient site with similar environmental conditions as the donor site (Edwards and Gomez 2007). Also, it has been shown that survivorship of coral transplants increases when they are relocated to reef areas with some degree of pre-existing healthy coral cover (Edwards 2010). For additional guidance on site selection for coral reef restoration, see reefresilience.org (2020b), and for guidance on shellfish restoration, see Fitzsimons et al. (2019).

\section{5 | Design Process}

The following engineering principles applied to the design of other coastal projects can be a starting point for the design of reef NNBF:

- Formulate the problem statement. Assess the root causes of the coastal hazard (flooding or erosion) at the project site and whether use of a reef NNBF is suitable for the site. At a most fundamental level, the organisms that form the reef must be appropriate for environmental conditions (present and likely future) at the site. This can be based on presence of similar organisms within natural reefs in the region around the site, and confirmation that the environmental conditions are suited to the organisms if none are currently present at a site. For cases where organisms were once present at a site, the root causes of the ecosystem changes should be understood and addressed prior to commencing a project.

- Understand the local coastal processes. Model and analyze the wave, current, water level, and sediment transport patterns to understand the processes that drive coastal flooding and erosion at a site and identify where a reef could be located to provide protection benefits and be self-sustaining.

- Propose alternatives. Develop alternatives that can modify and work with the coastal processes to ameliorate the coastal impacts (e.g., attenuating wave heights, modifying nearshore currents, or reducing or redirecting sediment transport). 
- Select the best option. Assess different criteria that may include cost, environmental, socioeconomic, and other considerations. The complete set of co-benefits beyond flood and erosion risk reduction (see Chapter 6 ) should be considered at this stage.

- Design the reef NNBF project-coastal protection. This implies ensuring the reef achieves its coastal protection function over its full range of design conditions, including that the structure itself is resilient to extreme conditions possible at a site. This step is analogous to approaches used to design coastal engineering structures (especially breakwaters). Although the approaches for the design of a reef structure may still differ from a typical breakwater, many of the approaches and formulations for the design of submerged breakwaters can be extended to reefs as a first approach for their design (e.g., USACE 2012).

- Design the reef NNBF project-environmental. This step involves the considerations and enhancements required to support the development of the reef as an ecosystem instead of a more traditional hard engineering structure. This may include considerations of factors that contribute to reef health (habitat requirements), gardening and planting of corals or shellfish, nurseries, other environmental benefits, selection of species, specific implementation methods and construction techniques, selection of materials, maintenance requirements, and other relevant ecological factors.

- Construction and implementation. Construction of a reef may differ from traditional submerged structures due to differences in design specifications, approaches required to build the structure (e.g., in small island communities with no access to large machinery), location (e.g., suitable substrate), and consideration of existing bathymetric features (e.g., respecting reef channels and other features).

- Adaptive monitoring and management. Monitoring is particularly important to assess the performance and functionality of the designs and implementation of structures for coastal protection, especially for designs and features that are more innovative and may require future adjustments and adaptive management. This would involve monitoring the structural stability of the reef, recruitment of desired reef-building organisms, and ecological and environmental benefits (e.g., fisheries), as well as the performance in addressing the coastal impacts for which the feature was originally planned, such as erosion and flooding mitigation.

Reef projects require detailed planning and should incorporate the multidisciplinary professional expertise of, for example, coastal engineers, ecologists, and restoration specialists in their design and construction because they represent features in challenging environments and with significant complex physical and ecological processes that are often coupled. However, how reefs affect coastal hydrodynamics makes them features with substantial potential for large-scale coastal protection compared to other measures deployed at the coastline. For these reasons, reefs require specific design considerations. 


\subsubsection{Design Considerations}

Research on both submerged breakwaters and artificial reefs has shown that improper designs of reefs can have unintended consequences, and in some cases, even lead to increased erosion (Ranasinghe and Turner 2006). Thus, it is essential to ensure that proper design considerations are applied while designing reef-related coastal defense projects.

There are many similarities between the design of natural and artificial reefs and engineered low-crested submerged breakwaters. For submerged breakwaters, the parameters that determine the effects of structures on erosion and flood reduction have been relatively well studied, which has helped to refine coastal engineering designs (e.g., Burcharth et al. 2007; Ranasinghe, Larson, and Savioli 2010). This knowledge and experience gained from coastal engineering should be considered to support the design of reefs for NNBF.

A proper design of NNBF reefs is also critical to avoid downstream (adverse) effects, such as downdrift erosion or sedimentation, similar to the issues considered in coastal structure design. If not carefully designed, engineered structures that aim to reduce wave energy in coastal areas can cause environmental damage by altering circulation and sediment transport in such a way that negatively impacts adjacent coastal habitats (Martin et al. 2005; Chapman and Underwood 2011). Important design considerations for engineered structures include their location, geometry, and materials used. Collectively, a reef design project should consider the following factors for restoring natural reefs or incorporating nature into engineered structures for coastal defense:

- Hydrodynamic function of the reef. The location, dimensions, and configuration of the reef must be designed to achieve the intended modification to the nearshore processes, including wave attenuation, nearshore circulation, and sediment transport. Guidance from within coastal engineering manuals and texts should be consulted (e.g., USACE [2012] and CIRIA, CUR, and CETMEF [2007]). The placement of engineered structures on the seabed is one of the most critical aspects that directly influences hydrodynamics in reef environments. A detailed assessment of the existing bathymetry, coastal hydrodynamics, and sediment transport processes at a site is necessary to be able to properly design the size and shape of engineered structures. Both the long-term effects and the response under extreme conditions (e.g., storms) should also be considered. For precise assessments of impacts on the nearshore wave fields, nearshore circulation, and sediment transport patterns, 2D horizontal (2DH) or 3D numerical models or physical models are required.

- Ecological factors to consider in the hydrodynamic design. Specific ecological design characteristics may include assessing not only the optimum design to protect coastlines but also the design features needed to create suitable environmental conditions for the reef ecosystem (e.g., submergence depth or layout patterns for multiple structures). For example, submerged reefs can be deployed in arrays that include gaps between units to 
allow flushing and circulation. The placement of the reef structures may also be dictated by mimicking the natural geomorphology of an existing or pre-existing reef platform to enhance or favor biological growth.

- Ecological performance. How well a specific material functions in attracting and maintaining aquatic organisms, to provide habitat, and its suitability for coral or oyster growth and fishery production potential are important design parameters. Favorable materials may include, for example, recycled oyster shells, natural limestone, and units with rugosity and voids that provide shelter and habitat. Biological enhancement can also be achieved in coral reef systems by attaching live coral fragments to speed up the colonization or by adding "spat-on-shell" (hatchery-reared larvae that have settled onto recycled oyster shells) to shellfish restoration sites.

- Materials and construction techniques. The materials used in engineered reef structures are also critical to their overall performance, including durability and stability. The materials and construction techniques need to be compatible with the local marine environment and habitat. Inadequate materials can become sources of marine pollution due to, for example, antifouling paints, plastic components, and heavy metals as the artificial structures break down. Materials such as tires and plastics can release chemicals dangerous to the species and do not offer enough weight to be stable in high wave-energy environments. Materials not suitable for long-term use in the marine environment should also be avoided (e.g., materials with poor long-term chemical and physical resistance to the marine environment). Likewise, the choice of material also can strongly influence the reef ecosystem function (e.g., some materials are better suited for recruitment of corals [such as limestone] and oysters [such as recycled oyster shells]) (Lukens and Selberg 2004). Because reefs are often built in shallow water, particular attention needs to be paid to access for construction equipment. For example, barges generally require approximately $1 \mathrm{~m}$ of draft. Shallower areas can be accessed, but this usually incurs a cost increase.

- Structural stability. The structure needs to be designed to sustain hydrodynamic loads associated with waves and currents, particularly under probable extreme conditions. Otherwise, if dislodged, the structure could fail to provide future coastal protection and risk damaging adjacent habitat. For example, individual pieces may include interlocking designs to comply with this requirement. In addition, in areas with soft sediments, a structural underlayment may be necessary to support the weight of the reef to minimize settlement and scour. In the absence of better methods, structural criteria and formulae used for submerged breakwaters may provide some guidance (for examples, see USACE [2012] and CIRIA, CUR, and CETMEF [2007]), factoring the differences in the equivalent composition of the reef elements (e.g., weight, geometry).

- Designing the living layer. Nurseries are often a critical part of all the different options outlined above for restoring or establishing both oyster and coral reefs. For oyster reefs, there is a strong analogy to the processes used in oyster aquaculture, and these businesses can provide seed oysters for restoration projects where there is not enough natural 
biological production of spat. For corals, farms (mainly noncommercial) use either oceanor land-based nurseries. These corals are often fragmented multiple times until they are outplanted onto the reef once they reach a certain size. One strategy that is currently implemented is to outplant many species of corals to genetically diversify the species of corals on a reef. The design should also consider risk factors and assess the effect of the NNBF on the ecosystem. For example, artificial reefs may attract fish away from natural coral and shellfish reef habitats. Materials used should also preferably be similar to those present in the surroundings and provide a variety of voids or spaces to create diversity in habitat. The profile, shape, and materials of new constructions may promote the colonization of marine life over time. Transplanting of reef-building coral and shellfish after construction may also speed up the colonization process.

\subsubsection{Design Tools and Models}

To accurately assess and predict how reefs can reduce coastal flooding and erosion, robust design tools and models must be applied that account for the complex hydrodynamic and sediment transport processes in reef environments.

Predicting coastal flooding requires accounting for the factors that generate extreme water levels at a shoreline (see Section 12.3.4 and Figure 12.4). Among them, wave run-up includes a static increase in sea level, known as wave setup, but also swash motions at the shoreline. Swash in reef environments can be a critical contributor to flooding (Roeber and Bricker 2015). Similarly, predicting shoreline variability behind reefs (including beach erosion and accretion patterns) requires models that accurately account for the relevant hydrodynamic processes that drive sediment transport and morphological change.

Although simple analytical and empirical models have been developed to estimate extreme water levels and shoreline change along open coastlines, ranging from wave run-up formulations to equilibrium shoreline models, these are not generally suitable for reef-fronted coastlines due to the very different coastal processes generated by reefs. Simple empirical models also exist to predict wave transmission and shoreline responses behind reefs (including analogous submerged breakwaters, summarized in Section 12.5.1); however, these simple models will not generally capture the range of hydrodynamic and sediment transport processes that can be important to predicting coastal flooding and erosion behind reefs. Instead, the use of process-based numerical models is usually necessary to account for how the spatially variable bathymetry and bottom roughness of reefs modifies nearshore hydrodynamics and sediment transport. Although a wide range of numerical models employed in coastal engineering exist, here we focus on the general classes of these models that can be used to aid in the design of reef NNBF (including specific examples of some widely used, open-source models). Table 12.3 provides examples of design tools and models to assess coastal flooding and erosion. 
Table 12.3. Examples of Design Tools and Models to Assess Reef Performance and Coastal Hazard Risk Reduction

\begin{tabular}{|c|c|c|c|c|c|}
\hline $\begin{array}{l}\text { Spatial } \\
\text { Scale }\end{array}$ & $\begin{array}{c}\text { Intended } \\
\text { use }\end{array}$ & $\begin{array}{c}\text { Representative } \\
\text { resolution }\end{array}$ & Hydrodynamics & Erosion & $\begin{array}{c}\text { Example } \\
\text { applications }\end{array}$ \\
\hline $\begin{array}{l}\text { Large-scale } \\
\text { assessment }\end{array}$ & $\begin{array}{l}\text { Scoping } \\
\text { flooding and } \\
\text { erosion risk, } \\
\text { with limited } \\
\text { modeling of } \\
\text { reef processes }\end{array}$ & $\sim 100 \mathrm{~m}$ to $\mathrm{km}$ & $\begin{array}{l}\text { Regional } \\
\text { phase-averaged } \\
\text { wave models with } \\
\text { empirical wave run-up } \\
\text { formulations }\end{array}$ & $\begin{array}{l}\text { Empirical } \\
\text { beach erosion } \\
\text { models }\end{array}$ & Beck et al. 2018 \\
\hline $\begin{array}{l}\text { Regional } \\
\text { scale }\end{array}$ & $\begin{array}{l}\text { Scoping } \\
\text { flooding and } \\
\text { erosion risk }\end{array}$ & $\sim 100 \mathrm{~m}$ to $\mathrm{km}$ & $\begin{array}{l}\text { Process-resolving } \\
\text { approaches along the } \\
\text { shoreline, Surfbeat } \\
\text { models (e.g., XBeach } \\
\text { on a transect basis) or } \\
\text { flood mapping }\end{array}$ & $\begin{array}{l}\text { Empirical } \\
\text { beach erosion } \\
\text { models or } \\
\text { morphological } \\
\text { models (e.g., } \\
\text { XBeach) }\end{array}$ & $\begin{array}{l}\text { Storlazzi et al. } \\
2019 \\
\text { Reguero et al. } \\
2019\end{array}$ \\
\hline Local scale & $\begin{array}{l}\text { Assessing } \\
\text { coastal } \\
\text { responses to } \\
\text { reefs (coastal } \\
\text { flooding } \\
\text { and erosion } \\
\text { mitigation) }\end{array}$ & $\sim 10$ to $100 \mathrm{~m}$ & $\begin{array}{l}\text { Wave models that } \\
\text { account for breaking, } \\
\text { refraction, and } \\
\text { diffraction (e.g., SWAN, } \\
\text { XBeach, SWASH, } \\
\text { Boussinesq) }\end{array}$ & $\begin{array}{l}\text { Morphological } \\
\text { models (e.g., } \\
\text { XBeach, } \\
\text { Delft3D) }\end{array}$ & $\begin{array}{l}\text { Reguero et al. } \\
2018 \text { a } \\
\text { Quataert et al. } \\
2015 \\
\text { Drost et al. } 2019\end{array}$ \\
\hline \multirow[t]{4}{*}{$\begin{array}{l}\text { Detailed } \\
\text { reef design }\end{array}$} & \multirow[t]{4}{*}{$\begin{array}{l}\text { Conducting } \\
\text { detailed } \\
\text { structural } \\
\text { design, such } \\
\text { as for artificial } \\
\text { reef structures }\end{array}$} & \multirow[t]{4}{*}{$<1 \mathrm{~m}$} & $\begin{array}{l}\text { Physical models (e.g., } \\
\text { in wave flumes and } \\
\text { basins) to assess reef } \\
\text { hydrodynamics and } \\
\text { structural stability }\end{array}$ & $\begin{array}{l}\text { Physical } \\
\text { models } \\
\text { with mobile } \\
\text { sediment beds }\end{array}$ & $\begin{array}{l}\text { Kramer et al. } \\
2005 \\
\text { Ranasinghe, } \\
\text { Turner, and } \\
\text { Symonds } 2006 \\
\text { Pomeroy et al. } \\
2015\end{array}$ \\
\hline & & & $\begin{array}{l}\text { Computational fluid } \\
\text { dynamics models for } \\
\text { detailed hydrodynamic } \\
\text { load and performance } \\
\text { predictions }\end{array}$ & \multirow[t]{3}{*}{$\begin{array}{l}\text { Not generally } \\
\text { applicable }\end{array}$} & $\begin{array}{l}\text { Higuera, Lara, } \\
\text { and Losada } \\
2013 \\
\text { Altomare et al. } \\
2015\end{array}$ \\
\hline & & & $\begin{array}{l}\text { For example: } \\
\text { Mesh-based RANS } \\
\text { models (e.g., OpenFOAM } \\
\text { (e.g., OpenFOAM) }\end{array}$ & & Lowe et al. 2019 \\
\hline & & & $\begin{array}{l}\text { Mesh-free (e.g., } \\
\text { Smooth Particle } \\
\text { Hydrodynamics) }\end{array}$ & & \\
\hline
\end{tabular}


A general approach to assess the risk reduction benefits of coastal ecosystems, including reefs, can be defined by a sequence of steps, as outlined in Chapter 6 . These steps are reflected in the design process summarized in Section 12.5. To initially assess the performance of different reef designs, the use of the variety of tools summarized in Table 12.3 can be used, which vary in level of accuracy and spatial coverage. Using output from these models, the flood and erosion risk reduction can also be used for direct economic valuation. Although large-scale assessments, such as regional assessments of flood risk reduction, may help identify the suitability of a site for possible reef NNBF, the design of the reef itself requires resolving finer-scale processes in the nearshore to properly evaluate wave-driven coastal processes at the scale of reef features and adjacent coastlines. Therefore, defining an appropriate approach for each case, and hence the appropriate predictive tools and models, is a critical step for ensuring the most successful outcomes. Several considerations must be taken into account to determine what tools are best suited to the design of a reef NNBF for coastal protection.

The following are key considerations to identifying the appropriate approach:

- Purpose. Can the tool address the problem and provide suitable outcomes that are required for design?

- Geographic scale. What is the overall spatial domain of a project both in terms of reef-relevant processes (hydrodynamics) and its potential broader impacts?

- Spatial and temporal resolution. What is the spatial and temporal resolution required to model the relevant processes?

- Data availability. What is the quality and resolution of necessary information (bathymetry or metocean data for model forcing and validation)?

- Capacity availability. What skill sets does the project have access to, and are there appropriate resources and skills to conduct the proposed modeling and design approaches?

Of these five considerations, both the geographic scale and required spatial and temporal resolution can often be most restrictive because these factors govern the resources required to apply appropriate models (e.g., computational resources or required technical expertise). In addition, many reef-based coastal impact assessments and designs are based on wave modeling approaches on cross-shore profiles (e.g., wave-attenuation studies) but ignore other longshore effects that can be critical in reef environments (e.g., lagoon circulation, gradients in mean water levels, and wave refraction and diffraction). Although a cross-shore approach can be adequate for initial site selection in large-scale assessments, the detailed design of reef NNBF requires assessing the cross-shore and longshore effects (i.e., 2DH or 3D approach) to assess whether the project delivers the intended benefits (e.g., modifying sediment transport and flood protection). 
A summary of the main tools used to support key steps in the reef NNBF design modeling process is provided in Table 12.4, with an overview provided in Sections 12.5.2.1 through 12.5.2.5. An example of the design steps for a reef NNBF project is also included in Figure 12.8.

Table 12.4. Key Steps in the Reef NNBF Design Modeling Process

\section{Type of approach \\ Description \\ Example applications}

\begin{tabular}{|c|c|c|c|}
\hline \multirow{3}{*}{$\begin{array}{l}\text { Step } 1 \\
\text { Assessment of offshore } \\
\text { wave and water-level } \\
\text { climate }\end{array}$} & \multirow{2}{*}{$\begin{array}{l}\begin{array}{l}\text { Wave and } \\
\text { water-level } \\
\text { databases }\end{array} \\
\text { Analytical or } \\
\text { semiempirical } \\
\text { approximations }\end{array}$} & \multicolumn{2}{|l|}{$\begin{array}{l}\text { Satellite, wave buoy, tide gauge, } \\
\text { wave hindcast, and water-level } \\
\text { hindcast models }\end{array}$} \\
\hline & & $\begin{array}{l}\text { Approximate wave generation for } \\
\text { a body of water with a relatively } \\
\text { simple geometry based on fetch } \\
\text { (distance)-limited or duration } \\
\text { (time)-limited conditions }\end{array}$ & Rohweder et al. 2008 \\
\hline & $\begin{array}{l}\text { Numerical } \\
\text { modeling }\end{array}$ & $\begin{array}{l}\text { Third-generation wave models } \\
\text { (e.g., SWAN, WAVEWATCH III) }\end{array}$ & $\begin{array}{l}\text { Reguero et al. } 2012 \\
\text { Hersbach et al. } 2020\end{array}$ \\
\hline \multirow[t]{4}{*}{$\begin{array}{l}\text { Step } 2 \\
\text { Site assessment of coastal } \\
\text { hydrodynamics }\end{array}$} & $\begin{array}{l}\text { Analytical or } \\
\text { semiempirical } \\
\text { approximations }\end{array}$ & $\begin{array}{l}\text { Wave ray analysis: approximates } \\
\text { wave propagation for idealized } \\
\text { geometries, using linear theory }\end{array}$ & Beck et al. 2018 \\
\hline & \multirow[t]{3}{*}{$\begin{array}{l}\text { Numerical } \\
\text { modeling }\end{array}$} & $\begin{array}{l}\text { Third-generation wave models } \\
\text { (e.g., SWAN, WAVEWATCH III) }\end{array}$ & $\begin{array}{l}\text { Lowe et al. } 2009 \\
\text { Camus, Méndez, and }\end{array}$ \\
\hline & & $\begin{array}{l}\text { Phase-resolving models } \\
\text { (e.g., Boussinesq-type, } \\
\text { nonhydrostatic, computational } \\
\text { fluid dynamics) }\end{array}$ & $\begin{array}{l}\text { Medina } 2011 \\
\text { Lashley et al. } 2018\end{array}$ \\
\hline & & $\begin{array}{l}\text { Shallow-water equation } \\
\text { circulation models }\end{array}$ & \\
\hline \multirow{7}{*}{$\begin{array}{l}\text { Step } 3 \\
\text { Quantifying interactions } \\
\text { between the } \\
\text { hydrodynamics and reef } \\
\text { structures }\end{array}$} & \multirow[t]{2}{*}{$\begin{array}{l}\text { Analytical or } \\
\text { semiempirical } \\
\text { approximations }\end{array}$} & \multirow{2}{*}{$\begin{array}{l}\text { Wave transmission past the } \\
\text { reef: transmission coefficient } \\
\text { formulations for submerged } \\
\text { breakwaters }\end{array}$} & $\begin{array}{l}\text { d'Angremond, van } \\
\text { der Meer, and De } \\
\text { Jong } 1997\end{array}$ \\
\hline & & & Ahrens 1987 \\
\hline & \multirow[t]{5}{*}{$\begin{array}{l}\text { Numerical } \\
\text { modeling }\end{array}$} & $\begin{array}{l}\text { Third-generation wave models } \\
\text { (e.g., SWAN, WAVEWATCH III) }\end{array}$ & $\begin{array}{l}\text { Buckley, Lowe, and } \\
\text { Hansen } 2014\end{array}$ \\
\hline & & \multirow{4}{*}{$\begin{array}{l}\text { Phase resolving models (e.g., } \\
\text { XBeach, SWASH, FUNWAVE): } \\
\text { provide better definition of } \\
\text { wave processes, such as } \\
\text { wave breaking and nonlinear } \\
\text { interactions }\end{array}$} & $\begin{array}{l}\text { Filipot and Cheung } \\
2012\end{array}$ \\
\hline & & & Reguero et al. 2018a \\
\hline & & & Quataert et al. 2015 \\
\hline & & & Wandres et al. 2021 \\
\hline
\end{tabular}



applications

\section{Step 4}

Calculating coastal flooding and sediment transport and morphological change (erosion or accretion)

Step $4 a$ Calculating effect on coastal flooding

\section{Step 4}

Calculating coastal flooding and sediment transport and morphological change (erosion or accretion)

\section{Step $4 b$}

Calculating the effect on coastal erosion
Analytical or semiempirical

\section{Numerical} modeling approximations

Estimation of run-up from semiempirical formulations; contribution of run-up to total water-level estimation

\section{Same as Step 2}

Phase-resolving hydrodynamic models (e.g., XBeach, SWASH, Boussinesq): definition of wave run-up and swash, and inland flooding

Analytical or semiempirical approximations

Sediment transport formula (e.g., Coastal Engineering Research Center [CERC]) equation [USACE 2012])

Analytical expressions of shoreline responses behind submerged breakwaters and reefs

$\begin{array}{ll}\text { Numerical } & \text { Sediment transport models } \\ \text { modeling } & \end{array}$

van der Meer and Stam 1992

Buckley et al. 2016

Quataert et al. 2015

Reguero et al. 2019

Hoeke et al. 2021

Black and Andrews 2001

Ranasinghe, Larson, and Savioli 2010 Shoreline equilibrium models

Cuttler et al. 2018

McCall et al. 2010

Reguero et al. 2018a

Rosenberger et al. 2021

\section{Step 5}

Detailed design of the reef structure

$\begin{array}{ll}\text { Physical } & \begin{array}{l}\text { Use of scaled models of reef } \\ \text { modeling }\end{array} \\ & \begin{array}{l}\text { structures in wave flumes and } \\ \text { basins to test the performance } \\ \text { and stability of different designs }\end{array}\end{array}$
structures in wave flumes and and stability of different designs

van der Meer and Daemen 1994

Vidal, Losada, and Mansard 1995

Kramer et al. 2005

Ranasinghe, Turner, and Symonds 2006

$\begin{array}{ll}\text { Numerical } & \begin{array}{l}\text { Computational fluid dynamics } \\ \text { modeling of design loads and } \\ \text { stability of reefs }\end{array}\end{array}$

Mizutani, Mostafa, and Iwata 1998

Huang, Chang, and Hwung 2003

Altomare et al. 2014 
Figure 12.8. Example of Steps Used for the Design of a Coral Reef NNBF Project

HAZARDS: Downscaling waves to shore

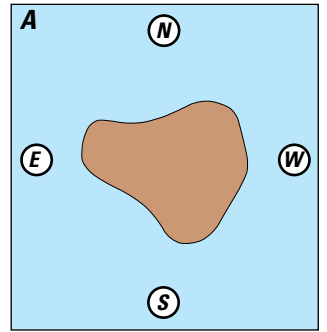

Offshore wave data

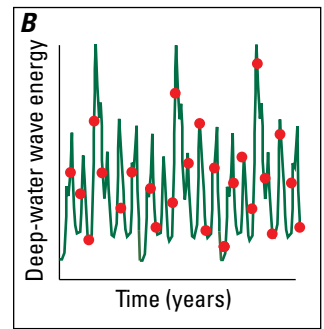

Representative sea states

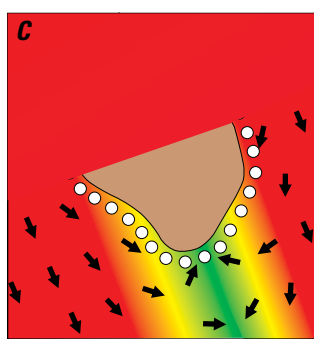

Propagate to nearshore

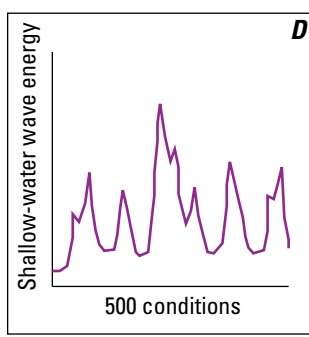

Reconstruct shallow water wave data

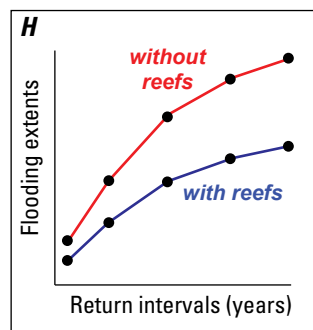

Flood frequency

\section{ECOSYSTEM: Reef flood modeling}

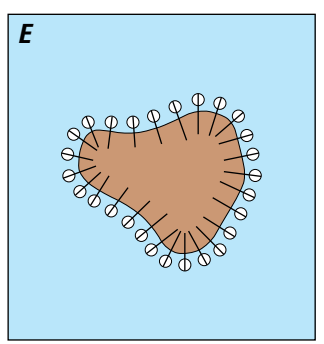

100-m reef profiles

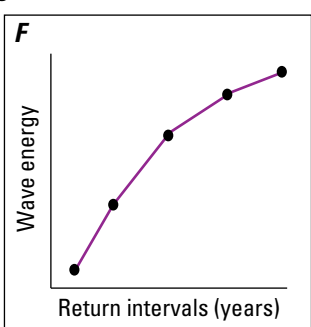

Storm intensity

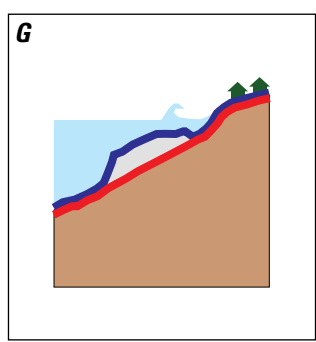

Effects of the reef

CONSEQUENCES: Assessing impact and benefits

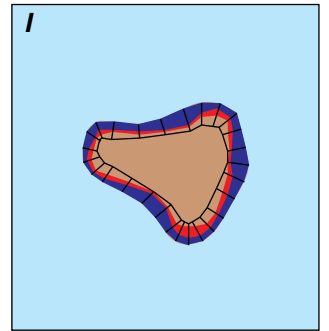

Map flood zones

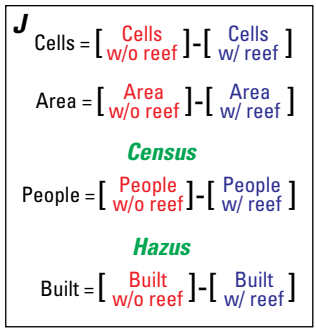

Assess exposure
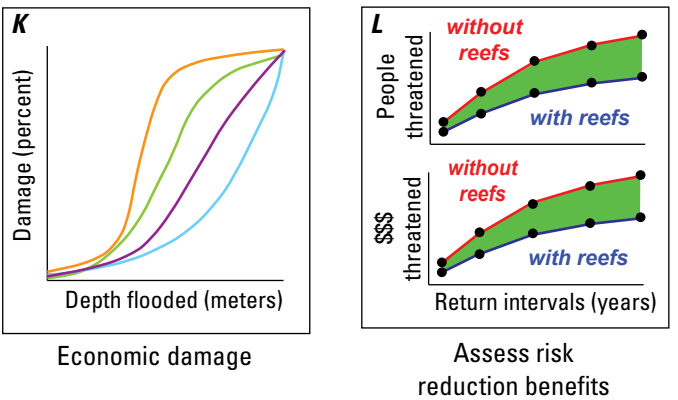

Note: These schematic drawings show an example of the methodology used to evaluate the role of coral reefs in hazard risk reduction.

Source: Storlazzi et al. 2019; Reguero et al. 2021 


\subsubsection{Step 1: Assessment of Offshore Wave and Water-Level Climate}

When initially identifying the suitability of a site for a reef NNBF project, it is first important to understand the main drivers of coastal flooding and erosion within the region to confirm that the reef has the potential to provide suitable coastal protection benefits. Analysis should start with an assessment of both typical and extreme offshore hydrodynamic conditions, which include a statistical characterization of wave climate (wave heights, periods, and direction) and sea levels (including sea-level rise, interannual variations in the MSL, atmospheric surges, and astronomical tides). It is important to isolate the individual components (drivers) of coastal flooding and erosion because a reef is more efficient at mitigating some components than others (e.g., nearshore reefs would be much more efficient at mitigating wave-driven floods than storm surges). This analysis would also include an extreme value analysis of waves and water levels at a site to understand and predict the likelihood of extreme wave and water-level conditions across a range of return intervals. There are a number of global datasets that can be used to define the offshore climate, including satellite measurements (Challenor et al. 2006; Krogstad and Barstow 1999), historical buoy measurements or hindcasts (e.g., Reguero et al. 2012; Hersbach et al. 2020), future wave climate conditions (Mentaschi et al. 2017; Wang, Feng, and Swail 2014; Morim et al. 2020), sea-level datasets (Losada et al. 2013; Vitousek et al. 2017), and global storm tracks (Bengtsson, Hodges, and Roeckner 2006).

\subsubsection{Step 2: Site Assessment of Coastal Hydrodynamics}

Offshore wind waves (periods of 5 to 25 seconds) can transform significantly as they approach a reef from deep to shallow water. These wave transformations occur over relatively large scales (kilometers or even much larger) depending on the coastal bathymetry, coastline orientation, bottom roughness properties, and incident wave conditions, which govern how waves refract, shoal, diffract, and initially dissipate energy. At these scales (e.g., 1 to $100 \mathrm{~km}$ ), it is generally only feasible to model the statistical properties of directionally propagating wave fields using phase-averaged (also referred to as spectral) wave models (e.g., SWAN [Booij, Ris, and Holthuijsen 1999] or WAVEWATCH III [Tolman 1991]-both open-source models). Because these phase-averaged models directly model the behavior of waves based on linear wave theory, key nonlinear processes-such as dissipation (both by wave breaking and bottom friction), wave energy transfers, and diffraction-can only be parameterized within these models using empirical formulations.

Within the nearshore zone where reef NNBF occur (typically less than $1 \mathrm{~km}$ from a coast), waves can transform and dissipate rapidly, especially within the surf zone where wave breaking occurs. As detailed in Section 12.3.4, this wave breaking can lead to increases in mean water level (wave setup), wave-driven currents, and generation of low-frequency (infragravity) waves that may have a dominant influence on the coastline. Given that surf zone regions are typically less than $100 \mathrm{~m}$, this requires much finer-scale wave models (on the order of $10 \mathrm{~m}$ ) 
to resolve these key nearshore hydrodynamic processes. Moreover, to apply phase-averaged wave models, such as SWAN, model coupling to flow models is required to resolve wave setup and wave-driven flows, with Delft3D (Lesser et al. 2004) and ROMS (Warner et al. 2010) being common open-source examples. Alternatively, phase-resolving, wave-flow models can also be used, which simulate individual wave motions and resulting hydrodynamics. These phase-resolving, wave-flow models are generally based on Boussinesq or nonhydrostatic wave assumptions, which directly simulate the nonlinear properties of waves, including generation of wave setup, wave-driven currents, and low-frequency waves. Common open-source examples of these models include Boussinesq models such as FUNWAVE (e.g., Shi et al. 2012) and the nonhydrostatic models XBeach (Roelvink et al. 2009) and SWASH (Zijlema, Stelling, and Smit 2011). The primary drawback of these phase-resolving models is computational expense, which, depending on the scale of an application, may be prohibitive.

The success of any coastal model application also depends on the quality of the input data that are available, including bathymetry and forcing conditions (including available offshore wave and water-level data from Step 1). Finally, all coastal model applications should ideally be validated with some field observational data to provide confidence in model predictions and quantify potential sources of error prior to use for subsequent design.

\subsubsection{Step 3: Quantifying Interactions between the Hydrodynamics and Reef Structures}

Once the baseline coastal hydrodynamics of a site are understood and can be accurately predicted, the same models can be applied to investigate how different design scenarios of the reef NNBF modify the local coastal processes. Initial guidance can be obtained using simple analytical and empirical models to estimate how different design parameters (e.g., reef types, cross-shore and longshore dimensions, reef depths, and distance from shore) are expected to modify waves, water levels, and currents along a coastline. However, for subsequent detailed design assessments, numerical models should be applied, including at a finer scale than Step 2 , to resolve rapidly varying flow properties that can occur across a reef.

In addition, the influence of enhanced bottom roughness created by the expected reef organisms should be assessed. Because the scales of this bottom roughness are generally much finer than model resolution, the effect of this roughness is assessed using empirical drag formulations (e.g., specification of bottom-drag coefficients and wave-friction factors). Because there is some inherent uncertainty in the relationships between reef physical roughness characteristics and drag forces, a sensitivity analysis of the influence of drag parameters should be conducted to define the likely influence and uncertainty in how bottom roughness properties influence the hydrodynamic processes. 


\subsubsection{Step 4: Calculating Coastal Flooding and Sediment Transport and Morphological Change (Erosion or Accretion)}

The tools available to calculate coastal flooding and erosion or accretion are different and reflect further extensions of the models developed in Steps 1 through 3.

\section{Step 4a: Calculating the Effect on Coastal Flooding}

Extremes in water levels that drive coastal flooding are due to a number of processes (Section 12.3.4, Figure 12.4), including (1) variations in offshore sea levels that contribute to mean water-level variability (e.g., MSL, astronomical tides, and storm surges); and (2) wave-driven, water-level variations due to wave run-up, driven by both wave setup and swash excursions at the shoreline.

An initial (first pass) assessment of present coastal flooding scenarios at a given site (without a reef) can be obtained by analyzing offshore water-level conditions to obtain extreme value distributions of mean water levels, which can be combined with extreme value estimates of offshore wave conditions and empirical wave run-up formulations to estimate the wave-driven flooding contribution. More detailed assessments of present coastal flooding impacts can be obtained by detailed application of numerical models developed in Step 2, for a subset of scenarios given the computational demand. Although phase-resolving, wave-flow models are capable of directly resolving both the wave setup and swash contributions to wave run-up (including sea-swell and low frequency wave swash motions), the use of phase-averaged models only accounts for wave setup; therefore, estimating the effect of swash motions may rely on more uncertain empirical run-up formulations.

Similarly, investigation of the effectiveness of different reef NNBF designs to mitigate coastal flooding requires applying the models developed in Step 3 for the same offshore wave and water-level extreme value scenarios. This should include not only present scenarios but also the potential longer-term changes (including forecast sea-level rise) over a future time frame that are consistent with coastal management and planning guidelines. During this design phase, it is critical for there to be feedback and iteration between different design options (based on hydrodynamic performance) and other key design factors, including project costs, environmental benefits, and sustainability.

\section{Step 4b: Calculating the Effect on Coastal Erosion}

Changes in coastal morphology due to erosion and accretion result from the cumulative transport of sediments from beaches by nearshore waves and currents. Coastal erosion can occur rapidly during large storms or develop over long timescales due to more slowly varying processes that evolve coastlines. Erosion is usually studied by modeling both the cross-shore 
(i.e., beach profile changes) and longshore sediment transport (i.e., changes in shoreline position). The sediment transport processes that govern coastal morphological changes are ultimately driven by the hydrodynamic processes in Steps 1 through 3, which can be simulated by coupling sediment transport models with morphological bed updating. However, small uncertainties in hydrodynamic processes generally translate into greater uncertainties in sediment transport, which can make accurate predictions of coastal morphological changes challenging (particularly long-term evolution).

As a consequence, empirical shoreline equilibrium models are often used as a starting point to assess the probable response of the coastal morphology to submerged reefs with a given set of parameters (wave, water level, and reef dimensions) (e.g., Ranasinghe, Larson, and Savioli 2010). A framework for predicting shoreline responses to reefs can also be drawn from analogous literature on submerged breakwaters (e.g., Burcharth et al. 2007; Ranasinghe, Larson, and Savioli 2010) that describe how these structures will likely contribute to beach accretion (or under some scenarios, undesirable erosion). The same models can be applied to reef environments to assess the effects that reefs have on shorelines (e.g., Reguero et al. 2018a). Equilibrium models can be applied to natural and artificial reefs following a similar rationale to an engineered structure, showing that natural breakwaters also modify currents and waves in such a way that the equilibrium of shorelines can be quantitatively predicted. This solution has the potential to explain the existing shoreline but also, very importantly, it can be used to predict potential changes, including those related to reef degradation.

Although equilibrium shoreline models can provide a simple estimate of likely shoreline responses to given reef NNBF designs, it is important to acknowledge the uncertainties these approaches carry because they may ignore important processes (or even dominant processes) that drive sediment transport within complex natural reef ecosystems. Therefore, the use of process-based hydrodynamic-morphodynamic models has the potential to provide significantly more insight into the likely responses of shorelines to submerged structures (Roelvink and Reniers 2011). For these model applications, hydrodynamic models developed and validated in Steps 1 through 3 are expanded to include sediment transport formulations and accounting for morphological changes of the seabed. For example, open-source models such as Delft3D, ROMS, and XBeach all include sediment transport-morphodynamic models that can be used to simulate how a shoreline will likely evolve in response to a submerged structure. However, to more accurately simulate these coastal sediment dynamics requires additional information about the site, including sediment properties and habitat maps to account for how bottom roughness can modify rates of sediment transport and determine the mobility of the seabed (Pomeroy et al. 2017). 


\subsubsection{Step 5: Detailed Design of the Reef Structure}

Once a decision is made on the type of reef NNBF that will be implemented and its main features (e.g., location, size), a final detailed design analysis is needed to ensure all components of the reef structure are stable even under the most extreme conditions. For example, when artificial reef units are to be deployed as substrate for coral and shellish growth, design loads should be quantified to ensure the units are of the proper size and material to be stable under extreme conditions. Similarly, for reefs built on soft sediment, a detailed analysis of scour potential should occur and mitigation strategies should be identified. For this detailed structure design step, various guidelines and literature exist to support coastal structure design (e.g., USACE [2012]; CIRIA, CUR, and CETMEF [2007]); however, it is common to conduct physical model testing of different designs in wave flumes and basins given the complex interactions that occur between the hydrodynamics and structure that can be difficult to accurately predict (Table 12.4). High-resolution computational fluid dynamics models are also increasingly being used to support coastal structure design applications (Table 12.4).

\section{Model Application to Quantify Flood Risk Benefits of Conserving Existing Reefs in the United States for Flood Projection}

Coral reef barriers provide flood protection to more than 18,000 coastal citizens and $\$ 1.8$ billion U.S. dollars (USD) worth of coastal infrastructure in the United States and its trust territories. A study by the U.S. Geological Survey analyzed flood risk and assessed reef benefits of populated U.S. reef-lined coasts of Hawaii, Florida, American Samoa, Guam, the Commonwealth of the Northern Mariana Islands, Puerto Rico, and the U.S. Virgin Islands. The study modeled flooding impacts to people and economic damages at a 10 -square-meter (108-square-foot) resolution along more than $3,100 \mathrm{~km}(1,920$ miles) of populated U.S. coral reef-lined shoreline.

Engineering, ecologic, social, and economic tools were combined to provide this quantitative valuation of the coastal protection benefits of coral reefs off populated coastlines of the United States. The goal was to identify how, where, and when coral reefs provide the most significant coastal flood reduction benefits in social and economic terms. The analysis followed a risk quantification valuation framework to estimate the risk reduction benefits from coral reefs and provide annual expected benefits in social and economic terms. 
Across $3,100 \mathrm{~km}$ of the U.S. coastline, the topmost $1 \mathrm{~m}$ of coral reefs prevents the 100 -year flood from growing by $23 \%$ ( 113 square kilometers), avoiding flooding effects for 53,800 people ( $62 \%$ of the population in this $3,100 \mathrm{~km}$ of coastline), avoiding USD $\$ 2.7$ billion in damages to buildings along this coastline, and avoiding USD\$2.6 billion in indirect economic effects.

\section{Figure 12.9. Map Showing How Coral Reefs Influence 100-Year Flood Areas on the Coast of Maui, Hawaii}

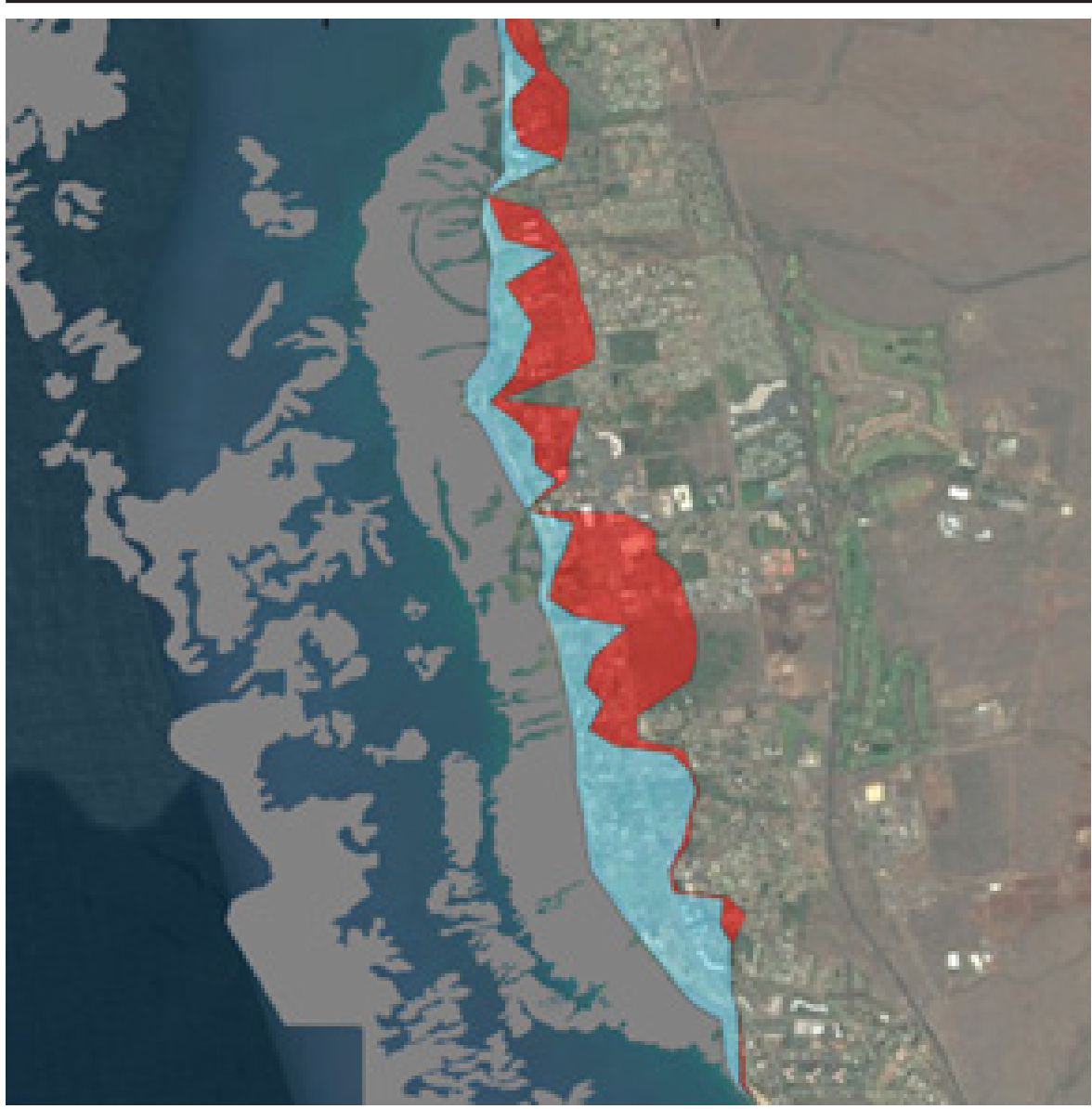

Notes: The map shows 100-year flood areas, defined as areas with a $1 \%$ chance of a very large flood in any given year, on the coast of Maui, Hawaii. Blue shading denotes the areas that would flood during a 100 -year storm; the red shading denotes the regions that would flood without the presence of coral reefs (marked in gray) and thus are protected by coral reefs.

Source: Storlazzi et al. 2019; Reguero et al. 2021 


\section{6 | Construction Considerations and Methods for Reef Restoration}

Full reef habitat creation or re-creation, at one end of the restoration spectrum, is a complex and expensive option. Therefore, restoration that focuses on reduction and management of stressors (such as excess sedimentation) can be a more cost-effective approach to facilitate recovery of reef benefits, including coastal protection. Restoration of lost or degraded reefs has become a field of active research and experimentation in recent decades. The restoration of coral reefs has mainly focused on enhancing coral cover and the subsequent ecosystem services provided by degraded reefs, rather than the return of reefs to the same form that was lost (Hancock, Lewis, and Conklin 2017). This has changed in the last few years because some restoration projects have begun to focus on restoring the areas of coral rubble left after destructive fishing and destructive storms. However, this remains the exception, with experiments focused mainly in Indonesia and Australia. Shellfish reefs have been destroyed in most areas historically occupied by reefs. Thus, establishing shellish reefs in areas where they have been completely eliminated is far more common (Beck et al. 2011; Gillies et al. 2018; zu Ermgassen et al. 2016) than the enhancement of degraded reefs.

The biological restoration of coral reefs involves the enhancement of corals by either sexual or asexual reproduction. Asexual reproduction consists of the fragmentation of corals and subsequent grow out of fragments in nurseries, either in the water or in nurseries onshore. When sufficiently large, these new colonies are either outplanted to the reef or again fragmented to grow multiple new colonies of the same genotype. This technique was developed using fast-growing, branching corals and gained traction as an endangered species recovery technique for Acropora sp. in Florida and the Caribbean (Johnson et al. 2011). As an endangered species recovery technique, the intention was only peripherally aiming for whole reef restoration, but it has proven to be a powerful technique for enhancing coral cover, typically for the faster growing, branching corals (although these corals may offer less protection benefit than others). The approach has been adapted for use with multiple species that are capable of restoring reef function, but the use of fragmentation for massive species is still in development. Since 2015, the technique of microfragmentation has proved to be a viable method of speeding the growth of the massive species that are often important in forming reef structure but are also slow growing (Forsman et al. 2015). These fragments will fuse when they come into contact because they are the same genotype, allowing the development of large colonies in a few years that would normally take decades to grow. Sexual reproduction involves either capturing coral spawn and fertilizing gametes in aquaculture facilities or capturing fertilized zygotes during natural spawning. Larvae are then settled and grown in tanks before outplanting or introduced directly to a degraded reef as competent planula ready to settle (dela Cruz and Harrison 2017). A major challenge facing the coral reef restoration community 
is how to restore reefs at the scale required to compensate for the scale of reef loss. Coral reef restoration efforts have demonstrated varying degrees of success at local scales, but large-scale restoration techniques are still in the early stages of development.

In higher latitudes or estuarine areas where oyster reefs should dominate, the removal (often by trawling and dredging) of oysters for consumption and the subsequent mining of the shell resource to burn for lime production have resulted in complete removal of habitat. Restoration of shellfish reefs begins with an assessment of whether the system is substrate-limited or larvae-limited, or both. Where substrate is lacking, a reef base needs to be built to form a suitable substrate for natural settlement. The biological function of the reef is then generated when larvae settle naturally or when the reef base is seeded with juvenile shellfish. The production of shellfish larvae and the settlement of those larvae on substrate convenient for seeding restoration areas is a well-known practice. In many parts of the world, mussels and oysters are routinely produced from hatcheries for the aquaculture industry and this production can be adapted to produce seed stock suitable for restoration (zu Ermgassen et al. 2016).

\subsubsection{Restoring Biotic Reef Structure}

Both coral and shellish reefs comprise an underlying calcium carbonate reef structure with a veneer of living organisms occupying the outer layer and adding to the reef structure over successive generations. Where this structure has been damaged or removed, restoration of the ecosystem services that a reef provides, particularly wave attenuation, may be necessary. Rebuilding reef structures that are designed for reintroduction of the corals or shellish provides the opportunity to engineer reef structures designed for shoreline protection. The materials used to create or re-create a reef structure vary widely. Previously, it was common to use oyster shell as a replacement of the natural structure for a new reef. This has changed over time because oyster shell availability has declined, and it is also due to the recognition that many substrates may be suitable to promote oyster settlement and may even provide additional benefits over oyster shells. For example, rock and concrete structures have become common substitutes. In the Chesapeake Bay, reefs constructed using a stone-substrate base averaged four times higher oyster recruitment and survival than reefs built using the available whelk and clam shell substrate as a base (NOAA 2017, 2018). Similarly, a variety of concrete structures have been used for ease of construction and stability during the time required for oysters to settle and grow (zu Ermgassen et al. 2016).

The structural integrity of the reef framework is an important feature to consider in the context of coastal protection. Physical impacts to coral and shellfish reefs can occur from storm damage (due to both hydrodynamic forces and burial or smothering by sediment), as well as human impacts (e.g., ship groundings, coral mining or shellfish harvesting, and blast fishing). 
Such impacts can undermine the integrity of the underlying carbonate framework of the reef, cause loss of live reef-building species, and lead to an overall reduction in reef rugosity. Without active structural restoration interventions, the degraded reef crest can experience further deterioration (e.g., a widening of a breach by subsequent storms). For the case of coral reefs, most examples of physical restoration of a reef crest come from the United States. Following a ship grounding on a reef crest in the Florida Keys, the reef structure was physically restored using concrete and limestone to rebuild the shallow buttresses (Precht 2006). Adding structure to a degraded barrier reef to re-create or enhance wave-reduction function is in its infancy as a technique. One example is in Grenada in the Caribbean, where heavy steel gabions filled with rock have been tested (Reguero et al. 2018a). In this case, the structures have been designed using local materials and labor, with the aim of releveling a large section of degraded barrier reef to re-create the historical wave-energy reduction function.

\subsubsection{Building Artificial Reefs}

Artificial reefs could be considered NNBF when they are both designed for coastal protection and provide settlement substrate for corals or shellish supporting the restoration of reef ecosystems. Artificial reefs designed as hybrid gray and green infrastructure for shoreline protection refer to engineered interventions (e.g., low-crested structures) that are also designed to promote coral or shellfish recruitment and growth. The structure of an artificial reef can be built from diverse materials, such as limestone blocks, rock piles, molded cement, steel, and a variety of other materials that are placed on the seafloor. As with any application, including coastal defense, artificial structures have the benefit of immediately increasing relief and topographic complexity, providing immediate benefits. However, if not properly designed, they can also cause substantial negative environmental damage to the ecosystem by interfering with pre-existing natural habitat and altering circulation and sediment transport that adjacent habitats may depend on (Chapman and Underwood 2011; Martin et al. 2005). Poorly designed artificial reefs may further degrade coastal habitats and displace erosion problems to other sections of coastline. Engineered hard structures can also require substantial maintenance to prevent failure.

There are a variety of structural reef restoration approaches (i.e., restoration approaches that aim to rebuild habitat). These include Reef Balls and other analogous structures; concrete structures such as mattresses and blocks; BioRock, a steel skeleton with added electro-deposition; EcoReefs (ceramic units); and rock and rubble piling. As of 2004, there were more than 44 different designs that had been patented in the United States alone (Lukens and Selberg 2004). Concrete blocks of diverse forms are a very common option, although in some areas of the world the availability of concrete can be limiting (e.g., small island developing states). Other novel approaches include 3D printing and other complex 
3D structures that try to mimic the natural structure of a reef (Abelson 2006). Most of these materials and techniques are expensive, and although many promote biological growth, there is often a lack of evidence of their longer-term durability and function for coastal defense applications. Although these approaches are increasingly being applied in coastal engineering, examples are scarce in high wave-energy environments. A potential drawback of these systems is that when they are formed of individual units, they may lack the required interlocking to provide stability under high wave-energy conditions, jeopardizing the integrity of the overall structure. In addition, artificial reefs placed on unconsolidated sediment can experience scour of the reef foundation that over time may cause the structure to settle into the seabed or become unstable. For such cases, consideration of scour protection measures is needed that accounts for the local hydrodynamic conditions (including during extreme conditions) and the geotechnical properties of the seabed.

\section{Hybrid Reefs as Shoreline Protection}

For communities in Grenville Bay, Grenada, located in the Caribbean, managing shoreline erosion has been a significant challenge. The shoreline has retreated approximately $200 \mathrm{~m}$ from 1951 to 2012, and severe coastal erosion and flooding have been threatening homes and critical infrastructure. In response, The Nature Conservancy in partnership with the Government of Grenada, Grenville Bay community members, Grenada Fund for Conservation, and Grenada Red Cross Society began implementing the At the Water's Edge project (coastalresilience.org 2021). As a community-based initiative, the project's main goal was to reduce the communities' vulnerability and enhance resilience to the impacts of climate change, with the use of nature-based solutions, such as coral reefs and mangroves, through nonstructural (socioeconomic) and structural (reef restoration) components. The structural component involved restoring the elevation of the eroded barrier reef such that the wave-breaking function was restored. The aim was to effect shoreline protection (reduced erosion and run-up flooding) by addressing the source of the issue-the eroding barrier reef-rather than using the more familiar shoreline interventions such as groins, riprap, bulkheads, or seawalls. A reef restoration pilot project was launched in January 2015 to build 30 m of submerged hybrid breakwater structures over the most severely degraded reefs in the bay. The pilot project included testing of the engineering design prior to installing a 300-m hybrid gray-green reef array along the fringing reef in Grenada's Grenville Bay, thus providing the first replicable, local, community-based intervention to restore the shoreline protection function of a degrading barrier reef. The project used rock-filled, metal-rebar baskets (Figure 12.10) that were mounted onto the degraded fringing coral reef crest. Remnant corals on the structure footprint were removed and reattached to the metal-rebar baskets after construction. 
This project demonstrated the feasibility of the hybrid structure in a high-energy environment to increase biodiversity at the site including natural biological growth and accretion of coral and crustose coralline algae. It used small boats, local community labor, and construction with common local materials at costs lower than traditional gray infrastructure. The project also included the implementation of a monitoring program to measure the structure's stability and performance, and shoreline stabilization over time.

\section{Figure 12.10. Hybrid Reef Structure at Grenville Bay, Grenada}

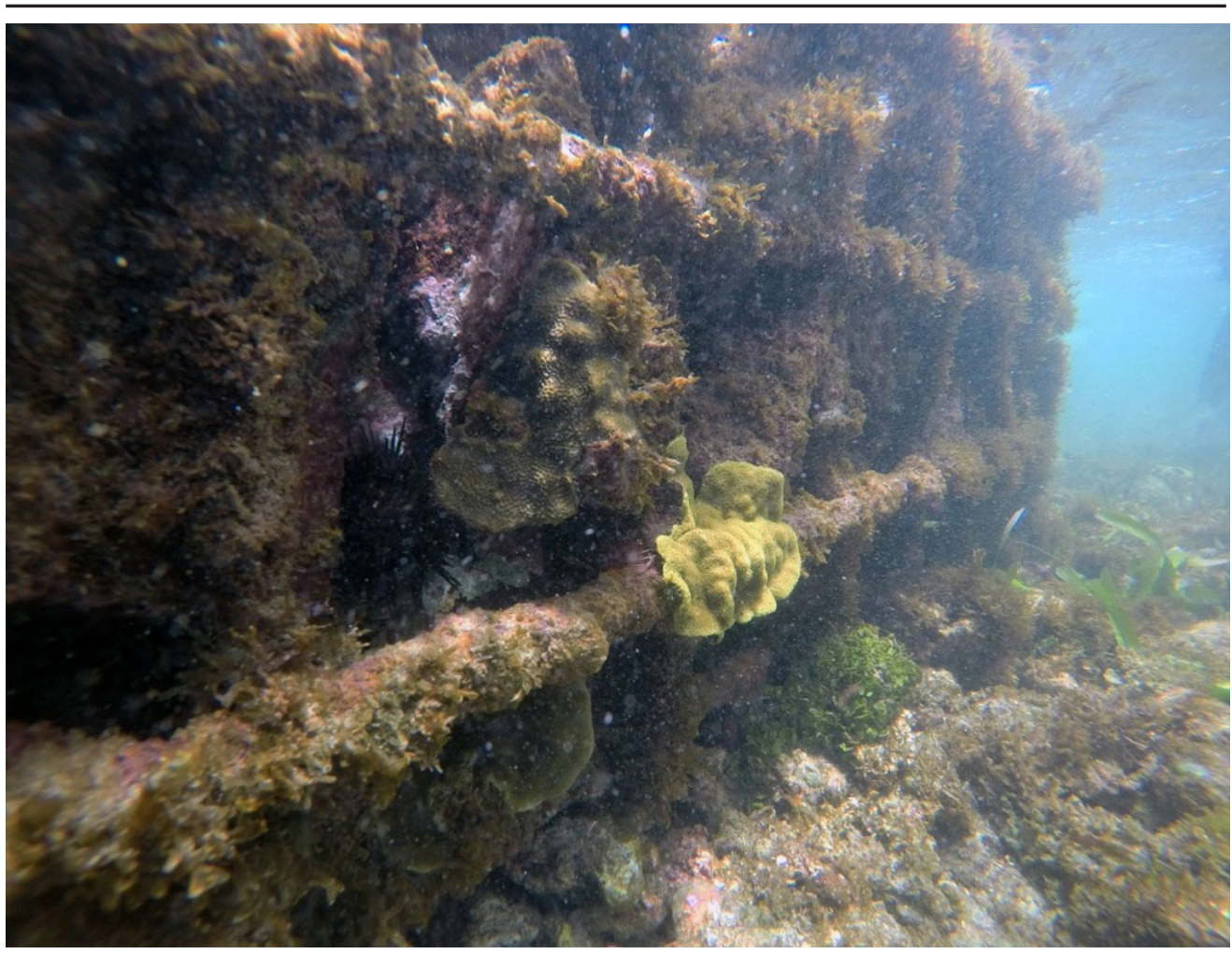

Note: This photograph shows the surface of a single metal-rebar basket with a variety of naturally recruited coral colonies, crustose coralline algae, and associated organisms 3 years after installation.

Source: B. Hancock, The Nature Conservancy 


\section{7 | Costs and Benefits}

Identifying the costs and benefits of reef NNBF (see Chapter 6 for details of the overall approach) requires an understanding of the general capital costs, such as the cost of design, construction, and permitting, as well as the associated maintenance and monitoring costs. Construction costs include construction of both the hard (natural or artificial) substrate and construction involved with developing and maintaining the living layer (i.e., restoration component). General benefits include those associated with coastal hazard risk reduction, such as the economic value of reducing flood damage and the value of erosion reduction and shoreline stabilization at a given location. Additional co-benefits include ecosystem goods and services associated with a reef system, such as benefits to fisheries, water quality, tourism, and recreation. Although the monetary value of the costs and benefits involved in a reef NNBF are not all clearly defined, some detailed methods for quantification of costs and benefits have been developed. Coastal protection can only be reasonably claimed as a benefit if the project is of a scale that can be demonstrated to truly protect coastlines over a range of conditions with a likelihood of occurrence at a site. However, developing a project of appropriate scale may also incur high costs. Due to the large scale and cost involved, it is critical to consider the whole project lifetime when evaluating costs and benefits, including communicating this information to stakeholders.

\subsubsection{Construction Costs}

Although construction costs generally depend on site-specific factors, a comparison of the cost of coral reef restoration efforts to the construction of traditional breakwaters in tropical environments showed that reef restoration was, on average, less expensive than building breakwaters, whereas the observed wave attenuation was similar (Ferrario et al. 2014). In that meta-analysis, the average cost (in 2012 USD) of building tropical breakwaters ranged from USD $\$ 450$ to USD $\$ 189,000$ per $\mathrm{m}$, with a median project cost of approximately USD\$20,000 per $\mathrm{m}$; whereas the cost of structural coral reef restoration projects ranged from USD\$20 to USD $\$ 155,000$ per $\mathrm{m}$, with a median project cost of approximately USD $\$ 1,300$ per $\mathrm{m}$ (Ferrario et al. 2014).

Estimates of the construction of oyster reefs built as living shorelines vary, with costs ranging from approximately USD $\$ 330$ to USD $\$ 1,500$ per $m$ (in 2014 USD) depending on the materials used (e.g., Reef Balls and rock breakwater) (Herder et al. 2014). Note that these estimates provide a cost range for shallow, nearshore projects; costs for construction of natural and hybrid oyster reefs that are deeper or farther from shore may be more expensive due to added deployment costs. In a subsequent analysis, oyster restoration costs ranged from a low of USD\$3,800 per hectare to USD\$2.2 million per hectare, with an average cost of approximately USD $\$ 300,000$ per hectare (Hernandez et al. 2018). Despite the wide range of costs due to the site-specific nature of many projects, there is evidence that both coral and 
oyster nature-based reef construction can be less expensive than traditional breakwater and bulkhead construction (Narayan et al. 2016); further, reefs also provide the additional benefits of ecosystem services (e.g., fisheries, water quality improvements, tourism, biodiversity). Narayan et al. (2016) compared costs of nature-based coastal defense projects and engineering structures and showed that salt marshes and mangroves can be built two to five times cheaper than a submerged breakwater for wave heights up to $0.5 \mathrm{~m}$ and, within their limits, become more cost-effective at greater depths. However, Narayan et al. (2016) did not explicitly account for increases in restoration costs due to adverse ecological or geomorphic site conditions, which can significantly increase restoration costs.

\subsubsection{Maintenance and Monitoring Costs}

In addition to the capital costs of a project, it is also important to incorporate maintenance and monitoring costs within a comprehensive cost-benefit analysis of a reef project. Hybrid and artificial reefs may require regular maintenance and upkeep, and thus additional, periodic expenses should be included in estimates of project cost over time. The costs associated with developing and maintaining a living coral layer are highly variable, depending on the restoration method used and resources available (Bayraktarov et al. 2019), and can also be dependent on national regulations (e.g., U.S. designation of threatened coral species). For example, larval enhancement of corals can range from USD\$6,000 to USD\$4 million per hectare in 2010 USD; whereas total coral gardening costs (collection, nursery, and transplantation) range from USD $\$ 130,000$ to USD $\$ 380,000$ per hectare (Bayraktarov et al. 2019). In addition, maintenance or repair costs following large disturbance events, such as extreme storms, may be required to maintain flood risk benefits. These maintenance and repair activities may be required more frequently in the beginning stages of reef development when the biological layer may be more susceptible to damage. When placing these reef NNBF in the context of using conventional engineering structures, these whole-of-life costs (including expected long-term maintenance and repair activities of conventional structures) should be accounted for within the cost analysis for the project.

\subsubsection{Flood Risk Reduction Benefits}

Methods for rigorously quantifying flood risk reduction benefits by reefs have been developed using models and approximations developed by engineers and are fully consistent with the approaches utilized for assessing alternatives for coastal protection. For example, methods for the valuation of flood risk reduction benefits from coral reef NNBF projects have utilized index-based approaches and generalized areal coverage (van Zanten, van Beukering, and Wagtendonk 2014; Yee, Dittmar, and Oliver 2014; Pascal et al. 2016). More recently, more rigorous methods that incorporate hydrodynamic, geospatial, and economic models have been developed to quantify the coastal protection benefits of coral reefs adjacent to populated U.S. coastlines (Beck et al. 2018; Reguero et al. 2021; see "Model Application to Quantify Flood 
Risk Benefits of Conserving Existing Reefs in the United States for Flood Projection"). A recent analysis combining coastal hazards, reef flood models, and impact and benefit assessments estimated that U.S. coral reefs protect approximately 18,000 people per year and provide more than USD\$1.8 billion a year in coastal storm flooding protection (Storlazzi et al. 2019). Such approaches could be used to evaluate other reef NNBF projects, including application to shellifish reef projects.

Using a similar method that also incorporates hazard assessment, assets at risk, and potential damages resulting from storm events, oyster reefs and associated marsh NNBF were predicted to be cost effective measures and to contribute substantially to overall damage reduction from flood risk on the U.S. Gulf Coast (Reguero et al. 2018b). Costs associated with shore stabilization in the United States were estimated at USD\$500 to USD\$750 per $\mathrm{m}$ depending on structure type (stone groin, bulkhead, or stone sill); whereas the adjusted costs of constructing oyster reefs to similarly protect the same amount of shoreline were significantly reduced at approximately USD\$105 to USD\$150 per m (Grabowski et al. 2012).

\subsubsection{Co-Benefits}

There are many potential co-benefits provided by reef NNBF (refer to Chapter 6 for a general overview of how to assess the co-benefits of NNBF projects). These include, but are not limited to, recreational and commercial fin, crab, and bivalve fisheries; water quality benefits such as filtration and removal of nutrients; enhancement of habitat both directly and indirectly; and human recreation activities such as fishing, boating, and beach use. There have been a number of efforts to quantify ecosystem goods and services and co-benefits of reef systems (Cesar and van Beukering 2004; Molberg and Folke 1999; Brander, van Beukering, and Cesar 2007; Grabowski et al. 2012). It is beyond the scope of this document to provide a comprehensive assessment of reef co-benefits. However, some examples are provided to give a sense of their financial scale. In an evaluation conducted in the Hawaiian Islands that incorporated direct use (e.g., fisheries, mariculture, and pharmaceuticals), nondirect use (e.g., carbon storage), and nonuse values (e.g., threatened and endangered species habitat), the average annual value of the coral reef ecosystem was estimated to be USD\$364 million (Cesar and van Beukering 2004). In a study estimating the value of services provided by restored and protected oyster reefs using avoided cost proxy estimation, the annual value of nonoyster harvest services was predicted to vary from approximately USD $\$ 10,000$ to USD $\$ 100,000$ per hectare, depending on the location of the reef and the specific services the reef provides (Grabowski et al. 2012).

In addition to the co-benefits described, there are also co-benefits that are not often evaluated. These include the valuation of the aesthetic perception of the feature or shoreline it is protecting; the potential for increased land value as a result of more stable, protected, and viable shores; carbon sequestration; and new markets due to reduced flood risk, improved habitat, and other nontangible benefits. 


\section{8 | Monitoring, Operations, Maintenance, and Management}

The monitoring guidelines presented in this section identify parameters and metrics (summarized in Tables 12.2 and 12.5) that can be used to assess the performance of reefs made out of a variety of natural and artificial materials (i.e., metrics that can be used to evaluate how the performance objectives of reef NNBF vary in time).

Post-construction monitoring and maintenance of reef projects are required to assess whether project objectives are being met and identify any corrective actions that may be needed. Because each reef project is uniquely tailored to its site and desired project goals, there is no one-size-fits-all monitoring plan. The six steps of a well-designed adaptive management program (plan, design, build, monitor, evaluate, and adapt) are described in detail in Chapter 7. Therefore, the focus here is on how to implement monitoring, evaluation, and adaptation of reef systems as part of a nature-based, flood risk management scheme.

Monitoring, occurring both pre- and post-construction, is necessary to evaluate if a reef structure (i.e., coral, shellfish, or artificial reef) is providing the intended benefits. Baseline data prior to implementation of a project are essential to evaluate the impact of the project, positive and negative, and how it changes from the initial (baseline) conditions. Post-implementation monitoring should be designed to show progress toward project objectives and whether corrective action is needed. Reef monitoring plans should at a minimum encompass parameters and metrics that address key elements of the reef function during both typical conditions and extreme events (Goergen et al. 2020).

Some guidelines for monitoring reefs have been developed separately for coral reefs (Thayer et al. 2005) and oyster reefs (Thayer et al. 2005; Goergen et al. 2020; Brumbaugh et al. 2006; Baggett et al. 2014; NAS 2017). For example, typical metrics for coral reef restoration include restored reef aerial dimension, reef elevation, coral size frequency distribution, estimated coral live tissue, coral genetic diversity, and water quality parameters (Goergen et al. 2020). Typical oyster restoration metrics include reef aerial dimension, reef height, oyster density, and oyster size frequency distributions (Baggett et al. 2014). For specific restoration goals, additional metrics are suggested. For coral population enhancement, specific metrics include coral abundance and cover, reproductive maturity and capacity, coral health, and genetic diversity (Goergen et al. 2020). For coral reef community and habitat enhancement, specific metrics include enhancing the diversity and abundance of invertebrate communities, enhancing the diversity and abundance of fish communities, creation or restoration of a 3D high-relief habitat, and habitat quality (Goergen et al. 2020). 
Table 12.5. Guidance on Monitoring Parameters, Metrics, and Performance Criteria

\begin{tabular}{|c|c|c|c|c|}
\hline $\begin{array}{l}\text { Monitoring } \\
\text { parameter }\end{array}$ & Metric & Performance criteria & $\begin{array}{l}\text { Frequency of } \\
\text { monitoring }\end{array}$ & $\begin{array}{c}\text { Example } \\
\text { applications }\end{array}$ \\
\hline \multirow[t]{3}{*}{$\begin{array}{l}\text { Wave energy } \\
\text { offshore and } \\
\text { onshore of a } \\
\text { reef }\end{array}$} & $\begin{array}{l}\text { Sea-swell wave } \\
\text { conditions } \\
\text { (heights, } \\
\text { periods, and } \\
\text { directions) }\end{array}$ & \multirow[t]{3}{*}{ Reduced wave energy } & \multirow[t]{3}{*}{$\begin{array}{l}\text { Annually in } \\
\text { years } 1 \text { to } 5 \text { after } \\
\text { implementation }\end{array}$} & \multirow[t]{3}{*}{ Not applicable } \\
\hline & $\begin{array}{l}\text { Low-frequency } \\
\text { wave motions }\end{array}$ & & & \\
\hline & Wave setup & & & \\
\hline $\begin{array}{l}\text { Nearshore } \\
\text { currents }\end{array}$ & $\begin{array}{l}\text { Mean currents } \\
\text { in the lee of } \\
\text { reefs }\end{array}$ & $\begin{array}{l}\text { Nearshore current patterns } \\
\text { conducive to beach accretion } \\
\text { (rather than erosion) }\end{array}$ & $\begin{array}{l}\text { Annually in } \\
\text { years } 1 \text { to } 5 \text { after } \\
\text { implementation }\end{array}$ & Not applicable \\
\hline $\begin{array}{l}\text { Shoreline } \\
\text { creation } \\
\text { (sediment } \\
\text { accretion) }\end{array}$ & $\begin{array}{l}\text { Shoreline loss } \\
\text { or gain }\end{array}$ & $\begin{array}{l}\text { Should exceed minimum } \\
\text { accepted design criteria }\end{array}$ & $\begin{array}{l}\text { Monthly to seasonally } \\
\text { in years } 1 \text { to } 3 \text {; } \\
\text { annually thereafter }\end{array}$ & $\begin{array}{l}\text { Baggett et al. } \\
2014\end{array}$ \\
\hline $\begin{array}{l}\text { Shoreline } \\
\text { erosion }\end{array}$ & Not applicable & $\begin{array}{l}\text { Should be stable or } \\
\text { decreasing relative to } \\
\text { reference sites }\end{array}$ & $\begin{array}{l}\text { Monthly to seasonally } \\
\text { in years } 1 \text { to } 3 \text {; } \\
\text { annually thereafter }\end{array}$ & Not applicable \\
\hline \multirow{7}{*}{$\begin{array}{l}\text { Coral reef } \\
\text { sustainability }\end{array}$} & Coral cover & Increase in coral density per & \multirow{7}{*}{$\begin{array}{l}\text { Dependent on reef } \\
\text { type and biological } \\
\text { growth rates }\end{array}$} & NAS 2019 \\
\hline & Coral size (mean & unit area & & Edwards 2010 \\
\hline & $\begin{array}{l}\text { size and size } \\
\text { frequency) }\end{array}$ & $\begin{array}{l}\text { Increase in coral size (width } \\
\text { and height) }\end{array}$ & & $\begin{array}{l}\text { Thayer et al. } \\
2005\end{array}$ \\
\hline & \multirow[t]{4}{*}{$\begin{array}{l}\text { Coral survival } \\
\text { rate }\end{array}$} & $\begin{array}{l}\text { Maintain or exceed design } \\
\text { survivorship (i.e., 80\%) }\end{array}$ & & \multirow[t]{4}{*}{$\begin{array}{l}\text { Hill and } \\
\text { Wilkinson } 2004\end{array}$} \\
\hline & & $\begin{array}{l}\text { Successful recruitment of } \\
\text { new corals }\end{array}$ & & \\
\hline & & Disease or bleaching limited & & \\
\hline & & $\begin{array}{l}\text { Water quality parameters in } \\
\text { range for species survival }\end{array}$ & & \\
\hline \multirow[t]{5}{*}{$\begin{array}{l}\text { Shellfish reef } \\
\text { sustainability }\end{array}$} & \multirow[t]{4}{*}{ Shellfish density } & \multirow{4}{*}{$\begin{array}{l}\text { Increased shellfish density } \\
\text { per square meter, including } \\
\text { evidence of recruitment } \\
\text { Increased structural integrity } \\
\text { Increased vertical relief } \\
\text { Disease limited }\end{array}$} & \multirow{5}{*}{$\begin{array}{l}\text { Immediately after } \\
\text { deployment if } \\
\text { using seed oysters; } \\
\text { otherwise, annually } \\
\text { at the end of oyster } \\
\text { growing season (will } \\
\text { vary by region), } 1 \text { to } \\
2 \text { years at minimum; } \\
\text { preferably } 4 \text { to } 6 \\
\text { years }\end{array}$} & \multirow{5}{*}{$\begin{array}{l}\text { Brumbaugh et } \\
\text { al. } 2006 \\
\text { Baggett et al. } \\
2014 \\
\text { DeAngelis and } \\
\text { Geselbracht } \\
2019\end{array}$} \\
\hline & & & & \\
\hline & & & & \\
\hline & & & & \\
\hline & $\begin{array}{l}\text { Size frequency } \\
\text { distribution }\end{array}$ & None & & \\
\hline \multirow{3}{*}{$\begin{array}{l}\text { Submerged } \\
\text { aquatic } \\
\text { vegetation, } \\
\text { mangrove, } \\
\text { and marsh } \\
\text { enhancement } \\
\text { leeward of reef }\end{array}$} & \multirow[t]{3}{*}{ Vegetation cover } & \multirow[t]{3}{*}{$\begin{array}{l}\text { Increase in vegetation cover } \\
\text { shoreward of the reef }\end{array}$} & \multirow[t]{3}{*}{ Annually } & $\begin{array}{l}\text { Bell, Fonseca, } \\
\text { and Motten } 1997\end{array}$ \\
\hline & & & & $\begin{array}{l}\text { Brumbaugh et } \\
\text { al. } 2006\end{array}$ \\
\hline & & & & $\begin{array}{l}\text { Baggett et al. } \\
2014\end{array}$ \\
\hline
\end{tabular}




\subsubsection{Monitoring Reef Hydrodynamics}

Wave conditions, currents, and water levels should be monitored at a project site to assess whether the reef structure is modifying the hydrodynamics as expected. These site characteristics should be monitored pre- and post-implementation to quantify progress (or lack of) toward the project objectives.

Wave conditions and currents should be monitored offshore and onshore of the reef, initially as continuously as possible following construction (i.e., over years 1 to 5 following implementation). This could occur at set periods (e.g., weeks) each year. The longer the monitoring record, the more likely a range of metocean conditions will be encountered (including extreme conditions), and this will provide greater confidence that the reef is performing as expected. Mean current patterns at multiple locations behind the reef structure should also be initially monitored (even for shorter durations) to understand how the currents may promote long-term beach accretion (or erosion) behind the reef (see Section 12.3.5).

\subsubsection{Monitoring Shoreline Coastal Morphology Changes}

Monitoring changes in the shoreline and beach volume behind the reef is critical to confirm a reef is functioning as expected based on the project objectives. Measuring the functioning of a reef to prevent erosion or even promote accretion can be as simple as monitoring the shoreline position with a handheld GPS or installing stakes or other markers along the shoreline or providing a baseline to measure shoreline migration relative to a reference site (Brumbaugh et al. 2006). Shore-based camera systems can also provide both qualitative and quantitative (when georeferenced) shoreline change information (Holman and Haller 2013). Broader-scale assessments of shoreline variability through aerial photographs and GIS image analysis can also provide the landscape-scale analysis of reef habitat and changes (Brumbaugh et al. 2006). The use of modern high-resolution, publicly available satellite imagery also provides new opportunities to automate shoreline monitoring behind reefs at weekly timescales (Cuttler et al. 2020). As with other monitoring parameters, to accurately assess the role of the reef in sediment accretion, monitoring must be designed with both pre-project and post-project sampling and include control and reference sites.

\subsubsection{Monitoring Biological Reef Components}

The longevity and sustainability of coral and shellfish reefs depends in part on the biological health of the reef and recruitment of the organisms-the ability of the reef-building organisms to reproduce, sustain, and add to the reef elevation profile. For example, measuring the growth and recruitment of shellfish provides important information about how the reef can continue to function to dissipate wave energy. The life cycle of the shellfish species needs 
to be considered when determining the monitoring required for project evaluation. A time frame, thought to be ecologically meaningful, should include multiple recruitment phases, for a monitoring period of 4 to 6 years following construction (Baggett et al. 2014). Quadrat samples used to quantitatively estimate shellfish abundance on different locations of the reef can then be used to estimate changes in population density and size classes (Brumbaugh et al. 2006). A variety of techniques, including quadrats and transects (belt and linear, chain, and line intercept), can be considered for similar underwater coral reef monitoring, each with limitations and advantages (Thayer et al. 2005).

Biological monitoring in shellfish reef projects can provide the data needed to determine if a site needs to be reseeded with live shellfish spat or spat on shells. For coral reef projects, biological monitoring can determine whether to have coral outplants added to maintain the project objectives. Due to slow growth of many coral species, the biological components are expected to enhance over decades. For artificial materials, sustainability and the ability to provide the desired function for the project goals may depend on the materials used and site characteristics and placement (Rendle 2016).

To measure the elevation of a reef in relation to the surrounding substrate, surveys using differential GPS (DGPS) equipment can be used to monitor changes to the 3D topography of an intertidal reef; whereas side-scan sonar, echosounders, and depth finders can be used on subtidal reefs (Baggett et al. 2104). The spatial extent of a reef can show growth and increased natural infrastructure properties. Spatial reef extent can be measured in a variety of ways, including satellite and aerial photographs, echosounders, side-scan sonar, and lidar (Thayer et al. 2005).

\subsubsection{Monitoring Reef Project Longevity}

Given that the full benefits of a reef NNBF project may take many years to be realized, some form of long-term (e.g., over a decade and longer) monitoring should be built into the project scope, even if at reduced monitoring frequency (e.g., annually). Given that many of the organisms that help to grow reefs (especially corals) can be slow growing, it may take many years to verify the reef is growing as intended and other co-benefits (e.g., ecosystem services) are being achieved. These monitoring techniques would generally follow those detailed in Sections 12.8 .1 to 12.8 .3 , but generally at reduced monitoring intensity (including temporal and spatial resolution). By monitoring the longevity of a project, the project can also have broader implications for use of reef NNBF regionally and globally (e.g., by validating approaches, providing useful case studies that validate approaches). Such long-term monitoring efforts, when combined with similar efforts globally, will also provide critical information for the international community to develop further guidelines for implementing reef NNBF and give coastal managers and decision-makers increased confidence in using such approaches as an alternative to traditional coastal defense structures. 


\subsubsection{Management Recommendations}

Managing reef systems as part of nature-based, flood risk management follows many of the same recommendations as managing for reef health, survival, and recovery from disturbance. Addressing local stressors prior to implementing a project is critical; otherwise, a project may fail. Controlling local stressors such as pollution, overfishing and destructive fishing, coastal development, recreational use, and tourism impacts, and planning for climate change are important considerations when designing and implementing a reef NNBF project. For coral reefs, it is generally important to improve habitat quality and restore keystone species and functional processes such as herbivory to sustain adult colonies and promote successful recruitment. Managing predation by removing coral predators (e.g., crown-of-thorns starfish) and assisting in reef recovery following storm damage (e.g., reattachment of broken coral or stabilization of substrate) may also be helpful to stimulate reef recovery. For shellfish reefs, controlling overharvest and habitat destruction and improving water quality are also important considerations.

Including adaptive management approaches within projects, especially those not meeting desired objectives, is important to ensure long-term success. Potential corrective actions that can be taken on reefs that are not meeting project objectives include adding structural materials (corals or shellfish or materials expected to support recruitment), adding additional reef material, and modifying the design (NOAA 2016).

Effective policies and plans are needed to support the reduction of local stressors to reefs (e.g., coastal zone management plans or protected area management legislation) and restoration following disturbance (e.g., rapid response plans). Political will is important to secure the necessary and sustained resources that may be required to maintain healthy coral and shellfish reefs. Additionally, building public awareness of the environmental and social benefits of healthy reef ecosystems can increase local support for their protection. The development of alternative livelihoods (e.g., ecotourism) may also reduce the dependence on marine resources and, therefore, reduce threats facing reef systems. Finally, increasing partnerships between tourism operators, developers, and management agencies can help create new incentives and revenue streams that support reef protection and restoration (e.g., parametric reef insurance; nature.org 2019) or investments in reef NNBF (e.g., resilience insurance mechanisms; Reguero et al. 2020). 


\section{9 | Gaps and Future Directions}

Reefs can be a very effective form of NNBF for coastal flood risk reduction while also delivering added benefits of ecosystem services provided by natural reefs. However, to scale up the implementation of NNBF, further work is still needed to help optimize the performance of a reef NNBF to achieve both ecological and coastal protection benefits. Variability in success among studies and location highlights gaps in the ability to design projects that simultaneously support coastal protection and self-sustaining reefs (La Peyre, Schwarting, and Miller 2013; Morris et al. 2019).

Effectiveness in reducing wave-driven flood risk. Reefs tend to be very effective at reducing wave-driven coastal flooding (e.g., due to extreme storm events) by dissipating wave energy through breaking and bottom friction associated with roughness. Moreover, quantitative measures of the reduction of wave-driven flooding in the lee of reefs can be predicted using modern coastal hydrodynamic models, which can help to optimize the design of specific reef NNBF projects. Although the protective function of reefs in dissipating incident sea-swell wave energy can be accurately predicted given adequate bathymetry, robust predictions of bottom-friction (drag) dissipation due to organisms living on a reef can be much more challenging to predict and generally have greater uncertainty. This uncertainty is due to the complex and variable morphologies of the communities of organisms that compose a reef, which often makes identifying the bottom-drag forces responsible for dissipation more ambiguous. Although various approaches have been proposed to describe the influence of reef roughness on the hydrodynamics and show promise for practical applications, further work is needed to improve and ground truth these predictions across a range of different types of reefs.

Effectiveness in reducing coastal erosion risk. Despite the clear role that reefs play in reducing coastal flooding, coastal erosion responses in the presence of reefs can be more complex and difficult to predict. Designing a reef NNBF to achieve a desired shoreline response can be challenging due to the complex hydrodynamic processes that govern wave-driven mean current patterns in the lee of reefs, which have the potential to add sediment to (accretion) or remove sediment from (erosion) an adjacent shoreline. Although there have been improvements to knowledge and models to help predict the shoreline response behind low-crested (submerged) breakwaters and artificial reefs, further work is needed to improve and validate these models within reef NNBF projects. This can be achieved by focusing future efforts on improving models used to predict the coupled hydrodynamic-morphodynamic processes along reef coastlines, as well as by monitoring shoreline variability behind the reefs and validating models against additional field measurements.

Links between reefs and coastal sediment budgets. Over long timescales (i.e., more than a decade), there are also knowledge gaps needed to be filled to project the long-term responses of coastlines to reef NNBF projects. This is partially because productive reef ecosystems can 
produce significant volumes of carbonate sediment once established (i.e., via calcification by shellfish, corals, coralline algae, and numerous other organisms living within reefs). For natural reefs, this carbonate sediment production is usually a primary source of sediment to adjacent coastlines. However, for a new reef NNBF project, it is unclear the extent and timescales over which a project could have an additional positive input to coastal sediment budgets. Therefore, future work is needed to understand the links between the ecosystems that comprise various reef NNBF projects and coastal sediment budgets. A greater number of long-term NNBF projects with long-term monitoring programs (decades and longer) will be essential to better understand changes to the sources and composition of coastal sediments and the influence on the long-term trajectories of local coastlines.

\section{Linking reef restoration projects to flood and coastal risk reduction. Technical} advancements are also needed to help scale up reef restoration projects to support joint flood and coastal risk reduction with environmental conservation objectives. For example, current efforts to combine microfragmentation and larval propagation of corals show promise for improving the success of reef restoration efforts, but more work is needed to accelerate deployment of reef fragments, increase outplanting success, and include heatresistant corals in restoration projects. For shellifish reefs, research is needed to guide the selection of substrate for shellfish reef restoration. Historically, restoration projects used recycled, fossilized, or dredged native oyster shell for use as substrate, but the decreased availability of shell and the need to support large-scale restoration projects has resulted in the use of alternative materials to create reef substrate including, for example, limestone, concrete, porcelain, and nonoyster shell (mussel, clam). The choice of substrate depends on the characteristics of the substrate and the scale, methods, and goals of restoration projects (Goelz, Vogt, and Hartley 2020). Monitoring data can help inform substrate material selection based on an improved understanding of the trade-offs between these materials. Technological advances are also needed to support increased survival and fitness of shelliish reared in hatcheries (e.g., use of probiotics) and selective breeding programs for disease resistance. Additionally, economic studies that account for the full suite of ecosystem benefits that natural reefs provide are needed to incentivize the protection and restoration of coral and shellifish reefs. Economic studies that compare the costs of gray versus green coastal protection projects will also help clarify the costs and benefits associated with natural reef, hybrid, and traditional shoreline armoring approaches. A further need is to develop markets for the services that natural reefs provide (e.g., credits for the water filtration and denitrification provided by restored shellfish reefs could be bought and sold). It is critical to address the significant threats facing natural reef ecosystems. The ability for natural reefs to provide coastal protection benefits will be limited by declines in reef health due to climate change impacts and other human impacts (e.g., pollution, sedimentation, overfishing, and destructive fishing). The control of these stressors, including an urgent reduction of carbon dioxide emissions, is critical to helping reef systems maintain the suite of ecosystem services that they provide into the future. 
Efficacy of various reef materials in the marine environment. Additional studies are needed to monitor and document the efficacy of materials used in reef construction (e.g., considering the oxidative nature of metals). The long-term performance of different materials typically used in reef restoration (including concrete, reinforcements [e.g., rebar, steel], and abandoned structures) should be monitored over a period of time, in different marine environments. For example, there are studies documenting the oxidation of an abandoned vessel in Palmyra Atoll promoting the growth of an invasive and destructive algae in the lagoon. Additional studies are needed in various regions to further this knowledge base.

Broadening the application of reef NNBF. Future work is needed to develop innovative solutions to accelerate the broader application of reef NNBF, which will benefit by working to further increase the cost-effectiveness of designs that are appropriate for a range of local socioeconomic conditions. This could include a focus on developing new lower-cost artificial reef structures, reducing the costs of construction materials and methods (which are also fit-for-purpose to local conditions), and developing new strategies to upscale reef restoration efforts at reduced cost.

\subsection{0 | References}

Abelson, A. 2006. "Artificial Reefs vs Coral Transplantation as Restoration Tools for Mitigating Coral Reef Deterioration: Benefits, Concerns, and Proposed Guidelines." Bulletin of Marine Science 78: 151-159.

Ahrens, J. P., 1987. Characteristics of Reef Breakwaters. CERC-TR-87-17. Vicksburg, MS: Coastal Engineering Research Center.

Albert, S., J. X. Leon, A. R. Grinham, J. A. Church, B. R. Gibbes, and C. D. Woodroffe. 2016. "Interactions between Sea-Level Rise and Wave Exposure on Reef Island Dynamics in the Solomon Islands." Environmental Research Letters 11 (5): 054011.

Alongi, D. A. 2008. “Mangrove Forests: Resilience, Protection from Tsunamis, and Responses to Global Climate Change." Estuarine, Coastal and Shelf Science 76 (1):1-13.

Altomare, C., A. J. Crespo, B. D. Rogers, J. M. Domínguez, X. Gironella, and M. Gómez-Gesteira. 2014. "Numerical Modelling of Armour Block Sea Breakwater with Smoothed Particle Hydrodynamics." Computers \& Structures 130: 34-45.

Altomare, C., A. J. Crespo, J. M. Domínguez, M. Gómez-Gesteira, T. Suzuki, and T. Verwaest. 2015. "Applicability of Smoothed Particle Hydrodynamics for Estimation of Sea Wave Impact on Coastal Structures." Coastal Engineering 96: 1-12.

Alvarez-Filip, L., N. K. Dulvy, J. A. Gill, I. M. Côté, and A. R. Watkinson. 2009. “Flattening of Caribbean Coral Reefs: Region-Wide Declines in Architectural Complexity." Proceedings of the Royal Society of London B: Biological Sciences 276 (1669): 30193025. 
Andréfouët, S., F. E. Muller-Karger, J. A. Robinson, C. K. Kranenburg, D. Torres-Pulliza, S. A. Spraggins, and B. Murch. 2006. "Global Assessment of Modern Coral Reef Extent and Diversity for Regional Science and Management Applications: A View from Space." Proceedings of the 10th International Coral Reef Symposium 1732-1745.

Baggett, L. P., S. P. Powers, R. Brumbaugh, L. D. Coen, B. DeAngelis, J. Greene, B. Hancock, and S. Morlock. 2014. Oyster Habitat Restoration Monitoring and Assessment Handbook. Arlington, VA: Nature Conservancy.

Baine, M. 2001. "Artificial Reefs: A Review of Their Design, Application, Management and Performance." Ocean and Coastal Management 44 (3-4): 241-259.

Baldock, T. E., A. Golshani, D. P. Callaghan, M. I. Saunders, P. J. Mumby. 2014. "Impact of SeaLevel Rise and Coral Mortality on the Wave Dynamics and Wave Forces on Barrier Reefs." Marine Pollution Bulletin 83 (1): 155-164.

Baldock, T. E., B. Shabani, and D. P. Callaghan. 2019. “Open Access Bayesian Belief Networks for Estimating the Hydrodynamics and Shoreline Response behind Fringing Reefs Subject to Climate Changes and Reef Degradation." Environmental Modelling \& Software 119: 327-340.

Barbier, E. B., S. D. Hacker, C. Kennedy, E. W. Koch, A. C. Stier, and B. R. Silliman. 2011. “The Value of Estuarine and Coastal Ecosystem Services." Ecological monographs 81 (2): 169-193.

Bayraktarov, E., P. J. Stewart-Sinclair, S. Brisbane, L. Boström-Einarsson, M. I. Saunders, C. E. Lovelock, H. P. Possingham, P. J. Mumby, and K. A. Wilson. 2019. “Motivations, Success, and Cost of Coral Reef Restoration." Restoration Ecology 27 (5): 981-991.

Beck, M. W., I. J. Losada, P. Menéndez, B. G. Reguero, P. Díaz-Simal, and F. Fernández. 2018. "The Global Flood Protection Savings Provided by Coral Reefs." Nature Communications 9 (1): 2186.

Beck, M. W., R. D. Brumbaugh, L. Airoldi, A. Carranza, L. D. Coen, C. Crawford, O. Defeo, et al. 2011. “Oyster Reefs at Risk and Recommendations for Conservation, Restoration, and Management." Bioscience 61 (2):107-116.

Bell, S. S., M. S. Fonseca, and L. B. Motten. 1997. "Linking Restoration and Landscape Ecology." Restoration Ecology 5 (4): 318-323.

Bengtsson, L., K. I. Hodges, and E. Roeckner. 2006. "Storm Tracks and Climate Change." Journal of Climate 19 (15): 3518-3543.

Black, K. P., and C. J. Andrews. 2001. "Sandy Shoreline Response to Offshore Obstacles, Part 1: Salient and Tombolo Geometry and Shape." Journal of Coastal Research 82-93.

Bohnsack, J. A., and D. L. Sutherland. 1985. "Artificial Reef Research: A Review with Recommendations for Future Priorities." Bulletin of Marine Science 37 (1): 11-39.

Booij, N. R. R. C., R. C. Ris, and L. H. Holthuijsen. 1999. "A Third-Generation Wave Model for Coastal Regions: 1. Model Description and Validation." Journal of Geophysical Research: Oceans 104 (C4): 7649-7666. 
Bowen, A. J., D. L. Inman, and V. P. Simmons. 1968. "Wave 'Set-Down' and Set-Up." Journal of Geophysical Research 73 (8): 2569-2577.

Brander, L. M., P. van Beukering, and H. S. Cesar. 2007. "The Recreational Value of Coral Reefs: A Meta-Analysis." Ecological Economics 63 (1): 209-218.

Broughton, K. 2012. Office of National Marine Sanctuaries Science Review of Artificial Reefs. Marine Sanctuaries Conservation Series ONMS-12-05. Silver Spring, MD: National Oceanic and Atmospheric Administration, Office of National Marine Sanctuaries.

Brumbaugh, R. D., M. W. Beck, L. D. Coen, L. Craig, and P. Hicks. 2006. A Practitioners' Guide to the Design and Monitoring of Shellfish Restoration Projects: An Ecosystem Services Approach. Arlington, VA: Nature Conservancy.

Buckley, M. L., R. J. Lowe, and J. E. Hansen. 2014. "Evaluation of Nearshore Wave Models in Steep Reef Environments." Ocean Dynamics 64 (6): 847-862.

Buckley, M. L., R. J. Lowe, J. E. Hansen, and A. R. van Dongeren. 2015. “Dynamics of Wave Setup over a Steeply Sloping Fringing Reef." Journal of Physical Oceanography 45 (12): 3005-3023.

Buckley, M. L., R. J. Lowe, J. E. Hansen, and A. R. van Dongeren. 2016. “Wave Setup over a Fringing Reef with Large Bottom Roughness." Journal of Physical Oceanography 46 (8): 2317-2333.

Buckley, M. L., R. J. Lowe, J. E. Hansen, A. R. van Dongeren, and C. D. Storlazzi. 2018. "Mechanisms of Wave-Driven Water Level Variability on Reef-Fringed Coastlines." Journal of Geophysical Research: Oceans 123 (5): 3811-3831.

Buddemeier, R. W., and S. V. Smith. 1988. "Coral Reef Growth in an Era of Rapidly Rising Sea Level: Predictions and Suggestions for Long-Term Research." Coral Reefs 7 (1): 51-56.

Burcharth, H. F., S. J. Hawkins, B. Zanuttigh, and A. Lamberti. 2007. Environmental Design Guidelines for Low Crested Coastal Structures. Volume 419. Oxford: Elsevier Science.

Burke, L., K. Reytar, M. Spalding, and A. Perry. 2011. Reefs at Risk Revisited. Washington, DC: World Resources Institute.

Camus, P., F. J. Méndez, and R. Medina. 2011. "A Hybrid Efficient Method to Downscale Wave Climate to Coastal Areas." Coastal Engineering 58 (9): 851-862.

Camus, P., F. J. Méndez, R. Medina, A. Tomas, and C. Izaguirre. 2013. “High Resolution Downscaled Ocean Waves (DOW) Reanalysis in Coastal Areas." Coastal Engineering 72 $56-68$

Cesar, H. S., and P. van Beukering. 2004. "Economic Valuation of the Coral Reefs of Hawai'i." Pacific Science 58 (2): 231-242. 
Challenor, P., D. Woolf, C. Gommenginger, M. Srokosz, D. Cotton, D. Carter, and N. Sykes. 2006. "Satellite Altimetry: A Revolution in Understanding the Wave Climate." Paper presented at Proceedings of the Symposium on 15 Years of Progress in Radar Altimetry, Venice, IL, March 13-18, 2006.

Chapman, M. G., and A. J. Underwood. 2011. "Evaluation of Ecological Engineering of 'Armoured' Shorelines to Improve Their Value as Habitat." Journal of Experimental Marine Biology and Ecology 400 (1-2): 302-313.

Chowdhury, M. S. N., B. Walles, S. M. Sharifuzzaman, M. S. Hossain, T. Ysebaert, and A. C. Smaal. 2019. "Oyster Breakwater Reefs Promote Adjacent Mudflat Stability and Salt Marsh Growth in a Monsoon Dominated Subtropical Coast." Scientific Reports 9 (1): 8549.

Christianen, M. J. A., J. van Belzen, P. M. J. Herman, M. M. van Katwijk, L. P. M. Lamers, P. J. M. van Leent, and T. J. Bouma. 2013. "Low-Canopy Seagrass Beds Still Provide Important Coastal Protection Services." PLOS ONE 8 (5): e62413. doi:10.1371/journal. pone.0062413.

CIRIA, CUR, and CETMEF. 2007. The Rock Manual. The Use of Rock in Hydraulic Engineering. 2nd Edition. Report C683. London: CIRIA.

coastalresilience.org. 2021. At the Waters Edge. Coastal Resilience. https://coastalresilience. org/project/grenada-at-the-waters-edge/.

coastalwiki.org. 2020. Detached breakwaters. Coastal Wiki. http://www.coastalwiki.org/wiki/ Detached_breakwaters.

coris.noaa.gov. 2021. What Are Coral Reefs? Coral Reef Information System, National Oceanic and Atmospheric Administration. https://www.coris.noaa.gov/about/what_are/.

Cuttler, M. V. W., J. E. Hansen, R. J. Lowe, and E. J. F. Drost. 2018. “Response of a Fringing Reef Coastline to the Direct Impact of a Tropical Cyclone." Limnology and Oceanography Letters 3 (2): 31-38.

Cuttler, M. V., J. E. Hansen, R. J. Lowe, J. A. Trotter, and M. T. McCulloch. 2019. “Source and Supply of Sediment to a Shoreline Salient in a Fringing Reef Environment." Earth Surface Processes and Landforms 44 (2): 552-564.

Cuttler, M. V. W., K. Vos, P. Branson, J. E. Hansen, M. O'Leary, N. K. Browne, R. J. Lowe. 2020. “Interannual Response of Reef Islands to Climate-Driven Variations in Water Level and Wave Climate." Remote Sensing 12: 4089.

Dandan, S. S., J. L. Falter, R. J. Lowe, and M. T. McCulloch. 2015. “Resilience of Coral Calcification to Extreme Temperature Variations in the Kimberley Region, Northwest Australia." Coral Reefs 34 (4): 1151-1163.

d'Angremond, K., J. W. van der Meer, and R. J. De Jong. 1997. "Wave Transmission at LowCrested Structures." Coastal Engineering Proceedings 19961 (25): 2418-2427. 
DeAngelis, B. M., and L. Geselbracht. 2019. "Why Monitor Shellfish Reefs." In Restoration Guidelines for Shellfish Reefs. Edited by J. Fitzsimons, S. Branigan, R. D. Brumbaugh, T. McDonald, and P. S. E. zu Ermgassen. Arlington, VA: Nature Conservancy.

de Alegria-Arzaburu, A. R., I. Mariño-Tapia, C. Enriquez, R. Silva, and M. González-Leija. 2013. "The Role of Fringing Coral Reefs on Beach Morphodynamics." Geomorphology 198: 69-83.

De'ath, G., K. E. Fabricius, H. Sweatman, and M. Puotinen. 2012. "The 27-Year Decline of Coral Cover on the Great Barrier Reef and Its Causes." Proceedings of the National Academy of Sciences 109 (44): 17995-17999.

De'ath, G., and K. Fabricius. 2010. "Water Quality as a Regional Driver of Coral Biodiversity and Macroalgae on the Great Barrier Reef." Ecological Applications 20 (3): 840-850.

dela Cruz, D. W., and P. L. Harrison. 2017. "Enhanced Larval Supply and Recruitment Can Replenish Reef Corals on Degraded Reefs." Scientific Reports 7: 13985.

Drost, E. J., M. V. Cuttler, R. J. Lowe, and J. E. Hansen. 2019. “Predicting the Hydrodynamic Response of a Coastal Reef-Lagoon System to a Tropical Cyclone Using PhaseAveraged and Surfbeat-Resolving Wave Models." Coastal Engineering 152: 103525.

Duarte, C. M., I. J. Losada, I. E., Hendriks, I. Mazarrasa, and N. Marbà. 2013. “The Role of Coastal Plant Communities for Climate Change Mitigation and Adaptation." Nature Climate Change 3: 961-968.

Edwards, A. J., and E. D. Gomez. 2007. Reef Restoration Concepts and Guidelines: Making Sensible Management Choices in the Face of Uncertainty. St. Lucia, AU: Coral Reef Targeted Research and Capacity Building for Management Program.

Edwards, A. J., ed. 2010. Reef Rehabilitation Manual. St. Lucia, AU: Coral Reef Targeted Research and Capacity Building for Management Program.

Ferrario, F., M. W. Beck, C. D. Storlazzi, F. Micheli, C. C. Shepard, and L. Airoldi. 2014. “The Effectiveness of Coral Reefs for Coastal Hazard Risk Reduction and Adaptation." Nature Communications 5: 3794. https://doi.org/10.1038/ncomms4794.

Filipot, J. F., and K. F. Cheung. 2012. "Spectral Wave Modeling in Fringing Reef Environments." Coastal Engineering 67: 67-79.

Fitzsimons, J., S. Branigan, R. D. Brumbaugh, T. McDonald, and P. S. E. zu Ermgassen. 2019. Restoration Guidelines for Shellfish Reefs. Arlington, VA: Nature Conservancy.

Forsman, Z. H., C. A. Page, R. J. Toonen, and D. Vaughan. 2015. “Growing Coral Larger and Faster: Micro-Colony-Fusion as a Strategy for Accelerating Coral Cover." PeerJ 3: e1313. https://doi.org/10.7717/peerj.1313.

Gawehn, M., A. van Dongeren, A. van Rooijen, C. D. Storlazzi, O. M. Cheriton, and A. Reniers. 2016. "Identification and Classification of Very Low Frequency Waves on a Coral Reef Flat." Journal of Geophysical Research: Oceans 121 (10): 7560-7574. 
Gillies, C. L., I. M. McLeod, H. K. Alleway, P. Cook, C. Crawford, C. Creighton, B. Diggles, et al. 2018. "Australian Shellfish Ecosystems: Past Distribution, Current Status and Future Direction." PLOS ONE 13(2): e0190914.

Goelz, T., B. Vogt, and T. Hartley. 2020. “Alternative Substrates Used for Oyster Reef Restoration: A Review." Journal of Shellfish Research 39 (1): 1-12.

Goergen, E. A., S. Schopmeyer, A. L. Moulding, A. Moura, P. Kramer, and T. S. Viehman. 2020. Coral Reef Restoration Monitoring Guide: Methods to Evaluate Restoration Success from Local to Ecosystem Scales. NOAA Technical Memorandum NOS NCCOS 279. Silver Spring, MD. 145 pp. doi:10.25923/xndz-h538.

Gourlay, M. R. 1994. "Wave Transformation on a Coral Reef." Coastal Engineering 23: 17-42.

Gourlay, M. R. 1996a. "Wave Set-Up on Coral Reefs. 1. Set-Up and Wave Generated Flow on an Idealised Two Dimensional Horizontal Reef." Coastal Engineering 27: 161-193.

Gourlay, M. R. 1996b. "Wave Set-Up on Coral Reefs. 2. Set-Up on Reefs with Various Profiles." Coastal Engineering 28: 17-55.

Grabowski, J. H., and C. H. Peterson. 2007. "Restoring Oyster Reefs to Recover Ecosystem Services." In Ecosystem Engineers: Plants to Protists. Edited by K. Cuddington, J. Byers, W. Wilson, and A. Hastings. Volume 4. Burlington, MA: Academic Press.

Grabowski, J. H., R. D. Brumbaugh, R. F. Conrad, A. G. Keeler, J. J. Opaluch, C. H. Peterson, M. F. Piehler, S. P. Powers, and A. R. Smyth. 2012. “Economic Valuation of Ecosystem Services Provided by Oyster Reefs." BioScience 62 (10): 900-909.

Guannel, G., K. Arkema, P. Ruggiero, and G. Verutes. 2016. "The Power of Three: Coral Reefs, Seagrasses and Mangroves Protect Coastal Regions and Increase Their Resilience." PLOS ONE 11 (7): e0158094.

Gutiérrez, J. L., C. G. Jones, D. L. Strayer, and O. O. Iribarne. 2003. "Mollusks as Ecosystem Engineers: The Role of Shell Production in Aquatic Habitats." Oikos 101: 79-90.

Gutiérrez, J. L., C. G. Jones, J. E. Byers, K. K. Arkema, K. Berkenbusch, J. A. Committo, C. M. Duarte, et al. 2011. "Physical Ecosystem Engineers and the Functioning of Estuaries and Coasts." In Treatise on Estuarine and Coastal Science. Edited by E. Wolanski and D. McLusky. 53-81. Amsterdam: Elsevier.

Hancock, B., K. Lewis, and E. Conklin. 2017. "The Restoration of Coral Reefs." Routledge Handbook of Environmental and Ecological Restoration. Edited by S. K. Allison and S. D. Murphy. London: Routledge.

Hardy, T. A., and I. R. Young. 1996. "Field Study of Wave Attenuation on an Offshore Coral Reef." Journal Geophysical Research: Oceans 101 (C6): 14311-14326.

Harris, D. L., A. Rovere, E. Casella, H. Power, R. Canavesio, A. Collin, A. Pomeroy, J. M. Webster, and V. Parravicini. 2018. "Coral Reef Structural Complexity Provides Important Coastal Protection from Waves Under Rising Sea Levels." Science Advances 4 (2): eaao4350. 
Herder, T., K. Barfoot, C. Boyd, J. DeQuattro, F. Foley, K. Duhring, R. Gittman, et al. 2014. Living Shorelines: A Guide for Alabama Property Owners. Edited by J. DeQuattro, C. Ferraro, D. Foster, S. Gibson, E. Morgan, R. Swann, R. Vanderhart, B. Subramanian, and B. Webb. Alabama Department of Natural Resources and Mobile Bay National Estuary Program.

Hernandez, A. B., R. D. Brumbaugh, P. Fredrick, R. Grizzle, M. W. Luckenbach, C. H. Peterson, and C. Angelini. 2018. "Restoring the Eastern Oyster: How Much Progress Has Been Made in 53 Years?" Frontiers in Ecology and the Environment 16 (8): 463-471.

Hersbach, H., B. Bell, P. Berrisford, S. Hirahara, A. Horányi, J. Muñoz-Sabater, J. Nicolas, et al. 2020. "The ERA5 Global Reanalysis." Quarterly Journal of the Royal Meteorological Society 146 (730): 1999-2049.

Higuera, P., J. L. Lara, and I. J. Losada. 2013. “Simulating Coastal Engineering Processes with OpenFOAM®." Coastal Engineering 71: 119-134.

Hill, J., and C. Wilkinson. 2004. Methods for Ecological Monitoring of Coral Reefs: A Resource for Managers. Version 1. Townsville, AU: Australian Institute of Marine Science.

Hoegh-Guldberg, O., P. J. Mumby, A. J. Hooten, R. S. Steneck, P. Greenfield, E. Gomez, C. D. Harvell, et al. 2007. "Coral Reefs under Rapid Climate Change and Ocean Acidification." Science 318 (5857): 1737-1742.

Hoeke, R. K., H. Damlamian, J. Aucan, and M. Wandres. 2021. "Severe Flooding in the Atoll Nations of Tuvalu and Kiribati Triggered by a Distant Tropical Cyclone Pam." Frontiers in Marine Science 7: 991.

Holman, R., and M. C. Haller. 2013. "Remote Sensing of the Nearshore." Annual Review of Marine Science 5: 95-113.

Hsu, J. R-C., M-J. Yu, F-C. Lee, and L. Benedet. 2010. "Static Bay Beach Concept for Scientists and Engineers: A Review." Coastal Engineering 57 (2): 76-91.

Huang, C. J., H. H. Chang, and H. H. Hwung. 2003. "Structural Permeability Effects on the Interaction of a Solitary Wave and a Submerged Breakwater." Coastal Engineering 49 (1-2): 1-24.

Huang, Z. C., L. Lenian, W. K. Melville, J. H. Middleton, B. Reineman, N. Statom, and R. M. McCabe. 2012. "Dissipation of Wave Energy and Turbulence in a Shallow Coral Reef Lagoon." Journal of Geophysical Research: Oceans 117 (C3): C03015.

Hughes, T. P., J. T. Kerry, M. Álvarez-Noriega, J. G. Álvarez-Romero, K. D. Anderson, A. H. Baird, R. C. Babcock, et al. 2017. "Global Warming and Recurrent Mass Bleaching of Corals." Nature 543 (7645): 373.

Hughes, T. P., K. D. Anderson, S. R. Connolly, S. F. Heron, J. T. Kerry, J. M. Lough, A. H. Baird, et al. 2018. "Spatial and Temporal Patterns of Mass Bleaching of Corals in the Anthropocene." Science 359 (6371): 80-83. 
Johnson, M. E., C. Lustic, E. Bartels, I. B. Baums, D. S. Gilliam, E. A. Larson, D. Lirman, M. W. Miller, K. Nedimyer, and S. Schopmeyer. 2011. Caribbean Acropora Restoration Guide: Best Practices for Propagation and Population Enhancement. Arlington, VA: Nature Conservancy. https://nsuworks.nova.edu/occ_facreports/71.

Kennedy, A. B., J. J. Westerink, J. M. Smith, M. E. Hope, M. Hartman, A. A. Taflanidis, S. Tanaka, et al. 2012. "Tropical Cyclone Inundation Potential on the Hawaiian Islands of Oahu and Kauai." Ocean Modeling 52-53: 54-68.

Kitsikoudis, V., K. M. Kibler, and L. J. Walters. 2020. “In-Situ Measurements of Turbulent Flow over Intertidal Natural and Degraded Oyster Reefs in an Estuarine Lagoon." Ecological Engineering 143: 105688.

Komyakova, V., D. Chamberlain, G. P. Jones, and S. E. Swearer. 2019. "Assessing the Performance of Artificial Reefs as Substitute Habitat for Temperate Reef Fishes: Implications for Reef Design and Placement." Science of The Total Environment 668: 139-152.

Kramer, M., B. Zanuttigh, J. W. van der Meer, C. Vidal, and F. X. Gironella. 2005. “Laboratory Experiments on Low-Crested Breakwaters." Coastal Engineering 52 (10-11): 867-885.

Kramer, P. A., 2016. "Chapter 3: Coastal Defense Services Provided by Coral Reefs." In Managing Coasts with Natural Solutions: Guidelines for Measuring and Valuing the Coastal Protection Services of Mangroves and Coral Reefs. Edited by M. W. Beck and G-M. Lange. Washington, DC: World Bank.

Krogstad, H. E., and S. F. Barstow. 1999. “Satellite Wave Measurements for Coastal Engineering Applications." Coastal Engineering 37 (3-4): 283-307.

La Peyre, M. K., L. Schwarting, and S. Miller. 2013. Preliminary Assessment of Bioengineered Fringing Shoreline Reefs in Grand Isle and Breton Sound, Louisiana. Open-File Report 2013-1040. Reston, VA: U.S. Geological Survey.

Lashley, C. H., D. Roelvink, A. van Dongeren, M. L. Buckley, and R. J. Lowe. 2018.

"Nonhydrostatic and Surfbeat Model Predictions of Extreme Wave Run-Up in Fringing Reef Environments." Coastal Engineering 137: 11-27.

Leeworthy, V. R., T. Maher, and E. A. Stone. 2006. "Can Artificial Reefs Alter User Pressure on Adjacent Natural Reefs?" Bulletin of Marine Science 78 (1): 29-37.

Lenihan, H. S., F. Micheli, S. W. Shelton, and C.H. Peterson. 1999. “The Influence of Multiple Environmental Stressors on Susceptibility to Parasites: An Experimental Determination with Oysters." Limnology and Oceanography 44 (3): 910-924.

Lesser, G. R., J. V. Roelvink, J. A. T. M. van Kester, and G. S. Stelling. 2004. “Development and Validation of a Three-Dimensional Morphological Model." Coastal Engineering 51 (8-9): 883-915.

Lokesha, V. Sundar, and S. A. Sannasiraj. 2013. "Artificial Reefs: A Review." Journal of Ocean and Climate: Science, Technology and Impacts 4 (2): 117-124. 
Longuet-Higgins, M. S., and R. W. Stewart. 1962. "Radiation Stress and Mass Transport in Gravity Waves, with Application to 'Surf Beats."' Journal of Fluid Mechanics 13 (4): 481-504. https://doi.org/10.1017/S0022112062000877.

Losada, I. J., B. G. Reguero, F. J. Méndez, S. Castanedo, A. J. Abascal, and R. Mínguez. 2013. "Long-Term Changes in Sea-Level Components in Latin America and the Caribbean." Global and Planetary Change 104: 34-50.

Lowe, R. J., C. Hart, and C. B. Pattiaratchi. 2010. "Morphological Constraints to Wave-Driven Circulation in Coastal Reef-Lagoon Systems: A Numerical Study." Journal of Geophysical Research: Oceans 115 (C9): C09021.

Lowe, R. J., and J. L. Falter. 2015. "Oceanic Forcing of Coral Reefs." Annual Review of Marine Science 7: 43-66.

Lowe, R. J., J. L. Falter, J. R. Koseff, S. G. Monismith, and M. J. Atkinson. 2007. “Spectral Wave Flow Attenuation within Submerged Canopies: Implications for Wave Energy Dissipation." Journal of Geophysical Research: Oceans 112 (C5): C05018. doi:10.1029/2006JC003605.

Lowe, R. J., J. L. Falter, M. D. Bandet, G. Pawlak, M. J. Atkinson, S. G. Monismith, and J. Koseff. 2005. "Spectral Wave Dissipation over a Barrier Reef." Journal of Geophysical Research 110 (C4): C04001.

Lowe, R. J., J. L. Falter, S. G. Monismith, and M. J. Atkinson. 2009. "A Numerical Study of Circulation in a Coastal Reef-Lagoon System." Journal of Geophysical Research: Oceans 114 (C6): C06022.

Lowe, R. J., M. L. Buckley, C. Altomare, D. P. Rijnsdorp, Y. Yao, T. Suzuki, and J. Bricker. 2019. “Numerical Simulations of Surf Zone Wave Dynamics Using Smoothed Particle Hydrodynamics." Ocean Modelling 144: 101481.

Lowe, R. J., M. V. W. Cuttler, and J. E. Hansen. 2021. “Climatic Drivers of Extreme Sea Level Events along the Coastline of Western Australia." Earth's Future 9: e2020EF001620. https://doi.org/10.1029/2020EF001620.

Lugo-Fernandez, A., H. H. Roberts, and W. J. Wiseman Jr. 1998. "Tide Effects on Wave Attenuation and Wave Set-Up on a Caribbean Coral Reef." Estuarine, Coastal and Shelf Science 47 (4): 385-393.

Lukens, R. R., and C. Selberg. 2004. Guidelines for Marine Artificial Reef Materials. Second Edition. Arlington, VA: Gulf and Atlantic States Marine Fisheries Commissions.

Martin, D., F. Bertasi, M. A. Colangelo, M. de Vries, M. Frost, S. J. Hawkins, E. Macpherson, et al. 2005. “Ecological Impact of Coastal Defense Structures on Sediment and Mobile Fauna: Evaluation and Forecasting Consequences of Unavoidable Modifications of Native Habitats." Coastal Engineering 52 (10-11): 1027-1051.

McCall, R. T., J. V. T. de Vries, N. G. Plant, A. R. van Dongeren, J. A. Roelvink, D. M. Thompson, and A. J. H. M. Reniers. 2010. "Two-Dimensional Time Dependent Hurricane Overwash and Erosion Modeling at Santa Rosa Island." Coastal Engineering 57 (7): 668-683. 
McLeod, E., K. R. N. Anthony, P. J. Mumby, J. Maynard, R. Beeden, N. A. J. Graham; S. F. Heron, et al. 2019. "The Future of Resilience-Based Management in Coral Reef Ecosystems." Journal of Environmental Management 223: 291-301.

Mentaschi, L., M. I. Vousdoukas, E. Voukouvalas, A. Dosio, and L. Feyen. 2017. “Global Changes of Extreme Coastal Wave Energy Fluxes Triggered by Intensified Teleconnection Patterns." Geophysical Research Letters 44 (5): 2416-2426.

Mizutani, N., A. M. Mostafa, and K. Iwata. 1998. "Nonlinear Regular Wave, Submerged Breakwater and Seabed Dynamic Interaction." Coastal Engineering 33 (2-3): 177-202.

Molberg, F., and C. Folke. 1999. "Ecological Goods and Services of Coral Reef Ecosystems." Ecological Economics 29 (2): 215-233.

Monismith, S. G. 2007. "Hydrodynamics of Coral Reefs." Annual Review of Fluid Mechanics 39: 37-55.

Mora, C., and P. F. Sale. 2011. “Ongoing Global Biodiversity Loss and the Need to Move beyond Protected Areas: A Review of the Technical and Practical Shortcomings of Protected Areas on Land and Sea." Marine Ecology Progress Series 434: 251-266.

Morim, J., C. Trenham, M. Hemer, X. L. Wang, N. Mori, M. Casas-Prat, A. Semedo, et al. 2020. "A Global Ensemble of Ocean Wave Climate Projections from CMIP5-Driven Models." Scientific Data 7 (1): 1-10.

Morris, R. L., D. M. Bilkovic, M. K. Boswell, D. Bushek, J. Cebrian, J. Goff, K. M. Kibler, et al. 2019. "The Application of Oyster Reefs in Shoreline Protection: Are We Over-Engineering for an Ecosystem Engineer?" Journal of Applied Ecology 56 (7): 1703-1711. https://doi. org/10.1111/1365-2664.13390.

Mumby, P. J. and A. R. Harborne. 2010. "Marine Reserves Enhance the Recovery of Corals on Caribbean Reefs." PLOS ONE 5 (1): e8657.

Narayan, S., M. W. Beck, B. G. Reguero, I. J. Losada, B. Van Wesenbeeck, N. Pontee, J. N. Sanchirico, J. C. Ingram, G. M. Lange, and K. A. Burks-Copes. 2016. "The Effectiveness, Costs and Coastal Protection Benefits of Natural and Nature-Based Defences." PLOS ONE 11 (5): e0154735.

NAS (National Academies of Sciences, Engineering, and Medicine). 2017. "Oyster Reef Restoration Monitoring." In Effective Monitoring to Evaluate Ecological Restoration in the Gulf of Mexico. Washington, DC: National Academies Press. https://doi. org/10.17226/23476.

NAS. 2019. A Research Review of Interventions to Increase the Persistence and Resilience of Coral Reefs. Washington, DC: National Academies Press. https://doi. org/10.17226/25279.

nature.org. 2019. Insuring Nature to Ensure a Resilient Future. The Nature Conservancy. https://www.nature.org/en-us/what-we-do/our-insights/perspectives/insuringnature-to-ensure-a-resilient-future/. 
NOAA (National Oceanic and Atmospheric Administration). 2016. Monitoring Plan for DWH NRDA Early Restoration Project: Swift Tract Living Shorelines. Galveston, TX: NOAA Restoration Center.

NOAA. 2017. 2016 Oyster Reef Monitoring Report Analysis of Data from Large-Scale Sanctuary Oyster Restoration Projects in Maryland. Silver Spring, MD: NOAA.

NOAA. 2018. 2017 Oyster Reef Monitoring Report Analysis of Data from Large-Scale Sanctuary Oyster Restoration Projects in Maryland. Silver Spring, MD: NOAA.

NRC (National Research Council). 2004. Nonnative Oysters in the Chesapeake Bay. Washington, DC: National Academies Press.

Nwogu, O., and Z. Demirbilek. 2010. "Infragravity Wave Motions and Runup over Shallow Fringing Reefs." Journal of Waterway, Port, Coastal, and Ocean Engineering 136 (6): 295-305.

Palumbi, S. R., D. J. Barshis, N. Traylor-Knowles, and R. A. Bay. 2014. “Mechanisms of Reef Coral Resistance to Future Climate Change." Science 344 (6186): 895-898.

Pascal, N., M. Allenbach, A. Brathwaite, L. Burke, G. Le Port, and E. Clua. 2016. “Economic Valuation of Coral Reef Ecosystem Service of Coastal Protection: A Pragmatic Approach." Ecosystem Services 21: 72-80.

Pearse, V. B., and L. Muscatine. 1971. "Role of Symbiotic Algae (Zooxanthellae) in Coral Calcification." The Biological Bulletin 141 (2): 350-363.

Pearson, S. G., C. D. Storlazzi, A. R. van Dongeren, M. F. S. Tissier, and A. J. H. M. Reniers. 2017. "A Bayesian-Based System to Assess Wave-Driven Flooding Hazards on Coral ReefLined Coasts." Journal of Geophysical Research: Oceans 122 (12): 10099-10117.

Péquignet, A. C. N., J. M. Becker, M. A. Merrifield, and J. Aucan. 2009. “Forcing of Resonant Modes on a Fringing Reef during Tropical Storm Man-Yi." Geophysical Research Letters 36 (3): L03607.

Perry, C. T., G. N. Murphy, P. S. Kench, E. N. Edinger, S. G. Smithers, R. S. Steneck, and P. J. Mumby. 2014. "Changing Dynamics of Caribbean Reef Carbonate Budgets: Emergence of Reef Bioeroders as Critical Controls on Present and Future Reef Growth Potential." Proceeding of the Royal Society B 281 (1796): 2014-2018.

Perry, C. T., G. N. Murphy, P. S. Kench, S. G. Smithers, E. N. Edinger, R. S. Steneck, and P. J. Mumby. 2013. "Caribbean-Wide Decline in Carbonate Production Threatens Coral Reef Growth." Nature Communications 4: 1402.

Perry, C. T., L. Alvarez-Filip, N. A. Graham, P. J. Mumby, S. K. Wilson, P. S. Kench, D. P. Manzello, et al. 2018. "Loss of Coral Reef Growth Capacity to Track Future Increases in Sea Level." Nature 558 (7710): 396.

Perry, C. T., T. Spencer, and P. S. Kench. 2008. “Carbonate Budgets and Reef Production States: A Geomorphic Perspective on the Ecological Phase-Shift Concept." Coral Reefs 27 (4): 853-866. 
Pomeroy, A., R. Lowe, G. Symonds, A. van Dongeren, and C. Moore. 2012. “The Dynamics of Infragravity Wave Transformation over a Fringing Reef." Journal of Geophysical Research: Oceans 117 (C11): C11022.

Pomeroy, A. W., R. J. Lowe, A. R. van Dongeren, M. Ghisalberti, W. Bodde, and D. Roelvink. 2015. "Spectral Wave-Driven Sediment Transport across a Fringing Reef." Coastal Engineering 98: 78-94.

Pomeroy, A. W., R. J. Lowe, M. Ghisalberti, C. Storlazzi, G. Symonds, and D. Roelvink. 2017. "Sediment Transport in the Presence of Large Reef Bottom Roughness." Journal of Geophysical Research: Oceans 122 (2): 1347-1368.

Precht, W. F., ed. 2006. Coral Reef Restoration Handbook. Boca Raton, FL: CRC Press.

public.tableau.com, n.d. Workbook: Coral Restoration Database - Visualisation. Tableau. https://public.tableau.com/views/CoralRestorationDatabaseVisualisation/Coralrestorationmethods?:embed=y\&:display_ count=yes\&publish=yes\&:showVizHome=no\#1.

Puotinen, M., E. Drost, R. Lowe, M. Depczynski, B. Radford, A. Heyward, and J. Gilmour. 2020. "Towards Modelling the Future Risk of Cyclone Wave Damage to the World's Coral Reefs." Global Change Biology 26 (8): 4302-4315.

Quataert, E., C. Storlazzi, A. van Rooijen, O. Cheriton, A. van Dongeren. 2015. “The Influence of Coral Reefs and Climate Change on Wave-Driven Flooding of Tropical Coastlines." Geophysical Research Letters 42 (15): 6407-6415.

Ranasinghe, R., I. L. Turner, and G. Symonds. 2006. "Shoreline Response to Multi-Functional Artificial Surfing Reefs: A Numerical and Physical Modelling Study." Coastal Engineering 53 (7): 589-611.

Ranasinghe, R., and I. L. Turner. 2006. "Shoreline Response to Submerged Structures: A Review." Coastal Engineering 53 (1): 65-79.

Ranasinghe, R., M. Larson, and J. Savioli. 2010. "Shoreline Response to a Single Shore-Parallel Submerged Breakwater." Coastal Engineering 57 (11-12): 1006-1017.

reefresilience.org. 2020a. Restoration. Reef Resilience Network. https://reefresilience.org/ restoration/.

reefresilience.org. 2020b. Project Planning. Reef Resilience Network. https://reefresilience. org/restoration/project-planning/.

Reguero, B. G., M. Menéndez, F. J. Méndez, R. Mínguez, and I. J. Losada. 2012. "A Global Ocean Wave (GOW) Calibrated Reanalysis from 1948 Onwards." Coastal Engineering 65: 3855.

Reguero, B. G., M. W. Beck, D. Schmid, D. Stadtmüller, J. Raepple, S. Schüssele, and K. Pfliegner. 2020. "Financing Coastal Resilience by Combining Nature-Based Risk Reduction with Insurance." Ecological Economics 169: 106487. 
Reguero, B. G., F. Secaira, A. Toimil, M. Escudero, P. Díaz-Simal, M. W. Beck, C. D. Storlazzi, R. Silva, and I. J. Losada. 2019. "The Risk Reduction Benefits of the Mesoamerican Reef in Mexico." Frontiers in Earth Science 7: 125.

Reguero, B. G., M. W. Beck, V. N. Agostini, P. Kramer, and B. Hancock. 2018a. “Coral Reefs for Coastal Protection: A New Methodological Approach and Engineering Case Study in Grenada." Journal of Environmental Management 210: 146-161. https://doi. org/10.1016/j.jenvman.2018.01.024.

Reguero, B. G., M. W. Beck, D. N. Bresch, J. Calil, and I. Meliane. 2018b. “Comparing the Cost Effectiveness of Nature-Based and Coastal Adaptation: A Case Study from the Gulf Coast of the United States." PLOS ONE 13 (4): e0192132. https://doi.org/10.1371/ journal.pone.0192132.

Reguero, B. G., C. D. Storlazzi, A. E. Gibbs, J. B. Shope, A. D. Cole, K. A. Cumming, M.W. Beck. 2021. "The Value of US Coral Reefs for Flood Risk Reduction" Nature Sustainability 4, 457. https://doi.org/10.1038/s41893-021-00706-6.

Rendle, E. J., and L. D. Rodwell. 2014. "Artificial Surf Reefs: A Preliminary Assessment of the Potential to Enhance a Coastal Economy." Marine Policy 45: 349-358.

Rendle, E. J. "The Environmental, Social and Economic Impacts of an Artificial Surf Reefthe UK Experience." PhD thesis, University of Plymouth, 2016. http://hdl.handle. net/10026.1/5152.

Ridge, J. T., A. B. Rodriguez, F. J. Fodrie, N. L. Lindquist, M. C. Brodeur, S. E. Coleman, J. H. Grabowski, and E. J. Theuerkauf. 2015. "Maximizing Oyster-Reef Growth Supports Green Infrastructure with Accelerating Sea-Level Rise." Scientific Reports 5: 14785.

Rijnsdorp, D. P., M. L. Buckley, R. F. da Silva, M. V. W. Cuttler, J. E. Hansen, R. J. Lowe, R. H. Green, and C. D. Storlazzi. 2021. "A Numerical Study of Wave-Driven Mean Flows and Setup Dynamics at a Coral Reef-Lagoon System." Journal of Geophysical Research: Oceans 126: e2020JC016811. https://doi.org/10.1029/2020JC016811.

Roberts, H. H. 1980. "Physical Processes and Sediment Flux through Reef-Lagoon Systems." Coastal Engineering 19801 (17): 946-962.

Rodriguez, A. B., F. J. Fodrie, J. T. Ridge, N. L. Lindquist, E. J. Theuerkauf, S. E. Coleman, J. H. Grabowski, et al. 2014. "Oyster Reefs Can Outpace Sea-Level Rise." Nature Climate Change 4: 493-497.

Roeber, V., and J. D. Bricker. 2015. “Destructive Tsunami-Like Wave Generated by Surf Beat over a Coral Reef during Typhoon Haiyan." Nature Communications 6: 7854.

Roelvink, D., A. Reniers, A. P. van Dongeren, J. V. T. de Vries, R. McCall, and J. Lescinski. 2009. "Modelling Storm Impacts on Beaches, Dunes and Barrier Islands." Coastal Engineering 56 (11-12): 1133-1152.

Roelvink, D., and A. Reniers. 2011. A Guide to Modeling Coastal Morphology: Advances in Coastal and Ocean Engineering. Volume 12. Singapore: World Scientific. 
Rohweder, J. J., J. T. Rogala, B. L. Johnson, D. Anderson, S. Clark, F. Chamberlin, and K. Runyon 2008. Application of Wind Fetch and Wave Models for Habitat Rehabilitation and Enhancement Projects. Open-File Report 2008-1200. Reston, VA: U.S. Geological Survey.

Rosenberger, K. J., C. D. Storlazzi, O. M. Cheriton, A. W. M. Pomeroy, J. E. Hansen, R. J. Lowe, and M. L. Buckley, M.L. 2020. “Spectral Wave-Driven Bedload Transport Across a Coral Reef Flat/Lagoon Complex." Frontiers in Marine Science 7: 875.

Scyphers, S. B., S. P. Powers, K. L. Heck Jr, and D. Byron. 2011. "Oyster Reefs as Natural Breakwaters Mitigate Shoreline Loss and Facilitate Fisheries." PLOS ONE 6 (8): e22396.

Shamberger, K. E., A. L. Cohen, Y. Golbuu, D. C. McCorkle, S. J. Lentz, and H. C. Barkley. 2014. "Diverse Coral Communities in Naturally Acidified Waters of a Western Pacific Reef." Geophysical Research Letters 41 (2): 499-504.

Sheppard, C., D. J. Dixon, M. Gourlay, A. Sheppard, and R. Payet. 2005. “Coral Mortality Increases Wave Energy Reaching Shores Protected by Reef Flats: Examples from the Seychelles." Estuarine, Coastal and Shelf Science 64 (2): 223-34.

Shi, F., J. T. Kirby, J. C. Harris, J. D. Geiman, and S. T. Grilli. 2012. "A High-Order Adaptive Time-Stepping TVD Solver for Boussinesq Modeling of Breaking Waves and Coastal Inundation." Ocean Modelling 43: 36-51.

Spalding, M. D., C. Ravilious, and E. P. Green. 2001. World Atlas of Coral Reefs. Berkeley, CA: University of California Press.

Spalding, M., L. Burke, S. A. Wood, J. Ashpole, J. Hutchison, and P. zu Ermgassen. 2017. "Mapping the Global Value and Distribution of Coral Reef Tourism." Marine Policy 82: 104-113.

Stockdon, H. F., R. A. Holman, P. A. Howd, and A. H. Sallenger Jr. 2006. “Empirical Parameterization of Setup, Swash, and Runup." Coastal Engineering 53 (7): 573-588.

Storlazzi, C. D., S. B. Gingerich, A. van Dongeren, O. M. Cheriton, P. W. Swarzenski, E. Quataert, C. I. Voss, et al. 2018. "Most Atolls Will Be Uninhabitable by the Mid-21st Century Because of Sea-Level Rise Exacerbating Wave-Driven Flooding." Science Advances 4 (4): eaap9741.

Storlazzi, C. D., B. G. Reguero, A. D. Cole, E. Lowe, J. B. Shope, A. E. Gibbs, B. A. Nickel, R. T. McCall, A. R. van Dongeren, and M. W. Beck. 2019. Rigorously Valuing the Role of U.S. Coral Reefs in Coastal Hazard Risk Reduction. Open-File Report 2019-1027. Reston, VA: U.S. Department of the Interior and U.S. Geological Survey.

Styles, R. 2015. "Flow and Turbulence over an Oyster Reef." Journal of Coastal Research 31 (4): 978-985.

Taebi, S., R. J. Lowe, C. B. Pattiaratchi, G. N. Ivey, G. Symonds, and R. Brinkman. 2011. "Nearshore Circulation in a Tropical Fringing Reef System." Journal of Geophysical Research: Oceans 116 (C2). 
Thayer, G. W., T. A. McTigue, R. J. Salz, D. H. Merkey, F. M. Burrows, and P. F. Gayaldo. 2005. Science-Based Restoration Monitoring of Coastal Habitats, Volume Two: Tools for Monitoring Coastal Habitats. NOAA Coastal Ocean Program Decision Analysis Series No. 23. Silver Spring, MD: NOAA National Centers for Coastal Ocean Science.

Tolman, H. L. 1991. "A Third-Generation Model for Wind Waves on Slowly Varying, Unsteady, and Inhomogeneous Depths and Currents." Journal of Physical Oceanography 21 (6): 782-797.

USACE (U.S. Army Corps of Engineers). 2012. Coastal Engineering Manual. EM 1110-2-1100. Vicksburg, MS: USACE, Engineer Research and Development Center.

van der Meer, J. W., and C. J. M. Stam. 1992. "Wave Runup on Smooth and Rock Slopes of Coastal Structures." Journal of Waterway, Port, Coastal, and Ocean Engineering 118 (5): 534-550.

van der Meer, J. W., and I. F. Daemen. 1994. "Stability and Wave Transmission at LowCrested Rubble-Mound Structures." Journal of Waterway, Port, Coastal, and Ocean Engineering 120 (1): 1-19.

van Hooidonk, R., J. Maynard, J. Tamelander, J. Gove, G. Ahmadia, L. Raymundo, G. Williams, S. F. Heron, and S. Planes. 2016. "Local-Scale Projections of Coral Reef Futures and Implications of the Paris Agreement." Scientific Reports 6: 39666.

van Oppen, M. J., R. D. Gates, L. L. Blackall, N. Cantin, L. J. Chakravarti, W. Y. Chan, C. Cormick, et al. 2017. "Shifting Paradigms in Restoration of the World's Coral Reefs." Global Change Biology 23 (9): 3437-3448. doi:10.1111/gcb.13647.

van Zanten, B. T., P. J. van Beukering, and A. J. Wagtendonk. 2014. “Coastal Protection by Coral Reefs: A Framework for Spatial Assessment and Economic Valuation." Ocean \& Coastal Management 96: 94-103.

Vidal, C., M. A. Losada, and E. P. Mansard. 1995. "Stability of Low-Crested Rubble-Mound Breakwater Heads." Journal of Waterway, Port, Coastal, and Ocean Engineering 121 (2): 114-122.

Vitousek, S., P. L. Barnard, C. H. Fletcher, N. Frazer, L. Erikson, and C. D. Storlazzi. 2017. "Doubling of Coastal Flooding Frequency within Decades due to Sea-Level Rise." Scientific Reports 7 (1): 1399.

Wandres, M., J. Aucan, A. Espejo, N. Jackson, N. Y. Antoine De Ramon, and H. Damlamian. 2021. "Distant-Source Swells Cause Coastal Inundation on Fiji's Coral Coast." In Flooding on Coral Reef-Lined Coasts: Current State of Knowledge and Future Challenges. Edited by C. D. Storlazzi, W. J. Skirving, J. J. Marra, R. T. McCall, and A. W. M. Pomeroy. Lausanne: Frontiers Media SA. doi:10.3389/978-2-88966-478-8.

Wang, X. L., Y. Feng, and V. R. Swail. 2014. "Changes in Global Ocean Wave Heights as Projected Using Multimodel CMIP5 Simulations." Geophysical Research Letters 41 (3): 10261034. 
Warner, J. C., B. Armstrong, R. He, and J. B. Zambon. 2010. “Development of a Coupled OceanAtmosphere-Wave-Sediment Transport (COAWST) Modeling System." Ocean Modelling 35 (3): 230-244.

Wernberg, T., A. Campbell, M. A. Coleman, S. D. Connell, G. A. Kendrick, P. J. Moore, B. D. Russell, D. A. Smale, and P. D. Steinberg. 2012. "Macroalgae and Temperate Rocky Reefs." In Marine Climate Change in Australia: Impacts and Adaptation Responses: 2012 Report Card. Edited by E. S. Poloczanska, A. J. Hobday, and A. J. Richardson. Clayton, AU: CSIRO Publishing.

Whitman, E. R., and M. A. Reidenbach. 2012. "Benthic Flow Environments Affect Recruitment of Crassostrea virginica Larvae to an Intertidal Oyster Reef." Marine Ecology Progress Series 463: 177-191.

Wiberg, P. L., S. R. Taube, A. E. Ferguson, M. R. Kremer, and M. A. Reidenbach. 2019. "Wave Attenuation by Oyster Reefs in Shallow Coastal Bays." Estuaries and Coasts 42 (2): 331-347.

Winter, G., R. J. Lowe, G. Symonds, J. E. Hansen, and A. R. van Dongeren. 2017. “Standing Infragravity Waves over an Alongshore Irregular Rocky Bathymetry." Journal of Geophysical Research: Oceans 122 (6): 4868-4885.

Wolanski, E. 1994. Physical Oceanographic Processes of the Great Barrier Reef. Boca Raton, FL: CRC Press

Wong, P. P., I. J. Losada, J.-P. Gattuso, J. Hinkel, A. Khattabi, K. L. McInnes, Y. Saito, A. Sallenger. 2014. "Coastal Systems and Low-Lying Areas." In Climate Change 2014: Impacts, Adaptation, and Vulnerability. Part A: Global and Sectoral Aspects, Working Group II Contribution to the Fifth Assessment Report of the Intergovernmental Panel on Climate Change. Edited by C. B. Field, V. R. Barros, D. J. Dokken, K. J. Mach, M. D. Mastrandrea, T. E. Bilir, M. Chatterjee, et al. Cambridge, UK, and New York: Cambridge University Press, 361-410.

World Bank and Ministry of Environment, Energy and Climate Change of Seychelles. 2019. Seychelles Coastal Management Plan: 2019-2024. Washington, DC: World Bank; and Victoria, Seychelles: Ministry of Environment, Energy and Climate Change of Seychelles.

Yee, S. H., J. A. Dittmar, and L. M. Oliver. 2014. "Comparison of Methods for Quantifying Reef Ecosystem Services: A Case Study Mapping Services for St. Croix, USVI." Ecosystem Services 8: 1-15.

Young, C. N., S. A. Schopmeyer, and D. Lirman. 2012. "A Review of Reef Restoration and Coral Propagation Using the Threatened Genus Acropora in the Caribbean and Western Atlantic." Bulletin of Marine Science 88 (4): 1075-1098.

Ysebaert, T., B. Walles, J. Haner, and B. Hancock. 2019. “Habitat Modification and Coastal Protection by Ecosystem-Engineering Reef-Building Bivalves." In Goods and Services of Marine Bivalves. Edited by A. Smaal, J. G. Ferreira, J. Grant, J. K. Petersen, and $\theta$. Strand, 253-273. Cham, CH: Springer Publishing. https://link.springer.com/ book/10.1007/978-3-319-96776-9. 
Zepeda-Centeno, C., I. Mariño-Tapia, E. McLeod, R. Rodríguez-Martínez, L. Alvarez-Filip, A. T. Banaszak, M. Escudero-Castillo, R. Silva-Casarín, and E. Mendoza-Baldwin. 2018. Guidance Document for Reef Management and Restoration to Improve Coastal Protection: Recommendations for Global Applications Based on Lessons Learned in Mexico. MX: Nature Conservancy.

Zijlema, M., G. Stelling, and P. Smit. 2011. "SWASH: An Operational Public Domain Code for Simulating Wave Fields and Rapidly Varied Flows in Coastal Waters." Coastal Engineering 58 (10): 992-1012.

zu Ermgassen, P., B. Hancock, B. DeAngelis, J. Greene, E. Schuster, M. Spalding, and R. Brumbaugh. 2016. Setting Objectives for Oyster Habitat Restoration Using Ecosystem Services: A Manager's Guide. Arlington, VA: Nature Conservancy. 


\section{Acknowledgments}

\section{Lead Authors}

Ryan J. Lowe, The University of Western Australia, Australia

Elizabeth McLeod, The Nature Conservancy, United States

\section{Co-Authors}

Borja G. Reguero, University of California, Santa Cruz, United States

Safra Altman, U.S. Army Corps of Engineers, United States

Janine Harris, National Oceanic and Atmospheric Administration, United States

Boze Hancock, The Nature Conservancy, United States

Remment ter Hofstede, Van Oord, the Netherlands

Emma Rendle, Resilient Coasts, United Kingdom

Elizabeth Shaver, The Nature Conservancy, United States

Jane McKee Smith, U.S. Army Corps of Engineers, United States 

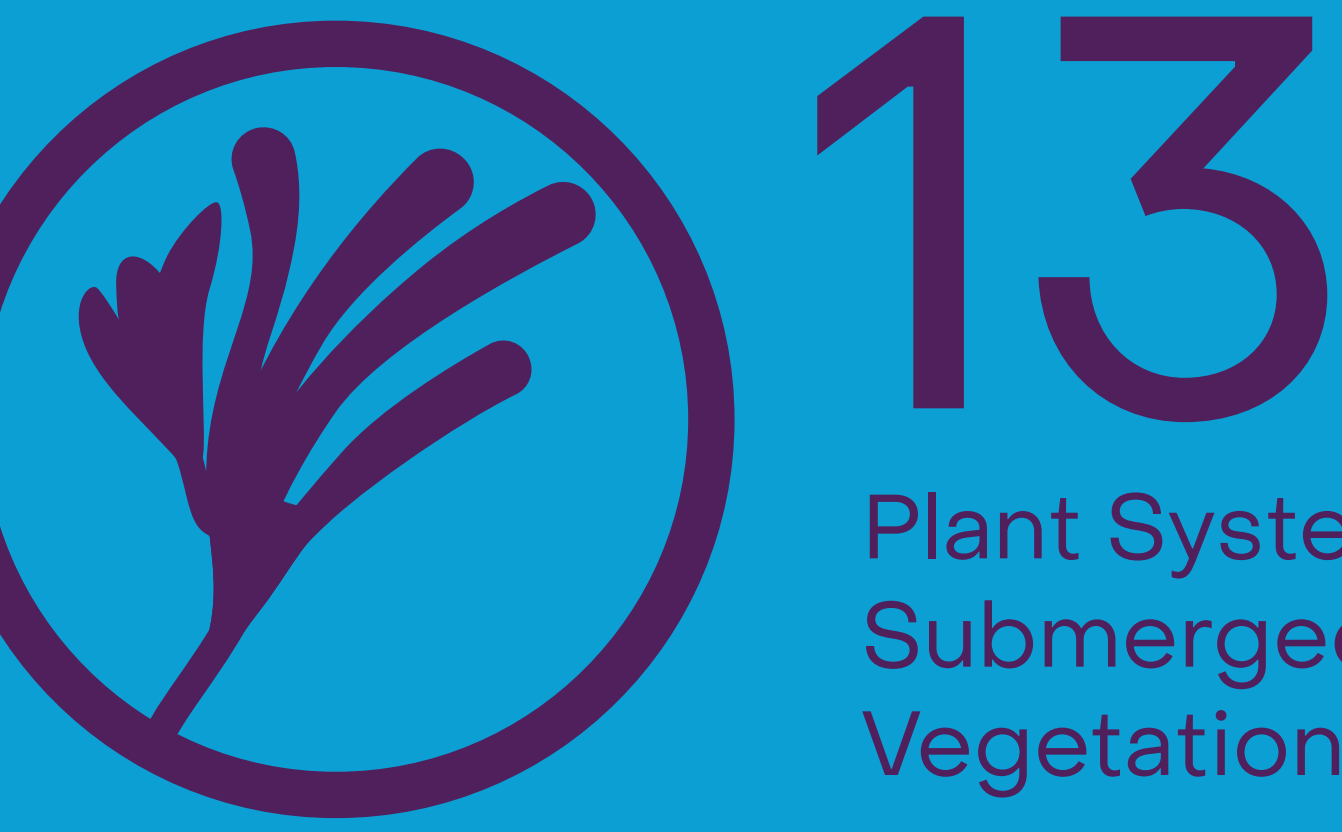

Plant Systems:

Submerged Aquatic

Vegetation and Kelp

\section{Suggested Citation:}

Altman, S., C. Cairns, P. Whitfield, J. Davis, M. Finkbeiner, and B. McFall. 2021. “Chapter 13: Plant Systems: Submerged Aquatic Vegetation and Kelp." In International Guidelines on Natural and Nature-Based Features for Flood Risk Management. Edited by T. S. Bridges, J. K. King, J. D. Simm, M. W. Beck, G. Collins, Q. Lodder, and R. K. Mohan. Vicksburg, MS: U.S. Army Engineer Research and Development Center.

Full acknowledgments appear at the end of this chapter. 


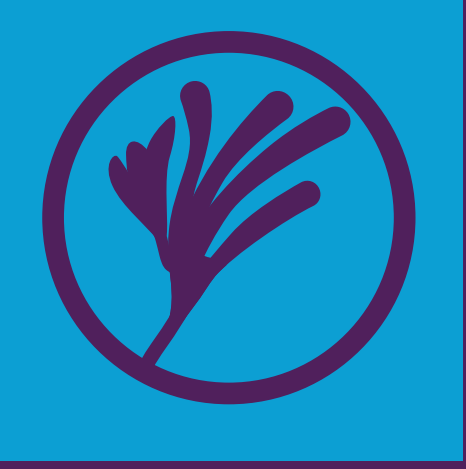

\section{Key Messages}

1. Plant systems can provide coastal protection through sediment stabilization and wave attenuation. Submerged aquatic vegetation (SAV) near shorelines can absorb waves and slow water movement, which can provide valuable shoreline protection. Kelp beds can also attenuate wave energy.

2. The magnitude of wave attenuation is dependent on the height and rigidity of the canopy relative to the total water-column height. For SAV, the protective value is maximized when canopy height and water-column height are equal.

3. SAV can also provide ecological benefits, such as nursery habitat for commercially important fish and shellish, and water quality improvements, such as excess nutrient removal.

4. Due to its size and ephemeral qualities, it is important to use SAV or kelp at appropriate scales to be effective. SAV or kelp can complement other natural and nature-based features (NNBF) techniques (such as beaches, islands, dunes, or wetlands) and should be considered for use in larger NNBF projects that incorporate multiple features. Small-scale projects in low-energy environments are well suited for SAV and would maximize its effectiveness in coastal protection.

5. Restoring or introducing a plant system NNBF in conditions that are not suitable for the habitat of interest will likely result in failure. It is critical to match the plant system to the site.

6. SAV habitats are spatially dynamic and as a result, robust monitoring is required to understand their condition and health trajectory. 


\section{1 | Introduction}

Plant systems represent an important natural and nature-based features (NNBF) component that can provide aboveground and belowground benefits. Upland plants can modify soil stability by trapping and binding particles (Feagin et al. 2015), aboveground and belowground plant structure can alter wave energy during storms, and upland plants can alter wind energy and provide land surface stability, as well as protection for built coastal infrastructure. Over the past 50 years, the protective role of coastal dune vegetation during storm events has been largely acknowledged but has not been measured extensively in the field (Bruun 1962; Edelman 1972; McHarg 1969; Silva et al. 2016). Through their natural ability to protect shorelines against erosion and flood risks and to grow up with long-term sea-level rise, vegetated systems-such as beach and dune grasses, tidal salt marshes, mangroves, and seagrass beds-play an important role in sustainable coastal flood reduction strategies and can increase the resilience of the coast (Temmerman et al. 2013; Silva et al. 2016). Empirical data suggest some vegetated habitats have the capacity to reduce wave energy substantially, with estimates of up to $40 \%$ in seagrasses, $72 \%$ in mangroves, and $82 \%$ in salt marshes (Wayne 1975; Horstman et al. 2014; Möller et al. 2014). This chapter highlights submerged aquatic vegetation (SAV) and kelp as two examples of plant systems that are useful NNBF. Although specific details of developing NNBF for other plant systems would differ, the general approaches and considerations would follow the guidance provided here for SAV and kelp. Additional information regarding wetlands, marshes, and mangroves can be found in Chapter 10, and regarding dune plant systems can be found in Chapter 9 . Figure 13.1 shows coastal plant systems that can serve as NNBF. Because plant systems themselves are subject to natural habitat succession, it is critical to understand that functional, plant-based NNBF may not persist as a particular habitat type in perpetuity. Habitat succession, switching, and change are all to be expected. 


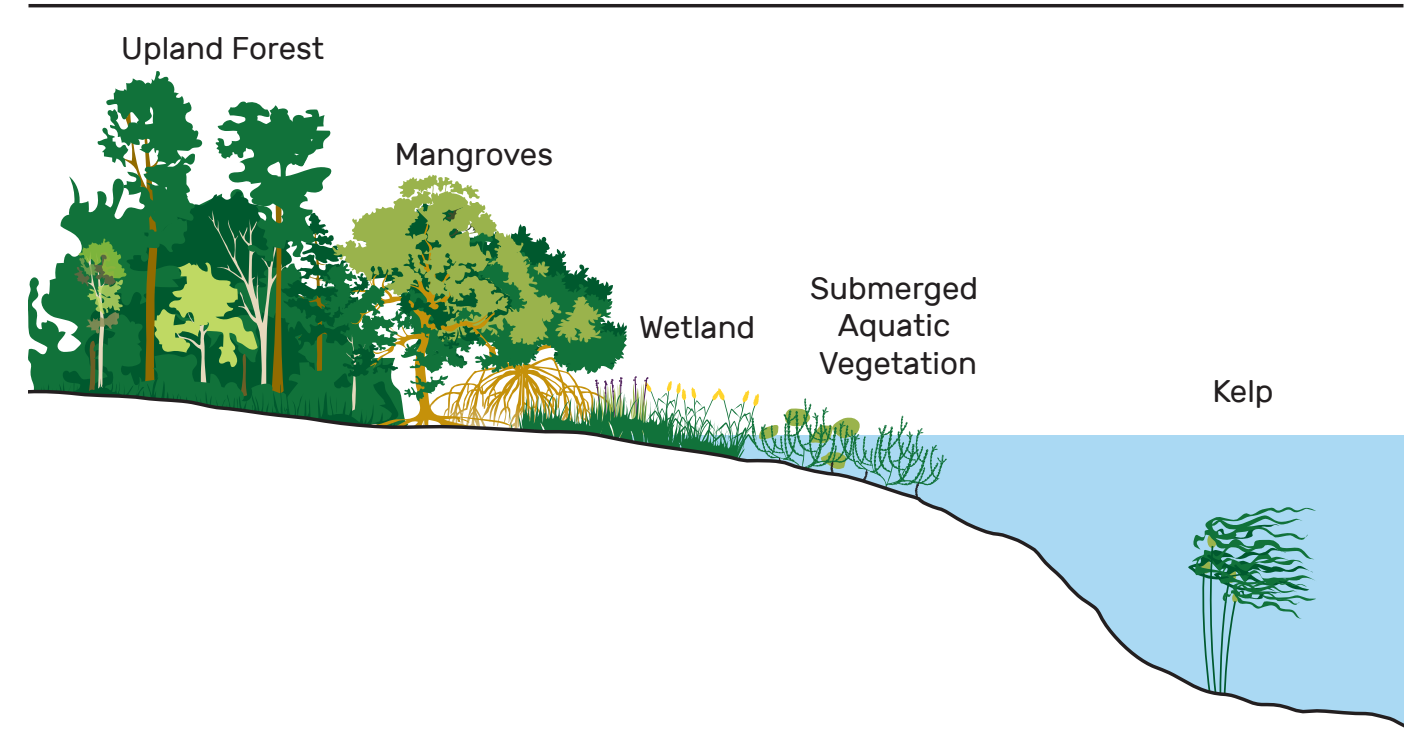

Note: Mangroves and wetland vegetation are discussed in $\underline{\text { Chapter } 10 .}$. Dune vegetation is discussed in $\underline{\text { Chapter } 9}$. This chapter discusses SAV and kelp.

Incorporating SAV or kelp in an NNBF project is a useful option for project planners due to their ability to reduce wave energy. Planting SAV or establishing kelp near shorelines can attenuate waves and reduce in-canopy currents, which can provide valuable shoreline protection.

In contrast to many of the NNBF discussed elsewhere in these guidelines, the benefits of SAV or kelp for coastal protection are optimized in relatively low-energy environments and when used in conjunction with other techniques. For practitioners who need to supplement and enhance a larger coastal protection scheme such as an island, wetland, beach, or dune, or are in a low-energy wave environment, SAV or kelp can fill an important NNBF niche, providing valuable coastal protection. This chapter discusses the role SAV and kelp can play in coastal protection and details where it can work best. 


\section{2 | Defining the Feature, Its Values, and Contexts for Application}

\subsubsection{Nature of SAV and Kelp}

The term SAV refers collectively to marine, estuarine, and freshwater flowering plants that grow completely or predominantly submerged in the water column and reproduce through flowering on or above the water surface. Unlike typical flowering land plants, SAV lack stomata and exchange nutrients and gasses with the surrounding water through diffusion across a thin cuticle layer. Seagrasses, a marine and estuarine subset of SAV, grow and reproduce underwater. Macroalgae are an additional group of photosynthetic algae that often grow fully submerged, and despite having different life cycles and growth forms than SAV, they may have similar benefits in terms of coastal protection. Although SAV and algae occur in both marine and freshwater systems, the discussion here will largely focus on estuarine to marine settings. However, the principles of their use in NNBF solutions as discussed in this chapter are also applicable in freshwater systems. In fluvial systems, SAV habitat may provide additional flood reduction benefits by reducing current or tidal flow velocity but will still provide shoreline stabilization, as well as ecological and social co-benefits that could improve overall project value. We limit the discussion of algae in this chapter to a large and broadly distributed group of brown algae known as the kelps. Kelp, a group of photosynthetic macroalgae that can grow in dense beds or forests in shallow oceans, is discussed in this chapter because of its similarity in function to SAV and its applicability in NNBF.

All forms of SAV and algae are photosynthetic. As a result, their depth distribution is primarily a function of light availability. Seagrasses are a group of approximately 60 species of marine flowering plants (there are some disagreements related to taxonomy) that are distinguished from freshwater flowering plants by their ability to tolerate full-strength seawater. Seagrasses occur in large stands on every continent except Antarctica (Green and Short 2003). Seagrasses have high light requirements that limit their distribution to shallow, clear waters (Dennison et al. 1993). Most seagrass species produce flat, elongated leaves that range in length from 2 or 3 centimeters (cm) (Halophila decipiens) to 7 meters (m) (Zostera caluscens) and produce an extensive belowground system of roots and rhizomes (Duarte and Chiscano 1999). Seagrasses often grow in large monospecific meadows, although stands of mixed species and patchy beds are also common. Efforts to document the total global abundance of seagrasses via remote sensing are challenging due to their subtidal existence. The best available global estimates of seagrass extent are based on a combination of point-based sampling, remote sensing, and interpolation, and range from 17.7 to 60 million hectares (ha) (Pendleton et al. 2012; Figure 13.2). According to Duarte (2002), seagrasses cover approximately $0.1 \%$ to $0.2 \%$ of the global ocean. SAV provides many beneficial ecological services including the following: provides habitat for fish and shellfish; forms an important 
part of the diets of turtles, manatees, sea urchins, and waterfowl, among others; enhances water quality through nutrient uptake and sediment trapping; and protects shorelines by wave absorption (Orth, Larkum, and Duarte 2010; Chen, Liu, and Zou 2019). SAV meadows also function as ecosystem engineers (Bouma et al. 2005; van der Heide et al. 2012) where biophysical feedbacks enhance local sedimentation, resulting in improved water quality and stabilization of the seabed (Christianen et al. 2013). Eelgrass meadows are also highly productive ecosystems that store most of their production in the sediments as organic carbon, known as blue carbon (Mcleod et al. 2011; Greiner et al. 2013), or export to neighboring ecosystems. Zostera marina is recognized as a valuable coastal resource deserving of conservation and restoration (Hemminga and Duarte 2000).

\section{Figure 13.2. Global Seagrass and Kelp Distribution}

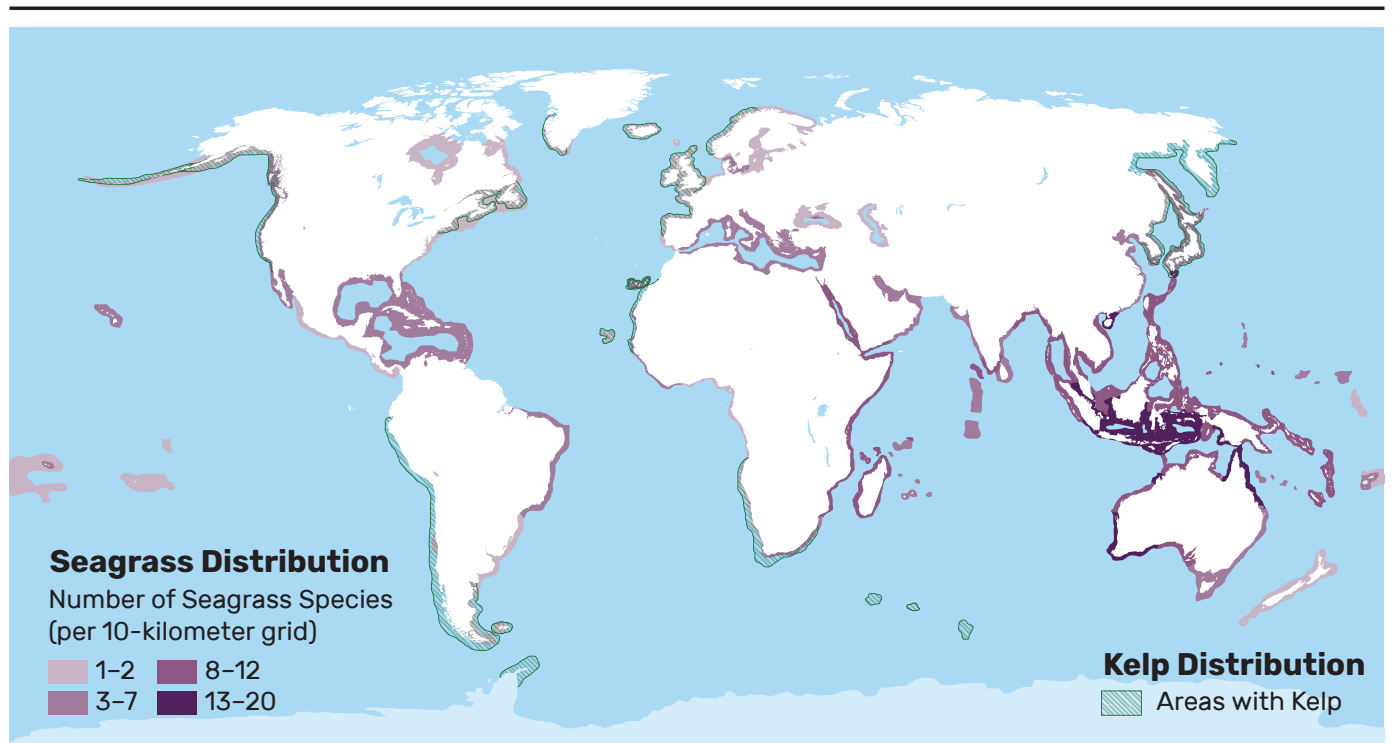

Note: This graphic shows global seagrass distribution and richness (adapted from Short et al. 2011) and kelp distribution (adapted from Gundersen et al. 2017 [accessed on ResearchGate from Ecosystem Services in the Coastal Zone of the Nordic Countries] and Steneck and Johnson 2013).

Although the total global expanse of SAV is not well defined (Short, Short, and Novak 2016; seagrassnet.org 2010), there is strong evidence demonstrating that these systems are declining due to a wide range of human-made and environmental stressors (Orth et al. 2006; Waycott et al. 2009). SAV loss is often a result of land-use practices, degraded water quality, and increased temperatures that result in limited water-column light penetration, and promotion of epiphytic algae that cover the plants. The most commonly cited threats to SAV communities include changes in water quality due to increased nutrient and sediment loading (Kemp et al. 2005), direct impacts from destructive fishing and boating practices (Montefalcone et al. 2008), dredging (Erftmeijer and Lewis 2006), and recent temperature 
increases and extreme conditions (Moore, Shields, and Parrish 2014; Cardoso, Raffaelli, and Pardal 2008), among others. One analysis indicated that areal cover of SAV has an increasing rate of global decline, with the majority of sites analyzed (58\%, 126 sites) showing decline (Waycott et al. 2009). Because SAV provides so many vital ecosystem services or co-benefits, continued losses are likely to have deleterious consequences for coastal systems.

Kelp are a group of nonflowering photosynthetic macroalgae. Kelp require available hard substrate (usually, rocky surfaces) for holdfast attachment (because they do not produce true roots), high-nutrient conditions, and light for growth (Figure 13.3). Kelp are abundant in rocky, nearshore waters of the temperate and polar zones (Steneck et al. 2002). They are largely absent from tropical waters where surface warming results in water-column stratification, and, therefore, low nutrient conditions. Kelp are able to occur in deep waters. Kelp in the Laminaria genera typically grow in waters from the mean low water mark to 12 to $15 \mathrm{~m}$ deep, whereas the Agarum species occupy waters 12 to $20 \mathrm{~m}$ deep (Estes and Steinberg 1988). The global distribution of kelp forest habitat is estimated at greater than 2.35 million ha or approximately $0.65 \%$ of the total global ocean (Graham et al. 2007). Kelp forests form the basis of a complex food web that would not exist without their presence. Their canopies provide habitat, nursery areas, and food for a host of mobile and benthic organisms. Kelp is also a source of food for herbivores and detritivores. Kelp forests provide habitat to species adapted to low light levels through their shading effects (Santelices and Ojeda 1984; see Steneck et al. 2002). Similar to SAV, kelp canopies can influence hydrodynamic conditions by attenuating waves and reducing current velocities in the canopy, which leads to decreasing coastal erosion and increasing sedimentation, benthic primary production, and species recruitment (Duggins, Eckman, and Sewell 1990; see Steneck et al. 2002).

\section{Figure 13.3. Young Kelp with Holdfasts Attached to Beach Rocks}

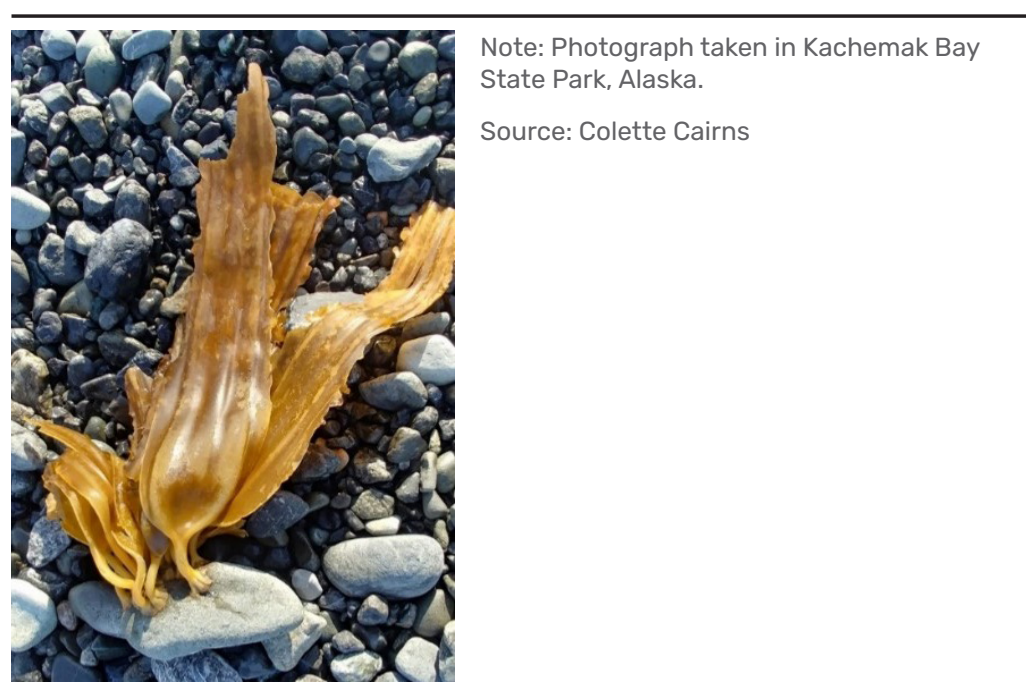


Kelp have a global distribution in a diversity of environments and in the northern hemisphere are found on rocky shorelines from $40^{\circ}$ to $60^{\circ}$ north latitude, with high temperatures limiting their distribution to the south and low temperatures and light limiting their distribution to the north (Figure 13.2). Kelp can be used as an NNBF in coastal protection projects where seagrasses would not be possible, such as colder climates with deeper waters and rocky bottoms. Similar to SAV, kelp's in-water biomass and often dense canopy structure reduces wave energy and current velocities, thereby slowing erosion of adjacent shorelines (Dubi and Terum 1997).

Kelp forests are a keystone habitat in cold, clear, nutrient-rich coastal waters throughout the globe (Krumhansl et al. 2016). They provide important 3D habitat for many marine vertebrates and invertebrates including fish, sea otters, and marine birds. Kelp plant material also has economic value as a source of pharmaceutical compounds, fertilizer, and a human food gelling agent (Krumhansl et al. 2016). These values are sufficient to support long-term harvest activities in many regions.

Primary productivity in kelp forests rivals that of tropical rain forests, and intensively cultivated agricultural fields; individual kelp plants can achieve growth rates of up to $18 \mathrm{~cm}$ per day and can have net primary production of up to 2,000 grams of carbon square meters $\left(\mathrm{m}^{2}\right)$ per year (oceana.org, n.d.; Krumhansl et al. 2016; Mann 1973). Nevertheless, kelp forests are vulnerable to a number of threats including grazing by sea urchins, storms, and certain fishing practices. As a result, kelp forests are among the most dynamic habitats on Earth, with even more spatial variability than SAV.

Because of their demonstrated ability to attenuate waves and slow erosion rates (Christianen et al. 2013; Fonesca and Cahalan 1992), SAV and kelp can be valuable additions to NNBF projects. Although SAV and kelp are rarely used in isolation, numerous coastal resiliency projects have included SAV and kelp to help ensure the integrity of created features such as beaches and dunes (Hanley et al. 2014). The Seattle seawall project (in the State of Washington, United States) used kelp alongside other NNBF (e.g., beaches; Toft et al. 2013).

\subsubsection{Types and Setting of SAV and Kelp}

Geomorphological characteristics of a coastal environment can heavily influence whether it is a suitable habitat for SAV or kelp. Coastal and estuarine SAV species primarily occur in relatively shallow-water environments where they have sufficient light and protection from waves (with some exceptions-e.g., Phyllospadix spp. along the rocky Pacific coast) (Eleuterius 1987; Short et al. 2007; Yates, Greening, and Morrison 2011). These requirements place coastal SAV in bays and estuaries, behind barrier islands, or in most other protected, shallow coastal environments (Short et al. 2007). In semienclosed, large bodies of water, such as bays, lagoons, and sounds, SAV typically occurs along mainland shorelines where wave energy is minimized. 
In estuaries, SAV is found in the intertidal and subtidal zone along fringing marsh, and within tidal creeks and tributaries. Generally, more protected from coastal waves than bays, lagoons, and sounds, estuaries typically support finer-grained and organic-rich substrates, often contributing to an increase in suspended matter (sediment and organic) and subsequently turbidity. This can reduce the habitable depth for SAV due to reduced light penetration. The geomorphology of barrier islands is very dynamic and can change slowly or rapidly, effecting SAV distribution (Short et al. 2007). The overall size of a barrier island plays a significant role in the establishment and long-term survival of SAV. Larger barrier islands provide more protection from wave and current energies such that the area behind the island is more conducive for SAV growth and survival (Fonseca 1996; Fonseca and Bell 1998; Koch 2001; Koch et al. 2006; Fonseca, Koehl, and Kopp 2007). SAV can also grow around rocky islands, within estuaries, and in shallow areas. Rocky islands may be present within bays or estuaries in certain coastal systems such as those mentioned previously. The enclosing waterbody may be sheltered from waves, allowing the island to add extra protection for SAV habitats. Rocky coastal zones tend to support coarser-grained sediments, and often clearer water, leading to a trend in increased depth of SAV habitat in these environments. A limited subset of SAV species such as plants in the genus Phyllospadix provide the only exception to the typical low-energy, soft-bottom environmental requirements and inhabit the rocky, nearshore swash zone. These seagrasses attach to rocks in the intertidal and subtidal zones and can withstand a moderate amount of wave energy (Wyllie-Echeverria and Ackerman 2003).

Most SAV species have been reported to grow in a wide range of substrates from coarse sand to silts and clays. The effect of sediment grain size on SAV growth in both marine and estuarine environments has been shown to be species specific, however, different species vary in their response to substrate conditions (Batiuk et al. 1992; Leschen et al. 2010; Dunton 1990), especially the percentage of fine sediment. Table 13.1 lists published values for the percentage of fines in sediment colonized by a subset of healthy SAV in either natural or simulated estuarine and marine environments.

Table 13.1. Sediment Grain Sizes Colonized by Healthy SAV in Estuarine and Marine Environments

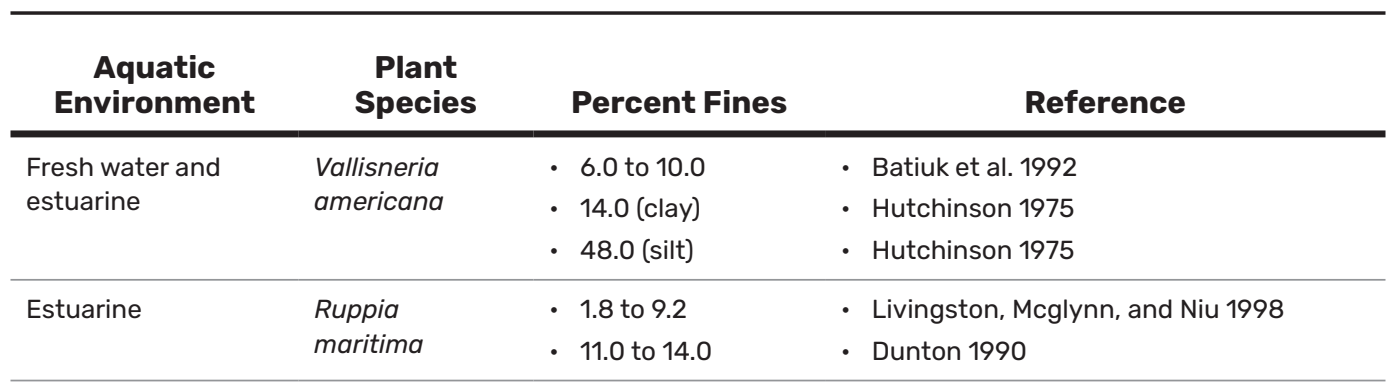




\begin{tabular}{|c|c|c|c|}
\hline $\begin{array}{c}\text { Aquatic } \\
\text { Environment }\end{array}$ & $\begin{array}{c}\text { Plant } \\
\text { Species }\end{array}$ & Percent Fines & Reference \\
\hline Estuarine and marine & Halodule wrightii & $\begin{array}{l}\text { - } 1.8 \text { to } 9.2 \\
\text { - } 14.0 \\
\text { - } 8.1 \text { to } 28.8 \\
\text { - } 10.2 \text { to } 12.4 \\
\text { - } 0.8 \text { to } 14.7\end{array}$ & $\begin{array}{l}\text { - Livingston, Mcglynn, and Niu } 1998 \\
\text { - Dunton 1994; Dunton } 1990 \\
\text { - Murphey and Fonseca } 1995 \\
\text { - Hoskin } 1983 \\
\text { - Grady } 1981\end{array}$ \\
\hline \multirow[t]{3}{*}{ Marine } & $\begin{array}{l}\text { Syringodium } \\
\text { filiforme }\end{array}$ & $\begin{array}{l}\text { - } 1.8 \text { to } 9.2 \\
\text { - } 7.3 \text { to } 9.9 \\
\text { - } 1.9\end{array}$ & $\begin{array}{l}\text { - Livingston, Mcglynn, and Niu } 1998 \\
\text { - Hoskin } 1983 \\
\text { - Wood, Odum, and Zieman } 1969\end{array}$ \\
\hline & $\begin{array}{l}\text { Thalassia } \\
\text { testudinum }\end{array}$ & $\begin{array}{l}\text { - } 22.0 \\
\text { - } 23.0 \text { to } 35.0 \\
\text { - } 4.8 \\
\text { - } 14.6 \\
\text { - } 2.2 \text { to } 17.1 \\
\text { - } 1.0 \text { to } 34.0 \\
\text { - } 12.2 \text { to } 34.1 \\
\text { - } 0.8 \text { to } 14.7\end{array}$ & $\begin{array}{l}\text { - Lee and Dunton } 1996 \\
\text { - Kaldy and Dunton } 2000 \\
\text { - Wood, Odum, and Zieman } 1969 \\
\text { - Scoffin } 1970 \\
\text { - Koch } 2001 \\
\text { - Burrell and Schubel } 1977 \\
\text { - Hoskin } 1983 \\
\text { - Grady } 1981\end{array}$ \\
\hline & $\begin{array}{l}\text { Zostera } \\
\text { marina }\end{array}$ & $\begin{array}{l}\text { - } 35.0 \\
\text { - } 2.3 \text { to } 56.3 \\
\text { - } 13.0 \\
\text { - } 14.0 \\
\text { - } 15.0\end{array}$ & $\begin{array}{l}\text { - Leschen, Ford, and Evans } 2010 \\
\text { - Koch } 2001 \\
\text { - Krause-Jansen et al. } 2011 \\
\text { - Marshall and Lukas } 1970 \\
\text { - Orth } 1977\end{array}$ \\
\hline
\end{tabular}

Source: Adapted from Eisemann et al. (forthcoming)

There are several key parameters controlling SAV abundance and distribution. Five water quality parameters of critical importance for SAV are dissolved inorganic phosphorous and nitrogen, water-column light-attenuation coefficient, planktonic chlorophyll-a, and total suspended solids (TSS; Kemp et al. 2004). In many places where SAV is well studied, specific requirements with respect to each of these parameters are often documented (e.g. Chesapeake Bay, Puget Sound, Florida, Northeast United States), providing an important resource to NNBF project managers looking to assess a site's suitability for SAV. In contrast to $S A V$, kelp require a rock or boulder substrate for their holdfasts to adhere. Their distribution is largely limited to shallow, rocky reef areas that are less than $40 \mathrm{~m}$ in depth (Carr and Reed 2016). 


\subsubsection{Values and Context for Application}

SAV and kelp can play a vital role in coastal protection by attenuating wave energy and reducing the current velocity in the canopy, near the bed. The reduced hydrodynamic conditions can influence sediment transport in the canopy by increasing bed stabilization, reducing sediment resuspension, and creating an environment more conducive for suspended sediment deposition. The magnitude of wave attenuation by SAV and kelp has been investigated in laboratory and field studies and has been found to be dependent on the height of the canopy relative to total water-column height, with increased wave attenuation when the canopy occupies a larger portion of the water column. As a result, the amount of wave-energy attenuation provided by SAV is not constant but varies as a function of tidal stage, wave characteristics, and seasonal patterns in vegetative growth.

Where canopy height and water-column height are equal (i.e., leaves extend all the way to the water surface), the wave-attenuation value of SAV is maximized. Even a 1-m-long patch of SAV can result in a $40 \%$ reduction in wave energy when SAV blades extend through the full water column (Fonseca and Cahalan 1992).

Where canopy height is much less than total water-column height, the movement of waters overlying the canopy are relatively unaffected by the presence of SAV below (Jacobsen, McFall, and van der A 2019). In these cases, SAV still provides a valuable service by trapping and stabilizing sediments, however, there is no immediate benefit to adjacent shorelines in terms of reducing the height of waves traveling over the canopy. Depending on the distance of the SAV bed from shore, SAV and algae alone provide less storm-protection benefits in terms of flood or erosion reduction than other habitat types (Guannel et al. 2016). Although coral reefs and marsh have greater potential to reduce wave height, SAV and kelp can reduce wave height by $11 \%$ to $40 \%$ (Elginoz, Kabdasli, and Tanik 2011; Narayan et al. 2016).

The presence of biomass in the form of leaves and stems in the water column provide frictional resistance to the movement of water and have been shown to decrease currents moving through the vegetative canopy. SAV is more effective at reducing flows in areas with low (i.e., 5 to 16 centimeters per second [cm/s]) to medium (i.e., 23 to $40 \mathrm{~cm} / \mathrm{s}$ ) currents (Heller 1987). The density of individual shoots is an additional determinant of the amount of wave attenuation provided by any given vegetated benthic habitat (Paul and Amos 2011).

Similar to SAV, large forests of giant kelp (e.g., Macrocystis pyrifera) create drag in the water column from the dampening effect of the kelp fronds interacting with the flowing water. This creates drag from viscous shear and bottom friction forces that dampen the propagation of internal waves. Currents are reduced by a factor that corresponds to the amount of surface canopy cover (Jackson 1984; Jackson and Winant 1984; Rosman et al. 2007). Turbulent flow is also decreased within the kelp forest compared to outside kelp forests. Due to their large size, the drag effect created by giant kelp (M. pyrifera) extends uniformly within the water column. 
The presence of SAV can influence sediment transport rates by stabilizing the bed, reducing in-canopy sediment mobilization, and increasing suspended sediment deposition. SAV roots and rhizomes bind sediments, helping to stabilize them against water movement (Fonseca 1989; Christianen et al. 2013). The slowing of water flow caused by SAV reduces turbulence, causing suspended particles to settle out of the water column (Ward, Kemp, and Boynton 1984). This sediment deposition increases seafloor elevation, bringing it closer to the water surface. This sediment trapping provides a positive feedback because wave energy is limited by water-column depth. Rates of sediment deposition are positively correlated with the depth of the water column, thus as sea levels rise, the rate of elevation gain will also increase, as long as the suspended sediment and other sediment (e.g., silts and sands) supply is not limited. Because of this feedback between sea-level rise and elevation increase, these systems have the potential to act as self-sustaining shoreline protection. In some systems, detached leaves accumulate as wrack on beaches during storms. By physically sheltering beach sand from wave energy, wrack can help to stabilize the beachface while simultaneously providing a nutrient source to the sediments (Borum et al. 2004).

When combined with other natural shoreline habitat types, SAV play a critical role in preserving the integrity of natural infrastructure solutions. Known as the multiple lines of defense strategy, coastal management practitioners are increasingly taking a systems approach to shoreline protection (Lopez 2009; Guannel et al. 2016; Arkema et al. 2017; Figure 13.4). The idea is that multiple habitat types from offshore to onshore, perhaps combined with some elements of conventional engineering, can be used as a buffer against storms and chronic-erosion events, making the community as a whole more resilient to storm events (see La Quinta Channel Expansion case study). A strategy of multiple natural features for storm protection (e.g., coral reefs, SAV, and mangroves) is more effective than any single habitat alone (Guannel et al. 2016).

\section{Figure 13.4. Multiple Lines of Defense Strategies}

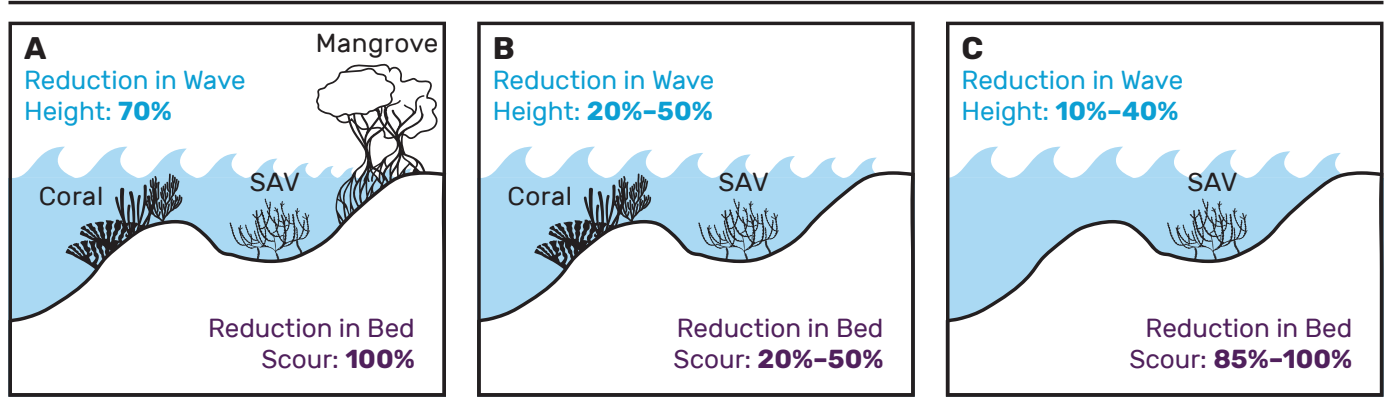

Note: Strategies that incorporate multiple NNBF measures provide more effective shoreline and storm protection. 


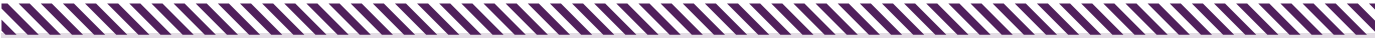

CASE STUDY:

East Coast Park (Singapore)

At East Coast Park in Singapore (Figure 13.5), managers developed a design that included several NNBF techniques to mitigate erosion. Project managers experimented with installing habitat-promoting ecotiles on seawalls, monitoring coral reefs and mangroves, and setting up protective shading nets to foster conditions where SAV can grow and thrive (de Vriend and van Konigsveld 2012). By taking advantage of numerous natural features, project managers were able to create a coastal protection scheme that took site-specific conditions into account and promoted biodiversity.

Figure 13.5. SAV Meadows in East Coast Park, Singapore

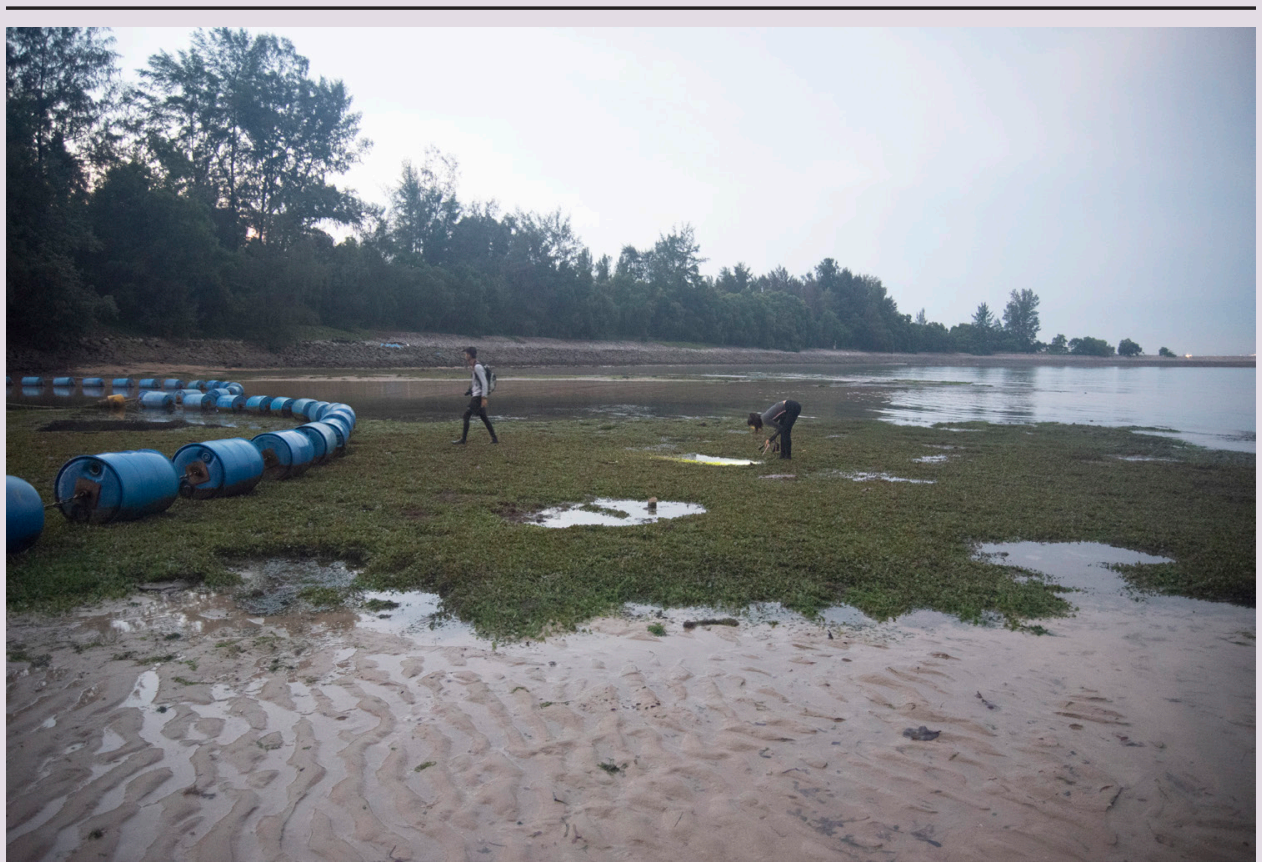

Source: "Seagrass meadows at East Coast Park canal," by Ria Tan, Flickr (https://www.flickr.com/ photos/wildsingapore/33473681724), CC BY-NC-ND 2.0

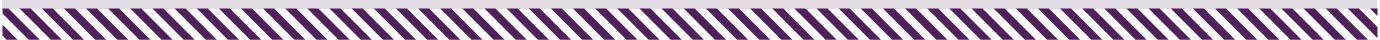


In addition to the positive influence of SAV and kelp on shoreline protection, they can also provide ecological co-benefits. Both seagrasses and kelp provide essential habitat for commercially and ecologically valuable fish and other aquatic species. Kelp forests have a thermal-insulating effect on the water; the long fronds packed densely together act to trap water and insulate the area from temperature extremes (Jackson 1984; Rosman et al. 2007). By using seagrasses or kelp in NNBF projects, planners can help improve and expand foraging habitat for numerous species including sea turtles, manatees, and dugongs, helping to promote species recovery.

Using SAV and kelp can also help provide or restore ecological services and provide an overall benefit to an ecosystem. Although in the context of NNBF, the co-benefits of these ecological services are "secondary" to providing shoreline and flood risk protection, they can have immense value in promoting NNBF techniques and garnering public support from stakeholders who would benefit from these ecological services.

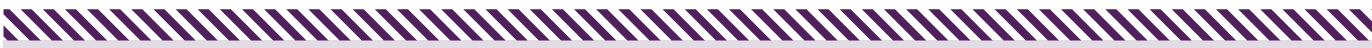 \\ CASE STUDY: \\ Julia Tuttle Seagrass Mitigation (Miami, Florida, United States)}

During the feasibility study for the expansion of PortMiami, it was determined that unavoidable impacts to seagrass would occur adjacent to the expanded channels and basins. During the project development and public review process under the National Environmental Policy Act, U.S. Army Corps of Engineers and the nonfederal sponsor, PortMiami, determined that these impacts would require compensatory mitigation. Many mitigation options were reviewed, but the final selection was restoration of seagrass beds in Biscayne Bay, the same watershed where the impacts would occur. The U.S. Army Corps of Engineers proposed a 50 plus-year-old, 7.6-m (25-foot)deep borrow hole located north of the Julia Tuttle Causeway to be filled with dredged material to an elevation similar to surrounding seagrass beds to encourage seagrass growth. During feasibility investigations, it was determined that this hole was unlikely to fill naturally, effectively preventing any native seagrass to recruit into the area. The restoration area serves as compensatory mitigation via ecosystem restoration as well as a demonstration project for future efforts looking to utilize dredged material for seagrass restoration and beneficial reuse. 
The Miami Harbor deepening project was advertised with performance and environmental protection and mitigation criteria but means and methods were not proscribed. For the seagrass mitigation, the selected construction contractor, Great Lakes Dredge \& Dock Company, LLC, designed an approximately 7-ha site named the "Julia Tuttle Seagrass Mitigation Site" (Figure 13.6). The site was first filled with approximately 428,400 cubic meters $(560,000$ cubic yards) of excavated dredged material obtained during construction of the project to form the base fill component. The dredged material was then capped with 65,000 cubic meters $(85,000$ cubic yards) of upland quarried select fill material per requirements of the state permit, and approximately 3 ha of the site was planted with 115,000 manatee grass (Syringodium filiforme) sprigs obtained from adjacent donor sites.

At the 30-day, post-construction monitoring period, the transplanted seagrass had a documented $97.6 \%$ survival rate. Seagrass is expected to continue to recruit naturally through the remaining 4 ha of available unplanted area, and recruitment of four of the five southeast Florida seagrass species has already been documented. A variety of wildlife, including the endangered Florida manatee (Trichechus manatus latirostris), have been documented using the site, including grazing on the transplanted seagrass. Monitoring of the site will continue for at least 3 years to document seagrass expansion and growth. The restoration site is believed to be the largest contiguous successful seagrass restoration effort undertaken within the United States. This effort demonstrates the beneficial value of navigation-dredged material in the construction of compensatory mitigation and ecosystem restoration projects. 
Figure 13.6. Julia Tuttle Seagrass Mitigation

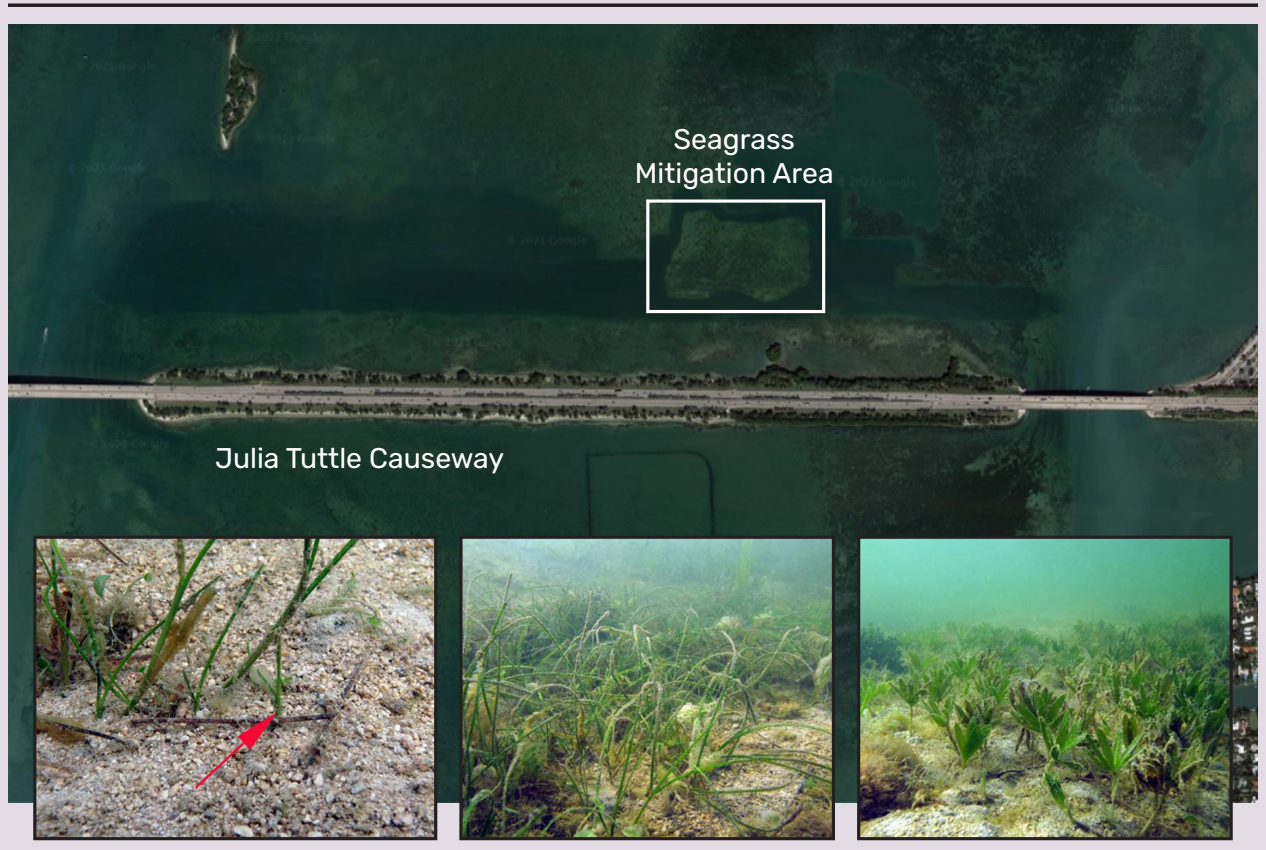

Rhizome extension and new shoot formation in planted

Volunteer seagrasses 6 weeks after select fill material seagrass 2 weeks after placement completed

planting

Source: Adapted from Jordan-Sellers 2016

\section{AHIHก)}




\section{3 | Conceptual System Understanding}

Incorporating SAV and kelp successfully in NNBF projects requires careful consideration of the physical system and habitat requirements (i.e., determining what controls seagrass and kelp distribution and survival, the socioeconomic co-benefits, and the governance context).

\subsubsection{Physical System}

Light, nutrients, temperature, and physical energy are the primary factors governing SAV distribution globally. Changes in sedimentation, water temperature, or chemistry, and disturbances such as excessive herbivory, are driving factors in the recent global losses of SAV. Restoring or introducing SAV into a system that does not support their habitat requirements will result in failure (Fonseca, Kenworthy, and Thayer 1998). Managers need to understand species-specific requirements and what the system currently supports prior to making a decision to include these features in NNBF projects.

SAV can reproduce via flowering and dispersal of seeds or through clonal growth of an apical meristem. The latter mechanism has been much studied as the primary way that SAV beds can be self-sustaining. The role of seeding (via seed bank or seedling dispersal) is important in some SAV species such as Halophila decipiens and Zostera marina (Kenworthy et al. 1980; Orth, Luckenbach, and Moore 1994).

SAV beds can be found in patchy or continuous bed forms, depending on the physical energy at the site or variation in temperature, with more continuous SAV beds found in lower energy settings or those with little temperature variation, and patchy beds found in higher energy settings or those experiencing periods of temperature stress (Fonseca and Bell 1998; Table 13.2). SAV, as well as other plant systems generally, can be expected to survive in locations where they fit habitat requirements for light, nutrients, and temperature, as well as the physical energy of the site (i.e., site does not exceed their root and rhizome's ability to remain within the sediment). Generalized physical habitat fitting requirements for SAV are described in Table 13.2. The different physical requirements for individual SAV species can vary; project planners must carefully review the environmental parameters of a proposed site to choose appropriate SAV.

Table 13.2. Critical Physical Requirements for SAV

\begin{tabular}{llllll}
\hline & Critical factor & $\begin{array}{c}\text { SAV } \\
\text { (fresh water) }\end{array}$ & $\begin{array}{c}\text { SAV } \\
\text { (marine) }\end{array}$ & Kelp \\
\hline $\begin{array}{l}\text { Water } \\
\text { temperature }\end{array}$ & Minimum $\left({ }^{\circ} \mathrm{C}\right)$ & Variable by species & Variable by species & 5 & \\
\cline { 2 - 6 } & Maximum $\left({ }^{\circ} \mathrm{C}\right)$ & Variable by species & Variable by species & 20 \\
\hline
\end{tabular}




\begin{tabular}{|c|c|c|c|c|}
\hline \multicolumn{2}{|c|}{ Critical factor } & \multirow{2}{*}{$\begin{array}{c}\begin{array}{c}\text { SAV } \\
\text { (fresh water) }\end{array} \\
0.04 \text { to } 5\end{array}$} & \multirow[t]{2}{*}{$\begin{array}{c}\text { SAV } \\
\text { (marine) }\end{array}$} & \multirow{2}{*}{\begin{tabular}{l}
\multicolumn{1}{c}{ Kelp } \\
Sheltered \\
environment
\end{tabular}} \\
\hline $\begin{array}{l}\text { Water } \\
\text { movement }\end{array}$ & $\begin{array}{l}\text { Minimum velocities } \\
(\mathrm{cm} / \mathrm{s})\end{array}$ & & & \\
\hline & $\begin{array}{l}\text { Maximum velocities } \\
(\mathrm{cm} / \mathrm{s})\end{array}$ & 7 to 50 & 50 to 180 & $\begin{array}{l}\text { Wave-swept } \\
\text { environment }\end{array}$ \\
\hline \multirow[t]{2}{*}{ Wave tolerance } & Height $<0.5 \mathrm{~m}$ & $\begin{array}{l}\text { Limited growth, } \\
\text { canopy-formers }\end{array}$ & $\begin{array}{l}\text { Limited growth, } \\
\text { canopy-formers }\end{array}$ & $\begin{array}{l}\text { Inshore } \\
(<0.5 \mathrm{~m})\end{array}$ \\
\hline & Height $<2 \mathrm{~m}$ & $\begin{array}{l}\text { Tolerant growth, } \\
\text { meadow-formers }\end{array}$ & $\begin{array}{l}\text { Tolerant growth, } \\
\text { meadow-formers }\end{array}$ & $\begin{array}{l}\text { Offshore } \\
(>2 \mathrm{~m})\end{array}$ \\
\hline \multirow[t]{2}{*}{ Sediment } & Substrate & Soft & Soft & Hard \\
\hline & Grain size & $\begin{array}{l}2 \% \text { to } 62 \% \text { silts and } \\
\text { clays }\end{array}$ & $\begin{array}{l}0.4 \% \text { to } 72 \% \text { silts and } \\
\text { clays }\end{array}$ & $\begin{array}{l}100 \% \text { small } \\
\text { pebbles, rocks, } \\
\text { and hard } \\
\text { substrate }\end{array}$ \\
\hline \multirow{3}{*}{$\begin{array}{l}\text { Porewater } \\
\text { sulfide }\end{array}$} & $<1$ millimolar & Healthy & Healthy & Not applicable \\
\hline & $>1$ millimolar & Reduced growth & Reduced growth & Not applicable \\
\hline & $>2$ millimolars & Death & Death & Not applicable \\
\hline
\end{tabular}

Source: Adapted from Kemp et al. 2004 and The Bay Foundation 2018

Biological considerations such as bioturbation and presence of grazers can also impact SAV growth and establishment. Bioturbation by stingrays, crabs, polychaetes, burrowing shrimp, and echinoderms can be a critical factor in failure of SAV to establish, because it can uproot, damage, or kill SAV transplants and seedlings (De Witt 2009). However, the presence of low-intensity bioturbators such as epibenthic oysters can also enhance SAV success by oxygenating sediments, decreasing turbidity, and increasing the efflux of hydrogen sulfide and ammonia from surrounding porewater. The presence of sea urchins in kelp forests can lead to urchin-induced kelp deforestation when urchin growth is uncontrolled by predators (Steneck et al. 2002; see case study "Removal of Sea Urchin Grazers Promotes Kelp Growth and Wave Reduction [Palos Verdes, California, United States]" for more detail). Therefore, in areas where SAV were previously known to occur, it is important to investigate the drivers for bioturbation and kelp deforestation and address those drivers if necessary (e.g., herbivore removal). However, a continued imbalance of the food web structure (i.e., ratio of predators to herbivores) without management actions to prevent overgrazing or extensive bioturbation may render the NNBF habitat short lived. 


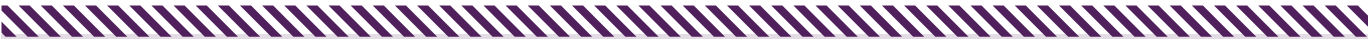 \\ CASE STUDY: \\ Removal of Sea Urchin Grazers Promotes Kelp Growth and Wave Reduction (Palos Verdes, California, United States)}

Due to their extensive grazing, sea urchin presence must be assessed and addressed prior to using kelp as an NNBF technique. There has also been a disruption of kelp forest food web connectivity through the "fishing down" of top predators to their kelp-grazing invertebrate prey (Steneck et al. 2002). Kelp forests with more diverse predators and herbivores tend to be the most stable systems. Kelp forests lacking in species diversity can be most at risk of deforestation. In a recent restoration project in Palos Verdes, California, human-induced removal of the overly abundant purple sea urchins (Strongylocentrotus purpuratus) was sufficient to promote rapid, natural reforestation of kelp. This rapid recovery of the kelp forest led to a $14 \%$ decrease in alongshore current velocities in inshore sites but had no impact on surface wave fluctuation (The Bay Foundation 2018; Figure 13.7).

Figure 13.7. Results from the Southern California Kelp Forest Hydrodynamics Study
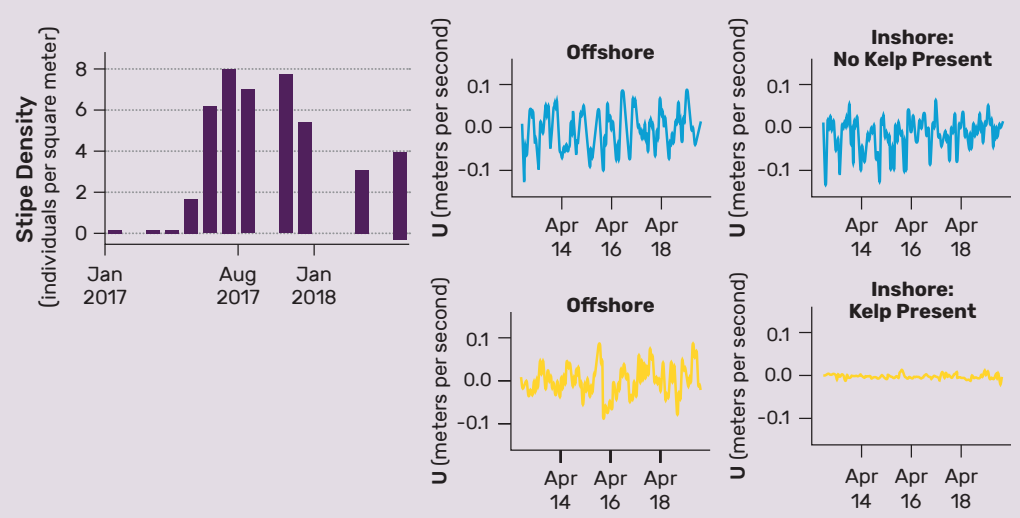

Notes: The graph on the left shows a temporal variation of kelp stipe (stalk) density $\left(p e r \mathrm{~m}^{2}\right)$ following removal of urchins. Bars represent the number of stipes per $\mathrm{m}^{2}$, averaged across the eight transects. Error bars represent standard error of the mean. The graphs on the right show depth-averaged alongshore velocities $U(\mathrm{~m} / \mathrm{s})$ patterns of alongshore flow within the kelp forest habitat ("Inshore: Kelp Present") decrease in magnitude in the presence of kelp.

Source: Adapted from The Bay Foundation 2018

\section{NHIH}




\subsubsection{Socioeconomic System}

SAV provides numerous socioeconomic co-benefits. The most recognized economic value of SAV beds in developing areas is from the fisheries they support, upon which local economies and trade depend (Unsworth, Nordlund, and Cullen-Unsworth 2019). The economic value of SAV contributions to the secondary production of fish species in south Australia was calculated to be $\$ 114$ million Australian dollars (AUD) (\$89 million U.S. dollars [USD]) annually (McArthur and Boland 2006). Tuya, Haroun, and Espino (2014) examined the economic value of SAV by looking at the economic value of the fisheries they support in Gran Canaria in the eastern Atlantic. The economic value of SAV as fishery grounds was calculated to be approximately $€ 886$ euros per ha (USD $\$ 1,000$ per ha), with the value of SAV as nursery grounds for commercially important fishes estimated at €95.75 euros per ha (USD\$120 per ha) per year (Tuya, Haroun, and Espino 2014). On the Great Southern Reef in Australia, Bennet et al. (2015) estimated the combined fishing and tourism value of the kelp forests in the region to be approximately AUD\$10 billion (USD\$8 billion) per year. In a broad valuation of kelp beds in northern Chile, Vásquez et al. (2014) estimated the fishery, biodiversity, cultural, and climate change buffer values to be USD\$540 million.

\subsubsection{Governance System}

Governments around the world have recognized the value of vegetated nearshore coastal systems, and in many cases, have enacted conservation, protection, and restoration programs to protect SAV. SAV are often protected by federal, state, and local laws, so permits or other authorizations are usually required for any activity that may result in disturbance or loss of SAV. Governance of SAV restoration actions can vary by country or, in the case of the United States, by state (see example in the case study "Governance Example for SAV Permitting [Maryland and Virginia, United States]").

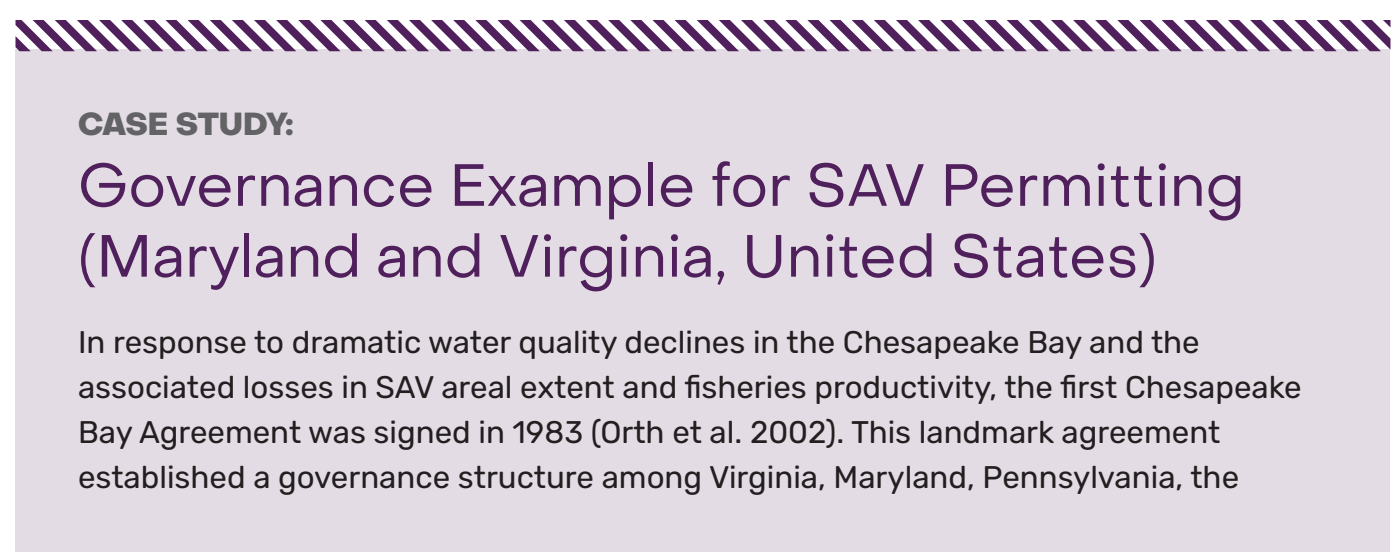


District of Columbia, the Chesapeake Bay Commission, and the U.S. Environmental Protection Agency to jointly share management responsibilities to limit pollution entering the bay and to establish the policy direction for the restoration and protection of the Chesapeake Bay. Subsequent regulations and policies established since 1983 have bolstered the protection and conservation of SAV in the bay and established clear objectives for increasing SAV acreage and for monitoring water quality. Figure 13.8 shows aerial imagery and 2019 SAV bed outlines in Hampton, Virginia.

Figure 13.8. Aerial Imagery and 2019 SAV Bed Outlines, Hampton, Virginia

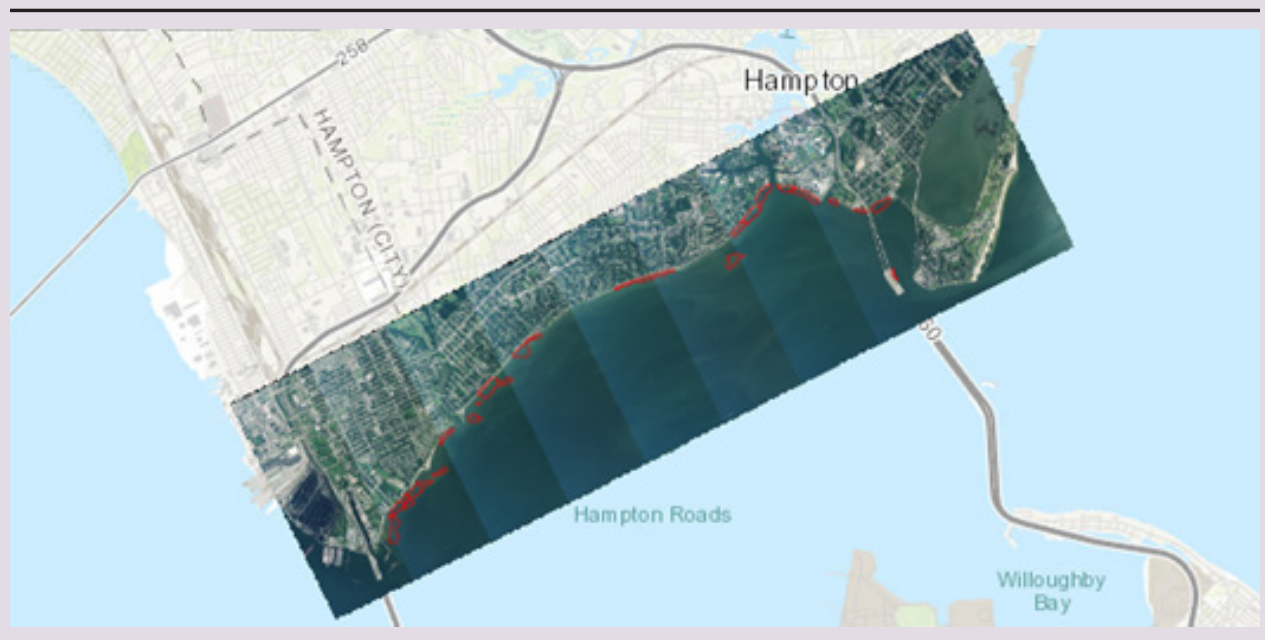

Source: Data visualization from Virginia Institute of Marine Science interactive SAV map (vims.edu 2021)

Maryland and Virginia have established a joint permit application process with the U.S. Army Corps of Engineers for projects that have the potential to impact SAV in the Chesapeake Bay region (Orth, Larkum, and Duarte 2010). In Maryland, no permits are required to restore SAV, but harvest of SAV plants or seeds requires a permit from the Maryland Department of Natural Resources (MDDNR). MDDNR also requests the location of the restoration site and a copy of the final report to track project success and lessons learned. Further, MDDNR encourages the beneficial use of clean dredge material in habitat restoration projects, including SAV, marsh, and island restoration (MDE 2017; see also Chapter 11). Virginia has published a regulation on SAV transplantation guidelines (4 Vac 20-337-10 et seq. Submerged Aquatic Vegetation Transplantation Guidelines). The transplantation guidelines walk applicants through the joint permit application process to restore SAV, including the kind of information 
required and time of year for conducting such work. The level of permitting required for SAV projects depends on the scope of the project. A project that includes strictly planting SAV may qualify for a permit exemption, whereas projects requiring contouring or regrading of the substrate may require a general or individual permit similar to other types of wetland restoration projects (see Chapter 10 for additional detail).

Therefore, for projects using SAV in Maryland and Virginia, the most efficient way to initiate the regulatory process is to contact the state permitting agencies to determine the appropriate permitting approach.

\section{NHINHก)}

In the United States, SAV habitat is protected under federal laws that govern activities impacting wetlands such as the Clean Water Act and the Essential Fish Habitat provisions of the Magnuson-Stevens Act. Numerous states have legislative mandates that encourage additional conservation and protection measures.

Impact avoidance and conservation of SAV have been increasing as the option of choice due to the recognition of the ecosystem services they provide. Generally, government agencies are more amenable to activities that promote or restore SAV than those that would harm them. Activities that damage or adversely impact existing SAV beds are likely to receive thorough review and be difficult to permit.

\section{4 | Objectives and Metrics}

Many of the performance metrics that might be considered in an NNBF project require a comparison to baseline information to be meaningful. Ideally, during site selection and preparation, practitioners will collect data connected to the project's desired outcome. SAV meadow and forest size, sediment type and distribution, shoreline profile (e.g., elevation, slope), water quality parameters, and similar metrics can provide an adequate picture of what conditions were like before the SAV NNBF project is installed.

Projects should be designed with specific operational objectives in mind. Performance metrics for individual NNBF projects will vary based on the desired outcomes for those projects, and performance metrics need to be linked to those objectives. If the goal of SAV is to stabilize sediment around a dredge material island, bathymetry and sedimentation should be measured periodically. If the goal of SAV is to reduce wave energy, wave attenuation should be 
monitored. If the SAV is intended to provide habitat for juvenile fishes, faunal surveys should be conducted. Establishing performance metrics and monitoring plans allow practitioners to document the performance of the NNBF project and facilitate effective project management.

From an initial logistical standpoint, it is important to determine if the SAV has been installed properly and is expanding. Design metrics to assess the SAV condition can include habitat footprint over time (e.g., expansion by area after planting), transplant longevity (e.g., presence of transplants in subsequent years), and indicators of SAV health (e.g., shoot size, density, canopy volume). These measures will allow project planners to make a quantitative assessment of whether the SAV has become established and provide a baseline for comparison against subsequent monitoring data.

Field measurements have demonstrated flow reduction in SAV meadows compared to nearby unvegetated channels. Flow-reduction capability is related to the stem and leaf biomass of the SAV meadow, and thus changes seasonally as the SAV grows and dies back over the year. An SAV shoal in the upper Chesapeake Bay exerted greater flow reduction in June (when biomass was greater) than it did in August (Gurbisz et al. 2017). Equipment such as acoustic Doppler current profilers and acoustic Doppler velocimeters can be used to measure current velocity and provide data for this performance metric.

Measuring sedimentation rates and characterizing sediment type (e.g., fine sand, coarse sand), prevalence, and organic content can help determine how the SAV is performing in terms of stabilizing sediment. This can also indicate the continued site suitability for the SAV-too much sedimentation can reduce SAV growth and expansion, or even smother plants.

Ideally, an NNBF project will include a comprehensive monitoring component where the ecological co-benefits of SAV or kelp can be evaluated. Monitoring methods for ecological co-benefits depends on the desired outcome, and can include faunal surveys (e.g., census of fishes and invertebrates present in new SAV or kelp habitat), and measuring the accumulation of organic matter, sedimentation and siltation, and carbon accumulation rates using sediment cores.

It is possible to qualitatively describe social co-benefits by conducting interviews or surveys of the local community to understand site use (e.g., fishing, recreation) or determine if their perception of the site's aesthetic value has changed. Economic co-benefits can be tied to the fishing or recreation activities (e.g., how much is spent locally on fishing gear, licenses, outdoor equipment, or tours) and can serve as a quantitative metric for using SAV in an NNBF project. 
To evaluate project performance, NNBF planners should establish quantitative and qualitative metrics in the planning stage to determine the success of using vegetation in an NNBF project (see example in Table 13.3). These performance metrics should be tied to the desired outcomes, and it might be useful to think of the desired outcomes in terms of primary and secondary goals. The primary goal for an NNBF project planner will likely be coastal protection. Determining the secondary goal should be made after the public scoping process, and the project planners should incorporate the needs and priorities of stakeholders in the action area. For example, if there are many fishers in an area who are particularly concerned about nursery habitat for commercially important fish species, project planners might focus on that as an ecological co-benefit in the SAV NNBF project.

Table 13.3. Example of Performance Objectives, Metrics, and Criteria for a Hypothetical SAV NNBF Project

\section{Primary metrics* to determine success of habitat creation}

Performance objective

Bed size
Metric

Areal extent of created habitat
Performance criteria

Constant or increasing coverage
Vegetative condition
Shoot density and height; percent cover
Should be similar to reference sites in comparable physical settings

\begin{tabular}{lll}
\hline Sediment stabilization & TSS in water column & $\begin{array}{l}\text { Decreased TSS relative to nearby } \\
\text { unvegetated areas? }\end{array}$ \\
\hline Wave attenuation & Wave energy & Percentage of decrease
\end{tabular}

*Note: This is not an exhaustive list; actual metrics would depend on project-specific goals. 


\section{5 | Design Considerations}

Sections 13.5.1 through 13.5.7 discuss design considerations for using SAV and kelp in a coastal protection project, and Section 13.5.8 discusses costs and benefits.

\subsubsection{Guiding Principles}

It is critical to consider the following guiding principles:

- Match the site selection with the history of vegetated habitat at the site.

- Understand the physical conditions of the project footprint (e.g., wave energy, bathymetry, sediment grain size, water quality).

- Align the life history and growth traits of vegetation with the project goals and implementation timeline.

Successful establishment of SAV relies on identification of SAV species whose habitat requirements are appropriate for the site in question (van Katwijk et al. 2009). Some species are not well suited for transplanting, so seeding might be a viable option instead. Genetic diversity and using locally sourced, ecotypic plant materials in transplanted seagrass meadows are important for their long-term survival and should be considered in the planning process (Fonseca, Kenworthy, and Thayer 1998). Only native species should be used in NNBF projects. Species that have historically been present in the project area or that occur in nearby settings with similar physical characteristics are likely to be well suited to the site conditions. If the project site is currently unvegetated, it is critical to determine if the site was previously vegetated. It may be possible to use satellite imagery to determine the past historical extent of vegetative cover and species composition (Wabnitz et al. 2008). If there is no indication the site was previously vegetated, there is a low likelihood the project will be successful, unless it includes components that will fundamentally change site characteristics to benefit SAV.

Important considerations in project site design include parameters such as habitat width, ratio of habitat width to commonly experienced wavelength, ratio of vegetation height to water depth, and ratio of habitat length to the mean tide level. These parameters strongly influence the overall effectiveness of natural features in wave height reduction for coastal protection against flooding and erosion (Narayan et al. 2016). For instance, SAV beds substantially influence wave energy when they are broad, shallow (approximately $1 \mathrm{~m}$ deep) meadows (Fonseca and Cahalan 1992).

The wave energy at a proposed site is a critical component for projects involving SAV; establishing SAV in high-energy environments is unlikely to be successful unless the project includes other elements such as reefs (see Chapter 12) that will reduce wave energy. Estimation of a site's relative exposure index has been proposed by Fonseca et al. (2002) to 
quantify wave exposure. The relative exposure index calculates the intensity and frequency with which winds blow from each of the eight major compass headings and compares that to site orientation to estimate a site's relative exposure to wind waves. The equation is described as follows (Fonseca et al. 2002):

$$
R E I=\sum_{i=1}^{\infty}\left(V_{i} \times P_{i} \times(i d w F i)\right)
$$

where

$\mathrm{i}=\quad=\quad$ ith compass heading ( 1 through 8 [e.g., north, northeast, east], in $45^{\circ}$ increments) and based on data from the previous 3 years,

$v=$ top $5 \%$ of hourly wind observations $(\mathrm{m} / \mathrm{s})$ over the preceding 3 years,

$\mathrm{P}=$ percent frequency which wind occurred from the ith direction,

$\mathrm{F}=$ effective fetch $(\mathrm{m})$, and

$\mathrm{idw}=$ application of an inverse distance weighting function on the variable water depth, where weighting is controlled by $\mathrm{F}$.

NNBF project planners can adapt the relative exposure index approach to more completely understand wave exposure in the project area. Fonseca et al. (2002) recommend that SAV be planted in areas with lower water depth (less than $2 \mathrm{~m}$ ) and with relative exposure index values less than 4,000, in conjunction with structures such as bars and shoals to provide protected areas for SAV. Whether or not the proposed site is subject to chronic disturbance from storms or from boat wake energy should also be considered; SAV thrive in quiescent settings, and it would not be advisable to plant them in a high-energy environment.

It is also important to consider the life history strategies of the SAV species used for restoration project sites that harbor more stressful or dynamic conditions; projects may benefit from using a native species or ecotype that is considered to be more colonizing on the spectrum of colonizing, opportunistic, and persistent SAV genera (Kilminster et al. 2015; Figure 13.8). Colonizing SAV species are those that invest heavily in sexual reproduction, exhibit dramatic fluctuations in year-to-year biomass, and tend to recover from disturbances more quickly (Kilminster et al. 2015).

Colonizing, opportunistic, and persistent seagrass traits are presented in Figure 13.9, and a flowchart for general design principles for SAV and kelp NNBF is presented in Figure 13.10. 


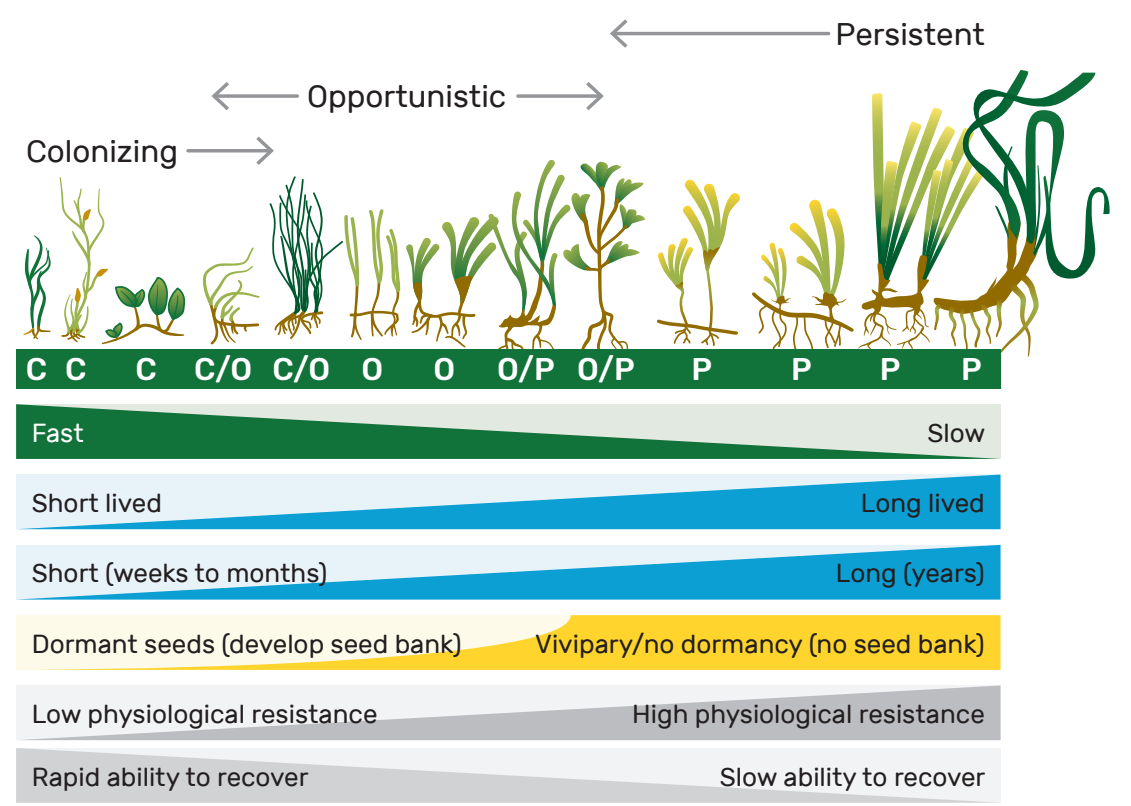

Abbreviations:

C: colonizing

O: opportunistic

P: persistent

Note: This graphic represents dominant traits among colonizing, opportunistic, and persistent seagrass genera with respect to shoot turnover, genet persistence, time to sexual maturity, and seed dormancy.

Source: Adapted from Kilminster et al. 2015 
Figure 13.10. Flowchart for General Design Principles for SAV and Kelp NNBF

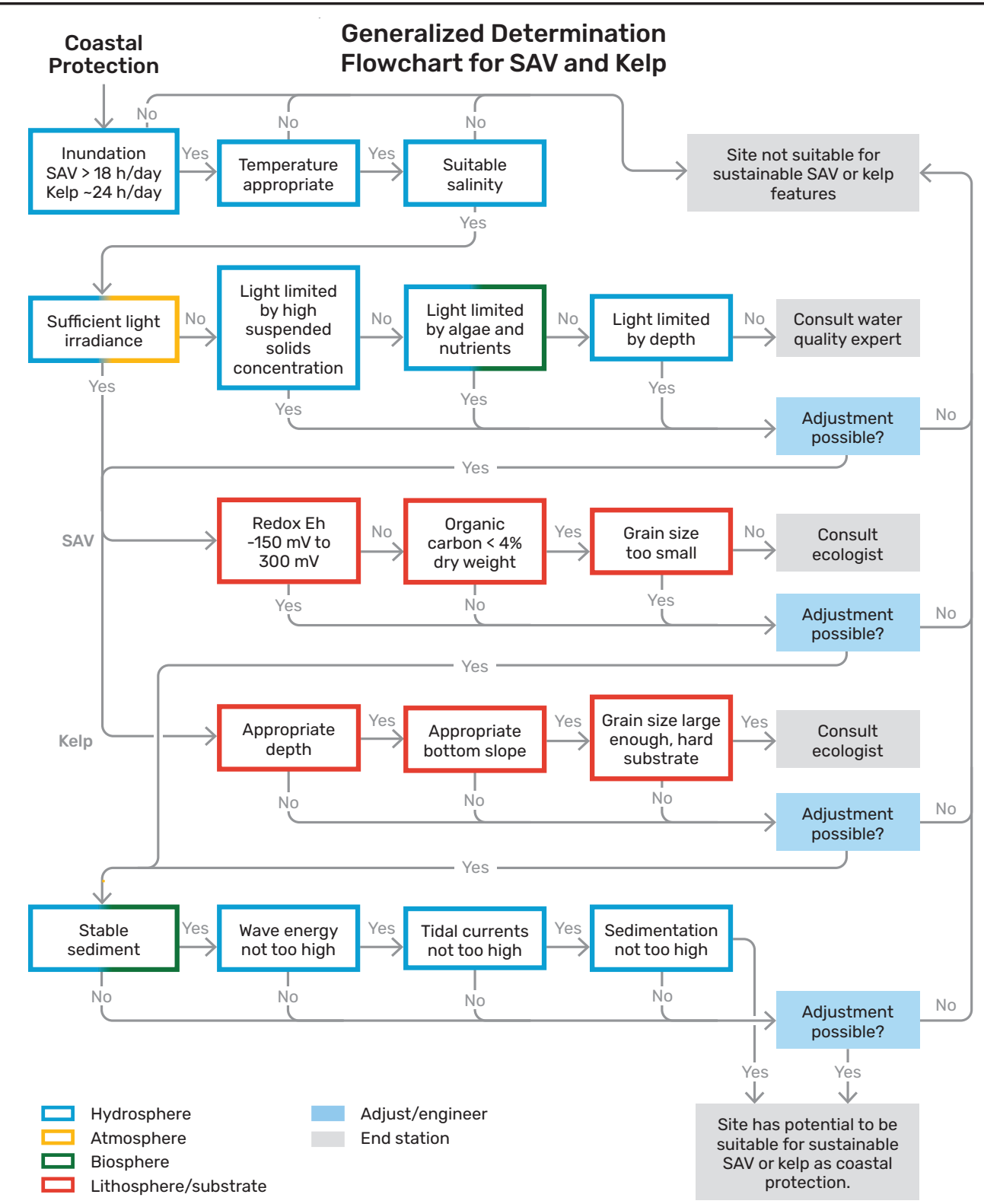

Abbreviations: h/day: hours per day, $\mathrm{mV}$ : millivolt, Redox Eh: oxidation-reduction potential in $\mathrm{mV}$ Note: The project timeline should be aligned with species life history and growth patterns.

Source: EcoShape 


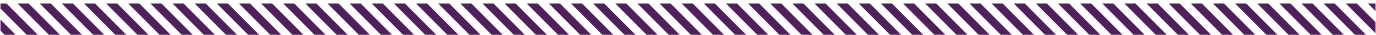

CASE STUDY:

Governance Example for SAV Permitting (Maryland and Virginia, United States)

In Galveston Bay, Texas, United States, a 900-acre, shallow-water cove named Snake Island Cove had lost more than 200 acres of SAV habitat since 1956, and the marsh was fragmenting and eroding rapidly ( 5 feet per year). From 2007 to 2011 , the Galveston Bay Foundation used 4,900 linear feet of geotextile tube breakwater to protect the marsh and created more than 75 acres of shallow-water habitat so that SAV could re-establish (ser-rrc.org 2021) (Figure 13.11).

Figure 13.11. SAV Habitat Expansion in Snake Island Cove, Texas
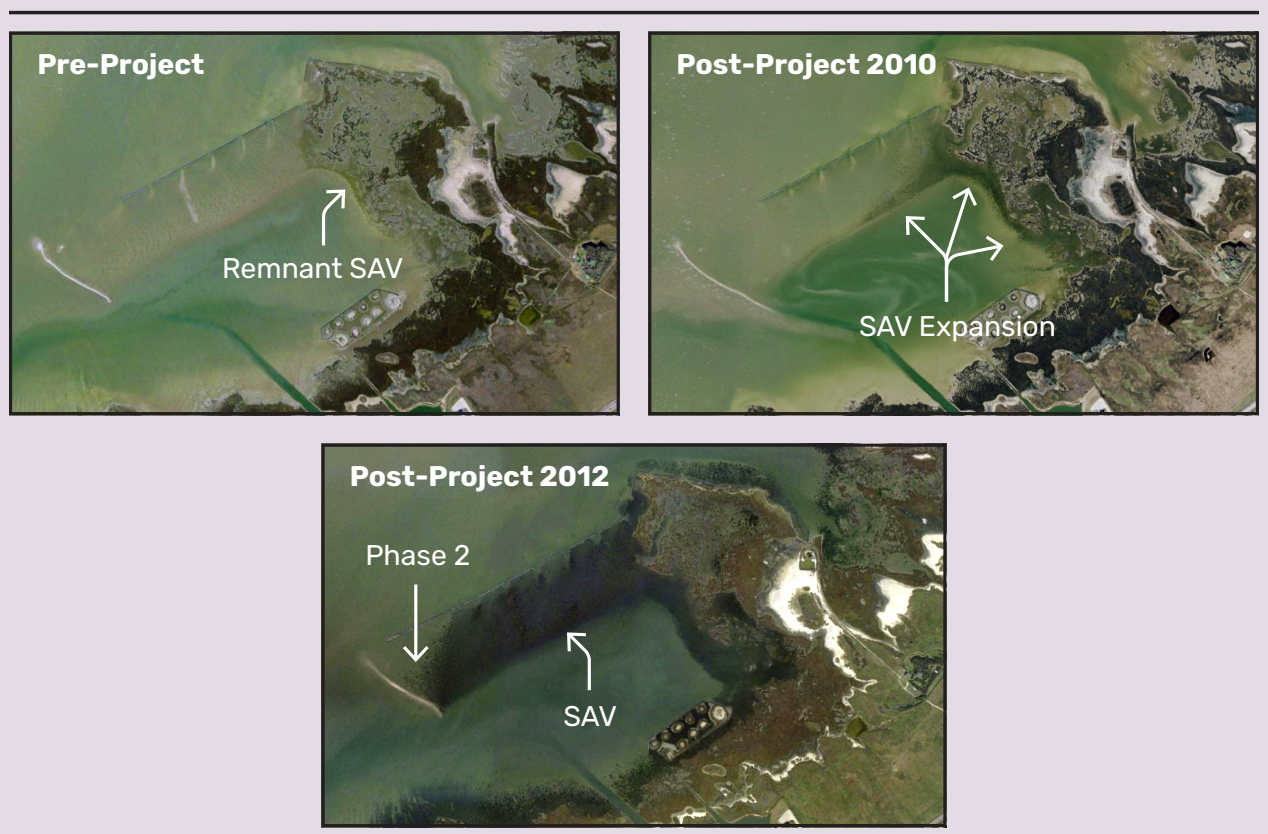

Note: This figure shows the expansion of remnant habitat over time as highlighted by arrows.

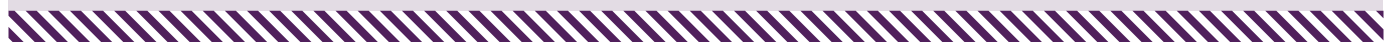




\subsubsection{Project Footprint and Area of Influence}

The project footprint is defined as the area within which all the direct and indirect effects of the project will occur. For SAV and kelp NNBF projects, the project footprint will be based on a number of factors such as project objectives, cost, available area, environmental influences (e.g., physical setting), availability of donor and source material (e.g., possible limits on the amount that can be collected from an existing SAV bed), and other NNBF components of the project. As mentioned previously, SAV complement other NNBF such as islands, reefs, and wetlands. Incorporation of SAV can affect the overall project footprint because SAV can change flow dynamics and wave energy in and around the immediate area.

SAV and kelp are affected by environmental factors such as sedimentation, water currents, temperature, and herbivory, among others, which need to be taken into account to successfully use SAV and kelp as an NNBF technique. SAV and kelp are sensitive to human-caused conditions as well, such as thermal effluent from power plants (Zieman 1975), anthropogenic pollution affecting water transparency and light availability (Fonseca, Kenworthy, and Thayer 1998), dredge and fill activities, vessel impacts, and propeller scarring. Practitioners should consider the project footprint as broadly as possible-from the outside (i.e., anthropogenic) and from the inside (i.e., how the SAV and NNBF project will influence the surrounding environment).

There are positive feedback mechanisms present in SAV and kelp beds that should be recognized when thinking about the project footprint. As living NNBF, plant systems have unique properties to self-perpetuate and affect their environment in ways that other NNBF techniques might not. For example, through stabilizing bottom sediments, the presence of SAV increases water clarity. This establishes a positive feedback loop in which the presence of SAV improves water quality, which, in turn, increases SAV survivorship, persistence, and potential bed expansion, as well as the bed's potential to reduce wave height and current velocity (van der Heide et al. 2012; de Boer 2007).

SAV beds also have a positive feedback mechanism to engineer or alter the water quality within the bed itself through the ability of the SAV leaves to attenuate waves and reduce sediment resuspension (Gurbisz et al. 2016; Orth et al. 2017). Studies on the ability of an SAV bed to resist storm damage illustrate the physical ability of the bed to increase the dampening effect of wave and current energy within the bed interior even when there is plant loss on the bed edges from severe erosional forces. In addition, studies have documented a positive 
"spill-over" effect whereby water quality conditions are improved in areas adjacent to the SAV bed, facilitating SAV recovery in those areas. Presumably, the larger the SAV bed, the greater the area of influence of the self-perpetuating, wave- and current-attenuation footprint and positive water quality feedback mechanism. The larger SAV bed also leads to greater resilience of the system as a whole (Gruber, Hinkle, and Kemp 2011; Orth et al. 2012; Gurbisz et al. 2016).

Assuming the hydrodynamic principles are similar between SAV beds and kelp forests, then we can also expect a similar positive feedback mechanism acting within kelp forests. That is, the greater the density and cover of kelp forest canopy, the greater the hydrodynamic stability within the forest. This is due to the wave- and current-attenuating properties and reductions in turbulent flow within the kelp forest canopy. This suggests that the greater the kelp forest cover, the more likely the forest will be resilient to perturbations and further canopy loss from storm events. The size and orientation of the kelp forest footprint also influences the flood risk management benefits conferred by a given forest. Also, this lack of turbulence helps to contain kelp spores within the forest, thereby perpetuating more kelp recruitment within the forest and a more stable forest ecosystem (Rosman et al. 2007).

\subsubsection{Baseline Conditions and Habitats}

SAV are found in a wide variety of basic settings, such as fluvial, intertidal, rocky intertidal, subtidal estuarine, subtidal coastal or nearshore (less than $10 \mathrm{~m}$ ), and deep water (greater than $10 \mathrm{~m}$ ). Broadly speaking, factors such as freshwater inflow, high turbidity, and tidal amplitude can inhibit SAV occurrence (Fonseca, Kenworthy, and Thayer 1998). The success of SAV used in an NNBF project in any of these settings primarily depends on the adequacy of the water quality and physical energy conditions (waves and currents, which influence sediment type) at the site being considered (Fonseca, Kenworthy, and Thayer 1998; Orth et al. 2017) (Figure 13.10). Adequate sediment to support the SAV root and rhizome structure is a necessity (Fonseca and Bell 1998). Habitat considerations for SAV and kelp are outlined in Figure 13.12. 
Figure 13.12. Habitat Considerations for SAV and Kelp

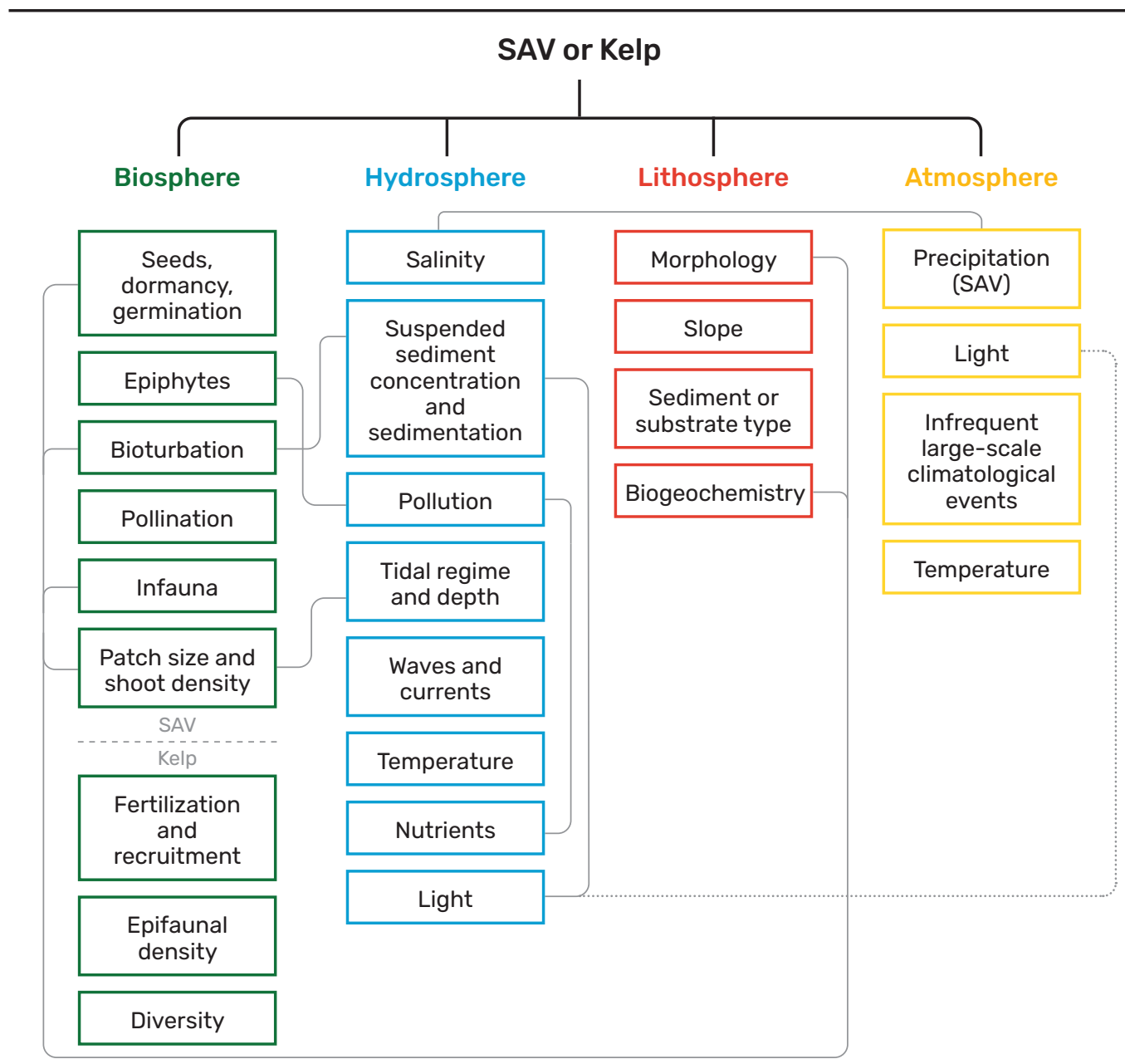

Source: EcoShape 


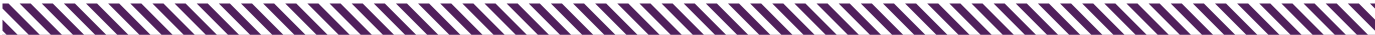

CASE STUDY:

Positive and Negative Feedback Loops (Chesapeake Bay, Maryland)

The loss of SAV from the Chesapeake Bay in the 1960s and 1970s and the current resurgence of certain species to more than 100,000 acres in 2018 (B. Landry [MDDNR], pers. comm., July 3,2018 ) are primarily attributed to the reductions in total point source nutrient loadings through management actions that began to show results in the early 1990s. Not only has SAV cover increased but species diversity and native to non-native species diversity have increased within the Chesapeake Bay (Orth et al. 2017; Figure 13.13). Once established, the positive feedback loop attributed to the SAV bed structure itself continues to increase water quality through reductions in wave height and current velocity and increases in sediment and nutrient deposition in the process (de Boer 2007). For example, models from van der Heide et al. (2007) show that as eelgrass density increases from 0 to 1,000 shoots per $\mathrm{m}^{2}$, the relative remaining maximum orbital velocity amplitude can decrease by as much as $80 \%$, and the maximum (free-stream) flow velocity can decrease as much as $40 \%$.

However, there are examples of negative SAV feedback loops within Chesapeake Bay as well. Coverage of eelgrass in the southern bay has continued to decline since the 1970s due to a combination of tropical storms, poor water quality, and increases in temperature. In exposed beds, the direct physical disturbance to the SAV root structure from erosional processes such as high currents and waves can undermine the ability of a bed to stabilize the sediments, and ultimately result in the loss of SAV plants (Gurbisz et al. 2016). Following eelgrass decline in the Wadden Sea, van der Heide et al. (2007) found that current and wave velocities were no longer reduced, and suspended sediment concentrations and related turbidity levels became too high to sustain eelgrass growth. This exemplifies a negative feedback, with the unstable conditions perpetuating more SAV plant loss, thereby reducing the ability of the SAV bed to recover through clonal growth (Orth et al. 2017). 
Figure 13.13. Examples of Positive and Negative Feedback Loops in SAV Habitat in Chesapeake Bay

\section{Chesapeake Bay Estuary}

Healthy Bay - Positive Feedbacks

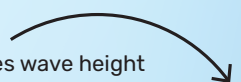

SAV minimizes wave height and current velocity, increases sediment deposition, and provides food and shelter for animals in the bay

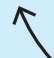

Together this system supports

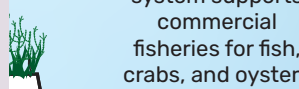

And enriches the water with oxygen that sustains high abundance of animals<smiles>CC</smiles>
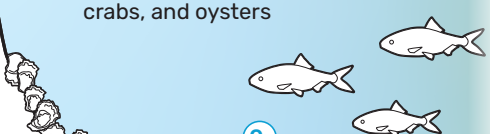<smiles>C1=CCC2(C1)CCC21CC1</smiles>

Degraded Ecosystem - Negative Feedbacks

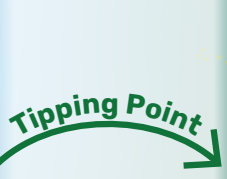

Nutrient runoff

Sedimentation

Overfishing

Storms Phytoplanktor

Nutrients from runoff feed plankton blooms

and decrease water

clarity; SAV health is

compromised and root

structures degrade

leading to bed

destabilization and

$$
\text { erosion }
$$

These microbes use

up all the oxygen.

creating anoxic zones that cannot

support fish, crabs, or

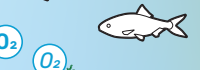

(02)

oysters

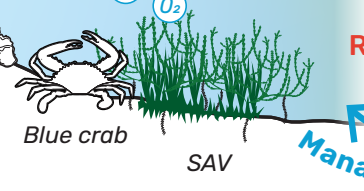

Reduce nutrient inputs

The diversity of animals in Chesapeake Bay relies on clean water to enable vegetation to thrive and support commercial fisheries
Agricultural and urban runoff has impaired the bay's water quality and led to low or no oxygen zones that cannot support most marine life 


\subsubsection{Developing Conceptual Designs}

Because SAV and kelp bed spatial patterns and distribution will vary depending on the physical energy (i.e., wave and current) of a site, the conceptual design of SAV or kelp projects need to consider the potential spatial dynamics of the bed at a given location. For example, SAV beds in high wave and current settings often form discrete, mounded patches that are dynamic and move (or migrate) spatially over time. At the other end of the spectrum, in relatively quiescent settings, SAV beds generally form physically stable, continuous meadows that can cover vast areas, provided there is sufficient sediment on top of the underlying bedrock (Fonseca 1990; Fonseca and Bell 1998). Information about a site's suitability for SAV or kelp can potentially be found using historical imagery, observations, or surveys. Table 13.4 provides instruction on how practitioners can walk through the site selection and conceptual design process for using SAV or kelp in an NNBF project.

Table 13.4. Steps in Site Selection and Conceptual Design Process for SAV and Kelp

\section{Step 1}

Confirm the historical presence of SAV or kelp in or near the site location, unless it is a newly constructed location.

\section{Details - the "how"}

Evidence includes historical SAV imagery, anecdotal information, SAV or kelp databases, or data on occurrence or distribution.

Examine the site for the presence of hardened structures (e.g., seawalls) and their impact on wave energy and erosion.

Consider boat wake energy (SAV) and boater use patterns.

\section{Step 2}

If historical habitat has been lost, confirm the cause of loss has been remedied and site conditions are suitable for SAV or kelp survival and establishment.

\section{Details - the "how"}

Helps to ensure adequate water quality (light, nutrients, temperature, salinity), sediment and substrate type and depth, and hydrodynamic conditions ( $<0.5 \mathrm{~m}$ for inshore kelp, $>2 \mathrm{~m}$ for offshore kelp, $<0.5 \mathrm{~m}$ for canopy-forming SAV, $<2 \mathrm{~m}$ for meadow-forming SAV) will support SAV or kelp. Determine whether there were successful SAV or kelp plantings in the area in the past, if SAV or kelp habitat is present within $500 \mathrm{~m}$ of the site, or if test plot planting survives for at least 12 months. If there is no evidence of historical habitat, suitable conditions may be created by using other NNBF (e.g., creation of islands or reefs could reduce wave energy to suitable levels for SAV). 


\section{Step 3}

Select the SAV or kelp species and optimal planting depth or method based on species in the local area or species historically present at the site location.

\section{Details - the "how"}

To match site conditions to the appropriate species, select source planting material to be the same as species historically present. This helps to ensure the species will be adapted to the salinity and depth zone at the site.

Sources of planting can be from aquatic nursery, greenhouse stock, or donor bed. Consider the utility and benefit of seeding in addition to planting or transplanting.

Ensure plants or algae are planted at the appropriate bottom depth relative to the tide level because exposure to air causes desiccation, and heat and light can be a limiting factor in deep or turbid waters.

\section{Step 4}

Design the project footprint and determine the total acreage. The total acreage may match the size of the historical habitat footprint or may be more extensive depending on the goals of the NNBF and local conditions. An NNBF project may be designed to create conditions for SAV or kelp growth.

Match the design of the plantings to the project size, physical environment, and species characteristics (e.g., growth rates).

\section{Details - the "how"}

Project area may be driven by cost, availability of donor material, and environmental factors such as physical setting.

Impacts to SAV donor beds need to be considered if they are being used. To minimize effects to donor beds, project proponents may need to limit the removal and consider both the density and overall acreage as a guide. Removal methods may be dictated by the jurisdiction with authority over the submerged bottom. For example, the State of Virginia (United States) encourages plants be removed by hand, but excavation by shovel is allowed if spacing is separated by at least $1 \mathrm{~m}$.

An understanding of the physical environment will inform the amount and spacing of SAV or kelp. The greater the sediment instability, as in high-energy environments, the closer the spacing of the plants. Often, they are planted at a 1-m spacing.

If appropriate, design of the project footprint should be linked to the local regulatory process. Project managers should provide regulators with enough detail about the project to start the review process.

\section{Step 5}

Select the planting method based on, for example, the physical energy, species growth rate, successful planting in other projects, budget, and plant survival rate.

\section{Details - the "how"}

Common methods for SAV planting include peat pot, staple, core tube, or seed or seedling broadcasting (Orth, Luckenbach, and Moore 1994). Common strategies for kelp include providing appropriate substrate for recruitment, recruitment enhancement, direct seeding, and transplantation (Fredriksen et al. 2020). Plant at depths determined by either local SAV or kelp beds or by appropriate bathymetric, hydrodynamic, and water quality conditions.

Plantings should occur quickly (within 24 hours) following collection (if applicable). Seasonal time frame for planting should be specific to the species and region. 


\section{Step 6}

Once the plan is drafted, inform the appropriate federal, state, or provincial entities with jurisdiction over submerged bottoms in the area of the plan to determine the appropriate regulatory approach for the project.

\section{Details - the "how"}

The design process is integrally connected to the relevant regulatory guidance and processes in the regions of interest. If the link to the regulatory process has not already been started, it should begin at this point. See also Section 13.3.3.

\subsubsection{Developing Detailed Designs and Specifications}

Some aspects of performance in an NNBF project can be controlled by the project design and other aspects cannot. Proper site evaluation is essential in developing the design and specifications for an NNBF project.

Poor site selection causes high failure rates of SAV projects (e.g., choosing sites with high wave energy, high levels of sediment movement and erosion, poor water quality, pollution, thermal stress due to effluent from nearby power plants). Factors outside a planner's control include illegal trawling damaging SAV beds, hull groundings, or stochastic events such as storms (Bayraktarov et al. 2016). Kelp can likewise be impacted by similar problems with site selection, as well as the presence of sea urchins, which can deplete the kelp forest.

SAV are well adapted to coastal photic waters throughout the world and occur on every continent except Antarctica (as mentioned in Section 13.2.1). Despite their presence in a wide variety of environments, they are vulnerable to many stressors, including elevated water temperature, physical stress from storm and wave events, reductions in water clarity, epiphytization, and disease. Year-to-year variation in extent and condition of SAV meadows is highly variable due to direct impacts, as well as long-term weather and climate influences (e.g., increased salinity due to seasonal droughts). SAV meadow response to positive and negative influences can vary dramatically over time and space, with some areas experiencing loss and other areas experiencing gain within close proximity. All of these factors result in SAV habitats being spatially dynamic and, thus, in need of robust monitoring efforts (see Section 13.7) to understand their condition and health trajectory.

Therefore, project planners must conduct a detailed and thorough evaluation of the proposed site to help to ensure the highest possible likelihood of success when using SAV or kelp in an NNBF project. 
Aside from the critical importance of site selection, other design specifications for SAV and kelp contribute to the success and performance of the feature. Once an appropriate site has been evaluated and selected, project planners need to consider proper specifications for planting SAV. These specifications include spacing intervals, bed configuration, planting depths, and anchoring methods. Project planners can rely on guidance documents developed by SAV restoration specialists (e.g., Fonseca, Kenworthy, and Thayer 1998). Such guidance provides detailed instructions on planting techniques, appropriate tools, stock selection (wild or laboratory), and other methods that can aid in the actual planting of SAV in the NNBF project.

In addition to site selection, critical design elements for kelp features relate specifically to the shallow reef relief (to which kelp attaches), the proportion of hard substrate and sand, and the type and size of substrate used for construction. It is important to consider both the biological and physical aspects of the intended kelp feature area and nearby areas that support kelp habitat. Ideal designs will consist of solid rock substrate with moderate sand coverage and moderately low relief rock reefs that incorporate small cobbles (rock size class 0 to $20 \mathrm{~cm}$ ) as opposed to large boulders (Deysher et al. 2002). Design materials that have been successful include quarry rock, concrete, concrete and rock combinations, and artificial materials (Deysher et al. 2002). Planting design specifications to be considered when using kelp in an NNBF project include anchoring methods for transplanting kelp, patch size, density, and variety of age classes (e.g., juvenile and adult kelp planted together) (Carney et al. 2005; Correa et al. 2006; Layton et al. 2019).

\subsubsection{Other Design Considerations}

NNBF practitioners should consider designing for resiliency of the SAV feature by creating SAV beds large enough to withstand floods and storms, with the knowledge that such events will likely remove leading edges of the SAV bed. SAV beds can attenuate flow during flood events even as the flood removes or damages SAV on the edge of the beds (Gurbisz et al. 2016). Because the inner parts of the SAV beds are protected from the high flows, large SAV beds will be more resilient to storms than small beds. In one example, an SAV shoal of approximately $50 \mathrm{~m}^{2}$ demonstrated flow attenuation during storms and the potential to recover lost SAV (Gurbisz et al. 2016). By anticipating the resiliency of designed SAV beds, project planners can create a feature that can reduce flow during flood events, and also set it up to recover naturally after a flood.

Additional design considerations that apply to both SAV and kelp features include, but are not limited to, developing a phased construction approach and schedule, planning to minimize negative effects on the environment (both natural habitat and other NNBF in the locale) during construction, and operations and maintenance phases, permitting, and public and worker health and safety. 


\subsubsection{Online Tools and Guidance Documents}

The following online tools and guidance documents can help project planners in designing and planning an NNBF project using SAV or kelp:

- Building with Nature (ecoshape.org 2020)

- National Oceanic and Atmospheric Administration (NOAA) Digital Coast Tools data site (coast.noaa.gov 2020)

- InVest (Integrated Valuation of Ecosystem Services and Tradeoffs)-an online mapping and modeling tool from the Natural Capital Project (naturalcapitalproject.standford.edu, n.d.)

- The Virginia Institute of Marine Science's project devoted to the restoration of SAV in the Chesapeake Bay and coastal bays, including monitoring reports, maps, data, baseline information, and ongoing research (vims.edu 2021)

- Guidelines for the Conservation and Restoration of Seagrasses in the United States and Adjacent Waters (Fonseca, Kenworth, and Thayer 1998)

- Greater Farallones Association Kelp Recovery (farallones.org 2020)

- Kelp Forest Restoration Project (santamonicabay.org 2014)

\subsubsection{Costs and Benefits}

Most of the information available on the costs of SAV and kelp plantings comes from published restoration studies.

There is a large range of costs per square meter in SAV restoration projects. According to a report submitted by the Keys Restoration Fund in 2015, 14 SAV restoration projects of varying size and complexity in the Florida Keys from 1986 to 2013 cost anywhere from USD\$5 to USD $\$ 550$ per $\mathrm{m}^{2}$ (Coastal Resources Group 2015). These projects used methods such as fill, transplant, stakes, and planting only, with projects using only planting costing USD\$140 per $\mathrm{m}^{2}$. Examples from Chesapeake Bay fall within this cost range but trend lower (USD\$8 to USD\$25 per $\mathrm{m}^{2}$ ), with an estimate cost of USD\$4 to USD\$7 per shoot (Treat and Lewis 2006). Given the variability in costs, protection of existing SAV is very likely to be more cost-effective than reintroduction.

An analysis of the breakdown of SAV project expenses indicated that planting accounted for approximately $20 \%$ of total project cost, whereas monitoring incurred the biggest portion of the budget (approximately 60\%; Treat and Lewis 2006). The remainder of the costs comprised mapping and ground truthing, contracting, and government oversight (Treat and Lewis 2006). 
The cost for transplanting juvenile kelp in one study was USD\$12 per plant (approximately 17 plants per $\mathrm{m}^{2}$ ), with a maximum cost estimate per $\mathrm{m}^{2}$ of USD $\$ 570$ due to variations in planting technique and the reliance on scuba divers for planting (Carney et al. 2005; Layton et al. 2020). Recent innovative methods such as green gravel-small rocks seeded with kelp and reared to sizes of 2 to $3 \mathrm{~cm}$-can be less expensive (USD\$7 per $\mathrm{m}^{2}$ ) compared to traditional methods (Fredriksen et al. 2020). Transplanting adult or juvenile kelp from a donor site would be expensive over time; designing a project to encourage natural recruitment would be more effective and less costly (Layton et al. 2020). In addition, costs for culling urchin grazers to a density that will allow kelp recovery can be steep; an estimate for reducing urchin densities is approximately USD $\$ 1,500$ per day for 685 days, for reduction from 1.5 to $0.1 \mathrm{~m}^{2}$ across a 1 square kilometer area (Tracey et al. 2014).

It is worth pointing out that if SAV is being used in an NNBF project in part to stabilize the sediment of another NNBF (e.g., a dune or an island), SAV can help to ensure the longevity and effectiveness of that feature. In these cases, any extra cost posed by installing SAV should be viewed in terms of an investment to the overall project.

\section{Benefits: Ecological Co-Benefits of SAV and Kelp}

The following are ecological co-benefits (many of which are difficult to monetize) provided by SAV and kelp:

- Provision of oxygen to waters and sediments

- Carbon sequestration from the atmosphere (also referred to as blue carbon)

- Organic carbon export to adjacent ecosystems

- Sediment stabilization

- Prevention of sediment resuspension

- Trapping and cycling of nutrients

- Water quality improvements (e.g., excess nutrient removal, leading to reduced potential for harmful algae blooms and anoxia, improved water clarity)

- Shoreline protection (wave attenuation)

- Habitat for microbes, invertebrates, and vertebrates

- Provision of food for coastal food webs

- Nursery habitat (e.g., fishes, and in particular, threatened and endangered juvenile salmon species [Shaffer 2003])

- Foraging habitat (especially for threatened and endangered species such as green sea turtles, manatees, and dugongs) 
As discussed previously, SAV and kelp have distinct economic value (Tuya, Haroun, and Espino 2014; McArthur and Boland 2006; Bennet et al. 2015; Duarte 2002). Beyond that, SAV can provide economic value to coastal communities in the form of sediment retention. Erosion along shorelines and wetlands is a significant and costly problem. As shorelines erode, more silt makes its way into the water and adjacent shipping channels and waterways, creating a need for more frequent dredging and channel maintenance, leading to higher costs. SAV planted along shorelines can stabilize them, trapping sediment and keeping it out of shipping channels. This can decrease the amount of dredging and channel maintenance necessary, saving local agencies money.

Comparing these economic benefits to the cost of the construction and monitoring of a coastal resiliency project is a critical component of the project planning. To garner support for an NNBF project that uses SAV or kelp, conducting a cost-benefit analysis is crucial, not only for the project itself, but for use as a case study to promote wide-scale adoption. It can be difficult to translate the ecological and secondary values of SAV or kelp into economic terms, but there are ways to do it (Tuya, Haroun, and Espino 2014; MacArthur and Boland 2006; Bennet et al. 2015).

\section{6 | Construction Considerations and Methods}

Proper construction considerations are essential and will determine the success of an NNBF project. Because SAV and kelp are living entities, as opposed to some other NNBF techniques, some particular requirements must be met to be successful.

There are several factors to consider when beginning a construction project using SAV in an NNBF project. The flow dynamics of a proposed site have to be properly evaluated in order for SAV planting to be a feasible technique. Generally, low-flow areas are conducive to SAV beds and recruitment. Lower current velocities promote SAV recruitment areas (e.g., less than $2 \mathrm{~m}$ per second). Other existing human-made features in an area can affect water flow. For instance, vertical breakwaters in a high-current environment displace tidal flows and increase the magnitude of the tidal current. This can cause scour to adjacent areas, or a potential proposed SAV bed.

Turbidity is another important factor during construction that could impact SAV. Depending on the water quality standards required by a local government, project managers may need to calculate a plume area caused by the construction activities to prevent damage to existing SAV meadows. Another requirement might be using fixed turbidity barriers aligned with the direction of the currents to help protect existing SAV beds. Because of the turbidity caused by construction, it might be necessary to wait before planting SAV until conditions are suitable. 


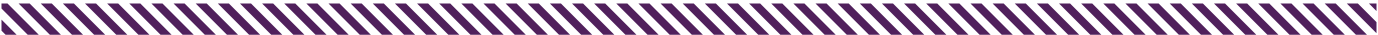

\section{CASE STUDY:}

\section{La Quinta Channel Expansion (Corpus Christi, Texas, United States)}

This case study, based on Maristany, Horine, and Carangelo (2018) provides an example of a successful NNBF project with wetland, SAV, and constructed features. To address the objectives of the Port of Corpus Christi during the La Quinta Channel expansion and deepening projects, an 80-ha site was constructed to beneficially reuse dredge material and protect the shoreline adjacent to the La Quinta Channel from predominant wave conditions. Construction at the site included creating an armored emergent levee for wave protection, creating a submerged nearshore levee, and placing fill material at elevations favorable for SAV propagation and creation of marsh habitat. Following construction, the La Quinta Terminal Aquatic Habitat Mitigation Project (Figure 13.14) was completed in two phases. In Phase I, aquatic habitat mitigation berms were constructed and then planted with smooth cordgrass (Spartina alterniflora), a type of marsh vegetation, creating 3.2 ha of Spartina alterniflora habitat. In the second phase, a $450-\mathrm{m}$-long earthen protection berm structure was constructed and covered with a geotextile scour apron to reduce erosion. In addition, approximately 1 ha of estuarine marsh habitat and more than 8 ha of SAV shoal grass (Halodule wrightii) habitat were created. The largest known actively planted SAV project in the State of Texas, after Phase I and Phase II, more than 5 ha of estuarine marsh habitat and more than 10 ha of shoal grass were planted in addition to the 450-m berm. When Hurricane Harvey impacted the site in August 2017, there were no observed losses to marsh or SAV habitat and there was only minor structural damage to the berm even though storm conditions exceeded design of the berm. 
Figure 13.14. La Quinta Terminal Aquatic Habitat Mitigation Project

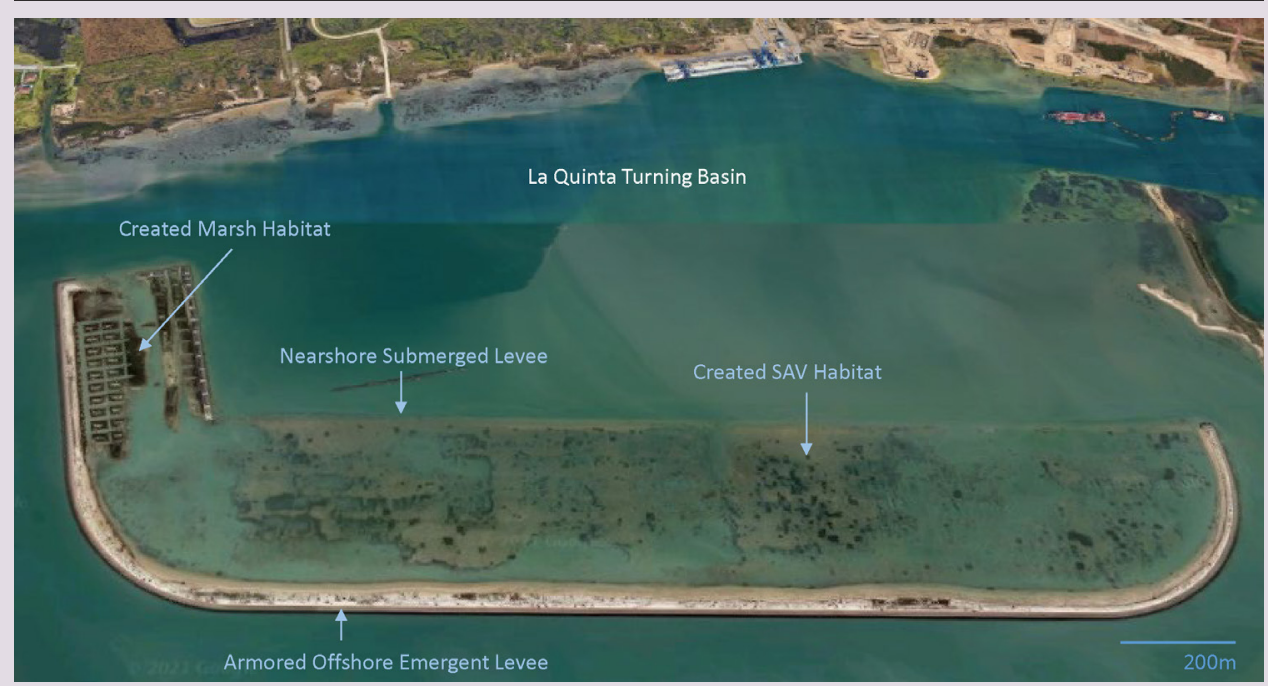

Source: Google Earth

\section{NHIHก)}

To avoid damage to substrate and keep it conducive to future SAV planting, work should ideally be conducted from a shallow-draft barge, floating above any existing substrate and habitat. If a site has been altered during construction, it might be necessary for project managers to restore the substrate so that SAV planting is possible. Boats can damage SAV meadows through propeller scarring, hull groundings, and mooring anchors by uprooting SAV, excavating sediment, and modifying the biophysical properties of the sediment. It is important to ensure the bottom conditions are appropriate so that project managers can use SAV as an NNBF technique. Repairing substrate can also make it suitable for future SAV colonization (Kenworthy et al. 2018). Failure to account for gouges caused by vessel damage could limit the success of SAV plantings in an NNBF project. Protecting newly planted beds from disturbance is obviously crucial to their continued development, and functionality as an NNBF. One way to avoid damage to an SAV meadow could be to install signs to alert boaters, so as to protect it from propeller damage, groundings, and bottom scouring. 
The timing of planting SAV is important and may depend on whether practitioners are transplanting SAV shoots or are using seeds. Marion and Orth (2010) collected flowering shoots of eelgrass (Zostera marina) in mid-May through early June, when seeds were being released from the flowers. Seeds were collected, stored at $25^{\circ} \mathrm{C}$, and broadcasted in the fall before germination in November. Planting SAV, however, should be done in the spring (April through early June in the Northern Hemisphere) (Fonseca, Kenworthy, and Thayer 1998).

Construction methods for kelp habitat creation often focus on development of shallow rocky reefs to support kelp growth. Site selection and rocky reef placement should consider both oceanographic and geomorphological conditions to identify a site likely to be self-sustaining physically, biologically, and ecologically. It is important to identify site conditions that avoid scour or sinking of rocky reef materials and also provide necessary water quality and sediment movement for kelp establishment. Ideal conditions include sites of 8 to $20 \mathrm{~m}$ (depending on location and water clarity), with bedrock covered in 0.5 to $0.75 \mathrm{~m}$ of sand to ensure that the artificial reef will not sink below the sand surface (Ambrose et al. 2018). Construction using long-lasting materials like quarry rock or concrete allow for physical persistence of the hard rocky substrate to which kelp will attach. Natural rock materials are preferred for shallow rocky reef construction, but concrete and other non-natural materials can be used as well. The green gravel technique, in which kelp spores are seeded on gravel in a laboratory setting and transplanted to the field once the kelp are 2 to $3 \mathrm{~cm}$ in size, may also be a promising method or component for kelp habitat construction (Fredriksen et al. 2020). Placement of a constructed kelp feature should be close enough to other existing kelp beds to ensure connectivity and propagule exchange, allowing for self-sustaining kelp systems. Kelp establishment techniques can involve transplanting and securing of laboratory-grown or drifting algae into the marine environment, usually by divers. The kelp may also be moved while still attached to boulders, from one productive site (donor bed) to the injured location (recipient bed). Yet another method involves cutting the receptacles (reproductive structures) from donor beds and placing them in mesh bags and allowing them to release their gametes (reproductive material) onto the rocks, as they would if adult plants were present (NOAA 2015).

Choosing the correct season for transplanting kelp is essential because the relative presence of grazers and the strength and frequency of storms, as well as the right water temperatures and amount of available light, can all play a role in the success of the transplants. For example, Carney et al. (2005) found that transplanting bull kelp (Nereocystis luetkeana) in early spring (i.e., March) was the best season for successful transplanting, because there were fewer grazing gastropods (Lacuna vincta) present, giving the kelp a chance to establish and grow. 
The size of the transplants plays a role in the success of kelp establishment. Smaller stipes, approximately 6 to $12 \mathrm{~cm}$, showed survival rates that matched or exceeded survival rates of larger (e.g., greater than $1 \mathrm{~m}$ ) transplanted kelp in other studies (Carney et al. 2005; Duggins et al. 2001). Smaller stipes are easier to transport, and more stipes can be transplanted. Juvenile kelp stipes are extremely vulnerable to damage, even from small injuries, so users must be very careful in collecting stipes for transplanting.

The source of the transplanted kelp matters; kelp from a wave-sheltered site had high mortality when transferred to a wave-exposed site, likely owing to the differences in phenotypic blade morphologies (Druehl 1978). Carney et al. (2005) urged practitioners to carefully consider the potential impacts to an existing kelp forest when choosing transplants, and to instead use kelp from areas where they are unlikely to survive to maturity (i.e., the midto low-intertidal zone).

There are several methods for attaching kelp stipe transplants, including plastic clips with epoxy, but tying transplants to substrate using seeded twine or cloth strips appears to be the most effective attachment method (Carney et al. 2005; Duggins et al. 2001).

\section{7 | Monitoring and Adaptive Management}

This section describes overarching considerations when monitoring SAV meadows and kelp forests, including the physical and biological parameters of concern.

Following site assessment, design, and implementation, a process of continual evaluation of project function and viability is needed. This process of monitoring consists of making repeatable observations and measuring a variety of parameters in a systematic way. Although monitoring may require project resources over a long term, the ability to detect and correct problems early will often result in saved time and effort. Most marine aquatic vegetation (SAV and macroalgae) monitoring has been done to assess the condition of these habitats or understand overall estuary health. Despite this, the monitoring protocols are also applicable at smaller scales associated with individual projects.

When considering a monitoring strategy for SAV in the context of its ecosystem services for shoreline protection, it is important to understand whether the changes evident within the project (e.g., gain or loss of SAV, bed fragmentation) are a function of larger ecosystem trends or a result of engineering or design aspects of the project. Thus, some level of monitoring both inside and outside the project area is recommended. 


\subsubsection{Scale of Monitoring}

Existing monitoring strategies for SAV meadows range in scale from whole estuaries and coasts to small plots associated with individual research projects. A number of protocols and monitoring strategies have been adopted that have potential utility for assessing the success of SAV NNBF efforts. The Texas Coastal Bays and Estuaries Program has instituted a monitoring program for Texas coastal waters modeled on work (Neckles et al. 2012) that includes three tiers of monitoring for SAV ranging from remotely sensed data (Tier 1) to detailed in situ sampling (Tier 3) (Table 13.5). Tier 1 data provide the landscape distribution and extent necessary to understand system-wide changes, whereas Tier 3 data allow assessment of plant health and ecological processes in a bed. Neckles et al. (2012) outlined an approach by which the data from each tier informed each of the others and allowed the detailed information to be defensibly extended over larger geographies. This approach also has the potential to identify trends occurring within a project to be compared to natural processes nearby. A similar strategy of integrating in situ measurements with repeated aerial mapping has long been operational in the Indian River Lagoon system of eastern Florida. The St. Johns River Water Management District has established 59 fixed transects over 300 kilometers of the lagoon. A variety of SAV parameters are recorded at fixed intervals along these transects, complementing the areal extent, distribution, and patch density derived from the remotely sensed data (Virnstein, Steward, and Morris 2007).

In October 2017, the Gulf of Mexico Alliance's Habitat Resources Team convened a workshop of more than 30 SAV experts to identify monitoring needs in the Gulf of Mexico. Table 13.5 shows monitoring parameters identified by workshop attendees organized in the context of the three-tiered approach developed by Neckles et al. (2012). The following tier definitions are based on Neckles et al. (2012) but slightly modified to be more applicable at the international scale:

- Tier 1 characterizes a few ecosystem properties simultaneously at a very large spatial scale, typically high-resolution, remote-sensing methods.

- Tier 2 includes broadscale surveys in bays, sounds, and lagoons used to address specific environmental issues or biotic and abiotic ecosystem properties at a finer resolution that provides more detailed information using field in-water sampling.

- Tier 3 consists of small area surveys addressing a greater number of properties at a much smaller number of locations or index sites. These locations can be processed-based investigations or hypothesis testing conducted at a site or sites within the larger system.

Note that some parameters occur in multiple tiers. This is a function of how the information from that parameter is being applied. 
Table 13.5. Parameters to Be Measured under the Three Tiers Monitoring Approach and Grouped by Parameter Type

\begin{tabular}{|c|c|c|c|}
\hline Tier & $\begin{array}{c}\text { Parameter } \\
\text { type }\end{array}$ & \multicolumn{2}{|c|}{ Parameter } \\
\hline \multirow[t]{3}{*}{1} & SAV & $\begin{array}{l}\text { - Acreage } \\
\text { - Bed patchiness } \\
\text { - Species composition } \\
\text { - Geographic distribution }\end{array}$ & \\
\hline & Macroalgal* & $\begin{array}{l}\text { - Presence or absence } \\
\text { - Geographic distribution } \\
\text { - Bed extent and perimeter (including }\end{array}$ & olygons, linear bands, isolated small clusters) \\
\hline & Conditional & $\begin{array}{l}\text { - Propeller scarring } \\
\text { - Bioturbation }\end{array}$ & \\
\hline \multirow[t]{5}{*}{2} & SAV & $\begin{array}{l}\text { - Canopy height } \\
\text { - Observed condition } \\
\text { - Deep edge } \\
\text { - Percent cover }\end{array}$ & $\begin{array}{l}\text { - Percent cover by species } \\
\text { - Biomass } \\
\text { - Species composition }\end{array}$ \\
\hline & Environmental & $\begin{array}{l}\text { - Depth } \\
\text { - Sediment or substrate (grain size, or }\end{array}$ & anic content) \\
\hline & Macroalgal* & $\begin{array}{l}\text { - Presence or absence } \\
\text { - Drift or attached } \\
\text { - Holdfast diameter and stipe count } \\
\text { (above } 1 \mathrm{~m} \text { ) }\end{array}$ & $\begin{array}{l}\text { - Canopy species composition } \\
\text { - Canopy density } \\
\text { - Grazer presence and abundance }\end{array}$ \\
\hline & Water Quality & $\begin{array}{l}\text { - Dissolved oxygen } \\
\text { - Light attenuation (photosynthetic } \\
\text { active radiation profile and Secchi) } \\
\text { - Ph } \\
\text { - Salinity }\end{array}$ & $\begin{array}{l}\text { - Temperature } \\
\text { - Turbidity and TSS } \\
\text { - Color or colored dissolved organic matter } \\
\text { - Chlorophyll-a }\end{array}$ \\
\hline & Community & $\begin{array}{l}\text { - Community composition, including } \\
\text { - Fish counts (along transect, within c } \\
\text { - Invertebrate community sampling } \\
\text { - Zooplankton sampling }\end{array}$ & $\begin{array}{l}\text { her constituents (e.g., sponges) } \\
\text { ladrat, and roving observations) }\end{array}$ \\
\hline
\end{tabular}




\begin{tabular}{|c|c|c|c|}
\hline \multirow[t]{2}{*}{ Tier } & $\begin{array}{c}\text { Parameter } \\
\text { type }\end{array}$ & \multicolumn{2}{|c|}{ Parameter } \\
\hline & Conditional & $\begin{array}{l}\text { - Propeller scarring } \\
\text { - Bioturbation } \\
\text { - Elemental composition of leaf tissue }\end{array}$ & carbon, nitrogen, phosphorus) \\
\hline 3 & SAV & $\begin{array}{l}\text { - } \text { Biomass } \\
\text { - Canopy height } \\
\text { - Observed condition } \\
\text { - Stable isotope analysis of carbon and } \\
\text { nitrogen } \\
\text { - Percent cover } \\
\text { - Percent cover by species } \\
\text { - Shoot count and density } \\
\text { - Species composition } \\
\text { - Elemental composition of leaf tissue } \\
\text { (carbon, nitrogen, phosphorus) }\end{array}$ & $\begin{array}{l}\text { - Flowering } \\
\text { - Presence or absence of keynote species } \\
\text { - Growth and productivity } \\
\text { - Stable isotopes (carbon, nitrogen, } \\
\text { phosphorus, sulfur) } \\
\text { - Herbivory } \\
\text { - Genetic diversity } \\
\text { - Stressor proteins } \\
\text { - Leaf allometry }\end{array}$ \\
\hline & Environmental & $\begin{array}{l}\text { - Sediment or substrate (grain size, org } \\
\text { - Porewater chemistry } \\
\text { - Wave energy } \\
\text { - Tidal exposure } \\
\text { - Freshwater inflow }\end{array}$ & anic content) \\
\hline & Macroalgal* & $\begin{array}{l}\text { - Biomass } \\
\text { - Canopy height } \\
\text { - Drift versus attached algae }\end{array}$ & \\
\hline & Water Quality & $\begin{array}{l}\text { - Dissolved oxygen } \\
\text { - Light attenuation (LI-COR and } \\
\text { Secchi) } \\
\text { - TSS } \\
\text { - Colored dissolved organic matter and } \\
\text { NTU } \\
\text { - Chlorophyll-a } \\
\text { - Salinity }\end{array}$ & $\begin{array}{l}\text { - Temperature } \\
\text { - Turbidity } \\
\text { - Nutrients } \\
\text { - Polycyclic aromatic hydrocarbons } \\
\text { - Ph } \\
\text { - Stable isotopes (carbon, nitrogen, } \\
\text { phosphorus, sulfur) }\end{array}$ \\
\hline & Community & $\begin{array}{l}\text { - Community composition, including } \\
\text { other constituents (e.g., sponges) } \\
\text { - Fish counts (along transect, within } \\
\text { quadrat, and roving observations) } \\
\text { - Zooplankton sampling } \\
\text { - Epiphytic grazers } \\
\text { - Invertebrate community sampling }\end{array}$ & $\begin{array}{l}\text { - Epiphytic load } \\
\text { - Faunal usage and abundance } \\
\text { - Herbivory } \\
\text { - Presence or absence of keystone species } \\
\text { - Secondary productivity }\end{array}$ \\
\hline
\end{tabular}




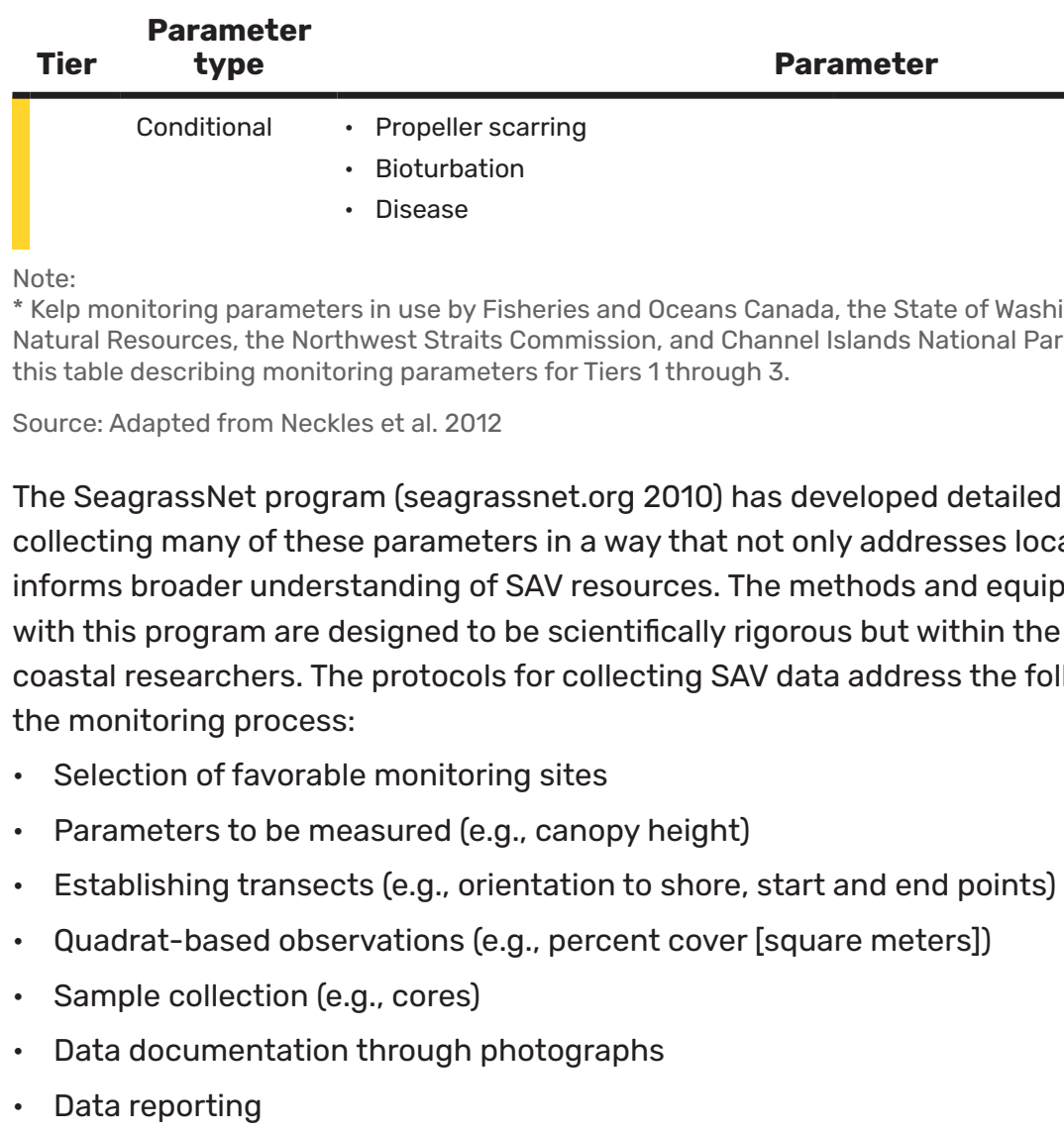

The Seagrass-Watch program (seagrasswatch.org 2020) is similar and collects similar parameters. Both efforts highlight the importance of deciding the objective of any monitoring effort, selecting the correct parameters to monitor, establishing consistent protocols for data collection, and setting appropriate goals and metrics.

A 2017 National Academy of Sciences (The National Academies of Sciences, Engineering, and Medicine 2017) report describes general approaches to monitoring SAV restoration projects to determine whether intended targets were being achieved. These guidelines could be applied in the context of an NNBF project and can be broken down by the type of monitoring process needed, as follows:

- Construction monitoring is an essential mapping component for status and trends documentation of SAV meadow areal extent and patchiness before and immediately after the next primary growing season post-restoration.

- Performance monitoring is an assessment program (see Neckles et al. 2012) to evaluate achievement of restoration objectives using fixed stations that are sampled annually. 
- Adaptive management monitoring is an optional, integrated approach that includes permanent stations and transects that are aligned with high-resolution construction monitoring to examine the presumptive factors associated with changes in SAV areal extent, depth limits, and patchiness.

It is important to have a clear idea of the desired target species when using SAV as an NNBF technique, as well as a commitment to long-term monitoring. By examining the area surrounding the project site, project managers can determine the appropriate SAV species to plant. A fast-growing, subordinate species such as shoal grass can initially pave the way for a climax species such as turtlegrass (Thalassia testidunum), but without monitoring and adaptive management, improper nutrient conditions could prevent the target species from establishing.

Establishing an adequate time frame for monitoring is critical. Subordinate SAV species such as shoal grass or manatee grass (Syringodium filiforme) can take 2 to 3 years to establish. By comparison, turtlegrass recovery is much slower, taking 5 to more than 10 years. In one study, turtlegrass recruitment was incomplete 5 to 7 years after planting (Furman et al. 2018). Managing expectations about SAV outcomes is important to properly frame metrics of success.

Because of their natural resource and commercial importance, kelp forests are regularly monitored by a variety of public- and private-sector organizations. These monitoring techniques can be transferred to monitoring an NNBF project using kelp. The parameters of concern in kelp monitoring strongly mirror those relevant to SAV.

\subsubsection{Methods for Gathering Monitoring Information}

Methods for gathering monitoring information fall into the following three general categories based on the observation platform:

- Aerial - Using remote-sensing technologies

- Surface - Using kayaks, jet skis, or other small boats

- Subaqueous - Relying on diver surveys

Remote-sensing approaches take advantage of the surface expression of many kelp forests and their strong near-infrared reflectivity. These make them relatively easy to detect over extensive geographies. However, given the depths at which kelp can occur, there is likely some portion of kelp forests that is undetected using these methods.

Surface methods have lower logistical requirements but are more limited in terms of the number of observations that can be completed within a certain time frame. However, due to the ability to come in direct contact with the kelp, more information can be obtained. 


\subsubsection{Additional Considerations in Implementing Monitoring}

After identifying the goals, relevant parameters, and metrics of a monitoring plan, several implementation considerations must be addressed. The long-term value of any monitoring effort depends on consistent, comparable results. Three important elements that improve comparability are trained observers, sound sampling protocols, and environmental conditions.

Individuals collecting data or interpreting field conditions (e.g., bed patchiness) should be familiar with their subject and have a shared perception of the target with others collecting data. Mentoring, example photography, and periodic cross-checking can help ensure that results among analysts are consistent and that expertise is preserved over time.

Field data forms and templates and well-documented sampling protocols are important to scientifically reliable data, especially for chemical and biological information.

Finally, collecting monitoring data at the right time of day and year and under the right environmental conditions will help ensure comparable data. Field observations should be made when key animal species of interest are present, when aquatic vegetation is at high biomass, or when vegetation diversity is at a maximum. Collecting data at the proper tidal stage can make physical observations easier (e.g., snorkeling to do SAV shoot counts). Remote and field observations of kelp forests should take place when currents are minimal to avoid the situation where the canopy is prevented from reaching the surface. This will also make dive operations more efficient.

The general monitoring guidelines presented or referenced here can be considered a framework for individual project-based monitoring plans. Specific target metrics are not included because they should be determined in the context of each project's goals and the ecosystem functions of concern. Several of the source documents for this section have detailed field data-recording protocols that should be useful for many other projects.

\subsubsection{Adaptive Management}

Adaptive management for both SAV and kelp is critically tied to the results of ongoing monitoring. Adaptive management of any feature relies on (1) identification of clear goals and performance criteria from the project start, (2) developing an understanding of whether project goals are being met through monitoring, and (3) determining the reasons for failure if goals are not being met. If aspects of the project are not reaching intended goals, adaptive management is required to address the reasons for failure and adjust the project approach. Following adaptive management actions, additional monitoring will confirm whether project goals are on track once again. 


\section{8 | Inherent Uncertainties}

In many settings, SAV are ephemeral habitats that may be transformed to other habitat types over time. Shallow-water systems are dynamic-sediments can shift, SAV beds can migrate, and different SAV species can establish in succession. By recognizing that SAV habitats will change naturally, and that external factors such as sediment transport, weather events, and climate change can come into play, practitioners can design for these uncertainties.

Ocean temperature changes on the local, regional, and global scales are a potential threat to kelp forest systems worldwide (Steneck et al. 2002). This threat is evidenced in the regional impacts caused by the El Niño - Southern Oscillation, which can lead to kelp habitat degradation as a result of increased water temperature, decreased nutrient availability, and changes in wave intensity (Edwards 2019). Similar to SAV, reductions in water quality from increases in turbidity associated with coastal development have the potential to reduce kelp abundance and limit their distribution. Because of their fast growth rate, kelp is capable of responding to disturbances. An important exception to this resiliency is warming ocean temperatures because kelp generally require cold, nutrient-rich water. Warming ocean trends in various parts of the world (eastern Canada, Sweden, and Australia) have contributed to a shift from kelp-dominated coastal areas to turf-forming or invasive algae (Filbee-Dexter, Feehan, and Scheibling 2016).

\section{9 | Gaps and Future Directions}

In the future, changing ocean temperatures and sea-level rise are expected to present challenges to coastal resiliency. If carefully planned for, SAV can be a part of NNBF projects that provide coastal protection in the face of changing conditions. Data on sea-level rise forecasts at a proposed site can allow managers to design a project to have space for SAV colonization and species succession as conditions change in the future.

Collecting baseline data is crucial in informing future decisions. Obtaining metrics for baseline information such as beach erosion rate and beach-profile changes would be very useful in quantifying the contribution of SAV to coastline protection. In projects where SAV has been planted near beaches to prevent erosion, using remote-sensing techniques (Cheng, Wang, and Guo 2016)-such as the lidar method and unmanned aerial vehicles-to collect images before and after storm events can help determine the efficacy of SAV in providing storm protection. 


\subsection{0 | References}

Ambrose, R., P. Raimondi, S. Anderson, M. Baskett, J. Caselle, M. Carr, C. Edwards, et al. 2018. Ocean Restoration Methods: Scientific Guidance for Once-Through Cooling Mitigation Policy. Oakland, CA: California Ocean Science Trust.

Arkema, K., R. Griffin, S. Maldonado, J. Silver, J. Suckale, and A. D. Guerry. 2017. “Linking Social, Ecological, and Physical Science to Advance Natural and Nature-Based Protection for Coastal Communities." Annals of the New York Academy of Sciences 1399 (1): 5-26. doi:10.1111/nyas.13322.

Batiuk, A., R. Orth, K. Moore, W. Stevenson, J. Stevenson, L. Staver, V. Carter, et al. 1992. Chesapeake Bay Submerged Aquatic Vegetation Habitat Requirements and Restoration Targets: A Technical Synthesis. USEPA-CBP 68-WO-0043. Annapolis, MD: U.S. Environmental Protection Agency.

Bay Foundation, The. 2018. State Coastal Conservancy Final Report: Southern California Kelp Forest Hydrodynamics Study. Grant No. 15-013. Los Angeles, CA: The Bay Foundation.

Bayraktarov, E., M. I. Saunders, S. Abdullah, M. Mills, J. Beher, H. P. Possingham, P. J. Mumby, and C. E. Lovelock. 2016. "The Cost and Feasibility of Marine Coastal Restoration." Ecological Applications 26 (4): 1055-1074.

Borum, J., C. M. Duarte, D. Krause-Jensen, and T. M. Greve. 2004. European Seagrasses: An Introduction to Monitoring and Management. Copenhagen, DE: Monitoring and Managing of European Seagrass Beds (M\&MS) Project.

Bouma, T. J., M. B. De Vries, E. Low, G. Peralta, I. V. Tánczos, J. van de Koppel, and P. M. J. Herman. 2005. "Trade-Offs Related to Ecosystem Engineering: A Case Study on Stiffness of Emerging Macrophytes." Ecology 86 (8): 2187-2199.

Bruun, P. 1962. "Sea-Level Rise as a Cause of Shore Erosion." Journal of the Waterways and Harbors Division 88 (1): 117-130.

Burrell, C., and J. Schubel. 1977. "Seagrass Ecosystem Oceanography." In Seagrass Ecosystems. Edited by C. P. McRoy and C. Helfferich. New York: Marcel Dekker, Inc.

Cardoso, P. G., D. Raffaelli, and M. A. Pardal. 2008. "The Impact of Extreme Weather Events on the Seagrass Zostera noltii and Related Hydrobia ulvae Population." Marine Pollution Bulletin 56 (3): 483-492.

Carney, L. T., J. R. Waaland, T. Klinger, and K. Ewing. 2005. "Restoration of the Bull Kelp Nereocystis luetkeana in Nearshore Rocky Habitats." Marine Ecology Progress Series 302: 49-61.

Carr, M. H., and D. C. Reed. 2016. "Shallow Rocky Reefs and Kelp Forests." In Ecosystems of California. Edited by H. Mooney and E. Zavaleta. Oakland, CA: University of California Press.

Chen, H., X. Liu, and Q. P. Zou. 2019. "Wave-Driven Flow Induced by Suspended and Submerged Canopies." Advances in Water Resources 123: 160-172. 
Cheng, J., P. Wang, and Q. Guo. 2016. "Measuring Beach Profiles along a Low-Wave Energy Microtidal Coast, West-Central Florida, USA." Geosciences 6 (4): 44.

Christianen, M. J. A., J. van Belzen, P. M. J. Herman, M. M. van Katwijk, L. P. M. Lamers, P. J. M. van Leent, and T. J. Bouma. 2013. "Low-Canopy Seagrass Beds Still Provide Important Coastal Protection Services." PLOS ONE 8 (5): e62413. doi:10.1371/journal. pone.0062413.

coast.noaa.gov. 2020. Tools. Office for Coastal Management DigitalCoast. https://coast.noaa. gov/digitalcoast/tools/.

Coastal Resources Group, Inc. 2015. Appendix B: Past Keys Seagrass Restoration Projects Review and Cost Analyses Report. Keys Restoration Foundation In-Lieu Fee Mitigation Program. Venice, FL: Coastal Resources Group, Inc.

Correa, J. A., N. A. Lagos, M. H. Medina, J. C. Castilla, M. Cerda, M. Ramírez, E. Martínez, et al. 2006. "Experimental Transplants of the Large Kelp Lessonia nigrescens (Phaeophyceae) in High-Energy Wave Exposed Rocky Intertidal Habitats of Northern Chile: Experimental, Restoration and Management Applications." Journal of Experimental Marine Biology and Ecology 335 (1): 13-18.

de Boer, W. F. 2007. "Seagrass-Sediment Interactions, Positive Feedback and Critical Thresholds for Occurrence: A Review." Hydrobiologia 591: 5-24. doi:10.1007/s10750007-0780-9.

de Vriend, H. J., and M. van Konigsveld. 2012. Building with Nature: Thinking, Acting, and Interacting Differently. Dondrecht, NL: EcoShape, Building with Nature.

Dennison, W. C., R. J. Orth, K. A. Moore, J. C. Stevenson, V. Carter, S. Kollar, P. W. Bergstrom, and R. A. Batiuk. 1993. "Assessing Water Quality with Submersed Aquatic Vegetation." BioScience 43 (2): 86-94.

DeWitt, T. H. 2009. "10.0 The Effects of Bioturbation and Bioirrigation on Seagrasses." In Seagrasses and Protective Criteria: A Review and Assessment of Research Status. Edited by W. G. Nelson. EPA/600/R-09/050. Newport, OR: Office of Research and Development, National Health and Environmental Effects Research Laboratory.

Deysher, L. E., T. A. Dean, R. S. Grove, and A. Jahn. 2002. "Design Considerations for an Artificial Reef to Grow Giant Kelp (Macrocystis pyrifera) in Southern California." ICES Journal of Marine Science 59 (suppl): S201-S207.

Druehl, L. D. 1978. "The Distribution of Macrocystis integrifolia in British Columbia as Related to Environmental Parameters." Canadian Journal of Botany 56 (1): 69-79.

Duarte, C. M., and C. L. Chiscano. 1999. "Seagrass Biomass and Production: A Reassessment." Aquatic Botany 65 (1-4): 159-174.

Duarte, C. M. 2002. "The Future of Seagrass Meadows." Environmental Conservation 29 (2): 192-206. 
Dubi, A., and A. Torum. 1997. "Wave Energy Dissipation in Kelp Vegetation." In Coastal Engineering 1996. Edited by B. L. Edge. Orlando, FL: American Society of Civil Engineers.

Duggins, D. O., J. E. Eckman, and A. T. Sewell. 1990. “Ecology of Understory Kelp Environments. II. Effects of Kelps on Recruitment of Benthic Invertebrates." Journal of Experimental Marine Biology and Ecology 143 (1-2): 27-45.

Duggins, D., J. E. Eckman, C. E. Siddon, and T. Klinger. 2001. "Interactive Roles of Mesograzers and Current Flow in Survival of Kelps." Marine Ecology Progress Series 223: 143-155.

Dunton, K. 1990. "Production Ecology of Ruppia maritima and Halodule wrightii in Two Subtropical Estuaries." Journal of Experimental Marine Biology and Ecology 143: 147-164.

Dunton, K. 1994. "Seasonal Growth and Biomass of the Subtropical Seagrass Halodule wrightii in Relation to Continuous Measurements of Underwater Irradiance." Marine Biology 120: 479-489.

ecoshape.org. 2020. Building with Nature. EcoShape. https://www.ecoshape.org/en/.

Edelman, T. 1972. "Dune Erosion during Storm Conditions." Coastal Engineering Proceedings 1 (13): 66. doi:10.9753/icce.v13.66.

Edwards, M. S. 2019. "Comparing the Impacts of Four ENSO Events on Giant Kelp (Macrocystis pyrifera) in the Northeast Pacific Ocean." Algae 34 (2): 141-151.

Eisemann, E., C. Thomas, M. Balazik, D. Acevedo-Mackey, and S. Altman. Forthcoming. "Substrate and Geomorphological Characteristics for Desired Vegetation and SAV in Restoration Projects: A Review." Engineer Research and Development Center Technical Report.

Eleuterius, L. 1987. "Seagrass Ecology along the Coasts of Alabama, Louisiana, and Mississippi." Florida Marine Research Publications 42: 11-24.

Elginoz, N., M. S. Kabdasli, and A. Tanik. 2011. “Effects of Posidonia oceanica Seagrass Meadows on Storm Waves." Journal of Coastal Research 64: 373-377.

Erftmeijer, P. L. A., and R. R. R. Lewis III. 2006. “Environmental Impact of Dredging on Seagrasses: A Review." Marine Pollution Bulletin 52 (12): 1553-1572.

Estes, J. A., and P. D. Steinberg. 1988. "Predation, Herbivory, and Kelp Evolution." Paleobiology 14 (1): 19-36.

farallones.org. 2020. Kelp Recovery. Greater Farallones Association. https://farallones.org/ climate/kelp/.

Feagin, R. A., J. Figlus, J. C. Zinnert, J. Sigren, M. L. Martínez, R. Silva, W. K. Smith, D. Cox, D. R. Young, and G. Carter. 2015. "Going with the Flow or Against the Grain? The Promise of Vegetation for Protecting Beaches, Dunes, and Barrier Islands from Erosion." Frontiers in Ecology and the Environment 13 (4): 203-210. https://doi.org/10.1890/140218. 
Filbee-Dexter, K., C. J. Feehan, and R. E. Scheibling. 2016. "Large-Scale Degradation of a Kelp Ecosystem in an Ocean Warming Hotspot." Marine Ecology Progress Series 543: $141-152$.

Fonseca, M. 1996. "The Role of Seagrasses in Nearshore Sedimentary Processes a Review." In Estuarine Shores: Evolution Environments and Human Alteration. Edited by K. F. Nordstrom and C. T. Roman. Chichester, UK: John Wiley and Sons.

Fonseca, M. S. 1989. "Regional Analysis of the Creation and Restoration of Seagrass Systems." Wetland Creation and Restoration: The Status of the Science 1: 175-198.

Fonseca, M. S., and J. A. Cahalan. 1992. "A Preliminary Evaluation of Wave Attenuation by Four Species of Seagrass." Estuarine Coastal and Shelf Science 35 (6): 565-576.

Fonseca, M. S., and S. Bell. 1998. "Influence of Physical Setting on Seagrass Landscapes near Beaufort, North Carolina, USA." Marine Ecology Progress Series 171: 109-121.

Fonseca, M. S., B. D. Robbins, P. E. Whitfield, L. Wood, and P. Clinton. 2002. Evaluating the Effect of Offshore Sandbars on Seagrass Recovery and Restoration in Tampa Bay through Ecological Forecasting and Hindcasting of Exposure to Waves. Final Report. Mote Technical Report No. 851. Sarasota, FL: Mote Marine Laboratory. https://dspace.mote. org/bitstream/handle/2075/3152/MTR\%20851.pdf? sequence=1\&isAllowed=y.

Fonseca, M. S., W. J. Kenworthy, and G. W. Thayer. 1998. Guidelines for the Conservation and Restoration of Seagrasses in the United States. National Oceanic and Atmospheric Administration (NOAA) Coastal Ocean Program Decision Analysis Series No. 12. Silver Spring, MD: NOAA Coastal Ocean Office.

Fonseca, M., M. Koehl, and B. Kopp. 2007. “Biomechanical Factors Contributing to SelfOrganization in Seagrass Landscapes." Journal of Experimental Marine Biology and Ecology 340: 227-246. doi:10.1016/j.jembe.2006.09.015.

Fredriksen, S., K. Filbee-Dexter, K. M. Norderhaug, H. Steen, T. Bodvin, M. A. Coleman, F. Moy, and T. Wernberg. 2020. "Green Gravel: A Novel Restoration Tool to Combat Kelp Forest Decline." Scientific Reports 10 (1): 1-7.

Furman, B. T., M. Merello, C. P. Shea, W. J. Kenworthy, and M. O. Hall. 2018. “Monitoring of Physically Restored Seagrass Meadows Reveals a Slow Rate of Recovery for Thalassia testudinum." Restoration Ecology 27 (2): 421-430. https://doi.org/10.1111/rec.12877.

Grady, J. 1981. “Properties of Seagrass and Sand Flat Sediments from the Intertidal Zone of St. Andrews Bay, Florida." Estuaries 4: 335-344.

Graham, M. H., B. P. Kinlan, L. D. Druehl, L. E. Garske, and S. Banks. 2007. “Deep-Water Kelp Refugia as Potential Hotspots of Tropical Marine Diversity and Productivity." Proceedings of the National Academy of Sciences 104 (42): 16576-16580.

Green, E. P., and F. T. Short, eds. 2003. World Atlas of Seagrasses. Berkeley, CA: University of California Press in Association with United Nations Environment Programme World Conservation Monitoring. 
Greiner, J. T., K. J. McGlathery, J. Gunnell, and B. A. McKee. 2013. "Seagrass Restoration Enhances 'Blue Carbon' Sequestration in Coastal Waters." PLOS ONE 8 (8): e72469.

Gruber, R. K., D. C. Hinkle, and W. M. Kemp. 2011. "Spatial Patterns in Water Quality Associated with Submersed Plant Beds." Estuaries and Coasts 34 (5): 961-972. doi:10.1007/ s12237-010-9368-0.

Guannel, G., K. Arkema, P. Ruggiero, and G. Verutes. 2016. "The Power of Three: Coral Reefs, Seagrasses and Mangroves Protect Coastal Regions and Increase Their Resilience." PLOS ONE 11 (7): e0158094.

Gundersen, H., T. L. Bryan, W. Chen, F. E. Moy, A. N. Sandman, G. Sundblad, S. Schneider, J. H. Andersen, S. Langaas, and M. G. Walday. 2017. Ecosystem Services in the Coastal Zone of the Nordic Countries. Albertslund, DE: Rosendahls-Schultz Grafisk.

Gurbisz, C., W. M. Kemp, J. C. Cornwell, L. P. Sanford, M. S. Owens, and D. C. Hinkle. 2017. “Interactive Effects of Physical and Biogeochemical Feedback Processes in a Large Submersed Plant Bed." Estuaries and Coasts 40: 1626-1641.

Gurbisz, C., W. M. Kemp, L. P. Sanford, and R. J. Orth. 2016. “Mechanisms of Storm-Related Loss and Resilience in a Large Submersed Plant Bed." Estuaries and Coasts 39: 951-966.

Hanley, M. E., S. P. G. Hoggart, D. J. Simmonds, A. Bichot, M. A. Colangelo, F. Bozzeda, H. Heurtefeux, et al. 2014. "Shifting Sands? Coastal Protection by Sand Banks, Beaches and Dunes." Coastal Engineering 87: 136-146.

Heller, D. Y. 1987. "Sediment Transport in Seagrass Beds." PhD diss., MS thesis, University of Virginia.

Hemminga, M. A., and C. M. Duarte. 2000. Seagrass Ecology. Cambridge, UK: Cambridge University Press.

Horstman, E. M., C. M. Dohmen-Janssen, P. M. F. Narra, N. J. F. van den Berg, M. Siemerink, and S. J. M. H. Hulscher. 2014. "Wave Attenuation in Mangroves: A Quantitative Approach to Field Observations." Coastal Engineering 94: 47-62.

Hoskin, C. 1983. "Sediment in Seagrasses near Link Port, Indian River, Florida." Florida Scientist 46: 153-161.

Hutchinson, G. 1975. A Treatise of Limnology, Limnological Botany. New York: John Wiley and Sons.

Jackson, G. A. 1984. "Internal Wave Attenuation by Coastal Kelp Stands." Journal of Physical Oceanography 14 (8): 1300-1306.

Jackson, G. A., and C. D. Winant. 1983. "Effect of a Kelp Forest on Coast Currents." Continental Shelf Research 20 (1): 75-80.

Jacobsen, N. G., B. C. McFall, and D. A. van der A. 2019. "A Frequency Distributed Dissipation Model for Canopies." Coastal Engineering 150: 135-146. 
Jordan-Sellers, T., E. P. Summa, B. Hope, C. J. Kruempel, D. Nelson, A. McCarthy, M. S. Fonseca, S.R. Conger, and C. Pomfret. 2016. "The Value of Navigation Dredged Material to Ecosystem Restoration and Coastal Resiliency." 21st World Dredging Congress 2016 (WODCON XXI) Proceedings: Innovations in Dredging. Western Dredging Association (WEDA), Curran Associates, Inc.

Kaldy, J., and J. Dunton. 2000. "Above- and Below-Ground Production, Biomass and Reproductive Ecology in a Subtropical Coastal Lagoon." Marine Ecology Progress Series 193: 271-283.

Kemp, W. M., R. Batiuk, R. Bartleson, P. Bergstrom, V. Clark, C. L. Gallegos, W. Hunley, et al. 2004. "Habitat Requirements for Submerged Aquatic Vegetation in Chesapeake Bay: Water Quality, Light Regime, and Physical-Chemical Factors." Estuaries 27 (3): 363-377.

Kemp, W. M., W. R. Boynton, J. E. Adolf, D. F. Bosch, W. C. Boicourt, G. Brush, J. C. Cornwell, et al. 2005. "Eutrophication of Chesapeake Bay: Historical Trends and Ecological Interactions." Marine Ecology Progress Series 303: 1-29.

Kenworthy, W. J., M. O. Hall, K. K. Hammerstrom, M. Merello, and A. Schwartzchild. 2018. "Restoration of Tropical Seagrass Beds Using Wild Bird Fertilization and Sediment Regrading." Ecological Engineering 112: 72-81.

Kenworthy, W. J., M. S. Fonseca, J. Homziak, and G. W. Thayer. 1980 “Development of a Transplanted Seagrass (Zostera marina L.) Meadow in Back Sound, Carteret County, North Carolina." Proceedings of the Seventh Annual Conference on the Restoration and Creation of Wetlands. Edited by D. P. Cole. Tampa, FL: Hillsborough Community College.

Kilminster, K., K. McMahon, M. Waycott, G. A. Kendrick, P. Scanes, L. McKenzie, K. R. O'Brien, et al. 2015. "Unravelling Complexity in Seagrass Systems for Management: Australia as a Microcosm." Science of the Total Environment 534: 97-109.

Koch, E. 2001. "Beyond Light: Physical, Geological, and Geochemical Parameters as Possible Submersed Aquatic Vegetation Habitat Requirements." Coastal and Estuarine Research Federation 24 (1): 1-17.

Koch, E., L. Sanford, S. Chen, D. Shafer, and J. Smith. 2006. Waves in Seagrass Systems: Review and Technical Recommendations. ERDC TR-06-15. Vicksburg, MS: U.S. Army Engineers Research and Development Center.

Krause-Jensen, D., J. Carstensen, S. Nielsen, T. Dalsgaard, P. Christensen, H. Fossing, and M. Rasmussen. 2011. "Sea Bottom Characteristics Affect Depth Limits of Eelgrass Zostera marina L." Marine Ecology Progress Series 425: 91-102.

Krumhansl, K. A., D. K. Okamoto, A. Rassweiler, M. Novak, J. J. Bolton, K. C. Cavanaugh, S. D. Connell, et al. 2016. "Global Patterns of Kelp Forest Change over the Past HalfCentury." Proceedings of the National Academy of Sciences 113 (48): 13785-13790.

Layton, C., M. A. Coleman, E. M. Marzinelli, P. D. Steinberg, S. E. Swearer, A. Vergés, T. Wernberg, and C. R. Johnson. 2020. "Kelp Forest Restoration in Australia." Frontiers in Marine Science 7: 74. 
Layton, C., V. Shelamoff, M. J. Cameron, M. Tatsumi, J. T. Wright, and C. R. Johnson. 2019. "Resilience and Stability of Kelp Forests: The Importance of Patch Dynamics and Environment-Engineer Feedbacks." PLOS ONE 14 (1): e0210220.

Lee, K., and K. Dunton. 1996. "Production and Carbon Reserve Dynamics of the Seagrass Thalassia testudinum in Corpus Christi Bay, Texas, USA." Marine Ecology Progress Series 143: 201-210.

Leschen, A., K. Ford, and N. Evans. 2010. “Successful Eelgrass (Zostera marina) Restoration in a Formerly Eutrophic Estuary (Boston Harbor) Supports the Use of a Multifaceted Watershed Approach to Mitigating Eelgrass Loss." Estuaries and Coasts 33 (6): 1340-1354.

Livingston, R., S. Mcglynn, and X. Niu. 1998. "Factors Controlling Seagrass Growth in a Gulf Coastal System: Water and Sediment Quality and Light." Aquatic Botany 60: 135-159.

Lopez, J. A. 2009. “The Multiple Lines of Defense Strategy to Sustain Coastal Louisiana." Journal of Coastal Research 54 (10054): 186-197. https://doi.org/10.2112/SI54-020.1.

Mann, K. H. 1973. "Seaweeds: Their Productivity and Strategy for Growth." Science 182 (4116): 975-981.

Marion, S. R., and R. J. Orth. 2010. “Innovative Techniques for Large-Scale Seagrass Restoration Using Zostera marina (Eelgrass) Seeds." Restoration Ecology 18: 514-526. doi:10.1111/j.1526-100X.2010.00692.x.

Maristany, L. M., A. Horine, and P. Carangelo. 2018. “La Quinta Terminal Mitigation Project: Large Scale Dredged Material Beneficial Re-Use Facility for Estuarine Habitat Creation in Corpus Christi Bay, TX." Proceedings of the Western Dredging Association Dredging Summit \& Expo '18, Norfolk, VA, June 25-28, 2018.

Marshall, N., and K. Lukas. 1970. "Preliminary Observations on the Properties of Bottom Sediments with and without Eelgrass, Zostera marina, Cover." Proceedings of the National Shellfisheries Association 60: 107-111.

McArthur, L. C., and J. W. Boland. 2006. "The Economic Contribution of Seagrass to Secondary Production in South Australia." Ecological Modelling 196 (1-2): 163-172. https://doi. org/10.1016/j.ecolmodel.2006.02.030.

McHarg, I. L. 1969. Design with Nature. Garden City, NY: Natural History Press.

Mcleod, E., G. L. Chmura, S. Bouillon, R. Salm, M. Björk, C. M. Duarte, C. E. Lovelock, W. H. Schlesinger, and B. R. Silliman. 2011. “A Blueprint for Blue Carbon: Toward an Improved Understanding of the Role of Vegetated Coastal Habitats in Sequestering C02." Frontiers in Ecology and the Environment 9 (10): 552-560.

MDE (Maryland Department of the Environment). 2017. Innovative Reuse and Beneficial Use of Dredged Material Guidance Document. Baltimore, MD: Maryland Department of the Environment. 
Möller, I., M. Kudella, F. Rupprecht, T. Spencer, M. Paul, B. K. van Wesenbeeck, G. Wolters, et al. 2014. "Wave Attenuation over Coastal Salt Marshes under Storm Surge Conditions." Nature Geoscience 7 (10): 727-731.

Montefalcone, M., M. Chiantore, A. Lanzone, C. Morri, G. Albertelli, and C. N. Bianchi. 2008. "BACI Design Reveals the Decline of the Seagrass Posidonia oceanica Induced by Anchoring." Marine Pollution Bulletin 56 (9): 1637-1645.

Moore, K. A., E. C. Shields, and D. B. Parrish. 2014. "Impacts of Varying Estuarine Temperature and Light Conditions on Zostera marina (Eelgrass) and Its Interactions with Ruppia maritima (Widgeongrass)." Estuaries and Coasts 37: 20-30.

Murphey, P., and M. Fonseca. 1995. "Role of High and Low Energy Seagrass Beds as Nursery Areas for Penaeus duorarum in North Carolina." Marine Ecology Progress Series 121: 91-98.

Narayan, S., M. W. Beck, B. G. Reguero, I. J. Losada, B. van Wesenbeeck, N. Pontee, J. N. Sanchirico, J. C. Ingram, G. M. Lange, and K. A. Burks-Copes. 2016. "The Effectiveness, Costs and Coastal Protection Benefits of Natural and Nature-Based Defences." PLOS ONE 11 (5): e0154735.

naturalcapitalproject.stanford.edu, n.d. InVEST. Natural Capital Project. https:// naturalcapitalproject.stanford.edu/software/invest.

Neckles, H. A., B. S. Kopp, B. J. Peterson, and P. S. Pooler. 2012. "Integrating Scales of Seagrass Monitoring to Meet Conservation Needs." Estuaries and Coasts 35 (1): 23-46.

Nelson, W. G., ed. 2009. Seagrasses and Protective Criteria: A Review and Assessment of Research Status. EPA/600/R-09/050. Newport, OR: Office of Research and Development, National Health and Environmental Effects Research Laboratory.

NOAA (National Oceanic and Atmospheric Administration). 2015. Programmatic Environmental Impact Statement. Silver Spring, MD: NOAA Restoration Center, Office of Habitat Conservation.

oceana.org, n.d. Marine Science and Ecosystems: Kelp Forest. Oceana: Protecting the World's Oceans. https://oceana.org/marine-life/marine-science-and-ecosystems/kelpforest.

Orth, R. J. 1977. "The Importance of Sediment Stability in Sea-Grass Communities." In Ecology of Marine Benthos. Edited by B. C. Coull. Columbia, SC: University of South Carolina Press, Columbia.

Orth, R. J., A. W. D. Larkum, and C. M. Duarte, eds. 2010. Seagrasses: Biology, Ecology and Conservation. Dordrecht, NL: Springer.

Orth, R. J., K. A. Moore, S. R. Marion, D. J. Wilcox, and D. B. Parrish. 2012. "Seed Addition Facilitates Eelgrass Recovery in a Coastal Bay System." Marine Ecology Progress Series 448: 177-195. 
Orth, R. J., M. Luckenbach, and K. A. Moore. 1994. "Seed Dispersal in a Marine Macrophyte: Implications for Colonization and Restoration." Ecology 75 (7): 1927-1939.

Orth, R. J., R. A. Batiuk, P. W. Bergstrom, and K. A. Moore. 2002. "A Perspective on Two Decades of Policies and Regulations Influencing the Protection and Restoration of Submerged Aquatic Vegetation in Chesapeake Bay, USA." Bulletin of Marine Science 71: 1391-1403.

Orth, R. J., T. J. B. Carruthers, W. C. Dennison, C. M. Duarte, J. W. Fourqurean, K. L. Heck Jr., A. R. Hughes, et al. 2006. "A Global Crisis for Seagrass Ecosystems." Bioscience 56: 987-996.

Orth, R. J., W. C. Dennison, J. S. Lefcheck, C. Gurbisz, M. Hannam, J. Keisman, J. B. Landry, et al. 2017. "Submersed Aquatic Vegetation in Chesapeake Bay: Sentinel Species in a Changing World." Bioscience 67 (8): 698-712.

Paul, M., and C. L. Amos. 2011. "Spatial and Seasonal Variation in Wave Attenuation over Zostera noltii." Journal of Geophysical Research: Oceans 116 (C8).

Pendleton, L., D. C. Donato, B. C. Murray, S. Crooks, W. A. Jenkins, S. Sifleet, C. Craft, et al. 2012. “Estimating Global 'Blue Carbon' Emissions from Conversion and Degradation of Vegetated Coastal Ecosystems." PLOS ONE 7 (9): e43542. doi:10.1371/journal. pone.0043542.

Rosman, J. H., J. R. Koseff, S. G. Monismith, and J. Grover. 2007. "A Field Investigation into the Effects of a Kelp Forest (Macrocystis pyrifera) on Coastal Hydrodynamics and Transport." Journal of Geophysical Research 112 (1-16): C02016. doi:10.1029/2005JC003430.

santamonicabay.org. 2014. Kelp Forest Restoration Project. The Bay Foundation. https://www. santamonicabay.org/explore/in-the-ocean/kelp-forest-restoration/.

Santelices, B., and F. P. Ojeda. 1984. "Effects of Canopy Removal on the Understory Algal Community Structure of Coastal Forests of Macrocystis pyrifera from Southern South America." Marine Ecology Progress Series 14 (2): 165-173.

Scoffin, T. P. 1970. "The Trapping and Binding of Subtidal Carbonate Sediments by Marine Vegetation in Bimini Lagoon, Bahamas." Journal of Sedimentary Petrology 40: 249-273.

seagrassnet.org. 2010. SeagrassNet. http://www.seagrassnet.org.

seagrasswatch.org. 2020. Seagrass-Watch. https://www.seagrasswatch.org.

ser-rrc.org. 2021. USA: Texas: West Galveston Bay Seagrass Restoration. Society for Ecological Restoration. https://www.ser-rrc.org/project/usa-texas-west-galveston-bayseagrass-restoration/.

Shaffer, J. A. 2003. "Preferential Use of Nearshore Kelp Habitats by Juvenile Salmon and Forage Fish." In 2003 Georgia Basin/Puget Sound Research Conference. Edited by T. W. Droscher and D. A. Fraser. Olympia, WA: Puget Sound Water Quality Authority. 
Short, F. T., C. A. Short, and A. Novak. 2016. "Seagrasses." In The Wetland Book: II: Distribution, Description and Conservation. Edited by C. Finlayson, G. Milton, R. Prentice, and N. Davidson. Dordrecht, NL: Springer Science. doi:10.1007/978-94-007-6173-5_262-1.

Short, F., T. Carruthers, W. Dennison, and M. Waycott. 2007. “Global Seagrass Distribution and Diversity: A Bioregional Model." Journal of Experimental Marine Biology and Ecology 350 (1-2): 3-20.

Short, F. T., B. Polidoro, S. R. Livingstone, K. E. Carpenter, S. Bandeira, J. S. Bujang, H. P. Calumpong, et al. 2011. "Extinction Risk Assessment of the World's Seagrass Species." Biological Conservation 144 (7): 1961-1971.

Silva, R., M. L. Martínez, I. Odériz, E. Mendoza, and R. A. Feagin. 2016. “Response of Vegetated Dune-Beach Systems to Storm Conditions." Coastal Engineering 109: 53-62.

Steneck, R., M. H. Graham, B. J. Bourque, D. Corbett, J. M. Erlandson, J. A. Estes, and M. J. Tegner. 2002. "Kelp Forest Ecosystems: Biodiversity, Stability, Resilience and Future." Environmental Conservation 29: 436-459.

Steneck, R. S., and C. R. Johnson. 2013. “Kelp Forests: Dynamic Patterns, Processes and Feedbacks." In Marine Community Ecology and Conservation. Edited by M. Bertness, J. Bruno, B. Silliman, and J. Stachowicz. Sunderland, MA: Sinauer Associates, Inc.

Temmerman, S., P. Meire, T. J. Bouma, P. M. Herman, T. Ysebaert, and H. J. de Vriend. 2013. "Ecosystem-Based Coastal Defence in the Face of Global Change." Nature 504 (7478): 79-83.

The National Academies of Sciences, Engineering, and Medicine. 2017. Effective Monitoring to Evaluate Ecological Restoration in the Gulf of Mexico. Washington, DC: The National Academies Press. doi:10.17226/23476.

Toft, J. D., A. S. Ogston, S. M. Heerhartz, J. R. Cordell, and E. E. Flemer. 2013. “Ecological Response and Physical Stability of Habitat Enhancements along an Urban Armored Shoreline." Ecological Engineering 57: 97-108.

Tracey, S., C. Mundy, T. Baulch, M. Marzloff, K. Hartmann, S. Ling, and J. Tisdell. 2014. Trial of an Industry Implemented, Spatially Discrete Eradication/Control Program for Centrostephanus rodgersii in Tasmania. FRDC Project No. 2011/087. Hobart, TAS: Fisheries Research and Development Corporation.

Treat, S. F., and R. R. Lewis, eds. 2006. "Seagrass Restoration: Success, Failure, and the Costs of Both." Selected papers presented at a workshop at Mote Marine Laboratory, Sarasota, FL, March 11-12, 2003.

Tuya, F., R. Haroun, and F. Espino. 2014. “Economic Assessment of Ecosystem Services: Monetary Value of Seagrass Meadows for Coastal Fisheries." Ocean \& Coastal Management 96: 181-187. https://doi.org/10.1016/j.ocecoaman.2014.04.032.

Unsworth, R. K., L. M. Nordlund, and L. C. Cullen-Unsworth. 2019. “Seagrass Meadows Support Global Fisheries Production." Conservation Letters 12 (1): e12566. 
van der Heide, T., L. L. Govers, J. de Fouw, H. Olff, M. van der Geest, M. M. van Katwijk, T. Piersma, et al. 2012. "A Three-Stage Symbiosis Forms the Foundation of Seagrass Ecosystems." Science 336 (6087): 1432-1434.

van der Heide, T., E. H. van Nes, G. W. Geerling, A. J. Smolders, J. J. Bouma, and M. M. van Katwijk. 2007. "Positive Feedbacks in Seagrass Ecosystems: Implications for Success in Conservation and Restoration." Ecosystems 10 (8): 1311-1322.

van Katwijk, M. M., A. R. Bos, V. N. Jonge, L. S. A. M. Hanssen, D. C. R. Hermus, and D. J. de Jong. 2009. “Guidelines for Seagrass Restoration: Importance of Habitat Selection and Donor Population, Spreading of Risks, and Ecosystem Engineering Effects." Marine Pollution Bulletin 58: 179-188.

Vásquez, J. A., S. Zuñiga, F. Tala, N. Piaget, D. C. Rodríguez, and J. M. Alonso Vega. 2013. "Economic Valuation of Kelp Forests in Northern Chile: Values of Goods and Services of the Ecosystem." Journal of Applied Phycology 26: 1081-1088. https://doi. org/10.1007/s10811-013-0173-6.

vims.edu. 2021. VIMS SAV Monitoring Program. Virginia Institute of Marine Science. https:// www.vims.edu/research/units/programs/sav/.

Virnstein, R. W., J. S. Steward, and L. J. Morris. 2007. "Seagrass Coverage Trends in the Indian River Lagoon System." Florida Scientist 70 (4): 397-404.

Vuik, V., S. N. Jonkman, B. W. Borsje, and T. Suzuki. 2016. "Nature-Based Flood Protection: The Efficiency of Vegetated Foreshores for Reducing Wave Loads on Coastal Dikes." Coastal Engineering 116: 42-56.

Wabnitz, C. C., S. Andréfouët, D. Torres-Pulliza, F. E. Muller-Karger, and P. A. Kramer. 2008. "Regional-Scale Seagrass Habitat Mapping in the Wider Caribbean Region Using Landsat Sensors: Applications to Conservation and Ecology." Remote Sensing of Environment 112 (8): 3455-3467.

Ward, L. G., W. M. Kemp, and W. R. Boynton. 1984. "The Influences of Waves and Seagrass Communities on Suspended Particles in an Estuarine Embayment." Marine Geology 59 (1-4): 85-103.

Waycott, M., C. M. Duarte, T. J. Carruthers, R. J. Orth, W. C. Dennison, S. Olyarnik, A. Calladine, et al. 2009. "Accelerating Loss of Seagrasses across the Globe Threatens Coastal Ecosystems." Proceedings of the National Academy of Sciences 106 (30): 1237712381.

Wayne, C. J. 1975. "Sea and Marsh Grasses: Their Effect on Wave Energy and Nearshore Transport." PhD diss. and MS thesis, Florida State University College of Arts and Sciences.

Wood, E., W. Odum, and J. Zieman. 1969. "Influences of Seagrasses on the Productivity of Coastal Lagoons." In Coastal Lagoons. Edited by A. A. Castanares and F. B. Pflueger. Ciudad Universitaria, Mexico: Universidad Autonoma de Mexico. 
Wyllie-Echeverria, S., and J. D. Ackermann. 2003. "The Seagrasses of the Pacific Coast of North America." In World Atlas of Seagrasses. Edited by E. P. Green and F. T. Short. Berkeley, CA: University of California Press.

Yates, K., H. Greening, and G. Morrison, eds. 2011. “Integrating Science and Resource Management in Tampa Bay, Florida." U.S. Geological Survey Circular 1348: 280. https:// pubs.usgs.gov/circ/1348/.

Zieman, J. C. 1975. "Tropical Seagrass Ecosystems and Pollution." In Tropical Marine Pollution. Edited by E. L. F. Wood and R. E. Johannes. Amsterdam, NL: Elsevier Scientific Publishing Company. 


\section{Acknowledgments}

\section{Lead Authors}

Safra Altman, U.S. Army Corps of Engineers, United States

Colette Cairns, National Oceanic and Atmospheric Administration, United States

\section{Co-Authors}

Paula Whitfield, National Oceanic and Atmospheric Administration, United States Jenny Davis, National Oceanic and Atmospheric Administration, United States Mark Finkbeiner, National Oceanic and Atmospheric Administration, United States Brian McFall, U.S. Army Corps of Engineers, United States

\section{Contributors}

Janine Harris, National Oceanic and Atmospheric Administration, United States Gregory Miller, U.S. Army Corps of Engineers, United States

Robert Ramsdell, III, Dredging Consultant, United States 


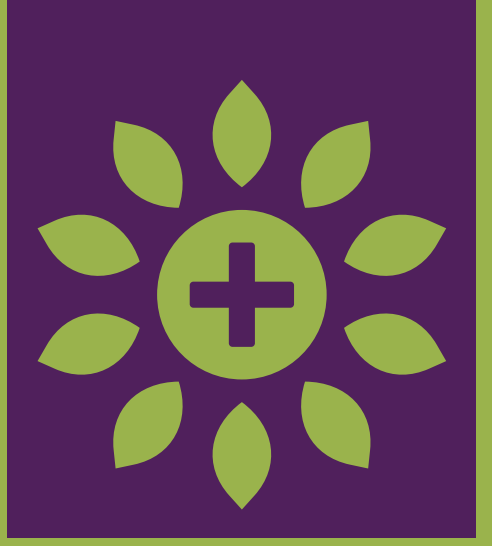

\section{Key Messages}

1. Enhancing structures through the use of natural and nature-based features (NNBF) can take multiple forms, serving as a continuum of measures over broad scales and structure types in both coastal and fluvial environments.

2. Ecological enhancements have the potential to offer multiple benefits, such as structural in the form of increased engineering design life and flood risk reduction, environmental in the form of ecological habitat, and societal in the form of recreational opportunities and improved well-being.

3. Opportunities to enhance structures can occur at any stage during the design life of the structure, including during new construction and repair, maintenance, or modification of the structure.

4. The implementability of enhancements can be increased by identifying and quantifying the value NNBF provide so that the costs and benefits associated with them can be compared effectively against conventional structural measures. 


\section{Key Definitions}

Enhancement is the application of NNBF measures to augment ecological, social, and economic benefits of existing coastal and fluvial infrastructure.

Conventional structural measure refers to structures such as levees, seawalls, floodwalls, breakwaters, dikes, groins, tide gates, and storm-surge barriers designed for coastal and fluvial flood protection.

\section{1| Introduction}

\subsubsection{Scope and Objective}

This chapter explores the potential for incorporating nature-based elements with flood risk management (FRM) conventional structural measures (e.g., levees, seawalls, breakwaters). These nature-based elements fall along a spectrum-from enhancements to the structural measure to create environmental benefits (e.g., modifying the surface texture of a concrete breakwater to facilitate the development of hard-bottom communities) to the full-scale integration of natural and nature-based features (NNBF) with conventional structural measures (e.g., construction of a wetland complex in front of a levee). This chapter emphasizes coastal and estuarine applications, with some discussion of fluvial systems. For a more detailed analysis of fluvial systems and NNBF, see Chapters 15 through 19.

The global dialogue on incorporating nature-based elements into FRM has been underway for several years; examples include the U.S. Army Corps of Engineers (USACE) Engineering With Nature (EWN) Initiative in the United States, the Building with Nature approach in the Netherlands, and the integrated green-gray infrastructure and natural FRM efforts (see Chapters 15 through 19) in the United Kingdom. Ultimately, these multinational efforts have revealed a demand for authoritative guidance on the application of nature-based solutions, including ways to enhance the value of existing structural measures.

NNBF discussed here include coastal, estuarine, and fluvial landscapes that are naturally occurring or engineered to mimic some aspect of a natural condition and still provide flood risk reduction (USACE 2013). Redesigning or retrofitting existing infrastructure to attain NNBF principles can range in complexity from a design that simulates a single natural aspect to an entire landscape-level design (see photographs in Figures 14.1, 14.2, 14.3, and 14.4, and see Chapters 15 through 19). This chapter builds on the aforementioned efforts by providing a focused plan for reassessing conventional structural measures, while also providing a more rigorous list of features and offering examples that vary with respect to the natural value and design complexity. 
Taking these factors into consideration, the overall objective of this chapter is to illustrate how to approach expanding environmental and social value from existing conventional FRM structures by applying NNBF.

Applying NNBF to existing infrastructure is characterized by a continuum across many forms and scales. Simple examples in coastal areas include the following: applying small-scale features on existing structures to create habitat at the base of the food chain (Figure 14.1), adding large wood to a rubble-mound structural repair after storm damage along a riverbank (Figure 14.2), reinforcing an existing aging coastal dike to reduce flood risk and increase habitat (Figure 14.3), and adding fish passage features to existing dam structures (Figure 14.4).

\section{Figure 14.1. Formed Blocks Applied to Existing Coastal Structures Create Habitat for Invertebrates and Other Species}

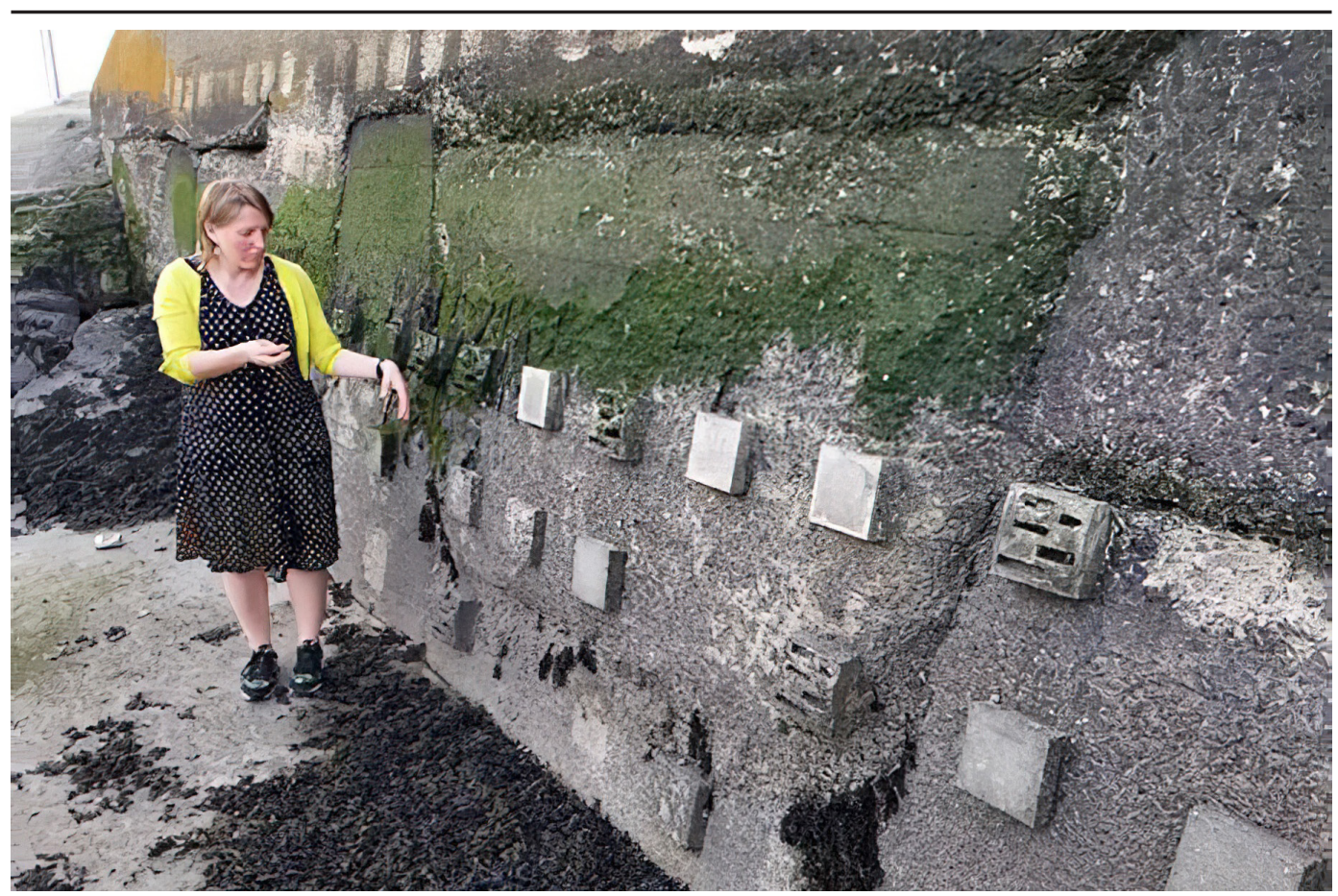

Note: Larissa Naylor shows how existing coastal structures can be enhanced by applying relatively small, formed blocks to create habitat for invertebrates and other species in the intertidal zone along the coast at Edinburgh, Scotland.

Source: Burton Suedel, U.S. Army Corps of Engineers 
Figure 14.2. Coal Creek Drive Long-Term Bank Protection Project

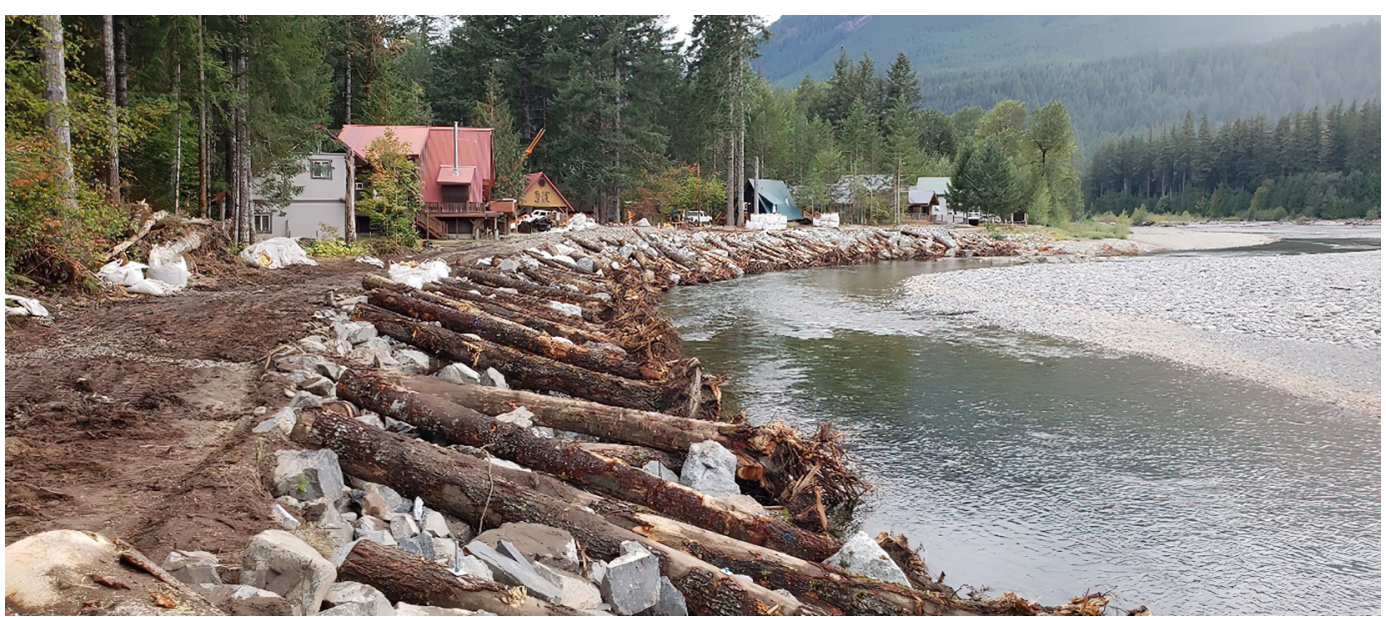

Note: The Coal Creek Drive long-term bank protection project used large wood to create riparian and edge water habitat to help stabilize the eroding structure while also protecting existing infrastructure.

Source: Mark Eberlein, Federal Emergency Management Agency (FEMA) (photograph by David Spicer, State of Washington Emergency Management Division)

\section{Figure 14.3. Sand Reinforcement of the Houtribdijk Dam}

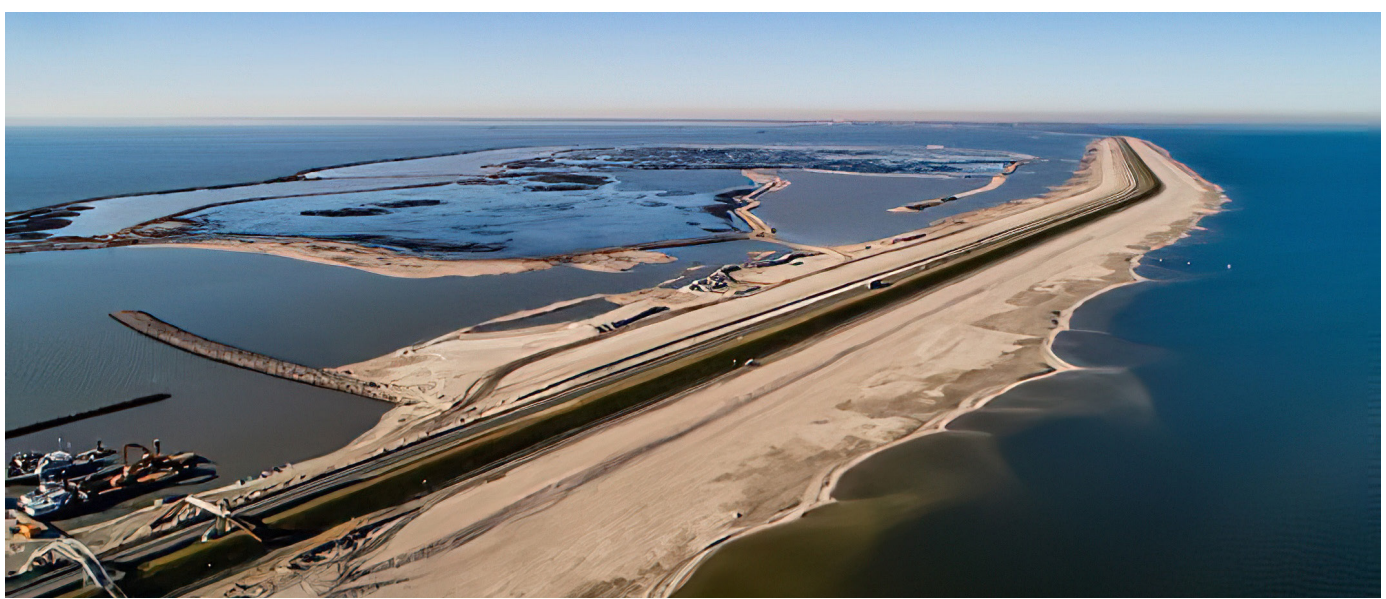

Note: Sand reinforcement of the Houtribdijk dam along the coast of the Netherlands helped to reinforce the dike, which no longer met revised flood risk reduction standards, and also was strategically placed to create habitat for a wide variety of aquatic species.

Source: Frank Janssens, Rijkswaterstaat 


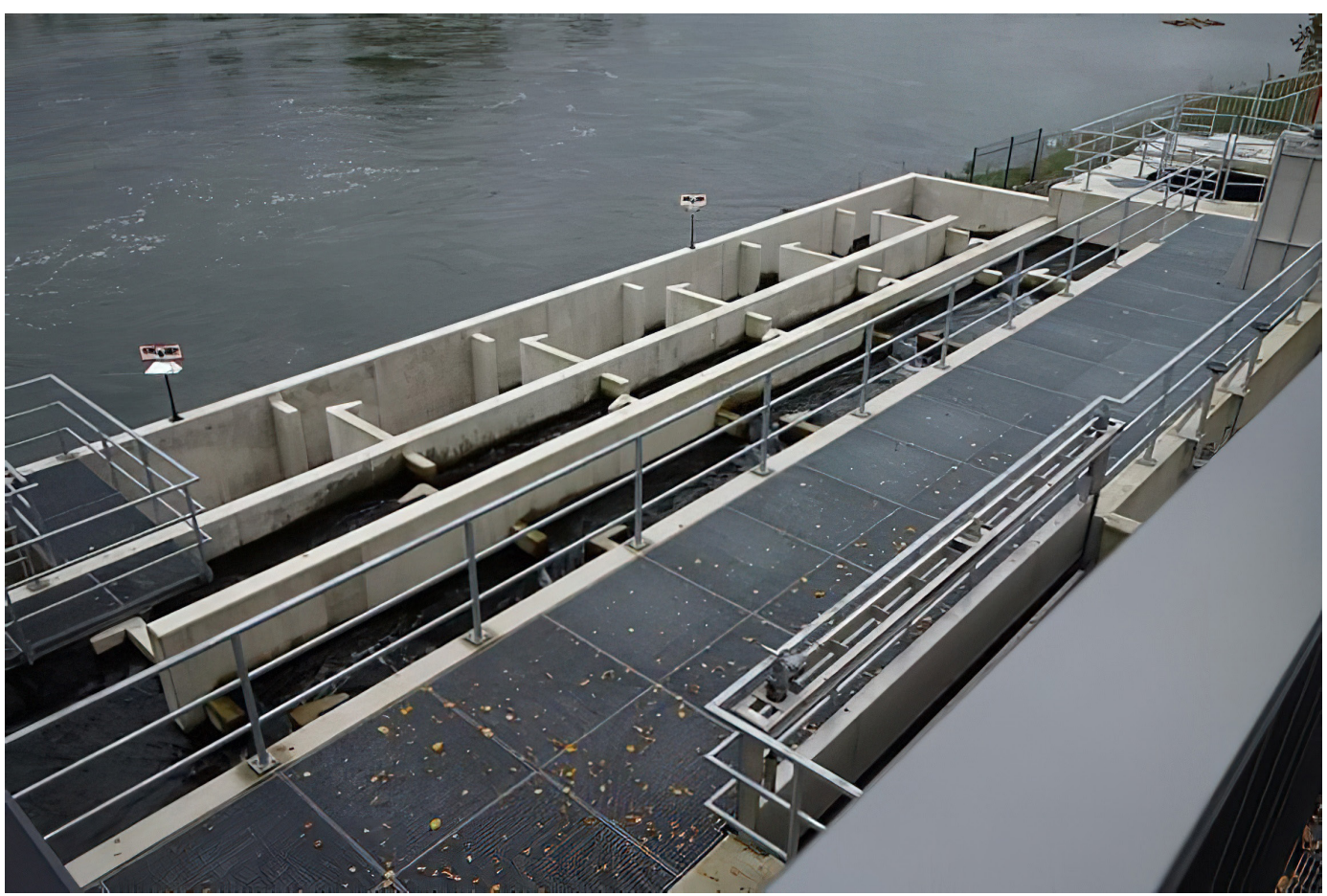

Note: The addition of a fish passage feature-such as the Mosellum Erlebniswelt in Koblenz, Germany-to an existing dam structure supports fish migration to spawning grounds upstream.

Source: Rijkswaterstaat

The primary emphasis of this chapter is on enhancing existing conventional infrastructure, because most of the current opportunities to enhance structures in the United States, the Netherlands, the United Kingdom, and elsewhere are during maintenance, repairs, and modifications of existing structures (e.g., there are 48,280 kilometers [30,000 miles] of levees in the United States alone that are aging). Nevertheless, the concepts and guidance provided in this chapter can also be applied to the design and construction of new or replacement structures and are recommended for use where standalone NNBF measures in other chapters are not technically, economically, or socially feasible (Naylor et al. 2017a).

\subsubsection{Principles}

Conventional structural measures play an important role in FRM. Infrastructure systems in coastal, estuarine, and fluvial areas include rock or concrete structures such as bulkheads, seawalls, sheet piling, and floodwalls, in addition to levees and dikes that may combine earthen and rock and concrete structures. These conventional structural measures provide FRM 
benefits by attenuating flood surge and waves. This chapter presents ways of enhancing the value of structural measures through the inclusion of nature-based elements that expand the value of the infrastructure by providing additional engineering, environmental, and social benefits (see chapter 6 ). This is accomplished by highlighting opportunities for creating enhanced value for infrastructure designers, operators, landowners, and decision-makers and by providing guidance on how to implement these interventions. Such opportunities can occur throughout the life cycle of the structural measure, at the initial construction, or during repair or maintenance of the structure. Engaging stakeholders in the process of identifying opportunities to enhance value and benefits from structural measures, including recreational benefits or improvements to habitat and water quality, can broaden the base of support for infrastructure projects. Incorporation of nature-based elements can also aid project owners and local governments in their efforts to comply with environmental laws and regulations.

This chapter provides an approach for evaluating and implementing nature-based elements to enhance coastal and fluvial structural measures and infrastructure systems. Nature-based options for engineers, owners, and asset managers exist for a plethora of circumstances (Figure 14.5). The examples provided in this chapter are relevant in places where existing structural measures are the prominent means to protect against flooding or erosion.

Figure 14.5. Continuum of Nature-Based Techniques Used in Practice, from Simple Additions to Existing Infrastructure to More Elaborate Schemes Incorporating a Suite of Nature-Based Elements

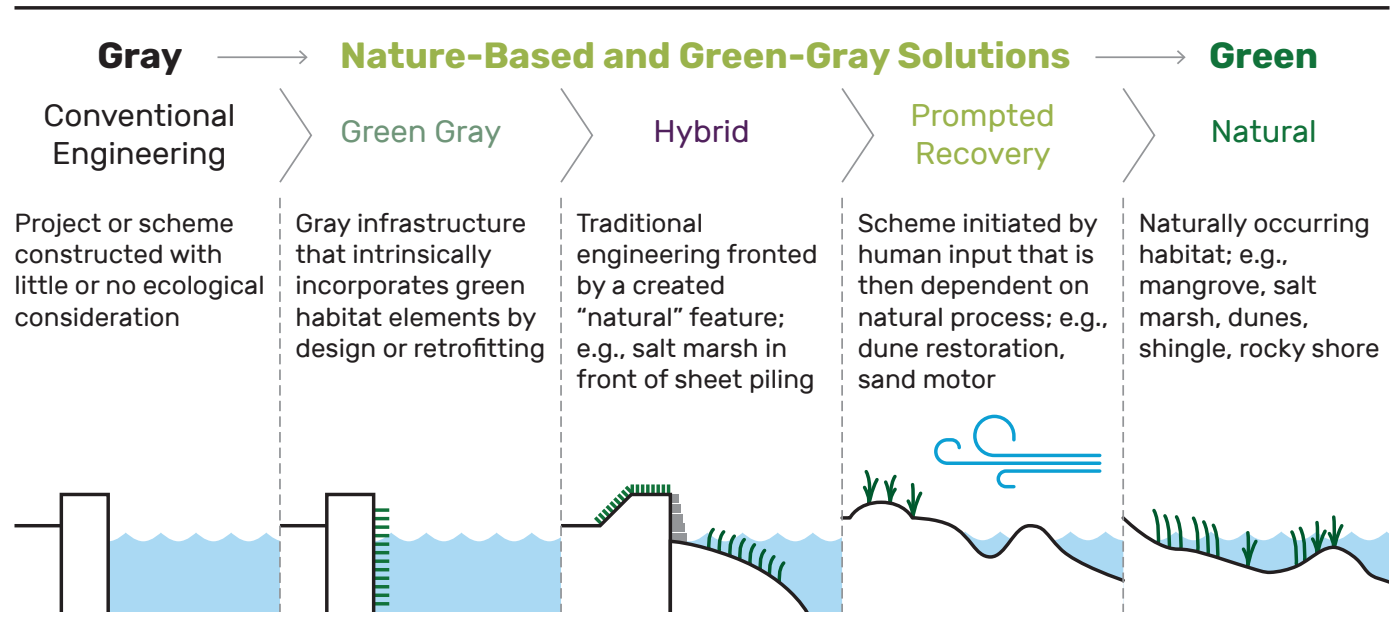


This chapter is unique from other NNBF techniques presented in this International Guidelines on Natural and Nature-Based Features for Flood Risk Management in that it demonstrates the versatility in the timing of applying NNBF concepts to existing infrastructure. An ideal time to incorporate nature-based techniques is during the planning stages for repair and maintenance of existing infrastructure. Conventional structural measures, which have reached the end of their life cycle and need updating, can be brought up to date using nature-based techniques to modernize the structure to meet a broader suite of stakeholder needs, in addition to mitigating flood risk. It is valuable to assess infrastructure before those decision points.

To determine the applicability of nature-based techniques, planners need to assess their project using the NNBF project development framework detailed in Chapter 2 and summarized here. This chapter follows the Scoping Phase, Planning Phase, Decision-Making Phase, Implementation Phase, and Operations Phase that make up the NNBF project development framework (detailed in Chapter 2, see Figure 2.1 in Chapter 2). Important aspects of incorporating NNBF in existing infrastructure occur in the Planning Phase, where managers must characterize the environment in the proposed location for the infrastructure project. This includes assessing the area's current flood risk due to storms and tides, potential changes in vulnerability due to sea-level rise, and potential changes in the magnitude or frequency of flooding and coastal storms. The state of the existing infrastructure (e.g., age, maintenance, necessary repairs, performance) and what protection performance is anticipated in the future are then assessed (see also Chapter 5 ). After managers have identified the structure's protective priorities, they should identify other values of interest. These values can include ecosystem services, habitat improvements, aesthetic value, and recreational opportunities. Reaching out to stakeholders in the community can help identify these values during the Scoping Phase. It is important to determine and accurately communicate whether these additional benefits have economic value (e.g., tourism, fishing, property value) that could offset the cost of the infrastructure project. In some cases, an NNBF technique may add to the performance and life of a structure-for example, barnacles on the structure or Reef Balls in front of the structure can attenuate wave action, reducing strain on the structure, which can reduce the frequency of maintenance and increase its life expectancy. Regardless of the value added, an economic valuation may provide important information in some decision contexts.

The examples in Table 14.1 illustrate the broad range of applicability of the environmental enhancement of existing infrastructure concept. Projects that naturally enhance existing infrastructure are being used around the world, showing the broad desire to use these methods (Figure 14.6; see also EWN Project Mapper [ProMap] for more examples).

Benefits associated with NNBF can be distinguished as both risk reduction-related benefits and co benefits (see Chapter 6 ). Risk reduction benefits refer to flood protection and erosion control; co benefits include benefits that people derive from natural systems. Multiple engineering benefits related to risk reduction can be realized via NNBF enhancement, 
including the sustainability of the infrastructure itself. Ecological co-benefits can include improved fish habitat and water quality, which can promote socioeconomic benefits through increased recreational or commercial fishing. Overall, enhancing conventional infrastructure in this way ultimately makes it more sustainable via the creation of future value, and increases stakeholder support.

\section{Figure 14.6. EWN Project Mapper (ProMap)}

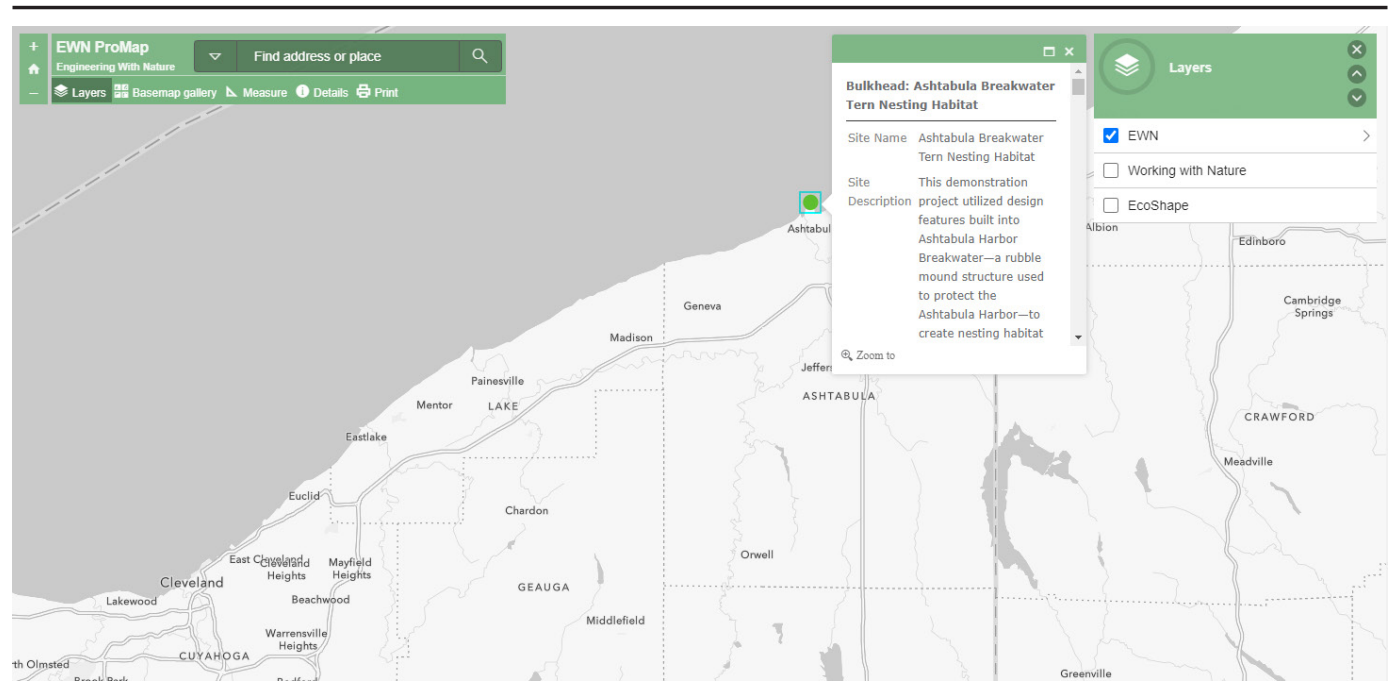

Note: Resources such as the EWN Project Mapper (ProMap) document project details on how incorporating NNBF has enhanced infrastructure around the world (ewn.el.erdc.dren.mil, n.d.).

Enhancements to existing structural measures have the potential to improve the effectiveness of the structure while concomitantly reducing flood risk. Enhancements fit within the following two general themes: (1) the design is adapted to allow organisms to grow on and occupy the feature or people to use the feature or (2) the infrastructure is adapted so that new habitats or spaces adjacent to the feature can now exist and provide value. Only those characteristics impacted positively are summarized. Case study examples from the EWN Project Mapper (ProMap; ewn.el.erdc.dren.mil n.d.) are provided in Table 14.1. If $25 \%$ or more of the case studies for a particular infrastructure type demonstrated an improvement, the characteristic is listed in the "often improves" column; if less than $25 \%$ demonstrated an improvement, the characteristic is listed in the "sometimes improves" column. 


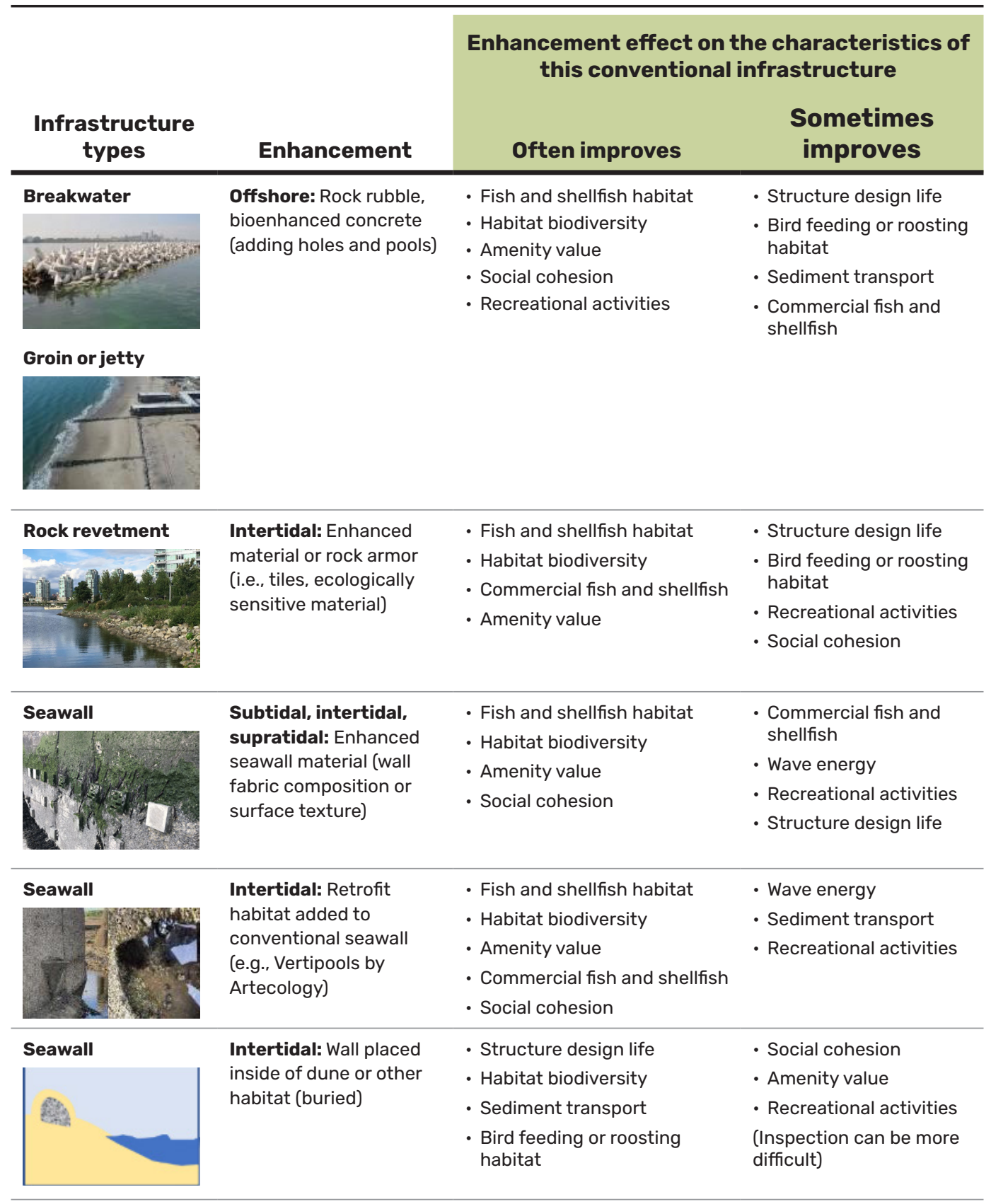


Enhancement effect on the characteristics of this conventional infrastructure

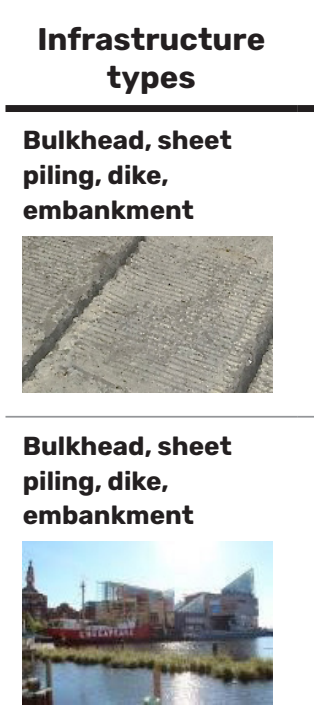

\section{Enhancement}

Intertidal to river:

Enhanced surface roughness and holes, to

increase complexity

- Bird feeding or roosting habitat

- Habitat biodiversity

Sometimes

- Amenity value

- Social cohesion improves

- Structure design life

- Structure inspection or maintenance

- Recreational activities

\section{Intertidal to estuarine} or freshwater river: Added front habitat (salt flat and mud flat, floating wetland, dune, or forest)
- Structure design life

- Structure inspection or maintenance

- Wave energy

- Amenity value

- Social cohesion

- Recreational activities

- Commercial fish and shellfish

- Bird feeding or roosting habitat

- Fish and shellfish habitat

- Habitat biodiversity

Floodplain storage
and stormwater
retention

River: Floodplain storage, planted banks (i.e., reduce flow, erosion control)
- Fish and shellfish habitat

- Bird feeding or roosting habitat

- Habitat biodiversity

- Commercial fish and shellfish
- Sediment transport

- Coastal flooding

(Risk of failure after, if plant growth is required)

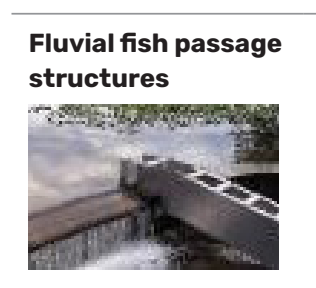

- Structure design life

fish elevator, activated flood gates, temporary structures
- Fish and shellfish habitat
- Bird feeding or roosting habitat
- Habitat biodiversity
- Commercial fish and shellfish
- Recreational activities
- Social cohesion

- Sediment transport

- Recreational activities 
Research and practice into enhancing a range of coastal engineering assets and river bioengineering practice continue to develop worldwide; a series of "art of the possible" examples for practitioners can be found in the following:

- Naylor et al. (2017a) and estuaryedges.co.uk (2021) for refreshing the edges of estuaries

- Strain et al. (2018) and O'Shaunessy et al. (2020) for recent reviews for hard coastal assets

- Roca et al. (2017) for river bioengineering enhancements

- Vozzo et al. (2021) for results of recent seeding experiments to enhance the ecological value of existing coastal structures

\section{2 | Project Goals, Objectives, and Values}

In pre-planning for the design enhancement of existing infrastructure, multiple factors should be considered. This chapter provides information on those considerations when formulating the project early within the NNBF project development framework (see Chapter 2). Specifically, engineering and enhancement goals, objectives, and values should be identified, and all proposed environmental enhancements to existing infrastructure should be considered for implementation (discussed in detail in Section 14.4).

An important early Scoping Phase activity is assessing the inventory of enhancements considered for the project. The features and potential for adding value that fit the enhancement should be determined. The following scenarios provide opportunities for incorporating enhancements: routine operations and maintenance, repairs, major rehabilitations or modifications, and new infrastructure construction. One opportunity is including enhancement project ideas as part of routine urban planning exercises (i.e., enhancing multifunctionality and delivering multiple benefits or net ecological gain).

Setting overall goals and specific objectives in the Scoping Phase is necessary to clearly articulate and manage enhancement project expectations (see also Chapters 5 , $\underline{6}$, and $\underline{9}$ ). Design ideas can then be developed and evaluated against these targets. Determining whether existing infrastructure enhancement objectives can be met depends on the knowledge of the benefits that can be realized from such enhancements (i.e., the ecosystem services they can provide). In the coastal and fluvial projects presented in this chapter (see especially the case studies presented in Section 14.9), achieving project objectives for flood risk reduction involves combining hardened infrastructure with enhanced measures that provide additional value.

Meaningful stakeholder engagement is a key factor in achieving successful projects that enhance existing infrastructure (see the Brouwersdam case study in Section 14.9). Early active participation of stakeholders in the Scoping Phase can improve the setting of goals and objectives and contribute to a positive and more successful decision-making process. 
Central to this success is identifying and involving stakeholders who are motivated to innovate in ways that enhance existing infrastructure. There may be strong policy drivers or willing asset owners who can also be engaged and who can advance project objectives.

The actions that can be taken to implement this process include identifying key policy and legislative drivers, exploring enhancement opportunities, incorporating NNBF into the initial design, soliciting input from stakeholders and others, and finalizing and constructing the design. Implicit in this process is education and outreach with stakeholders and others so that benefit enhancement opportunities are incorporated (Naylor et al. 2012; Evans et al. 2017). In addition to social factors, enhancement designs should include careful consideration of location-specific factors such as local hydrodynamics, geomorphological processes, and weather conditions.

\section{3 | Project Benefits}

The type of benefits and co-benefits that would be desirable from enhancing a given feature should be identified early in the project. Protective FRM benefits can be designed into the project through increased protection or improved structural performance of the feature. This can include, for example, adding texture that enhances colonization of species that can protect the feature (e.g., barnacles; Coombes et al. 2017), reducing stress on the desired feature, extending and improving benefits and life cycle (e.g., reducing chloride ingress and weathering-related deterioration with barnacles), and providing additional coastal protection (e.g., reducing flood risk through additional marsh or oyster reef). A detailed discussion on how NNBF benefits can be assessed (including those relevant to enhancing existing infrastructure) is presented in Chapter 6 .

In addition to FRM benefits, the following co-benefits can be included in the project design (see Table 14.1; also see Brouwersdam beach case study in Section 14.9 as an example of incorporating co-benefits):

- Adding or improving habitat via aquatic or terrestrial animals and plants

- Adding or improving habitat to enhance recreational or commercial fishing

- Providing new or improved access for people

- Improving amenities or social and recreational value (e.g., paths for bird watching)

- Adding property value (e.g., aesthetics)

- Providing regulating services (e.g., trapping pollutants in a fringe marsh)

- Adding features that provide carbon reduction co-benefits (e.g., reduced carbon footprint through the use of innovative, less-carbon-intensive materials) 
An example of a successful application of the incorporation of enhancement considerations as part of performance objectives and indicators (discussed in Section 14.4) is the Milwaukee Harbor project (see Figure 14.7 and Milwaukee Harbor breakwater project case study). This project incorporated fish habitat by designing enhancement features consisting of stone at the appropriate water depth, slope, and size such that it does not interfere with the normal functioning of the breakwater structure that is used to protect navigation in the harbor. This is a good example of a project where NNBF was incorporated early in the design of the structural repair.

\section{Figure 14.7. Smaller Stones Placed Underwater to Repair the Breakwater Structure at Milwaukee Harbor}

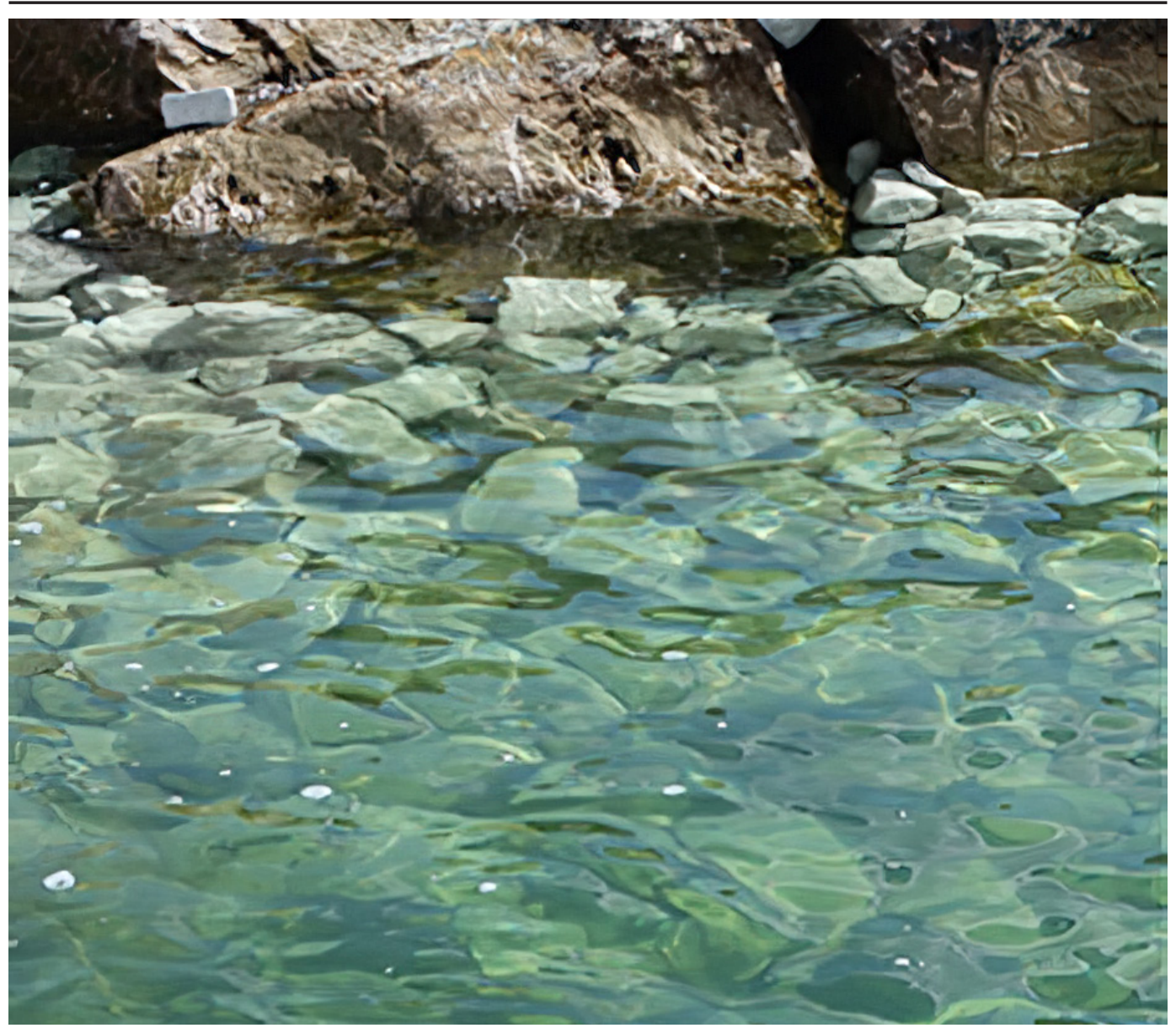

Note: This close-up photograph shows the smaller stones placed underwater to repair the breakwater structure at Milwaukee Harbor. The stones were integrated into the repair design of the breakwater structure to serve as fish habitat.

Source: Burton Suedel, U.S. Army Corps of Engineers 


\subsubsection{Planning and Feasibility Stage: Key Recommendations for Practitioners}

It is recommended that several actions be taken during the Planning Phase to increase the likelihood that enhancements will be part of a completed project. This includes identifying opportunities for enhancements and creating design features or funding streams to realize them by answering the following questions:

1. What are the optimal ecological conditions required at a given location?

a. For example, what range of actions would provide additional fish habitat, and which actions are best suited for this location?

b. What design ideas from precedent projects can be used to demonstrate proof of concept to aid delivery of enhancements for the project?

2. What specific policy or procedural actions can be used to support the project?

3. What net gain, natural capital, or site mitigation requirements or reputational gains are drivers to deliver the enhancements?

4. What funding mechanisms can be used to deliver enhancements? Which cost-benefit assessments can demonstrate the benefits of including enhancements?

5. What are the construction, inspection, maintenance, and design life benefits or implications of enhancements and how can they be addressed to enable delivery of enhancements?

6. What are the most appropriate metrics for evaluating the success of any enhancements, including the gathering of baseline ecological data against which the success of the enhancements can be compared?

7. What are the parameters needed to design enhancement features that are sustainable over the design life of the structure and are appropriate for predicted climate change effects on ecological processes over this time period?

\section{4 | Design Considerations}

A well-integrated, multidisciplinary team is required to facilitate the development and execution of a successful project. This is particularly true with NNBF projects that require teams of multidisciplinary specialists (e.g., biologists, ecologists, coastal engineers, civil engineers, geomorphologists, climate change scientists). Unlike conventional infrastructure projects, where engineering discipline roles are well defined and understood by team members, NNBF projects require the integration of expertise from practitioners who may not customarily work together and who do not fully understand each other's technical discipline, principles of practice, and work process. 
Engineers are formally trained to problem solve and design by following established principles and methods. The delineation between engineering disciplines is often well established, with team members understanding how the contributions from each member provide design input and inform the work of the others. NNBF require that disciplines such as engineers and biologists work together in a collaborative manner throughout the design process. In comparison to conventional infrastructure projects, additional effort and collaboration are required from all to realize success.

When the project objective is driven by an engineering functional need, and NNBF is intended to enhance or add value, the design process will traditionally be led by an engineer, with a principal objective of achieving the requisite engineering functional requirements. In situations such as this, there can be a tendency for engineering designers to consider NNBF as a secondary priority, or to place less attention on incorporating NNBF into the design. Even in situations where engineering designers understand the value of implementing NNBF, there can be a reluctance due to lack of understanding of desired functionality, concerns pertaining to lack of performance specifications and design certainty, lack of understanding pertaining to the integration of the feature into the design, and concerns pertaining to functionality, constructability, construction sequencing, and sourcing of materials, along with monitoring and maintenance uncertainty. In the presence of engineering uncertainty, incorporating NNBF into designs to the extent desired by advocates for NNBF and technical contributors may not be achieved.

To overcome these challenges, NNBF technical team members and contributors must understand the engineering design process. NNBF specialists must align with the design development progression and be prepared to provide requisite design input at the required phases of the design evolution.

\subsubsection{Design Objectives: Engineering and Enhancement}

A typical design process begins in the Planning Phase with predesign planning investigations to determine which of several alternatives best meets the objectives (see Chapter 2 for details). During predesign, conceptual and schematic designs are explored and developed. These discussions ideally need to take place with the NNBF team members to determine which enhancements can coexist with the engineering purpose of the feature and when and where in the design life of a structure these enhancements can be incorporated (Figure 14.8). These are important considerations, because there are several insertion points in the project life cycle where NNBF enhancements can be incorporated. Such enhancements can be included as part of a new or replacement scheme, as a retrofit onto an existing structure, as part of routine maintenance, or as part of repairs to the structure, as the various "entry points" in Figure 14.8 illustrate. Such additions contrast with NNBF options presented in other chapters because these enhancements are added to existing assets (or, in some cases, new 
assets where more natural forms of NNBF from other chapters are not possible) throughout the design life. Many of these "during design life" enhancements can be simple, inexpensive changes to conventional practice that incorporate features presented in Table 14.1. Whether the infrastructure is new build, replacement, retrofit, repair, or altered maintenance practice, each enhancement of it should be placed in contextually relevant locations and should not interfere with the engineering function, operation, or maintenance of the structural measure (hereafter, engineering function). For example, for many reinforced seawalls, engineering requirements for concrete cover (e.g., between 70 and 100 millimeters) and allowable defect tolerances during construction can limit the size of enhancements, limiting the range of ecological design options that are allowable.

\section{Figure 14.8. Activities Associated with Enhancing Existing Conventional Infrastructure Following the NNBF Framework}

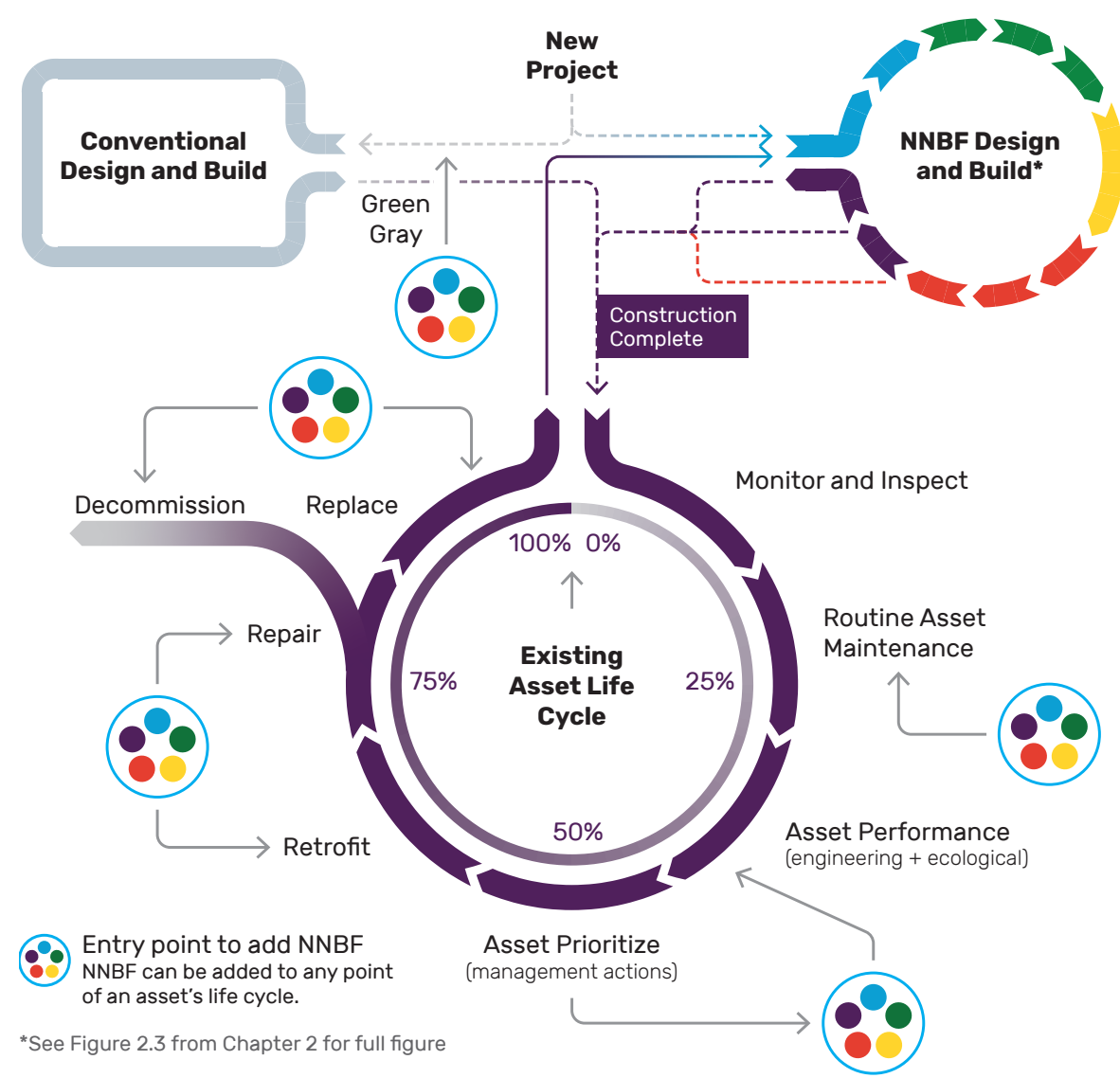

Note: NNBF enhancement opportunities exist at various phases of a project, including at the design and build, maintenance, and repair phases, with both new and existing assets. 
Enhancements create opportunities to improve the multifunctionality of structures throughout their design life (Figure 14.8). These can be thought of as insertion points for adding enhancements. The case studies (Section 14.9) and "Hartlepool Coastal Flood Alleviation Scheme" illustrate where in the engineering design life of structural measures enhancements have been added (Figure 14.8). Further examples of these NNBF applications in a wide variety of projects in coastal and fluvial environments are found in the EWN Project Mapper (ProMap) database (ewn.el.erdc.dren.mil, n.d.).

\section{Hartlepool Coastal Flood Alleviation Scheme}

The Hartlepool coastal flood alleviation scheme in the United Kingdom offers a good example of how ecological enhancements were successfully incorporated into a flood protection project. The first steps identified which enhancements could meet desired, wider project goals (e.g., to improve habitat for a particular species or group or to comply with a particular policy instrument) and how feasible these were to include while maintaining engineering function (Figure 14.8). The Hartlepool case study (Section 14.9) incorporated ecological enhancements in a replacement flood protection scheme as mitigation to comply with statutory habitat policy instruments (e.g., replace and wider benefits [see Figure 14.8]). This requirement led to identifying specific ecological performance goals (e.g., food species for protected birds), ecological design options, and the final enhanced design that was constructed. The enhanced design used in the project demonstrates how simple, inexpensive design alterations (e.g., enhanced design in Figure 14.8) in terms of material choice and positioning of rock armor can lead to ecological gains without any impact on cost or engineering function (Naylor et al. 2017b; MacArthur et al. 2020). Although incorporated as part of a replacement, the technique could equally be used as part of small-scale repairs.

Often, including an ecological enhancement in an engineering scheme means that some aspects of the construction or major rehabilitation phases will be different, more complicated, and more expensive than a conventional engineering project. For example, constructing a seawall with a form liner to add ecological enhancements is more complicated than constructing a seawall without one, and adding habitat in front of sheet piling changes the construction during major rehabilitation compared with replacing sheet piling. It is essential that the key people are involved early enough and that the list of engineering options and enhancements can be developed in close partnership with this team to better allay any concerns with doing something different and to enable opportunities for enhancement to be optimized. 
Enhancements to structural planning and design should be integrated into the feasibility and design activities of the Planning Phase (preliminary and detailed). At the same time, the importance of increasing ecological services should be established, either as an integral part of, or in parallel with, structural measures where other NNBF are not suitable, or as additions to existing conventional structural measures. Support to include enhancements as part of replacement or new build, major rehabilitations, or repairs can be gained from public and statutory consultees (e.g., government agencies) that can help identify alternative funding schemes to support inclusion of enhancements to, for example, mitigate habitat loss or improve corporate reputation. Overall, value and benefits such as the following can be gained from engaging stakeholders: new ideas for improving the project, new sources of funding for project elements, in-kind support for implementation (e.g., monitoring), and broader community support for the project. It is important to note that engaging stakeholders is crucial for forming and sustaining partnerships and for clarifying long-term responsibilities and risks. Effective stakeholder engagement takes both time and funding up front, yet ultimately it will be cost-effective over time due to increased value derived from the NNBF enhancement over both the short term and the long term. Detailed information about stakeholder engagement for incorporating NNBF can be found in $\underline{\text { Chapter } 3 .}$

\subsubsection{Uncertainty and Options Appraisal}

Despite efforts to clearly describe an enhancement project and consider the interaction with values and associated constraints, there often remains a level of uncertainty in that confidence in the available evidence showing the benefits of enhancements may be low, even when the likelihood of realizing benefits is high. Section 14.4.2.1 provides two examples of how uncertainties can be addressed in practice.

\subsubsection{Examples of Addressing Uncertainties When Incorporating NNBF}

It is important to draw on evidence from beyond the immediate project site area and, where necessary, consider making use of expert judgment to evaluate the potential success of an NNBF addition based on past experience and local environmental conditions. Rather than delaying construction of a project by performing additional studies, a monitoring program, or other field data-gathering exercise, an alternative approach is considering how these uncertainties might be captured through adaptive management during the project Implementation Phase.

One example of addressing uncertainties when incorporating NNBF involves uncertainty about the potential effects of a project on the timing of a particular fish spawning period. Rather than wait until detailed data and other information are available, tailored monitoring and actions can 
be built into the project's environmental management plan to define how the project can adapt and what actions can be taken to lessen impacts when monitoring detects the actual onset of spawning. In this manner, considering adaptive management early can facilitate the continued development of the viable enhancement alternative in the face of uncertainty and thus help keep enhancements included in the project.

Another example involves the design phase, when concerns over whether a design will work at a location can be addressed by drawing on the rapidly growing body of evidence from projects where similar species have colonized enhanced designs in broadly compatible environmental settings. As this chapter was being written, this approach was being used the tender stage of a replacement flood scheme in England (EnvironmentAgencyTV 2020).

\subsubsection{Decision-Making Tools for Comparing NNBF Project Alternatives}

Depending on the complexity and scale of a project, the alternatives appraisal process could be simple, with just a single evaluation activity that results in a selected alternative (e.g., as part of ongoing maintenance or a repair; Figure 14.8). Selection of an enhancement alternative for more complex and consequential projects may require multiple iterations to allow stakeholder input to prioritize risk and eliminate unacceptable alternatives, followed perhaps by a more detailed evaluation ranking of a short list of alternatives prior to final selection in the Decision-Making Phase (see Chapter 2). This process has been used in the alternatives selection stage for strategic FRM initiatives in the United Kingdom (e.g., Team2100 [the Environment Agency's 10-year program to refurbish and replace tidal flood defenses in London; gov.uk 2015] and the Welsh Government's The National Strategy for Flood and Coastal Erosion Risk Management in Wales [Welsh Government 2020]), where enhancements are part of the alternatives appraisal mix to increase ecological and other values and to reduce the number of conventional structural measures using NNBF. These decision-making tools are designed to help better understand the trade-offs that need to be made when comparing various enhancement alternatives (e.g., deciding between two alternatives, such as whether to notch existing dikes or to remove select dikes to increase habitat value in secondary river channels while maintaining safe navigation).

Several methods and techniques have been used to compare alternatives in environmental projects. For more straightforward projects, practical actions including developing a list of relevant costs, benefits, risks, and uncertainties for the nature-based enhancements under consideration may be sufficient for decision-making. Naylor et al. (2017a) provide an example of how such a simple approach can be used in practice. This approach involved creating a set of engineering, ecological, and policy critical success factors (engineering, environmental, social, cost) by which an enhanced (NNBF-influenced) design, retrofit, repair, or maintenance regime could be compared against conventional structural measures (Naylor et al. 2017a; 
Roca et al. 2017). Such comparisons allow the costs and benefits associated with one or more enhancements to be better calculated or assessed, which can strengthen the business case for including enhancements in a project and help to keep NNBF additions as part of the design, maintenance, or repair stages. For projects with benefits that may require detailed economic quantification, more formal methods such as multicriteria decision analysis, socioeconomic cost-benefit analysis, and cost-efficiency analysis (PIANC 2014, 2018) may be appropriate. A discussion of the trade-offs associated with incorporating NNBF can be found in Chapter 6 .

\section{5 | Costs versus Benefits}

The cost of implementing NNBF should be determined in the Planning Phase, along with whether additional funding is needed to include the enhancement. One of the key challenges in getting enhancements approved as part of new, replacement, repair, or changed maintenance in projects is comparing the costs and benefits of the nature-based enhancement options to conventional business-as-usual engineering solutions (see Chapter 6). Naylor et al. (2017a) provide a useful method of estimating costs of nature-based enhancement approaches against business-as-usual costs (see Section 14.4).

When weighing costs against the economic, social, and environmental benefits of enhancements in a project, it is important that multiple alternatives be considered and that enhancement alternatives are not simply restatements of the same option. This needs to be balanced with contemplating too many alternatives, which may lead to decision paralysis. Generating new alternatives enables the consideration and incorporation of new opportunities for positive environmental outcomes when implementing NNBF into the project design.

On some projects, routine maintenance or repair activities can serve as opportunities to incorporate the enhancements (see Section 14.1). Changing routine maintenance to reduce mowing of grasses on earthen embankments has been shown to provide a win-win situation, saving money by reducing maintenance and improving biodiversity without adversely affecting structural integrity (see "Embankment Mowing for Bees"). Structures coming to the end of their design life or existing infrastructure degraded by storms can provide an opportunity to include enhancements in the design of the repair (see Figure 14.8 and the Elliott Bay shoreline case study in Section 14.9). These interventions can sometimes be cost neutral or save money, both in the short term and the long term, as noted in "Embankment Mowing for Bees" (Naylor et al. 2017a). 


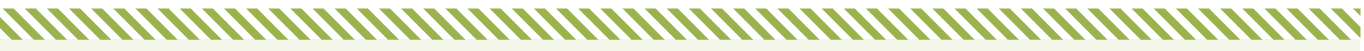

\section{CASE STUDY:}

\section{Embankment Mowing for Bees (Canvey Island, Essex and Kent, United Kingdom)}

The Environment Agency in the United Kingdom implemented an innovative approach to alter an established mowing regime (Figure 14.9) to improve habitat for bumble bees and other pollinators while concomitantly reducing maintenance costs (Naylor et al. 2017a). A reduced mowing maintenance regime (cutting once after mid-September; see Figures 14.10 and 14.11) compared favorably to business-as-usual maintenance (cutting up to four times per year; see Figure 14.9) on an earthen embankment flood defense on Canvey Island. This was subsequently implemented across 120 kilometers of earthen embankments in Essex and Kent, representing an estimated annual cost savings of $£ 25,000$ Great Britain pounds (GBP) (\$32,000 U.S. dollars [USD]) and GBP£75,000 (USD\$107,000), respectively, per 100 kilometers mown. The grasses play a vital role in the structural integrity of the leeward side of the flood embankments. The change in maintenance regime has no known effect on engineering performance or design life, and the taller vegetation during the growing season was shown not to inhibit biannual inspections.

Figure 14.9. Business-As-Usual Mowing Regime at Canvey Island

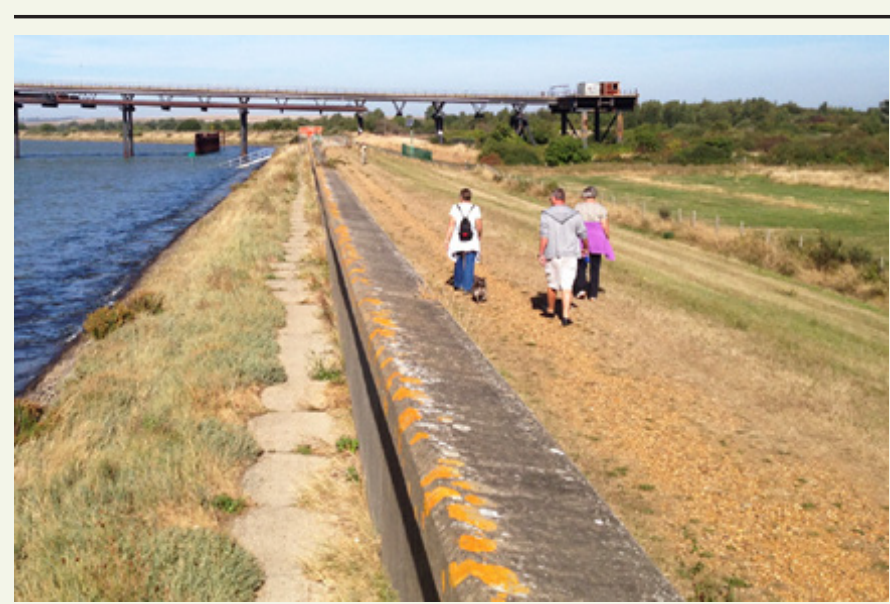

Note: Business-as-usual mowing practice at Canvey Island can be seen to the right of the wall, showing poor habitat quality along the regularly mown earthen embankment.

Source: Larissa Naylor, University of Glasgow 
Figure 14.10. Changed Mowing Regime at Canvey Island

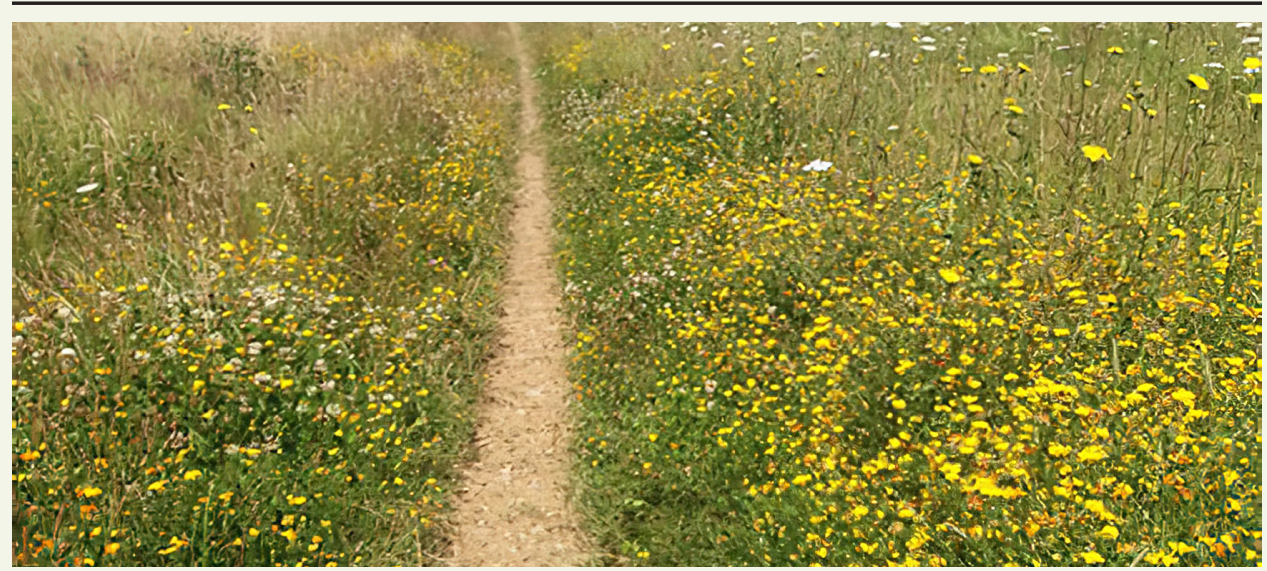

Note: The changed mowing practice at a separate location on Canvey Island shows a thriving habitat that attracts bees and other pollinators.

Source: Tim Gardiner, Environment Agency (United Kingdom)

\section{Figure 14.11. Changed Mowing Regime Attracting Native Pollinators}

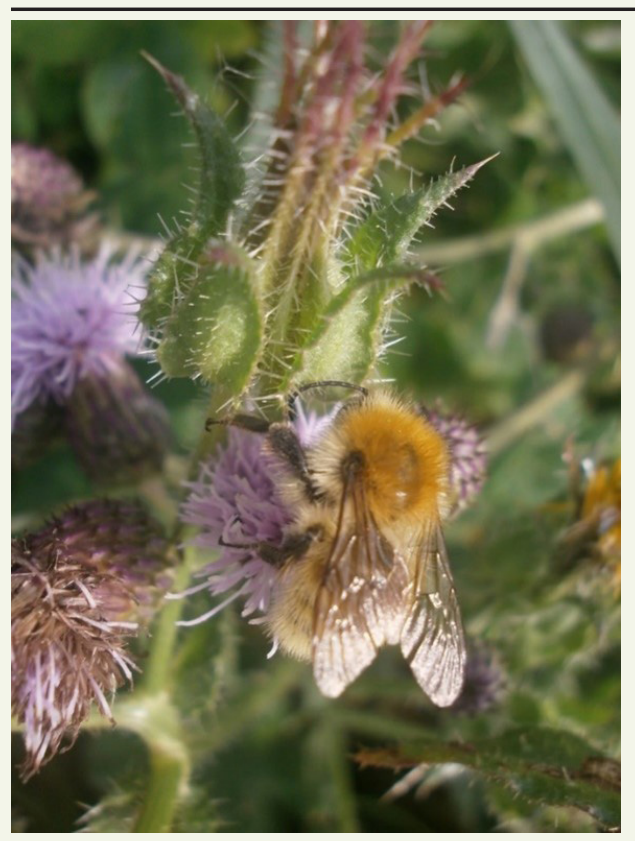

Note: The brown-banded carder-bee (Bombus humilis) is one of the native bumblebee species using the enhanced habitat.

Source: Tim Gardiner, Environment Agency (United Kingdom) 
It is worth noting that there can be multiple benefits for the financing organization that incorporates NNBF enhancements, ranging from near-term financial benefits from co-funding projects and winning awards due to enhancements (see Section 14.5.1) to longer-term reputational gains from enhancements (e.g., being seen as the go-to organization for enhancements).

\subsubsection{Financing Enhancements}

Sometimes alternative funding sources need to be sought for incorporating value-added and incremental costs associated with an enhancement project. This funding can often be advantageous to the project because it can extend the wider benefits achieved on large capital investment projects renewing structural measures and because the inclusion of enhancements has led to awards, improving the reputation of all project partners. Funding sources vary depending on location and can include the following:

- Local, regional, and national government agencies (e.g., federal, state, and city cost sharing; see Elliott Bay shoreline case study [Figure 14.12 and Section 14.9])

- Cost-sharing partners and nongovernmental organizations (e.g., The Nature Conservancy)

- Partnerships (e.g., partnering with organizations to help deliver multiple benefits such as improved amenities and biodiversity)

- Public-private partnerships and education, social, and community funding (e.g., see Vertipools in Naylor et al. [2017a])

- Corporate social responsibility funding (e.g., Caterpillar Inc.)

\section{Figure 14.12. Habitat Bench Incorporated into Design at Elliott Bay Shoreline}

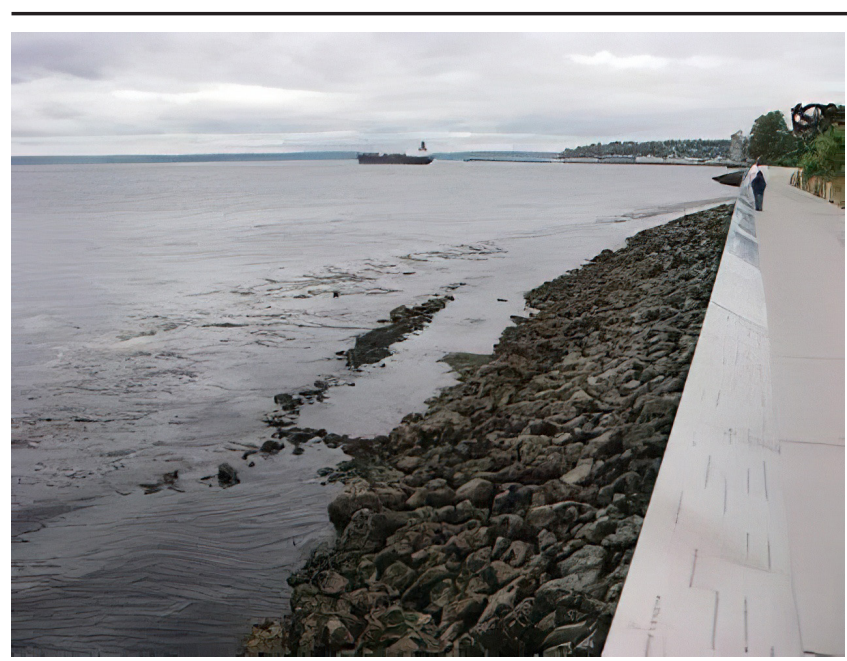

Notes: In the Olympic Sculpture Park project, part of the broader Elliott Bay shoreline case study (Section 14.9), a habitat bench was incorporated into the design. At low tide (left), kelp is visible on the outer margin, growing in sediments placed there specifically for achieving this beneficial use. Successful integration of stakeholders and cost sharing was key to the success of this project.

Source: University of Washington 
Collaborations with research organizations and universities have also been key to creating the database of enhancement features in this chapter and, importantly, help fund crucial design and monitoring of trials to build a robust evidence base of their success (e.g., the majority of examples in Naylor et al. [2017a] involved university partnerships). This can also reduce the costs of post-construction monitoring because small contributions from the owner can often be used to leverage more substantive research cofunding to support graduate research (e.g., see Hartlepool case study in Section 14.9). To reduce the cost of enhancements, it is important to have clearly specified tender briefs for the design or construction of enhancements that limit the risk of cost escalation by bidders. It is also important that proposed designs have estimated costs up front, where efforts are made to minimize costs of enhancements, such as by working closely with contractors and manufacturers to identify key areas of cost escalation and working to minimize them during the design phase. One example is having a contractor create precast form liners to make concrete forms for creating habitat features (MacArthur et al. 2019). Although there are up-front costs associated with designing and constructing the liner, the liner can be reused repeatedly, thus amortizing up-front costs over time.

Key to the success of securing alternative funding for a project is effective communications early in the project and thinking creatively to help identify funding streams that otherwise may be overlooked (e.g., arts, correction service, or community-based funds; see Vertipools in Naylor et al. [2017a]). To fully optimize investment opportunities, the full potential range of benefits from adding NNBF enhancements to structural measures needs to be identified, considered, and communicated up front so that potential funding streams or reputational benefits that may arise from enhancement while meeting project objectives are not overlooked. In essence, investment often follows identified value, thus further emphasizing why valuation of multiple potential benefits is needed.

\section{6 | Agreements and Licenses}

Once agreement in principle for including enhancements in any given proposed project is made, it is important to obtain written agreements for key topics, including the following:

- Site mitigation plans to limit impacts of the construction of the enhancements or the entire project to existing fully functioning habitat (e.g., Charles and Edwards [2015]) and to describe the mitigation, remedial, or compensatory measures that would be required for any impact

- Plans for how the enhancements will be monitored and managed over time, including measures for signatories to be accountable for future actions, and appropriate measures of success (Note that measures of success could be ecological [e.g., meeting biodiversity targets] or engineering [achieving overall project goals]; these will be project-specific 
targets and are often a catalyst to require enhancements. Baseline monitoring or comparative studies [comparing enhanced to nonenhanced areas] are often needed to evaluate success.)

- Engineering approval that the designs are within the engineering requirements of any given scheme

- Agreement on who owns the liabilities associated with any enhancement, especially where there is partnership funding or where there are nongovernmental organization or university research partners helping design the scheme

It is important to note that although there may be short-term impacts during construction of the project, they may be far outweighed by the longer-term benefits of the completed project (see also Chapter 9). This would also pertain to projects where the current infrastructure provides minimal functional habitat or provides habitat incidentally (e.g., small mammals may use the site periodically for foraging). Agreements could be used for such projects, particularly where existing infrastructure is being enhanced or modified to provide habitat, or where such structures are being repaired or maintained to serve as a future enhancement. As an example of the importance for having a written agreement in place, shorebirds may be using dredged sediment being strategically placed to serve as beneficial use habitat on an active dredging project. Such wildlife utilization during an ongoing enhancement project should not restrict the ability to continue placing sediment at the habitat until the project has been completed. There are multiple examples (e.g., in the United Kingdom) where such projects are then managed as part of the flood risk asset maintenance cycle (Naylor et al. 2017a).

\section{7 | Implementation Phase Considerations}

This section discusses specific construction-related considerations when adding enhancements to structural measures as part of new build, replacement, or repairs. As with all construction projects, there is a need to use environmentally sensitive construction practices to minimize impacts on local biodiversity or cultural, archaeological, or geodiversity concerns in parallel with any infrastructure or operational factors that may affect construction activities (e.g., gas pipelines and dredging windows, respectively). A balanced approach is needed to address any short-term impacts of the project. Short-term impacts (days, weeks, months) due to construction need to be weighed against the longer-term (years, decades) benefits of the project. In many cases, the long-term benefits of adding environmental function will greatly outweigh any short-term impacts.

For most enhancement types, construction is very similar to mainstream engineering approaches. Examples include beach renourishment techniques for sand- or gravel-based enhancements, reflooding by cutting notches in dikes (e.g., see Loosahatchie Bar case study 
in Section 14.9), and using precast units that are textured for increasing ecological benefits but otherwise identical to standard wall (e.g., see Elliott Bay shoreline case study in Section 14.9) or revetment construction.

In the case of repairs, the construction process is often altered, such as by changing the materials used (from conventional, hard gray engineering materials to softer materials such as mud and gabion baskets) or changing the position relative to the asset being repaired (e.g., setting back sheet piling and creating habitat in front of it).

Enhancement types can also be added in situ, identifying common issues to consider in the construction phase to enable enhancements to be included or their application optimized in a given location (e.g., see "Seawall Terraces and Sea Aster Conservation in Tokyo Bay"). For example, to accelerate the rate of colonization of native species, seeding or planting can be incorporated into the design to improve the rate of plant or animal species establishment and reduce the risk of establishment by non-native species. This can also be achieved by changing (i.e., reducing) maintenance regimes to improve ecological outcomes (e.g., see "Embankment Mowing for Bees").

\section{AnthH}

\section{CASE STUDY:}

\section{Seawall Terraces and Sea Aster Conservation in Tokyo Bay}

\section{Background and Motivation}

Sea aster (Aster tripolium) is an endangered plant in Tokyo Bay, Japan (Figure 14.13). Researchers from Meiji University have studied sea aster in Tokyo since 2000. There are two small local populations in Kasai Rinkai Park and Kasai Kaihin Park in Tokyo Bay, as well as scattered locations elsewhere. At Kasai Rinkai Park, sea aster was found growing in the mud on concrete blocks of the lowest seaward terrace of the seawall flood defense (Figure 14.14), which is located in the intertidal zone (Kuramoto et al. 2017). The distribution of sea aster is correlated with the thickness of the mud on the concrete block terraces. Sea aster grows only in mud that is more than 3 millimeters thick in the spaces between concrete blocks and behind rocks where present (Figure 14.15), although it does not grow in freshly deposited mud (Mishima, Gardiner, and Kuramoto 2019). 


\section{How the Project was Successfully Executed}

In 2016, a proposal was made to the Tokyo Metropolitan Government that small rocks should be installed on the Kasai Rinkai Park terraces to trap mud (Mishima, Gardiner, and Kuramoto 2019). The port engineers stated that the seawall in Tokyo Bay must be hard engineered because the wave power is high, with the threat of tsunami damage on the Pacific coast (Kuramoto et al. 2017). However, small-scale trials have been undertaken to illustrate how rocks placed on the terraces can be used to encourage sedimentation on Tokyo seawalls.

On the seawall at Kasai Rinkai Park, simple structures to promote sedimentation on the terraces are being designed to encourage salt marsh flora to colonize (including sea aster) following research and small-scale trials. Additionally, if new seawalls are built, rock structures promoting sedimentation on terraces should be included to encourage silt to build up and sea aster to colonize (Cousins et al. 2017). In Tokyo, rocky shore terraces have been installed in front of steel-piled urban flood defenses-these also encourage sedimentation if set at the correct level. Terraces of sea aster on the riverside slope of flood defenses in Japan may be of some value for six species of grasshoppers (orthoptera), which could benefit from the increased provision of Asteraceae flowers on which Figure 14.13. Sea Aster (Aster tripolium)

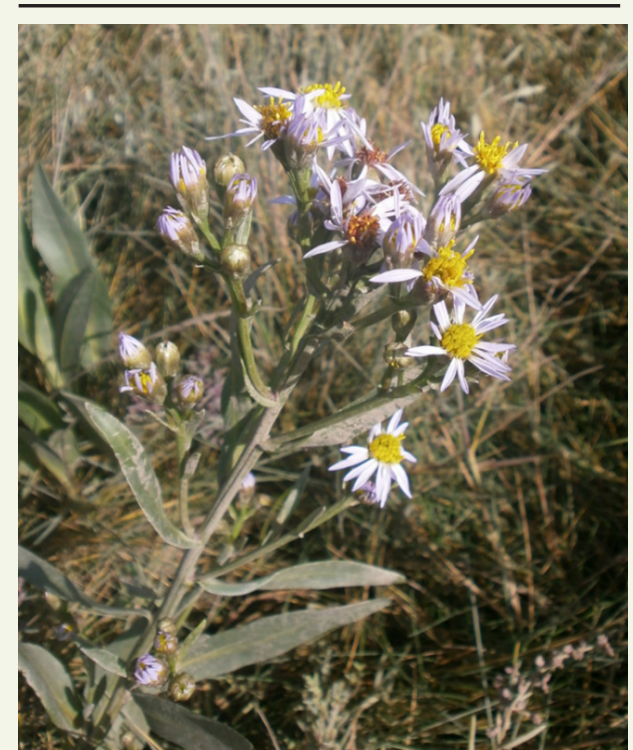

Source: Tim Gardiner, Environment Agency (United Kingdom) they feed and provide a valuable food source for avian predators. Pollinators may also be attracted to sea aster flowers providing ecosystem services. 
Figure 14.14. Tokyo Bay Tidal Terrace with Vegetation Growing in between Concrete Blocks

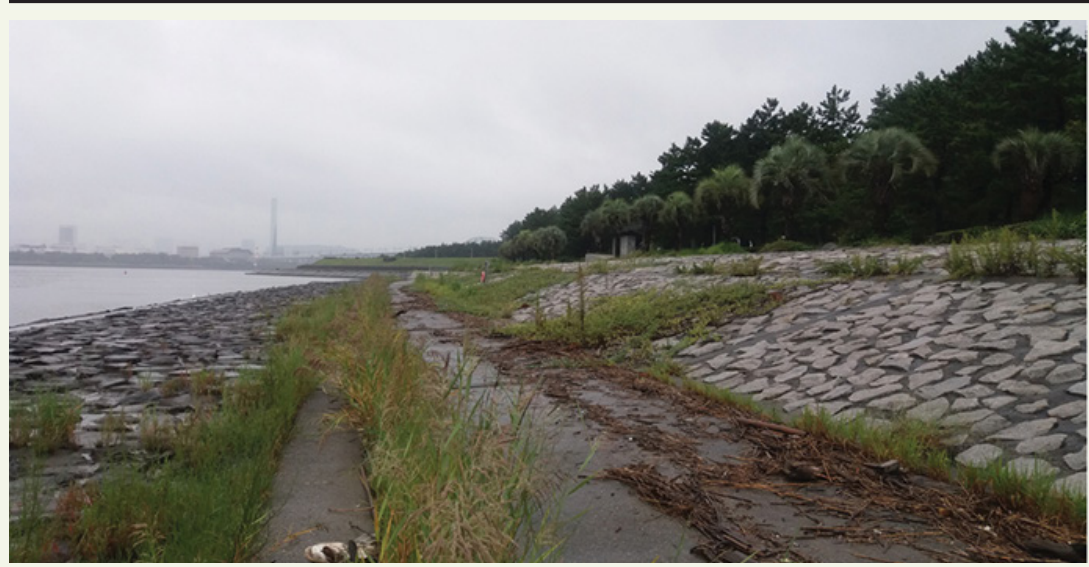

Note: Vegetation found between concrete blocks includes the endangered sea aster (Aster tripolium). Source: Tim Gardiner, Environment Agency (United Kingdom)

\section{Figure 14.15. Tidal Terrace Rocks in Tokyo Bay}

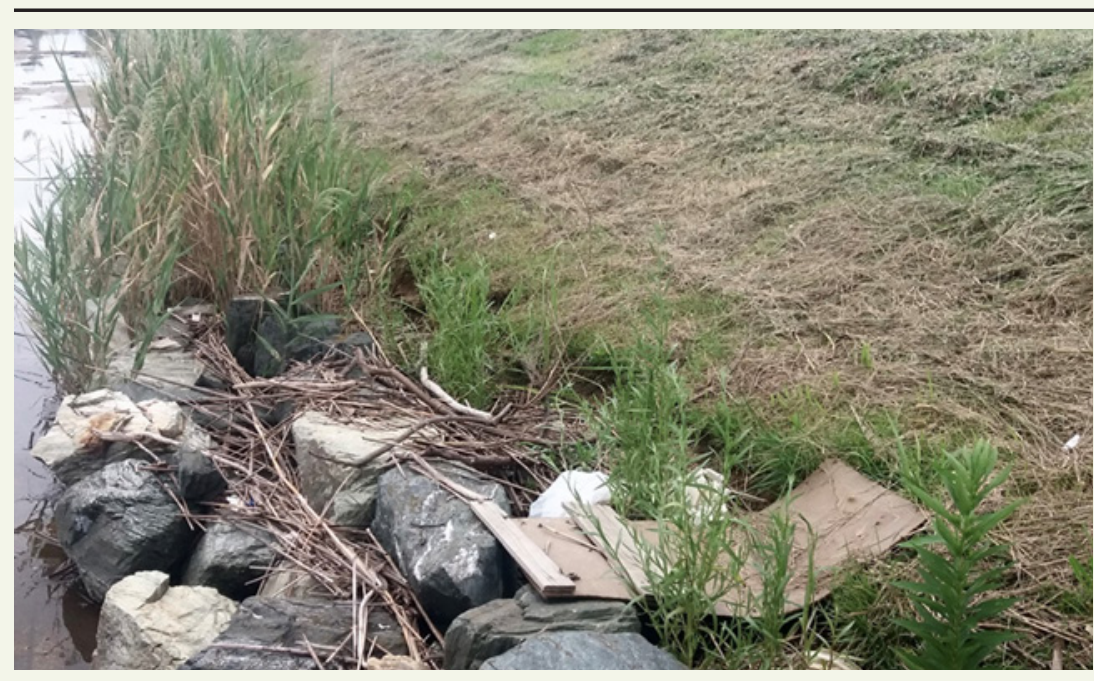

Note: These tidal terrace rocks protect the seaward slope of the flood defense and provide opportunities for sedimentation and sea aster colonization.

Source: Tim Gardiner, Environment Agency (United Kingdom)

\section{NHIH}




\subsubsection{Cost Estimates}

During the design of an infrastructure project, it is common industry practice to develop an estimate for the capital cost of construction. The estimate should provide for the establishment of a realistic prediction of cost and be sufficient to establish a project budget and obtain approval for financing. Indicative cost estimates are first developed at the conceptual design stage and progressively elaborated through the design process. In this manner, the predicted accuracy of the estimate relative to actual construction cost is increased as the design is advanced and final design details are established. Upon completion of the final detailed design, a revised estimate of cost is prepared based on complete or substantially complete working drawings and specifications prior to calling for competitive bids. A high degree of confidence (+ $5 \%$ to $10 \%$ of actual award price) is typically targeted for this estimate. Based on industry standards, in a competitive bidding environment, the estimate is expected to be higher than the lowest and second lowest bid, and not higher than the highest bid.

Cost estimates are generated based on a variety of inputs, namely cost data and actual unit prices for items such as materials, labor, and overhead, and in consideration of logistical and project complexity, availability of local resources and expertise, schedule, contract terms, and local market conditions. A strong reliance is often placed on actual cost data from similarly completed projects in the region of delivery.

New and emerging design features and construction approaches such as NNBF inherently have uncertainty, particularly when there are limited comparative cost data for analogous projects in the region of delivery. This can lead to price estimate inflation as cost contingencies are added in an attempt to compensate for the uncertainty. Although the addition of contingencies for project risk and uncertainty is common practice and advised, the enhanced degree of uncertainty pertaining to NNBF and the lack of actual data for similar projects can lead to an inflated and potentially overstated contingency allowance.

Adding a contingency factor to all cost estimate inputs and embedding the overall contingency carried to compensate for the NNBF-related uncertainty is not advised because it inhibits transparency and clarity in evaluation. When properly applied, cost contingencies for NNBF uncertainty should be specified as a standalone line item in the overall cost estimate so proponents can clearly understand how uncertainty is being addressed. This is particularly important when completing a comparative cost analysis for a conventional infrastructure project versus a project where NNBF is being applied. It is important to guard against overcompensating and artificially inflating the cost for implementing NNBF simply to address uncertainty. 
Contractor bids may also be influenced by the degree of project complexity, uniqueness,

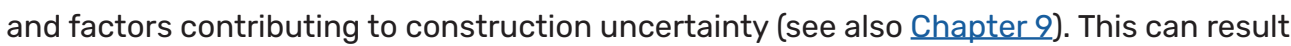
in premiums being applied to bids to guard against perceived risk. Contract terms, such as warranties, schedule requirements, and payment conditions, can also influence price. Price escalation may occur to offset contractor risk and liability. Given the unique aspects of NNBF projects, particular consideration is advised when developing contracting mechanisms and terms.

\subsubsection{Procurement and Construction}

Conventional infrastructure projects are typically procured via tender-based methods, with award of compliant bids based on low price. This is often appropriate when there is a community of experienced contractors well versed in the delivery of the project type. With NNBF projects that may be novel or emerging, or where there is limited local contractor experience and expertise completing similar work, it may not be appropriate to award to the lowest bidder, without any evaluation of technical expertise, approach, and experience.

Where the project entails substantial NNBF, and is unique for the region of delivery, it may be appropriate to consider an alternative procurement strategy for the construction, such as a request for proposal process or a design and build delivery mechanism. This way, qualification- and experienced-based selection criteria can be incorporated into the evaluation process. This may help to facilitate overall project success and enable qualified contractors to be engaged and appropriate construction processes implemented throughout project delivery. Another route is to hire experts from elsewhere to help the local contractors manage uncertainty and risks by aiding them at various points in the construction process (for examples, see Seattle and Hartlepool case studies in Section 14.9 of this chapter and EnvironmentAgencyTV [2020]).

Deliberate thought needs to be given when defining roles, responsibilities, and performance expectations. Substantial completion, warranty periods, insurance, long-term monitoring requirements, and responsibilities may be unique for NNBF projects relative to conventional infrastructure projects. These considerations need to be contemplated and defined well in advance of contract development. This will be particularly true when multiple stakeholders assume responsibility for overall project delivery and success. Biological processes are not as predictable as conventional construction, where these processes may not even be considered. The relationship and expectations pertaining to the responsibilities of the owner, designer, constructor, and community stakeholders should be clear and well defined. Contract terms will need to clearly reflect these intents and sharing of responsibilities. 


\subsubsection{Sustainable Project Delivery}

Based on the project location and local climate, schedule considerations may be a key factor for consideration and control when planning project delivery. Sourcing of biological and living construction materials, transport, temporary staging and storage, acclimatization, and establishment to limit issues with viability, as well as aligning with growing seasons, will be paramount and procured in a timely manner within the project construction schedule. Sourcing of native species and novel products of limited availability may require notable up-front planning and may necessitate letting go of preliminary contracts to source required materials, notably those with long lead times for delivery. It is also important to select materials and species based on the design life of the enhancement providing suitable long-term habitat for species in a changing climate so that species selected can better adapt to changing temperatures (e.g., lighter colored rocks to reduce heat stress) and sea-level rise (e.g., create habitat niches that allow species to migrate to higher tidal elevations; Naylor et al. 2017c; MacArthur et al. 2020). Such measures taken will ultimately help to enable the long-term sustainability of the NNBF-enhanced project.

\subsubsection{Material Choice}

The materials considered appropriate for enhancing structures depend on several factors related to cost, carbon dioxide footprint, engineering performance, and ecological suitability. Factors that should be taken into consideration include the following: (1) the availability of suitable construction materials and the availability of cost-effective source materials; (2) distance to the project site (and thus the carbon dioxide used) when considering transport of dredged or other materials, including sediments, rock, or stone; (3) construction materials because they need to withstand the multiple hydrodynamic and atmospheric forces subjected to the structure over time; and (4) the compatibility of the material to effectively serve as an enhancement (type of stone) and the ability of natural materials to be physically enhanced (textured with indentations or ridges) to improve habitat (see Milwaukee Harbor breakwater project and Hartlepool case studies in Section 14.9). For examples, see Perkol-Finkel and Sella (2015) and Perkol-Finkel et al. (2018) and the Fowl River Private Living Shorelines and Rich Revetments: Enhancing Hard Substrates for Ecology projects in Bridges et al. (2018) and MacArthur et al. (2020) for rock armor selection. It is also worth noting that there is a growing body of research exploring alternative, lower carbon or more ecologically suitable concrete mixes for use in coastal and marine ecoengineering (e.g., Dennis et al. [2018]). Recent experiments to test the efficacy of altering the $\mathrm{pH}$ of concrete to enhance ecological colonization rates have found no difference in ecological performance compared to conventional marine concrete mixes (Hsuing et al. 2020). 
For projects using dredged sediments for beneficial use, other factors should be considered. These include the following: depth that the material is being dredged; thickness of the sediment area to be dredged, which affects dredging efficiency; type of material being dredged (e.g., rock, sand, stiff clay); compatibility of dredged material to effectively serve as an enhancement feature and longevity of material to remain in place for enhancing the infrastructure (as it relates to grain size); equipment type (e.g., cutterhead dredge, hopper dredge, bucket dredge, truck haul); and access and local availability of equipment (see also Chapters 9 and 11).

\section{8 | Monitoring, Operations, Maintenance, and Management}

After adding an enhancement to a structural measure during the Implementation Phase, the enhancement may need to be monitored, maintained, or managed to confirm that the enhancement meets project objectives in the Operations Phase. A properly designed and implemented monitoring effort should provide the project owner the information needed to determine whether project objectives are being met. To this end, the objectives of the monitoring effort should be clearly articulated up front, focusing on generating data outputs that inform whether project objectives are being met. There are several ways in which the success (or failure) of an ecological enhancement installation should be evaluated via monitoring activities. Such monitoring pertains to both the ecological enhancement itself (to measure success or otherwise of this intervention) and how to monitor the primary engineering function of the structure, with the ecological enhanced elements that have been incorporated. For example, typical maintenance activities appropriate for enhanced structures should include engineering inspections, which may have to be adapted slightly, such as scraping off non-native biota during inspections as an adaptive management measure (see Perkol-Finkel and Sella [2015], where the biology was shown to cause no damage to the asset) or using unmanned technologies (e.g., ciria.org 2018) when access is limited due to safety concerns.

\subsubsection{Monitoring of Ecological Enhancements}

Monitoring of the enhanced structure should be performed so the current and future value gained for both the protective (i.e., primary engineering function of the asset; see Section 14.4) and nonprotective (ecological, social, economic) benefits being realized by the project can be evaluated. A monitoring program should be developed to evaluate the success of the project and to develop the data needed to inform project objectives. Post-implementation planning should include the agreed on design that allows for adaptively managing the enhanced infrastructure. 
Monitoring plans developed for the enhancements should include the nature and extent of the survey and the frequency of monitoring, which will depend on location, type of features, and funding. Monitoring frequency can be dependent on design life of the project, potential environmental impacts, storm frequency and intensity, and regulatory requirements. Monitoring plans may need to extend beyond the immediate project boundary due to external effects of the project.

Opportunities should be sought to monitor baseline conditions prior to construction of the enhancement. This will allow for a comparative assessment between pre- and post-construction of the project, thereby allowing a direct assessment of the enhancement benefits. As part of any monitoring effort, lessons learned should be reported so that the project can be managed adaptively, successes can be applied elsewhere, and missed opportunities can be identified and improved. Such activities should help encourage documentation of present and future value so that the value of such projects can be articulated for future applications. Setting of appropriate objectives and metrics can be key to successfully managing the project adaptively and thereby optimizing project value.

\subsubsection{Post-Construction Monitoring}

Evaluating the relative success of an enhancement project requires both an evaluation of the ecological parameters for which the scheme is designed to improve habitat and, crucially, an understanding and, where necessary, altering of standard asset inspections for the engineered elements of the infrastructure. This section considers both aspects as part of the Operations Phase.

\subsubsection{Funding Considerations for Post-Construction Monitoring Considerations for Ecological Enhancements}

Effective post-construction monitoring ideally needs to be budgeted at the outset of the project; however, this is often time-limited due to budgetary constraints and the limited post-construction requirements of mitigation. To overcome this issue, several enhancement projects have adopted innovative cofinancing mechanisms to help improve the scientific rigor and temporal scope of monitoring. This can include cofunding with universities (see the Hartlepool case study in Section 14.9), nonprofits, local communities, and partnerships (see the Loosahatchie Bar case study in Section 14.9). Regardless of the funding mechanism, there is a key need for monitoring programs to include a baseline prior to the enhancement (or an adjacent unenhanced area that is similar enough to use as a baseline; Naylor et al. [2012]). This monitoring ideally needs to happen before construction starts (see the Hartlepool case study in Section 14.9 for issues when this is not possible), and where possible, occur during construction and post-construction. Costs associated with such monitoring need to be included during cost estimating (see Section 14.7.1). 


\subsubsection{Understanding and Altering Engineering Inspections for Structures with Enhancements}

Equally important is understanding whether and how routine engineering inspections of the existing conventional structural elements will be affected by adding ecological enhancements and, if so, whether these methods can be adapted to monitor engineering performance effectively without impacting the ecological enhancements (e.g., nondestructive testing methods that do not rely on visual inspections). Engineers often voice this as a key concern prior to an ecological enhancement being approved for a scheme. This concern can be addressed by having early discussions with project engineers (as early as the design phase; see Figure 14.8) so that potential issues are identified and addressed (see Section 14.7). In this manner, alternative systems for asset inspection can be developed that meet engineering requirements while not compromising the enhanced elements providing other benefits.

\subsubsection{Inspection Issues within the Design Life Enhancements}

One of the key perceived barriers to implementing ecological enhancements to conventional engineering structures is the issue of the greening measures or biology interfering with operations, engineering inspections (see Section 14.8.2.2), repairs, or modifications.

Perspectives on this vary between engineers-some see this of little concern (because biology is often smaller than the scale of deterioration that is monitored), whereas others may view this as a barrier to including enhancements in a scheme. To address this concern, it is recommended to have early discussions with project engineers (as early as the design phase) to identify potential issues and to develop alternative systems for asset inspection that meet engineering requirements but also do not compromise the ecological benefits. For example, some species (seaweeds and barnacles) are known to increase asset resilience to weathering-related deterioration (e.g., Kawabata, Kato, and Iwanami [2012]; Coombes et al. $[2013,2017])$. Thus, it is possible that inspection frequency could be reduced in areas where these species are providing a bioprotective buffer.

\subsubsection{Inspection, Maintenance, and Management}

Monitoring plans offer an opportunity to compare the enhanced project with the original unenhanced design to determine project performance in terms of providing current as well as future value. Monitoring should also be used to estimate when the next maintenance event may be required and, when and where possible, whether further enhancements can be made at that time, building on lessons learned from the current enhancement or drawing on case studies from elsewhere to improve practice locally (see, e.g., the Hartlepool case study in Section 14.9). 
Monitoring can be used to inform future enhancement project designs and any necessary redesigns of the original enhancement. Monitoring data should be compared to the original design specifications and a determination made as to whether the project is performing as expected or modifications to the design are required.

One example of how monitoring may be effective would be to assess the volume and movement of sediments strategically placed as a part of the enhancement project. Any sediment lost could be replaced during the next maintenance event to maintain the enhancement feature associated with the placed sediment. Permitting efforts should start well in advance, sufficiently in time for the next maintenance or construction event. The outcomes of an effective monitoring effort are improved knowledge of the effectiveness of the enhancement design, how to effectively monitor the structure in the future, and how to monitor similar projects applied elsewhere.

\section{9 | Case Studies}

There is a large variety of ways that environmental enhancements to existing coastal and fluvial infrastructure may be achieved. For this reason, six case studies are presented in this section to illustrate the ways in which these enhancements have been achieved in practice. These case studies show how enhancement can occur during maintenance, repairs, and modifications to existing flood alleviation schemes. Sometimes these projects involve a relatively minor enhancement that does not expand the current footprint of the structure, as in the Milwaukee Harbor breakwater project (Section 14.9). Others involve a larger enhancement, like the Seattle seawall project as part of the Elliott Bay shoreline case study (Section 14.9), which added a shelf to the seawall by creating nearshore shallow habitat and replaced riprap armor with a pocket beach. The lessons learned in the case studies include how to improve the applied technique for future projects, the importance of incorporating anthropogenic use into performance measures, the importance of stakeholder support and involvement, and how to integrate an NNBF perspective in the project design to provide ecological habitat in ways to maximize benefits. Case studies were selected for presentation in this chapter based on the following:

- Benefits produced, from engineering to environmental

- Various scales, from small demonstrations to larger, full-scale projects

- A continuum of benefits produced

- Available data (both quality and quantity), especially data quantifying benefits desired

- Broad geographical distribution

The level of detail provided for each case study varies depending on the size and complexity of the project and the amount of available information. 


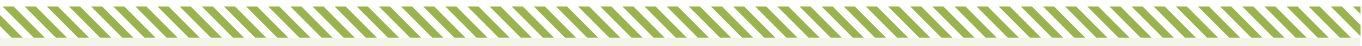

\section{CASE STUDY:}

\section{Milwaukee Harbor Breakwater Fish Habitat Demonstration Project (Milwaukee, Wisconsin, United States)}

The Milwaukee Harbor breakwater project demonstrates the importance of monitoring. The project achieved increased habitat availability for native fishes and increased recreational fishing opportunities. Post-enhancement monitoring showed that the use of habitat patches rather than a continuous feature to create more edge habitat would attract even more aquatic species. Future habitat projects of this kind should, therefore, be managed adaptively, using lessons learned to redesign habitat as patches, rather than as a continuous feature.

\section{Background and Motivation}

This case study describes a USACE Detroit District project that successfully incorporated NNBF into an existing conventional breakwater structure during a scheduled repair, designed to protect the City of Milwaukee (Wisconsin, United States) shoreline and Milwaukee Harbor from Lake Michigan waves and storms (Geisthardt, Suedel, and Janssen 2021; Figure 14.16). The enhancement project on the breakwater structure in Milwaukee Harbor exemplifies many of the phases in the NNBF project development framework from a Great Lakes coastal protection perspective. The primary objective of the project was to broaden the environmental (fish habitat), economic, and social benefits that the breakwater structure could provide by making simple and easily integrated low-cost modifications to the design of the rubble mound rocks used to repair the structure during ongoing maintenance activities. The key aspects of the project that best exemplify the NNBF project development framework are included in this section. 
Figure 14.16. Breakwater Structure at Milwaukee Harbor Repaired after Decades of Exposure to Lake Michigan Waves and Storms

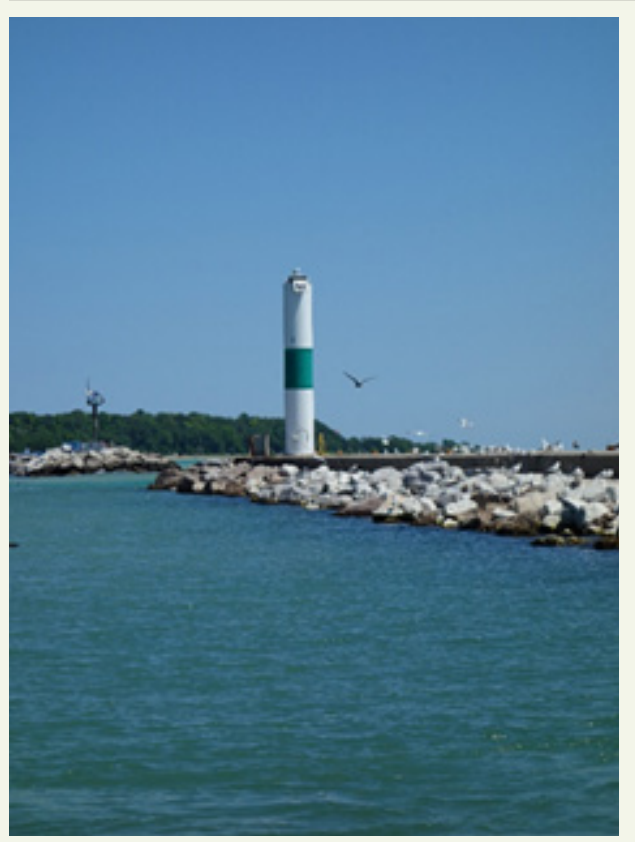

Notes: The breakwater structure at Milwaukee Harbor needed repair after decades of exposure to Lake Michigan waves and storms. The large, 6- to 10-ton stones typically used for such repairs appear above the water level in this photograph of the harbor side of the breakwater structure after repairs had been completed on this section.

Source: Burton Suedel, U.S. Army Corps of Engineers

\section{How the Project Was Successfully Executed}

Up front, the project team was formed by identifying the appropriate stakeholders that could provide direct scientific input into the redesign of the breakwater structure repair to create fish habitat. A key stakeholder was the Wisconsin Department of Natural Resources, which had the fisheries biology expertise needed to provide input into the specifications in the design that would attract local native fish species. Meetings were scheduled with stakeholders to discuss project objectives, design criteria, and scheduling constraints. No permits were needed for the project because the footprint of the breakwater structure did not change.

Funding sources were secured early in the project design phase, with funding originating from both the U.S. Environmental Protection Agency Great Lakes Restoration Initiative and the USACE EWN program. With funding in place, costs were established that met the project budget while meeting the overall project objective. 
The overall vulnerability and resilience of the project was determined early in the design process. To reduce vulnerability and thereby increase resilience of the project, the placement of the habitat was on the harbor side of the breakwater structure to eliminate direct contact with waves from Lake Michigan. This reduced the vulnerability of the habitat to waves, thereby increasing the structural integrity of the habitat over time.

The appropriate features considered in the redesign of the breakwater structure repair were the depth, slope, substrate material, and substrate size to create the habitat. The heterogeneity of the selected stone sizes and variation in water depth were designed to reflect natural reef structures occurring in the Great Lakes and are serving as habitat for lithophilic spawning fish such as walleye, lake perch, and smallmouth bass. No other options were considered because the redesign mimicked natural rocky fish habitat substrates in Lake Michigan. Several benefits were expected to be realized as a result of constructing the project. Expected environmental benefits included greater fishery utilization of the habitat along with greater aquatic biodiversity on the redesigned breakwater structure. Economic benefits expected center on recreational fishing along the breakwater structure. Social benefits include reduced wave rebound off the structure due to the placement of rocks to absorb the waves, increasing recreational opportunities for kayakers in the harbor. The additional construction costs associated with the redesign are expected to be modest compared to the longer-term socioeconomic benefits of the project.

Costs (in the Implementation Phase; see Chapter 2) for completing the redesign and implementation of the project were low relative to the cost of project construction. The construction of the habitat occurred during the normally scheduled repair of the breakwater structure by the USACE Detroit District floating plant, greatly reducing costs. The total cost of the project was $18 \%$ greater than the conventional repair design; the project was inherently cost-effective because the added environmental and other benefits associated with the project were considered to far outweigh the up-front construction cost.

Monitoring was an important aspect of the project because this particular redesign had not been previously implemented on a Great Lakes breakwater structure. The project team partnered with the University of Wisconsin-Milwaukee School of Freshwater Sciences to monitor the performance of the habitat over a 2-year period to confirm that the habitat was attracting a more diverse aquatic species assemblage compared to the areas of the breakwater structure repair where the habitat was absent. 


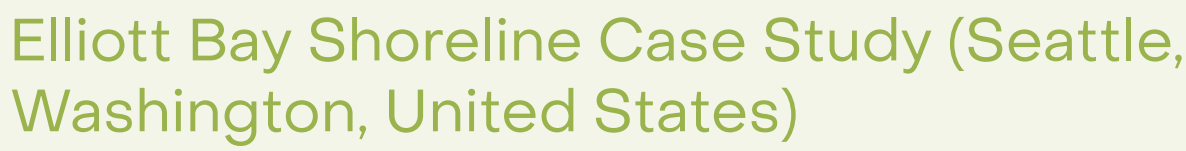

Several lessons were learned during the post-construction monitoring of the Elliott Bay shoreline project. Monitoring results showed that the shoreline enhancement features increased densities of larval fishes and juvenile salmon (Toft et al. 2013). Measurements of juvenile salmon feeding behavior varied by year, and the new features provided habitat for invertebrate assemblages that were different from armored shorelines and had high taxa richness. Fish foraging opportunities increased due to the increased biodiversity of epibenthic invertebrates, a staple food for salmon. Riparian value was increased to a certain extent because some types of terrestrial insects increased in abundance and taxa richness where shoreline vegetation was planted. Progression to a fully naturalized riparian zone will be limited due to routine maintenance and the urban park setting.

The connectivity restored between aquatic and terrestrial habitats provided a way for more natural biological and physical processes to return. In this manner, the pocket beach served as a coarse clastic beach to decrease adverse impacts of harder shoreline stabilization features (e.g., increased wave energy, scour, and interrupted sediment supply), thereby restoring natural beach processes and habitats.

The physical resilience of the enhanced structure depends on both natural processes and human activities, demonstrating the need to incorporate anthropogenic use into the design and management of this urban shoreline project. A pocket beach was also constructed to replace old riprap armoring, creating rare public access to Elliott Bay in Puget Sound.

The Elliott Bay shoreline case study includes two separate projects (the Seattle seawall project and the Olympic Sculpture Park project) that, although implemented separately, had similar goals whereby NNBF was successfully incorporated into an existing conventional coastal seawall structure designed to protect the downtown Seattle waterfront from Puget Sound storms (Toft et al. 2013; Cordell et al. 2017; Munsch, Cordell, and Toft 2017). The Seattle seawall project included features such as incorporating texture and relief into the seawall face and placement of light-penetrating surfaces in the sidewalk directly overhead of the seawall. The texture and relief features were designed to increase the complexity and enhance 
production of invertebrates and algae. The strategic placement of light-penetrating surfaces in the sidewalk was designed to provide ambient lighting for promoting juvenile salmon migration and feeding and for improving productivity under the piers. Additional details about this project can be found in Cordell et al. (2017).

The Olympic Sculpture Park project was initiated due to concerns about the seismic stability of the existing seawall. Two main enhancement features-a habitat bench and a pocket beach-were constructed at the park's seawall. These two features replaced a conventional seawall and riprap armoring, respectively.

The overall objective of both projects was to enhance existing infrastructure that could support greater diversity and numbers of fishes and invertebrates, while providing flood risk reduction, public shoreline access, and ecological benefits. The following provides additional details about the Olympic Sculpture Park project, which generally followed the NNBF project development framework process (Chapter 2). Additional details about the vegetated solutions incorporated into this project can be found in Chapter 13. Vegetated solutions can range from large-scale interventions such as those previously described (and in Chapter 13) to simple, inexpensive changes in routine maintenance practices of flood embankments that increase food and habitat for pollinators by mowing less often (Gardiner and Vetori 2015; Naylor et al. 2017a, 2017b). This is a win-win that saves money and improves biodiversity outcomes for key pollinators (see Figures 14.10 and 14.11).

\section{Background and Motivation}

The Olympic Sculpture Park project was created by building or retrofitting existing hard infrastructure with NNBF offering multifunction benefits. The seawall structure itself was left intact, with portions replaced with similar materials. The project created two distinct additional features. A habitat bench was constructed as a shelf at the base of the existing seawall, creating shallow-water habitat (i.e., a nursery area) for fish, including juvenile salmon, numerous aquatic invertebrates, and aquatic plants (i.e., a kelp forest in the subtidal zone). A pocket beach was also constructed to replace old riprap armoring, creating shallow-water habitat, a public beach in an urban setting (providing rare public access to Elliott Bay in Puget Sound), and riparian habitat (i.e., supratidal native trees and associated terrestrial insects; Figure 14.17). 
Figure 14.17. Pocket Beach Post-Construction at the Olympic Sculpture Park

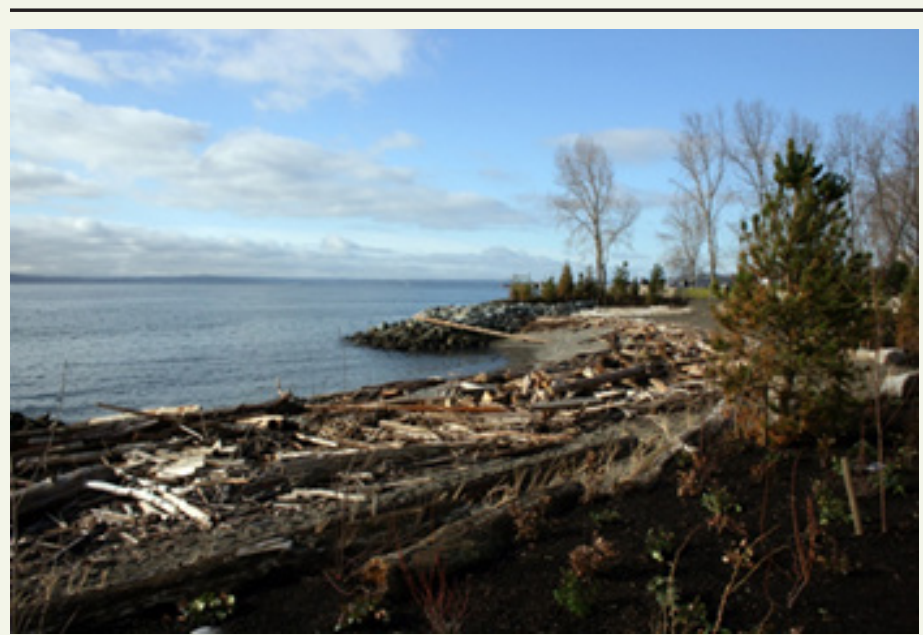

Notes: This photograph shows the pocket beach post-construction at the Olympic Sculpture Park. Native vegetation was planted and driftwood placed on the beach to mimic natural beaches in the area. The beach offers rare direct public access to Elliott Bay in Puget Sound.

Source: Anchor QEA, LLC

\section{How the Project Was Successfully Executed}

Developing a collaborative process involving stakeholders and partners was critical to the success of the Olympic Sculpture Park project, which organized and focused interests, stakeholders, and partners. Funding (secured early in the project) and support came from private, state, city, county, and federal parties, including Seattle Public Utilities, Seattle Art Museum, King Conservation District, Estuary and Salmon Restoration Program, and Washington Department of Fish and Wildlife. With funding in place, costs were established that met the project budget and the overall project objective. An endowment from a private party covers costs for the park's operations, ensuring that the project site will remain open to the public and free of charge in perpetuity.

The overall vulnerability of the existing seawall was well understood early in the design process. There were concerns regarding the stability of the existing seawall to seismic activity, a long-term infrastructure concern in the region. To reduce vulnerability and thereby increase resilience of the project, portions of the seawall were repaired, and in other sections a habitat bench was added to the base of the seawall. In a separate 
adjacent area, existing ecologically unproductive riprap armoring was replaced with a pocket beach to maintain coastal storm resilience while concurrently restoring nearshore coastal habitat.

The appropriate features considered in the redesign of the seawall were an important aspect of the successful design of both the habitat bench and pocket beach features (Toft et al. 2013). The type of substrate material (angular, coarse-grained sediment from local sources) was critical to create the habitat bench and simulate natural habitat functioning. No other options were considered because the design mimicked natural intertidal habitat in the region.

Costs for completing the project were low relative to the cost of a more conventional repair of the existing seawall. The cost for reinforcing sections of the existing seawall and the associated habitat enhancements was USD\$5.5 million. This compares favorably to the estimated cost of USD\$50 million to USD\$80 million to replace that same section of seawall.

Monitoring was an important aspect of the project to confirm the performance of both the physical features of the created habitat and the biota utilizing the shallow-water habitat. Physical features of the created habitats were monitored in post-enhancement years to measure their stability.

\section{MHINH}

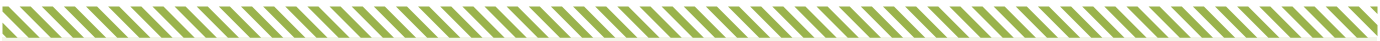

\section{CASE STUDY:}

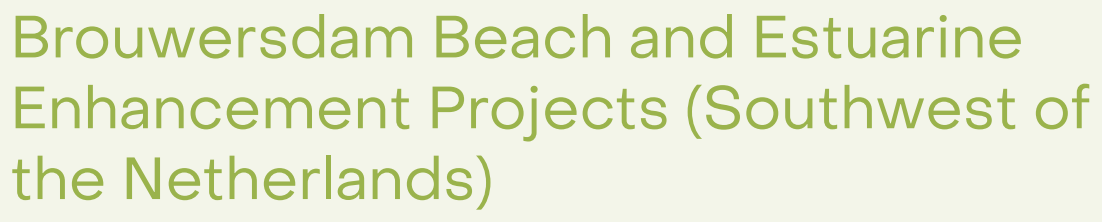

The coastal Netherlands is lined by land and sea dikes that control the penetration of seawater inland. Dikes in the Netherlands are enhanced in multiple ways, including through burial in nature-based dunes or utilization for transportation, with roads running across the top of the structures. Brouwersdam is one of 13 sea dikes built across the mouths of small estuaries in the southwest of the Netherlands during the twentieth century to protect against storm surge at the cost to ocean-estuary 
connectivity (Elias, van der Spek, and Lazar 2016). The Brouwersdam region relies on the sea dike for transportation and protection.

The Brouwersdam beach and estuarine enhancement project offers four principal lessons, as follows:

- Successful projects should continue to monitor and adapt sites to meet the needs of the environment and society.

- A project can take advantage of unexpected funding availability by having welldeveloped plans and proposals ready for consideration before funds are available, as well as a strategy for initiating dialogue and contributing funds (Huibregtse 2013). This was accomplished in this case study through the annual National Delta Program (deltaprogramma.nl n.d.), which works annually with stakeholders.

- Involving stakeholders in land management planning and persistence by both managers and stakeholders are often key ingredients in successful projects. Although the involvement of stakeholders for nonprotective enhancement came recently in this case study, stakeholders have been engaged for decisions on coastal safety for many years. The stakeholders even paid for part of the beach nourishment and inserted themselves into the process to become a key component in the management decisions.

- Enhancements with multiple benefits for multiple stakeholders with clear economic benefit will gain the most traction. These principles led to successful enhancement of the Brouwersdam beach, enabling it to remain above sea level.

The Brouwersdam site offers transportation benefits, economic value, recreational opportunities, and improved ecosystem health, and it may include green energy. The primary managing entity is Rijkswaterstaat (rijkswaterstaat.nl n.d.), the agency responsible for the design, construction, management, and maintenance of the main infrastructure facilities (e.g., roads, waterways, and water systems) in the Netherlands. An important coastal highway (N57) runs on top of the dike, and a large beach is on the North Sea side of the dike (Figure 14.18). The beach was not a design feature of the original project because the dike already guarantees flood safety, though it has become an integral feature in the region. However, the beach had eroded heavily from wave action in the south and without nourishment would disappear in the near future, creating a decision point in 2007. 
Figure 14.18. Brouwersdam Beach - Before and After the Enhancement Projects

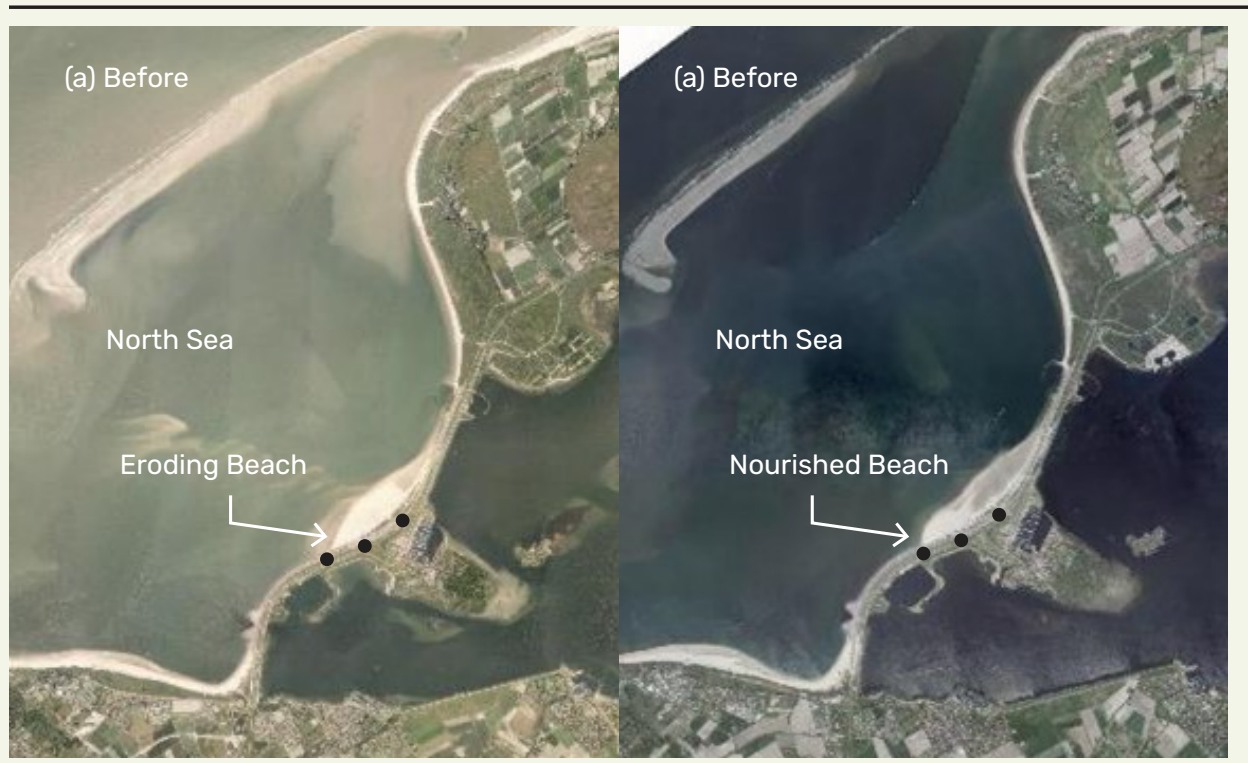

Note: The Brouwersdam beach, located in the center of the dike between the two large land bodies, provided no protection but offered recreational value, including multiple beach vendors (black dots). The beach had eroded heavily from wave action (shown in the photograph in panel [a], taken in 2013) in the south, and without nourishment would have disappeared. A stakeholder-driven process led to an economically defensible use of sand nourishment targeted for protection, for supply to Brouwersdam beach for recreation (shown in the photograph in panel [b], taken in 2016), through a private-public funding partnership, and allowed for improved coastal protection of properties (see black dots).

Source: Rijkswaterstaat

The National Delta Program started officially in $\mathbf{2 0 1 0}$ with a focus on "investing in a safe and attractive Netherlands, now and tomorrow" and initiated the Pearl Projects in 2012. (The municipality Schouwen-Duiveland was the first Pearl Project.) This initiative has followed more of an adaptive approach and led to major enhancement for multifunctional benefits of the Brouwersdam dike. Successful enhancement of the dike came from involving stakeholders, careful planning, and persistence by managers and stakeholders that led to an evolution in management considerations toward inclusion of nonprotective enhancements via a creative funding scenario.

Rijkswaterstaat has a formal consideration process for engaging stakeholders and partners (Scoping Phase) for coastal flood protection and is required to consider ecological enhancement as part of the Nature Conservation Act. This process involved the following partners: Rijkswaterstaat, the water board (dune manager), Evides 
(the drinking water supplier), the local municipality (the recreation promoter), local beach entrepreneurs, the Dutch Forestry Commission, and Deltares (an independent institute for applied research in water and related topics). Everyone's engagement was required because the only available funding for sand nourishment was for those projects currently targeting protection, leading to a debate regarding whether sand targeted for protection should be used for recreational value. Though the beach does not offer flood protection, an economic analysis (Planning Phase) of the beach estimated its value at more than $€ 46$ million euros (USD\$54 million) per year. This value came from its attraction of tourists, surfing enthusiasts, and boaters (marina), and use for large concerts (such as the Concert at Sea, at the time of this writing scheduled at Brouwersdam in July 2022; concertatsea.nl n.d.).

A vulnerability assessment (Planning Phase) had to be performed to determine whether sand used for regular protection on Schouwen beach could be safely used for erosion recovery at Brouwersdam beach, increasing the south part of Brouwersdam beach (economic enhancement). The beach at Brouwersdam was a second Pearl Project that included nature restoration on Schouwen beach (initiated by the provincial government), which facilitated the opportunity for sand nourishment at Brouwersdam beach. The actual restorations not only maintain the total sand available but also stabilize the beach and dunes, reducing the amount of beach erosion that occurs and reducing sand delivery inland to the gray dunes, which are successional dune habitats colonized with herbaceous vegetation. This led the provincial government to recommend delaying a regular nourishment at Schouwen beach in the interest of providing more opportunity for the wind and waves to transport the sand to the gray dunes, and for the potential economic benefits from the sand going to Brouwersdam beach instead. Rijkswaterstaat was asked to investigate whether it was possible to skip only one regular supplement to aid the Brouwersdam beach without negative impacts to protection provided by the Schouwen dunes to local drinking water sources (flood defense dunes occur inland). Following an assessment by Deltares, Rijkswaterstaat supported the use of a single nourishment cycle at Brouwersdam beach.

No additional regional support was available because the project offered no coastal protection value to roads, buildings, or fresh water. Instead of ending the effort or performing a nourishment with a shorter return, the local government and stakeholder community came together and demonstrated the importance of the beach because they financed the remaining sand $\left(100,000\right.$ cubic meters $\left.\left[\mathrm{m}^{3}\right]\right)$ needed to provide the full 10 years of erosion compensation (Decision-Making Phase). 
Rijkswaterstaat developed the final plans and requested permits (Implementation Phase) from the Ministry of Economic Affairs. Permission was required under the Natura 2000 management plan (ec.europa.eu 2020), and a Nature Conservation Act permit was acquired, which is required for the extraction of sand on the North Sea. The effort also required approval from members of the pilot covenant (Implementation Phase), which includes Rijkswaterstaat, the water board, Evides, the local municipality, local beach entrepreneurs, the Dutch Forestry Commission, and Deltares. The covenant has set conditions to act if saltwater infiltrate passes a demarcated line, threatening the freshwater facilities. All groups had to confirm that they were comfortable with the decision to skip a nourishment, knowing that a miscalculation would require an expensive emergency nourishment to Schouwen beach. Rijkswaterstaat executed the beach nourishment at Brouwersdam beach (Implementation Phase) and continues annual monitoring of beach erosion on Schouwen beach (Operations Phase; Figure 14.19).

Figure 14.19. Rijkswaterstaat-Executed Beach Nourishment at Brouwersdam Beach

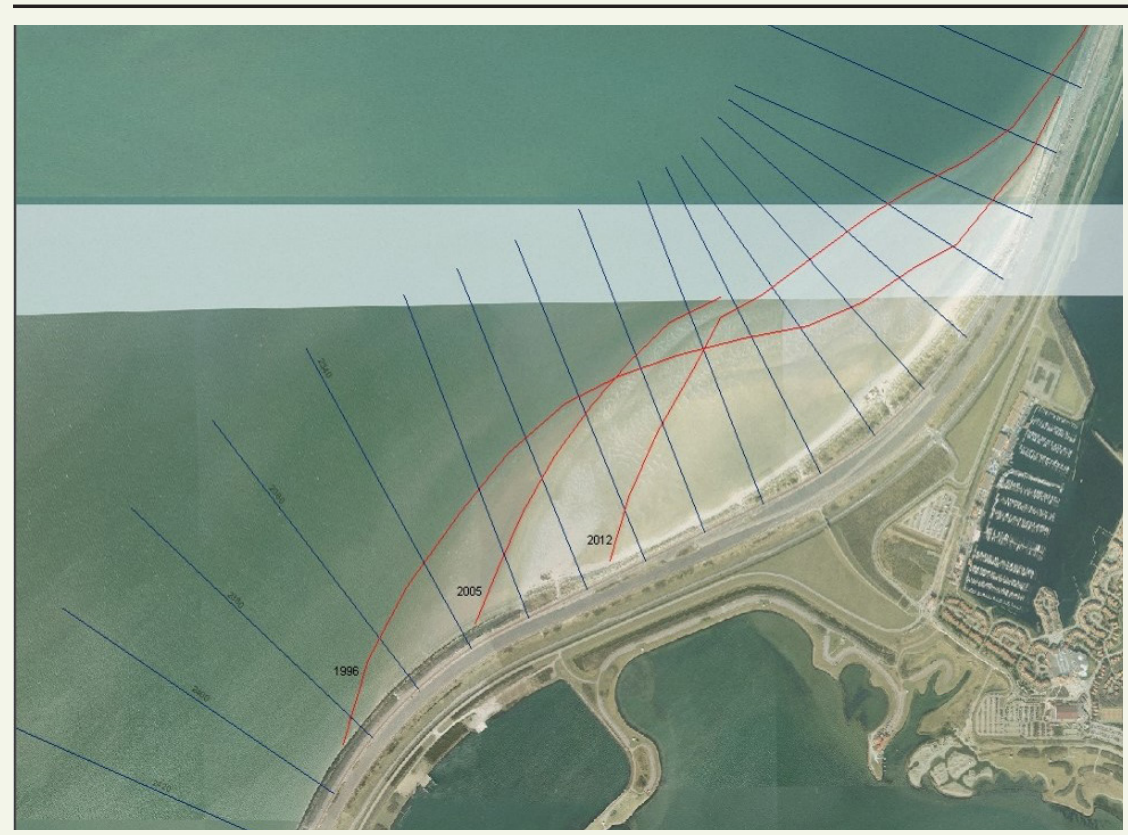

Note: The three red lines indicate Brouwersdam beach lost between 1996, 2005, and 2012; the orange line is the 2023 projection absent nourishment.

Source: Rijkswaterstaat 
The regional economic value is already apparent. A beach vendor business (pavilion owner) that left the eroded beach in 2006 returned to the restored beach in 2016 , 10 years after the planning for the beach nourishment effort began (Figure 14.19). In addition, this sand will still contribute to the local sand foundation; in other words, when sand erodes, it does not vanish, it moves along the coast, providing protective value across the local region. The nourishment plan enabled another decade of beach recreation and economic value, though the future remains unsecured (Figure 14.20).

Figure 14.20. Brouwersdam Beach Looking toward the North Sea from a Beach Vendor

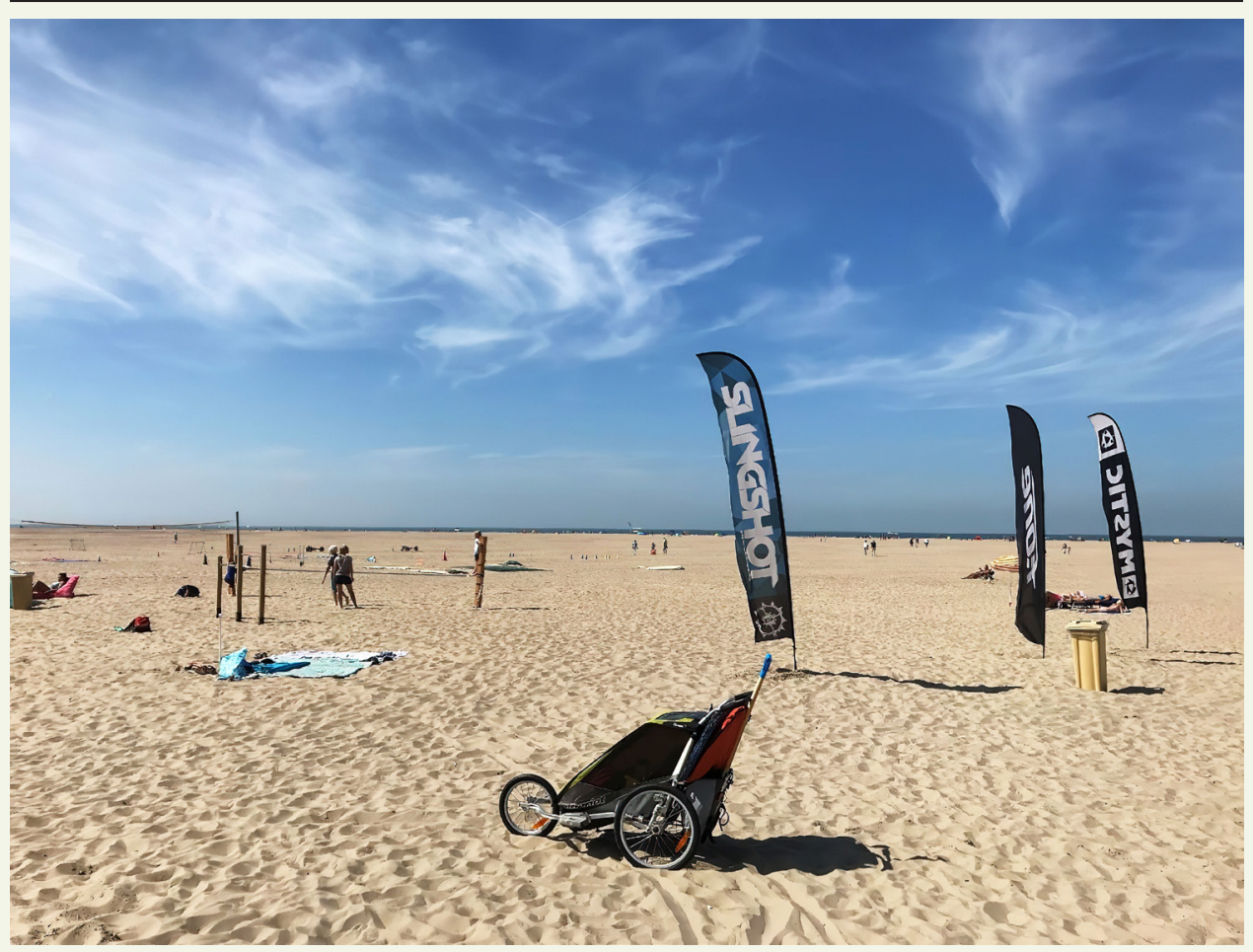

Note: A view of Brouwersdam beach looking toward the North Sea from a beach vendor (see Figure 14.18 Panel [b], beach vendor is represented by middle black dot).

Source: Marian Lazar 


\section{Planning for the Future}

In 2016 the region bought time, but many questions for the region remained. Where will sand come from next time (Scoping Phase)? Can natural estuary-North Sea connectivity be improved for healthier ecosystems and fisheries? What else can be enhanced? The health of the estuary would benefit from increases in the natural tidal connectivity (Elias, van der Spek, and Lazar 2016). In parallel with the beach nourishment effort, a study of a passage in the Brouwersdam to improve the water quality in the Grevelingen Lake was completed (Huibregtse 2013) because it was known that future support would be necessary. In March 2018, the Minister of Infrastructure and Water Management signed for the passage ( $€ 75$ million euros [USD\$88 million]). Rijkswaterstaat is now investigating the possibility for a tidal power plant (much more expensive at $€ 250$ million euros [USD\$295 million]), along with commercial interest (Figure 14.21). A tidal power plant (tidal range 0.5 meter [m]) means 25 megawatt hours and 85 gigawatt-hours per year, enough for 25,000 inhabitants. To support the tidal power plant, dredging and breakwater structures are necessary, which could stabilize the beach and provide partial nourishment to the beach. For ecological reasons, a tidal power plant with a tidal range of $0.4 \mathrm{~m}$ is envisaged. The dike enhancement would improve ecosystem health, provide green energy, and provide a long-term beach maintenance opportunity, addressing the big questions of Brouwersdam. If these enhancements are brought to fruition, the Brouwersdam region has a bright future (Planning Phase). 
Figure 14.21. Drawing of Potential Tidal Power Plant at Brouwersdam

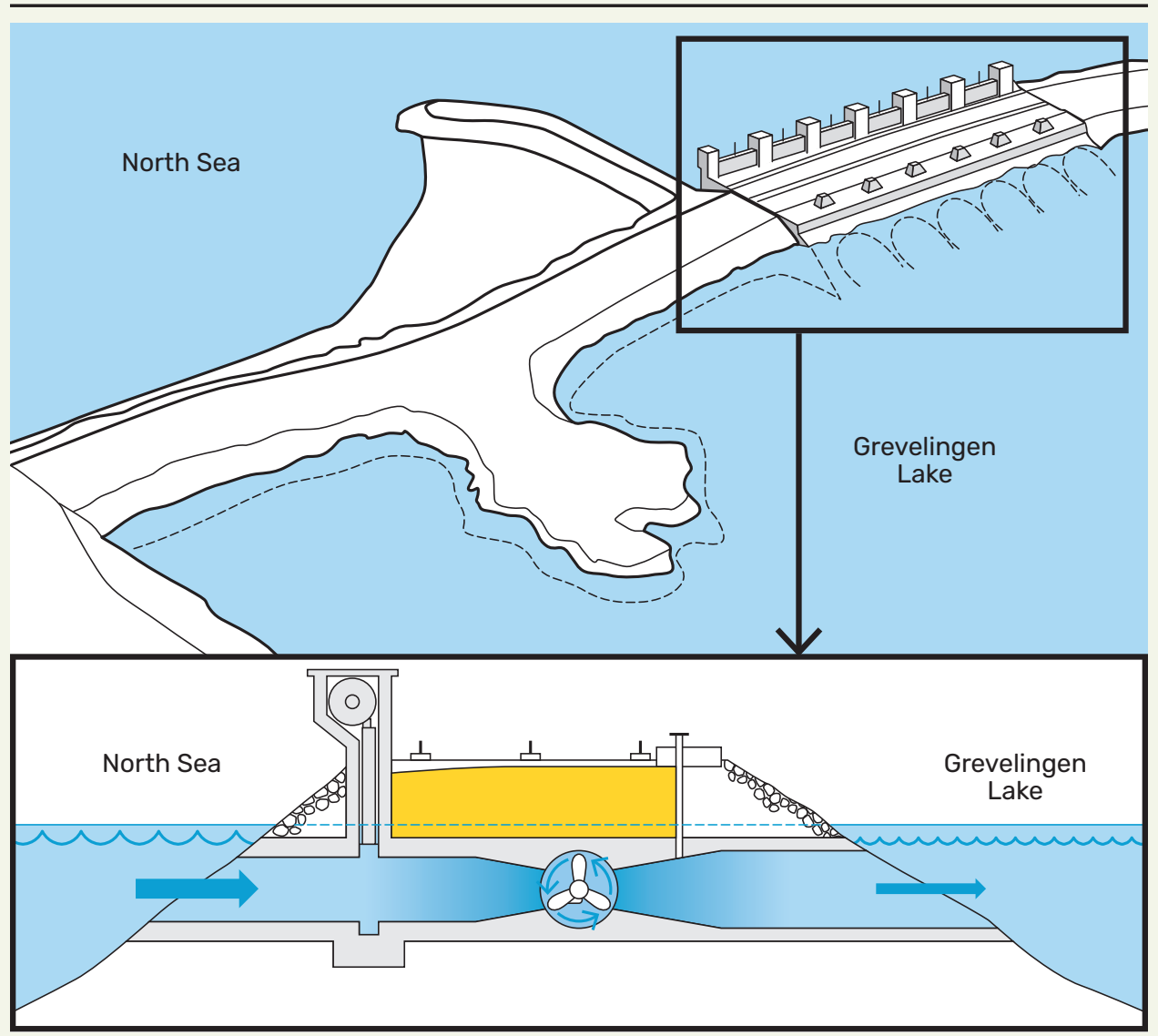

Notes: A potential long-term design for a tidal power plant at Brouwersdam may include energy generation and improved tidal transport between the estuary and ocean (depicted in the upper image) for improved ecological recovery. Bacterial blooms (i.e., Begglatoa bacteria) are an issue in the region. Turbines could deliver substantial energy to the region, and the cleaned sand from the intake dredging could be used for beach nourishment in the region; additionally, a sluice could allow natural tidal transfer. An average flow rate of 950 to $1,000 \mathrm{~m}^{3}$ per second could be observed through the turbine passage (depicted in the lower image).

Source: Province South Holland 
CASE STUDY:

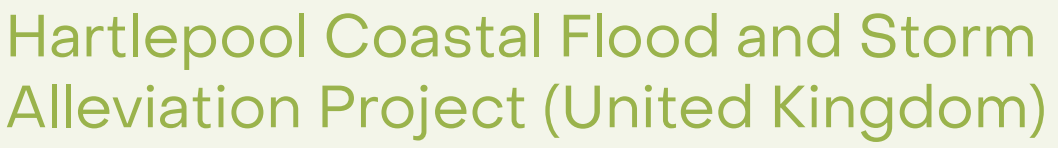

The Hartlepool Coastal Flood and Storm Alleviation project in the United Kingdom is an example of a project for which recommended enhancements may not be operationally feasible (e.g., too expensive or not technically practicable). The risks perceived by government agencies responsible for approving enhancements-due to a lack of local evidence of their ecological success-can reduce capacity to apply NNBF or enhancement measures in new locations. In this example, the smallest ecological enhancements recommended were included in the construction phase, but more active enhancement options were ruled out on cost and risk grounds. Results show that the ecological enhancement options used (material selection and passive position) enabled the scheme to achieve a less disturbed ecological community within 2 years post-construction. However, the passive positioning of boulders provided limited additional ecological benefit compared with optimal material selection alone.

Academic and local government partnerships can help lever further funding to support early monitoring or extend monitoring beyond the scope of what is required as part of any formal ecological mitigation. This also serves to increase the evidence base to aid more widespread implementation elsewhere. Proper controls are hard to build into operational structures, so showing that passively enhanced boulders are an improvement over other materials chosen only for engineering reasons is limited; future trials are needed to test different materials side by side on live engineering schemes. It is also important to test passive enhancement alongside more active measures (such as engineered rock pools or rock armor units that are optimized for ecology).

\section{Background and Motivation}

This Hartlepool case study presents an example of enhancing for a particular conservation goal in a high-energy, open-coast wave environment. The goal was to provide ecological enhancement on the coastal flood alleviation, which allows the scheme to be approved by fulfilling the European Union Habitats Directive requirements of maintaining ecologically favorable status as well as engineering and cost criteria. The local government tried to get the scheme approved previously but had not been successful. Bringing in a specialist team of ecological enhancement 
advisors allowed the scheme to be approved by the government body responsible for ensuring compliance with the regulatory requirements of the Habitats Directive (Naylor et al. 2017b). This was particularly timely because it allowed the local authority to gain access to time-limited central government funding.

A clear set of procedures was followed to get the flood risk scheme's options appraisal established. This included the lead partner (local government) appointing engineering consultants to oversee the initial design and options appraisal stage. Due to the international designations for the site, environmental and ecological impacts of the proposal scheme had to be considered. Ecological enhancements were brought into these discussions after the initial options appraisal was completed, because the preferred flood alleviation option encroached ( $11 \mathrm{~m}$ seaward) into the protected site. A Habitats Regulations Assessment (to determine ecological mitigation) was conducted for the short-listed options. This was needed to help gain approval for the scheme. Academics and specialists were brought in as ecological enhancement advisors at this stage.

\section{How the Project Was Successfully Executed}

Enhancement recommendations from the mitigation approval document (and discussions with the engineering consultant and local government) were used to inform the contractor briefing. Adaptive measures were built into the design recommendation so that if the enhancements that were used did not achieve the required ecological mitigation targets, additional enhancement measures could be added by retrofitting. Cost and risk constraints meant that more actively enhanced solutions such as artificial rock pools were not possible to include in this scheme. Instead, recommendations were made to optimize the ecological potential of the granite rock armor being used for the rock revetment at the toe of the flood alleviation scheme. These recommendations included the lightest-colored, coarsest-grained granite with the largest number of natural concavities or quarrying features (e.g., blast lines or holes) to be selected for use (i.e., partially enhanced; see first photograph in Figure 14.22) and, during construction, smartly positioned (i.e., enhanced; see second photograph in Figure 14.22) to optimize their potential for ecological enhancement. This included orienting any concavities or quarrying features to hold water where possible and creating overhangs or sheltered space within the structure to optimize the range of microhabitats species could colonize, increasing the potential to provide food for internationally protected bird species. 
Figure 14.22. Examples of Partially Enhanced and Enhanced Material

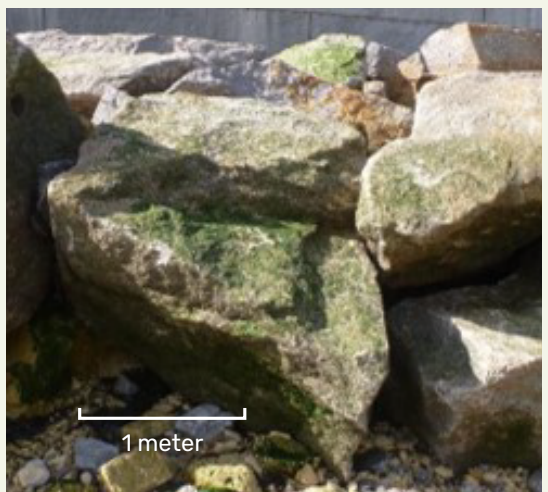

Note: Partially enhanced (material only) with poor positioning; year 0 , less than 3 months of colonization

Source: Mairi MacArthur, University of Glasgow

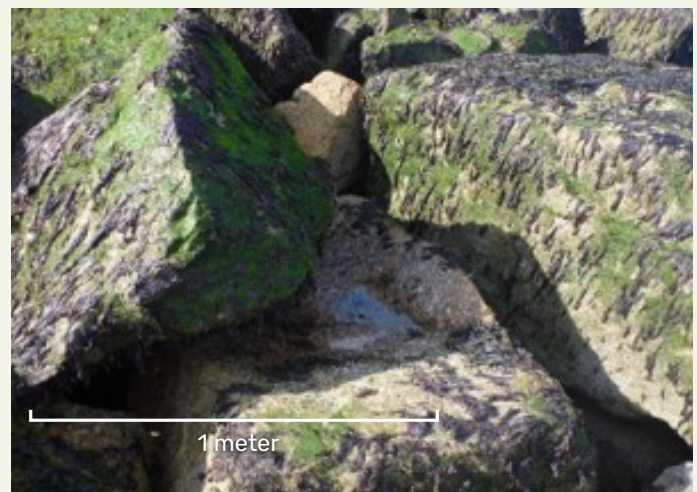

Note: Enhanced (material + position); year 1, 12 to 18 months of colonization; the dark brown material is Porphyra spp.

Source: Mairi MacArthur, University of Glasgow

\section{Initial measures of ecological success}

Within 12 to 18 months of installation, key intertidal species (e.g., limpets, barnacles, fucoid seaweeds) had successfully colonized the rock revetment, matching the initial baseline biotope. However, species richness and the overall quantity of mobile and sessile species were not significantly different between the two enhanced treatments after 12 to 18 months. Importantly, key prey species (the limpet Patella vulgata) on enhanced rock armor showed statistically significant abundances similar to the baseline shore platform and significantly higher than partially enhanced rock armor (MacArthur et al. 2020).

\section{Passive enhancement by rock choice and positioning}

The preliminary data show that well-chosen rock armor material and boulder enhancement using positioning can match baseline biotope conditions in 12 to 18 months and that, for some key prey species, positioning-enhanced rock armor rapidly matches baseline conditions. This facilitates rapid rock revetment colonization, enabling good recruitment of food species and favorable conditions for internationally designated threatened or endangered waterbird species. More active enhancements (e.g., see retrofit habitat in Table 14.1) are recommended alongside this technique where overall biodiversity gains are a goal of the flood risk scheme. 


\section{CASE STUDY:}

\section{Enhancing Existing Infrastructure on Loosahatchie Bar at Redman Point (near Memphis, Tennessee, United States)}

Through careful planning, strong science, and broad stakeholder engagement, a range of social, environmental, and economic benefits were gained by enhancing existing inland navigation structures while carefully maintaining core navigation and flood control missions.

\section{Background and Motivation}

A comprehensive dike program began in the 1960 s to direct river water into the main navigation channel to maintain depth of the Mississippi River. As of 2012, there were 774 dikes on the lower Mississippi River. The construction of these rock dikes led to unintended consequences-such as decreased productivity of nesting by interior least terns, prevented fish movement, and ended seasonal flooding regime for forested wetlands (Koch et al. 2012; Koontz et al. 2016). The USACE Memphis District and Mississippi Valley Division developed designs to install 10 notches in seven dikes, one chevron, and two round-point navigation structures on the Loosahatchie Bar at Redman Point, near Memphis, Tennessee, United States (Figure 14.23), to direct flow through 11.25 miles (18 kilometers) of secondary channel habitats of the Mississippi River.

This project was envisioned by a coalition of state and federal agencies, designed by the USACE, funded by the U.S. Fish and Wildlife Service, and constructed by the Lower Mississippi River Conservation Committee. A key to the project's success was the collaboration between various stakeholders, including the Mississippi River Trust, U.S. Geological Survey, U.S. Environmental Protection Agency, and U.S. Department of Agriculture Natural Resources Conservation Service. 
Figure 14.23. Plan Map of the Loosahatchie Bar Environmental Project at Redman Point

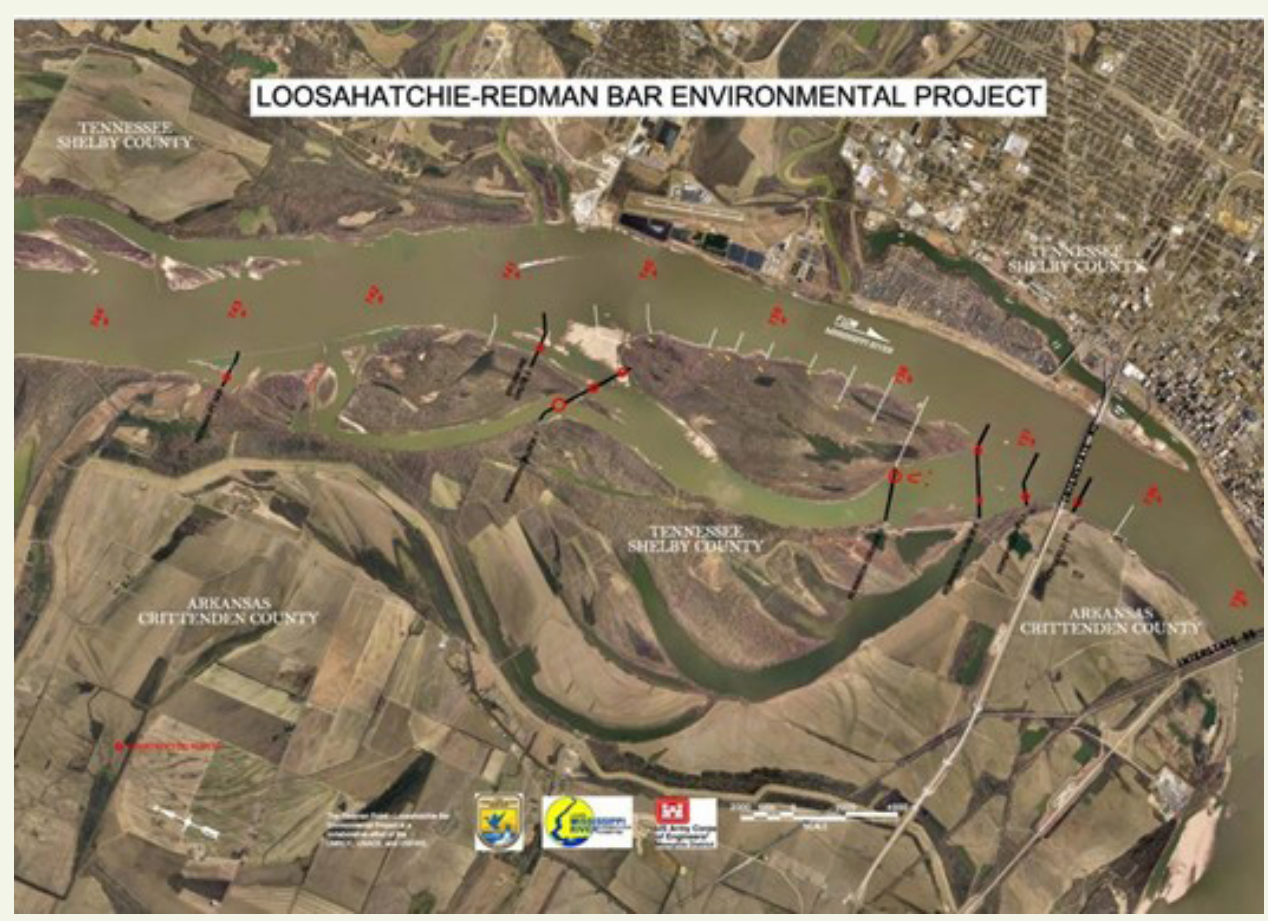

Notes: The Loosahatchie Bar at Redman Point project site is located immediately north of the Interstate 40 bridge crossing into Arkansas from Memphis, Tennessee. Red numbers on the main channel of the Mississippi River represent river mile designations. Black lines note navigation infrastructure targeted for enhancement with connections to the side channel. Open red circles denote locations where infrastructure was notched to improve habitat.

Source: USACE Memphis District

The effort was undertaken to improve recreational opportunities for the public and habitat conditions for wildlife. Habitat for three U.S. federally listed endangered species of wildlife in particular were targeted: the pallid sturgeon (Scaphirhynchus albus), the fat pocketbook mussel (Potamilus capax), and the interior least tern (Sterna antillarum). The notching of the existing conventional infrastructure in this manner as part of carefully designed modifications was not expected to adversely affect its intended function of maintaining flow in the federal navigation channel in the mainstem of the river nor adversely affect flooding downstream. During high water flows, water levels were decreased slightly in the adjacent navigation channel, thereby providing an FRM benefit. 


\section{How the Project Was Successfully Executed}

The success of this project was due to a meaningful stakeholder engagement process. The project team used science and engineering to identify secondary channel habitats that would support the three endangered species but would have no detrimental effects on the navigation and flood-control missions. The project team developed a small-scale, physical, moveable-bed model (i.e., micro model) to maximize the amount of habitat recovered while avoiding impacts to navigation. The resultant project yielded ecological enhancements along this reach of the river by enhancing existing inland navigation infrastructure, thus creating social, economic, and environmental benefits.

The rock dikes that were notched measured between 100 and $600 \mathrm{~m}$ in length, 7.5 to $60 \mathrm{~m}$ wide at the top, and 20 to $64 \mathrm{~m}$ wide at the bottom. Each notch was 0.9 to $3.3 \mathrm{~m}$ deep. Environmental modifications were strategically located on the structures, allowing the river to naturally recreate a low-water channel through the project area during seasonal high flows (Figure 14.24). The project was designed to use a natural process to maximum benefit. This process was designed to decrease the possibility of future sedimentation; the effort will also allow fish passage, increase the creation of natural habitat for a variety of fish and bird species, and provide additional recreational opportunities to local communities.

\section{Figure 14.24. Rock Dike Structure at Loosahatchie Bar at Redman Point Project Site}

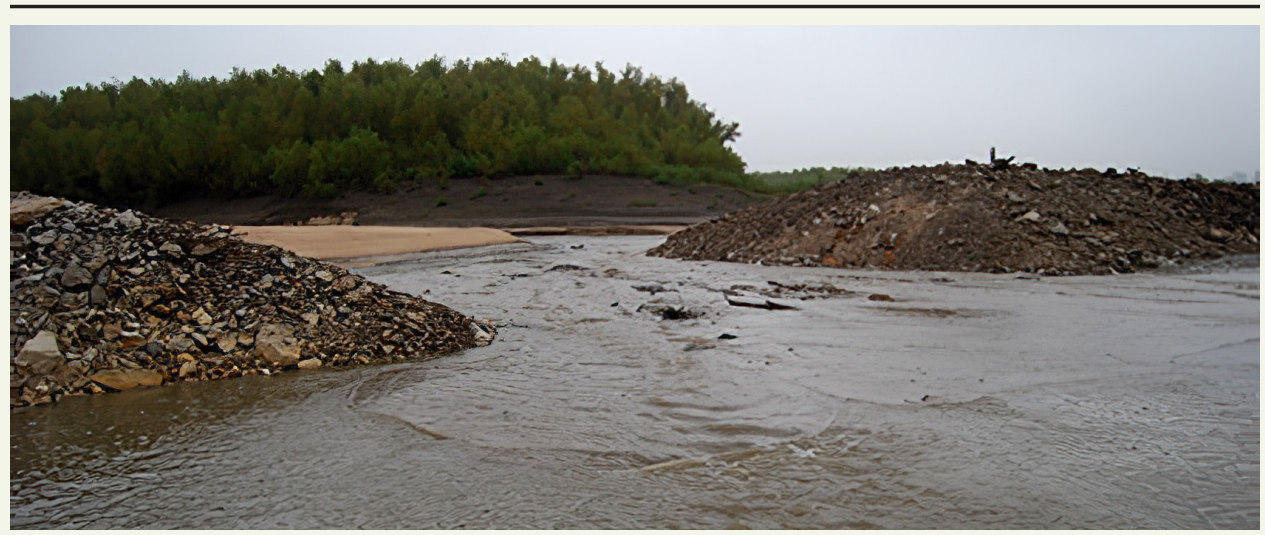

Note: This rock dike structure was notched to create aquatic habitat along a side channel of the Mississippi River at the Loosahatchie Bar at Redman Point Project Site.

Source: USACE Memphis District 


\section{Outcomes}

The Loosahatchie Bar at Redman Point project contributed substantively to the goal of increasing industry and inland navigation infrastructure. Although the notching of inland navigation infrastructure such as rock dikes is not new, strategically notching multiple infrastructure elements along the side channel of the Mississippi River was an innovative application of the modification. The project has had no detrimental effects on navigation and flood control, enabling industry along the river to continue to prosper. The project promotes nature-based tourism by providing recreational access (e.g., boating, fishing, and bird watching) to the 11.25-mile (18-kilometer) reach outside the navigation channel, which is near the large metropolitan area of Memphis, Tennessee. This project also provides opportunities for conservation education. Collaborative processes were used to organize and focus interests, stakeholders, and partners.

The resulting habitat offers excellent habitat to the three target federally listed endangered species and a host of recreational and commercial fish species, neotropical migratory birds, and migratory shorebirds. The side channel acts as a conduit for sedimentation during high flows, keeping the sediments out of the main navigation channel while creating habitat. The notched dikes enabled a return of a seasonal flooding regime that pulsed inputs of nutrients and sediment into these wetlands and increased the net primary production of the forested wetland, in evidence during post-construction monitoring (Koontz et al. 2016). 
CASE STUDY:

\section{Daylighting Westerly Creek - Averting Flood Damage and Creating Green Space (Denver, Colorado, United States)}

Once a buried river, Westerly Creek operates as an urban stormwater conveyance system with the features of a natural high-plains ecosystem, greatly improving ecosystem benefits. There are miles of walking, hiking, and horseback riding trails in the area- $67 \%$ of community residents use the trails weekly and $22 \%$ use them daily. These recreational benefits, combined with the cost savings and flood risk reduction benefits, represent a triple-win over conventional, hard structures.

\section{Background and Motivation}

Deculverting, also known as daylighting, reopens creeks and irrigation canals once covered by pavement or diverted into pipes. The practice of "burying water" may have adequately managed waters in decades past, but increased development, populations, and impervious surface cover in urban environments have increased stormwater flow during rain events. Burying water in such cases also eliminates possible environmental benefits. The existing hard infrastructure cannot accommodate the additional waters, and flooding has become a problem for many urban environments.

Daylighting rivers and creeks presents a clear example of enhancing existing infrastructure. In many cases, the existing infrastructure was deteriorating, insufficient for modern needs, or both. By re-thinking conventional hard structures and incorporating greener techniques, practitioners can apply NNBF methods in fluvial environments as well as in coastal settings.

In 1989, the City of Denver, Colorado, in the United States, decided to build the new Denver International Airport and decommission the existing Stapleton International Airport in the mid-1990s (landscapeperformance.org, n.d.). The Stapleton International Airport had served Denver for decades, and it had buried Westerly Creek 30 feet below a runway for 40 years. The City of Denver had grappled with stormwater management issues and had a history of flood control problems in the area. In 1965, a 3-day storm flooded the city's industrial area, killing 21 people and causing USD\$9 million in damages. Seeing an opportunity to reduce flood risk and make use 
of available land from the defunct Stapleton International Airport, the city and other partners decided in 2001 to use the buried Westerly Creek to improve flood control with an innovative, more natural approach.

The primary feature of the project was Westerly Creek, and the goal was to open the stream channel so it could convey stormwater discharge and serve as green space providing recreational benefits to the nearby community (Figure 14.25).

Figure 14.25. Schematic of Westerly Creek before and after Daylighting

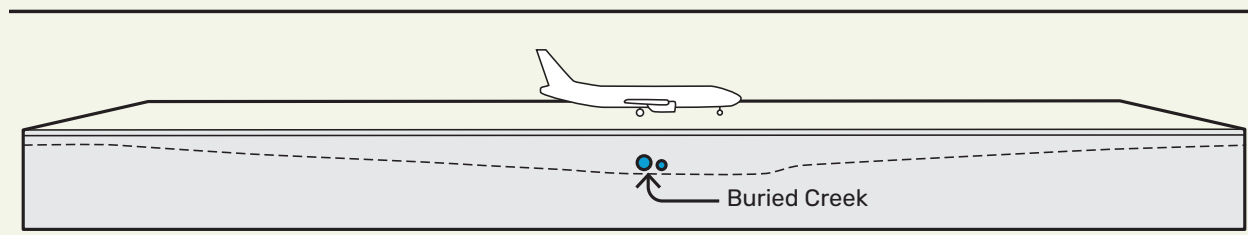

Before Conditions (Stapleton International Airport)

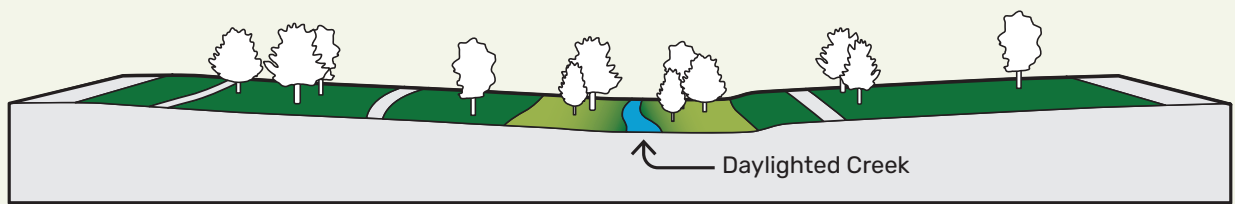

After Conditions (Westerly Creek Park)

Source: Jessica Canfield (adapted from landscapeperformance.org, n.d.)

\section{How the Project Was Successfully Executed}

Westerly Creek was daylighted by removing 4,000 linear feet (1.2 kilometers) of culvert pipe and more than 860,000 cubic feet $\left(24,353 \mathrm{~m}^{3}\right)$ of contaminated soil. Instead of being deposited off site, the soil was reused as architectural berms on site. The concrete from the airport runways was also used on site in a variety of ways, including as pathway edging and dry stack seating walls. Both of these methods resulted in cost savings compared to depositing the materials off site. To accommodate water, the stream channel was set 25 feet $(7.6 \mathrm{~m})$ below the adjacent urban grade in a basin 800 feet ( $244 \mathrm{~m}$ ) wide and 0.75 mile ( 1.2 kilometers) long. The channel was designed with a 4:1 vegetated slope, with gentle meanders for aesthetic appeal and habitat value. 
Sustainable features were worked into the design of the restored creek, including vegetated coir logs and coir mats to encourage plant growth in the early stages of restoration and buried riprap that allows vegetation to grow. Because the project planted native prairie grasses as opposed to bluegrass sod, less water is needed for irrigation, providing significant cost savings and an annual water budget reduction. The native plants also require less herbicide and fertilizer, resulting in further savings.

Monitoring efforts for the Westerly Creek restoration quantified numerous flood reduction benefits. The water conveyance capacity increased from 1,500 to 6,000 cubic feet per second ( 42.5 to $170 \mathrm{~m}^{3}$ per second). Water velocities were reduced to 1 to 5 feet per second ( 0.3 to $1.5 \mathrm{~m}^{3}$ per second) under low flow conditions and 3 to 5 feet per second ( 0.9 to $1.5 \mathrm{~m}^{3}$ per second) under peak flow conditions. By adding 35 acres ( 0.14164 square kilometer) of pervious surfaces, the restoration project increased stormwater infiltration in the subwatershed by $9 \%$. The stormwater management features of Westerly Creek were tested in 2011 (Figure 14.26) and 2013, when heavy rains were slowed and absorbed, averting flood damage (Finley 2018).

\section{Figure 14.26. After Daylighting, a 90-Year Flood Occurred at Westerly Creek in} July 2011

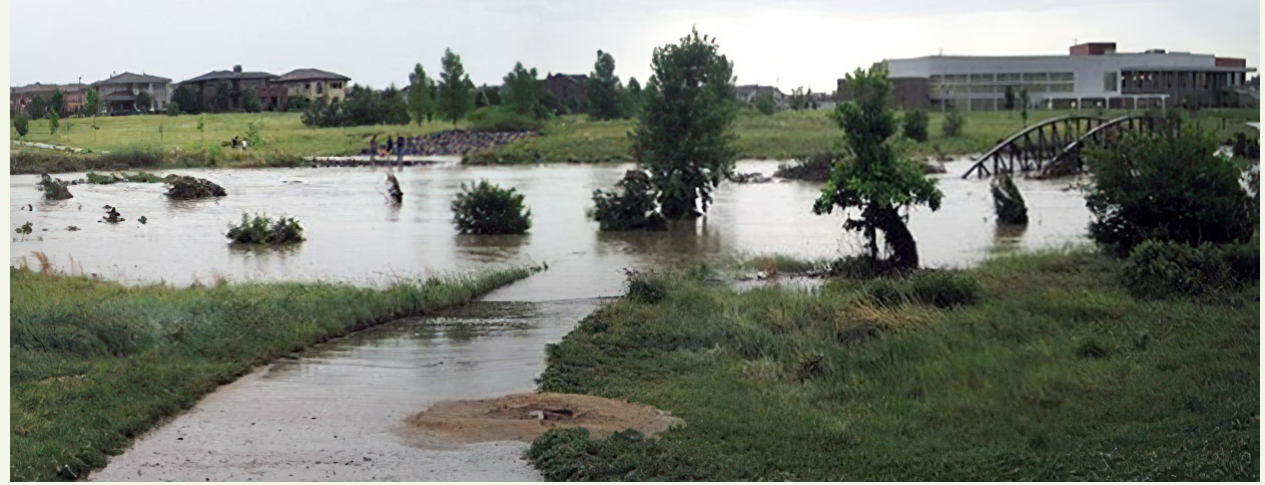

Figure continues on next page. 


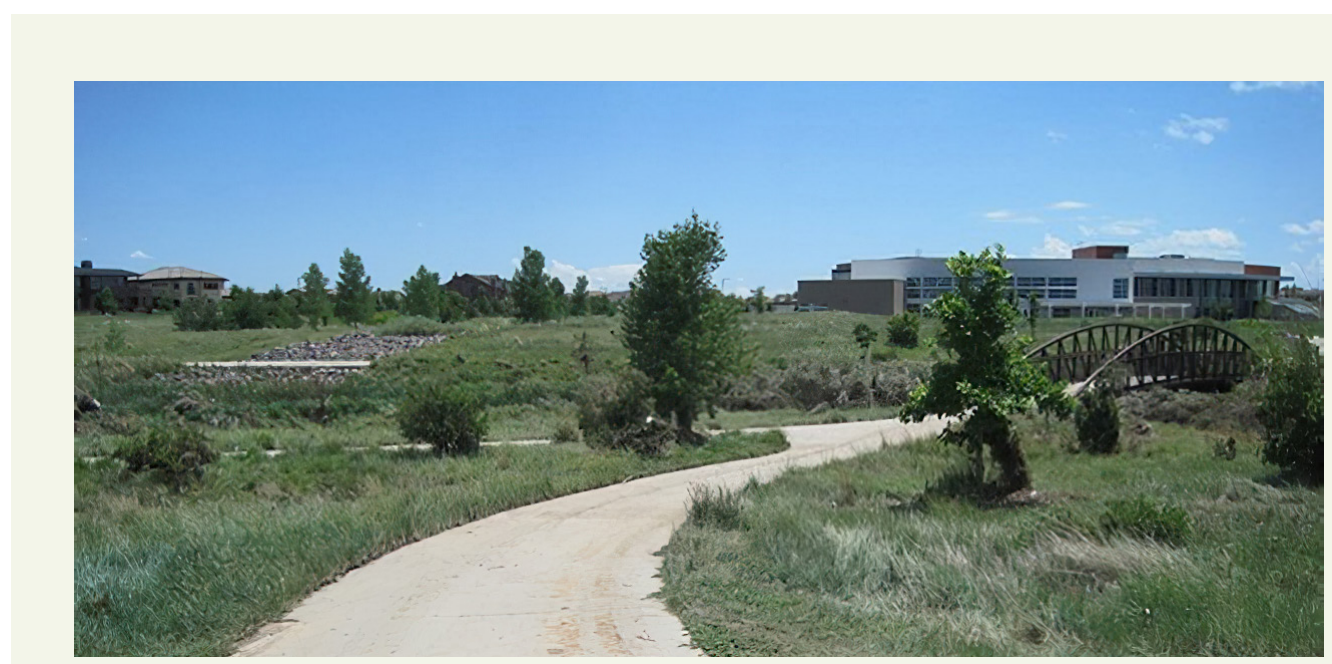

Notes: The photographs show Westerly Creek during a flood in July 2011 (top) and 16 hours later (bottom), demonstrating the creek's ability to protect and recover from flood events.

Source: Jessica Canfield (landscapeperformance.org, n.d.)

\section{Al}

\subsection{0 | Managing Risks and Uncertainties}

As with any project, there are risks and uncertainties associated with incorporating NNBF in a coastal or fluvial project that require consideration on a case-by-case basis (Fredette et al. 2011; Naylor et al. 2017a). Such risks and uncertainties include obtaining project approval (especially costs), hampering future maintenance, and compromising structural integrity, as well as choice of project materials, timing, location, ecological connectivity, project scale, and climate change. Guidance is provided in this section to help address these challenges when incorporating NNBF into existing infrastructure.

\subsubsection{Managing Costs}

One risk to incorporating NNBF into existing coastal infrastructure concerns the cost of obtaining approval to incorporate NNBF. Concerns related to project costs may include direct construction-related costs and long-term costs, including possible changes to asset resilience and inspection and maintenance costs. Any concerns related to costs of implementing NNBF should consider comparisons to business-as-usual costs, prospects for cost sharing, and long-term benefits. To address cost concerns, goals should be developed collaboratively with stakeholders for increasing the application of NNBF on a national or regional scale. This may be in the form of annual goals and broader 5-, 10-, or 50-year targets. Case studies 
should be used where possible to demonstrate the economic, environmental, and social benefits that can be gained from adding NNBF enhancements. If examples of successful policies that have been used as statutory or nonstatutory drivers are available, they should be used as evidence of successful applications. Where no statutory mitigation is required, gaining approval may only require a willingness to innovate. Some case studies illustrate how simple changes in operational practice can yield improvements in ecological outcomes for less, or minimal extra, cost compared to business-as-usual alternatives (Naylor et al. 2017a). For innovations not covered by existing case studies, or where detailed local cost-benefit assessments are required, it is possible to use the approach developed by Naylor et al. (2017a, 2017b) to qualitatively or semiquantitatively evaluate the costs of the NNBF compared to business-as-usual alternatives.

\subsubsection{Reducing Future Maintenance Restrictions}

Another key risk concerns NNBF hampering future maintenance of coastal infrastructure projects. The main concern with future maintenance centers on potential environmental restrictions that could result from their implementation; this has led in some cases to NNBF not being adopted (Fredette et al. 2011). An evaluation of NNBF innovations related to waterborne transport in the United Kingdom, Canada, and the United States found negligible impacts on engineering performance, inspection, or maintenance from the NNBF, and, in some cases, the ecology helped improve asset resilience (Fredette et al. 2011). These innovations were implemented on infrastructure such as breakwaters, river-training and bank-line structures (e.g., blunt-nose chevrons and off-bank revetments), locks and dams, channels, and anchorages. Some concerns center on the process of enhancing the environmental value of a project hindering any future ability to properly and efficiently maintain the project. One potential solution to this challenge is to develop an interagency agreement, such as a memorandum of understanding, that would acknowledge and accept the enhancement will be disturbed by maintenance and also would recognize that, unless the periodic disturbance is accepted, the enhancement would not exist at all. Additional potential solutions include promotion of success stories (e.g., Bridges et al. [2018]); these will provide important lessons learned and ways in which projects have been successfully applied in a wide variety of coastal environments. Frequently maintained structures are often less appropriate to enhance, but there are notable exceptions (see "Embankment Mowing for Bees").

Research needs were also identified that could help reduce risks and uncertainties, including those associated with future maintenance (Fredette et al. 2011). These included developing more widely distributed documentation of existing projects and conducting proof-of-concept pilot studies. Research needs identified that address feasibility and success included adding reef modules to breakwaters, creating upland sand habitat on the protected sides of jetties or breakwaters, creating shelves in channel side slopes at the optimum depth for seagrasses, and seeding infrequently dredged anchorages with shellfish. 


\title{
14.10.3 Addressing Risk and Uncertainty in Infrastructure Integrity
}

\begin{abstract}
A source of uncertainty is the potential for the enhancement to compromise the structural integrity or primary flood risk reduction function of the coastal infrastructure. This concern should be addressed as part of any proposal to incorporate NNBF and requires consideration as part of the overall project review and planning. None of the 18 measures on NNBF included in Naylor et al. (2017a) were found to pose any risks to structural integrity or primary flood function. Where the innovations were applied to operational engineering structures (rather than trials), local engineers evaluated the risks and approved their installation as part of both retrofits and new structures.
\end{abstract}

Choice of materials, timing, location, scale, and ecological connectivity, which are also key considerations associated with implementing NNBF measures, create uncertainties related to incorporating infrastructure enhancements. The engineering design life of NNBF materials in a coastal environment (e.g., granite, limestone, concrete) should be considered in terms of their resilience and ability to provide habitat for desired species over time (Strain et al. 2018) and whether bioprotective species can be targeted that can help reduce risks of weathering-related deterioration (Coombes et al. 2013, 2017). Location should consider the natural processes present and, to the extent possible, harness this energy to help create or restore the desired habitats (e.g., rocky intertidal habitat). Timing involves completing construction during a time of the year that will encourage settlement or recruitment of native species and avoid or reduce colonization by invasive species. Risks associated with scale include concerns about isolated project benefits without clear benefits on a broader (e.g., watershed) scale. One approach to address this risk would be to consider ecological connectivity because there are potential benefits to be realized if connectivity can be created or restored at both the project and larger scales (e.g., emergent marsh food chain).

\subsubsection{Managing Climate Change Risks}

Aspects of a changing climate such as sea-level rise and increased storm intensity are uncertainties that can potentially affect NNBF implementation. Decisions should be made as to whether the objective is to hold the line or advance the line so that the NNBF incorporated into the project design meets project objectives. Within a hold the line policy context, where a structural measure is the preferred option, it should be designed to provide future accommodation space for intertidal species to reduce the risks associated with coastal squeeze (Perkol-Finkel and Sella 2015; Perkol-Finkel et al. 2018; Naylor et al. 2017c). 


\subsection{1 | Gaps and Future Directions}

The enhancement of existing infrastructure for environmental, social, and engineering benefits in both coastal and fluvial environments across multiple scales has seen meaningful progress over the past decade. Yet, work remains that would advance this practice from merely occasional implementation to being the preferred alternative. There are several knowledge gaps and data needs that need to be overcome to promote increasing practice. As discussed in Section 14.10.2, research needs (Fredette et al. 2011) include developing more widely distributed documentation of existing projects and conducting pilot studies to establish proof of concepts. Such pilot studies could include adding NNBF to breakwater structures, creating habitat on the protected sides of jetties or breakwaters using dredged sediments, creating shelves in channel side slopes at the optimum depth for seagrasses, and seeding infrequently dredged anchorages with shellfish.

Education, training, and technical transfer-related needs include documentation of case studies, development of webinars and workshops to disseminate best practices, and coordination of site visits to observe firsthand how innovations are being implemented in practice. Education efforts should be promoted because NNBF may be a relatively new concept for some stakeholders. Just simply introducing the idea may produce an immediate change in how a risk manager might perceive a proposed project. The focus is on the primary project objective (i.e., reducing coastal flood risk), but NNBF introduces the question, Could we be creative and do more for ecosystem services in addition to serving the primary objective? Education, training, and technical transfer-related solutions have proven successful in the United Kingdom, where they have helped raise awareness and improve the confidence of practitioners who are keen to promote NNBF projects.

The following common elements help to advance the practice of enhancing structures with NNBF and achieving successful long-term projects:

- Early and often stakeholder communications

- Meaningful community engagement

- Partnering and collaborations among stakeholders to help monitor project success

- Designing to simultaneously achieve multiple benefit objectives (engineering as well as economic, social, and environmental)

- Developing a monitoring program that identifies and quantifies the costs and multiple short- and long-term benefits of the project

Increased adoption of enhancements can be encouraged by identifying and quantifying the value NNBF provides so that the costs and benefits associated with them can be made. Monitoring data should be pursued to improve our understanding of not only the costs and benefits but also the future value added that applying such approaches in practice can 
achieve and how effectively the enhancements can integrate into broader flood protection measures. The short- and long-term benefits of NNBF enhancements compare favorably to prevailing risks and uncertainties (e.g., cannot degrade the structure or reduce access for maintenance or repairs); such enhancements should be framed in this context.

Effective communications both internally within the project team and externally with stakeholders are imperative so that successful NNBF projects can be applied elsewhere. Key gaps in the previously described training aspects include the following:

- Assisting design and build teams on large projects to learn how enhancements can be incorporated more readily into their practice and to create a forum for their concerns

- Training contractors involved in routine maintenance and repairs to help them identify opportunities to include NNBF at the design stages and to provide advice on writing tenders to include NNBF enhancements

Enhanced projects that relay lessons learned are informative and useful for applying these concepts elsewhere. In this respect, additional projects are needed to further demonstrate and document that NNBF enhancements can be successfully applied at multiple spatial and temporal scales.

Emerging technologies should be considered within the adaptive management framework to improve planning and ensure the most effective infrastructure enhancement practices are used. Technological advancements regularly occur in terms of NNBF enhancement options, materials available for construction, remote-sensing capabilities for planning and monitoring, and model advancement for evaluating design performance and project siting. Novel designs are regularly emerging for creating habitat niches for a variety of species, thereby promoting biodiversity and replacing conventional hardened shoreline structures with innovative hybrid structures (Bridges et al. 2018, 2021). Advancement in construction materials expands design possibilities and offers added value, such as reduced carbon dioxide emissions during construction of hardened materials (e.g., enhancing concrete with natural materials to create Reef Balls). Improvements to remote sensing, including lidar-derived and real-time kinematic GPS-adjusted topography to improve elevation data (Alizad et al. 2020; Buffington et al. 2016) and unmanned aerial and surface systems that have miniaturized payloads (e.g., lidar) offer the ability to capture higher resolution and more accurate data. These detection systems can also help monitor hard-to-access NNBF and animal populations (e.g., birds) to better quantify enhancement performance. The improved available data have enabled advancements in the development of integrated models that provide dynamic predictions of project performance under land management, sea-level, and storm-surge scenarios (Bilskie et al. 2014). Finally, documentation of the use of these emerging technologies will be key to the proliferation of the most valuable advancements. 


\subsection{2 | References}

Alizad, K., S. C. Medeiros, M. R. Foster-Martinez, and S. C. Hagen. 2020. “Model Sensitivity to Topographic Uncertainty in Meso- and Micro-Tidal Marshes." IEEE Journal of Selected Topics in Applied Earth Observations and Remote Sensing 13: 807-814. doi:10.1109/ JSTARS.2020.2973490.

Bilskie, M. V., S. C. Hagen, S. C. Medeiros, and D. L. Passeri. 2014. "Dynamics of Sea Level Rise and Coastal Flooding on a Changing Landscape." Geophysical Research Letters 41 (3): 927-934. http://dx.doi.org/10.1002/2013GL058759.

Bridges, T. S., E. M. Bourne, J. K. King, H. K. Kuzmitski, E. B. Moynihan, and B. C. Suedel. 2018. Engineering with Nature: An Atlas. ERDC/EL SR-18-8. Vicksburg, MS: U.S. Army Engineer Research and Development Center. http://dx.doi.org/10.21079/11681/27929.

Bridges, T. S., E. M. Bourne, B. C. Suedel, E. B. Moynihan, and J. K. King. 2021. Engineering with Nature: An Atlas, Volume 2. ERDC SR-21-2. Vicksburg, MS: U.S. Army Engineer Research and Development Center. http://dx.doi.org/10.21079/11681/40124.

Buffington, K. J., B. D. Dugger, K. M. Thorne, and J. Y. Takekawa. 2016. “Statistical Correction of Lidar-Derived Digital Elevation Models with Multispectral Airborne Imagery in Tidal Marshes." Remote Sensing of Environment 186: 616-625.

Charles, P., and P. Edwards. 2015. Environmental Good Practice on Site Guide. Fourth Edition. PUB C741. London: Construction Industry Research and Information Association. https://www.thenbs.com/Publicationlndex/documents/ details?Pub=CIRIA\&DocID=309502.

ciria.org. 2018. New Guidance Using Drone Technology for Asset Management. CIRIA. https:// www.ciria.org/news/CIRIA_news2/UAVs_for_managing_assets.aspx.

concertatsea.nl, n.d. Concert at Sea. https://www.concertatsea.nl/.

Coombes, M. A., H. A. Viles, L. A. Naylor, and E. C. La Marca. 2017. “Cool Barnacles: Do Common Biogenic Structures Enhance or Retard Rates of Deterioration of Intertidal Rocks and Concrete?" Science of the Total Environment 580: 1034-1045. doi:10.1016/j. scitotenv.2016.12.058.

Coombes, M. A., L. A. Naylor, H. A. Viles, and R. C. Thompson. 2013. “Bioprotection and Disturbance: Seaweed, Microclimatic Stability and Conditions for Mechanical Weathering in the Intertidal Zone." Geomorphology 202: 4-14. doi:10.1016/j. geomorph.2012.09.014.

Cordell, J. R., J. D. Toft, S. H. Munsch, and M. Goff. 2017. "Benches, Beaches, and Bumps: How Habitat Monitoring and Experimental Science Can Inform Urban Seawall Design." In Living Shorelines: The Science and Management of Nature-Based Coastal Protection. Edited by D. M. Bilkovic, M. M. Mitchell, M. K. La Peyre, and J. D. Toft. Boca Raton, FL: CRC Press. 
Cousins, L. J., M. S. Cousins, T. Gardiner, and G. J. C. Underwood. 2017. "Factors Influencing the Initial Establishment of Salt Marsh Vegetation on Engineered Sea Wall Terraces in SE England." Ocean and Coastal Management 143: 96-104. https://doi.org/10.1016/j. ocecoaman.2016.11.010.

deltaprogramma.nl, n.d. Delta Programme. National Delta Programme. https://english. deltaprogramma.nl/delta-programme.

Dennis, H. D., A. J. Evans, A. J. Banner, and P. J. Moore. 2018. "Reefcrete: Reducing the Environmental Footprint of Concretes for Eco-Engineering Marine Structures." Ecological Engineering 120: 668-678. https://doi.org/10.1016/j.ecoleng.2017.05.031.

ec.europa.eu. 2020. Natura 2020. European Commission. https://ec.europa.eu/environment/ nature/natura2000/index_en.htm.

Elias, E. P. L., J. F. van der Spek, and M. Lazar. 2016. “The 'Voordelta,' the Contiguous Ebb-Tidal Deltas in the SW Netherlands: Large-Scale Morphological Changes and Sediment Budget 1965-2013; Impacts of Large Scale Engineering." Netherland Journal of Geosciences 96 (3): 27. doi:10.1017/njg.2016.37.

EnvironmentAgencyTV. 2020. "What is the Elmer Beach Management Scheme?" Uploaded on July 2, 2002. YouTube video, 08:02. https://www.youtube.com/watch?v=MqF ZhNMWWK.

estuaryedges.co.uk. 2021. Estuary Edges. https://www.estuaryedges.co.uk/.

Evans, A., B. Garrod, P. Moore, L. B. Firth, S. J. Hawkins, E. Morris, H. Goudge, and P. Moore. 2017. "Stakeholder Priorities for Multi-Functional Coastal Defence Developments and Steps to Effective Implementation." Marine Policy 75: 143-155.

ewn.el.erdc.dren.mil, n.d. Tools. Engineering With Nature. https://ewn.el.erdc.dren.mil/tools. html.

Finley, B. 2018. “Denver Accelerates 'Daylighting' of Lost Waterways, 'Undoing History' with Decades-Long Re-Engineering Effort." The Denver Post. Colorado News. September 2, 2018. https://www.denverpost.com/2018/09/02/denver-irrigation-waterwayreengineering/.

Fredette, T. J., C. M. Foran, S. M. Brasfield, and B. C. Suedel. 2011. “Environmental Engineering of Navigation Infrastructure: A Survey of Existing Practices, Challenges, and Potential Opportunities." Integrated Environmental Assessment and Management 8 (1): 175182.

Gardiner, T., and C. Vetori. 2015. "Incorporating Pollinator Friendly Grassland Management Regimes into the Thames Estuary Asset Management (TEAM 2100) Programme of Flood Defence Works." Paper presented at ECSA 55 Unbounded Boundaries and Shifting Baselines: Estuaries and Coastal Seas in a Rapidly Changing World, London, September 2015. 
Gardiner, T., N. Kuramoto, and M. Matsuba. 2019. "Big in Japan: The Importance of Riparian Corridors for Orthoptera." Journal of Orthoptera Research 28 (1): 27-35. https://doi. org/10.3897/jor.28.31380.

Geisthardt, E. J., B. C. Suedel, and J. A. Janssen. 2021. Monitoring the Milwaukee Harbor Breakwater: An Engineering With Nature (EWN) Demonstration Project. ERDC/EL TR21-2. Vicksburg, MS: U.S. Army Engineer Research and Development Center. https:// erdc-library.erdc.dren.mil/ispui/bitstream/11681/40022/1/ERDC-EL\%20TR-21-2.pdf.

gov.uk. 2015. "Thames Estuary Asset Management 2100 Programme (TEAM2100)." UK Government. https://www.gov.uk/government/news/thames-estuary-assetmanagement-2100-programme-team2100.

Huibregtse, W. 2013. "Brouwersdam: Morphological Analysis of the Beach at Brouwersdam." Master's thesis, Section of Coastal Engineering, TU Delft.

Hsuing, A. R., W. T. Tan, L. H. L. Loke, L. B. Firth, E. C. Heery, J. Ducker, V. Clark, et al. 2020. “Little Evidence That Lowering the $\mathrm{pH}$ of Concrete Supports Greater Biodiversity on Tropical and Temperate Seawalls." Marine Ecological Progress Series 656: 193-205. https://doi. org/10.3354/meps13365.

Kawabata, Y., E. Kato, and M. Iwanami. 2012. “Enhanced Long-Term Resistance of Concrete with Marine Sessile Organisms to Chloride Penetration." Journal of Advanced Concrete Technology 10 (4): 151-159.

Koch, B., R. C. Brooks, A. Oliver, D. Herzog, J. E. Garvey, R. Hrabik, R. Colombo, Q. Phelps, and T. Spier. 2012. "Habitat Selection and Movement of Naturally Occurring Pallid Sturgeon in the Mississippi River." Transactions of the American Fisheries Society 141 (1): 112-120. doi:10.1080/00028487.2011.652008.

Koontz, M., C. Lundberg, R. Lane, J. Day, and R. Pezeshki. 2016. "Aboveground Net Primary Productivity in a Riparian Wetland Following Restoration of Hydrology." Biology 5 (1): 10.

Kuramoto, N., R. Mishima, N. Okada, and T. Gardiner. 2017. "Aster tripolium (Sea Aster) and Greening of the Sea Wall in Tokyo Bay." Paper presented at 8th Asian Wetland Symposium, Wetlands for Sustainable Life, Saga, Japan, November 2017.

landscapeperformance.org, n.d. Westerly Creek at Stapleton. Landscape Performance Series. https://www.landscapeperformance.org/case-study-briefs/westerly-creek-atstapleton.

MacArthur, M., L. A. Naylor, J. D. Hansom, M. Burrows, L. Loke, and I. Boyd. 2019. “Maximising the Ecological Value of Hard Coastal Structures Using Textured Formliners." Ecological Engineering 1: 100002. https://doi.org/10.1016/j.ecoena.2019.100002.

MacArthur, M., L. A. Naylor, J. D. Hansom, and M. T. Burrows. 2020. “Ecological Enhancement of Coastal Engineering Structures: Passive Enhancement Techniques." Science of the Total Environment 740: 139981. https://doi.org/10.1016/i.scitotenv.2020.139981. 
Mishima, R., T. Gardiner, and N. Kuramoto. 2019. “Examination into the Distribution of Aster tripolium L. on a Seawall in Kasai Rinkai Park." Journal of the Japanese Society of Revegetation Technology 45 (1): 196-199. https://doi.org/10.7211/jjsrt.45.196.

Munsch, S. H., J. R. Cordell, and J. D. Toft. 2017. "Effects of Shoreline Armoring and Overwater Structures on Coastal and Estuarine Fish: Opportunities for Habitat Improvement." Journal of Applied Ecology 54 (5): 1373-1384. doi:10.1111/1365-2664.12906.

Naylor, L. A., M. A. Coombes, O. Venn, S. D. Roast, and R. C. Thompson. 2012. “Facilitating Ecological Enhancement of Coastal Infrastructure: The Role of Policy, People and Planning." Environmental Science and Policy 22: 36-46. http://dx.doi.org/10.1016/j. envsci.2012.05.002.

Naylor, L. A., H. Kippen, M. A. Coombes, B. Horton, M. MacArthur, and N. Jackson. 2017a. Greening the Grey: A Framework for Integrated Green Grey Infrastructure (IGGI). Glasgow: University of Glasgow. http://eprints.gla.ac.uk/150672/.

Naylor, L. A., M. A. Coombes, H. Kippen, B. Horton, T. Gardiner, M. R. Cordell, J. Simm, and G. J. C. Underwood. 2017b. "Developing a Business Case for Greening Hard Coastal and Estuarine Infrastructure: Preliminary Results." In Coasts, Marine Structures and Breakwaters 2017: Realising the Potential. Edited by K. Burgess. London: ICE Publishing. https://www.icevirtuallibrary.com/doi/pdf/10.1680/cmsb.63174.0801.

Naylor, L. A., N. MacArthur, S. Hampshire, K. Bostock, M. A. Coombes, J. Hansom, R. Byrne, and T. Folland. 2017c. "Rock Armour for Birds and Their Prey: Ecological Enhancement of Coastal Engineering." Proceedings of the Institution of Civil Engineers: Maritime Engineering 170 (2): 67-82. doi:10.1680/jmaen.2016.28.

O'Shaughnessy, K. A., S. J. Hawkins, A. J. Evans, M. E. Hanley, P. Lunt, R. C. Thompson, R. A. Francis, et al. 2020. "Design Catalogue for Eco-Engineering of Coastal Artificial Structures: A Multifunctional Approach for Stakeholders and End-Users." Urban Ecosystems 23: 431-443. https://doi.org/10.1007/s11252-019-00924-z.

Perkol-Finkel, S., and I. Sella. 2015. "Blue is the New Green - Harnessing Urban Coastal Infrastructure for Ecological Enhancement." Proceedings of the Institute of Civil Engineers: Maritime Engineering 168 (3): 102-110. https://www.icevirtuallibrary.com/ doi/abs/10.1680/imaen.15.00017.

Perkol-Finkel, S., T. Hadary, A. Rella, R. Shirazi, and I. Sella. 2018. “Seascape Architecture - Incorporating Ecological Considerations in Design of Coastal and Marine Infrastructure." Ecological Engineering 120: 645-654.

PIANC (The World Association for Waterborne Transport Infrastructure). 2014. Working Group EnviCom 143: Initial Assessment of Environmental Effects of Navigation and Infrastructure Projects. Brussels, BE: PIANC.

PIANC. 2018. Working Group EnviCom 175: A Practical Guide to Environmental Risk Management (ERM) for Navigation Infrastructure Projects. Brussels, BE: PIANC.

rijkswaterstaat.nl, n.d. Rijkswaterstaat. https://www.rijkswaterstaat.nl/English. 
Roca, M., M. Escarameia, O. Gimeno, L. De Vilder, J. D. Simm, B. Horton, and C. Thorne. 2017. Green Approaches in River Engineering - Supporting Implementation of Green Infrastructure. Wallingford, UK: HR Wallingford. https://eprints.hrwallingford. com $/ 1250 /$.

Strain, E. M. A., C. Olabarria, M. Mayer-Pinto, V. Cumbo, R. L. Morris, A. B. Bugnot, K. A. Dafforn, et al. 2018. "Eco-Engineering Urban Infrastructure for Marine and Coastal Biodiversity: Which Interventions Have the Greatest Ecological Benefit?" Journal of Applied Ecology 55: 426-441. https://doi.org/10.1111/1365-2664.12961.

Toft, J. D., A. S. Ogston, S. M. Heerhartz, J. R. Cordell, and E. E. Flemer. 2013. “Ecological Response and Physical Stability of Habitat Enhancements along an Urban Armored Shoreline." Ecological Engineering 57: 97-108.

USACE (U.S. Army Corps of Engineers). 2013. Coastal Risk Reduction and Resilience. Washington, DC: U.S. Army Corps of Engineers Civil Works Directorate.

Vozzo, M. L., M. Mayer-Pinto, M. J. Bishop, V. R. Cumbo, A. B. Bugnot, K. A. Dafforn, E. L. Johnston, P. D. Steinberg, and E. M. A. Strain. 2021. "Making Seawalls Multifunctional: The Positive Effects of Seeded Bivalves and Habitat Structure on Species Diversity and Filtration Rates." Marine Environmental Research 165. https://doi.org/10.1016/j. marenvres.2020.105243.

Welsh Government. 2020. The National Strategy for Flood and Coastal Erosion Risk Management in Wales. Cardiff, UK: Welsh Government. https://gov.wales/sites/ default/files/publications/2020-10/the-national-strategy-for-flood-and-coastalerosion-risk-management-in-wales_0.pdf. 


\section{Acknowledgments}

\section{Lead Authors}

Burton C. Suedel, U.S. Army Corps of Engineers, United States

Larissa A. Naylor, University of Glasgow, United Kingdom

\section{Co-Authors}

Trevor Meckley, National Oceanic and Atmospheric Administration, United States

Colette Cairns, National Oceanic and Atmospheric Administration, United States

Jason Bernier, CBCL Limited, Canada

Ed Morgereth, Biohabitats, United States

Wendell Mears, Anchor QEA, LLC, United States

Candice D. Piercy, U.S. Army Corps of Engineers, United States

Remment ter Hofstede, Van Oord, the Netherlands

\section{Contributors}

Marian Lazar, Rijkswaterstaat Sea and Delta, the Netherlands, co-authored the Brouwersdam case study.

The contributors and co-authors of the North American Electric Reliability Corporation (NERC)-funded (NERC reference number NE/R009236/1) integrated green-gray infrastructure report (Naylor et al. 2017a) are acknowledged for providing excellent examples of ecological enhancements that have been referenced in this chapter. 

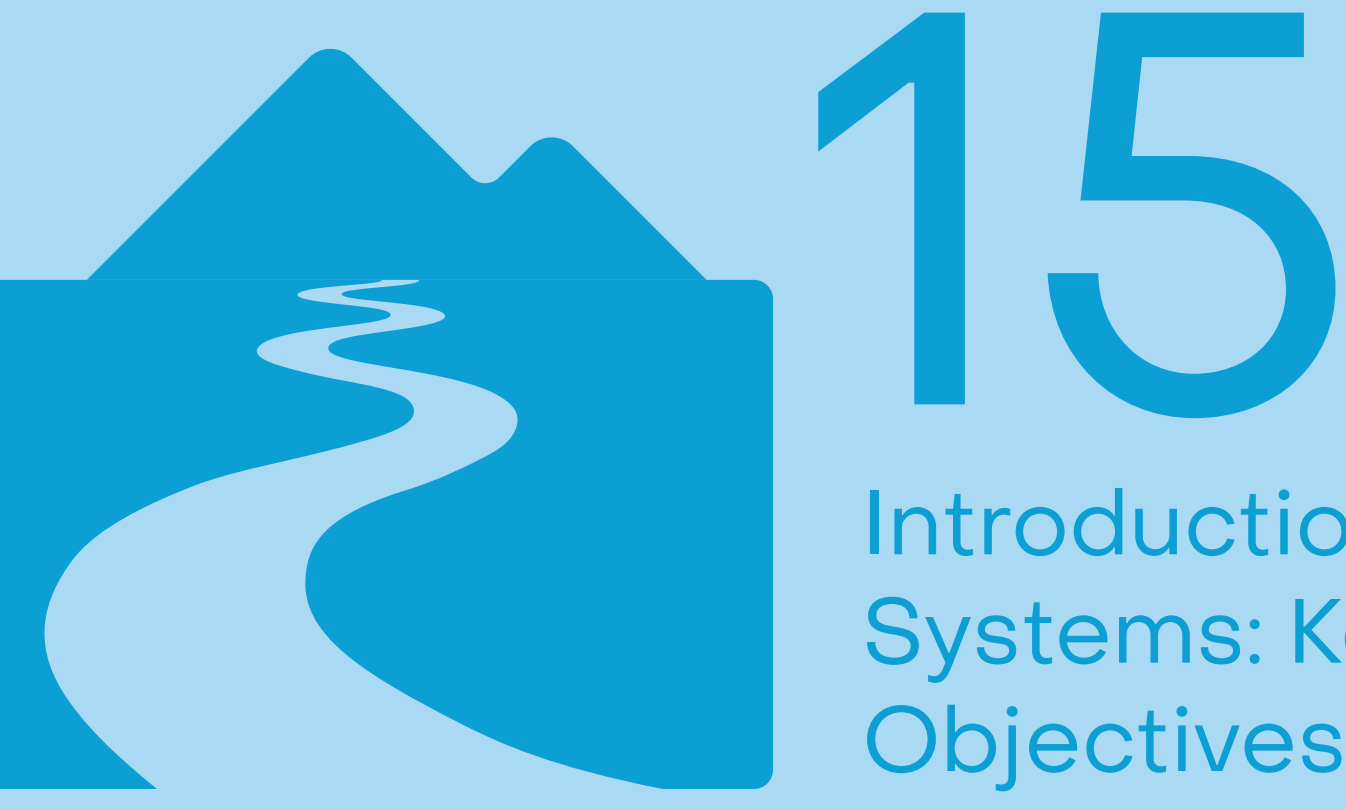

\section{Introduction to Fluvial Systems: Key Themes, Objectives, Gaps, and Future Directions}

\section{Suggested Citation:}

Haring, C., R. Schielen, J. Guy, and L. Burgess-Gamble. 2021. "Chapter 15: Introduction to Fluvial Systems: Key Themes, Objectives, Gaps, and Future Directions." In International Guidelines on Natural and Nature-Based Features for Flood Risk Management. Edited by T. S. Bridges, J. K. King, J. D. Simm, M. W. Beck, G. Collins, Q. Lodder, and R. K. Mohan. Vicksburg, MS: U.S. Army Engineer Research and Development Center.

Full acknowledgments appear at the end of this chapter. 


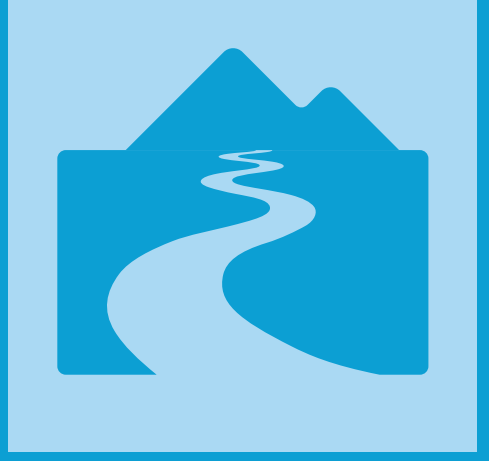

\section{Key Messages}

This chapter introduces natural and nature-based features (NNBF) applications for fluvial settings (discussed in Chapters 15 through 19). Key messages for the fluvial NNBF chapters are summarized in the following:

1. Applications of NNBF in fluvial systems can reduce flood risk by integrating hydrologic, hydraulic, morphological, and ecological principles. Despite the variety in scales of catchments, there are common measures that apply to all scales.

2. Incorporating NNBF in flood risk management has, apart from reducing flood risk, many economic, social, and environmental co-benefits.

3. Use a holistic watershed approach to fluvial flood risk management-avoid transferring risks downstream, upstream, or to adjacent areas.

4. Where possible, use nested NNBF responses within the watershed.

5. Conserve, as much as possible, the natural features and processes throughout the watershed that store and attenuate floodwaters.

6. Employ proactive watershed management strategies to minimize sediment input into the fluvial system, while minimizing stormwater runoff.

7. Formulate a plan and involve stakeholders, nongovernmental organizations, landowners, and local authorities to get their full support.

8. Develop a long-term plan to monitor specific processes and parameters including adaptive management. 
The fluvial section of this International Guidelines on Natural and Nature-Based Features for Flood Risk Management publication includes the following five chapters:

\section{Chapter 15}

Introduction to Fluvial Systems: Key Themes, Objectives, Gaps, and

Future Directions

\section{Chapter 16}

Fluvial Systems and Flood Risk Management

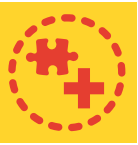

\section{Chapter 17}

Benefits and Challenges in the Application of NNBF in Fluvial Systems

\section{Chapter 18}

Description of Fluvial NNBF

\section{Chapter 19}

Fluvial NNBF Case Studies

These five fluvial chapters are interconnected but can also be read independently. They provide generalities about fluvial systems and their connection with human use of the landscape. This chapter (Chapter 15) introduces the natural and nature-based features (NNBF) applications for fluvial settings. Chapter 16 describes fluvial systems and their relation to flood risk management (FRM). Chapter 17 describes the benefits and challenges associated with NNBF in fluvial systems. Chapter 18 provides an overview of the role and range of NNBF available for fluvial applications. Chapter 19 provides case study examples of different types of fluvial NNBF applications from around the world.

Watersheds are the appropriate scale for planning and designing FRM infrastructure in fluvial systems. They comprise numerous natural features and physical processes that together regulate the flow of water, sediment, and nutrients through the system (Figure 15.1). Watersheds include forests and prairie uplands, wetlands ranging from alpine wet meadows to bottomland swamps, glacial landscapes, and river channels and floodplains. Fluvial geomorphic processes interact with vegetation and with large wooded and floodplain environments, and they work with aquifers that retain and release water over time into surface waterbodies in a process of groundwater-surface water exchange. Fluvial and associated 
floodplain ecosystems naturally store floodwaters, dissipate flow energy, store sediments, cleanse water, cycle nutrients, and provide habitats and food sources for aquatic, riparian, and terrestrial biological communities. Watersheds often include developed urban areas, where a combination of human-made infrastructure and the natural environment control the flow of water.

\section{Figure 15.1. Schematic Overview of a Watershed}

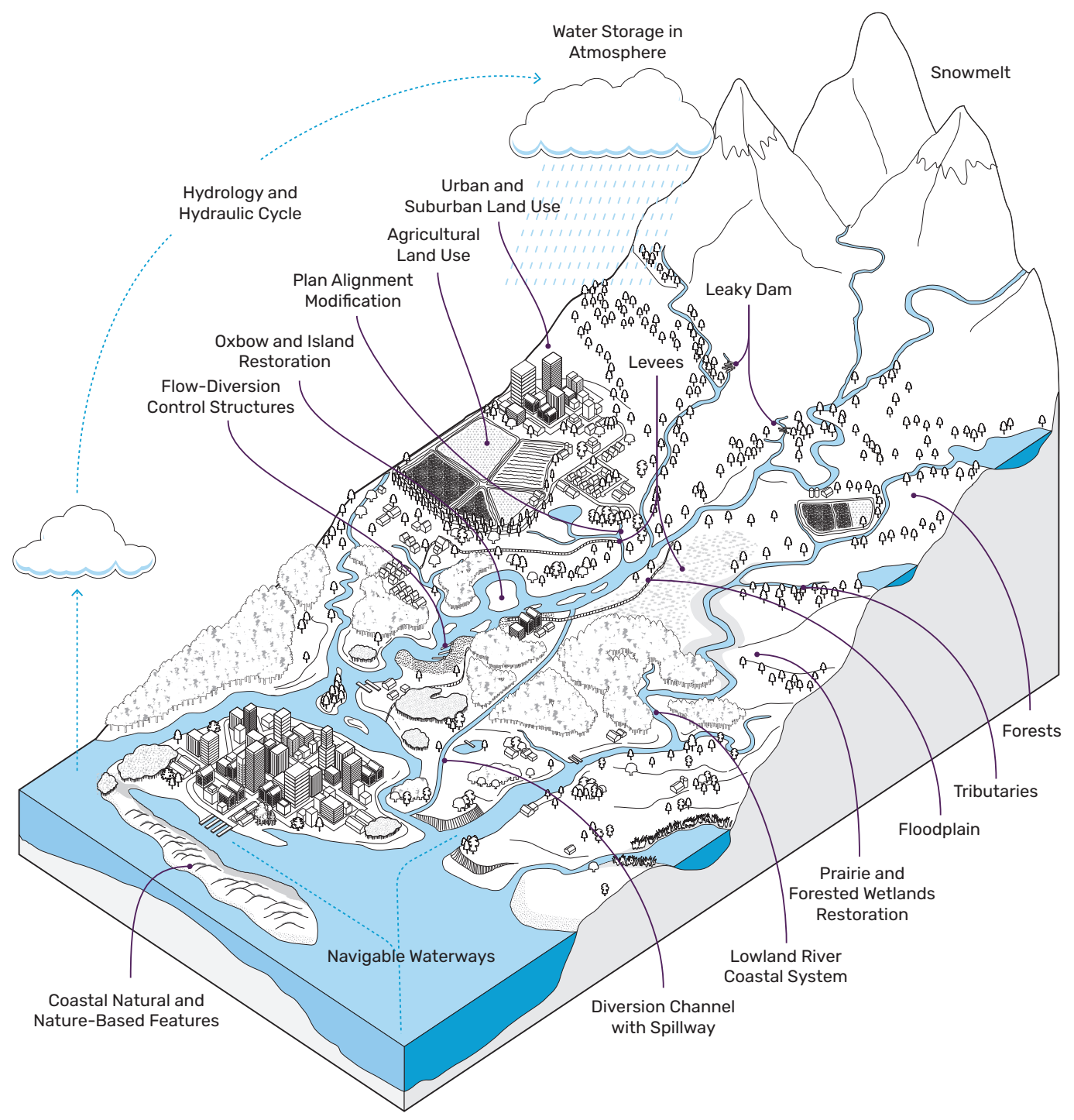




\section{1 | Objectives for NNBF in Fluvial Settings}

The primary objective in applying NNBF in fluvial settings is to reduce flood risk by restoring, enhancing, or mimicking natural hydraulic, morphological, and ecological functions and processes (Lane 2017). Although the scale and physiography of watersheds vary, there are common reasons to apply NNBF, such as the following:

- To capture, retain, slow, or disperse floodwaters throughout the upper and middle watershed, using native vegetation where possible to capture and retain water and sediment and to slow erosion. NNBF help dissipate flood energy, mitigate land loss to erosion, and reduce channel incision and aggradation.

- To improve the connectivity and interaction of the watercourse with the floodplain (creating space for water and room for the river)-especially where open spaces are also designated floodways. This approach should decrease the need for interventions to maintain conveyance, such as dredging or clearing vegetation.

- To preserve or restore sediment balance (Wohl et al. 2015) to maintain not only stream channel geomorphology but also floodplains and deltas through appropriate sediment-building processes. Work with natural processes to provide resilient and sustainable designs.

- To restore or maintain lowland and river delta functions in ways that replicate or mimic natural features or processes. This includes naturalizing and balancing channel capacity and conveyance to provide channel stability, aquatic restoration, and flood-control alternatives.

Incorporating NNBF that have these functions into watershed planning and engineering helps economically mitigate local and downstream flood peaks and impacts while providing ecosystem service co-benefits, such as the following:

- Groundwater recharge and drought amelioration

- Water quality improvement and greater freshwater availability

- Biodiversity enhancement and habitat improvement

- Improved aesthetics compared to conventional infrastructure

- Human health, welfare, and recreational opportunities

Fluvial NNBF may involve enhancements, redesigns, or realignments of existing engineered systems-not necessarily the wholesale replacement of structural measures. NNBF measures should be viewed as integral components of the FRM portfolio that can often enhance conventional flood-control infrastructure. 


\section{2 | Gaps and Future Directions}

Additional work is required in the following areas pertaining to fluvial NNBF:

1. Improved scientific evidence is needed to support efficient decision-making. Lack of knowledge on individual and system performance and monitoring prevents this at present.

2. Increased communications and local understanding are needed. Underappreciation of the local context and importance of stakeholders hinders broader application of NNBF.

3. There is a risk of the business case for fluvial NNBF not being "bankable" (i.e., funders being unwilling to commit to it or to participate in co-funding). Understanding benefit streams and optimizing funding arrangements might reduce this issue.

4. Governance and institutional gaps complicate realization of NNBF. Suboptimal governmental and institutional setting or too little attention to these factors hinders or even prevents NNBF.

5. NNBF differ with respect to location in a watershed but also differ from country to country and from developed world to developing world. The latter gives an opportunity to compare benefits of NNBF and couple this to the United Nations' Sustainable Development Goals (SDGs) and make countries achieve SDGs. This could further enhance the well-being of the citizens.

Opportunities to use NNBF to counteract climate change effects need additional research. We foresee the following areas of development in the field of fluvial FRM:

1. Develop an appropriate assessment framework for NNBF. Make a connection to the United Nations' SDGs to show the added value of NNBF in contributing to a better and more sustainable future for the world. Improve the empirical basis for better understanding of the performance of Engineering With Nature (EWN) measures.

2. At the planning stage, invest in long-term (10 years and longer) monitoring programs (e.g., ecological, morphological, flood risk, social support) and analyze the data and scientific evidence about the functioning of the EWN measures.

3. Map the local stakeholders, social networks, nongovernmental organizations, inhabitants of (local) communities, and associated networks to provide a solid support for NNBF measures. Develop new approaches to participatory decision-making, involving all key stakeholders.

4. It will be advisable to study NNBF in more detail depending on the exact position within the watershed where EWN measures may be implemented, including a focus on the potential advantages of using NNBF in an urban development. Watersheds vary in geographical scale, and flood risk problems may occur anywhere in the watershed (headwaters, middle reach, delta). To a certain extent, the position in the watershed will determine which EWN measures will achieve best results in terms of effectiveness and value (where best must be defined, probably with the use of a proper assessment framework). 
5. Invest in modeling tools for ecology, morphology, and hydraulics. Perform benchmark studies to learn from the different models and implement best practices. In this respect, also invest in remote-sensing tools and the associated analysis of satellite and remotesensing data because they can be used not only to quickly construct detailed digital terrain models, which can be used to set up models, but also for rapid monitoring and assessment of river habitats and floods. Use the models to describe the effectiveness of EWN measures at watershed scale, as well as on medium scale (order of 500 meters to several kilometers).

6. Strengthen the policy and legal frameworks to support the implementation of EWN measures. This can be on a local, national, and even continental (e.g., European) or international scale. Although in some countries there is a legal requirement to consider EWN measures as an alternative, there is still a need to support possible implementation of EWN measures as an integral part of flood risk appraisal.

\section{3 | References}

Lane, S. N. 2017. “Natural Flood Management." WIREs Water 4 (3): e1211. https://doi. org/10.1002/wat2.1211.

Wohl, E., B. P. Bledsoe, R. B. Jacobson, N. L. Poff, S. L., Rathburn, D. M. Walters, and A. C. Wilcox. 2015. "The Natural Sediment Regime in Rivers: Broadening the Foundation for Ecosystem Management." BioScience 65 (4): 358-371. 


\section{Acknowledgments}

\section{Lead Authors}

Christopher Haring, U.S. Army Corps of Engineers, United States

Ralph Schielen, Rijkswaterstaat, the Netherlands

Jo Guy, Environment Agency, United Kingdom

Lydia Burgess-Gamble, Environment Agency, United Kingdom 

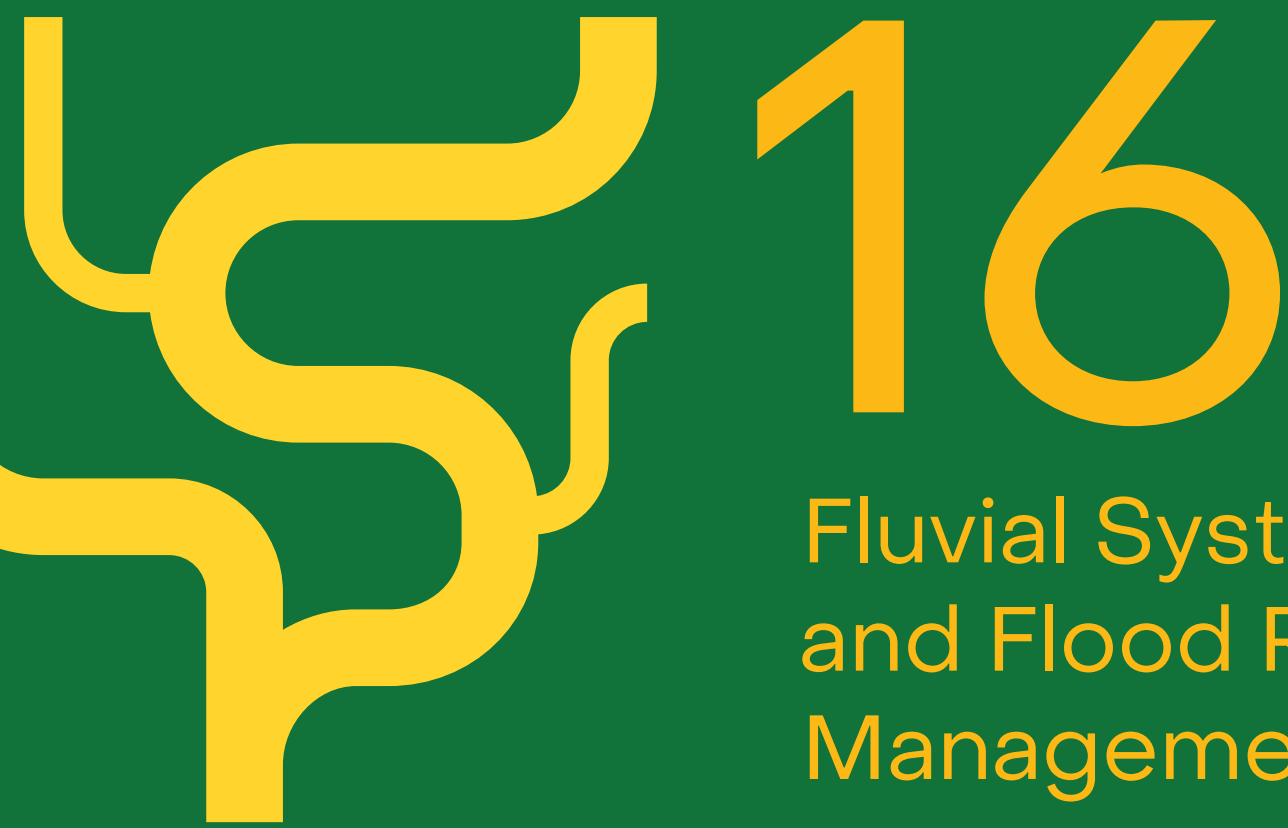

\section{Fluvial Systems and Flood Risk Management}

\section{Suggested Citation:}

Haring, C., R. Schielen, J. Guy, L. Burgess-Gamble, and B. Bledsoe. 2021. "Chapter 16: Fluvial Systems and Flood Risk Management." In International Guidelines on Natural and Nature-Based Features for Flood Risk Management. Edited by T. S. Bridges, J. K. King, J. D. Simm, M. W. Beck, G. Collins, Q. Lodder, and R. K. Mohan. Vicksburg, MS: U.S. Army Engineer Research and Development Center.

Full acknowledgments appear at the end of this chapter. 


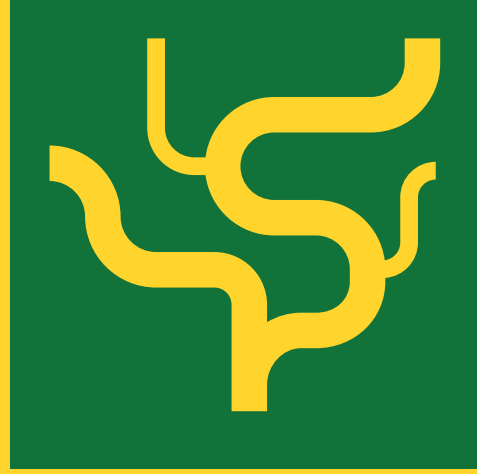

\section{Key Messages}

1. Past modifications of rivers and their basins have increased the risk of flooding. Climate change, anthropogenic features, and land use changes have increased the stress on natural fluvial systems and their functions, asserting more pressure on flood risk management infrastructure.

2. Natural and nature-based features (NNBF) help mitigate these impacts, reducing both the level of flood risk and our dependence on engineered flood control structures while also restoring the natural environment, providing societal and ecological co-benefits.

3. As the benefits of NNBF are realized, more people are likely to see these benefits and want NNBF implemented in their watersheds. Monitoring and adaptive management of NNBF are needed to demonstrate the added benefits.

4. Adhering to the five fluvial NNBF general principles is key to ensuring sound fluvial applications. 


\section{1 || Introduction}

As mentioned in Chapter 15, the fluvial section of this International Guidelines on Natural and Nature-Based Features for Flood Risk Management publication includes Chapters 15 through 19. Chapter 15 introduces the natural and nature-based features (NNBF) applications for fluvial settings. Chapter 16 builds on Chapter 15 and describes fluvial systems and their relation to flood risk management (FRM). Chapter 17 describes the benefits and challenges associated with NNBF in fluvial systems, Chapter 18 provides an overview of the role and range of NNBF available for fluvial applications, and Chapter 19 provides case study examples of different types of fluvial NNBF applications from around the world.

Section 16.2 discusses the story of human interaction with watersheds and its consequences. As humans maximized not only access to rivers but also their use of the adjoining land, they came into conflict with the natural water cycles and processes. Floods in natural rivers (defined here as rivers unaffected or almost unaffected by humans) are not considered to be major events or even catastrophes. A disaster starts when the river floods areas where there is human occupation or economic activity. In those cases, the river is most often (but not always) engineered, with engineered floodplains and confined by embankments. If there are then periods of increased precipitation, the system will respond in the same way-floodplains are inundated and, if the capacity is insufficient, the levees, embankments, or walls overflow or break. It is because of this that the renowned U.S. geographer Gilbert White said, "Floods are 'acts of God,' but flood losses are largely acts of man" (White 1945). In the United States alone, there are more than 23,600 kilometers of federally built or regulated levees and floodwalls, and up to 140,000 kilometers of historical and nonfederal levees (ASCE 2013).

Section 16.2.1 describes the growth in flood risk and ways of reducing it. Storms that cause floods do not necessarily occur at the location of the flooding. Flooding is often the result of multiple days or even weeks of precipitation falling in upstream areas of a watershed. As water runs off into tributaries and then into the main river channel, flooding occurs downstream of the precipitation event. Flood risks are being exacerbated by a number of factors, including climate change (which causes increased discharges), land use changes (e.g., urbanization, deforestation, or transforming floodplains into agricultural land), and river engineering (e.g., construction of embankments and dams or the straightening of river stretches).

Section 16.2.2 discusses the ways in which flood risk in watersheds can be managed using fluvial NNBF. By resolving or mitigating flood risk, NNBF also provide important co-benefits and thus NNBF can be used for reasons other than reducing flood risk (e.g., river restoration for ecological purposes) and, as discussed in more detail in Chapter 17, in those cases will also provide additional benefits; Figure 16.1 illustrates the watershed features potentially addressed by NNBF. 
Finally, Section 16.3 discusses constraints that need to be taken into account when considering the use of NNBF to address the challenges discussed in Section 16.2.

\section{Figure 16.1. The Positioning of the Features in a Watershed}

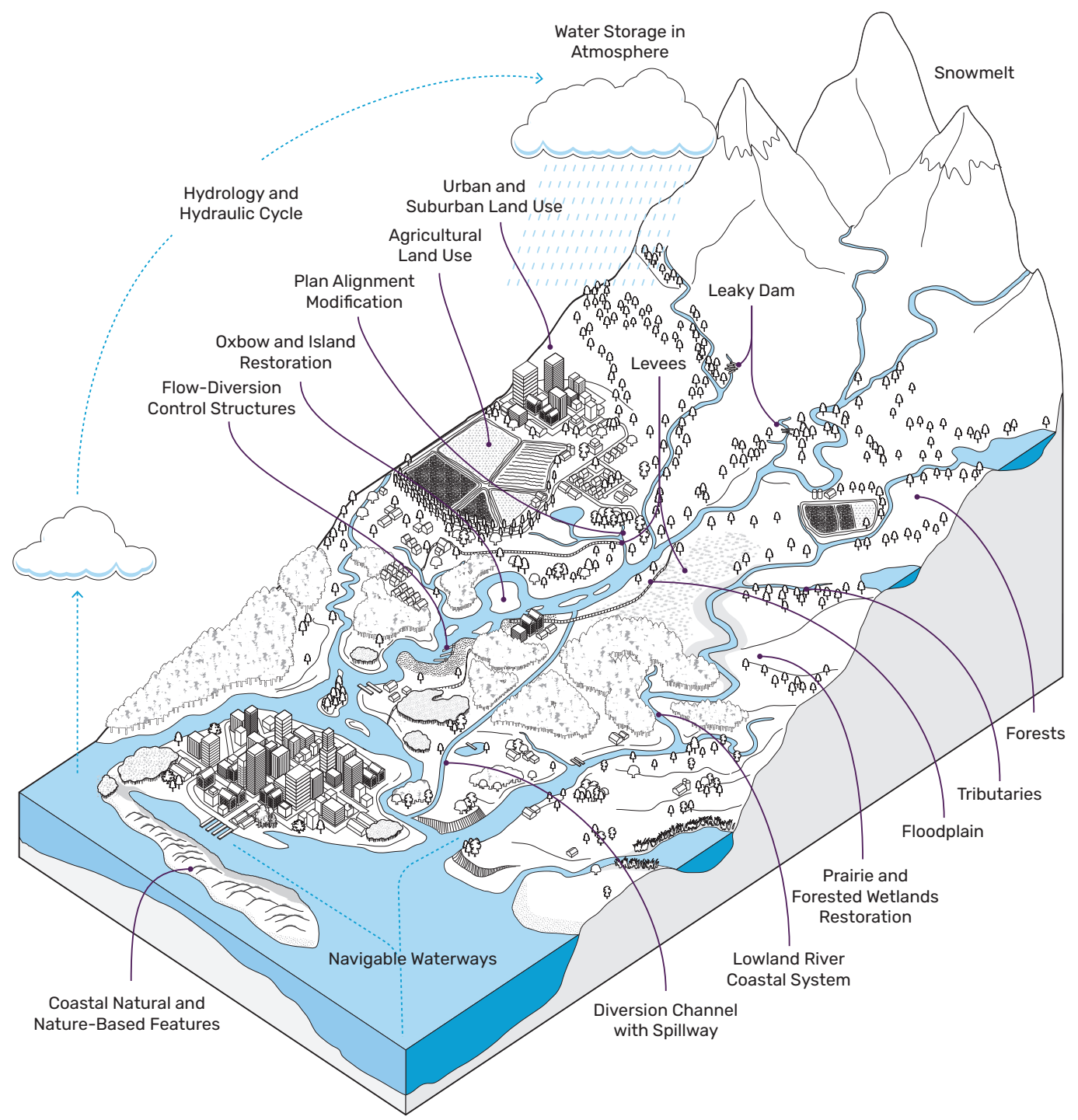




\section{2 | Stress on Fluvial Systems and the Story of Human Impacts}

Rivers are a primary source of fresh water upon which human civilizations heavily depend, and thus they are a source of life, energy, revenue, recreation, and spiritual inspiration. Rivers provide potable water and water for use in irrigation, fertile floodplains for agriculture, and transportation corridors for people, agriculture, and industry. They sustain fisheriessubsistence, commercial, and recreational-and provide critically important fish and wildlife habitat and migration corridors. River floodplains also facilitate surface-groundwater exchange and groundwater recharge, replenishing aquifers that sustain ecosystems and store freshwater resources. Human civilizations have also expressed profound spiritual and recreational connections to rivers throughout time and across cultures. Evidence increasingly shows that proximity and access to natural areas has human health as well as economic (e.g., property value) co-benefits (CABE 2004). More than $50 \%$ of the world's population lives within 3 kilometers of a surface freshwater body, and although technological advances have enabled many urban populations to receive drinking water via pipelines and canals, many still depend directly on surface fresh water for survival (Kummu et al. 2011).

To maximize rivers' most highly valued benefits, humans have dramatically re-engineered many of the world's major river systems and surrounding landscapes so they can inhabit floodplains and control or reroute river flows. In many countries, rivers flow through highly developed industrialized landscapes and are no longer in a natural state. River channels have been reshaped for purposes as varied as transportation, agriculture, flood risk reduction, and urban development, and the rivers' free meandering behavior is often constrained. Most rivers have been affected in this way, with resulting changes in bathymetry (width and depth), and are no longer in a state of equilibrium or sediment balance (Grill et al. 2019). For some rivers, this trend started some time ago. The Rhine, for example, has seen three distinct periods of regulation since 1800. Other rivers, such as the Ayeyarwady in Myanmar, are on the brink of being regulated, whereas still others, like the Drin, which flows through Albania, Kosovo, and Macedonia, remain rather pristine.

Associated land use changes. Many watersheds throughout the world have been affected at least partially by removing or changing the natural land cover and the functionality of the original native species. Relatively undisturbed, pristine fluvial landscapes are rare-and, in reality, may not exist at all considering the far-reaching impacts of human-induced climate change (Grill et al. 2019). As soon as human activity starts to evolve, land use changes. As a result, ecosystem alterations and complex interactions among physical, chemical, and biological processes drive fluvial changes. Such changes commonly occur in these three general stages: 
1. Change begins in a pre-development situation in which there is a symbiosis between the human actions in the watershed and the dynamics of the fluvial system itself.

2. As human activity grows, the watershed is increasingly affected by deforestation and the removal of other vegetation. Clearing naturally vegetated uplands and floodplains for agriculture and other uses interferes with the physical and biological functions of watersheds that would otherwise store and slowly release water (Poff, Bledsoe, and Cuhaciyan 2006). The erosion of cleared soil and the removal of the organic-rich surface layers leads to less rainfall absorption, increased runoff rates, and further soil erosion. Excess erosion destabilizes the fluvial system and increases flood levels as eroded material is deposited in the channel.

3. In the third stage, intensifying urbanization (settlements, houses, industrial activity) increases impervious surface area, changing the watershed hydrology and surface water runoff characteristics. The result can be system-wide instability due to the disconnection of fluvial channels and their natural interactions with floodplains. Such changes are estimated to take on the order of decades to centuries. Urbanization also leads to human encroachment into floodplains and the construction of bridges, embankments, and other structures that constrict river channels, modify hydraulic conditions, impede sediment transport, and further alter ecosystems.

Note that stage 3 does not always occur. Some countries have long recognized the function of floodplains, and settlements and industrial activities have been limited or even prohibited by laws and regulations.

Large percentages of floodplains have disappeared even during recent decades (Hayes et al. 2018; Tockner and Stanford 2002). Among the reasons for floodplain loss are the expansion of agricultural activities and increased occupation of the floodplains (i.e., urbanization and industrialization) followed by the construction of levees and other flood risk control structures to protect assets. For example, almost 55,000 hectares of floodplains in the Netherlands disappeared between 1850 and 1995 because dikes were relocated riverward, floodplains were claimed for industrial use, and diversions used during high discharges were closed.

As vegetation is cleared and agricultural and urban development accelerates, impervious land area increases and amplifies flood risks by producing more rapid and higher volumes of runoff. This also has consequences for the long-term behavior of the river system, and the flood wave that now passes more quickly through the system puts downstream communities at greater risk of flooding (see Section 16.2.1). Developing on floodplains, alluvial fans, or deltas often puts residential areas and businesses in the path of floodwaters. 
Effects of levees. Levees or embankments have often been used to maximize human use of floodplains. "Two Typical Fluvial Flood Risk Situations" and Figures 16.2 and 16.3 provide examples of the extreme changes a levee system can make to a floodplain by confining floodwater to reduce risks to a community. Sometimes, engineering solutions that control floods or erosion in one location only transfer flood risks upstream or downstream. Although levees can reduce flood risks at any given time or place, overemphasizing certain benefits may come at the expense of co-benefits. Disregarding the role that natural watershed features play in absorbing and retaining floodwaters can be the cause of catastrophic flooding, mudslides, and debris flows.

\section{Two Typical Fluvial Flood Risk Situations}

\section{Figure 16.2. FRM Levee System Depicting Confined Flood Levels with No Access to Adjacent Floodplain}

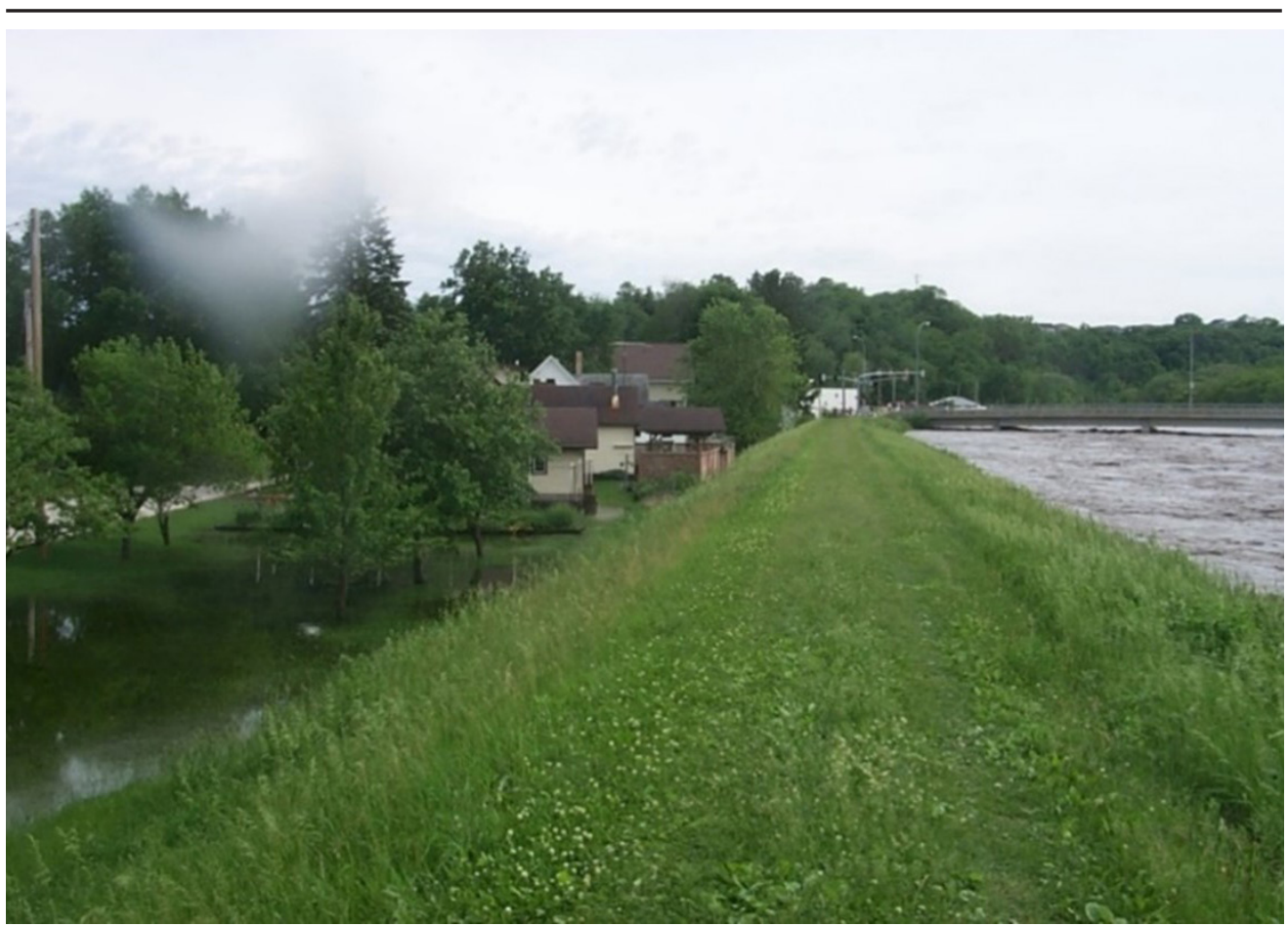

Note: This photograph of levees on the Upper lowa River, Decorah, lowa, United States, depicts confined and elevated flood levels with no access to the adjacent floodplain.

Source: Christopher Haring, U.S. Army Corps of Engineers 
Figure 16.3. Elements Used to Evaluate Flood Risk for a Large River and a Small Stream

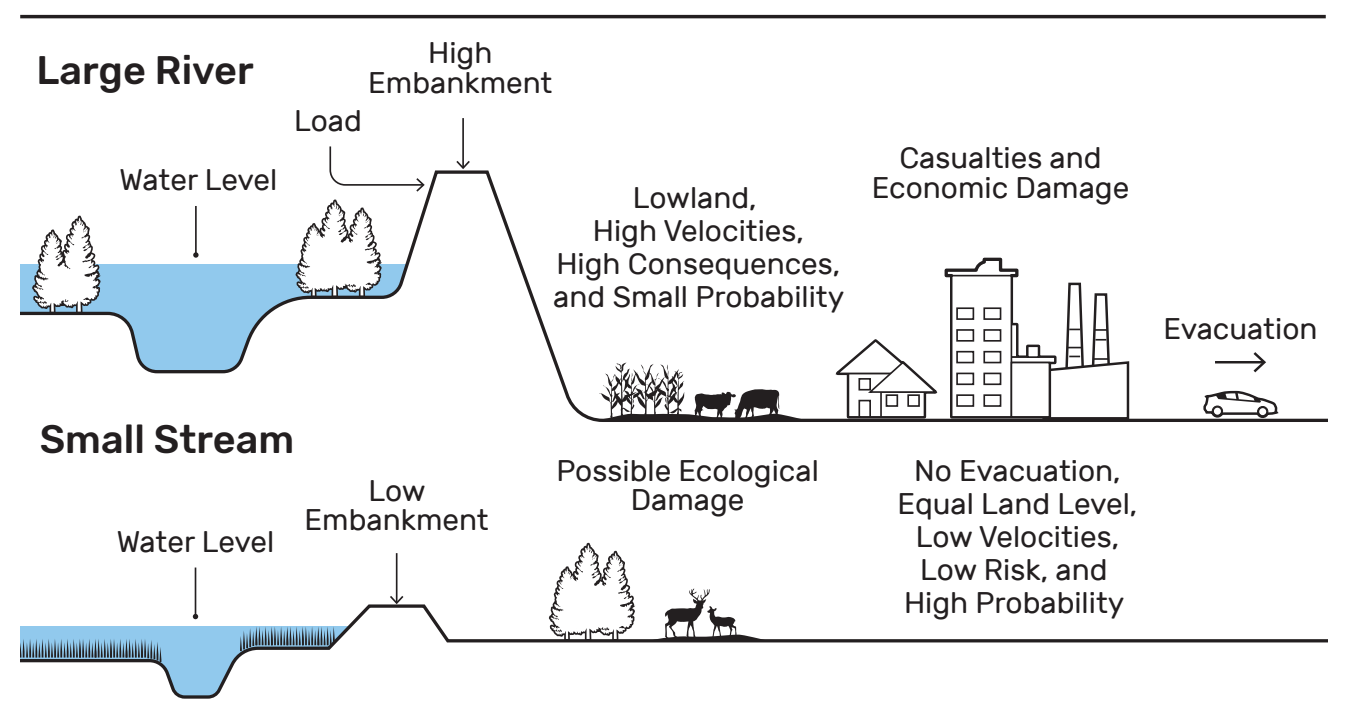

In a natural system, floodplains inundate regularly, supplying nutrients and sediment on the floodplains. In engineered systems, the main channel often loses connection with the floodplain and, consequently, floodplains inundate less frequently.

If a community sits in a floodplain on land that is above or below normal river levels and is protected by a levee, should the levee breach, deep floodwater inundation levels with significant associated consequences are possible (see the large river example in the top half of Figure 16.3).

Although levees generally protect the floodplain from inundation, they may also prevent sediment from reaching the riverside floodplain and depositing on its surface. As a result, sediment that otherwise is transported downstream and to the active floodplain fills floodplain areas behind the levee. In cases where an embankment or levee does not exist, flooding will be governed by the inundation depth and flow velocity.

In smaller rivers or at the headwaters of larger rivers, the potential consequences of flooding may be less severe because the inundation depths are less, there is less human activity in the floodplain, or both (see Figure 16.3). The overtopping or breaching of a smaller levee system is less likely to cause loss of life. And although the associated economic damages can still be considerable, an overtopping or beaching may enhance the floodplain ecosystem by adding fertile sediment. This is a natural process that makes the floodplain and nearby grounds productive agricultural and vegetative lands. 
Watershed scale. These guidelines focus on NNBF that primarily reduce the probability of flooding by lowering water levels or reducing hydraulic loads. Although they can be implemented throughout the upstream portion of a watershed, most are often implemented in the navigation channel or the floodplains of engineered rivers. In larger rivers, where overtopping of the embankments can lead to embankment failure and severe floods (causing great economic damage and possible loss of life), NNBF measures generally try to reduce the hydraulic load on the embankments, thereby reducing flood risk.

Levee and embankment systems in general are lower in headwaters and small streams (see "Two Typical Fluvial Flood Risk Situations"), and these small systems tend to overtop rather than break when discharges run high. Because there is little or no human activity in these floodplains, most of the possible damage is ecological; however, floods in headwaters and small streams are very often also beneficial because they deposit fertile sediment on the land.

For larger rivers, risk can be reduced by lowering the probability of flooding (determined by the return time of the occurrence of the water level, which is determined by the discharge) or the vulnerability of assets in flood-prone areas. But for smaller streams, the emphasis is on slowing the flow (preferably using NNBF), which attenuates the discharge wave and reduces its peak. Peak reduction (and hence decrease of peak water level) implies risk reduction.

\subsubsection{Increases in Flood Risk in Fluvial Systems}

Flood risk is the combination of the probability of a flood and its consequences. Worldwide, the risk of fluvial flooding is increasing due to human changes to watersheds and climate change. Fluvial flooding can be frequent, costly, deadly, and place mounting stress on society and its supporting infrastructure. Between 2005 and 2014, floods caused an average of 6,000 reported deaths per year, accounted for roughly $45 \%$ of all natural disasters (and the people affected by them), and caused $\$ 34$ billion U.S. dollars (USD) in annual damages worldwide (IFRC 2015). From 1980 to 2014, flood fatalities surpassed 3,000 and property losses exceeded USD\$270 billion in the United States alone (NTHMP 2016). Flood risk is expected to increase with the growth of populations inhabiting low-lying floodplains and coastal areas (nasa.gov 2013). Compared to other natural disasters, floods in 2018 globally affected the greatest number of people (CRED 2019).

As documented in literature, increases in flood risk are caused by a wide range of individual and local factors. The main causes include the following:

- Human modifications to hydrology. Often aimed at reducing flood damages by constructing confinements such as dikes, levees, dams, and embankments, these efforts frequently separated floodplains from their rivers, leading to a loss of flood storage. Currently, worldwide there is much more focus on floodplain restoration programs to re-establish natural floodplain connections and functions and assist with reducing FRM risk. 
- Upstream changes in the availability, volume, and composition of sediment. These changes are responsible for altering downstream channels. For example, a series of dams on the upper Missouri River in the United States restricts natural fluvial processes by limiting sediment supply, which leads to degradation of the downstream channel. The degradation destabilizes the fluvial system, affecting reservoir capacity, navigation, river training structures, FRM infrastructure, and ecological resources. The geomorphic processes that alter fluvial systems can be simulated by the channel evolution model developed by Schuum, Harvey, and Watson (1984) and other, later channel evolution models (Simon and Hupp 1986; Hawley et al. 2012; Cluer and Thorne 2013).

- Changes in population and land use. These changes increase the magnitude of runoff and flow, especially in urban areas, and amplify the consequences of flooding. Figure 16.4 shows how an example hydrograph changed due to increased urbanization. Changes in the hydrograph affect the channel network by altering natural geomorphic thresholds established between the balance discharge and slope versus sediment mobilization and transport. As one or more of these components change (Lane 1955), the channel stability balance is disturbed, and the fluvial system adjusts accordingly. The adjustments to the fluvial system vary based on the magnitude of the disturbance and will tend to rebalance over time.

Figure 16.4. Changes in Hydrograph as Urbanization Increases

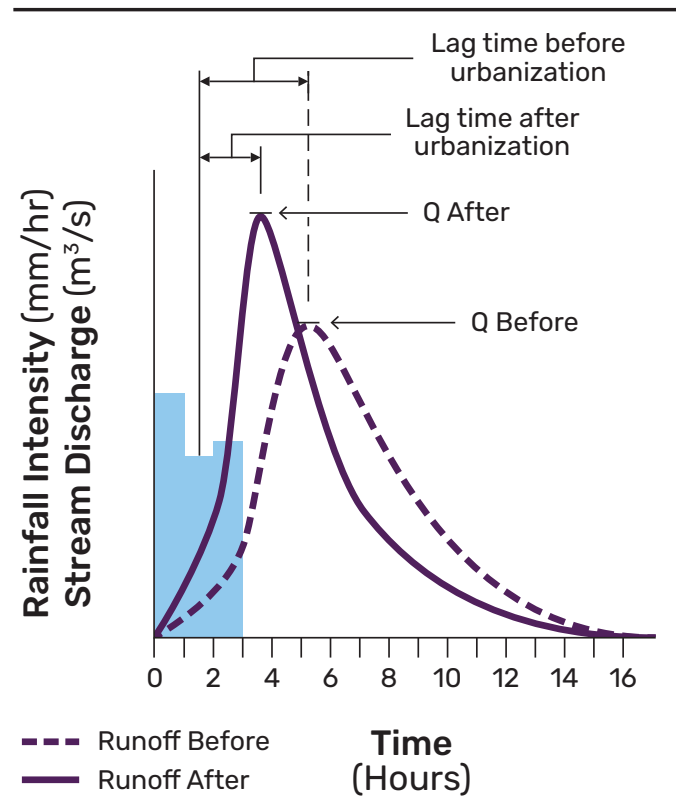

Abbreviations:

$\mathrm{mm} / \mathrm{hr}$ : millimeters per hour

$\mathrm{m}^{3} / \mathrm{s}$ : cubic meters per second
- Climate change. Increasingly a driver of large alterations in the hydraulic and morphological regimes of watersheds, climate change and its consequences are still being studied to further understand their impacts on individual regions and watersheds. The patterns of climate change and its attendant consequences vary by geographical location (Blöschl et al. 2019) and occasionally are marked by dry winters followed by wet summers, causing flooding in summer (e.g., the 2007 and 2012 flood events in the United Kingdom). Conversely, climate change may also cause increased discharge in the winter. The result is increased flood risk arising from the following: 
- Altered precipitation patterns and increased precipitation intensity, which can lead to flash floods in steeper watersheds and cause enormous damage and often loss of life (see "Precipitation Variability - Examples and Consequences")

- Increased discharge in parts of the watersheds and subwatersheds

- Sea-level rise and storm surges, which reduce the ability of rivers to discharge to the ocean and increase the resulting river flood levels

- Intensified drought conditions in arid regions, which may increase the frequency and severity of wildfires that destroy vegetation, decrease soil infiltration capacity, and increase erosion, leading to potentially catastrophic downstream flooding and mudslides

However, there are watersheds that receive considerably less discharge throughout the year (hence in winter and summer), which means that flood risk can decrease as a result of climate change (IPCC 2012). This obviously combines with other problems, mainly related to desiccation, droughts, and the loss of biodiversity.

\section{Precipitation Variability - Examples and Consequences}

Climate change has exacerbated flood risks around the world in numerous ways, as heavy precipitation increases in some regions, whereas others become more arid and prone to drought and wildfire.

For example, more prolonged heavy rain events and more powerful hurricanes in the eastern United States are contributing to historically destructive floods. By contrast, parts of the western United States are grappling with droughts, historic wildfires, and changing snowpack regimes as more precipitation falls as rain rather than snow. Intense precipitation on top of areas burned by wildfires increases the risks of floods and landslides because soil permeability and water infiltration are reduced, vegetation that directly intercepts precipitation is lost, and root systems can only take up less water.

Similar patterns are seen in the United Kingdom. For example, more frequent high-intensity rainfall is causing floods that overwhelm existing flood protection measures; however, in contrast, outbreaks of wildfires on the moors in the uplands of England's Peak District are increasing due to hotter summers. 


\subsubsection{Reducing Flood Risk in Fluvial Systems Using NNBF}

In the context of these guidelines, reduction of flood risk is the primary goal of fluvial NNBF. Flood risk can be reduced by structural and nonstructural measures based on NNBF principles. For example, in the case of nonstructural measures, this can be accomplished by elevating the buildings themselves above flood levels or purchasing properties to remove from further flood risk. For structural measures, this is achieved by constructing elevation in the form of barriers such as levees or walls. Essential to applying nonstructural and structural measures is an increased focus on restoration of natural ecological functions to deliver sustainable and resilient designs that take into account future climate change and other scenarios. The designs should not only reduce flood risk-they should also provide a wide range of ecological, social, environmental, and economic co-benefits (see Chapter 6).

To mitigate flood risk, practitioners should determine the most appropriate strategy for the area, generally focusing on the probability of a flood, of reducing the consequences, or both. The appropriate strategy (i.e., the exact choice of measures) depends on geomorphic setting, river size, gradient and length of the river (e.g., relatively steep and short), location (e.g., near the sea and under tidal influence), and any existing measures such as levees. As noted in Chapter 15, the choice of measures also depends on the location of flooding in the watershed (headwaters versus middle or lower reaches). Strategies should also be balanced by traditions and practices of a specific region or country. The following general principles apply:

- In steeper basins with relatively short rivers, in smaller tributaries or small streams, or in the headwaters of larger rivers, the focus should be on NNBF that reintroduce floodplain connections, when possible, to reduce runoff, slow the flow, and decrease peak discharges by retaining and storing water. Such measures also help manage sediment by retaining it in the subwatershed. For example, properly functioning floodplains provide areas for fine sediment deposition and nutrient cycling, decreasing potential morphological and water quality problems downstream.

- In midwatershed areas and larger tributaries, the measures adopted should reconnect rivers with their floodplains, thereby making more room for the river, creating floodwater storage, and thus decreasing flood levels. Depending on a watershed's geomorphic setting, larger tributaries and midwatershed areas may have characteristics comparable to those of the smaller tributaries in the headwaters, making similar NNBF treatment strategies appropriate. 
- In lower gradient parts of large rivers basins, which are often protected by engineered levees, the flood risk reduction strategy should be to reduce peak water levels by reconnecting floodplains (including levee setbacks) and increasing conveyance capacity, as follows:

- Reconnecting floodplains is also crucial for re-establishing natural functions for nutrient exchange and carbon sequestration, water quality, and terrestrial and aquatic ecological co-benefits. Low gradient river systems typically offer some of the greatest opportunities to obtain the largest co-benefits from NNBF.

- Levee setbacks provide additional reconnection of floodplains and may be a more locally acceptable FRM option than removing the entire levee system. The benefits of levee setbacks are similar to those of floodplain reconnection.

- Increasing conveyance capacity is typically achieved by providing secondary channels to enlarge floodplain capacity. Other ways are removing obstacles (e.g., former industrial activities) or excavating floodplains. Secondary channel projects that increase conveyance are becoming more common in the United Kingdom, where rivers are relatively short and have intermediate channel slopes. Projects to increase conveyance by deepening or widening river channels are more common in the Netherlands, which has low-gradient rivers.

- Caution is needed because increasing conveyance of flows in one location can unintentionally increase flood risk and channel instability downstream. This holds especially for headwaters and smaller streams. The morphological response of large rivers to measures in the floodplain may lead to long-term aggradation of the main channel, which can affect navigation and lead to economic losses. Increasing conveyance to manage flood risk generally leads to co-benefits such as greater recreational and ecological values, which can include increased biodiversity (e.g., spawning grounds for fish) and the possibility to use the side channel for recreation.

Samples of approaches to managing and reducing flood risk in the Netherlands, United Kingdom, and United States are provided in Table 16.1.

\section{Table 16.1. Sample Approaches to Managing and Reducing Flood Risk}

\section{The Netherlands}

\footnotetext{
Approach: Approximately $25 \%$ of the low-lying Netherlands is below mean sea level, and $60 \%$ of the population lives in flood-prone areas that generate $70 \%$ of gross domestic product. Thus, flood protection is of utmost importance to Dutch society. For larger rivers like the Rhine and the Meuse and for canals, strong embankments are the primary defense against flooding. Since 2005, these traditional approaches have been combined with NNBF in the Room for the River program to store and slow flood flows, rather than speed conveyance. The Netherlands also has a 24 hours per day, 7 days per week operational prediction and flood warning system for the Rhine, the Meuse, lakes, and coastal areas (Werner et al. 2013).
} 


\section{United Kingdom}

Approach: Before 1990, the United Kingdom's approach to reducing and managing flooding emphasized flood "defenses" and "protecting" and "defending" people and property, generally by constructing hard engineered defenses to speed drainage and conveyance. This approach changed after a succession of floods showed it is not possible to fully protect or defend people from flooding because there is always the potential for these defenses to be breached. Thus, the focus shifted to managing and reducing the risk of flooding through a wide variety of approaches such as structural measures, NNBF, flood warnings, property-level resilience measures, and temporary defenses. Measures are designed to slow, store, and hold back floodwaters, then release them slowly without increasing conveyance. These NNBF and "natural" FRM approaches help reduce flood risk and often enable the delivery of a wide range of ecosystem services.

\section{United States}

Approach: Despite several decades of federally led flood control and floodplain management programs that largely emphasize structural approaches, the United States faces increasing annual flood damages. But a new FRM paradigm is emerging. One of the most significant indicators of this change is the profound reframing of natural systems as being, in part, infrastructure, which has led the engineering community to begin recognizing floodplains, forests, wetlands, and other NNBF as essential components of flood infrastructure systems. This awareness is reorienting the long-standing tendency to replace natural infrastructure-vegetation, soils, floodplains, and wetlands that store precipitation and runoff-with hard gray infrastructure. Green infrastructure is now widely used for urban stormwater management, and river restoration projects involving floodplain reconnection have been widely implemented at a variety of scales. Prioritizing natural infrastructure interventions in watersheds and increasing partnerships with private landowners are emerging priority areas for FRM.

\section{3 || Principles of Fluvial NNBF}

Five foundational principles, critical to the overall success of an NNBF project, were introduced in Chapter 2. Practitioners should adhere to these principles to ensure sound fluvial applications of NNBF. This section expands on how these principles should be applied in a fluvial context. 


\subsubsection{Principle 1: Use a Systems Approach to Leverage Existing Components and Projects and Their Interconnectivity}

Holistic watershed approach. A watershed perspective is essential to understand and address the core causes of flooding. This means factoring into watershed planning and engineering designs the natural water retention functions of watershed features and processes so that land use planning and engineering designs work with, rather than against, nature at a local scale and within the broader context of the watershed system. Interventions can be targeted strategically at geomorphic settings in the watershed (see Chapter 4 , Section 4.3.2). For example, valleys that are a few kilometers long, more than six or seven times wider than the river channel, and have less than $2 \%$ slopes and an appreciably rough floodplain will likely attenuate flood peaks much more effectively than valleys that are much more confined, steep, and smooth (Habersack, Schober, and Hauer 2015). NNBF measures targeted at the core causes of flooding and at the proper scale will be much more effective than measures sited in an isolated, nonstrategic manner (Dixon et al. 2016; Lane 2017). Watershed modeling can be an important tool in strategic placement of NNBF in fluvial systems (Metcalfe et al. 2017).

Avoid transferring risks downstream, upstream, or to adjacent areas. NNBF applications must use sound engineering practices to provide FRM and other benefits without increasing risks to other areas in the fluvial system. In some cases, reducing flood risk and increasing benefits in one area may have negative impacts for other areas. The approach, including the need for embankments or levees, or appropriate NNBF, should always be optimized based on local FRM preferences.

Dealing with synchronization risks. Flood reduction measures, whether structural, NNBF, or a hybrid, can alter the timing of flood waves from different subbasins and tributaries of river systems (Lane 2017) and thus affect the timing of flood peak arrival at downstream locations targeted for flood risk reduction (Figure 16.5). For example, conventional stormwater control infrastructure (e.g., retention basins) used to mitigate the effects of urbanization often reduce peak flow magnitude but extend peak flow duration. As a result, the likelihood of downstream synchronization of flow peaks from different subbasins may be increased and, consequently, flood hazards inadvertently exacerbated. Therefore, existing or new structural FRM measures should be evaluated together with proposed NNBF measures to determine significant changes in flood peak timing at the system level. Physically based hydrologic and hydraulic models typically are required to determine whether flood waves will be inadvertently synchronized and to identify opportunities to retime and desynchronize flood hydrographs to ensure FRM measures are effective. 
Figure 16.5. Fluvial Networks and Understanding Their Interconnectivity with Effective FRM
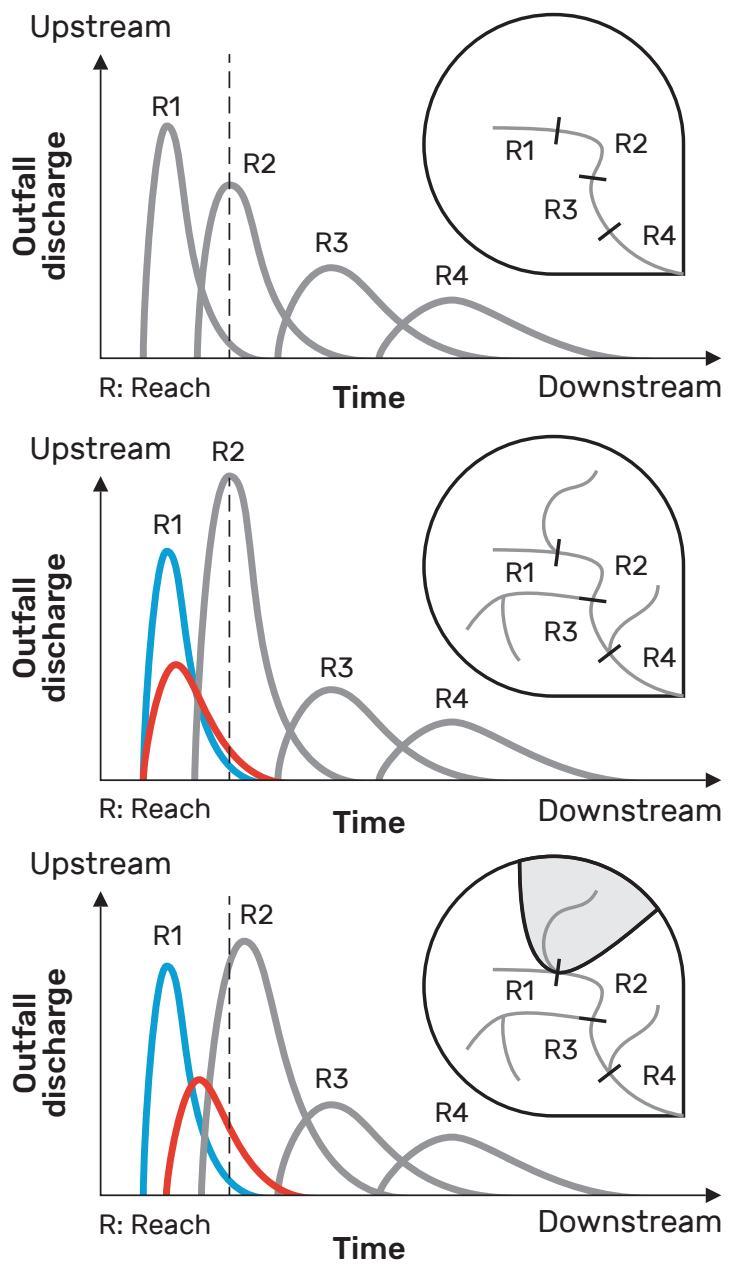

\section{(A) The Attenuation Process}

Once runoff reaches the river channel, if there is not delivery of water by tributaries, the discharge peak reduces in amplitude and the water wave becomes stretched with distance downward. The water is not necessarily lost; it is a natural process (attenuation) related to processes that slow the downstream flux of water, such as turbulence, secondary circulation, or river flow on a floodplain, where flow velocity is reduced.

\section{(B) River Process}

Attenuation is countered by tributary inputs of water, which increase the amplitude of the discharge peak. Here, a tributary arrives at the outlet of Reach 1 (red) resulting in a higher magnitude flood peak (gray) at the outlet of Reach 2. In general, inputs increase peak discharge more rapidly than attenuation decreases, such that peak discharge increases downstream. Rivers become wider, deeper, and faster as a result.

\section{(C) Decoupling Tributaries}

The tributary that arrives at the outlet of Reach 1 (red) is now decoupled more from the main stem (blue). This reduces the maximum discharge at the outlet of Reach 2 (gray). Thus, the maximum flow in a river is a function of the relative timing of tributary responses. Decoupling tributaries is a possible flood risk management solution. But the vertical dashed line shows that in the decoupled case, the discharge peak is delayed, potentially changing its timing with respect to other tributaries downstream.

Use of nested NNBF responses within the watershed. Fluvial NNBF systems have a nested nature analogous to the multilayered defenses in coastal systems. This means a portfolio of NNBF measures ought to be used to address uncertainties and avoid the "silver bullet" syndrome of seeking simple "one-shot" solutions to FRM. Watersheds have fractal-like properties-within a watershed are smaller watersheds related to the tributaries, and within those are even smaller watersheds related to the tributaries of the tributaries, and so on. This may permit parts of a watershed, rather than the entire watershed, to be considered when contemplating which combinations of NNBF could best reduce flood risk throughout a fluvial system. 


\title{
16.3.2 Principle 2: Engage Communities, Stakeholders, Partners, and Multidisciplinary Team Members to Develop Innovative Solutions
}

Land use planning. With multidisciplinary partners and teams that engage with communities and stakeholders (see Chapter 3), imaginative and potentially multiple co-uses of land are possible as space is released to implement NNBF and avoid constraining a river within its floodplain. The following are among the approaches to provide space for the river to flood and change course while avoiding flood pressure on developed areas:

- Levee setbacks

- Relocating flood-prone communities and neighborhoods

- Zoning restrictions on land use

- Designated floodways

- Restoring unproductive agricultural and industrial land and returning it to functioning floodplains

- Waterfront revitalization to create recreational green space

- Holistic watershed management that considers the entire fluvial system (including upper catchment NNBF applications)

\subsubsection{Principle 3: Identify Sustainable and Resilient Solutions That Produce Multiple Benefits}

\author{
Conserve, as much as possible, the natural features and processes throughout the \\ watershed that store and attenuate floodwaters. This includes practices that conserve \\ snowpack, restore or create wetlands to retain floodwaters upstream, and establish, protect, \\ and expand a network of riparian stream buffers. Restoring and maintaining floodplain \\ functions in the watershed, building deltas through sound sediment and groundwater \\ management, and restoring channel shape and roughness for flood attenuation and habitat \\ are also included. Whenever possible, use native vegetation to capture and attenuate \\ floodwaters and prevent stream-bank erosion. In some situations, placing wood in streams \\ and working with beaver to provide flood attenuation functions may be feasible. Reducing \\ the effects of upland and riparian land use changes such as urbanization or agricultural \\ encroachment on the floodplain is also recommended.
}

Achieve sediment balance in the watershed. Allowing natural channel mobility and adjustment is an important goal of FRM using NNBF. But some form of channel stabilization (i.e., armoring) may be the only practicable alternative in urbanized areas and other settings where streams are highly constrained by infrastructure and adjacent land uses. 
Although channel stabilization may provide some measurable benefits and reduce erosion in certain situations, the resulting decline in sediment delivery may increase the risk of channel instability and habitat degradation downstream. Consequently, flood reduction measures that create a static channel must be tempered by an understanding of the potential responses of the downstream channels. This underscores the need to consider local actions in a broader context by assessing and monitoring downstream segments during planning and post-project evaluation. Similarly, system instability may lead to major impacts on navigation channel operations and maintenance. Whether formulating new or renovating old navigation project designs, NNBF is strongly encouraged to provide more resilient and sustainable projects.

Minimize stormwater runoff and maximize the capture and use of rainwater. These can be achieved by the following actions:

- Promoting strategies that use green infrastructure to reduce stormwater runoff

- Reducing or minimizing impervious surface cover

- Protecting, restoring, and creating strategically placed wetlands and riparian buffers to attenuate flooding and discourage development in flood-prone locations

Common co-benefits. Such approaches can also deliver the following:

- Protection of groundwater, surface water, and potable raw water supplies from pollutants

- Sustainable management of soil as a resource, maximizing the use of cover crops in agricultural regions

- Balanced surface water and groundwater exchanges through coordinated management of these resources in designated surface-to-groundwater recharge areas throughout the watershed

- Habitat protection

- Recreational areas

- Local cooling benefits

\subsubsection{Principle 4: Anticipate, Evaluate, and Manage Risk in Project or System Performance}

Understanding the underlying principles that influence FRM and risk reduction is important. Figure 16.6 depicts a tiered approach to reducing risk by implementing a series of tools to reduce overall flood risks. The options include management strategies, education, and implementation of structural and nonstructural projects. Federal, state, and local organizations implement various approaches depending on their authority. The goal is to reduce flood risk by anticipating, evaluating, and managing the cumulative effects of the tools 
used to provide the greatest reduction in flood risk, thereby lowering the residual risk. Residual risk is the risk that remains after all risk management actions are considered. For example, if zoning and building code tools are implemented, there is still a large residual risk based on the limited influence on FRM. Implementing all of the tools greatly reduces the associated residual risks but does not entirely remove it.

Figure 16.6. Methods for Buying Down Flood Risk through Implementation of Local, Regional, and National Programs

Shared Flood Risk Management: Buying Down Risk

Initial Risk

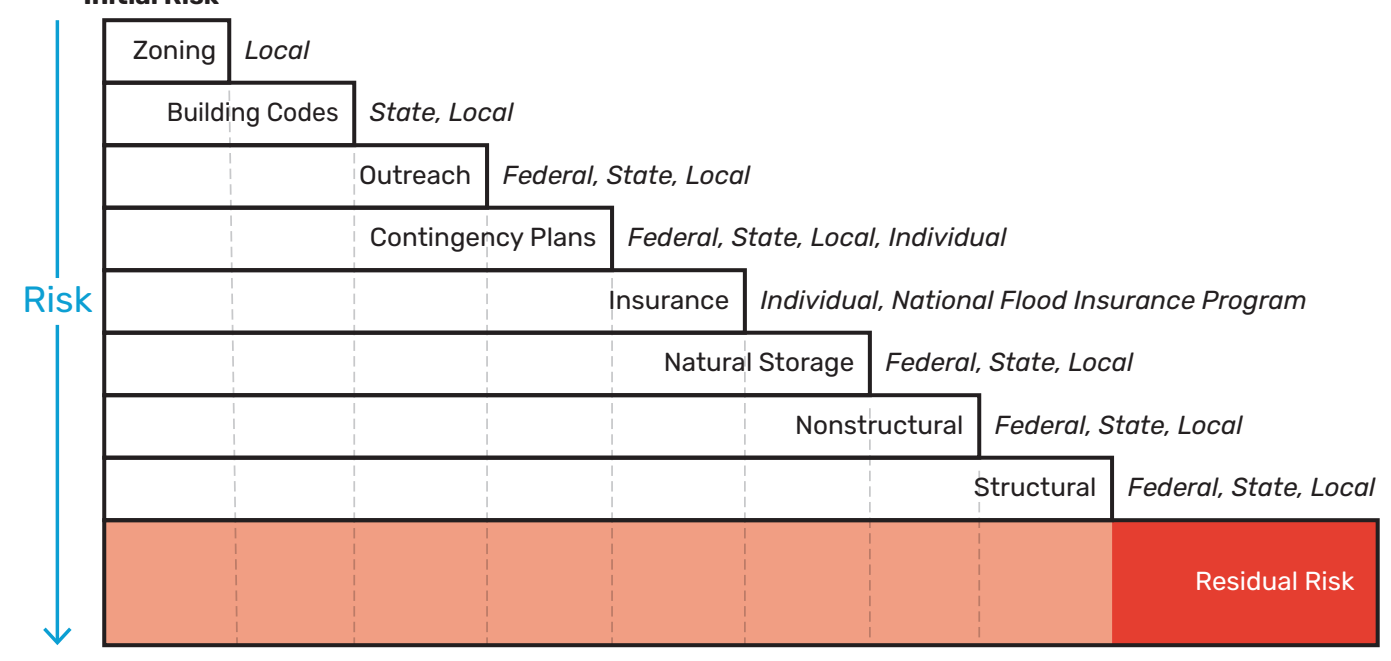

Risk Buy-Down Measure

Area represents proportional reduction effect on risk

\section{Residual Risk}

Risk remaining after buy-down measures

All stakeholders contribute to reducing risk.

\subsubsection{Principle 5: Expect Change and Manage Adaptively}

Assembling monitoring and adaptive management plans is critical for understanding how NNBF functions complement FRM projects. Irrespective of time or budget constraints, effort should be put in to ensure that, as a project nears the end of its planning and design process, the monitoring plan is fully developed. Monitoring plans are vital to provide information on NNBF benefits that could be used to identify the enhancements to which NNBF measures might be applied. 
Climate change adaptation. Precipitation projections based on climate change and related flood risk models should be incorporated in management options. Designing and retrofitting infrastructure with watershed and floodplain management goals in mind is important to develop sustainable and resilient NNBF enhancements. It becomes even more important as global climate change forecasts become increasingly complex (see Chapter 7 and see Section 16.2 of this chapter).

Land use change management. Additional attention to urban waterfronts and all floodplain management planning, zoning, and land use ordinances is critical for long-term success and flood risk reduction.

\section{4 || Chapter Summary}

This chapter introduced the fluvial system and relationships to natural processes and FRM. Most of the chapter was assimilated to provide the reader with background information on natural processes and how human habitation, climate change, and other factors affect FRM. Chapter 17 builds on these topics, with more focused discussion of challenges and benefits of NNBF in the fluvial setting.

\section{5 || References}

ASCE (American Society of Civil Engineers). 2013. 2013 Report Card for America's Infrastructure. Washington, DC. https://doi.org/10.1061/9780784478837.

Blöschl, G., J. Hall, A. Viglione, R. A. P. Perdigão, J. Parajka, B. Merz, D. Lun, et al. 2019. "Changing Climate Both Increases and Decreases European River Floods." Nature 573: 108-111.

Cluer, B., and C. Thorne. 2014. "A Stream Evolution Model Integrating Habitat and Ecosystem Benefits." River Research and Applications 30 (2): 135-154. doi:10.1002/rra.2631.

CABE (Commission for Architecture and the Built Environment). 2004. The Value of Public Space: How High Quality Parks and Public Spaces Create Economic, Social and Environmental Value. London: CABE Space. https://www.designcouncil.org.uk/sites/ default/files/asset/document/the-value-of-public-space1.pdf.

CRED (Centre for Research on the Epidemiology of Disasters). 2019. Natural Disasters: 2018. Brussels, BE: Centre for Research on the Epidemiology of Disasters. https://www.cred. be/natural-disasters-2018.

Dixon, S. J., D. A. Sear, N. A. Odoni, T. Sykes, and S. N. Lane. 2016. “The Effects of River Restoration on Catchment Scale Flood Risk and Flood Hydrology." Earth Surface Processes and Landforms 41 (7): 997-1008. 
Grill, G., B. Lehner, M. Thieme, B. Geenen, D. Tickner, F. Antonelli, S. Babu, et al. 2019. “Mapping the World's Free-Flowing Rivers." Nature 572 (7768): E9. doi:10.1038/s41586-019-13799.

Habersack, H., B. Schober, and C. Hauer. 2015. “Floodplain Evaluation Matrix (FEM): An Interdisciplinary Method for Evaluating River Floodplains in the Context of Integrated Flood Risk Management." Natural Hazards 75 (1): 5-32.

Hawley, R. J., B. P. Bledsoe, E. D. Stein, and B. E. Haines. 2012. “Channel Evolution Model of Semiarid Stream Response to Urban-Induced Hydromodification." Journal of the American Water Resources Association 48 (4): 1-23. doi:10.1111/j.17521688.2012.00645.x.

Hayes, D. S., J. M. Brändle, C. Seliger, B. Zeiringer, T. Ferreira, and S. Schmutz. 2018. "Advancing Towards Functional Environmental Flows for Temperate Floodplain Rivers." Science of The Total Environment 633: 1089-1104. https://doi.org/10.1016/j. scitotenv.2018.03.221.

IFRC (International Federation of Red Cross and Red Crescent Societies). 2015. World Disasters Report. Geneva, CH: IFRC.

IPCC (The Intergovernmental Panel on Climate Change). 2012. "Summary for Policymakers." In Managing the Risks of Extreme Events and Disasters to Advance Climate Change Adaptation. Edited by C. B. Field, V. Barros, T. F. Stocker, D. Qin, D. J. Dokken, K. L. Ebi, M. D. Mastrandrea, et al., 1-19. A Special Report of Working Groups I and II of the Intergovernmental Panel on Climate Change. Cambridge, UK, and New York, NY: Cambridge University Press.

Kummu, M., H. de Moel, P. J. Ward, and O. Varis. 2011. "How Close Do We Live to Water? A Global Analysis of Population Distance to Freshwater Bodies." PLOS ONE 6 (6): e20578.

Lane, E. W., 1955. "Importance of Fluvial Geomorphology in Hydraulic Engineering." American Society of Civil Engineers 81 (745): 745-761.

Lane, S. N., 2017. “Natural Flood Management." WIREs Water 4 (3): e1211. https://doi. org/10.1002/wat2.1211.

nasa.gov. 2013. "Brown Ocean" Can Fuel Inland Tropical Cyclones. NASA. https://www.nasa. gov/content/goddard/brown-ocean-can-fuel-inland-tropical-cyclones/.

NTHMP (National Tsunami Hazard Mitigation Program). 2016. 2015 Accomplishments of the National Tsunami Hazard Mitigation Program: An Annual Report. Washington, DC: NTHMP. https://nws.weather.gov/nthmp/documents/2015AnnualReport.pdf.

Poff, N. L., B. P. Bledsoe, and C. O. Cuhaciyan. 2006. “Hydrologic Alterations due to Differential Land Use across the Contiguous United States: Geomorphic and Ecological Consequences for Stream Ecosystems." Geomorphology 79: 264-285. 
Simon, A., and C. R. Hupp. 1986. “Channel Widening Characteristics and Bank Slope Development along a Reach of Cane Creek, West Tennessee." Selected Papers in the Hydrologic Sciences. Edited by S. Subitzsky. U.S. Geological Survey Water-Supply Paper 2290. Washington, DC: U.S. Government Printing Office.

Tockner, K., and J. Stanford. 2002. "Riverine Flood Plains: Present State and Future Trends." Environmental Conservation. 29 (3): 308-330. doi:10.1017/S037689290200022X.

Werner, M., J. Schellekens, P. Gijsbers, M. van Dijk, O. van den Akker, and K. Heynert, 2013. "The Delft-FEWS Flow Forecasting System." Environmental Modelling \& Software 40: 65-77. https://doi.org/10.1016/j.envsoft.2012.07.010.

White, G. F. 1945. "Human Adjustment to Floods: A Geographical Approach to the Flood Problem in the United States." PhD diss., University of Chicago. 


\section{Acknowledgments}

\section{Lead Authors}

Christopher Haring, U.S. Army Corps of Engineers, United States

Ralph Schielen, Rijkswaterstaat, the Netherlands

Jo Guy, Environment Agency, United Kingdom

Lydia Burgess-Gamble, Environment Agency, United Kingdom

\section{Co-Author}

Brian Bledsoe, University of Georgia, United States

\section{Contributor}

Stacy Small-Lorenz, Small-Lorenz Ecology, LLC, United States 


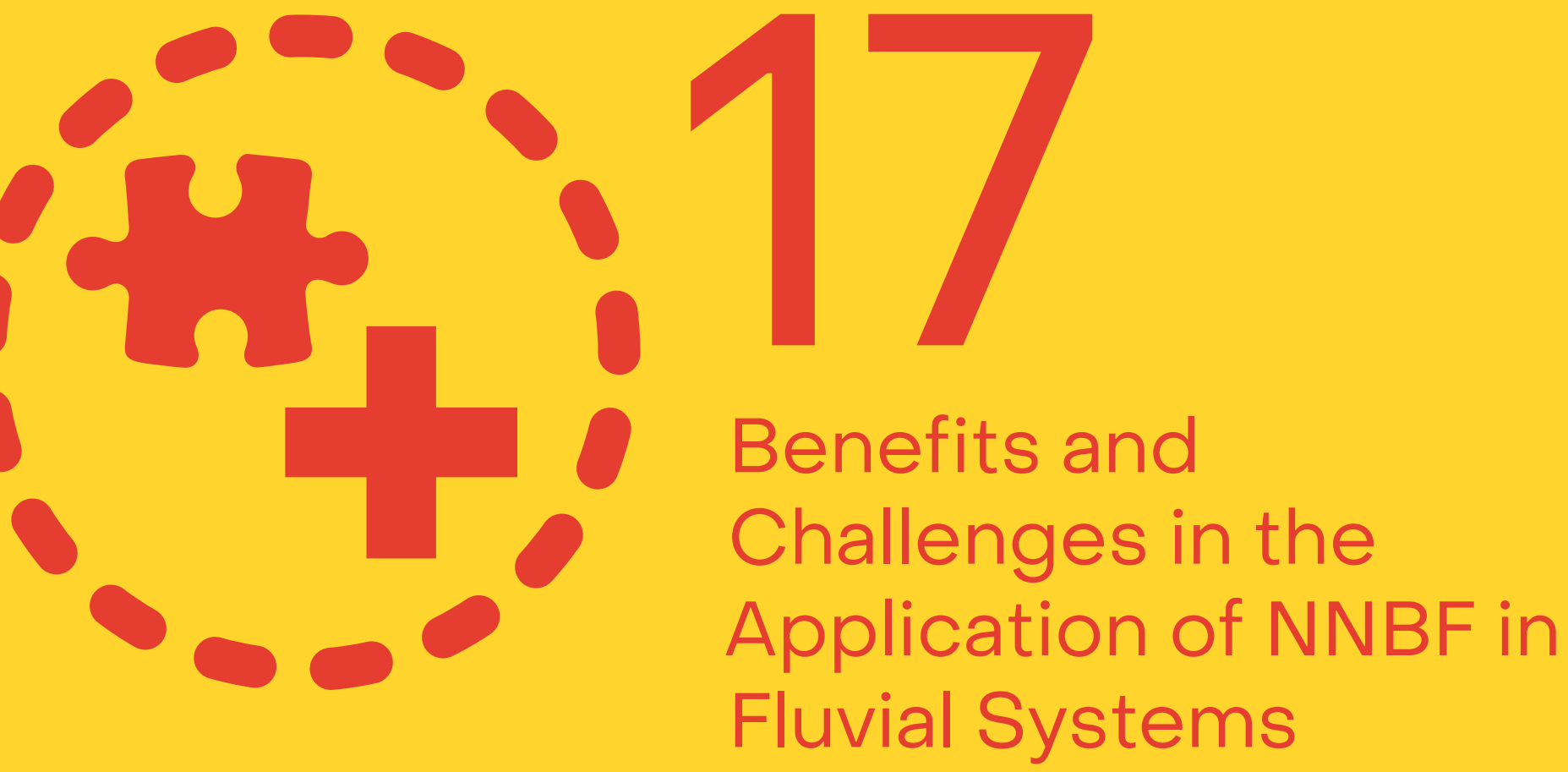

Suggested Citation:

Schielen, R., C. Haring, L. Burgess-Gamble, J. Guy, B. Bledsoe, and R. Mandel. 2021. "Chapter 17: Benefits and Challenges in the Application of NNBF in Fluvial Systems." In International Guidelines on Natural and Nature-Based Features for Flood Risk Management. Edited by T. S. Bridges, J. K. King, J. D. Simm, M. W. Beck, G. Collins, Q. Lodder, and R. K. Mohan. Vicksburg, MS: U.S. Army Engineer Research and Development Center.

Full acknowledgments appear at the end of this chapter. 


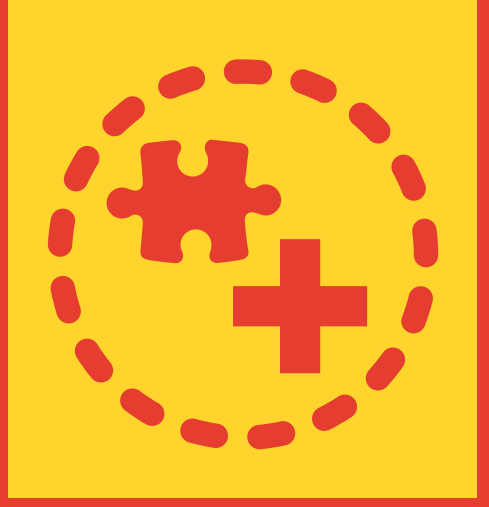

\section{Key Messages}

1. Measures in the past have altered river systems considerably and have left us with multiple challenges that come from the response of the river system to these changes. The challenges are associated with symptoms, causes, consequences, and benefits and co-benefits of natural and nature-based features (NNBF).

2. Many challenges are related to a river system that is out of balance, which is reflected by morphological changes such as incision and soil erosion from land into the river and degrading biodiversity. Most challenges can be addressed by applying NNBF.

3. There are multiple constraints to consider when applying NNBF (e.g., applying a systems approach), but application also leads to additional co-benefits.

4. NNBF can be categorized-each category has its own way of reducing flood risk by retaining, storing, or increasing conveyance capacity, in addition to managing natural erosion and sediment dynamics.

5. There are NNBF best practices to consider based on individual project characteristics. The list can be reviewed and case study examples can be studied to determine which suite of NNBF is appropriate for a project. 


\section{1 | Introduction}

As discussed in this International Guidelines on Natural and Nature-Based Features for Flood Risk Management publication, natural and nature-based features (NNBF) can help reduce flood risk by protecting, restoring, and emulating the natural functions of watersheds, floodplains, rivers, and coasts (Environment Agency 2010, 2012, 2017b). The fluvial section of this publication includes Chapters 15 through 19 . Chapter 15 introduces the NNBF applications for fluvial settings. Chapter 16 describes fluvial systems and their relation to flood risk management (FRM). Chapter 17 describes the benefits and challenges associated with NNBF in fluvial systems, Chapter 18 provides an overview of the role and range of NNBF available for fluvial applications, and Chapter 19 provides case study examples of different types of fluvial NNBF applications from around the world.

In this chapter, Section 17.2 describes some of the challenges encountered in managing rivers and reducing flood risk and the role that NNBF can play in that endeavor, and it relates the challenges to possible benefits and co-benefits that NNBF might have (compared with gray or gray-green alternatives). Section 17.3 discusses several concepts that need to be considered when applying NNBF, irrespective of scale and location. Section 17.4 elaborates on the benefits of NNBF and introduces a method to describe these. Section 17.5 describes five different categories (locations) in a watershed where NNBF can be applied. These categories are equipped with specific measures in Chapter 18. Section 17.6 discusses a list of concerns that should be considered when applying NNBF. Finally, Section 17.7 lists some gaps and suggests future research directions.

\section{2 | Challenges in River Management and the Contribution of NNBF}

River management often involves adopting measures to modify the planform of the river reach. For many rivers, this kind of management already started decades or even hundreds of years ago by removing meander bends, changing the land use of floodplains, and constructing embankments. The river itself adapts to those changes by changing its slope, width, and bed surface texture (Blom et al. 2017). The construction of embankments often means that adaptations in river width are limited, but slope and bed surface texture changes are still possible, leading to incision (riverbed erosion) and coarsening. Along with this, other issues arise such as lowering of the groundwater table, reduction in biodiversity, and disconnection of main channels and floodplains. 
Table 17.1 lists the challenges that rivers can face, coming from the engineering measures in the far or recent past. Addressing these challenges (and solving the consequences) often reduces flood risk. Using NNBF in fluvial systems (as a standalone measure or in addition to green or gray-green solutions), besides reducing flood risk, may also offer co-benefits that restore the river toward a more resilient and more robust natural system. For each challenge, Table 17.1 lists the symptoms that can arise and the causes that may have led to the issue for the river. It lists the consequences that may occur and indicates what NNBF can do to mitigate or reduce the challenges. Table 17.1 also addresses functions that NNBF have in addressing causes and lists the co-benefits that NNBF can bring to reduce or mitigate the consequences.

For example, one of the associated symptoms of the first challenge in Table 17.1, channel instability, is the loss and gain of sediments in floodplains that may be caused by straightening the river stretch or constructing dams. The possible consequences are instability of infrastructure and increased erosion of the riverbed or desiccation of the floodplain. A typical way an NNBF would function would be to restore the natural morphology. A co-benefit of using NNBF would be to reduce soil erosion.

Table 17.1. Challenges, Symptoms, Causes, Consequences, Functions, and Co-Benefits of NNBF

\section{Channel instability}

\section{Symptoms:}

- Excessive loss and gain of sediments in channels and floodplains

- Change in sediment size

- Incision and widening of the main channel

\section{Causes:}

- Dams (raw water for potable supply or FRM)

- High stream velocity due to conventional FRM measures

- Channelization

- Land use change

\section{Consequences:}

- Instability of infrastructure (bridges, dams, sluices)

- Loss of land next to river channel

- Coarsening and fining of the riverbed
- Economic damage

- Navigation difficulties

- Desiccation of floodplains

- Sediment deposited in ecosystems

\section{Function of NNBF in addressing causes:}

- Restore natural morphology by (1) reducing runoff from floodplain and (2) restoring river to a more natural morphological form

Co-benefits of NNBF:

- Reduction of soil erosion

- Reduced coarsening and fining of the riverbed

- Paving of the riverbed

- Reconnecting main channel and floodplain

- Improvement of natural flow and conveyance patterns 
Land use change (i.e., agricultural or urban extension)

\section{Symptoms:}

- Narrowing streambed width

- Soil erosion from land into river

- Channel instability

\section{Causes:}

- Inadequate regulatory (governmental) control

- Exposure of previously vegetated and forested soil to rainfall

\section{Consequences:}

- Fluvial flooding

- Sedimentation in river channel
- Loss of soil from land

- Pollution from agricultural or urban activities

- Increased turbidity of water column in river

Function of NNBF in addressing causes:

- Slow flow, thereby reducing sediment transport

- Restore (access by river to) floodplain

- Restore floodplains with vegetation

Co-benefits of NNBF:

- Restoration of streambed width

- Reduced soil erosion

- Improved water quality

- Natural channel morphology changes

\section{Loss of floodplains and wetlands}

\section{Symptoms:}

- Anthropogenic use of the floodplain and delta

Causes:

- Inadequate regulatory (governmental) control

\section{Consequences:}

- Economic loss of investment caused by flooding

- Decreased climate resilience from lost carbon sink
Function of NNBF in addressing causes:

- Restore (access by river to) floodplain

- Increase river conveyance by deepening and widening of existing floodplains or addition of extra channel or channels

\section{Co-benefits of NNBF}

- Restoration of floodplain function

- Restored carbon sequestration

Loss of flora and fauna (wildlife and biodiversity)

\section{Symptoms:}

- Reduction in flora and fauna population and diversity

- Local population extinction

Causes:

- Loss and/or fragmentation of habitat

- Disturbed natural food chains or food webs

\section{Consequences:}

- Reduction in local or regional biomes

- Loss of biomass

- Impaired or curtailed food chains

\section{Function of NNBF in addressing causes:}

- Restore and create vegetated habitats

- Direct revegetation

\section{Co-benefits of NNBF:}

- Restoration of biodiverse ecosystems

- Restored ecological functions and services

- Improved habitat and ecological resilience 


\section{Removal of vegetation}

\section{Symptoms:}

- Forest and grasslands lost to other anthropogenic land uses

\section{Causes:}

- Inadequate regulatory (governmental) control

- Increased wildfires caused by climate change

Consequences:

- Elevated runoff rates leading to higher peak flows

- Accelerated soil erosion

- Reduced infiltration

- Increased overland flow

\section{Function of NNBF in addressing causes:}

- Restore and create vegetated habitats

- Direct revegetation

Co-benefits of NNBF:

- Reduced deforestation

- Afforestation

- Increased soil health

- Additional carbon sequestration

\section{Water quality degradation}

\section{Symptoms:}

- Elevated levels of nutrients and toxins

- Decreased soil health and land quality

\section{Causes:}

- Overuse and excessive application of fertilizers and pesticides

- Urban pollutant runoff

\section{Consequences:}

- Increased water treatment requirements to provide potable water supply

- Decreased biodiversity

- Ecological degradation caused by pollutants in river sediments or coastal zone deposition

\section{Function of NNBF in addressing causes:}

- Restore filtration function provided by riparian filters

Co-benefits of NNBF:

- Reduction of the nutrients and pesticide loss to river or coastal zone

- Improvement of water quality

- Improved aquatic biodiversity

Note that there is sometimes a causative relation between the challenges in Table 17.1. For instance, the loss of floodplains and wetlands obviously leads to the loss of flora and fauna. But the reverse is not true-the loss of flora and fauna does not necessarily lead to the loss of floodplains and wetlands. Other relationships, however, may have multiple levels of causality; the loss of floodplains may be caused by changes in land use that can lead to less space that can store high flows. This means that the challenges are not standalone. They are interconnected by the symptoms, causes, and consequences.

Figure 17.1 places the challenges in a catchment; however, note that there is room for interpretation and discussion because challenges are not, per se, bounded to specific locations. The figure helps though, to get a rough idea where specific challenges occur. Loss of flora and fauna may happen at various places throughout the catchment. Water quality degradation is typically associated with urban development or agricultural activities on the floodplain. Hydropower and dams are usually found in the headwaters and possibly the middle reaches, and saltwater intrusion is a typical delta problem. 


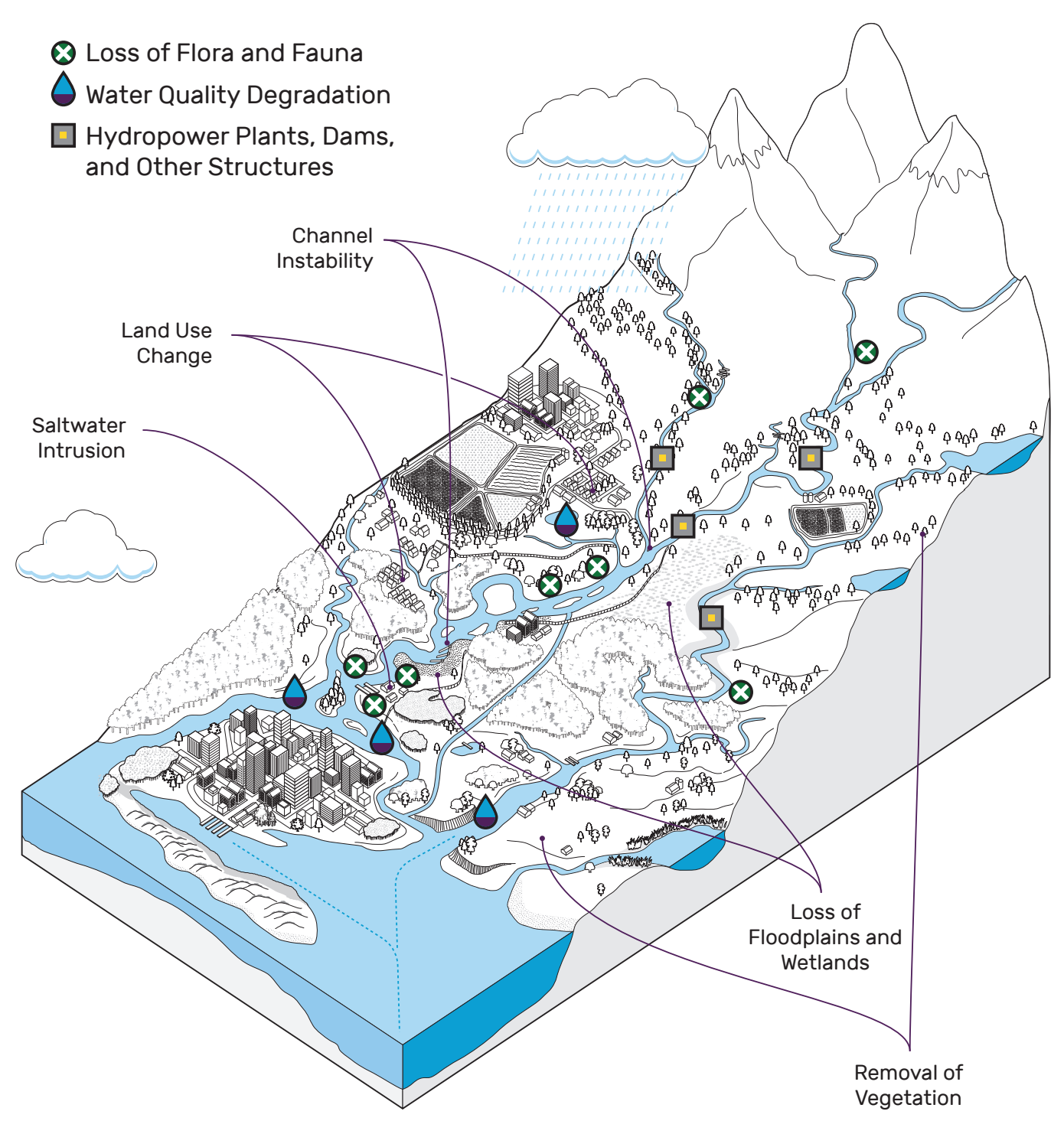

Sections 17.2.1 through 17.2.8 briefly describe and illustrate the challenges listed in Table 17.1 and suggest ways in which implementation of NNBF may be able to address these challenges. Figures 17.2 through 17.9 illustrate the challenges, with photographs from different international perspectives. 


\subsubsection{Channel Instability}

Most rivers have been affected by human intervention and are no longer in a state of equilibrium (Grill et al. 2019). For some rivers, this trend started centuries ago. For example, the Rhine River has been subjected to three distinct periods of regulation since 1800 (Havinga 2020). Some rivers, like the Ayeyarwady in Myanmar, are on the brink of being regulated, whereas others, like the Drin, which flows through Albania, Kosovo, and Macedonia, are still rather pristine.

Urbanization has led to large-scale bottlenecks such as bridges or embankments close to the main channels of some rivers, and such hard structures can constrict river channels. Floodplains are often disconnected from the adjacent river and often no longer have natural vegetation or functioning ecological communities. The planform has been altered, bends have been cut off, floodplains have been reduced in size, and free meandering behavior is (for the larger rivers) often constrained. Channelization, river training, dam construction, and dredging are causes of channel incision; as a result, flood waves pass through the systems more quickly and put downstream communities at greater risk of flooding. Figure 17.2 shows examples of bank erosion and channel bed incision.

\section{Figure 17.2. Examples of Bank Erosion and Channel Bed Incision in Rivers}

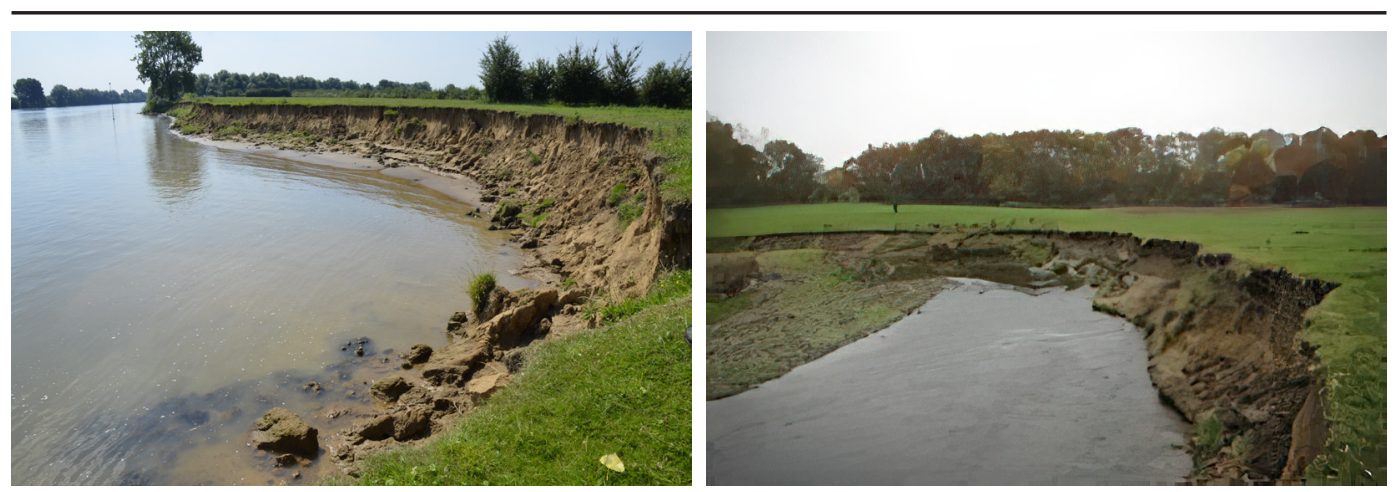

Notes: The photograph on the left shows bank erosion on the Meuse River, the Netherlands. The photograph on the right shows channel bed incision of the Wurm River, Germany.

Source: Left: Gonzalo Duro; Right: Michael Buchty-Lemke 
Although incision can be beneficial for navigation (larger ships can sail the river), additional problems (a lower groundwater table in the floodplains) may arise. Another result is that the floodplains become disconnected from the main channel and the sediment supply toward the floodplain decreases. The supply of nutrients (through the sediments) is also reduced. The effect of shipping is another topic that should be closely examined because dredging to maintain the channels can affect sediment transport and deposition zones. Likewise, the passage of vessels can cause propeller wash and vessel wakes, which can erode shorelines.

NNBF may be used to slow down the velocities in the main channel (counteracting incision) by restoring floodplains and by using bioengineering to reduce erosion from the floodplains toward the main channel. In general, widening of a river over a large stretch will lead to aggradation of the riverbed. The general idea is to rely on natural process, including the long-term morphological development of the rivers to facilitate desired commercial and recreational uses of the waterway.

\subsubsection{Land Use Change}

Unperturbed, pristine fluvial landscapes can still be found in some parts of the world, but they have become extremely rare (Grill et al. 2019). In all cases, the absence of human activity guarantees (by definition) such a pristine situation. As soon as human activity begins, land use changes. As a result, the complex ecosystems in which physical, chemical, and biological processes play a role are disturbed and rivers will change.

Many forms of land use changes affect rivers. Probably the most important form of land use change is using floodplains for agriculture (such as shown in Figure 17.3), which is often accompanied by the construction of small levees to keep the frequency of inundation within limits. The physical and chemical properties of soil, as well as its structure, will change. Removing original floodplain vegetation alters the state of the floodplain with respect to ecological parameters (biodiversity) and hydromorphic parameters (friction, sedimentation processes). In addition, cattle farming can increase soil compaction and thus reduce infiltration to aquifers and encourage runoff to streams and rivers. 
Another dramatic form of land use change is urbanization, the introduction of housing and industry into the floodplain. The disadvantages of urbanization are the same as for turning floodplains into agricultural land but with the added complication that people who live and work in the floodplain are in immediate danger during high discharges. Urbanization also increases the imperviousness of the subsoil, which increases runoff (Poff, Bledsoe, and Cuhaciyan 2006). This is why some countries, like the Netherlands, generally do not allow new houses to be built in floodplains (except for experiments such as floating houses). Living in a floodplain is much more common in other countries, such as the United Kingdom, United States, and France.

Changes in land use have temporal as well as physical aspects. They often start with a predevelopment situation in which there is a symbiosis between the "maintainers" of the floodplain and the dynamics of the fluvial system itself. Then, whenever activity is increased, the floodplain becomes more affected by deforestation and the removal of other vegetation and the bare soil is increasingly exposed to erosion. This destabilizes the system because the eroded material is deposited in the main channel. Urbanization (settlements, houses, industrial activity) can be considered a third stage in land use changes. In this stage, the impervious surface area in a floodplain is increased, which, in turn, leads to increased runoff and further disconnection of the floodplain from its river's main channel. The temporal scale associated with this is typically on the order of centuries.

Many hazardous chemicals, including synthetic organic materials, may attach to sediment. Sediment itself is also drained to the river through natural runoff processes. If this sediment is contaminated (e.g., by agricultural fertilizers) and introduced into the river, it has the potential to degrade water quality. It also increases water turbidity, which may affect spawning grounds for fish, decrease the ability of water plants to grow, and affect the food chain by destroying the habitat of the smallest benthic organisms. Suspended sediment is also known to increase water temperature and negatively affect fish populations in multiple ways (canada.ca. 2016).

There is evidence for a link between changes in land use and changes in flood risk, although this link seems to depend on a spatial context (related to the watershed) and a temporal aspect (related to the flood event). See, for example, Pattison and Lane (2011) for more information. 
With multidisciplinary partners and teams that engage with communities and stakeholders, imaginative and potentially multiple co-uses of land are possible as space is released to implement NNBF measures and avoid constraining the river within its floodplain. This can be achieved through a variety of approaches that provide space for the river to flood and change course while avoiding flood pressure on developed areas. These measures include the following:

- Levee setbacks

- Relocating flood-prone communities and neighborhoods

- Land-use zoning restrictions

- Designated floodways

- Waterfront revitalization to recreational green space

An added value of NNBF is that they generally restore floodplains to a more natural state. In doing so, they also increase the discharge capacity of the river and slow the flow in the main channel and upstream parts of the catchment by, for example, incorporating the planting of trees.

\subsubsection{Loss of Floodplains and Wetlands}

Fluvial floodplains and adjacent wetlands are under constant pressure. There is ample evidence that large percentages of floodplains and wetlands have disappeared over the past decades (Hayes et al. 2018; Tockner and Stanford 2002). Reasons for loss include increased occupation of the floodplains and wetlands (i.e., urbanization and industrialization) and an associated relocation of embankments and levees. In the Netherlands, for example, almost 55,000 hectares of floodplains disappeared between 1850 and 1995 for these reasons. The consequence is a loss of flood storage area and, as a result, higher and more peaked discharge waves in the effected rivers. Loss of floodplains can also lead to changes in sediment dynamics, as well as flood storage during high-flow events. For example, the summer erosion of the floodplain could provide sediment sources to downstream areas. Obviously, restoring floodplains and wetlands will counteract these impacts.

After 1995, almost 5,000 hectares of the Rhine River's lost floodplains were recovered through the Netherland's Room for the River Program. Floodplains should be restored in ways that provide additional co-benefits, such as increases in natural values, biodiversity, and recreational opportunities.

Whether floodplain restoration leads to sedimentation in the main channel depends on the size of the river. Floodplain restoration in larger rivers might result in more sediment in the main channel if the restoration leads to an increase in discharge capacity which, in turn, leads to decreased velocities in the main channel and, hence, sedimentation. Erosion and 
sedimentation patterns are a complicated issue that needs to be studied in detail using numerical models. They depend on the state of the river (whether it is aggrading or degrading) and whether the change in morphology is positive or not. Floodplain restoration in smaller streams (e.g., by reconnecting a river with its floodplains) might have a positive effect on the sediment balance. Through the reconnection, the floodplain can capture sediment and, hence, act as a sink that prevents the sediment from ending up in the main channel.

Typical NNBF measures are removing anthropogenic elements from the floodplain (houses, industrial activities) and restoring the area in line with the natural environment (forest, shrubs, other vegetation, side channels). This might have to be done in combination with relocation of embankments and levees to increase the discharge capacity of the river even more.

\section{Figure 17.4. Wetland and Floodplain near Santa Fe, Argentina}

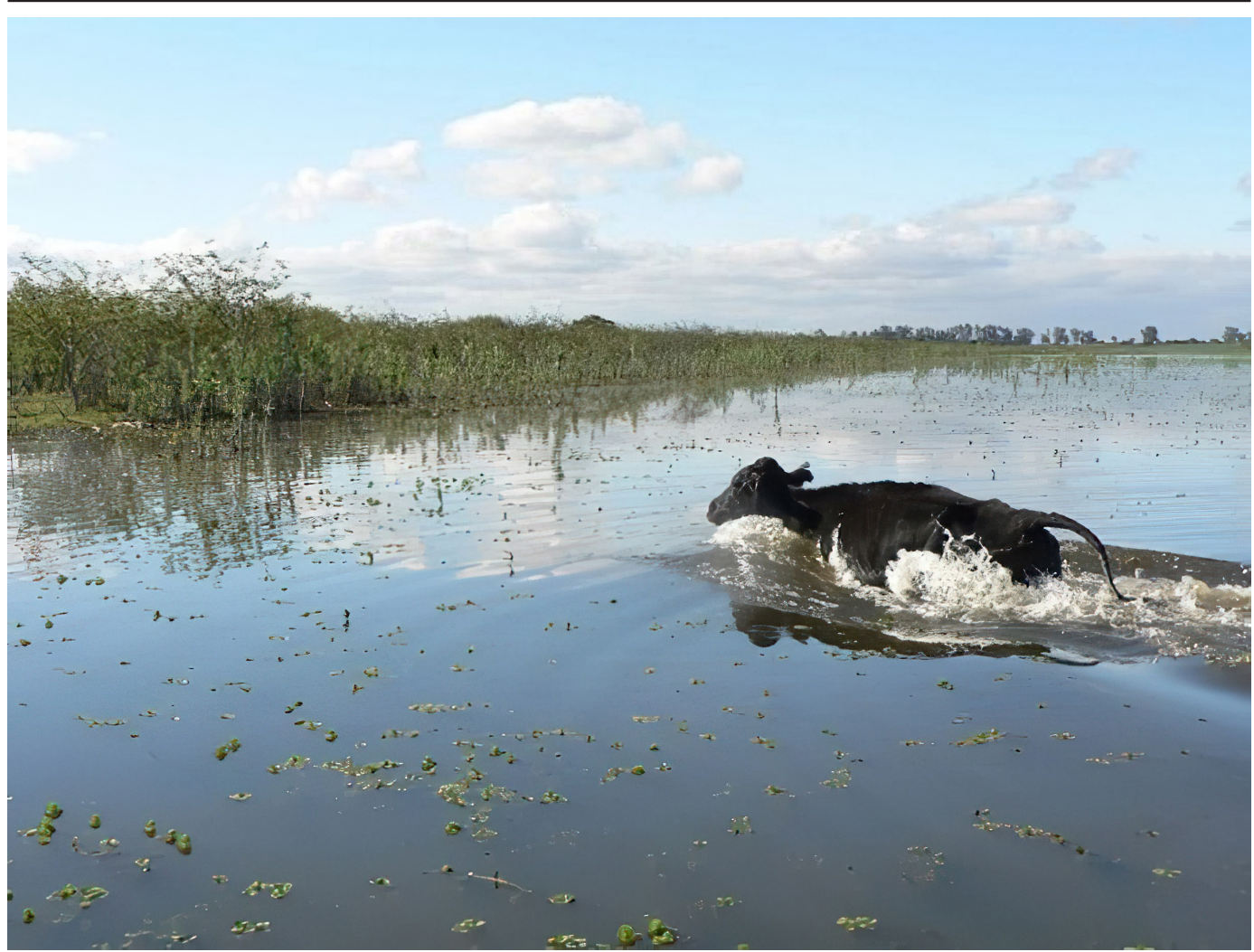

Source: Ralph Schielen, Beeldbank, Rijkswaterstaat 


\subsubsection{Loss of Flora and Fauna}

Changes in land use, floodplains disconnected from main river channels or lost outright, and deforestation will substantially affect the diversity of flora and fauna, including fish, birds, microbiota and macrobiota, and disparate assemblages of plant and wildlife species. These activities work through habitat loss, genetic erosion (in which the gene pool for a plant or animal population is diminished when individuals die before reproducing), reduced ecological connectivity, and numerous other ecological phenomena. There is evidence that restoring floodplains with NNBF increases biodiversity (Straatsma et al. 2017) and helps restore, enhance, and protect myriad ecological functions. However, it is not always clear how to score these elements and assess and compare the various NNBF (Calliari, Staccione, and Mysiak 2019).

Multiple NNBF techniques reintroduce or enhance grasses, graminoids, forbs (i.e., flowering monocots and dicots), shrubs, and trees. These techniques also restore or reconnect floodplains (see Section 17.2.3) by ensuring an improved spread of water over a landscape, allowing for increased retention and detention over time. Reintroduction of beneficial microbial species through soil amendment can also assist in restoring floodplains. Restoring habitat complexity, fauna, and biodiversity and reintroducing wildlife, such as beavers, have a beneficial effect on the added natural value and ecological functionality and services of floodplains.

\section{Figure 17.5. Black-Necked Goose in a Chilean Wetland}

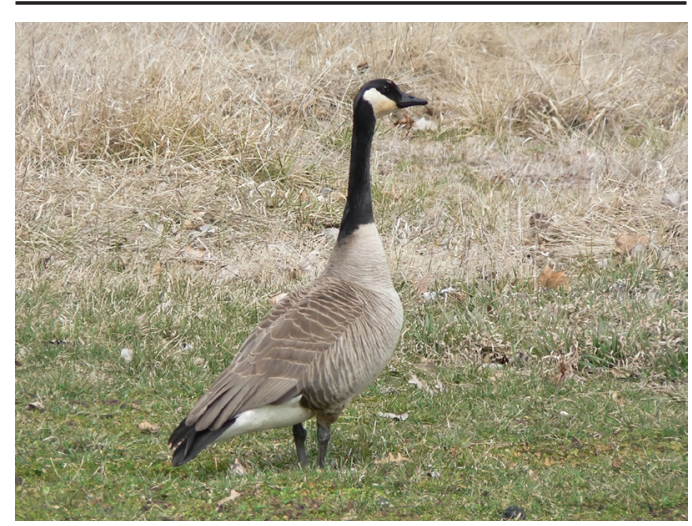

Source: Ralph Schielen, Rijkswaterstaat

Multiple NNBF techniques reintroduce or enhance grasses, graminoids, forbs (i.e., flowering monocots and dicots), shrubs, and trees. These techniques also restore or reconnect floodplains (see Section 17.2.3) by ensuring an improved spread of water over a landscape, allowing for increased retention and detention over time. Reintroduction of beneficial microbial species through soil amendment can also assist in restoring floodplains. Restoring habitat complexity, fauna, and biodiversity and reintroducing wildlife, such as beavers, have a beneficial effect on the added natural value and ecological functionality and services of floodplains. 


\subsubsection{Removal of Vegetation}

Deforestation has a negative impact on watersheds. In general, deforestation reduces wildlife, biodiversity, and ecological functions and increases the propensity for sedimentation. Individual shrubs and trees, as well as entire forests, can retain and slow pluvial flow. But because deforestation often accelerates runoff to smaller tributaries, runoff toward the mainstem of a river is also accelerated. Discharge waves become steeper and have higher peaks.

Deforestation occurs at many different locations in river watersheds. Figure 17.6 illustrates that even within a single stretch, vegetation is removed from one floodplain and maintained (or restored) on another floodplain. The main consequences of deforestation in the area of a river's headwaters (apart from the impacts on flora, fauna, and biodiversity at the site of the deforestation) are accelerated peak flows in the tributaries and, eventually, increased peak flows (in duration and magnitude) in the main channel. Most probably, sedimentation in the tributaries and the main channel is also increased because the sediment is no longer attenuated by tree roots and woody material. Deforestation can, therefore, lead not only to increased flood risks but also to significant sediment management issues.

If the floodplains of the main river itself are deforested, the consequences for peak flows can be quite severe because when the floodplains become smoother, the discharge wave is accelerated. The extent to which this happens depends again on where the deforestation occurs. Deforestation on the floodplains of the Rhine River in the Netherlands is no issue because there are hardly any forests there and those that are present are in low-velocity locations. But in the German and Swiss part of the Rhine River, the situation is less clear, and deforestation around the headwaters of rivers in the United States still happens.

There is a clear link between deforestation and land use changes. Deforestation often transforms forests into land for agriculture or for urban initiatives and extensions. In general, deforestation amplifies flood risk (Bradshaw et al. 2007). Surprisingly enough, and despite the previous line of reasoning, there is evidence that forest management (including road construction, ditching, logging, and soil compacting) may play a larger role in amplifying flood risk than the deforestation itself (European Commission 2013).

The most obvious NNBF measures in these cases, then, are direct revegetation and the restoration of vegetated habitats. 


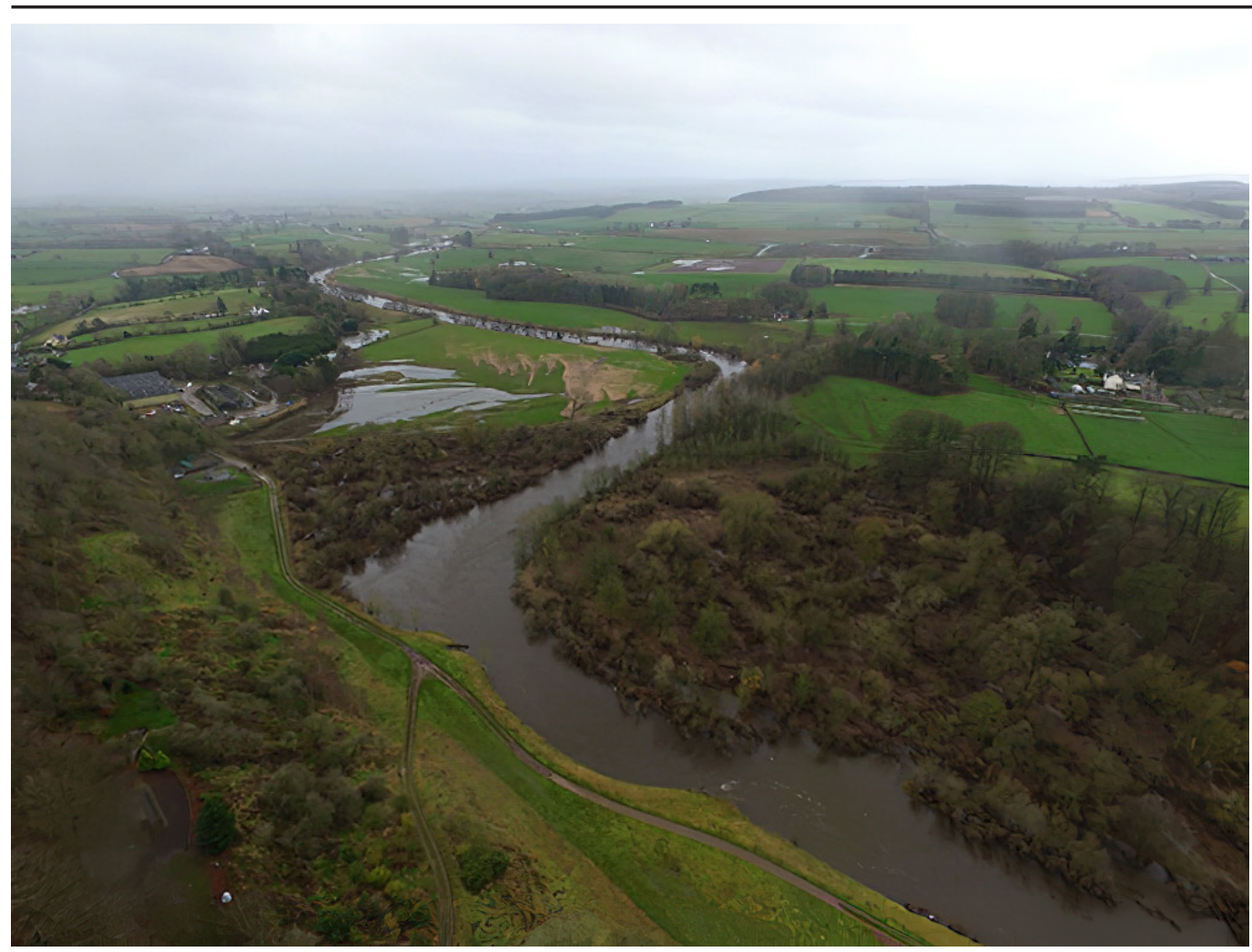

Source: Neil Entwistle

\subsubsection{Water Quality Degradation}

As noted in Section 17.2.2, human activity introduces into rivers and watersheds nutrients and synthetic organic materials in the form of fertilizers and pesticides. Largely related to the desire to increase agricultural productivity but also for pest control and aesthetic reasons in urban environments, these inputs are lost to the watershed and river after use.

Excessive application can cause fertilizer, pesticides, or their breakdown products to build up in watershed soils. Runoff mechanisms can move and concentrate these materials in a river, with watershed drainage moving them downstream and ultimately into the coastal zone. Common impacts from the use, and unintended release, of these products include eutrophication, changes in biodiversity, and downstream impacts in the coastal zone. 
Eutrophication is the process by which excessive nutrient loads lead to increased biomass growth (algae or plants). Groundwater can also be affected by nutrients or pesticides transmitted into aquifers by recharge. Fertilizer application and intensive livestock farming practices can lead to elevated nitrates in raw water, which requires additional treatment to remove the nitrates before the water is potable. Nutrient and pesticide use can also affect biodiversity. Plant, algal, invertebrate, fish, and animal communities have all demonstrated impacts caused by nutrients and synthetic organic materials as they move up the food chain.

Rain and melting snow flows from paved streets, parking lots, bare soil, lawns, and agricultural land toward smaller creeks and, ultimately, rivers. As this water flows, it collects what it encounters, including soil; plastics; pesticides; oil and grease; fertilizer, including nitrates and phosphates; other effluents; and litter. It is obvious that, once in the river, these materials may degrade the water quality and associated wildlife opportunities. If their concentration is too high, certain chemicals and effluents might pose a health risk at potable water intakes. They may also increase algae blooms and eutrophication. Toxic elements can also attach to sediment particles and be released at a later time or place, making the sediment another source of pollution.

\section{Figure 17.7. Detail of Wastewater Inflow in a River in the Netherlands}

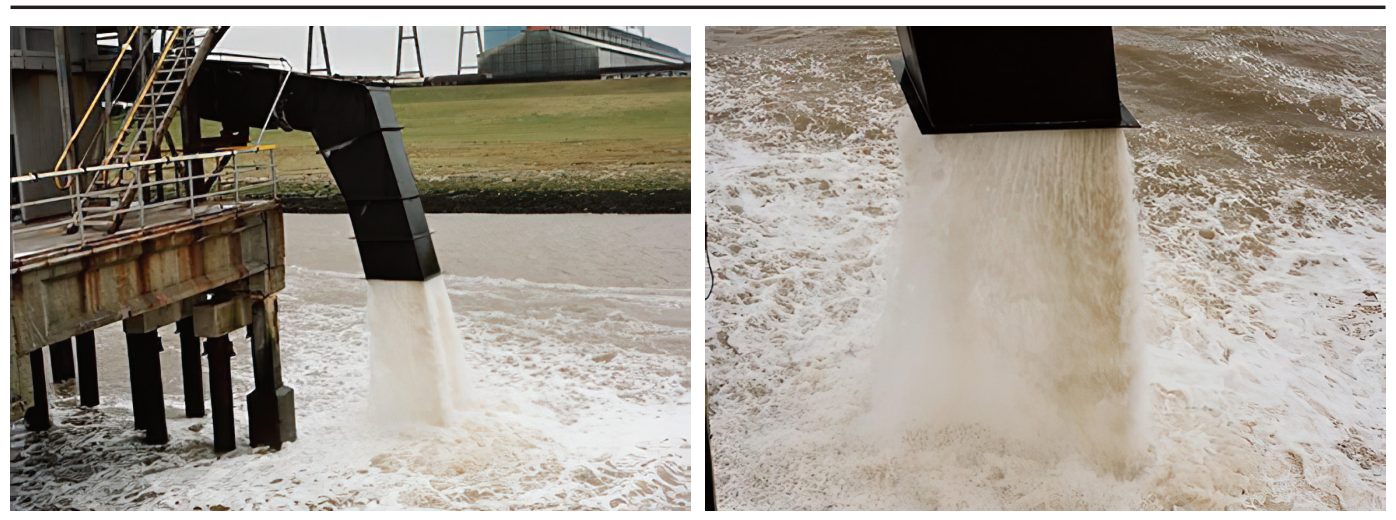

Source: Bart van Eyck, Rijkswaterstaat

The ability of NNBF to establish more stable river and watershed systems in dynamic equilibrium by capturing or slowing the release of nutrients and synthetic organic materials-along with efforts to reduce or end their use-can do much to reduce the water quality challenges listed in Table 17.1. One way to do this is to restore the functioning of riparian filters. 


\subsubsection{Saltwater (Tidal) Intrusion and Effects on Potable Raw Water}

Saltwater intrusion in river deltas (see Figure 17.8 for an example of a tidal inlet in Chile) through the various branches of an estuary is a natural phenomenon. In general, land use will fit with the circumstances of the estuary and the presence of salt or brackish water. The change in conditions within the system (i.e., the state of the estuary or sea-level rise) can increase the landward intrusion of salt water, causing problems for existing agricultural activities and the potable water supply. It is obvious that sea-level rise will increase saltwater intrusion as long as there is an open connection between the sea and a river. Longer and more intense periods of low river discharge also increase saltwater intrusion because the low fluvial flows provide less pressure against the salt water. Mitigation approaches include increasing the fluvial water supply by applying different transport routes. This is done in the Netherlands, for example, by a system of pumps and smaller canals that redirect potable raw water from other rivers, canals, and lakes.

\section{Figure 17.8. Mouth and Tidal Inlet of the Biobío River in Concepción, Chile}

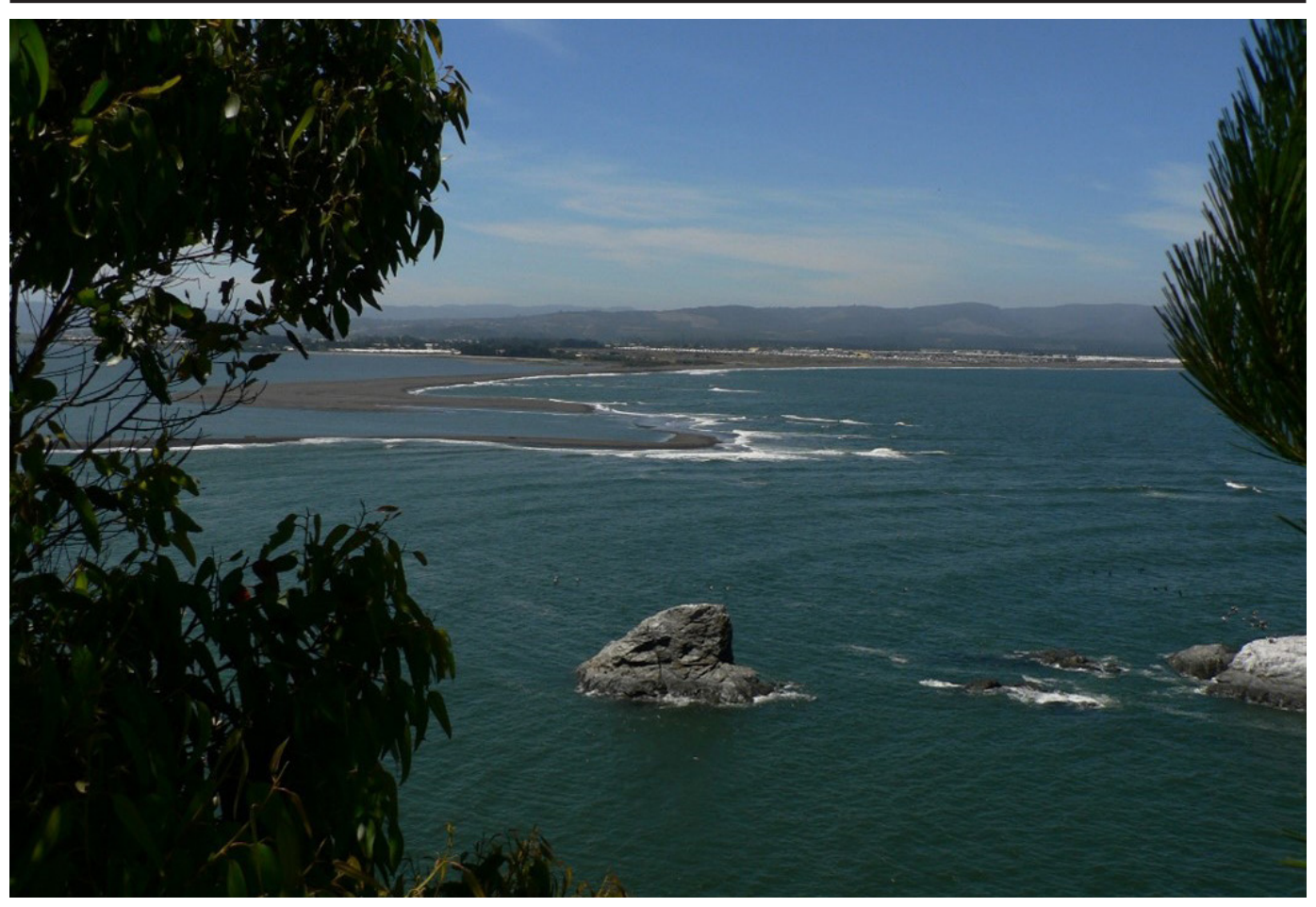

Source: Ralph Schielen, Rijkswaterstaat 
Not all rivers have an open connection to the sea. In the United Kingdom, for instance, almost all rivers have barriers at some point in their estuaries that prevent saltwater intrusion altogether. Potable water intakes are located upstream of these barriers. In those circumstances, low fluvial discharges in rivers or sea-level rise do not immediately cause problems with potable raw water supplies.

Other than on a conceptual level, there are no NNBF that specifically counteract saltwater intrusion. Any NNBF that increase infiltration of water so that aquifers are recharged, and hence the base discharge level of a river is increased, will help ameliorate the problem of saltwater intrusion. This is especially the case for smaller-scale watersheds, those typically with mainstems less than 100 kilometers long. Measures that increase the river discharge in times of low discharges (e.g., by rerouting water from an adjacent river branch or opening weirs) also help to counteract the intrusion of the saltwater wedge. It is questionable, however, if NNBF are able to contribute to this.

\subsubsection{Hydropower Plants, Dams, and Other Hydraulic Structures}

Almost all rivers have greater or smaller dams or other impoundments such as weirs. Europe's Rhine River has 12 dams, constructed over 83 years. The Mississippi River, in the United States, has 29 dams. Often, dams have multiple functions, such as generating hydropower and providing flood control. Among the main drawbacks of dams are that the natural variation in flow velocity vanishes and the inundation of the floodplain becomes limited. As a result, biodiversity is affected (e.g., fish passage is obstructed, and fish spawning areas are destroyed) and the quality of the floodplain soil deteriorates. 


\section{Figure 17.9. Hydropower Installation in Quilleco, Chile}

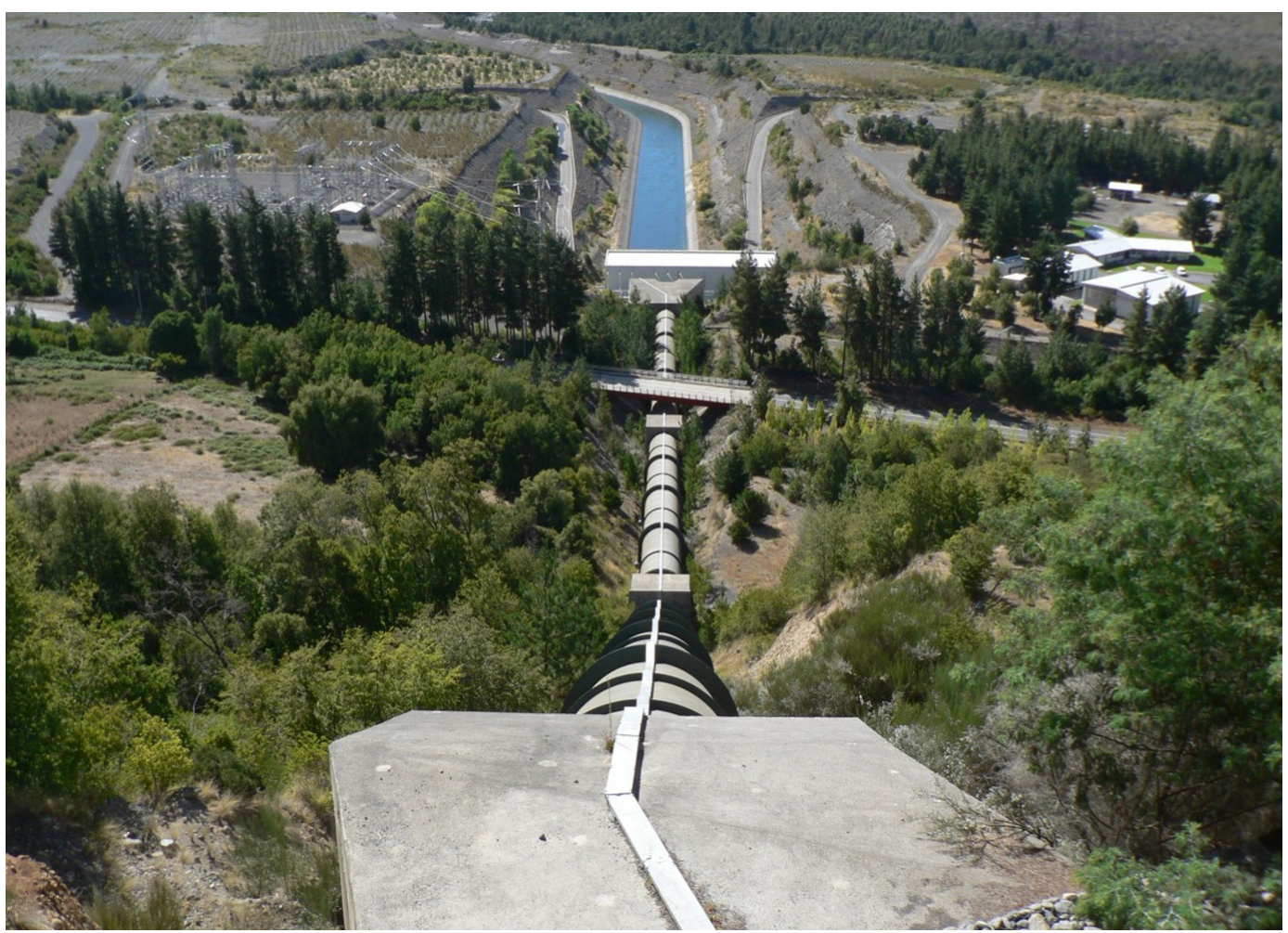

Source: Ralph Schielen, Rijkswaterstaat

More important, however, is the fact that dams block sediment transport in the river. Sediment supplied from upstream settles in the lake due to the slow flows. As the sediment slowly fills the lake, the dam's functionality is impeded. A common mitigating measure is to flush the lake, although this exacerbates environmental problems associated with large quantities of sediment being supplied downstream.

Trapping sediment in the lake also causes major problems with natural erosion and sedimentation patterns downstream of the dam. The balance between sediment transport and sediment supply is disturbed. Although the river has a predictable and consistent transport capacity downstream of the dam, the supply of sediment is close to zero. That means extensive erosion will occur downstream, leading to bed incision. One way to overcome this is to nourish the river with sediment from the basin itself or from elsewhere. These are, however, expensive measures that will need to be carried out as long as the dam is in place. Furthermore, the composition of the sediment is important; nourishment with sediment that is too coarse might increase erosion downstream. 
There are no typical NNBF measures to solve the problems related to this challenge. Removing the structure is an obvious first step, but several other measures must be taken to restore a balanced hydraulic, morphological, and ecological situation.

Section 17.3 addresses some broader considerations that apply when planning or using NNBF, regardless of the location or scale.

\section{3 | Constraints in the Application of Fluvial NNBF}

The key concepts and considerations related to NNBF introduced at a rather high level in Section 16.3 of Chapter 16 led to some general principles to consider when applying NNBF. The previous section discussed in more detail the challenges in river management that can benefit from NNBF. This section discusses the constraints that must be considered when applying NNBF regardless of scale and location.

\subsubsection{Need to Respect Hydraulic and Morphological Principles When Applying NNBF}

The measures that we consider in this International Guidelines on Natural and Nature-Based Features for Flood Risk Management are meant to reduce flood risk. The fact that they are NNBF implies that there are co-benefits and added values. The specific characteristics of an NNBF depend on its location within the watershed.

In the headwaters of larger rivers, or in smaller tributaries or small streams, the goal is to slow the flow, reduce runoff, and decrease peak discharges. These measures also affect sediment management. Most often, sediment is retained in the subwatershed, decreasing downstream morphological problems, such as excessive sediment flows or mud streams, in times of high discharge. Over the longer term, retaining sediment upstream may lead to incision downstream.

In larger rivers, which often are protected by engineered levees or embankments, the goal is to reduce peak water levels by increasing discharge capacity. There will be a morphological response in the main channel and on the floodplains. The main channel generally will aggrade, and the floodplains will silt up due to more frequent inundation. Although these principles are in general true, whether the decision is taken to increase discharge capacity depends on a country's traditions and practices. In the Netherlands, the principles are widely used and are at the base of large restoration programs like Room for the River. In the United Kingdom, side channels have been applied, such as at the Jubilee River. The Jubilee River alleviation 
scheme diverts from the Thames River, bypasses Maidenhead, Windsor, Eton, and Cookham, and rejoins the Thames River again. Such measures are more effective in mildly sloped rivers like the Rhine River (which has an average fall of approximately 11 centimeters per kilometer) than steeper rivers like the Thames River (with a fall of approximately 32 centimeters per kilometer). The efficiency of discharge-increasing measures strongly reduces closer to the estuary and sea. This is not to say that these measures cannot be used in steeper rivers, which is demonstrated by the example in the Jubilee River.

\subsubsection{Need to Recognize the Varying Spatial and Temporal Effectiveness of NNBF Measures}

The range of discharges over which a measure works (e.g., low flows, floods, or both, or the full range of discharges, from low to high) also has implications for its short-term, mid-term, and long-term hydraulic and morphological effects. Not all NNBF measures are effective immediately after construction. Measures that involve natural vegetation (e.g., planting trees or introducing other forms of vegetation) may take months to years before they are effective. A floodplain restoration project, for example, may start to perform immediately after completion-or a few months after vegetation has grown-but a reforestation measure may require years or even decades to have its full impact.

\subsubsection{Operations and Maintenance of NNBF}

Operations and maintenance of NNBF measures will be different in larger rivers than in smaller streams or tributaries. Restoration measures in engineered rivers protected by levees or embankments often are located in the floodplain. For example, floodplains may be excavated to reconnect them with the river's main channel, or vegetation may be reintroduced where there is little interaction with the flow. The ecology and morphology of these measures should be monitored carefully to determine when maintenance is necessary (see Chapter 7 for more information).

Maintenance is needed when vegetation develops above predefined thresholds, such as stem length or hydraulic roughness. In that case, friction due to the presence of vegetation causes floodwater levels to rise and makes maintenance necessary (e.g., cutting back the vegetation, possibly by means of cyclic rejuvenation; Baptist et al. 2004). The same holds for morphological developments in newly constructed side channels. Over time, side channels aggrade (Van Denderen et al. 2018), and after some years (depending on the history of discharges) maintenance dredging may be necessary. Again, proper monitoring is essential for this decision. Monitoring data for large and small systems can also be used to assess increases 
in co-benefits such as biodiversity or opportunities for recreation. Very often monitoring is underestimated and the budget for monitoring is limited, which hampers operations and maintenance. For more information on performance, metrics, and the necessity of proper monitoring, see chapter 5 .

\subsubsection{Implications of NNBF Measures for Navigability}

Shipping is one of the most prominent economic drivers for large rivers. The Waal River in the Netherlands, the most important branch of the Rhine River, is the most intensively used navigation way in Europe, traveled by approximately 110,000 vessels per year (an average of one vessel every 5 minutes) transporting 155 million tons of freight (Bureau Voorlichting Binnenvaart 2015). In the United States, the Mississippi River is the most important river and carries between 560 million and 580 million tons of freight per year (U.S. Army Corps of Engineers 2012). The Thames River is the most important inland waterway in the United Kingdom and handles more than half of all traffic on United Kingdom waterways (26.7 million tons in 2017; Department for Transport 2018). Maintaining the rivers to guarantee this economic activity in times of low and high discharges is important. Channel width and depth must be adjusted to meet shipping requirements, including the following:

- A clear navigational channel, either straight or with a maximum planform radius related to vessel size

- Minimum navigable depths maintained as required by groins, longitudinal bunds, or dredging

Therefore, the long-term morphological development of the rivers should not significantly limit shipping. Under normal conditions, periods of high discharge-a single wave or a combination of waves-may lead to local sedimentation patterns (depending on local variations in river width) that might hinder navigation in times of low discharge. This sediment is often dredged. If the dredged material is removed from the system, incision will increase because the river's transport capacity remains unchanged. Therefore, in the Netherlands and many countries, the dredged material is recycled and dumped upstream where it will not hinder navigation and from where it will be gradually added to the river by the system's natural dynamics.

NNBF measures-especially those that affect the width of a river-can also lead to additional morphological changes in the main channel and, hence, to increased dredging activity or, if that is not possible, to reduced vessel loads. Therefore, there is a tension between the application of NNBF, which also provides ecological co-benefits, and the economic activities of navigation. 


\subsubsection{The Regulatory Framework Controlling the Use of NNBF}

Laws, regulations, land ownership, and obligations to maintain land to control flood risk differ throughout the world. In some countries (e.g., the Netherlands), the government is legally permitted to take action to guarantee that flood risk measures can be constructed. In other countries (e.g., Sweden), landowners are responsible for maintaining levees and embankments. Because the rules differ from country to country, they should be considered when planning NNBF because they might significantly affect the complete cycle of proposing, planning, constructing, and evaluating projects.

Sometimes, modifying the regulations to facilitate the introduction of NNBF may be desirable. For example, in the United States, Section 1184 of the 2016 Water Infrastructure Improvements for the Nation Act introduced a requirement that NNBF be considered in all federal FRM and hurricane and storm damage-reduction projects.

\section{4 | The Benefits of NNBF}

Besides providing FRM benefits, NNBF can deliver a range of co benefits. Chapter 6 addresses those benefits in a general fashion, whereas this section takes a more detailed look at the co-benefits fluvial NNBF can provide. Co-benefits, also called "multiple benefits," "ecosystem services," or "goods and services," are benefits that humans derive from the natural environment and healthy ecosystems (see Daily 1997 and Boyd and Banzhaf 2007).

Documenting NNBF's primary FRM benefits and its co-benefits is vital when promoting NNBF to stakeholders and other decision-makers who provide resources and project funding. Although in the past the co-benefits associated with NNBF-based projects typically were not documented, it is essential to assess not only FRM but also the full suite of social, environmental, and economic co-benefits. There are important factors to consider when assessing the range of benefits from NNBF projects. Among them are the scale of the NNBF application, the type of project, the features to be included, and the local or regional influences on physical landscape processes associated with FRM (Habersack, Schober, and Hauer 2015; Lane 2017; Wilkinson et al. 2019).

There is a wide variety and scale of NNBF that are applied singularly or in combination and have different effects on FRM benefits. Table 17.2 shows three common types of NNBF and describes each one's benefits, physical processes, and typical performance factors. 
Table 17.2. Examples of Differing NNBF Spatial Scales for Levee Setbacks, Naturalization of Channel Design, and Watershed Treatments

\begin{tabular}{|c|c|c|}
\hline Type of NNBF & Benefits/processes & Performance factors \\
\hline Levee setback & $\begin{array}{l}\text { Decreased flood levels and velocities } \\
\text { - Reduced frequency of maintenance } \\
\text { and repair on levee } \\
\text { - Reduced navigational maintenance } \\
\text { - Reduction of erosion and scour and } \\
\text { operations and maintenance costs } \\
\text { - Increased recreational, cultural, and } \\
\text { educational opportunities }\end{array}$ & $\begin{array}{l}\text { - Amount of new floodplain affects } \\
\text { hydrologic loading } \\
\text { - Alignment options for improved hazard } \\
\text { mitigation } \\
\text { - Ecological goals of project with } \\
\text { increased floodplain connection } \\
\text { - Collaboration with stakeholders and } \\
\text { other federal agencies }\end{array}$ \\
\hline $\begin{array}{l}\text { Naturalization of } \\
\text { channel design }\end{array}$ & $\begin{array}{l}\text { Reduced frequency of maintenance } \\
\text { and repair on levee and restoration } \\
\text { projects } \\
\text { - Naturalization of flow regimes and } \\
\text { floodplain reconnection } \\
\text { - Ecological benefits to floodplain } \\
\text { habitat } \\
\text { - Reduction of erosion and scour and } \\
\text { operations and maintenance costs } \\
\text { - Increased recreational, cultural, and } \\
\text { educational opportunities }\end{array}$ & $\begin{array}{l}\text { - Type of practice determines hydrologic } \\
\text { loading } \\
\text { - Practice determines options for } \\
\text { improved hazard mitigation, erosion } \\
\text { control, and streambed and bank } \\
\text { stability } \\
\text { - Collaboration with stakeholders and } \\
\text { other federal agencies } \\
\text { - Sediment management options }\end{array}$ \\
\hline $\begin{array}{l}\text { Watershed } \\
\text { treatments }\end{array}$ & $\begin{array}{l}\text { - Naturalization of hydrologic watershed } \\
\text { regimes } \\
\text { - Reduced navigational maintenance } \\
\text { - Reduction of operations and } \\
\text { maintenance costs } \\
\text { - Increased recreational, cultural, and } \\
\text { educational opportunities } \\
\text { - Reduced frequency of maintenance } \\
\text { and repair on levee and restoration } \\
\text { projects }\end{array}$ & $\begin{array}{l}\text { - Watershed management options } \\
\text { determine effects on hydrologic } \\
\text { loading } \\
\text { - Practice determines options for } \\
\text { improved hazard mitigation, upland } \\
\text { erosion control, upland erosion control, } \\
\text { and groundwater recharge } \\
\text { - Sediment management options } \\
\text { - Collaboration with stakeholders and } \\
\text { other federal agencies }\end{array}$ \\
\hline
\end{tabular}

NNBF for FRM benefits occur across a wide range of spatial scales. A simple example of providing co-benefits associated with ecological enhancements to project design is adding natural materials to the upstream surface of a loose-rock, riffle-grade control structure to provide spawning habitat for fish. The primary FRM benefits were stabilizing the stream bed and reducing sedimentation downstream (effectively lowering the water-surface profile) and re-establishing access to the floodplain to allow flood flows to naturally dissipate energy and cycle nutrients and sediment across the floodplain. The additional benefit of expanded spawning habitat could be obtained by enhancing an existing structure or implementing this enhancement in a new project design. 
Reintroducing floodplain connections by removing levees is an example of a larger-scale NNBF project. The project's primary FRM benefits are increased conveyance, reduction of peak flows, and retention and attenuation of floodwaters. Among its co-benefits are the re-establishment of groundwater recharge areas, nutrient recycling and sediment storage, and ecological enhancements for riparian functions including habitat for terrestrial and aquatic species. Figure 17.10 shows examples of the scale of NNBF applications and their effectiveness in affecting the existing hydrograph and flood peaks. These impacts will vary depending on the scale of the final NNBF. For example, levee removal or setbacks on small tributaries reintroduces floodplain connections that have less storage and hydrograph-reduction impacts compared to the flood reduction from larger levee setbacks downstream. Contextual watershed, valley, slope, geologic, and other considerations require further investigation when comparing final benefits. Figure 17.10 illustrates generalized trends in how NNBF options can affect flood peak reduction strategies and flooding magnitude.

Figure 17.10. Effects of NNBF on Flood Peak Reduction as a Function of Flood Magnitude

\section{NNBF Potential Flood Risk Reduction}

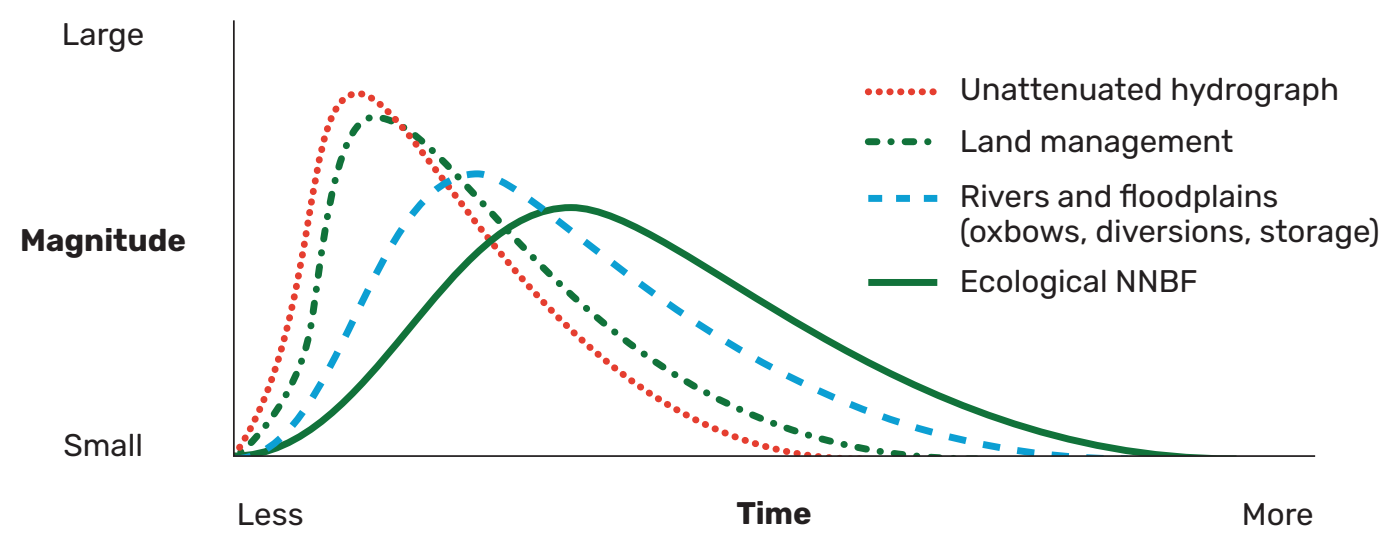

For example, NNBF in the upper portions of a watershed may include watershed treatments such as agricultural grassed waterways (Figure 17.11) or floodplain woodland plantings (Figure 17.12) to re-establish native floodplain conditions. The grassed waterways provide local erosion control benefits, whereas the floodplain woodland plantings increase floodplain roughness, effectively reducing flood flows, and provide nutrient cycling and increased deposition of sediments to the floodplain. If these measures are applied across a large enough area, they can beneficially influence watershed-wide hydrologic processes. However, these NNBF require extensive implementation and coordination at the watershed level, and their applicability typically varies from region to region. 
Figure 17.11. Agricultural Grassed Waterways in Bryant, lowa, United States

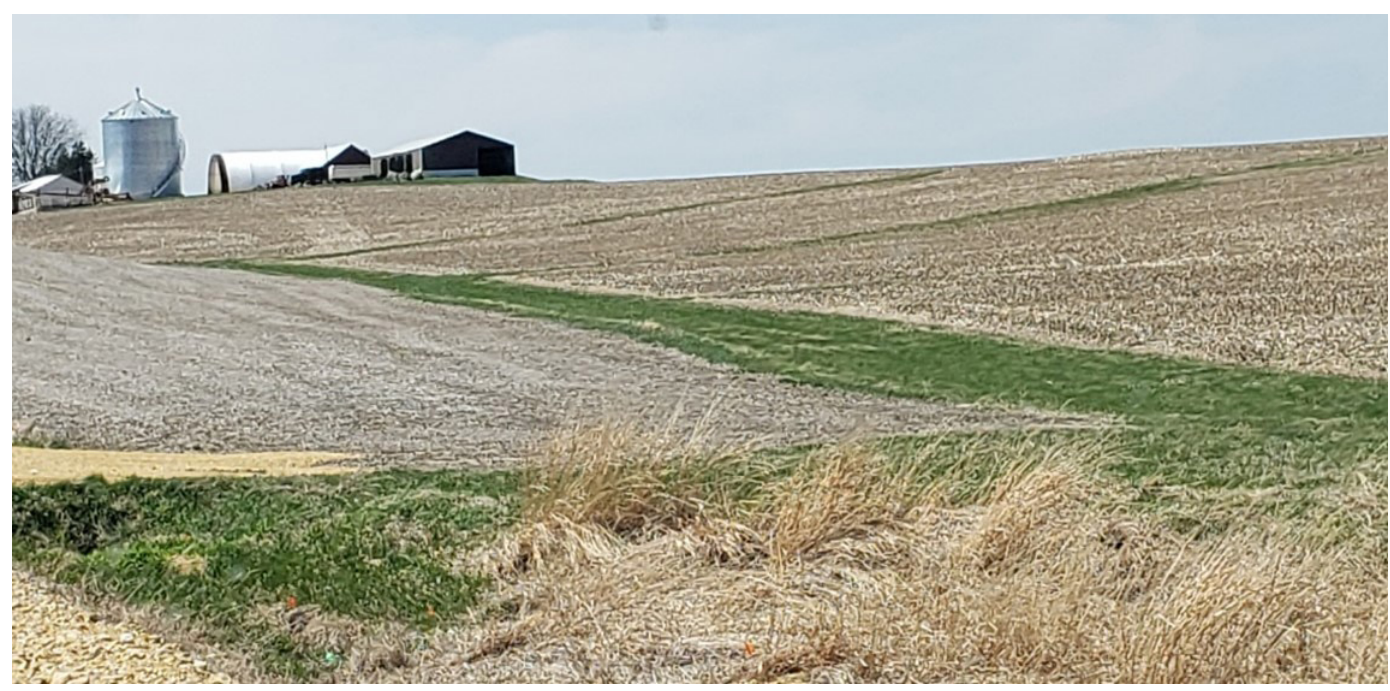

Source: Christopher Haring, U.S. Army Corps of Engineers

Figure 17.12. Floodplain Woodland Restoration in Galesburg, Illinois, United States

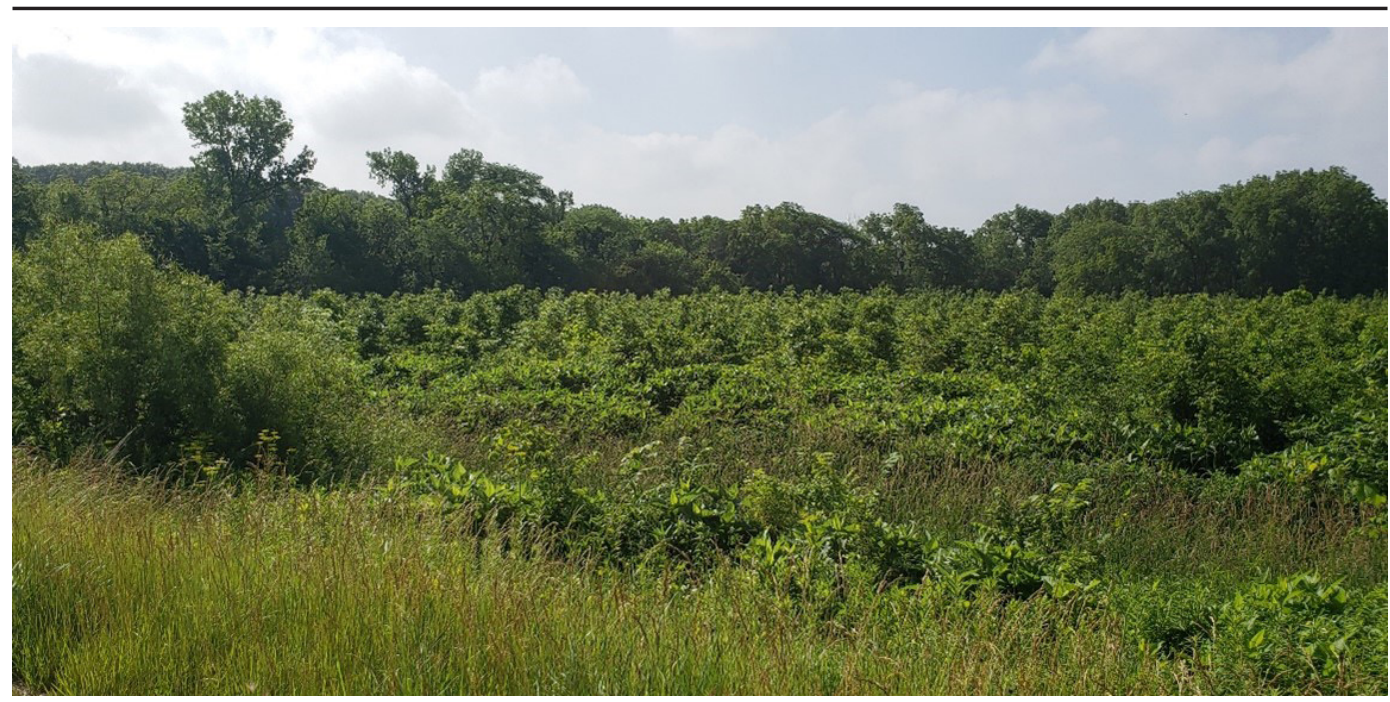

Source: Christopher Haring, U.S. Army Corps of Engineers 
One way to visualize benefits in a reproducible and objective way is to use "benefits wheels," which are discussed in greater detail in Chapters 18 and $\underline{19}$. Benefits wheels (Environment Agency 2017a; Figure 17.13) can be used to describe the services an NNBF could deliver. The benefits wheels are made up of 10 different benefit and co-benefit indicators that can be influenced by an NNBF. Each different benefit indicator is scored on a 1-to-5 scale according to the impact an intervention or measure can have on it. The higher the score, the greater the benefit. This semiquantitative ranking indicates the relative contribution a measure or intervention can make to the provision of certain benefits. Scores are assigned on the assumption that the measure or intervention is well planned, well designed, and well maintained. The scoring is undertaken collaboratively by the organization developing the NNBF project, its partner organizations, and local community groups. Scoring is qualitative, based on available knowledge of the river, its watershed, and the potential benefits of different types of NNBF. The benefits wheels developed for this document use the 10 benefit indicators used by the Environment Agency (in the United Kingdom) in its own NNBF guide (Environment Agency 2017a). However, when developing benefits wheels for future projects, the ecosystem service co-benefits listed in Table 17.3 should be reviewed and the co-benefits most relevant to the project under consideration should be used.

Figure 17.13 is an example of a benefits wheel for river restoration. In this case, the "Habitat" co-benefits of river restoration score a 5. "Flood (Fluvial)" benefits score a 4, and the "Air Quality" co-benefits of river restoration score a 1.

The benefits wheel in Figure 17.13 depicts visually the multiple benefits that can be achieved through river restoration. The wedges in this benefits wheel could be larger or smaller depending on how well the NNBF was designed and constructed. A poorly designed project could result in fewer benefits.

Ecosystem services are typically grouped into four categories (see Table 17.3). The colors

\section{Figure 17.13. Example of a Benefits Wheel}

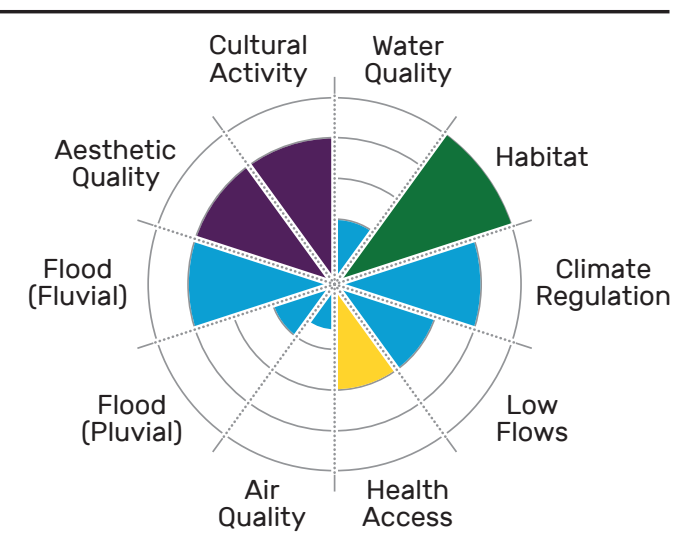

Cultural

Supporting

Regulating

\section{Provisioning} of the ecosystem services in Figure 17.13 correspond to the colors of the four groups in Table 17.3 into which they fall. 
Table 17.3. Ecosystem Services Co-Benefit Categories

\begin{tabular}{|c|c|c|c|}
\hline $\begin{array}{c}\text { Provisioning } \\
\text { services }\end{array}$ & Regulating services & $\begin{array}{l}\text { Cultural } \\
\text { services }\end{array}$ & $\begin{array}{l}\text { Supporting } \\
\text { services }\end{array}$ \\
\hline $\begin{array}{l}\text { Products that are } \\
\text { obtained from } \\
\text { ecosystems, such as } \\
\text { food, fiber, fuel, genetic } \\
\text { resources, biochemicals, } \\
\text { natural medicines, } \\
\text { pharmaceuticals, water, } \\
\text { and building materials }\end{array}$ & $\begin{array}{l}\text { Benefits obtained } \\
\text { from the regulation } \\
\text { of ecosystem } \\
\text { processes, such as air } \\
\text { quality maintenance, } \\
\text { climate regulation, } \\
\text { water regulation and } \\
\text { purification, erosion } \\
\text { control, waste treatment, } \\
\text { regulation of human } \\
\text { diseases, biological } \\
\text { control, pollination, and } \\
\text { protection from extreme } \\
\text { weather and climatic } \\
\text { events }\end{array}$ & $\begin{array}{l}\text { Nonphysical co-benefits } \\
\text { that humans obtain from } \\
\text { ecosystems through } \\
\text { spiritual enrichment, } \\
\text { cognitive development, } \\
\text { reflection, recreation, and } \\
\text { aesthetic experiences }\end{array}$ & $\begin{array}{l}\text { Services that are } \\
\text { necessary to produce } \\
\text { all other ecosystem } \\
\text { services (their impacts } \\
\text { on humans are indirect } \\
\text { or occur over a long time } \\
\text { period); examples are } \\
\text { atmospheric oxygen } \\
\text { primary production, soil } \\
\text { formation and retention, } \\
\text { nutrient cycling, water } \\
\text { cycling, and habitat } \\
\text { provision }\end{array}$ \\
\hline
\end{tabular}

Note: Co-benefits are grouped into four categories according to the types of ecosystem services they provide.

Table 17.4 lists the benefits and co-benefits most commonly achieved by NNBF in fluvial systems, which are discussed in Chapters 18 and 19 .

Table 17.4. Benefits and Co-Benefits Covered in Chapters 18 and 19

\begin{tabular}{llll}
\hline $\begin{array}{c}\text { Provisioning } \\
\text { services }\end{array}$ & Regulating services & $\begin{array}{c}\text { Cultural } \\
\text { services }\end{array}$ & $\begin{array}{c}\text { Supporting } \\
\text { services }\end{array}$ \\
\hline - Health access & - Flood risk (fluvial) & - Cultural activity & - Habitat provision \\
& - Flood risk (pluvial) & - Aesthetic quality & \\
& - Water quality & & \\
& - Climate regulation & \\
& - Low flows & \\
& Air quality
\end{tabular}

\section{5 | Overview of Fluvial NNBF Categories}

Implementing NNBF can greatly enhance an existing FRM system and provide sustainable designs. The purpose of such enhancements is to provide resilient engineering designs that not only increase ecosystem services but also provide additional FRM benefits. We consider the following NNBF categories (see also Figure 17.14) and point out that these categories can be combined in a specific intervention, and that that intervention can be located somewhere in the catchment. 
The following NNBF categories are depicted in Figure 17.14 and discussed in Sections 17.5.1

through 17.5.5, respectively:

- River and floodplain management

- Vegetation management

- Rural runoff management

- Urban runoff management

- Erosion management

Figure 17.14. NNBF Categories for Application in Fluvial Systems

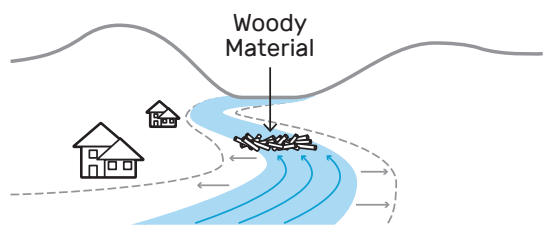

River and Floodplain Management

- Slows flood flows

- Encourages flood storage

- Creates bypasses to move water away from communities

- Provides ecological/aquatic habitat benefits

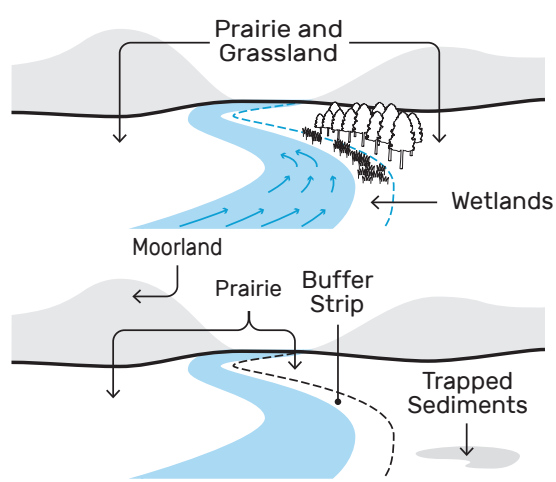

\section{Vegetation Management}

- Slows water

- Encourages infiltration in soil

- Enables evapotranspiration

- Increases roughness and slows flow

\section{Rural Runoff Management}

- Captures water flow

- Slows and stores water

- Encourages infiltration

- Traps sediments

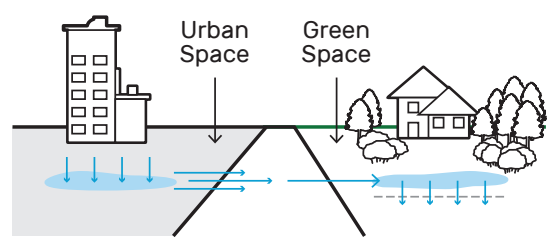

\section{Urban Runoff Management}

- Retains and stores water in green space

- Slows delivery of water to sewer system

\section{Erosion Management}

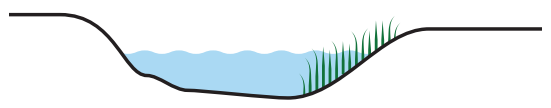

- Protects riverbanks

- Reduces erosion of banks

- Replaces hard engineering with vegetated banks 


\subsubsection{River and Floodplain Management NNBF}

River and floodplain management NNBF (as illustrated in Figure 17.15) include river and floodplain restoration with wetland and off-line storage options. These features provide a wide range of environmental and cultural co-benefits and may be applied to any part of a watershed with varying degrees of impacts or reductions in FRM. The river restoration features attempt to restore natural physical processes and features to the channel and adjacent floodplain. Floodplain and wetland enhancement features restore natural connections to floodplains, provide floodwater storage, and give aquatic species access to areas that were once naturally available. Off-line storage NNBF adapt and restore natural processes to retain and attenuate floodwaters in a managed way. Strategically placed and designed containment structures increase water storage, effectively reducing discharge downstream and providing FRM benefits to the watershed.

Note that in applying river and floodplain management NNBF, it is important to recognize their position in the catchment. Measures in the headwaters (upper catchment) intend to slow the flow by means of retention, tree planting, or leaky barriers. In the middle reach, where the discharge is generally higher, NNBF intend to increase (restore) discharge capacity to reduce peak water flood levels. Side channels are an example of such a measure. Although one can also increase the discharge capacity of a river by dredging the main channel (and hence, making the main channel deeper or wider), dredging as such is not normally considered to be an NNBF.

Figure 17.15. Schematic of River and Floodplain Management

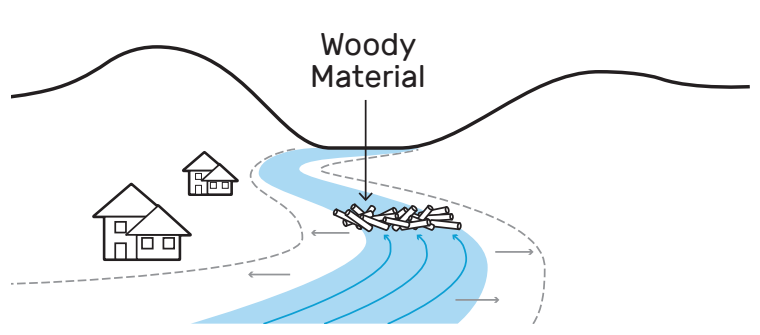

\section{River and Floodplain Management}

- Slows flood flows

- Encourages flood storage

- Creates bypasses to move water away from communities

- Provides ecological/aquatic habitat benefits

The following includes some of the many guides that give information on river and floodplain management NNBF:

- The NFM Manual (Wren et al., forthcoming)

- Building Community Resilience with Nature-Based Solutions: A Guide for Local Communities (Federal Emergency Management Agency 2020)

- Building with Nature: Creating, Implementing and Upscaling Nature-Based Solutions (van Eekelen and Bouw 2020) 
- Natural Flood Management Toolbox: Guidance for Working with Natural Processes in Flood Management Schemes (Environment Agency 2017a)

- Working with Natural Processes: Evidence Directory (Environment Agency 2017b)

- Implementing Nature-Based Flood Protection: Principles and Implementation Guidance (van Wesenbeeck et al. 2017)

- Natural Flood Management Measures: A Practical Guide for Farmers (Yorkshire Dales National Park Authority 2017)

- Natural and Nature-Based Flood Management: A Green Guide (World Wildlife Fund 2016)

- Natural Flood Management Handbook (Forbes, Ball, and McLay 2015)

- Manual of River Restoration Techniques (The River Restoration Centre 2013)

- Building with Nature: Thinking, Acting and Interacting Differently (de Vriend and van Koningsveld 2012)

In addition to these guides, the following are two relevant websites with links to an NNBF atlas, papers, podcasts, and more:

- Engineering With Nature (ewn.el.erdc.dren.mil 2021)

- Eco-Logical Approach (environment.fhwa.dot.gov 2021)

\subsubsection{Vegetation Management NNBF}

Vegetation management NNBF (illustrated in Figure 17.16) includes watershed-wide enhancements to woodlands, riparian corridors, prairies, meadows, and other natural landscape features. Some common practices are revegetation with native species, reduction of competing invasive species, and methods that reduce flows and naturally dissipate energy through vegetation alterations.

Figure 17.16. Schematic of Vegetation Management

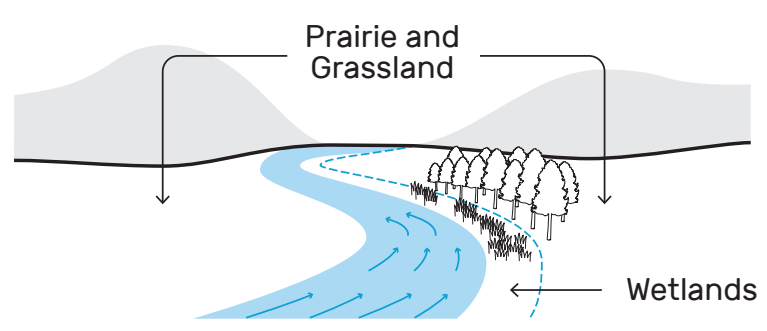

\section{Vegetation Management}

- Slows water

- Encourages infiltration in soil

- Enables evapotranspiration

- Increases roughness and slows flow 


\subsubsection{Rural Runoff Management NNBF}

Rural runoff management NNBF (illustrated in Figure 17.17) restore functions and processes that intercept overland flows and sediments, restore soils to help them store water, encourage infiltration and sediment deposition, and increase the hydraulic roughness and morphological complexity of rivers and floodplains. Common NNBF of this type include headwater drainage management, agricultural practices, and sediment traps.

\section{Figure 17.17. Schematic of Rural Runoff Management}

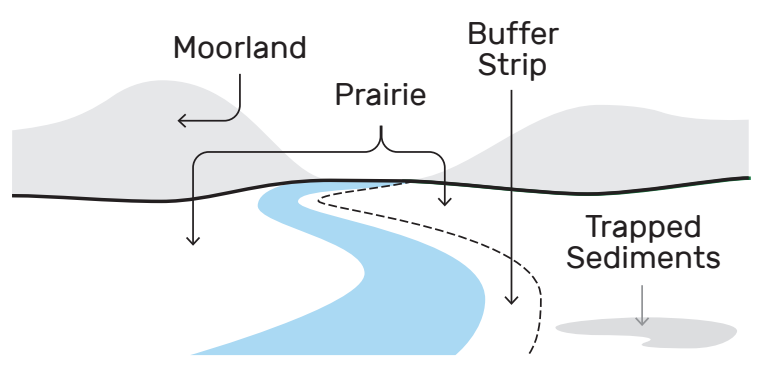

\section{Rural Runoff Management}

- Captures water flow

- Slows and stores water

- Encourages infiltration

- Traps sediments

\subsubsection{Urban Runoff Management NNBF}

Urban runoff management NNBF (illustrated in Figure 17.18) are used primarily to manage increased surface water runoff and the associated fluvial channels. Typical NNBF of this type increase water infiltration and water retention. They include permeable surfaces, rain gardens, retention and detention basins, and constructed wetland complexes.

Figure 17.18. Schematic of Urban Runoff Management

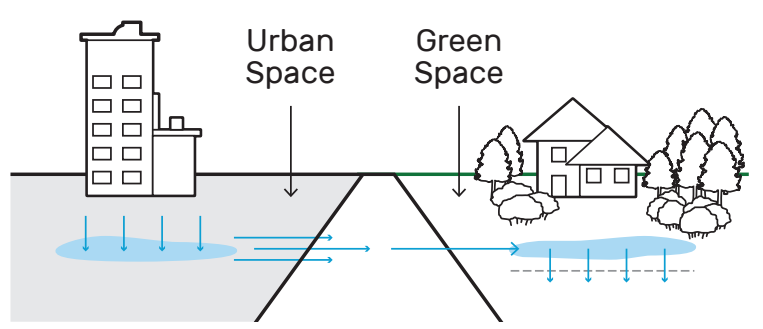

\section{Urban Runoff Management}

- Retains and stores water in green space

- Slows delivery of water to sewer system 


\subsubsection{Erosion Management NNBF}

Erosion management NNBF (illustrated in Figure 17.19) provide stabilization options for fluvial systems. There is a wide variety of NNBF in this category, including bioengineering and lower impact structural stabilization that includes more bioengineering methods.

Figure 17.19. Schematic of Erosion Management

\section{Erosion Management}

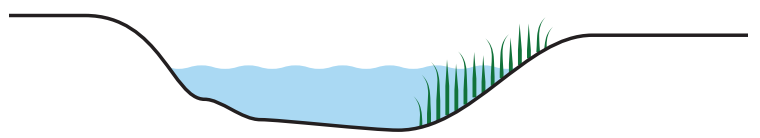

- Protects riverbanks

- Reduces erosion of banks

- Replaces hard engineering with vegetated banks

\section{6 | Best Practices in Selecting NNBF}

When selecting and constructing NNBF for flood risk reduction, several steps must be taken to achieve the greatest added value from the measure in the watershed or subwatershed. Not every NNBF can solve a specific problem. Some measures better (or only) fit in the upper catchment. Others may be applied in the middle or lower catchment. All the NNBF have specific co-benefits that may contribute to an increase in the natural values of the environment or enhance economical or recreational functions. The following proposed 11-step scheme might help in choosing appropriate NNBF measures:

\section{Step 1: Complete a system analysis.}

- An NNBF measure never stands alone but always fits within a larger system. Therefore, performing a system analysis before considering an NNBF is advisable. A systems perspective (see Chapter 4 ) is essential to understand and address the root causes of flooding. NNBF measures targeted at the scales at which they will operate will be much more effective than isolated measures sited in a nonstrategic manner (Dixon et al. 2016; Lane 2017).

\section{Step 2: Specify your specific challenge.}

- Setting a well-described objective or objectives (the societal goal) that solves for the specific challenge (or challenges) when the NNBF is applied is crucial. The co-benefits that are part of the predefined goal should be inventoried so the NNBF's efficiency and effectiveness can be assessed. Table 17.1 has information about possible associated co-benefits of NNBF. Table 17.1 can also be used as inspiration to define the objectives (e.g., reduce channel instability, improve water quality, or restore floodplains and wetlands). 


\section{Step 3: Locate your position in the catchment (upper, middle, or lower).}

- The objective in the upper catchment typically is to slow the flow by means of increased storage or infiltration, or by measures that partially block the flow (leaky dams, tree planting). In the middle catchment, where the discharge is usually larger due to the added discharge coming from the tributaries, the system is protected by (high) levees, and the economic development behind the levees is substantial. NNBF aims to increase the discharge capacity and, hence, reduce the floodwater levels. Because some NNBF aim to slow the flow, and other NNBF increase discharge capacity, the project's position in the catchment is important in the selection of NNBF.

- Headwater streams in mountainous alpine watersheds may provide only limited opportunities to apply NNBF because of the very steep slopes and limited available space. Slowing the river flow is often not possible because of the river's high velocities, any structures will likely be washed away, and the effects of any NNBF measures taken there are hardly noticeable downstream.

\section{Step 4: Create awareness of the challenge.}

- Awareness helps get support for solving a challenge. If a challenge is not yet recognized, a possible solution most probably will not get support from the public or will be debated or disputed by the public. This will lead to resistance in the planning and constructing procedure, and it might lead to legal action to prevent implementation of the NNBF measure.

\section{Step 5: Select a measure appropriate for your challenge and location in the catchment.}

- If the nature of the challenge and location in the catchment are clear, a measure that either holds back the flow or helps increase discharge capacity can be selected. Also consider the measure's co-benefits and whether they fit to the problem.

- Using NNBF, slowing the flow is generally the most beneficial approach in the headwaters of a watershed. For example, grass waterways, water and sediment control basins, ponds, and retention structures can be placed strategically in the upper (nonalpine) watershed to reduce peak discharges and lower flood risk downstream. These measures typically apply to small-scale, relatively steep watersheds but can also be used in urban areas to provide additional storage and reduce flood peaks as inflows increase due to the expansion of impervious areas. 


\section{Step 6: Formulate a design and involve stakeholders, nongovernmental organizations, landowners, and local authorities to get their support.}

- A balanced approach to stakeholder participation will help generate necessary support for a project during its design.

\section{Step 7: Select appropriate models to simulate the measure's effect.}

- Numerous hydraulic, morphological, and ecological models are available. A digital terrain model of the local geography is often a starting point for hydraulic and morphological calculations. Detailed topographical measurements made using lidar or other techniques, in combination with multibeam measurements of the river's bathymetry, are necessary inputs for digital terrain models. Hydraulic models can then be used to assess the discharges, velocities, and water levels resulting from the measure, and morphological models can be used to simulate morphological evolution. The outputs from the hydraulic and morphological models may be used as inputs for ecological or other models needed to assess the co-benefits of the measure.

- There should be a willingness to adjust the design of a measure if its modeled effects are not what was anticipated.

- Because modeling can be expensive, determination of modeling requirements needs to be scaled appropriately. Modeling can refer to hydrologic, hydraulic, morphological, ecological, permitting-related issues, and possibly other subjects. Small projects in rural areas do not require detailed models (because the risks and possible consequences are limited), whereas small projects in urbanized areas will require more detailed surveys and modeling (sometimes put forward in legislation).

\section{Step 8: Formulate a long-term plan to monitor specific processes and parameters including adaptive management.}

- Defining a proper monitoring scheme is essential to determine whether the goal set in Step 2 is reached and to assess whether the co-benefits considered in Step 5 are obtained. Anticipated use of complex hydraulic, morphological, and ecological models also sets demands on monitoring schemes (indicators, duration, and density). The well-described objective (Step 2) might also set extra demands on additional indicators to monitor.

- The reference situation (i.e., the conditions on the ground before the NNBF measure is implemented) should be measured for comparison to the results of post-construction, long-term monitoring to identify changes due to implementation of the measure. 


\section{Step 9: Make sure there is sufficient funding to construct the measure.}

- Once the cost-effective FRM benefits of an NNBF project are shown, all the funding and financing approaches available for equivalent gray measures (e.g., building a dam or a weir or constructing chevrons for river training purposes) become available to the NNBF effort. Funding and finance differ from country to country, but in general financial resources can come from traditional bonds (municipal, state, provincial, federal), new bonds (green bonds, climate resilience bonds), infrastructure banks, hazard mitigation funding, disaster recovery funding, and insurance.

\section{Step 10: After construction, implement the monitoring plan.}

- Post-construction monitoring should continue for at least several years to identify trends as a result of the implemented measure and to account for natural variability in the hydrograph. The effects of the measure should be monitored during periods of low, mid-range, and high discharges.

\section{Step 11: Regularly check whether the objective is being reached and the measure is working as anticipated.}

- Assessing a project's output is, at its simplest, determining whether the project was constructed as designed. The output may differ from the outcome, which is related to the societal goal put forward in Step 2. A project may score well on output but poor on outcome.

- Not all NNBF work the same way. Floodplain restoration, for example, generally means that, among other things, the discharge capacity of a river is increased so that flood levels are reduced. This happens as soon as the project is finished. However, if reforestation is used to increase biodiversity and counteract erosion, flood risk may increase because reforestation will increase hydraulic friction in the floodplain. And those effects of reforestation probably will not be seen right after construction because trees take time to grow, and years or decades may pass before the NNBF measure is fully functional.

- As at Step 7, there should be a willingness to adjust the design of a measure if long-term monitoring shows it is not functioning as anticipated and is not achieving the objectives set out for it.

Throughout the process of design, implementation, and evaluation, the principles of adaptive management may be taken into consideration to take into account risks and uncertainties. See Chapter 7 for a detailed discussion of adaptive management. 


\section{7 | Gaps and Future Directions}

There is increasing support for the use of NNBF in reducing flood risk. This increased support has identified knowledge gaps, which can shape and define the future direction for research to further embed NNBF as a technique for FRM. In this section, we indicate gaps that must be filled to further the application of NNBF and future directions for policy, research, and practice that contribute to closing these gaps.

\subsubsection{Observed Gaps in the Application of NNBF}

The following are observed gaps that must be filled to further the application of NNBF:

- There is a growing body of qualitative evidence that NNBF has multiple FRM co-benefits, but there is limited direct quantitative scientific evidence to demonstrate this. In part, this is due to the developing discipline of physical- and performance-based system understanding. Longer-term and higher-frequency system-wide monitoring will improve this performance-based system understanding. Chapter 6 provides more detail on the benefits of NNBF.

- Local residents, authorities, and nongovernmental organizations know their systems well. Using this knowledge and experience contributes to the acceptance of NNBF. The importance of local context is very well understood by local stakeholders; however, this context can sometimes be less visible at an institutional level. Processes that proactively explore and consider the benefit of local context maximize the benefits arising from the application of NNBF. Chapter 3 provides more detail on community engagement.

- With the increased use of NNBF comes a growing need to develop governance and assurance processes for business cases that propose their use. Increasing use of NNBF as a method of delivering FRM means governance and assurance processes need to evolve to properly assess NNBF, or hybrid, solutions against more traditionally engineered program or project options. This will involve actively expanding familiarity and knowledge of NNBF and optimization of capital and funding arrangements to ensure NNBF is considered equitably. Further study to identify and consider costs and benefits, especially co-benefits, provides an ideal opportunity to help tackle this challenge.

- Realization is needed that proposals to adopt the strategic use of NNBF need to be supported by, and navigate successfully through, institutional and governmental processes. NNBF as a method of FRM is increasing in maturity-with this comes the need for governmental and institutional processes to reflect this maturity in their strategic policy and tactical processes. There is a need for such organizations to align their corporate and delivery strategies to enable further uptake of NNBF. Without such alignment, the undoubted benefits of NNBF will not be adequately considered when setting strategic policy direction or tactical delivery of FRM programs. 
- The context of a catchment system, location within a catchment (headwaters, middle reach, delta), FRM approaches used by a country, and location of the country in the world need to be considered when assessing which NNBF measures will best address the challenge. NNBF measures always provide co-benefits, and it is for program or project stakeholders to decide the scale at which they will be delivered. All NNBF measures directly support sustainability, and the 231 unique indicators that make up the 17 United Nations' Sustainable Development Goals (SDGs). Identifying NNBF contribution to SDGs provides the ability to capture these benefits in business cases. Opportunity exists in this space to develop an objective NNBF assessment framework that also captures the contribution to United Nations' SDGs. Capturing these NNBF can, and will, be seen to contribute to the overall well-being of a country.

- It is clear that NNBF can contribute to mitigation of climate change impacts-either directly via provision of FRM and co-benefits, the inherent resilience of NNBF measures because they are natural or nature based, or avoided flood damages. NNBF make use of natural processes and, as a result, have a positive effect on mitigating climate change impacts, either due to the inherent circularity of natural materials many NNBF utilize, or material use avoided in comparison to more traditionally engineered program or project solutions. However, the collection of empirical evidence to support this is relatively new for the FRM sector, so there is a need to better quantify these climate change mitigation opportunities.

\subsubsection{Future Directions that Contribute to Motivating the Application of NNBF}

The following are future directions for policy, research, and practice that contribute to motiving the application of NNBF:

- To evaluate NNBF, there is a need for an objective, integrated assessment framework. This inspires a better understanding of the performance of NNBF by taking the empirical base to a more scientifically supported base. A next step would be to couple this framework with the United Nations' SDGs to demonstrate that NNBF contributes to more sustainable solutions, which deliver infrastructure that is resilient to climate change.

- Monitoring and adapting NNBF in regard to hydrologic, hydraulic, morphological, ecological, flood risk, governance, social support, and general well-being quantifies the added value of NNBF. At the planning stage, it is advisable to establish long-term monitoring and adaptive management plans (10 years and longer). Analysis of this data contributes to a general understanding of the functioning of NNBF. Chapter 7 provides more detail on adaptive management. 
- Solid support for NNBF is crucial for implementation. For this, insight into the interaction of local stakeholders, social networks, and nongovernmental organizations is vital. NNBF approaches should inspire new stakeholders and stimulate participatory decision-making.

- To a large extent, the scale of the catchment and the location (headwaters, middle reach, delta) in the catchment determine the nature of the NNBF measures that are most suitable. A better understanding of the properties individual NNBF contributes is needed to support best practice in the selection of measures. A proper assessment framework tool is needed to support selection. This especially holds for the application of NNBF in urban environments.

- Although there are models to quantify hydrologic, hydraulic, ecological, morphological, and other aspects of NNBF, there is a need to improve these models to reduce uncertainty. Focused benchmark model studies applied to localized case studies can improve existing models to provide clarity for NNBF applications and address uncertainty.

- There is great potential in the use of remote-sensing methods and application of unmanned aerial vehicles (drones). They can be used to rapidly develop digital terrain models, which, in turn, can be used to identify the most suitable NNBF measures. The data can be used to improve models for rapid assessment of river habitats in addition to post-project monitoring and adaptive management, contributing to an increase to our scientific knowledge of NNBF.

- Implementation of NNBF will be supported yet further by the direction of governmental and institutional strategies and evolution of governance and assurance processes. Evaluation and adaptation at all levels from policy to local law (international, national, federal, and local) will contribute to smoother planning and delivery of NNBF. In the future, NNBF should be an integral part of FRM evaluation, and assessment should be scaled to the size of the watershed and local conditions.

\section{8 | References}

Baptist, M. J., W. E. Penning, H. Duel, A. J. M. Smits, G. W. Geerling, G. E. M. van der Lee, and J. S. L. van Alphen. 2004. "Assessment of the Effects of Cyclic Floodplain Rejuvenation on Flood Levels and Biodiversity along the Rhine River." River Research and Application 20 (3). https://doi.org/10.1002/rra.778.

Blom, A., L. Arkesteijn, V. Chavarrias, and E. Viparelli. 2017. "The Equilibrium Alluvial River under Variable Flow and Its Channel Forming Discharge." Journal of Geophysical Research: Earth Surface 122 (10): 1924-1948. doi:10.1002/2017JF004213.

Boyd, J., and S. Banzhaf. 2007. "What Are Ecosystem Services? The Need for Standardized Environmental Accounting Units." Ecological Economics 63 (2-3): 616-626. https:// doi.org/10.1016/j.ecolecon.2007.01.002. 
Bradshaw, C. J. A., N. S. Sodhi, K. S. H. Peh, and B. W. Brook. 2007. “Global Evidence That Deforestation Amplifies Flood Risk and Severity in the Developing World." Global Change Biology 13 (11): 2379-2395. doi:10.1111/j.1365-2486.2007.01446.x.

Bureau Voorlichting Binnenvaart. 2015. Bevaarbaarheid van de Waal, nu en in de toekomst vanuit het perspectief van vaarweggebruikers en hun klanten [Navigability of the Waal River, Now and in the Future, Considered from the Perspective of Shipping and Their Customers]. The Blue Road duurzaam vervoer over water.

Calliari, E., A. Staccione, and J. Mysiak. 2019. "An Assessment Framework for Climate-Proof Nature-Based Solutions." Science of the Total Environment 656: 691-700.

canada.ca. 2016. Water Pollution: Erosion and Sedimentation. Government of Canada. https:// www.canada.ca/en/environment-climate-change/services/water-overview/ pollution-causes-effects/erosion-sedimentation.html.

Daily, G. 1997. Nature's Services: Societal Dependence on Natural Ecosystems. Washington, DC: Island Press.

de Vriend, H., and M. van Koningsveld. 2012. Building with Nature, Thinking, Acting and Interacting Differently. Dordrecht, NL: EcoShape, Building with Nature.

Department for Transport. 2018. Domestic Waterborne Freight: UK 2017. London: Department for Transport.

Dixon, S. J., D. A. Sear, N. A. Odoni, T. Sykes, and S. N. Lane. 2016. “The Effects of River Restoration on Catchment Scale Flood Risk and Flood Hydrology." Earth Surface Processes and Landforms 41 (7): 997-1008.

ewn.el.erdc.dren.mil. 2021. Engineering With Nature.https://ewn.el.erdc.dren.mil/.

Environment Agency. 2010. Working with Natural Processes to Manage Flood and Coastal Erosion Risk. Guidance Document. Bristol, UK: Environment Agency.

Environment Agency. 2012. Greater Working with Natural Processes in Flood and Coastal Erosion Risk Management: A Response to Pitt Review Recommendation 27. Bristol, UK: Environment Agency.

Environment Agency. 2017a. Natural Flood Management Toolbox: Guidance for Working with Natural Processes in Flood Management Schemes. Bristol, UK: Environment Agency.

Environment Agency. 2017b. Working with Natural Processes: Evidence Directory. Bristol, UK: Environment Agency.

environment.fhwa.dot.gov. 2021. FHWA Initiatives to Accelerate Project Delivery. U.S. Department of Transportation/Federal Highway Administration. https://www. environment.fhwa.dot.gov/env_initiatives/eco-logical.aspx.

European Commission. 2013. "Land Use Change and Land Management Influence Floods in Small Catchments." Science for Environment Policy, Thematic Issue: Flooding 40 (9). 
Federal Emergency Management Agency. 2020. “Building Community Resilience with NatureBased Solutions: A Guide for Local Communities." USA. https://www.fema.gov/sites/ default/files/documents/fema_riskmap_nature-based-solutions-guide_2020.pdf.

Forbes, H., K. Ball, and F. McLay. 2015. Natural Flood Management Handbook. Stirling, UK: Scottish Environment Protection Agency.

Grill, G., B. Lehner, M. Thieme, B. Geenen, D. Tickner, F. Antonelli, S. Babu, et al. 2019. “Mapping the World's Free-Flowing Rivers." Nature 569: 215-221. doi:10.1038/s41586-019-13799.

Habersack, H., B. Schober, and C. Hauer. 2015. “Floodplain Evaluation Matrix (FEM): An Interdisciplinary Method for Evaluating River Floodplains in the Context of Integrated Flood Risk Management." Natural Hazards 75 (1): 5-32.

Havinga, H. H. 2020. “Towards Sustainable River Management of the Dutch Rhine River." Water 12 (6): 1827. https://doi.org/10.3390/w12061827.

Hayes, D. S., J. M. Brändle, C. Seliger, B. Zeiringer, T. Ferreira, and B. Schmutz. 2018. “Advancing Towards Functional Environmental Flows for Temperate Floodplain Rivers." Science of the Total Environment 633: 1089-1104. https://doi.org/10.1016/j.scitotenv.2018.03.221.

Lane, S. N. 2017. “Natural Flood Management." WIREs Water 4 (3): e1211. https://doi. org/10.1002/wat2.1211.

Pattison, I., and S. N. Lane. 2011. “The Link between Land-Use Management and Fluvial Flood Risk: A Chaotic Conception?" Physical Geography 36 (1). doi:10.1177/0309133311425398.

Poff, N. L., B. P. Bledsoe, and C. O. Cuhaciyan. 2006. “Hydrologic Alterations Due to Differential Land Use across the Contiguous United States: Geomorphic and Ecological Consequences for Stream Ecosystems." Geomorphology 79: 264-285.

River Restoration Centre, The. 2013. Manual of River Restoration Techniques. Bedfordshire, UK: The River Restoration Centre. http://www.therrc.co.uk/manual-river-restorationtechniques.

Straatsma, M. W., A. M. Bloecker, H. J. R. Lenders, R. S. E. V. Leuven, and M. G. Kleinhans. 2017. "Biodiversity Recovery Following Delta-Wide Measures for Flood Risk Reduction." Science Advances 3 (11): e1602762. doi:10.1126/sciadv.1602762.

Tockner, K., and J. Stanford. 2002. "Riverine Floodplains: Present State and Future Trends." Environmental Conservation 29: 308-330. doi:10.1017/S037689290200022X.

USACE (U.S. Army Corps of Engineers). 2012. MR\&T 2011 Post Flood Report: Documenting the 2011 Flood, the Corps' Response, and the Performance of the MR\&T System. Washington, DC: U.S. Army Corps of Engineers.

Van Denderen, R. P., R. M. J. Schielen, S. G. Westerhof, S. Quartel, and S. J. M. H. Hulscher. 2019. "Explaining Artificial Side Channel Dynamics Using Data Analysis and Model Calculations." Geomorphology 327: 93-110. doi:10.1016/j.geomorph.2018.10.016. 
van Eekelen, E., and M. Bouw. 2020. Building with Nature: Creating, Implementing and Upscaling Nature-Based Solutions. Rotterdam, NL: NAi Publishers.

van Wesenbeeck, B. K., S. IJff, B. Jongman, S. A. B. Balog, S. M. Kaupa, L. V. Bosche, G. Lange, et al. 2017. Implementing Nature-Based Flood Protection: Principles and Implementation Guidance. Washington, DC: World Bank Group.

Wilkinson, M. E., S. Addy, P. F. Quinn, and M. Stutter. 2019. "Natural Flood Management: SmallScale Progress and Larger-Scale Challenges." Scottish Geographical Journal 135 (1-2): $23-32$.

World Wildlife Fund. 2016. Natural and Nature Based Flood Management: A Green Guide. Washington, DC: World Wildlife Fund.

Wren, E., M. Barnes, M. Janes, A. Kitchen, N. Nutt, C. Patterson, M. Piggott, J. Robins, M. Ross, C. Simons, M. Taylor, S. Timbrell, and D. Turner. Forthcoming. The NFM Manual. London: CIRIA.

Yorkshire Dales National Park Authority. 2017. Natural Flood Management Measures: A Practical Guide for Farmers. North Yorkshire, UK: Yorkshire Dales National Park Authority. 


\section{Acknowledgments}

\section{Lead Authors}

Ralph Schielen, Rijkswaterstaat, the Netherlands

Christopher Haring, U.S. Army Corps of Engineers, United States

Lydia Burgess-Gamble, Environment Agency, United Kingdom

Jo Guy, Environment Agency, United Kingdom

\section{Co-Authors}

Brian Bledsoe, University of Georgia, United States

Randy Mandel, Ramboll, United States

\section{Contributors}

Marta Roca Collell, HR Wallingford, United Kingdom

David Ramsbottom, HR Wallingford, United Kingdom

Jonathan D. Simm, HR Wallingford, United Kingdom 

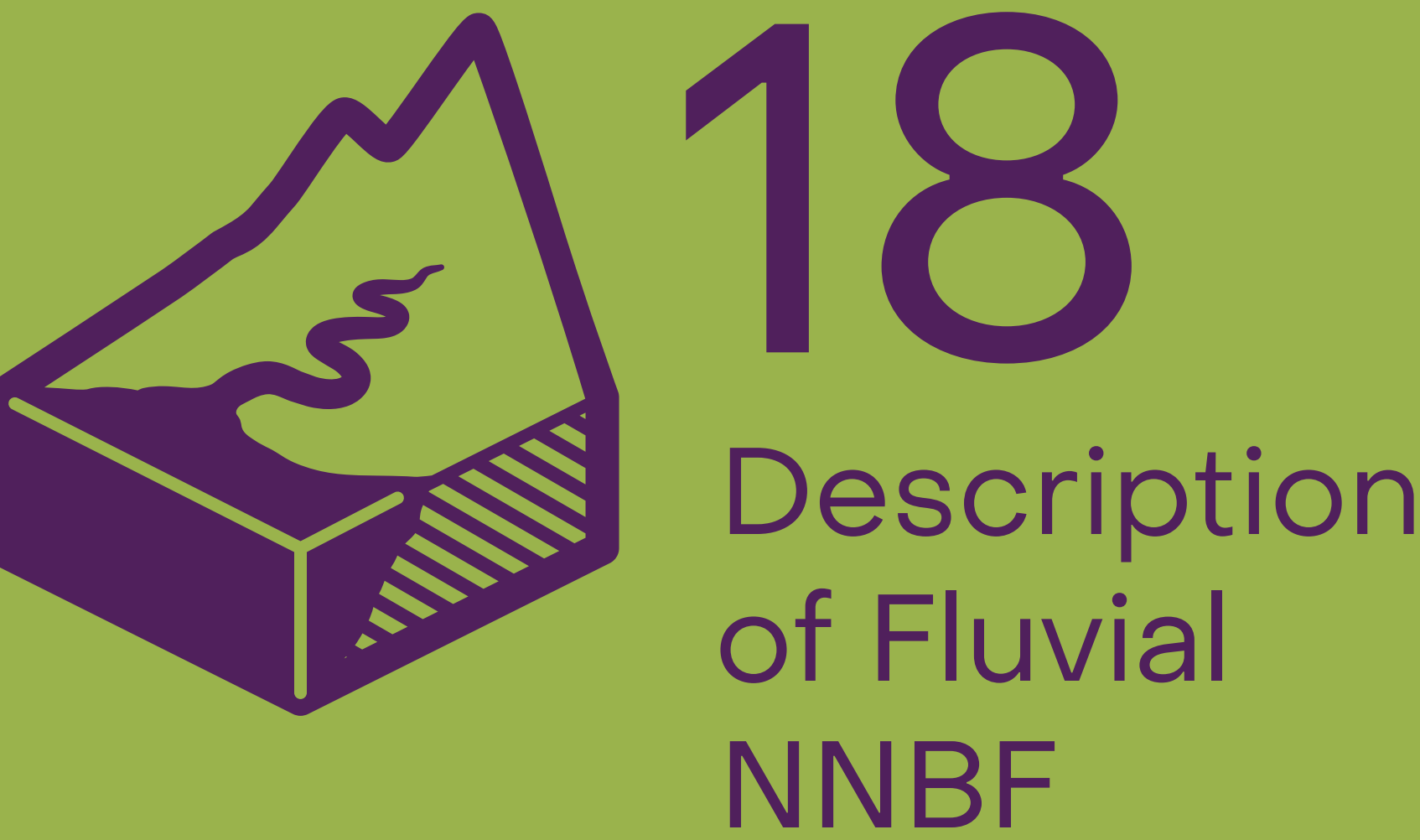

Suggested Citation:

Burgess-Gamble, L., C. Haring, R. Schielen, J. Guy, D. Ramsbottom, B. Woods Ballard M. Roca Collell, R. Glover, and F. Van Zoest. 2021. "Chapter 18: Description of Fluvial NNBF." In International Guidelines on Natural and Nature-Based Features for

Flood Risk Management. Edited by T. S. Bridges, J. K. King, J. D. Simm, M. W. Beck,

G. Collins, Q. Lodder, and R. K. Mohan. Vicksburg, MS: U.S. Army Engineer Research and Development Center.

Full acknowledgments appear at the end of this chapter. 


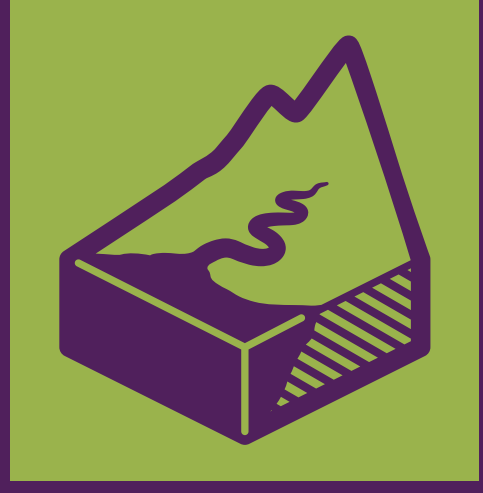

\section{Key Messages}

1. There are many different types of fluvial natural and nature-based features (NNBF) that can be used throughout a watershed to help reduce the risk of flooding.

2. Fluvial NNBF measures can be implemented in both rural and urban environments.

3. NNBF measures can be used alone. However, in many cases, they are most effectively used in combination with engineered flood risk management infrastructure, helping to enhance their resilience in the face of climate change.

4. Before selecting NNBF, it is important to fully understand the sources, pathways, and receptors of flooding because this will help in selecting the right measures to address the flood risk problems at their source.

5. In most circumstances, there will be no "silver bullet" solution to a flooding problem; instead, a range of NNBF will usually need to be implemented upstream of the area at risk of flooding.

6. NNBF measures can be designed in such a way that they not only reduce flood risk but also provide a range of co-benefits and help redress specific environmental challenges faced within a watershed. 


\section{1 | Introduction}

This chapter provides a description of fluvial natural and nature-based features (NNBF). As discussed in this International Guidelines on Natural and Nature-Based Features for Flood Risk Management publication, NNBF can help reduce flood risk by protecting, restoring, and emulating the natural functions of watersheds, floodplains, rivers, and coasts (Environment Agency 2010, 2012, 2017). NNBF can also provide wave attenuation by slowing the movement of water and waves over the feature. The fluvial section of this publication includes Chapters 15 through 19. Chapter 15 introduces the NNBF applications for fluvial settings. Chapter 16 describes fluvial systems and their relation to flood risk management (FRM). Chapter 17 describes the benefits and challenges associated with NNBF in fluvial systems, Chapter 18 provides an overview of the role and range of NNBF available for fluvial applications, and Chapter 19 provides case study examples of different types of fluvial NNBF applications from around the world.

NNBF takes many different forms (Figure 18.1) and can be applied in urban and rural areas and in small streams, rivers, estuaries, and coasts. This chapter covers and describes the different NNBF and their effect on flood risk, including the following:

- River and floodplain management

- Vegetation management

- Rural runoff management
- Urban runoff management

- Erosion management

The selection of the appropriate NNBF requires a watershed-wide understanding of the hydrological system, morphological and ecological processes, and history of changes that have occurred and any societal constraints. NNBF can have the following effects on flooding:

- Retain runoff from rainfall, thus reducing the downstream flow

- Increase the proportion of rainfall that infiltrates into the ground, thus reducing the amount of runoff from rainfall and, therefore, the downstream flow

- Delay the flow of water by reducing the velocity

- Retain sediments that could otherwise deposit in river channels, reducing their conveyance

- Decrease lowland floodwater levels by increasing conveyance capacity

The extent to which NNBF can reduce upstream, local, and downstream flooding depends on many factors including the magnitude of the storm (annual exceedance probability and duration); the morphological and ecological condition of the watershed; the number, size, and location of the NNBF; and the arrangement of the NNBF within the watershed. Environment Agency (2017), Oxford Martin School (2017), and POST (2014) describe in detail the scientific evidence behind the effectiveness of NNBF at reducing flood risk. To understand the effect of NNBF requires a systems approach, which needs an understanding of how the watershed functions and how it will interact with the hydrological cycle (for more information on a systems approach, see Chapter 4 ). 
Among the NNBF previously described for coastal flood risk reduction in this publication, wetlands are the most common NNBF that are also applied in fluvial systems. This chapter covers the following three types of wetlands relevant to fluvial systems:

- Freshwater floodplain wetlands (Section 18.2.2)

- Nonfloodplain wetlands constructed in the rural environment to trap overland flow and runoff from the land (Section 18.4.2)

- Constructed wetlands in the urban environment (Section 18.5.2)

Figure 18.1. Examples of NNBF in a Watershed

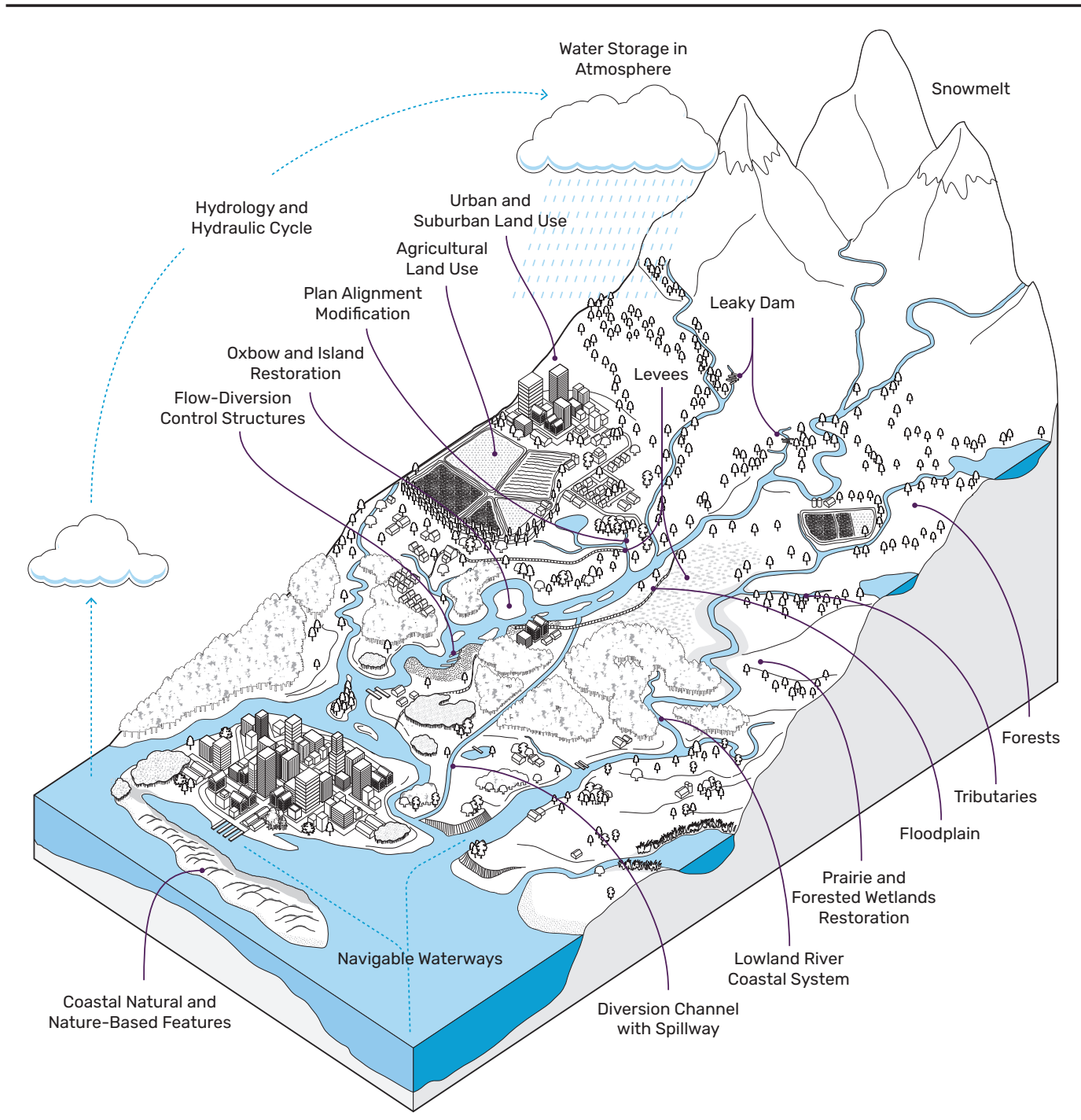




\section{2 | River and Floodplain Management}

Restoring the natural processes and NNBF within rivers and floodplains can provide a wide range of benefits for the environment and people. From an FRM perspective, these types of NNBF are often designed to increase the hydraulic roughness and morphological complexity of rivers and floodplains, which, in turn, slows floodwaters and reconnects rivers to floodplains to store water and provide co-benefits. These measures typically apply to smaller rivers and streams (e.g., in the United Kingdom), as well as tributaries of larger rivers.

This section also covers measures typically used in the Netherlands to increase the discharge capacity of larger rivers (e.g., the Rhine River, the Danube River, and the Mississippi River). Increasing the discharge rates accelerates the flow and lowers peak water levels. These measures do not involve increasing roughness but aim to widen the river.

In both cases, the measures can also modify sediment patterns, reducing potential negative impacts on channel conveyance.

Sections 18.2.1, 18.2.2, and 18.2.3, respectively, describe the following river and floodplain management NNBF:

- River restoration

- Floodplain and floodplain wetland restoration

- Off-line storage areas

The effects of these different types of river and floodplain management NNBF on flood risk are described in Figure 18.2 and Table 18.1.

\section{Figure 18.2. Schematic of River and Floodplain Management}

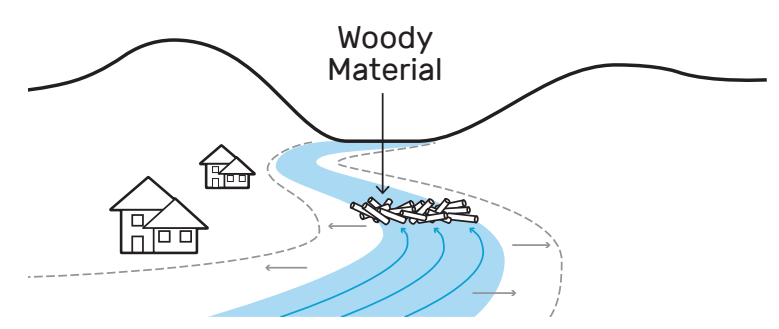

\section{River and Floodplain Management \\ - Slows flood flows \\ - Encourages flood storage \\ - Creates bypasses to move water away from communities \\ - Provides ecological/aquatic habitat benefits}




\section{Riparian buffer corridor area}

Riparian buffer strips along the tops of banks of watercourses can help to slow the flow of water off the land into the river. This can also help trap sediment and pollutants. Riparian buffer strips can also act as corridors for fauna and flora.

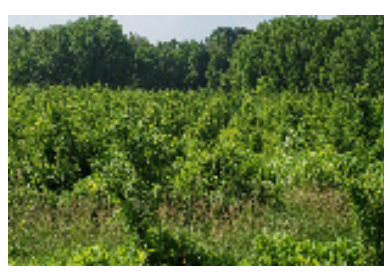

Photograph source:

U.S. Army Corps of Engineers (USACE)

\section{Off-line storage areas}

Off-line storage areas are floodplain areas adapted to retain and attenuate floodwater in a managed way. They usually include a containment bund and an inlet, an outlet, and potentially a spillway mechanism.

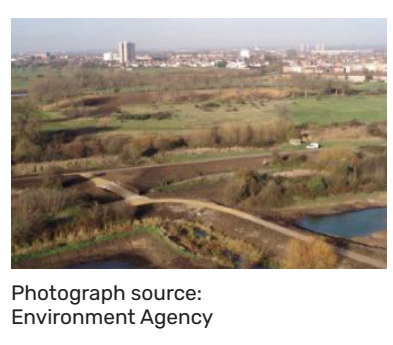

\section{Floodplain restoration and reconnection \\ (breaching and removal of embankments)}

Floodplain restoration aims to restore the hydrological connection between rivers and floodplains so they are inundated and store water during times of high flow. This can involve removing flood embankments and other barriers to floodplain connectivity.

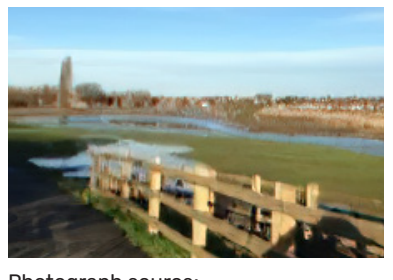

\section{Reconnection of oxbow lakes and similar NNBF}

Rivers have been altered throughout time; in many cases, old paleochannels and oxbow lakes can still be seen in the landscape. When rivers and floodplains are restored, there is the potential to restore the river along its old route, connecting it up past oxbow lakes.

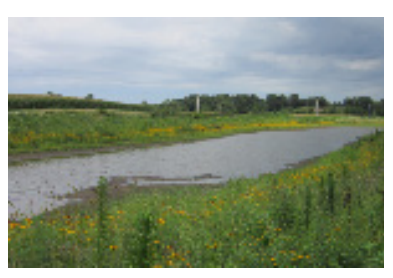

Photograph source: USACE

\section{Levee notching}

If there is no infrastructure behind a levee, holes can be added to allow water to access the floodplain during a flood and take the peak off the hydrograph.

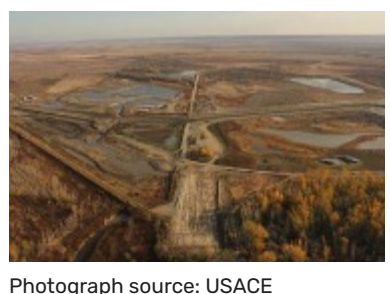

Photograph source: USACE 


\section{Removing obstacles from the floodplains}

In the past, many different structures have been constructed in floodplains that hinder the flow at high discharge. These can include, for example, small levees to protect farmland, local regulation works, hideaways for livestock, and ramps of bridges. Removing these obstacles increases the discharge capacity of the floodplain and lowers flood levels.

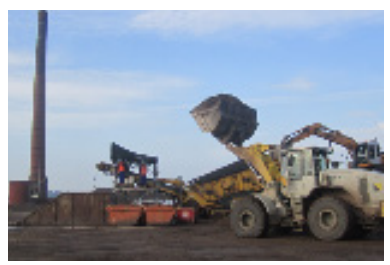

Photograph source: Rijkswaterstaat

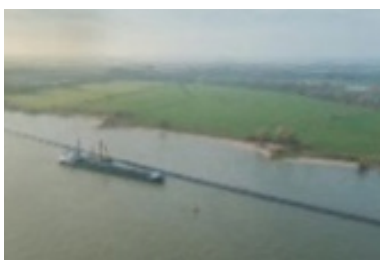

Photograph source: Rijkswaterstaat

\section{Longitudinal dams}

Longitudinal dams are structural walls that create a secondary channel in a river system. Although it is a gray solution, longitudinal dams involve creating side channels that can have a high ecological value. Conditions are more suitable for fish spawning (because the dam also limits the effects of ship-induced waves) and helps increase biodiversity. Longitudinal dams decrease flood levels (causing less friction than the groins) and ensure more navigational depth in periods of low discharge.

\section{Renaturalization of polder areas}

A polder is a low-lying tract of land enclosed by embankments or barriers known as dikes. Dikes form an artificial hydrological entity in which there is no connection between the watercourse and the land on the other side of the dikes, other than through manually operated devices. Renaturalization involves enhancing polders to better store water and provide habitat co-benefits.

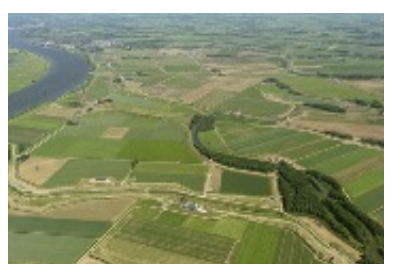

Photograph source: Rijkswaterstaat

\section{Loose-rock, riffle-grade control structures}

These measures are used in high-emergency systems in places where it is necessary to control and stabilize the streambed or stream banks.

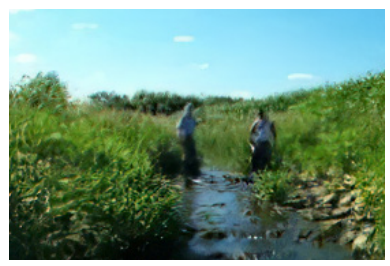

Photograph source: USACE

\section{Restoration and reconnection of seasonal streams}

Seasonal and ephemeral streams are watercourses that flow only at certain times of the year. Because they are often dry, they can be neglected with limited value placed on them. Their restoration and preservation can ensure that they provide an FRM function during times of high flow.

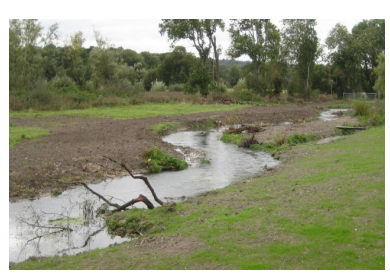

Photograph source:

Environment Agency 


\section{Lowering floodplains}

Over the past decades, navigation channels in many engineered rivers have been eroding at a rapid rate due to the use of river training measures and also due to sediment becoming blocked by dams or impoundments. This has resulted in floodplains becoming disconnected from the river system. Floodplain lowering reconnects the floodplains to the main channel, creating a more natural situation whereby the discharge capacity is increased and flood levels lowered. Floodplains also flood more

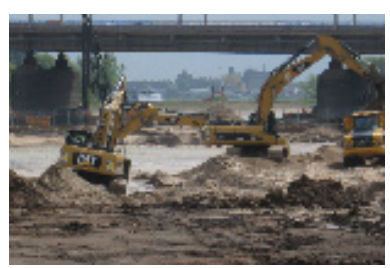

Photograph source: Rijkswaterstaat frequently, with sediment being deposited on them.

River restoration (remeandering, bed and bank renaturalization)

Rivers have been physically modified through a variety of means for the purposes of navigation, drainage, and industrial development. River restoration is the reinstatement of the natural physical processes (e.g., renaturalizing flow and sediment supply regimes by removing weirs) and NNBF (e.g., adding wood, altering river shape, and introducing sediment gravel) that are characteristic of a river.

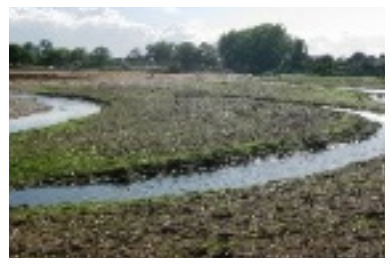

Photograph source: Environment Agency

\section{Constructing side channels}

Side channels are a popular measure. They enlarge the discharge capacity of a river while improving biodiversity and creating habitat (e.g., spawning grounds for fish). Side channels often have weirs at the upstream entrance to control the capacity. They have a tendency to aggrade, so maintenance (dredging) is often necessary. They also have morphological consequences in the main channels.

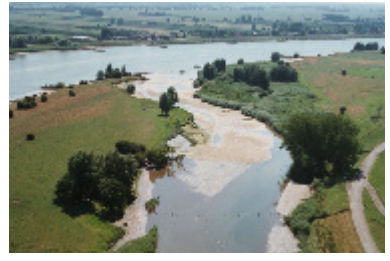

Photograph source: Rijkswaterstaat

\section{Stream biofilters}

These can trap sediments and infiltrate runoff water. This, in turn, improves water quality because they can reduce ammonia, nitrates, dissolved organic solids, carbon dioxide, nitrogen, and suspended solids.

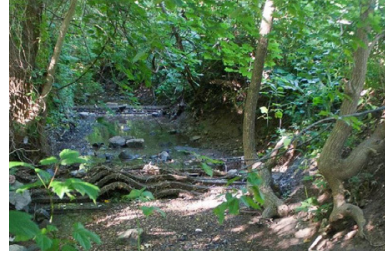

Photograph source: USACE 


\section{Modification of culverts and stream daylighting}

Urbanization has in the past led to many rivers and streams being encased in concrete culverts. When opportunities arise, concrete culverts should be removed and streams daylighted to restore the river and create more space for water to be stored on the floodplain.

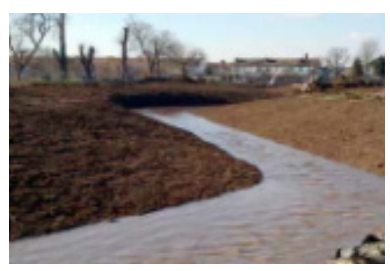

Photograph source:

Environment Agency

\section{Wetland creation and restoration}

Wetlands are dynamic and changing habitats that include fens, dune slacks, grazing marsh, swamp, peat bog, reed bed, salt marsh, wet woodland, wet grassland, and wet heathland. They can be created or restored to help store floodwaters.

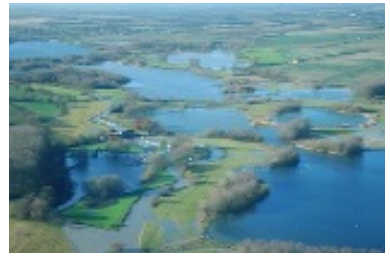

Photograph source:

Environment Agency

\section{Modifications to dams and weirs}

Many watercourses are impounded. These structures can be altered to, for example, enable the passage of fish.

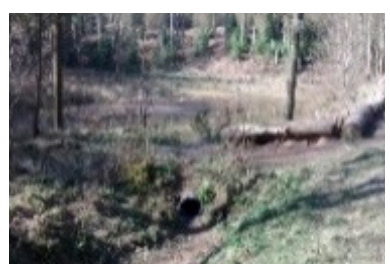

Photograph source:

Environment Agency

\section{Wildfire recovery}

Rivers and their watersheds that have been damaged by wildfires can be restored using in situ materials to stabilize channels and banks.

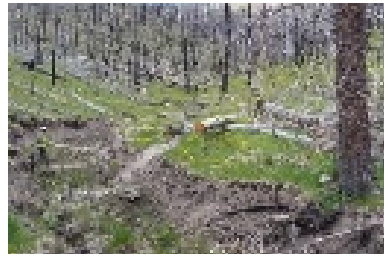

Photograph source: USACE 
Each of these NNBF is described in detail, summarizing the challenges and benefits associated with each NNBF. Chapter 19, Section 19.1, includes the following case studies that exemplify the different NNBF that are described in this section:

- Eddleston Water Restoration (INTERREG Building with Nature), Scotland, United Kingdom

- Colorado Watershed Flood Recovery, Colorado, United States

- Missouri River Floodplain Connectivity via Large-Scale Levee Setbacks, lowa, United States

- Noordwaard, the Netherlands

- IJssel River near Deventer, the Netherlands

- Lower Mississippi River Dike Notching for Habitat Development, United States

- Beam Washlands, Dagenham, London, United Kingdom

- Jubilee River alongside Thames River, United Kingdom

\subsubsection{River Restoration}

Rivers have been physically modified through a variety of means for the purposes of navigation, irrigation, drainage, industrial development, and FRM (see Chapter 17). River restoration can be defined as the reinstatement of the natural physical processes (e.g., renaturalizing flow and sediment supply regimes by removing weirs) and NNBF (e.g., adding wood, altering river shape, and introducing sediment gravel) that are characteristic of a natural river system (Addy et al. 2016).

River restoration does not necessarily mean restoring river forms and processes to their preindustrial condition because this can be difficult or impossible due to societal constraints and the ever-changing nature of rivers (Dufour and Piégay 2009). Also, a pristine condition may no longer fit with the equilibrium state of the river in current or future times. However, restoring channel stability through naturalizing hydraulic, sediment transport, and ecological processes directly or indirectly by reinstating the physical form of a channel may help a river adjust toward a more natural form.

For ease of reference, this chapter discusses river restoration and floodplain restoration separately. However, restoring a river channel often restores the connection between a river and a floodplain and vice versa. This section covers the restoration of the riparian zone-the river, its channel, and its banks. Section 18.2.2 focuses on the floodplain-the area beyond the top of the riverbank that may flood during high flows. 
River restoration can take many forms (see Table 18.1); in some cases, very little effort is needed (assisted natural recovery), whereas in other cases, more extensive engineering and construction are needed. River restoration can include techniques such as the following:

- Remeandering of the river channel

- Natural bank stabilization

- Removal of hard-engineered riverbank protection, weirs, culverts, bridges, and dams

- Restoration and reconnection of streams, seasonal streams, backwater complexes, and oxbows

- Reconnection of paleochannels

- Constructing longitudinal dams (as an alternative to lowering of groins)

- Revegetation of riparian zone

- Removal of invasive species that affect flooding

- Installation of in-channel NNBF that reduce erosion

River restoration can also include measures in the floodplain (see also Section 18.2.2), such as the following:

- Constructing side channels

- Removing obstacles and large structures (e.g., building in floodplain)

- Restoring floodplains to a more natural state (excavation and combination of other measures)

From an FRM perspective, restoration often increases hydraulic roughness and morphological complexity, which can reduce water velocities, help to reconnect rivers to their floodplains, create temporary water storage, and improve sediment transport patterns by retaining sediments in floodplain areas. River and floodplain restoration usually occur in tandem so as to give the greatest FRM benefits. Because the flooding benefits will be accrued downstream of the restored area, it should be considered whether the increase of water levels in the location of the project is acceptable and no additional risks are involved.

In the case of lowland rivers (e.g., in the Netherlands), NNBF are not used to slow and store water but to increase conveyance capacity, which, in turn, leads to a lowering in water levels, which reduces the frequency of inundation. Lowering water levels at one (lowland) location, via the backwater effect, means that water levels are also lowered (but to a lesser degree) upstream as well. Hence, inundation frequencies are lowered to some extent in these locations as well. Secondary channels can also be used to bypass a location at risk of flooding, channeling water on to a floodplain or a location further downstream. 
Ideally, maintenance should be kept to a minimum because the purpose of the NNBF is to restore the river to its natural state, but some maintenance may be needed to ensure that the project keeps providing sustainable benefits (see Environment Agency 2015). When possible, it is advised to use locally sourced materials.

This NNBF can also address many of the challenges discussed in Chapter 17, and if well designed, can deliver a range of co-benefits, in addition to reducing flooding. River restoration challenges addressed and co-benefits, including a benefits wheel (discussed in Chapter 17), are provided in the following graphic.

\section{River Restoration Challenges Addressed and Co-Benefits}

\section{Challenges Addressed:}

This type of NNBF can address a wide range of different challenges. River restoration can help redress habitat loss and also restores connection between rivers and floodplains, reducing erosion.

\begin{tabular}{lc}
\multicolumn{1}{c}{ Challenge } & Present \\
\hline Channel instability & Yes \\
\hline Land use change & No \\
\hline Water quality degradation & Yes \\
\hline Loss of flora and fauna & Yes \\
\hline Saltwater (tidal) intrusion & No \\
\hline Removal of vegetation & No \\
\hline $\begin{array}{l}\text { Loss of floodplains and } \\
\text { wetlands }\end{array}$ & Yes \\
\hline
\end{tabular}

Hydropower plants, dams, and No other hydraulic structures

\section{Co-Benefits:}

River restoration can deliver a wide range of co-benefits. It is particularly good at restoring habitat and providing aesthetic and cultural benefits.

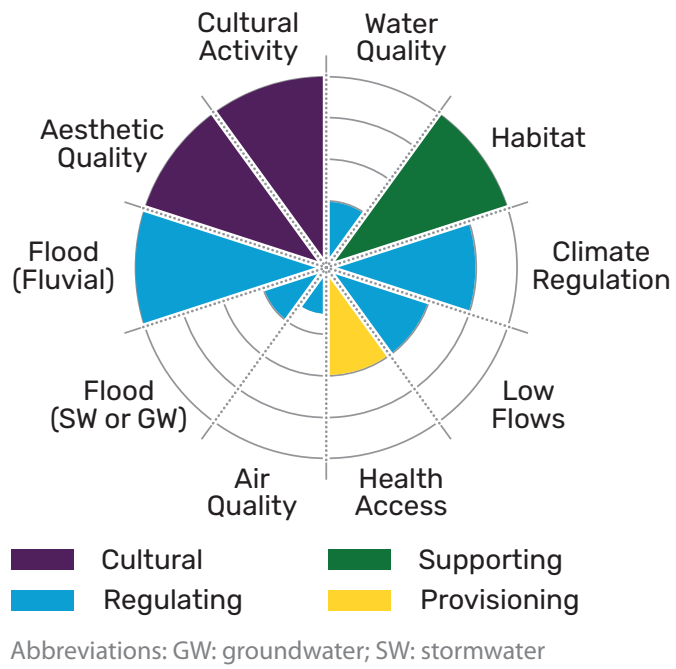




\subsubsection{Floodplain and Floodplain Wetland Restoration}

Floodplains and floodplain wetlands can be restored or created to store large volumes of water to reduce flood risk and provide ecological co-benefits. Wetlands are dynamic and changing habitats that include fens, dune slacks, grazing marsh and swamp, upland and lowland peat bog, reed bed and salt marsh, wet woodland, wet grassland, and wet heathland.

Floodplain restoration aims to restore the hydrological connection between rivers and floodplains so that floodwaters inundate specific floodplains where little-to-no damage will occur during inundation. As a result, the floodplains store water during times of high flows, lessening downstream flooding. This can involve removing flood embankments and other barriers to floodplain connectivity such as sluices and dikes.

In some cases, it is not possible to completely restore floodplains because of existing development. However, there are many different ways of restoring floodplains (see Table 18.1) to reduce flood risk, such as the following:

- Lowering the floodplain

- Removing hydraulic obstacles from the floodplain

- Removing built infrastructure from the floodplain

- Constructing secondary or side channels

- Providing FRM protection locally by moving flood banks away from the river to reduce the floodwater level

- Providing FRM protection locally through two-stage channels by constructing bunds to increase the conveyance capacity of a watercourse without changing the natural low-flow channel

- Renaturalizing a polder (a polder is an area of low-lying land protected by flood banks) by reconnecting polder areas to the river by removing flood banks (this could cover part of a polder or the entire polder depending on the existing land use)

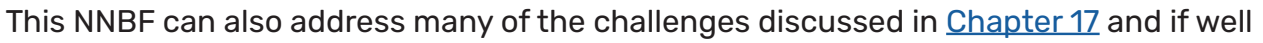
designed can deliver a range of co-benefits, in addition to reducing flooding. Floodplain and floodplain wetland restoration challenges addressed and co-benefits, including a benefits wheel (discussed in Chapter 17), are provided in the following graphic. 
Floodplain and Floodplain Wetland Restoration Challenges Addressed and Co-Benefits

\section{Challenges Addressed:}

This type of NNBF can address a wide range of different challenges. Floodplain and floodplain wetland restoration can help redress habitat loss and also restore connection between rivers and floodplains, reducing erosion.

\begin{tabular}{lc}
\multicolumn{1}{c}{ Challenge } & Present \\
\hline Channel instability & Yes \\
\hline Land use change & Yes \\
\hline Water quality degradation & Yes \\
\hline Loss of flora and fauna & Yes \\
\hline Saltwater (tidal) intrusion & No \\
\hline Removal of vegetation & No \\
\hline $\begin{array}{l}\text { Loss of floodplains and } \\
\text { wetlands }\end{array}$ & Yes \\
\hline
\end{tabular}

Hydropower plants, dams, and other hydraulic structures

\section{Co-Benefits:}

Floodplain and floodplain wetland restoration can deliver a wide range of co-benefits, in addition to reducing flood risk; specifically, it is often designed to restore or re-create habitat for flora and fauna. It also provides a wide range of human benefits from an aesthetic, health, and cultural activity perspective.

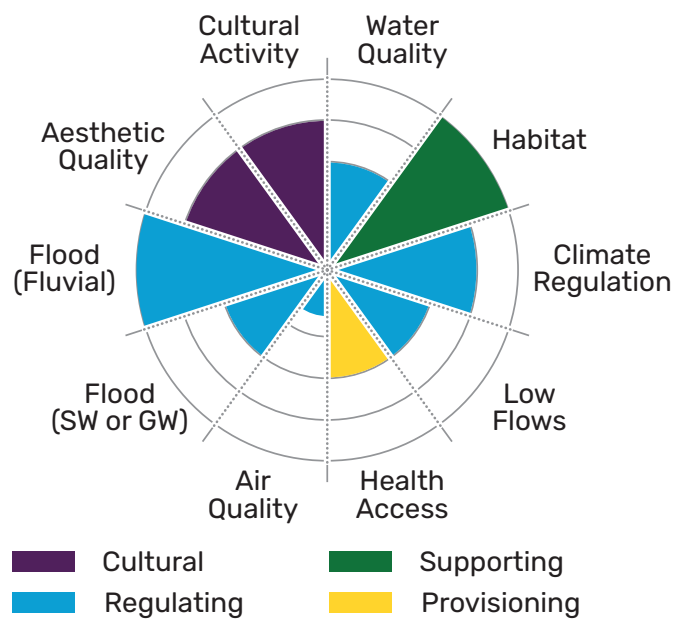

Abbreviations: GW: groundwater; SW: stormwater 


\subsubsection{Off-Line Storage Areas}

Off-line storage areas are floodplain areas that have been adapted to retain and attenuate floodwater in a managed way (Table 18.1). They usually require the construction of a containment bund, which increases the amount of water that can be stored on a floodplain and may also require an inlet, outlet, and potentially a regulated spillway mechanism.

Many different terms are used internationally to describe off-line storage areas; the important difference between these definitions is the size and amount of engineering involved in the design. For example, the terms washlands (larger scale) and runoff attenuation NNBF (smaller scale) are frequently used. Although the scale is different, the principle of creating temporary flood storage is the same.

When excess water is stored, the discharge downstream is reduced, which may help to reduce the flood risk. The retention ponds are connected to the river with a (regulated) weir. Their function is to store the topmost part of the discharge wave. Retention areas can have beneficial functions (e.g., with respect to recreation and nature development).

Retention areas come in different sizes, as follows:

- For the smaller streams and for rivers within the headwaters of watersheds, the retention areas typically cover several tens of hundreds of square meters, with storage volumes in the order of 1,000 cubic meters.

- For larger rivers (e.g., the Rhine or Mississippi Rivers), retention areas can be in the order of 100 square kilometers, with a storage volume of millions of cubic meters, as in the following examples:

- A projected retention area upstream of the Rhine River (in the Netherlands) has a water storage volume of 60 million cubic meters.

- The Mississippi River at David Pond (in the United States) has an area of 6,000 square kilometers and can store 75 million cubic meters of water.

This NNBF can also address many of the challenges discussed in Chapter 17, and if well designed can deliver a range of co-benefits, in addition to reducing flooding. Off-line storage areas challenges addressed and co-benefits, including a benefits wheel (discussed in Chapter 17), are provided in the following graphic. 


\section{Challenges Addressed:}

This type of NNBF can address a wide range of different challenges. Off-line storage areas can help address water quality challenges because they can trap sediment.

\begin{tabular}{lc}
\multicolumn{1}{c}{ Challenge } & Present \\
\hline Channel instability & No \\
\hline Land use change & No \\
\hline Water quality degradation & Yes \\
\hline Loss of flora and fauna & Yes \\
\hline Saltwater (tidal) intrusion & No \\
\hline $\begin{array}{l}\text { Removal of vegetation } \\
\text { Loss of floodplains and } \\
\text { wetlands }\end{array}$ & No \\
\hline
\end{tabular}

Hydropower plants, dams, and No other hydraulic structures

\section{Co-Benefits:}

Off-line storage areas predominantly achieve flood risk benefits, but they also help regulate low flows.

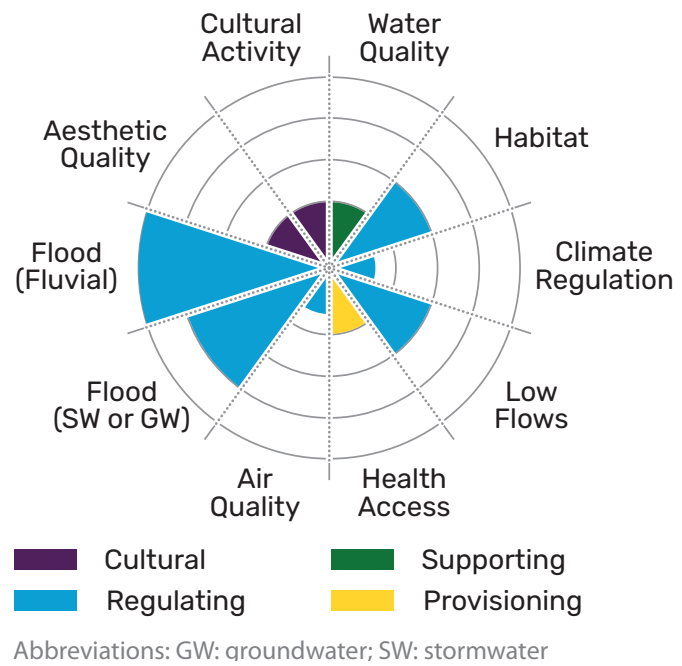

\section{3 | Vegetation Management}

Planting and re-establishing vegetation can help reduce flood risk through multiple means, including the following:

- Increased soil infiltration and absorption through the creation of improved soil structure, organic matter, and porosity

- Increased bank stability and reduction of scour

- Improved ecological structural complexity

- Increased absorption into living aboveground and belowground biomass

- Improved spread and reabsorption into the floodplain (analogous to rewetting of a sponge)

- Gradual rerelease of water over time through increased holding capacity

- Re-created wetland and lacustrine features, allowing for attenuated runoff and increased absorption capacity 
- Increased friction, serving to slow down water flow and causing increased spread and absorption, as well as reduced hydraulics and velocity, thereby increasing resilience and retention over time

- Potential for the retention of large woody matter that can reduce downstream transport of this material, which otherwise could potentially cause blockages on bridges, culverts, and other vulnerable points, causing damming and potential catastrophic release

Environment Agency (2014) describes the role that aquatic plants can play in reducing flood risk and suggests appropriate approaches to managing vegetation in channels and on the banks of watercourses. New woodland planting and the management of existing woodlands can reduce runoff by increasing infiltration and evapotranspiration. Woodland planted in floodplains and river corridors introduces roughness to the floodplain and can also slow floodwaters, which can increase biodiversity and provide spawning grounds for fish. These benefits can be further enhanced by the use of leaky wooden barriers within watercourses and across floodplains to slow and attenuate floodwaters.

Prairies and floodplain meadows offer sediment retention, erosion control, and ecological biodiversity. These benefits are due to the large biomass of aboveground stems and belowground roots. The root networks of these habitats encourage water to infiltrate into the soil, which helps to attenuate flow and recharge aquifers. These habitats also provide ecological biodiversity increases for mammals, birds, and insects.

Sections 18.3.1, 18.3.2, 18.3.3, and 18.3.4, respectively, describe the following woodland management NNBF:

- Watershed-wide woodland

- Floodplain and riparian woodland

- Prairies and floodplain meadows

- Leaky and woody barriers

The effects of these different types of vegetation management NNBF on flood risk are described in Figure 18.3 and Table 18.2.

Figure 18.3. Schematic of Vegetation Management

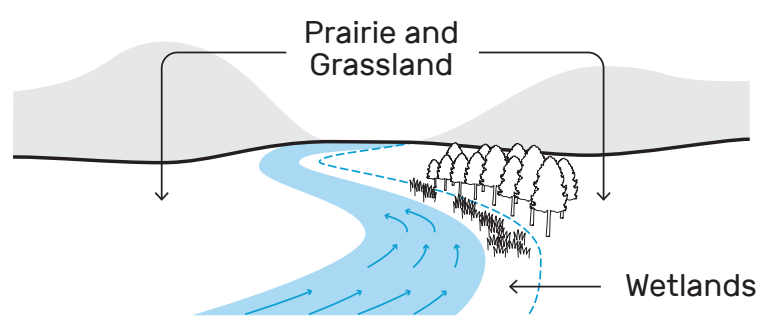

Vegetation Management

- Slows water

- Encourages infiltration in soil

- Enables evapotranspiration

- Increases roughness and slows flow

18 | Description of Fluvial NNBF 


\section{Prairies and floodplain meadows}

Grasslands in the floodplain (referred to as prairies or floodplain meadows) are highly biodiverse habitats that support many plants and animals. Restoration of this habitat alongside alterations to levees and embankments can restore these habitats to help reduce flood risk.

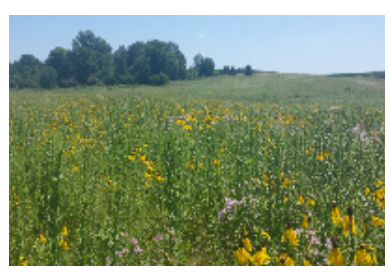

Photograph source:

US Fish and Wildlife Service

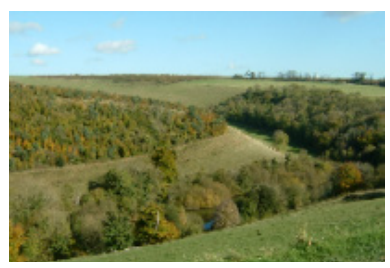

Photograph source: Environment Agency

\section{Watershed-wide woodland planting}

Watershed-wide woodland is defined as the total area of all woodland

within a watershed. It combines general woodland cover of all types and species, including plantations, plus specific forms where present, such as cross-slope, riparian, and floodplain woodland.

\section{Floodplain and riparian woodland planting}

Floodplain woodland refers to all woodland lying within the fluvial floodplain that is subject to an intermittent, regular planned, or natural flooding regime. Its main role is to slow down and hold back flood flows within the floodplain, as well as to enhance sediment deposition and thereby reduce downstream siltation.

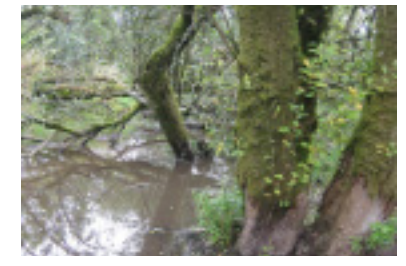

\section{Woody dams in streams and riparian zone}

Woody dams and barriers usually consist of pieces of wood, occasionally combined with some living vegetation, that accumulate in river channels and on riverbanks and floodplains. They occur naturally along rivers as a result of trees falling locally into watercourses. Similar structures can also be engineered by humans to restore rivers and floodplains to slow and store flood water.

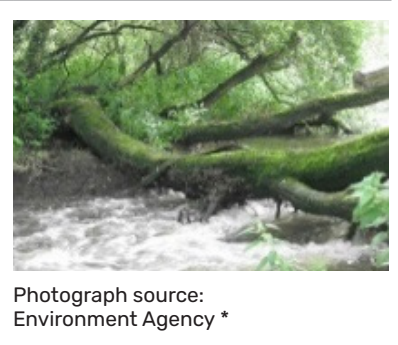


Each of these NNBF is described in detail, summarizing the challenges and benefits associated with each NNBF. Chapter 19, Section 19.2, includes the following case studies that exemplify the different NNBF that are described in this section:

- Slowing the Flow, Pickering, Yorkshire, United Kingdom

- Hierdense Beek, the Netherlands

\subsubsection{Watershed-Wide Woodland}

Watershed-wide woodland (see Table 18.2) is defined as the total area of all woodland within a watershed. It combines general woodland cover of all types and species, including plantations, plus specific forms where present, such as cross-slope, riparian, and floodplain woodland. A comprehensive review of the effects of woodland planting on flood risk was undertaken by the Centre for Ecology and Hydrology in 2017 (see ceh.ac.uk 2017).

Watershed-wide woodlands are likely to affect the following:

- The generation and conveyance of flood flows

- The related effects of snow accumulation and melting

- Soil infiltration beneath woodland

- The hydraulic roughness exerted by woodland leading to a slowing down of flood flows

- Reduction of soil erosion and sediment delivery (because woodland planting binds the soil and reduces the amount of eroded soil entering watercourses)

There are many areas of the world where mature woodlands are being cut down, thus causing a potential increase in flood risk. The protection and enhancement of existing woodlands (and other existing NNBF) is, therefore, an important element of natural river basin management.

This NNBF can also address many of the challenges discussed in Chapter 17, and if well designed can deliver a range of co-benefits, in addition to reducing flooding. Watershed-wide woodland challenges addressed and co-benefits, including a benefits wheel (discussed in Chapter 17), are provided in the following graphic. 


\section{Watershed-Wide Woodland Challenges Addressed and Co-Benefits}

\section{Challenges Addressed:}

This NNBF can address a wide range of challenges.

\begin{tabular}{lc}
\multicolumn{1}{c}{ Challenge } & Present \\
\hline Channel instability & Yes \\
\hline Land use change & Yes \\
\hline Water quality degradation & Yes \\
\hline Loss of flora and fauna & Yes \\
\hline Saltwater (tidal) intrusion & No \\
\hline Removal of vegetation & Yes \\
\hline $\begin{array}{l}\text { Loss of floodplains and } \\
\text { wetlands }\end{array}$ & No \\
\hline
\end{tabular}

Hydropower plants, dams, and No other hydraulic structures

\section{Co-Benefits:}

Watershed-wide woodland can deliver a range of co-benefits.

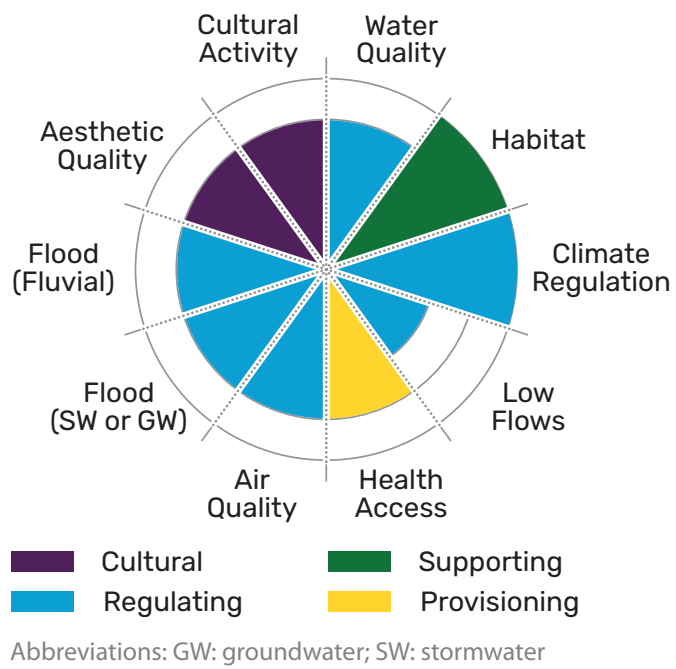

\subsubsection{Floodplain and Riparian Woodland}

Floodplain and riparian woodlands are woodlands within the fluvial floodplain that is subject to an intermittent, regular planned, or natural flooding regime. Floodplain woodland also includes planting in the riparian zone along the river corridor.

The main role of floodplain and riparian woodland from an FRM perspective is to slow down and hold back flood flows within the floodplain, as well as to enhance sediment deposition and thereby reduce downstream siltation. This is because planting woodland on a floodplain increases hydraulic roughness and slows down the flow of water, which, in turn, can encourage the creation of pools, backwaters, and areas of slack water that store and slow flood flows. Woodland planting along river corridors and floodplains can also reduce the frequency and severity of channel migration (which can damage infrastructure and exacerbate flooding). 
This NNBF can also address many of the challenges discussed in Chapter 17, and if well designed can deliver a range of co-benefits, in addition to reducing flooding. Floodplain and riparian woodland challenges addressed and co-benefits, including a benefits wheel (discussed in Chapter 17), are provided in the following graphic.

\section{Floodplain and Riparian Woodland Challenges Addressed and Co-Benefits}

\section{Challenges Addressed:}

This NNBF can address a wide range of different challenges. In particular, it can help restore rivers and their floodplains, addressing habitat loss.

\begin{tabular}{lc}
\multicolumn{1}{c}{ Challenge } & Present \\
\hline Channel instability & Yes \\
\hline Land use change & Yes \\
\hline Water quality degradation & Yes \\
\hline Loss of flora and fauna & Yes \\
\hline Saltwater (tidal) intrusion & No \\
\hline Removal of vegetation & Yes \\
\hline $\begin{array}{l}\text { Loss of floodplains and } \\
\text { wetlands }\end{array}$ & Yes \\
\hline $\begin{array}{l}\text { Hydropower plants, dams, and } \\
\text { other hydraulic structures }\end{array}$ & No
\end{tabular}

Hydropower plants, dams, and other hydraulic structures

\section{Co-Benefits:}

Floodplain and riparian woodlands can deliver a range of co-benefits, in addition to reducing flood risk. They are particularly beneficial as a carbon sink and can help restore habitat and improve water quality.

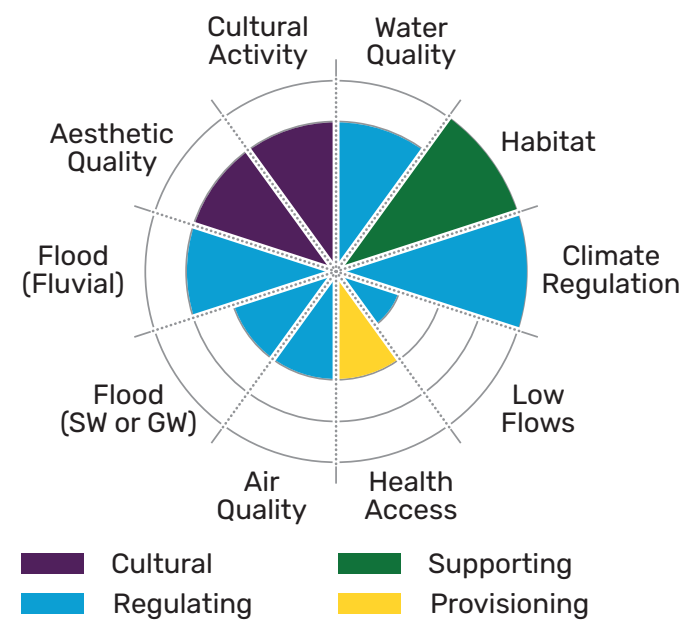

Abbreviations: GW: groundwater; SW: stormwater 


\subsubsection{Prairies and Floodplain Meadows}

Prairies and floodplain meadows slow down floodwaters, filter stormwater runoff (reducing nutrient delivery downslope), sequester carbon, and provide increased ecological biodiversity to the environment.

This NNBF can also address many of the challenges discussed in Chapter 17 , and if well designed can deliver a range of co-benefits, in addition to reducing flooding. Prairies and floodplain meadows challenges addressed and co-benefits, including a benefits wheel (discussed in Chapter 17), are provided in the following graphic.

\section{Prairies and Floodplain Meadows Challenges Addressed and Co-Benefits}

\section{Challenges Addressed:}

This type of NNBF can address a wide range of different challenges.

\begin{tabular}{lc}
\multicolumn{1}{c}{ Challenge } & Present \\
\hline Channel instability & Yes \\
\hline Land use change & Yes \\
\hline Water quality degradation & Yes \\
\hline Loss of flora and fauna & Yes \\
\hline Saltwater (tidal) intrusion & No \\
\hline Removal of vegetation & Yes \\
\hline $\begin{array}{l}\text { Loss of floodplains and } \\
\text { wetlands }\end{array}$ & Yes \\
\hline
\end{tabular}

Hydropower plants, dams, and other hydraulic structures

\section{Co-Benefits:}

Prairies and floodplain meadows can deliver a range of co-benefits, in addition to reducing flood risk.

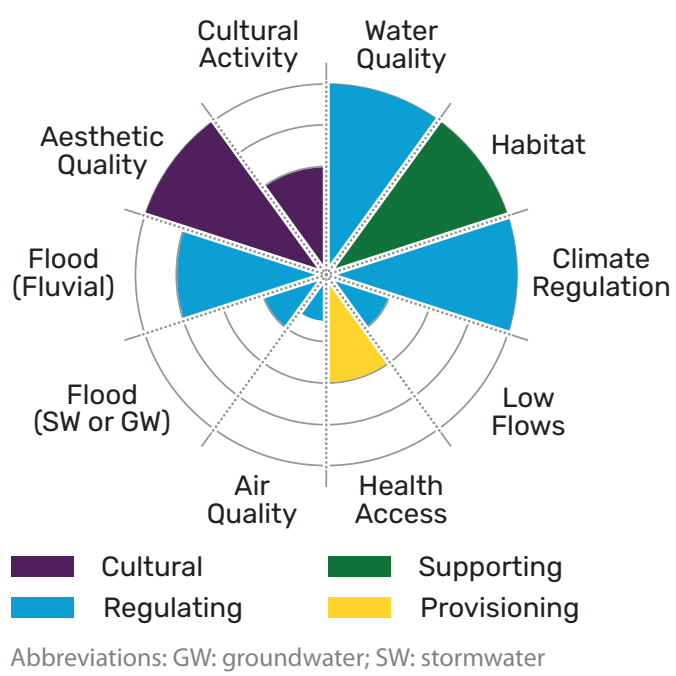




\subsubsection{Leaky and Woody Barriers}

Leaky barriers usually consist of pieces of wood (see Table 18.2), occasionally combined with some living vegetation, that accumulate in river channels as well as on riverbanks and floodplains. Leaky barriers are known by many other names, such as the following:

- Coarse woody material

- Large woody material

- Large wood

- Wood accumulations

- Wood jams and barriers

- Beaver dams

Although the word barrier evokes thoughts of hard engineering, leaky barriers occur naturally along rivers as a result of trees falling locally into watercourses through snagging of natural wood or occasionally due to beaver activity. Similar structures can also be engineered by humans to restore rivers and floodplains to slow and store floodwater. Floodplain restoration would be achieved by reducing the flow capacity of the river channel and forcing water out of the channel on to the floodplain. Forest Research (2008) provides a detailed evaluation of the effectiveness of woody barriers.

When engineered, this NNBF is often referred to as wood placements, engineered log jams, or flow restrictors. The term leaky barriers is used here because it has fewer negative connotations than the word dam.

This NNBF can also address many of the challenges discussed in Chapter 17, and if well designed can deliver a range of co-benefits, in addition to reducing flooding. Leaky and woody barriers challenges addressed and co-benefits, including a benefits wheel (discussed in Chapter 17), are provided in the following graphic. 


\section{Leaky and Woody Barriers Challenges Addressed and Co-Benefits}

\section{Challenges Addressed:}

This type of NNBF can address a wide range of different challenges, with the exception of saltwater intrusion, land use change, and hydropower plants, dams, and other hydraulic structures.

\begin{tabular}{lc}
\multicolumn{1}{c}{ Challenge } & Present \\
\hline Channel instability & Yes \\
\hline Land use change & No \\
\hline Water quality degradation & Yes \\
\hline Loss of flora and fauna & Yes \\
\hline Saltwater (tidal) intrusion & No \\
\hline Removal of vegetation & Yes \\
\hline $\begin{array}{l}\text { Loss of floodplains and } \\
\text { wetlands }\end{array}$ & Yes \\
\hline Hydropower plants, dams, and
\end{tabular}

Hydropower plants, dams, and other hydraulic structures

\section{Co-Benefits:}

Leaky and woody barriers can deliver a range of co-benefits, in addition to reducing flood risk. They are particularly good at trapping sediment and improving water quality.

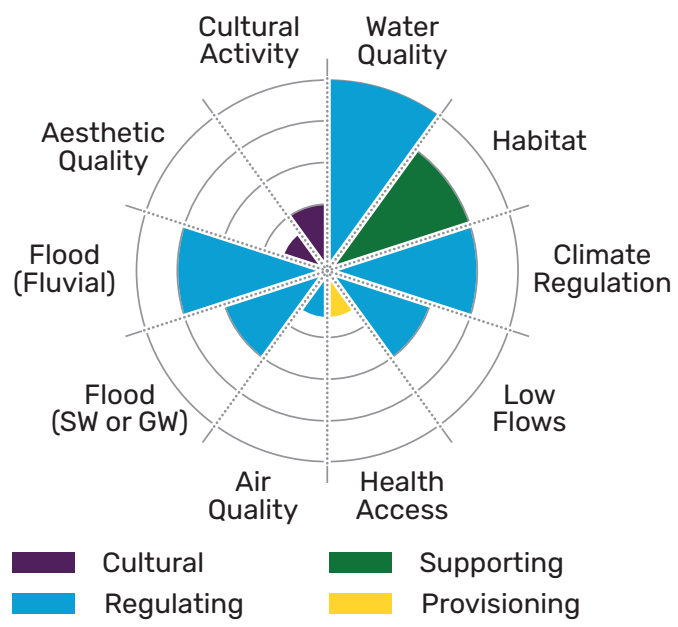

Abbreviations: GW: groundwater; SW: stormwater

\section{4 | Rural Runoff Management}

Restoring natural processes across the rural landscape can provide a wide range of benefits for the environment and people. From an FRM perspective, these types of NNBF can intercept overland flow and sediments, restore soils to help store water, encourage infiltration and sediment deposition, and increase the hydraulic roughness and morphological complexity of rivers and floodplains, which, in turn, slows floodwaters and reconnects rivers to floodplains to store water. Of the NNBF included in this section, some of the runoff management NNBF are seen to be the most engineered, involving the construction of flow control structures and other gray infrastructure to enable their full operation. 
Sections 18.4.1, 18.4.2, and 18.4.3, respectively, describe the following rural runoff management NNBF:

- Soil and land management

- Headwater drainage management

- Rural runoff management

The effects of these different types of rural runoff management NNBF on flood risk are described in Figure 18.4 and Table 18.3.

Figure 18.4. Schematic of Rural Runoff Management

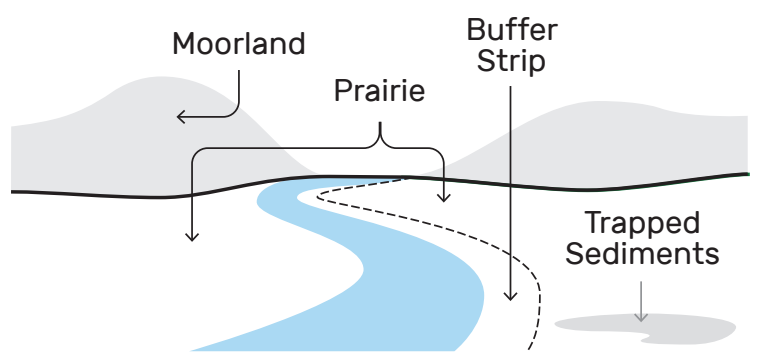

\section{Rural Runoff Management}

- Captures water flow

- Slows and stores water

- Encourages infiltration

- Traps sediments

Table 18.3. Rural Runoff Management NNBF

\section{Agricultural underdrainage management}

Agricultural underdrains were installed below ground in the past to help drain water from fields. There is now an interest in removing or disrupting these drains to restore soils to improve their ability to store and filter water.

\section{Field corner bunds}

Earth bunds can be created in the corner of fields to intercept and temporarily store overland flow. In some cases, the bunds can be designed to also act as a raised access track during times of flood.

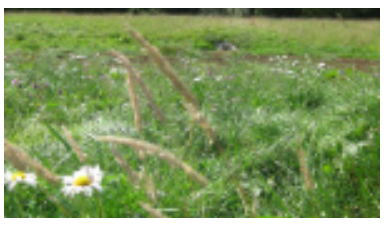

Photograph source: Environment Agency

\section{Agricultural contour planting for slope erosion control}

Planting vegetation along the contours of slopes or ploughing fields along their contours helps to intercept overland flow and runoff into watercourses trapping flow and sediments.

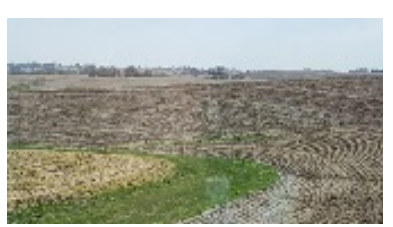

Photograph source: USACE 


\section{Grade control structures}

With a stable outlet for water from headlands into stream/ drainage system. Grade control structures can reduce erosion and improve water quality.

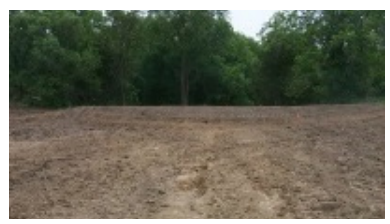

Photograph source: USACE

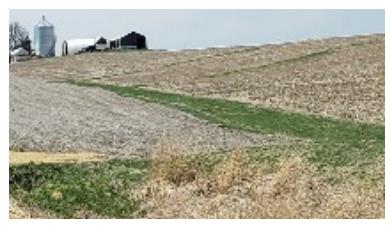

Photograph source: USACE

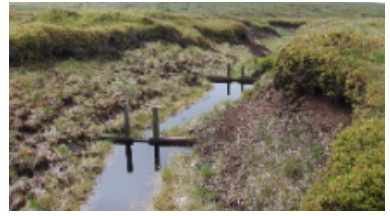

Photograph source: Environment Agency

\section{Gully and grip blocking}

Gullies can dry out land as they lower water tables. They also carry away eroded sediments and they cause a high runoff. These effects can be reduced by blocking the gullies with dams made of wood, heather bales, or stone. This is used on gullies on steep slopes. In moorland environment, it is used to restore peat habitats.

\section{Buffer strips}

Buffer strips are strips of land often between fields and hedgerows or between fields and rivers. These strips of land are not cultivated and are used to slow the rate of overland flow, trap pollutants, and act as a corridor for flora and fauna.

\section{Hedges}

Hedges are planted along field boundaries. They can encourage infiltration into the soil and reduce surface runoff and overland flow. They also create corridors for flora and fauna.

Conservation tillage (including low tillage and no tillage)

Traditionally on farms, soil is ploughed each year to prepare it for the new season. Conservation tillage aims to reduce or stop the tillage of the soil to retain soil moisture, reduce soil erosion and runoff, and increase crop yields.

Runoff attenuation NNBF (also known as retention basins, ponds, and swales)

These NNBF are constructed within farmed fields. They typically slow and store water by disconnecting overland flow and channel flow.

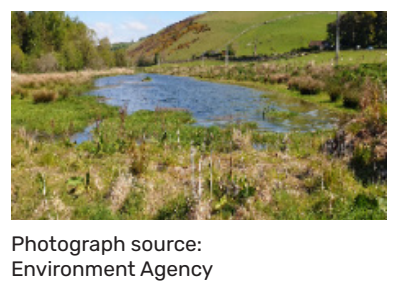




\section{Controlling flow on tracks and paths}

The intensive use of farming machines causes soil compaction. Controlling farm traffic can help to reduce and manage the compaction of soils. Intercepting flow paths created through the compaction of field and farm tracks and paths can help to store and filter water. In some cases, moving farm gates or cross-slope planting and cultivation can help to intercept and store water.

\section{Sediment-capture ponds and sediment traps}

Sediment-capture ponds are ponds placed along a network of ditches to slow flows and cause sediment to be deposited within the ponds to improve water quality by removing diffuse pollutants.

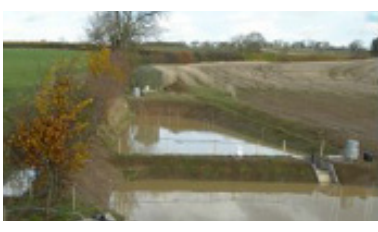

Photograph source: Environment Agency

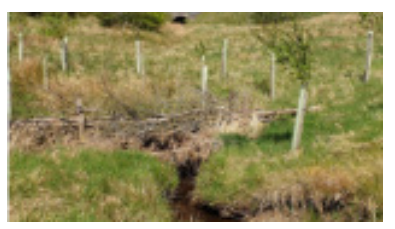

Photograph source: Environment Agency

\section{Controlling flow in ditches}

Farms also often have open drainage ditches that, if planted or practically blocked, can help to attenuate flows.

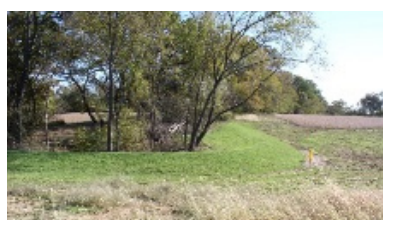

\section{Sediment-control basins}

Typically applied where steep drainage ways exit fields in places where there is a lot of grade difference (elevation) and channel instability (e.g., headcuts and nickpoints). These basins provide minor storage within the hickenbottom inlet riser pipe and a stable pipe outlet at the downstream outlet.

Photograph source: USACE

\section{Crop rotation}

Repeatedly planting the same crop in the same location can remove a soil's nutrients and cause erosion, both of which affect crop yield. Rotating the types of crop planted in any one location can help soils to recover and be more productive.

\section{Soil aeration and subsoiling}

Soil aeration and subsoiling are methods used to restore compacted soils (e.g., tractors or grazing regimes) in the topsoil and subsoil. Both methods help the soil store and drain water. 


\section{Early sowing and cover crops (in green cover crops)}

Early sown cover crops are noncash crops sown in the autumn to provide winter ground cover when the field would otherwise be fallow. They also reduce loss of nutrients and soil erosion and can help trap and treat pollutants.

\section{Stocking density}

Grazing animals can compact soils, affecting the soil's ability to store and infiltrate water. Altering the stocking density on fields can help restore soil structure so it can store and slow water.

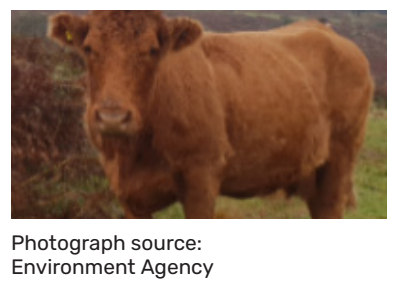

Each of these NNBF is described in detail, summarizing the challenges and benefits associated with each NNBF. Chapter 19, Section 19.3, includes the following case studies that exemplify the different NNBF that are described in this section:

- Belford, Northumberland, United Kingdom

- Arvari River Watershed, Alwar, Rajasthan, India

- Making Space for Water, Peak District, United Kingdom

\subsubsection{Soil and Land Management}

Soil and land management NNBF involves changes to agricultural practices (see Table 18.3) so that more rainfall infiltrates into the ground or is held by plants, thus reducing the amount of runoff and sediment transport and consequently downstream flood risk. The NNBF considered here generally involve agricultural methods that retain water and encourage infiltration, crops, and crop rotations that provide ground cover and protect the soil during the flood season, and NNBF to reduce soil compaction and, therefore, runoff. Land management practices can increase the amount of surface storage, rate of infiltration, and capacity of the soil to store water (Leopold and Maddock 1954; Hudson 1995).

This NNBF can also address many of the challenges discussed in Chapter 17 , and if well designed can deliver a range of co-benefits, in addition to reducing flooding. Soil and land management challenges addressed and co-benefits, including a benefits wheel (discussed in Chapter 17), are provided in the following graphic. 


\section{Soil and Land Management Challenges Addressed and Co-Benefits}

\section{Challenges Addressed:}

This NNBF can address a wide range of different challenges. It is especially effective at addressing pollution challenges by reducing the amount of sediment and agricultural runoff entering rivers.

\begin{tabular}{lc}
\multicolumn{1}{c}{ Challenge } & Present \\
\hline Channel instability & Yes \\
\hline Land use change & Yes \\
\hline Water quality degradation & Yes \\
\hline Loss of flora and fauna & Yes \\
\hline Saltwater (tidal) intrusion & No \\
\hline Removal of vegetation & Yes \\
\hline $\begin{array}{l}\text { Loss of floodplains and } \\
\text { wetlands }\end{array}$ & Yes \\
\hline
\end{tabular}

Hydropower plants, dams, and other hydraulic structures

\section{Co-Benefits:}

Soil and land management can deliver a range of co-benefits, specifically water quality benefits, in addition to reducing flood risk.

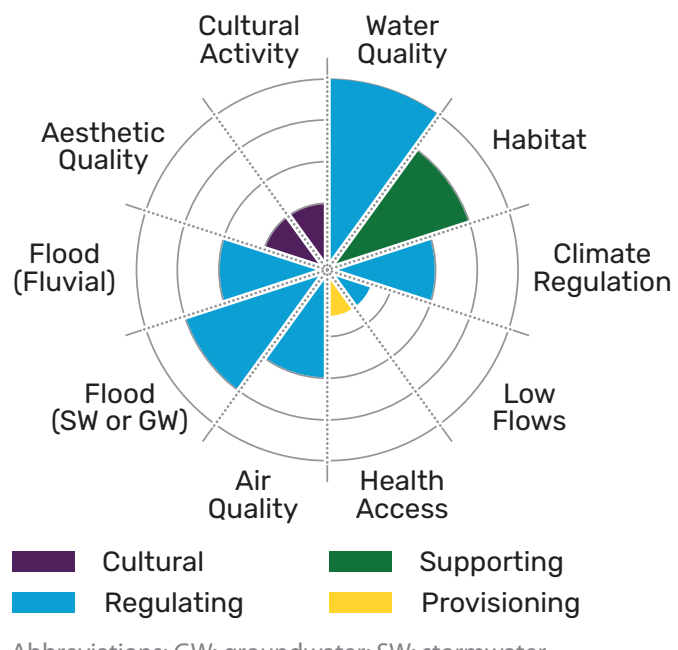

Abbreviations: GW: groundwater; SW: stormwater

\subsubsection{Headwater Drainage Management}

This section looks at drainage management NNBF suitable in headwater watersheds (see Table 18.3), which are mainly found in rural locations. Headwater watersheds are loosely defined as typically small watershed areas up to several square kilometers in size. Within these headwater drainage networks, there are potential opportunities to intervene in the landscape to change the storage and the travel time of water within them by slowing the flow of water before it reaches the drainage network. Headwater drainage management measures are described in Table 18.3. Typically, such measures try to capture and store overland flow to reduce the rate at which the water enters the watercourse. This could involve intercepting overland flow pathways through gully blocking. Headwater drainage management could also include restoring peat bog and fenland habitats to attenuate water and encourage its infiltration into the aquifer. 
This NNBF can also address many of the challenges discussed in Chapter 17, and if well designed can deliver a range of co-benefits, in addition to reducing flooding. Headwater drainage management challenges addressed and co-benefits, including a benefits wheel (discussed in Chapter 17), are provided in the following graphic.

\section{Headwater Drainage Management Challenges Addressed and Co-Benefits}

\section{Challenges Addressed:}

This NNBF can address a wide range of different challenges. It is specifically good at reverse land use change impacts.

\begin{tabular}{lc}
\multicolumn{1}{c}{ Challenge } & Present \\
\hline Channel instability & No \\
\hline Land use change & Yes \\
\hline Water quality degradation & Yes \\
\hline Loss of flora and fauna & Yes \\
\hline Saltwater (tidal) intrusion & No \\
\hline Removal of vegetation & Yes \\
\hline $\begin{array}{l}\text { Loss of floodplains and } \\
\text { wetlands }\end{array}$ & No \\
\hline
\end{tabular}

Hydropower plants, dams, and No other hydraulic structures

\section{Co-Benefits:}

Headwater drainage management can deliver a range of co-benefits, in addition to reducing flood risk.

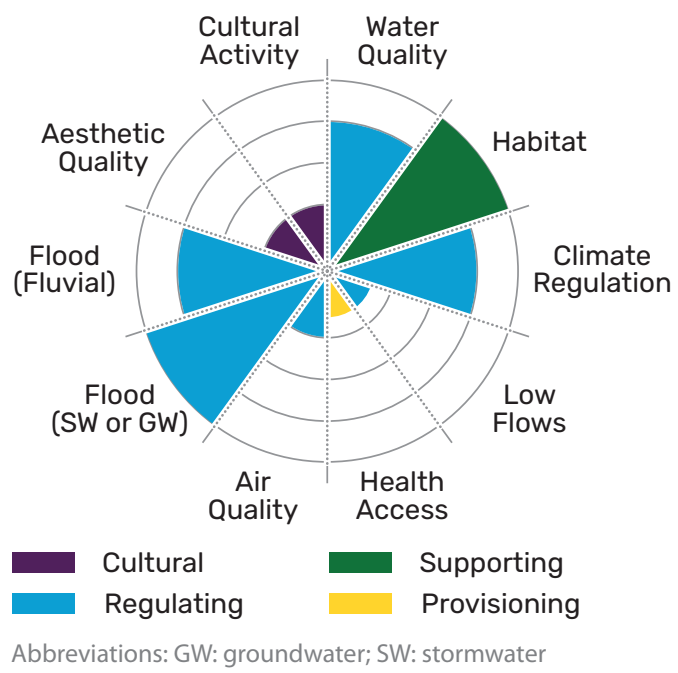




\subsubsection{Rural Runoff Management}

Rural runoff management NNBF (see Table 18.3) are intended to mimic natural hydrological regimes to minimize the impact of human activity on surface water drainage discharge, reducing flooding and pollution of waterways and groundwater (Environment Agency 2012). They have the potential to regulate runoff through the temporary storage of floodwater, disconnecting and lengthening of flow pathways, increasing travel time, and roughening the floodplain during flood events (Nicholson et al. 2012).

This section describes some of the NNBF that can be added to farmed landscapes to slow and store water across the landscape. These NNBF are described collectively and referred to here as runoff attenuation NNBF-they are also included in Table 18.3. Section 18.5 describes similar NNBF for working in an urban location.

Water retention involves retaining water in watersheds during storm events and, therefore, reducing downstream flood flows. Any area where water accumulates can be used to retain water including storage areas on drainage paths and watercourses at different scales-from ponds in the corners of fields to areas on or adjacent to watercourses that take advantage of local topography to provide large flood storage volumes.

This NNBF can also address many of the challenges discussed in Chapter 17, and if well designed can deliver a range of co-benefits, in addition to reducing flooding. Rural runoff management challenges addressed and co-benefits, including a benefits wheel (discussed in Chapter 17), are provided in the following graphic. 


\section{Rural Runoff Management Challenges Addressed and Co-Benefits}

\section{Challenges Addressed:}

This NNBF can address a small number of other challenges, such as water quality and land use change challenges.

\begin{tabular}{ll}
\multicolumn{1}{c}{ Challenge } & Present \\
\hline Channel instability & No \\
\hline Land use change & Yes \\
\hline Water quality degradation & Yes \\
\hline Loss of flora and fauna & No \\
\hline Saltwater (tidal) intrusion & No \\
\hline Removal of vegetation & No \\
\hline $\begin{array}{l}\text { Loss of floodplains and } \\
\text { wetlands }\end{array}$ & No \\
\hline
\end{tabular}

Hydropower plants, dams, and other hydraulic structures

\section{Co-Benefits:}

Rural runoff management can deliver a range of co-benefits, in addition to reducing flood risk.

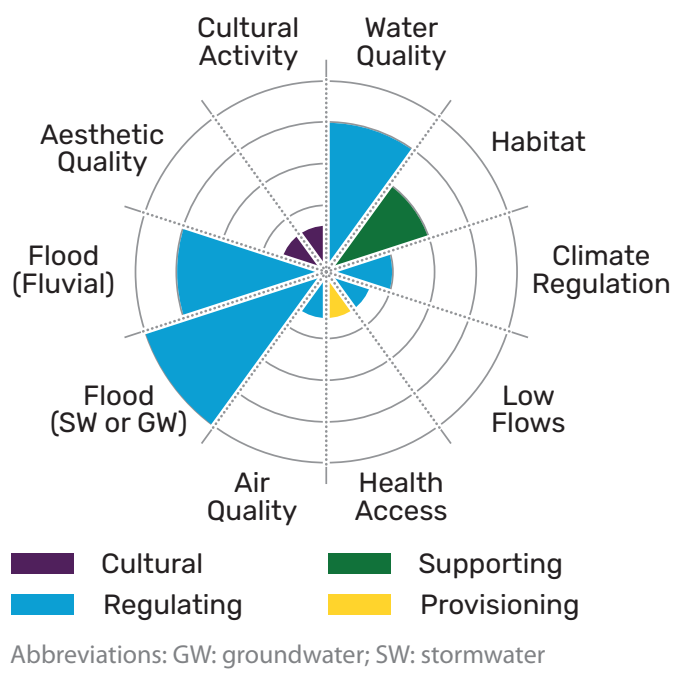

\section{5 | Urban Runoff Management}

These NNBF are primarily used for managing surface water in urban areas and are variously referred to as Sustainable Urban Drainage Systems (also known SUDS), low impact development, best management practices, or green infrastructure.

These NNBF mimic natural hydrological processes managing rainfall close to where it falls and offering benefits in FRM, as well as water quality, biodiversity, and public amenity. The principle behind sustainable drainage systems, low impact development, and green infrastructure is that surface water is a valuable resource and should be managed for maximum benefit. The Construction Industry Research and Information Association (CIRIA) SUDS manual provides a comprehensive review and description of these NNBF (CIRIA 2015). 
These NNBF have an impact on flood risk by reducing the following:

- The peak discharge, which normally increases in urban areas compared to its previous greenfield state because the runoff drains off the impervious surfaces much quicker

- The runoff volume, which also increases in urban areas because less water is able to penetrate the ground, be evapotranspired, or be intercepted in other ways

- The level of pollutant loads from urban runoff, which increases in urban areas due to increases in pollutant sources, less infiltration, and less trapping of sediments and contaminants

Urban NNBF are very similar to the rural NNBF described in Section 18.4 because they can be designed to do the following:

- Harvest rainfall to be used close to where it falls

- Intercept overland flow and slowly convey it on the surface

- Store water and release it slowly

- Encourage infiltration and soil water storage to support river base flows and groundwater recharge

- Provide opportunities for evapotranspiration

What is different about these NNBF measures is they are designed to accommodate runoff from roads, buildings, and hard surfaces rather than farmland.

Sections 18.5.1 and 18.5.2, respectively, describe the following urban runoff management NNBF:

- Water infiltration management

- Water retention (storage)

The effects of these different types of urban runoff management NNBF on flood risk are described in Figure 18.5 and Table 18.4.

Figure 18.5. Schematic of Urban Runoff Management

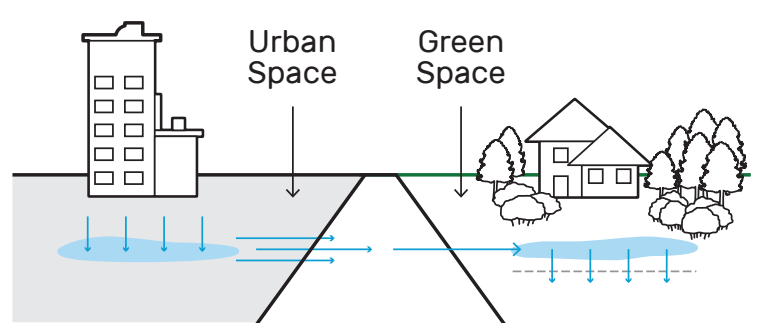

Urban Runoff Management

- Retains and stores water in green space

- Slows delivery of water to sewer system 


\section{Constructed wetlands}

The benefits of wetlands include flood water storage, filtration of runoff water, and improved water quality. Wetlands also promote environmental co-benefits by providing habitat for species of both plants and animals.

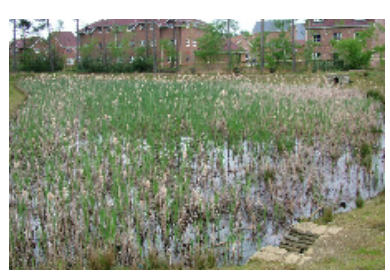

Photograph source: HR Wallingford

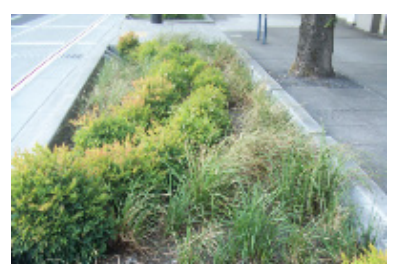

Photograph source: IIIman Young

\section{Rain gardens and bioretention systems}

These are shallow landscaped depressions that store and infiltrate runoff volume. They usually have a simple inflow where rainwater enters the garden, vegetation, a filter medium, a drainage layer, and an outlet for the overflow. They provide attractive landscape features, habitat, and biodiversity.

\section{Detention basins}

Detention basins are areas of land typically in a park that have been depressed to create low-lying areas. They are usually dry and fill up with water temporarily to create storage during heavy rain.

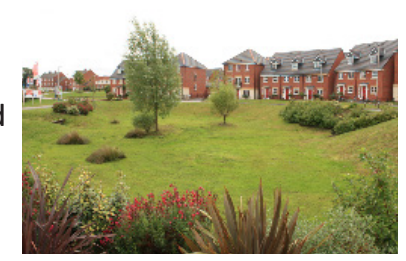

Photograph source: CIRIA

\section{Rainwater harvesting}

Rainwater harvesting is the collection of rainwater, usually from roofs and other impermeable areas, that is stored and then used as nonpotable supply water. It needs a storage tank and, in some cases, filtration systems, pumps, and pipework.

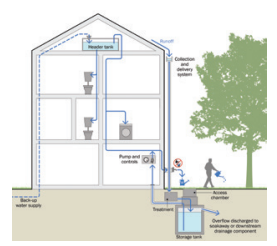

Photograph source: CIRIA, Report C753

\section{Filter strips}

Filter strips are longitudinal planted strips that capture overland flow from adjacent surfaces, encouraging infiltration, filtration, and sediment deposition. They should extend the length of the area they are draining. They have mainly water quality co-benefits.

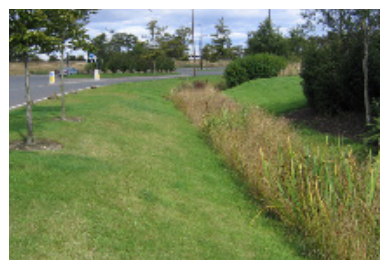

Photograph source: CIRIA 


\section{Retention ponds}

Retention ponds are ponds that permanently contain water, but they have extra capacity to accommodate heavy rainfall events. They are usually designed to reduce flood risk, improve water quality, and create habitat.

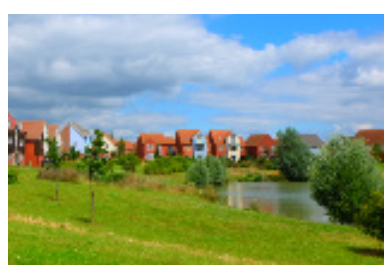

Photograph source: HR Wallingford

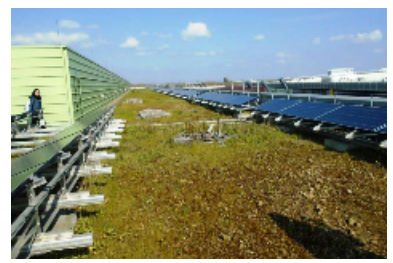

Photograph source: HR Wallingford

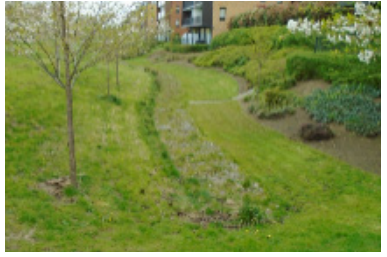

Photograph source: HR Wallingford

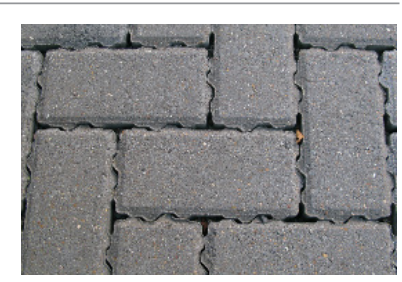

Photograph source: HR Wallingford

\section{Permeable surfaces and paving}

Permeable forms of paving encourage surface water to drain through the surface of the paving into the soil or subbase or belowground storage tanks. This process intercepts, infiltrates, stores, and treats runoff. Expected traffic loadings and visual appearance are key design parameters.

Swales are shallow, flat-bottomed, vegetated open channels. Their main purpose is to convey, treat, and attenuate surface runoff. They usually have a trapezoidal cross-section, which is easy to maintain.

\section{Urban forest parks}

Trees in urban forest parks increase transpiration, interception, and infiltration. They manage surface water runoff from a local area and require appropriate space, soil, drainage, and supply of water. Trees also provide aesthetic, biodiversity, and quality of life co-benefits.

Each of these NNBF is described in detail, summarizing the challenges and benefits associated with each NNBF. Chapter 19, Section 19.4, includes the following case studies that exemplify the different NNBF that are described in this section:

- Anwa Sustainable Landscape Design, Kibera, Nairobi, Kenya

- Upton Development, Northampton, United Kingdom 


\subsubsection{Water Infiltration Management}

Water infiltration NNBF allow runoff to infiltrate into the ground over a period of time, reducing the runoff volume. For a soil to be suitable for infiltration, it should be permeable, unsaturated, and sufficiently thick. Soil properties define the rate at which infiltration might occur, and determining an accurate infiltration coefficient for the soil is key to designing water infiltration NNBF.

When designing water infiltration NNBF, it is also important to assess the possible risks that infiltrating water may have on nearby structures (e.g., buildings), slopes (e.g., retaining walls), and groundwater flows. This requires an assessment of geotechnical and hydrogeological conditions of the site.

This NNBF can also address many of the challenges discussed in Chapter 17, and if well designed can deliver a range of co-benefits, in addition to reducing flooding. Water infiltration management challenges addressed and co-benefits, including a benefits wheel (discussed in Chapter 17), are provided in the following graphic.

\section{Water Infiltration Management Challenges Addressed and Co-Benefits}

\section{Challenges Addressed:}

This NNBF can address water supply challenges.

\begin{tabular}{lc}
\multicolumn{1}{c}{ Challenge } & Present \\
\hline Channel instability & Yes \\
\hline Land use change & Yes \\
\hline Water quality degradation & Yes \\
\hline Loss of flora and fauna & Yes \\
\hline Saltwater (tidal) intrusion & No \\
\hline Removal of vegetation & No \\
\hline $\begin{array}{l}\text { Loss of floodplains and } \\
\text { wetlands }\end{array}$ & No \\
\hline
\end{tabular}

Hydropower plants, dams, and No other hydraulic structures

\section{Co-Benefits:}

Water infiltration management can deliver a range of co-benefits, in addition to reducing flood risk.

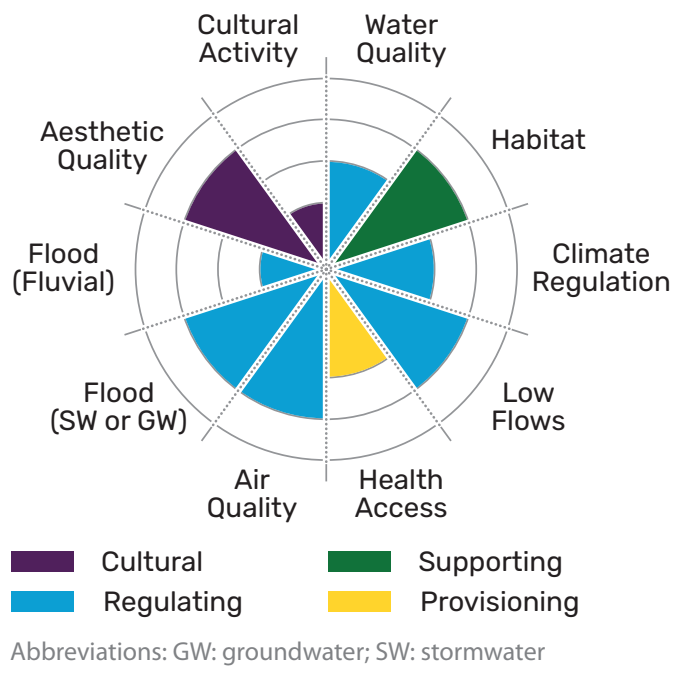




\subsubsection{Water Retention (Storage)}

Water retention NNBF temporarily store water during events, slowing and storing flood volumes and draining flow afterward at a rate controlled by an outlet structure. Larger-scale storage measures are described in Section 18.2.3. The measures described here are smaller scale and usually associated with new urban development or redevelopment. The measures described here are the urban equivalent of the rural NNBF described in Section 18.4.

Water retention NNBF can be implemented online, when all the runoff from the contributing development flows through the storage, or off-line, when the storage facility is out of the main conveyance path. Online storage has the advantage of providing some treatment of the initial runoff, which is normally the most polluted, and off-line storage has the advantage of storing water only when required, through the operation of a diversion structure. Off-line storage is normally most valuable for more extreme, less frequent events, allowing the area to perform an amenity function for the majority of the time. Constructed wetlands are often used to retain water, and the plants within these can help to break down pollutants while providing biodiversity and amenity benefits.

Different types of water retention NNBF are described in Table 18.4.

This NNBF can also address many of the challenges discussed in Chapter 17, and if well designed can deliver a range of co-benefits, in addition to reducing flooding. Water retention (storage) challenges addressed and co-benefits, including a benefits wheel (discussed in Chapter 17), are provided in the following graphic. 


\section{Water Retention (Storage) Challenges Addressed and Co-Benefits}

\section{Challenges Addressed:}

This NNBF can address a wide range of different challenges.

\begin{tabular}{lc}
\multicolumn{1}{c}{ Challenge } & Present \\
\hline Channel instability & Yes \\
\hline Land use change & Yes \\
\hline Water quality degradation & Yes \\
\hline Loss of flora and fauna & Yes \\
\hline Saltwater (tidal) intrusion & No \\
\hline Removal of vegetation & Yes \\
\hline $\begin{array}{l}\text { Loss of floodplains and } \\
\text { wetlands }\end{array}$ & Yes \\
\hline
\end{tabular}

Hydropower plants, dams, and other hydraulic structures

\section{Co-Benefits:}

Water retention NNBF can deliver a range of co-benefits, in addition to reducing flood risk.

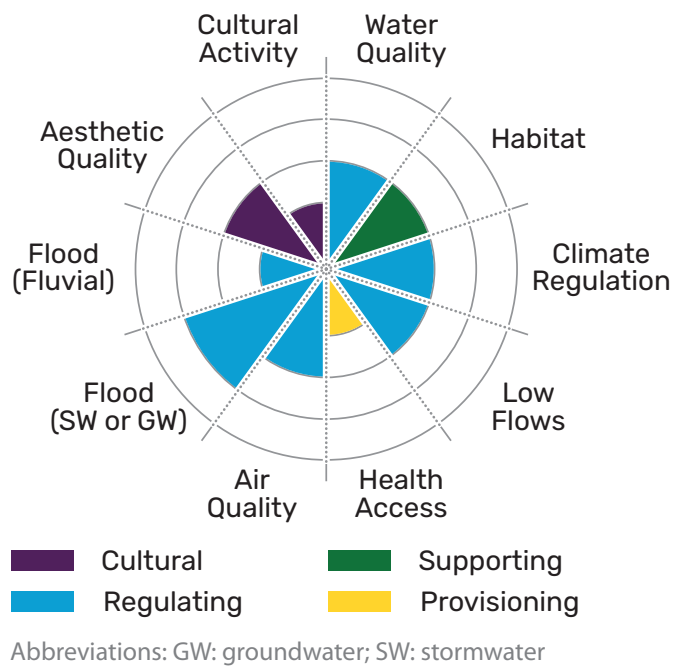

\section{6 | Erosion Management}

This section covers NNBF for protecting riverbanks and riverbeds from erosion in areas where banks should not be left to erode naturally due to constraints such as flood protection, urban development, or the presence of other infrastructure such as roads and pipelines. These NNBF are typically referred to as stream bioengineering or green infrastructure (Roca et al. 2017). Although the term green infrastructure is increasingly used to describe a broad suite of nature-based stormwater control measures including upland management practices, the term green infrastructure is used in this chapter to describe the application of NNBF and bioengineering techniques to channels for erosion management. 
Material eroded from the riverbanks or riverbed can deposit in the main channel, reducing its conveyance capacity and thus increasing flood risks. Therefore, these NNBF contribute to reducing flood risks, although their main objective is to stabilize channel banks. When implementing other NNBF for FRM that involve modifying the river planform or channel cross section, such as river or floodplain restoration NNBF, erosion management NNBF based on nature (green infrastructure and bioengineering) should be considered to protect watercourses from erosion.

This section describes erosion management NNBF. The effects of erosion management NNBF on flood risk are described in Figure 18.6 and in Table 18.5.

Figure 18.6. Schematic of Erosion Management

\section{Erosion Management}

- Protects riverbanks

- Reduces erosion of banks

- Replaces hard engineering with vegetated banks

Table 18.5. Erosion Management NNBF

\section{Aquatic and riparian vegetation management}

Native plants well adapted to living in streams can be used to protect the banks and toe of the riverbank by retarding flow velocities and providing root reinforcement to the toe and banks.

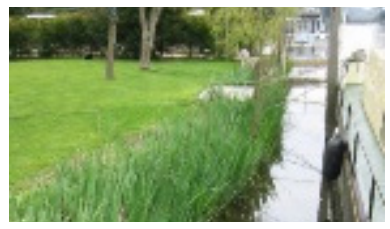

Photograph source: Environment Agency

\section{Vegetated gabions and mattresses}

Gabions and mattresses are wire-mesh baskets filled in situ with stone, with woody vegetation inserted as posts and poles through the basket. They are used to stabilize the bank toe by piling up on top of each other or are extended on the bank to retain it.

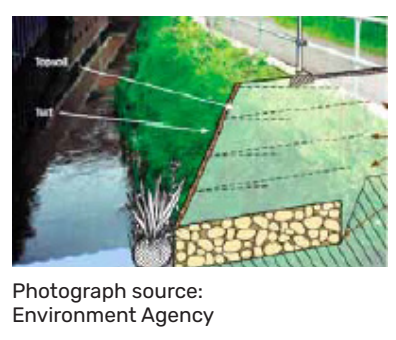




\section{Coir matting and rolls}

Coir matting and rolls are made of biodegradable material from natural fibers (such as coir) pressed into shapes including matting or sausage-shaped elements (rolls). They provide a rooting base for vegetation to establish. Rolls can be used to stabilize the toe of the slope.

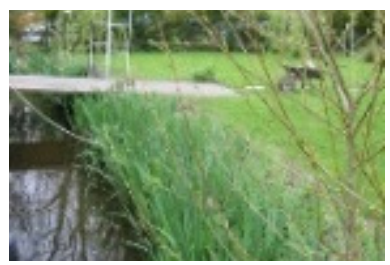

Photograph source:

Environment Agency

\section{Vegetated reinforced earth}

Grasses or live cut branches intermixed with soil wrapped in a natural fabric or geotextile to protect the bank face.

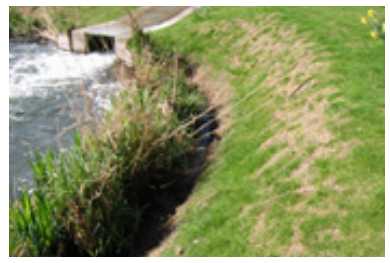

Photograph source:

Environment Agency

\section{Longitudinal peaked stone toe protection}

Longitudinal peaked stone toe protection includes bioengineering and an erosion-control blanket.

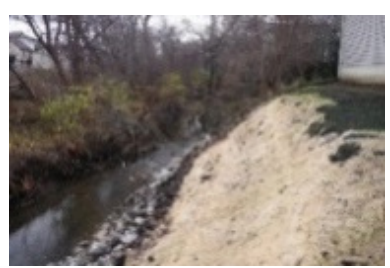

Photograph source: USACE

\section{Vegetated riprap}

Layers of stone and boulders with poles, brush-layers, or live-staking are used to stabilize the bank and toe.

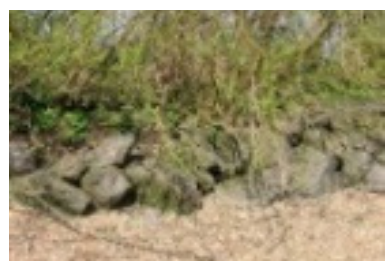

Photograph source: Environment Agency

\section{Staking}

Live or dead stakes are used to reinforce banks, promote vegetation regrowth, and anchor other vegetated measures until they are fully developed. Staking is also used at the toe as scour protection.

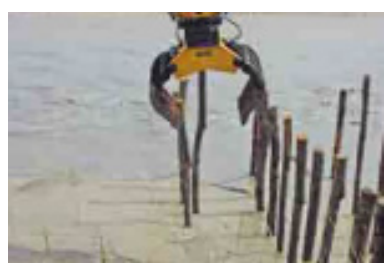

Photograph source: USACE 


\section{Willow plantings}

Willow plantings can form a fence-like structure backfilled with soil or in hurdles to deflect flow away from the bank and promote nearbank deposition.

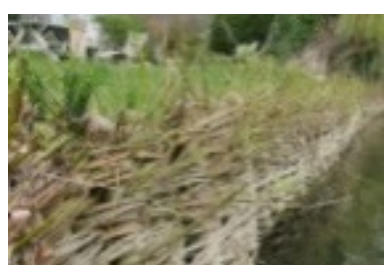

Photograph source: Environment Agency

\section{Vegetated concrete blocks}

Vegetated concrete blocks are articulated block systems with vegetation inserted through the openings in the blocks into the soil beneath them.

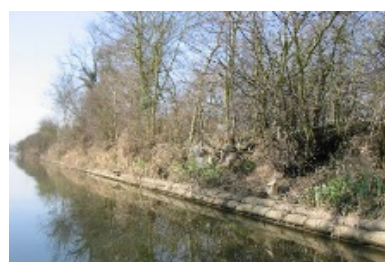

Photograph source: Environment Agency

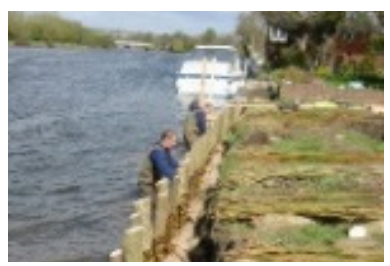

Photograph source: Environment Agency

This NNBF is described in detail, summarizing the challenges and benefits associated with it. Chapter 19, Section 19.5, includes the following case studies that exemplify the different NNBF described in this section:

- Delta Headwaters Project, United States

- Bank Protection in the Clun River, United Kingdom

- Bank and Toe Protection in the Monnow River, Wales, United Kingdom

- Hå River, Norway

\subsubsection{Green Infrastructure and Bioengineering}

Green infrastructure and bioengineering approaches are effective at reducing flow velocities and protecting banks under a range of flow conditions. They can be combined in existing schemes and with other structural NNBF by selecting the right species and materials to match site conditions. 
From a technical aspect, the success of these NNBF depends on, among other factors, understanding the conditions of the watercourse, with the support of a geomorphological assessment. Designing the NNBF must take into account bank slopes, development of scour, and transitions of material. During the installation, care must also be taken to assess the condition of live species and the time of the year to ensure the NNBF is effectively installed. This type of NNBF can help reduce incision.

The different types of erosion management NNBF are described in Table 18.5.

This NNBF can also address many of the challenges discussed in Chapter 17, and if well designed can deliver a range of co-benefits, in addition to reducing flooding. Green infrastructure and bioengineering challenges addressed and co-benefits, including a benefits wheel (discussed in Chapter 17), are provided in the following graphic.

\section{Green Infrastructure and Bioengineering Challenges Addressed and Co-Benefits}

\section{Challenges Addressed:}

This NNBF can address a wide range of different challenges especially related to erosion and channelization.

\begin{tabular}{lc}
\multicolumn{1}{c}{ Challenge } & Present \\
\hline Channel instability & Yes \\
\hline Land use change & Yes \\
\hline Water quality degradation & Yes \\
\hline Loss of flora and fauna & Yes \\
\hline Saltwater (tidal) intrusion & No \\
\hline Removal of vegetation & Yes \\
\hline $\begin{array}{l}\text { Loss of floodplains and } \\
\text { wetlands }\end{array}$ & Yes \\
\hline
\end{tabular}

Hydropower plants, dams, and No other hydraulic structures

\section{Co-Benefits:}

Green infrastructure and bioengineering NNBF can deliver a range of co-benefits, in addition to reducing flood risk such as aesthetic quality and habitat.

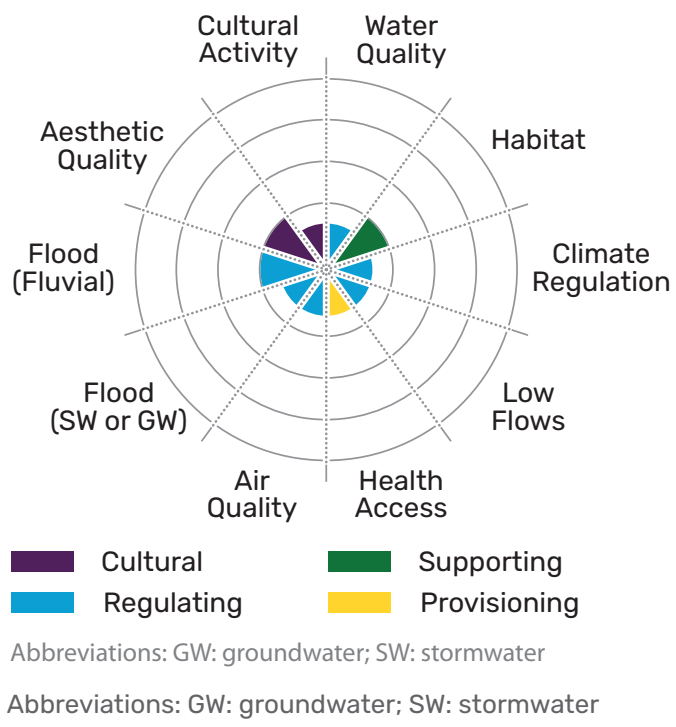




\section{7| References}

Addy, S., S. Cooksley, N. Dodd, K. Waylen, J. Stockan, A. Byg, and K. Holstead. 2016. River Restoration and Biodiversity: Nature-Based Solutions for Restoring the Rivers of the UK and Republic of Ireland. Aberdeen: Centre for Expertise in Water (CREW).

ceh.ac.uk. 2017. Systematic Review to Examine Evidence on How Trees Influence Flooding. UK Centre for Ecology and Hydrology. https://www.ceh.ac.uk/news-and-media/news/ review-launched-examine-how-trees-influence-flooding.

CIRIA (Construction Industry Research and Information Association). 2015. The SUDS Manual. CIRIA Report C753. London: CIRIA.

Dufour, S., and H. Piégay. 2009. "From the Myth of a Lost Paradise to Targeted River Restoration: Forget Natural References and Focus on Human Benefits." River Research and Applications 25 (5): 568-581.

Environment Agency. 2010. Working with Natural Processes to Manage Flood and Coastal Erosion Risk. Guidance document. Bristol, UK: Environment Agency.

Environment Agency. 2012. Greater Working with Natural Processes in Flood and Coastal Erosion Risk Management: A Response to Pitt Review Recommendation 27. Bristol, UK: Environment Agency.

Environment Agency. 2014. Aquatic and Riparian Plant Management: Controls for Vegetation in Watercourses. Series of reports from Joint Defra and Environment Agency FCERM R\&D programme, Project SC120008. Bristol, UK: Environment Agency.

Environment Agency. 2015. Channel Management Handbook for Flood Risk Management. Bristol, UK: Environment Agency.

Environment Agency. 2017. Working with Natural Processes: Evidence Directory. Bristol, UK: Environment Agency.

Forest Research. 2008. The Robinwood Robinflood Report: Evaluation of Large Woody Debris in Watercourses. Report for the Robinwood Project, an INTEREG IIIc Regional Framework Operation project. Farnham, UK: Forest Research.

Hudson, N., 1995. Soil Conservation. Third edition. London: B. T. Batsford.

Leopold, L. B., and T. Maddock. 1954. The Flood Control Controversy. New York: Ronald Press.

Nicholson, A. R., M. E. Wilkinson, G. M. O'Donnell, and P. F. Quinn. 2012. "Runoff Attenuation Features: A Sustainable Flood Mitigation Strategy in the Belford catchment, UK." Area 44 (4): 463-469. 
Oxford Martin School. 2017. A Restatement of the Natural Science Evidence Concerning Catchment-Based "Natural" Flood Management in the UK. Oxford Martin Restatement 4. Oxford: Oxford Martin School, University of Oxford.

POST (Parliamentary Offices of Science and Technology). 2014. Catchment-Wide Flood Management. POST-PN-484. London: POST.

Roca, M., M. Escarameia, O. Gimeno, L. de Vilder, J. D. Simm, B. Horton, and C. Thorne. 2017. Green Approaches in River Engineering - Supporting Implementation of Green Infrastructure. Wallingford, UK: HR Wallingford. 


\section{Acknowledgments}

\section{Lead Authors}

Lydia Burgess-Gamble, Environment Agency, United Kingdom

Christopher Haring, U.S. Army Corps of Engineers, United States

Ralph Schielen, Rijkswaterstaat, the Netherlands

Jo Guy, Environment Agency, United Kingdom

\section{Co-Authors}

David Ramsbottom, HR Wallingford, United Kingdom

Bridget Woods Ballard, HR Wallingford, United Kingdom

Marta Roca Collell, HR Wallingford, United Kingdom

Rachel Glover, Environment Agency, United Kingdom

Felix van Zoest, Rijkswaterstaat, the Netherlands 


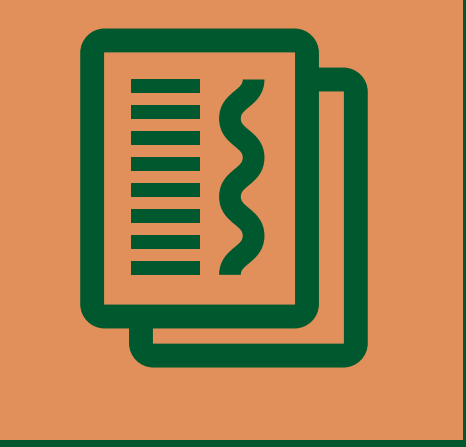

\section{Key Messages}

1. Although using natural and nature-based features (NNBF) to help alleviate flooding is relatively new, there are already a wide range of examples of their application globally.

2. Case studies can act as an inspiration for river managers worldwide to select the appropriate NNBF to reduce flood risk.

3. Case studies enable river managers to do the following:

a. Learn and share their experiences so that others can learn from past successes and failures

b. Reflect back and understand what worked well and what could have been done differently, which enables the science and practice of NNBF to develop 


\section{1 | Introduction}

This is the final chapter of the fluvial section of the International Guidelines on Natural and Nature-Based Features for Flood Risk Management. To summarize, the fluvial section includes Chapters 15 through 19 . Chapter 15 introduces the natural and nature-based features (NNBF) applications for fluvial settings. Chapter 16 describes fluvial systems and their relation to flood risk management (FRM). Chapter 17 describes the benefits and challenges associated with NNBF in fluvial systems, Chapter 18 provides an overview of the role and range of NNBF available for fluvial applications, and Chapter 19 provides case study examples of different types of fluvial NNBF applications from around the world.

The case studies in this chapter are organized to provide consistent information for ease of comparison. Each case study provides information on project dates, costs, and stakeholders, as well as contacts and resources for further information. Each case study also includes detailed descriptions of the project, the flood risk impacts, co-benefits, and lessons learned.

Figure 19.1 shows the locations of the different case studies in a representative watershed to provide context on the relevant area of the watershed. However, each case study presents projects from around the world, and Figure 19.1 is not intended to convey a realistic map. 


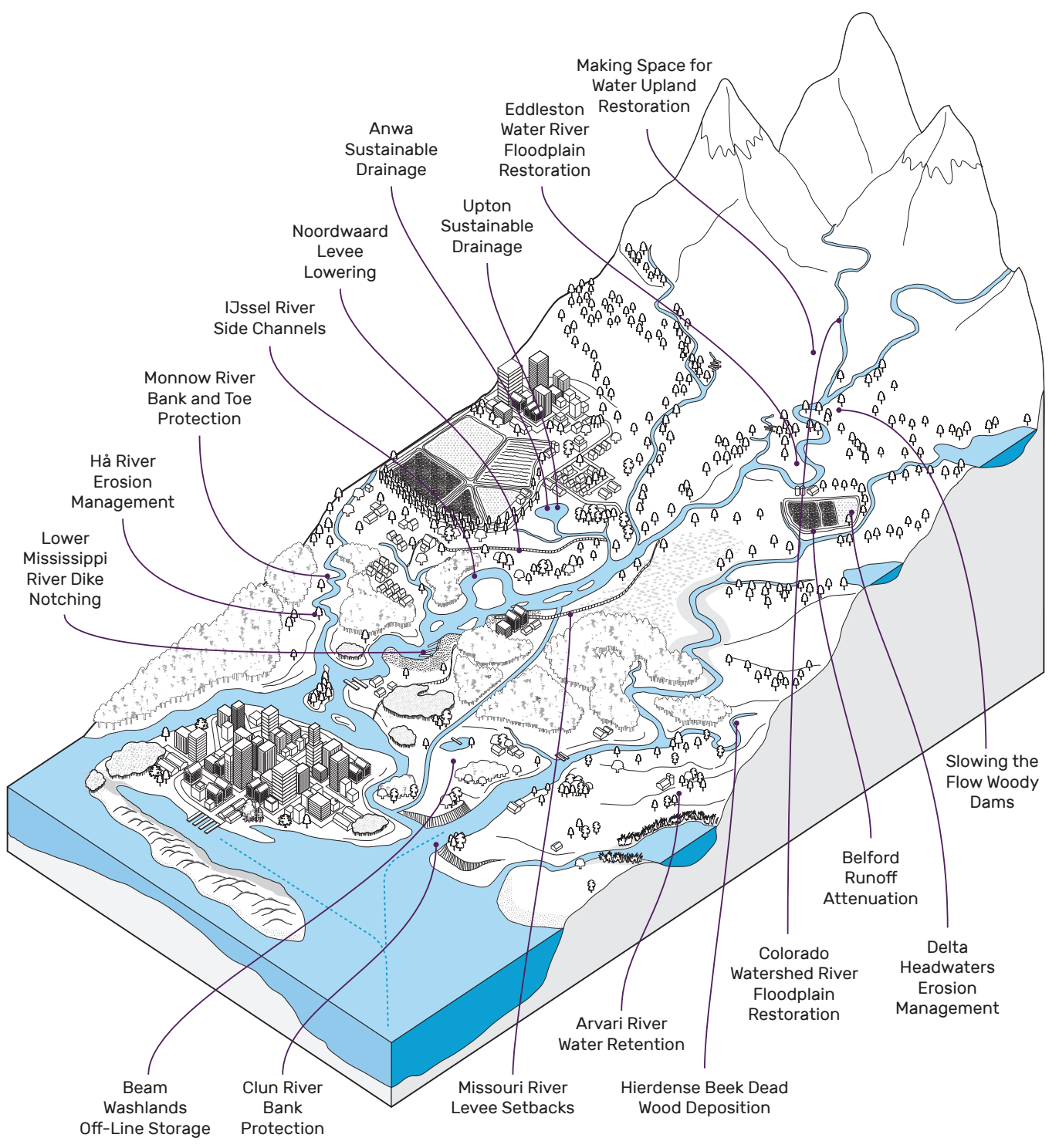


CASE STUDY:

\subsubsection{Missouri River Floodplain Connectivity via Large-Scale Levee Setbacks, lowa, United States}

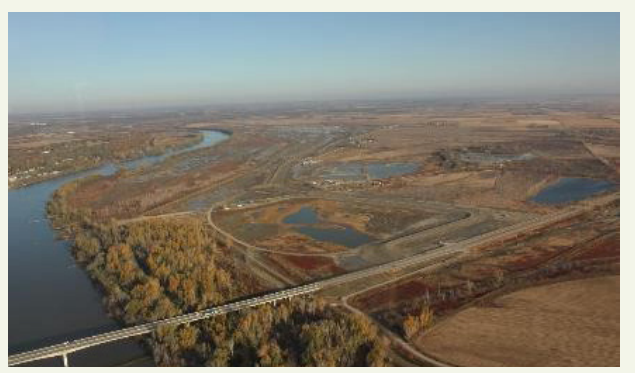

Source: David Crane, U.S. Army Corps of

Engineers, Omaha District

Construction date:

2012 to 2013

Total cash cost of the project:

$\$ 60$ million U.S. dollars (USD)

(approximately USD\$4 million per

kilometer of setback)

Measures included:

Levee setback

Project funders:

U.S. Army Corps of Engineers,

Omaha District
Challenges addressed:

\begin{tabular}{lc}
\multicolumn{1}{c}{ Challenge } & Present \\
\hline Channel instability & Yes \\
\hline Land use change & Yes \\
\hline Water quality degradation & Yes \\
\hline Loss of flora and fauna & Yes \\
\hline Saltwater (tidal) intrusion & No \\
\hline $\begin{array}{l}\text { Removal of vegetation } \\
\text { Loss of floodplains and } \\
\text { wetlands }\end{array}$ & No \\
\hline $\begin{array}{l}\text { Hydropower plants, } \\
\text { dams, and other hydraulic } \\
\text { structures }\end{array}$ & Yes \\
\hline
\end{tabular}

\subsubsection{Description - What Did the Project Do?}

The 2011 Missouri River flood resulted in extreme riverward and landward scouring along the $L 575$ levee toes and expansive sand boils, which indicated levee foundational damage from underseepage. After the flood, the levee sponsors, adjacent landowners, and U.S. Army Corps of Engineers (USACE), Omaha District, 
discussed creating floodplain connectivity through the implementation of levee setbacks at three locations under the USACE Disaster Operations Public Law (PL) 84-99 Program. 'The objective of a levee setback is to relocate a segment of a levee from its current alignment near the banks of a river to a location farther from the banks. Two levee setbacks approximately 6 kilometers $(\mathrm{km})$ long were constructed-one north and south of Highway 2 in Fremont County, lowa (the Highway 2 setback), and one (the Frazers Bend setback) $5 \mathrm{~km}$ south, opposite the Nebraska Public Power District coal-fired power plant in Nebraska City. A third hydraulically significant levee setback was constructed on the lower end of the L-594 levee across the river from a natural bluff. It should be noted that levee setbacks may be implemented under PL 84-99 as a nonstructural alternative plan, but they were not implemented as a nonstructural alternative plan at the L-575 or L-594 levees in 2012 and 2013. PL 84-99 generally requires that USACE implement the lowest cost, technically practical alternative for levee rehabilitation. These setbacks were the least costly alternative compared to in-line repairs. They were technically practical because the land provided for the setback was already owned for the purpose of habitat restoration under the USACE's Missouri River Recovery Program.

\subsubsection{Flood Risk Impacts of the Project}

The following are the flood risk impacts of the Missouri River floodplain connectivity via large-scale levee setbacks:

- Levee setbacks result in decreased flood stages and loading frequency, providing reduced exposure and reduced risk within and upstream of the project area. Because real estate was provided by the USACE's Missouri River Recovery Program, the new levee segments could be placed on more suitable geotechnical foundations farther from the Missouri River at higher elevations, which reduced velocities, erosion, and scour and provided better subsurface materials within the project area. These improvements resulted in increased levels of levee performance within the setback areas.

- A levee setback alignment can result in increased flood conveyance. Increased conveyance decreases water surface elevations and subsequent pressure on levees, thereby increasing the protection and resiliency provided by the system. Decreased water surface elevations could potentially result in a decrease in operations, maintenance and repair, rehabilitation, and replacement activities. 
- The Highway 2 bridge was the most constrictive floodwater conveyance hydraulic "pinch point" along the Missouri River and was reduced by construction of the Highway 2 setback. A project conducted by the lowa Department of Transportation in 2019 further reduced the remnant hydraulic constriction at this location by raising Highway 2.

- The Frazers Bend setback helped reduce floodwater velocities and stage elevations across the Missouri River at the Nebraska Public Power District power plant.

\subsubsection{Co-Benefits of the Project}

By combining the resources of federal, state, and local agencies and their programs, natural ecological co-benefits can be attained through implementing levee setbacks on land established for purposes of habitat restoration. This helps alleviate the responsibility of local levee sponsors to purchase real estate from adjacent private landowners.

Increasing co-benefits while enhancing engineering designs is a main goal of USACE's Engineering With Nature Initiative (ewn.el.erdc.dren.mil, n.d.), but it is not a priority or an authorized purpose of the PL 84-99 Program. Some of the co benefits realized as a result of the levee setback practices are ecosystem sustainability, increased recreational opportunities, aesthetics, and cultural and educational opportunities. Regarding the L-575 levee setbacks specifically, the Missouri River Recovery Program lands were used as borrow mining areas, which were then converted to wetlands following material excavation. Drainage ditches run through some of these borrow pits, providing added nutrient treatment opportunities for the ditch water carried from surrounding agricultural lands to be filtered through wetlands before entering the Missouri River channel.

The USACE Omaha District is responsible for operation and maintenance of the Missouri River Bank Stabilization and Navigation Project and the mainstem reservoirs. Those responsibilities include taking actions under the U.S. Endangered Species Act to address listed species that may be affected by the operation of the Missouri River. A biological opinion provided USACE with a Reasonable and Prudent Alternative that, if accomplished, would likely avoid jeopardizing three listed species (pallid sturgeon [Scaphirhynchus albus], least tern [Sternula antillarum], and piping plover [Charadrius melodus]). Actions taken to address biological opinion requirements occur under the Missouri River Recovery Program. 


\subsubsection{Lessons Learned}

The following lessons were learned over the course of the project, particularly those that relate to fluvial systems and NNBF:

- Community and political desire for levee setbacks greatly supports prioritization and construction of levee setbacks.

- Multiagency coordination and cooperation are critical for successful and timely implementation of levee setbacks. Real estate for borrow material, levee setback footprint, and other crucial project elements may require rapid interagency collaboration in order for a levee setback to be completed under PL 84-99. For the L 575 levee setbacks, the following agencies and other stakeholders collaborated to make the project a success: USACE, Natural Resources Conservation Service, Federal Highway Administration, U.S. Fish and Wildlife Service, lowa Department of Natural Resources, lowa Department of Transportation, Fremont County, L-575 levee sponsor and drainage districts, and local landowners.

- The ability to be flexible and to find creative solutions to complex problems will be required of all parties for successful setback implementation under PL 84-99.

\subsubsection{Further Information}

ewn.el.erdc.dren.mil, n.d. EWN Initiative. Engineering With Nature. https://ewn.el.erdc. dren.mil/about.html.

Krause, T., K. Baxter, D. Crane, and R. Behm. 2015. "Evaluation of Levee Setbacks as a Sustainable Solution along the Missouri River." Paper presented at the Proceedings of the Joint Federal Interagency Conference 2015: Sustainable Water Resources in a Changing Environment. Reno, NV. April 19-23, 2015. https://acwi.gov/sos/pubs/3rdJFIC/Contents/4E-Krause.pdf.

USACE (U.S. Army Corps of Engineers). 2013. Finding of No Significant Impact \& Revision to: December 2011 Tiered Environmental Assessment. Omaha, NE: USACE Omaha District. https://cdm16021.contentdm.oclc.org/digital/ collection/p16021coll7/id/298. 
CASE STUDY:

\subsubsection{Noordwaard, the Netherlands}

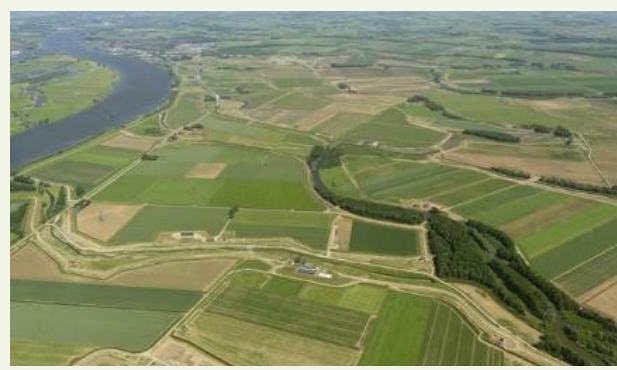

Source: https://beeldbank.rws.nl, Rijkswaterstaat

Construction date:

2009 to 2014

Total cash cost of the project:

$€ 375$ million euros (USD\$442 million)

Measures included:

Lowering of main levee to create extra discharge area, construction of polders, application of vegetation on a dike to reduce impact of waves

Project funders:

Ministry of Infrastructure and Water

Management, Ministry of Economic Affairs

Omaha District

Main contacts:

Room for the River Program
Challenges addressed:

\begin{tabular}{lc}
\multicolumn{1}{c}{ Challenge } & Present \\
\hline Channel instability & No \\
\hline Land use change & Yes \\
\hline Water quality degradation & Yes \\
\hline Loss of flora and fauna & Yes \\
\hline Saltwater (tidal) intrusion & No \\
\hline Removal of vegetation & No \\
\hline $\begin{array}{l}\text { Loss of floodplains and } \\
\text { wetlands }\end{array}$ & Yes
\end{tabular}

Hydropower plants, No dams, and other hydraulic structures

\subsubsection{Description - What Did the Project Do?}

The Noordwaard is a relatively large area in the Dutch Rhine Delta, enclosed by the New Merwede River and the Meuse River. The Noordwaard has an area of approximately 4.500 hectares (ha) and is one of the largest projects within the Room 
for the River Program." The levee at the upstream part of the New Merwede River was lowered, meaning that the area is inundated at lower peak discharges and, hence, the flood risk for the upstream area is reduced. The area is divided into two sections-a section that floods multiple times each year but is suited for cattle farming and a section that floods once every 100 to 1,000 years and is suited for agriculture. In the agricultural section, farms are located on mounds.

\subsubsection{Flood Risk Impacts of the Project}

These restoration measures together resulted in the following flood risk impacts:

- A 60-centimeter flood level reduction at the entrance to the site and a 30 -centimeter flood level reduction $10 \mathrm{~km}$ upstream of the entrance

- Increased frequency of floodplain inundation

\subsubsection{Co-Benefits of the Project}

Improving the spatial quality of the area was an important aspect of this project. The relandscaping was inspired by maps from 1905. More than 30 bridges (necessary because of the construction of the polders and creeks) have been built to make the area accessible. Recreation is possible but somewhat restricted to guarantee the privacy of the rest of the inhabitants. An existing dike protecting an old fort had to be reinforced, so willow vegetation was used on the dike to reduce wave impact, which also reduced the overall height of the dike. The Noordwaard connects with a national park (De Biesbosch) and has been used to reinforce the Natura 2000 network (Natura 2000 is a European initiative to increase nature protection and improve biodiversity). The measure also introduced a tide difference, which was also present until 1970.

\subsubsection{Lessons Learned}

The following lessons were learned during the course of this project:

- Getting inspired by the historical layout of the area and taking this into account in the relandscaping worked well and improved the experience of entering the Noordwaard. 
- Small roads and irregular fields form part of the design of the new Noordwaard. However, farmers sometimes find it difficult to access their land using these small roads. Also, the shape of their field is not (yet) optimal from an economic point of view.

- Conducting a good start-up meeting right after commissioning this project probably could have avoided some miscommunication in the redesign.

\subsubsection{Further Information}

issuu.com. 2016. Verantwoordingsrapportage ruimtelijke kwaliteit ontpoldering noordwaard [in Dutch] [Accountability Report: Spatial Quality in the Noordwaard]. ISSUU. https://issuu.com/ruimtevoorderivier/docs/ verantwoordingsrapportage_ruimtelii.

rijkswaterstaat.nl., n.d. Ruimte voor de rivieren [in Dutch] [Room for the River - Noordwaard]. Rijkswaterstaat. https://www.rijkswaterstaat.nl/ water/waterbeheer/bescherming-tegen-het-water/maatregelen-omoverstromingen-te-voorkomen/ruimte-voor-de-rivieren/index.aspx.

ruimtevoorderivier. 2015. "Project Noordwaard Ruimte voor de Rivier" [in Dutch]. Uploaded on September 24, 2015. YouTube video, 02:32. https://www. youtube. $\mathrm{com} /$ watch? $\mathrm{v}=$ Wf8zVOY991M. 
CASE STUDY:

\subsubsection{IJssel River near Deventer, the Netherlands}

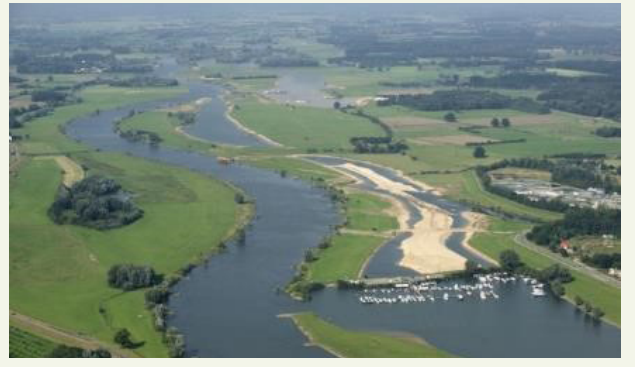

Source: gedin.nl 2013

Construction date:

2010 to 2015

Total cash cost of the project:

$€ 105$ million euros (USD\$124 million)

Measures included:

Constructing side channels

Project funders:

Ministry of Infrastructure and Water

Management, Ministry of Economic Affairs

Main contacts:

Room for the River Program
Challenges addressed:

\begin{tabular}{lc}
\multicolumn{1}{c}{ Challenge } & Present \\
\hline Channel instability & Yes \\
\hline Land use change & Yes \\
\hline Water quality degradation & No \\
\hline Loss of flora and fauna & Yes \\
\hline Saltwater (tidal) intrusion & No \\
\hline $\begin{array}{l}\text { Removal of vegetation } \\
\text { Loss of floodplains and } \\
\text { wetlands }\end{array}$ & No \\
\hline
\end{tabular}

Hydropower plants, No structures

\subsubsection{Description - What Did the Project Do?}

Along the IJssel River, in and near the City of Deventer, in the Netherlands, a number of side channels were constructed on both sides of the river, with an average width of 100 meters $(\mathrm{m})$. This created extra discharge capacity and, hence, lowered floodwater levels. Some smaller levees in the floodplain were removed such that the area behind the former levees could be inundated by floodwater in an earlier stage, thus 
decreasing the height of the floodwaters. A characteristic hotel located near the river was provided with a green waterfront. A floating jetty was constructed to connect the city front with the floodplain. In the northern part of the project area, space was created for an ecological water farm that also maintains the floodplain by cattle grazing. The farm itself is located on a newly constructed mound.

\subsubsection{Flood Risk Impacts of the Project}

The construction of the side channels resulted in a 10- to 19-centimeter reduction of the upstream flood levels at high discharges.

\subsubsection{Co-Benefits of the Project}

The side channels provide opportunities for increasing biodiversity and add to the goals of the European initiative Natura 2000."ii Recreation possibilities are increased for hiking, biking, and water sports. Rowing clubs have been given additional opportunities for training. The panorama along the river has changed for the better, and there is more coherence in the area with respect to fragmented planting. An ecological farm has been built, and the cattle from this farm help in keeping the vegetation low such that no obstruction for the water occurs.

\subsubsection{Lessons Learned}

The success of this project was mainly due to good cooperation with the private party Stichting IJssellandschap (a local stakeholder that preserves landscapes, farms, and houses around the City of Deventer), which owns almost all the land and also had a clear vision on how to combine ecological farming with water safety. The merging of the governmental plans and the initiative of Stichting IJssellandschap made this project possible.

The combination of different interests requires very careful zoning of functions, such as water safety, farming, nature, and recreation (hotel, camping, harbor, rowing, fishing, hiking, and cycling). For example, recreation should be extensive in those areas that are primarily reserved for nature goals. This can be a problem especially near the city. Another example of conflicting interests is the discharge of the side channels. For flood safety, the side channels should be reasonably large, but they might cause sedimentation in the main channel. Simultaneously, at low discharges, 
the large side channels have limited added value with respect to the aims of the Water Framework Directive. (The Water Framework Directive commits European Union member states to achieve good water quality status for all waterbodies.)

\subsubsection{Further Information}

gedin.nl. 2013. Rumte voor de Rivier - Deventer [in Dutch]. Gedin Engineering. http:// gedin.nl/nl/projecten/ruimte-voor-de-rivier-deventer/.

rijkswaterstaat.nl., n.d. Ruimte voor de rivieren [in Dutch] [Room for the River Deventer]. https://www.rijkswaterstaat.nl/water/waterbeheer/beschermingtegen-het-water/maatregelen-om-overstromingen-te-voorkomen/ruimtevoor-de-rivieren/index.aspx.

ruimtelijkeplannen.deventer.nl, n.d. 4.6 Ruimtelijke kwaliteit [in Dutch] [Municipality of Deventer - Room for the River]. Ruimte voor de Rivier. http:// ruimtelijkeplannen.deventer.nI/plans/NL.IMRO.0150.D130-/NL.IMR0.0150. D130-OW01/t_NL.IMR0.0150.D130-OW01_4.6.html.

ruimtevoorderivier. 2011. "Ruimte voor de Rivier, Deventer - NL" [in Dutch] [Room for the River, Deventer - NL]. Uploaded on December 8, 2011. YouTube video, 03:24. https://www.youtube.com/watch?v=0_3rOgNw6PM. 


\section{CASE STUDY:}

\subsubsection{Jubilee River alongside Thames River, United Kingdom}

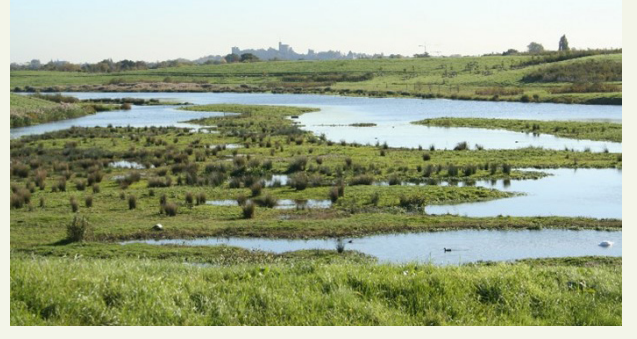

Source: Environment Agency

Construction date:

1996 to 2001

Total cash cost of the project:

$€ 110$ million euros (USD\$130 million)

Measures included:

Constructing side channels

Project funders:

Environment Agency

Main contacts:

Environment Agency
Challenges addressed:

\begin{tabular}{lc}
\multicolumn{1}{c}{ Challenge } & Present \\
\hline Channel instability & Yes \\
\hline Land use change & Yes \\
\hline Water quality degradation & No \\
\hline Loss of flora and fauna & Yes \\
\hline Saltwater (tidal) intrusion & No \\
\hline Removal of vegetation & No \\
\hline $\begin{array}{l}\text { Loss of floodplains and } \\
\text { wetlands }\end{array}$ & No \\
\hline
\end{tabular}

Hydropower plants, No dams, and other hydraulic structures

\subsubsection{Description - What Did the Project Do?}

Jubilee River extends for a total length of $11.6 \mathrm{~km}$ to the east of the Thames River, west of London. It leaves the Thames River on the east bank immediately upstream of Boulters Weir in Maidenhead, flowing in a southeasterly direction. It continues alongside the M4 Motorway near Slough before re-entering the Thames River downstream of Black Potts Viaduct in Eton. Combined with levees, the Jubilee River project significantly reduces flood risk to more than 5,500 homes and businesses 
in Maidenhead, Windsor, and Eton. In addition, it reduces the risk of flood-related disruption to vital transport links with London and the United Kingdom's Silicon Valley, including a mainline rail route and the M4 Motorway. It also overcame many of the problems of the Thames River not functioning as a natural river in this area.

\subsubsection{Flood Risk Impacts of the Project}

The project provides protection from flooding up to a total discharge in the combined Thames and Jubilee Rivers of 450 cubic meters $\left(\mathrm{m}^{3}\right)$ per second. It thereby provides protection up to a one-in-65-year event. In December 2002, the Jubilee River catchment area experienced more than twice the average rainfall for the month. None of the 5,500 properties previously at risk experienced any flooding.

\subsubsection{Co-Benefits of the Project}

The Jubilee River channel incorporates some of the features of a natural river environment and, in some aspects, improves on the nearby channelized section of the Thames River, with the new channel and flood defenses being designed to integrate with the existing environment and character of the surrounding areas. A key feature of the design was to create a green corridor, to encourage the natural movement of animals and regeneration of biodiversity, providing significant wildlife benefits to a much wider area than the channel corridor itself. The final route was selected to minimize destruction of existing habitat features and communities and to avoid residential areas so that no existing buildings needed to be demolished. These practical and ecological considerations resulted in a meandering route for the new river channel, which resembled the shape that a natural river might take.

Although the low-flow channel has a basic trapezoidal design to move $200 \mathrm{~m}^{3}$ per second, varying widths, depths, and aquatic features were incorporated into the channel itself to meet the ecological objectives of creating a viable and diverse aquatic ecosystem within the overriding engineering objective of providing cost-effective flood relief. In addition, every opportunity was taken along the river corridor to utilize additional land where available, and to enhance the landscape-adding terraces and organic morphology to allow habitats to be incorporated. Use of native plants was prioritized. (For example, advance collection of local provenance seeds of plant species characteristic of the local area, including acorns from the ancient oaks at Windsor Great Park, allowed plant germination by specialist nurseries in readiness for the major planting program.) Land remediation, 
including removal of $130,000 \mathrm{~m}^{3}$ of contaminated soil, enabled the creation of Dorney Wetlands, the location of old sewage treatment works, and allowed reinstatement of reed beds and extensive areas of marginal habitats.

The project also provided the local community with new and improved green open spaces offering recreational opportunities and facilities. The construction of $14 \mathrm{~km}$ of long-distance, new paths, cycleways and bridleways, and parking facilities allowed convenient and safe access to the river and its surrounding environment.

\subsubsection{Lessons Learned}

1. Partnership and interdisciplinary working between engineers, landscape architects, and other key design professionals is not optional but is essential for success. A sense of ownership of the project was created through ongoing consultation with more than 60 government, industry, and specialist interest groups, including a competition to name the completed project.

2. A critical aspect of the cost-effectiveness of the scheme was maximizing the reuse of materials. Gravels were exported for sale as aggregates, which offset some of the project costs. As important, a cut-fill balance was created, with a hub site that allowed exchange materials and avoided hauling earthworks on main roads.

3. Transport infrastructure was maintained and enhanced in a highly populated area. No road or mainline rail closures took place during the 5 years of construction, and a total of 11 new bridges were created. 
CASE STUDY:

\subsubsection{Beam Washlands, Dagenham, London, United Kingdom}

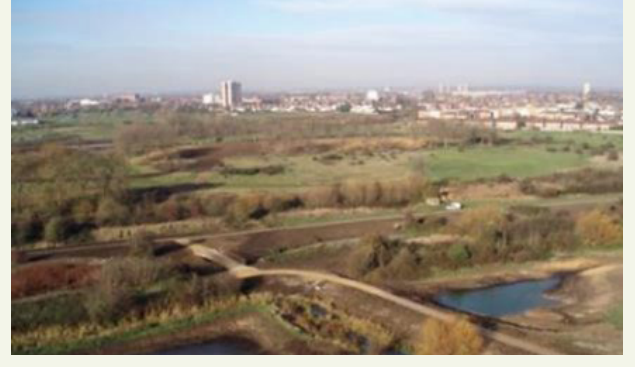

Source: Environment Agency

Construction date:

2012

Total cash cost of the project:

- Total-£8.2 million Great Britain pounds (GBP) (USD\$11.3 million)

- Capital project-GBP£4.5 million (USD\$6.2 million)

- NNBF-GBP£3.7 million

(USD\$5.1 million)

Measures included:

Washland storage area, river, and

floodplain restoration

Project funders:

Environment Agency, London

Development Agency (European Regional Development Fund), Communities and

Local Government Parklands Fund,

Landfill Tax Credits Scheme, and London

Borough of Barking and Dagenham

Main contacts:

Environment Agency
Challenges addressed:

\begin{tabular}{lc}
\multicolumn{1}{c}{ Challenge } & Present \\
\hline Channel instability & Yes \\
\hline Land use change & Yes \\
\hline Water quality degradation & Yes \\
\hline Loss of flora and fauna & Yes \\
\hline Saltwater (tidal) intrusion & No \\
\hline Removal of vegetation & No \\
\hline $\begin{array}{l}\text { Loss of floodplains and } \\
\text { wetlands }\end{array}$ & Yes \\
\hline
\end{tabular}

Hydropower plants, No

dams, and other hydraulic structures 


\subsubsection{Description - What Did the Project Do?}

This multi-award-winning partnership project built on a GBP£4.5-million (USD\$6.2-million) flood and coastal risk management project to improve the integrity and capacity of the flood storage washland, providing better protection to more than 570 homes and businesses.

The project provides a large, habitat-rich, community parkland in one of east London's most deprived communities. This includes 12.6 ha of habitat, $150 \mathrm{~m}$ of river restoration, $600 \mathrm{~m}$ of riverbank reprofiling, and $300 \mathrm{~m}$ of in-channel features on the Beam River. The project was completed in 2012, and maintenance is funded and delivered by partner organizations.

\subsubsection{Flood Risk Impacts of the Project}

The following are the flood risk impacts of the Beam Washlands Project:

- The original storage capacity of the washlands was approximately $433,000 \mathrm{~m}^{3}$. This project increased its capacity by $25,660 \mathrm{~m}^{3}$ to $458,660 \mathrm{~m}^{3}$.

- The process of containing the fluvial flows within the washlands provides a standard of protection to downstream properties up to a one-in-25-year flood event.

- The provision and operation of the pumping stations (operated if the fluvial flow exceeds the storage area's design capacity) provides an enhanced standard of protection of up to a one in-150-year event.

- This project as a whole reduces the risk of flooding for 570 homes and 90 businesses.

- The estimated economic benefits of the project are significant. It is estimated the project provides a gross asset value of avoided flood damage benefits worth GBP£591,000 (USD\$813,000) per year, compared with GBP£193,000 (USD\$265,000) per year before the project was constructed.

\subsubsection{Co-Benefits of the Project}

The Beam Washlands Project is an excellent example of how off-line storage areas can be used as an NNBF intervention while also delivering multiple social and environmental co benefits. This includes 53 ha of open space, including 12.6 ha of habitat for a range of species, the economic benefits of which have been estimated at GBP£536,000 (USD\$737,000). 
Prior to the flood risk project, the land was largely unmanaged and underutilized by the local community. During the design stages, the local community was engaged to help shape the design of the new washlands area, and now many residents enjoy the green recreational space.

\subsubsection{Lessons Learned}

The following lessons were learned over the course of the project, particularly those that relate to fluvial systems and NNBF:

- Gaining support at an early stage to make better use of the washlands was vital in convincing those involved in the project that it was a viable engineering solution.

- The early establishment of a partnership with the local authority and the Land Trust was critical to explore and create a project that delivers co-benefits.

- Drawing together external funding sources, including legacy funding, for future maintenance is important in ensuring the project's long-term performance.

\subsubsection{Further Information}

Burgess-Gamble, L., n.d. Case Study 19: Beam Washlands. London: Defra and Environment Agency Joint Flood and Coastal Erosion Risk Management Research and Development Programme. https://www.therrc.co.uk/sites/ default/files/projects/19_beam.pdf.

Environment Agency. 2013. Dagenham, Beam Washlands: Profiling Partnership Funding. Bristol, UK: Environment Agency. http://www.eacg.org.uk/Docs/PF/ Dagenham_washland_PF_final.pdf.

EFTEC (Economics for the Environment Consultancy Ltd). 2015. Beam Parklands Natural Capital Account. London: EFTEC. https://www.london.gov.uk/sites/ default/files/beam_parklands_natural_capital_account_final_report_ eftec_november_2015.pdf.

Natural England. 2013. Beam Parklands: Green Infrastructure Case Study. Peterborough, UK: Natural England. http://publications.naturalengland.org. uk/publication/12629856. 
CASE STUDY:

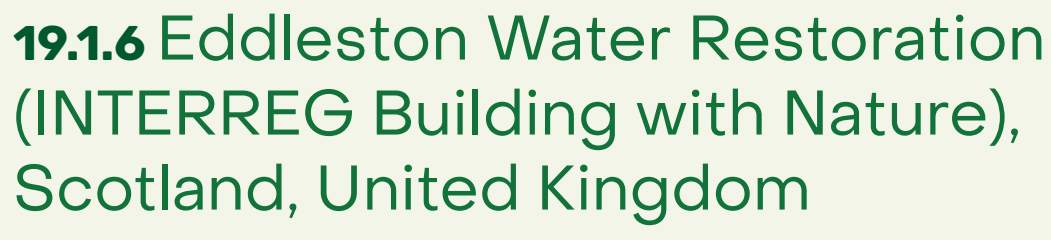

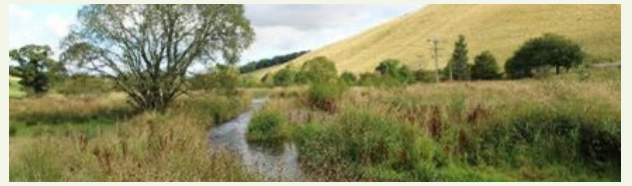

Source: Christopher Spray, University of Dundee

\section{Construction date:}

- 2009 and 2010-scoping study

- 2011 and 2012-installation of detailed monitoring network

- 2012 to 2016-implementation of natural flood management measures and monitoring

- 2016 to 2020-monitoring, further project development, evaluation, and modeling

Total cash cost of the project:

- Scoping, set up, characterization, and baseline monitoring-GBP£355,000 (USD\$488,000)

- Design and capital worksGBP£982,000 (USD\$1.4 million)

- Monitoring, evaluation, and modelingGBP£627,000 (USD\$863,000)

Measures included:

Upland (source) areas:

- Woodland planting-207 ha with more than 330,000 native trees

- Large wood structures-116 high-flow log structures

- Upstream ponds-28 wetlands have been created ( 8,000 square meters)
Valley and floodplain (pathway) areas:

- $2.8 \mathrm{~km}$ of river remeandered and 2,900 m of flood bank removed

- One floodplain pond

- $1 \mathrm{~km}$ of contour hedges planted

Project funders:

Scottish Government, Scottish

Environment Protection Agency,

Tweed Forum, Scottish Borders Council, Scottish Forestry, Scottish Natural Heritage, Forest Carbon, CEMEX, Woodland Trust, British Geological Survey, and University of Dundee

Main contacts:

Tweed Forum

Challenges addressed:

\begin{tabular}{lc}
\multicolumn{1}{c}{ Challenge } & Present \\
\hline Channel instability & Yes \\
\hline Land use change & Yes \\
\hline Water quality degradation & Yes \\
\hline Loss of flora and fauna & Yes \\
\hline Saltwater (tidal) intrusion & No \\
\hline Removal of vegetation & No \\
\hline Loss of floodplains and & Yes \\
wetlands &
\end{tabular}

Hydropower plants, No dams, and other hydraulic structures 


\subsubsection{Description - What Did the Project Do?}

Eddleston Water is a tributary of the Tweed River in the Scottish Borders and has a watershed of 70 square kilometers $\left(\mathrm{km}^{2}\right)$. It is a typical rural Scottish watershed, with a mix of forestry, rough grazing, and improved grassland. The Eddleston Water Project addresses the potential contribution that natural flood management (NFM) measures can make to reduce flood risk and improve habitats. Following a scoping study in 2009, the Eddleston Water Project has developed into a long-term national research study funded by the Scottish Government.

The project has the following three main objectives:

- Investigate the potential to reduce the risk of flooding to downstream communities by using NFM measures

- Improve habitats for flora and fauna and raise the ecological status of the river

- Work with landowners and farmers in the local community to maximize the benefits of the work while sustaining farming livelihoods and practices

The project aims to generate robust evidence of the impact, cost, and benefits of working with natural processes. The project took an empirical approach from the outset, with a detailed monitoring network and survey program, including the following features:

- River flow and flood gauges

- Groundwater surveys and boreholes

- Rainfall and weather stations

- River habitats, hydromorphology, and channel sediments

- River biology, including fish, aquatic macroinvertebrates, and aquatic plants

- Landowner and community engagement

In addition, the project investigates the costs and benefits of NFM interventions, including flood costs avoided, and additional co-benefits through the development of a series of integrated hydraulic and hydrological models to further explore the effect of NFM measures on flood risk. 


\subsubsection{Flood Risk Impacts of the Project}

These restoration measures have yet to be tested by a big flood. However, early evidence suggests that at the different watershed scales, NFM measures can reduce flood risk by both temporarily storing surface waters and delaying peak floods, as well as through increased surface roughness and groundwater connectivity. Early evidence also suggests that appreciable flood risk reduction through NFM is likely only to be achievable through the widespread application of many types of approaches across the entire watershed.

Impacts of individual NFM measures are as follows:

- Impacts of planting trees. Infiltration under mature broadleaf woodland is five to eight times that under adjacent grazed pasture.

- Modeled impacts of planting trees. Modeling landscape-scale tree planting under different climate change scenarios shows up to a maximum $40 \%$ reduction in peak flows (20-year return period), and flood peaks delayed by 45 minutes.

- Impacts of large wood flow restrictors. Those located in the upper watershed have been found empirically to be associated with a delay in time to peak flood of 30 to 60 minutes.

- Modeled impact of large wood flow restrictors. Modeling shows a reduction in peak water level and delays in predicted travel time of flood peaks at flows of 1.5 years and above, with greater storage at higher flows but limited extra gains beyond that.

- Impacts of ponds in the upper watershed. Measurements of pond levels show that the 27 ponds in the upper watershed can readily store water, providing quick wins, but modeling suggests this will only have a relatively small effect on total subwatershed runoff at this scale.

- Cost-benefit analysis. An analysis of the impacts of modeled extensive watershed afforestation on peak river flows under United Kingdom Climate Projections (UKCP) 2009, and on additional co-benefits, shows significant potential positive net present values. 


\subsubsection{Co-Benefits of the Project}

The project has included detailed research on the ecological impacts of NFM measures, as well as an analysis of current and historical (1940s) distribution and levels of provisional co-benefits across the watershed. In addition to reducing flood risk, NFM and habitat enhancement measures provide a wide range of co-benefits, as follows:

- Remeandering of the previously straightened river course led to an increase in area and overall physical diversity of habitats.

- Remeandering was followed by a rapid recolonization of the channel by aquatic macroinvertebrates, and a significant relationship was found between species richness and habitat variability.

- Remeandering of the river course also increased the number and extent of available spawning habitats for salmon and is leading to improved fish weights.

The study has also provided social co-benefits by addressing farmer attitudes and encouraging engagement with NFM approaches.

A recent study (Mott MacDonald 2020a) has found that the Eddleston Water Project NNBF scheme has already delivered GBP£950,000 (USD\$1.3 million) of net present value benefit in terms of avoided flood damages and GBP£4.2 million (USD\$5.8 million) of net present value from other ecosystem service benefits. The same study found that if the amount of NNBF in the catchment is optimized, the scheme could deliver GBP£2.85 million (USD\$3.9 million) of avoided flood damages and GBP£17.7 million (USD\$24 million) in other ecosystem service benefits.

\subsubsection{Lessons Learned}

The following lessons were learned over the course of the project, particularly those that relate to fluvial systems and NNBF:

- Empirical studies are critical to gaining a full understanding of the effectiveness of NFM measures on the ground and for subsequent parameterization of models.

- Where possible, the study design should include measurements both before and after interventions are implemented, with control and experimental sites.

- Monitoring should cover the full range of environmental conditions (high and low periods of precipitation and flooding) and cover more than one season both pre- and post-implementation. 
- Different NFM measures can reduce flood risk, but this will best be achieved through the widespread application of many types of approaches across the entire watershed.

- When considering NFM measures, the watershed needs to be assessed in terms of sources (upland), pathways (channels), and receptors (floodplain and downstream communities).

- When addressing sources and impacts of flooding, the linkages between surface water and groundwater need to be considered.

- The full cost and benefit of NFM measures can only be assessed by including their delivery of other co-benefits (e.g., biodiversity, water quality, carbon storage, recreation, and landscape), the gains from which may be greater than those solely for flood risk reduction.

- Economic and flood study appraisals should consider benefits for NFM beyond just flood risk reduction to enable policy-makers to make decisions reflecting the true net present value of investment in NFM.

- Engagement with land managers, especially to recruit them to host NFM measures, is best undertaken through a trusted intermediary, such as Tweed Forum, who understands farming and farm businesses and can communicate effectively.

\subsubsection{Further Information}

Black, A., L. Peskett, A. MacDonald, A. Young, C. Spray, T. Ball, H. Thomas, and A. Werritty. Forthcoming. “Natural Flood Management, Lag Time and Catchment Scale: Results from an Empirical Nested Catchment Study." Journal of Flood Risk Management.

Dittrich, R., T. Ball, A. Wreford, D. Moran, and C. J. Spray. 2018. “A Cost-Benefit Analysis of Afforestation as a Climate Change Adaptation Measure to Reduce Flood Risk." Journal of Flood Risk Management 12 (4): e12482.

Mott MacDonald. 2020a. Integrating Natural Capital into Flood Risk Management Appraisal: Study Report. Edinburgh, UK: Mott MacDonald and Tweed Forum. https://northsearegion.eu/media/15157/integrating-natural-capital-intoflood-risk-management-appraisal-report-v3.pdf.

Mott MacDonald. 2020b. Integrating Natural Capital into Flood Risk Management Appraisal: Practical Guide: Study Report. Edinburgh, UK: Mott MacDonald and Tweed Forum. https://northsearegion.eu/media/15158/integrating-naturalcapital-into-frm-appraisal-practical-guide-v3.pdf. 
Ncube, S., C. Spray, and A. Geddes. 2018. "Assessment of Changes in Ecosystem Service Delivery: A Historical Perspective on Catchment Landscapes." International Journal of Biodiversity Science, Ecosystem Services and Management 14 (1): 145-163.

northsearegion.eu, n.d. Building with Nature. Interreg North Sea Region. https:// northsearegion.eu/building-with-nature/.

Ó Dochartaigh, B. É., N. A. L. Archer, L. Peskett, A. M. MacDonald, A. R. Black, C. A. Auton, J. E. Merritt, D. C. Gooddy, and M. Bonell. 2018. “Geological Structure as a Control on Floodplain Groundwater Dynamics." Hydrogeology Journal 27: 703-716.

Spray, C., A. Baillie, H. Chalmers, L. Comins, A. Black, E. Dewell, S. Ncube, et al. 2017. Eddleston Water Project Report 2016. Melrose, UK: Tweed Forum.

tweedforum.org. 2020. The Eddleston Water Project. Tweed Forum. http:// tweedforum.org/our-work/projects/the-eddleston-water-project/. 
CASE STUDY:

\subsubsection{Lower Mississippi River Dike Notching for Habitat Development, United States}

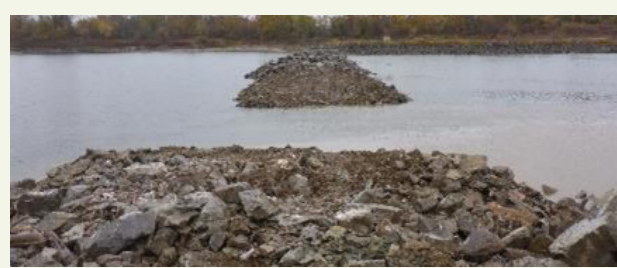

Source: Angie Rodgers, U.S. Fish and Wildlife Service

\section{Construction date:}

Multiple locations since the 1980 s

Total cash cost of the project:

Approximately USD $\$ 80,000$ to USD\$100,000* per notching site

*Amount does not include significant in-kind costs associated with nonconstruction costs such as site selection, engineering and design, and permitting.

\section{Measures included:}

Longitudinal navigation dike notching for the establishment and re-establishment of secondary channels favorable for habitat development and sustainability

\section{Project funders:}

U.S. Army Corps of Engineers and Lower Mississippi River Conservation Committee

\section{Main contacts:}

U.S. Fish and Wildlife Service, Lower Mississippi River Fish and Wildlife Conservation Office, and Lower Mississippi River Conservation Committee
Challenges addressed:

\begin{tabular}{lc}
\multicolumn{1}{c}{ Challenge } & Present \\
\hline Channel instability & No \\
\hline Land use change & No \\
\hline Water quality degradation & No \\
\hline Loss of flora and fauna & Yes \\
\hline Saltwater (tidal) intrusion & No \\
\hline Removal of vegetation & No \\
\hline $\begin{array}{l}\text { Loss of floodplains and } \\
\text { wetlands }\end{array}$ & No \\
\hline $\begin{array}{l}\text { Hydropower plants, } \\
\text { dams, and other hydraulic } \\
\text { structures }\end{array}$ & No
\end{tabular}




\subsubsection{Description - What Did the Project Do?}

Navigational dikes at various locations along the Mississippi River were notched near the bank to direct flow through previously blocked secondary channels. Substantial environmental benefits have resulted from this practice.

\subsubsection{Flood Risk Impacts of the Project}

Current studies are underway, but the flood risk impact of the Lower Mississippi River Dike Notching for Habitat Development Project is likely negligible, if not favorable.

\subsubsection{Co-Benefits of the Project}

The following are co-benefits of the project:

- Increased habitat complexity or habitat heterogeneity

- Increased connectivity and, therefore, habitat availability, between the secondary channel and the main channel

- The mainland is not connected to the islands and sandbars, which means that nesting birds are protected from land-based predators

- Created recreational areas for paddlers and anglers off the main navigation channel

\subsubsection{Lessons Learned}

The following lessons were learned over the course of the project, particularly those that relate to fluvial systems and NNBF:

- Several high-water events may be needed to allow for adequate scour of accumulated sediments within the secondary channel.

- Length, width, and depth of notches can vary, and likely should vary, depending on the location of the notches and other factors to be considered case by case. 


\subsubsection{Further Information}

flickr.com, n.d. Lower Mississippi River Conservation Committee. flickr. https://www. flickr.com/photos/Imrra/albums/with/72157632164691304.

fws.gov, n.d. Fish Passage Projects at Work: On the Ground and in the Water. U.S. Fish and Wildlife Service Fish and Aquatic Conservation. https://www.fws.gov/ fisheries/fish-passage/fish-passage-projects-at-work.html.

fws.gov, n.d. National Fish Passage Program. U.S. Fish and Wildlife Service Fish and Aquatic Conservation. https://www.fws.gov/fisheries/fish-passage.html.

Imrcc.org. 2020. Restoring America's Greatest River Initiative. LMRCC: Lower Mississippi River Conservation Committee. http://www.Imrcc.org/programs/ restoring-americas-greatest-river-initiative/.

LMRCC (Lower Mississippi River Conservation Committee). 2015. Restoring America's Greatest River: A Habitat Restoration Plan for the Lower Mississippi River. Vicksburg, MS: LMRCC. https://www.Imrcc.org/wp-content/ uploads/2020/12/RARG-plan.pdf.

youtube.com. LMRCC Tube. YouTube. https://www.youtube.com/user/LMRCCvideos. 
CASE STUDY:

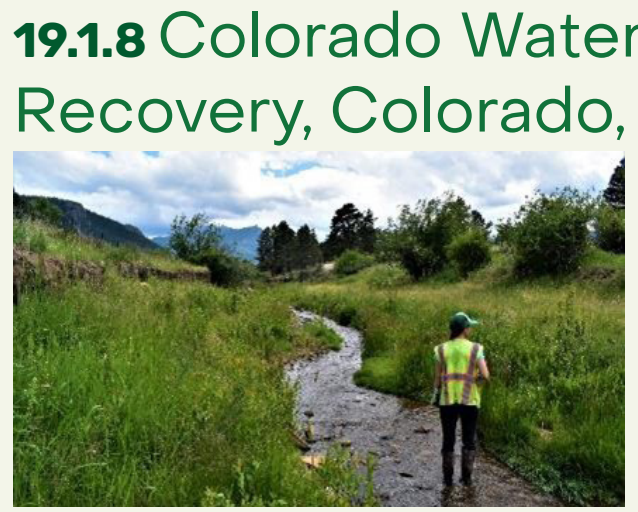

Source: State of Colorado Department of Natural Resources, Colorado Water Conservation Board

Post-construction monitoring along Lower Fish Creek

Construction date:

2013 to 2018

Total cash cost of the project:

USD\$68.3 million

Measures included:

Depositional zones, instream habitat, overflow channels, natural woody materials, vegetation and biostabilization, and floodplain and riparian habitat

\section{Project funders:}

Colorado Department of Natural

Resources - Colorado Water Conservation Board, Colorado Department of Local Affairs, U.S. Department of Agriculture Natural Resources Conservation Service, U.S. Department of Housing and Urban Development - Community Development Block Grant Disaster Recovery Program
Challenges addressed:

\begin{tabular}{lc}
\multicolumn{1}{c}{ Challenge } & Present \\
\hline Channel instability & Yes \\
\hline Land use change & Yes \\
\hline Water quality degradation & Yes \\
\hline Loss of flora and fauna & Yes \\
\hline Saltwater (tidal) intrusion & No \\
\hline Removal of vegetation & No \\
\hline Loss of floodplains and & Yes \\
wetlands &
\end{tabular}

Hydropower plants, No dams, and other hydraulic structures 


\subsubsection{Description - What Did the Project Do?}

In September 2013, several days of heavy rain caused massive flooding across Colorado's Front Range. Streams reclaimed their historical corridors and, in doing so, destroyed roads, bridges, and buildings and ripped vegetation from their banks. In total, the flood caused approximately USD $\$ 4$ billion in damage to infrastructure and to public and private property. Emergency repairs reopened highways and roads, but in the process excavated and filled many of the river corridors, destroyed emergent wetlands, severely impacted aquatic and riparian ecosystems and channelized creeks, and left many rivers unstable and disconnected from their floodplains.

After seeing the anthropogenic impacts on floodplains and recognizing the need to build resilience into the creek systems, the State of Colorado took a more holistic approach to disaster recovery. Most uniquely, the State of Colorado committed to implementing cross jurisdictional projects at a watershed scale with an emphasis on using natural geomorphic processes, river function, and ecological function as the basis for providing FRM and resilience. These projects were intended to replace traditional FRM strategies, also known as gray infrastructure, that failed on a grand scale in 2013.

The intent of the project was to protect life and property for the approximately 4.5 million residents of Colorado's Front Range communities. The project increased resiliency and functionality for 14 watersheds and approximately $105 \mathrm{~km}$ of fluvial systems. Key accomplishments included completing 117 flood recovery projects, improving $105 \mathrm{~km}$ of Front Range rivers and floodplains, engaging more than 700 private landowners, and extensive region wide planning including 12 watershed master plans, 34 resiliency planning studies, and 23 recovery planning studies. Project photographs are provided in Figures 19.2 through 19.7, at the end of this case study.

\subsubsection{Flood Risk Impacts of the Project}

At the individual project level, conceptual designs were created carefully to address physical and ecologic concerns at their foundation. Care was taken to ensure that proposed solutions did not transfer problems to adjacent properties or to downstream communities. The designs incorporated the following features:

- Planned depositional zones 
- Overflow channels

- Natural woody materials

- Extensive vegetation and biostabilization

- Space for the river to move

\subsubsection{Co-Benefits of the Project}

The co-benefits of the project included the following:

- Creation of instream habitat for native fish

- Creation of instream, wetland, and floodplain habitat for macroinvertebrates, amphibians, and zooplankton

- Diversification of the plant communities (increased biodiversity)

- Installation of site-specific native dicots that directly benefited pollinator species through the creation of season-long forage, habitat, and refugia

- Floodplain and riparian habitat for site-specific vegetation, including sensitive species

\subsubsection{Lessons Learned}

The following lessons were learned over the course of the project, particularly those that relate to fluvial systems and NNBF:

- To fully implement flood recovery, numerous partners were needed to sponsor, manage, and provide guidance for projects. These partners included the following:

- Nine watershed coalitions (local community stakeholder groups)

- Nine government agencies

- Four nonprofit organizations

- One special district

- One state agency, which directly managed and contributed financially to the watershed flood recovery projects in partnership with Colorado Water Conservation Board and Department of Local Affairs

- The partnerships with the watershed coalitions were essential to the program because they enabled community engagement and education.

- Watershed coalitions directly engaged citizens to communicate flood risk and to have open discussions about project goals, objectives, and limitations. They also 
advocated for the watershed and negotiated solutions that benefited multiple landowners. Finally, watershed coalitions became the main point of contact for concerned residents because coalition staffs were geographically close to-and could easily interface with-landowners, which enabled county, state, and federal entities to keep moving forward.

- It was important to provide empathy and support to landowners who were struck by the disaster because their main point of focus was the recovery of their personal property and the establishment of a "new normal" for their lives.

\subsubsection{Further Information}

coloradoewp.com, n.d. Colorado EWP Program. https://www.coloradoewp.com/.

\subsubsection{Project Photographs}

Figure 19.2. Volunteer Revegetation Work on Fish Creek Improvements in Estes Park Implemented by the Estes Valley Watershed Coalition

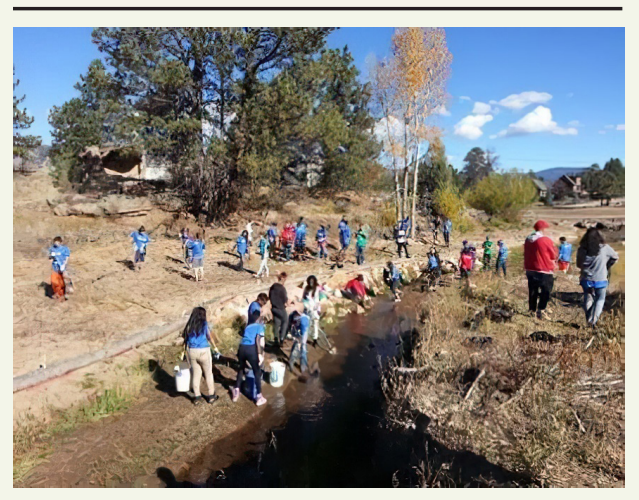

Source: State of Colorado Department of Natural Resources, Colorado Water Conservation Board
Figure 19.3. Improvements on the North Fork of the Big Thompson River Implemented by the Big Thompson Watershed Coalition

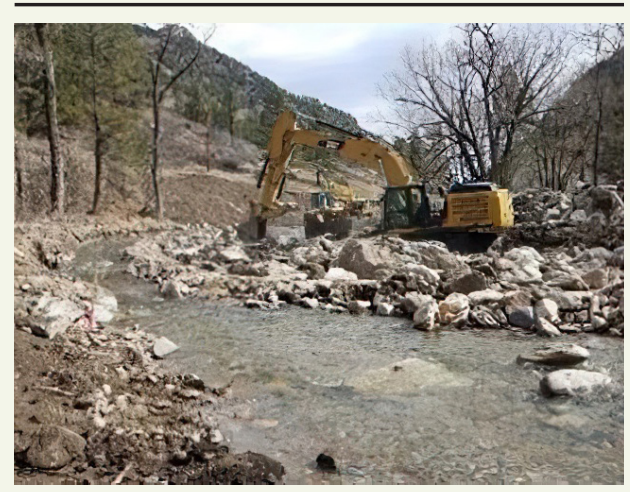

Source: State of Colorado Department of Natural Resources, Colorado Water Conservation Board 
Figure 19.4. Biostabilization Techniques on the Streamcrest Project along Left Hand Creek Implemented by the Left Hand Watershed Oversight Group

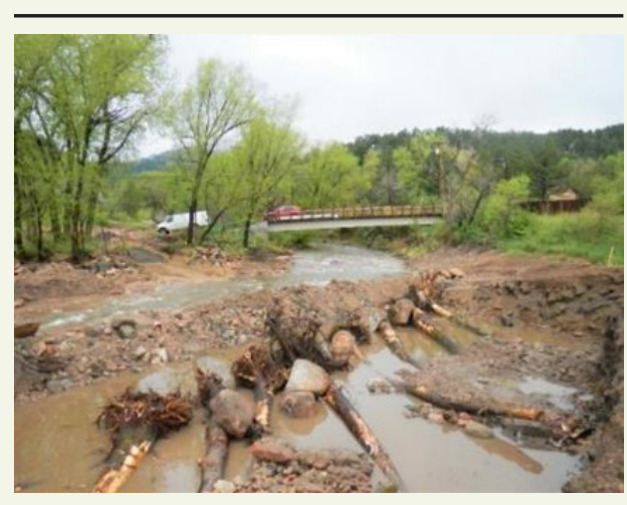

Source: State of Colorado Department of Natural Resources, Colorado Water Conservation Board

Figure 19.5. 1 Year Post-Restoration on the Coal Creek Improvements Project Managed by Coal Creek Watershed Coalition

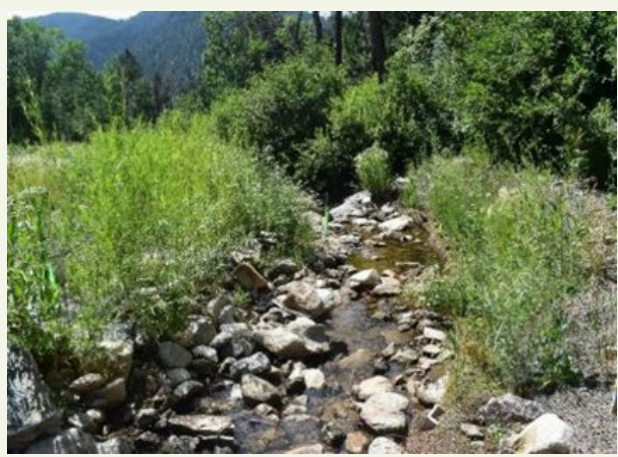

Source: State of Colorado Department of Natural Resources, Colorado Water Conservation Board
Figure 19.6. Created Overflow Channels Providing Conveyance during Future Flooding Events for the North Fork of the Big Thompson River Project Implemented by Big Thompson Watershed Coalition

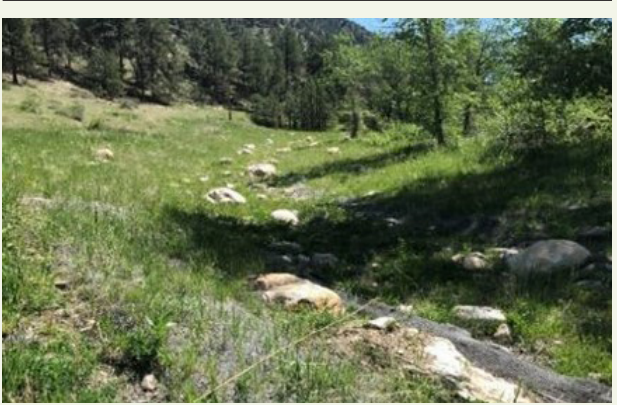

Source: State of Colorado Department of Natural Resources, Colorado Water Conservation Board

Figure 19.7. Biostabilization Techniques on the State Highway 60 Project along the South Platte River Implemented by the Middle South Platte River Alliance

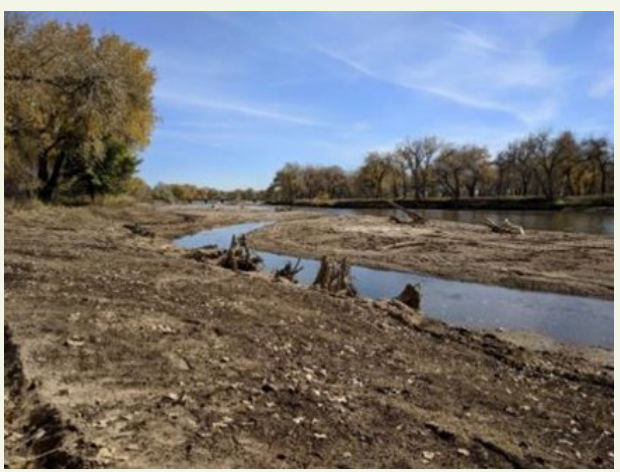

Source: State of Colorado Department of Natural Resources, Colorado Water Conservation Board 


\section{2 | Vegetation Management}

CASE STUDY:

19.2.1 Slowing the Flow, Pickering, Yorkshire, United Kingdom

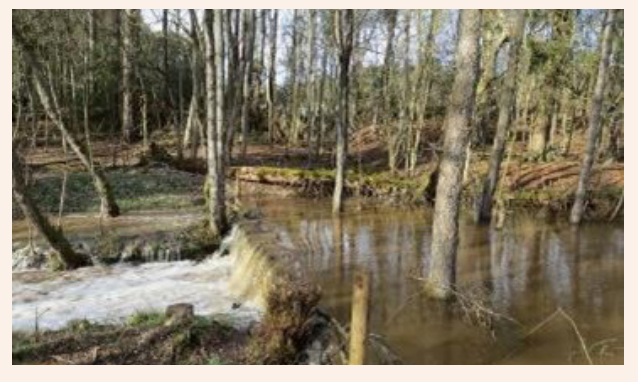

Pickering leaky woody structure during flood

Source: Forest Research

Construction date:

2009 to 2015

Total cash cost of the project:

More than GBP£3.1 million (USD\$4.3

million) (GBP£2.7 million [USD\$3.7 million] for construction)

Measures included:

Woodland planting, leaky woody

structures, farm and moorland

management measures, and conventional

flood storage reservoir

Project funders:

Defra, Forestry Commission England,

Environment Agency, North Yorkshire

Moors National Park Authority, Natural

England, North Yorkshire County Council,

Ryedale District Council, Pickering Town

Council, Sinnington Parish Council, and

Yorkshire Flood and Coastal Committee
Main contacts:

Forestry Commission and

Forest Research

Challenges addressed:

\begin{tabular}{lc}
\multicolumn{1}{c}{ Challenge } & Present \\
\hline Channel instability & Yes \\
\hline Land use change & Yes \\
\hline Water quality degradation & Yes \\
\hline Loss of flora and fauna & Yes \\
\hline Saltwater (tidal) intrusion & No \\
\hline Removal of vegetation & Yes \\
\hline Loss of floodplains and & Yes \\
wetlands &
\end{tabular}

Hydropower plants, No

dams, and other hydraulic structures 


\subsubsection{Description - What Did the Project Do?}

The Slowing the Flow Project demonstrated how land use and land management techniques could be used to reduce flood risk to the Town of Pickering in North Yorkshire, which has a long history of regular flooding. The largest flood as of the writing of this chapter was in 2007, causing GBP£7 million (USD\$9.6 million) of damage to 85 residential and commercial properties in the town. Cost-benefit analysis showed that an engineered flood alleviation project was not viable, so the Slowing the Flow approach was adopted. The project gained funding in 2009 , with the central aim of using a combination of measures to increase the whole watershed's natural flood storage capacity. A key target was to reduce the chance of flooding in the town from $25 \%$ to $4 \%$ or less in any given year.

\subsubsection{Flood Risk Impacts of the Project}

The following are the flood risk impacts of the Slowing the Flow Project:

- The project has delivered a set of measures that are calculated to reduce the chance of flooding in the Town of Pickering to less than $4 \%$ in any given year.

- The flood storage reservoir provides $120,000 \mathrm{~m}^{3}$ of storage. The planted woodland and leaky woody structures provide 8,000 to $9,000 \mathrm{~m}^{3}$ of storage, and the moorland and farmland measures provide another $500 \mathrm{~m}^{3}$ of storage.

- On December 26, 2015, 50 millimeters of rain fell over a 36-hour period, during which time the conventional flood storage reservoir coupled with the NNBF measures helped protect properties in the town from flooding. The flood peak was estimated to have been reduced by $15 \%$ to $20 \%$, with approximately half of the reduction due to the NNBF measures.

\subsubsection{Co-Benefits of the Project}

In total, the project created 29 ha of riparian woodland and 15 ha of farm woodland, restored 5.9 ha of riparian woodland buffers, installed 167 leaky woody structures and 187 heather bale check dams, improved 3.2 ha of heathland through reseeding, and repaired $800 \mathrm{~m}$ of eroding footpath. An aggregated net present value was calculated for the project, which ranged from GBP£600,000 (USD\$825,000) to GBP£3.2 million (USD\$4.4 million), with a median estimate of GBP£1.9 million (USD\$2.6 million). 


\subsubsection{Lessons Learned}

The following lessons were learned over the course of the project, particularly those that relate to fluvial systems and NNBF:

- Land management measures can make a significant contribution to downstream flood alleviation. The bigger the contribution to FRM needed, the larger and more extensive the measures need to be at the watershed level to make a difference.

- Measuring the impact of land management measures on flood flows at the watershed level is extremely difficult.

- Modeling is an important step in the process of locating and designing land management measures to reduce downstream flood risk.

\subsubsection{Further Information}

Nisbet, T., H. Thomas, and P. Roe, n.d. Case Study 12: Slowing the Flow at Pickering. London: Defra and Environment Agency Join Flood and Coastal Erosion Risk Management Research and Development Programme. https://www.therrc. co.uk/sites/default/files/projects/12_pickering.pdf. 
CASE STUDY:

19.2.2 Hierdense Beek, the Netherlands

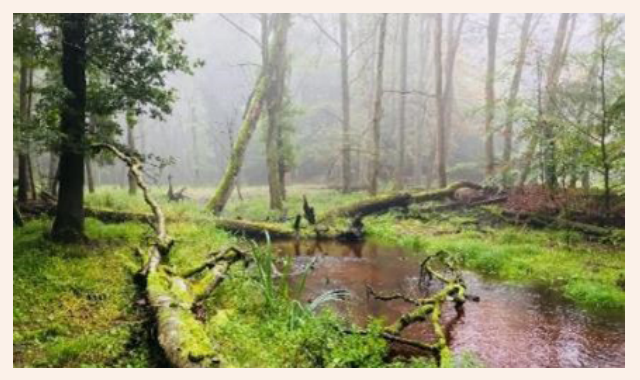

Source: Maarten Veldhuis, Waterschap Vallei en Veluwe (Water board Vallei en Veluwe)

\section{Construction date:}

2011 to 2019

Total cash cost of the project:

$€ 200,000$ euros (\$USD236,000)

Measures included:

- 2011 to 2013-dead wood deposition (monitored) and shading (not monitored)

- 2014-dead wood deposition, shading, mowing management, $8,000 \mathrm{~m}^{3}$ sand deposition (2014 to 2019), water level management, and nature-friendly riverbanks, creating a 70-ha floodplain forest area or fluvial wetlands and filling up an artificially created brook upstream

\section{Project funders:}

Water board Vallei en Veluwe and nature conservation agency Natuurmonumenten Main contacts:

Water board Vallei en Veluwe
Challenges addressed:

\begin{tabular}{lc}
\multicolumn{1}{c}{ Challenge } & Present \\
\hline Channel instability & Yes \\
\hline Land use change & Yes \\
\hline Water quality degradation & Yes \\
\hline Loss of flora and fauna & Yes \\
\hline Saltwater (tidal) intrusion & No \\
\hline Removal of vegetation & No \\
\hline Loss of floodplains and & Yes \\
wetlands &
\end{tabular}

Hydropower plants, No dams, and other hydraulic structures 


\subsubsection{Description - What Did the Project Do?}

In many lowland streams in northwestern Europe, the number and magnitude of peak discharges increased due to land use changes and climate change. This often leads to channel incision and degradation of the stream ecosystem. One of those streams was the Hierdense Beek in the Netherlands. Here, the water board Vallei en Veluwe and the nature conservation agency Natuurmonumenten sought to restore the stream by artificially supplying sand to the stream, creating sand slugs, which elevated the streambed and reconnected the stream with its original riparian zone. The sand was supplied from 15 locations along $6 \mathrm{~km}$ of the stream and dispersed by the stream naturally, in accordance with the Building with Nature principles. Large woody material was also placed in the stream to prevent new incision.

\subsubsection{Flood Risk Impacts of the Project}

Due to the measures described previously, more water is retained in the upstream forest. On a yearly basis, an average of $60 \%$ of the discharge is retained and infiltrated in the forest. Thus, discharges and water levels downstream are significantly reduced by the measures.

\subsubsection{Co-Benefits of the Project}

To assess the impact of this restoration measure on the stream ecosystem, bed morphology, substrate heterogeneity, macroinvertebrate assemblage structure, and riparian vegetation composition have been monitored since the start of the measures in 2014. After recovery from the initial disturbance, increases in instream microhabitat heterogeneity and current velocity were observed, which were also reflected in the macroinvertebrate community recorded. Rewetting of the riparian zone resulted in the establishment of a fringe of marsh vegetation along the stream margins. In summary, locally supplying sand to incised lowland streams resulted in noticeable short-term ecological effects, indicating the potential of this rarely applied restoration measure. 


\subsubsection{Lessons Learned}

Relatively simple and small-scale measures were taken, but the impacts are great. By supplying sand and applying woody material, the conveyance capacity of the stream is reduced, and a large inundation zone is created to allow for water retention in the forest during peaks.

The impacts extend beyond the stream itself. Due to the frequent inundations, trees along the stream die and leave an open zone where a marshy wetland can develop.

The measures triggered a fast ecosystem response, with effects being measured after the first year.

\subsubsection{Further Information}

sprengenbeken.nl, n.d. Hierdense Beek en Zilverbeekje. Bekenstichting: Behoud van Veluwse sprengen en beken [in Dutch]. https://www.sprengenbeken.nl/ hierdense-beek/.

vallei-veluwe.nl, n.d. Impuls om Hierdense Beek te verbeteren. Waterschap Vallei en Veluwe [in Dutch]. https://www.vallei-veluwe.nl/toptaken/bij-mij-in-debuurt/in-uitvoering/impuls-hierdense/. 


\section{3 | Rural Runoff Management}

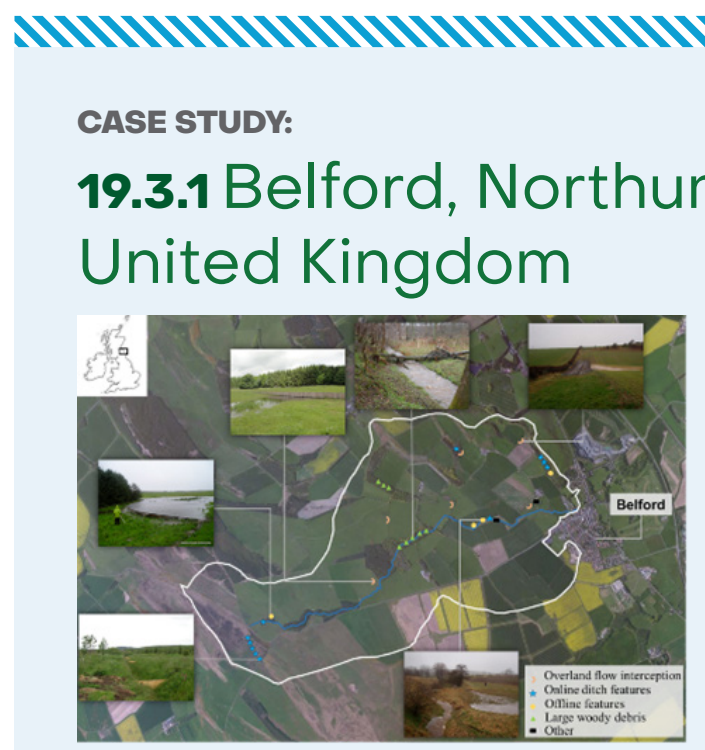

The Belford Project

Source: Newcastle University

Construction date:

2015

Total cash cost of the project: GBP£450,000 (USD\$619,000)

Measures included:

Runoff attenuation features, corner-of-field ponds, overland flow disconnection, flow diversion structures, leaky dams, off-line floodplain storage, online ditch management, wooden screens, wooden dams, and riparian planting

\section{Project funders:}

Local Levee and Engineering and Physical Sciences Research Council through Flood Risk Management Consortium Phase 2 research program
Main contacts:

Newcastle University and Arup

Challenges addressed:

\begin{tabular}{lc}
\multicolumn{1}{c}{ Challenge } & Present \\
\hline Channel instability & No \\
\hline Land use change & Yes \\
\hline Water quality degradation & Yes \\
\hline Loss of flora and fauna & Yes \\
\hline Saltwater (tidal) intrusion & No \\
\hline Removal of vegetation & Yes \\
\hline Loss of floodplains and & Yes \\
wetlands &
\end{tabular}

Hydropower plants, No dams, and other hydraulic structures 


\subsubsection{Description - What Did the Project Do?}

The Village of Belford lies within a 6- $\mathrm{km}^{2}$ watershed of the Belford Burn. The Belford Burn had regularly flooded the village; there were seven flood events from 1997 to 2007. Unfavorable cost-benefit analysis and the proximity of properties to the watercourse meant that traditional flood defenses could not be implemented. With no flood defenses in place, 54 properties and a campground were at risk of flooding from the river in a one-in-100-year flood event, and 25 properties were at risk in a one-in-2-year flood event.

The Belford NNBF project was developed to reduce flood risk to the Village of Belford using rural runoff attenuation features. A runoff attenuation feature is a human-made landscape intervention that intercepts and attenuates a hydrological flow pathway to provide FRM benefits and co-benefits such as improved water quality. The runoff attenuation features in Belford included a wooden storage area referred to as "the whisky barrel," soil bunds, floodplain reconnection, leaky wooden dams, and online ditch sediment traps. Between 2008 and 2013, approximately 45 runoff attenuation features (approximately $12,000 \mathrm{~m}^{3}$ of upstream storage) have been constructed across the watershed; these were informed by ongoing hydraulic monitoring, flow, and rain gauges. Monitoring of individual runoff attenuation features showed that they were able to have a significant impact (up to $10 \%$ reduction) on the flood peak in small to medium events but that they were overwhelmed by larger events.

\subsubsection{Flood Risk Impacts of the Project}

The following are the flood risk impacts of the Belford Project:

- Belford flooded seven times between 1997 and 2007. Since the runoff attenuation features were constructed, only one property has been affected by flooding.

- Monitoring of individual runoff attenuation features showed significant impacts (up to $10 \%$ reduction) on flood peak in small to medium events.

- The Pond Network Model demonstrates how a series of hypothetical off-line storage ponds could reduce flood peak magnitude for a range of return period events, including the one in-100-year design storm with $15 \%$ to $30 \%$ net reduction at the Village of Belford.

- The research and modeling demonstrated that a minimum amount of new storage was required to help mitigate the flood risk (approximately $2,000 \mathrm{~m}^{3}$ per $\mathrm{km}^{2}$ of watershed). The availability of this storage at the time of peak is of paramount importance. 


\subsubsection{Co-Benefits of the Project}

Co-benefits associated with this project include water quality improvements (through sediment retention and reductions in nutrient concentration) and habitat creation. Woodland planting in the riparian area replaced sycamore trees, which were felled to create the large woody material dams, with shorter native species. The trees do not have large canopies and allow more light to enter the woodland, which enables more vegetation to develop on the woodland floor. In addition to helping create greater floodplain roughness during periods of flood, the vegetation provides a richer habitat for small mammals and birds. Great crested newt habitat was restored in a runoff attenuation feature.

\subsubsection{Lessons Learned}

The following lessons were learned over the course of the project, particularly those that relate to fluvial systems and NNBF:

- Good community and stakeholder engagement are essential for the successful implementation of the project.

- Monitoring of the river network and NNBF was imperative for measuring the impact of features and communicating the findings to the community and flood risk managers.

- It is useful to develop a watershed systems engineering approach that is based around engaging with stakeholders and using evidence arising from field science to make decisions and modify measures to provide a wider range of co-benefits.

\subsubsection{Further Information}

Nicholson, A. R., G. M. O'Donnell, M. E. Wilkinson, and P. F. Quinn. 2019. “The Potential of Runoff Attenuation Features as a Natural Flood Management Approach." Journal of Flood Risk Management 13 (51): e12565. https://doi.org/10.1111/ jifr3.12565.

Nicholson, A. R., M. E. Wilkinson, G. M. O'Donnell, and P. F. Quinn. 2012. “Runoff Attenuation Features: A Sustainable Flood Mitigation Strategy in the Belford Catchment, United Kingdom." Area 44: 463-469. 
Quinn, P., A. Nicholson, M. Hardwick, P. Welton, and P. Kerr, n.d. Case Study 14: Belford Burn Runoff Attenuation Scheme - Northumberland. London: Defra and Environment Agency Join Flood and Coastal Erosion Risk Management Research and Development Programme. https://www.therrc.co.uk/sites/ default/files/projects/sc120015_case_study_14.pdf.

Quinn, P., G. O'Donnell, A. Nicholson, M. Wilkinson, G. Owen, J. Jonczyk, N. Barber, M. Hardwick, and G. Davies. 2013. Potential Use of Runoff Attenuation Features in Small Rural Catchments for Flood Mitigation: Evidence from Belford, Powburn and Hepscott. Newcastle, UK: Newcastle University, Royal Haskoning, and Environment Agency Report.

research.ncl.ac.uk. 2011. Belford. Newcastle University. https://research.ncl.ac.uk/ proactive/belford/.

Wilkinson, M. E., P. F. Quinn, and P. Welton. 2010. "Runoff Management during the September 2008 Floods in the Belford Catchment, Northumberland." Journal of Flood Risk Management 3: 285-295. 
CASE STUDY:

\subsubsection{Arvari River Watershed, Rajasthan, India}

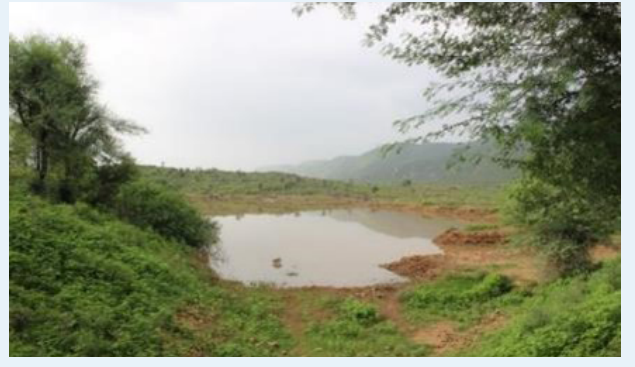

Examples of Johads (an off-line storage feature)

Source: The Flow Partnership

Construction date:

Ongoing since 1985

Total cash cost of the project:

Not available

Measures included:

Johads (water retention measures)

Project funders:

Local community leaders and community groups

Main contacts:

The Flow Partnership
Challenges addressed:

\begin{tabular}{lc}
\multicolumn{1}{c}{ Challenge } & Present \\
\hline Channel instability & Yes \\
\hline Land use change & Yes \\
\hline Water quality degradation & Yes \\
\hline Loss of flora and fauna & Yes \\
\hline Saltwater (tidal) intrusion & No \\
\hline Removal of vegetation & Yes \\
\hline $\begin{array}{l}\text { Loss of floodplains and } \\
\text { wetlands }\end{array}$ & No
\end{tabular}

Hydropower plants, No dams, and other hydraulic structures

\subsubsection{Description - What Did the Project Do?}

Rajasthan, which is India's largest state by area, accounts for $10.4 \%$ of India's land area, $60 \%$ of which is arid, $40 \%$ semi-arid, with $90 \%$ of annual rainfall occurring in the monsoon months of July to September. Agriculture in Rajasthan relies heavily on groundwater, and overexploitation of this resource has led to frequent droughts and an exodus from the state's villages to cities. 
Community-driven, decentralized water management using traditional methods of rainwater harvesting by the nongovernmental organization Tarun Bharat Sangh has led to the rejuvenation of many seasonal rivulets as perennial rivers in this very dry and arid part of India. Since 1985, seven rivers have been revived in the region and more are on the way.

The 90-km-long Arvari River rises from the Aravalli Hills on a geology of folded and fractured conglomerate, grit, and arkosic quartzite rock through which groundwater flows (Rathore 2003). The 476- $\mathrm{km}^{2}$ Arvari watershed is semi-arid and comprises 46 microwatersheds, with a covering sand sheet on flatter land downstream that protects the aquifer and soils that are fertile but lack water (Rathore 2003; Glendenning 2009).

In the 1980s, Rajasthan suffered several years of drought, leaving remote villages with hardly any water to meet the needs of their inhabitants. Removal of water management responsibilities from local control led to a shift in perception of the value of water, disengagement, and a lack of self-responsibility of local people for the management of these natural assets. This led to widespread abandonment, and the consequent degradation of community water management structures became widespread and prevalent (Rathore 2003).

Rajendra Singh, the head of Tarun Bharat Sangh, started working in the Arvari watershed in 1985. An elder of Kishori Village showed Singh the countless earthen check dams (locally referred to as Johad) that had held monsoon water for use year-round. Those traditional earthen check dams had fallen into disrepair and their reservoirs had silted up. The Johads were remnants of a rainwater collection tradition that dated back thousands of years in India, a system that used the natural terrain to channel and store the brief monsoon downpours for year-round use. But community rainwater collection projects fell out of favor during British rule, and after independence in 1947, their neglect, coupled with overpumping of groundwater, led to a severe drought in villages throughout western India.

The model of engagement used by Tarun Bharat Sangh to revive Arvari River was ensuring that every household in a village located along the river watershed that was suffering from drought would contribute something according to capacity-land, material, or labor. Tarun Bharat Sangh would raise the necessary $30 \%$ to $70 \%$ of the cash required for the building work. The work would be done professionally or by the villagers themselves depending on the availability of the funds. The first few Johads were built in strategic places in the landscape to recharge the underground aquifer 
as well as the surplus overflow on the path of the river. These were self-funded by the richer villagers in the area. Between 1985 and 1995, approximately 350 Johads were built on the Arvari River watershed with the help of funds from various European development agencies working in partnership with Tarun Bharat Sangh.

\subsubsection{Flood Risk Impacts of Project}

As the Johads were built, the river started to flow seasonally, and within 12 years the Arvari River became perennial. The following is according to Singh (Rajendra Singh, pers. comm.):

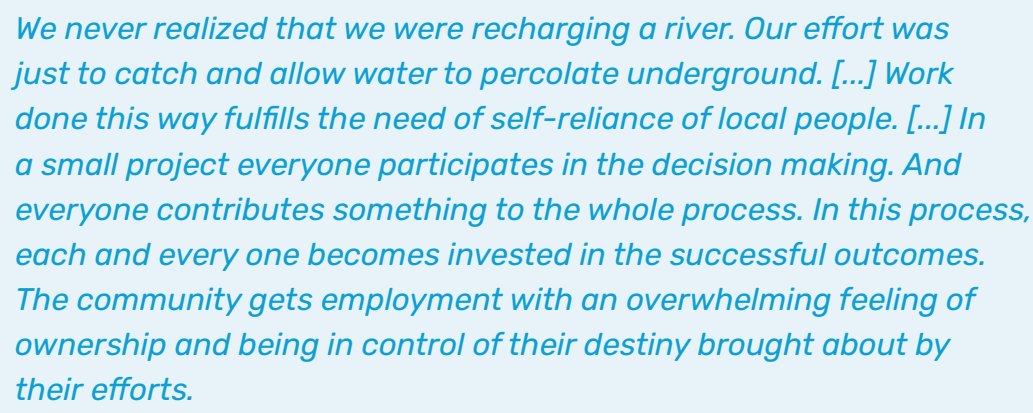

Before Tarun Bharat Sangh's intervention, 35\% of the rainwater was lost immediately as seasonal runoff, $50 \%$ was lost due to evaporation or transpiration, and only $15 \%$ of the rainwater naturally recharged the groundwater. The following flood risk benefits occurred after the Johads were built:

- Seasonal runoff of the rainwater has now come down to only $10 \%$ from more than $35 \%$ directly and an additional $50 \%$ indirectly.

- Soil moisture has increased.

- Approximately $22 \%$ of the runoff (excluding the $10 \%$ seasonal runoff during the monsoon) is now better regulated and spread out over the year. This has been crucial in reviving these small rivers. If this runoff had not been regulated, the rivulets would not flow throughout the year (Dr. R. N. Athavale, National Geophysical Research Institute, Hyderabad, pers. comm.).

The following are water resource benefits:

- Additional recharge of groundwater by $20 \%$, raising the groundwater table

- Additional seepage of $17 \%$ of rainfall to the river in nonmonsoon months, reviving the Arvari River and making it perennial 


\subsubsection{Co-Benefits of the Project}

The Arvari River watershed is still drought free, with ample groundwater available year-round. The watershed has experienced a dramatic increase in vegetation, from no crop growth prior to 1985 to up to three harvests a year since 1997.

When the water in Arvari River returned, the fish in it also returned abundantly. At one point, the government wanted to start selling licenses for fishing in the revived river without the permission of the 80 villages along its banks. The people resisted and the government had to cancel the fishing contract. This led to the formation of the Arvari River Sansad (Arvari River Parliament). The Arvari River Parliament has two representatives from each of the 80 villages along the river. The primary objective of the Arvari River Parliament, which convenes twice a year, is to engage the communities and safeguard the efforts of the communities along the river watershed. It does this by developing a coherent water use policy for the waters of the revived river, enforcing rules to govern the integrated management of the interlinked natural resources such as water, soils, and the forest for the well-being of the villagers and other life-forms. It also functions as the intermediary at village-level conflicts, resolving them through cordial discussion and mutual consent. The Arvari River Parliament follows the Gandhian ethos of a participatory, equitable, and decentralized paradigm for water management (Jal Swaraj), where decisions are made at the grassroots and not by centralized institutions.

The Arvari River Parliament has framed 11 rules for the river basin conservation and management on issues such as which crops to grow, when the water can be drawn from the wells, how much of it can be drawn, not allowing the cutting of trees along the watershed without the permission of the parliament, and small-scale production of food and grains so as not to overuse the groundwater. Although the Arvari River Parliament has no legal status and its decisions are not legally binding, it has a moral force that makes its decisions binding for the villages along the river.

\subsubsection{Lessons Learned}

Participation of the local population is a prerequisite for the success of such local projects. Work to rejuvenate a local area becomes sustainable and replicable when local knowledge is applied in addition to science. By understanding the community's relationship with water and soil resources and by soliciting community approval for work in support of these resources, projects can be implemented and truly successful. 
In this case study, the success of the Arvari River Parliament has ensured that every member of the rural community is forever engaged in the process; they bear the onus of ownership of the river and its waters responsibly. This contributes to ensuring the safety and maintenance of the river and its watershed for the foreseeable future.

\subsubsection{Further Information}

Glendenning, C. 2009. "Evaluating the Impacts of Rainwater Harvesting (RWH) in a Case Study Catchment: The Arvari River, Rajasthan, India." PhD diss., The University of Sydney.

Rathore, M. S. 2003. Community Based Management of Groundwater Resources: A Case Study of Arwari River Basin. Institute of Development Studies, Jaipur.

tarunbharatsangh.in, n.d. Tarun Bharat Sangh. https://tarunbharatsangh.in/.

theflowpartnership.org. 2016. The Flow Partnership. https://www.theflowpartnership. org/\#introduction. 
CASE STUDY:

\subsubsection{Making Space for Water, Peak District, United Kingdom}

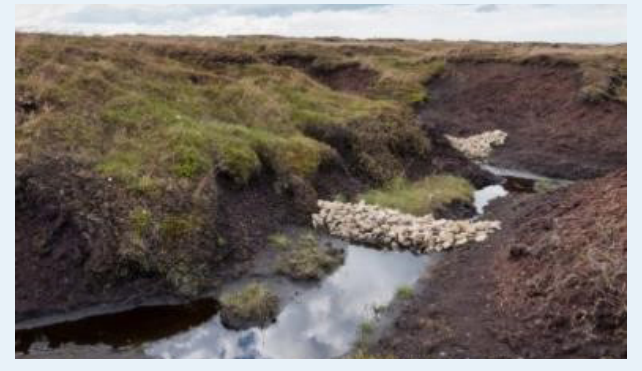

Gully blocking

Source: Moors for the Future

Construction date:

2011

Total cash cost of the project:

- Capital works-GBP£556,000 (USD\$765,000)

- Monitoring and modelingGBP£377,000 (USD\$519,000)

Measures included:

Land cover change involving stabilization and revegetation of bare peat and installation of runoff attenuation features (gully blocks)

\section{Project funders:}

Defra, Environment Agency, and

National Trust

Main contacts:

Moors for the Future Partnership and

University of Manchester

Challenges addressed:

\begin{tabular}{lc}
\multicolumn{1}{c}{ Challenge } & Present \\
\hline Channel instability & No \\
\hline Land use change & Yes \\
\hline Water quality degradation & Yes \\
\hline Loss of flora and fauna & Yes \\
\hline Saltwater (tidal) intrusion & No \\
\hline Removal of vegetation & No \\
\hline $\begin{array}{l}\text { Loss of floodplains and } \\
\text { wetlands }\end{array}$ & No \\
\hline $\begin{array}{l}\text { Hydropower plants, } \\
\text { dams, and other hydraulic } \\
\text { structures }\end{array}$ & No \\
\end{tabular}

\subsubsection{Description - What Did the Project Do?}

The Making Space for Water Project was developed as a flood demonstration watershed project funded by Defra. The project was located on upland blanket bog habitat in the South Pennine Moors Special Area of Conservation and aimed to gather evidence on the impact of the bare and eroding peat on this type of habitat. 
Since the 1850s, the Peak District uplands have experienced severe atmospheric pollution, which, along with overgrazing, wildfires, and climate change, has resulted in the loss of sphagnum mosses and created significant areas of bare peat. The consequent lack of vegetative cover was linked to high levels of erosion and gullying. From a flood risk perspective, blanket peatlands are naturally flashy systems in hydrological terms, responding rapidly to rainfall events with relatively short hydrograph lag times. The degraded condition of the peatlands was thought to be increasing the flashiness and leading to higher storm flow peaks. As a result, the potential FRM benefits and co-benefits of restoring the peatland vegetation were highlighted.

The Moors for the Future Partnership, in collaboration with the University of Manchester, undertook work on Kinder Plateau to help understand the value of ecological restoration including its FRM benefits. The main aims of the study were as follows:

- Establish the hydrological and runoff characteristics of restored and unrestored peatlands.

- Evaluate changes in storm flow behavior following restoration.

- Establish the causes of any detected change in storm flow behavior.

\subsubsection{Flood Risk Impacts of Project}

The following are the flood risk impacts of the Making Space for Water Project:

- Storm flow was slowed or attenuated, leading to the following statistically significant changes:

- Reductions in peak storm discharge (37\%)

- Increases in storm flow lag times (267\%)

- Increases in the level of the phreatic surface of water tables ( $35 \mathrm{~mm}$ )

- Increases in overland flow production (18\%)

- Modeling demonstrated a reduction in peak storm flows of up to $12 \%$ at the larger watershed scale $\left(9 \mathrm{~km}^{2}\right)$.

\subsubsection{Co-Benefits of the Project}

Through the Making Space for Water Project, 84 ha of severely damaged blanket bog habitat have been stabilized. After four growing seasons, the area of bare peat 
declined by $88 \%$, replaced mainly by a dominant cover of grasses (predominantly wavy hair grass) and acrocarpous mosses. Levels of particulate organic carbon washing off the land were reduced by $90 \%$ following revegetation.

\subsubsection{Lessons Learned}

The following lessons were learned over the course of the project, particularly those that relate to fluvial systems and NNBF:

- Surface revegetation and gully blocking increased surface roughness.

- The revegetation reduced overland flow velocities; gully blocks and associated gully floor revegetation may also have reduced in-channel velocities.

- Bare peat restoration by revegetation and gully blocking reduced downstream flood risk by slowing the flow in peatland headwater watersheds.

- Data collected up to 3 years after revegetation and gully blocking showed that the watersheds had become wetter.

- There was no change in watershed storage during storms (no change in percent runoff).

\subsubsection{Further Information}

Alderson, D. M., M. G. Evans, E. L. Shuttleworth, M. Pilkington, T. Spencer, J. Walker, and T. E. Allott. 2019. "Trajectories of Ecosystem Change in Restored Blanket Peatlands." Science of the Total Environment 665: 785-796.

moorsforthefuture.org.uk. 2021. Making Space for Water. Moors for the Future Partnership. https://www.moorsforthefuture.org.uk/our-work/our-projects/ making-space-for-water.

Shuttleworth, E. L., M. G. Evans, M. Pilkington, T. Spencer, J. Walker, D. Milledge, and T. E. Allott. 2019. "Restoration of Blanket Peat Moorland Delays Stormflow from Hillslopes and Reduces Peak Discharge." Journal of Hydrology X 2: 100006.

Walker, J., M. Pilkington, and A. Baker. Case Study 35: Making Space for Water. London: Defra and Environment Agency Join Flood and Coastal Erosion Risk Management Research and Development Programme. https://www.therrc. co.uk/sites/default/files/projects/35_moorsforthefuture.pdf. 


\section{4 | Urban Runoff Management}

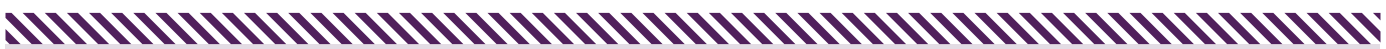

CASE STUDY:

19.4.1 Anwa Sustainable Landscape Design, Nairobi, Kenya

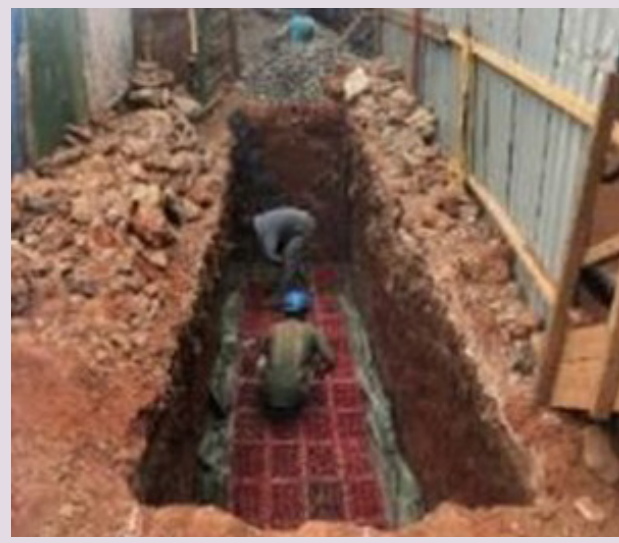

Sustainable Urban Drainage Systems (SUDS) construction

Source: Kounkuey Design Initiative

Construction date:

2018

Total cash cost of the project:

- Infiltration pit-USD\$1,000

- Sewer-USD\$6,000

Measures included:

SUDS

Project funders:

Kounkuey Design Initiative, Anwa Junior Academy, The Jeffrey Cook

Charitable Trust

Main contacts:

Kounkuey Design Initiative
Challenges addressed:

\begin{tabular}{lc}
\multicolumn{1}{c}{ Challenge } & Present \\
\hline Channel instability & No \\
\hline Land use change & Yes \\
\hline Water quality degradation & Yes \\
\hline Loss of flora and fauna & No \\
\hline Saltwater (tidal) intrusion & No \\
\hline Removal of vegetation & No \\
\hline $\begin{array}{l}\text { Loss of floodplains and } \\
\text { wetlands }\end{array}$ & No
\end{tabular}

Hydropower plants, No dams, and other hydraulic structures 


\subsubsection{Description - What Did the Project Do?}

Kibera is an informal settlement in Kenya's capital city, Nairobi. The settlement is constructed across three valleys and a number of rivers and streams including the Ngong River. Nairobi's characteristically intense rains pose a significant risk to Kibera's residents. Pluvial risk is intensified by the lack of absorption, the high-density settlement, and an almost entirely impervious surface of corrugated-iron roofs. The drainage systems are the settlement's major waste removal system and are filled with all manner of solid waste, restricting runoff and causing blockages.

Upstream, the pluvial risk issue is compounded by Nairobi's rapid urbanization. Population growth and increasing density are adding cumulative pressure to the existing, overloaded systems. Although pluvial flooding is one specific hazard in Kibera, it exacerbates a broader set of vulnerability issues, including sanitation, public health, and security. Limited formal water distribution to the settlement intensifies a range of issues in greater Nairobi, such as water shortages and water quality.

Anwa Junior Academy is a primary school located on high ground $100 \mathrm{~m}$ from a tributary of the Ngong River. This project responds to the clear need for improved learning facilities in Kibera as a fundamental component of sustainable development, but it also incorporates Sustainable Urban Drainage Systems (SUDS) to minimize local flooding impacts on the surrounding areas. SUDS is one solution to pluvial and supply issues in Kibera at the local level. Larger-scale interventions have proven difficult because of the lack of space and because of governance issues related to land and maintenance. By demonstrating how these types of techniques can effectively manage rainwater and be cost-effective at a smaller scale within a well-defined boundary and maintenance structure, there is an opportunity to influence the uptake of SUDS more widely.

\subsubsection{Flood Risk Impacts of the Project}

Anwa Junior Academy has a network of three water tanks holding a total of 21,000 liters. The tanks are filled during rains and provide gray water for cleaning and flushing. The roof area that feeds this tank system is 292 square meters. The system is chiefly designed for rainwater harvesting and providing a clean and cheap water supply alternative to the school for nonpotable uses. However, it also acts as a rainwater retention system where previously there was none. Key features are as follows: 
- Excess rainwater at Anwa Junior Academy is diverted to an infiltration pit created in the central courtyard. The infiltration pit is designed to hold a one-in-100-year flood event, including a $25 \%$ allowance for increased rainfall under climate change. It retains water and reduces local flood risk.

- The infiltration pit is constructed from used plastic soda crates to form a storage area below ground, wrapped by maize sacks acting as a pervious geotextile. The crates are held in place with rebar and are surrounded by crushed 40 -millimeter gravel. Soda crates were subsequently tested for structural stability. They provided a low-cost alternative to conventional structured storage systems that are not widely available or affordable.

- After completion, the tank system was seen to be putting less water into the drains.

\subsubsection{Co-Benefits of the Project}

Community engagement and involvement in this project has been key. The school's foul waste runs through a sewer built as part of the school project and owned and maintained by a local sewer line committee made up of community representatives in the area. The sewer line connects to the municipal main line 200 m downstream of the school site. The sewer represents a novel approach in informal settlements, where the assistance of an urban intermediary has resulted in a community taking ownership and maintaining a system that connects to municipal infrastructure. The value of this approach in an area where the vast majority of sewage flows into rivers via open drains is complex; however, it also reduces the risk of pluvial flooding within and surrounding the school by effectively reducing the content of solid waste in open drains. The intention is that ultimately the sewer line could be adopted and maintained by the water utility. All design was undertaken with reference to national and international best practices to enable this process.

\subsubsection{Lessons Learned}

The following lessons were learned over the course of the project, particularly those that relate to fluvial systems and NNBF:

- Reuse of soda crates offers a cheap and sustainable alternative to more engineered or off-the-shelf solutions and can be replicated in other locations. 
- Where existing infrastructure (in this case, sewers) is inadequate, it is possible for autonomous communities to successfully operate and maintain a system for their collective benefit.

- Incorporating a SUDS in a school offers an excellent opportunity for the practical education of students in issues associated with waste, flooding, and health.

\subsubsection{Further Information}

kounkuey.org. 2021. Projects. Kounkuey Design Initiative. https://www.kounkuey.org/ projects/kibera_public_space_project_08.

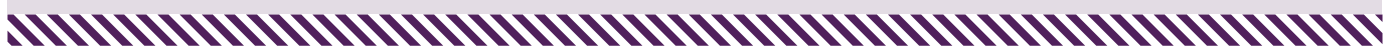




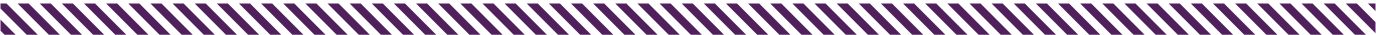

\section{CASE STUDY:}

19.4.2 Upton Development, Northampton, United Kingdom

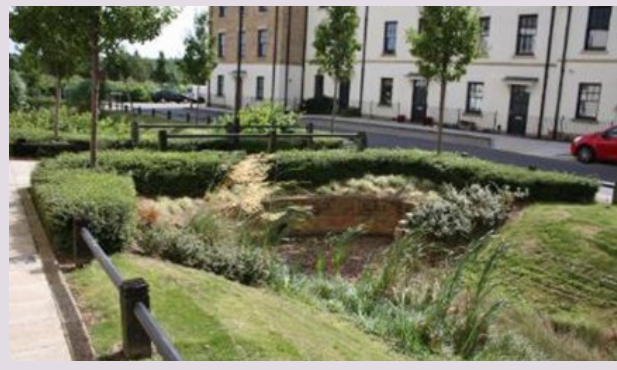

Source: Ballard and Shaffer 2018

Construction date:

2007

Total cash cost of the project:

Not available

Measures included:

SUDS

Project funders:

English Partnerships (now Homes and

Communities Agency) in partnership with

Northampton Borough Council
Challenges addressed:

\begin{tabular}{lc}
\multicolumn{1}{c}{ Challenge } & Present \\
\hline Channel instability & No \\
\hline Land use change & Yes \\
\hline Water quality degradation & Yes \\
\hline Loss of flora and fauna & No \\
\hline Saltwater (tidal) intrusion & No \\
\hline Removal of vegetation & No \\
\hline $\begin{array}{l}\text { Loss of floodplains and } \\
\text { wetlands }\end{array}$ & No
\end{tabular}

Hydropower plants, No

dams, and other hydraulic structures

\subsubsection{Description - What Did the Project Do?}

Upton's key development principle was to promote sustainable growth and an enduring and distinctive environment. The resultant design code and urban framework plan embedded sustainability principles at their core. From the drainage perspective, this included the following: 
- Involving stakeholders from an early stage

- Using SUDS to manage surface water runoff, including swales to convey water, detention basins and wetlands to temporarily store water, and permeable pavement systems for infiltration

- Managing extreme flows and mitigating impacts on downstream systems

\subsubsection{Flood Risk Impacts of Project}

The site is directly north of the Nene River floodplain and west of Northampton. Northampton suffered river flooding during 1998, and residents were extremely sensitive to potential impacts from a large new development.

Surface water runoff for the one-in-30-year event is conveyed by swales and, for more extreme events, diverted into local highways, which transfer flows to the downstream detention basin and wetlands. These storage components attenuate the runoff to a one-in-100-year greenfield rate to mitigate the impact of the development on downstream flood risk.

\subsubsection{Co-Benefits of the Project}

The swales form a network of green corridors through the site, delivering amenity and biodiversity benefits. All the SUDS components provide high-value recreational and ecological space. Photographs of the SUDS are provided in Figure 19.8, at the end of this case study.

\subsubsection{Lessons Learned}

The following lessons were learned over the course of the project, particularly those that relate to fluvial systems and NNBF:

- A partnership approach to developing the master plan helped gain acceptance for measures from the local community.

- Considering drainage at the start of the development planning process resulted in a complementary design that created attractive green corridors lined with exceedance flow pathways on the highway, which fit with the development overall.

- Using computer modeling of the drainage system and exceedance pathways helped when amending the surface topography (e.g., the highway profile to reduce the chance of property flooding). 
- Using the contours of the land and development can help to define exceedance pathways.

- It is important to think about inspection and maintenance of these structures at the outset because swales can become blocked and cause overland flow.

\subsubsection{Further Information}

Ballard, B. W., and P. Shaffer. 2018. Managing Urban Flooding from Heavy Rainfall - Encouraging the Uptake of Designing for Exceedance (C738). Case Study 11. London: Construction Industry Research and Information Association. https://www.ciria.org/Resources/Free_publications/c738. aspx\#: :text=Managing\%20urban\%20flooding\% 20 from $\% 20$ heavy\%20 rainfall\%20-\%20encouraging,other\%20measures\%20to\%20reduce $\% 20$ the $\% 20$ impact $\% 20$ of\%20flooding.

\subsubsection{Project Photographs}

Figure 19.8. Photographs of the Sustainable Urban Drainage Systems (SUDS)
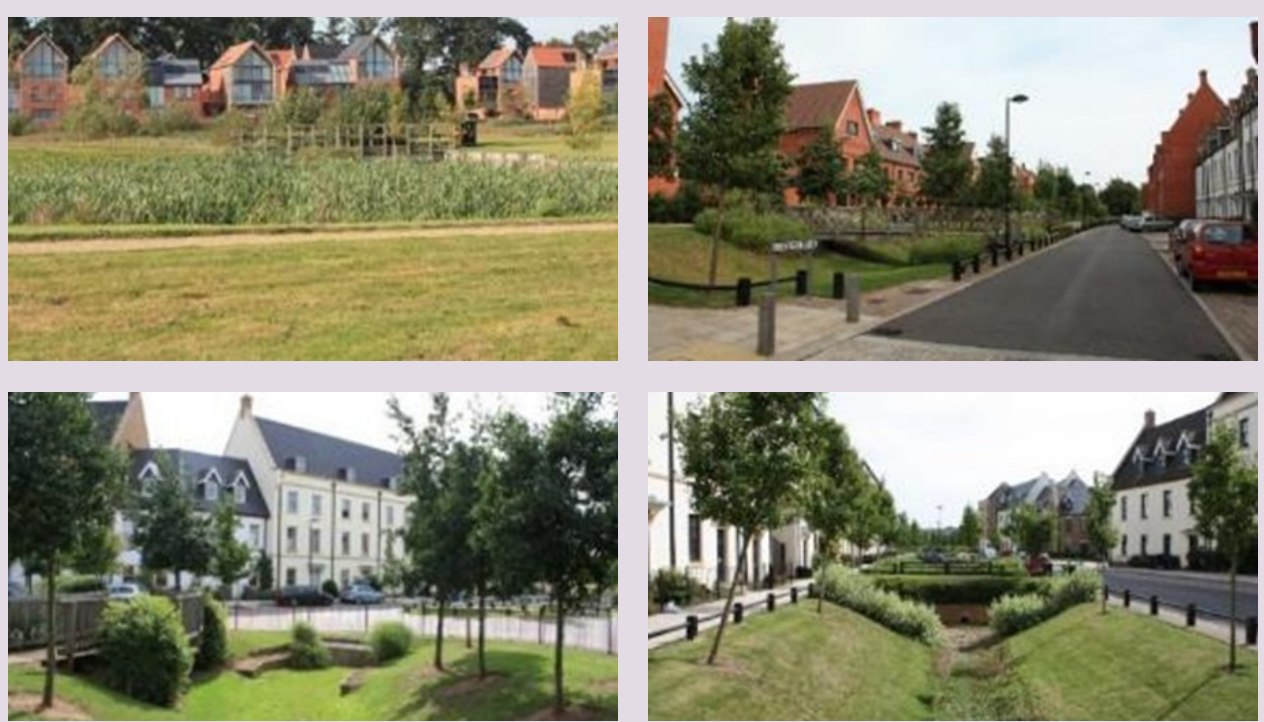

Source: Paul Saffer, Construction Industry Research and Information Association (CIRIA)

Note: Listed in order from top left to right are examples of a balancing pond, filter strips, rain gardens, detention basin, and a swale.

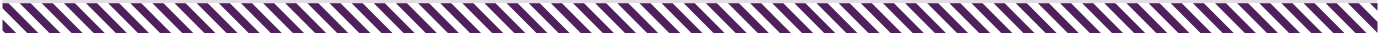




\section{5 | Erosion Management}

CASE STUDY:

19.5.1 Delta Headwaters Project, United States

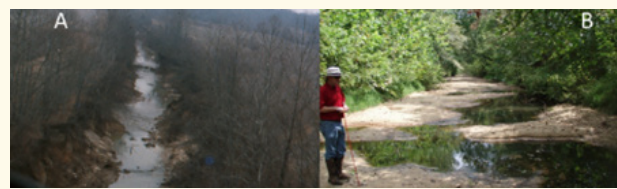

Source: U.S. Army Corps of Engineers

A: Hotopha Creek in 1970s showing severe head cutting and bank instability

B: Hotopha Creek in 2010 showing sediment deposition, bank stability, and development of a new floodplain

\section{Construction date: \\ 1985 to present}

Total cash cost of the project:

USD\$1 million+ per year

\section{Measures included:}

Grade control structures; bank stabilizations (stone toe, bioengineering, hard points, bendway weirs); riser pipes for gully control, land treatments, and nutrient reduction measures; floodwater retarding structures; and channel improvements

\section{Project funders:}

Mississippi River and Tributaries Project

Main contacts:

U.S. Army Corps of Engineers,

Vicksburg District
Challenges addressed:

\begin{tabular}{lc}
\multicolumn{1}{c}{ Challenge } & Present \\
\hline Channel instability & Yes \\
\hline Land use change & Yes \\
\hline Water quality degradation & Yes \\
\hline Loss of flora and fauna & Yes \\
\hline Saltwater (tidal) intrusion & No \\
\hline Removal of vegetation & Yes \\
\hline Loss of floodplains and & Yes \\
wetlands &
\end{tabular}

Hydropower plants, No dams, and other hydraulic structures 


\subsubsection{Description - What Did the Project Do?}

The Delta Headwaters Project (DHP), formerly the Demonstration Erosion Control Project, seeks to develop and demonstrate a watershed systems approach to address problems associated with watershed instability-erosion, sedimentation, flooding, and environmental degradation. Initiated by the federal government of the United States in 1984, DHP activities targeted 16 watersheds comprising $6,800 \mathrm{~km}^{2}$ in the Yazoo River Basin in the Lower Mississippi Valley. Primary features being used to achieve the project goals include grade control structures, floodwater retarding structures, bank stabilization measures, pipe drop structures, and land treatment measures. A key component of the DHP is monitoring to determine the impact of various features on the system, particularly with respect to reductions in sediment delivery. Monitoring also supports the development of advanced technologies that can be used in projects outside the DHP watersheds.

Historically, Hotopha Creek has been one of the most severely incised streams in the DHP. Degradation of approximately $6 \mathrm{~m}$ has occurred since the early 1960s. Photograph A in the box at the top of this case study shows a reach of Hotopha Creek in 1978 that is deeply incised with severe bank instability. In the late 1980s and early 1990 s, a series of grade control structures was constructed in this reach. These structures raised the channel bed approximately $3 \mathrm{~m}$ and significantly improved the stability of the stream. Photograph B in the box at the top of this case study shows the Hotopha Creek reach in $\mathbf{2 0 1 0}$ with considerable sediment deposition in the channel bed, vegetated and stable banks, and a new floodplain.

Photographs A through D (in Figure 19.9) of Johnson Creek (in the Long Creek watershed) show the successful construction of a minimal longitudinal peaked stone toe structure placed at 1 ton per foot. All views are looking upstream. The large tree at the upstream end of the bend provides a reference point in all four photographs. Photograph A shows the pre-project condition, with severe bank erosion along the left bank. Photograph B shows the same site a few months after construction. Photograph $\mathrm{C}$ shows that, within approximately 1 year, natural vegetation was being established behind the stone toe. Photograph $D$ shows that, within 2 years, the bank was very stable with heavy vegetation growth throughout the bend. 
Figure 19.9. Johnson Creek Bank Stabilization Reach

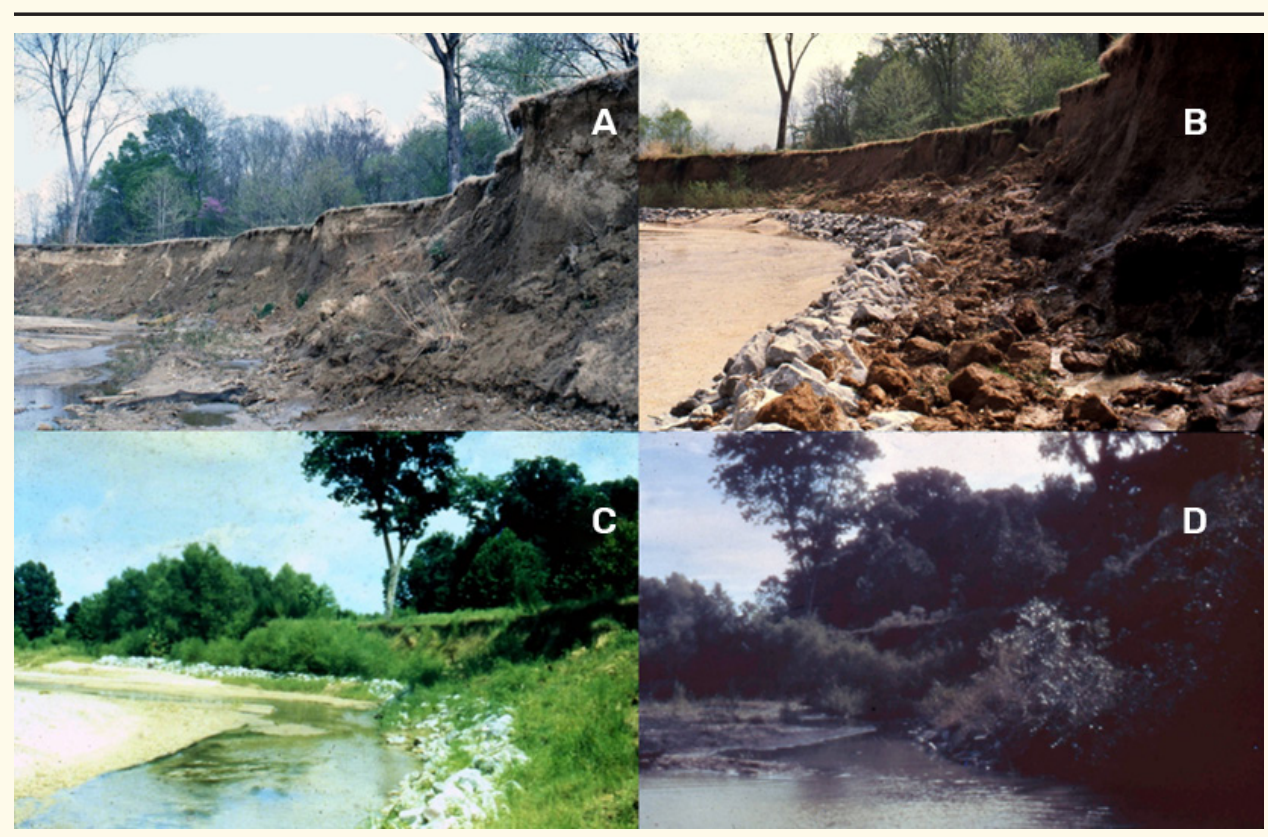

Source: USACE

\subsubsection{Flood Risk Impacts of the Project}

Flood risk impacts were a serious concern throughout the DHP watersheds. Through the DHP efforts, these impacts were significantly reduced through a program that considers an innovative watershed approach. The innovative approach includes pilot projects and various stream bank and streambed stabilization measures that are now widely applied around the United States. The reduction in sediment delivery from the various stabilization measures has provided FRM benefits downstream by maintaining channel cross-sectional area and conveyance.

\subsubsection{Co-Benefits of the Project}

Based on the bank and bed stabilization of DHP watersheds, reductions in sediment delivery to mainstem channels provides direct ecological benefits to aquatic and terrestrial habitats. In addition, stabilization of watersheds and smaller tributaries has provided co-benefits for protecting bridges and roadways from continued channel instability. 


\subsubsection{Lessons Learned}

Through the DHP, there have been many advances in technology that have led to the improved ability to plan, design, construct, and evaluate sediment management features on a watershed basis. The following is a brief list of some of the important technology advances that have been developed as part of the DHP:

- A systems approach for watershed and channel studies

- The Sediment Impact Analysis Method (SIAM)

- Improved bank stabilization measures

- Improved grade control measures

\subsubsection{Further Information}

Biedenharn, D. S., C. M. Elliott, and C. C. Watson. 1997. The WES Stream Investigation and Streambank Stabilization Handbook. Prepared for USEPA Workshops. Vicksburg, MS: Waterways Experiment Station, U.S. Army Corps of Engineers.

Darby, S. E., and A. Simon. 1999. Incised River Channels: Processes, Forms, Engineering, and Management. Chichester, UK: John Wiley.

NRCS (Natural Resources Conservation Service). 2007. Stream Restoration Design Handbook. Part 654 of National Engineering Handbook. Washington, DC: U.S. Department of Agriculture. 


\section{CASE STUDY:}

\subsubsection{Bank Protection in the Clun River, United Kingdom}

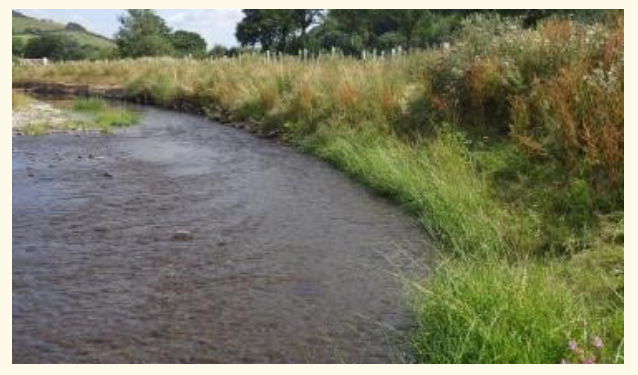

Bank protection with grown vegetation

Source: Environment Agency

\section{Construction date:}

2013

Total cash cost of the project: USD $\$ 12,000$

Measures included:

Live stakes, large woody material, dead hazel wood bundles, seeded geotextile

Project funders:

Natural England, Environment Agency, and the owner of the site
Main contacts:

Environment Agency

Challenges addressed:

\begin{tabular}{lc}
\multicolumn{1}{c}{ Challenge } & Present \\
\hline Channel instability & Yes \\
\hline Land use change & No \\
\hline Water quality degradation & Yes \\
\hline Loss of flora and fauna & Yes \\
\hline Saltwater (tidal) intrusion & No \\
\hline Removal of vegetation & No \\
\hline Loss of floodplains and & Yes \\
wetlands &
\end{tabular}

Hydropower plants, No dams, and other hydraulic structures

\subsubsection{Description - What Did the Project Do?}

Various bank protection measures such as live stakes, large woody material, bundles of dead hazel wood, seeded geotextile, and bank regrading were tested in 2013 on the fast-eroding banks of the Clun River near Purslow (Shropshire, United Kingdom) to offer short- to medium-term protection to a new riparian zone while vegetation was establishing. 
Water pollution problems were detected near a drinking trough where cattle were trampling the riverbanks. The responsible farmer had the option of either facing law enforcement for the pollution his cattle caused or adopting more sensitive farming practices for which he could get public funding. Aerial photographs showing significant loss of land due to river meandering (up to $1 \mathrm{~m}$ per year at the fastest eroding banks) contributed to the farmer's decision to change his practices.

The main objective of the bank protection project was to establish well-vegetated riparian zones for approximately $2 \mathrm{~km}$ along both sides of the river. However, there was a concern that the rapidly meandering river could threaten new plantings in the riparian zone. Environment Agency decided to test a range of bank protection measures at key points, to allow time for the riparian zones to become fully grown, and to use the site to showcase nature-based protection measures to the farming community.

The riparian zones were established by fencing 6- to 20-m-wide buffer zones. Vulnerable or unstable trees in these areas were cut back (either coppiced or pollarded) to promote growth and maintain bank stability and to reduce the impacts of Phytophthora, a large group of plant-damaging water molds prevalent in the watershed. The Woodland Trust, the largest woodland conservation charity in the United Kingdom, undertook extensive planting to help develop better shrub and tree habitat and improve bank stability and thermal regulation of the river. Two fords were created to control livestock access, and drinking bays were installed along with solar-powered troughs. All feeding stations and mineral licks for cattle were located away from the river.

No hydraulic study was performed to underpin the design of the bank protection techniques tested at key points along the river. The aim of the techniques was to reduce erosion rates and provide short- to medium-term protection while vegetation and habitat structure developed in the riparian zones. The techniques used included the following:

- Placement of woody material (live coppiced and pollarded material, dead stakes, and dead hazel wood bundles) in front of eroding banks

- Bank reprofiling to reduce the height of vulnerable banks

- Use of seeded geotextile to protect exposed soil

All the measures were devised on the spot and there was no consideration of lifetime expectations. However, it was hoped the riverbank protection works would last for 3 to 5 years, allowing the buffer zones time to become fully grown. When these riparian 
zones are well developed, the measures are expected to last for decades. Project photographs are provided in Figures 19.10 and 19.11, at the end of this case study.

\subsubsection{Flood Risk Impacts of the Project}

The Clun River is a single thread, meandering river in a wide floodplain with a bank-full discharge estimated at $24 \mathrm{~m}^{3}$ per second and an average velocity of $1.2 \mathrm{~m}$ per second. The area around the site is agricultural land, just like most of the watershed. The project is located $10 \mathrm{~km}$ upstream of a Special Area of Conservation.

The project helped reduce the loss of floodplain and the negative impacts of sediment eroded from the banks being transported downstream.

\subsubsection{Co-Benefits of the Project}

The Environment Agency's initial concern about pollution due to fine sediments and nutrients entering the watercourse was reduced. There is a public walkway adjacent to the river and a footbridge close to the protection works from where the natural protection can be seen contributing to the aesthetic quality of the site and to the educational purposes of the project. Restoration of the banks would also lead in the long term to the regeneration of riverbank habitat.

\subsubsection{Lessons Learned}

Three years after implementation, approximately one-half of the initial protection works were well established and vegetated. The other parts showed signs of further erosion but were not considered critical for the overall project. Because most of the live protection was well established, the riparian zones were given time to develop.

High flows occurred in the first season (2013 to 2014) and the bundles of wood, which were placed on the fastest eroding banks, were outflanked. Because the bundles were protecting a bank near a road, they were reinstated. Afterward, the dead wood bundles did trap silt and were vegetated by Himalayan balsam. Although this invasive species was planned to be controlled by sheep, which the farmer could let graze alongside the river, the farmer also let in his cattle and they knocked over some trees and slightly damaged the site. 


\subsubsection{Further Information}

Roca, M., M. Escarameia, O. Gimeno, L. de Vilder, J. Simm, B. Horton, and C. Thorne. 2017. Green Approaches in River Engineering: Supporting Implementation of Green Infrastructure. Wallingford, UK: HR Wallingford. https://eprints. hrwallingford.com/1250/.

\subsubsection{Project Photographs}

Figure 19.10. Post Being Driven into the Bank to Place the Wood Bundles

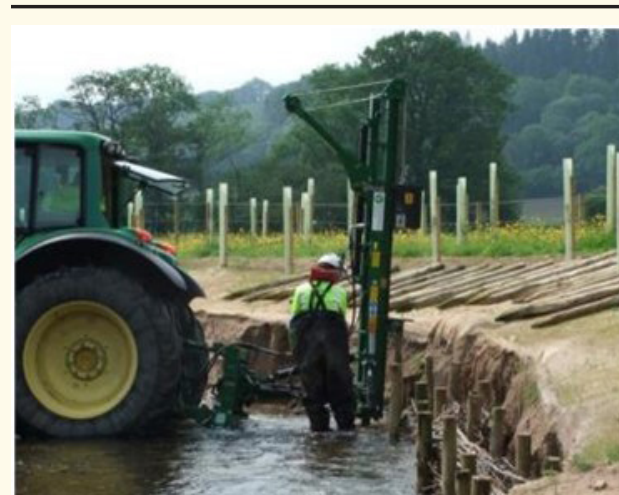

Source: Environment Agency
Figure 19.11. Well-Vegetated Bank 1 Year after Implementation

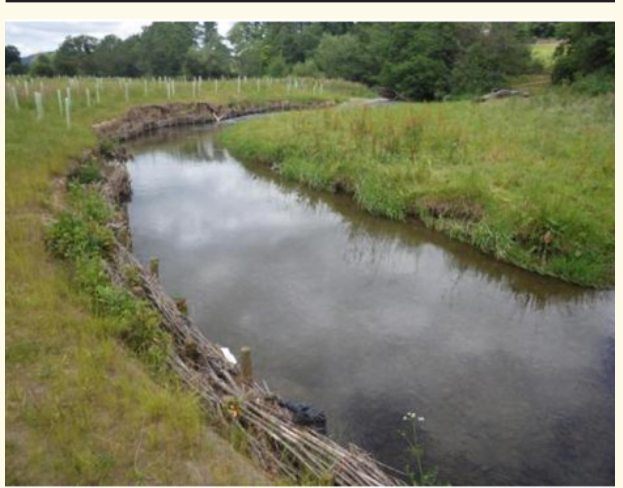

Source: Environment Agency 


\section{CASE STUDY:}

\subsubsection{Bank and Toe Protection in the Monnow River, Wales, United Kingdom}

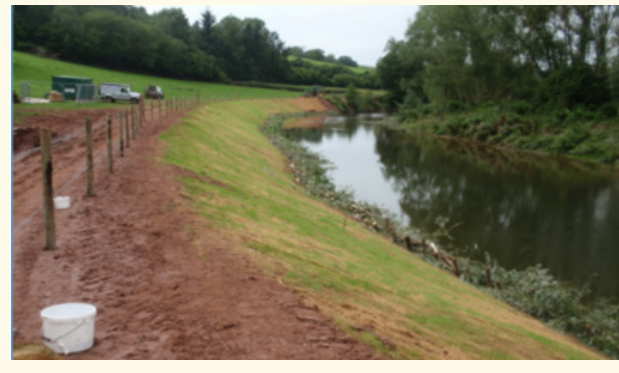

Bank immediately after work was completed

Source: Natural Resources Wales

\section{Construction date:}

2013

Total cash cost of the project:

USD $\$ 18,000$

\section{Measures included:}

Bank regrading, rock rolls, seeded coir matting, and stakes

Project funders:

Natural Resources Wales

Main contacts:

Natural Resources Wales
Challenges addressed:

\begin{tabular}{lc}
\multicolumn{1}{c}{ Challenge } & Present \\
\hline Channel instability & Yes \\
\hline Land use change & No \\
\hline Water quality degradation & Yes \\
\hline Loss of flora and fauna & No \\
\hline Saltwater (tidal) intrusion & No \\
\hline Removal of vegetation & No \\
\hline $\begin{array}{l}\text { Loss of floodplains and } \\
\text { wetlands }\end{array}$ & Yes \\
\hline
\end{tabular}

Hydropower plants, No dams, and other hydraulic structures

\subsubsection{Description - What Did the Project Do?}

Following the removal of a weir as part of a river restoration project to improve fisheries, erosion occurred upstream along $250 \mathrm{~m}$ of the outer bank of Monnow River. Natural Resources Wales, the government body responsible for ensuring the 
sustainability of natural resources in Wales (United Kingdom), decided to move away from hard engineering and use green protection for the eroded bank instead.

The bank was regraded to roughly a $30^{\circ}$ angle and a V-channel was excavated at both the top and bottom of the bank to allow seeded coir matting to be stretched, pegged, and laid in vertical strips on the bank. The V-channel at the top of the embankment was packed with excess fill to hold the top of the coir matting, and willow was planted along the area to help regeneration. Rock rolls were placed on the toe to weigh down the matting and were further secured by driving in a series of $750-\mathrm{mm}$-long chestnut stakes. Branches of cut willow from the adjacent bank were wired down between the chestnut stakes to trap sediment and encourage growth at the toe. The site was also protected from animal damage by a fence at the top of the bank. Project photographs are provided in Figures 19.12 through 19.14, at the end of this case study.

\subsubsection{Flood Risk Impacts of the Project}

The Monnow River is a meandering river with a watershed up to the protected bank covering an area of $354 \mathrm{~km}^{2}$. The estimated bank-full discharge is $108 \mathrm{~m}^{3}$ per second. The waterbody has an overall Water Framework Directive status of good. On either side of the project is agricultural land.

The project was completed in 2013. High flows very soon after completion did not allow for the stakes to establish properly. Small pockets of erosion were detected at the toe, but the coir mat was not damaged. During this over bank-full event, with discharges up to $168 \mathrm{~m}^{3}$ per second, the velocities along the outer bank were estimated to be between 2.1 and $2.7 \mathrm{~m}$ per second.

\subsubsection{Co-Benefits of the Project}

The project stopped the degradation of the bank, improving the aesthetic quality of the site and reducing the amount of sediment delivered to the river, which contributed to reducing pollution and possible sedimentation problems downstream. Restoration of the banks would also in the long term lead to the regeneration of riverbank habitat.

\subsubsection{Lessons Learned}

Removal of weirs may have major impacts on the stability of riverbanks upstream of the location of the weirs. The nature-based project built at the site provided the level 
of protection required. This was a one-off project with no operational responsibility to undertake long-term repairs and, therefore, no allowance was made for inspection and maintenance. Maintenance operations may be needed if damage occurs during high flows.

\subsubsection{Further Information}

Roca, M., M. Escarameia, O. Gimeno, L. de Vilder, J. Simm, B. Horton, and C. Thorne. 2017. Green Approaches in River Engineering: Supporting Implementation of Green Infrastructure. Wallingford, UK: HR Wallingford. https://eprints. hrwallingford.com/1250/.

\subsubsection{Project Photographs}

\section{Figure 19.12. Bank Erosion Following Weir Removal (2013)}

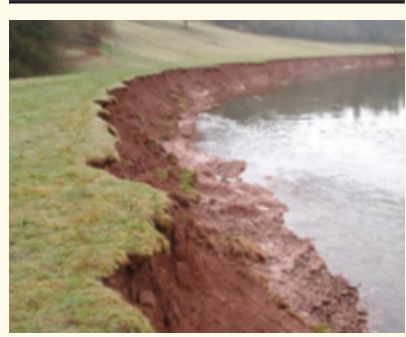

Source: Natural Resources Wales

\section{Figure 19.13. Protection Works in High Flows (2014)}

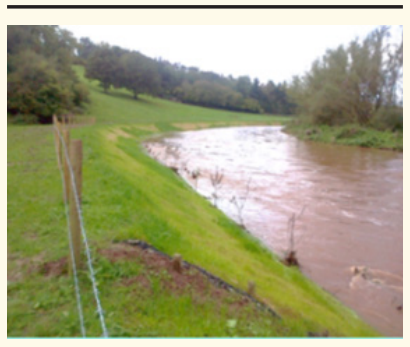

Source: Natural Resources Wales
Figure 19.14. Protection Works (2018)

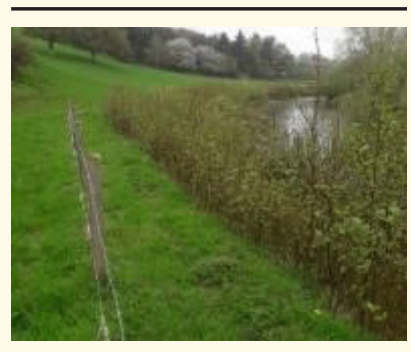

Source: Natural Resources Wales 


\section{CASE STUDY:}

\subsubsection{Hå River, Norway}

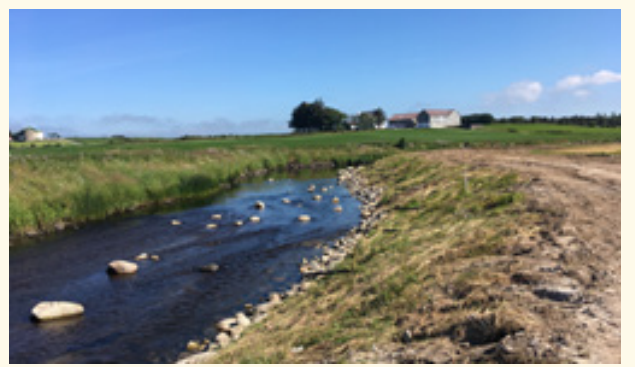

Source: Karin Hansen, Hå Municipality

\section{Construction date:}

2019 to 2021

Total cash cost of the project:

Estimated 10 million Norwegian krone

(NOK) (USD\$1.2 million)

\section{Measures included:}

Expanded riverbanks, erosion control, and habitat improvement; cleaning the gravel and adding rocks for flow variation; loose stone layer for better habitat

\section{Project funders:}

Hå Municipality, Time Municipality, Rogaland County, Department of Environment, Norwegian Water Resources and Energy Directorate, Department of Agriculture (program for farmers)

Main contacts:

Karin Hansen, Hå Municipality
Challenges addressed:

\begin{tabular}{lc}
\multicolumn{1}{c}{ Challenge } & Present \\
\hline Channel instability & Yes \\
\hline Land use change & No \\
\hline Water quality degradation & Yes \\
\hline Loss of flora and fauna & No \\
\hline Saltwater (tidal) intrusion & No \\
\hline Removal of vegetation & No \\
\hline Loss of floodplains and & Yes \\
wetlands &
\end{tabular}

Hydropower plants, No dams, and other hydraulic structures 


\subsubsection{Description - What Did the Project Do?}

Over the years, land use along the Hå River has intensified and the nearby town has grown considerably. This has led to an increase in flooding and a higher discharge of nutrients and particulates. There has also been some channelizing, and rocks have been removed. The aim of the project was to open up the riverbanks to reduce erosion, increase retention, and improve the habitat for salmon and pearl mussels. Erosion control was achieved by placing a loose stone layer and adding rocks at the bottom of the banks. Soil and reed canary grass were placed on the banks to encourage vegetation to establish quickly. The habitat is improved by cleaning the spawning gravel to make it free of sediment and adding new gravel, as needed. In addition, a number of rocks were placed in the river to increase flow variation. Another part of the program was to reduce discharges of nutrients from arable land, which was achieved by legislation to manage the spreading of manure and by giving subsidies for various specific measures that farmers could carry out.

\subsubsection{Flood Risk Impacts of the Project}

More water will be retained in the river during smaller floods, thus flood risk is reduced.

\subsubsection{Co-Benefits of the Project}

The aim of the project was to improve the habitat for local populations of pearl mussels, salmon, and other species. The improvements to the habitat are being monitored as part of the project.

\subsubsection{Lessons Learned}

The work is done in cooperation with the landowners. It is important to have a good dialogue with them. The landowners have supplied the project with a huge amount of rocks. They have received the soil from the banks, and they have contributed to the work with tractors and trailers. This has kept the project costs low. In addition, work has to be conducted when convenient to the landowner.

The landowners have a tradition of only grass at the banks of the river. The reed canary grass has good ability to stabilize the soil, provided there is a maximum slope of $45^{\circ}$. The authorities would like to have more trees and bushes, but there seems 
to be no interest in this from the landowners. The idea is to plant more trees and bushes on a small scale and show the landowners that it will work and give more diversification.

\subsubsection{Further Information}

The project plan for this study was composed by NORCE, an organization that works to find solutions that benefit the community and increase sustainable value creation nationally and globally. 


\section{Acknowledgments}

\section{Lead Authors}

Lydia Burgess-Gamble, Environment Agency, United Kingdom

Ralph Schielen, Rijkswaterstaat, the Netherlands

Christopher Haring, U.S. Army Corps of Engineers, United States

Jo Guy, Environment Agency, United Kingdom

\section{Co-Authors}

Rachel Glover, Environment Agency, United Kingdom

Randy Mandel, Ramboll, United States

Bridget Woods Ballard, HR Wallingford, United Kingdom

Marta Roca Collell, HR Wallingford, United Kingdom

\section{Case Study Contributors}

Luke Comins, Tweed Forum, United Kingdom

Richard Copas, Environment Agency, United Kingdom

David Crane, U.S. Army Corps of Engineers, United States

Forest Research, United Kingdom

Karin Hansen, Hå Municipality, Norway

Christian Huising, Waterschap Vallei en Veluwe, the Netherlands

Minni Jain, The Flow Partnership, United Kingdom

Tony Kraus, U.S. Army Corps of Engineers, United States

Manchester University, United Kingdom

Moors for the Future, United Kingdom 
Joe Mulligan, Kounkuey Design Initiative, Kenya

Natural Resources Wales, United Kingdom

Alex Nicholson, Arup, United Kingdom

Lower Mississippi River Fish and Wildlife Conservation Office, United States

Paul Quinn, Newcastle University, United Kingdom

Angie Rodgers, U.S. Fish and Wildlife Service, United States

Room for the River Project, the Netherlands

Joe Rooms, Environment Agency, United Kingdom

Christopher Spray, University of Dundee, United Kingdom

Jeffrey Sickles, Colorado Water Conservation Board, United States

Chris Sturm, Colorado Water Conservation Board, United States

Cory Winders, U.S. Army Corps of Engineers, United States 


\section{Endnotes}

i “The Flood Control and Coastal Emergency Act establishes an emergency fund for preparedness for emergency response to natural disasters; for flood fighting and rescue operations; for rehabilitation of flood control and hurricane protection structures." Source: U.S. Army Corps of Engineers, n.d. Flood Control and Coastal Emergency Act. USACE Disaster Operations Public Law 84-99. Vicksburg, MS: U.S. Army Corps of Engineers. https:/l www.nab.usace.army.mil/Portals/63/docs/EMO/PL84-99factsheet.pdf.

ii The "Room for the River" was a government design plan active from 2006 to 2015 "intended to address flood protection, master landscaping and the improvement of environmental conditions in the areas surrounding the Netherlands' rivers."

Source: wikipedia.org. 2020. "Room for the River (Netherlands)." Wikipedia. https://en.wikipedia. org/wiki/Room for the River_(Netherlands).

iii "Natura 2000 is a European network of core breeding and resting sites for rare and threatened species, and some rare natural habitat types which are protected in their own right."

Source: ec.europa.eu, n.d. "Natura 2000." European Commission. https://ec.europa.eu/ environment/nature/natura2000/index_en.htm\#: : text=Natura\%202000\%20is\%20a\%20 network,on\%20land\%20and\%20at\%20sea. 

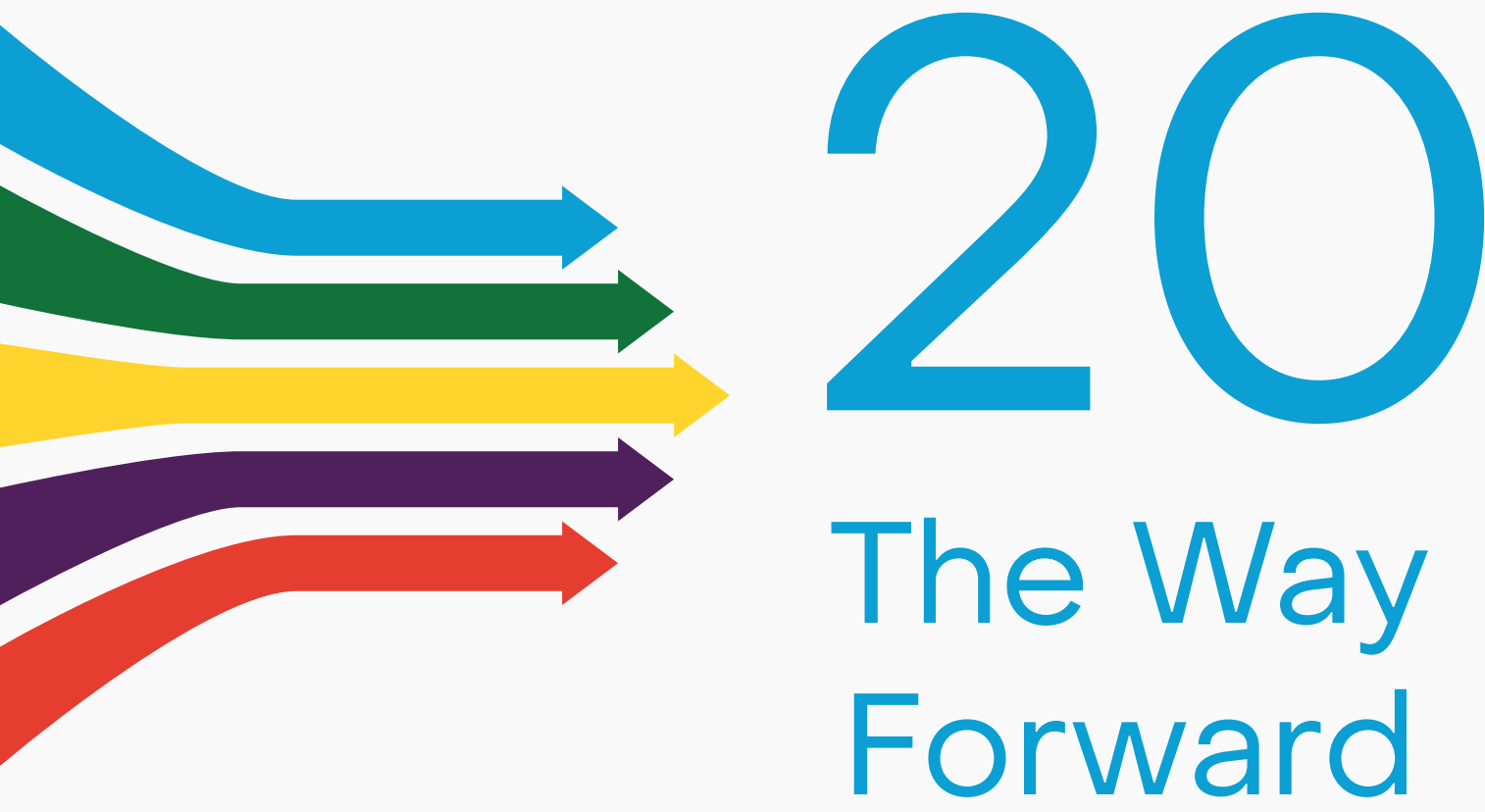

\section{Suggested Citation:}

Bridges, T. S., J. K. King, and J. D. Simm. 2021. "Chapter 20: The Way Forward." In International Guidelines on Natural and Nature-Based Features for Flood Risk Management. Edited by T. S. Bridges, J. K. King, J. D. Simm, M. W. Beck, G. Collins, Q. Lodder, and R. K. Mohan. Vicksburg, MS: U.S. Army Engineer Research and Development Center.

Full acknowledgments appear at the end of this chapter. 


\section{Everything that depends on the action of nature is by nature as good as it can be.}

- Aristotle

Nature-based solutions have a significant role to play in infrastructure systems in the twenty-first century, and natural and nature-based features (NNBF) will be an important part of future flood risk management (FRM) strategies and systems. The goal of this International Guidelines on Natural and Nature-Based Features for Flood Risk Management publication is to inform future practice for NNBF by drawing together knowledge and experience from around the world. Effective and timely implementation of NNBF to address current and future FRM challenges will depend on progress in three overarching areas of activity-developing and delivering, communicating and collaborating, and elevating and educating, discussed in Sections 20.1, 20.2, and 20.3, respectively.

\section{1 | Developing and Delivering}

These guidelines were written to support developing and delivering FRM projects that incorporate NNBF. Organizations and teams responsible for infrastructure projects will be familiar with the call to deliver projects "faster, cheaper, and better." NNBF can, do, and will contribute to all three parts of this refrain. Although efforts to deliver infrastructure projects on time and within budget will continue to be important, organizations must also be careful to deliver the "right" project that provides sustainable and resilient solutions over the long term.

A systems approach to FRM provides a comprehensive view of and vision for processes, functions, relationships, and engineering interventions that are critical to achieving successful project outcomes. Ultimately, interventions, whether structural or NNBF, will work as part of a system that includes physical, environmental, social, and political elements. Understanding and working with the myriad connections among these elements is central to the long-term success, sustainability, and value achieved within the system. When project sponsors, developers, planners, and engineers are explicit and intentional about incorporating NNBF and supporting processes, the FRM system will be strengthened and the long-term value from infrastructure investments will be expanded.

Measuring and managing engineering interventions-whether structural, nonstructural, or NNBF measures-within FRM systems is an evolving discipline. The combination of aging, decades-old FRM projects and climate change is prompting new thinking and practices about performance, especially in relation to improving overall resilience. Project performance 
can be viewed narrowly in terms of the integrity and functioning of the physical structures that compose a system. Performance can also be viewed broadly to include a project's long-term benefits and value, such as economic damages avoided, co-benefits produced, and greater system resilience provided. In both a narrow and a broad sense, further progress in the multidisciplinary activity of assessing project performance is needed and should be encouraged.

The modern age of FRM engineering, which has emerged over the past 100 years, provides a wealth of data and experience that can inform future work. As today's surge in infrastructure investment continues, we should be deliberate about learning from FRM and NNBF projects so we can advance policy and technical practices. Particularly important is the opportunity to expand our consideration of all the costs and benefits of projects, including their structural, nonstructural, and NNBF components. Failing to fully consider all of a system's relevant costs and benefits has led in the past-and will lead in the future-to dissatisfying outcomes and missed opportunities to create diversified value from infrastructure investments.

There is a need to continue improving numerical models and practices for FRM, and for NNBF in particular. Much of today's modeling capability to support FRM is designed to support the analysis of structural measures. Developing truly integrative approaches to FRM that include NNBF measures will require advancing models and modeling practice with respect to natural features, processes, and systems.

As the modern environmental movement enters its seventh decade, there is a need to continue advancing environmental regulation and management to conserve and protect natural systems. There is also a need to build on the growing recognition of natural value and capital so that communities can fully leverage natural systems and functions to address the dynamic challenges posed by FRM and climate change. Efficient and timely regulatory decision-making will support the delivery of NNBF projects and the wide range of benefits for ecosystems and the people who depend on natural systems.

\section{2 | Communicating and Collaborating}

In a world filled with competing interests, perspectives, and voices, communication and collaboration are increasingly important skills for individuals and organizations, including project teams. Many infrastructure projects in the past were implemented with little, if any, substantive engagement with the communities "receiving" the project. That more engagement is occurring now is a measure of progress; however, more can be done to improve communication and collaboration during the development of infrastructure projects. Engagement, communication, and collaboration that bridge the gaps between technical disciplines, organizations, and the public are increasingly recognized as fundamental 
to successful project development and implementation. The need for carefully planned and purposeful investments in communication and engagement when developing and implementing FRM projects remains critical.

Effective internal and external communications are necessary for implementation of successful FRM projects and NNBF. Within an organization or agency, effective communication is necessary to align the internal stakeholders that hold different responsibilities and perspectives relative to NNBF. Such alignment might even be considered a precondition for effective external communication about NNBF with other organizations.

Because they can produce diverse benefits, NNBF provide an important opportunity to engage people and perspectives about value creation through infrastructure investment. Substantive dialogue about the diversity of economic, environmental, and social co-benefits of multipurpose FRM projects that include NNBF will pull from expertise across the physical, biological, and social sciences. Some benefits of FRM and NNBF projects are readily monetized, but the inability to monetize a benefit does not necessarily make the benefit less "real" or important. Many environmental and social co-benefits that may be difficult or even inappropriate to monetize are critical to establishing a project's overall value proposition. Habitat for threatened or endangered species, and biodiversity in general, are examples of such important co-benefits. The use of infrastructure to support social equity in communities is an increasingly important benefit to incorporate into twenty-first century investment planning.

Many challenging topics complicate communication about FRM and climate change. They include uncertainty about the dynamics of the physical and natural systems that comprise FRM projects and the effects and uncertainties of climate change. Progress here will directly support the implementation of adaptive management as a critical component of FRM and NNBF projects. People tend to think and communicate in terms of "either/or" with respect to FRM alternatives-either structural measures or NNBF. But most future FRM systems will include both structural and NNBF measures. Practitioners must be careful to think and communicate about FRM in inclusive, rather than exclusive, ways.

Collaboration across the public and private sectors is fundamental to delivering FRM solutions that include NNBF. Such collaboration includes the creative exchange of ideas between the public agencies that sponsor FRM projects and the private companies that support their delivery. It also includes opportunities for jointly financing NNBF projects and for developing markets (e.g., for carbon sequestration) relevant to the diverse benefits that NNBF can provide. 


\section{3 | Elevating and Educating}

NNBF often provide FRM benefits by elevating part of the landscape to influence the movement of water. These guidelines were developed to raise and advance FRM practice by providing information that is relevant to planning, designing, engineering, and operating FRM projects. Education and training are critical to influencing the long-term trajectory of FRM practice.

Education is sharing information. NNBF education has three primary goals. The first is to expand public awareness of NNBF options and share information about sustainable, resilient solutions for FRM problems. The second is to share emerging technical information and approaches with today's engineers, environmental scientists, lawyers, and other professionals supporting infrastructure development. The third is to develop new educational programs and courses to support communities and future professionals in their efforts to develop infrastructure solutions. When society as a whole understands that natural systems can and do contribute to tangible human needs such as FRM, public and private institutions will be better able to support the natural systems and environmental conditions that are foundational to sustaining NNBF.

The organizations and agencies that develop and operate FRM projects and systems must be intentional about knowing the status and future condition of their projects and systems. Actively managing and adapting projects in a timely manner requires an ongoing financial commitment to monitoring and analysis to determine current conditions and future project needs.

Progress is a watchword of modernity. Progress is achieved through a collective commitment to harnessing innovation to meet future challenges. Policies at all levels should encourage-rather than intentionally or unintentionally hinder-appropriately managed innovation. Each institution contributing to FRM should consider its own policies, procedures, and practices in view of the process of innovation and whether there is evidence of sufficient innovation in its activities. Such self-assessment is part of an organization's commitment to continual learning and the stewardship of its technical competence.

We live in a period of increasingly rapid change and technological advancement. Although these conditions pose many challenges to society, organizations, and individuals, they also present opportunities to create value from the flood of data, information, and experience that flows around us. When we each take the time to document what happened in our own NNBF projects and share that experience across the international community of practice, the benefits generated will be good for humanity and for nature. 


\section{Acknowledgments}

\section{Lead Author}

Todd S. Bridges, U.S. Army Corps of Engineers, United States

\section{Co-Authors}

Jeffrey K. King, U.S. Army Corps of Engineers, United States

Jonathan D. Simm, HR Wallingford, United Kingdom 

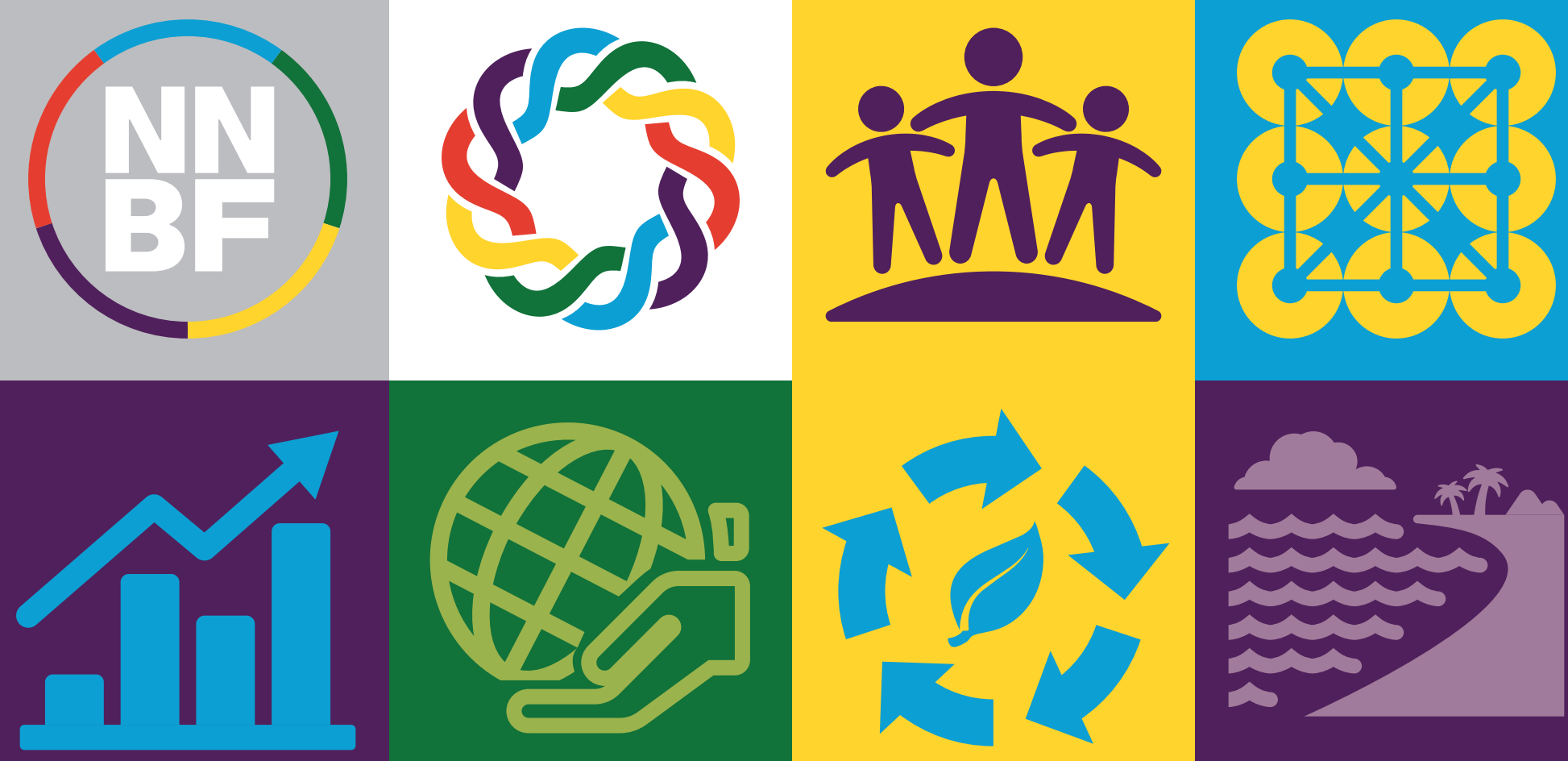
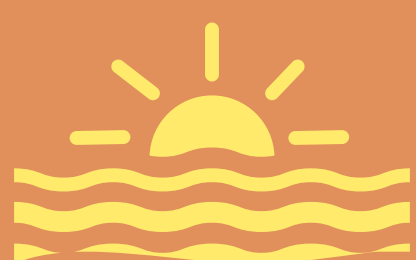
2

Tor
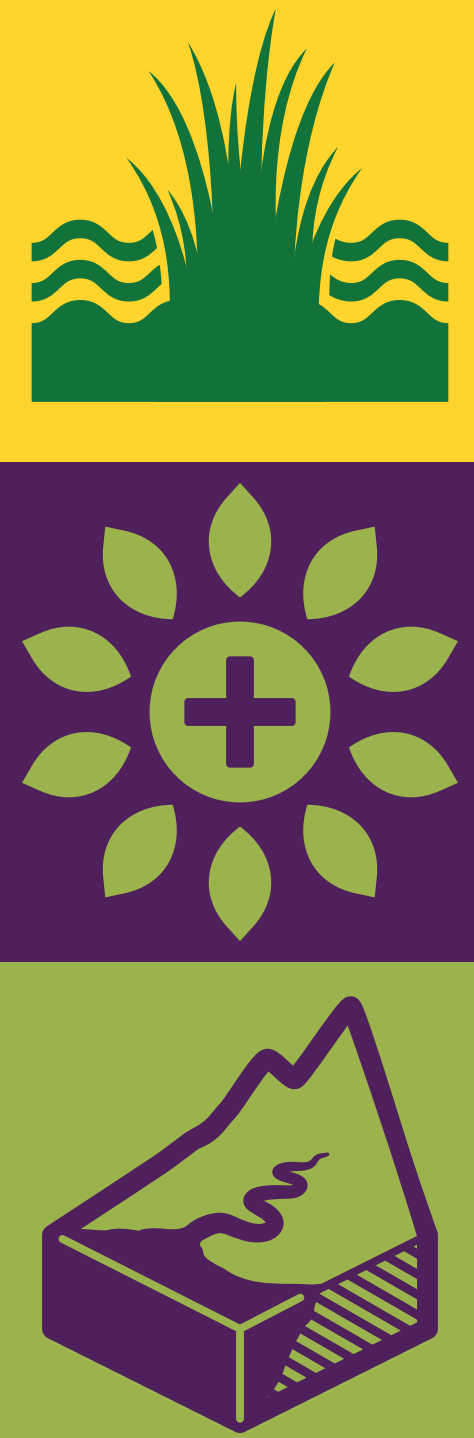

\section{यदित}

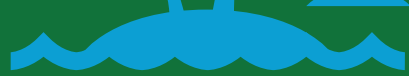

10

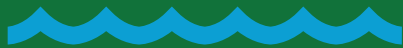

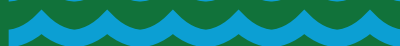

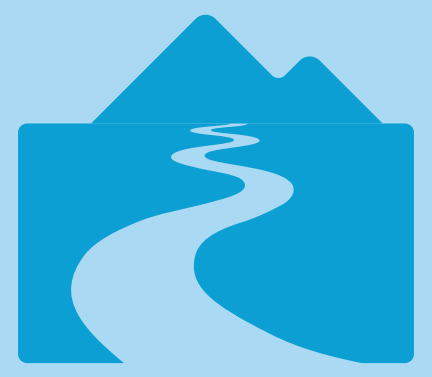

सा? $358 ?$

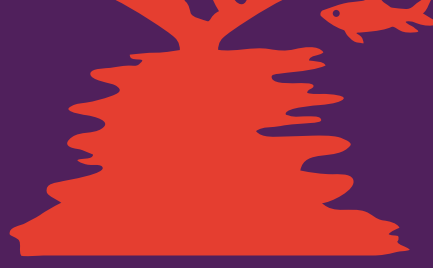

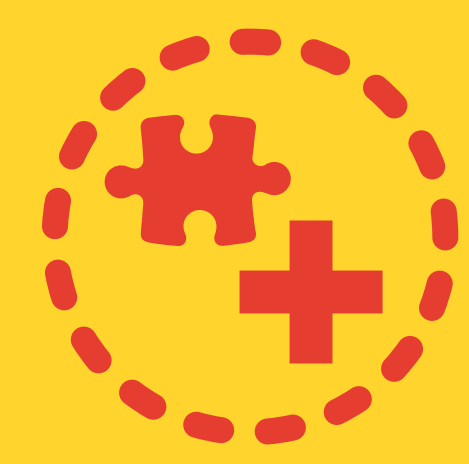
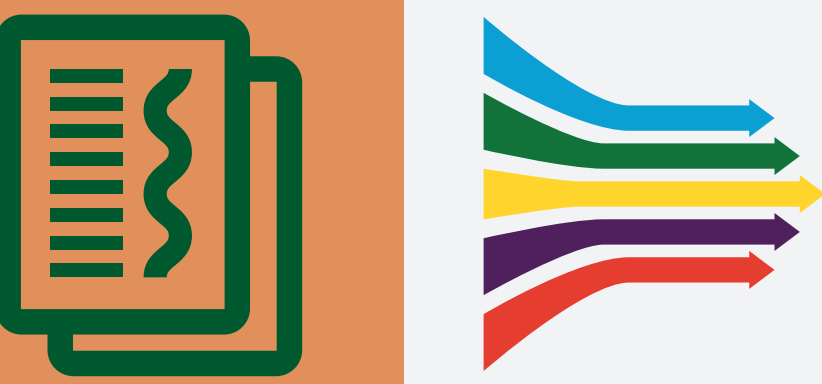


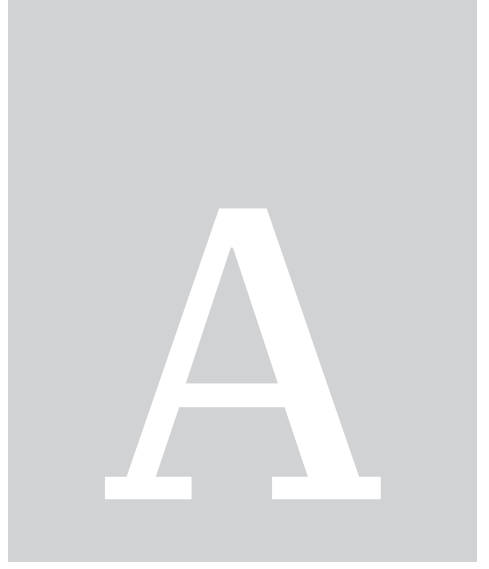

\section{Abbreviations List}

+MSL above mean sea level

2DH 2D horizontal

AM adaptive management

AUD Australian dollar

BACI before-after-control-impact

BCR benefit-cost ratio

BKL Basis KustLijn, which is the reference line for coastal management in reference to the RSP

BRI benefit relevant indicator

BwN Building with Nature

C colonizing

CBA cost-benefit analysis

CEA cost-effectiveness analysis

CFR Code of Federal Regulations

CIRIA Construction Industry Research and Information Association

cm centimeter

$\mathbf{c m} / \mathbf{k m} \quad$ centimeters per kilometer

$\mathbf{c m} / \mathbf{s} \quad$ centimeters per second

CMS Coastal Modeling System

CoP community of practice

DAD Decide, Announce, Defend

DAPP Dynamic Adaptive Policy Pathways 


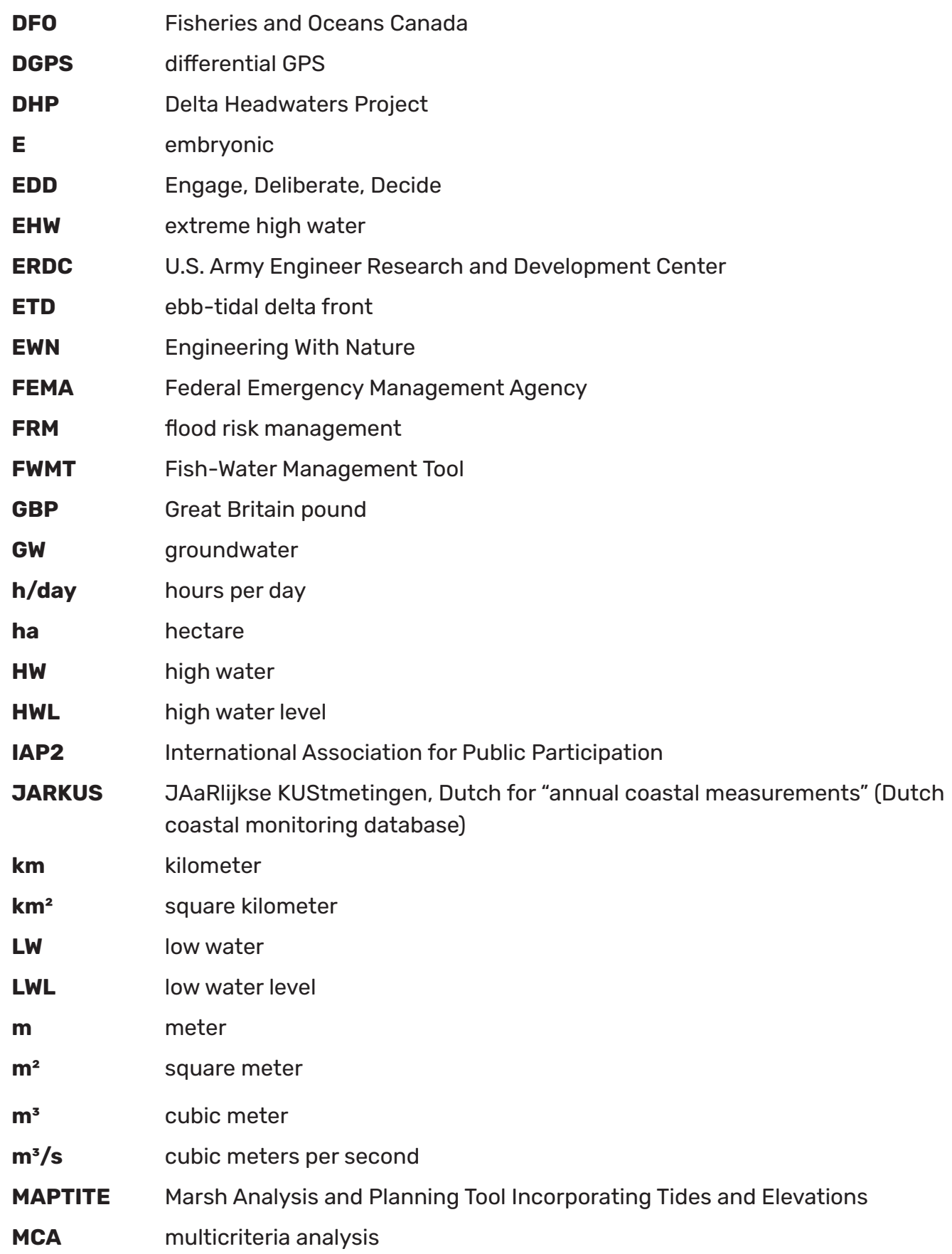




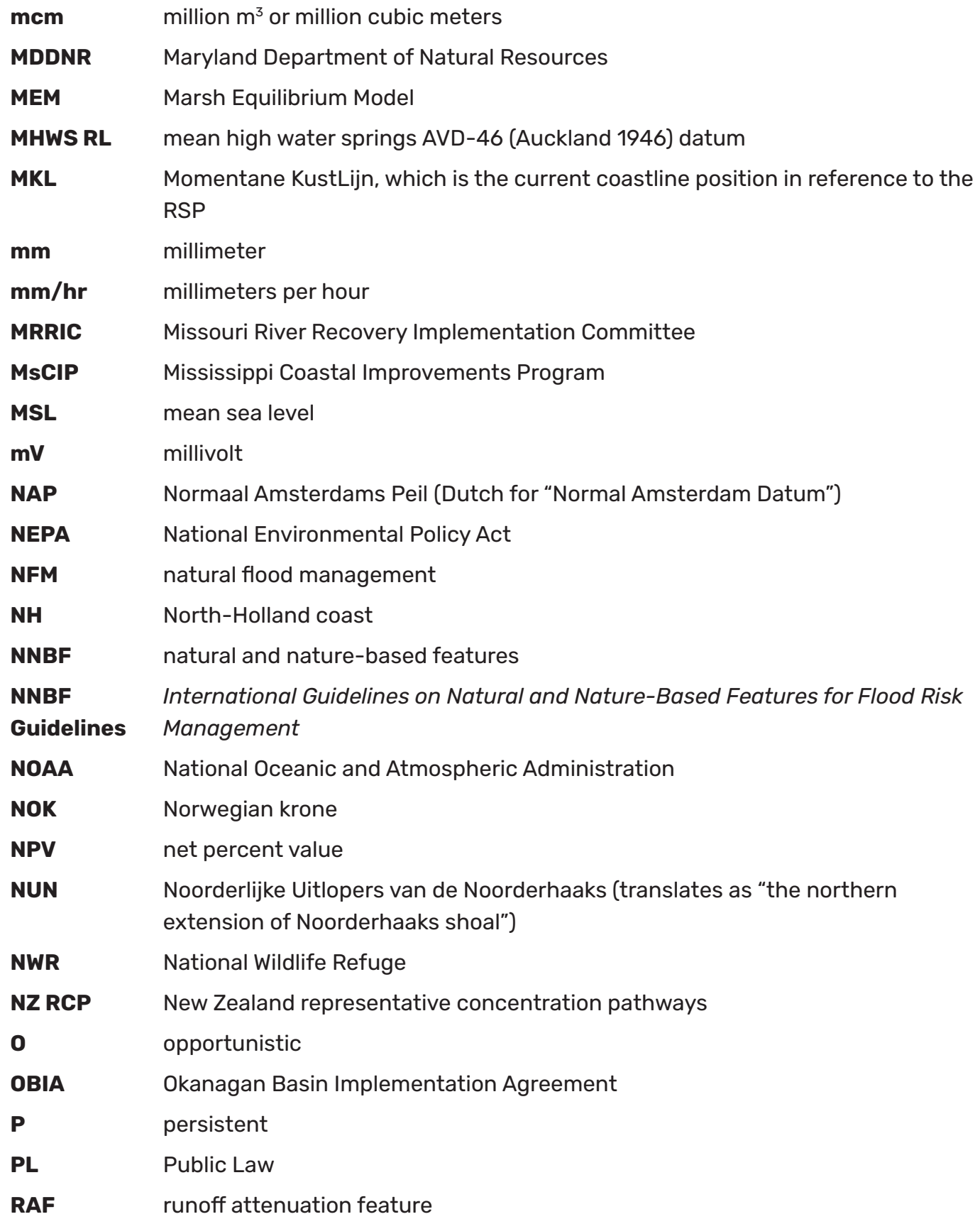




$\begin{array}{ll}\text { RDM } & \text { robust decision-making } \\ \text { Redox Eh } & \text { oxidation-reduction potential in mV } \\ \text { RSP } & \text { RijksStrandPalen lijn, which is a reference for monitoring } \\ \text { SAV } & \text { submerged aquatic vegetation } \\ \text { SDG } & \text { Sustainability Development Goals } \\ \text { SLAMM } & \text { Sea Level Affecting Marshes Model } \\ \text { SIAM } & \text { Sediment Impact Analysis Method } \\ \text { SMART } & \text { specific, measurable, achievable, relevant, and time-bound } \\ \text { SPRC } & \text { source-pathway-receptor-consequence } \\ \text { SUDS } & \text { Sustainable Urban Drainage Systems } \\ \text { SW } & \text { stormwater } \\ \text { TKL } & \text { Toekomstige KustLijn, which is the expected future coastline position in } \\ & \text { reference to the RSP } \\ \text { TLP } & \text { thin-layer placement } \\ \text { TSS } & \text { total suspended solids } \\ \text { UKCP } & \text { United Kingdom Climate Projections } \\ \text { USACE } & \text { U.S. Army Corps of Engineers } \\ \text { USD } & \text { U.S. dollars } \\ \text { WARMER } & \text { Wetland Accretion Rate Model for Ecosystem Resilience } \\ \text { WD } & \text { white dunes } \\ \text { WMA } & \text { Wildlife Management Area } \\ \text { WTP } & \text { willingness to pay }\end{array}$




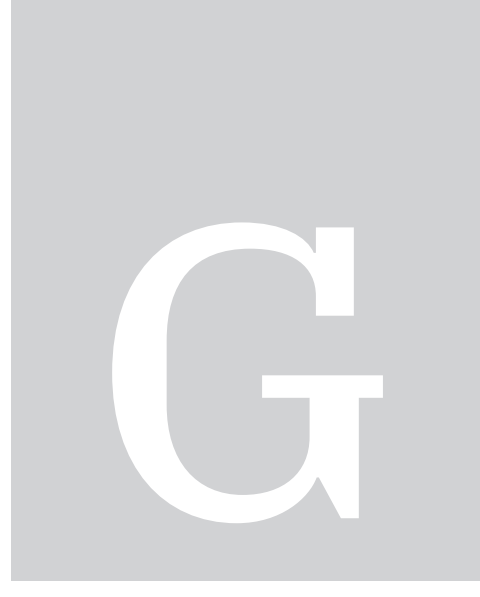

\section{Glossary}

A

Active adaptive

management

Involves a more rigorous approach where the management action is conducted in the context of an explicit hypothesis and associated monitoring protocol aimed at determining whether the proposed management action produces a given result (Gold 2006).

Adaptive

management

A structured decision-making method, the core of which is a multistep, iterative process for adjusting management measures to changing circumstances or new information about the effectiveness of NNBF projects or the system being managed.

Advance the line Building new defenses further out in the sea than the existing defense line in an attempt to reduce the stress on current defenses and possibly extend the coastline slightly.

\section{Bio-rights}

Payments to communities only provided subject to successful restoration.

Blue economy The sustainable use of ocean resources for economic growth, improved livelihoods, and jobs while also sustaining the ocean ecosystem health (worldbank.org 2017).

Co-benefits

Any other relevant benefit beyond FRM derived from NNBF. These include habitat for fisheries, nature-based tourism and recreational opportunities, carbon storage and sequestration, and human health benefits. Co-benefits are highly specific to each type of NNBF; the main categories of co-benefits adopted in these guidelines are described in Chapter 6.

Coastal landscape The combination of a range of coastal features, some erosional, some depositional, arising from an interaction between the coastal materials, the prevailing wave and current climate, the inputs and outputs of sediments into the particular section of coast, and the amount of time that has passed to develop or interrupt processes operating to produce features. 
Coastal change

Coastal

management

Coastal sediment cells

Coastal wetlands

Conventional structural measure
Any long-term trend at the coast such as in mean sea level, wave height, wind speed, drift rate, erosion, or deposition.

The process of managing a coast in a way that reflects an acceptable compromise in light of available finance, between coastal defense, nature conservation, public amenity, and industrial objectives.

A length of coastline in which interruptions to the movement of coastal sediment along the beaches or nearshore seabed do not significantly affect beaches in the adjacent lengths of coastline.

Vegetated environments occupying the intertidal and supratidal zone to the landward extent of coastal hydrologic influence and including salt marshes, brackish marshes, mangrove forests, and tidal freshwater marshes. Specific regulatory definitions of coastal wetlands may deviate from this broad definition.

Structures such as levees, seawalls, floodwalls, breakwaters, dikes, groins, tide gates, and storm-surge barriers designed for coastal and fluvial flood protection.
Ecological The production of the desired ecological functions by the NNBF.

performance

Economic performance

Ecosystem connectivity

Ecosystem services

Effectiveness

Engagement

Engineering With Nature

Enhancement
Pertains to the reduction in economic damages, as well as the economic value related to other FRM, ecological, and social co-benefits produced by the feature.

Connections between different spatially separated ecosystems.

The benefits provided by ecosystems that contribute to making human life both possible and worth living.

Monitoring to evaluate whether the management action had the expected effect and typically including a comparison to baseline or reference data (Murray and Marmorek 2003).

Any interaction between the organization or agency responsible for delivering the NNBF project and relevant stakeholders, as well as communities where NNBF projects may be built. This interaction can include a wide range of different types of engagement, from one-way communication of information through to consultation and collaborative discussion. Other terms used may include public participation, community engagement. stakeholder engagement, or involvement.

The intentional alignment of natural and engineering processes to efficiently and sustainably deliver economic, environmental, and social benefits through collaboration.

The application of NNBF measures to augment ecological, social, and economic benefits of existing coastal and fluvial infrastructure. 
Feedback mechanism

Flood risk management

Flood risk reduction

Floodplain

FRM performance

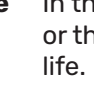

Response of the system to change, such as an event of intervention.

Abbreviated as FRM. Activities that aim to reduce the likelihood and the impact of floods.

The reduction in flood risk, where flood risk is understood as the combination of the probability of the flood source, the probability of any defense breach, and the consequences of flooding (loss/damage) frequently expressed in economic terms or as loss of life.

An area of land adjacent to a river, which stretches from the banks of the channel to the base of the enclosing valley walls or engineered embankments and which experiences flooding during periods of high discharge. The soils usually consist of clays, silts, sands, and gravels deposited during floods.

In the context of NNBF, the reduction in physical forces that produce flooding or damages or that otherwise contribute to FRM for the full range of possible events over a project's<smiles>C=C1C=C2CC1C2</smiles>

Horizontal levee Composed of a traditional flood-control levee core with a seaward ecotone slope on the order of 10:1 to 30:1, grading smoothly to a low marsh elevation. The slope is planted with native wetland and transitional species, restoring habitats that have largely been lost in the region, as well as providing adaptive capacity allowing wetlands to adjust landward as sea levels rise.

Hypothesis

A suggested but unconfirmed assertion or explanation of observed patterns. Hypotheses can take many forms, such as a hypothesized magnitude of a resource attribute or a mathematical relationship between attributes. Hypotheses are tested by comparison against field data (Williams, Szaro, and Shapiro 2009). constructed as intended and reduces implementation uncertainty (Murray and Marmorek 2003).

Living shoreline

Term commonly used in the United States to describe a type of NNBF that involves the use of native vegetation to protect against shoreline erosion. 
Maintain the line Coastal defenses are maintained along the existing geographic line.

Managed
realignment Restoration of tidal flow to previously reclaimed estuarine wetlands for flood control.

Managed retreat (or retreat the

The coastal defense line is withdrawn landward to reduce erosional pressures on the coast line)

Mental models An explanation in a person's thought process for how something works in real life.

Metrics

Metrics are specific parameters or properties of the NNBF, typically quantifiable, that are associated with some desired aspect of performance.

Multi-layered

An approach that involves using more than one component to achieve a reduction in approach flood risk or erosion, for example as multiple lines of defense on the coast or as multiple interventions in a watershed.

Multiple lines of A combination of different types of measures to incrementally reduce the risk of flooding. defense

$\mathbf{N}$

Natural and nature-based features
Abbreviated as NNBF. The use of landscape features to produce FRM benefits and other economic, environmental, and social benefits (known as co-benefits).

All physical and biological materials and their intertwined processes.

\section{Objectives Specific targets within an overall goal.}

Uses relatively simple models (though emphasizing stakeholder involvement for identifying management objectives) that are then modified as experience grows over time without explicit experimentation or hypothesis testing (McFadden, Hiller, and Tyre 2011). 
Performance

Project goals

Project objectives
The ability of a system to meet one or more desired and declared objectives. Performance is measured using a set of predetermined metrics designed to ascertain whether the NNBF is producing the desired benefits.

Goals that are broad, abstract, and indicative of the general intention of the project and that are important to establish the ultimate desired outcome.

Objectives that are narrow, precise, and concrete; define details of how the project goals will be accomplished; and are measurable.

\section{(Regional) sediment management \\ Coordinated management of sediment transport patterns within a specific area.}

Residual performance

\section{Risk}

\section{Risk reduction and resilience benefits}

River catchment

\section{Run-off attenuation features}

Performance of a measure in a degraded or damaged state, so the probability of failure may not reach $100 \%$ even under extreme loading.

A function of the probability that an adverse event (e.g., flooding or coastal erosion) will occur and the consequence associated with that event. Thus, risk $=f$ (probability and consequence), generally simplified to risk = probability $x$ consequence .

The risk reduction properties of NNBF, specifically flood protection and erosion control. Flood protection is achieved through (storm) water absorption through infiltration, flood storage, or wave and surge attenuation. NNBF can help to build and stabilize shorelines and riverbanks, thus reducing erosion. NNBF are often a more resilient solution because they are able to adapt to changing conditions such as sea-level rise or land subsidence.

The geographical area that drains to a river. This area is always bounded by mountains or hills. The catchment also includes the catchments of the tributaries of the main stem.

Abbreviated as RAF. Landscape elements that store and retain the discharge of rainfall water.
Sediment

management

Social performance

Social system

Status and trend

Systems thinking
Actively moving, adding, and extracting sediment by human activities for maintenance, or to achieve preset targets with respect to safety, shipping, nature, or other goals.

Refers to the desired social co-benefits produced by the NNBF.

The patterned series of interrelationships existing between individuals, groups, and institutions and forming a coherent whole.

Evaluates broader objectives that could be influenced by other external factors and could be paired with a causal relationship evaluation (Murray and Marmorek 2003).

Considering physical, biological, and social processes, and their interactions in evaluating flood risk problems and solutions and identifying ways to reduce conflict and maximize synergies to produce sustainable solutions. 


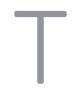

Threshold The limiting value of a resource attribute that triggers a change in management actions. Management strategies often include thresholds, such that one action is specified for resource values less than the threshold and a different action is specified for larger resource values (Williams, Szaro, and Shapiro 2009).

Tidal flats

Intertidal areas largely void of vegetation, composed of mud or sand, and frequently associated with coastal wetlands. Wave-dominated shores such as beaches and dunes are excluded.

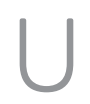

Uncertainty Arises as a result of imperfect or missing knowledge. In the context of FRM, two types of uncertainty in processes are commonly distinguished: natural variability (aleatoric uncertainty) and limitations in knowledge (epistemic uncertainty).

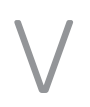

Validation and

Focuses on general understanding of the system to reduce scientific uncertainties directly research related to the project (Murray and Marmorek 2003).

W

Water retention Actively diverting river discharge and subsequently storing the water in designated areas for flood risk reduction purposes.

Watershed See river catchment.

\section{References}

Gold, B. 2006. "Active vs. Passive Adaptive Management." Adaptive Management: Summer Solstice IV (2). https://www.biohabitats.com/newsletter/adaptive-management-2/active-vs-passive-adaptivemanagement/.

McFadden, J. E., T. L. Hiller, and A. J. Tyre. 2011. “Evaluating the Efficacy of Adaptive Management Approaches: Is There a Formula for Success?" Journal of Environmental Management 92 (5): 1354-1359.

Murray, C., and D. Marmorek. 2003. "Adaptive Management: A Science-Based Approach to Managing Ecosystems in the Face of Uncertainty." Paper presented at the Fifth International Conference on Science and Management of Protected Areas: Making Ecosystem Based Management Work, Victoria, BC, May 2003.

Williams, B. K., R. C. Szaro, and C. D. Shapiro. 2009. Adaptive Management: the U.S. Department of the Interior Technical Guide. Washington, DC: U.S. Department of the Interior.

worldbank.org. 2017. Infographic: What is the Blue Economy? The World Bank. https://www.worldbank.org/en/ news/infographic/2017/06/06/blue-economy. 
coastal sediment cells 321

co-benefit $4,11,13,23,24,34,52,55,60,108,113,151$, $163,164,168,169,173,174,185,186,187,191$, $195,197,198,205,206,207,208,209,210,211$, $213,216,217,218,221,222,224,225,230,232$, $233,234,238,243,245,249,250,251,252$, $275,325,332,355,373,416,419,421,422,427$, $431,443,447,448,449,456,457,459,467$, $468,469,479,482,483,504,510,511,516,517$. $518,562,581,588,608,610,614,640,642$, $649,652,655,658,659,675,709,713,773,776$, $781,782,784,786,791,792,797,804,805,806$, $808,813,821,822,824,825,826,829,830$, $832,835,836,837,838,839,840,893,897$ $900,903,906-907,909-910,912,913,914$, $914-916,915,918,922,926,929,932,933,938$ $941,945,948,952,956,959,962$

containment structure $307,462,541,832$

berm $334,339,361,362,366,440,456,461,531$, $540,543,545,547,677,759$

silt curtain 541

contract $41,172,178,310,380,383,387,393,397$, $398,400,470,536,537,548,730,731,732,938$

coral bleaching $567,580,584$

cost-benefit analysis $209,243-246,721$

CBA 209, 211, 226, 229, 232, 238, 241, 242, 243, 244, 246

cost-effectiveness analysis 209

CEA 209, 211, 217, 238, 241, 242

cross-shore profile $323,324,325,333,362,530,593$

D

defense line 322,323

depth of closure $363,364,365,396$

dunes $4,9,22,53,54,144,168,170,173,180,192,212$, $215,221,251,297,320,325,326,329-412,416$, $508,511,523,538,637,643,743,746$

embryonic $369,370,371$

foredune 350

gray dunes 350,746

habitat $131,349,350,352,369,370,746$

succession $350,351,372$

white/yellow dune $369,370,371$

르

ecological performance $163,168,176,184-201,185$, $186,187,188$

ecology $105,106,108,141,321,340,372,374,525,751$, $762,778,823$ disturbance 331,372

recovery $331,361,372,750$

economic performance $162,163,168,170,171,175$, $176,186-201,197$

ecosystem 163,166, 169, 179, 187, 188

ecosystem connectivity 132

ecosystem services $3,11,23,34,115,127,132,141$, $207,208,209,213,219,221,225,231,338-342$, $421,431,515,562,563,603,604,609,614,616$, $617,641,642,657,674,680,708,712,728,764$. $793,825,829,830$

effectiveness $14,94,97,108,125,131,134,151,169$, $170,171,175,177,274,277,286,295,298,305$, $374,531,563,567,568,584,599,616,618$, $637,660,675,709,736,777,778,823,827,835$, $848,868,914$

engagement $6,23,31,33,34,39,43,44,56,58,59$, $105,114,115,116,211,239,243,274,279,280$, $286,290,291,300,303,356,357,374,391$ $394,428,431,447,448,470,471,517,518,528$, $584,712,719,746,754,756,764,839,912,914$, $915,922,936,945$

Engineering With Nature iii, iv, $x, 5,703,708,709,718$, $777,833,897$

enhancement $63,128,139,273,286,306,308,325$, $326,339,361,374,392,400,703,708,709,710$, $712,713,714,715,716-719,718,719,720,721$, $724,725,726,732,733,733-734,734,735,736$, $762,764,798,825,826,827,831,832,864,914$

erosion $x i, 4,8,9,80,116,117,118,119,134,165,167$, $168,172,175,179,183,184,205,206,209,211$, $212,213,217,218,219,225,226,227,228,230$, $232,240,241,249,252,289,320,321,324$, $332,334,338,341,346,347,351,353,356$, $362,366,367,368,369,371,373,374,377,414$, $416,417,421,422,423,424,425,429,431,432$, $434,435,441,444,445,448,449,450,451$, $452,453,455,456,458,459,461,463,464$, $465,466,467,470,476,478,480,483,486$, $504,506,508,510,511,512,513,516,517,521$, $530,533,534,538,541,543,545,546,638$, $562,563,564,565,569,571,577,578,579,580$, $581,582,584,585,587,588,589,591,592$, $595,597,599,600,605,606,608,613,616$, $642,643,646,647,648,660,670,672,676$ $677,687,689,707,708,711,746,747,776,785$, $786,790,796,797,804,805,806,807,810$, $812,856,813,815,821,826,827,830,831,835$, $838,852,864,883-887,887,888,26,870$, $871,872,941,950,951,955,956,958,959$

EWN. See Engineering With Nature expected damage function $226-241,230,231,232$ 
$\mathbf{F}$

feedback mechanism 126, 149, 151, 571, 665, 666

floodplain $39,75-76,82,83,113,116,119,121,124,125$, $148,185,711,791,792,793,794,796,799,827$ $828,831,832-845,834,835,838,848,849$. $850-855,862,865,867,868,869,884,895$, $896,899,900,902,905,863,915,917,920$, $921,922,925,928,931,932,933,935,943$, $947,948,950,951,954,956,958,961$

flood risk management $x, 3,4,6,8,9,10,11,12,13$, $14,22,23,24,26,27,40,41,43,44,59,62,104$, $108,109,110,111,112,113,115,148,162,163,164$ $165,166,168,169,171,173,175,176,177,178$, $179,180,182,184,185,186,187,190,191,192$, $193,194,195,196,197,198,211,273,283,286$. $289,294,295,312,320,321,323,324,416,417$. $419,422,427,430,431,433,434,435,441$, $442,443,444,445,448,449,450,451,453$, $454,455,456,458,461,467,468,469,477$, $478,481,483,506,508,524,526,528,529$, $531,534,535,537,547,611,615,666,703,704$. $706,713,720,755,773,774,776,777,780-802$, $805,847,848,850,852,855,856,858,865$, $869,877,884,893,921,927,932,941,952$

flood risk reduction $22,26,38,50,104,105,109,115$, $116,121,125,133,141,150,205,208,209,212$, $217,221,224,226,231,232,251,252,273,275$, $276,323,376,383,396,402,571,584,593$, $609-635,616,702,703,705,712,741,758,763$, $784,792,794,799,835,849,913,915$

frame of reference method 145

frictional resistance $324,414,646$

FRM. See flood risk management

FRM performance $163,166,168,169,177,179-201$, $184,186,188,195,196,197$

goals $x i, 4,14,23,30,31,32,43,44,74,78,94,110,113$, $114,137,151,164,169,205,247,251,277,282$. $283,284,286,296,298,352,415,431,444$, $477,520,521,537,548,582,611,614,617,659$, $660,671,684,686,712,718,725,740,761,799$, $826,903,922,951$

operational 351

strategic $351,352,357,401$

tactical 351,402

grain size $339,358,361,362,363,368,388,394,399$, $421,442,443,479,536,537,644,653,660$, 683,733

beach $358,361-364,394$
H

habitat diversity $421,446,522,523,524$ habitat switching $509,517,523,533,549$ habitat trade-offs $502,509,518$

hypothesis $221,275,289,681$

Iceberg Model 112, 113

implementation $51,56,58,59,60,64,67,70,78,85$ $87,97,222,233$

implementation and compliance 298, 299

interconnectedness 483

island migration 512 . See also rolling over

islands $4,9,22,24,36,122,212,284,325,461,501-$ $558,564,570,601,610,637,644,665,670,918$ barrier $8,143,310,504,505,506,508,511,511-558$, $513,514,516,525,534,537,643,644$

deltaic $504,506-558,508,511,513-558,516,533$

in-bay or in-lake $504,508,514$

morphology 506,508,510,543

platform $510,512,513,536,537,538,547$

$\mathbf{K}$

knowledge development 12,131

M

managed realignment $236,322,323,353,358,383$, $417,424,430,441$

managed retreat 236,356 . See also retreat the line

management strategy $32,37,38,39,44,134,145$, $164,289,294,352,401,520$

MCA. See multicriteria analysis

mental model 108,112

metrics $66,162,163,169,170,171,172,173,174,175$, $176,177-201,179,182,183,186,187,191,198$

monitoring $25,31,42,43,44,45,48,50,52,59,67$, $68,80,94,113,131,145,151,162,169,173,174$, $176,192,196,210,211,215,236,249,250,251$, $252,273,274,275,278,279,280,281,283,284$. $286,287,289,293,295,297-312,297-318,301$, $303,304,305,308,310,311,314,326,330$ $354,355,356,357,381,385,388,394,401$, $519,470,471,477,482,520,523,525,527,588$, 
$536,537,543,546,547,547-555,548,589$, $680,607,609-635,611,611-612,616,617,716$, $719,680,681,684,685,686,717,719,720,725$, $726,731,733,737,739,740,743,747,751,757$, $764,765,768,777,778,798,823,824,837,838$, $839,840,841,911,68,912,920,932,933,684$. See also adaptive management

monitoring and adaptive management 397,434 , $543,546,548,680,685,781,798,840,841$. See also adaptive management

multicriteria analysis 209, 211, 217, 222, 238, 241, 242,243

multidisciplinary $23,30,33,34,44,104,109,114,151$, $524,588,715,796,813$

multiple lines of defense $143,323,647$ performance $25,42,43,63,104,108,111,135,145,151$, 161-202

policy $x i i, 10,11,13,80,81,123,128,136,174,187,207$, $208,209,216,221,234,238,239,241,246,247$, $249,313,353,354,355,357,361,584,656,713$, $715,718,720,763,778,839,840,841,915,938$

principal measure 323

project goals $30,31,32,35,44,169,284,444,477$, $520,521,537,548,611,612,614,686,688$, $712-714,718,725,922,951$

project objectives $33,74,77,168,169,170,171,173$, $177,180,218,249,275,294,304,434,443$, $468,471,477,520,521,524,530,547,581,611$ $613,614,615,665,712,725,733,738,763$

\section{$\mathbf{N}$}

natural system $35,105,108,112,115,116,119,121,124$, $127,141,195,211,245,246,333,338,356,366$, $375,379,382,435,708,787,793,806$

nourishment $61,80,127,131,136,137,183,184,189$, $192,289,301,310,311,324,334,341,346,361$, $386,388,470,477,560,564,744,746,747$, 749,821

beach $80,123,324,356,358,359,362,367,726$, $744,748,750$

shoreface $196,348,367,375$

numerical modeling $583,594,595$

objectives $30,31,33,43,49,58,66,70,71,74,77,78$, $82,83,88,89,90,91,94,95,96,97,98,108$, $109,110,113,122,123,128,137,145,149,162$, $163,168,169,170,171,173,177,180,184,209$, $210,218,238,239,243,246,249,250,277,278$, $280,281,284,286,287,288,294,295,296$, $298,303,326,351,352,354,355,357,361,381$, $383,387,393,400,401,402,431,435,442$, $443,467,468,471,473,477,480,481,482,518$, $520-524,524,525,530,531,537,547,581$, $582,611,613,614,615,617,656,657-660,665$, $677,684,712,712-714,714,716,733,734,738$, $763,764,776-779,835,838,906,912,922$

ocean acidification 567,580

overwash $382,383,384,512,514,521,523,525,531$, 534

oysters $564,565,567,585,590,604,612$

\section{RAF. See runoff attenuation feature}

recovery 372

reef 559

artificial reef $565,566,568,569,578,581,587,589$, $591,592,600,601,605,611,616,618$

coral reef $560,561,562,563,564,565,566,567$, $568,569,570,571,572,574,579,585,590,596$, $601,602,603$

hybrid reefs $606-607$

reef construction 609,618

reef design $582,589,592,593$

reef morphology $563,570,573,575,578$

reef roughness $569,574,616$

shellfish reef $561,562,563,564,565,568,569,570$, $571,572,574,575,583,584,586,591,603,604$, $610,612,613,614,615,617$

regional sediment management $131,133,134,149$ residual performance 180

resilience $x$ iii, $3,8,9,10,11,23,24,26,37,43,78,111$, $116,122,189,190,191,192,198,205,206,277$, $282,314,324-328,330,339,351,360,361$, $373,380,391,398,399,403,430,450,457$, $504,506,508,509,510,511,512,513,516,520$ $523,525,528,529,530,532,536,540,548$, $550,638,561,606,615,666,735,739,740,742$, $744,761,762,763,793,807,838,840,847$, $862,921,549$

restoration $8,11,22,53,57,63,64,115,117,118,119$, $122,143,145,146,150,169,179,194,195,206$, $207,209,213,214,215,217,221,223,235,236$, $237,240,241,242,247,252,301,320,325$, $400,416,417,419,420,430,434,435,436$, $437,439,441,442,444,445,446,447,448$, rainbowing 540 
$449,458,460,465,467,468,469,473,474$, $475,478,480,482,510,511,514,516,517,519$, $520,523,530,533,537,549,561,562,567$, $568,581,586,587,588,590,603-604,608$, $609,611,615,617,618,641,649,650,655,656$, $657,661,673,674,684,746,760,776,782,788$, $791,793,807,813,816,821,822,823,826,828$, $829,832,850,855-887,858-887,868,896$, $897,900,863,908,909,911,924,929,941$, $942,956,958,959$

retreat the line $323,353,358,378,383,439,444$. See also managed retreat

risk reduction benefits $205,206,207,209,210,211$, $216,217,218,218-226,221,224,226,227,230$, 232,233

rolling over 512 . See also overwash; See also washover

runoff attenuation feature $131,139,140,141,931$, $932,933,940$

sand nourishment $127,183,310,386,388,560,564$. 746

scale $6,8,13,14,35,59,63,149,150,151,173,179,182$, $185,187,211,218,222,227,231,250,252,274$. $276,279,280,281,282,284,286,295,300$, $303,304,309,313,330,342,343,346,347$, $371,373,399,417,422,423,424,433,435$ $436,439,441,446,448,459,464,465,468$, $482,483,517,518,519,529,534,535,565,570$ $574,581,588,592,593,595,597,598,604$. $608,610,613,616,617,637,676,680,681-700$, $702,703,704,718,720,735,736,741,756,761$, $763,764,765,773,774,776,777,778,788,793$, $794,805,810,812,820,822,825,826,827$, $829,835,836,840,841,860,876,882,895$, $896,913,921,929,930,944,963$

scale transfer 126

sea-level rise $3,9,50,57,80,81,111,116,125,136,150$, $163,164,165,189,190,206,211,215,221,226$, $229,273,310,321,322,324,325,330,340,341$ $343,354,355,356,373,374,387,402,415$, $420,424,430,432,433,436,437,446,469$, $471,481,502,504,508,509,510,511,512,513$, $515,525,530,535,560,564,567,569,572$, $575,580,583,584,597,599,638,647,687$. $708,732,763,790,819,820$

sediment $10,14,41,44,80,117,121,124,129,131,133$, $136,193,205,212,215,219,235,236,237,250$, $297,301,305,306,307,310,320,321,322$, $324,325,366,367,368,369,371,372,373$, $396,400,400-411,399-411,402,415,416,418$, $419,420,421,422,423,424,427,428,430$,
$432,433,434,435,436,437,439,440,441$, $442,443,444,445,447,452,456,458,461$, $462,463,464,465,466,469,470,472,473$, $474,475,476,477,502,504,506,508,510,511$, $512,513,514,515,517,520,521,522,523,525$, $526,527,529,531,532,537,538,539,540$, $540-558,543,545,546,547,548,550,564$. $567,569,570,572,587,590,592,599,601$, $604,605,612,613,616,617,637,641,644,646$, $647,653,657,658,659,665,666,670,671,672$, $675,678,679,682,683,724,726,732,733,736$, $740,743,757,764,774,775,776,784,785,787$, $788,789,791,796,797,806,807,808,812,813$, $814,818,821,822,824,827,836,837,848$, $850,855,862,864,865,869,878,886,932$, $933,851,853,863,912,870,871,872,918,879$

budget $133,149,330,334,339,341-342,366,509$, $510,522,525,529,531,564,616,617$

dynamics $136,330,436,524,529,600,687,804$ transport $33,126,133,138,219,321,333,343,351$, $362,367,368,369,371,396,428,430,441$, $458,463,464,465,504,510,512,513,529,531$, $533,535,538,543,547,562,564,568,570$, $571,575,579,583,587,589,591,593,595,646$, $687,710,711,785,820,821,856,873$

sediment management $24,134,305,522,816,822$, 826,953

social performance $163,168,174,175,186$

social system $3,105,110,119,245,273,275,276,277$, $286,288,294,295$

stakeholder $x i, 23,33,34,39,41,43,44,48,49,50,51$, $52,55,59,60,62,63,64,66,67,68,69,70,71$. $75,77,78,79,80,81,82,83,84,86,87,88,89$. $90,92,93,94,95,96,97,105,108,110,112,114$ $115,116,174,206,209,211,217,218,221,222$, $223,224,239,243,246,249,250,251,252$, $273,274,279,280,283,284,285,286,287$. $290-294,293,296,297,300,303,312,313$, $314,428,351,354,355,356,357,374,381,382$, $391,517,431,447,470,471,517,518,520,581$, $525,528,533,534,649,581,583,584,608$, $659,660,708,712,719,720,742,744,745,746$ $754,756,757,777,813,796,824,825,826,837$, $839,840,841,893,898,903,68,922,933$

start small $104,109,149$

status and trend $286,298,684$

storm protection $53,134,419,508,647,687$

strategies $3,11,23,25,31,32,39,40,50,59,60,118$, $131,174,221,226,229,236,251,282,286,302$, $313,330,353,358,378,584,618,638,647$, $661,671,681,773,791,797,827,839,841,921$

hold the line $145,352,358,359,361,366,378,386$, $387,393,439,444,763$

rollback $339,353,358,360,366,384$

structural profile $324-328$ 
submerged breakwater $565,568,578,588,589,590$, $591,594,595,600,609$

subsidence $117,193,206,244,306,321,387,389,445$, $504,506,508,511,513,529,530,535$

supporting measure 323

sustainability xiii, 3, 4, 11, 14, 23, 38, 44, 57, 109, 111, $119,121,164,251,252,324,377,445,446,482$, $510,512,543,564,567,599,612,613,614,709$, $732,840,897,917,947,959$

synergies $22,33,104$

system functions 110

systems thinking $104,106,108,109,113,114,127,128$, 149, 151

think big 104, 109, 149

threshold $247,281,300,300-318,301,302,303,304$, $352,358,548,789$

triple bottom line 110

validation and research 298

vision $30,66,74,109,112,121,122,123,351,127,149$, $351,352,356,68$

\section{W}

washover 334

water retention $711,794,834,876,878,882,930$, $879,929,935$

watershed $22,83,121,122,123,125,149,196,197,513$, $760,763,791,793,794,795,796,799,805,812$ $816,817,818,820,822,826,827,829,832$, $833,835,836,841,848,849,860,864-887$, $874,893,894,854,912,913,914,915,920,921$. $922,923,924,926,932,933,935,936,938$, $939,940,942,951,952,953$

wave diffraction 530

wave energy $24,54,57,167,211,212,227,324,332$, $334,337,338,339,363,366,370,371,418,421$, $422,424,428,429,435,436,440,445,452$, $456,460,461,464,506,511,520,521,563,565$, $566,568,569,570,571,572,574,575,576,577$, $578,579,580,584,585,589,597,612,613,616$, $638,639,643,644,646,647,657,659,660$, $665,670,672,683,710,711,740$

wave models $592,594,597,598$

wave reduction $440,441,454,458,463,570,654$

wave setup $563,575,576,579,591,597,598,599,612$ 


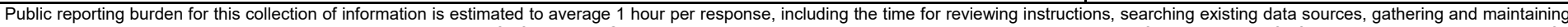

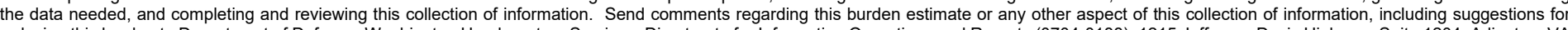

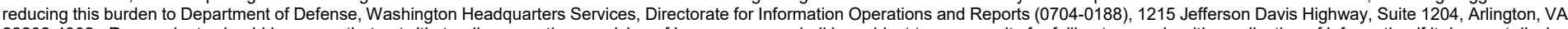

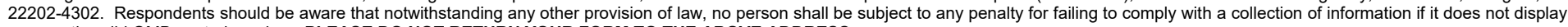
a currently valid OMB control number. PLEASE DO NOT RETURN YOUR FORM TO THE ABOVE ADDRESS.
1. REPORT DATE (DD-MM-YYYY)
2. REPORT TYPE
3. DATES COVERED (From - To)

09-15-2021

SR

\section{TITLE AND SUBTITLE}

International Guidelines on Natural and Nature-Based Features for Flood Risk Management

5a. CONTRACT NUMBER

5b. GRANT NUMBER

5c. PROGRAM ELEMENT NUMBER

\section{AUTHOR(S)}

Todd S. Bridges, Jeffrey K. King, Jonathan D. Simm, Michael W. Beck, Georganna

Collins, Quirijn Lodder, and Ram K. Mohan, eds.

5d. PROJECT NUMBER

5e. TASK NUMBER

5f. WORK UNIT NUMBER

\section{PERFORMING ORGANIZATION NAME(S) AND ADDRESS(ES)}

8. PERFORMING ORGANIZATION REPORT

U.S. Army Engineer Research and Development Center

3909 Halls Ferry Road

Vicksburg, Mississippi 39180-6199 NUMBER

ERDC SR-21-6

\section{SPONSORING / MONITORING AGENCY NAME(S) AND ADDRESS(ES)}

Headquarters, U.S. Army Corps of Engineers

441 G Street Northwest

Washington, District of Columbia 20314-1000

10. SPONSOR/MONITOR'S ACRONYM(S)

USACE

11. SPONSOR/MONITOR'S REPORT NUMBER(S)

\section{DISTRIBUTION / AVAILABILITY STATEMENT}

Approved for public release; distribution is unlimited.

\section{SUPPLEMENTARY NOTES}

Initially it was funded from the Dredging Operations Environmental Research Program (DOER), now it is out of the Engineering With Nature Program (EWN).

Project title, "Developing Engineering Guidance for Natural and Nature-Based Features"

Project No. 16-12

\section{ABSTRACT}

The International Guidelines on Natural and Nature-Based Features for Flood Risk Management emphasize the role of nature-based solutions and natural infrastructure (e.g., beaches, dunes, islands, marshes) as an alternative to conventional hardened infrastructure for flood and coastal storm risk reduction and represents the state of the science on conceptualizing, planning, designing, engineering, implementing and maintaining NNBF. The Guidelines will equip decision-makers, project planners, and practitioners with strategies that reduce flood risks to communities and improve infrastructure resilience. The document is organized so readers can begin where their interests lie. The chapters were developed in a collaborative environment where there was communication and engagement across chapter teams. Each chapter begins with a list of its key, high-level messages, includes references to other chapters, and uses icons and case studies to draw attention to key topics covered elsewhere in the Guidelines.

\section{SUBJECT TERMS}

Environmental engineering, Flood risk management

\begin{tabular}{|l|l|c|c|}
\hline \multicolumn{2}{|l|}{ 16. SECURITY CLASSIFICATION OF: } & $\begin{array}{c}\text { 17. LIMITATION } \\
\text { OF ABSTRACT }\end{array}$ & $\begin{array}{c}\text { 18. NUMBER } \\
\text { OF PAGES }\end{array}$ \\
\begin{tabular}{|c|c|c|c|} 
a. REPORT \\
Unclassified
\end{tabular} & $\begin{array}{c}\text { b. ABSTRACT } \\
\text { Unclassified }\end{array}$ & $\begin{array}{c}\text { None PAGE } \\
\text { Unclassified }\end{array}$ & 1020 \\
\hline
\end{tabular}

19a. NAME OF RESPONSIBLE PERSON

19b. TELEPHONE NUMBER (include area code) 
